


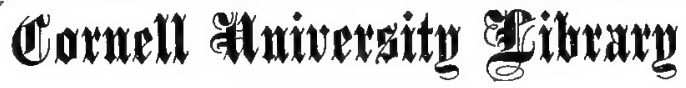

BOUGHT WITH THE INCOME FROM THE

SAGE ENDOWMENT FUND THE GIF"T OF

Henty Th. Sage r89x

A.64436 
arV19069 Cornell University Library

arV19069

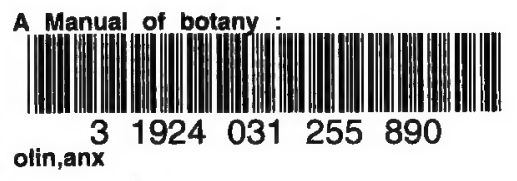




\section{Cornell University Library}

The original of this book is in the Cornell University Library.

There are no known copyright restrictions in the United States on the use of the text. 
MANUAL OF BOTANY. 
By the same.

In one volume, royal 8vo, pp. I II 7 , price 2 Is.

CLASS-BOOK OF BOTANY,

Illustrated with I 800 Wood Engravings.

Unitorm with above, price 7s. 6d.

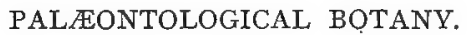

In foolscap 8vo, illustrated, price $35.6 \mathrm{~d}$.

ELEMENTS OF BOTANY.

In fcap. 8vo, second Edition, with Map, 3s. 6d.

THE FLORA OF EDINBURGH. 


\title{
MANUAL OF BOTANY
}

BEING

\section{AN INTRODUCTION}

TO THE

STUDY OF THE STRUCTURE, PHYSIOLOGY, AND . CLASSIFICATION OF PLANTS

BY

JOHN HUTTON BALFOUR, A.M., M.D. EDIN., F.R.S., Sec. R.S.E., F.L.S.,

PROFESSOR OF MEDIGINE AND BOTANY AND DEAN OF THE MEDICAL FACULTY IN THE UNIVERSTY OF EDINBURGH, EER MAJESTY'S BOTANIST FOR SCOTLAND, AND REGIJS FWEPER OF THE ROYAL BOTANIC GARDEN,

\author{
FIFTH EDITION
}

WITH UPWARDS OF NINE HUNDRED ILLUSTRATIONS

EDINBURGH ADAM AND CHARLES BLACK 
Printed by R. \& R. CLARK, Edinburgh, 
ORIGINAL DEDICATION IN 1849.

TO

\section{ROBERT KAYE GREVILLE, LLD.}

AS A SMALL BUT SINCERE

MARK OF REGARD FOR HIS EMINENGE AS A BOTANIST, OF GRATITUDE

FOR HIS KIND BOTANICAL SERVICES,

AND OF ESTEEM

FOR HIS CHARACTER AS A. CHRISTIAN FRIEND,

THE FOLLOWING PAGES ARE

DEDICATED BY

J. H. BALFOUR. 



\section{PREFACE.}

IN drawing up this Manual of Botany, the object has been to give a comprehensive, and, at the same time, a condensed view of all departments of the science, including the microscopical structure of plants and their morphology, the functions of their various organs, their classification and distribution over the globe, and their condition at various geological epochs. Care has been taken to notice the plants used for commercial and economical purposes, and particularly those having medicinal properties. The principles of adaptation and order which prevail in the vegetable kingdom have been prominently brought into view, with their bearings on symmetry and arrangement.

The physiology of plants has been considered in connection with the anatomical structure of their different organs, and the recent views in regard to the embryogenic process in flowering and flowerless plants have been brought under notice. In the department of classification, the system of De Candolle has been more or less completely followed, and the characters of the Natural Orders have been briefly given. It has been shown that the great object of classification is to arrange plants according to their affinities in all important particulars, and thus to trace, what may be considered to be, 
the plan of the Almighty and all-wise Creator. At the same time, in all systems it is necessary to have artificial means to aid in the study of genera and species. Such means, like an index, must be easily applied so as to assist the beginner in his studies. It is only the Botanist, who has an extended knowledge of the vegetation of the globe, who has examined the effects produced on vegetation by climate and other circumstances of existence, and who has studied aberrant forms in connection with natural orders, that can take a correct view of the alliances of plants.

The divisions of geographical and palæontological Botany are still in an imperfect state, and are undergoing constant changes from the discoveries of naturalists in various parts of the world. All that has been attempted in this volume is to give a very general outline of these subjects, and to call the attention of the student to the points which still require elucidation. In the Appendix will be found a description of the microscope, of its use as an instrument of research in histological Botany, and of the mode of making vegetable preparations. There are also added directions as to the collecting of plants and the formation of a herbarium, with hints as to alpine travelling, and as to the examination of a country in a botanical point of view. A full glossary of the ordinary botanical terms is likewise given.

The study of Botany is well fitted to call the observant faculties into active exercise. It teaches the student to mark the differences and resemblances between objects, and leads to habits of correct observation and diagnosis. In the present day there is a growing feeling of its importance in mental 
culture, and a tendency to include it as a subject of study in the curriculum of Arts, as well as in that of Medicine. It is now also taking a place in our school-books, and thus becoming part of the education of the young. It is a science fitted for all ages, for all ranks, and for all seasons. "In youth, when the affections are warm and the imagination vivid; in more advanced life, when sober judgment assumes the reins ; in the sunshine of fortune and the obscurity of poverty, it can be equally enjoyed. The opening buds of spring; the warm luxuriant blossoms of summer; the yellow bower of autumn; and the leafless desolate groves of winter, equally afford a supply of mental amusement and gratification to the Botanist." It is hoped that the present Manual may aid in the promotion of a science the study of which is so well calculated to contribute to the enjoyment and wellbeing of mankind. The examination of the plants which clothe the surface of the globe, of the lilies of the field, and of the meanest moss or lichen in our path, is well fitted to call forth exalted views of the eternal power and Godhead of Him who hath made all these for His own glory, and whose providential care extends to the clothing of the grass of the field, which to-day is, and to-morrow is cast into the oven.

27 INVERLeith Row, EdinbUrgh, April 1875. 



\section{INTRODUCTORY REMARKS.}

IT has too often been supposed that the principal object of Botany is to give names to the vegetable productions of the globe, and to arrange them in such a way that these names may be easily found out. This is a most erroneous view of the science, and one which was perhaps fostered by some of the advocates of the Linnæan system. The number of species collected by a botanist is not considered now-a-days as a measure of his acquirements, and names and classifications are only the mechanism by means of which the true principles of the science are elicited. The views in regard to a natural system proposed by Ray and Jussieu did much to emancipate Botany from the trammels of artificial methods, and to place it in its proper rank as a science. Their labours have been ably carried out by De Candolle, Brown, Endlicher, Lindley, Hooker, Arnott, Bentham, and others. The relative importance of the different organs of plants, their structure, development, 'and metamorphoses, are now studied upon philosophical principles. The researches of Gaudichaud, Mirbel, and Trecul, as to the structure and formation of wood; the observations of Schleiden, Schwann, and Mohl on cell-development; the investigations of Brown, Schleiden, Fritzsche, Amici, Hofmeister, Tulasne, Darwin, Strasburger, Pringsheim, Cohn, Hermann Müller, and others, into the functions of the pollen, the fertilisation of plants, both phanerogamous and cryptogamous, the development of the ovule and spore, and the formation of the embryo; the experiments of Schultz, Decaisne, and Thuret, on the movements observed in the cells, vessels, and spores of plants, and various other physiological inquiries, have promoted much our knowledge of the alliances and affinities of plants. Thus the labours of vegetable anatomists and physiologists all tend to give 
correct views of the relation which plants bear to each other, of the laws which regulate their development, and of the great plan on which they were formed by the Creator.

There is a tendency, however, to speak of the laws of nature as if they were in themselves executive, and this has led to erroneous views of the system of the universe. Some there are who attempt to shut out God from His works by this means. The Creator is regarded as looking at the development of His plan, and watching its progress, but not requiring to exercise constant and unwearied superintendence of the minutest event. Nay, even when $\mathrm{He}$ creates animals with certain instincts, and plants with certain functions, $\mathrm{He}$ is represented like an imperfect workman taking a lesson from the operations of the beings which $\mathrm{He}$ has made, and which, by their own efforts of selection, or by their own struggles for existence, complete what the Creator had set on foot. A certain mechanism is set agoing in some unknown way, and it continues to work according to definite laws. But what are laws unless there is some one to carry them out? The great Author of these laws must be always working in them and by them, and upholding them in their integrity and efficiency. No doubt the Creator is a God of order and method, and the operations of His wisdom and power are displayed in what we call laws. The execution of these laws, however, is just as wonderful and miraculous as is a fiat of creation, and requires equally the exercise of Almighty power. The uniformity of nature depends on the wisdom that made these laws and adapted them to all the varying conditions of the universe. In the course of Providence, however, there are every now and then marked events which seem to be at variance with this uniformity, as when a deluge overwhelms mankind, or when a sudden convulsion destroys the cities of the plain. Such events show that all things do not continue as they were from the beginning of the creation. Those who look for a progressive development and a gradual and eternal advance towards perfection in the living beings which cover the earth, without further creative fiats or movements per saltum, forget, in their speculations, that a time is coming when, as the Apostle says, "the earth and the works that are therein 
shall be burned up," and then shall there be ushered in " a new earth," wherein righteousness shall dwell. We cannot but honour the man, who, by his genius and talent, has been enabled to develop one of the great laws of nature, and who feels and acknowledges that he has been the humble instrument to lift the veil to a certain extent which conceals the workings of the Almighty; but we have no sympathy with that discoverer in science, who, puffed up with intellectual superiority, puts the laws which he has elucidated in the place of the Creator, whose personality and ever-working omnipresence he ignores.

In studying, therefore, the laws which are exhibited in the economy of living beings, let us never, in the pride of science and philosophy, forget Him who not only created all things but upholds all things, and by whom all things consist. While we apply ourselves with the earnestness of zealous students to examine those wondrous works which are sought out of all that have pleasure therein, let us take everything in connection with that Word which is the sole record of Truth, and which, as coming from the God of nature, must be in perfect harmony with the laws of nature.

The Botanist, in prosecuting his researches, takes an enlarged and comprehensive view of the vegetation with which the earth is clothed. $\mathrm{He}$ considers the varied aspects under which plants appear in the different quarters of the globe, from the Lichen on the Alpine summits or on the Coral reef, to the majestic Palms, the Bananas, and Baobabs of tropical climesfrom the minute aquatics of our northern pools to the gigantic Victoria of the South American waters-from the parasitic fungus, only visible by the aid of the microscope, to the enormous parasite discovered by Raftles in the Indian Archipelago.

It is interesting to trace the relation which all these plants bear to each other, and the mode in which they are adapted to different climates and situations. The lichens are propagated by spores or germs so minute as to appear like thin dust, and so easily carried by the wind that we can scarcely conceive any place which they cannot reach. They are the first occupants of the sterile rock and the coral-formed island-being fitted to derive 
the greater part of their nourishment from the atmosphere and the moisture suspended in it. By degrees they act on the rocks to which they are attached, and cause their disintegration. By their decay a portion of vegetable mould is formed, and in progress of time a sufficient quantity of soil is produced to serve for the germination of the seeds of higher plants. In this way the coral island is, in the course of years, covered with a forest of coco-nut trees. Thus it is that the most despised weeds lay the foundation for the denizens of the wood; and thus, in the progress of time, the sterile rock presents all the varieties of meadow, thicket, and forest.

The Creator has distributed His floral gifts over every part of the globe, from the poles to the equator. Every climate has its peculiar vegetation, and the surface of the earth may be divided into regions characterised by certain predominating tribes of plants. The same thing takes place on the lofty mountains of warm climates, which may be said to present an epitome of the latitudinal distribution of plants. Again, if we descend into the bowels of the earth, we find there traces of vegetation-a vegetation, however, which flourished at distant epochs of the earth's history, and the traces of which are seen in the coal, and in the fossil plants which are met with in different strata. By the labours of Brongniart, Goeppert, Schimper, and others, these fossil remains have been rendered available for the purposes of science. Many points have been determined relative to their structure, as well as in regard to the climate and soil in which they grew, and much aid has been afforded to the Geologist in his investigations.

The bearings which Botany has on Zoology are seen when we consider the lowest tribe of plants, such as Diatomacer. These bear a striking resemblance to the lowest animals, and have been figured as such by Ehrenberg and others. The observations of Thwaites on Conjugation have confirmed the view of the vegetable nature of many of these bodies. There appear, however, to be many productions which occupy a sort of intermediate territory between the animal and regetable kingdom, and for the time being the Botanist and Zoologist must consent to joint occupancy. The application of botanical science to Agriculture and Horti- 
culture has of late attracted much attention, and the chemistry of plants has been carefully examined by Liebig, Mülder, and Johnston. The consideration of the phenomena connected with germination and the nutrition of plants has led to important conclusions as to sowing, draining, ploughing, the rotation of crops, and the use of manures.

The relation which Botany bears to Medicine has often been misunderstood. The medical student is apt to suppose that all he is to acquire by his botanical pursuits is a knowledge of the names and orders of medicinal plants. The object of the connection between scientific and mere professional studies is here lost sight of. It ought ever to be borne in mind by the medical man, that the use of the collateral sciences, as they are termed, is not only to give him a great amount of general information, which will be of value to him in his after career, but to train his mind to that kind of research which is essential to the student of medicine, and to impart to it a tone and a vigour which will be of the highest moment in all his future investigations. What can be more necessary for a medical man than the power of making accurate observations, and of forming correct distinctions and diagnoses? These are the qualities which are brought into constant exercise in the prosecution of the botanical investigations to which the student ought to turn his attention, as preliminary to the study of practical medicine. In the prosecution of his physiological researches, it is of the highest importance that the medical man should be conversant with the phenomena exhibited by plants. For no one can be reckoned a scientific physiologist who does not embrace within the range of his inquiries all classes of animated beings; and the more extended his views, the more certain and comprehensive will be his generalisations.

To those who prosecute science for amusement, Botany presents many points of interest and attraction. Though. relating to living and organised beings, the prosecution of it calls for no painful experiments nor forbidding dissections. It adds pleasure to every walk, affords an endless source of gratification, and it can be rendered available alike in the closet and in the field. The prosecution of it combines healthful and spirit-stirring recrear 
tion with scientific study; and its votaries are united by associations of no ordinary kind. He who has visited the Scottish Highlands with a botanical party, knows well the feelings of delight connected with such a ramble-feelings by no means of an evanescent nature, but lasting during life, and at once recalled by the sight of the specimens which were collected. These apparently insignificant remnants of vegetation recall many a tale of adventure, and are associated with the delightful recollection of many a friend. It is not indeed a matter of surprise that those who have lived and walked for weeks together in a Highland ramble, who have met in sunshine and in tempest, who have climbed together the misty summits, and have slept in the miserable shieling-should have such scenes indelibly impressed on their memory. There is, moreover, something peculiarly attractive in the collecting of alpine plants, Their comparative rarity, the localities in which they grow, and frequently their beautiful hues, conspire in shedding around them a halo of interest far exceeding that connected with lowland productions. The alpine Veronica displaying its lovely blue corolla on the verge of dissolving snows; the Forgetme-not of the mountain summit, whose tints far excel those of its namesake of the brooks; the Woodsia, with its tufted fronds, adorning the clefts of the rocks; the nival Gentian concealing its eye of blue in the ledges of the steep crags ; the alpine Astragalus enlivening the turf with its purple clusters; the dwarf mountain Lychnis choosing the stony and dry knoll for the evolution of its pink petals ; the Sonchus, raising its stately stalk and azure heads in spots which try the enthusiasm of the adventurous collector; the pale-flowered Oxytropis confining itself to a single British cliff; the Azalea forming a carpet of the richest crimson; the Saxifrages, with their white, yellow, and pink blossoms, clothing the sides of the streams; the Saussurea and Erigeron crowning the rocks with their purple and pink capitula; the pendent Cinquefoil blending its yellow flowers with the white of the alpine Cerastiums and the bright blue of the stony Veronica; the stemless Silene giving a pink and velvety covering to the decomposing granite; the yellow Hieracia, whose varied transition forms have been such a fertile cause of dispute among Botanists; the slender and deli- 
cate grasses, the chickweeds, the carices, and the rushes, which spring up on the moist alpine summits; the graceful ferns, the tiny mosses, with their urn-like thecre, the crustaceous dry lichens, with their spore-bearing apothecia; all these add such a charm to Highland Botany, as to throw a comparative shade over the vegetation of the plains.

Many are the important lessons which may be drawn from the study of plants when prosecuted in the true spirit of Wisdom. The volume of Creation is then made the handmaid of the volume of Inspiration, and the more that each is studied, the more shall we find occasion to observe the harmony that subsists between them. It is only Science, falsely so-called, which is in any way opposed to Scripture. Never, in a single instance, remarks Gaussen, do we find the Bible in opposition to the just ideas which Science has given us regarding the form of our globe, its magnitude, its geology, and the productions which cover the surface. "The invisible things of God from the creation of the world are clearly seen, being understood by the things that are made, even his eternal power and Godhead." The more minutely we examine the phenomena of the material world, and the more fully we compare the facts of Science with Revealed Truth, the more reason shall we have to exclaim, in adoring wonder, with the Psalmist of old, "O Lord! how manifold are thy works! in wisdom hast thou made them all ; the earth is full of thy riches." 



\section{TABLE OF CONTENTS.}

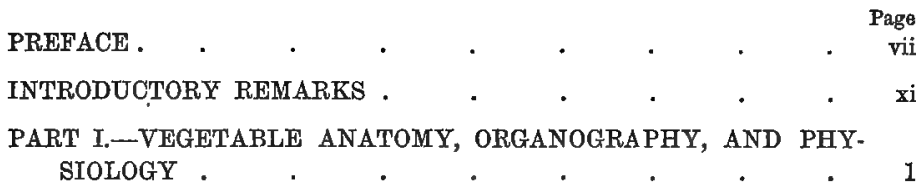

CHAPTER I.-ELEMENTARY ORGANS, OR VEGETABLE TISSUES 1

Section I.-CeLlular Tissue . . . . . . 3

1. Form and Arrangement of Cells . . . . 3

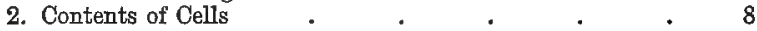

3. Development and Functions of Cells : $\quad$. $\quad$. 13

Section II. - Vascular TISSUE $\quad$. . . 16

1. Form and Arrangement of Vessels . . . 16

2. Development and Functions of Vessels . . . 21

Tabular Arrangement of Vegetable tissues . . . . 23

CHAPTER II.-COMPOUND ORGANS FORMED BY THE TISSUES 25

SECTION I.—ORGaNS OF NUTRITION OR VEGETATION . . 25

1. Structure, Arrangement, and Special Functions . . 25

General Integument . . . . . . 25

Stomata $. \quad . \quad . \quad . \quad . \quad . \quad . \quad 28$

Hairs . . . . . . 30

Glands $\quad . \quad$. $\quad . \quad$. $\quad 34$

Functions of the Epidermis . . . . $\quad 36$

Root or Descending Axis . $\quad$ - $\quad$. $\quad$. $\quad 37$

Structure of Roots . . . . . . 37

Forms of Roots . . . . . 40

Functions of Roots . $\quad . \quad$. $\quad$. $\quad$. $\quad$. 43

Stem or Ascending Axis . $\quad$. $\quad$. $\quad$. $\quad$. $\quad$. 44

Forms of Stems . . . . . . . 44

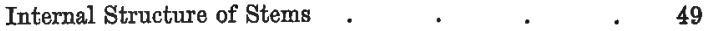

Exogenous or Dicotyledonous Stem . $\quad$ - $\quad$. 49

Anomalies in its Structure . $\quad$. $\quad$. 60

Endogenous or Monocotyledonous Stem $\quad$. $\quad$. 64

Acrogenous or Acotyledonous Stem . . $\quad 70$

Formation of the different parts of Stems, and their special Functions . . . . 75

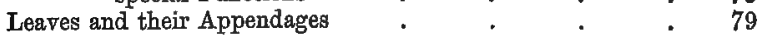

Structure of Leaves $\quad . \quad . \quad . \quad . \quad . \quad .79$ 


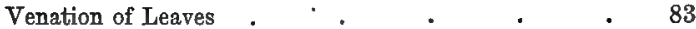

Forms of Simple Leaves . . . . $\quad$. $\quad 85$

Forms of Compound Leaves . $\quad$. $\quad$. $\quad 91$

Petiole or Leaf-Stalk . $\quad$. $\quad$. $\quad$ - $\quad$. 94

Stipules . $\quad . \quad$. $\quad 97$

Anomalous Forms of Leaves and Petioles . $\quad$. 99

Structure and Form of Leaves in the Great Divisions of the Vegetable Kingdom . . . . 100

Phyllotaxis, or the Arrangement of Leaves on the Axis 101

Leaf-buds . . . . . . 108

Vernation : $\quad . \quad$ : $\quad . \quad$ : 110

Aerial and Subterranean Leaf-buds : : : 114

Anomalies and Transformations of Leaf-buds . $\quad 116$

Tendrils . . . 120

Special Functions of Leaves : $\quad: \quad$ : $\quad 121$

Section II.-Generat VIEW OF THE FunOtions OF THE NUTRITIVE ORGANS

1. Food of Plants, and Sources whence they derive their

Nourishment

Chemical Composition of Plants : $\quad$. $\quad 124$

Organic Constituents and their Sonrces . $\quad$. 126

Inorganic Constituents and their Sources . $\quad 128$

Chemical Composition of Soils . . 134

Application of Manure . . . . . 136

Various kinds of Manure $\quad$. $\quad . \quad 136$

Epiphytic and Parasitic Plants $\quad$. $\quad$. 141

2. Absorption and Circulation of Fluids . . . 142

3. Respiration of Plants . . . . . 155

Effects of Certain Gases on Living Plants $\quad 159$

4. Products and Secretions of Plants . . . 161

Semion III.-ORgans of RePRoduction . . . 171

Structure, Arrangement, and Functions . 171

1. Inflorescence or the arrangement of the flowers on the axis

Tabular View of Inflorescence or Anthotaxis * 172

2. Bracts or Floral leaves $\quad$. $\quad . \quad 189$

3. The Flower and its Appendages $\quad$. $\quad . \quad$. 191

Flower-bud, xstivation . . . 193

External Floral Whorls, or the Floral Envelopes $\quad 195$

Calyx . . . . . . 195

Corolla : $\quad . \quad$. $\quad . \quad$. $\quad$. 200

Nectaries and Anomalies of the Petals $\quad$. 209

Inner Floral Whorls, or the Essential Organs of Reproduction

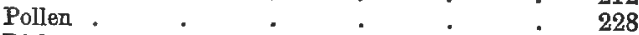

Disk . . . . . . . 234

Pistil, Carpels, and Placenta $\quad$. $\quad$. $\quad$. 235

4. Functions of the Florai Envelopes $\quad \cdot \quad \cdot \quad 251$

5. Functions of the Stamens and Pistil; Fertilisation or

Fecundation 
Fertilisation in Cryptogamous or Flowerless Plants

Fertilisation in Phanerogamous or Flowering Plants

Embryogenic process in Gymnospermons Flowering Plants .

Embryogenic process in Angiospermous Flowering Plants

6. Fruit or the Pistil arrived at maturity ${ }^{\circ} \quad{ }^{*} \quad \cdot \quad 298$

Fruits which are the produce of a single flower : 309

Fruits which are the produce of several flowers united

Tabunar • 316

7. Maturation of the Pericarp

Ripening of

Grafting ".

8. Seed or Fertilised Opule arrived at Maturity - • 323

Embryo . . . : 335

9. Functions of the Seed. $\quad$. $\quad$. $\quad 343$

Germination . . . . . . 344

Vitality of Seeds $\quad . \quad$. $\quad . \quad$. 348

Transportation of Seeds . . . $\quad 349$

Direction of Plumule and Radicle . $\quad$. 352

Proliferous Plants . $\quad$. $\quad$. $\quad 357$

Duration of the Life of Plants . $\quad$. $\quad 359$

10. General Observations on the Organs of Plants, and on

the mode in which they are arranged . . $\quad 362$

Symmetry of Organs . . . . 363

Teratology : . . . . 365

Section IV. - Some Germeral Phenomena donnecteid with VEGETATION

1. Vegetable Irritability . . . . . . 374

2. Temperature of Plants $\quad$. $\quad . \quad$. $\quad . \quad 388$

3. Luminosity of Plants . $\quad$. $\quad$. $\quad$. $\quad$. 389

4. Colours of Plants $\quad$. $\quad$ : $\quad$. $\quad$. $\quad . \quad 390$

5. Odours of Flowers $\quad$. $\quad . \quad$. $\quad . \quad 396$

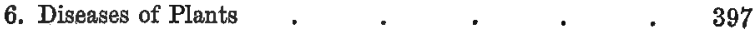

PART II. -SYSTEMATIC BOTANY, TAXONOMY, OR THE CLASSIFICATION OF PLANTS • . . . 405

CHAPTER I._SYSTEMS OF CLASSIFICATION . . 405

Nomenclature and Symbols . . . . . . . 411

Linnæan System . . . . . . . . . 413

Natural System $\quad$. $\quad$. $\quad$. $\quad$. $\quad$. $\quad .415$

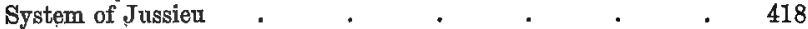

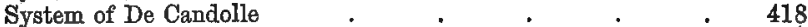

System of Endlicher . $\quad$. $\quad$. $\quad$. $\quad$. $\quad . \quad 419$

System of Lindley $\quad$ - $\quad . \quad$. $\quad . \quad$. $\quad . \quad 420$

Henslow's Comparison of Systems . . . . . 422

Natural arrangement by Hooker . . . . . 423 
CHAPTER II.-CHARACTERS OF THE CLASSES AND NATURAL ORDERS .

Sub-Kingdom I.-Phanerogamous Plants . . 425

Class I.-Dicotyledones or Exogenæ . . $\quad 425$

Sub-class 1.-Thalamifloræ . . . 425

1. Ranunculacex . 426

2. Dilleniacer . . 428

3. Magnoliaceæ . 428

4. Anonaceæ . . 429

5. Menispermaceæ 430

6. Berberidacex . 430

7. Nymphæaceæ . 431

8. Sarraceniaceæ .432

9. Papaveraceæ . 433

10. Fumariaceæ . 434

11. Crucifere . 434

12. Capparidaceæ . 437

13. Resedacex . 438

14. Cistacex . . 439

15. Canellaceæ . . 439

16. Biraceæ. . . 439

17. Violacex . . 440

18. Droseraceæ . . 441

19. Polygalaceæ . 441
20. Tremandraceæ. 442

21. Tamaricaceæ . 442

22. Frankeniaceæ . 443

23. Elatinaceæ - . 443

24. Caryophyllaceæ 444

25. Portulacaceæ . 445

26. Malvaceæ , . 446

27. Sterculiaceæ . 448

28. Byttneriacex . 449

29. Tiliacex . . 450

30. Dipterocarpaceæ 451

31. Chlænaceæ. . 451

32. Ternstromiaceæ 452

33. Olacaceæ . . 453

34. Aurantiaceæ . 453

35. Hypericaceæ . 455

36. Guttiferæ . 456

37. Erythroxylaceæ 457

38. Malpighiaceæ . 457
39. Aceraceæ - . 458

40. Sapindaceæ . 458

41. Meliaceæ . 459

42. Cedrelaceæ . . 460

43. Ampelideæ . . 460

44. Geraniacexe . . 462

45. Vivianacer .463

46. Linaceæ . . . 463

47. Balsaminaceæ . 464

48. Oxalidaceæ. . 464

49. Tropæolaceæ . 465

50. Pittosporaceæ . 465

51. Zygophyllaceæ. 466

52. Rutaceæ . . 467

53. Xanthoxylaceæ 468

54. Simarubaceæ . 468

55. Ochnaceæ . . 469

56. Coriariacese . 470

Sub-class 2.-Calycifloræ. Section 1.-Polypeteho. - 470

57. Stackhousiaceæ 470

58. Celastraceæ . 471

59. Staphyleacex . 472

60. Rhamnaceæ . 472

61. Anacardiaceæ . 473

62. Burseraceæ. . 475

63. Connaraceæ . 476

64. Leguminosæ . 476

65.-Moringaceæ . 482

66. Rosaceæ . . 483

67. Calycanthaceæ. 487

68. Lythracere . . 487
69. Rhizophoraceæ 488

70. Vochysiaceæ . 488

71. Combretaceæ . 488

72. Melastomaceæ 489

73. Philadelphaceæ 489

74. Myrtace . . 490

75. Onagracex . . 492

76. Halorageaceæ . 493

77. Loasaceæ . . 493

78. Cucurbitaceæ . 494

79. Papayaceæ . 496

80. Passifloraceæ . 497
81. Turneraceæ. 498

82. Paronychiaceæ . 498

83. Crassulaceæ 499

84. Ficoideæ . . 500

85. Cactaceæ . 500

86. Grossulariaceg 502

87. Saxifragaceæ . 502

88. Bruniaceæe . 504

89. Hamamelidaceæ 504

90. Umbelliferæ . 505

91. Araliaceæ . . 509

92. Cornacex . . 509

Sub-class 2.-Calycifloræ. Section 2.-Gamopetaloe. . 510

93. Caprifoliaceæ . 510

94. Rubiaceæ . . 511

95. Valerianaceæ . 514

96. Dipsacaceæ. . 515
97. Calyceraceæ . 515|101. Stylidiaceæ . . 523

98. Compositæ . . 517 102. Campanulaceæ . 524

99. Brunoniaceæ . 522 103. Lobeliaceæ . 525

100. Goodeniaceæ . 522 104. Vacciniaceæ .525

Sub-class 3.-Corollifloræ

526

105. Ericaceæ . . $526 \mid$ 112. Jasminaceæ . $531 \mid$ 119. Gentianaceæ . 539 106. Epacridaceæ . 527 113. Columelliaceæ. 532 120. Bignoniaceæ : 540 107. Ebenaceæ . . 528 114. Oleaceæ . . . 532 121. Gesneraceæ: . 541 108. Styracaceæ. . 529 115. Salvadoraceæ . 534 122. Polemoniaceæ . 541 109. Aquifoliaceæ . 529 116. Asclepiadaceæ . 534 123. Hydrophyllaceæ 542 110. Sapotaceæ . . 530 117. Apocynaceæ . 536 124. Convolvulaceæ. 542 111. Myrsinaceæ . 531 118, Loganiaceæ . 537 125. Cordiaceæ . . 545 
126. Boraginaceæ . $545 \mid$ 130. Labiatæ . . 552|134. Primulaceæ . 557

127. Solanaceæ . . 547 131. Verbenaceæ . 555 135. Plumbaginaceæ 559

128. Orobanchaceæ . 550 132. Acanthaceæ . 556 136. Plantaginaceæ. 559

129. Scrophulariaceæ 551 133. Lentibulariaceæ 557

Sub-class 4.-Monochlamydeæ. Section A.-Angiospermo $\quad .560$

137. Nyctaginaceæ. $560 \mid$ 153. Santalaceæ. . 574|168. Podostemaceæ. 588

138. Amaranthaceæ 562 154. Loranthaceæ . 574 169. Stilaginaceæ . 588

139. Chenopodiaceæ 562 155. Aristolochiaceæ 575 170. Monimiaceæ . 588

140. Phytolaccaceæ 563 156. Balanophoraceæ 577 171. Atherospermaceæ 589

141. Polygonaceæ . 563 157. Cytinaceæ . . 577 172. Lacistemaceæ . 589

142. Begoniaceæ .566 158. Rafflesiaceæ . 577 173. Chloranthace 590

143. Lauraceæ. . 566 159. Nepenthaceæ . 578 174. Saururaceæ . 590

144. Myristicaceæ . 569 160. Datiscaceæ . .578 175. Piperaceæ . . 590

145. Proteaceæ. . 570 161. Empetraceæ . 579 176. Salicaceæ . . 591

146. Elæagnaceæ . 570 162. Euphoṛbiaceæ, 579 177. Myricaceæ . . 592

147. Penæaceæ. . $571 \mid$ 163. Urticaceæ . . 583 178. Casuarinaceæ . 593

148. Thymelæaceæ . 571 164. Cannabinaceæ. 584 179. Betulaceæ . . 593

149. Aquilariaceæ . 572 165. Ulmaceæ . . 585 180. Platanaceæ. . 593

150. Chailletiaceæ . 572 166. Moraceæ . . 586 181. Corylaceæ . . 594

$\begin{array}{llll}\text { 151. Samydaceæ . } 573 & \text { 167. Ceratophyllaceæ } 588 & \text { 182. Juglandaceæ . } 595\end{array}$

152. Homaliaceæ . 573

Section B.-Oymnospermce $\quad$ - $\quad$. $\quad$ - $\quad$ - $\quad 529$

183. Coniferæ . . . $596 \mid \mathbf{1 8 4 .}$ Cycadaceæ . . 600

Class II.-Monocotyledones or Endogenæ . . . 601

Sub-class 1.-.Petaloider . , , 601

a.-Epigynæ . . . . . . . . 601

185. Hydrocharidaceæ601 189. Musaceæ . . $607 \mid$ 193. Dioscoreaceæ. 610

186. Orchidaceæ . 602 190. Iridaceæ . . 608 194. Amaryllidaceæ 611

187. Zingiberaceæ . 605 191. Burmanniaceæ. 610 195. Hypoxidaceæ 612

188. Marantaceæ .606 192. Hæmodoraceæ . 610 196. Bromeliaceæ . 612

b.-Нypogynæ

197. Liliaceæ • $613 \mid 201^{\circ}$. Gilliesiaceæ *618| 205. Palmæ : 619

198. Melanthaceæ . 616 202. Pontederiaceæ . 618 206. Commelynaceæ 622

199. Smilaceæ . .617 203. Xyridaceæ . .618 207. Alismaceæ . 623

200. Trilliaceæ . . $617 \mid$ 204. Juncaceæ . . $619 \mid 208$. Butomaceæ . 623

c.-Incompletæ

209. Pandanaceæ . . . 624 |211. Naiadaceæ . . . 626

210. Araceæ . . . . $625^{\prime} 212$. Restiaceæ . . . 627

213. Cyperaceæ Sub-class 2.-Glumiferæ $627 \mid 214$. Graminex : . . $\quad 627$

Sub-Kingdom II. -Cryptogamous Phants . . . . . 635 Class III.-Acotyledons . . . . . . . . 635

Sub-class 1.-Acrogenæ 635

215. Equisetace» . $636 \mid$ 217. Marsileaceæ , $640 \mid 219$. Musci . 641

216. Filices - . $637 \mid$ 218. Lycopodiaceæ $640 \mid 220$. Hepaticæ . 643

Sub-class 2.-Thallogenæ • $647 \mid 223$. Characeæ : 644

$$
\text { 224. Algœ . . . } 652
$$

Additional Remarles on Fertilisation of Gramineæ $\quad$. $\quad 656$ 
PART III.-GEOGRAPHICAL BOTANY, OR THE DISTRIBUTION

I. - EPIRRHEOLOGY, OR THE INTLUENCE OF VARIOUS EXTERNAT

Agents on Prants

1. Effects of Temperature . $\quad . \quad 658$

2. Effects of Moisture $\quad . \quad 662$

3. Effects of Soil, Light, and other Agents : $\quad$ : $\quad$. 662

II.-Dissemination of Plants $\quad$. $\quad . \quad$. 668

1. Agents employed in their Dissemination . . 668

2. General and Findemic Distribution of Plants : $\quad$. 670

3. Conjectures as to the mode in which the Earth was originally clothed with Plants

4. Distribution of Plants considered Physiognomically and Statistically

Physiognomy of Vegetation

5. Phyto-geographical Division of the Globe

671

675

\begin{tabular}{ll|l} 
Latitudinal Range of Vegetation 678 & Altitudinal Range of Vegetation $\quad 695$
\end{tabular}

\begin{tabular}{l|ll} 
Schouw's Phyto-geographic Re- & iZones of Marine Vegetation . 699
\end{tabular} gions . . 679 Distribution of Plants in Britain 702

Meyen's Phyto-geographical Zones 692 Acclimatising of Plants . . 716

PART IV.--FOSSIL BOTANY - . $\quad$ - $\quad$. $\quad$. 718

\begin{tabular}{l|ll} 
Character and arrangement of Fossil & Fossiliferous Rocks . & 723
\end{tabular}

Plants

719 Fossil Plants of different Strata

1. Flora of the Primary or Palæozoic Period . . . 728

Reign of Acrogens . . . . . 728

2. Flora of the Secondary or Mesozoic Period . . . 745

Reign of Gymnosperms . $\quad$. $\quad$. $\quad$. $\quad$. 745

3. Flora of the Tertiary or Cainozoic Period . $\quad$. $\quad$. 750

Reign of Angiosperms $\quad$. $\quad$. $\quad . \quad$. $\quad .750$

APPENDIX • . . . . . . . $\quad$. 761

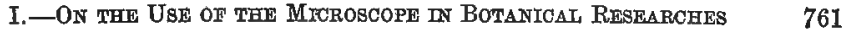

II.-ON Collecting and Examining Plants, and on the FormaTION OF A HRRBARIOMI . . . . . . 795

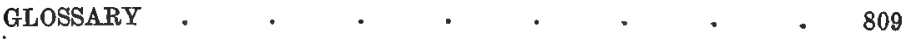

ABBREVIATIONS AND SYMBOLS . $\quad$ - . $\quad . \quad$. 830

INDEX 


\section{PART I.}

\section{VEGETABLE ANATOMY, ORGANOGRAPHY, AND PHYSIOLOGY.}

Botany is that branch of Biological science which comprehends the knowledge of all that relates to the Vegetable kingdom. It embraces a consideration of the external configuration of plants, their structure, the functions which they perform, the relations which they bear to each other, and the uses to which they are subservient. It takes a comprehensive view of the vegetation with which the earth is clothed at the present day, and of that which covered it at former epochs. It has been' divided into the following departments:-1. Structural Botany, or Organography, having reference to the anatomical structure and the forms of the various parts of plants, including vegetable histology, or the microscopical examination of tissues ; and morphology, or the transformations which the organs undergo. 2. Physiological Botany, the consideration of the functions performed by the living plant, or the phenomena of life as exhibited by its various organs during the processes of development, growth, and multiplication. 3. Systematical, or Taxological Botany, the arrangement and classification of plants. 4. Geographical Botany, the distribution of plants in space, 5. Fossil, or Palceontological Botany, the distribution of plants in time, with a deseription of the form and.structure of the plants found in a fossil state in the various geological formations.

\section{CHAPTER I.}

ELEMENTARX ORGANS, OR VEGETABLE TISSUES.

IN their earliest and simplest state plants consist of minute vesicles, each of them bounded by a transparent membrane, which is composed of a substance called Cellulose. This.substance is of general occurrence, and constitutes the basis of vegetable tissues. It is composed of carbon, hydrogen, and oxygen, and the chemical formula representing 
it is $\mathrm{C}_{6} \mathrm{H}_{10} \mathrm{O}_{5}$ * It was long considered as essentially a vegetable product, not found in animal structures; but it has now been detected in the tissues of the ascidia, and other molluscous animals. It is a white substance, insoluble in water, alcohol, or ether, but soluble in an ammoniacal solution of cupric oxide. It is allied to starch, into which it is convertible by the action of heat, the addition of sulphuric acid, or caustic potash. It becomes yellow on the addition of iodine, and when acted upon by iodine and sulphuric acid, a blue colour, like that of iodide of starch, is produced. The acid appears to convert the cellulose into starch. When cellulose is acted on by a mixture of equal volumes of strong sulphuric and nitric acid it forms gun-cotton (pyroxylin), ( $\pi \tilde{u} g$, fire, and $\xi u \lambda_{0}$, wood), and this when dissolved in a mixture of ether and alcohol yields a solution called collodion. The membrane formed by cellulose is permeable by fluids, and becomes altered in the progress of growth, so as to acquire various degrees of consistence. A modification of cellulose occurs in the form of woody matter or lignin. The hard cells in the stone of the peach, in the shells of other fruits, and in the coats of seeds, consist of cellulose, with deposits of lignin. In the advanced stages of growth, plants consist of two kinds of tissue, Cellular and Vascular, which, under various modifications, constitute their Elementary organs; and these, by their union, form the Compound organs, by which the different functions of plants are carried on.

The elementary organs are vesicles and tubes, which vary in form and size, and, when united in different ways, constitute the tissues. Vesicles or cells may be defined as closed sacs, composed of

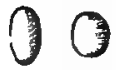
solid membrane, containing fluid or semifluid matter, and having a diameter nearly equal in every direction (fig. 1);

Fig. 1. while tubes or vessels are similar sacs with the longitudinal much exceeding the transverse diameter (figs. 3, 4). Cellular tissue is formed by a combination of these cells or vesicles; a similar union of vessels constitutes vascular tissue.

Fig. 1. Vesicles or small cells, each of them enclosed by a membrane of cellulose.

* These symbols indicate the equivalents of Carbon (C), Hydrogen (H), and Oxygen (O), which enter into the composition of cellulose. For the meaning of these and other chemical symbols, see Chap. II. Seet. I. Div. 2, on the Food of Plants. 


\section{Section: I.-Celiduar Tissut.}

\section{1.-Form and Arrangement of Cells.}

Cellolar TIssue is formed by the union of minute vesicles or bladders, called cells, cellules, or utricles. This tissue is often called Parenchyma ( $\pi \alpha \rho a$, through, and " $\gamma_{\chi} \psi \mu \alpha$, an infusion). The terms Parenchymatous, Areolar, Utricular, and Vesicular, when

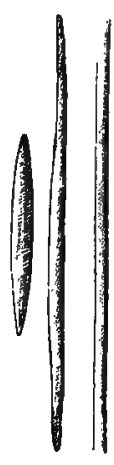

Figs.

2. 3. 4 . applied to vegetable tissues, may be considered as synonymous. The individual cells of which this tissue is composed, when allowed to develop equally in all directions, are usually of a more or less rounded form (figs. 5, 6, 7); but during the progress of development they frequently become more elongated in one direction than in another (fig. 2), and often assume angular or polyhedral forms (fig. 8).

The following names have been applied by Morren and other authors to the tissue made up of variously-formed cells:-1. Parenchyma, a general name for cellular tissue, but often applied to that consisting of dodecahedral cells (figs. 8, 12, 13), which, when cut in any direction, exhibit a hexagonal form (figs. 14, 15), and hence the

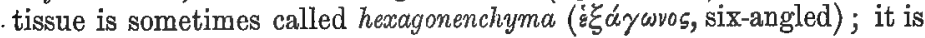

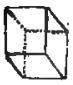

Fig. 9.

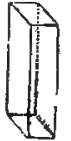

Fig. 10 .

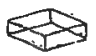

Fig. 11.

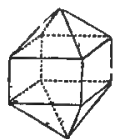

Fig. 12.

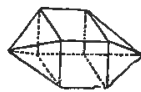

Fig. 13.

seen in the pith of the Elder, and in young palm sterns. 2. Sphorenchyma (бфaị̂ $\alpha$, a sphere), spheroidal cells (fig. 5). 3. Merenchyma

Fig. 2. F'tusiform or spindle-shaped cell. 8. Cells, or utricles, separate and combined. the forms of cells.
Figs. 3, 4. Tubes or vessels. Figs. 5, 6, 7 Figs, 9, 10, 11, 12, 13. Figures representing 


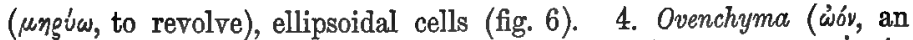
egg), oval cells. Round, elliptical, and oval cells, are common in

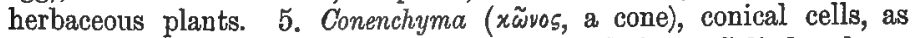
hairs. 6. Columnar cellular tissue, divided into Cylindrenchyma

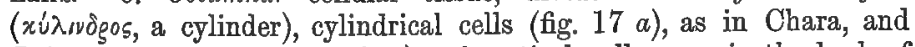

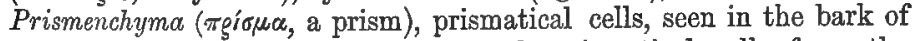
some plants (fig. 10). When flattened, prismatical. cells form the muriform. (murus, a wall, like bricks of a building) tissue of the medullary rays of woody stems, and when much shortened they

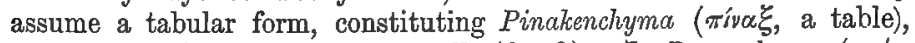
tabular cells (fig. 11), or square cells (fig. 9). 7. Prosenchyma ( $\pi$ gós, indicating addition), or Atractenchyma (äręrros, a spindle), fusiform or spindle-shaped cells, seen in woody structures (fig. 2). 8. Colpenchyma ( $x^{\prime} \lambda \pi 05$, a sinus or fold ), sinuous or waved cells, as in the cuticle of leaves. 9. Cladenchyma ( $\varkappa \lambda \alpha^{\prime} \delta 05$, a branch), branched cells, as in some hairs. 10. Actinenchyma (á\%ric, a ray), stellate or radiat-

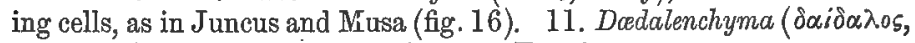
entangled), entangled cells, as in some Fungi.

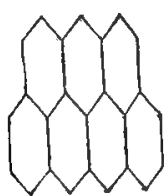

Fig. 14.

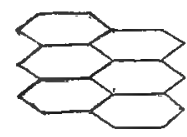

Fig. 15.

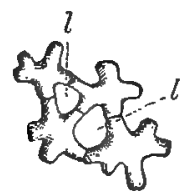

Fig. 16.

The size of cells varies not less than their figure in different plants, and in different parts of the same plant. They are frequently seen from $\frac{1}{800}, \frac{1}{500}$, to $\frac{1}{1000}$ of an inch in diameter. In cork, which is cellular, there are about a thousand in the length of an inch. In the pith of Elder cells $\frac{1}{120}$ of an inch in diameter are seen. In many succulent vegetables, and in the pith of some aquatic plants, large cells ranging from $\frac{1}{50}$ to $\frac{1}{30}$ of an inch in diameter occur; while the cells in spores of Fungi have been computed at $\frac{1}{500}$ of an inch in diameter. In a cubic inch of the leaf of a carnation, there are said to be upwards of three millions of cells.

Each cell has originally a separate membranous wall, but in the progress of growth the walls of contiguous cells may become united. When cells are united by their extremities (fig. 17), their, partitions are occasionally absorbed so as to form continuous tubes. When cells are united in a rectilinear manner, those in contiguous rows are

Figs. 14, 15. Hexagonal cells, cut longitudinally and transversely. Fig. 16. Branching, stellate, or radiating cells of Vicia Faba, the common bean. $l l$, Intercellular lacunx, or air-spaces between the cells. 
either directly opposite to each other, that is, are placed at the same height (fig. 18), or are alternate, from being placed at different heights (fig. 19); cells sometimes communicate with each other laterally (fig. $20 \mathrm{a} a$ ). Isolated cells, as spores of sea-weeds, occasionally have free filaments, or cilia (cilium, an eyelash), developed on their surface.

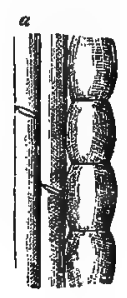

Fig. 17.

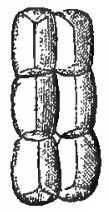

Fig. 18.

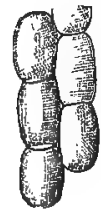

Fig. 19.

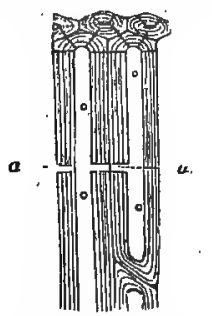

Fig. 20.

The simplest kinds of plants, as mushrobms and sea-weeds, are composed entirely of cellular tissue, and are called Cellulares. The pulpy and succulent parts of all plants contain much cellular tissue, and the object of horticultural operations is to increase the quantity of this tissue in ordinary fruits and vegetables. The pith of trees, and plants during their early development are cellular; so also are cotton and rice-paper. The cell may be considered as the ultimate structural element of all organisms. In the simplest vegetable forms, as in unicellular algæ, it is adequate to all the purposes of plant life. Vital operations are carried on in all plants by means of cells, the constitution and functions of which vary according to the nature of the plants and the position in the scale of organisation which they occupy. In the higher classes of plants, certain cells are concerned in the secretion of organisable products, which are elaborated by others into new tissues. The life of the higher species of plants results from the regular action of cells, which are of unequal value as regards the formation of new organs and new products. In cells there are observed the absorption and movements of fluids, the elaboration of these by exposure to air and light, and the formation of new cells. Schacht remarks that a plant is composed of one or more cells, and that it is only, in the lowest species that the cells are of the same value; in other words, are of the same chemical and physical nature, and of the same physiological importance. Even amongst the mushroom and seaweed orders, it is only the lowest plants which have cells concerned alike in the processes of vegetation and reproduction. The higher planits of these orders are composed of parts having different values.

Figs. 17, 18, 19. Cells united together by their extremities. thickened cells from the root of the Date Palm. a a, Canals of communication.

Fig. 20. Elongated 
In general, no visible openings can be detected in cells, although fluids pass readily into and out of them. Harting and Mülder, however, state, that they have observed perforations in the cells of Hoya carnosa, Asclepias syriaca, Cycas revoluta, Virginian spiderwort, and Traveller's joy. In one cell (from a Euphorbia), having a transverse diameter of 0.03777 millimetres, ${ }^{*}$ they counted 45 minute holes. In some mosses, also, openings have been found in the cells, as in Sphagnum and Leucobryum glaucum.

Porous or PrtTed Celds are those in which the membrane is thickened at certain parts, leaving thin rounded spots intervening, which, when viewed by transmitted light, appear like perforations or pores (figs. 21, 28). The unequal deposit of the internal encrusting cellulose or woody matter, is the cause of this condition. The pores of contiguous cells usually correspond as regards position, and sometimes the membrane becomes absorbed between them, so as to allow a direct communication by means of lateral canals, as is seen in the cells from the root of the Date (fig. $20, a a$ ). When porous cells are united end to end, so as to form tubes,

21. ${ }^{\text {Figs. }} 22$ the tissue is denorninated articulated Bothrenchyma or

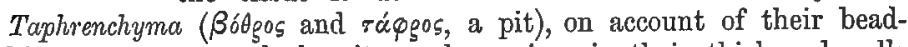
like appearance, and the pits or depressions in their thickened walls (fig. 22). Pitted cells are seen in Elder pith.

FIBROus oR SPIRAL CELLS are those in which there is a spiral elastic fibre coiled up in the inside of the membrane (fig. 23). When united they form fibro-cellular tissue, or Inenchyma (iv\&5, fibres). These

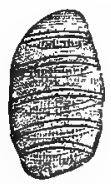

Fig. 23.

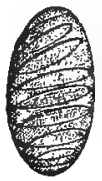

Fig. 24.

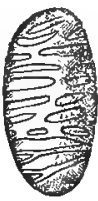

Fig. 25.

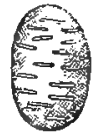

Fig. 26.

cells generally consist of membrane and fibre combined, but the former appears to be sometimes absorbed wholly or partially during the progress of growth. The membrane, in some instances, is easily dissolved by water, and then the elastic close convolutions of the fibre spring out with considerable force, as in the outer covering of the seeds of Collomia linearis, and in the pericarp of Salvia. Spiral cells

Fig. 21. Porous cell, from the Elder (Sambucus nigra).

Fig. 22, Articulated Bothrenchyma, or Taphrenchyma, from Mistleto, having a moniliform appearance. Figs. 23, 24, 25. Spiral, annular, and reticulated cells, from Mistleto (Viscum album). Fig. 26. Scalariform and dotted cell, from Elder (Sambucus nigra). 
abound in many of the Orchidaceous plants, as Oncidium and Pleurothallis ruscifolia, also in the garden Balsam, in the leaf of the moss called Sphagnum, and in the Cactus tribe. They are also found in the inner covering of anthers, in the spore-cases of many of the lower tribes of plants, and in the coats of the seeds' of Acanthodium spicatum, Sphenogyne speciosa, Calempelis scaber, and Cobæa. The spiral filaments sometimes exhibit peculiar movements when placed in water.

The fibre in these cells varies from about $\frac{x}{2000}$ to $\frac{1}{1080}$ of an inch in diameter; it is solid, and presents either a circular, an elliptic; or a quadrangular section. The coils of the fibre sometimes separate from each other, and become broken up and united in various ways, so as to appear in the form of rings, bars, or dots, thus giving rise to annular (fig. 24), reticulated (fig. 25), scalariform and dotted cells (fig. 26), which constitute the spurious or imperfect Inenchyma of authors. Annular cells are met with in Opuntia, and in the endothecium of Cardamine pratensis ; reticulated cells, caused by fibres forming a sort of mesh or network, are seen in the wing of the seed of Swietenia, the pericarp of Picridium tingitanum, the leaf of Sanseviera guineensis, and the pith of Rubus odoratus and Erythrina Corallodendron, as well as in the endothecium of the sea-pink and the butterwort.

In certain parts of plants cells are placed closely together, and touch each other by flat surfaces, filling up space completely, and leaving no intervals; they then form the perfect Parenchyma of Schleiden (figs. 8, 27). In lax tissues, however, the cells retain a rounded shape, and then touch each other at certain points only, leaving intervals of various sizes and shapes, and forming the imperfect Parenchyma of Schleiden (figs. 7, 28). These intervals, when of moderate size and continuous, are called intercellular passages or canals; when large, irregular, and circumscribed, intercellular spaces, or Lacunce. (fig. 16, ll).

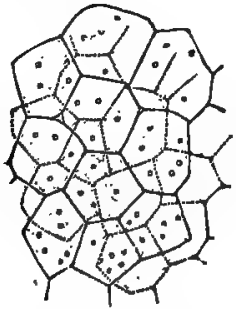

Fig. 27.

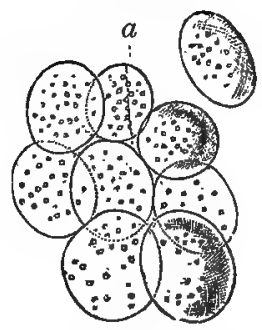

Fig. 28.

A difference of opinion prevails as to the mode in which cells are united together. Some maintain that the cell-walls in the young

Fig. 27. Cellular tissue, from pith of Fider. Fig. 28. Porous merenchyma, from Houseleek (Sempervivum tectorum). $\quad$, Intercellular canal. 
state unite together directly, and become agglutinated, more or less, according to their places of contact. Others, as Mohl and Henfrey, hold that there is an intercellular matter which acts as a sort of

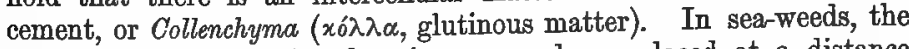
cells, of which the entire plant is composed, are placed at a distance from each other (fig. 29, a a), and the intervals are filled up by this intercellular substance (fig. 29, b), which thus forms a large part of their bulk. In the higher classes of plants, when the cells touch each other, the layer of intercellular matter must be very thin, except in the intercellular canals or spaces. Mirbel looks upon it as the

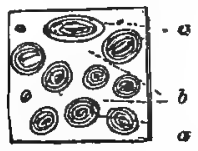

Fig. 29.

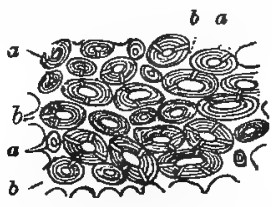

Fig. 30.

remains of the mucilaginous fluid in which the cells were originally developed, and which has become thickened to a greater or less degree, as in the root of the Date (fig. 30), where $a$ a a indicate the cells, and $b b b$ the interposed substance.

\section{2.-Contents of Cells.}

The external membrane of cells is composed of the unazotised substance called Cellulose, and in their interior a mucilaginous matter is contained, which undergoes changes in the progress of growth. This mucilaginous matter is the Protoplasm ( $\pi \rho \tilde{\omega} \pi 05$, first, and $\pi \lambda \alpha \dot{\alpha} \sigma \mu \alpha$, formative matter) of Mohl, the Cytoblastema (xiros, a cell, and

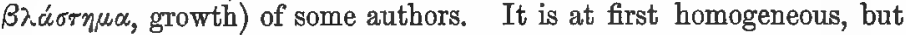
ultimately assumes a granular form. The appearance of granules may be regarded as the earliest evidence of the formative process. Protoplasm contains nitrogen in its composition, or is azotised, and it assumes a brownish colour when acted upon by iodine. It forms a mucilaginous layer on the inner surface of the cell-wall, and thus gives rise to the internal utricle of Harting and Mülder, the primordial utricle of Mirbel. This inner membrane is visible in the young state of the cell, and under the action of tincture of iodine may be made to contract and separate from the outer cell-wall. It may also be rendered distinct by the action of strong hydrochloric acid, and by diluted sulphuric acid. When the process of lignification or thickening has advanced, this utricle disappears, in consequence of becoming incorporated with the cell-wall.

Fig. 29. Cellutar tissue of Sea-wreed (Himanthalia lorea). $a, a$, Cells. $b$, Intercellular matter. Fig. 80. Central portion of young root of Date. $a a a$, Thickened cells. $b b b$, ntercellular substance of Mirbel. 
When small portions of vegetable tissue are soaked in Beale's Carmine solution, only those cells containing protoplasm appear stained. The nuclei and granules in the protoplasm seem alone to be affected. The depth of colouring depends on the number of granules in the protoplasm and the size of the nuclei.

In certain cells the membranous wall consists throughout life of a thin layer of cellulose, while in others it becomes thickened by the deposition of matter on its inner side. These secondary deposits are sometimes of a gelatinous consistence; at other times they are hard. In the latter case, the matter is looked upon as a modification of cellulose, and has received the name of lignin (lignum, wood), or

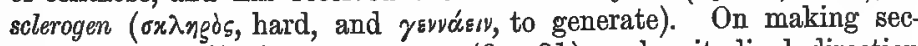
tions of such cells, in a transverse (fig. 31) or longitudinal direction (fig. 32), the successive layers may be seen either continuous all round, or leaving parts of the membrane uncovered. Cells of this kind are well seen under the microscope in thin sections of the hard shell of the Coco-nut, and Attalea funifera, and of the hard seed of the. Ivory Palm. In all cell deposits there is a tendency to a spiral arrangement. When

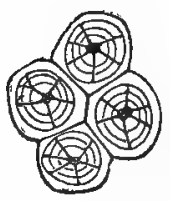

Fig. 31.

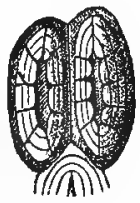

Fig. 32. the deposition is uniform over the whole surface, this arrangement may not be detected; but when interruptions take place, then the continued coil becomes evident. In spiral cells the fibre seems to be formed before the full development of the cell, the coils of the fibre being at first in contact, and afterwards separated, whereas the secondary thickening layers are deposited after the cell is fully formed. According to the observations of Barry, Agardh, and others, the filamentous origin of fibrous structures is recognisable in the earliest stage of cell growth, and the interweaving of these filaments constitutes the cell-walls.

Each cell is found to contain at some period of its existence a small body called a nucleus (fig. $33, n n n$ ), in which there are often one or two, rarely more, minute spots called nucleoli. The nucleus is of a round or oval shape, granular and dark, ог homogeneous and transparent, bearing some resemblance to a smaller internal cell. Nucleoli are not always present. They are either vesicles and granules contained in the nucleus, or minute cavities in its substance. The latter view

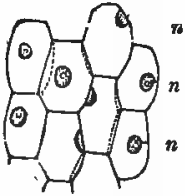

Fig. 33. is supported by Barry, who holds that a peculiar substance called hyaline ( $v \alpha \lambda \circ 5$, glass) is developed there, which, according to him, is the origin of the nucleus. The nucleus is situated at different parts of the cell. It is either free in its cavity, or connected with its walls by mucilaginous

Fig. 31. Transverse section of cells from pulp of Pear. of the same. Fig. 33. Nucleated ceils from the Beet.

Fig. 32. Longitudinal section 
threads, or embedded in the substance of the membrane. The addition of acetic acid often renders the nucleus distinct.

STARCHY MaTTER is found in cells, which constitute the tissue called by Morren, Perenchyma ( $\pi^{\prime} \rho \alpha^{\prime}$, a sac). Starch exists in the form of granules, which are minute cells (perhaps nuclei, as Mülder states), in which nutritious matter is stored up. This matter may be deposited in such a way as to give the appearance of striæ surrounding a point or hilum, which is considered as an opening into the cell. Allman says the starch granule consists of a series of lamellæ, in the form of closed hollow shells, included one within another, the most internal inclosing a minute cavity filled with amorphous amylum. The concentric striæ visible on the granule indicate the surface of contact of these lamellæ, and the so-called nucleus of Fritsche corresponds to the central cavity. The external and internal lamellæ differ in consistency, and in other conditions of integration. The lamellæ are deposited centripetally. The starch granule differs from a true vegetable cell in the absence of a proper nucleus, and in presenting no chemical difference between the membrane and the contents. The grains of starch are well seen in the cells of the potato (fig. 34). In

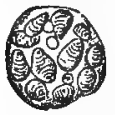

Fig. 34.

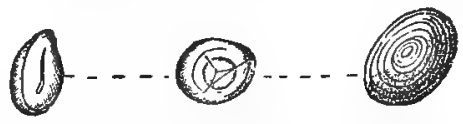

Fig. 35.

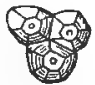

Fig. 36.

wheat (fig. 35), and in maize (fig. 36), the form of the granules, and the successive layers of deposit, are also seen. The grains in the stem of Nuphar luteum show the centripetal formation, that is, the increase by layers deposited within each other. The addition of iodine causes the grains of starch to assume a blue colour, and marks the difference between them and the walls of the cell containing them. Schleiden affirms that starch is the most widely diffused substance in the vegetable kingdom; its presence may be regarded as in a measure indicating the age of the cell. With its formation in many cells, we have a limitation of vital activity, by which the organism is brought into such a condition that the power of germination may be preserved for a very long period.

CRYstals are found in the interior of cells. They probably owe their origin to the union between the acids produced or taken up by plants, as oxalic, phosphoric, malic and carbonic, and the alkaline matter, as lime and potash, absorbed from the soil and circulating in the sap. The crystals usually lie loose in the cells (figs. 37, 38); but they are sometimes found in a distinct tissue called a cystolith

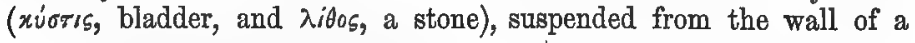

Fig. 34. Cell of Potato, containing striated starch grains.

Wheat. Fig. 36. Grains of starch of Maize.

Fig. 35. Grains of atarch of 
large cell (fir. 39) - filling what some have supposed to be the base of an undereloped hair. The crystals are of different sizes and forms Occasionally, a single large crystal nearly fills a cell, as in the outer scales of the onion, but in general there are numerous erystals united together. Sometimes the crystals radiate from a common point (figs. 40, 41), and form a conglomerate mass; at other times they lie parallel, and have the appearance of bundles of fine needles (figs. 3i, 38). To the latter, the name of Raphidis ( $\alpha<i=$ a needle), or acicular crystals (acus, a needle), was originally given. It has been said that these crrstals exist also in the intercellular spaces;

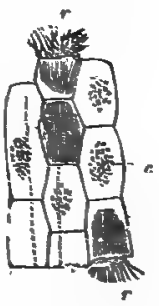

Fig. 37. but this seems to depend on the mode in which the section of the plant is made, for when raphidian cells (fig. $42, r r r r$ ) are situated close to a lacuna, the crystals may easily be pushed into it accidentally by the knife. Raphides consist principally of phosphate and oxalate of lime. They abound in some plants, especially Cacti, and thes are common in Squill, and in the officinal Turkey Rhubarb, the latter of which ores its grittiness to their presence. One hundred grains of rhubarb root

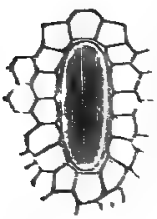

Fig. 38.

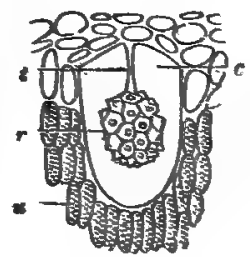

Fig. 39.

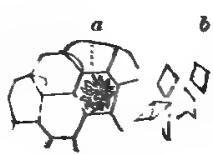

Fig. $\frac{2}{2} 0$.

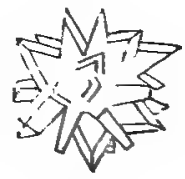

Fig. 41.

contain abont $\mathbf{3 0}$ or $\mathbf{4 0}$ grains of oxalate of lime crystals. Acicular crystals mas be easily seen by making a section of any Liliaceons plant. as the hyacinth, and spreading the thick mucilaginous matter of the cells on the field of the microscope Radiating raphides are seen in the sepals of Geranium robertianum and Incidum; the crystals, consisting of oxalate of lime, fill the whole of the cells in the middle of the sepal. their size varjing from $\frac{1}{200}$ to $\frac{13}{1500}$ of an inch. Quekett found them in all the species of Pelargonium and Monsonia that he examined, and he thinks that ther are as general as the beautiful markings in the cuticle of the petals of these plants. Clustered crystals have been detected in Malvaceous plants, under the cutiale of the

Fig. is. Cellular tissue of Arum maculatum. c Cells containing chlorophyll. Ir, Raphidian cells. Fig. 3s Cells of Arum maculatum. Clusters of raphides in a large oral cell surrounded by smaller cells. Fig. \$9. Cellolar tissue from leaf of Fìcus elastica. c, A large cell, $r$, Crstolith, an agglomeration of corystals (sphreraphides) suspended in a sac by a tabe, $t$. Utricles filled with grains of chlorophyll. Fig. 10 . Cells of Beet with conglomerate radiating crystals, a $b$, Separate crystuls of difterent forms. Fig. 41. Conglomerate erystals of oralate of lime from Rhubarb. 
Marvel of Peru, and in the sepals of the strawberry; numerous acicular crystals have been observed in Fuchsias, and solitary cubical crystals in the superficial cells of the sepals of

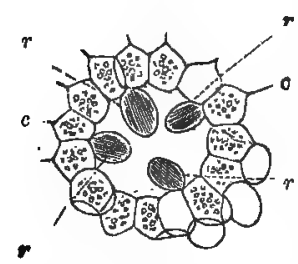

Fig. 42 .

r Prunella vulgaris and Dianthus Caryophyllus. In the outer covering of the seed of Ulmus campestris, the sinuous boundaries of the compressed cells are traced out completely by minute rectangular crystals adhering to each other. Unger detected oxalate of lime crystals in Ficus indica and Calathea zebrina. According to Dr. Gulliver the presence or absence of raphides may be used for distinguishing certain natural orders. He says that Balsaminaceæ, Onagraceæ, and Galiaceæ, may be specially called Raphis-bearing orders. In the epidermal cells of many Urticaceæ coneretions of carbonate of lime (cystoliths) are found.*

ChlorophyLl ( $\chi^{\lambda}$ wegés, green, and $\phi i \lambda \lambda_{0}$, a leaf), or the green colouring matter of plants, floats in the fluid of cells, accompanied by starch grains. It differs from starch in being confined to the superficial parenchyma, and in being principally associated with the phenomena of active vegetable life. It has a granular form (fig. 39, $u$; $42, c)$, is soluble in alcohol, and is developed under the agency of light. It is well seen in leaves. Under the influence of darkness it undergoes changes which are seen in the phenomenon of blanching or etiolation. Its granules are usually separate, but sometimes they unite in masses (fig. $37, e$ ). Stokes says that the chlorophyll of land plants consists of four substances, two green and two yellow, all possessing highly distinctive optical properties. The green substances yield solutions exhibiting a strong red phosphorescence; the yellow substances do not. These substances are soluble in the same solvents. Green sea-weeds agree with land plants. Red sea-weeds in addition to chlorophyll contain a red colouring matter of an albuminoid nature. Chlorophyll is important in a physiological point of view. It is developed under the influence of light, and the granules exhibit marked movements, as have been observed in the leaves of some mosses. Chlorophyll gives a black band in the red of the spectrum. Green vesicles or granules allied to ehlorophyll are found in some of the lower animals, as Hydra viridis. Other kinds of colouring matter are also produced during vegetation, and occur in the form of fluids or of granules in the interior of cells.

OILS and Restinous MATTER are found in the interior of cells, as well as in intercellular spaces. The cavities containing them are denominated cysts, reservoirs of oil, and receptacles of secretions. They are easily

Fig. 42. Cellular tissue of Colocasia odora. c c, Cells with grains of chlorophyl. $r r r r$, Raphidian cells projecting into a lacuna or intercellular space.

* See Papers by Dr. Gulliver, in the Annals of Natural History, 3d ser. xv. et seq. 
detected in the rind of the orange and lemon, and in the leaves of Myrtaceæ and Hypericaceæ. When small portions of the fresh leaf of Schinus Molle are thrown on water, the resinous matter, by its rapid escape, causes them to move by jerks, and the surface of the fluid is covered with the exudation. In the bark of the Fir tribe there are cavities with thick walls containing turpentine. In the fruit of Umbelliferæ, canals occur called vittoe (vitta, a head-band, from surrounding the fruit), containing oil.

AIR-CELLS, or cavities containing air, consist either of circumseribed spaces surrounded by cells (fig. 43), or of lacunæ formed by the rupture or disappearance of the septa between a number of contiguous cells, as in grasses, Equisetum, Umbelliferous plants, and pith of Walnut. They are often large in aquatic plants, and serve the purpose of floating them, as in Pontederia, Trapa, Aldrovanda, and sea-weeds. The air-cells of Limnocharis Plumieri are beautiful objects.

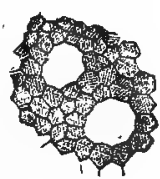

Fig. 43.

\section{3.-Development and Functions of Cells.}

The subject of Cell-development, or Cytogenesis (xuros, a cell, and $\gamma^{\prime} \dot{\varepsilon v \sigma / \zeta}$, origin), has given rise to great diversity of opinion among physiologists. We have already noticed that in the interior of growing cells there is a mucilaginous matter called protoplasm, which contains granules. The first lining of the cell-wall arising from the protoplasm, is the primordial utricle. It forms a sort of film around the protoplasm, and in certain cases it may supply the place of the proper cell-membrane. In the protoplasm cavities are sometimes seen filled with a watery sap, and called vacuoles. In the interior of the young cell may be seen a nucleus or cytoblast (xíros, a cell, and

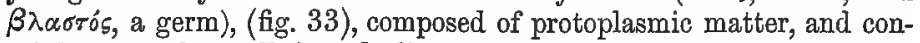
taining granules, called nucleoli.

The nucleus often becomes attached to one side of the utricle. It is sometimes, however, retained in the centre of the cell by means of cords of protoplasm, which ultimately form the boundaries of vacuoles, or spaces containing fluid. Most physiologists think that the cytoblast is not specially concerned in cytogenesis, but only takes part in the various chemical and other changes which occur in the contents of the cell during its growth and nutrition.

It is supposed by some that cells may be formed by the simple aggregation of granular matter, which becomes enveloped in a membrane, and thus forms a cell with granular contents. Dr. Bennett advocates a molecular view of cell formation. He traces cytogenesis to the presence of histogenetic (iorós, veil, web, or tissue, and $\gamma^{\prime} \varepsilon \varepsilon \sigma / \xi$, origin) molecules, which unite together to form the cell-wall. New

Fig. 43. Air-cells in Renunculus aquatilis. 
cells are also produced by the division of the primordial utricle, which gradually folds inwards about the middle, forming an annular constriction, and ultimately a complete separation of the utricle into two parts. Each of these afterwards becomes covered by a permanent cell-wall. This is seen in Palmella (fig. 44). Henfrey has supported this view by observations made on the hairs of Tradescantia and of Achimenes grandiflora, in which he has traced the gradual formation of a septum. Unger traces in Algæ the development of new cells by a fissiparous (fissus, split, and pario, I produce) or merismatic ( $\mu \varepsilon g r \sigma \mu o ́ s$, division) separation of the old ones into two or four divisions, in the same Fig. 44. way as occurs in pollen. In some of the most simple plants, multiplication takes place by a sort of sprouting of new cells from old ones, like buds from a stalk: the portion thus shooting out being afterwards separated from the parent plant by a partition. This is seen in Torula, the yeast plant.

The various theories of cell-development (cytogenesis) may be reduced to the following: 1. Formation of cells in protoplasm, existing in the interior of a cell; 2. Formation of cells in protoplasm, not

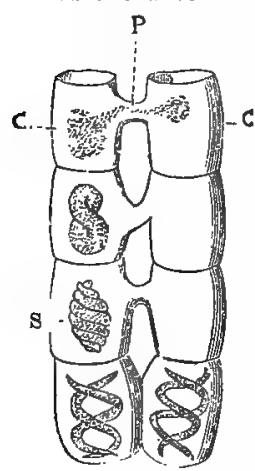

Fig. 45. contained in a cell, but isolated; 3 . Formation of cells by merismatic division of the primordial utricle, or protoplasmic lining of the cell; 4. Formation of cells by a process of budding. Cells are also formed by what has been called Conjugation, or by the union of two cells, which by their mutual action give origin to a third. This is particularly seen in some of the lower Algæe, such as Zygnema (fig. 45).

The formation of cells goes on with great rapidity, especially in the case of fungi. From an approximative calculation, it is found that in Bovista gigantea 20,000 new cells are formed every minute. Ward has noticed a similar occurrence in Phallus impudicus. In warm climates, at the commencement of the wet - season, the production of cells in the higher classes of plants proceeds with astonishing rapidity.

In connection with the propagation of cellular plants much discussion has taken place as to the existence of their germs in the atmosphere, which, coming in contact with fluids of various kinds, are said to give rise to different species of fungi, such as Torula, Penicillium,

Fig. 44. Unicellular Alga (Palmella cmeuta). The cell, $a$, absorbs, secretes, and forms new cells, by a process of fissiparous division, first into two, $b b$, and then into four parts, $c$. Fig. 45. Two filaments of a cellular plant (Zygnema), uniting together by means of tubes, $p$. The plant consists of a filament formed by a series of cells united in a single row. The cells, c c, appear to have different functions. Cell, s, produced by conjugation. 


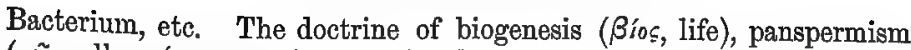
( $\pi \tilde{u} \nu$, all, $\sigma \pi \xi_{g} g \alpha \alpha$, seed), or the development of cells in fluid from germs introduced from the atmosphere, has been advocated by Pasteur and his followers ; while the doctrine of abiogenesis $(\alpha$, privative, and Bios, life), heterogenesis ("grsgos, different, diverse), or what is called spontaneous generation, has been supported by Pouchet and his followers. All that is known in regard to the growth of the lower class of plants, and their appearance in islands recently elevated by volcanic forces in the midst of the ocean, seems, independently of laboratory experiments, to favour Pasteur's views.*

The organised cells of plants appear to be the more immediate seats of the various changes which constitute the functions of nutrition and reproduction. In cellular plants they are the only form of elementary tissue produced throughout the whole of life. They absorb nourishment through their walls, elaborate secretions, and give rise to new individuals. In the newly-formed tissue of vascular plants, cells alone at first exist. Fluid matters are absorbed by them, and are transmitted from cell to cell by a process of transudation. The name of Endosmose ("zvoov, inwards, $\mu \alpha_{\alpha}^{\prime \prime} \omega, \mu \tilde{\omega}$, I seek), and Exosmose ( ${ }^{\prime \prime} \xi \omega$, outwards), were given by Dutrochet to the process of transudation, which leads to the motions of fluids of different densities placed on opposite sides of animal and vegetable membranes. This process appears to be of universal occurrence in plants, being concerned in the movements of the sap, the opening of seed-vessels, and many other phenomena. The capsule of the Elaterium, for instance, opens with great force by a process of endosmose going on in the cells, and such is also the case with that of the Balsam. The power which cells possess of absorbing fluids is well seen in sea-weeds, which after being dried can easily be made to assume their natural appearance by immersion in fluids. It is also observable in the spores of the Equisetum, the teeth of Mosses, the seed-vessels of some Fig-marigolds, the Rose of Jericho (Anastatica), and some Lycopodia.

Various organic secretions, which are necessary for growth and nourishment, are formed by the internal membrane of cells. It is in cells that the azotised and unazotised matters are deposited, which are afterwards applied to the purposes of vegetable life. In them we meet with the protein compounds, albumin, fibrin, and casein, consisting of carbon, oxygen, hydrogen, and nitrogen, with proportions of sulphur and phosphorus; as well as starch, gum, sugar, oil, and colouring matters, in which no nitrogen occurs. Some of the organic matters found in plants have been artificially formed by chemical means, while others have as yet only been met with in the living organism. Spiral cells sometimes contain air.

* See Professor Lister on Bacteria, in Medical Journal, Oetober 1873; and Dr. Pettigrew's Lecture on Physiology, in Lancet, 15th November 1873. 


\section{Section II.-VAscular Tissue.}

\section{Form and Arrangement of Vessels.}

VASCULAR TrSSUE, or Angienchyma ("̈ryos, a vessel), consists of tubes, whose length greatly exceeds their breadth. These may be formed of membrane only, or of membrane altered in various ways by deposits of fibre, or of thickening matter.

Fibrous T'Ubes, or Ligneous Tissue, Pleurenchyma ( $\pi \lambda$ sugá, a rib, from its firmness), (fig. 46), consists of tubes, or, according to some, elongated cells, of a fusiform (fusus, a spindle) or spindle-like shape (fig. 3), having their walls thickened so as to give great firmness. This form of tissue does not exist in cellular plants. Some have called this tissue Prosenchyma, a term, however, generally ap-

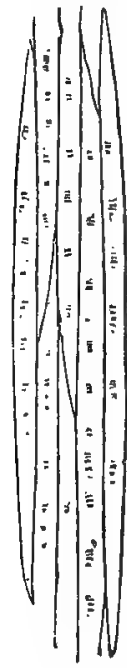

Fig. 46.

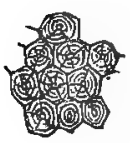

Fig. 47 . plied to shortened fusiform cells only. Pleurenchymatous vessels lie close together, overlap each other, and, by their union, give strength and solidity to the plant. Their membrane becomes thickened by successive deposits of layers of cellulose and sclerogen, and in a transverse section the tubes present the appearance of concentric circles, occasionally with intervals, where the ligneous matter is deficient (fig. 47). The wood of trees is made up of fibres or tubes of this kind, and they are found in the inner bark, and in the veins of leaves. The fibrous tissue may be separated from the cellular parts of plants by maceration. In this way Flax and Hemp are procured, as well as the Bast used for mats. The strength of the fibres of different plants varies. Thus, New Zealand Flax, the produce of Phormium tenax, is superior in tenacity to Common Hemp; while the latter, in its turn, excels Common Flax, as well as Pita Flax, which is the produce of Agave americana. Linen is formed from woody tissue. Cotton, on the other hand, consists of elongated cells or hairs, the membrane of which becomes contracted in the process of drying, so as to appear twisted when viewed under the microscope. By this character mummy cloth was shown to be composed of linen. Fibrous tissue, in fabric, forms muslin, lace, etc. (some fine Indian muslins only are formed from this tissue; other muslins are made of cotton); when whence paper is made.

Fig. 46. Fibres of Pleurenchyma, from Clematis Vitalba. of the same.

Fig. 47. Transverse gection 
In their ordinary form, Pleurenchymatous tubes have no definite markings on their walls; but in some instances markings present themselves in the form of simple discs (fig. 48), or of discs with smaller circles in the centre (fig. 49). These dises occur in the wood of Firs, Pines, and Winter's bark, which has received the name of glandular or punctated woody tissue. The markings are formed by concave depressions on the outside of the walls of contiguous tubes, which are closely applied to each other, forming lenticular cavities between the vessels, like two watch-glasses in apposition, and when viewed by transmitted light they appear like discs (fig. 48). In the centre of the depression there is a canal, often funnel-shaped, and the part of the tube corresponding to it being thus

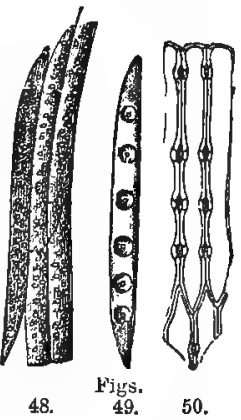
thinner than the surrounding texture, gives the aspect of a smaller circle in the centre (fig. 49). When a thin section is made through two parallel lines of punctations, the slits or fissures are seen which give rise to the appearances mentioned (fig. 50). That these markings are cavities between the fibres was proved by Quekett in the case of fossil pine wood, where he separated lenticular masses of solid matter from the discs. There is sometimes observed a thickening layer, in the form of a spiral fibre, surrounding the discs more or less completely, as in the yew. The discs are usually arranged in single rows, but they occur also in double and triple rows, as in Araucaria, where the markings alternate with each other.

Fibro-V ascular TISsUe, or Trachenchyma (trachea, windpipe; requis, rough), is formed of membranous tubes tapering at each end, less firm than Pleurenchyma, and either having a fibre coiled up spirally in their interior, or having the membrane marked with rings, bars, or dots, arranged in a more or less spiral form.

TRUt SpIRAL Vessels (spiroidea, trachece), constituting the typical form, present themselves as elongated tubes clustered together, overlapping each other at their conical extremities, and having a spiral fibre or fibres surrounding the interior of the cylinder (fig. 51). Their outer membrane is thin, and consists of cellulose. At the point

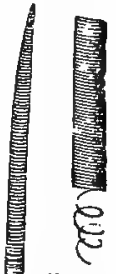

Fig. 52.

Fig. 48. Woody tubes, with circular spots where the membrane is thin, Bignonia. Fig. 49. Punctated woody tissue, with double circles or dises, from common \$cotch fir. Fig. 50. Longitudinal section of the same, showing the union between the fibres, and the mode in which the circles are formed. Fig. 51. Two spiral vessels united. Fig. 52. Simple trachea, with fibre uncoiled. Fig. 53. Spiral vessel with a ribbend of united fibres (Pleiotrachea), from the Banana. 
where they overlap, it is sometimes absorbed, so as to allow direct communication between the vessels. The fibre or spiral filament is generally single, forming simple trachece (fig. 52); but sometimes numerous fibres, varying from two to more than twenty, are united together, as in the banana, assuming the aspect of a broad ribband (fig. 53), and constituting Pleiotrachea ( $\pi \lambda$ síw , more). The fibre is ełastic, and can be unrolled. This can be seen by taking the leaf of a Pelargonium, and after making a superficial cut round the stalk, pulling the parts gently asunder, when the fibres will appear like the threads of a cobweb.

Spiral vessels were first noticed as early as 1661 , by Henshaw. They occur principally in the higher classes of plants, and are well

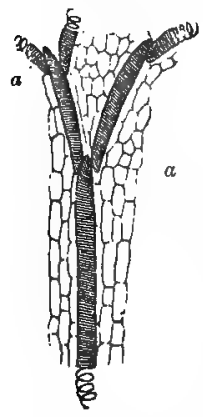

Fig. 54. seen in annual shoots, as in Asparagus; in the stems of Bananas and Plantains, where the fibres may be pulled out in handfuls, and used as tinder; in many aquatics, as Nelumbium and Nymphra; and in Liliaceous plants. In hard woody stems they are principally found in the sheath surrounding the pith, and they are traced from it in to the leaves. They are rarely found in the wood, bark, or pith. Spiral vessels occasionally exhibit a branched appearance. This may arise from the union of separate vessels in an angular or jointed manner, as where a leaf or branch is given off (fig. 54, wa), or it may depend on a reggular division of the fibres, as is seen in the Mistleto, House-leek, and Gourd (fig. 55).

The fibre is on the inside of the membrane. Quekett has shown this in silicified spiral vessels, where the mark of the spital was on the outside of the mineral matter filling the tube. The fibre usually turns from left to right, if we suppose the observer placed in the axis of the tube (fig. $56)$, or from right to left, if we suppose him looking at the vessel in its natural position. The fibre retains its direction throughout the length of the vessel. When examined under the microscope there is often the appearance of the crossing of fibres (fig. 56), in consequence of Figs.

56. ${ }^{57 . ~ t h e ~ t r a n s p a r e n c y ~ o f ~ t h e ~ m e m b r a n e, ~ a n d ~ t h e ~ o b s e r v e r ~ s e e i n g ~}$ the fibre on each side of the vessel at the same time. In twining plants, the direction of the fibre does not always correspond with

Fig. 54. spiral vessels, united so as to have a branched appearance. Fig. 55. Branching fibre, from spiral vessels of Gourd (Cueurbita Pepo). Fig. 56. Spiral vessels. Coils seen on both sides. Fig. 57. Coils of fibre, much separated in trachea of Gourd. 
that of the stem. The coils of the spiral fibre may be close together (fig. 52), or be separated (fig. 57). Sometimes they become united together, and to the membrane of the tube, so that they cannot be unrolled. Such vessels are called closed tracheæ, or closed ducts, and are seen in ferns.

False or Spuriods Traches, the ducts of some authors, are vessels in which the internal fibre does not form a complete spiral coil. The chief varieties are annular, reticulated, and scalariform vessels, or ducts. In annular vessels (annulus, a ring), the fibres

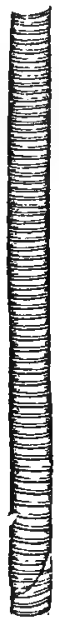

Fig. 58.

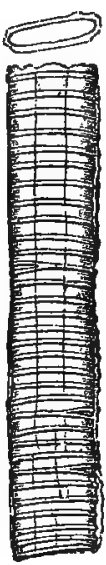

Fig. 59.
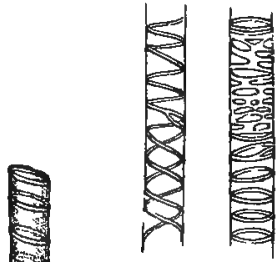

61. Figs. 62.

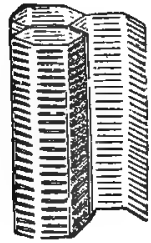

Fig. 64.

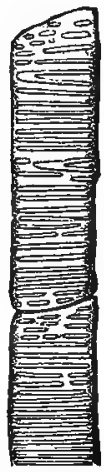

Fig. 63.

form complete rings round the tubes (fig. 58). They resemble the tracheæ of animals more than spiral vessels do. The rings are by no means regular ; they may be horizontal or inclined, simple or forked (fig. 59), placed near to each other or separated by considerable intervals, the intermediate spaces being sometimes occupied by a fibre of an elongated spiral form, which is continuous with the rings or distinct from them (fig. 60). All these forms are easily recognised in the common Balsam. Occasionally, the ring becomes very much thickened in a direction perpendicular to the walls of the vessel, so as to leave only a small space in the centre, as in some of the Cactus tribe. When separate fibres cross each other, forming a kind of network on the walls of the tubes (fig. 61), the vessels become reticulated

Figs. 58, 59, 60. Annular vessels from the stem of the Common Balsam. Fig. 61. Spiral ressel. Wide coil, and flbre dividing. Fig. 62. Vessel showing rings of fibre and dots. Fig. 63. Scalariform vessel from the Vine. Fig. 64. Prismatic scalariforn vessel from Royal Fern (Osmunda regalis). 
(reticulum, a net); and the name dotted is sometimes applied when the fibre is so broken up as to leave small isolated portions adhering to the membrane (fig. 62). In scalariform vessels (scala, a ladder), there are short horizontal lines or bars, composed of fibre, arranged along the sides of the tubes, at nearly equal distances, like the steps of a ladder, and presenting a striated appearance. In some cases, as in the Vine (fig. 63), they are composed of tubes united to each other by thin, broad, oblique extremities; at other times they taper like spiral vessels. They generally assume a prismatic form, the angles being unmarked by lines, as is seen in Ferns (fig. 64).

Pitted Vessels.-Another kind of vessel common in plants is the pitted vessel, so called from the appearance of pits or depressions on its surface. The tissue formed by pitted vessels has received the name of Vasiform tissue, Pitted tissue, Bothrenchyma, or Taphrenchyma (ßótgos or rúpgos, a pit). The vessels are of large size, and are easily observed

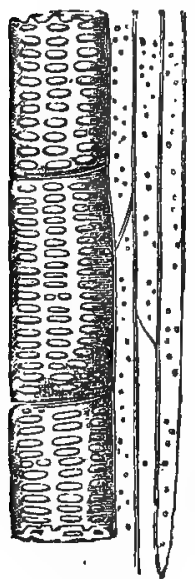

Fig. 65. in the Vine (fig. 65), Sugar Cane, Bamboo, Gourd (fig. 116 ter), and other plants, in which the sap circulates rapidly. They consist of cylinders more or less elongated, in which the thickening matter is so deposited as to leave part of the membrane uncovered, thus giving rise to the porous or pitted appearance. The uncovered portions of membrane are sometimes absorbed in old

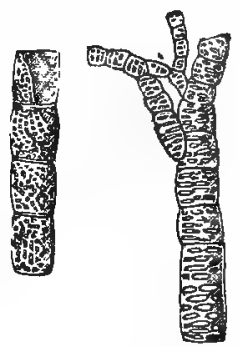

Fig. 66 . vessels, and a direct communication is established between them. The pits or so-called pores have sometimes a bordered aspect, .which, according to Schleiden, depends on air contained in the cavities between contiguous vessels. Pitted or porous vessels are usually united to each other by a broad and often oblique septum.

This kind of vessel occasionally presents a beaded appearance, as if formed by pitted cells, with distinct constrictions at their point of union (fig. 67). This articulated Bothrenchyma is by some considered as a form of cellular tissue (fig. 22). To vessels exhibiting contractions of this kind, whether spiral or pitted, the terms moniliform (monile, a necklace), or vermiform (vermis, a worm), have been applied; and the tissue com-

Fig. 65. Pitted vessel (Bothrenchyma) from the Vine, showing its connection with woody fibres, and the broad septa or partitions of the vessel itself. Fig. 66. Pitted vessel from Traveller's joy (Clematis Vitalba). Fig. 6t. Moniliform pitted vessels from the Common Balsam. 
posed of these moniliform vessels has been denominated phleboidal ( $\phi \lambda \dot{\xi} \psi, \varphi \lambda_{\varepsilon} \beta \dot{o} s$, a vein).

Laticiferous Vessels (latex, fluid, and fero, I bear) form the tissue called Cinenchyma ( $x$ vÉw, I move, from movements observed in their contents). They are the Milk-vessels, and the Proper vessels of old authors, and have been particularly described by Schultz. They consist of long, branched, homogeneous tubes, having a diameter of about $\frac{1}{150}$ of an inch, which unite or anastomose freely (fig. 68), thus resembling the vessels of animals. At first the tubes are very slender and uniformly cylindrical (fig. $69 \mathrm{a}$ ), but afterwards they enlarge and present irregular distensions at different parts of their course (figs. $69 \mathrm{~b}, 70$ ), giving rise to an articulated appearance. Their walls vary in thickness, and are not marked by any depressions or

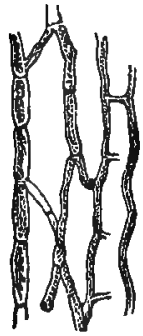

Fig. 68.

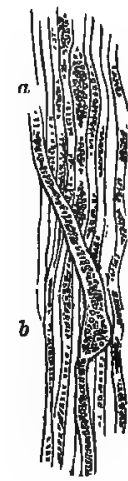

Fig. 69.

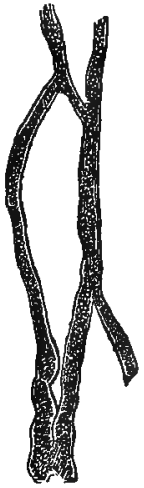

Fig. 70.

fibres. These vessels are met with in the inner bark, and they contain a granular fluid called latex, which is at first transparent, but often becomes of a white, yellow, or reddish colour. Some suppose that these vessels are simply intercellular canals lined with a continuous membrane, containing a peculiar fluid. The tissue can be easily examined in the India-rubber tree, in Dandelion, Lettuce, and Celandine, and in various species of Ficus and Euphorbia.

\section{Development and Functions of Vessels.}

The simple cell is the form in which vegetable tissue first makes its appearance. It is the primary form of all the textures subsequently

Fig. 68. Laticiferous vessels (Cinenchyma) from Euphorbia dulcis. Figs. 69, 70. Vessels of Latex from Celandine (Chelidonium majus). ، 
produced in vascular plants. To the elongation of cells, and the deposition of thickening layers and fibres in their interior, the various vessels owe their origin. Thus when cells are elongated, as spindleshaped tubes, and their walls are thickened and hardened by depositions of ligneous matter, they give rise to Pleurenchyma; and when elongated membranous tubes are strengthened by spiral fibres, the different kinds of Fibro-vascular tissue are produced. The spiral vessel may be considered as the type of the last-mentioned tissue, and all its varieties may be traced to different conditions in development of the fibre. In the case of some vessels, their forma-

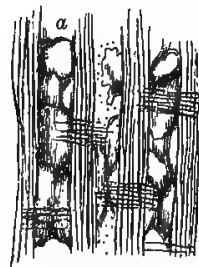

Fig. 71. tion can be distinctly traced to cells placed end to end, the partitions between which have been $a b-$ sorbed. The moniliform or beaded appearance often presented by the different kinds of vessels, more especially the Pitted, plainly indicates this mode of formation. Occasionally cellular prolongations are seen in the interior of pitted vessels, giving rise to what

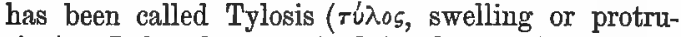
sion). It has been noticed in the vessels of Oak, Chestnut, Walnut (fig. 71 a), Ash, Elm, etc.

As in cells, so in vessels, the walls are composed of cellulose, and there are usually no visible perforations; the communication between them taking place by imbibition or osmose. In some instances, when vessels are closely applied to each other, especially when they overlap, the membrane becomes absorbed, and direct communication takes place. This has been seen in spiral and pitted vessels. The pits or depressions on the walls of vessels, and the thinning of the tissue at particular points, appear to serve the purpose of allowing the rapid transmission of fluids.

Pleurenchyma, in its early state, contains fluids, and conveys them from one part of the plant to another. In the progress of growth, the secondary deposits obliterate the vessels, as in the perfect or heart wood of ordinary trees. These deposits are often of a very hard nature, and assume particular colours in different kinds of trees. From the firmness of this tissue, it is well fitted to give solidity to the stems and to strengthen the leaves of plants. In Spiral vessels, the fibre adds to their elasticity, and keeps the tubes always pervious. The fibre, when once formed, does not increase much in thickness, and the secondary deposits do not obliterate the canal. Various opinions have prevailed regarding the contents of these vessels. The name Tracheæ, given by Grew and others, was partly from their structure, and partly from the idea that they contained air. The accurate experiments of Bischoff lead to the conclusion that the perfect spiral

Fig. 71. Longitudinal section of the stem of a species of Walnut (Juglans cinerea), showing ylosis in pitted vessels, $a$. 
vessels convey air, which often contains an excess of oxygen in its composition. Hales showed that air was evolved from the vessels of the Vine when cut, and Decandolle thought that part of the air in these vessels was derived from the pores of the leaves. Hoffman from his experiments concludes that spiral vessels in the ordinary state contain air, but that when a large quantity of fluid is applied to the leaves it enters the spirals. Other authors look upon these vessels as conveying fluids, while a third set maintain that both air and fluids are present, the air being derived in part from decompositions going on in the interior of the plant. The other kinds of vascular tissue, and especially the pitted vessels, are the means by which the fluids taken up by the roots of plants are conveyed to the leaves, and to all parts of the plants. Laticiferous vessels contain, according to Schultz, the elaborated sap or latex on its return from the leaves to the bark. This latex is either transparent or opaque, colourless or coloured. These vessels, when examined with the microscope in the living plant, exbibit movements in their fluid contents of a peculiar kind, which will be considered under Cyclosis.

The cell has been already shown to be the type of all the tissues of plants, and to be the basis of all vegetable structure. It is of equal importance as regards function. In the lowest plants, as the Palmella (Protococcus) nivalis, or the Alga found in red snow, and other species of Palmella (fig. 44), also in Nostoc and Hæmatococcus, cells constitute the whole substance, and perform all the functions of life; they absorb and assimilate, thus performing the functions of nutrition and secretion, and they form new cells, thus reproducing individuals like themselves. When a more complex structure exists, as in the higher tribes of plants, certain cells are appropriated for absorption, others are concerned in assimilation, and others in forming and receiving secretions. When a certain degree of solidity is required to support the stem, leaves, and flowers, ligneous matter is deposited, and bast fibres are formed. When the transmission of fluids and air is carried on rapidly, the elastic fibres of the fibro-vascular tissue seem to keep the elongated cells and vessels pervious, and when the elaborated sap is conveyed continuously without interruption, anastomosing tubes occur in the form of laticiferous vessels. Cells and vessels are thus differentiated for the performance of special functions.

\section{Tabular arrangement of Vegethable Tissues.}

A.-Cellular Tissue (Parenchyna), composed of membrane, or of membrane and fibre, having the form of vesicles whose length does not greatly exceed their breadth.

1. Membranous Cellular Tissue ; cells formed by membrane alone, of varying thickness, but without markings on it; when thickened and fusiform they constitute prosenchyma, composed of bast cells. 
2. Pitted Cellular Tissue; cells formed by membrane, which has been unequally thickened in such a way as to Ieave rounded depressions at regular intervals.

3. Fibrous Cellular Tissue (Inenchyma) ; cells formed by membrane and fibre ; occasionally formed by fibre alone.

a. Spiral Cells, with a complete spiral fibre inside.

b. Dotted Cells, with opaque spots, which are isolated portions of fibre.

B.-Vascular or Tubular tissue (Angienchyma), composed of cylindrical tubes, which are more or less continuous, and usually overlap each other, or are united by broad oblique extremities.

I. Membranous Vascular Tissue; tubes formed by membrane alone, of varying thickness, but without markings on it.

1. Ligneous Tissue (Pleurenchyma), composed of fusiform tubes with thickened walls.

2. Laticiferous Tissue (Cinenchyma), composed of tuhes which anastomose, often present irregular dilatations, and convey a peculiar fluid, called Latex; this tissue may be formed by intercellular canals lined with a continuous membrane.

II. Pitted Vascular Tissue; tubes formed by membrane, with markings of a more or less circular form on their walls.

1. Pitted Vessels (Bothrenchyma or Taphrenchyma) ; large pitted tubes usually ending in broad extremities, the markings on their walls depending on internal depressions. This tissue sometimes exhibits contractions at regular intervals, as if formed of cells placed end to end, and then is called Moniliform, or Beaded (Articulated Bothrenchyma).

2. Punctated Vessels (Glandular Woody Tissue); fusiform woody tabes, the markings on the walls depending on external depressions, and presenting the appearance either of single or double circular discs.

III. Fibro-Vascular Tissue, composed of tubes in which the thickening matter is deposited in the form of spiral fibres, rings, bars, or dots.

a. Perfect Fibro-Vascular Tissue, composed of tubes, in which there is a complete spiral fibre.

1. Spiral Vessels (Trachex, Thachenchyma), in which the spiral fibre is elastic, and may be unrolled.

2. Closed Spiral vessels, or closed Trachex, in which the spiral fibre is brittle, or its coils so united to each other, and to the membrane, that they cannot be unrolled.

b. Imperfect Fibro-Vascular Tissue, composed of tubes marked by rings, lines, or dots, but without a complete fibre inside.

1. Annular Vessels or Ducts, having fibres in the form of detached rings, which are occasionally united by portions of fibre.

2. Reticulated Vessels, having fibres which cross each other, or are disposed so irregularly as to form a network.

3. Scalariform Vessels, having their walls marked by isolated portions of fibre, in the form of ladder-like bars.

4. Dotted Vessels, having their walls marked by isolated portions of fibre in the form of opaque dots or points.

Any of the ressels included under the Fibro-vascular tissue may exhibit contractions at regular intervals, so as to become moniliform. 


\section{CHAPTER II.}

\section{COMPOUND ORGANS FORMED BY THE TISSUES.}

Some plants consist of cells only, which continue throughout life to produce new cells, and to perform all the vital functions. The great mass of flowering plants, however, although originally cellular, produce organs composed of cells and vessels variously arranged, and " covered by an epidermis. These compound Organs may be divided into Nutritive, or those concerned in the nourishment of the plant; and Reproductive, or those which are employed in the production of new individuals. The former consist of the stem, root, and leaves; the latter, of the flower and fruit.

\section{Section I.-Organs of Nutrition or Vegetation.}

\section{1.-Structure, Arrangement, and Special Functions.}

Under this head will be considered the tissues of which the various nutritive organs are composed, the mode in which the parts are arranged, and the particular function which each of the organs performs.

\section{General Integument.}

GENERAL-INTEGUMENT is the name given to the external cellular covering of plants. It can be easily detached from young leaves and stems, usually in the form of a colourless transparent membrane. By prolonged maceration it has been shown to consist frequently of two layers; a superficial called Cuticle or Pellicle (fig. $72 p p$ ), and a deep layer, usually called the Epidermis (fig. 72 ee). Dr. Carpenter thinks that the term epidermis should be dropped as regards plants. . He applies the term cuticle to the general integument.

The Superficial Cuticum or Percicle (cutis and pellis,

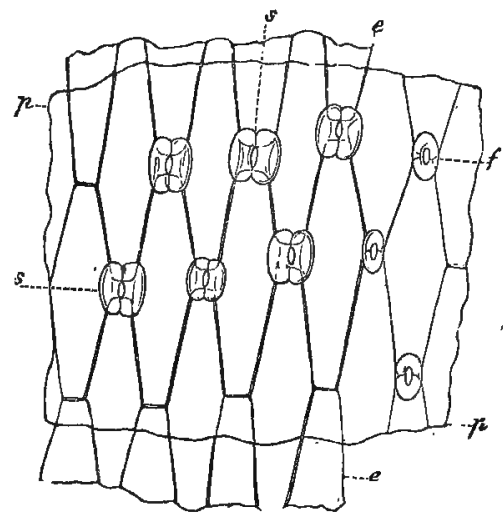

Fig, 72.

Fig. 72. General integument of a leaf of Iris germanica. $p p$, The Cuticular pellicle with slits, $f$, lying upon the proper epidermis, $e$ e, formed of hexagonal cells, and furnished with stomata, $s$. 
skin) is a very thin continuous membrane, which is spread over all parts except the openings called stomata; in some cases entering these openings, and lining the cavities beneath them.

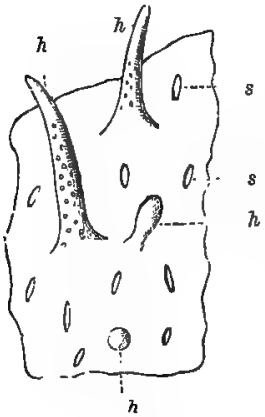

Fig. 73. It is formed from the epidermal cells below it. Treviranus, Schleiden, and Payen, consider it as a secretion on the outside of the cells, while Mohl and Henfrey look upon it as composed of the altered primary walls of the cells. Mitscherlich regards it as a corky substance, which preserves the humidity of the plant by preventing the evaporation of moisture. This substance is considered by him to be an important constituent of the cell-wall. In many plants we meet with a corky epidermis composed of cells containing air. The cork cells are flat and thin-walled; and in some cases they can be peeled off, as in the cork oak. In fig. 73 the pellicle is represented as detached from the leaf of the cabbage, forming a sheath over the hairs, $h h h h$, and leaving slits, $s s$, corresponding to the openings of the stomata. The pellicle is perhaps similar to the intercellular substance surrounding cells, and to the definite mucus (collenchyma) which is seen in seaweeds (fig. 29 b). It is possible that this matter, in place of being produced on the outside of cells, may be formed within them, and ultimately deposited externally by passing through their parietes. On the inner surface of the pellicle the impressions of the epidermal cells are sometimes observed. The pellicle is the only layer of integument which is present in aquatic plants, and in some of the lower trikes.

The EpIDermis ( $\varepsilon^{\prime} \pi i$, upon, and $\delta \dot{\varepsilon} \mu \alpha \alpha$, skin), (fig. $72 e e$ ), is extended over all the parts of plants exposed to the air, except the stigma. The internal cavities of seed-bearing organs are lined by a

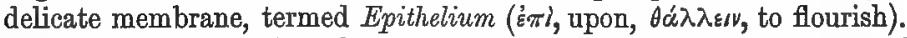
On the extremities of newly-formed roots the integument consists of loose cells, which are either the ordinary cellular tissue of the plant, or an imperfectly-formed epidermis, which has received the name of Epiblema ( $\dot{\varepsilon} \pi i$, upon, and $\beta \lambda \tilde{\eta} \mu \alpha$, wound, as being the tissue which first covers wounds). This latter kind of tissue occupies the place of the epidermis, in the parts of plants which are always under water. The cells forming the sheath of young roots are often densely filled with granular protoplesm, and contain nuclei. They become coloured in Beale's carmine solution. On the aerial roots of Orchidaceous

Fig. 73. Pellicle of Cabbage, detached by maceration, covering the hairs, $h h h h$, and having openings, $8 \mathrm{~s}$, corresponding to the stomata. 
plants, there is an epidermal layer consisting of spiral cells (fig. 23), containing air.

The epidermis is usually formed by a layer or layers of compressed cells, which assume a more or less flattened tabular shape, and have their walls bounded by straight or by fiexuous lines. Fig. $72 e e$, represents an epidermis formed of regular hexagonal cells; fig. 75 , one composed of irregular hezagons; while in fig. 74 the boundaries of the cells, 8 , are flexuous and wavy. The cells of the epidermis are so intimately united together, as to leave no intercellular spaces (fig. 77 e e).

The epidermis is sometimes thin and soft, at other times dense and hard. In the former case it may be easily detached from the subjacent cells; in the latter the cells have become thickened by de-

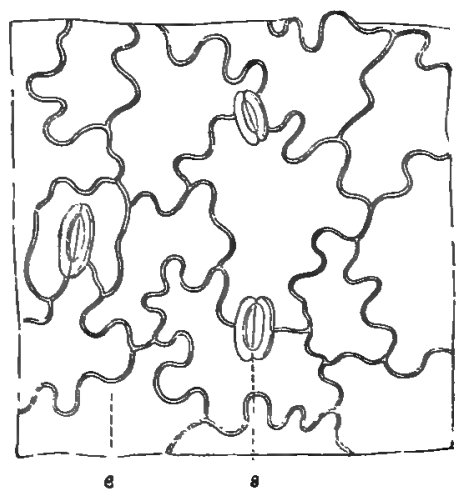

Fig. 74. posits, and sometimes the layers are so produced as to leave uncovered spots, which communicate with the interior of the cell by canals passing through the thickening layers, as in Cycas. In Rochea falcata (fig.

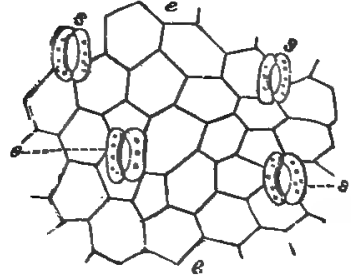

Fig. 75 .

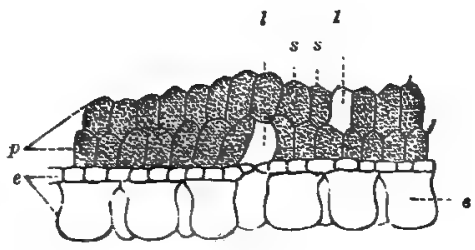

Fig. 76.

76), the epidermis, $e e$, consists of two layers of cells-the outer ones large, the inner small. The epidermis of Agave and Hoya is thickened by numerous secondary deposits; such is also the case with that of the branches of the mistleto. The cells of epidermis are usually filled with colourless fluid, but they sometimes contain resinous and

Fig. 74. Fpidermis, from lower surface of the leaf of Madder (Rubia tinctortm). a, Cell of the Epidermis. $s$, Stoma.

Fig. 75. Epidermal layer, from upper surface of a leaf of Ranunculus aquatilis when growing out of water. $e$, Epidermal cells. $s$ s s s, Stomata. Fig. 76. Vertical section of lower epidermis of the leaf of Rochea falcata. \& \& Double epidermal layjer, with very large external cells, small internal ones, pierced by a stoma, $s$, which communicates with a lacuns, 7 . $p$, Parenchyma of the leaf. 
other substances. Waxy matter is occasionally found in the epidermis, silica is met with in the integument of grasses and Equiseta, and carbonate of lime in that of Chara. The colour of the epidermis generally depends on that of the subjacent parenchymatous cells, from which it can be separated as a colourless layer. The epidermal cells are usually larger than those of the tissue below them; but sometimes, for instance in Ficus elastica, they are smaller.

Stomata ( $\sigma \sigma_{0} \mu \alpha$, a mouth) are openings existing between some of the cells of the epidermis on parts exposed to the air. They consist usually of two semilunar cells surrounding an oval slit or orifice (figs. $72 s s, 74 s$ ), supposed to resemble the lips and the orifice of the mouth. Stomata open or close according to the state of moisture or dryness in the atmosphere,- these changes depending on the hygroscopic character of the cells. By examining, under the microscope, thin stripes of epidermis in a moist and dry state, it will be seen that in the former case the lips are distended, they assume a crescentic or arched form, and leave a marked opening between them; while in the latter they collapse, approach each other, and close the orifice.

The cells surrounding the openings of stomata are sometimes numerous, as in Marchantia. In. Ceratopteris thalictroides, Allman observed stomata formed by three cells; two of which, in their open condition, are crescentic and concave inside, while the third surrounds them, except at a small space at the end of the long axis of the stoma, and has on this account been called peristomatic ( $\pi \varepsilon \rho i$, around). In Ficus elastica four cells form the stoma. In Equisetum, the stomata, which are about $\frac{1}{260}$ of an inch in their greatest diameter, consist of four pieces; two of which are arched and thick at their onter convex margin, becoming thin at their inner concave edge, where two other bodies occur, having numerous processes like the teeth of a comb, hence called pectinate (pecten, a comb). Occasionally the stomatic cells become united, so as to appear in the form of an uninterrupted rim; and at other times the stoma is a minute orifice in the walls of a cavity.

Stomata communicate with intercellular spaces (figs. $76 \mathrm{~s}, 77 \mathrm{~s}$ ), the connection being sometimes kept up by means of a funnel-shaped prolongation inwards of the cuticle, called, by Gasparrini, a cistoma (xíбテn, a cyst or bag, and $\sigma r^{\prime} \mu_{\alpha} \alpha$, a mouth). They are scattered over the surface of the epidermis in a variable manner. Sometimes they are placed at regular intervals corresponding to the union of the epidermal cells (fig. $72 \mathrm{~s}$ ); at other times they are scattered without any apparent order (figs. 74, 75); and in other instances they are united in sets of two or three, or in clusters at particular points, as may be seen in Begonia, Saxifraga (fig. $78 s s$ ), Crassula, and some Proteaceæ.

Stomata occur on the green parts of plants, especially on the leaves 
and their appendages. They are, however, also met with on parts not green, as on coloured sepals or petals, as those of the Marsh Marigold and Ornithogalum. They have also been seen on internal organs, as the replum of some cruciferous plants. They are not usually found in

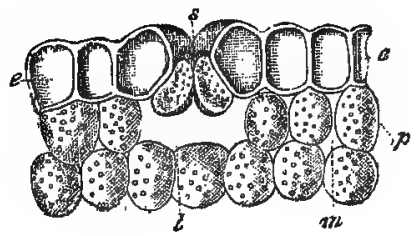

Fig. 77.

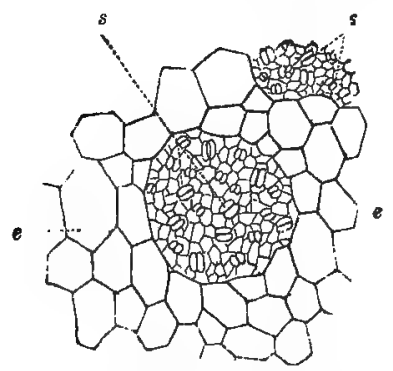

Fig. 78.

cellular plants, nor in plants always submerged, nor in pale parasites. This is not, however, a universal rule, for stomata have been detected in Marchantia and some other Cellulares; also in the submerged leaves of Eriocaulon setaceum, and in the pale parasite Orobanche Eryngii. They do not exist on roots, nor in plants kept long in darkness so as to be blanched or etiolated, and they are rare or imperfectly developed in succulent plants.

Stomata vary in their form. The oval form is very common, and may be easily seen in Liliaceous plants; the spherical occurs in Oncidium altissimum and the Primrose, the quadrangular in Yucca and Agave. In the Oleander, in connection with the stomata, there are cavities in the epidermis protected by hairs (fig. $79 s$ ).

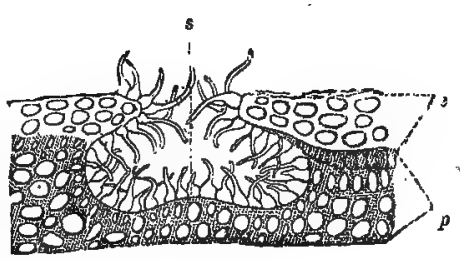

Fig. 79.

The development of stomata has been traced by Mirbel and Mohl. In the Hyacinthus orientalis, they appear first between the epidermal cells in the form of quadrangular spaces containing granular matter, which gradually collects towards the centre of the space, where a sep-

Fig. 77. Vertical section of epidermis, from the Iower surface of the leaf of Madder, showing the intimate union of the epidermal cells, $e e$, the loose subjacent parenchyma, $p$, with intercellular canais, $m$, and lacuna, $l$. 8. Stoma. Fig. 78. Epidermis of leaf of Saxifraga sarmentosa, showing clusters of stomata, $s$, surrounded by large epidernal cells, $e$. The cells among which the stomata occur are very small.

Fig. 79. Vertical section of lower epidermis of the leaf of Nerium Oleander. e, Epidermis composed of several layers of cells. $p$, Parenchyma of the leap. s, Cavity filled with hairs, at the bottom of which is a stoma. 
tuim or partition is formed. This septum ultimately splits, leaving a slit or opening which constitutes the stoma. Mohl has traced this process throughout the same leaf in different stages of growth. In Marchantia, Mirbel found several tiers of cells forming the stoma, and he supposed that the opening was produced by the absorption of a central cell, leaving the others to form the rim or border.

The number of stomata varies in different parts of plants. They are most abundant on the under surface of leares exposed to the air, and are often entirely wanting on the upper surface, more especially when it has a dense shining cuticle. In floating leaves the stomata, when present, are on the upper surface only. When plants usually under water are made to grow for some time in the air, their leaves exhibit stomata. When leaves grow vertically, the stomata are often equal in number on both sides. The number of stomata varies from a few hundreds to many thousands on a surface of one inch square. The following table exhibits the number of stomata in the leaves of a few plants :-

STOMATA IN ONE INCH SQUARE OF SURFACE OF THE LEAF.

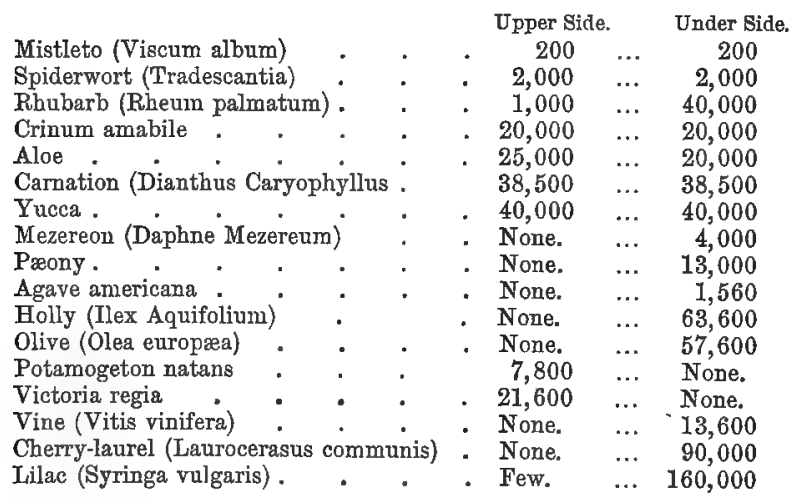

APPENDAGES OF THE EPIDERMis, or APPEŃdicular ORgans.The epidermis frequently exhibits projections or papillæ on its surface, in consequence of some cells being enlarged in an outward direction (fig. $76 e e$ ). When these assume an elongated or conical form they constitute hairs (pili or villi).

HAIRS, then, are composed of one or more transparent delicate cells proceeding from the epidermis, and covered with the cuticle (fig. 73). They are erect (fig. $80 \mathrm{e}$ ), or oblique, or they lie parallel to the surface, and are appressed. Sometimes they are formed of a single cell, which is simple and undivided (fig. 80), or forked (fig. 81) or 
branched (fig. 82); at other times they are composed of many cells either placed end to end, as in moniliform or necklace-like hairs (fig. 83 ), or united together laterally, and gradually forming a cone, as in

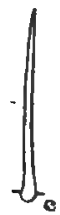

Fig. 80 .

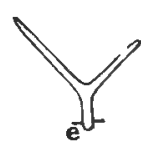

Fig. 81.

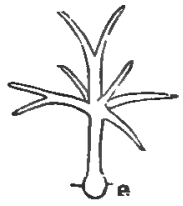

Fig. 82.

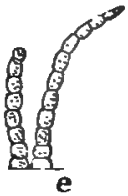

Fig. 83.

compound hairs (fig. 84), or branched (fig. 85). When several hairs proceed from a common centre, they become stellate (stella, a star), or radiated (fig. 86). The latter arrangement occurs in hairs of the Mallow tribe, and is well seen in those of Deutzia scabra, and on the stem of the Rice-paper plant (Fatsia papyrifera). When stellate hairs are placed closely together, so as to form a sort of membranous expansion (fig. 87), a scale or scurf is produced. In Bromeliacex the scurfiness of the leaves is a marked character. To such expansions of the epidermis the name lepis ( $\lambda \varepsilon \pi i \zeta$, a scale) is applied, and the surface is said to be lepidote. These scales have sometimes a beau-

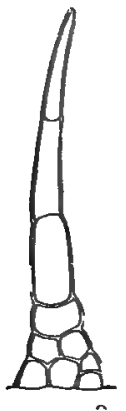

Fig. 84.

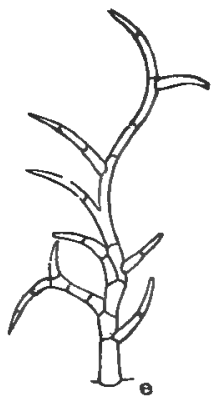

Fig. 85 .

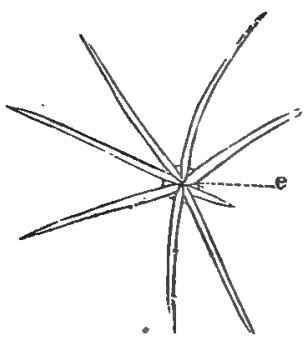

Fig. 86.

tiful silvery appearance, as in Elæagnus and Sea-buckthorn (fig. 87). Surrounding the base of the leaves of Ferns, a brown chaffy substance

Figs. 80-86. Forms of hairs. e, Epidermis. 80. Simple hair formed of a single, undivided, elongated, and tapering cell. 81. Forked or bifurcate hairs of Sisymbrium Sophis, formed by one cell of the epidermis, e, dividing into two. 82. Branched hair of Arabis alpina, formed by a simple hair of the epidermis, $e$, dividing into numerous conical cellalar branches. 83. Moniliform hair, from Lychnis chalcedonica.

Fig. 84. Partitioned, unbranched hair, from stem of Bryonia alba. Fig. 85. Partitioned, branehed hair, from flower of Nicandrs anomaln. Fig. 86. Stellate or star-like hair, from leaf of Althæa rosea. 


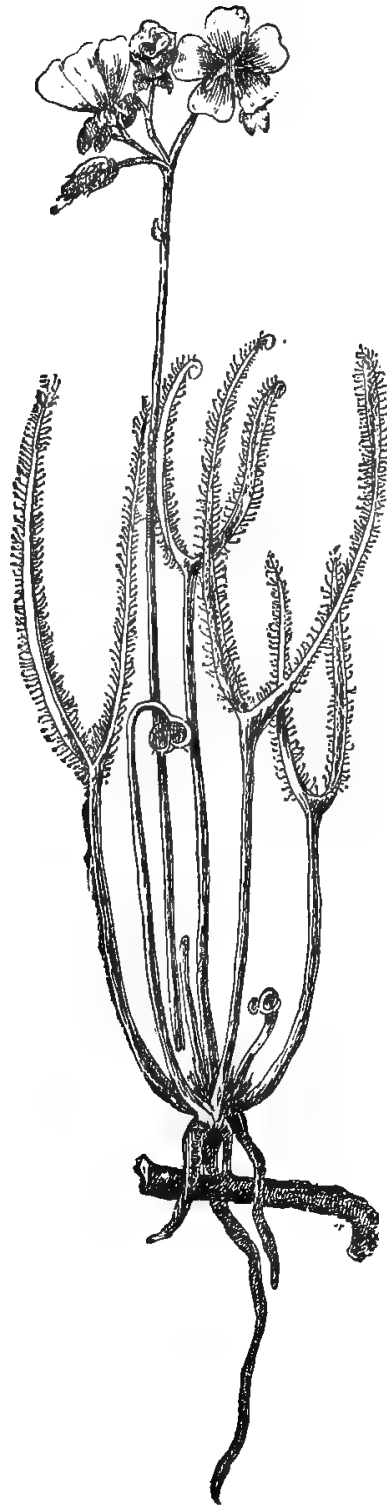

Fig. 88. occurs, consisting of elongated cells, to which the name of ramentaceous lairs, or ramenta (ramentum, a shaving), has been given. In Palms also a similar substance (but of firmer tex-

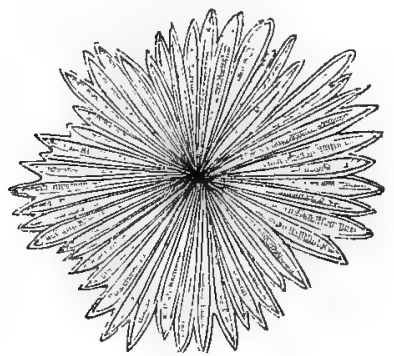

Fig. 87.

ture) occurs, called reticulum (reticulum, a net), or mattulla, (matta, a mat). Prickles or aculei, as in the Rose, are hardened hairs counected with the epidermis, and differ from spines or thorns, which have a deeper origin. Setoe are bristles or stiff hairs, and the surfaces on which they occur are said to be setose or setaceous. Some hairs, as those of Drosera, or sundew (fig. 88), have one or more spiral fibres in their interior.

Various names have been given to the different forms of hairs; they are clavate or club-shaped (clava, a club), gradually expanding from the base to their apex; capitate, having a distinct rounded head; rough or scabrous, with slight projections on their surface; hooked or uncinate (uncus, a hook), with a hook at their apex pointing downwards and to one side; barbed or glochidiate ( $\gamma^{\lambda} \omega \chi^{i}$, a barb), with

Fig. 87. Scale or scaly hair, from leaf of Hippophaë rhamnoides. Fig. 88. Drosera dichotoma, double-leaved sundew, showing leaves covered with glandular hairs. The gland is terminal, and there is a spiral fibre inside the stalk supporting the gland. 
two or more hooks around the apex; shield-like or peltate (pelta, a buckler), when attached by their middle, and projecting horizontally on either side, as in Malpighia urens (fig. 89), and in many cruciferous plants ; ciliated (cilium, an eyelash), when surrounding the margin of leaves. On the pod of the Cowitch (Mucuna pruriens), hairs are produced with projections on their surface, which cause irritation of the

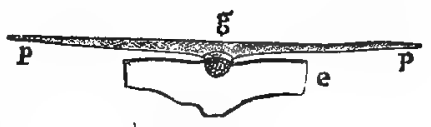

Fig. 89.

skin. In Venus' Fly-trap (Dioncea muscipula), stiff hairs exist on the blades of the leaf (fig. 202 e), which, when touched, cause their closure.

Hairs occur on various parts of plants ; as the stem, leaves, flowers, seed-vessels, and seeds, and even in the interior of vessels. In the interior of the spathe of some palms numerous ovate cells, analogous with hairs, occur in clusters, and when the spathe is dried they can be shaken out in the form of powder. Cotton consists of the hairs surrounding the seeds of Gossypium herbaceum and other species of Gossypium. Hairs are developed occasionally to a great extent on plants exposed to elevated temperatures, as well as on those growing at high altitudes. When occurring on the organs of reproduction they are connected with fertilisation, as the hairs on the style of Goldfussia, and the retractile hairs on the style of Campanula. Different organs of plants are transformed into hairs; as may be seen in the flowering stalks of the Wig-tree (Rhus Cotinus), and in the calyx of Compositæ.

Names are given to the surfaces of plants according to the presence or absence of hairs, as well as the nature of the hairs which cover them. The following are the more important terms:-Glabrous, smooth, having no hairs; hairy (pilosus), furnished with hairs; pubescent, covered with soft, short, downy hairs; villous, having long; weak, often oblique hairs; sericeous, covered with long, closely appressed hairs, having a silky lustre; hispid (hispidus, hirtus), covered with long stiff hairs not appressed; hirsute, having long tolerably distinct hairs, not stiff nor appressed; velvety (velutinus), with a dense covering of short down, like velvet; tomentose, covered with crisp, rather rigid, entangled hairs like cotton, which form a sort of felt (tomentum); woolly, with long curled and matted hairs like wool; bearded or stupose ( $\sigma \tau \dot{u} \pi \eta$, tow), when hairs occur in small tufts.

The hairs which are most frequently met with in plants are called lymphatic, from their not being connected with any peculiar secretion. Those, on the other hand, which have secreting cells at their base or apex, are denominated glandular, and are not to be distinguished from glands, under which therefore they will be considered. Lymphatic hairs occur on parts exposed to the air, and are wanting in blanched

Fig. 89. Peltate hair of Malpighia urens, $p p$, arising from epidermis, e. $g$, The gland, which communicates with the hair. 
plants. On young roots cellular projections occur (fig. $97 h$ ), which may be called radical hairs. Young leaves and buds are frequently thickly covered with protecting hairs. In this instance the hairs grow chiefly along the veins; and as the leaves increase in size, and the veins are separated, the hairs become scattered and apparently less abundant. On the parts of the flower (as in the Iris), coloured hairs occur which have been called corolline.

GLANDS are collections of cells forming secretions. The term has been vaguely applied to all excrescences occurring on the surfaces of plants. They are either stalleed (petiolate, stipitate), or not stalled (sessile).
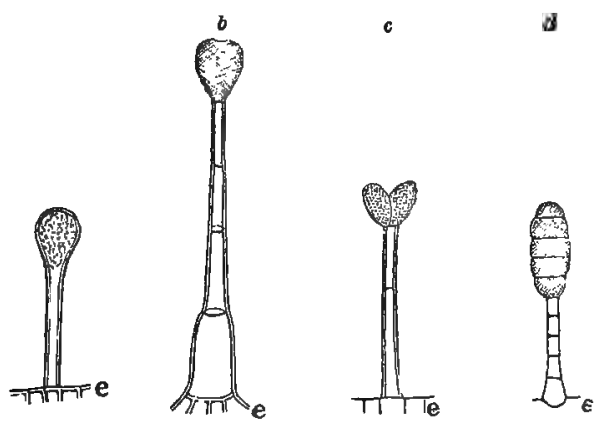

Fig. 90 .

The former may be called glandular hairs, having the secreting cells at the apex. Stalked glands, or glandular hairs, are either composed of a single cell, with a dilatation at the apex (fig. $90 a$ ), or of several cells united together, the upper one being the secreting cell (fig. $90 \mathrm{~b}$ ). In place of a single terminating

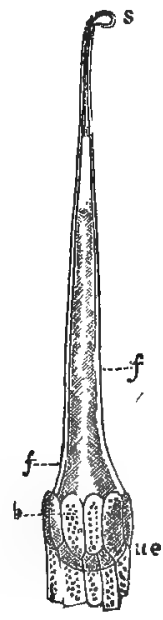

Fig. 91. secreting cell, there are occasionally two (fig. $90 \mathrm{c}$ ) or more (fig. $90 \mathrm{~d}$ ). Hairs sometimes serve as ducts through which the secretion of glands is discharged; these are glandular hairs, with the secreting cells at the base. Such hairs are seen in the nettle (fig. 91), in Loasa or Chili nettle, and in Malpighia (fig. 89), and are commonly called stings. In the nettle they are formed of a single conical cell, dilated at its base (fig. $91 b$ ), and closed at first at the apex, by a small globular button placed

Fig. 90. Glandular hairs. e, Epidermis. $a$, Hair formed by a single cell, from sisymbrium chilense. $b$, Hairs formed of several cells terminated by a secreting cell, from flower-stalk of Antirrhinum majus. c, Hair composed of several cells, terminated by two secreting cells united laterally, from flower-stalk of Lysimachia vulgaris. $d$, Compound hair, terminated by several secreting cells united end to end, from Geum urbanum. Fig. 91. Conical hair of Urtica dioica, or common nettle, ending in a button or swelling, $s$, with a dilatation or bulb at its base, $b$, which is surrounded by epidermal cells, $u e$. In this hair there are currents of granular protoplasm, $f f$. 
obliquely (fig. $91 \mathrm{~s}$ ). This button breaks off on the slightest touch, when the sharp extremity of the hair enters the skin, and pours into the wound the irritating fluid which has been pressed out from the elastic epidermal cells at the base. When a nettle is grasped with violence, the sting is crushed, and hence no injury is done to the skin. The globular apex of glandular hairs sometimes forms a viscid secretion, as in the Chinese primrose and sundew (fig. 88). The hairs of the latter plant, by this secretion, detain insects which happen to alight on them. The hairs gradually close on the insects, electrical phenomena taking place during the movement. Some think that in this case the insects are used as food by the plant.

When glands are sessile, they consist of epidermal cells either surrounding a cavity or enclosing small secreting cells. In fig. 92 is represented a gland taken from the flower-stalk of Dictamnus albus, cut vertically, to show the cavity surrounded by cells, which is filled with a greenish oil; while in fig. 93 there is a gland with a short thick stalk, full of cells, taken from Rosa centifolia. These figures show the transition from sessile to stalked glands. Some of the superficial cells of the epidermis are sometimes slightly elevated above the rest, and contain peculiar fluids. In the Ice-plant, the appearance of small pieces of ice on the surface is produced by cells containing a clear fluid, which is said to have an alka-

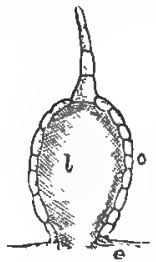

Fig. 92.

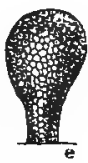

Fig. 93 . line reaction; in the Chick-pea, similar superficial cells contain an acid fluid. Clear glands are also seen on the under surface of the leaf of Passiflora lunata. Resinous glands are seen in the Hop and Hemp plants. Glandular depressions or pits occur, surrounded by secreting cells. At the base of the petals of the Crown-imperial, for instance, cavities are seen containing a honey-like fluid, secreted by what are called nectariferous glands. Cavities containing saccharine matter, surrounded by small thin-walled cells, are met with in the leaves of Acacia longifolia, also in Viburnum Tinus, and Clerodendron fragrans. The cavities communicate with the surface of the leaves by means of canals. Peculiar glands are found at the inner side of the base of the petioles of Cinchona and Ipecacuan plants (fig. 94).

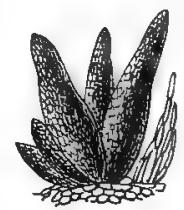

Fig. 94.

Glands are occasionally sunk in the epidermis, so as merely to have

Fig. 92. Gland from flower-stalk of Dictamnus albus, cut vertically, showing central cavity, $l$, filled with greenish oil, and surrounded by a layer of cells, $c$, which contain a red juice, and are connected with the epidermis, e. Fig. 93. Gland from Rosa centifolia; $e_{2}$ the epidermis. Fig. 94. Cluster of ovate-oblong cellular glands from the base of the stipule of the Ipecacuan plant (Cephaelis Ipecacuanha). 
the apex projecting ; at other times they lie below the epidermal cells, as in the Myrtle, Orange, St. John's-wort, and Rue. In the latter case they are sometimes called vesicular, and are formed by cells surrounding cavities containing oil (fig. 95). When

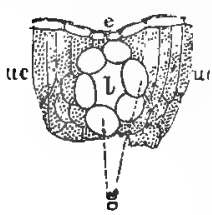

Fig. 95. they occur in the leaves, they give rise, when viewed by transmitted light, to the appearance of transparent points or dots. Verruce, or warts,' are collections of thickened cells on the surface of plants, assuming a rounded form, and containing starch or other matters. Lenticels, or Lenticular glands, are cellular projections on the surface of the bark, arising from its inner part. Trecul says that lenticels result from the formation of corky matter under decayed or decaying tissues, the corky particles surrounding sub-stomatic cavities. The corky matter protects the internal tissue from injurious atmospheric influence. Other lenticels are simply cracks of the epidermis before the production of cork or periderm, while a third set are produced on the surface of a peridermic layer.

The Spectal Functions of the epidermis and its appendages are to protect the parts beneath from various atmospheric and meteorological influences. In plants growing in dry climates, the epidermis is often very thick, and coated with a waxy secretion, to prevent too great transpiration or exudation of fluids. In those which inhabit humid places the epidermis is thin and absorbent; while in submerged aquatics there is no proper epidermal covering. The stomata regulate the transpiration; opening and closing, according to the state of humidity and dryness of the atmosphere surrounding them. When a plant is growing vigorously, the constant passage of fluids keeps the regulating cells around the stomata in a distended state, and thus opens the orifice; whereas, when the circulation is languid and the fluids are exhausted, the cells collapse and close the opening. The opinion that the succulency of plants is a sort of dropsical condition, caused by the absence of stomata to carry off the fluids, has not been confirmed by observation. Hairs, according to their structure, serve various purposes. Lymphatic hairs protect the surface, and regulate evaporation. Plants thickly covered with hairs, as Verbascum Thapsus (Great Mullein), have been known to resist an extended period of drought. When organs become abortive they sometimes assume the form of hairs. Glandular hairs, and glands in general, form secretions which are employed in the economy of vegetation, or are thrown off as excretions no longer fitted for the use of the plant itself. Many of these secretions constitute important articles of materia medica. Lenticels keep

Fig. 95. Vesicular gland from Ruta graveolens, or Common Rue. g, Gland formed by large transparent cells, surrounding a central lacuna, $l$. e, Epidermis from upper surface of the leaf. $u c, u c$, Cells filled with Chlorophyll. 
up a connection between the air and the inner bark, and probably perform the function of stomata in the advanced period of the growth of the plant. They are considered by Decandolle and others as being the points where young roots are produced in certain circumstances, and on that account they have been called Rhizogens ( $\dot{\delta} i \zeta \alpha$, a root, and yevvóziv, to produce). They are conspicuous in Willows, the young branches of which form roots very readily when placed in moist soil. Some hairs occurring on the styles of plants are called collecting hairs, from the functions which they perform in taking up the pollen. In the species of Campanula, these hairs are so formed that after the pollen has been discharged, their upper part is drawn within the lower. In many hairs, as in the nettle, a circulation of fluids takes place, connected apparently with their nutrition and development (fig. 91). In nettle hairs and in the moniliform purple hairs on the stamens of Tradescantia, or Spiderwort, this movement may be easily seen under the microscope. The subject of the circulation in hairs will be considered under Rotation.

\section{Root or Deiscending Axis.}

Structure of Roots.

Before proceeding to the consideration of the special nutritive organs, the root, stem, and leaves, a few remarks are required in reference to the general division of plants into three great classes, Acotyledons, Monocotyledons, and Dicotyledons. The first of these embraces flowerless plants, having a cellular embryo, and no seed-leaf, or, as it is called, Cotyledon. Such plants as Ferns, Mosses, Lichens, Sea-weeds, and Mushrooms, belong to this class. The second includes flowering plants having an embryo with one seed-leaf or Cotyledon, such as Lilies, Palms, Grasses ; while the third includes plants which have two seedleaves or Cotyledons, such as ordinary forest trees, and the majority of flowering plants. In these classes there are marked differences in the structure of the nutritive organs, to the consideration of which we now proceed.

In the young state there is no distinction between stem and root, as regards structure; both being cellular, and prolongations of each other in opposite directions. In stemless plants, as Thallogens, the root remains in a cellular state throughout the life of the plants. The root is afterwards distinguished from the stem by the absence of a provision for the development of leaf-buds, and by increasing from above downwards. It is not always easy to distinguish between a stem and a root. Many so-called roots bear at their upper part a portion called their crown, whence leaf-buds arise. Underground stems and roots are often confounded. Some plants, as the Moutan Pæony, the Plum-tree; 
Pyrus japonica, and especially Anemone japonica, have a power of forming buds on their roots. The last-mentioned plant develops these buds on every part of its extensively ramifying roots, which may be chopped into numerous pieces, each capable of giving rise to a new plant. Such is also the case with the annulated root of Ipecacuan. The part where the stem and root unite is the collum or neck. In woody plants, the fibres of the stem descend into the roots, and there is an internal arrangement of woody layers, similar to that seen in the stem itself.

Roots are usually subterranean and colourless. Externally, they have a cellular epidermal ćovering of a delicate texture, sometimes called epiblema (p. 26), in which no stomata exist. Their internal structure consists partly of cells, and partly of vascular bundles, in which there are no vessels with fibres which can be unrolled. Roots do not exhibit true pith, nor a medullary sheath. The axis of the root gives off branches which divide into radicles or fibrils (fig. 96), the ex-

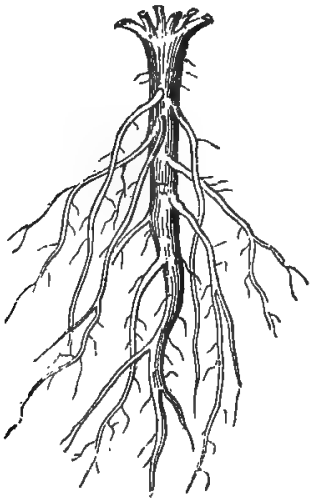

Fig. 96 .

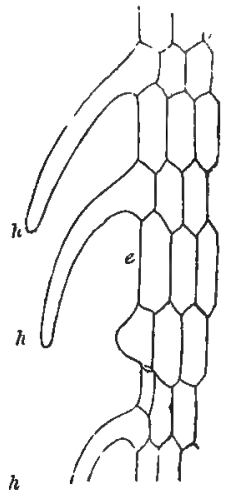

Fig. 97 .

tremities of which are composed of delicate cellular tissue, and have been erroneously called spongioles or spongelets. They are not separate organs, and have nothing of the character of a sponge. Over these root extremities a very thin layer of cells is extended, called a Pileorhiza ( $\pi \tilde{i} \lambda o s$, a cap, and $\dot{\rho} i \zeta \alpha$, a root). This sometimes becomes thickened, and separates in the form of a cup, as in Screw-pines (fig. 98 ), and in Lycopodia (fig. 138). Occasionally the extremities of roots are enclosed in a sheath, or ampulla, as in Lemna. Cellular papill:

Fig. 96. Tapering root of Malva rotundifolia, giving off branches and fibrils. Fig. 97. Young root of Madder, showing cellular processes, $h h h$, equivalent to hairs. $\quad$, Outer cells of the root not elongated into hairs. 
and hairs are often seen in roots, but no true leaves. These hairs consist of simple elongated cells, which occur singly, and appear to serve the purpose of absorption (fig. 97, $h h h$ ). Roots increase principally by additions to their extremities, which are constantly renewed, so that the minute fibrils serve only a temporary purpose, and represent deciduous leaves. The tissue at the extremities of roots is older and more dense than that immediately below it, so as to form a protecting covering.

Roots, in some instances, in place of being subterranean, become aerial. Such roots occur in plants called Epiphytes, or air-plants ('ं $\pi$, upon, and 申urd̀, a plant, from growing on other plants), as in Orchidaceæ; also in the Screw-pine (Pandanus), (fig. 98), the Banyan (Ficus indica), and many other species of Ficus, where they assist in supporting the stem and branches, and have been called adventitious or

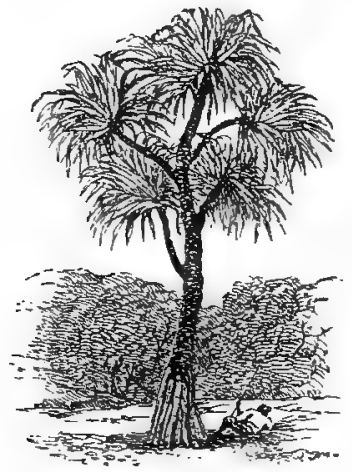

Fig. 98.

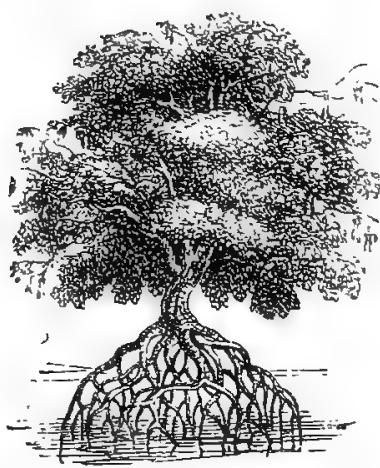

Fig. 99.

abnormal. In Serew-pines these aerial roots follow a spiral order of development. In Mangrove trees (fig. 99) they often form the entire support of the stem, which has decayed at its lower part. The name of adventitious is applied to roots arising from the sides of stems, as for instance those which are formed when portions of stems and branches of the Willow and Poplar are planted in moist soil. They appear first as cellular projections, into which the fibres of the stem are prolonged, and by some are said to proceed from lenticels. They frequently arise from points where the epidermis has been injured. A Screw-pine, in the palm-house of the Edinburgh Botanic Garden, had one of its branches injured close to its union with the

Fig. 98. Pandanus odoratissimus, the Screw-pine, giving off numerous aerial roots near the base of its stem. Fig. 99. Rhizophora Mangle, the Mangrove tree, supported, as it were, upon piles, by its numerous roots, which raise up the stem. The plant grows at the moddy mouths of rivers in warm climates. 
stem. This branch was at the distance of several feet above the part where the aerial roots were in the course of formation. At the part, however, where the injury had been inflicted, a root soon appeared, which extended rapidly to the earth, and then divided so as to form rootlets; thus the branch was firmly supported. The extremities of the aerial roots of Orchids are covered with a layer of delicate whitish tissue, composed of spiral cells. This layer is called velamen radicum, or covering of the roots.

Green-coloured aerial roots are frequently met with in endogenous plants. Such roots possess stomata. In the Ivy, root-like processes are produced from the stem, by means of which it attaches itself to trees, rocks, and walls. Those processes are subservient to the purposes of support rather than nutrition. In parasites, or plants which derive nourishment from other plants, such as Dodder (Cuscuta), roots are sometimes produced in the form of suckers, which enter into the cellular tissue of the plant preyed upon.

When roots have been exposed to the air for some time, they occasionally assume the functions of stems, losing their fibrils, and developing abnormal buds. Duhamel proved this experimentally, by causing the branches of a willow to take root while attached to the stem, and ultimately raising the natural roots into the air.

\section{Forms of Roots.}

The forms of roots depend upon the mode in which the axis descends and branches. When the central axis goes deep into the ground in a tapering manner, without dividing, a tap-root is produced (fig. 96). This kind of root is sometimes shortened, and becomes succulent, forming the conical root of carrot, or the fusiform, or spindleshaped root of radish, or the napiform root of turnip, or it is twisted, as in the contorted root of Bistort.

When the descending axis is very short, and at once divides into thin, nearly equal fibrils, the root is called fibrous, as in many grasses; when the fibrils become short and succulent the root is fasciculated, as in Ranunculus Ficaria and Asphodelus luteus (fig. 100); when the succulent fibrils are of uniform size, and arranged like coral, the root is coralline, as in Corallorhiza innata; when some of the fibrils are developed in the form of tubercules, containing starchy matter, the root is tubercular; the tubercules, in such cases, are in reality stemtubers, as seen in the Jerusalem Artichoke (Helianthus tuberosus), and in Orchis (fig. 101); when the fibrils enlarge in certain parts only, the root is nodulose, as in Spiræa Filipendula (fig. 102), or moniliform, as in Pelargonium triste (fig. 103), or annulated, as in Ipecacuan (fig. 104). Some of these so-called roots are formed of a stem and root combined, 
and when cut in pieces they give rise to buds and new plants. This occurs in the Ipecacuan plant.

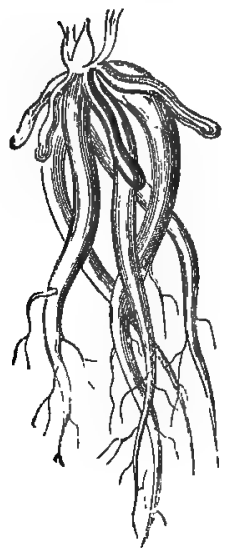

Fig. 100.

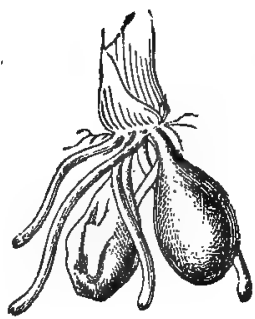

Fig. 101.

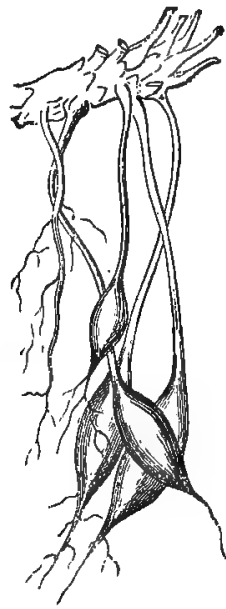

Fig. 102.

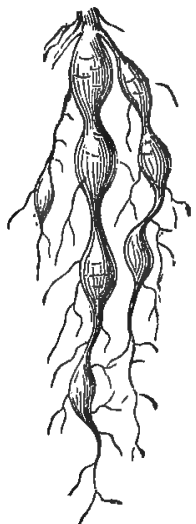

Fig. 103.

In some Dicotyledonous roots, as in the Carrot and Beet, there is a circle of fibro-vascular bundles, which are separated by medullary rays. In the turnip these bundles are immediately under the rind, and in the inner portion of the root the bundles are separated from each other by a great development of cellular tissue. In these peculiar thickened roots it is often difficult to determine their structure. They have more of the aspect of stems, and have been called Hypocotyledonary stems. The structure in several fleshy Dicotyledonous roots resembles that of Monocotyledons.

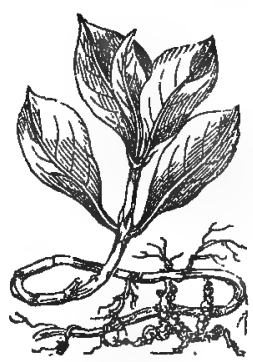

Fig. 104.

In Dicotyledonous plants the root, in its early state, or the radicle, as it is then called, is a prolongation of the stem, and elongates directly by its extremity. It then continues to grow in a simple or branched state (fig. 98). From this mode of root development,

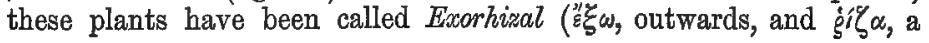

Fig. 100. Fasciculated root of Asphodelus Iuteus. Fig. 101. Tubercular roots or stemtubers of Orchis. Several of the radical fibres retain their cylindrical form, while two are tubercules containing starchy matter. Fig. 102. Nodulose root of Spirnea Filipendula. Fig. 103. Moniliform root of Pelargonium triste. Fig. 104. Ipecacuan (Cephaelis Ipecacuanha), with an annulated root. 
root), by Richard. In their after progress these roots follow the arrangement seen in the woody part of the stem. In some cases, as in the Walnut and Horse-chestnut, there is a prolongation of the pith into the root to a certain extent.

In Monocotyledonous plants the young root or radicle pierces the lower part of the axis (fig. $105 r$ ), is covered with a cellular sheath, $c$; numerous fibrils, $r^{\prime} r^{\prime} r^{\prime} r^{\prime}$, are then developed like adventitious roots. These plants are therefore called by Richard, Endorhizal

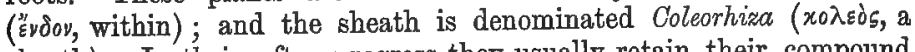
sheath). In their after progress they usually retain their compound character, consisting of fibrils, most of which often remain unbranched (figs. 100, 101). The first-formed roots which surround the axis, if the plant is perennial, gradually die, and others are produced in

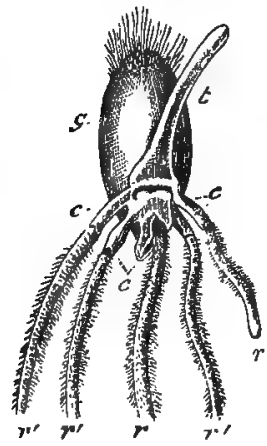

Fig. 105.

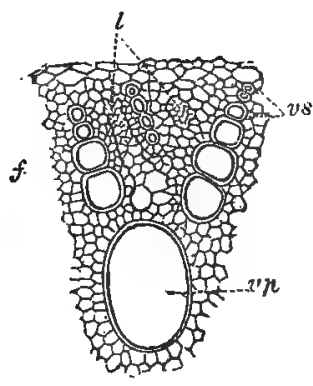

Fig. 106.

'succession farther from the central axis. In Endogenous roots, the same structure is observed as in the stem. Thus, fig. 106 represents a section of a root of a Palm, composed of cellular tissue, porous vessels, $v p$, modified spiral vessels, $v s$, fibrous or woody tissue, $f$, and laticiferous vessels, $l$. Roots are pushed out from various parts of the stems of many Palms, and are applied closely to the surface of the stem.

Fig. 105. Grain of wheat germinating. $g$, The mass of the grain. $t$, The young stem beginning to shoot upwards. $r$, The principal root from the axis. Lateral roots, $r^{\prime} r^{\prime} r^{\prime} r^{\prime}$, covered, like the preceding, with small hairs or threads. Coleorhiza or sheath, $c$ c $c$, with which each of the roots is covered at its base, while piercing the superficial layer of the embryo. Fig. 106. Transverse section of part of the root of a Palm (Diplothemium maritimum), to show the mode in which the cells and vessels are arranged. $v p$, Large porous vessels situated in the interior. $v \mathrm{~s}$, Scalariform or modified spiral vessels more external, and becoming smaller the farther they are from the centre. $f$, Fibrous tissue, or elongated celis, accompanying the ressels. $l$, Groups of laticiferous vessels of different sizes, the larger being inside. 
In Acotyledonous plants the young root is a development of superficial cells from no fixed point, and they have been called Heterorhizal (Eqsgos, diverse). In their subsequent progress these roots present appearances similar to those seen in the stem. They frequently appear in the form of fibres on the outer part of the stem, giving rise, by their accumulation at the base, to the conical appearance represented in fig. 135, $r$ a.

\section{Functions of Roots.}

Roots either fix the plant in the soil or attach it to other bodies. They absorb nourishment by a process of imbibition or endosmose (flow inward), through their spongioles or cellular extremities. The experiment of Duhamel and Senebier, conducted by inserting at one time the minute fibrils alone into fluid, and at another the axis of the root alone, showed clearly that the cellular extremities were the chief absorbing parts of the roots. Hence the importance, in transplanting large trees, of cutting the roots some time before, in order that they may form young fibrils, which are then easily taken up in an uninjured condition, ready to absorb nourishment. When an acorn is put into the ground, it first sends down a long tap root. This is not well fitted for feeding young stems and leaves, and hence numerous fibrous roots appear near the surface of the ground. The more numerous these fibres the more rapid the growth. The tap root is sometimes cut about seven inches under ground at an early period, and this causes numerous fibres to be thrown out.

The elongation of the roots by their extremities enables them to accommodate themselves to the soil, and allows the extremities of the rootlets to extend deeply without being injured. Roots, in their lateral extension, bear usually a relation to the horizontal spreading of the branches, so as to fix the plant firmly, and to allow fluid nutritive substances to reach the spongioles more easily. It is of importance to permit the roots to extend easily in all directions. By restricting or cutting the roots, the growth of the plant is to a certain degree prevented, although it is sometimes made to flower and bear fruit sooner than it would otherwise have done. The system of restrictive potting, formerly practised in green-houses, often injured the natural habit of the plants. The roots filled the pots completely, and even raised the plants in such a way as to make the upper part of the root appear above the soil.

To roots there are sometimes attached reservoirs of nourishment, in the form of tubercules, containing starch and gum (fig. 101), which are applied to the nourishment of the young plant. These are seen 
in the Dahlia and in terrestrial Orchids. In epiphytic Orchids, on the other hand, the roots are aerial, and the stems are much developed, forming pseudo-bulbs. Upon the roots of Spondias tuberosa there exist round black-coloured tubercules, about eight inches in diameter, consisting internally of a white cellular substance, which is full of water. These tubercules seem to be intended to supply water to the tree during the dry season. They are often dug by travellers, each of them yielding about a pint of fluid of excellent quality.

Roots also give off excretions of different kinds. These are eliminated by a process of exosmose (flow outwards), and consist both of organic and inorganic matter. They were examined by Macaire and Decandolle, and at one time they were thought to be injurious to the plant, and by their accumulation to cause its deterioration. It was also supposed that while they were prejudicial to the species of plant which yielded them, they were not so to others, and that hence a rotation of crops was necessary. Daubeny and Gyde have found by experiment that these excretions are not injurious, and it is now shown that the necessity for rotation depends on the want of certain nutritive matters in the soil.* In very rich and fertile land the same crop may be grown successively for many years.

\section{Stem or Ascending Axis.}

Forms of Stems.

The stem is that part of a plant which bears the leaves and flowers. It receives the name of Caulis in ordinary herbaceous plants which do not form a woody stem, Culn in grasses, Truncus in trees, Caudex or Stock in Palms and in some Cacti, and Stipe in Ferns. Herbaceous stems are those of annual and biennial plants, as well as the young yearly shoots of perennial plants. The term haulm is probably a corruption of culm; it is used by farmers to designate the stem of grasses and the herbaceous stems of plants. The stem is not always conspicuous. Plants with a distinct stem are called caulescent ; those in which it is inconspicuous are acaules. Some plants are truly stemless, and consist only of expansions of cellular tissue, called a Thallus, and hence

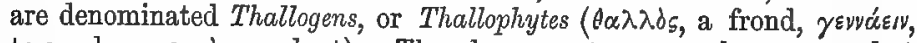
to produce, 申uzdy, a plant). They have no true vascular system, but are composed of cells of various sizes, which sometimes assume an elongated tubular form, as in Chara. The cells are sometimes united

\footnotetext{
* This subject is considered when the sources whence plants derive their nourishment are treated of.
} 
in one or several rows, forming simple filaments, as in Confervæ; or branched and interlaced filaments, as in some Fungi; or cellular expansions, as in Lichens and sea-weeds.

Stems have usually considerable firmness and solidity, but sometimes they are weak, and either lie prostrate on the ground, thus becoming procumbent; or climb on plants and rocks by means of rootlets like the Ivy, being then called scandent; or twist round other pląnts in a spiral manner like Woodbine, becoming volubile. Twining plants turn either from right to left, as the French bean, Convolvulus, Passionflower, and Dodder, Periploca, and Gourd ; or from left to right (left-handed screw), as Honeysuckle, Twining Polygonum, Hop, and Tamus. Bryony tendrils twine from right to left, and left to right, alternately. In warm climates twining plants (lianas) often form thick woody stems; while in temperate regions they are generally herbaceous. Exceptions, however, occur in the case of the Clematis, Honeysuckle, and Vine; the twining stem of the vine has been called sarmentum (sarmentum, a twig, or cutting of a vine). Some stems are developed more in diameter than in height, and present a peculiar shortened and thickened aspect, as Testudinaria or Tortoiseplant, Cyclamen, Melocactus, Echinocactus, and other Cactaceæ.

Stems have a provision for a symmetrical arrangement of leaves and branches, - nodes (nodus, a knot), or points whence leaf-buds are produced, being placed at regular intervals. No such provision occurs in roots, which ramify irregularly, according to the nature of the soil. The intervals between nodes are called internodes. The mode in which branches come off from the nodes gives rise to various forms of trees, such as pyramidal, spreading, or weeping; the angles formed with the stem being more or less acute or oblique. In the Italian Poplar and Cypress the branches are erect, forming acute angles with the upper part of the stem; in the Oak and Cedar they are spreading or patent, forming nearly a right angle; in the weeping Ash and Elm they come off at an oblique angle; while in the weeping Willow and Birch they are pendulous from their flexibility. The comparative length of the upper and under branches also gives rise to differences in the contour of trees, as seen in the conical form of Spruce, and the umbrella-like form of the Italian Pine (Pinus Pinea). The branching of some trees is very peculiar. In the Amazon district many Myristicaceæ and Monimiaceæ have verticillate branches coming off in fives. Some Amazon trees taper remarkably downwards, so as to have a form like an inverted cone or pyramid. This is seen in the Mulatto tree (Eukylista Spruceana), one of the Cinchonaceæ.

The buds of trees are developed in different ways. In some, such as the Oak and Birch, the terminal bud of each shoot produces yearly a new portion of the shoot, while the flowers come off from axillary buds. Again, in other trees, as Lilac and Horse-chestnut, the 
buds at the extremity produce inflorescence, which thus terminates the axis of the shoot, while the shoots of the succeeding year are from axillary buds. When the branches of trees bearing terminal buds have the axis of the shoot destroyed by wounds or by insects, then the lateral leafy buds become developed, giving rise to anomalous appearances seen in the Birch and other trees.

Plants which form permanent woody stems above ground are denominated trees and shrubs, while those in which the stems die down to the ground are called herbs. The term tree (arbor) is applied to those plants which have woody stems many times exceeding the height of a man, the lower part free from branches being the trunk; a small tree (arbusculus) is one not above 25 feet high; a shrub (frutex) has a stem about three times taller than a man, and branches from near the base: an undershrub (suffrutex or fruticulus) does not exceed the length of the arm; while a bush (dumus) is a low diminutive shrub, with numerous branches near the base. The terms arborescent, fruticose, suffruticose, and dumose, are derived from these.

The cylindrical form of the trunk of trees is sometimes interfered with by peculiarities in the production of woody tissue. In this way protuberances are formed of various kinds. This is very remarkable in some kinds of Bombax, and in the Bottle-tree of Australia, where the whole stem appears in the form of a large flask or bottle, tapering to each end, and swollen in the middle. So also, by interruption to the growth of the root and other causes, knobby stems are formed, as in the Yew (fig. 128).

Stems have usually a round form. They are sometimes compressed or flattened laterally, while at other times they are angular: being triangular, with three angles and three flat faces; trigonous ( three, and $\gamma$ vvi $^{\alpha}$, an angle), with three convex faces; triquetrous (triquetrum, a triangle), with three concave faces; quadrangular, or square; quinquangular, or five-angled; octangular, or eight-angled, etc. Various terms are applied to the forms of stems, as cylindrical or terete, jointed or articulated-that is, with contractions at intervals, many-angled or polygonal.

The stem has been called the ascending axis, from being developed in an upward direction. It does not, however, always ascend into the air; and hence stems have been divided into aerial, or stems which appear wholly or partially above ground; and subterranean, or those which are entirely under ground. The latter are often called roots, but they are distinguished by producing leaf-buds at regular intervals. Underground stems are common in Monocotyledons, and it is often found that the structure of Dicotyledonous underground stems, such as Jerusalem artichokes, resemble in structure Monocotyledons. The following are some of the more important modifications of stems :The Crown of the root is a shortened stem, often partially under ground, 
which remains in some plants after the leaves, branches, and flowerstalks have withered. In this case the internodes are very short, and the nodes are crowded together, so that the plant appears to be stemless. It is seen in perennial plants, the leaves of which die down to the ground annually. A Rhizome or root-stock (fig. 107 ) is a stem which runs along the surface of the ground, being partially covered by the soil, sending out roots from its lower side and leaf-buds from its upper. It occurs in Ferns, Iris, Hedychium, Acorus or Sweet Flag,

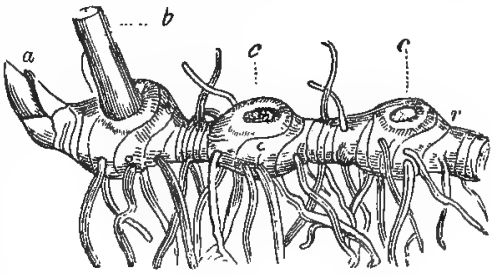

Fig. 107. Ginger, Water-lily, many species of Carex, Rushes, Anemone, Lathræa, etc. By many the term rhizome is applied to stems creeping horizontally, whether they are altogether or only partially subterranean. The short underground stem of Arum maculatum differs from the rhizome of Solomon's Seal, in the presence of the old axes in the latter, and their decay in the former. A rhizome may then be considered as a series of corms united together, the internodes or individual axes being more or less elongated, and usually covered with leaf scales. In rhizomes, called definite, the terminal bud gives off flowers, and the lateral buds form the stem; while in indefinite rhizomes the terminal leaf-bud is formed aunually. A rhizome sometimes assumes an erect form as in Scabiosa succisa, in which the so-called promorse (proemorsus, bitten at the end) root is in reality a rhizome, with the lower end decaying. The erect rhizome of Cicuta virosa shows hollow internodes, separated by partitions. A Pseudo-bulb is an enlarged bulbous-like aerial stem, common in Orchidaceous plants. It is succulent, often contains numerous spiral cells and vessels, and is covered with a thick epidermis. In the Kohl-rabi a peculiar thickened turnip-like stem is met with. A Soboles is a creeping underground stem, sending roots from one part and leaf-buds from another, as in couch grass, Carex arenaria, and Scirpus lacustris (fig. 108). It is often called a creeping root, but is really a rhizome with narrow elongated internodes. A Tuber is a thickened stem or branch produced by the approximation of the nodes and the swelling of the internodes, as in the potato (fig. $109 \mathrm{t}$ ). The eyes of the potato are leaf-buds. Tubers are sometimes aerial, occupying the place of branches.

Fig. 107. Portion of Rhizome, $r$, of Polygonatum multiflorum, Solomon s Seal, forming buds and adventitious roots. $a, \mathbf{A}$ bud in the progress of development. $\quad b$, A bud developed as a branch at the extrenity of the, rhizome. c c, Cicatrices or scars, indicating the situation of old branches which bave decayed. 
The ordinary herbaceous stem of the potato, when cut into slips and planted, sometimes sends off branches from its base, which assume the

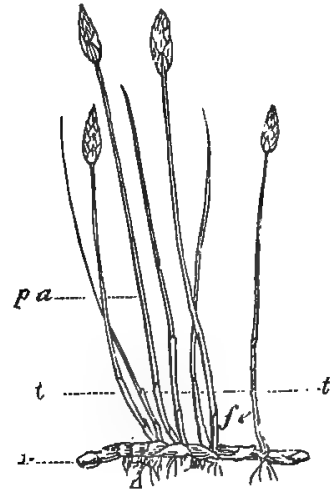

Fig. 108.

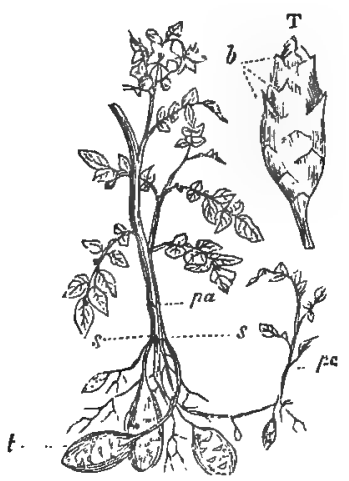

Fig. 109.

form of tubers. These tubers occasionally become nodulated, or elongated, or curved in various ways. Arrow-root is derived from the scaly tubers of Maranta arundinacea. In the Orchis the radicular

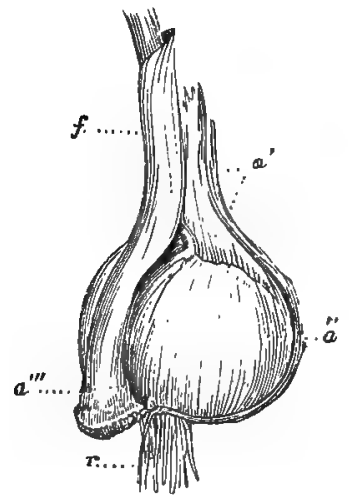

Fig. 110. bodies called tubercules, or by some tubers, belong to the root system (fig. 101). In the didymous (twin) tubers of Orchis mascula, we find at the end of the season one of them withered, while the other is vigorous, and bears a bud at its apex. The lowest leaf of this bud gives rise to another bud, and when the oldest tuber decays this new one enlarges, and next season becomes the bud-tuber, while its parent produces the flowering stem. A Corm is a solid underground stem which does not spread by sending out shoots, but remains of a rounded form, and is covered by thin scales on the outside (fig. 110). The scales are modified leaves specially developed on subterraneous stems, and they may produce buds in their axils. The corm occurs in Colchicum, Crocus, and

Fig. 108. Soboles, or creeping subterranean stem, $r$, of Scirpus lacustris. $f \cdot e_{,} f e$. Scales or modified leaves on the stem. $p a$, Aerial portion of the plant. $t t$, Level of the earth. Fig. 109. Lower portion of a potato plant. $s s$, Level of earth. $p a, p a$, Aerial portion bearing leaves. $t$, Subterranean portion, showing stem-tubers. $T$, Tuber showing eyes or leafbuds, covered by scales, $b$, which are equivalent to leaves. Fig. 110. Corm or underground stem of Colchicum autumnale. $r$, Roots. $f$, Leaf. $\alpha^{\prime}$, Ascending axis of preceding year, withered. $a^{\prime \prime}$, Axis of the year. $a^{\prime \prime \prime}$, Point where axis of next year would be formed. 
Gladiolus. A Corm is only of one year's duration, while a rhizome or root-stock consists of a string of annual growths, persistently connected. It is distinguished from a root by seading off buds annually in the form of small corms or thickened branches, either from the apex, as in Gladiolus, or from the side, as Colchicum (fig. $110 a^{\prime \prime}$ ). These buds feed on the original corm $a^{\prime}$, and absorb it. In the Crocus, after flowering, may be seen the withered parent corm; new corms, which are in reality the basis of the flowering axis, branching from the old corm; and in the axil of the leaves of the flowering stem small buds ready for another season. In Colchicum autumnale (Meadow Saffron), we find in autumn the flowering stem united to the side of the corm at its base. The two lowest sheaths of the flowering stem produce buds in their axils. The flowering stem withers, and the internodes between the two buds form a new corm, while the old one decays.

\section{Internal Structure of Stems.}

Stems, according to their structure, have been divided into three

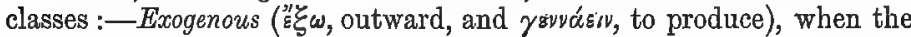
bundles of vascular tissue are produced regularly in succession externaily, and go on increasing indefinitely in an outward direction. Endogenous ("zvov, within), when the bundles of vascular tissue are produced in definite bundles and converge toward's the interior, additions being thus in the first instance made internally. Acrogenous (äxgos, summit), when the vascular bundles are developed at the same time and not in succession, the addition to the stem depending on the extension of the growing point or summit. The plants which exhibit these three kinds of stem are distinguished also by the structure of their embryo. Thus exogenous stems are met with in plants having an embryo or germ which has two cotyledons or seed-lobes, hence they

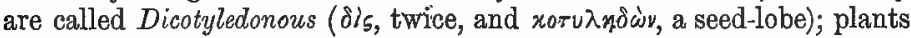
with endogenous stems have only one cotyledon, and are called Monocotyledonous ( $\mu$ óvos, one); while plants with acrogenous stems have no cotyledons, and are called Acotyledonous ( $\alpha$, privative). The terms connected with the embryo will be afterwards fully explained.

\section{Exogenous or Dicotyledonous Stem.}

The Exogenous or Dicotyledonous stem characterises the trees of this country. It consists of a cellular and vascular system; the former including the outer bark, medullary rays, and pith; the latter, the inner bark, woody layers, and medullary sheath. In the early stage of growth the young dicotyledonous stem is entirely cellular; but ere long fusiform tubes appear, forming bundles, having the 
appearance of wedges (fig. $111 w w$ ) arranged in a circle round a central cellular mass of pith (fig $112 p$ ), which is connected to the outer part or bark by meaus of cellular processes called medullary rays (fig.

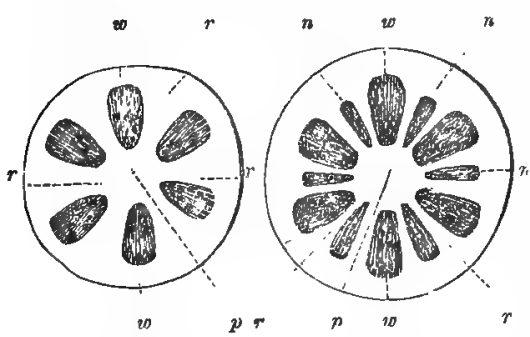

Fig. 111.

Fig. 112.

$111 r r r$ ). At first the cellular portion is large, - the pith, bark, and rays occupying a large portion of the stem; but by degrees new vascular bundles are formed, which are deposited between the previous ones (fig. $112 n n n$ ). By this means the pith is more circumscribed, the medullary rays become narrow, and the bark more defined. Such is the structure presented by an annual herbaceous dicotyledonous stem, consisting of pith, a circle of fibrovascular and woody tissue, medullary rays, bark, and epidermis.

The stems of trees and shrubs in their young state exhibit an arrangement similar to that represented as occurring in the herbaceous stem (fig. 112), with this difference, that the vascular circle is more firm and solid. As ligneous stems continue to grow, further changes take place by which their diameter is increased, and they are rendered more dense. The shoots or young branches given out annually, how-

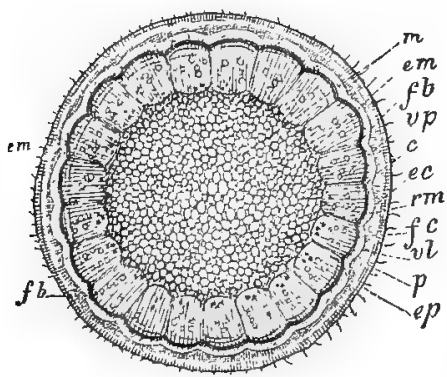

Fig. 113. ever, are similar in structure to annual herbaceous stems; and in making successive sections from the apex of a branch, which is succulent and green, to the base of a trunk, which is comparatively dry and hard, the various changes which take place can be easily traced. Fig. 113 represents a horizontal or transverse section of the upper part of a young branch of Acer campestre. In the centre, $m$, is the pith, very large at this period of growth, and occupying

Fig. 11l. Yonng Dicotyledonous or Exogenous stem. $w w$, Vascular bundles in the form of wedges. $p$, Pith. $r r r$, Medullary rays. Fig. 112. Same stem further advanced; the letters as in fig. 111, $n n n$, New vascular wedges interposed between those first formed. Fig. 113. Horizontal seetion of young stem of Acer campestre, magnified twentysix diameters. $m$, Pith. $e m, e m$, Medullary sheath. $f b, f b$, woody bundles. $v p$, Pitted ressels, $\quad r m$, Medullary rays. $c$, Cambium or zone of tissue between the xylem or wood portion, and phloem or bark portion. $f c$, Fibres of Endophloum. $v l$, Laticiferous vessels. e c, Cellular envelope, Mesophloum. $p$, Cnrky envelope, Epiphloum, e $p$, Epidermis. 
at least one-half of the whole diameter, its cells diminishing in size as they approach the circumference. Immediately surrounding the pith is a layer of a greenish hue, the medullary sheath, $e m$, from which the medullary rays, $r m$, proceed towards the circumference, dividing the vascular circle into numerous compact segments, which consist of woody vessels, $f b$, and of pitted vessels, $v p$. These are surrounded by a moist layer of greenish cellular tissue, $c$, called the cambium layer, which is covered by three layers of bark, $f c, e c$, and $p$, with laticiferous vessels, $v l$, the whole being enclosed by the epidermis, $e p$. On making a thin vertical section of a portion of the same branch, and viewing it under the microscope, the parts composing the different portions become more obvious (fig. 114). The pith, $m$, with its hexagonal cells decreasing

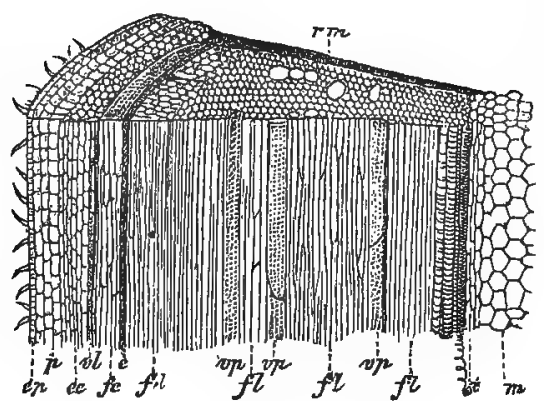

Fig. 114.

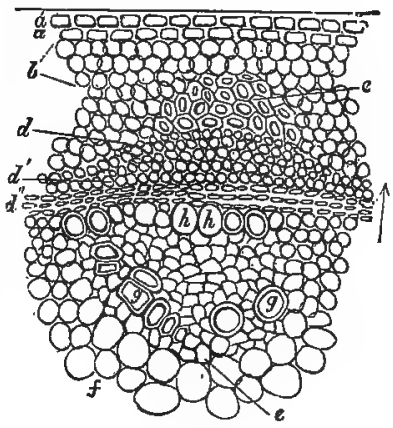

Fig. 115.

in size outwards, surrounded by a narrow fibro-vascular zone, the medullarry sheath, consisting chiefly of spiral vessels, $t$; the medullary ray, $r m$; the vascular zone, consisting of pitted vessels, $v p$, of large diameter, and forming the large round apertures seen in a transverse section; the fibres of the wood, $f l$, with their thick walls and smaller apertures; the inner bark or liber, $f c$, with the layer of cambium cells, $c$; the second layer of bark, or the cellular envelope, $e c$, with the laticiferous vessels, $v l$; the outer or suberous layer of bark, $p$, with the thin layer of epidermis, e $p$, having hairs seattered over its surface. A transverse section of a bundle of vascular tissue of a dicotyledonous plant, magnified 230 times, is represented in fig. 115. The arrow indicates the direction from within outwards. We here perceive the vascular bundle surrounded by a large-celled tissue $(a b b f)$. The

Fig. 114. Vertical section of the same stem more highly magnified. $t$, Tracheæ or spiral vessels. $f l, f l_{j} f l$, Woody fibres. The other letters as in fig. 113. Fig. 115. Transverse section of a bundle of vascular tissue of a Dicotyledonous plant. $\alpha d$, Epidermis. $b$, Largecolled tissue of bark. $c$, Fibres of bast layer. $d, d^{\prime}$, Woody layers and laticiferons vessels of inner bark. $d^{\prime \prime}$, Cambium cells. $g g$, and $h h$, Large pitted vessels. ¿, Woody tabes. $f$, Large cells. 
quadrangular cells, $a \tilde{a}$, form the epidermis, to which succeeds the cellular tissue of the bark, $b$. The latter surrounds a bundle of bast (phloem) fibres, $c$, and ligneous layers of inner bark, with laticiferous vessels, $d d^{\prime}$, which are separated, in the direction towards the interior, by a layer of cambium cells, $d^{\prime \prime}$, from the proper vascular tissue (xylem), consisting of pitted vessels with thick walls, $g g$, and others with thin walls, $h h$, mixed with woody tubes, $e$.

Such is the structure of a young shoot during the first year of its growth. At the end of a second year the shoot is found to have increased in diameter by the formation of a zone of vessels consisting

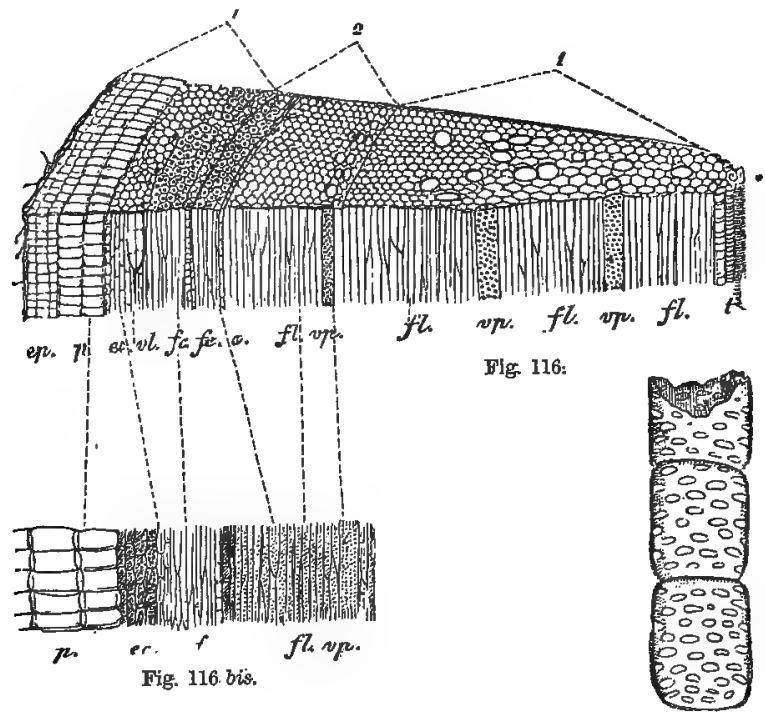

Fig. 116 ter.

of porous and woody tissue, and a zone of fibrous bark, the medullary rays being at the same time continued from within outwards. This is represented in fig. 116, where 1,1 indicates the section of the stem of the first year's growth (the letters referring to the same parts as in figs. 114, 115); and 2 shows the interposed zones of the second year, by which the diameter of the stem is increased.

The PItH, or the central part of a dicotyledonous stem, is com-

Fig. 116. Vertical section of a branch of common maple (Acer campestre) two years old, where $(1,1)$ indicates the portion formed the first year, and (2) that formed the second. The letters as in figs. 114 and 115. Fig. 116 bis. Certain parts of the preceding magnified, in order to show the structure of the vessels and cells, as well as their form and direction. Fig. 116 ter. A portion of a pitted vessel from the gourd, magnifled. 
posed of cellular tissue, which is developed in an upward direction, the cells diminishing in size towards the circumference, and being often hexagonal. In the young plant it occupies a large portion of the stem, and sends cellular processes outwards at regular intervals to join the medullary rays (figs. $111,112 p$ ). The pith has at first a greenish hue, and is full of fluid, but in process of time it becomes pale-coloured, dry, and full of air. These changes take place first in the central cells. Sometimes the pith is broken up into cavities, which have a regular arrangement, as in the Walnut, Jessamine, and Cecropia peltata; it is

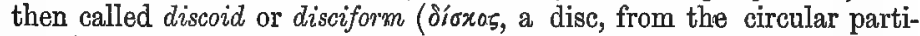
tions). At other times, by the rapid growth of the outer part of the stem, the pith is ruptured irregularly, and forms large cavities as in the fistular stem of Umbelliferous plants. Circumscribed cavities in the internal cellular portions of sterns are by no means unfrequent, arising either from rupture or absorption of the eells. In some rare instances vessels occur in pith, as in Elder, Pitcher-plant, and Ferula; and occasionally its cells are marked by pores indicating the formation of secondary deposits. The extent of pith varies in different plants, and in different parts of the same plant. In Ebony it is small, while in the Elder it is large. In the Shola plant, Atschynomene aspera, the interior of the stem is almost entirely composed of cellular tissue or pith; from this a kind of rice-paper is made, and light hats. The same kind of tissue occurs in the Papyrus of the Nile. Large pith is also seen in Fatsia papyrifera, or Chinese rice-paper plant. When the woody circle of the first year is completed, the pith remains stationary as regards its size, retaining more or less its dimensions, even in old truńks, and never becoming obliterated.

The Medullary Sheare is the fibro-vascular layer immediately surrounding the pith. It forms the inner layer of the vascular bundle of the first year (fig. $114 t$ ), and consists chiefly of true spiral vessels, which continue to exercise their functions during the life of the plant, and which extend into the leaves. With the spiral vessels there are a few woody fibres intermingled. The processes from the pith are prolonged into the medullary rays between the vessels of the sheath.

WOODY LAYERS.-During the first year the vascular circle consists of an internal layer of spiral vessels forming the medullary sheath, and external bundles of pitted and ligneous vessels. In subsequent years the layer of spiral vessels is not repeated, but concentric zones of pitted vessels (fig. 116 ter) and pleurenchyma are formed, constituting what are commonly called the woody circles of trees. The vascular bundles, from their, mode of development in an indefinite manner externally, have been called Exogenous; and, for the same reason, Schleiden has denominated them Indefinite. Exogenous plants have sometimes received the name of Cyclogens ( $x_{i} x \lambda 05$, a circle), in consequence of exhibiting concentric circles in their stems. On a 
transverse section, each zone or circle is usually seen to be separated from that next to it by a well-marked line of demarcation. This line, as in the Oak (figs. 117, 118), and in the Ash, is indicated by holes which are the openings of large pitted vessels; the remainder of the tissue in the circle being formed by pleurenchyma, with thickened walls and of smaller calibre. In some trees, as the Lime, Hornbeam,

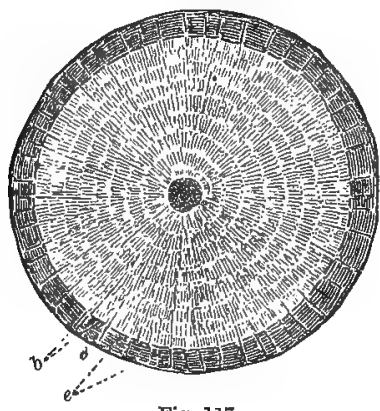

Fig. 117. and Maple, the line is by no means so well marked, as the openings are smaller and more generally diffused; but there is usually a deficiency of pitted vessels towards the outer part of the circle. In cone-bearing plants, as the Fir, in which the woody layers consist entirely of punctated woody tissue (fig. 49), without any large pitted vessels, the line of separation is marked by the pleurenchyma becoming dense and often coloured. In some kinds of wood, as Sumach, the zones are separated by a marked development of cellular tissue. The separation between the zones is said to be owing to the interruption in the growth of the tree during autumn and winter, and hence it is well defined in trees of temperate and cold climates. But even in tropical trees, the lines, although often inconspicuous, are still visible; the dry season, during which many of them lose their leaves, being their season of repose.

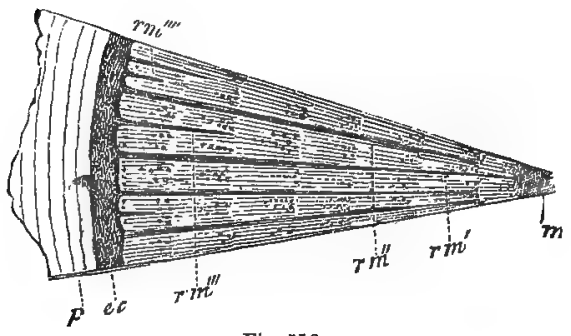

Fig. 118.

The woody layers vary in their texture at different periods. At first the vessels are pervious and full of fluid, but by degrees thickening layers are deposited which contract their canal, and sometimes obliterate it. The first-formed layers are those which soonest become thus altered. In

Fig. 117. Horizontal section of the stem of an oak eight years old. $b$, Wood, showing concentric circles or zones, separated by points which correspond to the opening of the large pitted vessels, or Bothrenchyma. e, Bark, showing also eight concentrie eircles, thinner and less distinct. The wood and bark are traversed by merdullary rays, some of which extend from the bark to the pith, and others reach only a certain way inwards. Fig. 118. Horizontal section of two woody bundles of Cork-oak, separated from each other by the medullary ray, $r m^{\prime}$. The two primary bundles are divided by secondary rays, $r m^{\prime \prime}$, $r m^{\prime \prime \prime}, r m^{\prime \prime \prime \prime}$, which vary in extent according to the period when tbey originated. $m$, Pith. $e c$, Cellular envelope. $p$, Corky envelope, which is highly developed, and exhibits several layers. 
old trees, there is a marked division between the central Heart-wood or Duramen (durus, hard), and the external Sap-wood or Alburnum (albus, white): the former being hard and dense, and often coloured, with its tubes dry and thickened; while the latter is less dense, is of a pale colour, and has its tubes permeable by fiuids. The difference of colour between these two kinds of woods is often very visible. In the Ebony tree, the duramen or perfect-wood is black, and is the part used for furniture, while the alburnum is pale; in the Beech, the heart-wood is light-brown; in the Oak, deep-brown; in Judas tree, yellow; in Guaiacum, greenish. The alteration in colour is frequent in tropical trees. In those of temperate climates, called white-wood, as the Willow and Poplar, no change in colour takes place; this is also the case in the Chestnut and Bombax. The relative proportion of alburnum and duramen varies in different trees. Duhamel says that in the oak, six inches in diameter, the alburnum and duramen are of equal extent; in a trunk one foot in diameter they are as two to seven; in a trunk two feet in diameter, as one to nine. The heart-wood is more useful than the sap-wood, and less liable to decay. The wood of different trees varies much in its durability. Pieces of wood $2 \frac{5}{8}$ inches square, were buried to the depth of one inch in the ground, and decayed in the following order:-Lime, American Birch, Alder, and Aspen, in three years ; Willow, Horse-chestnut, and Plane, in four years; Maple, Red Beech, and Birch, in five years; Elm, Ash, Hornbeam, and Lombardy Poplar, in seven years ; Robinia, Oak, Scotch Fir, Weymouth Pine, Silver Fir, were decayed to the depth of half an inch in seven years; while Larch, common Juniper, Virginian Juniper, and Arbor Vitæ, were uninjured at the end of that time.

From the mode in which the woody layers are formed, it is obvious that each vascular zone is moulded upon that which precedes it; and as, in ordinary cases, each woody circle is completed in the course of one year, it follows, that, by counting the concentric circles, the age of a tree may be ascertained. Thus fig. 117 represents an oak eight years old, having eight woody layers, $b$. This computation can only be made in trees having marked separations between the circles. There are, however, many sources of fallacy. In some instances, by interruption to growth, several circles may be formed in one year, and thus lead to an erroneous estimate. Care must be taken to have a complete section from the bark to the pith, for the circles sometimes vary in diameter at different parts of their course, and a great error might occur from taking only a few rings or circles, and then estimating for the whole diameter of the tree. When by the action of severe frost, or other causes, injury has been done to the tender cells from which the young wood is developed, while, at the same time, the tree continues to live, so as to form perfect woody layers in subsequent years, the date of the injury may be ascertained by counting the 
number of layers which intervene between the imperfectly formed circle and the bark. In 1800 , a Juniper was cut down in the forest of Fontainbleau, exhibiting near its centre a layer which had been affected by frost, and which was covered by ninety-one woody layers, showing that this had taken place in the winter of 1709 . Inseriptions made in the wood become covered, and may be detected in after years when a tree is cut down; so also wires or nails driven into the wood. As the same development of woody layers takes place in the branches as in the stem of an Exogenous tree, the time when a branch was first given off may be computed by counting the circles on the stem and branch respectively. If there are fifty circles, for instance, in the trunk, thirty in one branch and ten in another, then the tree must have been twenty years old when it produced the first, and forty when it formed the other.

In Exogenous stems the pith is not always in the centre. The layers of wood on one side of a tree may be larger than those on the other, in consequence of their fuller exposure to light and air, or the nature of the nourishment conveyed, and thus the pith may become excentric. Zones vary in size in different kinds of trees, and at different periods of a plant's life. Soft wooded trees have usually broad zones, and old trees form smaller zones than young ones. There are certain periods of a plant's life when it seems to grow most vigorously, and to form the largest zones. This is said to occur in the oak between twenty and thirty years of age.

Cambium. - External to the woody layers, and between them and the bark, there is a layer of mucilaginous semifluid matter, which is particularly copious in spring, and to which the name of Cambium (cambio, I change, from the alterations that take place in it) has been given (figs. 113, $114 \mathrm{c}$ ). In this substance cells are formed, called cambium cells, of a delicate texture, in which the protoplasm and primary utricle are conspicuous. These cells undergo changes, so as to assume an elongated fusiform shape, and ultimately become thick- ened pleurenchyma. So long as the primary utricle can be detected they appear to be in an active state, and capable of developing new cells. This cambium layer marks the separation between the wood and the bark, and may be regarded as constituting the active formative tissue of Dicotyledonous stems. It constitutes the thickening zone, by means of which the stem is enlarged-the cambium cells situated most internally being subservient to the purposes of the wood formation, while the external ones give origin to the new bark. According to Schacht this is the proper nourishing tissue.

Bark or Cortical (cortex, bark) System lies external to the wood, and, like it, consists of several layers. In the early state it is entirely cellular, and is in every respect similar to the pith ; but as the vascular bundles are developed, the bark and pith are separated, and the former 
gradually becomes altered by the formation of secondary deposits. The bark consists of a cellular and vascular system. In this respect it resembles the wood, but the position and relative proportion of these two systems is reversed. In the bark the cellular system is external, and is much developed; while the vascular is internal, and occupies comparatively a small space. The cellular portion of the bark consists of an external layer, or Epiphloum (ż $\pi$, upon, on the outside, and $\phi \lambda$ or ${ }^{\prime}$, bark), and the cellular envelope, or Mesophloeum ( $\mu \dot{\varepsilon} \sigma o s$, middle); while the vasular system forms the internal portion called Liber, or Endophloeum ("Evdov, within).

The inmer bark, or endophtceum (fig. $116 f \mathrm{c}$ ), is composed of elongated pleurenchyma mixed with laticiferous vessels and some cellular tissue. It is separated from the wood by the cambium layer. The pleurenchymatous tubes are thickened by concentric deposits in their interior, and thus they acquire a great degree of tenacity. The liber of the Lime tree and of Antiaris saccidora (the sack tree of Coorg) are used to form mats, cordage, and bags ; and the toughness of the fibres of the inner bark of flax, hemp, and of many of the nettle and mallow tribe, render them fit for various manufacturing purposes. The liber is sometimes, from its uses, called the bast-layer. Occasionally it is continuous and uninterrupted, as in the Vine and Horse-chestnut; at other times, as in the Oak, Ash, and Lime, the fibres are separated during the progress of growth, and form a sort of network, in the interstices of which the medullary rays are seen. The fibres of the lace-bark tree (Lagetta lintearia) are similar. In figure 119 is represented the bark of Daphne Laureola; $f$ indicating the woody fibres of liber, and $r$ the medullary rays. The endophlœum increases by layers on its inside, which are thin, and may be separated like the

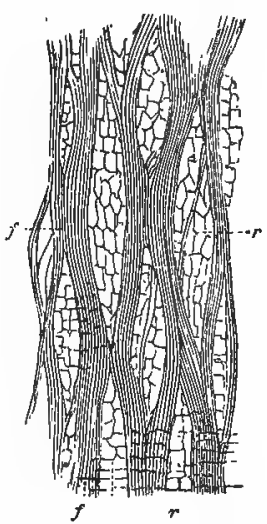

Fig. 119. leaves of a book, and hence the application of the name liber. The term liber may be derived from the fact of the inner bark being used for writing upon.

The cellular envelope, or mesophloum, lies immediately on the outside of the liber. It consists of polyhedral, often prismatical cells (fig. 116 e c), usually having chlorophyll, or green colouring matter, in their interior, but sometimes being colourless, and containing raphides. They are distinguished from those of the epiphloum by their form and direction, by their thicker walls, their green colour,

Fig. 119. Network formed by liber of Daphne Laureola. $f f$, Fibrous bundles. $r r$, Medullary rays. 
and the intercellular spaces which occur among them. This covering is usually less developed than the outer suberous layer, but sometimes, as in the Larch and common Fir, it becomes very thick, and separates like the epiphloum. In the cellular envelope laticiferous vessels occur.

The Epiphloum is the outer covering of the bark, consisting of cells which usually assume a cubical or flattened tabular form (fig. $116 \mathrm{bis}, p)$. The cells have no chlorophyll in their interior, are placed close together, and are elongated in a horizontal direction; and thus they are distinguished from the cells of mesophloeum. In the progress of growth they become often of a brown colour. This covering may be composed of a single layer of tabular cells; but in some trees it consists of numerous layers, forming the substance called cork, which is well seen in Quercus Suber, the Cork-oak (fig. $118 p$ ); hence the name suberous, or corky layer, which is given to it. The form of its cells varies in some instances, being cubical at one part, and more compressed or tabular at another, thus giving rise to the appearance of separate layers. After a certain period (sometimes eight or nine years), the corky portion becomes inactive, and is thrown off in the form of thickish plates, leaving a layer of tabular cells or periderm below. On the exterior of the epiphloum is situated the epidermis, which has already been described. It is formed of a layer of cells, which in woody stems serve only a temporary purpose, becoming ultimately dry, and being thrown off in the form of plates or shreds.

The bark, in its increase, follows an order exactly the reverse of that which occurs in the woody layers. Its three portions increase by additions to their inside. The layers of liber owe their increase to the cambium cells, which, by their constant reproduction, mark the separation between the vascular bundles of the wood and the fibres of the endophloum. These layers are often so compressed and united together as to be counted with difficulty, while at other times they are separated by rings of cellular tissue, and thus remain conspicuous. In the case of the cellular portions of the bark there are also successive additions, sometimes to a great exent, but they do not usually éxhibit any marked divisions.

As the additions are made to the woody layers on the outside, and to the bark on the inside, there is a constant distension going on, by which the bark becomes compressed, its layers of liber are condensed, the fibres are often separated (fig. 119) so as to form meshes (as in the lace-bark), its epidermis is thrown off, and the epiphloeum is either detached along with it, or, when thick, is ruptured in various ways, so as to give rise to the rugged appearance presented by such trees as the Elm and Cork-oak. In some instances the bark is very distensible, and its outer cellular covering is not much developed, so that the surface remains smooth, as in the Beech. The outer suberous layer sometimes separates with the epidermis, in thin plates or scales. 
In the Birch, these have a white and silvery aspect. There is thus a continual destruction and separation of different portions of the bark. The cellular envelope and liber may remain while the epiphloum separates, or they also may be gradually pushed off-the parts which were at first internal becoming external. In the case of some Australian trees, both the cellular and fibrous portions are detached in the form of thin flakes, and occasionally each annual layer of liber pushes off that which preceded it. The epidermis separates early, and no renewal of it takes place. There is, however, an internal covering, which is formed of various portions of the bark. To this covering

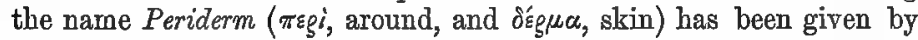
Mohl.

From the mode in which the outer layers of bark separate, it follows that inscriptions made on them, and not extending to the wood, gradually fall off and disappear. A nail driven into these layers ultimately falls out. In consequence of the continued distension of an exogenous stem, it is found that woody twining plants cause injury, by interrupting the passage of their fluids. Thus a spiral groove may be formed on the surface of the stem by the comapression exercised by a twining plant, such as honeysuckle: From what has been stated relative to the changes which take place in the bark, it will be understood that it is often difficult to count its annual. layers, so as to estimate the age of the tree by means of them. This may, however, be done in some cases, as shown at fig. 117, where there are eight layers of bark, e, corresponding to eight woody layers, $b$.

Meddllary Rays or Plates. - While the bark and pith become gradually separated by the intervention of vascular bundles, the connection between them is kept up by means of processes called medullary rays (figs. 111, $112 \%$ ). These form the silver grain of carpenters ; they communicate with the pith and the cellular envelope of the bark, and they consist of cellular tissue, which becomes compressed and flattened so as to assume a muriform appearance (fig. $120 m r$ ). At first they occupy a large space (fig. 111 r); but as the vascular bundles increase they become more and more narrow, forming thin laminæ or plates, which separate the woody layers. On making a transverse or horizontal section of a woody stem, the medullary rays present the aspect of narrow lines running from the centre to the circumference (figs. $117,118 \mathrm{rm}$ ); and in making a vertical section of a similar stem through one of the rays, the appearance represented in fig. 120 will be observed, where a medullary ray, $m r$, composed of flattened muriform cells, passes from the pith, $p$, to the cellular envelope, $c e$, crossing the trachere of the medullary sheath, $t$, the ligneous tissue, $l$, the pitted vessels of the wood, $b$, and the fibres of the liber, $c f$. The laminæ do not by any means preserve an uninterrupted course from the apex to the base of the tree. They are 
broken up by the intervention of woody fibres, as seen in a vertical section of a woody stem (fig. 121), tangentially to the medullary rays $m r, m r, m r$, which are separated by similar interlacing fibres, $l l$. The medullary rays are usually continuous from the pith to the

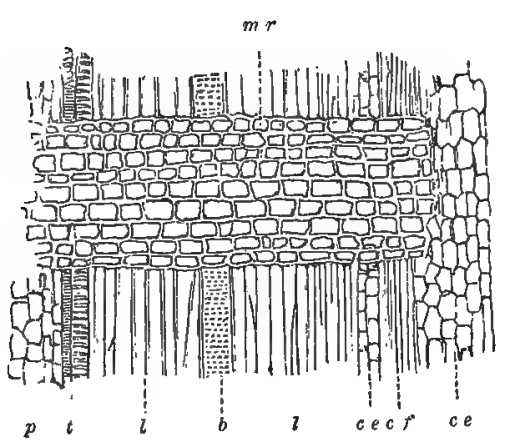

Fig. 120.

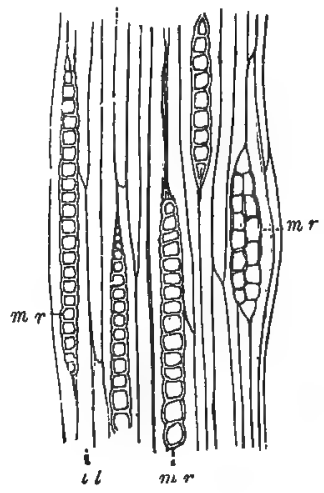

Fig. 121.

bark, additions being made to them as they proceed outwards. But, occasionally, secondary rays arise from the outer cells, which pass only to a certain depth between the vascular bundles, as in the Corkoak (fig. 118, r m, $r m^{\prime \prime \prime}$ ). Medullary rays are conspicuous in the Cork-oak, Hazel, Beech, Ivy, Clematis, Vine. They are not so well marked in the Lime, Chestnut, Birch, Yew.

\section{Anomalies in the Strueture of the Exogenous Stem.}

The stems of Dicotyledonous plants occasionally present anomalous appearances in the structure and arrangement of their wood, bark, and medullary rays. In place of concentric circles there are sometimes only a few rows of wedge-shaped vascular bundles produced during the life of the plant, additions being made by the interposition of bundles of a similar kind annually, resembling in this respect the formation of woody bundles in the early growth of herbaceous plants (fig. 112). In the Pepper tribe, Aristolochiaceæ, and Menispermaceæ, these anomalous stems occur. In Gnetum (fig. 122), the

Fig. 120. Vertical section of a one-year old branch of Acer campestre, highly magnified, and extending from the pith to the bark, parallel to the medullary rays. $m r$, A medullary ray or plate extending from the pith, $p$, to the bark, $c e$, crossing trachex, $t$, fibres of xylem or wood, $l$, pitted vessels, $b$, and cortical fibres, $c f$. Fig. 121. Vertical section of the same branch at right angles to medullary rays. $l l$, fibres of wood (xylem) which interlace, leaving spaces, $m r, m r, m r$, where the medullary rays pass. 
vascular bundles, $b \quad b \quad b \quad b \quad b$, form zones, which are each the produce of several years' growth, and are separated by layers, lllllll, which may be considered as representing different zones of liber.

In some of the Menispermum tribe, the separating layers are of a cellular and not of a fibrous nature. In Banisteria nigrescens (fig. 123), the young stem (1) presents a four-lobed surface; the lobes become more evident (2); and ul-

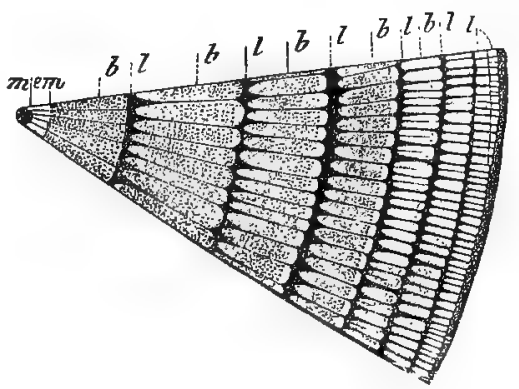

Fig. 122. timately (3) the stem is divided into a number of separate portions, the central one of which alone exhibits pith and medullary rays. The portions are separated by interposed cortical layers.

Many of the Malpighiaceæ, Sapindaceæ, and Bignoniaceæe of Brazil, exhibit stems in which the woody layers are arranged in a very irre-
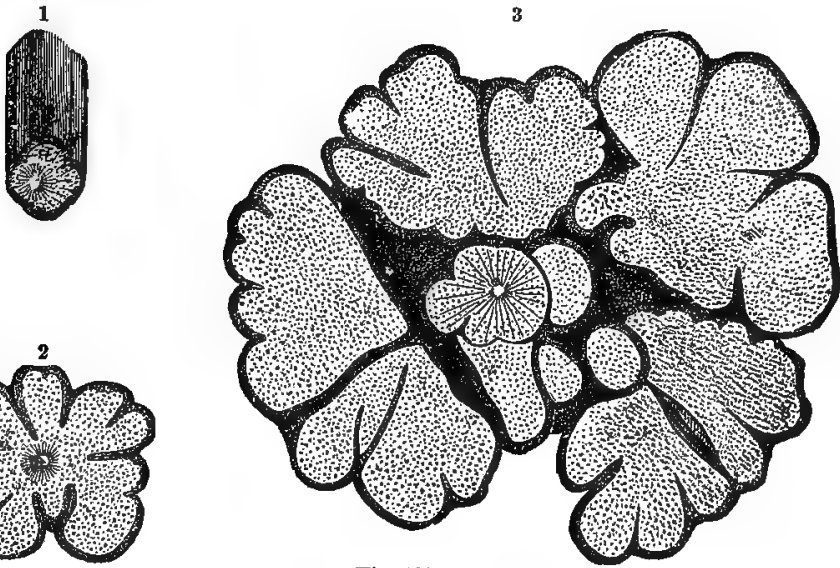

Fig. 123.

gular manner. In the stem of Calycanthus floridus, and of some

Fig. 122,-Horizontal section of stem of Gnetum. $m$, Pith. $e m$, Medullary sheath. $b \quad b \quad b \quad$, Woody bundles forming seven concentric zones, each of which is the produce of several years, $l l l l l l$, Fibres of liber forming interposed circles, equal in number to the woody zones. Fig. 123. Horizontal section of stem of Banisteria nigrescens at different ages. 1. Stem presenting four superficial lobes. 2. \$ix more marked lobes, with intermediate divisions. 3. The lobes separated by cellular tissue, the middle one alone having pith and medullary sheath. The dots indicate the orifices of pitted ressels. 
Brazilian Sapindaceæ, such as Paullinia pinnata (fig. 124), Serjania triternata and Selloviana, there is a central woody mass with from three to ten small secondary ones round it. Each of the masses contains true pith, derived either from the cortical cellular tissue, or from the original medullary centre. Gaudichaud and Jussieu state that around these separate collections of pith there is a medullary sheath and spiral vessels. No annual rings have been detected in the secondary masses, but medullary rays exist usually in their outer portion (fig. 124). In these anomalous Sapindaceæ, the central and

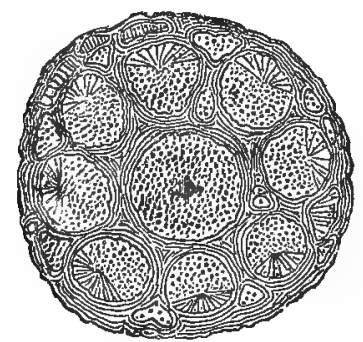

Fig. 124.

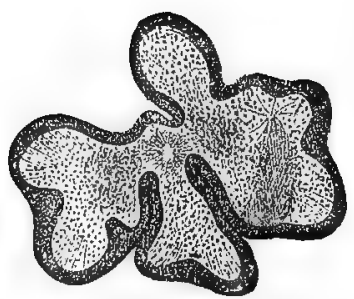

Fig. 126.

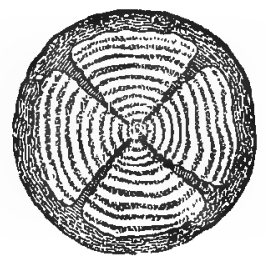

Fig. 125.

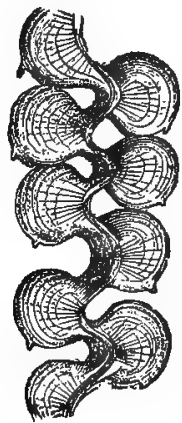

Fig. 127.

lateral woody masses are enclosed in a common bark, with a continuous layer of liber. Some have supposed that the lateral masses are undeveloped branches united together under the bark; but Treviranus

Fig. 124. Horizontal section of the stem of Paullinia pinnata, one of the Sapindacen of Brazil, showing numerous secondary woody masses surrounding a central one. Each of the separate masses has pith, often excentric, with a medullary sheath, containing spiral vessels, and a few medullary rays chiefly towards the circumference of the stem. Fig. 125. Horizontal section of the stem of Bignonia capreolata, showing the cruejal division of the woody layers. Fig. 126. Horizontal section of stem of Heteropterys anomala, one of the Brazilian Malpighiacem, showing an irregularly lobed surface. The dots indicate porous vessels. Fig. 127. Fragment of a stem of climbing species of Banisteria (B. scandens), showing the effects of compression. 
cousiders them as connected with the formation of leaves, and as depending on a peculiar tendency of the vascular bundles to be developed independently of each other round several centres.

In some Bignoniacere (fig. 125), the layers of wood are diwided in a crucial manner into four wedge-shaped portions by the intervention of plates differing in texture from the ordinary wood of the plant, and probably formed by introversion, or growing inwards of the liber. In some Guayaquil Bignonias, Gaudichaud perceived first four of these plates, next eight, then sixteen, and finally thirty-two. In Aspidosperma excelsum (Paddle-wood) of Guiana, and in Heteropterys anomala (fig. 126), the stem assumes a peculiar lobed and sinuous aspect; and in some woody climbing plants, pressure causes the stems to become flattened on the side next the tree on which they are supported, while from being twisted alternately in different directions, they present a remarkable zigzag form, having the woody layers developed only on one side (fig. 127). In Firs the wood is occasionally produced in an oblique in place of a perpendicular manner, thus injuring the timber, and causing it to split in an unusual way. The young plants produced from the seed of such twisted-wooded firs are said to inherit the peculiarity of their pa. rents. Occasionally the dicotyledonous stem, becomes swollen at certain

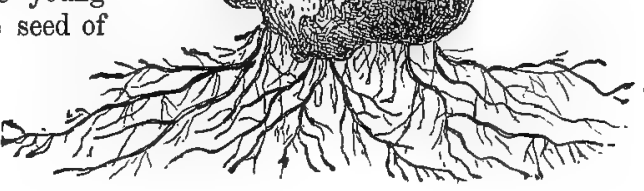

Fig. 128. places, especially near the root, and thus exhibits a tuberous appear-

Fig. 128. Swollen stem of Irish Yew (Taxus baccata, var. stricta). 
ance, as shown in fig. 128, which represents an Irish yew with an anomalous stem. This peculiar appearance is said to be liable to occur in coniferous plants grown from cuttings. A Sequoia (Wellingtonia) gigantea is mentioned in which a tuberous mass was produced 1 foot 6 inches in circumference, on a plant grown from a cutting, the plant being only 3 feet in height, with a stem $2 \frac{1}{2}$ inches in circumference.

\section{Endogenous or Monocotyledonous Stem.}

This kind of stem is composed of cells and vessels which are differently arranged from those of the Exogenous stem. The vascular bundles are scattered through the cellular tissue, and there is no distinction between pith, wood, or bark. There are no medullary rays,

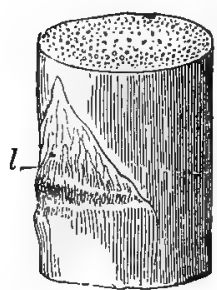

Fig. 129.

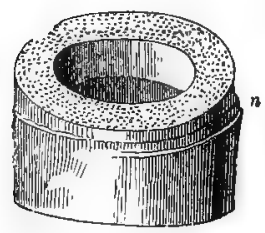

Fig. 130. nor concentric circles (fig. 129). . In the young state, the centre of the stem is occupied entirely by cells, which may be said to represent pith, and around this the vessels are seen, increasing in number towards the circumference. The central cellular mass bas no medullary sheath. In some cases its cells are ruptured, and disappear during the progress of growth, leaving a hollow cavity (fig. 130); but in general it remains permanent, and is gradually encroached upon by the development of the vascular system. The latter consists of vessels arranged in definite bundles, which do not increase by additions to their outside after being once formed, although they are developed in a progressive manner. These bundles may be considered as representing the vascular wedges, produced during the first year of an exogenous stem's growth (fig. 111). They consist of woody vessels enclosing some cellular tissue between them, with spiral and pitted vessels. The outer part of the stem is not formed by a separable bark, but consists of a dense mass of fibrous tissue, mixed with laticiferous vessels and cells. It is intimately connected to the inner part of the stem, without the intervention of medullary rays.

On making a transverse section of a young endogenous stem (fig. 131), there is observed a mass of cells or utricles, $u$, of various

Fig. 129. Part of the stem of Asparagus cut transversely, showing the vessels as poirts distributed through the cellular tissue. $l$, Leaf in the form of a scale. Fig. 130. Transverse section of stem of Phragmites communis, or common reed. The cellular tissue in the centre has disappeared, leaving a fistular or holkow stem, with a ring of cells and vessels, the latter indicated by dots. $n$, Node where the fibres cross, so as to form a solid partition. 
sizes, often small in the vicinity of the vascular bundles, spiral vessels or traches, $t$, large pitted vessels, $v p$, laticiferous vessels, $l$, and bast fibres, $f$, resembling those of liber, thickened by internal deposits. A similar section of a farther advanced endogenous stem, as of a Palm (fig. 132), shows numerous bundles of vessels dispersed irregularly in cellular tissue; those near the centre, $m$, being scattered at a distance from each other, while those towards the outside are densely aggregated, forming a darkish zone, $b$, and are succeeded at the circumference by a paler circle of less compact vessels, $l$, with some compressed cells, covered by an epidermis, $e$. The peripherical portion, $l e$, differs from true bark, in not being separable from the rest of the tissue. It has received the name of false bark, and consists of the epidermal

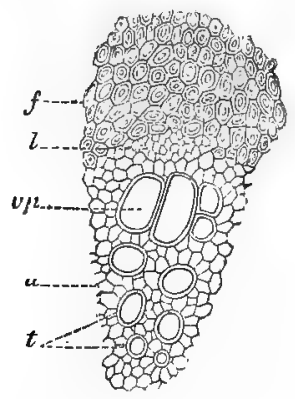

Fig. 131.

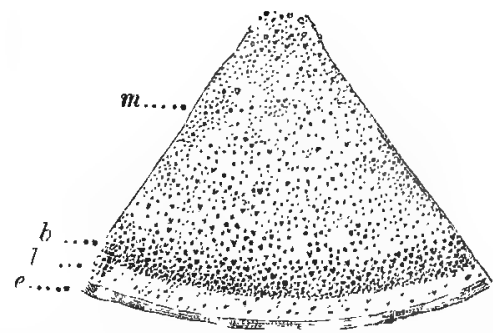

Fig. 182.

cells, e, and what has been called the cortical integument, $l$. This portion of the stem is often very inconspicuous, but sometimes it is much developed, as in"Testudinaria elephantipes, in which it is rugged, and is formed of a stbstance resembling cork in many respects.

Mohl states that in the stem of a Palm there may be distinguished a central region, a fibrous layer, and a cortical region; and the same divisions are pointed out by Henfrey in the stem of Sparganium ramosum and other monocotyledons. The central portion, representing the pith of dicotyledons, consists in Sparganium of spherical cells, containing starch, while the cortical or outer portion is formed by irregular cells, which are usually destitute of starch.

It was at one time supposed that the woody portion of these

Fig. 131. Horizontal section of a vascular bundle from the stem of a Palm (Corypha frigida). $t$, Tracheæ, or spiral vessels. $v p$, Large pitted vessels. $u$, Celis or utricles of various kinds surrounding the vessels, and forming the parenchyma. $l$, Laticiferous vessels. $f$, Fibres analogous to those of liber, thickened by concentric deposits. Fig. 132. Transverse section of part of the stem of a Palm (Astrocaryum Murumura). m, Central or medullary portion, in which the woody bundles are distant and. scattered. $b$, External woody portion, where the fibres are numerous and densely aggregated, so as to form a dark zone. $l$, Paler circle of more slender and less compact fibres, which may be considered as analogous to liber. $e$, Cellular epidermal portion. 
stems was increased by additions to the centre, so that the firstformed fibres were gradually pushed towards the circumference by those which succeeded them, in the manner represented in Fig. 133,

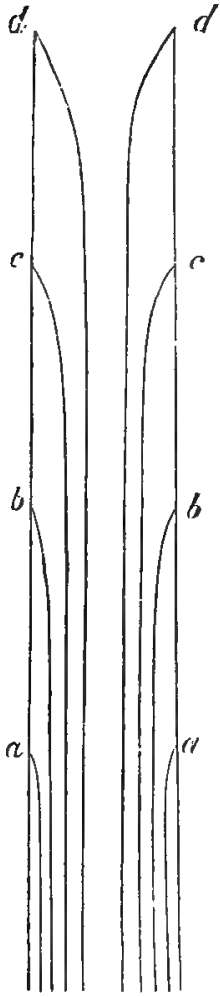

Fig. 133.

1: hence the term Endogenous

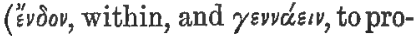
duce), meaning internal growth. But Mohl has shown that this is not strictly correct. For although the fibres connected with the leaves, in the first instance, are directed towards the centre, and are therefore always internal to those previously formed, yet, when they are traced downwards, they are found not to continue in a parallel direction, but to arch outwards, so as ultimately to reach the circumference. Hence, the newly-formed fibres really become external at the base, although internal above. On making a vertical section of an endogenous stem, as of a Palm, there is observed an interlacing of fibres, similar to what is represented in Fig. 133,2 , where the four vascular bundles, $a b c d$, are first directed towards the centre, and then curve outwards towards the circumference, so that those last formed ultimately become external. The term Endogenous will, therefore, only apply strictly to the fibres at the early part of their course. Of late years, the terms Endogenous and Exogenous have been discarded by many writers, the terms Monocotyledonous and Dicotyledonous being substituted. The true distinction between Exogenous and Endogenous stems is, that in the former the woody or vascular bundles increase indefinitely at their

Fig. 139. Diagrams illustrating the arrangement of four pairs of vascular bundies $(\alpha a$, $b b, c c, d d$ ), in endogenous stems. 1. According to the old idea of internal development throughout the stem. 2. According to the vlew of Mohl, who has shown that the fibres interlace, and that those which are at first internal become external, lower down. 
periphery, while in the latter they are arrested in their transverse growth at a definite epoch. The investing bark of the former permits an unlimited extension of woody growth beneath it; the fibrous cortical layer of the latter, by maintaining an intimate union with the subjacent tissue, prevents unlimited increase in diameter. Hence we find that true endogenous stems do not attain the enormous diameter exhibited by some exogenous trees, such as Sequoia (Wellingtonia) gigantea and the Baobab, - the former of which has been measured 116 feet in circumference.

The composition of the vascular bundles, in different parts of their course, varies. Thus, at the upper part, tracing them from the leaves towards the centre, they contain spiral vessels, pitted vessels with some cellular tissue, a few laticiferous vessels, and woody fibres resembling those of liber (fig. 131). As we descend, the spiral vessels disappear, then the pitted vessels; and when the bundles have reached the periphery, and have become incorporated with it, nothing but fibrous tissue, or pleurenchyma, remains, forming a complicated anastomosis or network. Thus, at the commencement, the bundles are large, but as they descend they usually become more and more attenuated. In some instances, however, as in Ceroxylon Andicola, they increase at different parts of their course, probably by interstitial growth, and give rise to irregular swellings of the stem. This distension takes place occasionally at the base of the stem, as in Euterpe montana.

There are many herbaceous plants in this country, as Lilies, Grasses, etc., having endogenous stems, in which the course of the vascular bundles may occasionally be traced, but there are no British endogenous plants with permanent aerial woody stems. All the British trees are exogenous. Illustrations of endogenous stems must therefore be taken from trees of foreign countries. Palms furnish the best examples. In them the stem forms a cylinder of nearly uniform diameter throughout. The leaves are produced from a single terminal and central bud, called a Phyllophor or Phyllogen ( $\varphi \dot{u} \lambda \lambda_{0} \nu$, a leaf, and Qogein to bear, and $\gamma^{g u v a c} \varepsilon(\nu$, to produce). Connected with the leaves are the vascular bundles, and the bases of the leaves remain attached to the outer part of the stem, surrounded by the mattulla or reticulum. While the leaves produced by one bud decay, another bud is developed in the centre. As the definite vascular bundles are produced, the stem acquires increased thickness, but it is arrested in its transverse diameter at a certain epoch. The bundles, although developed progressively, do not multiply indefinitely; and thus a Palm-stem seldom becomes of great diameter.

In consequence of this mode of formation, the outer part of a Palm-stem is the hardest and densest, and after acquiring a certain degree of firmness it resists all further distension, and frequently be- 
comes so hard as to withstand the blow of a hatchet. It has been already stated that in the exogenous stem provision is made for unlimited extension laterally, by the development of bundles of woody fibres and vessels indefinitely, and the formation of a separable bark which can be distended; but in the endogenous stem there is no such provision. Hence, when the first formed or lowest part of the stem has increased to a certain amount, its progress is stopped by the hard indistensible outer fibrous covering; and the same thing takes place successively in the higher parts of the stem, till at length all have acquired a comparatively uniform size, as is seen in the coco-nut palm (fig. 134, 1). In consequence of the small lateral increase of Palmstems, a woody twining plant does less injury to them than to trees of exogenous growth.

The growth of endogenous stems may be said to resemble an

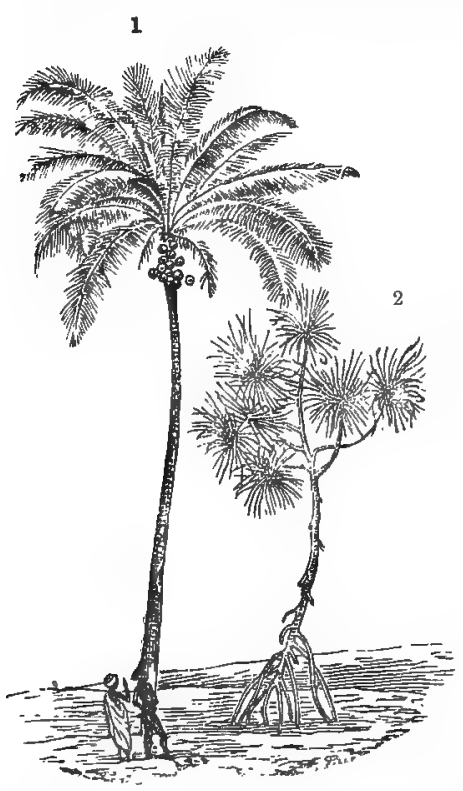

Fig. 134. upward growth of an Exogen by terminal buds only, for there is no cambium layer, and no peripherical increase. In Palms, while the terminal shoot is developed, there are no annual rings. The hardening of the stem depends, in all probability, partly on internal changes in the bast fibres, similar to what takes place in the heart-wood of Exogens. Occasionally, at the upper part of a palm-stem, there is an appearance of zones, but it does not contimue throughout the stem. From the absence of concentric circles, the age of a Palm cannot be estimated in the same way as that of an exogenous tree. The elongation, however, of each species of Palm is pretty regular, and by it some idea may be formed of its age. The rings on the stem do not usually indicate yearly growth.

Fig. 134. Two endogenous or monocotyledonous trees, belonging to different families. 1. Cocos nucifera, or coco-nut, belonging to the PaIm family. 2. Pandanus odoratissimus, or screw-pine, belonging to Pandanacex. The first has a simple unbranched stem, with a cluster of leaves at the summit; the second has a branched stem, with numerous leafy elusters, and peculiar aerial roots, proceeding from different parts of the stem. Two figures are given to indicate the height of the trees. 
In Palms, there is in general no provision for lateral buds, and no branches are formed. Hence, destroying the central bud will kill the tree. In some Palms, however, as the Doum palm of Egypt (Hyphone thebaica), the stem divides in a forked or dichotomous (di $x a$, two ways, and rífvelv, to cut) manner. Gardner, in his travels in Brazil, noticed a Palm in which the central bud having been destroyed, two side ones had been produced, so as to give it a forked appearance. Other plants with endogenous stems also produce lateral buds. In fig. 134, 2, there is a representation of such a stem, in the case of the Screw-pine (Pandanus odoratissimus), and examples are seen in Grasses as the Bamboo, in Asparagus, Cordyline, and Dracæna. In these cases the stem is more or less tapering, like that of Exogens, and the destruction of the terminal bud is not necessarily followed by the death of the plant. The development of lateral buds is often accompanied by an increased diameter of the stem. The famous Dracæna Draco, or Dragon tree of Orotava, in the Canary Islands, had a hollow stem capable of holding several men; and the fact of its living in this state is marked by Jussieu as an argument against the strict endogenous formation; for, if the centre were the youngest and newest part, its destruction would put an end to the existence of the tree in the same way as the removal of the outer part of the wood would destroy an exogenous stem. Professor Piazzi Smyth remarked that this famous Dragon tree was covered on the outside with root-like fibres, which descended from the branches to the ground. The tree is now destroyed. The branches in such plants are formed on the same principle as the stems; but their fibres do not proceed to the centre of the stem, but extend outside the pre-existing bundles, between them and the outer false bark (fig. 132, le), and thus give rise to lateral increase. In Grasses, the stem or culm is usually hollow or fistular (fig. 130), in consequence of the outer part, by its rapid increase, causing the rupture and ultimate disappearance of the internal cellular portion. The fibres in some Grasses cross from one side to the other, forming partitions, as in Bamboo, which add much to the strength of the stem.

When the internodes of the caudex of a Palm are not much elongated, the scars of the leares are seen forming spirals on the stem, as in the coco-nut and date. In Xanthorrhcea Hastile the same arrangement is observed. In Palms, such as species of Chamædorea, the internodes are much lengthened, and rings are seen on the stem at distant intervals, showing thickened node-like joints. Some Palm stems, as those of Calamus Rudentum, the common cane, are very thin and slender. In many Endogenous or Monocotyledonous plants the stem remains below ground, developing shoots which are simple, as in Banana and Plantain, or branched, as in Asparagus. In the former, the stem above ground is an herbaceous shoot, composed 
of the sheaths of the leaves. It dies after fruiting, and is succeeded by other shoots from the subterranean stem. The shoots or buds from such stems occasionally remain in part helow ground in the form of bulbs, as in Lilies, Tulips, and Hyacinths; or as corms, in Colchicum, Crocus, Gladiolus, and Arum.

In some instances the aerial stem has the usual endogenous structure, while in the underground stem the vascular bundles are in the form of wedges, with cellular tissue in the centre, thus resembling Exogens. This structure has been remarked in the Smilax or Sarsaparilla family. Lindley calls these plants Dictyogens (dixrvov, a net), from their netted leaves, by which they differ from most Endogens. Henfrey holds that the ring of woody fibres in these plants, as seen in Tamus and Smilax, is an alteration of the parenchymatous cells of the periphery, and is not produced in the same way as the zones of Dicotyledons. He considers this ring as probably analogous to the liber, and not to the indefinite vascular bundles of Exogenous stems.

\section{Acrogenous or Acotyledonous Stem.}

This stem, in its general external aspect, resembles that of Endogens. It is unbranched, usually of small, nearly uniform diameter, and produces leaves (fronds) at its summit. It is easily distinguished by its internal' structure. Tree Ferns furnish the best example of this kind of stem. In them it is denominated a Stipe, and it often attains the height of 120 feet (fig. 135). A transverse section of the stem (fig. 136) exhibits an irregular circle of vascular bundles, composed of masses, $z l$, of various forms and sizes, situated near the circumference; the centre, $m$, being formed of cellular tissue, and often becoming hollow. On the outside of the vascular circle, cells exist, $p$, covered by an epidermal layer or cellular integument, e, often of hard and dense consistence, and marked with the scars of the fronds.

The vascular bundles are formed simultaneousty, and not progressively, as in the stems already noticed; and additions are made in an upward direction. The stem is formed by additions to the summit, and by the elongation of vessels already formed; hence the name Acrogenous ("̈ugos, summit). The plants are also called Acrobrya (äxegos, summit, and Bgúuiv to germinate). The vascular system is of greater density than the rest of the tissue, and is usually distinguished by the dark colour of the pleurenchyma or prosenchyma (fig. $136 \mathrm{f}$ ), which surrounds the paler vessels in the centre (fig. $136 v v$ ). There is a continuous woody cylinder in the Fern stem. The vascular bundles, however, do not follow a straight course, but unite and separate, leaving spaces between them, similar 
to the meshes seen in the liber of Exogens (fig. 119). In these spaces vessels of communication pass between the outer or cortical, and the inner or central portions of the stem. From the point where the vascular bundles unite or anastomose, other vessels are given off to supply the fronds, and some pass into the adventitious roots, which are often produced abundantly on the outside of the stipe (fig. 135 ra).

The trunk of the Acrogen differs from that of the Exogen, by having its

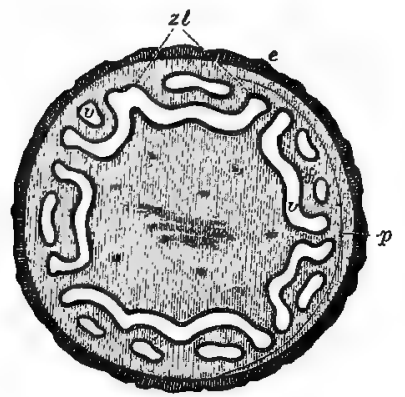

Fig. 136.

vascular cylinder penetrated by only one kind of horizontal tissue, namely, the vascular bundles belonging to the fronds; while the Exogen has in addition another horizontal tissue, namely, medullary rays, composed of cellular tissue, and performing a totally different function.

The acrogenous stem in the young state is solid, but it frequently becomes hollow in the progress of. growth, by the rupture and absorp-

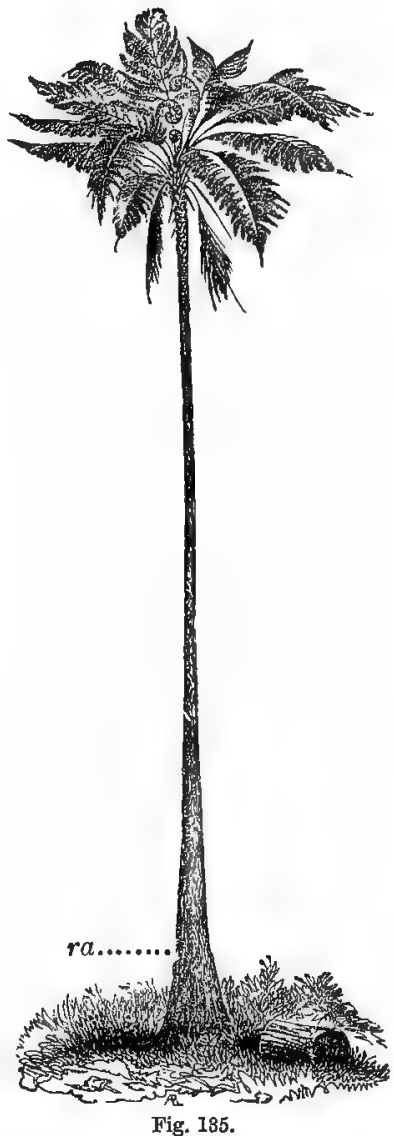

Fig. 185.

Fig. 135. Tree fern (Alsophila perrotetiona), of the East Indies. Stem or stipe is cylindrical, unbranched, and presents at its base, $r a$, a conical enlargement, formed by a mass of adventitious roots. The leaves are terminal, and in the young state are rolled up in a circinate manner. Fig. 136. Transverse section of the stem of a Tree fern (Cyathea). $m$, Cellular tissue, corresponding to pith, occupying the central part. $z l$, Vascular circle composed of numerous irregularly-formed masses. $f$, Dark-coloured woody or prosenchymatous fibres, forming the borders of the vascular masses. $v v$, Pale-coloured vessels, chiefly scalariform, occupying the centre of the masses. $p$, Parenchymatous or cellular external zone, communicating with the central portion, e, Hard epidermal envelope, occupying the place of the bark. 
tion of the walls of the cells in the centre. The bases of the leaves remain long attached, but ultimately fall off, leaving marked scars which are at first close together, but often separate afterwards by interstitial growth. On these scars or cicatrices (cicatrix, a wound) the markings of the vessels are easily seen, arranged in the same manner as those of the stem, with which they are continuous. The vascular system of ferns consists chiefly of scalariform vessels (fig. 64), mixed with annular (fig. 62), woody and pitted vessels (fig. 116 ter). There are no true tracheæ with fibres which can be unrolled. In the stems of Lycopodiaceæ closed tracheæ or ducts occur; and in Equisetacex the rings of the annular vessels are closely united.

The stem of Ferns is generally of small diameter; it does not increase much laterally, after having been once formed, and it does not produce lateral buds. Sometimes it divides into

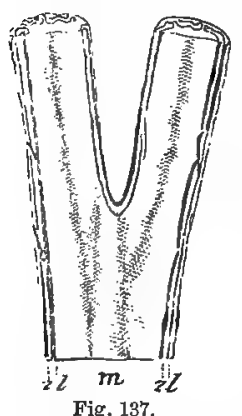
two (fig. 137), by the formation of two buds at its growing point. This, however, is an actual division of the stem itself, and differs from the usual branching of Exogenous and Endogenous stems. In the Ferns of this country the stems usually creep along and under the ground, and the leaves which they produce die annually, without giving origin to a conspicuous trunk. In the common Brake (Pteris aquilina), the arrangement of the vascular system may be seen by making a transverse section of the underground stem. The plant has received its name aquilina, from a supposed resemblance to a spread eagle, presented by the vessels when thus cut across.

The axis of Lycopodiacer or Club-mosses (fig. 138) exhibits a vascular bundle of scalariform vessels and closed spirals. The bundle is developed in an upward direction as the stem grows, each internode having its permanent bundle. Vessels pass from the stem to the leaves.

In Equiseta or Horse-tails (fig. 139) there is a circle of vascular bundles towards the exterior of the aerial stem; this vascular ring is covered by cortical cells of different kinds. The Equiseta have underground stems, from which the aerial branches are sent up annually. In some species the aerial stem attains a height of upwards of 30 feet. The largest species in Britain (Equisetum maximum), may be seen 5 to 6 feet high, with a diameter of halfan-inch. The aerial stem of the plant consists of hollow internodes, each with a transverse diaphragm at the base, and a sheath at tho

Fig. 137. Vertical section of part of the forked stem or stipe of Alsophila perrotetiana. $m$, Cellular central portion. $z l, z l$, Vascular zone, consisting chiefly of woody fibres and scalariform vessels. The forking is caused by an actral division of the stipe. 
upper end. The sheath of the lower internode embraces the base of the internode above it (fig. 139). The vascular bundles unite to form a hollow cylinder in the stem. In fig. 140 is shown the

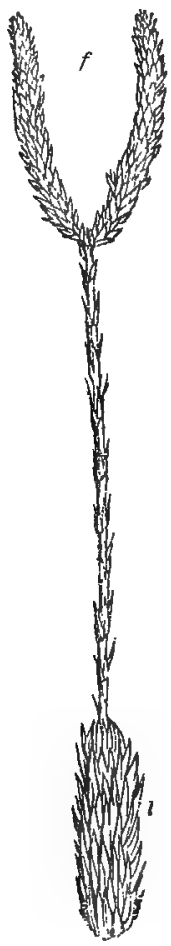

Fig. 138.

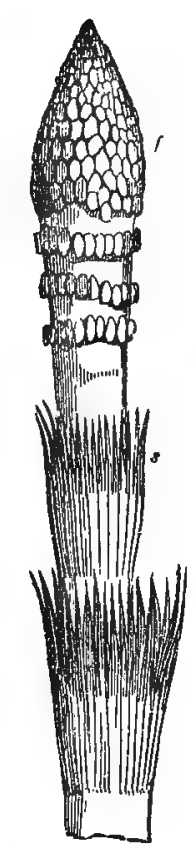

Fig. 139.

structure of a vascular bundle of Equisetum hyemale, with a hollow cavity or lacuna, $l$, round which are large annular and spiral vessels, $l v$, smaller vessels, $s v$, and peculiar cells, $c v$; which,

Fig. 138. Lycopodium clavatum, a species of Club-moss, showing a branch, $l$, covered with minute pointed leaves, from which proceeds a stalk bearing at its extremity two spikes, $f$, consisting of modified leaves with fructification. Fig. 139. Fructification of a species of Horse-tail (Equisetwm maximum). The stalk is surrounded by a series of membranous sheaths, $s s$, which are Pringed by numerous sharp processes or teeth. The fructification, $f$, is at the extremity of the shoot, in the form of a pyramidal mass of polygonal scales, bearing spores on their under surface. The fructification in some species is on the same branch with the leaves, while in others it is on a separate branch. 
by their union, and the partial absorption of their transverse walls, form what are called cribriform or sieve-like vessels (vasa propria), thickened bast cells $(b p)$, and bast fibres $(b f)$.

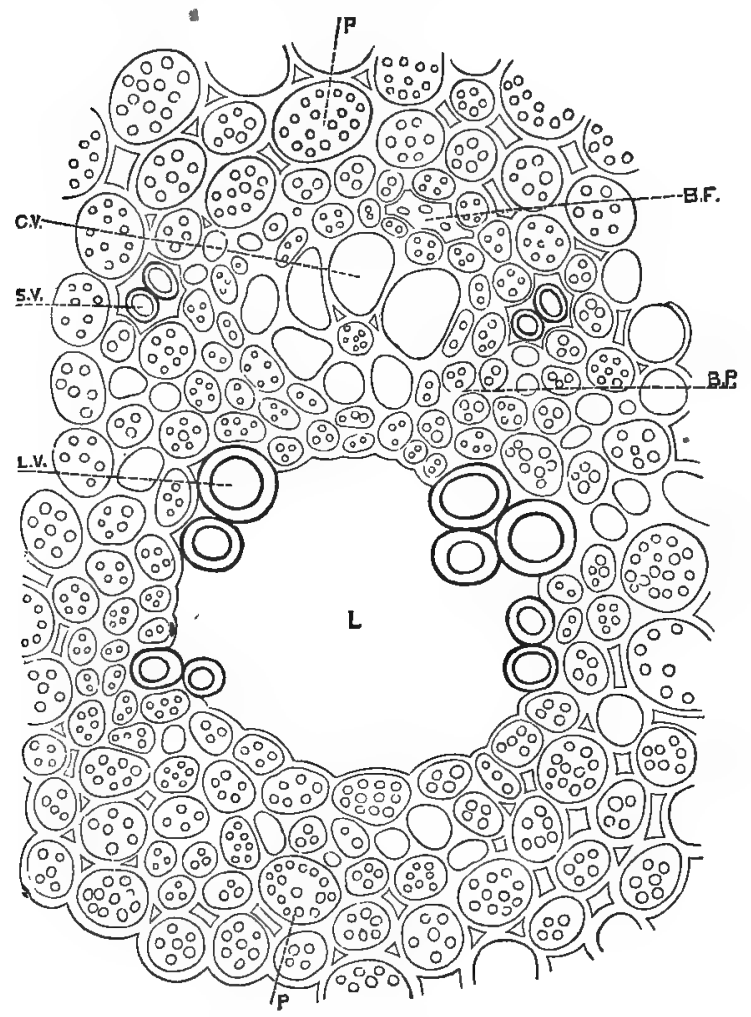

Fig. 140.

In some Thallogens the thallus or frond is supported by a stalk, in which there are concentric parenchymatous circles, with divisions in the form of rays, but no vascular bundles. These appearances are presented by some large antarctic seaweeds (species of D'Urvillæa and Lessonia), and by some lichens; as Usnea.

Fig. 140. Section of vascular bundle of stem of Equisetum hyemale $\times 310$. Lacans or a cavity, $l$; parenchyma, a form of starch cells, $p p$; large vessels, $l v$; small vessels, $s v$; bast cells, $b p$; and bast fibres, $b f$; cribriform vessels, $c v$, formed by united cells, with a partial absorption of their transverse walls.-Trans. Bot. Soc. Edin. 
There are thus three kinds of stems in the vegetable kingdom, which may be defined generally as follows:-

1. Exogenous or Dicotyledonous, having a separable bark; distinct concentric circles, composed of progressive indefinite vascular bundles, increasing at their periphery, the density diminishing from the centre towards the circumference; pith enclosed in a longitudinal canal or medullary sheath, with cellular prolongations in the form of medullary rays.

2. Endogenous or Monocotyledonous, having no separable bark; no distinct concentric circles; vascular bundles progressive and definite, not increasing at their periphery, the density diminishing from the circumference to the centre; no distinct pith, no medullary sheath nor medullary rays, the cellular tissue being interposed between the vascular bundles.

3. Acrogenous or Acotyledonous, having no separable bark; no concentric circles; vascular bundles simultaneous, forming an irregular circle; additions being made to the summit; no distinct pith, no medullary sheath nor medullary rays; conspicuous scars left by the bases of the leaves, stem in some cases entirely cellular.

\section{Formation of the different parts of Stems, and their special Functions.}

The stem produces the buds from which branches, leaves, and flowers are developed ; it exposes these organs to the atmosphere and light, conveys fluids and air, and receives secretions. Stems vary much in their size, both as regards height and diameter. Some oaks in Britain have a height of nearly 120 feet; forest trees in France have attained to 120 and 130 feet, and in America even to 450 feet. Some Palms attain a height of 200 feet. The trunks of the Baobab and Wellingtonia are sometimes 30 or 40 feet in diameter.

The pith, in its early state (fig. $111 p$ ), is of a greenish colour, and contains much fluid, which is employed in the nourishment of the young plant. After serving a temporary nutritive purpose it becomes dry, or disappears by rupture and absorption of the walls of the cells which enter into its composition. The medullary sheath, which is the first formed yascular layer (fig. $113 \mathrm{e} \mathrm{m}$ ), keeps up a connection between the central parts of the stem and the leaves, by means of spiral vessels, which seem to be concerned partly in the conveyance of air. This is the part of a Dicotyledonous stem in which these vessels ordinarily occur. The medullary rays (fig. $114 \mathrm{rm}$ ) preserve a communication between the bark and the pith. The cells of which they are composed are concerned in the production of leaf-buds, and they assist in the elaboration and conveyance of secretions. They have a direct connection with the cambium cells (fig. $114 \mathrm{c}$ ), or the cells between the wood and bark, whose function is to aid in the formation of 
new wood. The bark (fig. $114 f c, e c, p$ ) protects the tender wood, conveys the elaborated sap downwards from the leaves, and is the part in which many valuable products, such as gum, tannin, and bitter principles, are formed and deposited. The vascular bundles (fig. 114 $f l, v p$ ) convey the sap from the root to the leaves. This function is carried on during the life of the plant by the annular vessels and the pitted vessels, as well as other kinds of fibro-vascular tissue; but in the fibres of the wood it ceases at a certain epoch, in consequence of the tubes being filled up by secondary deposits, so as to form the perfect wood, which gives strength and stability to the stem.

Considerable differences of opinion have arisen on the subject of the formation of wood. All agree that it cannot be properly formed unless the leaves are exposed to air and light, but physiologists differ as to its mode of formation. Some say that it is produced in a horizontal, others in a vertical direction. There seems to be no doubt that the cambium cells perform an important part in the formation of wood, and that their activity depends on the proper development of leaves. These formative cells, although most easily detected in exogenous stems, are also present in the other forms of stems which have been described. In Monocotyledonous stems these cambium cells are situated in the centre of the bundles, and are concerned in the formation of the vascular tissue surrounding them. In woody Acotyledonous stems, as in Tree-ferns, these cells surround the vascular bundles. After a certain time the cambium zones in these stems become ligneous, and then the vascular bundles only grow at their extremity by means of unchanged cambium cells. In both these kinds of stems the vascular bundles are limited, and the stems can only increase laterally by ramifying or dividing dichotomously (fig. 137).

Knight espoused what is called the vertical theory, considering the wood as developed in a downward direction by the leaves, and in this view he was supported by Petit-Thouars and Gaudichand. These physiologists maintain that there are two vascular systems in plants, an ascending and descending; the one connected with the leaf-formation, or the spiral vessels; the other connected with the production of roots, or the ligneous fibres; the cellular tissue being more especially concerned in horizontal development. Every bud is thus, according to them, an embryo plant fixed on the stem, sending leaves upwards, and roots downwards. The dicotyledonous embryo was supposed to be formed by two phytons ( $\varphi$ uróv, a plant) united, having each an ascending and descending system of vessels, while the monocotyledonous embryo was composed of one such phyton. In Palms, Dracænas, and other Endogenous stems, the peculiar manner in which the fibres interlace (fig. 133,2) favours the opinion that they are developed like roots, by additions to their extremities; and this is also strengthened by the formation of adventitious or aerial roots, 
which burst through different parts of the stem in Palms, Screwpines (fig. 134, 2), the Banyan, and in the Fig tribe generally. In Vellozias and Tree Ferns, the surface of the stem is often covered with thin roots, protruding at various parts, and becoming so incorporated with the stem as to appear to be a part of it. In the TreeFern, represented in fig. 135, the lower part of the stem is enlarged in a remarkable degree by these fibres, so as to give it a conical form. In exogenous stems, when ligatures are put round the stem, and when portions of bark are removed, a swelling takes place above the parts where the injury has been inflicted, thus apparently proving that the new matter is developed from above downwards.

Gaudichaud endeavours to account for various anomalous forms of stems (figs. 123-126), by considering them as depending on the arrangement of the leaves, and on the mode in which the woody fibres are sent down from them. Thus, the four secondary masses surrounding the central one in the stem of Calycanthus floridus are traced to four vascular bundles from the leaves, penetrating the cellular tissue of the bark, distinct from the central wood and from each other, except at the nodes, where the cross bundles unite them so as to form a ring round the central mass. New fibres are formed on the inner side of these bundles, and by degrees they assume a crescentic shape, while the horns of the crescent ultimately unite on the outer side (centrifugally), and enclose a portion of the bark, which thus forms a kind of spurions excentric pith, with numerous woody layers on the inside, and a smaller number on the outside. Again, in Brazilian Sapindacer (fig. 124), with five, seven, nine, or ten woody masses, the same thing is said to occur, with this difference, that the pith of each of the masses is derived from the original medullary centre, portions of which are enclosed by the vascular bundles in a centripetal manner, or from without, inwards.

Treviranus states that the fibrous and vascular bundles descending from the leaves are destined in general to unite around a common centre, but that they retain a certain degree of independence, and may be developed separately in some instances, giving rise to anomalous fasciculated stems.

Gardner, from an examination of Brazilian Palms, adopts the vertical theory. It is, however, opposed by most vegetable physiologists, who consider the development of the vascular bundles as proceeding from below upwards; in Dicotyledons, by peripherical production of woody and vascular tissue from cambium cells; and in Monocotyledons, by a definite formation of woody and vascular bundles by means of terminal buds; the hardening of the stem depending on the interstitial changes which take place afterwards in the woody fibres.

All physiologists agree in believing that the formation of woody 
matter depends mainly on the functions of the leaves being carried on properly, and this can only be effected by exposure to air and light. The more vigorously the plant grows, the better is the wood produced. Experiments made in the British dockyards proved that those oaks which had formed the thickest zones yielded the best timber. Barlow's experiments at Woolwich showed that a plank of quick-grown oak withstood a greater strain than a similar plank of slow-grown oak. The stumps of fir-trees sometimes exhibit a circle of woody tissue which has been formed after the trees have been cut down, and without the agency of leaves. In some cases the vigour of these stumps has been traced to the roots being grafted into those of adjoining trees bearing branches and leaves.

In order that trees may grow well, and that timber may be properly formed, great care should be taken in planting at proper distances, and in soil fitted for the trees. Firs ought to be planted from 6 to 8 feet apart; and hardwood trees, for a permanent plantation, 28 feet distant, the spaces being filled up with larch, spruce, or Scotch fir, according to soil and situation. Hardwood is of no value till it has attained some age, while larch and spruce may be applied to use in ten or twelve years; and thus judicious thinning may be practised. When trees are set too close their leaves are interrupted in their functions; many of them fall off, leaving the stems bare; the wood is imperfectly formed, and the roots are not sent out vigorously. When such plantations are allowed to grow without being thinned, the trees are drawn ip without having a hold of the ground; and when some of them are subsequently removed the remainder are easily blown over by the wind. In thick plantations it is only in the trees next the outside, where the leaves and branches are freely formed, that the wood and roots are properly developed. When a tree is fully exposed to air and light on one side only, it is frequently found that the woody zones on that side are largest. When trees are judiciously planted, there is a great saving both in the original outlay and in the subsequent treatment. Pruning, or the shortening of branches, and the removal of superfluous ones, ought to be cautiously practised. It is only applicable to young branches and twigs; and is had recourse to chiefly in the case of fruit-trees, when the object is to make the plants produce flowers and fruit. If forest trees are properly planted and thinned, little pruning is required. 


\section{Leaves AND THEIR APPENDAges.}

\section{Structure of Leaves.}

Leaves are expansions of the bark, developed in a symmetrical manner, as lateral appendages of the stem, and having a connection with the internal part of the ascending axis. They appear at first as small projections of cellular tissue, continuous with the bark, and closely applied to each other. The points from which they arise are called nodes. In the early stages of their development they are undivided. The cellular papillæ, from which they originate, gradually expand in various ways, acquire vascular tissue, and ultimately assume their permanent form and position on the axis. They may be divided into aerial and submerged leaves, the former being produced in the air, and the latter under water.

AERIAL LEAVES.-These leaves consist of vascular tissue in the form of veins, ribs, or nerves, of cellular tissue or parenchyma filling up the interstices between the veins, and of an epidermal covering.

The Vascolar System of the leaf is continuous with that of the stem, those vessels which occupy the internal part of the stem becoming superior in the leaf, while the more external become inferior. Thus, in the upper part of the leaf, which may represent the woody layers, there are spiral vessels (fig. $141 t$ ), annular, reticulated, and pitted vessels, $v$, and ligneous fibres, $f$; whilst in the lower side, which may represent the bark, there are laticiferous vessels and fibres, resembling those of liber, $l$. There are usually two layers of fibro-vascular tissue in the leaf, which may be separated by maceration. They may be seen in what are called skeleton leaves, in which the cellular part is removed, and the fibro-vascular tissue is left. The vascular system of the leaf is distributed through the cellular tissue

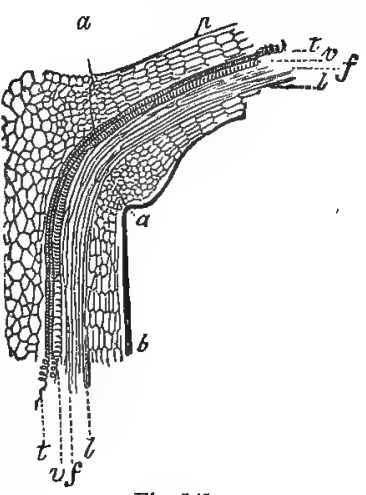

Fig. 141. in the form of simple or branching veins.

The Epidermis (fig. 142 e s, e $i$ ), composed of cells more or less compressed, has usually a different structure and aspect on the two

Fig. 141. Bundle of fibro-vascular tissue, passing from a branch, $b$, into a petiole, $p$. The vessels are first vertical, then nearly horizontal, but they continue to retain their relative position. Changes take place in the size of the cells at the articulation $a$. $t$, Trachee or spiral vessels in which the fibre can be unrolled. $v v$, Annular veasels. $f f$, Fibres of wood. $l l$, Cortical fibres, or fibres of liber, or the inner bark. 
surfaces of the leaf. It is chiefly on the epidermis of the lower surface (fig. $143 e i$ ), that stomata, $s s$, are produced, occupying spaces between the veins, and it is there also that hairs usually occur. In these respects the lower epidermis resembles the outer bark of young stems, with which it may be said to correspond. The lower epidermis is often of a dull or pale-green colour, soft, and easily detached. The upper epidermis (figs. 142 and $143 e s$ ) is frequently smooth and

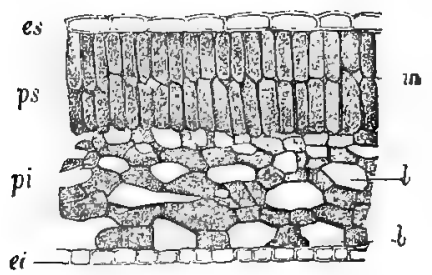

Fig. 142.

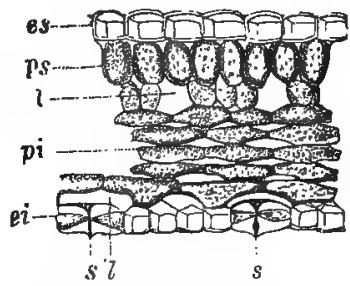

Fig. 143.

shining, and sometimes becomes very hard and dense. Many tropical plants present on the upper surface of their leaves several layers of compressed epidermal cells. These appear to be essential for the preservation of moisture in the leaf. In leaves which float upon the surface of water, as those of the water-lily, the upper epidermis alone possesses stomata (p. 30). On removing a strip of epidermis, part of the parietes of the cells below is often

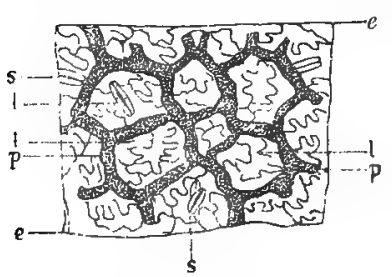

Fig. 144. detached in the form of a green network (fig. $144 p p$ ), and on examination under the microscope, the stomata, $s s$, are seen communicating with colourless spaces, $l l l$, surrounded by green matter.

The Parenchyma of the leaf is the cellular tissue surrounding the vessels, and enclosed within the epidermis (fig. $142 p s, p . i_{\text {. }}$ ) It has sometimes received the names of Diachyma ( $\delta \iota \alpha$, in the midst, and

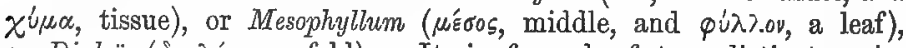

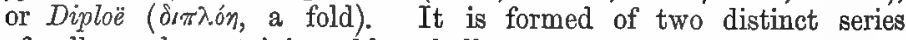
of cells, each containing chlorophyll or green-coloured granules, but

Fig. 142. Thin vertical section of the leaf of a Lily, highly magnified. es, Epidermis of upper pagina or surface. $e i$, Epidermis of lower surface. $p s$, Parenchyma of upper por. tion of the leaf, composed of close vertically-placed cells. $p i$, Parenchyma of lower portion, composed of loose horizontal cells. $m$, Intercelluiar passages, $l l$, Lacuna. Fig. 143. Similar section of the leaf of Balsam. The letters denote the same parts as in fig. 142. $s$ s, stomata. Fig. 144. Strip of the lower epidermis, $e e$, of the leaf of Balsam, showing a network formed by a portion of the parenchyma below, $p p$, being detached. The spaees of the net are lacunæ, $l l l$, often corresponding to stomata, $s \delta$. 
differing in form and arrangement. This may be seen on making a vertical section of a leaf, as in figs. 142 and 143. Below the epidermis of the upper side of the leaf there are one or two layers of oblong blunt cells, placed perpendicularly to the surface (fig. $142 \mathrm{ps}$ ), and applied so closely to each other as to leave only small intercellular spaces (fig. $142 \mathrm{~m}$ ), except when stomata happen to be present. On the under side of the leaf the cells are irregular, often branched, and are arranged more or less horizontally (fig. $142 p$ i), leaving cavities between them, $l l$, which often communicate with stomata (fig. $143 s s$ ). On this account the tissue has received the name of cavernous. The form and arrangement of the cells, however, depend much on the nature of the plant, and its exposure to light and air. Sometimes the arrangement of the cells on both sides of the leaf is similar, as occurs in leaves which have their edges presented to the sky. In very succulent plants the cells form a compact mass, and those in the centre are often colourless. In some cases the cellular tissue is deficient at certain points, giving rise to distinct holes in the leaf, as in Monstera Adansonii; such a leaf has been called pertuse (pertusus, bored through). In Victoria regia perforations in the leaf seem to be subservient to the purposes of nutrition, in permitting the gases collected beneath the large expanded leaf to escape, and thus allowing its under surface to be brought into immediate contact with the water.

SubMERgED LAAAEs.-Leaves which are developed under water differ in structure from aerial leaves. They have usually no fibro-

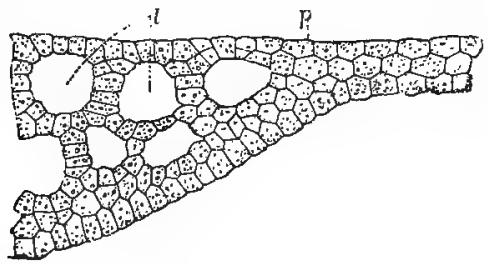

Fig. 145 .

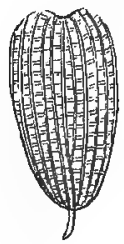

Fig. 146.

vascular system, but consist of a congeries of cells, which sometimes become elongated and compressed so as to resemble veins. They have a layer of compact cells on their surface (fig. $145 p$ ), but no true epidermis, and no stomata. Their internal structure consists of cells, disposed irregularly, and sometimes leaving spaces which are filled with air for the purpose of floating the leaf (fig. $145 l$ ). When exposed to the air these leaves easily part with their moisture, and become shrivelled and dry. In the submerged leaves of Trapa and

Fig. 145. Perpendicular section through a small portion of the submerged leaf of Potamogeton perfoliatus. $p$, Parenchyma. l, Lacunr. of filamentous cells, with intervening spaces.

Fig. 146. Fenestrate leaf composed 
Callitriche, spiral vessels have been seen. In some instances there is only a network of filamentous-like cells formed (fig. 146), the spaces between which are not filled with parenchyma, giving a peculiar skeleton appearance to the leaf, as in Ouvirandra fenestralis (lattice plant). Such a leaf has been called fenestrate (fenestra, a window).

A leaf, whether aerial or submerged, generally consists of a flat expanded portion (fig. $147 \mathrm{l}$ ), called the blade, limb, or lamina, of a narrower portion called the petiole (petiolus, a little foot or stalk) or stalk (fig. $147 \mathrm{p}$ ), and sometimes of a portion at the base of the

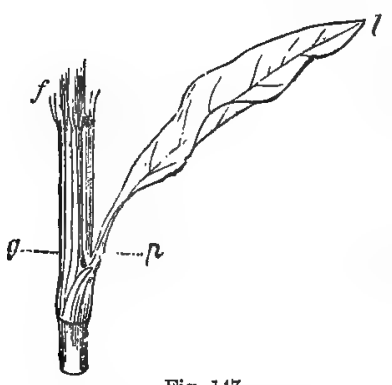

Fig. 147. petiole, which forms a sheath or vagina (fig. $147 \mathrm{~g}$ ), or is developed in the form of leaflets, called stipules (fig. 205). The sheathing portion is sometimes incorporated with the stem, and has been called tigellary (tige, Fr., a stem or stalk) by Gaudichaud. These portions are not always present. The sheathing or stipulary portion is frequently wanting, and occasionally only one of the other two is developed. When a leaf has a distinct stalk it is called petiolate; when it has none, it is sessile (sessilis, from sedeo, I sit). When sessile leaves embrace the stem, they are called amplexicaul (amplexor, I embrace, and caulis, a stem). The part of the leaf next the petiole or the axis is the base, while the opposite extremity is the apex. The surfaces of the leaf are called the pagince (pagina, a flat page), and its edges or margins form the circumscription of the leaf. The leaf is usually horizontal, so that the upper pagina is directed towards the heavens, and the lower pagina towards the earth. In some cases leaves, or leaf-like petioles, are placed vertically, as in Australian Acacias, Eucalypti, etc. In other instances, as in Alströmeria, the leaf becomes twisted in its course, so that what is superior at one part becomes inferior at another.

The upper angle formed between the leaf and the stem is called its axil (axilla, armpit), and everything arising at that point is called axillary. It is there that leaf-buds (p. 108) are usually developed. The leaf is sometimes articulated with the stem, and when it falls off a scar or cicatricula remains; at other times it is continuous with it, and then decays gradually, while still attached to the axis. In their early state all leaves are continuous with the stem, and it is only in their after growth that articulations are formed. When leaves fall

Fig. 147. Leaf of Polygonum Eydropiper, with a portion of the stem bearing it. $\quad l$, Limb, lamina, or blade. $p$, Petiole or leaf-stalk. $g$, Sheath or vagina, embracing the stem, and terminated by a fringe, $f$. 
off annually, they are called deciduous; when they remain for two or more years, they are evergreen. The laminar portion of a leaf is occasionally articulated with the petiole, as in the Orange (fig. 201), and a joint at times exists between the vaginal or stipulary portion and the petiole.

\section{Distribution of the Veins, or Venation of Leaves.}

The distribution of the veins has been called Venation, sometimes Nervation. In most leaves this can be easily traced, but in the case of succulent plants, as Hoya, Agave, Stonecrop, and Mesembryanthemum, the veins are obscure, and the leaves are said to be Hidden-veined (figs. $186,187)$. In the fronds of the lower tribes of plants, as seaweeds, and in submerged leaves, there are no true veins, but only condensations of elongated cellular tissue, and the term Veinless (avenia) is applied. In an ordinary leaf, as that of Lilac or Chestnut, there is observed a central vein larger than the rest, called the midrib (fig. $148 \mathrm{~nm}$ ); this gives off veins laterally (primary veins) $n s$ ns $n s$, which either end in a

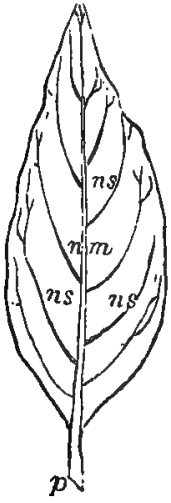

Fig. 148.

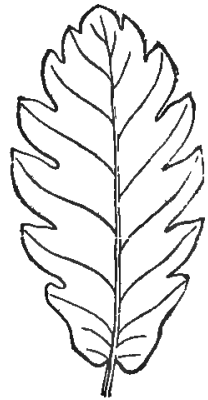

Fig. 149 ,

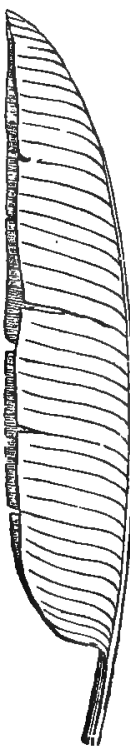

Fig. 150.

curvature within the margin, as in Lilac and Belladonna (fig. 148), or go directly to the edge of the leaf, as in Oak (fig. 149) and Chestnut. If they are curved, then external veins and marginal veinlets are inter-

Fig. 148. Leaf of Belladonna. p, Petiole or leaf-stalk. nm, Midrib. ns ns ns, Primary veins, ending in curvatures at their extremities. Fig. 149. Leaf of Oak, pinnatifid or divided into lateral lobes; feather-veined, the veins going directly to the margin. Fig. 150. Leaf of Ranana (Musa), showing the midrib, with the primary veins running parallel to each other in a transverse manner, and proceeding to the margin. No reticulation. Plant monocotyledonous. 
spersed through the parenchyma external to the curvature. There are also other veins of less extent (costal veins) given off by the midrib, and these give origin to small veinlets. In some cases, as Sycamore and Cinnamon, in place of there being only a single central rib, there are several which diverge from the part where the blade joins the petiole or stem. Thus, the primary veins give off secondary veins, and these in their turn give off tertiary veins, and so on, until a complete network of vessels is produced. To such a distribution of veins the name of Reticulated or Netted venation has been applied.

In the leaves of some plants there exists a central rib or midrib, with veins running nearly parallel to it from the base to the apex of the leaf, as in grasses (fig. 210); or with veins diverging in more or less parallel lines, as in Fan Palms; or with veins coming off from it throughout its whole course, and running parallel to each other in a straight or curved direction towards the margin of the leaf, as in Plantain and Banana (fig. 150). In these cases the veins are often united by cross veinlets, which do not, however, form. an angular network. These are called Parallel-veined.

Leaves may thus be divided into two great classes, according to their venation-Reticulated or netted-veined leaves, in which there is an angular network of vessels, as seen generally in dicotyledonous plants ; and Parallel-veined leaves, in which the vessels run in a straight or curved manner from base to apex, or from the midrib to the margin of the leaf, and in which, if there is a union, it is effected by transverse veins which do not form an angular network. This kind of leaf occurs commonly in monocotyledonous plants. In many acotyledonous plants there is no true vascular venation, but when it is present, there is frequently a tendency in the veins to divide in a forked (furcate) manner. This is seen in many Ferns, which have hence been called Fork-veined. Condensed cellular tissue forming false venation is seen in mosses and in seaweeds.

\section{Tabolar arrangement of Venation.}

A.-Reticulated Venation.

I. Onicostate (unus, one). A single rib or costa in the middle (midrib).

1. Primary veins coming off at different points of the midrib.

u. Veins ending in curvatures within the margin (fig. 148), and forming what have been called true netted leaves (Lilac).

b. Veins going directly to the margin (fig. 149), and forming feather-veined leaves (Oak and Chestnut).

2. Primary veins coming off aloug with the midrib (fig. 158) from the base of the leaf.

II. Multicostate (multus, many). More than one rib. In such cases there are frequently three (tricostate), as in fig. 177 , or five (quinquecostate), as in fig. 173. Authors usually give to these leaves the general name of costate or ribbed.

1. Convergent, Ribs converging, running from base to apex in a curved 
manner, as in Cinnamon and Melastoma (fig. 173). There is occasionally an obscure rib running close to the edge of the leaf, and called intramarginal, as in the Myrtle.

2. Divergent. Ribs diverging or proceeding in a radiating manner (fig. 159). This is called radiating venation, and is seen in Sycamore, Vine, Gexanium, Castor-oil plant (fig. 161).

B. - Parallel Venation. - The term parallel is not strictly applicable, for the veins often proceed in a radiating manner, but it is difficult to find a comprehensive term. This venation may be characterised as not reticulated.

I. Veins proceeding transversely from midrib to margin, usually with convexity towards the midrib, as in Musa (fig. 150) and Canna.

II. Veins proceeding longitudinally from base to apex.

1. Veins more or less convergent (fig. 188), as in Iris, Lilies, Grasses (fig. $210)$.

2. Veins more or less divergent, as in Fan Palms.

C. - Furcate Venation (furca, a fork). Veins dividing in a forked manner, as in the case of many Ferns.

\section{Forns of Leaves.}

Leaves are divided into simple and compound. The former have no articulation beyond the point of their insertion on the stem or

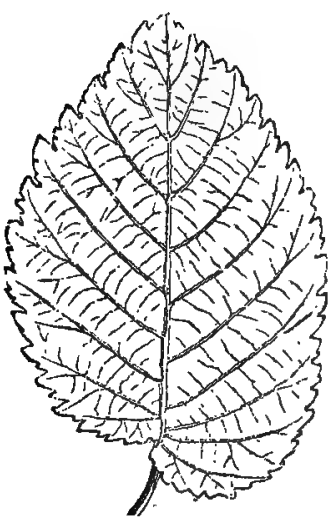

Fig. 151.

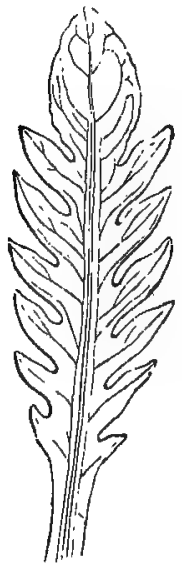

Fig. 152.

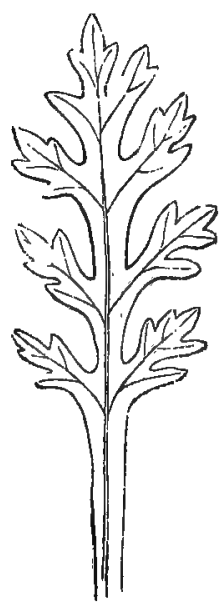

Fig. 153.

branch, and consist of a single blade, which, however, may be variously divided (figs. 151,152, 153, etc.) The latter have one or more articulations beyond the point of their insertion on the stem, and con-

Fig. 151. Leaf of Ulmus effusa. Reticulated venation ; primary veins gcing to the margin, which is serrated. Lea? unequal at the base. Fig. 152. Pinnatifid leaf of Valeriana dioica. Fig. 153. Bipinnatiffd leaf of Papaver Argemone. Feather-veined. 
sist of one or more leaflets (foliola) separately attached to the petiole or leaf-stalk (fig. 156). In a single leaf the blade may be either attached to a petiole or sessile on the stem; while in a compound leaf the blades or leaflets are separately attached to the petiole. In the earliest stage of growth all leaves are simple and undivided, and it is only during the subsequent development that divisions appear, which may commence at the base or at the apex of the leaf. The forms which the different kinds of simple and compound leaves assume are traced to the character of the venation, and to the amount of parenchyma produced.

Simple Leaves.-When the parenchyma is developed symmetrically on each side of the midrib or stalk, the leaf is equal (fig. 164); if otherwise, the leaf is unequal or oblique (fig. 151), as in Begonia. If the margins are even and present no divisions, the leaf is entire (integer), as in figs. 164 and 165; if there are slight projections of cellular or vascular tissue beyond the margin the leaf is not entire (fig. 151); when the projections are irregular and more or less pointed, the leaf is dentate or toothed (fig. 170); when they lie regularly over each
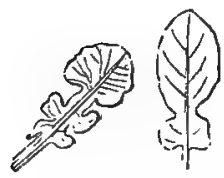

Fig. 154. Fig. 155.

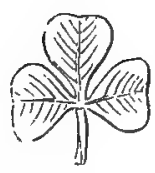

Fig. 156.

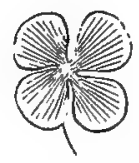

Fig. 157.

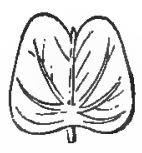

Fig. 158.

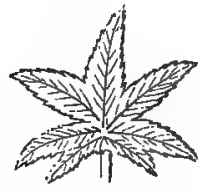

Fig. 159.

other, like the teeth of a saw, the leaf is serrate (figs. 151, 169); when they are rounded, the leaf is crenate (fig. 174). If the divisions extend more deeply than the margiu, the leaf receives different names according to the nature of the segments: thus, when the divisions extend about half-way down (figs. 149, 159), it is cleft (fissus), and its lines of separation are called fissures (fissura, a cleft); when the divisions extend nearly to the base or to the midrib (fig. 185), the leaf is partite, and its lines of separation are called partitions.

These divisions take place in simple leaves exhibiting different kinds of venation, and give rise to marked forms. Thus, if they occur in a feather-veined leaf (fig. 152), it becomes either pinnatifid (pinna, a wing or leaflet, and fissus, cleft), when the segments extend

Fig 154. Lyrate leaf of Barbarea.

Fig. 155. Panduriform, a fiddle-shaped leaf of Rumex pulcher.

Fig. 156. Compound leaf, ternate, the leaflets being obcordate. Fig. 157. Compound leaf; quaternate, the leaflets being rotundate-cuneiform, or wedgeshaped with rounded apices. Fig. 158. Two-lobed leaf, somewhat cordate at the base, emarginate, and mucronate. Fig. 159. Palmate leaf, the divisions acute and serrated at their margins. Radiating venation. 
to about the middle and are broad; or pectinate (pecten, a comb), when they are narrow; or pinnatipartite, when the divisions extend nearly to the midrib. These primary divisions may be again subdivided in a similar manner, and thus a feather-veined leaf will besome bipinnatifid (fig. 153), or bipinnatipartite; and still further subdivisions give origin to tripinnatifid and laciniated leaves. If the divisions of a pinnatifid leaf are more or less triangular, and are pointed downwards towards the base, the extremity of the leaf being undivided and triangular, the leaf is runcinate (runcina, a large saw), as in the Dandelion. When the apex consists of a large rounded lobe, and the divisions, which are also more or less rounded, become gradually smaller towards the base (fig. 154), as in Barbarea, the leaf is called lyrate, from its resemblance to an ancient lyre. Under the term lyrate some include compound pinnate leaves in which the several pinnæ are united at the apex of the leaf, and the others become gradually smaller towards the base. When there is a concavity on each side of a leaf, so as to make it resemble a violin, as in Rumex pulcher (fig. 155), it is called panduriform ( $\pi \alpha \nu \delta$ ov $g \alpha$, a fiddle).

The same kinds of divisions taking place in a simple leaf with radiating venation, give origin to the terms lobed, cleft, and partite (figs. 161, 189). When the divisions extend about half-way through the leaves, they may be three-lobed, five-lobed, seven-lobed, many-lobed; or, trifid, quinquefid, septemfid, multifid, according to the number of divisions. The name of palmate, or palmatifid (fig. 159), is the general term applied to leaves with radiating venation, in which there are several lobes united by a broad expansion of parenchyma, like the palm of the hand, as in Passion-flower and Rheum palmatum. The divisions of leaves with radiating venation may extend to near the base of the leaf, and the names bipartite, tripartite, quinquepartite or digitipartite, and septempartite, are given according to the number of the partitions, two, three, five, or seven. In Drosera dichotoma (fig. 88), bipartite and tripartite leaves are seen. The term dissected is applied to leaves with radiating venation, having numerous narrow divisions, as in Geranium dissectum. When in a radiating leaf there are three primary partitions and two lateral ones, spreading and forming divisions on their inner margin only, as in Helleborus (fig. 185), the leaf is called pedate or pedatifid (pes, a foot), from a fancied resemblance to the claw of a bird.

In all the instances already alluded to the leaves have been considered as flat expansions, in which the ribs or veins spread out on the same planes with the stalk. In some cases, however, the veins spread at right angles to the stalk. If they do so equally on all sides, and are united by parenchyma, so that the stalk occupies the centre (fig. 160), the leaf becomes orbicular (orbis, a circle), as in Hydrocotyle ; if unequally, so that the stalk is not in the centre, the leaf is peltate 
(pelta, a buckler), as in the Castor-oil plant (fig. 161). The edges or margins of orbicular and peltate leaves are often variously divided.

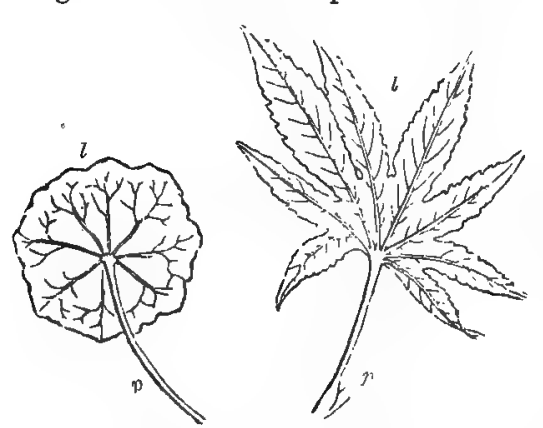

Fig. 160.

Eig. 161.

It has been thought by some that the order of the venation in the leaf bears a close analogy to the arrangement of the branches on the stem; that a certain unity so pervades vegetable organisation, that the root, the stem, and the leaves, may, in their ultimate arrangement, be regarded as being typical the one of the other. M'Cosh states, that the angles at which the veins are given off in the leaves are the same as those at which the branches come off from the stem. The angles as given by him vary from $30^{\circ}$ to $70^{\circ}$.*

Without attempting to notice all the forms of leaves, the following are enumerated as the most important. When the veins do not spread out, but run from the base to the apex with a narrow strip of parenchyma, the leaf is linear or acicular (acus, a needle), (fig. 162), as in Pines and Firs. These trees are hence called in Germany nadelholzer, or needle trees. When the veins diverge, those in the middle being longest, and the leaf tapering at each end (fig. 181), it be-
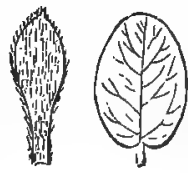

163.

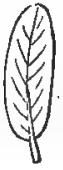

165.

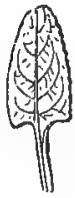

Figs.

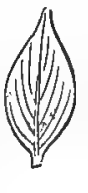

167.

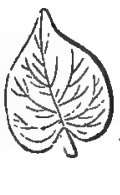

I08.

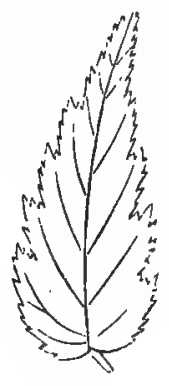

169.

Fig. 160. Orbicular leaf of Hydrocotyle vulgaris. Radiating venation. $p$, Petiole. $l$, Lamina. Fig. 161. Peitate leaf of the Castor-oil plant (Rieinus communis). Radiating venation. $p$, Petiole or leaf-stalk. $l$, Lamina or blade. Fig. 162. Linear, or acicular leaf of Fir. Fig. 163. Spathulate leaf of Daisy. Fig. 164. Oval leaf. Fig. 165. Oblong leaf. Fig. 166. Petiolated, reticulated, somewhat oblong leaf, truncate at the base. Fig. 167. Ovate pointed leaf. Fig. 168. Cordate pointed leaf. Fig. I69. Ovato-lanceolate leaf, i.e. lanceolate in its general contour, but ovate at the base; doubly serrated, or having large and small serratures alternately at the margin.

* M'Cosh on the plant morphologically considered. Proceed. of the Edin. Bot. Soc., July 1851. Bot. Gazette, September 1851. 
comes lanceolate (lancea, a lance). If the middle veins only exceed the others slightly, and the ends are convex, the leaf is either rounded (rotundatus), as in fig. 179, elliptical (fig. 177), oval (fig. 164), or oblong (fig. 165). If the veins at the base are longest, the leaf is ovate or egg-shaped, as in Chickweed (fig. 167), and if those at the apex are longest, the leaf is obovate, or inversely egg-shaped. Leaves are cuneate (cuneus, a wedge) or wedge-shaped, in Saxifraga (fig. 170); spathulate, or spatula-like, having a broad rounded apex, and tapering down to the stalk. in the Daisy (fig. 163); subulate (fig. 182), narrow and tapering like an awl (subula); acuminate, or drawn out into a long point, as in Ficus religiosa (fig. 174), mucronate, with a hard stiff point or mucro at the apex (figs. 175 and 158). When

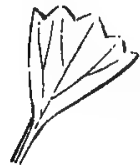

170.

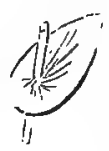

171.
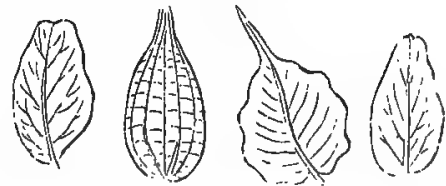

Figs.
173.

174.

175.

the parenchyma is deficient at the apex so as to form two rounded lobes, the leaf is obcordate or inversely heart-shaped; when the deficiency is very slight, the leaf is called emarginate (fig. 158) as having a portion taken out of the margin; when the apex is merely flattened or slightly depressed (fig. 172), the leaf is retuse (retusus, blunt); and when the apex ends abruptly in a straight margin, as in the Tulip tree (fig. 178), the leaf is truncate. When the venation is prolonged downwards at an obtuse angle with the midrib, and rounded lobes are formed, as in Dog-violet, the leaf is

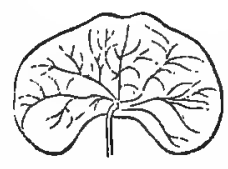

Fig. 176.

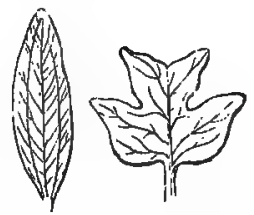

Fig. 177. Fig. 178. cordate or heart-shaped (fig. 168), or kidney-shaped (reniform) when the apex is rounded (fig. 176), as in Asarum. When the lobes are prolonged

Fig. 170. Cuneate or wedged-shaped leaf of Saxifraga, ending in an abrupt or truncate manner, and toothed or dentate at the apex. Fig. 171. Perfoliate leaf of Bupleurum perfoliatum, formed by lobes uniting at the base on the opposite side of the stem from that to which the leaf is attached. Fig. 172. Retuse leaf, i.e. slightly depressed at the apex. Margin slightly waved. Fig. 173. Ovate five-ribbed leaf. Fig. 174. Rounded acuminated Jeaf of Ficus religiosa, with the margin erenate or slightly sinuous. Fig. 275. Sub-ovate, retuse, mucronate leaf. Fig. 176. Reniform or kidney-shaped entire leaf of Asarum. Radiating venation. Fig. 177. Elliptical and-somewhat lanceolate leaf ; threeribbed. Fig. 178. Three-lobed, truncate, or abrupt leaf of Liriodendron tulipiforum. 
downwards and are acute (fig. 180), the leaf is sagittate (sagittc, an arrow); when they proceed at right angles, as in Rumex Acetosella, the leaf is hastate (hasta, a halbert) or halbert-shaped. When a simple leaf is divided at the base into two leaf-like appendages (fig. 184), it is called auriculate (auricula, little ear). When the veins spread out in various planes, and there is a large development of cellular tissue, so as

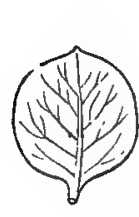

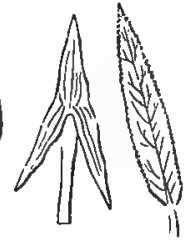

180.

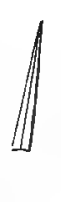

Figs.

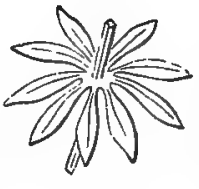

183.

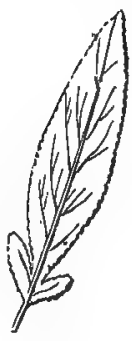

184.

to produce a succulent leaf, such forms occur as conical, prismatical, ensiform or sword-like (ensis, a sword), acinaciform (acinaces, a scimitar) or scimitar-shaped (fig. 187), and dolabriform (dolabra, an axe) or axe-shaped (fig. 186). When the development of cells is such that they more than fill up the spaces between the veins, the margins become wavy, crisp, or undulated, as in Rumex crispus and Rheum undulatum (fig. 189). By cultivation the cellular tissue is often

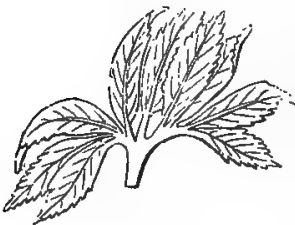

185.

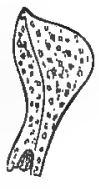

186.

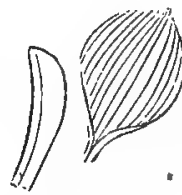

Figs.

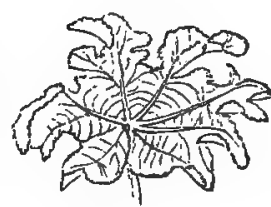

189.

much increased, giving rise to the curled leaves of Greens, Savoys, Cresses, Lettuce, etc. In rushes the shoots which act as leaves are

Fig. 179. Rounded entire leaf, ending in a short point. Fig. 180. Sagittate or arrowshaped leaf of Sagittaria. Fig. 181. Lanceolate, acute leaf, with minute teeth or dentations at the margin. Fig. 182. Subulate or awl-shaped leaf. Fig. 183. Whorl or verticil of linear-obovate leaves. Fig. 184. Auriculate lanceolate leaf, oblique at the base, with minute toothings at the margin. Fig. 185. Pedate or Pedatifid leaf of Hellebore. Radiating venation, Fig. 186. Dolabriform or axe-shaped fleshy succulent leaf. Hiddenveined. Fig. 187. Acinaciform or scimitar-shaped succulent leaf. Hidden-veined. Fig. 188. Oval leaf with converging veins; not reticulated. Fig. 189. Palmately-lobed leaf, crisp or undulated at the margin. Radiating venation. 
often terete. They are either barren or bear flowers. Their cellular tissue is often stellate, and the shoots sometimes exhibit a peculiar spiral twisting. (Fig. 190.)

Compound LEA ves are those in which the divisions extend to the midrib, or petiole (fig. 191), and receive the name of foliola or leaflets. The midrib, or petiole, has thus the appearance of a branch with separate leaves attached to it, but it is considered properly as one leaf, because in its earliest state it arises

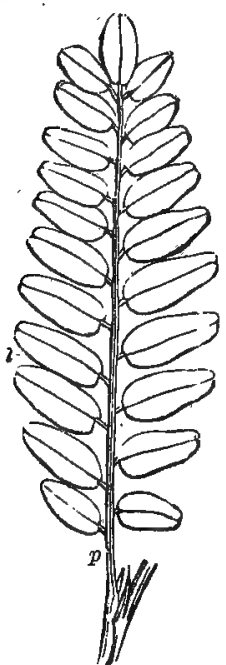

Fig. 191.

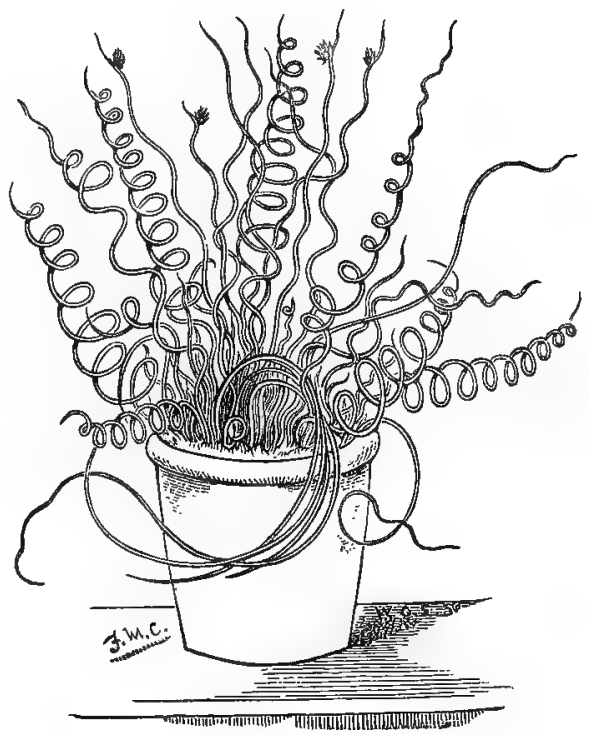

Fig. 190.

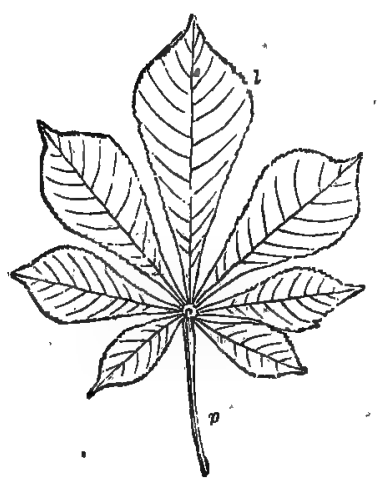

Fig. 192.

Fig. 190. Juncus effusus, voriety, with spiral leaves, called Screw-rush. . Fig. 191, Leaf of Robinia pseudacacia, often called Acacia. The leaf is impari-pinnate, or alternately pinnate. The pinnes are supported on stalks or petiolules, $p$, Petiole or leaf-stalk. $l$, Lamina or blade divided into separate leaflets or pinnæ. Fig. 192. Septenate leaf of Horse Chestnut (Esculus Hippocastanum). p, Petiole. $l$, Lamina divided into seven separate leaflets. 
from the axis as a single piece, and its subsequent divisions in the form of leaflets are all in one plane. The leaflets are either sessile (fig. 192), or have stalks, called petiolules (fig. 191), according as the vascular bundles of the veins spread out or divaricate at once, or remain united for a certain length.

Compound leaves have been classified according to the nature of the venation, and the development of parenchyma. If we suppose that in a simple feather-veined unicostate leaf, the divisions extend to the midrib, and each of the primary veins spreads out or branches so as to become covered with parenchyma, and thus form separate leaflets, which are usually articulated to the petiole or midrib (fig. 193), the leaf becomes compound and pinnate (pinna, a wing or feather). If the midrib and primary veins are not covered with parenchyma,

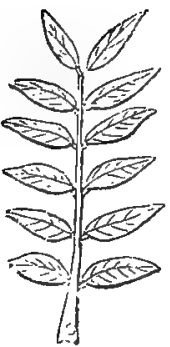

Fig. 193.

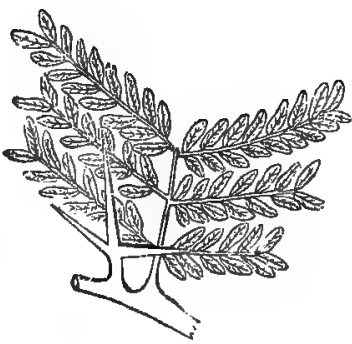

Fig. 194.

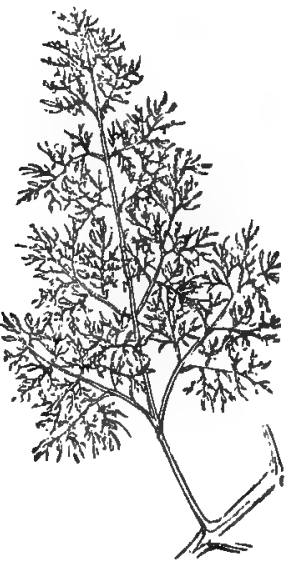

Fig. 195.

while the secondary (or those coming off in a feather-like manner from the primary veins) are, and separate leaflets are thus formed which are usually articulated with the veins, the leaf is bipinnate (fig. 194). In this case the secondary veins form as it were partial petioles. A farther subdivision, in which the tertiary veins only are covered with parenchyma and have separate leaflets, gives tripinnate or decompound, in which case the tertiary veins form the partial petioles; and a leaf divided still more is called supradecompound (fig. 195).

When a pinnate leaf has one pair of leaflets, it is unijugate (unum, one, and jugum, a yoke); when it has two pairs, it is bijugate; many

Fig. 193. Pari-pinnate leaf with six pairs of pinnæ (sexingate). Fig. 194. Bipinnate leaf, with sessile foliola or leaflets. Fjg. 195. Part of the supradecompound leaf of Laserpitium hirsutum. 
pairs, multijugate (fig. 191). When a pinnate leaf ends in a pair of pinnæ (fig. 193) it is equally or abruptly pinnate (pari-pinnate); when there is a single terminal leaflet (fig. 191), the leaf is unequally pinnate (impari-pinnate); when the leaflets or pinnæ are placed alternately on either side of the midrib, and not directly opposite to each other, the leaf is alternately pinnate (fig. 191); and when the pinnæ are of different sizes, the leaf is interruptedly pinnate (fig. 196).

In the case of a simple multicostate leaf with radiating venation, if we suppose the ribs to be covered with parenchyma, so as to form separate leaflets, each of which is articulated to the petiole, the digitate form of compound leaf is produced; if there are three leaflets, the form

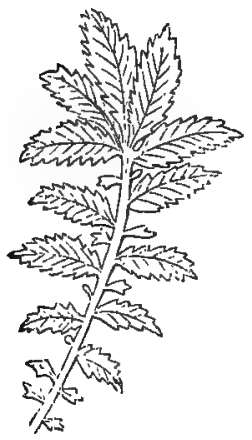

Fig. 196.

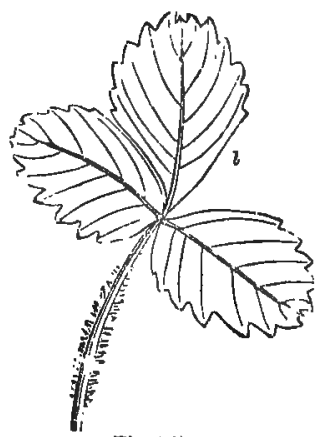

Fig. 19i.

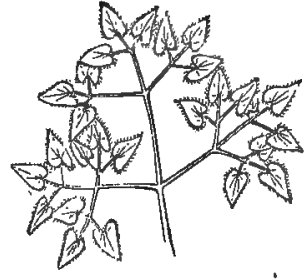

Fig. 198.

is ternate (figs. 156, 197); if four, quaternate (fig. 157); if five, quinate; if seven, septenate (fig. 192), and so on. If the three ribs of a ternate leaf subdivide each into three primary veins, which become covered with parenchyma so as to be separate articulated leaflets, the leaf is biternate; and if another three-fold division takes place, it is triternate (fig. 198).

General summary of facts connected with the venation and conformation of leaves:-

1. Leaves of flowering plants are either netted-veined (reticulated) or parallelveined.

2. Leaves have either a single midrib (uvicostate), or several ribs (multicostate); and the latter are either radiating (spreading out from one point), or con'vergent.

3. Unicostate leaves have veins proceeding at different angles from various points of the midrib, and arranged more or less like the parts of a feather.

Fig. 196. Impari- alternately and interruptedly pinnate leaf. Leaflets or pinnæ sessile, and serrated at the margin.

Fig. 197. Ternate leaf of Strawberry. Margin of leaflets, toothed or dentate. $p$, Petiole with projecting hairs. l, Lamina divided into three leaflets. Fig. 198. Triternate leaf. Leaflets cordate. 
4. The conformation of leaves depends partly on the venation, and partly on the mode in which the parenchyma is developed.

5. Leaves are either simple, i.e. composed of one piece, or compound, i.e. composed of one or more articulated leaflets.

6. Simple leaves are either entire or divided into segments. When the divisions are marginal, they are dentate, serrate, or crenate; when the divisions are deeper, cleft or partite.

7. Simple unicostate (one-ribhed) leaves having their parenchyma cut laterally into various lobes, so that the divisions extend to about the middle of each half of the lamina, may be referred to the Pinnatifid type, including bipinaatifid, pectinate, panduriform, runcinate, and lyrate forms; when the divisions extend nearly to the midrib the form is pinnati-partite.

8. Sinple multicostate (many-ribbed) leaves, with the ribs divergent, when cut longitudinally into various lobes, the divisions extending to about the middle of the lamina, may be referred to the Palmatifid type, including trifid, quinquefid, pedate, and dissected forms; when the divisions extend to near the base the forms are palmately-partite or dissected.

9. Simple leaves, with convergent ribs, are rarely divided deeply, and such is also the case with parallel-veined leaves, the margins of which are often entire.

10. Simple leaves, whether unicostate or multicostate, with lobes or divisions at their base, exhibit reniform, cordate, sagittate, and hastate forms; with lobes or divisions at their apex, enarginate and obcordate forms.

11. Compound unicostate leaves, having lateral articulated leaflets, may be referred to the Pinnate type, including bipinnate, tripinnate, and decompound forms.

12. Compound multicostate leaves, with divergent ribs, divided longitudinally into articulated leaflets, may be referred to the Digitate type, including ternate, triternate, quaternate, and quinate forms.

Pettole or Leaf-StalK.-This is the part which unites the limb or blade of the leaf to the stem (figs. 147 and $191 p$ ). It is absent in sessile leaves, and in many sheathing leaves is not well defined. It consists of one or more bundles of vascular tissue, with a varying amount of parenchyma. The vessels are spiral vessels, connected with the medullary sheath in Exogens, and with the fibro-vascular bundles in Endogens, porous vessels and other forms of fibro-vascular tissue, woody tissue, and laticiferous vessels. These vessels are enclosed in an epidermal covering, with few stomata, and are more or less compressed. When the vascular bundles reach the base of the lamina they separate and spread out in various ways, as already described under venation. A large vascular bundle is continued through the lamina to form the midrib (fig. 148, $n m$ ), and sometimes several large bundles form separate ribs (figs. 161, 177), whilst the ramifications of the smaller bundles constitute the veins and veinlets.

At the place where the petiole joins the stem there is frequently an articulation, or a constriction with a tendency to disunion, and at the same time there exists a swelling (fig. 220 p), called pulvinus (pulvinus, a cushion), formed by a mass of cellular tissue, the cells of which occasionally exhibit the phenomenon of contractility. At other times the petiole is not articulated, but is either continuous with the stem, or forms a sheath around it. At the point where the petiole is 
united to the lamina, or where the midrib joins the leaflets of a compound leaf, there is occasionally a cellular dilatation called struma (struma, a swelling), with an articulation. This articulation or joint is by many considered as indicating a compound leaf, and hence the leaf of the orange is considered as such, although it consists of one undivided lamina (fig. 201). In articulated leaves, the pulvinus may be attached either to the petiole or to the axis, and may fall with the leaf, or remain attached to the stem. When articulated leaves drop, their place is marked by a cicatrix or scar, seen below the bud in fig. 220. In this scar the remains of the vascular bundles, $c$, are seen; and its form furnishes characters by which particular kinds of trees may be known when not in leaf. In the case of many Palms and Tree-ferns, the scars or cicatrices of the leaves are very conspicuous. In fossil plants important characters are founded on them.

The petiole varies in length, being usually shorter than the lamina, but sometimes much longer. In some Palms it is fifteen or twenty feet long, and is so firm as to be used for poles or walking-sticks. In

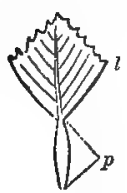

Fig. 199.

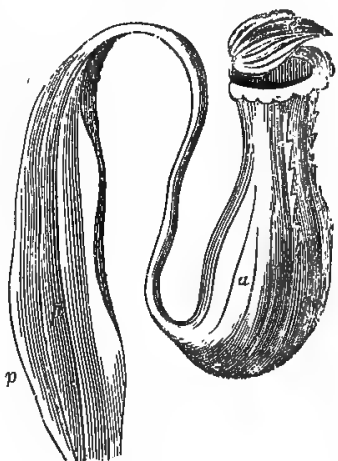

Fig. 200.

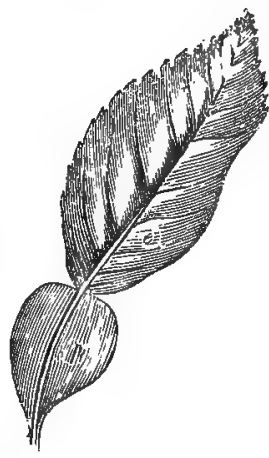

Fig. 201.

general, the petiole is more or less rounded in its form, the upper surface being flattened or grooved. Sometimes it is compressed laterally, as in the Aspen, and to this peculiarity the trembling of the leaves of this tree is attributed. In aquatic plants, the leaf-stalk is sometimes distended with air (fig. $199 p$ ), as in Pontederia and Trapa, so as to float the leaf. At other times it is. winged, or has a leaf-like appearance, as in the pitcher plant (fig. 200 p), orange (fig. $201 p$ ),

Fig. 199. Leaf with a quadrangular toothed lanina or blade, $l$, and an inflated petiole, $p$, containing air-cells. Fig. 200. Ascidium or pitcher of Nepenthes. $p$, Winged petiole which becomes narrowed, and then expands so as to form the pitcher $a$, by folding on itself. $e$, The operculum or lid, supposed to be formed by the blade of the leaf, and articu'lated to the pitcher. Fig. 201. Leaf of Orange, which some call compound. $p$, Dilated or winged petiole, united by an articulation to the blade. In such a leaf, if the vessels of the petiole were developed in a circular manner, so as to form a pitcher, the lamina or blade would form the jointed lid. 
lemon and Dionæa (fig. 202 p). In some Australian Acacias, and in some species of Oxalis, Bupleurum, etc., the petiole is flattened in a vertical direction, the vascular bundles separating immediately after quitting the stem, and running nearly parallel from base to apex.

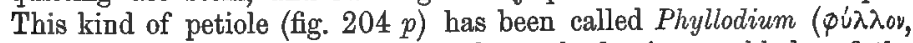
a leaf, and siofos, form). In these plants the laming or blades of the leaves are pinnate, bipinnate, or ternate, and are produced at the extremities of the phyllodia in a horizontal direction (fig. $204 l$ ); but

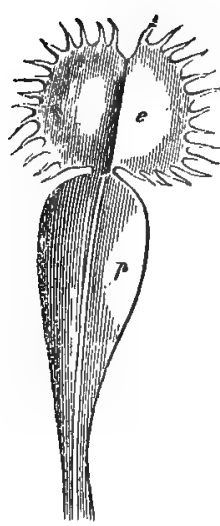

Fig. 202.

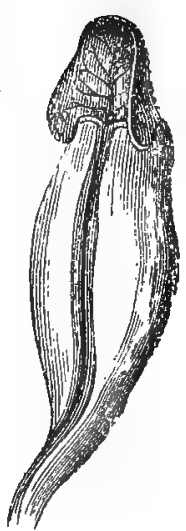

Fig. 203.

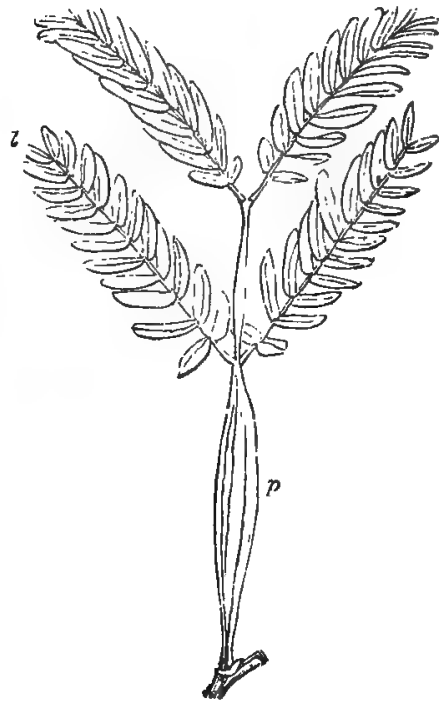

Fig. 204.

in many instances they are not developed, and the phyllodium serves the purpose of a leaf. Hence some Acacias are called leafless. These phyllodia, by their vertical position and their peculiar form, give a remarkable aspect to vegetation. On the same Acacia, there occur leaves with the petiole and lamina perfect; others having the petiole slightly expanded or winged, and the lamina imperfectly developed; and others in which there is no lamina, and the petiole becomes large and broad. Some petioles, in place of ending in a

Fig. 202. Leaf of Dionæa muscipula, or Venus' Fly-trap. $p$, Dilated or winged petiole. $\varepsilon$, Jointed blade, the two fringed halves of which fold on each other, when certain hairs on the upper surface are touched. Fig. 203. Ascidium, or Pitcher of Sarracenia, formed by the petiole of the leaf. The lid is not articulated to the pitcher as in Nepenthes (fig. 200). Fig. 204. Leaf of Acacia heterophylla. p, Phyllodium or enlarged petiole, with straight venation. $l l$, Lamina or blade, which is bipinnate. The blade is frequently wanting, and the phyllodium is the only part produced. 
lamina, form a tendril or cirrus (p. 120), so as to enable the plant to climb.

\section{Stipules.}

At the place where the petiole joins the axis, a sheath (vagina) is sometimes produced, which embraces the whole or part of the circumference of the stem (fig. $147 \mathrm{~g}$ ). This sheath is formed by the divergence of the vascular bundles, which separate so as to form a hollow cavity towards the stem. The sheath is occasionally developed to such a degree as to give a character to the plants. Thus, in the Rhubarb order, it is large and membranous, and has received the name of ochrea or boot (fig. $147 \mathrm{~g}$; ; while in Palms it forms a kind of network, to which the name of reticulum has been given (p. 32); and in umbelliferous plants it constitutes the pericladium ( $\pi \varepsilon g$ i, around, and $x \lambda \alpha_{0} \delta 05$, a branch). In place of a sheath, leaves are occasionally produced at the base of the petiole (fig. $205 \mathrm{ss}$ ), which have been denominated stipules (stipula, straw or husk). These stipules are often two in number, and they are important as supplying characters in certain natural orders. Thus they occur in the Pea and Bean family, in Rosaceous plants, and the Cinchona bark family. They are rarely met with in Monocotyledons, or in Dicotyledons with sheathing petioles, and they are not common in

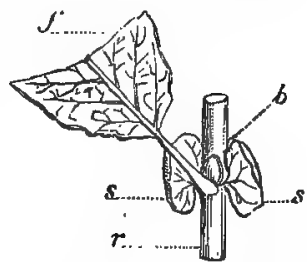

Fig. 205. Dicotyledons with opposite leaves. Plants having stipules are stipulate; those having none are exstipulate.

Stipules are formed by some of the vascular bundles diverging as they leave stem, and becoming covered with parenchyma, so as to resemble true leaves. Like leaves they are large or small, entire or divided, deciduous or persistent, articulated or non-articulated. Their lateral position at the base of the petiole distinguishes them from true leaves. In the Pansy the true leaves are stalked and crenate, while the stipules are large, sessile, and pinnatifid. In Lathyrus Aphaca, and some other plants, the true pinnate leaves are abortive, the petiole forms a tendril, and the stipules alone are developed, performing the office of leaves.

When stipules are attached separately to the stem at the base of the leaf, they are called caulinary. Thus, in fig. 205, $r$ is a branch of Salix aurita, with a leaf, $f$, having a bud, $b$, in its axil, and two caulinary stipules, $s s$. When stipulate leaves are opposite to each other, at the same height on the stem, it occasionally bappens that the

Fig. 205. Portion of a branch, $r$, of Salix aurita bearing a single petiolate leaf, $f$, which has been cut across. . $s$, Caulinary stipules. $b$, Bud in the axil of the leaf, 
stipules on either side unite wholly or partially, so as to form an interpetiolary or interfoliar (inter, between) stipule (fig. $206 \mathrm{~s}$ ), as in Cinchona and in Ipecacuan. In the case of alternate leaves, the stipules at the base of each leaf are sometimes united to the petiole and to each other, so as to form an adnate, adherent, or petiolary stipule, as in the Rose (fig. 207 s), or an axillary stipule, as in Houttuynia

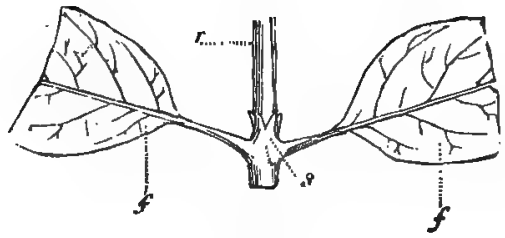

Fig. 206.

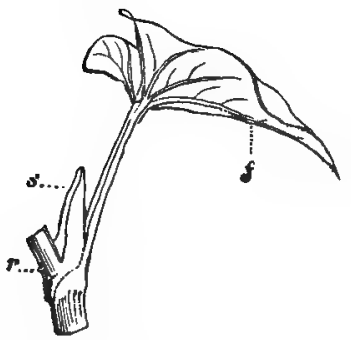

Fig. 208.

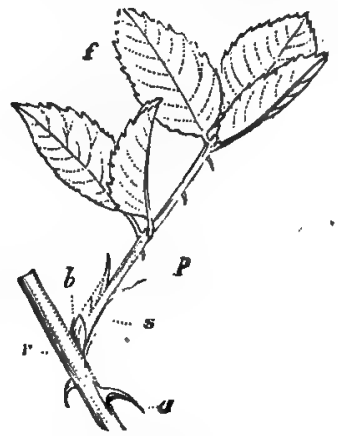

Fig. 207.

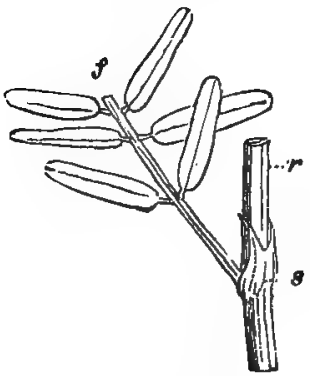

Fig. 209.

cordata (fig. 208 s). In other instances the stipules unite together on the side of the stem opposite the leaf, and become synochreate ( $\sigma$ iv, together), as in Astragalus (fig. $209 \mathrm{~s}$ ). The union or adhesion of

Fig. 206. Branch, $r$, and two leaves, $f f$, of Cephialanthus occidentalis, $s$, Interpetiolary or interfoliar stipule, formed by the partial union of two. Fig. 207. Portion of a branch, $\tau$, of Rosa canina, or dog-rose, bearing a single. leaf, $f$, with its petiole, $p$, its petiolary or adnate stipules, $s$, its axillary bud, $b$, and its aculei or prickles, $a$. Fig. 208. Portion of a branch, $r$, of Houttuynia cordata, with a leaf, $f$, and an axillary stipule, $s$, formed by the union of two. Fig. 209. Branch, $r$, and portion of the leaf, $f$, of Astragalus Onobrychis, with a synochreate stipule, $s$, formed by the union of two stipules on the opposite side of the branch from that to which the leaf is attached. The leaf is pinnate, and in the figure three pairs of leaflets or pinnis are left. 
stipules is not an accidental occurrence taking place after they have been developed, but is intimately connected with the general law, in accordance with which the parts of the plants are formed.

Stipules are sometimes large, enveloping the leaves in the young state, and falling off in the progress of growth, as in Ficus, Magnolia, and Potamogeton; at other times they are so minute as to be scarcely distinguishable without the aid of a lens, and so fugaceous as to be visible only in the very young state of the leaf. They may assume a hard and spiny character as in Robinia pseudacacia, or may be cirrose, as in Smilax, where each stipule is represented by a tendril; while in Cucurbitacer there is only one cirrose stipule. In grasses the sheath or sheathing petiole (fig. $210 \mathrm{~g} v$ ) has a prolongation or folding of the epidermis at its upper part, distinct from the leaf, to which the name of ligule (ligula, a small slip) has been given (fig. $210 \mathrm{gl}$ ). Some consider it as equivalent to a stipule. It is either long or short, acute or blunt, entire or divided, and thus gives rise to various characters. At the base of the leaflets or foliola of a compound leaf, small stipules are occasionally pro-

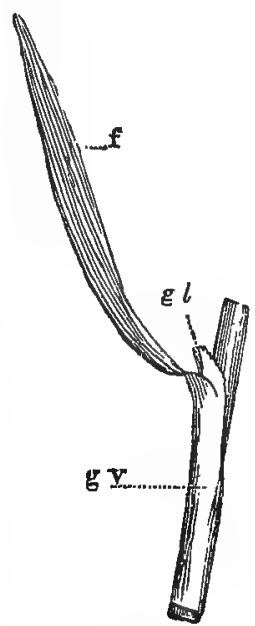

Fig. 210. duced, to which some have given the name of stipels.

\section{Anomalous Forms of Leaves and Petioles.}

Variations in the structure and forms of leaves and leaf-stalks are produced by the increased development of cellular tissue, by the abortion or degeneration of parts, by the multiplication or repetition of parts, and by adhesion. When cellular tissue is developed to a great extent, leaves become succulent, and occasionally assume a crisp or curled appearance. Such changes take place naturally, but they are often increased by the art of the gardener; and the object of many horticultural operations is to increase the bulk and succulence of leaves. It is in this way that Cabbages and Savoys are rendered more delicate and nutritious.

In some plants true leaves are not produced, their place being occupied by dilated petioles or phyllodia (p. 96), or by stipules (p. 97). In other instances scales are formed insteàd of leaves, as in Orobanche, Lathræa, and young Asparagus (fig. 129 l). Divisions take place in

:Fig. 210. Portion of a leaf of Phalaris arundinacea, one of the grasses. $f$, Laminar merithal or blade of the leaf, with straight parallel venation. $g v$, Vaginal, or sheathing portion, representing the petiole, ending in a membranous process or ligule, $g l$. 
leaves when there is a multiplication of their parts; and a union of two or more leaves, or of parts of leaves, occurs in many cases. When two lobes at the base of a leaf are prolonged beyond the stem and unite (fig, 171), the leaf is perfoliate (per, through, and folium, leaf), the stem appearing to pass through it, as in Bupleurum perfoliar tum, and Chlora perfoliata; when two leaves unite by their bases they become connate (con, together, and natus, born), as in Lonicera Caprifolium; and when leaves adhere to the stem, forming a sort of winged or leafy appendage, they are decurrent (decurro, to run down or along), as in Thistles.

The vascular bundles and cellular tissue are sometimes developed in such a way as to form a circle, with a hollow in the centre, and thus give rise to what are called fistular (fistula, a pipe) or hollow leaves, and to ascidia (ćaxísıov, a small bag) or pitchers. Hollow leaves are well seen in the Onion. Pitchers are formed either by petioles or by laminæ, and they are composed; of one or more leaves. In some Convallarias, two leaves unite to form a cavity. In Sarracenia (fig. 203) and Heliamphora, the pitcher is composed apparently of the petiole of the leaf. In Nepenthes (fig. 200) and perhaps in Cephalotus, while the folding of a winged petiole, $p$, forms the pitcher, a, the lid, $e$, which is united by an articulation, corresponds to the lamina. This kind of ascidium is called calyptrimor-

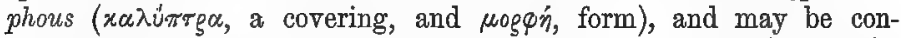
sidered as formed by a leaf such as that of the Orange (fig. 201) ; the lamina, $e$, being articulated to the petiole, $p$, which, when folded, forms the pitcher. In Dischidia Rafflesiana, a climbing plant of India, the pitchers, according to Griffith, are formed by the lamina of the leaf, and have an open orifice into which the rootlets at the upper part of the plant enter. These pitchers would seem therefore to contain a supply of fluid for the nourishment of the upper branches of the plant. In Utricularia, the leaves form sacs called ampullee. Some suppose that pitchers are not due to folding and adhesion, but that they are produced by a hollowing out of the extremity of the stalk.

\section{Structure and Form of Leaves in the Great Divisions of the Vegetable Kingdom.}

Leaves of Dicotruedons,-In Dicotyledons, the venation is reticulated, the veins, coming off at various angles, form an angular network of vessels (fig. 151), and the tracheæ communicate with the medullary sheath. They are frequently articulated, exhibit divisions at their margin, and become truly compound. There are no doubt instances in which the veins proceed in a parallel manner, but this will be found to occur chieffy in cases where the petiole may be considered as occupying the place of the leaf. Examples of 
this kind are seen in Acacias (fig. 204), as well as in Ranunculus gramineus and $\mathrm{R}$. Lingua.

Leaves of Monocotyledons.-In Monocotyledons, the leaves do not present an angular network of vessels, nor do they exhibit divisions on their margin (figs. 150, 210). Exceptions to this rule occur in some plants, as Tamus and Dioscorea, which have been called Dictyogens by Lindley, on account of their somewhat netted venation; and in Palms, in which, although the leaves are entire at first, they afterwards become split into various lobes. Leaves of Monocotyledons are rarely stipulate, unless the ligule of grasses be considered as being a stipule. Their leaves are often sheathing, continuous with the stem (forming a spurious stem in Bananas), and do not fall off by an articulation. When there is only a slight divergence of their veins, they may be looked upon more as enlarged and flattened petioles than as true laminæ. This remark is illustrated by the leaves of Typha and Iris. In some Monocotyledons, as in Sagittaria sagittifolia, the submerged and floating leaves are narrow, like petioles, while those growing erect above the water expand and assume an arrow-like shape (fig. 180).

Leaves of AcotYLeDons.-In Acotyledons, such as Ferns and their allies, the leaves vary much ; being entire or divided, stalked or sessile, often feather-veined, occasionally with radiating venation, the extremities of the veins being forked. The fibro-vascular bundles of the leaves resemble those of the stem both in structure and arrangement. In Thallogens, the leaves when present have no vascular venation. In many of them, as Lichens, Fungi, and Algæ, there are no true leaves.

\section{Phyllotaxis, or the Arrangement of the Leaves on the Axis.}

Leaves occupy various positions on the stem and branches, and have received different names according to their situation. Thus leaves arising from the crown of the root, as in the Primrose, are called radical; those on the stem are cauline; on the branches, ramal; on flower-stalks, floral leaves. The first leaves developed are deno-

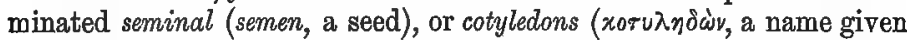
to a plant or a seed-lobe); and those which succeed are primordial (primus, first, and ordo, rank).

The arrangement of the leaves on the axis and its appendages is

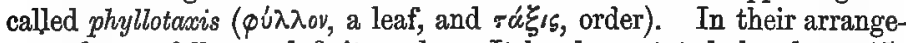
ment leaves follow a definite order. It has been stated already, p. 45, that there are regular nodes or points on the stem (fig. $211 n$ ) at which leaves appear, and that the part of the stem between the nodes is the internode (fig. $211 \mathrm{~m}$ ). Each node is capable of giving origin to a leaf. Occasionally several nodes are approximated so as to form 
as it were one, and then several leaves may be produced at the same height on the stem. When two leaves are thus produced, one on

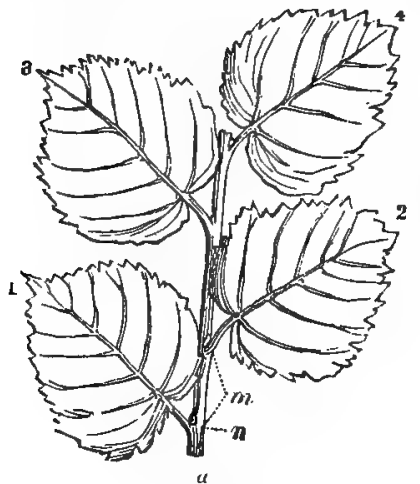

Fig. 211.
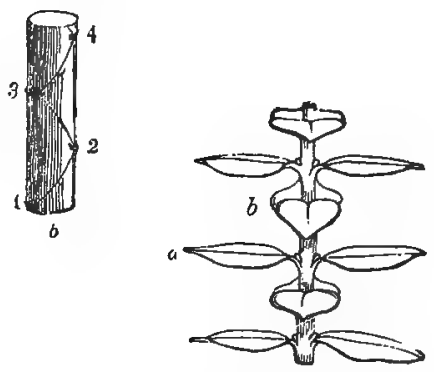

Fig. 212.

each side of the stem or axis, and at the same level, they are called

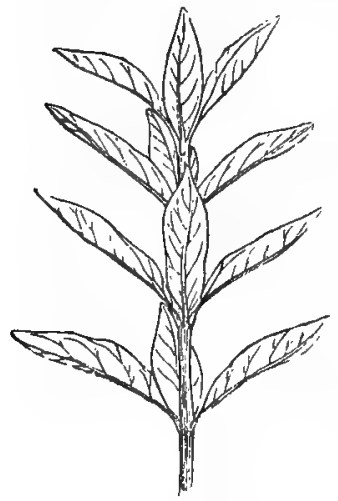

Fig. 213. opposite (fig. 212); when more than two are produced (figs. 183, 213), they are verticillate (verto, I turn), and the circle of leaves is then called a verticil or whorl. When leaves are opposite, the pairs which are next each other, but separated by an internode, often cross at right angles (fig. $212 a b$ ), or decussate (decusso, I cut crosswise), following thus a law of alternation. The same occurs in verticils, the leaves of each whorl being alternate with those of the whorl next to it; or, in other words, each leaf in a whorl occupying the space between two leaves of the whorl next to it. There are considerable irregularities, however, in this respect, and the number of leaves in different whorls is not always uniform, as may be seen in Lysimachia vulgaris (fig. 213).

Fig. 211. Portion of a branch of a Lime tree, with four leaves arranged in a distichous manner, or in two rows. $a$, The branch with the leaves numbered in their order, $n$ being the node, and $m$ the internode or merithal. $b$ Is a magnifled representation of the branch, showing the cicatrices of the Ieaves and their spiral arrangement, which is expressed by $\frac{1}{2}$, or one turn of the spiral and two leaves.

Fig. 212. Opposite, decussate leaves of Pimelea decussata. a, A pair of opposite leaves. $b$, Another pair placed at right angles. Fig. 213. Leaves of Lysimachia vulgaris, in verticils or whorls of three. The leaves of each vertioil alternate with those of the verticils next it. In this plant the number of the leaves in a verticil often varies. 
When a single leaf is produced at a node, and the nodes are separated so that each leaf occurs at a different height on the stem, the leaves are alternate (fig. 214). The relative position of alternate leaves varies in different plants, although it is tolerably uniform in each species. In fig. 211 , leaf 1 arises from a node, $n$; leaf 2 is separated by an internode, $m$, and is placed to the right or left; while leaf 3 is situated directly above leaf 1 . The arrangement in this case is distichous ( $\delta / \xi$, twice, and $\sigma \gamma^{\prime} \chi^{\circ}{ }^{\circ}$, order), or the leaves are arranged in two rows. In fig. 215, on the other hand, the fourth leaf is directly above the first, and the arrangement is tristichous ( $r \varepsilon_{\varepsilon} \tilde{\zeta}$, three, and orixos, order). The same arrangement continues throughout the stems, so that in fig. 215 the 7 th leaf is above the 4 th, the 10 th above the 7 th; also the 5 th above the $2 \mathrm{~d}$, the 6 th above the $3 \mathrm{~d}$, and so on. There is thus throughout a tendency to a spiral arrangement, the number of leaves in the spire or spiral cycle, and the number of turns, varying in different plants. In plants whose leaves are close to each other, the spiral tendency is easily seen. In the Screw pine (Pandanus odoratissimus), in the Pine-apple family, and in some Palms, as Copernicia cerifera, the screw-like arrangement of the leaves is obvious. This mode of development prevails in all parts of plants, and may be considered as depending on their manner of

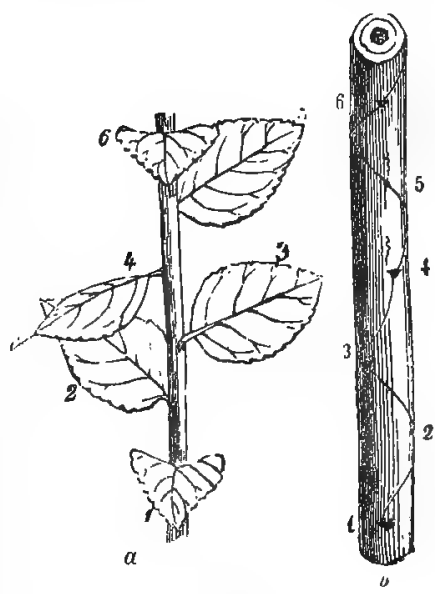

Fig. 214. growth in an upward and at the same time in a lateral direction, Alternation is looked upon as the normal arrangement of all parts of plants. This arrangement is liable to be interrupted by many causes, so that its distinct existence cannot be always detected.

In a regularly-formed straight branch covered with leaves, if a thread is passed from one to the other, turning always in the same direction, a spiral is described, and a certain number of leaves and of complete turns occur before reaching the leaf directly above that from which the enumeration commenced. This arrangement has been expressed by a fraction, the numerator of which indicates the number

Fig. 214. Part of a branch of a Cherry with six leaves, the 6th being placed vertically over the first, after two turns of the spiral. This is expressed by $\frac{2}{5}$ or the quincunx. $a$, The branch, with the leaves numbered in order. $b$, A magnified representation of the branch," showing the cicatrices of the ieaves or their points of insertion, and their spiral arrangement. 
of turns, and the denominator the number of leaves in the spiral cycle. Thus, in fig. 214, $a b$, the cycle consists of five leaves, the 6 th

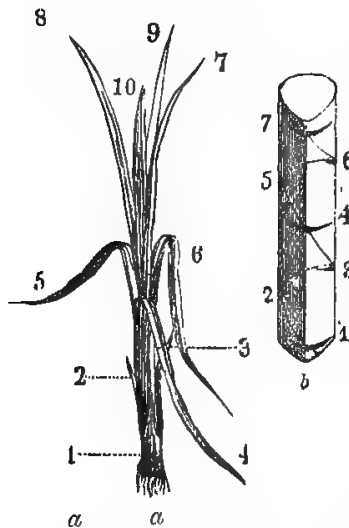

Fig. 215. leaf being placed vertically over the 1st, the 7 th over the $2 d$, and so on; while the number of turns between the 1st and 6 th leaf is two: hence, this arrangement is indicated by the fraction $\frac{2}{5}$. In other words, the distance or divergence between the first and second leaf, expressed in parts of a circle, is $\frac{2}{6}$ of a circle, or $360^{\circ} \div \frac{2}{6}=144^{\circ}$. In fig. 211 , $a b$, the spiral is $\frac{1}{2}$, i.e. one turn and two leaves; the third leaf being placed vertically over the first, and the divergence between the first and second leaf being one-half the circumference of a circle, $360^{\circ} \div \frac{1}{2}=180^{\circ}$. Again, in fig. 215 , $a b$, the number is $\frac{1}{3}$, or one turn and three leaves, the angular divergence being $120^{\circ}$.

The general forms of Phyllotaxy may be brought out by a continued fraction-

$$
\frac{1}{a+1}+1+1+1 \text {, etc. }
$$

where $a$ may have the values $1,2,3$, or 4 , etc.

The actual fractions thus resulting are-when

$$
\begin{aligned}
& a=1 \ldots \frac{1}{2} \frac{2}{3} \frac{3}{5} \frac{5}{8} \frac{8}{13}, \text { etc. } \\
& a=2 \ldots \frac{1}{2} \frac{1}{3} \frac{2}{5} \frac{3}{8} \frac{5}{13}, \text { etc. } \\
& a=3 \ldots \frac{1}{3} \frac{1}{4} \frac{2}{7} \frac{3}{13} \frac{5}{18}, \text { etc. } \\
& a=4 \ldots \frac{1}{4} \frac{1}{5} \frac{2}{8} \frac{3}{14} \frac{5}{2}, \text { etc. }
\end{aligned}
$$

Each fraction being obtained by adding together the numerator and denominator in the two preceding fractions.

When the leaves or scales are alternate, and run in a single series, they are unijugate; when the leaves are opposite, and there are two parallel rows produced, the arrangement is bijugate, while in the case of whorled leaves the arrangement may be trijugate or quadrijugate.

Fig. 215.- Young plant of Cyperus eseulentus, with leaves in three rows, or tristichous, expressed by the fraction $\frac{1}{s}$, or one turn and three leaves. $a$, The plant, with its leaves numbered in their order. . $b$, Magniffed representation of the stem, showing the insertion of the leaves and their spiral arrangement. 
In cases where the internodes are very short, and the leaves are closely applied to each other, as in the House-leek, it is difficult to trace what has been called the generating spiral, or that which passes through every leaf of the cluster. Thus in fig. 216, there are thirteen leaves which are numbered in their order, and five turns of the spiral marked by circles in the centre ( $\frac{5}{13}$ indicating the arrangement); but this could not be detected at once. So also in Fir cones (fig. 217), which are composed of scales or modified leaves, the generating spiral cannot be determined easily. In such cases, however, there are secondary spirals running parallel to each other, as is seen in fig. 217, where spiral lines pass through scales numbered $1,6,11,16$, etc.,

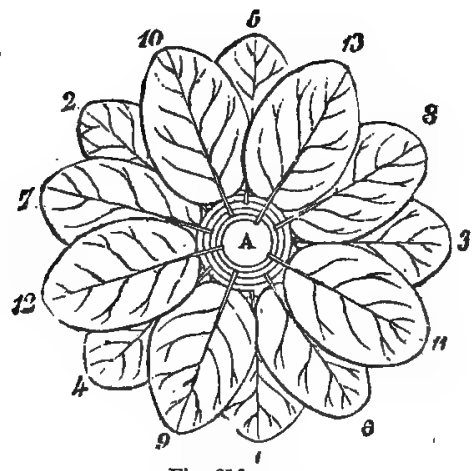

Fig. 216.

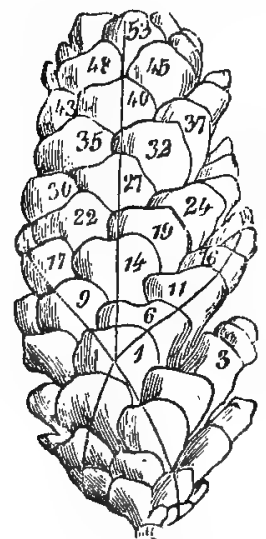

Fig. 217.

and $1,9,17$, etc., and by counting those which run parallel in different directions, the number of scales intervening between every two in the same parallel coil may be ascertained. Thus, in fig. 217 , it will be found that there are five secondary spirals running towards the right and parallel to each other, the first passing through the scales 1 , $6,11,16$, etc. ; the second through $9,14,19,24$, etc. ; the third through $17,22,27,32,37$, etc. ; the fourth through $30,35,40,45$, etc.; the fifth through $43,48,53$, etc.' 'The number of these secondary spirals indicates the number of scales intervening between every

Fig. 216. Cycle of thirteen leaves placed closely together so as to form a rosette, as in Sempervivum. $A$ is the very short axis to which the leaves are attached. The leaves are numbered in their order, from below upwards. The circles in the centre indicate the five turns of the spiral, and show the insertion of each of the leaves. The divergence is expressed by the fraction 5-thirteenths. Fig. 217. Cone of Abies alba, with the seales or modified leaves numbered in the order of their arrangement on the axis of the cone. The lines indicate a rectilinear series of scales, and two lateral secondary spirals, one turning from left to right, the other from right to left. 
two scales in each of these spirals-the common difference being five. Again, it will be found on examination that there are secondary spirals running to the left, in which the common difference between every two scales is eight, and that this corresponds to the number of secondary spirals, the first of which passes through the scales $1,9,17$, etc.; the second through $6,14,22,30$, etc. ; the third through $3,11,19$, $27,35,43$, and so on. Thus it is that, by counting the secondary spirals, all the scales may be numbered, and, by this means the generating spiral may be discovered.

In the cone of the American larch (fig. 218) there is a quincuncial arrangement of scales marked by the fraction $\frac{2}{5}$. There are five vertical ranks, as marked in the tabular numerical view at the side of

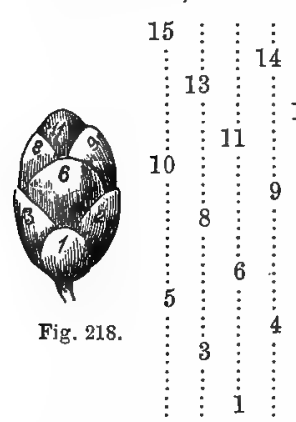
the cone-viz., $2,7,12 ; 4,9,14 ; 1,6,11$; $3,8,13 ; 5,10,15$, the common difference in each row being 5 . On looking at the cone 12 we find also parallel oblique ranks, two of which, ascending to the left, are marked by the numbers $1,3,5$, which, if the diagram is coiled round a cylinder, continue in the numbers $7,9,11,13,15$; and $2,4,6,8$, 10 , continued into 12,14 . There are thus two left-handed spirals, with 2 as the common difference in the numbering of the scales. Again, three oblique parallel spirals ascend to the right, marked by the numbers $1,4,7$, running into 10,$13 ; 3,6,9,12$, going on to 15 ; and $5,8,11,14$; here the common numbering of the scales is 3 , corresponding with the oblique right-handed spirals.

The primitive or generating spiral may pass either from right to left or from left to right. It sometimes follows a different direction in the branches from that pursued in the stem. When it follows the same course in the stem and branches, they are homodromous $\left(0 \mu_{0} 0,0 s\right.$,

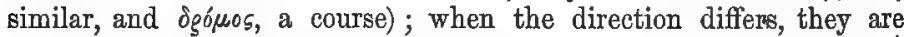
heterodromous ( same genus the phyllotaxis frequently varies.

Considering alternation as the usual leaf-arrangement, some have supposed that opposite leaves are due to the development of two spirals in opposite directions, while others look upon them as produced by two nodes coming close together without an internode. A verticil, in the latter view, will be the result of the non-development of more than one internode, and may occur in plants, the normal

Fig. 218. Cone of a species of Larch (Larix microcarpa), taken from Professor Asa Gray's work, with the scales numbered so far as seen. The arrangement is 2 in the fiveranked series. There are five vertical rows of scales, $1,6,11 ; 4,9,14 ; 2,7,12 ; 5,10,15$; and $3,8,13$, as shown in the diagram. 
arrangement of whose leaves is alternate. Thus, in fig. 211, if the space between 1 and 2 were obliterated, or the internode, $m$, not developed, the leaves would be opposite. In fig. 214 , if the spaces between each of the leaves were obliterated, there would be a verticil of five leaves. In many plants there is a law of arrestment of development, by which opposite and verticillate leaves are naturally produced: but in such cases the alternation is still seen in the arrangement of the different clusters of leaves.

In some cases the effect of interruption of growth, in causing alternate leaves to become opposite and verticillate, can be distinctly shown, as for instance in Rhododendron ponticum. In other cases, parts which are usually opposite or verticillate become alternate by the vigorous development of the axis : and on different parts of the same stem, as in Lysimachia vulgaris, there may be seen alternate, opposite, and verticillate leaves. When the interruption to development takes place at the end of a branch the leaves become fasciculate (fasciculus, a bundle) or clustered, as in the Larch. A remarkable instance of the shortening of internodes and the clustering of leaves occurred in the Palm-house of the Botanic Garden of Edinburgh, in the case of a Bamboo, which was exposed for many months to a low temperature, during the time that the roof of the house was being renewed. The plant had been growing rapidly, with its internodes of the usual length, but it was suddenly arrested near the summit, the internodes became gradually shortened, till the nodes were close to each other, and the leaves came off in bunches. All modifications of leaves follow the same laws of arrangement as true leaves-a fact which is of importance in a morphological point of view.

In Dicotyledonous plants, the first leaves produced, or the cotyledons, are opposite. This arrangement often continues during the life of the plant, but at other times it changes. Some tribes of plants are distinguished by their opposite or verticillate, others by their alternate, leaves. Labiate plants have decussate leaves, while Boraginaceæ have alternate leaves, and Tiliaceæ, usually have distichous leaves; Cinchonaceæ have opposite leaves; Galiaceæ, verticillate. Such arrangements as $\frac{2}{5}, \frac{3}{8}, \frac{5}{3}$, and $\frac{8}{21}$, are common in Dicotyledons. The first of these, called quincunx (quincunx, an arrangement of five), is met with in the Apple, Pear, and Cherry (fig. 214); the second, in the Bay, Holly, Plantago media; the third, in the cones of Pinus (Abies) alba (fig. 217); and the fourth, in those of the Pinus (Abies) Picea. In Monocotyledonous plants there is only one seed-leaf or cotyledon produced, and hence the arrangement is at first alternate; and it generally continues so more or less. Such arrangements as $\frac{1}{2}, \frac{1}{3}$ (fig. 215), and $\frac{2}{3}$, are common in Monocotyledons, as in Grasses, Sedges, and Lilies. In Acotyledons the leaves assume all kinds of arrangement, being opposite, alternate, and verticillate. It has been 
found in general that, while the number 5 occurs in the phyllotaxis of Dicotyledons, 3 is common in that of Monocotyledons.

Although there is thus, in the great divisions of the vegetable kingdom, a tendency to certain definite numerical arrangements, yet there are many exceptions. In speaking of Palms, which are Monocotyledonous plants, Martius states that the leaves of different species exhibit the following spirals- $\frac{1}{2}, \frac{3}{5}, \frac{5}{7}, \frac{5}{8}, \frac{7}{6}, \frac{8}{13}, \frac{13}{2}, \frac{21}{3}$. In the species of the genus Pinus, $\frac{2}{6}, \frac{6}{13}, \frac{8}{21}, \frac{13}{31}, \frac{21}{65}$, occur. Thus, while it has been shown that the phylloplastic ( $\varphi\langle\lambda \lambda \circ \nu$, a leaf, and $\pi \lambda \alpha \sigma \tau i x o s$, formative) or leaf-formative power moves in a spiral round the axis, it has been found impossible to apply phyllotaxis satisfactorily to the purposes of classification.

The spiral arrangement of the leaves allows all of them to be equally exposed to air and light, and thus enables them to carry on their functions with vigour. The form of the stem is also probably connected with the leaf-arrangement. M. Cagnat has remarked that an analogy in arrangement of leaves and character of stem may be traced. The leaves of juniper are in verticils of three, and the pith is triangular; the leaves of cypress being opposite, the pith presents the form of a cross. When leaves are opposite and decussate, the stems are often square, as in Labiate plants. The ordinary rounded stem appears to be associated with a certain degree of alternation in the separate leaves, or in the different pairs of leaves when they are opposite.

The study of the structure, forms, and arrangement of leaves, is of great importance, when it is considered that all parts of plants are to be looked upon as leaf-formations variously modified, in order to serve special purposes in the economy of vegetation. The morphological relations of leaves, or the varied forms which they assume, will be illustrated during the consideration of the organs of reproduction, and of the doctrine of metamorphosis, as propounded by Goethe and others. It is only by looking upon all the organs of plants in their relation to the leaf as a type, that a philosophical view can be given of the great plan on which they have been formed.

\section{Leaf-buds.}

LEAF-BUDS contain the rudiments of branches, and are found in the axil of previously-formed leaves (fig. $219 b a, b a, b a)$; or, in other words, in the angle formed between the stem and leaf. They are hence called axillary, and may be either terminal, bt, or lateral, $b a$. They commence as cellular prolongations from the medullary rays bursting through the bark. The central cellular portion is surrounded by spiral vessels, and is covered with rudimentary leaves. In the progress of growth, vascular bundles are 
formed continuous with those of the stem; and, ultimately, branches are produced, which in every respect resemble the axis whence the buds first sprang. The cellular portion in the centre remains as pith with its medullary sheath, which is closed and not continuous with that of the parent stem. Thus, in the stem and branch, this sheath forms a canal which, is closed at both extremities, and which sends prolongations of spiral vessels to the leaves. As the axis or central portion of the leaf-bud increases, cellular projections appear at regular intervals, which are the rudimentary leaves.

A leaf-bud may be removed in a young state from one plant and grafted upon another, by the process of budding, so as to continue to form its different parts; and it may even be made to grow in the soil, in some instances, immediately after removal. In certain cases

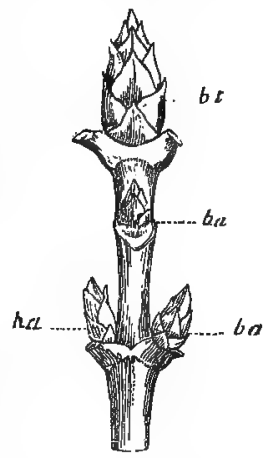

Fig. 219. leaf-buds are naturally detached during the life of the parent, so as to form independent plants, and thus propagate the individual. Leafbuds have on this account been called fuxed embryos, by Petit-Thouars and others, who' look upon them as embryo plants fixed to the axis, capable of sending stems and leaves in an upward direction, and bast or ligneous fibres downwards, which, according to them, may be considered as roots. A tree may thus be said to consist of a series of leaf-buds, or phytons ( $\varphi$ urdv, a plant), attached to a common axis or trunk. In ordinary trees, in which there is provision made for the formation of numerous lateral leaf-buds, any injury done to a few branches is easily repaired; but in PaIms, which only form central leaf-buds, and have no provision for a lateral formation of them, an injury inflicted on the bud in the axis is more likely to have a prejudicial effect on the future life of the plant.

In the trees of temperate and cold climates the buds which are developed during one season lie dormant during the winter, ready to burst out under the genial warmth of spring. They are generally protected 'by external modified leaves in the form of scales, tegmenta or perulo (tegmenta, coverings ; perulo, small bags), which frequently exhibit a firmer and coarser texture than the leaves themselves. These scales or protective appendages of the bud consist either of the altered laminæ, or of the enlarged petiolary sheath, or of stipules, as in the Fig and Magnolia, or of one or two of these parts combined.

\footnotetext{
"Fig. 219. Upper portion of a branch of Lonicera nigra in a state of hibernation, that is to say, after the fall of the leaves; covered with leaf-buds. $b t$, A termingl bud. $b a, b a$, ba, Axillary lateral buds. Below the buds the creatrix or scar left by the fallen leaves is seen.
} 
They serve a temporary purpose, and usually fall off sooner or later after the leaves are expanded. The bud is often protected by a coating of resinous matter, as in the Horse-chestnut and Balsam poplar, or by a thick downy covering, as in the Willow. Linnæus called leafbuds hibernacula, or the winter quarters of the young branch.

In the bud of a common tree, as the Sycamore (fig. 220), there is seen the cicatrix left by the leaf of the previous year, $c$, with the pulvinus or swelling, $p$, then the scales, $e e$, arranged alternately in a

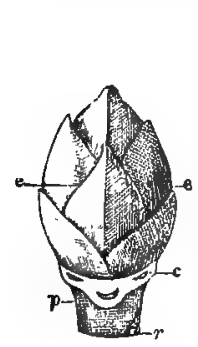

Fig 220 .

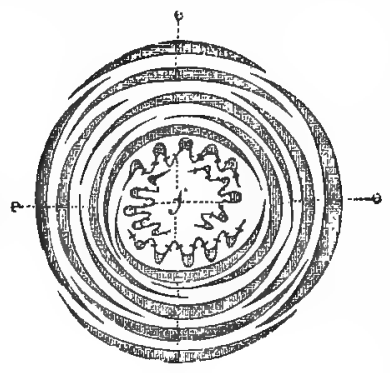

Fig. 221.

spiral manner, and overlying each other in what is called an imbricated (imbrex, a roof tile) manner. On making a transverse section of the bud (fig. 221), the overlying scales, $e$ e e e, are distinctly seen surrounding the leaves, $f$, which are plaited or folded round the axis orgrowing point. In plants of warm climates the buds are often formed by the ordinary leaves without any protecting appendages; such leaves are called naked.

VERNATION.-The arrangement of the leaves in the bud has been denominated vernation (ver, spring), or proffoliation (proe, before, and folium, leaf), or gemmation (gemma, a bud). In considering vernation we must take into account both the manner in which each individual leaf is folded and also the arrangement of the leaves in relation to each other. These vary in different plants, but in each species they follow a regular law. The leaves in the bud are either placed simply in apposition, as in the Mistleto, or they are folded or rolled up longitudinally or laterally, giving rise to different kinds of vernation, as delineated in fig. $222 a-n$, where the dot represents the axis and the folded or curved lines represent the leaves, the thickened part indicating the midrib; figs. $a$ and $g$ being vertical sections; $b-f$ and $h-n$, horizontal.

The leaf taken individually is either folded longitudinally from apex to base (fig. 222 a), as in the Tulip-tree, and called reclinate or replicate; or rolled up in a circular manner from apex to base, as

Fig. 210. Leaf-bud of Sycamore (Acer pseudo-platanus) covered with scales. r, The branch. $p$, Pulvinus or swelling at the base of the leaf which has fallen, leaving a scar or cicatricula, $c$, in which the remains of three vascular bundles are seen. ee, Imbricated scales of the bud. Fig. 221. Transverse section of the same leaf-bud. e e e e, The scales arranged in an imbricated manner, like the tiles on a house. $f$, The leaves folded in a plaited manner, exhibiting plicate vernation. 
in Ferns (fig. $222 \mathrm{~g}$ ), and called circinate (circino, I turn round) ; or folded laterally, conduplicate, as in Oak (fig. $222 b$ ); or it has several folds like a fan, plicate or plaited, as in Vine and Sycamore (figs. $221 \mathrm{f}$, $222 \mathrm{c}$ ), and in leaves with radiating vernation, where the ribs mark the foldings; or it is rolled upon itself, convolute or supervolute, as in Banana and Apricot (fig. $222 \mathrm{~d}$ ) ; or its edges are rolled inwards, involute, as in Violet (fig. $222 \mathrm{e}$ ) ; or outwards, revolute, as in Rosemary (fig. $222 \mathrm{f}$ ). The different divisions of a cut leaf may be folded or rolled up separately, as in Ferns, while the entire leaf may have either the same or a different kind of vernation.

Other kinds of vernation receive their names from the arrangement of the leaves in the bud, taken as a whole. Leaves in the bud

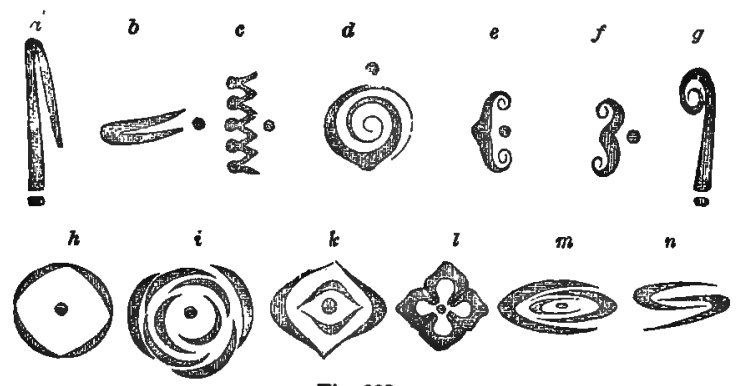

Fig. 222.

are opposite, alternate, or verticillate; and thus different kinds of vernation are produced. Sometimes they are nearly in a circle at the same level, remaining flat, or only slightly convex externally, and placed so as to touch each other by their edges, thus giving rise to valvate vernation (fig. $222, h$ ). At other times they are at different levels, and are applied over each other, so as to be imbricated, as in Lilac, and in the outer scales of Sycamore (figs. 220, 221); and occasionally the margin of one leaf overlaps that of another, while it, in its turn, is overlapped by a third, so as to be twisted, spiral, or contortive (fig. 222 i). When leaves are applied to each other, face to face, without being folded or rolled together, they are appressed. When the leaves are more completely folded they either touch at their

Fig. 222. Diagrams to show the different kinds of vernation. $a-g$, The folding of individual leaves; $a$ and $g$ being vertical sections, $b c d e$ and $f$ being horizontal. $a$, Reclinate or replicate. $b$, Conduplicate. $c$, Plicate. $d$, Convolute. e, Involute. $f$, Revolute. $g$ Circinate. $h$-n, Folding of leaves when united together in the leaf-bud. The sections are horizontal or transverse, and show the relative position of the leaves, and the mode in which each of then is folded. $h$, Valvate. $i$, Twisted, spiral, or contortive. $k$, Opposite or accumbent, with the margins reduplicate, $l$, Induplicate. $m$, Equitant. $n$, Obvolute or haif-equitant. In all the figures the thickened portion indicates the midrib of the leaf and the dot marks the position of the axis. 
extremities and are accumbent or opposite (fig. $222 k$ ), or are folded inwards by their margin, and become induplicate (fig. $222 l$ ); or a conduplicate leaf covers another similarly folded, which in turn covers a third, and thus the vernation is equitant (riding), as in Privet (fig. $222 \mathrm{~m}$ ); or conduplicate leaves are placed so that the half of the one covers the half of another, and thus they become halfequitant or obvolute, as in Sage (fig. $222 n$ ). The scales of a bud sometimes exhibit one kind of vernation, and the leaves another (fig. 221). The same modes of arrangement occur in the flower-buds, as will be afterwards shown.

Leaf-buds, as has been stated, are either terminal or lateral. By the production of the former (fig. $219 \mathrm{bt}$ ), stems increase in length, while the latter (fig. $219 b a, b a, b a$ ) give rise to branches, and add to the diameter of the stem. The terminal leaf-bud, after producing leaves, sometimes dies at the end of one season, and the whole plant, as in annuals, perishes; or part of the axis is persistent, and remains for two or more years, each of the leaves before its decay producing a leaf-bud in its axil. This leaf-bud continues the growth in spring.

In some trees of warm clinates, as Cycas, Papaw-tree, Palms, and Tree ferns, the production of terminal buds is well seen. In these plants the elongation of the stem is generally regular and uniform, so that the age of the plant may be estimated by its height. Such stems (often endogenous) may thus be considered as formed by a series of terminal buds, placed one over the other. From this mode of growth they do not attain a great diameter (fig. 134, I). In other trees, especially Exogens, besides the terminal bud there are also lateral ones. These, by their development, give rise to branches (rami), from which others, called branehlets or twigs (ramuli) arise. Such buds being always produced in the axil of leaves are of course arranged in a manner similar to the leaves. By the continual production of lateral leaf-buds, the stem of exogenous plants acquires a great diameter.

Although provision is thus made for the regular formation of leaf-buds, there are often great irregularities in consequence of many being abortive, or remaining in a dormant state. Such buds are called latent, and are capable of being developed in cases where the terminal bud, or any of the branches, have been injured or destroyed. In some instances, as in Firs, the latent buds follow a regular system of alternation; and in plants with opposite leaves, it frequently happens that the bud in the axil of one of the leaves only is developed, and the different buds so produced are situated alternately on opposite sides of the stem.

When the terminal bud is injured or arrested in its growth, the elongation of the main axis stops, and the lateral branches often acquire increased activity. By continually cutting off the terminal 
buds, a woody plant is made to assume a bushy appearance, and thus pollard trees are produced. Pruning has the effect of checking the growth of terminal buds, and of causing lateral ones to push forth. The peculiar bird-nest appearance often presented by the branches of the common Birch depends on an arrestment in the terminal buds, a shortening of the internodes, and a comsequent clustering or fasciculation of the twigs. In some plants there is a natural arrestment of the main axis after a certain time, giving rise to peculiar shortened stems. Thus the crown of the root (p. 46) is a stem of this nature, forming buds and roots. Such is also the case in the stem of Cyclamen, Testudinaria Elephantipes, and in the tuber of the potato. The production of lateral in place of terminal buds sometimes gives the stem a remarkable zigzag aspect.

In many plants with a shortened axis, the lateral buds produce long branches. Thus the flagellum (flagellum, a whip or twig), or runner of the Strawberry and Ranunculus, is an elongated branch, developing buds as it runs along the ground; the propagulum (propago, a shoot), or offset, is a short thick branch produced laterally in fleshy plants from a shortened axis, and developing a bud at its extremity, which is capable of living when detached, as in Houseleek. Fig. 223 represents a strawberry plant, in which $a^{\prime}$ is the primary axis, ending in a cluster of green leaves, $r$, and some rudimentary leaves, $f$, and not elongating ; from the axil of one of the leaves proceeds a branch or runner, $a^{\prime \prime}$, with a rudimentary leaf, $f^{\prime}$, about the

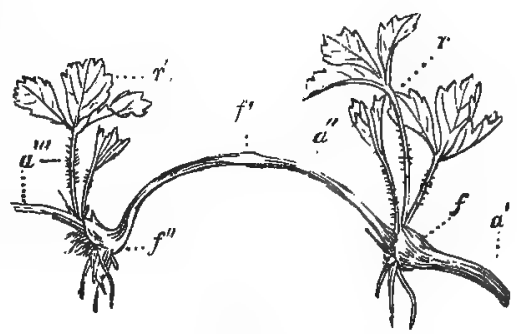

Fig. 223. middle, and another cluster of leaves, $f^{\prime \prime}$ and $r^{\prime}$, forming a young plant with roots ; from this a third axis comes off, $a^{\prime \prime \prime}$, and so on. In many instances the runner decays, and the young plant assumes an independent existence. Gardeners imitate this in the propagation of plants by the process of layering, which consists in bending a twig, fixing the central part of it into the ground, and, after the production of adventitious roots, cutting off its connection with the parent.

When the stem creeps along the surface of the ground, as in the Rhizome (fig. 107), or completely under ground, as in the Soboles

Fig. 223. Flagellum or Runner of the Strawberry. $a^{\prime}$, One axis which has produced a cluster of leaves, the upper, $r$, green, the lower, $f$, rudimentary. From the axil of one of the latter a second axis, $a^{\prime \prime}$, arises, bearing about the middle a rudimentary leaf, $f^{\prime}$, and a cluster of leaves, $r$, partly green and partly rudimentary, $f^{\prime \prime}$, at its extremity. From the axil of one of the leaves of this cluster a third axis, $a$, proceeds. 
or creeping stem (fig. 108), the terminal bud continues to elongate year after year, thus making additions to the axis in a horizontal manner. At the same time buds are annually produced on one side which send shoots upwards and roots downwards. Thus, in fig. 108 (soboles of a Rush), $r$ is the extremity of the axis or terminal bud, $f e$ the leaves in the form of scales, $p$ a the aerial shoots or branches, $t t$ being the level of the ground. Again, in fig. 107 (rhizome of Solomon's seal), $a$ is the terminal bud which has been formed subsequently to $b$, ' $b$ the bud which has sent up leaves, and which has decayed, $c c$ being the scars left by the similar buds of previous seasons.

Aerial and Subterranean Leaf-Buds. - According to the nature of the stems, leaf-buds are either aerial or subterranean; the former occurring in plants which have the stems above ground, the latter in those in which the stems are covered. In the case of Asparagus and other plants which have a perennial stem below ground, subterranean buds are annually produced, which appear above ground as shoots or branches covered with scales at first (fig. $129 \mathrm{l}$ ), and ultimately with true leaves. The young shoot is called a Turio (turio, a young branch). These branches are herbaceous and perish annually, while the true stem remains below ground ready to send up fresh shoots next season. In Bananas and Plantains, the apparent aerial stem is a shoot or leaf-bud sent up by an underground stem, and perishes after ripening fruit. In some plants several branches are sent up at once from the underground stem, in consequence of a rapid development of lateral as well as terminal buds ; and in such cases the lateral ones may be separated as distinct plants in the form of suckers (surculi). The potato is a thickened stem or branch capable of developing leaf-buds, which in their turn form aerial and subterranean branches, the former of which decay annually, while the latter remain as tubers to propagate the plant. Thus, in fig. $109, s s$ is the surface of the soil, $p a$ is the aerial portion of the potato covered with leaves, $t$ is the subterranean stem or tuber covered with small scales or projections, as represented at $T b$, from the axil of which leaf-buds are produced. This provision for a symmetrical development of axillary leaf-buds at once distinguishes the tuber of the potato from fleshy roots, like those of the Dahlia.

BuLB.-A good example of a subterranean bud occurs in the Bulb, as seen in the Hyacinth, Lily, and Onion. This is, a subterraneal leaf-bud covered with scales, arising from a shortened axis. From the centre of the bulb a shoot or herbaceous axis is produced which dies down. New bulbs, or cloves, as they are called, are produced in the axil of the scales arising from the subterranean axis. At the base of the scales there is a flattened disc, varying in thickness, which is formed by the base of the buds, and which has sometimes been called the stem. The parts of the bulb are seen in fig. 224, where $p$ marks the 
disc or round flat portion formed by the bases of the lateral buds from which the fasciculated roots, $r$, proceed, $e$ the scales or modified leaves, and $f$ the true leaves. In the vertical section (fig. 225), $b$ is the new bulb, formed like a bud in the axil of a scale. The new bulb sometimes remains attached to the parent bulb, and sends up an axis and leaves; at other times it is detached in the course of growth, and

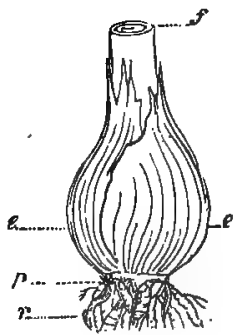

Fig. 224.

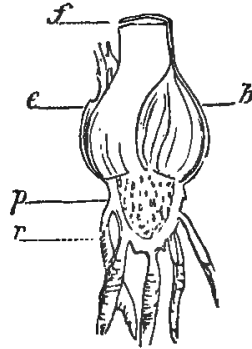

Fig. 225.

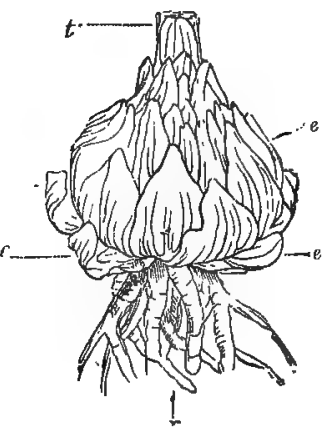

Fig. 226.

forms an independent plant. The new bulbs feed on the parent one, and ultimately cause its absorption. The scales are sometimes all fleshy, as in the scaly or nalced bulb of the white lily (fig. 226 e e e), or the outer ones are thin and membranous, overlapping the internal fleshy ones, and forming a tunicated bulb, as in the Onion, Squill, Tulip, and Leek (fig. 224).

The scales in bulbs vary in number. In Gagea there is only one scale; in the Tulip and Fritillaria imperialis they vary from 2 to 5 ; while in Lilies and Hyacinths there are a great number of scales. In the Tulip a bud is formed in the axil of an outer scale, and this gives rise to a new flowering axis, and a new bulb, at the side of which the former bulb is attached in a withered state. In some Liliaceous plants the bulbs continue for two or more years. The bulb may bear on the same axis growths belonging to two seasons; or it may bear numerous growths or shortened axes of several years. In the common hyacinth-there may be seen axes of four distinct generations on one bulb.

\section{The Corm (roguós, a stump) has already been noticed under}

Fig. 224. Tunicated bulb of Allium Porrum, or the Leek. $r$, Roots. $p$, A cireular dise, or shortened stem intervening between the roots and the bulbous swelling. $e e$, Scales or subterranean modified leaves. $f$, Upper leaves which become green. Fig. 225 Vertical section of the tunicated bulb of the Leek. The letters indicate the same parts as in the last figure. $b$, Bud situated in the axil of a scale, which, by its development, forms a new bulb. Fig. 226. Scaly or naked bulb of Lilium album. $r$, Roots. e e e, Scales or modifeced underground leaves. $t$, The flowering axis, cut. 
the head of subterranean stems (p. 48, fig. 110). It may be considered as a bulb in which the central portion or axis is much enlarged, while the scales are reduced to thin membranes. Some have called it a solid bulb. A Corm may be generally distinguished from a Bulb by a transverse section of the latter presenting a series of circles, equal in number to the fleshy scales arranged around its central axis. It is seen in the Colchicum, Crocus, and Gladiolus. It produces either terminal buds, as in Gladiolus and Crocus, in which several annual additions to the corm remain attached together, and the newly produced corms come gradually nearer and nearer to the surface of the soil ; or lateral buds, as in Colchicum, represented at fig. 110, where $r$ indicates the roots, $f$ the leaf, $\alpha^{\prime}$ the stem or axis of the preceding year withered, $a^{\prime \prime}$ the secondary axis, or the stem developed during the year, and taking the place of the old one, and which, in its turn, will give origin to a new axis, $a^{\prime \prime \prime}$, on the opposite side, according to the law of alternation. The new axes or corms being thus produced alternately at either side, there is very little change in the actual position of the plant from year to year. Bulbs and corms contain a store of starch and of other substances, for the nourishment of the young plants.

Anomalies and Transformations of LEaf-BUds.-Leaf-buds

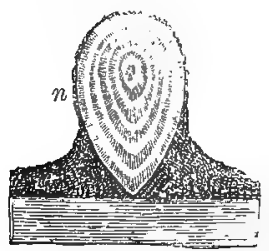

Fig. 227. arise from the medullary system of the plant, and in some instances they are found among the cellular tissue, without being in the axil of leaves. In this case they are extra-axillary, and have been called adventitious or abnormal. Such buds are produced after the stem and leaves have been formed, and in particular circumstances they are developed like normal buds. What have been called embryo-buds are woody nodules seen in the bark of the Beech, Elm, and other trees. They are looked upon as partially developed abnormal buds, in which the woody matter is pressed upon by the surrounding tissue, and thus acquires a very hard and firm texture. When a section is made, they present woody circles arranged around a central pith, and traversed by medullary rays (fig. 227). The nodules sometimes form knots on the surface of the stem, at other times they appear as large excrescences, and in some cases twigs and leaves are produced by them. Some consider embryo-buds as formed by layers of woody matter, which originate in the sap conveyed downward by the bark and cambium cells, and are deposited round a nucleus or central mass.

Fig. 227. Vertical section of a nodule, $n$, or embryo-bud embedded in the bark of the Cedar. It forms a projection on the surface. The woody layers form zones round a kind of pith. 
Leaf-buds sometimes become extra-axillary (fig. 228 b), in consequence of the non-appearance or abortion of one or more leaves; or on account of the adhesion of the young branch to the parent stem. In place of one leaf-bud, there are occasionally several accessory ones produced in the axil, giving origin to numerous branches (fig. 229 b).

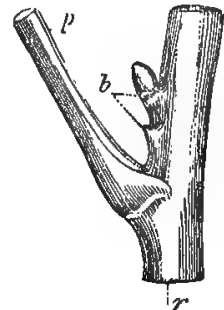

Fig. 228.

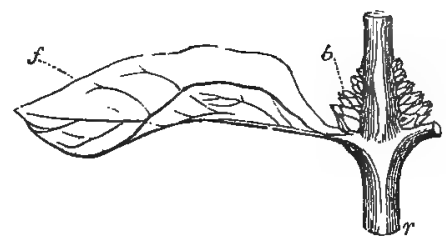

Fig. 229.

Such an occurrence is traced to the presence of latent or adventitious buds. Fig. 228 represents a branch, $r$, of walnut, $p$ the cut petiole, and $b$ two buds, of which the upper is most developed; while fig. 229 exhibits a branch of Lonicera tartarica, with numerous buds, $b$, in the axil of the leaves, the lowest of which are most advanced. By the union of several such leaf-buds, branches are produced, having a thickened or flattened appearance, as is seen in the Fir, Ash, and other trees. These fasciated (fascia, a band) branches, in some cases, however, are owing to the abnormal development of a single bud.

In the axil of the leaves of Lilium bulbiferum, Dentaria bulbifera, and some other plants, small conical or rounded bodies are produced, called bulbils or bulblets (fig. $230 \quad b \quad b \quad b$ ). They resemble bulbs in their aspect, and consist of a small number of thickened scales enclosing a growing point. These scales are frequently united closely together, so as to form a solid mass. Bulbils are therefore transformed leaf-buds, which are easily detached, and are capable of producing young plants when placed in

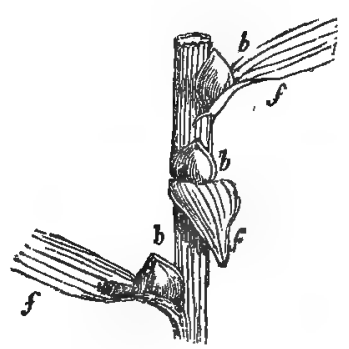

Fig. 230. favourable circumstances.

Occasionally leaf-buds are produced naturally on the edges of

Fig. 228. Portion of a branch, $r$, of the walnut, bearing the petiole, $p$, of a leaf which has been cut. In the axil of the leaf, several buds, $b$, are produced, the highest of which are most developed. Fig. 229. Portion of a branch, $r$, of Lonicera tartarica, bearing two opposite leaves, one of which has been cut, the other, $f$, being preserved. In the axil of the leaves clusters of buds, $b$, are seen, the lowest of which are most developed. Fig. 230. Portion of the stem of Lilium bulbiferum, with three alternate leaves, $f f f$, and three bulbils or bulblets, $b b b$, in their axils. 
leaves, as in Bryophyllum calycinum and Malaxis paludosa (fig. 231), and on the surface of leaves, as in Ornithogalum thyrsoideum (fig. 232). These are capable of forming independent plants. Similar buds are also made to appear on the leaves of Gesnera, Gloxinia, and Achimenes, by wounding various parts of them, and placing them in moist soil; this is the method often pursued by gardeners in their propagation. The Ipecacuan plant has been propagated by means of leaves inserted

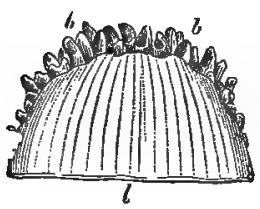

- Fig. 231.

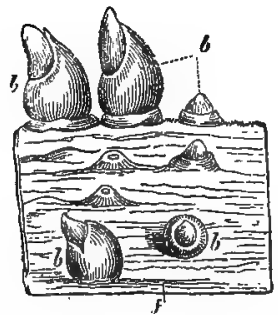

Fig. 232,

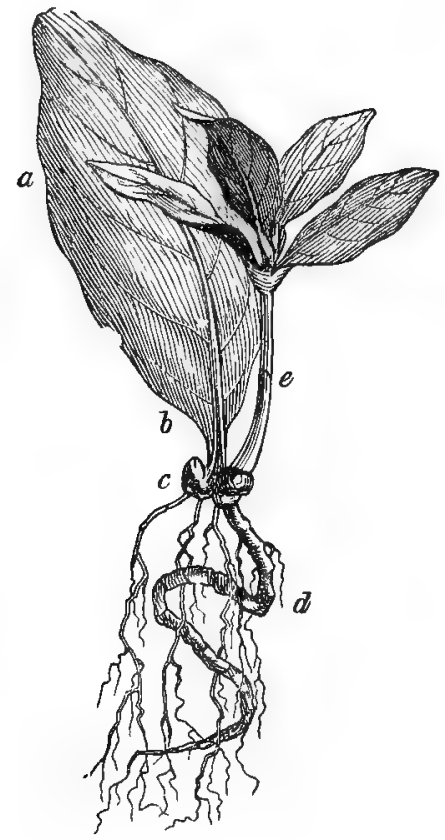

Fig. 233.

in the soil. In this case the lower end of the leaf becomes thickened like a corm, and from it roots are produced, and ultimately a bud and young plant, as shown in fig. 233. The cellular tissue near the surface of plants seems therefore to have the power of developing abnormal leaf-

Fig. 231. Extremity of a leaf, $l$, of Malaxis paludosa, the margin of which is covered with adventitious buds, $b \bar{b}$; thus becoming proliferous.

Fig. 232. Portion of the blade of a leaf, $f$, of Ornithogalum thyrsoideum, on the surface of which are developed adventitious or abnormal buds, $b b b b$, some of which are large. Fig. 233 . Ipecacuan leaf, with petiole, annulated root, and young plant. a, Lamina or blade of leaf. $b$, Petiole or leaf-stock. $c$, Swelling at the end of the petiole after being placed in the soil, $d$, Root proceeding from the swelling, showing an annulated form. e, Young plant arising from the swelling of the petiole. 
buds in certain circumstances. Even roots, when long exposed to the air, may thus assume the functions of stems. Leaves bearing buds on their margin are called proliferous (proles, offspring, and fero, I bear).

Spines or Thorns. Branches are sometimes arrested in their development, and, in place of forming leaves, become transformed into spines and tendrils. Spines or thorns are undeveloped branches, ending in more or less pointed extremities, as in the Hawthorn. Plants which have spines in a wild state, as the Apple and Pear, often lose them when cultivated, in consequence of their being changed into branches; in some cases, as in Prunus spinosa, or the Sloe (fig. 234), a branch bears leaves

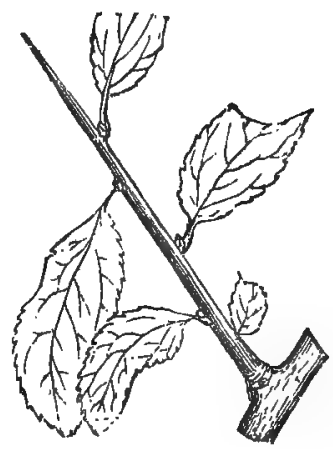

Fig. 234.

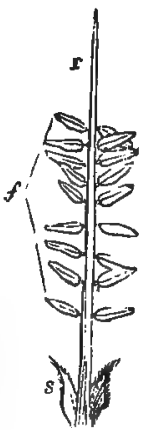

Fig. 235. at its lower portions, and terminates in a spine. Leaves them-

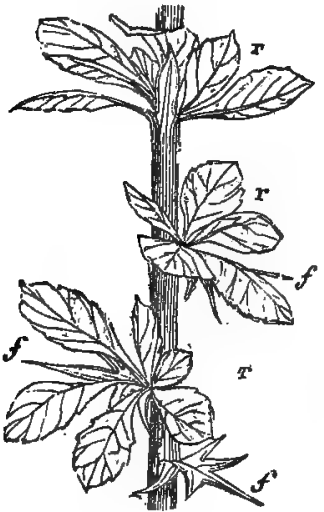

Fig. 236.

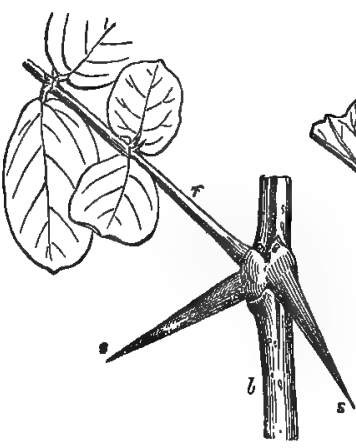

Fig. 237 .

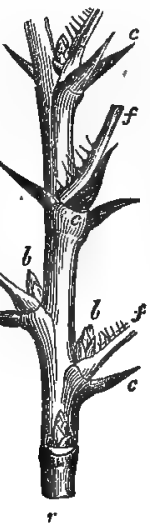

Fig. 238.

Fig. 234. Branch of Prunus spinosa, or Sloe, with alternate leaves, and ending in a spine or thorn. Fig. 235. Pinnate leaf of Astragalus massiliensis, the midrib of which, $r$, ends in a spine. $s$, Petiolary stipules. $f$, Nine pairs of leaflets. Fig. 236. Branch of Berberis valgaris, or Barberry, the leaves of which, $f f f$, are transformed into branching spines. In the axil of each, a cluster, $r r r$, of regularly formed leaves is developed. Fig. 237. Base of the pinnate leaf of Robinia pseudacacia, the stipules of which, $s s$, are converted into spines or thorns. $b$, Branch. r, Petiole. Fig. 238. Branch of Ribes Uva-crispa, in which the pulvinus or swelling, c c c, at the base of each of the leaves, $f f f$, is changed into a spine, which is either sinple, or double, or triple. $b b$, Leaf-buds arising from the axil of the leaves. 
selves often become spiny by the hardening of their midrib or primary veins, and the diminution or absence of parenchyma, as in Astragalus massiliensis (fig. $235 r$ ), where the midrib becomes spiny after the fall of some of the leaflets ; in the Holly, where all the veins are so ; and in the Barberry (fig. 236), where some of the leaves, $f f f$, are produced in the form of spiny branches, with scarcely any parenchyma. In place of producing a lamina or blade at its extremity, the petiole sometimes terminates in a spine. Stipules are occasionally transformed into spines, as in Robinia pseudacacia (fig. $237 \mathrm{~s} s$ ), and such is also the case with the swelling or pulvinus at the base of the leaf, as in Ribes Uva-crispa (fig. 238 c c c c). Branches are sometimes arrested in their progress at an early stage of their development, and do not appear beyond the surface of the stem ; at other times, after having grown to a considerable size, they undergo decay. In both instances the lower part of the branch becomes embedded and hardened among the woody layers of the stem, and forms a knot.

TENDRILs.-A leaf-bud is sometimes developed as a slender spiral or twisted branch, called a tendril or cirrus (cirrus, a curl). Tendrils have their homologues in various organs, such as stems, branches, leaves,

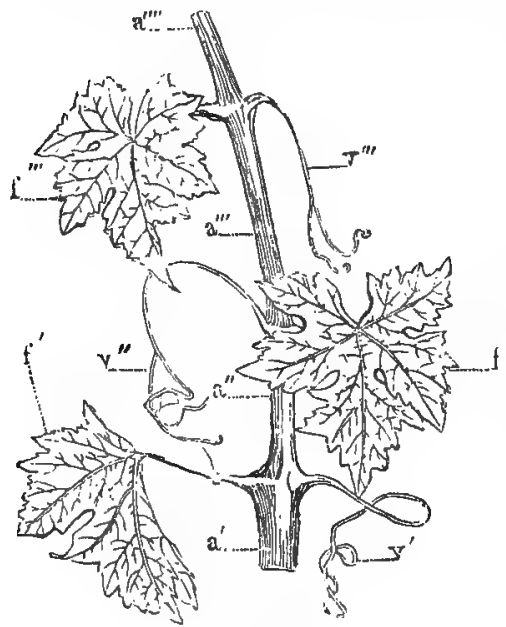

Fig. 239. stipules, buds, midribs, parts of the flower, etc. When tendrils occupy the place of leaves, and appear as a continuation of the leaf-stalk, they are called petiolary, as in Lathyrus Aphaca, in which the stipules perform the function of true leaves. In Flagellaria indica, Gloriosa superba, Anthericum cirrhatum, and Albuca cirrhata, the midrib of the leaf ends in a tendril ; and in Vetches, the terminal leaflet, and some of the lateral ones at the extremity of their pinnate leaves, are changed, so as to form a branching tendril. In the Passion-flower the lateral buds are thus altered,

Fig. 239. Portion of a branch of the Vine (Vitis vinifera). $a^{\prime}$, First axis, terminated by a tendril or cirrus, $v^{\prime}$, which assumes a lateral position, and bears a leaf, $f^{\prime}$. From the axil of this leaf a second axis, $a^{\prime \prime}$, comes off, which seems to be a continuation of the first, and is terminated also by a tendril, $v^{\prime \prime}$, bearing a leaf, $f^{\prime \prime}$. From the axil of this second leaf a third axis, $a^{\prime \prime \prime}$, arises, terminated by a tendril, $v^{\prime \prime \prime}$, and bearing a leaf, $f^{\prime \prime \prime}$, from the axil of which a fourth axis, $a^{\prime \prime \prime \prime}$, arises. 
with the view of enabling the plant to climb. In the Vine the tendrils are looked upon as the terminations of separate axes, or as transformed terminal buds, and are sometimes called sarmenta. In the Vine there are no young buds seen in the angle between the stem and leaves, nor between the stem and tendrils; and the latter are not axillary. Fig. 239 represents the branch of a Vine, in which $a^{\prime}$ is the primary or first formed axis, ending in $v^{\prime}$, a tendril or altered terminal bud, and having a leaf, $f^{\prime}$, on one side. Between this leaf and the tendril, which represents the axis, a leaf-bud was formed at an early date, producing the secondary axis, or branch, $a^{\prime \prime}$, ending in a tendril, $v^{\prime \prime}$, with a lateral leaf, $f^{\prime \prime}$, from which a tertiary axis or branch, $a^{\prime \prime \prime}$, was developed, ending in a tendril $v^{\prime \prime \prime}$, and so on. The tendrils of Ampelopsis Veitchii are terminated by discs which secrete a sticky matter, by means of which they adhere to walls, etc. The tendrils, like those of the Vine, are modifications of the axis.

Tendrils twist in a spiral manner, and enable the plants to rise into the air by twining round other plants. The direction of the spiral frequently differs from that of the climbing stem which produces the tendril. In the Vine, the lower part of the stem is strong, and needs no additional support; the tendrils therefore occur only in the upper part, where the branches are soft, and require aid to enable them to support the clusters of fruit. In the vanille plant (Vanilla aromatica) the tendrils are produced opposite the leaves, until the plant gains the top of the trees by which it is supported; the upper tendrils being then developed as leaves. The midrib is sometimes prolonged in a cup-like or funnel-shaped form; this is occasionally seen in the common cabbage, and seems to depend on the vascular bundles of the midrib spreading out at their extremity in a radiating manner, and becoming covered with parenchyma in such a way as to form a hollow cavity in the centre.

\section{Special Functions of Leaves.}

Leaves expose the fluids of plants to the influence of air and light. The fluids so exposed are elaborated, and thus fitted for the formation of the various vegetable tissues and secretions. For the proper performance of this function the structure of the leaves and their arrangement on the stem and branches, renders them well adapted. A plant, if constantly stripped of its leaves, is destroyed, from non-development of tissue and absence of secretions. On this principle, weeds, with creeping stems and vigorous roots, which are with difficulty eradicated, may be killed. The elaboration of fluids in the leaves necessarily implies interchange of their constituents with those of the surrounding atmosphere ; hence two processes are inevitable-a passing inwards into the leaf of the atmospheric elements 
by a process of absorption, and an outward current of the components of the plant-juices by a process of exhalation. In the cells of the leaves changes take place under the agency of light, by which oxygen is given off and carbon fixed. These will be considered under the head of vegetable respiration. The absorption of carbonic acid and of fluids is carried on by the leaves, chiefly through their stomata, and most rapidly by the under surface of ordinary leaves in which the cuticle is thinnest, the cellular tissue least condensed, and stomata most abundant; the upper surface of the leaf, which usually presents a polished and dense epidermis, with few stomata, taking little part in such a process. Hoffman has ascertained that leaves absorb fluids in large quantities; that during a fall of rain the vegetable fluids undergo from such a cause a process of dilution, leading to an immediate and more rapid descent of sap, which under such circumstances is capable of general diffusion throughout the several vegetable tissues. Some physiologists have expressed doubts as to absorption being carried on by the leaves in ordinary circumstances. Leaves also absorb gaseous matters. Saussure states that oxygen is absorbed by the leaves during night, the quantity varying according to the nature of the plant. . Boussingault found that the leaves of the Vine absorbed carbonic acid from the air. Other experiments prove that ammonia and nitrogen are similarly acted on.

Leaves also give off gases and liquids by a process of exhalation or transpiration. A moderate amount of carbonic acid is exhaled during darkness, and a large quantity of liquid is given off by transpiration. The number and size of the stomata regulate the transpiration of fluids, and it is modified by the nature of the epidermis. The absorbing power of leaves depending on similar causes, is capable of being increased by any process which removes either natural or imposed obstructions to the free action of their surface. It is thus that rain, while supplying the material for absorption, at the same time renders the leaf more capable of such action. In plants with a thick and hard epidermal covering, exhalation is less vigorous than in those where it is thin and soft. Some succulent plants of warm climates have a very thick covering. The peculiar character of the phyllodia of Australian plants is probably connected with the dry nature of the climate. The process of transpiration is more under the influence of light than of heat. It assists the process of endosmose, by rendering the fluid in the cells thicker, and thus promotes the circulation of sap.

The quantity of fluid exhaled varies in amount in different plants. A Sunflower three feet high gave off twenty ounces of watery fluid daily. Hales found that a Cabbage, with a surface of 2736 square inches, transpired on an average nineteen ounces per day; a Vine, of 1820 square inches, from five to six ounces. Deheran found that 
large leaves of Colza evolved in an hour from one to two per cent of their weight of water. Experiments have shown that the mean amount of water contained in the leaves of the Cherry' Laurel is 63.4 per cent, and of this only about 6 per cent could be easily removed by sulphuric acid or chloride of calcium. In the sun leaves transpire most in a saturated atmosphere. In the shade transpiration ceases when the atmosphere is loaded with watery vapour. Experiments on exhalation may be made by taking a fresh leaf with a long petiole, putting it through a hole in a card which it exactly fits, and applying the card firmly and closely to a glass tumbler, about two-thirds full of water, so that the petiole is inserted into the water, then inverting an empty tumbler over the leaf, and exposing the whole to the sun, the fluid exhaled will be seen on the inside of the upper tumbler. The experiment may be varied by putting the apparatus in darkness, when little or no exhalation takes place, or in diffuse daylight, when it is less than in the sun's rays. This process of exhalation imparts moisture to the atmosphere, and hence the difference between the air of a wooded country and that of a country deprived of forests. The cells in the lower side of a leaf where stomata exist are chiefly concerned in the aeration of the sap, whilst other assimilative processes go on in the upper cells.

Leaves, after performing their functions for a certain time, wither and die. In doing so, they frequently change colour, and hence arise the beautiful and varied tints of the autumnal foliage. This change of colour is chiefly occasioned by the diminished circulation in the leaves, and the higher degree of oxidation to which their chlorophyll has been submitted. Leaves which are articulated with the stem, as in the Walnut and Horse-chestnut, fall and leave a scar, while those which are continuous with it remain attached for some time after they have lost their vitality, as in the Beech. Most of the trees of this country have deciduous leaves, their duration not extending over more than a few months; while in trees of warm climates, the leaves often remain for two or more years. In tropical countries, however, many trees lose their leaves in the dry season. This is seen in the forests of Brazil, called Catingas. The period of defoliation varies in different countries according to the nature of their climate. Trees which are called evergreen, as Pines and Evergreen-oak, are always deprived of a certain number of leaves at intervals, sufficient being left, however, to preserve their green lappearance. Various causes have been assigned for the fall of the leaf. In cold climates, the deficiency of light and heat in winter causes a cessation in the functions of the cells of the leaf; its fluids disappear by evaporation; its cells and vessels become contracted and diminished in their calibre; various inorganic matters accumulate in the texture; the whole leaf becomes dry; its parts lose their adherence; a process of disjunction 
takes place by a folding inwards of the tissue at the point where the leaf joins the stem or branch, and this gradually extends; complete separation then takes place, and the leaf either falls by its own weight or is detached by the wind. In warm climates the dry season gives rise to similar phenomena.

\section{Section II.-General View of the Functions of the NUtRItive Organs.}

Is order that plants may be nourished, food is required. This food, in a crude state, enters the roots by a process of absorption or imbibition; it is then transmitted from one part of the plant to another, by means of the circulation or progressive movement of the sap; it reaches the leaves, and is there submitted to the action of light and air, which constitutes the function of respiration; and thus the fluids are finally fitted for the process of assimilation, and form various vegetable products and secretions.

\section{1.-Food of Plants and Sources whence they derive their Nourishment. Chemical Composition of Plants.}

The nutriment of plants can' only be ascertained when their chemical composition has been determined. The physiologist and chemist must unite in this inquiry, in order to arrive at satisfactory conclusions. Much has been done by chemists to aid the botanist in his investigations, and to place physiological science on a sound and firm basis. It is true that many processes take place in plants which cannot as yet be explained by the chemist, and to these the name of vital has been applied. This term, however, must be considered as implying nothing more than that the function so called occurs in living bodies, and in the present state of our knowledge cannot be fully explained by chemical or physical laws. A greater advance in science may clear up many difficulties in regard to some of the vital functions, while others may ever remain obscure.

Plants are composed of certain clemical elements, which are combined in various ways, to form organic and inorganic compounds. The former are composed of carbon, oxygen, hydrogen, and nitrogen or azote, with a certain proportion of sulphur and phosphorus; while the latter consist of various metals, combined with oxygen, other metalloids, and acids. In all plants there is a greater or less proportion of water, the quantity of which is ascertained by drying at a temperature a little above that of boiling water. By burning the dried plant the organic constituents disappear, and the inorganic part is left in 
the form of ash. The relative proportion of these constituents varies in different species, as seen in the following table by Solly, in which the proportions are given in 10,000 parts of the fresh plants :-

\begin{tabular}{|c|c|c|c|c|c|c|c|c|}
\hline \multirow{2}{*}{ Potato } & \multirow[b]{2}{*}{. } & \multirow[b]{2}{*}{. } & \multirow[b]{2}{*}{. } & \multirow{2}{*}{$\begin{array}{c}\text { Water. } \\
7713\end{array}$} & \multicolumn{3}{|c|}{ Organic Matter. } & \multirow{2}{*}{$\begin{array}{c}\text { Inorganic. } \\
114\end{array}$} \\
\hline & & & & & $\cdots$ & 2173 & & \\
\hline Turnip & . & 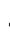 & & 9308 & $\ldots$ & 588 & $\ldots$ & 104 \\
\hline Sea Kal & . & . & & 9238 & ... & 705 & .. & 57 \\
\hline French & Beans & . & . & . 9317 & $\ldots$ & 619 & $\ldots$ & 64 \\
\hline Red Bee & & . & & . 8501 & ... & 1390 & $\ldots$ & 109 \\
\hline Asparag & & 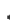 & & . 9210 & $\ldots$ & 735 & $\ldots$ & 55 \\
\hline Water C & ress & . & 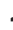 & 9260 & $\ldots$ & 633 & $\ldots$ & 107 \\
\hline Sorrel & . & 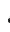 & 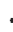 & 9207 & $\ldots$ & 702 & ... & 91 \\
\hline Parsley & . & . & 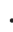 & 8430 & $\ldots$ & 1299 & $\cdots$ & 271 \\
\hline Fennel & - & P & . & 8761 & $\ldots$ & 1048 & ... & 191 \\
\hline Salsafy & - & & . & . 7951 & $\ldots$ & 1929 & $\ldots$ & 120 \\
\hline Mustard & & & 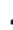 & . 9462 & $\ldots$ & 436 & $\ldots$ & 102 \\
\hline
\end{tabular}

An analysis of 100 parts of Fruits gives the following results :-

\begin{tabular}{|c|c|c|c|c|c|c|}
\hline & & Water. & & Organic. & & norgan \\
\hline Strawberry & & $90 \cdot 22$ & $\cdots$ & $9 \cdot 37$ & . & 0.41 \\
\hline Hage, & whole fruit & $83 \cdot 77$ & .. & 15 & & 0.40 \\
\hline Cherry, & do. & - 82 & $\ldots$ & 17 & $\ldots$ & 0.43 \\
\hline Pear, & do. & - 83 & $\ldots$ & $1.6 \cdot 04$ & $\ldots$ & 0.41 \\
\hline Apple, & do. & - 84 & $\ldots$ & $15 \cdot 72$ & $\cdots$ & 0.27 \\
\hline Gooseberry & • & . $\quad 90.26$ & $\ldots$ & $9 \cdot 35$ & $\ldots$ & $0 \cdot 39$ \\
\hline
\end{tabular}

The following table, by Johnston, represents the constituents in 1000 parts of plants and seeds, dried at $230^{\circ}$ Fahrenheit, and in the state in which they are given to cattle; the organic matter being indicated by the carbon, oxygen, hydrogen, and nitrogen; the inorganic by the ash :-

\begin{tabular}{|c|c|c|c|c|c|c|c|c|c|c|}
\hline & Wheat. & & Oats. & & Peas. & & Hay. & & Turnips. & Potatoes. \\
\hline $\operatorname{Var}$ & 455 & & 50 & $\ldots$ & 465 & & 458 & & 429 & 441 \\
\hline $\mathrm{Hy}$ & 57 & $\ldots$ & 6 & $\ldots$ & 6 & $\ldots$ & 50 & $\ldots$ & 56 & 0 \\
\hline 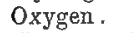 & 430 & $\ldots$ & 367 & $\ldots$ & 401 & $\ldots$ & 387 & $\ldots$ & 422 & 439 \\
\hline trogen & 35 & .. & 22 & $\ldots$ & 42 & $\ldots$ & 15 & $\ldots$ & 17 & 12 \\
\hline & 23 & $\ldots$ & 40 & $\ldots$ & 31 & $\ldots$ & 90 & . & 76 & 50 \\
\hline
\end{tabular}

By the process of drying, the 1000 parts of these substances lost water in the following proportions :-

$\begin{array}{lllll}\text { Wheat } 166 & \ldots & \text { Peas } 86 & \ldots & \text { Turnips } 925 \\ \text { Oats } 151 & \ldots & \text { Hay } 158 & \ldots & \text { Potatoes } 722\end{array}$

As plants have no power of locomotion, it follows that their food must be universally distributed. The atmosphere and the soil accordingly contain all the materials requisite for their nutrition. These materials must be supplied either in a gaseous or a liquid form, and hence the necessity for the various changes which are constantly going on in the soil, and which are aided by the efforts of man. Plants are capable of deriving all their nourishment from the mineral kingdom. 
The first created plants in all probability did so, but in the present day the decaying remains of other plants and of animals are also concerned in the support of vegetation.

\section{Organic Constituents and their Sources.}

Carbon (C) is the most abundant element in plants. It forms from 40 to 50 per cent of all the plants usually cultivated for food. When plants are charred the carbon is left, and as it enters into all the tissues, although the weight of the plants is diminished by the process, their form still remains. When converted into coal (a form of carbon), plants are frequently so much altered by pressure as to lose their structure, but occasionally it can be detected under the microscope. Carbon is insoluble, and therefore cannot be absorbed in its uncombined state. When united with oxygen, however, in the form of carbonic acid, it is readily taken up either in its gaseous state by the leaves, or in combination with water by the roots. The humus or vegetable mould in the soil contains carbon, and in soils of a peaty nature it exists in very large quantity. The carbon in the soil is converted into carbonic acid in order to be made available for the purpose of plant-growth. Carbon has the power of absorbing gases, and in this way, by enabling certain combinations to go on, it assists in the nourishment of plants. In the atmosphere, carbonic acid is always present, averaging about $\frac{1}{260}$ part, arising from the respiration of man and animals, combustion, and other processes. A certain atmospheric equilibrium is thus maintained, consequent on the difference between vegetable and animal respiration, the latter giving out carbonic acid, which the former consumes.

OXYGEN ( 0 ) enters into the composition of all plants, but never in quantity sufficient to convert all the hydrogen and carbon present in the plant into water and carbonic acid. In the ash of plants, oxygen, next to carbon, is the most abundant constituent. Oxygen in the air amounts to about 20.9 per cent, and it forms $\frac{8}{8}$ by weight of water. Combined with various elements it forms a great part of the soil and solid crust of the earth. It is chiefly in its state of combination with hydrogen to form water $\left(\mathrm{H}_{2} \mathrm{O}\right)$ that oxygen is taken up by plants, but also as carbonic acid $\left(\mathrm{CO}_{2}\right)$ and oxysalts.

HyDrogen $(\mathrm{H})$ is not found in a free state in nature, and with the exception of coal, it does not enter into the composition of the mineral masses of the globe. It forms $\frac{1}{3}$ by weight of water, and it is present in the atmosphere in combination with nitrogen. It is also found in the air united with sulphur (S) and carbon, as a product of vegetable decay. It is mostly from the decomposition of water by the combined action of chlorophyll and sunlight that plants obtain their supply of hydrogen. 
NitrogeN (N) is another element found in plants. It forms $79 \cdot 1$ per cent of the atmosphere, and abounds in animal tissues. It is therefore requisite for the purposes of animal life that nitrogen be furnished in food. Those vegetables containing the greatest quantity of nitrogenous matter are the most nutritive. Animal matters, during their decay, give off nitrogen, combined with hydrogen, in the form of ammonia $\left(\mathrm{NH}_{3}\right)$, which is absorbed in large quantities by carbon, is very soluble in water, and seems to be the chief source whence plants derive nitrogen. In tropical countries where thunderstorms are frequent, the nitrogen and oxygen of the air are sometimes made to combine, so as to produce nitric acid $\left(\mathrm{N}_{2} \mathrm{O}_{5}\right)$, which, either in this state, or in combination with alkaline matters, furnishes a supply of nitrogen. Daubeny thinks that the ammonia and carbonic acid in the atmosphere are derived in part from volcanic actions going on in the interior of the globe. The continued fertility of the Terra del Lavoro, and other parts of Italy, is attributed by him to the disengagement of ammoniacal salts and carbonic acid by volcanic processes going on underneath; and to the same source he traces the abundance of glutin in the crops, as evidenced by the excellence of Italian macaroni.

Muilder maintains that the ammonia is not carried down from the atmosphere, but is produced in the soil by the combination between the nitrogen of the air and the hydrogen of decomposing matters. The same thing takes place, as in the natural saltpetre caverns of Ceylon, with this exception, that, by the subsequent action of oxygen, ulmic, humic, geic, apocrenic, and crenic acids, are formed, in place of nitric acid. These acids consist of carbon, oxygen, and hydrogen, in different proportions, and they form soluble salts with ammonia. By all porous substances, like the soil, ammonia is produced, provided they are moist, and filled with atmospheric air, and are exposed to a certain temperature. It is thus, he states, that moist charcoal and humus become impregnated with ammonia.

These four elementary bodies then are supplied to plants, chiefly in the form of carbonic acid $\left(\mathrm{CO}_{2}\right)$, water $\left(\mathrm{H}_{2} \mathrm{O}\right)$, and ammonia $\left(\mathrm{NH}_{8}\right)$. In these states of combination they exist in the atmosphere, and hence some plants can live suspended in the air without any attachment to the soil. When a volcano or a coral island appears above the waters of the ocean, the lichens which are developed on it are nourished in a great measure by the atmosphere, although they subsequently derive inorganic matter from the rocks, to which they are attached. Air plants, as Bromelias, Tillandsias, some Orchidaceæ, and many species of Ficus, can grow for a long time in the air. In the Botanic Garden of Edinburgh a specimen of Ficus australis lived in this condition for upwards of twenty years, receiving no supply of nourishment except that afforded by the atmosphere and 
common rain water, containing, of course, a certain quantity of inorganic matter.

The elementary bodies already mentioned, in various states of combination, constitute the great bulk of plants. They occur in the form of binary compounds, as water and oily matters ; ternary, as starch, gum, sugar, and cellulose; quaternary, as glutin, albumin, casein, and fibrin. The latter compounds seem to require for their composition not merely the elements already noticed, in the form of a basis, called Protein, but certain proportions of sulphur and phosphorus in addition; thus, albumin $=10 \mathrm{Pr}$. $+1 \mathrm{P}+2 \mathrm{~S}$; fibrin $=10 \mathrm{Pr}$. $+1 \mathrm{P}+1 \mathrm{~S}$; casein $=10 \mathrm{Pr}$. $+1 \mathrm{~S}$. The tissues, into the composition of which these protein compounds enter, are tinged of a deep orange-yellow by strong nitric acid. These compounds are highly important in an agricultural point of view, and the consideration of them will be resumed when treating of the application of manures.

\section{Inorganic Constituents and their Sources.}

The consideration of the inorganic constituents of plants is no less important than the study of their organic elements. The organic substances formed by plants are decomposed by a moderately high temperature; they easily undergo putrefaction, especially. when exposed to a moist and warm atmosphere, and few of them have been formed by human art. Their inorganic constituents, on the other hand, are not so easily decomposed; they do not undergo putrefaction, and they have been formed artificially by the chemist.

The organic part of plants, even in a dried state, forms from 88 to 99 per cent of their whole weight. Consequently, the ash or inorganic matter constitutes a very small proportion of the vegetable tissue. It is not, however, on this account to be neglected, for it is found to be of great importance in the economy of vegetation, not merely on account of its entering directly into the constitution of various organs, but also from assisting in the production of certain organic compounds. Some of the lower tribes of cellular plants can exist apparently without any inorganic matter. Thus Mülder could not detect a particle of ash in Mycoderma vini, nor in moulds produced in large quantity by milk sugar. Deficiency of inorganic matter, however, in general injures the vigour of plants, and it will be found that, in an agricultural point of view, this requires particular attention-a distinct relation subsisting between the kind and quality of the crop, and the nature and chemical composition of the soil in which it grows. It has been shown, by careful and repeated experiments, that when a plant is healthy and fairly ripens its seeds, the quantity and quality of the ash is nearly the same in whatever soil it is grown; and that, when two different species are grown in 
the same soil, the quantity and quality of the ash varies-the difference being greater the more remote the natural affinities of the plants are.

The following are the inorganic elements of plants and their combinations :-

\begin{tabular}{|c|c|c|c|c|c|}
\hline Chlorine (Cl.) & combine & with & metals for & ming & chlorides. \\
\hline Iodine $\left(\mathrm{C}_{.}\right)$ & ... & $\ldots$ & metals & $\ldots$ & iodides. \\
\hline Bromine (Br.) & & $\cdots$ & metals & $\ldots$ & bromides. \\
\hline & & $\cdots$ & metals & $\cdots$ & des. \\
\hline Sulphur (S.) & & ... & hydrogen & $\ldots$ & $\begin{array}{l}\text { sulphuretted hydrogen, } \\
\text { hydro-sulphuric acid. }\end{array}$ \\
\hline Phosphorus (P.) & & $\begin{array}{l}\cdots \\
\cdots\end{array}$ & $\begin{array}{l}\text { oxygen } \\
\text { oxygen }\end{array}$ & $\begin{array}{l}\cdots \\
\cdots\end{array}$ & $\begin{array}{l}\text { sulphuric acid. } \\
\text { phosphoric acid, }\end{array}$ \\
\hline Potassium (K.) & & $\begin{array}{l}\ldots \\
\ldots\end{array}$ & $\begin{array}{l}\text { oxygen } \\
\text { chlorine }\end{array}$ & $\begin{array}{l}\cdots \\
\ldots\end{array}$ & $\begin{array}{l}\text { potash. } \\
\text { chloride of potassium. }\end{array}$ \\
\hline Sodium (Na.) & & $\begin{array}{l}\cdots \\
\cdots\end{array}$ & $\begin{array}{l}\text { oxygen } \\
\text { chlorine }\end{array}$ & $\begin{array}{l}\cdots \\
\ldots\end{array}$ & $\left\{\begin{array}{l}\text { chloride of sodium. } \\
\text { (common salt.) }\end{array}\right.$ \\
\hline Calcium (Ca.) & & $\cdots$ & $\begin{array}{l}\text { oxygen } \\
\text { chlorine }\end{array}$ & $\begin{array}{l}\cdots \\
\cdots\end{array}$ & $\begin{array}{l}\text { lime. } \\
\text { chloride of calcium. }\end{array}$ \\
\hline Magnesium (Mg.) & $\cdots$ & ... & oxygen & $\ldots$ & - magnesia. \\
\hline Aluminum (Al.) & .* & $\ldots$ & oxygen & $\ldots$ & alumina. \\
\hline $\begin{array}{l}\text { Silica (Si.) } \\
\text { Iron (Fe.) }\end{array}$ & $\ldots$ & $\ldots$ & oxygen & $\cdots$ & $\begin{array}{l}\text { silica. } \\
\text { oxides }\end{array}$ \\
\hline Manganese (Mn.) & " & $\cdots$ & oxygen & $\cdots$ & and \\
\hline Copper (Cu.) & & $\cdots$ & & $\cdots$ & sulphides. \\
\hline
\end{tabular}

To these we may add Fluorine (F), the presence of which in plants has been recently noticed. The extraordinary attraction of this element for Silica renders it a matter of impossibility to procure it in a separate state for examination. It is found in those vegetable structures in which Silica abounds, as in the stems of the Graminer and Equisetaceæ.

The quantity of inorganic matter or ash left by plants varies in different species, and in different parts of the same plant. The dried leaves usually contain a large quantity. Saussure found that-

\begin{tabular}{|c|c|c|c|c|c|c|}
\hline ed bar & & - & & \multicolumn{3}{|c|}{60 parts of ash in 1000} \\
\hline Dried 1 & & . & . & 53 & $\ldots$ & $\ldots$ \\
\hline Dried alburnum & & & ${ }^{*}$ & 4 & $\ldots$ & $\ldots$ \\
\hline Dried duramen & 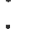 & . & . & 2 & $\ldots$ & $\ldots$ \\
\hline
\end{tabular}

The dried leaves of Elm contain more than 11 per cent of inorganic matter, while the wood contains less than 2 per cent; the leaves of the Willow, 8 per cent, wood, 0.45 ; leaves of Beech, 6.69 , wood, 0.36 ; leaves of Pitch-pine, 3.5 , wood 0.25 . Thus, the decaying leaves of trees restore a large quantity of inorganic matter to the soil.

The following tables show the relative proportion of inorganic compounds present in the ash of plants :- 
According to Sprengel, 1000 lbs. of wheat leave 11.77 lbs., and of wheat straw $35 \cdot 18$ lbs. of ash, consisting of-

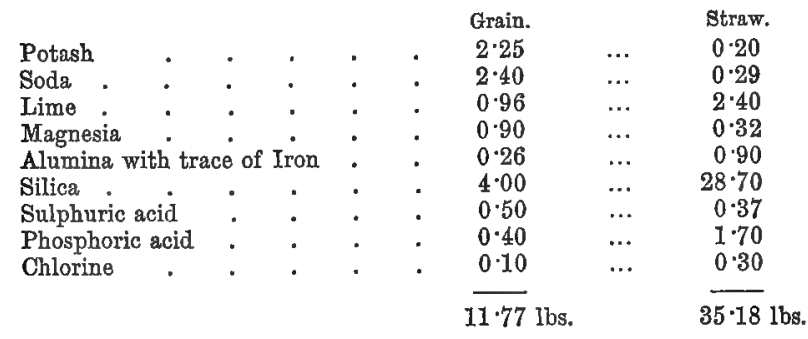

In $1000 \mathrm{lbs}$. of the grain of the Oat are contained 25.80 lbs., and of the dry straw $57 \cdot 40$ lbs. of inorganic matter, consisting of-

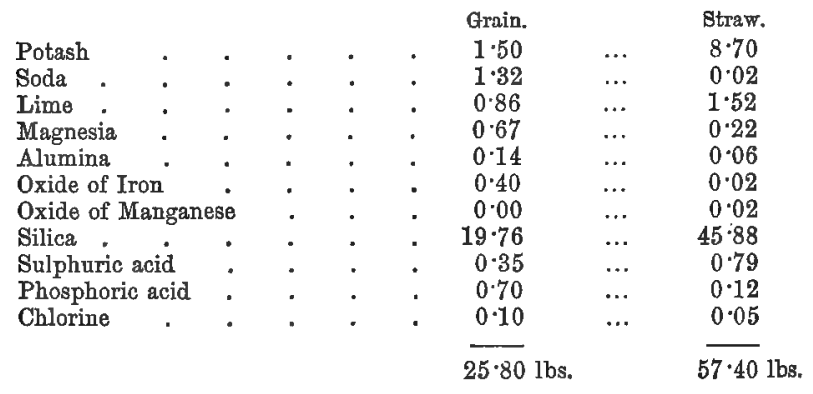

In $1000 \mathrm{lbs}$, of the field Bean, field Pea, and Rye-grass hay, after being dried in the air, the following is the amount of ash, and its composition :-

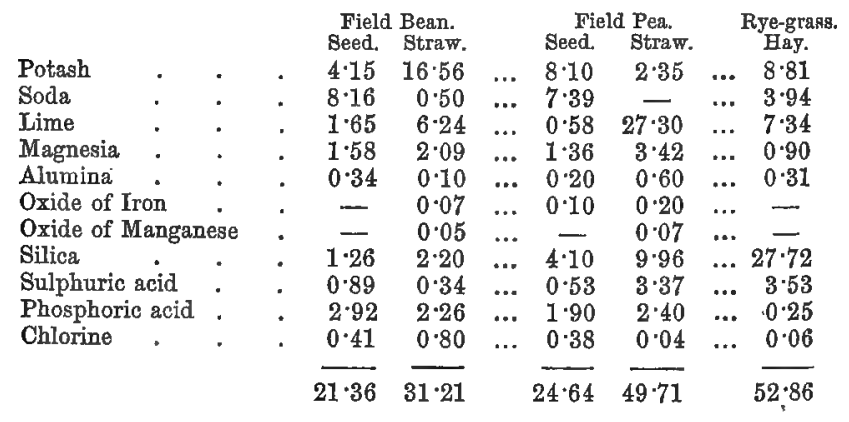

Dr. R. D. Thomson gives the following analysis of the inorganic matter in the stem and seeds of Lolium perenne :- 


\begin{tabular}{|c|c|c|c|c|c|c|c|}
\hline Silica & $\cdot$ & • & • & 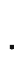 & $\begin{array}{l}\text { Stem. } \\
64 \cdot 57\end{array}$ & & $\begin{array}{r}\text { Seed. } \\
42-28\end{array}$ \\
\hline Phosphoric acid & . & . & . & ${ }^{*}$ & 12.51 & $\cdots$ & $18 \cdot 89$ \\
\hline Sulphuric acid & . & $\cdot$ & ${ }^{\circ}$ & $\theta^{\circ}$ & - & $\ldots$ & $3 \cdot 12$ \\
\hline Chlorine : & . & 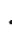 & 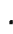 & . & - & $\ldots$ & trace. \\
\hline Carbonic acid & $\cdot$ & $\cdot$ & $\cdot$ & . & - & $\ldots$ & $3 \cdot 61$ \\
\hline Magnesia & • & , & • & & $4 \cdot 01$ & .. & $5 \cdot 31$ \\
\hline Lime : & $\cdot$ & " & $\cdot$ & & $6 \cdot 50$ & $\ldots$ & $18 \cdot 55$ \\
\hline Peroxide of Iron & . & $\cdot$ & ${ }^{\circ}$ & & $0 \cdot 36$ & $\ldots$ & $2 \cdot 10$ \\
\hline Potash. & • & • & & & 8.03 & $\ldots$ & $4 \cdot 80$ \\
\hline Soda. & . & . & • & • & $2 \cdot 17$ & $\ldots$ & $1 \cdot 38$ \\
\hline
\end{tabular}

These inorganic elements are variously combined in plants, in the form of sulphates, phosphates, silicates, and chlorides. Some plants, as Wheat, Oats, Barley, and Rye, contain a large quantity of Silica in their straw; others, such as Tobacco, Pea-straw, Meadow-clover, Potato-haulm, and Sainfoin, contain much lime ; while Turnips, Beetroot, Potatoes, Jerusalem-artichoke, and Maize-straw, have a large proportion of salts of potash in their composition. Sulphates and phosphates are required to supply part of the material necessary for the composition of the nutritive protein compounds found in grain.

Silica $\left(\mathrm{SiO}_{2}\right)$ abounds in Grasses, in Equisetum, and other plants, giving firmness to their stems. The quantity contained in the Bamboo is very large, and it is occasionally found in the joints in the form of Tabasheer. Reeds, from the quantity of siliceous matter they contain, are said to have caused conflagrations, by striking against each other during hurricanes in warm climates. In species of Equisetum, the silica in the ash is as follows:-

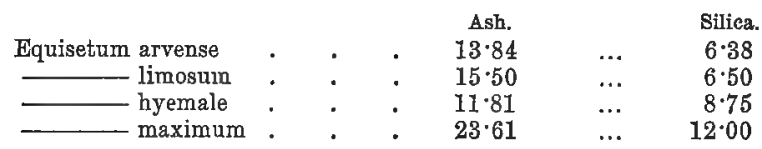

The third of these furnishes Dutch Reed, used for polishing mahogany. The silica is deposited in a regular manner, forming an integral part of the structure of the plant. Many insoluble matters, as silica, seem to be deposited in cells by a process of decomposition; thus, silicate of potash in a vegetable sap may combine with oxalic acid, by which oxalate of potash and silicic acid will be produced, as in the cells of Grasses and Equisetum. Chara translucens has a covering of silicic acid, while $\mathrm{C}$. vulgaris has one composed of silicic acid and carbonate of lime; and Chara hispida has a covering of carbonate of lime alone. Silica, the only known oxide of Silicon, contains 28 parts silicon, and 32 parts oxygen. It is in reality an acid, though a very weak one at ordinary temperatures. Its insolubility in water prevents the manifestation of its acid properties under ordinary circumstances. In those plants in which silica most abounds, Fluorine has also been discovered. 
The test for the presence of the latter rests in acting on the fluoride with concentrated sulphuric acid, and so producing hydrofluoric acid, which possesses the property of etching glass ; the glass being coated with wax, and the design to be etched traced with a pointed instrument.

LIME is found in all plants, and in some it exists in large quantity. It occurs sometimes in the form of carbonate on the surface of plants. Thus, many of the Characeæ have a calcareous encrustation. The crystals or raphides (p. 10), found in the cells of plants, have lime in their composition. In the roots of Turkey and East India Rhubarb the crystals of oxalate of lime have been estimated at about 25 per cent, while in those of the English plant the proportion is about 10 per cent. In the Cactus tribe crystals of the same kind have been observed, the presence of which, in excessive quantity, imparts brittleness to the stem of the old plant.

SODA AND POTASH occur abundantly in plants. They are taken up from the soil in combination with acids. Those growing near the sea have a large proportion of soda in their composition, while those growing inland contain more potash. Various species of Salsola, Salicornia, Halimocnemum, and Kochia, yield soda for commercial purposes, and are called Halophytes (à $\lambda \varsigma$, salt, and qúrov, plant). The young plants furnish more soda than the old ones. There are certain species, as Armeria maritima, Cochlearia officinalis, Plantago maritima, and Silene maritima, which are found both on the seashore and high on the mountains removed from the sea. In the former situation they contain much soda and some iodine; while in the latter, potash prevails, and iodine disappears.

Iron, Manganese, and CopPeR, especially the two latter, exist in small quantity in plants. Iron exists in the soil either as an oxide, sulphide, or carbonate, usually occurring as peroxide. Iron when held in solution as carbonate is capable of being absorbed into the vegetable tissues. ' Copper has been detected in coffee.

All these inorganic matters are derived in a state of solution from the soil, and plants are said to have, as it were, a power of selection, certain matters being taken up by their roots in preference to others. Saussure made a series of experiments on this subject, and stated that when the roots of plants were put into solutions containing various saline matters in equal proportions, some substances were taken up by imbibition in larger proportion than others. Bouchardat doubts the accuracy of Saussure's conclusions on this point. $\mathrm{He}$ thinks that errors arose from the excretions of the plants and other causes. He performed similar experiments with plants of Mint, which had been growing for six months in water previous to experiment, and he found that in watery solutions of mixed salts the plant absorbed all in equal proportions. Daubeny states, that if any par- 
ticular salt is not present, the plant frequently takes up an isomorphous one.

The differences in the absorption of solutions depend, perhaps, on the relative densities alone, and not on any peculiar selecting power in roots, for it is well known that poisonous matters are absorbed as well as those which are wholesome. The following experiments show that poisonous matters in solution, varying from half a grain to five grains in the ounce of water, are taken up by roots, and that some substances which are poisonous to animals do not appear to act energetically upon plants :-

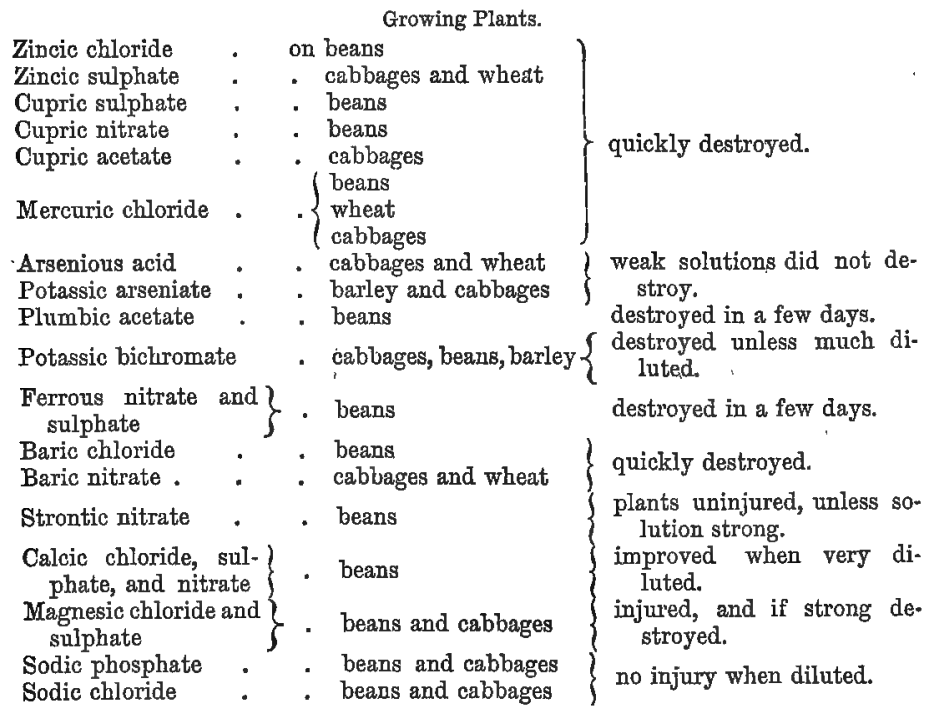

Rotation of Crops.-As the inorganic materials which enter into the composition of plants vary much in their nature and relative proportions, it is evident that a soil may contain those necessary for the growth of certain species, while it may be deficient in those required by others. It is on this principle that the rotation of crops is founded; those plants succeeding each other in rotation which require different inorganic compounds for their growth. In ordinary cases, except in the case of very fertile virgin soil, a crop if grown for several years in succession in the same field will deteriorate in a marked degree. This has been tested by growing plants on the same and on different plots in successive years, with the following results :- 


\begin{tabular}{|c|c|c|c|c|c|c|c|c|}
\hline \multirow[b]{2}{*}{ Potatoes } & \multicolumn{2}{|c|}{$\begin{array}{l}\text { in the same plot } \\
\text { in different plots }\end{array}$} & & & & & \multicolumn{2}{|c|}{$\begin{array}{l}\text { Average of } 5 \text { years } \\
72.9 \text { lbs. tubers. }\end{array}$} \\
\hline & & & . & . & & & $92 \cdot 8$, & , \\
\hline Flax & same & - & . & . & . & & $\begin{array}{l}15 \cdot 0.1 \mathrm{bs} . \\
19 \cdot 9\end{array}$ & \\
\hline & same & - & 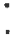 & . & & & $32 \cdot 8$ & \\
\hline Beans & different & . & . & • & & & $34 \cdot 8$ & \\
\hline Barley & same & - & . & . & & & $30 \cdot 0$ & \\
\hline Dalley & different & - & - & - & & & $46 \cdot 5$ & \\
\hline Turnips & same & - & . & . & & & $104^{\circ} 0$ & \\
\hline & different & - & . & . & & & $173^{\circ} 0$ & \\
\hline Oats & same & - & - & - & & & $280^{\circ}$ & \\
\hline & different & - & . & - & & & & \\
\hline
\end{tabular}

This shows a manifest advantage in shifting crops, varying from 1 to 75 per cent; the deficiency of inorganic matter being the chief cause of difference. As this matter is of great importance to plants, it follows that the composition of soil requires special notice.

\section{Chemical Composition of Solls.}

Soils have been divided according to the proportion of clay, sand, and lime, which they possess, into-

1. Argillaceous soils, possessing little or no calcareous matter, and above 50 per cent of clay.

2. Iroamy soils, containing from 20 to 50 per cent of clay.

3. Sandy soils, not more than 10 per cent of clay.

4. Marly soils, 5 to 20 per cent of calcareous matter.

5. Calcareous soils, more than 20 per cent of carbonate of lime.

6. Humus soils, in which vegetable mould abounds.

Below the superficial soil there exists what is called subsoil, which varies in its composition, and often differs much from that on the surface. Into it-the rain carries down various soluble inorganic matters, which, when brought to the surface by agricultural operations, as trenching and subsoil ploughing, may lmaterially promote the growth of crops. The advantages of subsoil ploughing are dependent on the nature of the soil. By means of it the subsoil is loosened, so as to be easily acted upon by air and water, and the efficiency of the drainage is increased. It is not fitted for all soils, and in some instances it may do harm. A knowledge of the chemical as well as mechanical nature of soils guides the agriculturist to a certain extent in his operations ; since, by the judicious application of manures, certain deficiencies may be supplied, and, by admixture, soils may be rendered more suitable for the purposes of vegetation.

HUMUs, or decaying woody fibre, called also ulmine, or coal of humus, exists in soils. It is soluble in alkalies, yielding a brown solution, which, when treated with an acid, produces a brown precipitate, said to contain humic, ulmic, and geic acids; but the separate 
existence of these compounds as definite acids is somewhat doubtful. Humus absorbs ammonia, and it is slowly acted upon by the atmosphere, so as to form carbonic acid by combination with oxygen. Peaty soils contain much of this substance. When peroxide of iron is present in such soils it loses part of its oxygen, and is converted into the protoxide.

Silica, in greater or less quantity, is found in all soils; but it abounds in sandy soils. In its ordinary state it is insoluble, and it is only when acted upon by alkalis in the soil that it forms compounds which can be absorbed by plants. Silica, in a soluble state, exists in minute quantities in soils, the proportion, according to Johnston, varying from 0.16 to 0.84 in 100 parts, while the insoluble siliceous matter varies from 60.47 to 83.31 in 100 parts. Wiegman and Polstorf found that plants took up silica from a soil composed entirely of quartz sand, from which everything organic and soluble had been removed. The following table shows the plants which germinated, the height to which they grew previously to being analysed, the quantity of silica they contained when planted, and the increase :-

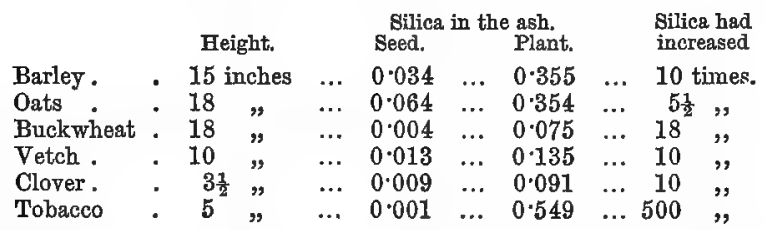

ALUMina exists abundantly in clayey soils, but it does not enter largely into the composition of plants. It has the power of absorbing ammonia and saline matters, and may prove beneficial in this way.

LIME is an essential ingredient in all fertile soils. In $1000 \mathrm{lbs}$. of such soil there are, according to Johnston, $56 \mathrm{lbs}$. of lime; while a soil is barren which contains only $4 \mathrm{lbs}$. The presence of phosphoric acid in soils, in the form of phosphates of potash, soda, and lime, is essential for the production of certain azotised compounds in plants ; and sulphuric acid, similarly combined, is required for the formation of others. Calcareous soils contain upwards of 50 per cent of lime. The addition of lime to soils is often highly beneficial, by destroying noxious weeds, and preventing disease in crops. Lime is a forcing agent, and is useful in stiff clayey soils where it decomposes the silicate of potash, forming silicate of lime, and liberating the potash which is taken up by the plants. In marly soils lime exists in the proportion of 5-20 per cent. In loamy soils lime is in smaller quantity.

A rough way of estinating the general nature of a soil is thus given by Professor Johnston :- 
1. Weigh a given portion of soil, heat it and dry it. The lose is water.

2. Burn what remains. The loss is chiefly vegetable matter.

3. Add hydrochloric acid to the residue, and from this the quantity of lime may be determined.

4. Wash a fresh portion of soil to determine the quantity of insoluble siliceous sand.

Such an analysis, however, is by no means sufficient for the purposes of the farmer.

The chemical composition of a plant being known, conclusions can be drawn as to the soil most suitable for its growth. This is a matter of great importance both to the farmer and to the planter. In order that a plant may thrive, even in a suitable soil, exposure and altitude must also be taken into account. It is only by attention to these particulars that agricultural and foresting operations can be successful. As regards trees, the following practical observations are given as an illustration of what has been stated. The Scotch Fir thrives best in a heathy soil, incumbent on a pervious subsoil, and at a high altitude; Larch in loam, with a dry subsoil, in a high situation, and on sloping banks; Spruce and Silver firs in soft loam or peaty soil, in a low moist situation, but they will also grow in a dry soil, and at a pretty high altitude; Oak in any soil and situation under 800 feet above the level of the sea, but it thrives best in clayey loam, on a rather retentive subsoil, and on gently sloping ground; Ash and Elm, on a gravelly loam, on gravel or sand, at an altitude under 500 feet above the level of the sea; Sycamore, at 100 feet higher than the ash or elm, and in a more retentive soil and subsoil ; Beech, on a dry gravelly soil, and in a rather bigh situation, but it is often luxuriant on strong retentive clay, and in a low damp situation.

\section{Application OF Mandre.}

If the soil does not contain the ingredients required for a crop, they must be added in the form of manure. The principle of manuring is to supply what the plant cannot obtain from the soil, and to render certain matters already in the soil available for nutrition. In order that this may be properly practised, there must be an analysis of the soil, of the plant, and of the manure. Hence the importance of agricultural chemistry to the farmer.

\section{Various kinds of Manure.}

Natural Mandres, as farmyard dung, are more valuable than simple manures; inasmuch as the former furnish all the substances required for the growth of plants, while the latter only supply a particular ingredient. Natural manures may be regarded as confer- 
ring on the soil the most lasting advantage, as from the slowness of their decomposition their beneficial effects are not so readily exhausted. Plants themselves, in a soluble state, would be the best manure. In ordinary farmyard manure the straw is again made available for the purpose of the plant. The whole crop of wheat and oats, however, cannot be returned to the soil, as part must be retained for food. A substitute, therefore, must be found for the portion thus taken away. This contains both azotised and unazotised matters, the former consisting of protein compounds which supply nitrogen for the muscular tissue of man and animals ; the latter of starchy, mucilaginous, and saccharine matters, which furnish carbon as a material for respiration and the formation of fat. The object of manuring is chiefly to increase the former, and hence those manures are most valuable which contain soluble nitrogenous compounds.

The value of manures is often estimated by the quantity of glutin which is produced by their application. Hermbstaedt sowed equal quantities of the same wheat on equal plots of the same ground, and manured them with equal weights of different manures, and from 100 parts of each sample of grain produced he obtained glutin and starch in the following proportions:-

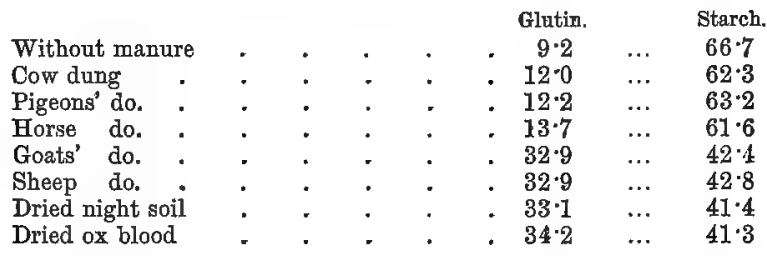

Manures containing ammonia owe their excellent qualities to the nitrogen which enters into their composition; hence the value of sulphate of ammonia, ammoniacal liquor of gas-works, and urine. The value of guano, or the droppings of sea-fowl, depends chiefly on the ammoniacal salts, and the phosphates which it contains; thus supplying the nitrogen and phosphorus requisite for the protein compounds which furnish the elements for flesh and blood. The guano which is imported is the excrement of numerous searfowl which frequent the rainless shores of South America and Africa. It often contains beautiful specimens of Diatoms, as Campylodiscus, Coscinodiscus, etc. The guano found in caves on the coasts of Malacea and Cochin-China is the produce of frugivorous and insectivorous bats, and of a species of swallow-the last being the best. .

The following analyses, by Dr. Colquhoun of Glasgow, which are the result of an examination of a large number of samples, give a general idea of the composition of guano. The term ammoniacal 
matter includes urate of ammonia and other ammoniacal salts, such as oxalate, phosphate, and chloride, as well as decayed organic matter of animal origin. The term bone earth includes phosphate of lime (always the principal ingredient), phosphate of magnesia (always in small amount), oxalate of lime; and in African guano a minute quantity of carbonate of lime, and from $\frac{1}{2}$ to 2 per cent of fragments of sea-shells. The fixed alkaline salts are various salts of sodium, as chloride, phosphate, and sulphate; a little of a potash salt has been detected.

\section{South American Guano.}

\begin{tabular}{|c|c|c|c|c|c|c|c|}
\hline & $\begin{array}{l}\text { Fine } \\
\text { iincha. }\end{array}$ & & Middling. & & Inferior. & & Low Qualities. \\
\hline Ammoniacal matter & 62 & $\ldots$ & 42 & $\cdots$ & 28 & $\cdots$ & $12 \ldots 15$ \\
\hline Bone earth & 20 & $\ldots$ & 24 & $\ldots$ & 30 & $\cdots$ & $50 \ldots 37$ \\
\hline Fixed alkaline salts & 10 & $\cdots$ & 14 & $\cdots$ & 21 & $\cdots$ & $10 \ldots 5$ \\
\hline Rock, sand, earth & 0.5 & $\cdots$ & 5 & $\cdots$ & 3 & $\ldots$ & $15 \quad \ldots .34$ \\
\hline Water & $7 \cdot 5$ & $\cdots$ & 15 & ... & 18 & $\cdots$ & $13 \ldots 9$ \\
\hline & $100 \cdot 0$ & & 100 & & 100 & & 100 \\
\hline
\end{tabular}

African Guano.

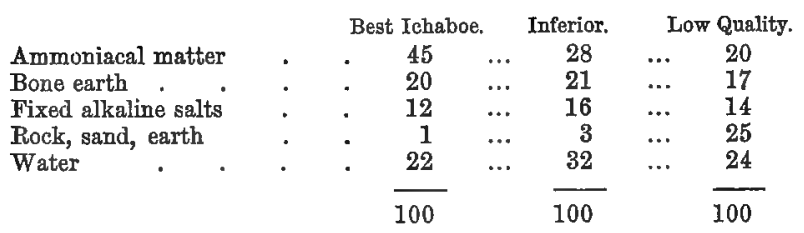

The guano from the islands on the British coasts contains the same ingredients, but the soluble salts are generally washed out by the action of rain. The following is the analysis, by Dr. R. D. Thomson, of guano gathered on Ailsa Craig :-

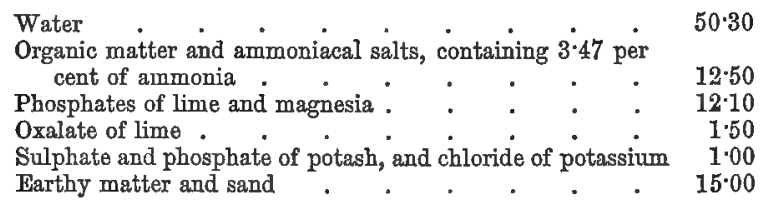

Simple MandRes supply only one or two of the materials required for the growth and nourishment of plants. The ammoniacal liquor of gas-works, in a very diluted state, has been advantageously applied to the soil, on account of the nitrogen which it contains. Soot has also been used, from furnishing salts of ammonia, Nitrates of potash and soda have been recommended not only on account of the 
alkalies, but also on account of the nitrogen which they contain, in the form of nitric acid. The quantity of glutin is said to be increased by the use of nitrates. Carbonate of potash and soda, and chloride of sodium, are frequently used as manures. The latter is especially useful in the case of plants cultivated inland, which were originally natives of the sea-shore, as Cabbage, Asparagus, and Sea-kale. As lime is found in all plants, the salts containing it are of great importance. It may be used in the caustic state with the view of decomposing vegetable matter. It also neutralises any acids previously in the soil, such as occur occasionally in boggy and marshy land, abounding in species of Juncus, Carex, and Eriophorum, with some Calluna vulgaris. Lime also combines with certain elements of the soil, and sets potash free, which reacts on the silica, and renders it soluble. Lime is sometimes washed down into the subsoil ; and in such cases trenching improves the land. Phosphate of lime is a valuable manure, both on account of the lime, and of the phosphorus which it contains. Without the presence of phosphates, glutin and the protein compounds of plants cannot be formed. Phosphate of lime exists abundantly in animal tissues, and hence it must be furnished by plants. The use of bone-dust as a manure depends in a great measure on the phosphate of lime which it contains. Besides phosphate of lime, bone-ash contains from 3 to 12 per cent of phosphate of magnesia, carbonate of lime, and salts of soda. The gelatine of bones also seems to act beneficially, by forming carbonic acid and ammonia. Bones are best applied after being acted on by sulphuric acid, so as to form soluble phosphates by decomposition. They are broken into pieces, and mixed with half their weight of boiling water, and then with half their weight of sulphuric acid. The superphosphate thus formed is applied to the soil, either in a dry state by the drill, with sawdust and charcoal added, or in a liquid state, diluted with 100 to 200 parts of water. Phosphates and other inorganic matters sometimes exist potentially in the soil, but in a dormant state, requiring the addition of something to render them soluble. Allowing the ground to lie fallow, stirring and pulverising it, are methods by which air and moisture are admitted, time being allowed for the decomposition of the materials, which are thus rendered available for plants. Sulphur exists in considerable quantity in some plants, as Cruciferæ, and it forms an element in albumin; hence the use of sulphuric acid and of sulphates as manures. Sulphate of lime or gypsum is well fitted as a manure for clover, by supplying sulphur and lime, and absorbing ammonia. Charcoal in a solid state has been applied with advantage as a manure. It acts partly by taking up ammonia in large quantity, and partly by combining slowly with oxygen, so as to form carbonic acid. The effects of carbonic acid on vegetation are said to be remarkably conspicuous in some volcanic countries, in which this 
gas is evolved from the bottom of lakes. When it accumulates in large quantities, however, it destroys plants as well as animals.

Manuring with Green Crops is sometimes practised. The mode adopted is to sow certain green crops, the roots of which extend deeply into the soil; and when the plants have advanced considerably in growth, to plough them in, and sow a crop of some kind of grain. In this way the nutritive matter from the deeper part of the soil is brought within reach of the roots of the grain crop. Manuring with seaweeds is also resorted to in cases where they are accessible. They supply abundance of carbonate, phosphate, and sulphate of lime, besides chloride of sodium. There are considerable differences in their chemical composition; thus, while in Laminaria saccharina, alkaline carbonates, potash, and iodine, predominate; in Fucus vesiculosus and serratus, sulphates and soda are in excess, and iodine is less abundant. In the cultivation of the Coco-nut Palm seaweeds act beneficially.

Liguid ManURes have of late years been much employed, and the formation of tanks for their reception has been strongly recommended, in which the ammonia is fixed by the addition of sulphuric acid or charcoal. They can be applied after vegetation has advanced, and they are in a state to be at once available to the crop. Some have advocated steeping seeds and grains in certain solutions before sowing them. Professor Johnston suggests a mixture of phosphate of soda, sulphate of magnesia, nitrate of potash, common salt, and sulphate of ammonia ( $1 \mathrm{lb}$. of each), in ten gallons of water, to steep 300 lbs. of seeds, which are afterwards to be dried with gypsum or quicklime.

The following experiment, conducted by Mr. Wilson, at Knock, near Largs, shows the mode of estimating the effects of manures. The land was a piece of three-year-old pasture, of uniform quality. It was divided into ten lots, and these.were treated with different kinds of manure. The quantity of well-made hay is given in lbs.-

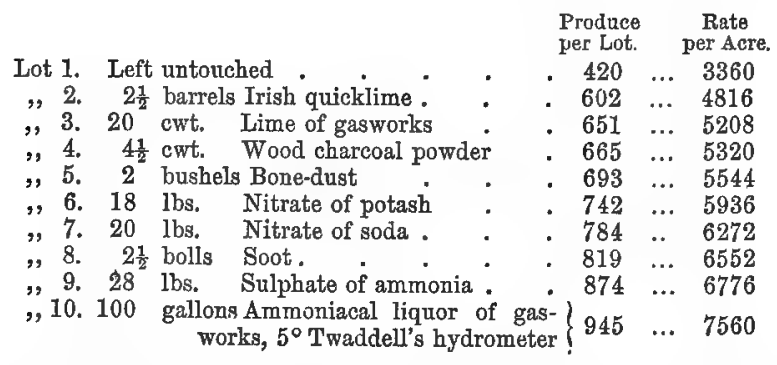

The value of each application was the same, all were applied at the same time, and the grass also was cut at the same time. 
Plants are thus employed to form from the atmosphere and soil those organic products which are requisite for the nourishment of man and animals. Nutrition derivable from the atmosphere being generally diffused, is accessible to all plants, and is perpetually renewed. Nutrition derivable from the soil being fixed to certain localities, requires that those elements contributing to it be mechanically supplied as they become exhausted. While an animal consumes carbon so as to form carbonic acid, gives off ammonia in various excretions, transforms organised into mineral matters, and restores its elements to air and earth; a plant, on the other hand, fixes carbon in its substance, and gives off oxygen, forms from ammonia solid compounds, transforms mineral into organised matters, and derives its elements from the air and earth. Thus, says Dumas, what the atmosphere and soil yield to plants, plants yield to animals, and animals return to the air and earth, a constant round, in which matter merely changes its place and form.

\section{Eipiphytic and Parasitic Plants.}

Some plants grow without any attachment to the soil, and are able to derive in a great measure, from the atmosphere, all the materials

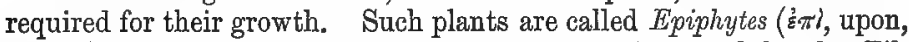
and $\varphi$ urov, a plant), or air-plants, and may be illustrated by the Tillandsias, Bromelias, and Orchids of warm climates. Such plants, when attached to the surface of trees, may perhaps derive some nourishment from the inorganic matter in the decaying bark; but they do not become incorporated with, nor do they send prolongations into, the trees. Orchidaceous plants, which are always perennial, are found in the greatest variety and profusion in those regions where heat and moisture abound. Extremes of cold or dryness are the least favourable to their growth. Tillandsias and Bromelias flourish in dry hot air without any contact with the earth.

There are other plants, however, which are true Parasites ( $\pi \alpha g \alpha$, beside, and oiros, food, deriving food from another), sending prolongations of their tissue into other plants, and preying upon them. Many Fungi, for instance, develop their spores (seeds) and spawn (mycelium) in the interior of living or dead plants, and thus cause rapid decay. The diseases of corn, called smut and rust, and the dry rot in wood, are due to the attacks of these parasitic Fungi. The minute dust or powder produced by these plants consists of millions of germs which are easily carried about in the atmosphere, ready to fix themselves on any spot where they can find a nidus. There are also flowering plants which grow parasitically, and they may be divided into two classes : 1. Those which are of a pale or brownish colour, and have scales in place of leaves; and 2. Those which are of a green colour, and have 
leaves. The former, including Orobanche or broom-rape, Lathræa or toothwort, Cuscuta or dodder, derive nourishment entirely from the plant to which they are united; while the latter, as Loranthus, Viscum or mistleto, Myzodendron, Thesium, Euphrasia, Melampyrum, and Buchnera, elaborate sap in their leaves under the action of air and light. By this power of elaboration, the mistleto is able to grow on different species of plants, as on the apple, beech, oak, etc. Some parasites are attached by suckers to the roots of plants, as in the case of Broom-rape, Toothwort, and Thesium, and are called root-parasites; while others, as Dodder, Mistleto, etc., derive nourishment from stems, and are called stem-parasites. The specific names of many parasites are taken from the plants on which they grow. The species of Cuscuta or dodder inhabit all the temperate and warm parts of the globe, and are peculiarly destructive to clover and flax. They are produced from seed which at first germinates in the soil like other plants; but after the stem has coiled closely round another plant, and become attached to it by means of suckers, then all connection with the soil is severed, and the Dodder lives as a true parasite. A remarkable genus of parasites, called Rafflesia, has been found in Sumatra and Java. The species are leafless, and produce brown-coloured flowers, which are sometimes three feet in diameter. On account of their only

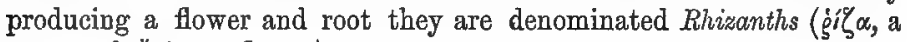
root, and aैv0os, a flower).

\section{2.-Absorption and Circulation of Fluids.}

While the leaves and other aerial organs of plants have the power of absorbing fluids, it is chiefly by the roots that this process takes place. The cells of the spongioles or fibrils of the roots are covered by a very delicate membrane (p. 38), which allows the imbibition of fluids to proceed rapidly; and as additions are made to their extremities, they are constantly placed in circumstances favourable for the reception of fresh nutriment for the plant. Animals having the power of locomotion are enabled, as they exhaust the nutritive matter of one locality, to remove to another. Plants having no provision for locomotion would perish, after taking up all the nourishment in the soil in their immediate neighbourhood, were it not that the roots spread over large areas in search of food. The nutritive materials in the soil, partly derived from the decomposition of its organic and inorganic materials, and partly from the atmosphere, are supplied to the roots in a state of solution; and as the substances in the cells of plants are usually colloid and denser than the external liquid crystalloid matters, a process of endosmose takes place by which the latter pass in large quantities into the cell through its membranous covering, while a small portion of the former is excreted by exosmose. These move- 
ments in the contents of cells and vessels take place when fluids of different densities are separated by an animal or vegetable membrane.

If, on opposite sides of an animal or vegetable membrane, we place two fluids of unequal density, having an affinity for the interposed membrane and for each other, the fluid on the one side being thick and gelatinous, whilst the other is thin and watery, two unequal and opposite currents are at once established-the thin fluid setting with a strong and full current through the membrane towards the thicker fluid, which it penetrates ; the thicker fluid, with a more feeble current and in less quantity, reaching the thin fluid with which it mingles. This constitutes Osmose. The inequality in strength and amount of the two currents depends, not so much on the density of the liquids, as on their character, those of a gluey or albuminous nature passing slowly, whilst those of a more liquid nature transude very rapidly. If the membrane form a sac or bladder, in which the thick gelatinous fluid is contained, then the thin fluid rapidly passing inwards into the sac penetrates the thick fluid, and thus the amount of fluid in the bladder is increased and its walls are distended. To this inward current the term Endosmose is applied, and conversely, Exosmose refers to the slow and feeble outward current of the thick contained fluid. In this instance the Endosmose current is the stronger, but a reversal of the relation of the fluids to the membrane renders the Exosmose current the stronger, consequently the contents of the sac are diminished in amount and its walls collapse. The relative rapidity of the Exosmose and Endosmose currents depends on the position of the liquids as regards the membrane; the strongest current always setting in towards the most colloid body. In fig. 240 is represented the mode of showing endosmose by means of a bladder full of syrup; which is attached to the end of a tube, and immersed in water. In this case the water passes rapidly into the bladder

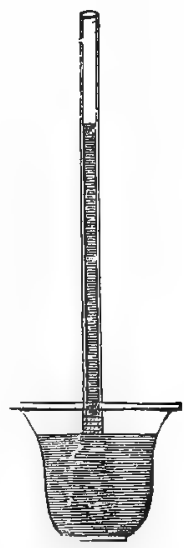

Fig. 240.

by endosmose, so that the fluid rises in the tube, while a portion of the thicker fluid passes out by exosmose. The force of this endosmose may be measured by a graduated tube, as in the figure, or by a tube with a double curvature, as fig. 242, the lower part of which is filled with mercury. In the latter case the mercury is pushed upwards into a graduated tube, and thus an endosmometer ( $\mu \varepsilon^{\prime}$ gov, a measure), or measure of the force of endosmose, is formed.

Fig. 240. Instrument to show Endosmose and Exosmose, consisting of a bladder containing syrup attached to a tube, and plunged in a vessel of water. The inward motion of the water (endosmose) exceeds the outward movement of the syrup (exosmose). 
Dutrochet found that with a membrane of 40 millimetres in diameter, a tube of 2 millimetres, and a solution of sugar, the density of which was 1.083 , the fluid rose 39 millimetres in the space of an hour and a half; with symup, of density $1 \cdot 145$, the rise was 68 millimetres; and with syrup, of density $1 \cdot 228$, the rise was 106 millimetres. Syrup, of density $1 \cdot 3$, produced a current capable of raising a column of mercury of 127 inches, which is equal to a pressure of $4 \frac{1}{2}$ atmospheres. Thus the velocity and force of the rise depend in this instance on the excess of density of the enclosed liquid over that of the water outside. Different'substances act with varying intensity in producing endosmose. The following ratio expresses the variable intensity of endosmose in different cases in which the density of the solution was the same :- Solution of gelatin, 3 ; of gum, $5 \cdot 17$; of sugar, 11 ; of albumin, 12 . In order that endosmose and exosmose may take place, the liquids must have an affinity for the interposed membrane, and an affinity for each other, and be miscible. The interposed membrane, whether animal or vegetable, is very actively concerned in the intensity and direction of the endosmotic current. Graham assigns a chemical character to osmose, accompanied with a constant decomposition of membrane. In the living plant the renewal of the membrane forming the septum is constantly taking place, and thus the osmotic action is kept up.

The fluid matters, absorbed by the roots, are carried upwards through the cells and vessels of the stem, as ascending sap; they pass into the leaves, where they are exposed to the influence of air and light, and afterwards return through the inner bark as descending or elaborated sap, and a portion ultimately reaches the root, where it is either excreted or mixed with the new fluid entering from the soil. The presence of light is essential for the elaboration of the sap. Vegetable growth cannot progress unless the vegetable circulation be perfectly accomplished. This act of vegetable vitality may, however, be effected while the plant is removed from the action of light, but the oxygenation of the juices cannot be perfected without their free exposure to its influence.

Numerous experiments have been performed in order to show the course of the fluids in oxogenous stems, such as making incisions or notches in the bark and wood of trees at different heights, and noting the points where the sap first made its appearance at different periods of the year, more especially in spring; also in plunging plants, with their roots, entire into certain coloured solutions, and marking the course of the coloured fluids. These experiments led to the conclusion that the sap ascends chiefly through the alburnum or newer wood, proceeds to the leaves, and returns by the bark to the root. If incisions are made into the trunk of a tree at different heights early in spring, it is found that the flow of sap (called bleeding) 
takes place, first from the lower parts of the incisions, and chiefly from the alburnum; while at a later period of the year it occurs on both sides of the incision, chiefly from the new wood on the lower side, and from the bark on the upper side. If a plant be plunged into a weak solution of acetate of lead (which is capable of being absorbed), the metal may be detected by means of a salt of iodine, first in the new wood, next in the leaves, and then in the bark. A similar experiment may be made by means of weak solutions of potassic ferrocyanide, and of a persalt of iron.

From the minuteness of the tissue, and the difficulty of examining the circulation in a living plant, it is not easy to determine the vessels through which the sap moves. In its upward course it appears to pass through the intercellular spaces, the recent woody tissue and the porous vessels, and in its downward course through the laticiferous vessels and cellular tissue of the bark, being also transmitted laterally through the cells of the medullary rays. In some cases, when the bark has been removed, the descent of the sap takes place by the cells of the medullary rays. The sap nourishes the different organs, its carbonic acid and water are partly decomposed, combinations take place with nitrogen, protoplasm or formative matter is produced, and various secretions are formed in the cells and intercellular passages.

Gaseous matters are taken up by the roots of plants, and circulated along with the sap as well as in the spiral vessels. These usually consist of air, carbonic acid, and oxygen. Hales showed the existence of air in the vessels of the Vine, and Geiger and Proust proved that the sap of this plant contained carbonic acid. Some plants, as Pontederia and Trapa, float in water by means of air contained in the vessels or in the intercellular spaces. In Vallisneria, the large cells in the centre of the leaves are surrounded by air-cavities, which are seen as dark lines under the microscope.

Changes take place in the composition and density of the sap in its upward course. The chief alterations in it take place in the leaves, where it is exposed to the influence of light and air. By this means carbon is fixed, oxygen is given off, and an exhalation of watery fluids takes place. The fluids pass from cell to cell through the leaves, where they are acted upon by air through the stomata, and reach the vascular and cellular tissue of the bark, where further changes take place. Walker, from his experiments, concluded that no descent takes place until after the development of the leaves.

The sap, after being elaborated in the leaves, is sometimes clear and transparent, at other times it is milky or variously coloured and opaque. The elaborated sap has been called latex, and the vessels transmitting it have been denominated laticiferous (p. 21). The latex contains granules, which exhibit certain movements under the microscope. The movements are analogous to those observed in the 
capillary circulation of animals. On account of these movements in the latex, the laticiferous vessels have been denominated Cinenchymatous (xuv'w, I move), and the movements themselves are included under the name Cyclosis ( $x$ ux $\lambda$ os, a circle).

The plants in which the movements are best observed are those having the latex milky or coloured, such as various species of Ficus, Euphorbia, and Chelidonium. In fig. 241 there is represented

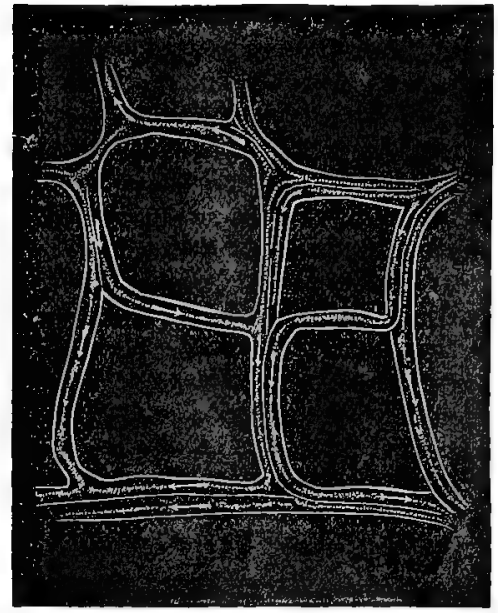

Fig. 241. a small fragment of a leaf of Chelidonium majus (celandine), which shows the current of orange granules in the laticiferous vessels, their direction being indicated by arrows. If the young unexpanded sepal of the Celandine is removed from the plant, and put under the microscope, or if the inner lining of the young stipule of Ficus elastica be treated in a similar manner, very obvious motion is seen in the granular contents of the vessels, and this motion is modified by pricking the vessels or by pressure. If the microscope be applied to the stipule of Ficus elastica, while still attached to the plant and uninjured, pressure with any blunt object on the stipule will be observed to cause a marked oscillation in the vessels, thus showing their continuity. There will also be seen a regular movement from the apex towards the base, independent of external influences, when the stipule is allowed to lie on the field of the microscope without any pressure or injury whatever. This movement has been observed to continue for at least twenty minutes. It is of importance to distinguish between those molecular movements which are caused by injury and pressure, and those which depend on changes going on in the interior of the living plant.' The elaborated sap descends through the ressels of the liber.

It appears, then, that in the case of Exogenous plants, the fluid matter in the soil, containing different substances in solution, is absorbed by the extremities of the roots, ascends to the stem, passes

Fig. 241. Small portion of the leaf of Chelidonium majus or Celandine (highly magnified), showing a network of laticiferous vessels. The direction of the currents in the vessels is indicated by the arrows. 
through the woody tissue, porous vessels, and cells, dissolving starch and other matters, and appropriating various new substances. Proceeding upwards and outwards, this sap reaches the leaves, where it is exposed to the air, and is elaborated by the function of respiration. It then returns, or descends chiefly through the bark, either directly or in a circuitous manner, communicating with the central parts by the medullary rays, depositing various secretions, more especially in the bark, and giving origin to substances which are destined to nourish and form new tissues. Finally, it reaches the extremity of the root, where absorption commenced; a small portion is there excreted, while the remainder mixes with the newly-absorbed fluids, and again circulates in the sap. The rapidity with which the sap ascends is dependent on the endosmotic property of the cells in the roots, and on the density of the fluids. An absorption of water, containing various matters in solution, is constantly going on through the extremities of the rootlets. The sap thus formed is carried forward through the cells, vessels, and intercellular passages, by a force which acts by propulsion. The stimulus of light, acting on the cellular tissue of the leaves, enables them to elaborate the organic compounds which are necessary for vegetable nutrition. The leaf-action may be reckoned one of attraction or suction, transpiration 'giving rise to a constant flow of fluids to supply the place of those exhaled.

Dr. Pettigrew has given the following views as to the circulation in plants, and has illustrated them in the accompanying diagram (fig. 242). In spring the sap being mainly concerned in the growth of the branches, development of buds, and evolution of leaves - a vigorous and rapid movement takes place in an upward direction, as at $a$. During summer, when the plant is elaborating secretions, and storing up nourishment, the course of the sap is partly upwards and partly downwards, represented by the arrows at $c d$; the ascending and descending currents are indicated as continuous in the direction of the leaves and roots, and thus as it were constituting a true circulation. In autumn, owing to the fall of the leaf, excess of moisture, and a general waning activity in the plant, there is a marked descent of the sap, as

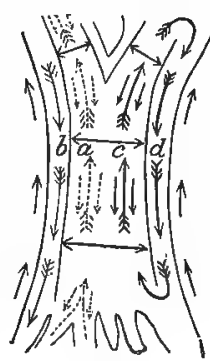

Fig. 242. shown at $b$. But besides, and consequent on, those main currents, others exist. Thus the ascending spring and descending autumn currents, being in great measure endosmotic, give rise to unequal

Fig. 242. Diagram representing the ascending, descending, and transverse currents in the plant. $a$, Ascending or spring current. $b$, Descending ol autumn current. $c d$, Ascending and descending currents of summer; these being continuous in the direction of the leaves and roots. $a c$, Transverse currents. The arrows in this diagram represent the endosmotic currents, the darts the exosmotic ones. 
exosmotic currents in an opposite direction-i.e. downwards and upwards respectively. In summer exosmotic currents flow equally in both directions. These counter-currents are indicated on the diagram by darts pointing in a direction opposite to that of the arrows. One other current exists-viz., a lateral current, represented by horizontal darts. By this current, sap which has been abstracted from the currents passing along the main channels, is diffused into surrounding tissue. Although the upward and downward currents are respectively most vigorous in spring and autumn, still at all periods of the year currents of sap pass both upwards, downwards, and transversely.

In the case of Endogenous plants, observations are still wanting by which to determine the exact course of their fluids. The vascular bundles contain woody vessels, which probably are concerned in the ascent of the sap, and vessels equivalent to those of the bark and of the latex, by which it descends. The cellular tissue is also probably concerned in the movements. Cambium is produced in these plants in the neighbourhood of the vascular bundles, and is thus generally diffused through the texture of the stem. In Acrogenous stems it is likely that the sap follows the same course as in Endogens, although, in regard to both, experiments are still wanting; according to Hoffmann there is no channel for the descent of fluids in Acrogens, the sap simply ascending and diffusing itself in the substance of the plant in its progress. In cellular plants transmission of the sap takes place from one cell to another; and as their texture is often delicate, the movements are rapid. Many of these, as seaweeds, when plunged into water, after having been dried by evaporation, imbibe the fluid with very great rapidity.

The Cadse of the Progression of the SaP has been investigated by numerous physiolegists. While the capillarity of the vessels in the higher plants operates to a certain degree, it would appear that the process of endosmose is that by which the continued imbibition and movement of fluids is chiefly carried on. From the loss of its watery contents, by exhalation, and the metamorphoses going on during the process of nutrition and secretion, the sap becomes gradually more and more dense, and thus throughout the whole plant there is a forcible osmotic transmission of the thinner fluids, and a constant change in the contents of the cells and vessels. These movements will of course take place with greater vigour and rapidity according to the activity of the processes going on in the leaves, which thus tend to keep up the circulation. While the ascending movement of the sap is powerfully promoted by the active operation at the surface of the leaves, its lateral movements are no less influenced by the individual relations of each distinct cell, since the different functions of separate cells, when actively exercised, call into action those vital agencies by which a transmission of the cellular contents is effected. 
Draper attributes the movement of the sap to capillary attraction, which he considers as an electrical phenomenon. This attraction takes place when a fluid moistens a capillary tube, and there can be no flow unless a portion of this fluid is removed from the upper extremity; for capillarity will not of itself raise a fluid beyond the end of the tube. Evaporation and transpiration, which take place in the leares, remove a portion of the vegetable fluids, and thus they promote the capillary action of the vessels. When two fluids of different kinds come into contact in a tube on different sides of a membrane (which membrane, being porous, may be considered as made up of numerous short capillary tubes), that will pass through most rapidly which wets it most completely, or has the greatest affinity for it. Hence, Draper explains the phenomena of endosmose and exosmose by referring them to capillary attraction, aided by transpiration.

Liebig adopts a somewhat similar view of the phenomena. He states that the accurate experiments of Hales have shown the effects of evaporation and transpiration on the movements of sap. Transpiration takes place chiefly in clear and dry weather ; and, consequently, is regulated by the hygrometric state of the atmosphere. When the weather is cloudy and the atmosphere moist, transpiration is checked, and stagnation of the juices takes place. The greater the transpiration, the greater the supply of fluid necessary. Hence, plants kept in the dry atmosphere of rooms fade from want of a due supply to compensate for transpiration; and henee the importance of pruning plants before transplanting them, so as to diminish the evaporating surface, and of performing the operation in dull and moist weather, so as to allow the absorption of fluids to keep pace with the transpiration. This process of transpiration, therefore, by forming a vacuum, assists capillary attraction and the atmospheric pressure, and thus the fluids rise. As the process of endosmose and exosmose depends on the chemical affinity and physical character of the fluids on each side of a membrane, the porosity of the membrane, and the attraction existing between it and either of the fluids, it follows that the nature of the parietes of the cells and vessels of plants must have a marked effect on their contents and secretions.

The observations of physiologists and chemists thus lead to the conclusion that there are four factors concerned in the circulation of the sap in plants-viz. nutrition, acting as a vis a fronte, as is shown by the current setting most strongly in the direction of most rapid growth; osmose, indicated by the difference in density between the fluids of the plants and those supplied to it from without; capillary attraction, consequent on the character of the vessels; and lastly, evaporation, by which the capillary attraction is kept up, osmose favoured, and nutrition facilitated. To these another may be added,-intermittent mechanical strain, produced by swaying in the 
wind, which, as Mr. Spencer has shown, exercises considerable influence not only propulsive on the main ascending and descending currents, but also extravasating into the lateral flows. It may be said that there is a vis a tergo, without the presence of leaves, as shown by the experiments of Hales (fig. 243), combined with a vis a fronte, depending on the suction power of the leaves.

When cut twigs or flowers are put into water, their functions are kept up for some time by endosmose and capillarity. The latter power has great influence in such a case, and hence the cleaner the cut the better, so that no lacerated or ragged edge may interrupt its operation. In these circumstances, also, small solid particles and colouring matters will enter the tubes. Boucherie found that felled trees, the extremities of which were immediately immersed in various solutions, continued to imbibe them with great force and rapidity for many days. A Poplar, 92 feet high, absorbed in six days nearly sixty-six gallons of a solution of pyrolignite of iron.

Heat and light have a powerful influence on the movements of the sap, by promoting transpiration and the action of the cells. After the winter's repose the first genial sunshine of spring stimulates the sap to activity, and after the leaves are expanded the circulation goes on with vigour. The effect of leaf-buds in promoting the movement of sap, may be exhibited by introducing a single branch of a vine growing in the open air into a hothouse during winter, thus exposing it to the action of heat as well as light. In this case the leaves are developed, and the fluids are set in motion from the roots upwards, so as to supply this single branch, although in the other branches there is no increase in the circulation.

In spring, the first effect of light and warmth is to stimulate the leaf-buds. These enlarge, and the osmotic action commences in their cells. The matter stored up during the winter undergoes changes; certain substances are dissolved, and thus the sap is thickened, so that the endosmotic process is powerfully increased, and the whole plant exhibits an active and vigorous circulation. The starch deposited in the previous season becomes converted into sugar and dextrin, it is thus readily acted on by the ascending fluids, and in a state of solution admits of being generally diffused. Towards the latter part of the season when the heat and light decrease, the leaves perform their functions more languidly, and there is a near approach to equilibrium in the density of the fluids, and ultimately there is a cessation of the circulation.

The height to which the sap rises in the case of lofty trees with spreading roots is very great. The force with which it ascends has been measured by Hales, and is found to vary according to the state of the weather and the vigour of the plant. By fastening a bent tube, containing mercury, on the stem of a vine, he found in one of his 
experiments that the sap raised the mercury upwards of thirty inches. The apparatus used by Hales is similar to that used by Dutrochet, to measure endosmose, as is represented at fig. 243, where $c$ is the stem of a vine cut, $t$ is a bent glass tube fitted to the cut extremity of the vine by a copper ring, $v$, carefully luted and secured by a bit of bladder, $m ; n n$, represents the level of the mercury in the two branches of the lower curvature, before the experiment, and $n^{\prime} n^{\prime}$ the level at the conclusion of it. He calculated that the force of the sap in the vine, in some of his experiments, was five times greater than that of the blood in the crural artery of the horse.

Speoial Movements of Fluids. -Besides this general circulation of the sap, special movements have been observed in the individual cells of plants, which have been included under the name of Rotation (rota, a wheel) or Gyration (gyrus, a circuit or circle). These motions have been detected in the cells of many aquatic plants, especially species of Chara and Vallisneria, and in the hairs of Tradescantia. The currents proceed in a more or less spiral direction, and are rendered visible by the granules of chlorophyll which they carry along with them. There exist also other granules in the fluids, which are coloured yellow by iodine, and are probably of a nitrogenous nature.

The species of Chara (fig. 244) in which rotation has been observed, are aquatic plants growing in stagnant ponds, and composed of a series of cylindrical cells, placed end to end. Some-

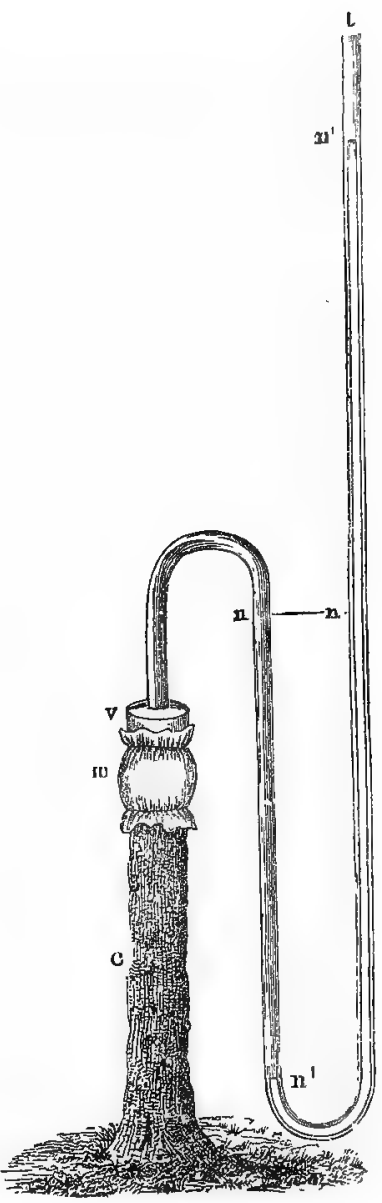

Fig. 243.

Fig. 243. Apparatus of Hales, to show the force of ascent of the sap. c, Stem of a vine cut. $t, \Delta$ glass tube with a double curvature attached to the upper part of the vine-stem, by means of a copper cap, $v$, which is secured by means of a lute and piece of bladder, $m$. $n n$, Level of the column of mercury in the two portions of the tube at the commencement of the experiment. $n w^{\prime}$, Level of the mercury at the conclusion of the experiment. 
times the plant consists of a single central cell ; at other times there are several smaller ones surrounding it, which must be removed in order that the movements which occur in the central cell may be seen. Many of the species are incrusted with calcareous matter, and thus become opaque, while others, as Chara or Nitella flexilis, have no incrustation, and are transparent. Those plants with unincrusted tubular, cells best exhibit movements. In these plants the movements take place between the two membranes of which the cell-wall is composed. They are not interrupted when a division of the cell has been made by

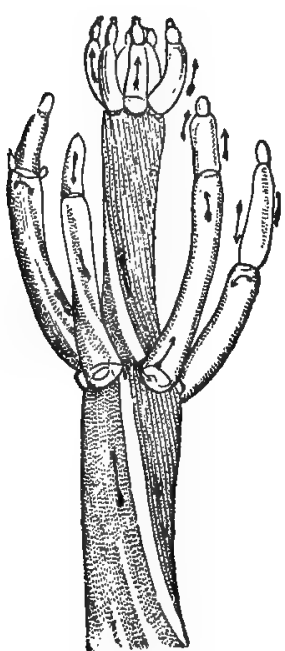

Fig. 241.

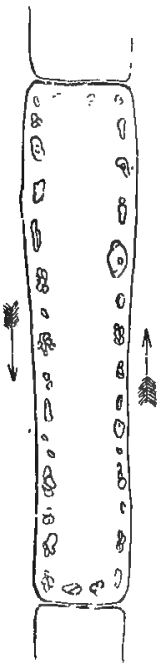

Fig. 245.

means of a ligature; an evident movement may still be observed in either section. Some granules, of a green colour, are attached to the cell-wall, while others are carried with the current which passes along one side and returns by the other, following an elongated spiral direction. In the cells of the branches the descending current is next to the axis. In figure 244 the course of the currents in different cells is indicated by arrows.

In Vallisneria spiralis (which includes V. Micheliana and Jac-

Fig. 244. A small portion of a Chara, magnifled to show the intracellular circulation. The arrows mark the direction of the fluid and granules in the different cells. The clear spaces are parts where there is no movement. The circulation in each cell is independent of that in the others. Fig. 245. Large internal cell of Vallisneria, showing the direction of the currents in intracellular rotation. There is an occasional nucleus seen in the course of the circulation along with the chlorophyll grains. 
quiniana), the cells in all parts of the plant, leaf, root, flower-stalk, and calyx, contain numerous green granules, and an occasional cytoblast or nucleus, which, under certain circumstances, are carried, with the juices of the plant, in continual revolution round the walls of each cell (fig. 245). Although in different cells the currents proceed often in different directions, still in any given cell the rotation is uniform; for if stopped by cold it resumes the same direction. Rotation will continue in detached portions of the plant for several days, or even for three or four weeks. The best way of showing these motions is to take a small portion of a young leaf and divide it in halves, by making a very oblique section on the plane of the leaf, by which means a transparent end is obtained. This should be done at least an hour before it is put under the microscope. The part is to be viewed in water, between two pieces of glass ; and a little heat is sometimes useful in promoting the movements. In Vallisneria the motion ceases at about $45^{\circ}$ Fahr., while in Chara it goes on at a lower temperature; if the temperature be raised above $150^{\circ}$ the motion ceases.

A similar intracellular circulation is seen in species of Potamogeton, Hydrocharis, and Anacharis, as well as in the moniliform purple hairs on the filaments, and in the calycine hairs, of Tradescantia virginica. In the examination of these hairs a higher microscopic power is required than in the case of the plants previously mentioned. A nucleus is usually seen in the cells of these hairs, and it may either remain immovable, or may be carried along with the current. The movements appear to be confined between a double cell-wall. Fig. 246 shows

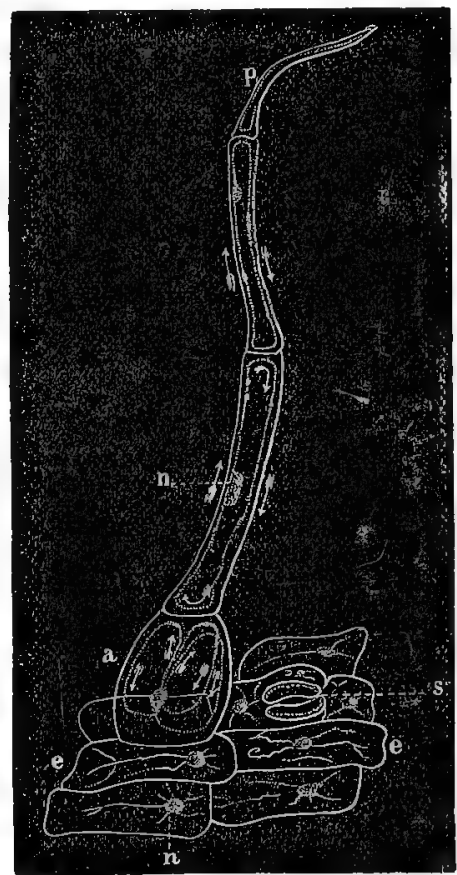

Fig. 246. a calycine hair, $p$, of Tradescantia virginica, with a small portion of

Fig. 246. Hair, $p$, taken from the calyx of Tradescantia virginica, with a small portion of the epidermis, $e e$, on which there is a stoma, $s$. In each of the epidermal cells there is a nucleus, $n$, and currents (rotation), the direction of which is indicated by the arrows. 
the epidermis, $e e$, on which a stoma, $s$, is seen. In each of the cells, both of the epidermis and the hair, there is a nucleus, $n$, and rotatory currents, the direction of which is indicated by the arrows. In each cell, as seen at $a$, there are several currents, which cross each other at the point where the nucleus is situated, thus giving rise to the appearance of an irregular network. The hairs of many other flowering plants exhibit rotation (fig. 90), and it is probable that in all young cells these currents may be observed. The circulating fluid is a mucilaginous protoplasm or formative matter, and in Chara and Vallisneria it forms a uniformly investing layer on the inner surface of the cell. The motions would appear to be connected in some way with the nutrition of cells and the formation of new ones; and while they continue throughout life in aquatics, they often cease in plants living in air, after they have attained a certain development. Mohl's experiments have shown that at the temperature of $66^{\circ}$ Fahrenheit the quickest motion was 1-125th of a Parisian line, ${ }^{*}$ the slowest, 1-600th, and the mean, 1-185th.

Schleiden says that in the Vallisneria cells it is not the cell-sap that is in motion, but a mucilaginous fluid, with which the chlorophyll granules and the nucleus are connected, and which flows in an uninterrupted manner along the cell-walls. In Chara, also, he states it is not the cell-sap which moves, but a denser fluid, present in large quantity, and occupying the outer part of the cell cavity. Mohl thinks that a homogeneous protoplasm fills these cells at first completely, but that during growth it becomes hollowed out into one or more cavities, and that around these the mucilaginous matter circulates.

The velocity of the currents in various plants, at $66^{\circ}$ to $68^{\circ}$ Fahrenheit, is thus given by Mohl :-

Filamental hairs of Tradescantia virginica, $\frac{1}{300}$ to $\frac{1}{00}$ of a Parisian line in a second ; mean, $\frac{1}{600}$.

Leaves of Vallisneria spiralis-quickest, $\frac{1}{125}$; slowest, $\frac{1}{600}$; mean, $\frac{1}{185}$; of a line in a second.

Stinging hairs of Urtica baccifera-quickest, $\frac{1}{627}$; slowest, $\frac{1}{875}$; mean, $\frac{1}{750}$.

Cellular tissue of young shoot of Sagittaria sagittifolia, $\frac{1}{\frac{1}{26}}$ to $\frac{1}{1066}$; mean, $\frac{1}{884}$.

". leaf of do., $1 \frac{1}{17}$ to $\frac{1}{1380}$; mean, $\frac{1}{1256}$.

Hairs of Cucurbita Pepo-quickest, $\frac{1}{770}$; slowest, $\frac{1}{2760}$; mean, $\frac{1}{1887}$.

The measurements were made by noting the passage of the globules across the field of a micrometer, fixed in the ocular of the microscope, and counting the strokes of a seconds pendulum. These movements appear more rapid to the observer; but then it must be recollected that the parts are seen in a highly magnified state.

The cause of those intracellular movements is obscure; both vital

* Parisian line $=088815$ of an inch. 
and physical causes having been adduced in explanation. By some they are considered as connected with the nourishment of the cell, the presence of the nucleus, and the process of cytogenesis. Certain authors have referred the phenomena to endosmose, dependent on varying density in the cell-contents, while electrical agency has been called into requisition by others. In Chara the chlorophyll granules lining the walls of the cells have been supposed to exercise a galvanic action upon the sap, and thus give rise to the motion.

Dr. Pettigrew, from experiments by which he succeeded in inducing similar movements artificially, concludes that the ultimate causes are mainly physical, of which absorption, resulting in endosmose and exosmose, and evaporation, are the chief; and that the phenomena are influenced by the general circulation. He says, "while the cells in the root of the plant inaugurate the general circulation, the general circulation in its turn influences the intracellular circulation. This follows, because when a current of fluid travels up the one side of a thin porous cell-wall, and another and opposite current travels down the other or opposite side, a certain proportion of the currents pass obliquely through the cell-wall, and cause the fluid contents of the cell to gyrate or move in a circle. The cell-contents are made to gyrate, even in the absence of opposing currents outside the cell, if endosmotic and exosmotic currents are induced within it; or if evaporation or capillarity be made to act at certain points."

\section{3.-Respiration of Plants.}

The changes which are produced in the atmosphere by living plants have been included under the title of Vegetable Respiration. The experiments of Priestley, in 1771, show that plants when exposed to light in an atmosphere containing a considerable proportion of carbonic acid, purify the air by removing carbon and producing oxygen. Air in which animals had died was thus rendered again fit for breathing. Percival confirmed those observations. Scheele made a series of experiments with nitrogen in place of carbonic acid, and he found that plants did not purify an atmosphere composed of nitrogen alone. The foul air then, in his experiments, differed completely from that in Priestley's experiments, and hence the difference of results. Ingenhouz and Senebier performed numerous experiments, which proved that during the day plants gave out oxygen gas, while during darkness this process was suspended. The former has shown that the green portions of all vegetables, irrespective of their specific properties, are equally available for such operations ; that it is from the under surface of the matured leaves that oxygen is chiefly given off; and that in plants placed in shade the action of the leaves does not prevent deterioration of the air. Saussure stated that 
during the night oxygen gas was absorbed in different quantities by plants. Fleshy plants absorbed least; next came evergreens, and then deciduous trees and shrubs. This absorption of oxygen is attended with the formation of carbonic and other acids. It has been said that some leaves, on account of this process of oxidation, are acid in the morning, and become tasteless during the day. Decandolle, Ellis, Daubeny, and numerous other observers, have confirmed the conclusions drawn by the early experimenters. The results. of all these observations are, that plants, more especially their leaves and green parts, have the power of decomposing carbonic acid under the influence of solar light, and of evolving oxygen. While in darkness no such decomposition takes place, oxygen is absorbed in moderate quantity, and some carbonic acid is given oft. The former process, caused by the deoxidising or rather decarbonising power of plants, much exceeds the latter in amount. And thus the respiratory process in plants and in animals is antagonistic, consisting in the former of the elimination of oxygen, while in the latter it is the elimination of carbon.

Burnett endeavoured to show that there are two processes constantly going on in plants, one being what he calls digestion, consisting in the fixation of carbon and the evolution of oxygen, and only carried on during the day; the other being what he calls proper respiration, consisting in the evolution of carbonic acid gas, and carried on at all periods of a plant's growth. He thinks that his experiments prove the disengagement of carbonic acid from the leaves of plants both during night and day. Carpenter entertains similar opinions, believing that under all circumstances regetable respiration is a process continued throughout, and essential for vegetable life; that it consists of the elimination from the system of the superfluous carbon, either by its entering into combination with the oxygen of the air, or by giving off carbonic acid to replace the oxygen absorbed. Mr. Pepys is of opinion that the evolution of carbonic acid indicates an abnormal condition of the leaf, which, in the process of healthy active vegetation, absorbs carbonic acid and disengages oxygen, He believes that the action of light leads to the greater perfection of this function, which is less energetically performed if not wholly suspended during the night. The changes produced in the atmosphere are mainly caused by the superficial green parts of plants. The oxygen evolved by plants appears to be derived from the carbonic acid of the atmosphere, the carbon of which is appropriated, and probably partly from the water, the hydrogen of which is assimilated. Light is necessary for these decompositions, and it is probable that the alkalies taken up by the roots aid the process.

If the leaves of a plant are bent under an inverted tumbler of water, in a pnenmatic trough, and exposed to the sun, bubbles of gas 
will soon be given off, which are found to be pure oxygen; and any carbonic acid in the water will be diminished in quantity. The same leaves in darkness will not evolve any oxygen, light being essential for the process. The brighter and longer continued the light, the more oxygen is given off, and the greater the quantity of carbon added to the plant. If a healthy plant is covered by a bell jar, and exposed to light for twelve hours, oxygen will be formed, and if carbonic acid be added to the air, it will be decomposed, and the oxygen will increase. During the night the action is reversed, and if the plant is left twelve hours in darkness, the oxygen will decrease, while carbonic acid will increase. Daubeny, from his experiments respecting the action of plants on a known amount of atmospheric air, states that leaves are requisite for the purification of the air, that the action of light on them gives rise to the emission of oxygen and the decomposition of carbonic acid, that for the elimination of oxygen the presence of carbonic acid is requisite, and that the greatest amount of oxygen which can, by vegetable respiration, be added to air confined within a jar is 18 per cent. The following is a simple experiment showing the production of oxygen by green leaves under the action of light. If a green leaf is placed in an atmosphere conıposed of hydrogen and carbonic acid, and a stick of phosphorus is introduced, no apparent action takes place in the dark, but the moment a beam of light, or the electric light rays, are thrown on it, white fumes of phosphorous anhydride are instantly produced, indicating the combination of the free oxygen, evolved from the leaf under the action of light, with the phosphorus.

The following are the results of Boussingault's experiments on the functions of leaves :-

1. The volume of $\mathrm{CO}_{2}$ decomposed, is identical with that of the oxygen produced.

2. Leaves decompose pure carbonic acid with extreme slowness.

3. Leaves in presence of ordinary air and $\mathrm{CO}_{2}$ effect readily the decomposition of the latter.

4. Leaves decompose $\mathrm{CO}_{2}$ in sunlight, when it is diluted with hydrogen, nitrogen, carbonic oxide, or marsh gas.

5. Leaves lose the power of decompasing carbonic acid as they lose water (becoming dry).

6. The upper surface of thick leaves, such as those of the Cherry Laurel, decompose more $\mathrm{CO}_{2}$ than the under, in the proportion of 4 to $\mathrm{I}$ in the sun; whereas in the shade it is as 2 to 1 . Tueaves having a thin parenchyma do not differ in the power of decomposing in the upper or under surface.

The fixation of carbon probably takes place gradually, giving rise, at different stages, to the formation of various organic compounds. Thus, two molecules of carbonic acid, by losing one atom of oxygen, become oxalic acid; this oxalic acid, with the aid of water, may yield other acids, from which, by the elimination of oxygen and the addition of the elements of water, various unazotised matters, as starch, gum, and sugar, may be derived; these changes being promoted by the 
presence of alkalies. The fixation of carbon and hydrogen from the decomposition of carbonic acid and water gives rise to the formation of the various secretions found in the bark and external cells, as chlorophyll, resin, oil, caoutchouc, and wax.

Carbonic acid in solution, as has already been noticed, is taken up in large quantity by the roots of plants from the soil, and it is also absorbed from the atmosphere by the leaves. It may even be formed in the cells of plants during the various chemical changes connected with the elaboration of their juices and secretions. In the interior of plants it is changed in various ways, but it is in the leaves more especially that its decomposition takes place. At night it is given off unchanged, by what Liebig considers as a mere process of exosmose, in consequence of the dissolved acid being no longer assimilated by the action of light. The quantity of this acid given off during the night is by no means equal to that which is absorbed by the plant during the day.

The parts of plants which are not green seem to absorb oxygen. Thus, roots and subterranean organs act in this way, and the presence of oxygen seems to be necessary for their growth. There are also certain periods in the life of a plant when carbonic acid is very largely given off, even during the day, depending on a chemical change taking .place in the starch of the plant, by which it is converted into sugar. These periods are germination, flowering, and fruiting. The changes alluded to will be discussed when these subjects are considered. When plants are decaying, or are in an unhealthy state, they undergo chemical changes, by which carbonic acid is formed.

Aquatic plants have the power of decomposing carbonic acid highly developed, and thus the preservation of the purity of lakes and ponds is provided for. In Batavian ponds Pistia Stratiotes is remarkable for its purifying effects, and Sir.H. Davy notices the great vigour of aquatic plants in the lake Solfatara, where carbonic acid was constantly bubbling up on the surface. The oxygenation of the water by aquatics has also been observed by Morren of Geneva.

In conclusion, three views of the respiratory process in plants have been advanced--

1. That oxygen is exhaled in large quantity during the day, and a moderate quantity of carbonic acid given off during the night.

2. That carbonic acid is exhaled in greater or less quantity at all times, but during the day it is decomposed, so that oxygen is evolved.

3. That no carbonic acid is evolved by leaves in a healthy state of the plant, but the elimination of oxygen only occurs.

The last view is not now accepted by physiologists. Of the others each has a number of adherents-many able physiologists 
ranging on either side. The view generally adopted is, that plants give out carbonic acid at certain times, and that the green parts of plants under the influence of light decompose the gas, fix the carbon, and eliminate the oxygen.

Experiments have been made as to the effect of the different rays of the spectrum in aiding the decomposition of carbonic acid, by the green parts of plants. The light-giving rays, or those nearest the yellow, appear to have the greatest effect in the fixation of carbon, and in the production of wood; while the heat-giving, and the tithonic or chemical rays, have scarcely any influence.

The tropics and warm climates, where a sky seldom clouded permits the 'glowing sun rays to shine on a luxuriant vegetation, are the constant and inexhaustible source of oxygen, thus contributing to the respiration of the animals, not only of their own latitudes, but also of the temperate and colder zones, where artificial light and warmth must replace the deficient light and heat of the sun, and which thus produce a copious supply of carbonic acid, to be expended on the nutrition of the tropical plants. The life of animals is thus connected intimately with the vegetable productions of the globe, not merely as regards the materials of their food, but also in reference to the air which they breathe.

While the breathing of man and animals, and the various processes of combustion, are constantly abstracting oxygen from the atmosphere, and substituting carbonic acid, plants are decomposing this noxious gas, and restoring the oxygen.

\section{Effects of certain Gases on living Plants.}

It has been already stated that plants can live in an atmosphere containing a considerable proportion of carbonic acid, provided they are exposed to the light. Thus, an atmosphere which could not be breathed by man and animals is capable of supporting vegetable life. Experiments show, however, that plants will not continue to exercise their functions in pure carbonic acid gas, but that in all cases a certain quantity of free oxygen must be present. It has been found that though plants do not thrive in pure nitrogen, nor in hydrogen gas, yet their vitality is not destroyed by the presence of these gases. Saussure observed that a plant of Lythrum Salicaria lived for five weeks in an atmosphere of hydrogen gas. Nitrogen has been proved to be innocuous. These gases seem of themselves to have no directly injurious effects, but to act chiefly by depriving the plants of carbon and oxygen.

There are certain gases, however, which have very prejudicial effects on plants, as proved by the experiments of Turner and Christison. Some of them act as irritant poisons, causing local dis- 
organisation; others as narcotic poisons, inducing a drooping and decay of the entire plant. To the former class belong sulphurous acid gas, hydrochloric acid gas, chlorine and nitrous acid gas; while amongst the latter are included sulphuretted hydrogen, cyanogen, carbonic oxide, and ammonia.

SUlphorous ACID GAS is highly injurious to plants. It produces greyish-yellow dry-looking spots on the leaves, which gradually extend until the leaves are destroyed. The effect resembles much the ordinary decay of the leaves in antumn. The proportion of gas, in some experiments, was only 1 in 9000 or 10,000 parts of air, and the quantity $\frac{1}{5}$ of a cubic inch; and yet the whole unfolded leaves of a mignonette plant were destroyed in forty-eight hours. This proportion of the gas is hardly or not at all discoverable by the smell.

HydRochloRic AcID GAS produces effects similar and scarcely inferior to those of the last-mentioned gas. When $\frac{1}{6}$ of a cubic inch is diluted with 10,000 parts of air, it acts destructively on Laburnum and Larch, destroying the whole vegetation in less than two days. Even when in quantity not perceptible by the smell, it still acts as an irritant poison.

SUlPhURETTED Hydrogen acts in a different way from the acid gases. The latter attack the leaves at the tips first, and gradually extend their operation to the leaf-stalks. When in considerable proportion, their effects begin in a few minutes; and, if diluted, the parts not attacked generally survive if the plants are removed into the air. But in the case of sulphuretted hydrogen, the leaves, without being injured in texture or colour, become flaccid and drooping, and the plant does not recover when removed into the air. It requires a larger quantity of this gas to produce the effects stated. When six cubic inches are added to sixty times their volume of air, the drooping begins in ten hours. This gas then acts like a narcotic poison, by destroying life throughout the whole plant at once.

These observations point out the great injury which is caused to plants by the gases given off during the combustion of coal, and more especially by certain chemical works. In the vicinity of the latter, the vegetation, for a considerable distance around, is often destroyed, particularly in the direction of the prevailing winds of the locality. The atmosphere of large manufacturing towns, in which fuliginous matter and sulphurous gases abound, is peculiarly hurtful to vegetable life. In order to protect plants from such prejudicial influences, Mr. N. B. Ward has invented close glass cases, in which plants can be grown independently of the noxious atmosphere around. These cases consist of a trough containing soil, and a frame of glass, which is accurately fitted upon it. The soil is well supplied with water at first, and after the plants are put in, they are kept exposed to the 
light. In these circumstances they will continue to thrive for a long time, even for years, without any fresh supply of moisture or any direct exposure to the air. These Cases are well fitted for rooms where the dryness of the atmosphere interferes with the vigour of plants, by causing greater exhalation than can be compensated by the absorption of moisture by the roots. Some plants, as Ferns, requiring a humid atmosphere, thrive well in such Cases.

But it is not merely as objects of luxury and curiosity that these Cases deserve notice. They supply an important means of transporting plants, in a living state, to and from foreign climates; and they are in constant use for that purpose. Plants have thus been brought to this country which could not have retained their vitality in the form of seed, and which would have been destroyed by exposure to the sea-breeze and to the vicissitudes of climate experienced during their transport. Plants of Musa Cavendishii have been thus introduced into the 'South Sea Islands, and Tea, Ipecacuan, and Cinchona into our Indian possessions. The stillness of the atmosphere in the Case contributes materially to prevent injurious consequences. In June 1833, Mr. Ward filled two Cases with Ferns, Grasses, etc., and sent them from Britain to Sydney, where they arrived in January 1834. The plants were taken out in good condition, and the Cases were refilled at Sydney, in February 1834, the thermometer then being between $90^{\circ}$ and $100^{\circ}$ Fahrenheit. In their passage to England they encountered very varying temperatures. The thermometer fell to $20^{\circ}$ on rounding Cape Horn, and the decks were covered a foot with snow. In crossing the line the thermometer rose to $120^{\circ}$, and fell to $40^{\circ}$ on their"arrival in the British Channel in the beginning of November, eight months after they had been enclosed. The plants were not once watered during the voyage, and received no protection by day or by night, nevertheless they reached London in a healthy and vigorous condition.

It is a mistake to suppose that the air in the Cases remains unchanged. They are not hermetically sealed; and by the law of diffusion of gases there is a constant although gradual mixture of the external air with that inside, free however from many impurities. Plants will continue to grow for a long time, even in Cases hermetically sealed, if supplied at first with abundance of good soil and water. By the united action of the plant and light, the air undergoes constant changes, and thus continues fit for vegetable life.

\section{4.-Products and Secretions of Plants.}

The sap in its progress through the cells and vessels, and especially in its passage through the leaves, is converted into organisable products, from which the vegetable tissues are nourished and the 
secretions are elaborated. Light, by enabling plants to fix carbon, has an important influence over these secretions. When plants are kept in darkness they become etiolated or blanched, and do not form their proper secretions. Gardeners resort to the practice of blanching when they wish to diminish or destroy certain secretions, and to render plants fit for food; a familiar example of which may be seen in their culture of Apium graveolens (Celery). In speaking of the contents of cells and vessels, allusion has already been made to some of the more important organisable products. It is proposed in this place to take a general view of those vegetable secretions which are connected with the nutrition of plants, or which are important on account of their medicinal or commercial uses. Some of these occur in small quantity, and are limited to certain plants only; others are abundant, and more universal in their distribution. Thus, while quinia and morphia, the active ingredients respectively of Peruvian bark, and opium, are circumscribed, both as regards quantity and distribution, starch, gum, sugar, woody matter, and certain nitrogenous compounds, are more abundant, and more generally diffused throughout the regetable kingdom. The latter substances therefore demand special attention. If a plant is macerated in water and all its soluble parts removed, lignin is left, and the water in which it has been macerated gradually deposits starch. If the liquid is boiled a scum coagulates, formed of albumin and some azotised matters, while gum and sugar remain in solution.

STARCH is a general product, being laid up as a store of nourishment, and undergoing changes at certain periods of a plant's life, which fit it for further uses in the economy of vegetation. It is not usually found in animal cells. It consists of $\mathrm{C}_{6} \mathrm{H}_{10} \mathrm{O}_{5}$, and occurs in grains of various sizes and shapes, having an external membrane, enclosing a soluble substance. By boiling in water, the pellicle bursts, and the contents are dissolved, becoming gelatinous on cooling. The circular markings and striæ seen on the grains, and the part called the hilum, have already been noticed (p. 10). The grains of potato starch, seen by polarised light, exhibit a well-marked black cross, the centre of which corresponds with the hilum. Some plants, such as potato, arrow-root, and wheat, contain a large quantity of starch, which varies, however, in quantity according to the period of growth. Thus, while starch abounds in the potato towards the latter part of the season, it decreases when the tubers begin to germinate in spring. It was found that $240 \mathrm{lbs}$. of potatoes, left in the ground, contained of starch-

In August .

"September

"October

"November

"April

"May
23 to $25 \mathrm{lbs}$, or 9.6 to 10.4 per cent.

32,38

32,40

38,45

38,28

28,20

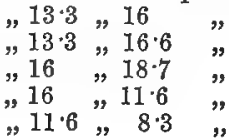


The quantity of starch remained the same during the dormant state in winter, but decreased whenever the plant began to grow.

Starch is stored up in many seeds. It exists in roots, especially in those which are fleshy; in stems; in the receptacles of flowers; and in pulpy fruits. The seed-lobes of the Bean and Pea, and many other leguminous plants; the roots and the underground stem of Maranta arundinacea (arrow-root), and of Canna coccinea (tousles-mois), Canna Achiras and C. edulis; the stem of Sago Palms (Sagus Rumphii and farinifera), and of the Cycas order; the receptacle of the artichoke, and the pulp of the apple, are familiar instances of parts in which starch abounds. The grains of potato-starch are of large size, with pearly or sparkling lustre, having one or more hila, and frequently cracks on the surface. Those of arrow-root are small, and have a dull white appearance, while those of tous-les-mois are larger, and glisten like potato-starch. In some cases starch is associated with poisonous or acrid juices, as in Jatropha Manihot, which yields Cassava and Tapioca, and in Arum maculatum, the underground stem of which furnishes Portland sago. Inulin $\left(\mathrm{C}_{6} \mathrm{H}_{10} \mathrm{O}_{5}\right)$ is a substance analogous to starch, to which Iodine communicates a brown colour. It is found in the roots and tubers of Inula Helenium (Elecampane), Dahlia variabilis, and Helianthus tuberosus (Jerusalem artichoke); while Lichenin is a variety of starch occurring in Cetraria islandica (Iceland moss). Lichenin or lichen starch consists of $\mathrm{O}_{6} \mathrm{H}_{10} \mathrm{O}_{5}$, and is deposited on the primary cell-wall of the plant, in the form of an encrusting layer. By the action of malt, or of sulphuric acid upon starch, by long boiling in water, or by heating up to $400^{\circ}$ Fahrenheit, a soluble gummy substance is produced called dextrin* $\left(\mathrm{C}_{6} \mathrm{H}_{10} \mathrm{O}_{5}\right)$, which, when dried, constitutes British gum. It is one of the steps in the process of the conversion of starch into sugar.

GUM is one of the substances which are produced abundantly in the vegetable kingdom. Its composition is $\mathrm{C}_{12} \mathrm{H}_{22} \mathrm{O}_{11}$, the same as that of Cane-sugar. It exists in many seeds, exudes from the stems and twigs of many trees, and is contained in the juices of others from which it does not exude. It is one of the forms through which organic matter passes during the growth of plants. The different kinds of gums have been divided into those which are soluble in eold water (Arabin, mucilage), and those which only swell up into a gelatinous matter (Bassorin or Tragacanth, Cerasin, and Pectin). Arabin is familiarly known by the name of gnm-arabic or gum-senegal, and is the produce of various species of Acacia, chiefly natives of Arabia, Egypt, Nubia, and Senegambia, such as Acacia Ehrenbergii, tortilis, Seyal, arabica, vera, and albida. From the bark of these plants it exudes in the form of a thick juice, which afterwards concretes into

\footnotetext{
* Dextrin is so celled from possessing the property of effecting the right-handed rotation
} of the plane of polarisation of a ray of polarised light. 
tear's. The characters of gum from the same species of plant are liable to considerable variation; the same tree may yield a transparent or an opaque, a light or a dark coloured gum. Old stunted trees, in hot and dry seasons, yield most gum. Arabin exists with cerasin in the gum of the Cherry and Plum. Mucilage is present in many of the Mallow tribe, as Malva sylvestris, and Althæa officinalis or marsh mallow, also in Linseed. In Sphærococcus crispus, mucilage is present, of which the formula is $\mathrm{C}_{12} \mathrm{H}_{20} \mathrm{O}_{10}$. Bassorin $\left(\mathrm{C}_{12} \mathrm{H}_{20} \mathrm{O}_{10}\right)$ forms the chief part of gum-tragacanth (the produce of several species of Astragalus), and of gum-bassora. It exists in Salep, procured from the tubercules of Orchis mascula, Cerasin $\left(\mathrm{C}_{12} \mathrm{H}_{20} \mathrm{O}_{10}\right)$ is that part of the gum of the Cherry (Cerasus), Plum, and Almond trees, which is insoluble in cold water. Pectin is a substance procured from pulpy fruits, as the apple and pear. It forms a jelly with water, and when dried, resembles gum or isinglass. It is changed by alkalies into pectic acid, which is found in many fruits and esculent roots.

SUGAR.--This substance, which forms an important article of diet, exists in many species of plants. Sugars have been divided into those which undergo vinous fermentation, as Cane and Grape sugar, and those which are not fermentescible, as Mannite. Cane sugar, $\mathrm{C}_{12} \mathrm{H}_{22}$ $\mathrm{O}_{11}$, is procured from Saccharum officinarum (sugar-cane), Beta vulgaris (beet-root), Acer saccharinum (sugar-maple), and many other plants. It has been conjectured that the Calamus or sweet cane mentioned in the old Testament, may be the sugar cane. At all events, the plant was known as early as the commencement of the Christian era. In the East and West Indies, at the present time, numerous varieties of cane are cultivated, such as Country cane, Ribbon cane, Bourbon cane, Violet or Batavian cane, which are distinguished by their size, form, the position and colour of their joints, their foliage, and their glumes. Bourbon cane is richest in saccharine matter. Canes demand a fertile soil, and for their perfect maturation they require from twelve to fourteen months. Those which are grown from planted slips are plant-canes, those which sprout up from the old stems are rattoons. After being cut, the canes are crushed (the pressed canes being called begass), the saccharine juice is extracted, evaporated, and crystallised, as Raw or Muscovado sugar, which is afterwards refined in vacuo, so as to form loaf sugar. In 1870 the import of unrefined sugar in Great Britain amounted to $12,798,631 \mathrm{cwts}$, and of refined sugar $1,710,176 \mathrm{cwts}$.

Maple Sugar is much used in America. It is procured from the sugar maple (Acer saccharinum) by making perforations in the stem, and allowing the sweet sap to flow out. Two or three holes, at the height of eighteen or twenty inches from the ground, are said to be sufficient for an ordinary tree. The season of collecting is from the beginning of February to the middle of April. Beet Sugar is the 
produce of the root of Beta vulgaris, and is extensively manufactured in many parts of the Continent. Manna Sugar, or Mannite, differs from the others in not being fermentescible. Its composition is $\mathrm{C}_{6}$ $\mathrm{H}_{14} \mathrm{O}_{6}$. It is the chief ingredient of Manna, which exudes from the Ornus europæa and rotundifolia. From Sicily and Calabria it is imported under the name of flake-manna. Mannite is found in the juices of Mushroom, in Celery, and in Laminaria saccharina, and Eucalyptus mannifera. Dr. Stenhouse has determined the quantity of Mannite in some sea-weeds as follows :-

Laminaria saccharina

Halydris siliquosa.

Laminaria digitata

Fucus serratus

Alaria esculenta .

Rhodymenia palmata

Fucus vesiculosus .

Fucus nodosus
12 to 15 per cent of Mannite.

5 to 6 per cent ",

4 to 5 per cent

rather less

about the same

2 to 3 per cent

1 to 2 per cent

nearly the same
"9

y

,7

37

9

Knop and Schnederman have detected Mannite in Agaricus piperatus, and other chemists have found it in Cantharellus esculentus, and Clavellaria coralloides.

Grape Sugar, called also Starch sugar or Glucose, is composed of $\mathrm{C}_{6} \mathrm{H}_{12} \mathrm{O}_{6}$. It occurs in the juices of many plants, and is a product of the metamorphosis of starch, cane sugar, and lignin. It may be extracted from dry grapes, and may be prepared from starch by the action of an infusion of malt, or of a substance contained in malt, called Diastase. It is less soluble and less sweet than cane sugar. It gives sweetness to gooseberries, currants, apples, pears, plums, apricots, and most other fruits. It is also the sweet substance of the chestnut, of the brewer's wort, and of all fermented liquors.

LIGNIN is the substance which gives hardness and solidity to the cells and vessels of plants. It exists abundantly in the woody tubes, which may be said to be composed of cellulose forming the parietes, and lignin or sclerogen, forming the encrusting matter in the interior. The latter dissolves in strong nitric acid, forming oxalic acid, while the former is left undissolved. Lignin cannot be separated in the pure state, and hence it's exact composition is unknown. When a portion of the stem of a herbaceous plant, or of newly cut wood, is reduced to small pieces and boiled in successive portions of water, alcohol, ether, diluted acids and alkalies, until everything soluble in these agents is removed, a white fibrous mass remains. This fibrous matter exists in linen and paper; and these substances, when subjected to the action of sulphuric acid, are converted into grape sugar. Lignin gives support to the vegetable texture, and is often deposited in concentric layers. It occurs in large quantity in the wood of trees, and is also present in the stem of herbaceous plants. In some 
cellular plants it is absent, and the object of many horticultural operations, as blanching, is to prevent its formation. Beet-root and white turnips contain only 3 per cent. Lignin is not coloured by iodine.

All these organic substances, consisting of carbon united with ${ }^{7}$ the elements of water, are easily convertible into each other by the action of sulphuric acid and heat. Similar changes are induced during the growth and development of plants, as will be noticed under the head of flowering, fruiting, and germination. In many unazotised matters the proportion of elements is the same, that is, they are isomeric. Thus, cellulose and starch have the same composition $\left(\mathrm{C}_{6} \mathrm{H}_{10} \mathrm{O}_{5}\right)$, and are said to be isomeric. The difference in their qualities seems to depend on the mode in which the atoms which make up the molecule are grouped. The form is altered by a re-arrangement of the component atoms. The unazotised products which have been noticed supply materials for the respiration of man and animals, and probably assist in the formation of fat. It is impossible to notice all the compounds of carbon, oxygen, and hydrogen, found in plants. For example, Salicin, $\mathrm{C}_{13} \mathrm{H}_{18} \mathrm{O}_{7}$, a bitter neutral crystalline substance, is procured from the bark of Salix alba, Helix, purpurea, viminalis, pentandra, etc. ; and Phlorizin, $\mathrm{C}_{21} \mathrm{H}_{24} \mathrm{O}_{10}$, an analogous substance, occurs in the bark of the roots of the apple, pear, cherry, and plum.

Azotised Products.-There are certain azotised products which exist in greater or less quantity in plants, and which are particularly abundant in grains and seeds. The nutritive matter of wheat consists of starch or unazotised matter, separable by washing, and of azotised matter or glutin. Glutin is composed of certain protein compounds (fibrin, casein, albumin, emulsin), containing carbon, oxygen, hydrogen, and nitrogen, with some phosphorus and sulphur. Vegetable fibrin is the essential part of the glutin of wheat, and of the cereal grains. It may be procured by treating with ether the glutinous mass left after kneading wheat flour in linen bags under water. Vegetable casein or legumin is an essential part of the seeds of Leguminous plants, and also of oily seeds. It may be procured in solution from kidney beans and peas, by bruising them in a mortar with cold water, and straining. Vegetable albumin occurs in a soluble form associated with casein. It forms a small proportion of cereal grains. Wheat is said to contain $\frac{3}{4}$ to $1 \frac{1}{2}$ per cent; Rye, 2 to $3 \frac{3}{4}$ per cent; Barley, $\frac{1}{10}$ to $\frac{1}{2}$ per cent; and Oats, $\frac{1}{5}$ to $\frac{1}{2}$ per cent. It is distinguished by coagulating at a temperature of $140^{\circ}$ to $160^{\circ}$, and by not being precipitated by acetic acid. Emulsin, or synaptase, has never been obtained in a state of purity. It is a nitrogenous compound, found in certain oily seeds, as in almonds. It exists in the milky emulsion which these seeds form in water, and it is coagulated by acetic acid, and by heat. In bitter almonds it is associated with a substance 
called amygdalin $\left(\mathrm{C}_{20} \mathrm{H}_{27} \mathrm{NO}_{11}\right)$, on which it acts in a peculiar manner, producing hydrocyanic acid. Diastase is an azotised substance procured from malt, and developed during the germination of plants. It is probably fibrin in an altered state, and it has the power of promoting the conversion of starch into sugar.

The azotised products of plants have a composition similar to blood and muscular fibre, and hence their value in the food of man and animals. The following table gives a general view of the quantity of azotised and unazotised matters occurring in certain plants, with the amount of water and inorganic matter :-

\begin{tabular}{|c|c|c|c|c|c|c|c|c|c|}
\hline \multirow[b]{2}{*}{ Peas. } & \multirow[b]{2}{*}{. } & \multicolumn{3}{|c|}{ Water. } & \multirow{2}{*}{$\begin{array}{c}\text { Azotised } \\
\text { matter. } \\
29\end{array}$} & \multicolumn{3}{|c|}{$\begin{array}{c}\text { Carbonaceous } \\
\text { matter. }\end{array}$} & \multirow{2}{*}{$\begin{array}{c}\text { Ashes } \\
3\end{array}$} \\
\hline & & . & 16 & ... & & $\cdots$ & 52 & $\ldots$ & \\
\hline Beans & ${ }^{\circ}$ & . & 14 & $\ldots$ & 31 & $\ldots$ & 52 & $\ldots$ & 3 \\
\hline Lentils & - & - & 16 & $\ldots$ & 33 & $\ldots$ & 48 & $\ldots$ & 3 \\
\hline Oats & - & - & 18 & $\ldots$ & 11 & $\ldots$ & 68 & $\ldots$ & 3 \\
\hline Barley & - & - & 16 & ... & 14 & $\ldots$ & 69 & $\ldots$ & 2 \\
\hline Potatoes & - & • & 72 & $\ldots$ & 2 & $\ldots$ & 25 & $\ldots$ & 1 \\
\hline Turnips & . & . & 89 & $\ldots$ & 1. & $\ldots$ & 9 & & 1 \\
\hline
\end{tabular}

The following arrangement is given by Fromberg of the comparative value of various plants as articles of food, taking into account the protein compounds, and the starch, gum, and saccharine matter which they contain, the highest value being 100 :-

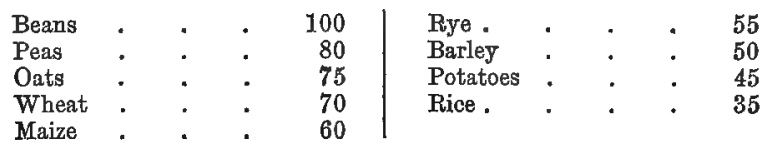

As regards the produce of different crops per acre, Johnston. gives the following estimate of the nutritive products which they yield :-

\section{Average produce pex acre of tubers and grain.}

Beet, Mangel-wurzel, and Turnip 30 tons .
No. of lbs. of true nutriment in produce of an acre. $672 \mathrm{Ibs}$.

\begin{tabular}{|c|c|c|c|c|c|}
\hline Beans & . & & & 30 bushels, or $1980 \mathrm{lbs}$. & 59 \\
\hline Potatoes & - & ${ }^{\circ}$ & & 8 tons & 35 \\
\hline Peas & ${ }^{\circ}$ & & & 20 bushels, or 1160 lbs. & 34 \\
\hline Barley & • & $\theta$ & & 36 bushels, or $1872 \mathrm{lbs}$. & 24 \\
\hline Jerusalem & Artichoke & . & & 10 tons & 22 \\
\hline Wheat & - & - & & 25 bushels, or $1500 \mathrm{lbs}$. & 1 \\
\hline Oats & . & - & - & 30 bushels, or $1200 \mathrm{lbs}$. & \\
\hline
\end{tabular}

FIXED OIIs are found in the cells and intercellular spaces of the fruit, leaves, and other parts of plants. Some of these are drying oils, as Linseed oil, from Linum usitatissimum; others are fat oils, as that from Olives (fruit of Olea europæa); while others are concrete, as Palm oil. The solid oils or fats procured from plants, are Butter of 
Cacao, from Theobroma Cacao; of Cinnamon, from Cinnamomum zeylanicum ; of Nutmeg, from Myristica moschata ; of Coco-nut, from Cocos nucifera; of Laurel, from Laurus nobilis; Palm oil, from Elais guineensis ; Shea butter, from Bassia Parkii; Galam butter, from Bassia butyracea; and Vegetable tallow, from Stillingia sebifera in China, from Vateria indica in India, and from Pentadesma butyracea in Sierra Leone. These oils contain a large amount of stearin, and are used as substitutes for fat. Castor Oil, from the seeds of Ricinus communis, differs from other fixed oils in its composition.

Decandolle gives the following table to show the quantity of oil got from seeds :--

\begin{tabular}{|c|c|c|c|c|}
\hline \multirow{2}{*}{\multicolumn{2}{|c|}{$\begin{array}{l}\text { Hazel-nut } \\
\text { Garden Cress }\end{array}$}} & \multicolumn{3}{|c|}{60 per cent by weight. } \\
\hline & & 57 & $"$ & " \\
\hline Olive. & . . & 50 & $"$ & $\eta$ \\
\hline Walnut & . & 50 & 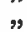 & 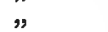 \\
\hline Poppy & - & 48 & 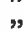 & " \\
\hline Almond & . & 46 & $"$ & $"$ \\
\hline Euphorb & a Lat & 41 & $"$ & $"$ \\
\hline Colza & - & 38 & $"$ & $"$ \\
\hline
\end{tabular}

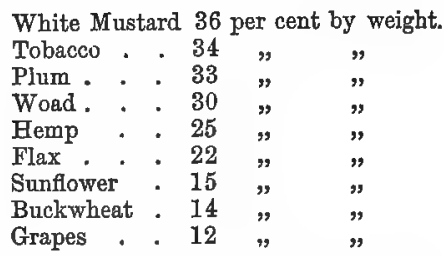

VEGETABLE $W_{\Delta X}$ is a peculiar fatty matter sometimes found in the stem and fruit of plants. It is procured from several species of Palms, as Ceroxylon Andicola, and Copernicia cerifera, and from the fruit of Myrica cerifera (candle-berry myrtle) and Myrica cordifolia. By boiling these plants in water and compressing them the wax exudes, floats on the water, and may be collected and melted. It is of a greenish yellow colour. By saponification it yields stéaric, margaric, and oleic acids, along with glycerin. It therefore more nearly approximates the character of fat than that of wax. Waxy matter also occurs on the exterior of fruits, giving rise to the bloom of grapes, plums, etc., on the outer surface of the bracts of Musa paradisiaca, and on the leaves of many species of Encephalartos. In Cork there exists a fatty substance which, when acted upon by nitric acid, yields suberic acid. Chlorophyll, or the green colouring matter of leaves, is allied to wax in its nature, being soluble in ether and alcohol, but insoluble in water.

Volatile or Essential OrLs occur in the stem, leaves, flowers, and fruit of many odoriferous plants, and are procured by distillation along with water. They are called essences, and contain the concentrated odour of the plant. They usually exist ready-formed, but occasionally they are formed by a kind of fermentation, as oil of bitter almonds, and oil of mustard. Some of them consist of carbon and hydrogen only, as oil of turpentine, procured from various species of Pinus and Abies; oil of juniper, from Juniperus communis; oil of savin, from Juniperus Sabina; oil of lemon and orange, from the rind 
of the fruit; and oil of neroli, from orange flowers. A second series contain oxygen in addition, as oil of cinnamon, from Cinnamomum zeylanicum; otto or attar of roses, from various species of Rose, especially Rosa centifolia; oil of peppermint, from Mentha viridis; oil of caraway, from Carum Carui ; oil of cloves, from Caryophyllus aromaticus. Oils of this kind are procured from many Labiatæ, as species of Lavandula, Origanum, Rosmarinus, Thymus ; and from the fruit of Umbelliferæ, as species of Anethum, Fœniculum, Coriandrum, Cuminum, Petroselinum, Pimpinella; and from some Compositæ, as species of Anthemis, Pyrethrum, and Artemisia. A third series have also sulphur in their composition, and have a peculiar pungent, often alliaceous smell, with an acrid burning taste, as oil of garlic, and of onion, procured from the bulbs of Allium sativum and Cepa; oil of assafotida, from Narthex Assafœetida; and oil of mustard, which is obtained from the seeds of Sinapis nigra when macerated in water by a kind of fermentation induced by the action of a nitrogenous body, myrosin, on a substance called myronic acid, or myronate of potash. A similar oil exists in many Cruciferæ, as in Alliaria officinalis, Armoracia rusticana, and Cochlearia officinalis, and in several Umbelliferæ, yielding gum-resin, as Opoponax, Ferula, Galbanum, etc. Many of the essential oils deposit a solid crystalline matter, called Stearoptene, allied to camphor. This latter substance, which consists of carbon, oxygen, and hydrogen, is procured from Camphora officinarum, a native of Japan and India. There is also another kind of camphor, produced in Borneo, from Dryobalanops Camphora.

Resinous PRODUCTs.-The milky and coloured juices of plants contain frequently resins mixed with volatile oils, in the form of balsams, besides a quantity of caoutchouc. The resinous substances found in plants are either fluid or solid. The former may be illustrated by Balsam of Tolu, procured from Myroxylon toluiferum; Balsam of Peru, from Myroxylon Pereiræ; Balsam of Copaiba from various species of Copaifera, especially Copaifera officinalis and multijuga; Carpathian Balsam, from Pinus Pinea; Strasburg turpentine, from Abies pectinata (silver fir) ; Bordeaux turpentine, from Pinus pinaster ; Canada Balsam, from Abies balsamea (Balm of Gilead fir); Chian turpentine, from Pistacia Terebinthus, etc. The latter may be illustrated by common resin or Colophony, and Burgundy pitch, from Pinus sylvestris ; Mastich, from Pistacia Lentiscus ; Sandarach, from Callitris quadrivalvis; Elemi, from several species of Amyris ; Guaiac, from Guaiacum officinale; Dragon's-blood, from Dracæna Draco, and Calamus Draco; Dammar, from Dammara australis and orientalis ; Labdanum, from Cistus creticus, and other spécies; Tacamahaca, from Calophyllum Cadaba, and from Elaphrium tomentosum ; Resin of Jalap, from Exogonium Purga; Storax, from Styrax officinale; Benzoin, from Styrax Benzoin; Copal, from Vateria indica, etc. Lac, from 
various species of Ficus, as Ficus indica, after attacks of Cocci, and from Aleurites laccifera, and Erythrina monosperma; Euphorbium, from Euphorbia officinarum, antiquorum, and canariensis.

OAOचтсноणC is in some respects analogous to essential oils. It is found associated with them and with resinous matters, in the milky juice of plants. It is the inspissated juice of various species of Ficus, as Ficus elastica, Radula, elliptica, and prinoides, also of Urceola elastica, Siphonia elastica, and Vahea gummifera. A kind of caoutchouc, called gutta percha, imported from Singapore and Borneo, is procured from Isonandra Gutta, one of the Sapotaceæ. The milky juice of many orders of plants, as of Euphorbiaceæ, Asclepiadacex, Apocynaceæ, Artocarpaceæ, and Papayaceæ, contains caoutchouc or gum elastic. Some of these coloured juices are bland, as that produced by the Cow-tree (Galactodendron utile); others are narcotic, as those of Poppy and Chelidonium ; others are purgative, as Gamboge; others diuretic, as Taraxacum.

ORGanTC ACIDS are produced by processes going on in living plants, and exist in vegetable juices often combined with peculiar bases and alkaloids. Thus Citric acid occurs in the fruit of the orange, lemon, lime, red currant, etc. ; Tartaric acid, in the juice of the grape, and in combination with potash in tamarinds ; Malic acid, in the fruit of the apple, gooseberry, and mountain ash ; Tannic acid or Tannin, in oak bark and nut-galls; Gallic acid, in the seeds of Mango; Meconic acid, in the juice of Papaver somniferum; Kinic acid, in the bark of various species of Cinchona. Besides these, there are numerous others, which are characteristic of certain species or genera. To these may be added Hydrocyanic acid, as found in Prunus Laurocerasus, etc., and Oxalic acid, which exists in combination with potash in Rumex acetosa, and Acetosella, Oxyria reniformis, Oxalis Acetosella, and in combination with lime in Rhubarb, and many species of Parmelia and Variolaria.

Alkaloids or Organic Bases are azotised compounds found in living plants, and generally containing their active principles. They occur usually in combination with organic acids. Quinia and Cinchonia exist in the bark of Cinchona, the former predominating in yellow bark, the latter in pale bark; Morphia, Narcotin, Codeia, Thebaia, and Narcein, occur in the juice of Papaver somniferum; Solania is an alkaloid found in many species of Solanum, as Solanum tuberosum, nigrum, and Dulcamara; Veratria exists in Veratrum Sabadilla and album; Aconitia in Aconitum Napellus; Strychnia in Strychnos Nux-vomica, Sancti Ignatii, Colubrina and Tieute; Brucia also in Nux-vomica or false Angustura bark; Atropia in Atropa Belladonna; Beberia in Nectandra Rodiei; Piperin in Piper longum and nigrum; Emetina in Cephäelis Ipecacuanha; Caffein (Thein and Guaranin) in Coffea arabica, Thea Bohea and viridis, Paullinia sorbilis and 
Ilex paraguensis; Theobromin in the seeds of Theobroma Cacao or chocolate; besides numerous others of less importance. These Alkaloids are often found in plants having poisonous properties.

CoLOURING MATTERS are furnished by many plants, either directly or by a process of fermentation. Yellow colouring matters are procured from the roots of Curcuma longa (turmeric), from the pulp surrounding the seeds of Bixa orellana (arnotto), from the Ceylon Gamboge plant (Hebradendron Cambogioides), and various species of Garcinia, as Garcinia Cambogia and' elliptica, from the flowers of Carthamus tinctorius (saflower), from the stigmata of Crocus sativus (saffron), from a kind of Mulberry (Morus tinctoria), from Reseda Luteola (weld), and from some Lichens, as Parmelia parietina (parietin or chrysophanic acid). Red colouring matters are produced from the root of Anchusa tinctoria (alkanet), from Pterocarpus santalinus, Dracæna Draco (dragon's-blood), the root of Rubia tinctorum or madder (alizarin), the root of Morinda citrifolia (sooranjee), from Hæmatoxylon campechianum (logwood), Cæsalpinia braziliana (Brazil wood), Camwood, Carthamus tinctorius (carthamine), and from some Lichens, as Roccella tinctoria (archil and litmus). Blue colouring matters are furnished by the flowers and fruits of many plants, and from the leaves of some, by chemical action. Indigo, a most valuable dye, is procured by fermentation from various species of Indigofera, as Indigofera tinctoria, Anil, cærulea and argentea, as well as from Wrightia tinctoria, Marsdenia tinctoria, Nerium tinctorium, Gymnema tingens, and Isatis tinctoria, etc. The plants in full flower are cut and put into vats with water, fermentation takes place, and a peculiar substance is formed, which, by absorption of oxygen, becomes blue. The best and the largest quantity of indigo is produced on the Delta of the Ganges. Several Lichens yield nitrogenous colouring matters, which give blue and purple colours with alkalies, etc. Lecanora tartarea yields cudbear (Gyrophoric acid). This acid also exists in Gyrophora pustulata.

\section{SeCTION III.-ORgans of REPRODUCTION.}

\section{Structure, Arrangement, and Functions.}

The reproductive organs consist of the flower and its appendages, the essential parts being the stamens and pistil. When the flower, or at least the essential organs, 'are conspicuous, the plants are called Phanerogamous ( $\phi \alpha v \varepsilon \rho \delta \varsigma$, conspicuous, and $\gamma \alpha \dot{\mu} \mu s$, union or marriage), or Flowering plants ; when they are inconspicuous, the plants are Crypto-

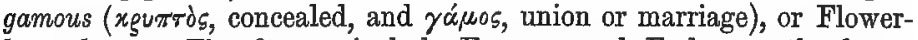
less plants. The former include Exogens and Endogens, the latter Acrogens and Cellular plants. On careful examination it will be 
found that the organs of reproduction and of nutrition are modifications of each other. The parts of the flower, as regards their development, structure, and arrangement, may all be referred. to the leaf as a type. They commence like leaves in cellular projections, in which fibrovascular tissue is ultimately formed; they are arranged in a more or less spiral manner, and are often partially or entirely converted into leaves.

\section{1.-Inflorescence, or the Arrangement of the Flowers on the Axis.}

The arrangement of the flowers on the axis, or the ramification of the floral axis, is called Inflorescence or Anthotaxis (ävAos, a flower, and $\tau \dot{\alpha} \xi \varsigma$, order). Flower-buds, like leaf-buds, are produced in the axil of leaves, and these are called floral leaves or bracts. A flower-bud

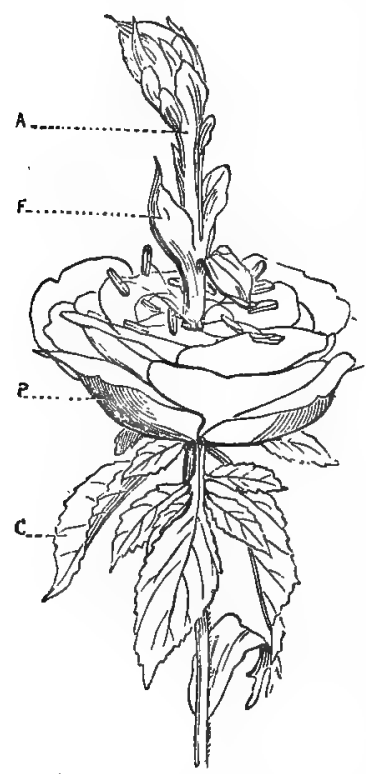

Fig. 247. has not in ordinary circumstances any power of extension by the development of its central cellular portion. In this respect it differs from a leafbud. In some cases, however, of monstrosity, especially seen in the Rose (fig. 247) and 'Geum, the central part, $A$, is prolonged, and bears leaves or flowers. In such cases the flowers are usually abortive, the essential organs being so altered as to unfit them for their functions. Such metamorphoses confirm Goethe's doctrine, that all the parts of the flower are modified leaves.

The general axis of inflorescence is sometimes called rachis ( $\dot{g} a ́ \chi \imath$, the spine); the stalk supporting a flower, or a cluster of flowers, is a peduncle (pes, a foot (fig. $252 a^{\prime}$ ); and if small branches are given off by it, they are called pedicels (fig. $252 a^{\prime \prime}$ ). A flower having a stalk is called pedunculate or pedicellate (fig. 252); one having no stalk is sessile (fig. 258). In describing a branching inflorescence, it is common to speak of the Rachis as the primary floral axis, its branches as the secondary floral axes, their divisions as the tertiary floral axes, and so on; thus avoiding

Fig. 247. Proliferous or monstrous Rose, showing the prolongation of the axis beyond the flowers. e, Calyx transformed into leaves. $p$, Petals multiplied at the expense of the stamens, which are reduced in number. $f$, Coloured leaves representing abortive carpels. $u$, Axis prolonged, bearing an imperfect flower at its apex. 
any confusion that might arise from the use of the terms rachis, peduncle, and pedicel.

The Peduncle may be cylindrical, compressed, or grooved ; simple, bearing a single flower, as in Primrose ; or branched, as in London-pride. It is sometimes succulent, as in the Cashew (fig. $248 p$ ), in which it forms the large coloured expansion supporting the nut; spiral, as in Cyclamen and Val-

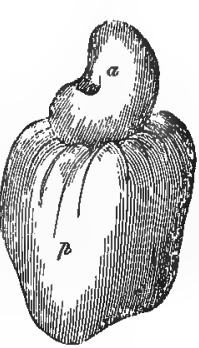

Fig. 248.

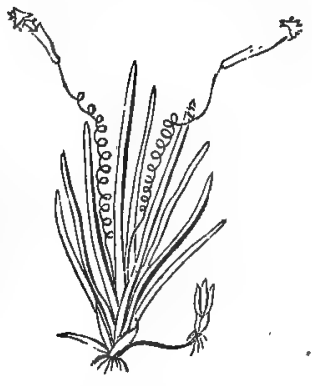

Fig. 249. lisneria (fig. 249); or spiny, as in Alyssum spinosum. In some

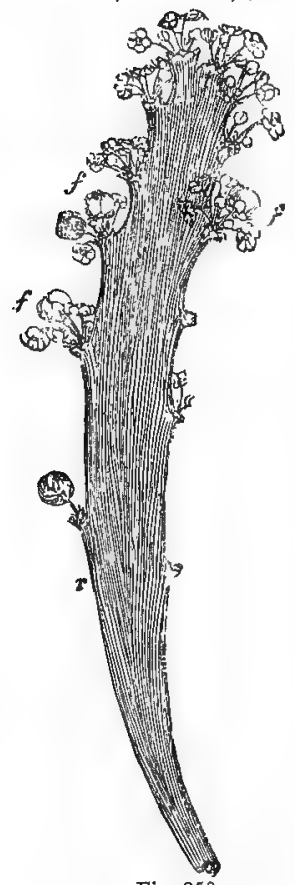

Fig. 250 . rushes there is a green terete and sometimes spiral floral axis (fig. 190). Sometimes the peduncle proceeds from radical leaves; that is, from an axis which is so shortened as to bring the leaves close together in the form of a cluster, as in the Primrose, Auricula, Hyacinth, etc. In such cases it is termed a scape. The floral axis may be shortened, assuming a flattened, convex, or concave form, and bearing numerous flowers, as in the Artichoke, Daisy, and Fig. In these cases it is called a Receptacle or

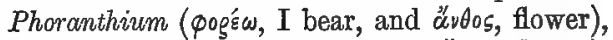
or Clinanthium ( $x \lambda$ ivn, a bed, and üudos, flower).

The Floral axis sometimes assumes a leaf-

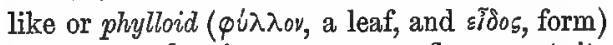
appearance, bearing numerous flowers at its margin, as in Xylophylla longifolia (fig. 250), and in Ruscus; or it appears as if formed by several peduncles united together, constituting a fasciated axis, as in the Cockscomb (fig. 251), in which the flowers form a peculiar crest at the apex of the flattened peduncles. Adhesions occasionally take place between the peduncle and the bracts or leaves of the plant, as in the Lime tree, Helwingia, Chailletia, several species of Hibiscus, and in Zostera. The adhesion of the peduncles to the stem

Fig. 248. Fruit of Cashew (Anacardium ocoidentale). $p$, Enlarged peduncle. $\alpha$, Fruit, or nut. Fig. 249. Pistilliferous plant of Vallisneria spiralis, showing spiral peduncles or flower-stalks, by the uncoiling of which the flowers reach the surface of the water, previous to fertilisation.

Fig. 250. Leaf-like (phylloid) flattened peduncle, $r$, of $\mathbf{X}$ ylophylla longifolia. $f f f$, Clusters of flowers developed in a centrifugal or cymose manner. 
accounts for the extra-axillary position of flowers, as in many Solanaceæ. When this union extends for a considerable length along the stem, several leaves may be interposed between the part where the peduncle becomes free, and the leaf whence it originated, and it may be difficult to trace the connection.

The peduncle occasionally becomes abortive, and in place of bearing a flower, is transformed into a tendril (p. 120); at other times it

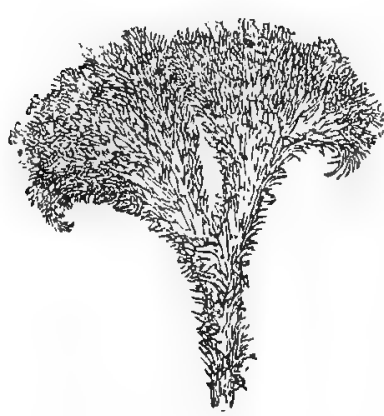

Fig. 251.

is hollowed at the apex, so as apparently to form the lower part of the outer floral envelope, as in Eschscholtzia.

The termination of the peduncle, or the part on which the whorls of the flower are arranged, is called the Thalamus or Torus. The term receptacle is also sometimes applied to this, whether expanded and bearing several flowers, or narrowed so as to bear one. It may be considered as the growing point of the axis, which usually is arrested by the production of the flowers, but which sometimes becomes enlarged and expanded. Thus, in the Geranium, it is prolonged beyond the flower in the form of a beak; in the Arum it is a club-shaped fleshy column (fig. 260, 2, a); in the Strawberry it becomes a conical succulent mass, on which the seed-vessels are placed; while in Nelumbium it forms a truncated tabular expansion, enveloping the seed-vessels. In some cases it bears naked seeds. In some monstrous flowers, as in Rose and Geum, it is prolonged as a branch bearing leaves (fig. 247). The flowers follow a spiral course round the floral axis, which is subject to laws similar to those which regulate phyllotaxis ; this is easily traced in such plants as Banksia.

There are two kinds of inflorescence - one in which flowers are produced in the axil of leaves, beyond which the axis continues to elongate and bears leaves and flowers; whilst in the other the axis ends in a single terminal flower. In the former the flowers are axillary, the axis extends in an indefinite manner, and the flowers, as they successively expand, spring from floral leaves placed higher on the axis than the leaf from which the first flower was developed. In the latter the single solitary flower terminates and arrests the axis, and the flowers developed subsequently, arise from floral leaves below this central flower, and therefore farther removed from the centre.

The first kind of inflorescence is Indeterminate, Indefinite, or Axillary.

Fig. 251. Upper part of flattened or fasciated flowering stem of Celosia cristata (Cockscomb), having the form of a crest, covered with pointed bracts, and supporting flowers on its summit. 
Here the axis is either elongated, producing flower-buds as it grows, the lower expanding first; or it is shortened and depressed, and the outer flowers expand first. The expansion of the flowers is thus centripetal, that is, from base to apex, or from circumference to centre. This kind of inflorescence is shown in fig. 252, where the leaf from which the cluster of flowers is produced, $f$, represents the bract or floral leaf. The rachis, or primary axis of the flower, is $a^{\prime}$; this produces small leaflets, $b$, which bear smaller flower-leaves or bractlets, from which peduncles or secondary axes spring, each bearing single flowers. The whole inflorescence is the product of one branch, the

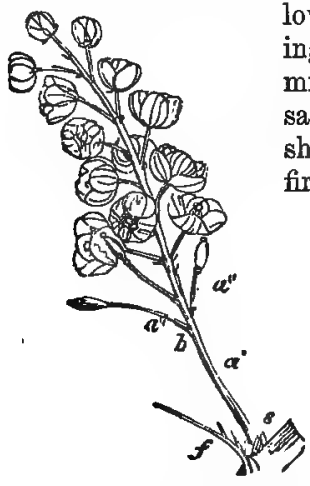

Fig. 252. lower flowers having expanded first, and bearing fruit, while the upper are in bud, and the middle are in full bloom. In fig. 253 , the same kind of inflorescence is shown on a shortened axis, the outer flowers expanding first, and those in the centre last.

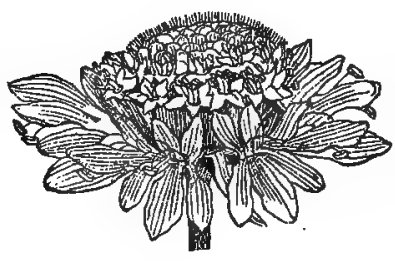

Fig. 253.

The second kind of Inflorescence is Determinate, Definite, of Terminal. In this the axis is either elongated and ends in a solitary flower, which thus terminates the axis, and if other flowers are produced, they belong to secondary axes farther from the centre; or the axis is shortened and flattened, producing a number of separate floral axes, the central one expanding first, while the others are developed in succession farther from the centre. The expansion of the flowers is in this case centrifugal, that is, from apex to base, or from centre to circumference. It is illustrated in fig. 254, where a representation is given of a plant of Ranunculus bulbosus; $a^{\prime}$ is the primary axis swollen at the base in a bulb-like manner, $b$, and with roots proceeding from it. From the

Fig. 252. Raceme of Barberry (Berberis vulgaris), produced in the axil of a leaf or bract, $f$, which has been transformed into a spine, with two stipules, $s$, at its base. $a^{\prime}$, Primary floral axis, bearing small alternate bracts, $b$, in the axil of which the secondary axes, $a^{\prime \prime} a^{\prime \prime}$, are produced, each terminated by a flower: The expansion of the flowers is centripetal, or from base to apex; the lower flowers have passed into the state of fruit, the middle are fully expanded, and those at the top are still in bud. Indeterminate simple inflorescence. Fig. 253. Head of flowers (capitulum) of Scabiosa atro-purpurea. The inflorescence is simple and indeterminate, and the expansion of the flowers centripetal, those at the circumference opening first. 
leaves which are radical proceeds the axis ending in a solitary terminal flower, $f$. About the middle of this axis there is a leaf or bract, from which a secondary floral axis, $a^{\prime \prime}$, is produced, ending in a single flower, $f$ ", less advanced than the flower $f$ '. This secondary axis bears a leaf also, from which a tertiary floral axis is produced, $a^{\prime \prime \prime}$, bearing an unexpanded solitary flower, $f^{\prime \prime \prime}$. From this tertiary axis a fourth is in progress of formation. Here $f^{\prime}$ is the termination of the primary axis, and this flower expands first, while the other flowers are developed centrifugally on separate axes. It is a definite inflorescence, with numerous floral axes.

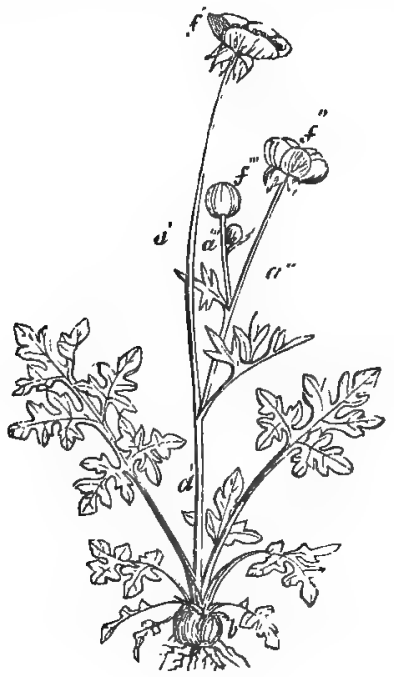

Fig. 254.

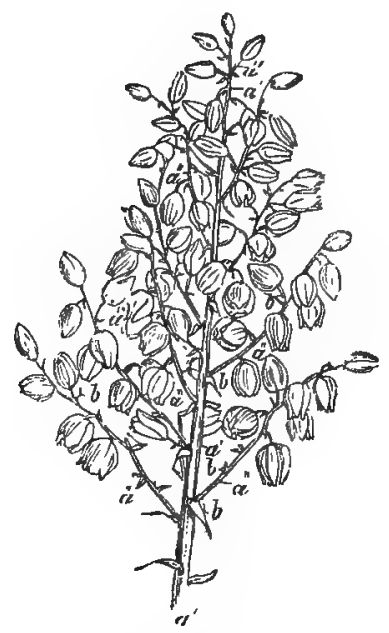

Fig. 255.

INDEFINITE INFLORESCENCE.-The simplest form of this inflorescence is when single flowers are produced in the axils of the ordinary

Fig. 254. Plant of Ranunculus bulbosus, showing determinate inflorescence, $a^{\prime}$, Primàry floral axis dilated at its base, so as to form a sort of bulb, $b$, whence the roots and radical leaves proeeed. $f^{\prime}$, Solitary flower, terminating the primary axis. About the middle of the axis a leaf is developed which gives origin to a secondary axis, $a^{\prime \prime}$, ending in a solitary flower, $f^{\prime \prime}$, which is not so advanced as $f^{\prime}$. On the secondary axis a leaf is formed, from the axil of which a tertiary axis, $a^{\prime \prime \prime}$, proceeds, ending in a flower, $f^{\prime \prime \prime}$, which is still in bud. On this axis another floral leaf and bud is in the progress of formation. Fig. 255. Branching raceme or so-called panicle of Yucca gloriosa. $a^{\prime}$, Primary axis or rachis. $a^{\prime \prime}$, Secondary azes or smaller peduncles. $a^{\prime \prime \prime}$, Tertiary axes or pedicels bearing flowers. $b b b b$, Bracts and bractlets, in the axil of which the axes are produced. The inflorescence is indeterminate and consists of a series of racemes on a common axis, $\alpha^{\prime}$. The expansion of the whole inflorescence is centripetal, and such is also the case with each of the racemes forming it, the flowers at the base of the successive axes opening first. 
leaves of the plant, the axis of the plant elongating beyond them, as in Veronica hederifolia, Vinca minor, and Lysimachia nemorum. The ordinary leaves in this case become floral leaves or bracts, by producing flower-buds in place of leaf-buds. The flowers, being all offshoots of the same axis, are said to be of the same generation or degree, and their number, like that of the leaves of this main axis, is indefinite, varying with the vigour of the plant. Frequently, however, the floral axis, arising from a more or less altered leaf or bract, instead of ending in a solitary flower, is prolonged, and bears numerous leaflets, called bracteoles or bractlets, from which smaller peduncles are produced, and those in their turn may be branched in a similar way. According to the nature of the subdivision, and the origin and length of the flowerstalks, numerous varieties of floral arrangements arise. When the primary peduncle or floral axis, as in fig. $\mathbf{2 5 2} a^{\prime}$, is elongated, and gives off pedicels, $a^{\prime \prime}$, of nearly equal length ending in single flowers, a raceme or cluster is produced, as in Currant, Hyacinth, and Barberry. If the secondary floral axes give rise to tertiary ones, the raceme is branching, and forms what is by some called a panicle; but it is better to restrict this term to the lax inflorescence of some grasses and rushes. In

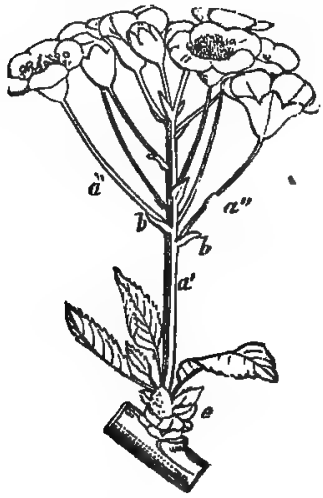

Fig. 256.

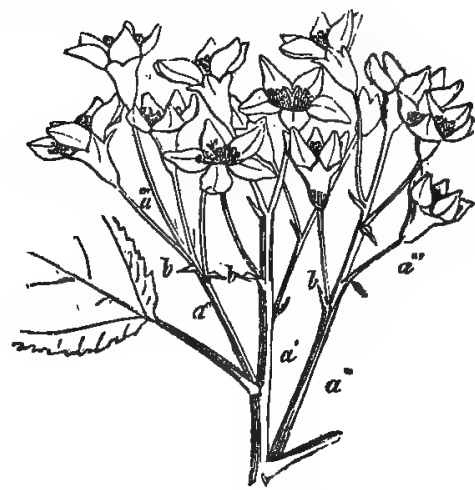

度g. 257.

fig. 255 is represented a branching raceme or so-called panicle of Yucca gloriosa, $a^{\prime}$ being the primary axis or rachis with bracts, giving off numerous secondary axes, $a^{\prime \prime}$, which in their turn develop tertiary axes,

Fig. 256. Corymb of Cerasus Mahaleb, produced in the axil of a leaf which has fallen, and terminating an abortive branch, at the base of which are modified leaves in the form of scales, $e$. $a^{\prime}$, Primary axis, or peduncle, or rachis, producing alternate bracts, $b b$, from the axil of which secondary axes or pedicels, $a^{\prime \prime} a^{\prime \prime}$, arise, each bearing a single flower. The expansion of the flowers is centripetal. Fig. 257. Branching corymb of Pyrus torminalis. $a^{\prime}$, Primary axis, $a^{\prime \prime} a^{\prime \prime}$, Secondary axes. $a^{\prime \prime \prime} a^{\prime \prime \prime}$, Tertiary axes or pedicels bearing the flowers. $b b b$, Bracts. 
$a^{\prime \prime \prime}$. The development in each of the secondary axes is centripetal, $b \quad b \quad b \quad b$ being the bracts from which the separate axes are produced. If in a raceme the lower flower-stalks are elongated, and thus all the flowers are nearly on a level, a corymb is formed, which may be simple, as in fig. 256, where the primary axis, $a^{\prime}$, divides into secondary axes, $a^{\prime \prime} a^{\prime \prime}$, which end in single flowers ; or branching, as in fig. 257, where the secondary axes again subdivide.

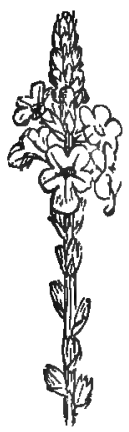

Fig. 258.

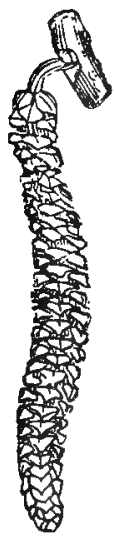

Fig. 259.

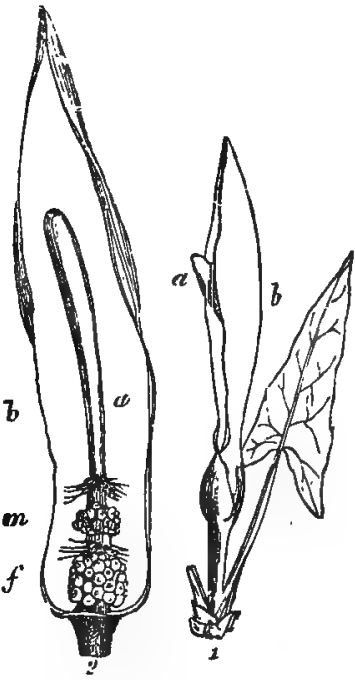

Fig. 260.

If the peduncles or secondary axes are very short or awanting, so that the flowers are sessile, a spike is produced, as in Plantago and Verbena officinalis (fig. 258). The spike sometimes bears unisexual flowers, usually staminiferous, the whole falling off by an articulation, as in Willow or Hazel (fig. 259), and then it is called an amentum or cat7in; at other times it becomes succulent, bearing numerous flowers

Fig. 258. Spike of Verbena officinalis, showing sessile flowers on a common rachis; the inflorescence indefinite, and the evolution of the Hower centripetal. The flowers at the lower part of the spike have passed into fruit, those towards the middle are in full bloom, and those at the top are only in bud. Fig. 259. Amentum or catkin of Hazel (Corylus Avellona), consisting of an axis or rachis covered with bracts in the form of scales (squama), each of which covers a male flower, the stamens of which are seen projecting beyond the scale. The catkin falls off in a mass, separating from the branch by an articulation. Fig. 260. Spadix or succulent spike of Arum maculatum. 1 Exhibits the sagittate leaf, the spathe or sheathing bract, $b$, rolled round the spadix, the apex of which, $a$, is seen projecting. 2 Shows the spathe, $b$, cut longitudinally, so as to display the spadix, $a$. $f$, Female flowers at the base. $m$, Male flowers. On the spadix above the male flowers there are numerous abortive flowers indicated by hair-like projections. 
surrounded by a sheathing bract or spathe, and then it constitutes a spadix, which may be simple, as in Arum maculatum (fig. 260), or branching, as in Palms. A spike bearing female flowers only, and covered with scales, is either a strobilus, as in the Hop; or a cone, as in the Fir (figs. 217,218 ). In grasses there are usually numerous sessile flowers arranged in small spikes, called Locustoe or spikelets, which are either set closely along a central axis, or are produced on secondary axes formed by the branching of the central one; to the latter form the term Panicle is applied.

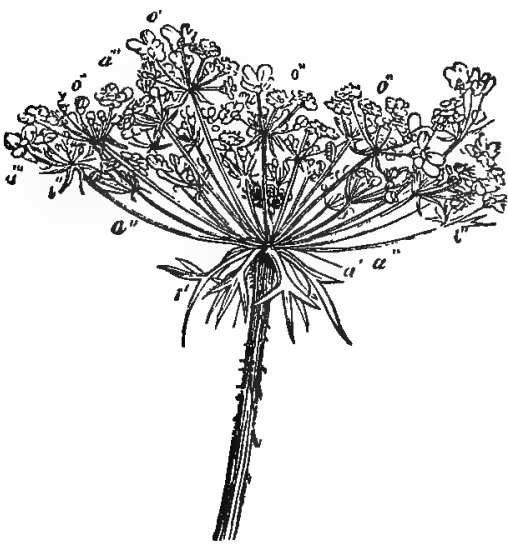

Fig. 262.

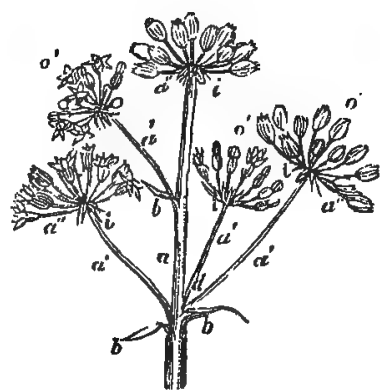

Fig, 261.

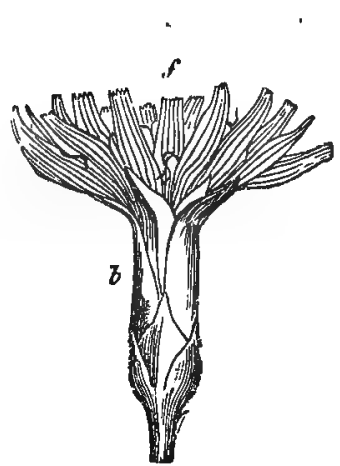

Fig. 263.

If the primary axis, in place of being elongated, is contracted,

Fig. 261. Several umbels, $o^{\prime} o^{\prime} o^{\prime} \sigma^{\prime}$, of Aralia racemosa. $a$, General Axis or the apex of the branch terninated by a single umbel farther advanced than the rest. $a^{\prime} a^{\prime} a^{\prime} a^{\prime}$, Axes arising from it, which are secondary as respects the general axis, $a$; each of them bears an umbel, and as regards this inflorescence they are primary. $a^{\prime \prime} a^{\prime \prime} a^{\prime \prime}$, Secondary axes, or the radii of the umbel. $b \quad b \quad$, Bracts placed alternately on the general axis. $d$, Shows a double budsproceeding from the axil of."one of these bracts, and thus giving rise to two stalked or stipitate umbels. $i i i$, Verticillate bracts, forming involucres at the base of the radii of the umbels. Fig. 262. Compound umbel of Carrot (Daucus Carota). $a^{\prime}$, Primary axis shortened and depressed, so as to present a convex surface. $a^{\prime \prime} a^{\prime \prime}$, Secondary axes, or radii of the general umbel, each ending in a partial umbel or umbellule, $o^{\prime \prime} o^{\prime \prime} o^{\prime \prime} o^{\prime \prime}$. $a^{\prime \prime} a^{\prime \prime \prime}$, Tertiary axes or radii of the partial umbels or umbellules. $i$, Pinnatipartite bracts, forming the general involucre. $i^{\prime \prime} i^{\prime \prime}$, Simple bracts, forming the partial involucre or involucel. Fig. 263. Capitulum, Anthodium, or Head of flowers of Scorzonera hispanica. b, Imbricated bracts, forming an involucre. $f$, Florets or small flowers on the receptacle, having a centripetal evolution. 
it gives rise to other forms of indefinite inflorescence. When the axis is so shortened that the secondary axes arise from a common point, and spread out as radii of nearly equal length, each

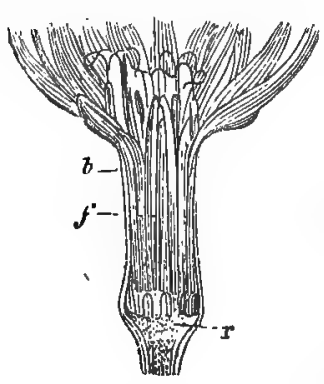

Fig. 264. ending in a single flower, or dividing again in a similar radiating manner, an $U m b e l$ is produced, as in figs. 261 and 262. In fig. 261 the floral axes, $a^{\prime} a^{\prime} a^{\prime}$, end in simple umbels, $o^{\prime} o^{\prime} o^{\prime}$, and the umbels are called stipitate or stallced; while in fig. 262 the primary floral axis, $a^{\prime}$, is very short, and the secondary axes, $a^{\prime \prime} a^{\prime \prime}$, come off from it in a radiating or umbrella-like manner, and end in small umbels, $o^{\prime \prime}$, which are called partial umbels or umbellules, to distinguish them from the general umbel arising from the primary axis. This inflorescence is seen in Hemlock, and other allied plants, which are hence called Umbelliferous.

If there are numerous flowers on a flattened, convex, or slightly

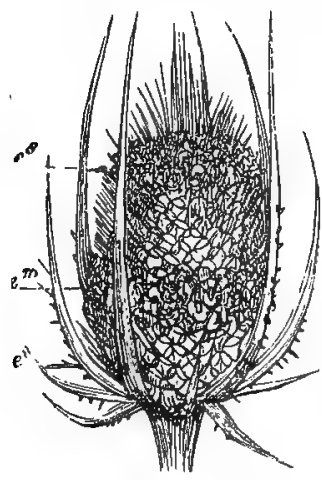

Fig. 265.

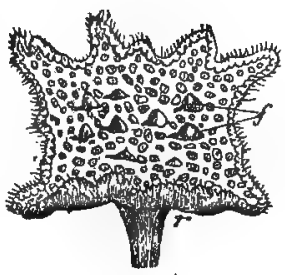

Fig. 266.

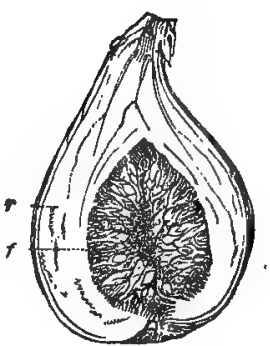

Fig. 267.

concave receptacle, having either very short pedicels or none, a capitulum (head) or anthodium ("̈vAos, a flower, óós, a way or method),

Fig. 264. Capitulum of Scorzonera hispanica cut vertically. r, Receptacle, Phoranthium, or the flattened and depressed apex of the peduncle, bearing the florets, $f$, which are surrounded by bracts, $b$. Fig. 265. Inflorescence of Dipsacus sylvestris. Capitulum, or head of flowers, each of which is surrounded by long pointed bracts. The flowers are evolved in a centripetal manner. $e i$, The first expanded, followed by those at $e m$, while those at the apex, $e s$, are in bud. Fig. 266. Inflorescence of Dorstenia Contrayerva, consisting of a broad slightly concave receptacle, $r$, in which numerous male and female flowers, $f$, are placed. Fig. 267. Inflorescence of Fig (Ficus Carica), showing the hollow receptacle, $r$, or peduncle (which is popularly called the fruit), covered with flowers, $f$, of various kinds. 


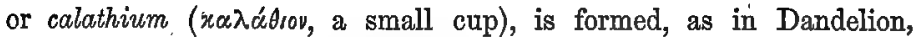
Daisy, and other composite plants (figs. 263 and 264); also in Scabiosa (fig. 253), and Dipsacus (fig. 265). Such a receptacle or shortened peduncle may sometimes be folded so as to enclose partially

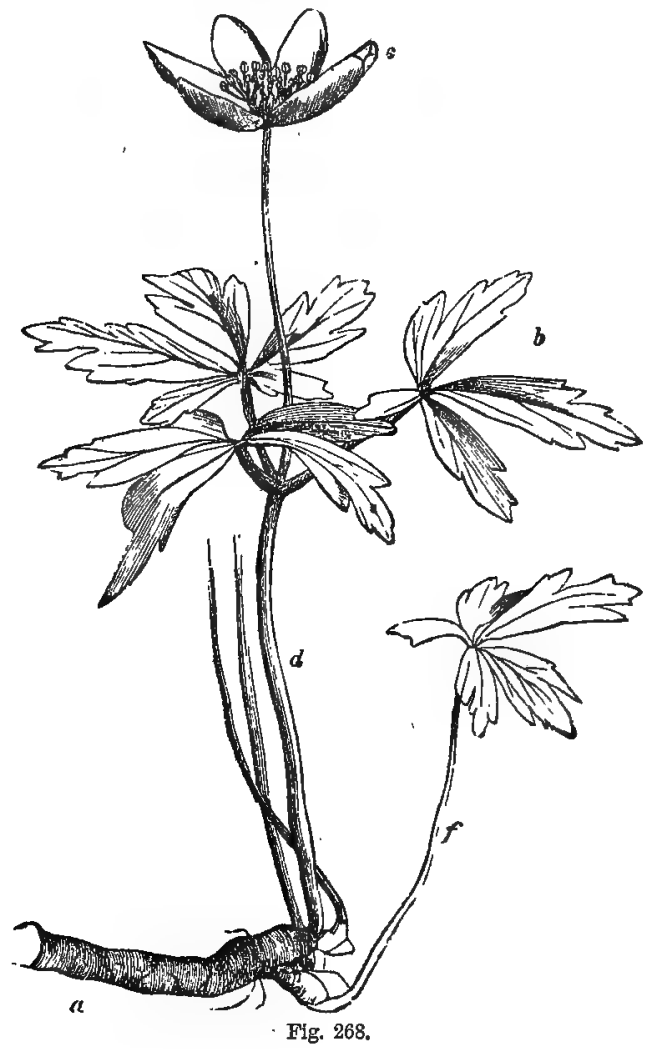

or completely a number of flowers (generally unisexual), giving rise to the peculiar inflorescence of Dorstenia (fig. 266), or to that of the Fig (fig. 267), where $f$ indicates the flowers placed on the inner surface of the receptacle, and provided with bracteoles. This inflorescence

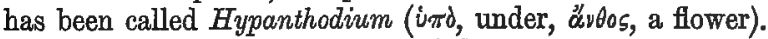

Lastly, we have what are called compound indefinite inflorescences.

Fig. 268. Anemone nemorosa. a, Subterranean stem: $f$, Leaf. $d$, Floral axis producing bracts, $b$, which form a three-leaved involucre. e, Solitary flower terminating the axis. Inflorescence detinite. 
Thus we may have a group of racemes arranged in a racemose manner, on a common axis forming a raceme of racemes or a compound raceme, as in Astilbe. In the same way we may have compound umbels, as in Hemlock and most Umbelliferæ (fig. 262), a compound spike, as in Rye-grass, a compound spadix, as in some palms, and a compound capitulum, as in the Hen-and-Chickens Daisy. Again, there may be a raceme of capitula, that is, a group of capitula disposed in a racemose manner, as in Petasites, a raceme of umbels as in Iry, and so on, all the forms of inflorescence being indefinite in disposition.

On reviewing these different kinds of inflorescence, it will be observed that the elongation or shortening of the axis, and the presence or absence of stalks to the flowers, determine the different varieties. Thus, a spike is a raceme in which the flowers are not stalked, the umbel is a raceme in which the primary axis is shortened, the capitulum or head is a spike in which the same shortening has taken place.

DEFINITE INFLORESCENCE. -The simplest form of this inflorescence is seen in Anemone nemorosa (fig. 268), or in Gentiana acaulis

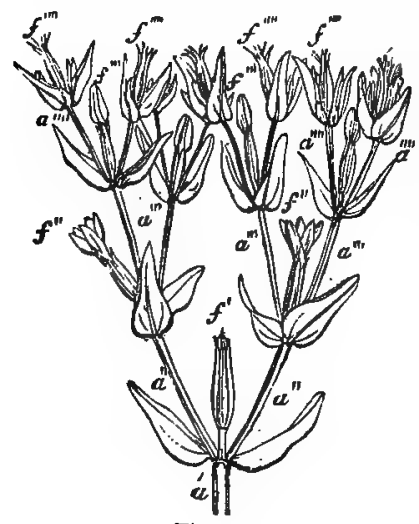

Fig. 269. (Gentianella), where the axis terminates in a single flower; and if other flowers are produced, they arise from the leaves below the first-formed flower. The general name of Cyme is applied to the arrangement of a group of flowers in a definite inflorescence. It is sometimes difficult to understand the mode of development or evolution of the flowers in such an inflorescence, if the axes are much contracted, and the flowers themselves are numerous. It may be distinctly traced, however, in plants with opposite leaves, in which the different axes are clearly developed. In fig. 269 is represented the flowering branch of Erythrea Centaurium. Here the primary axis, $a^{\prime}$, ends in a flower, $f^{\prime}$, which has passed into the state of fruit. At its base two leaves are produced, each of which is capable of developing buds. These are flower-buds, and constitute secondary axes, $a^{\prime \prime} a^{\prime \prime}$, ending in single flowers, $f^{\prime \prime} f^{\prime \prime}$, which are thus terminal and solitary; and at

Fig. 269. Flowering branch of Erythræa Centaurium. $a^{\prime}$, Primary axis, $a^{\prime \prime} a^{\prime \prime}$, Two secondary axes. $a^{\prime \prime \prime} a^{\prime \prime \prime} a^{\prime \prime \prime}$, Tertiary axes, four in number. $a^{\prime \prime \prime} a^{\prime \prime \prime} a^{\prime \prime \prime}$, Quaternary axes, eight in number. 'The flowers are shown in various stages of development. $f$ ', Solitary flower which has passed into fruit, terminating the primary axis. $f^{\prime \prime}$, Flowers less advanced, terminating the secondary axes. $f^{\prime \prime \prime}$, Flowers in bud at the extremity of the tertiary axes, and so on. Inflorescence definite or determinate. Evolution of flowers centrifugal. 
the base of these axes a pair of opposite leaves is produced, giving rise to tertiary axes, $a^{\prime \prime \prime} a^{\prime \prime \prime} a^{\prime \prime \prime}$, ending in single flowers, $f^{\prime \prime \prime} f^{\prime \prime \prime} f^{\prime \prime \prime}$, and so on. The divisions in this case always take place by two, or in a dichotomous ( $\delta^{\prime} x^{\alpha} \alpha$, in two ways, and $\tau^{\prime} \varepsilon \mu v \varepsilon v$, to cut) manner. Had there been a whorl of three leaves in place of two, the division would have been by three, or trichotomous (rgí $\chi \alpha$, in three ways).

This inflorescence constitutes the Cyme, by which we mean an inflorescence formed by the successive development of unifloral axes from pre-existing axes, limited in extent only by the vigour of the plant; the floral axes being thus evolved in a centrifugal manner. The cyme, elongated according to its development, has been characterised as biparous (bis, twice, and pario, I produce), or uniparous (unus, one). In figs. 270 and 271, the biparous cyme is represented

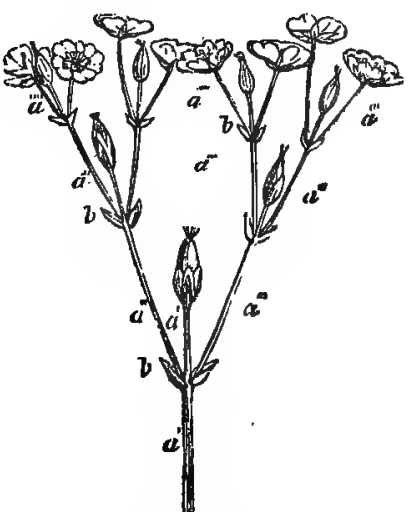

Fig. 270.

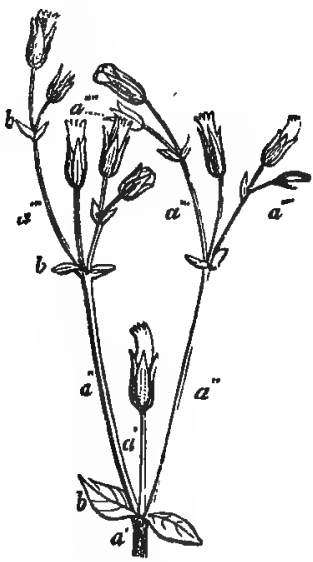

Fig. 271.

in two species of Cerastium, belonging to the natural order Caryophyllaces, in which cymose inflorescence is of general occurrence. The leaves in the figures are small bracts giving origin to flower-buds in the same way as in fig. 269 ; the flowers at $a^{\prime} a^{\prime}$ being the termination of the primary axis, and expanding first, the others being subsequently developed in a centrifugal order. In some of the Pink tribe, as Dianthus barbatus, Carthusianorum, etc., in which the peduncles are

Fig. 270. Inflorescence (biparous cyme) of Cerastium grandiflorum. $b \quad b \quad b$, Opposite bracts produced at each of the branchings. The axes are indicated as in last figure. The primary axis, $a^{\prime}$, ends in a flower which has passed into fruit. Inflorescence determinate. Evolution of flowers centrifugal. Fig. 271. Inflorescence (biparous eyme) of Cerastium tetrandrum. Letters have the same meaning as in the last two figures. In the quaternary axes, $a^{\prime \prime \prime \prime}$, the inflorescence becomes unilateral by the non-development of the flower-buds on one side. 
short, and the flowers closely approximated, with a centrifugal expansion, the inflorescence has a contracted cymose form, and receives the name of fascicle. A similar inflorescence is seen in such plants as Xylophylla longifolia (fig. 250). When the axes become very much shortened, the arrangement is more complicated in appearance, and the nature of the inflorescence is only indicated by the order of opening of

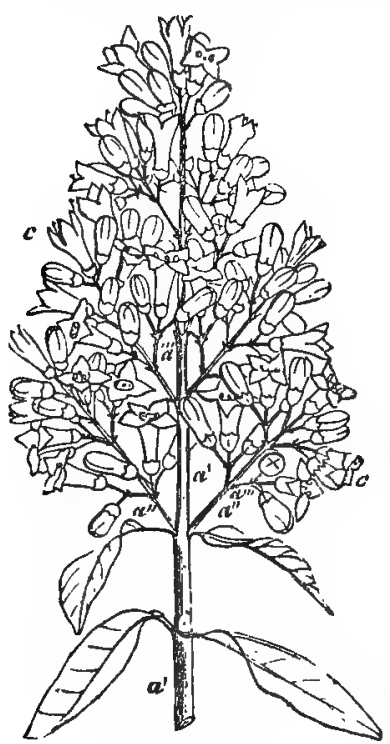

Fig. 272 . the flowers. In labiate plants, as the dead-nettle (Lamium), the flowers are produced in the axil of each of the leaves, and might be looked upon as ordinary whorls, but on examination it is found that the central flower expands first, and from its axis two secondary axes rise, and the expansion is thus centrifugal. The inflorescence is therefore a contracted biparous cyme, the flowers being sessile, or nearly so, and the clusters are called verticillasters (verticillus, a kind of screw). Sometimes, especially towards the summit of a biparous cyme, owing to the exhaustion of the growing power of the plant, one of the bracts only gives origin to a new axis, the other remaining empty, and thus the inflorescence becomes unilateral, and further development is arrested (fig. 271 b).

A branching biparous cyme is observed in the privet (fig. 272). In this the primary floral axis $\alpha^{\prime}$ gives rise to secondary axes $a^{\prime \prime} a^{\prime \prime}$, along its whole length. These, in a similar manner, produce tertiary axes, $a^{\prime \prime \prime}$, which again dividing in a cymose manner, the whole inflorescence acquires an appearance not unlike a bunch of grapes, and has received from some the name of thyrsus.

In the uniparous cyme a number of floral axes are successively developed one from the other, but the axis of each successive generation, instead of producing a pair of bracts, produces only a single one. Here the basal portion of the successive axes collectively forms an apparent or false axis, and the inflorescence thus simulates a raceme. In the raceme, however, we find only a single true axis, producing in succes-

Fig. 272. Branching biparous cyme or thyrsus of Privet (Ligustrum vulgare). The primary axis, $a^{\prime}$, gives off secondary axes, $a^{\prime \prime} a^{\prime \prime}$, which are opposite to eqch other, and produce tertiary axes, $a^{\prime \prime \prime} a^{\prime \prime}$, which are dichotomous, and consequently end in small three-flowered cymes, $c c$. Of the three flowers terminating these tertiary axes, the central one expands first, the evolution of the others being centrifugal. 
sion a series of bracts, from which the floral peduncles arise, and this each flower is on the same side of the true axis as the bract, in the axil of which it is developed; but in the uniparous cyme the flower of each of these axes, the basal part of which unites to form the false axis, is situated on the opposite side of the axis to the bract from which it apparently arises (fig. 275). But this bract is not the one from which the axis terminating in the flower arises, but is a bract produced upon that axis, and gives origin in its axil to a new axis, the basal portion of which, constituting the next part of the false axis (as in fig. 275), intervenes between this bract and its parent axis. The uniparous cyme presents two forms, the scorpioid (scorpio, a scorpion), and the

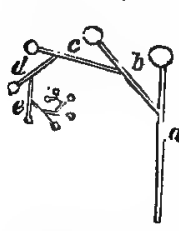

Fig. 273. helicoid ( $\delta \lambda$, \&idos, form). In the scorpioid the flowers are arranged alternately in a double row along one side of the false axis (fig. 274); the bracts when developed forming a second double

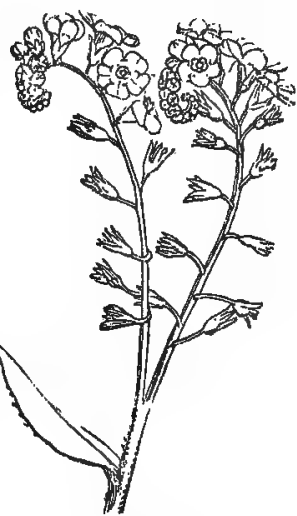

Fig. 274.

row on the opposite side, as seen in the Henbane; the whole inflorescence usually curves on itself like a scorpion's tail, hence its name. In fig. 273 we have a diagrammatic sketch of this arrangement. The false axis $a b c d$ is formed by successive genera- tions of unifloral axes, the flowers being arranged along one side alternately and in a double row; had the bracts been developed they would have formed a similar double row on the opposite side of the false axis ; the whole inflorescence is represented as curved on itself. In fig. 274 (Forget-me-not) the same scorpioid form of uniparous cyme is seen, with the double row of flowers on one side of the false axis, but in this case the bracts, which should appear on the opposite side, are not developed, and hence the cyme is not complete.

In the helicoid cyme there is also a false axis formed by the basal portion of the separate axes, but the flowers are not placed in a double row, but in a single row, and form a spiral or helix round the false axis. In Alströmeria, as represented in fig. 275, the axis, $a^{\prime}$, ends in a flower (cut off in the figure) and bears a leaf. From the axil of this leaf, that is between it and the primary axis, $a^{\prime}$, arises a secondary axis, $a^{\prime \prime}$, ending in a flower $f^{\prime \prime}$, and producing a leaf about the middle. From the axil of this leaf, a tertiary floral axis,

Fig. 273. Diagram to show the formation of a scorpioidal cyme, consisting of separate axes, $a b c d$ e. Fig. 274. Scorpioidal or gyrate cyme of Forget-me-not (Myosotis palustris). 
$a^{\prime \prime \prime}$, ending in a flower $f^{\prime \prime}$, takes origin. In this case the axes are arranged, not in two rows along one side of the false axis, but are placed at regular intervals, so as to form an elongated spiral round it.

In the Bell-flower (Campanula), (fig. 276), there is a racemose uniparous cyme, developed in a very irregular manner, and giving rise to a peculiar mixed inflorescence; $a^{\prime} a^{\prime}$ is the primary axis, ending in a

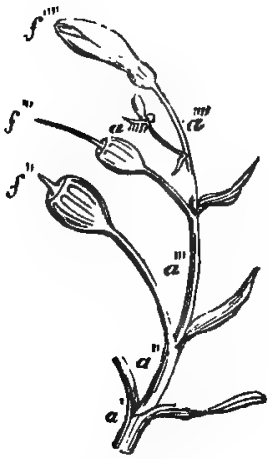

Fig. 275 .

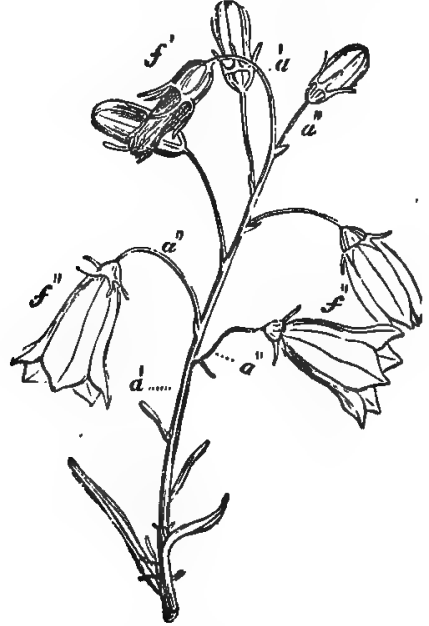

Fig. 276.

flower, $f^{\prime}$, which has withered, and giving off secondary axes, $a^{\prime \prime} a^{\prime \prime}$, each terminated by a flower, and developed centripetally, the lowest being most expanded. In Streptocarpus polyanthus, and in several calceolarias, we probably have examples of compound definite inflorescence. Here there are scorpioid cymes of pairs of flowers, each pair consisting of an older and a younger flower.

MIXED INFLORESCENCE.-Forms of inflorescence occur, in which both the definite and indefinite types are represented. Thus, in Compositæ, such as Hawkweeds (Hieracia), the heads of flowers, taken as a whole, are developed centrifugally, the terminal head first; while the

Fig. 275. False raceme or belicoid cyme of a species of Alströmeria. $a^{\prime} a^{\prime \prime} a^{\prime \prime \prime} a^{\prime \prime \prime}$. Separate axes successively developed, which appear to form a simple continuous raceme, of which the axes form the internodes. It is a defiuite uniparous inflorescence, however, with centrifugal evolution. Each of the axes is produced in the axil of a leaf, and is terminated by a flower, $f^{\prime} f^{\prime \prime} f^{\prime \prime \prime} f^{\prime \prime \prime}$, opposite to that leaf, and the axes have a spiral arrangement. Fig. 276. Uniparous racemose cyme, or cymose raceme of Campanula. $a^{\prime}$, Primary axis, terminated by a flower, $f^{\prime}$, which has already withered, and is beginning to pass into the state of fruit. $a^{\prime \prime} a^{\prime \prime} a^{\prime \prime}$, Secondary axes, each terminated by flowers, $f^{\prime \prime}$, which are more advanced the lower they are in their position. 
florets, or small flowers on the receptacle, open centripetally, those at the circumference first. So also in Labiatæ, such as dead-nettle (Lamium), the different whorls of inflorescence are developed centripetally, while the florets of the verticillaster are centrifugal. Sometimes this mixed character presents difficulties in such cases as Labiatæ, where the leaves, in place of retaining their ordinary form, become bracts, and thus might lead to the supposition of all being a single inflorescence. In such cases, the cymes are described as spiked, racemose, or panicled, according to circumstances. In Saxifraga umbrosa (London pride), and in the horse-chestnut, we meet with a raceme of scorpioid cymes; in sea-pink, a capitulum of contracted scorpioid cymes (often called a glomerulus); in Laurustinus a compound umbel of dichotomous cymes.

In concluding this subject of inflorescence, the following diagrams may serve to illustrate the different types of inflorescence:-

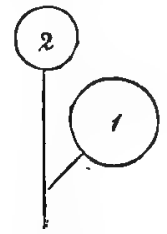

Fig. 277.

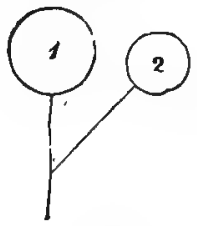

Fig. 278.

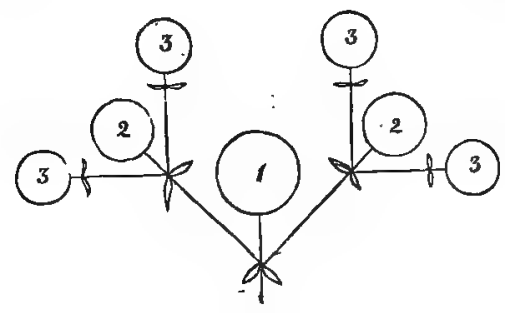

Fig. 279.

Fig. 277 shows an indefinite inflorescence-i.e. one in which all the flowers belong to the same axis. Here we have a single elongated axis, giving off laterally a floret (1), which expands first; beyond this the axis elongates and gives off another floret (2), which expands after the first one-and so on were the axis elongated farther. Thus, in this case, the flowers develop from below upwards, and if we were

Fig. 277 shows indefinite inflorescence, in which the lower floret (1) expinds first, and then the upper floret (2). Fig. 278 shows definite inflorescence, where the terminal floret (I) opens first, and then the lower floret (2). Fig. 279 shows definite inflorescence with numerous floral axes. The first floral axis bears a flower (1), which opens first; from this axis come off two floral axes (2 2), the flowers of which expand next; then each of these gives off two floral axes $(33,83)$, which expand third in order, and so on. 
to shorten the axis, and have all the flowers rising from its contracted termination, we should find that the outer flowers expanded first and were followed by the inner ones, the development being then centripetal, and as the development of flowers from the main axis is limited only by the vigour of the plant, the inflorescence is called indefinite. Fig. 278 shows a definite inflorescence. In this case all the flowers do not belong to the same axis, but the first axis elongates and terminates in a single floret ( 1 ), and no more flowers are produced on this axis, but if another flower exist in the inflorescence it constitutes the terminal floret of a new axis (2), similar to the first, and arising from it. And the flower of this new axis expands after that of the central axis, hence the expansion of florets is from above downwards, or from within outwards, i.e. centrifugal. And as each axis has the power of producing only one floret which terminates it, the inflorescence is definite. If more florets exist in this inflorescence, each one terminates an axis which arises in a manner similar to that already described. Thus the number of florets in such an inflorescence will depend on the number of bracts which are produced upon the several axes, and which give rise to new unifloral axes. Fig. 278 represents such a definite inflorescence, where two bracts are produced on each axis, giving rise to similar new axes; the whole inflorescence in this case being a biparous cyme.

\section{Tabolar VIFW OF INFLónesoence.}

A. Indefinite Centripetal Inflorescence.

I. Flowers solitary, axillary.

Vinca, Veronica hederifolia.

II. Flowers in groups, pedicellate.

1. Elongated form (Raceme), Hyacinth, Laburnum, Currant. (Corymb), Ornithogahum.

2. Contracted or shortened form (Umbel), Conslip, Astrantia.

III. Flowers in groups, sessile.

1. Elongated form (Spike), Plantago.

(Spikelet), Grasses.

(Amentum, Catkin), Willow, Hazel.

(Spadix) Arum, some Palms.

(Cone), Fir, Spruce.

(Strobilus), Hop.

2. Contracted or shortened form (Capitulum), Daisy, Dandelion, Scabious.

IV. Compound indefinite inflorescence.

a. Compound Spike, Rye-grass.

b. Compound Spadix, Palms.

c. Compound Raceme, Astilbe.

d. Compound Umbel, Hemlock and most Umbelliferæ.

e. Raceme of Capitala, Petasites.

$f$. Raceme of Umbels, Ivy.

B. Definite Centrifugal Inflorescence.

I. Flowers solitary, terminal.

Gentianella, Paony. 
II. Flowers in Cymes.

1. Uniparous Cyme.

a. Helicoid Cyme (axes forming a spiral).

* Elongated form, Alströmeria.

* Contracted form, Witsenia corymbosa.

b. Scorpioid Cyme (axes unilateral, two rows).

* Elongated form, Forget-me-not, Symphytum, Henbane.

* Contracted form, Erodium, Alchemilla arvensis.

2. Biparous Cyme (Dichotomous), including 3-5-chotomous Cymes.

a. Elongated form, Cerastium, Stellaria.

b. Contracted form (Verticillaster), Dead-nettle, Pelargonium.

3. Compound Definite Inflorescence.

Streptocarpus polyanthus, many Calceotarias.

C. Mixed Inflorescence.

1. Raceme of Scorpioid Cymes, Horse-chestnut.

2. Scorpioid Cyme of Capitula, Vernonia centriflora.

3. Compound Umbel of Dichotomous Cymes, Laurustinus.

4. Capitulum of contracted Scorpioid Cymes (Glomerulus), Sed-pinte.

\section{2.-Bracts or Floral Leaves.}

Flowers arise from the axil of leaves, called Bractece, bracts or floral leaves. The term bract is properly applied to the leaf, from which the primary floral axis, whether simple or branched, arises, while the leaves which arise on the axis between the bract and the outer envelope of the flower are bracteoles or bractlets. Bracts sometimes do not differ from the ordinary leaves, and are then called leafy, as in Veronica hederifolia, Vinca, Anagallis, and Ajuga. Like leaves, they are entire or divided. In general, as regards their form and appearance, they differ from ordinary leaves, the difference being greater in the upper than in the lower branches of an inflorescence. They are distinguished by their position at the base of the flower or flower-stalk. Their phyllotaxis is similar to that of the leaf. When the flower is sessile the bracts are often applied closely to the calyx, and may thus be confounded with it, as in Malvaceæ and Rosaceæ, where they have received the name of epicalyx (p. 198). In many cases bracts seem to perform the function of protecting organs, within or beneath which the young flowers are covered in their earliest stage of growth.

When bracts become coloured, as in Amherstia nobilis, Euphorbia splendens, Erica elegans, and Salvia splendens, they may be mistaken for parts of the corolla. They are sometimes mere seales of threads, and at other times they are abortive, and remain undeveloped, giving rise to the ebracteated inflorescence of Cruciferæ and some Boraginacer. Sometimes no flower-buds are produced in their axil, and then they are empty. A series of empty coloured bracts terminates the inflorescence of Salvia Horminum. The smaller bracts or bracteoles, which occur among the subdivisions of a branching inflorescence, often produce no flower-buds, and thus anomalies occur in the floral arrangements. 
Bracts are occasionally persistent, remaining long attached to the base of the peduncles, but more usually they are deciduous, falling off early by an articulation. In some instances they form part of the fruit, becoming incorporated with other organs. Thus, the cones of

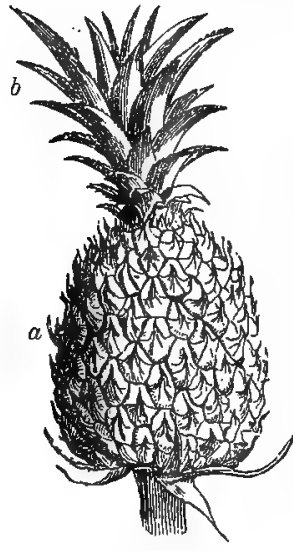

Fig, 280. Firs (figs, 217, 218) and the strobili of the Hop are composed of a series of bracts arranged in a spiral manner, and covering fertile flowers; and the scales on the fruit of the Pine-apple (fig. $280 \mathrm{a}$ ) are of the same nature. In Amenta or catkins (fig. 259) the bracts are called squamoe or scales. As regards their arrangement, they follow the same law as leaves; being alternate, opposite, or verticillate.

At the base of the general umbel in umbelliferous plants, a whorl of bracts often exists, called a general involucre (fig. $262 i^{\prime}$ ), and at the base of the smaller umbels or umbellules there is a similar leafy whorl called involucel or partial involucre (fig. $\left.262 i^{\prime \prime}\right)$. In Compositæ, the name involucre is applied to the leaves, scales, or phyllaries, surrounding the head of flowers (fig. 263 b), as in Dandelion, Daisy, Artichoke. This involucre is frequently composed of several rows of leaflets, which are either of the same or of different forms and lengths, and often lie over each other in an imbricated manner. When the bracts are arranged in two rows, and the outer row is perceptibly smaller than the inner, the involucre is sometimes said to be caliculate, as in Senecio. The leaves of the involucre are spiny in Thistles and in Dipsacus (fig. 265, e i), and hooked in Burdock. Such whorled or verticillate bracts may either remain separate (polyphyllous), or may be united by cohesion (gamophyllous), as in many species of Bupleurum, and in Lavatera. In the acorn they form the cupula or cup (fig. 281, c), and they also form the husky covering of the Hazel-nut. In the yew the bracts form a succulent covering of the seed.

When bracts become united together, and overlie each other in several rows, it often happens that the outer ones do not produce flowers, that is, are empty or sterile. In the artichoke, the outer imbricated scales or bracts are in this condition, and it is from the membranous white scales or bracts (palexe) forming the chole attached

Fig. 280. Fruit of Pine-apple (Ananassa sativa), composed of numerous flowers united into one mass ; the scales, $a$, being modified bracts or floral leaves. The crown, $b$, consists of a prolongation of the axis bearing leaves, which may be considered as a series of empty bracts, i.e. bracts not producing tlowers in their axil. 
to the edible receptacle, that the flowers are produced. The sterile bracts of the Daisy occasionally produce capitula, and give rise to the Hen-and-Chickens Daisy. In place of developing flower-buds, bracts may, in certain circumstances, as in proliferous or viviparous plants, produce leaf-buds.

A sheathing bract enclosing one or several flowers is called a spatha or spathe. It is common among Monocotyledons, as Narcissus, Snowflake, Arum (fig. $260 \mathrm{~b}$ ), and Palms. In some Palms it is 20 feet long, and encloses 200,000 flowers. It is often associated with the spadix, and may be coloured, as in Richardia rethiopica,

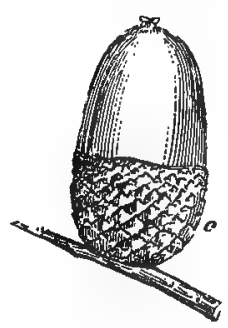

Fig. 281. sometimes called the Athiopian or Trumpet lily. When the spadix is compound or branching, as in Palms, there are smaller spathes, surrounding separate parts of the inflorescence, to which the name spathelloe has sometimes been given. The spathe protects the flowers in their young state, and often falls off after they are developed, or hangs down in a withered form, as in some Palms, Typha, and Pothos. In grasses the outer scales of the spikelets have been considered as sterile bracts, and have received the name of glumes; and in Cyperacer bracts enclose the organs of reproduction.

\section{3.-The Flower and its Appendages.}

The Flower consists of whorled leaves placed on an axis, the internodes of which are not developed. This shortened axis is the Thalamus or torus. There are usually four of these whorls or verticils :-1. The calyx, the outer one. 2. The corolla. 3. The stamens. 4. The most internal one, the pistil. Each of these consists normally of several parts, which, like leaves, follow a law of alternation. Thus, the flower of Crassula rubens (fig. 282) presents a calyx, $c c$, composed of five equal parts arranged in a whorl; a corolla, $p$, also of five parts, placed in a whorl within the former, and occupying the intervals be-

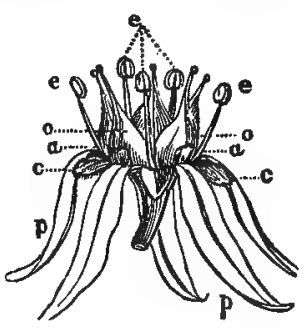

Fig. 282. tween the five parts of the calyx ; five stamens, $e e e$, in the space between the parts of the corolla, and consequently opposite those of the calyx; and five parts of the pistil, o 0 , which follow the same law

Fig. 281. Acorn, or Fruit of the Oak. *, Cupula or cup, formed by the union of numerous bracts or floral leaves, the free points of which are seen arranged in a spiral manner. Fig. 282. Flower of Crassula rubens. ec, Foliola of calyx or sepals. $p, p$, Petals. $e$, Stamens, o o, Carpels, each of them having a small scale-like appendage, $a$, at their base. 
of arrangement. Again, in Scilla italica, the parts are arranged in sets of three in place of five, as shown in fig. 283 , where $p^{\prime} p^{\prime} p^{\prime}$ are three parts of the external whorl ; $p^{\prime \prime} p^{\prime \prime} p^{\prime \prime}$, three of the next whorl ; $e^{\prime}$, an outer row of stamens; $e^{\prime \prime}$, an inner row ; 0 , the pistil formed of three parts. It is distinctly seen in these instances that the parts of the flower are to be regarded as leaves arranged on a depressed or shortened axis.

When all the parts of the flower are separate, and normally developed, there is no difficulty in tracing this arrangement; but in

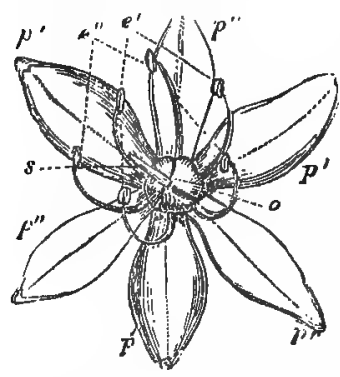

Fig. 283. many cases it is by no means an easy matter to do so, on account of changes produced by the union of one part to another, by degeneration, by the abortion or non-development of some portions, and by the multiplication or folding of others. Of the four whorls noticed, the two outer (calyx and corolla) are called floral envelopes; the two inner (stamens and pistil) are called essential organs. When both calyx and corolla are present, the plants are Dichlamydeous ( $\delta i s$, twice, and $\chi^{\lambda \alpha \mu \nu}$ s, a covering); occasionally one or both become abortive, and then the flower is either Monochlamydeous ( $\mu$ óvos, single), having a calyx only, or Achlamydeous ( $\alpha$, privative) or naked, having only the essential organs, and no floral envelope.

The Floral FinVELOPES consist of the calyz and corolla. In most cases, especially in Dicotyledons, these two whorls are easily distinguishable, the first being external and green, the latter internal, and more or less highly coloured. If there is only one whorl, then, whatever its colour or degree of development, it is the calyx. Some-

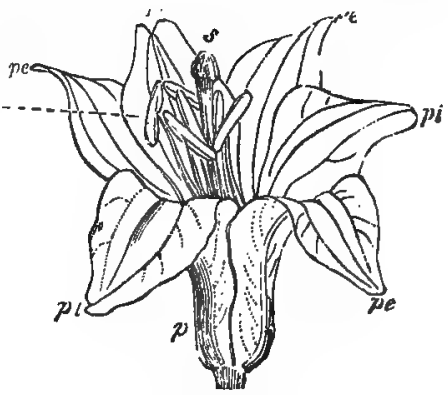

Fig. 284. times, as in many Monocotyledons, the calyx and corolla both display

Fig. 283. Flower of Scilla italica. $p^{\prime} p^{\prime} p^{\prime}$, Three external leaflets, or divisions of the Perianth or Perigone. $p^{\prime \prime} p^{\prime \prime} p^{\prime \prime}$, The three internal leaflets. $e^{\prime}$, Stamens, opposite to the first or external leaflets. $e^{\prime \prime}$, stamens, opposite the second or internal leaflets. o, Ovaries united together into one. $s$, Three styles, consolidated so as to form one. Fig. 284. Flower of White Lily (Lilium album). $\quad p$, Perianth or Perigone, having three parts exterior, $p e$, alternating with three interior, $p i$. e, Stamens, having versatile anthers attached to the top of the filaments. 8 , Stigma at the apex of the style. 
rich colouring, and are apt to be confounded. In such cases, the term

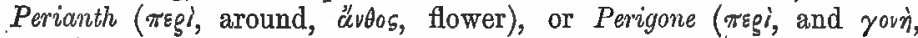
pistil) has been applied to avoid ambiguity. Thus, in the Tulip, Crocus, Lily, Hyacinth, authors speak of the parts of the perianth, in place of calyx and corolla, although in these plants, an outer whorl (calyx) may be detected, of three parts, and an inner (corolla), of a similar number, alternating with them. Thus, the perianth of the white Lily (Lilium album, fig. $284 p$ ) consists of three outer parts, $p e$, alternating with three internal parts, $p i$, surrounding the essential organs, $e$, the stamens, and $s$, the pistil.

The term perianth is usually confined to the flowers of Monocotyledons, whatever colour they present, whether green, as in Asparagus, or coloured, as in Tulip. Some use the term perianth as a general one, and restrict the use of perigone to cases where a pistil -only is present. In some plants, as Nymphæa alba (fig. 342), it is not easy to say where the calyx ends and the corolla begins; as these two whorls pass insensibly into each other.

FLOWER-BUD.-To the flower-bud, the name alabastrus (meaning rose-bud) is sometimes given, and its period of opening has been called anthesis ("̋)vnors, flower opening), whilst the manner in which the parts are arranged with respect to each other before opening is the cestivation (cestionus, belonging to summer), or prcefloration (prae, before, and flos, flower). The latter terms are applied to the flower-bud in the same way as vernation is to the leaf-bud, and distinctive names have been given to the different arrangements exhibited, both by the leaves individually and in their relations to each other. Thus the sepals and petals may be conduplicate, or they may be rolled outwards or inwards in various ways, or may be folded transversely, becoming crumpled or corrugated, as in the poppy. When the parts of a whorl are placed in an exact circle, and are applied to each other by their edges only, without overlapping or being- folded, thus resembling the valves of a seed-vessel, the æstivation is valvate, as in the calyx of Guazuma ulmifolia (fig. $285 \mathrm{c}$ ). The edges of each of the parts may be turned either inwards or outwards; in the former case, the rstiva tion is induplicate, as in the corolla of Guazuma ulmifolia (fig. 285 $p$ ), in the latter reduplicate, as in the calyx of Althra rosea (figs. $286 c, 287 \mathrm{c}$ ). When the parts of a single whorl are placed in a circle, each of them exhibiting a torsion of its axis, so that by one of its sides it overlaps its neighbour, whilst its side is overlapped in like manner by that standing next to it, the æstivation is twisted or contortive, as in the corolla of Althrea rosea (figs. $286 p, 288 p$ ). This arrangement is characteristic of the flower-buds of Malvaceæ and Apocynacer, and it is also seen in Convolvulaceæ and some Caryophyllacee. When the flower expands, the traces of twisting often disappear, but sometimes, as in Apocynaceæ, they remain: 
In these instances of æestivation, the parts of the verticils are considered as being placed regularly in a circle, and about the same height,

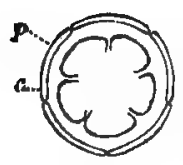

Fig. 285 .

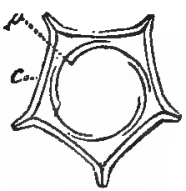

Fig. 286.

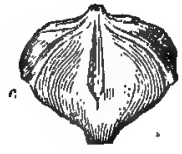

Fig. 287.

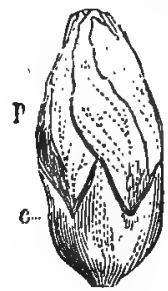

Fig. 288.

and they are included under circular æstivation.. But there are other cases in which there is a slight difference of level, and then the true spiral arrangement exhibits itself. This is well seen in the leaves of

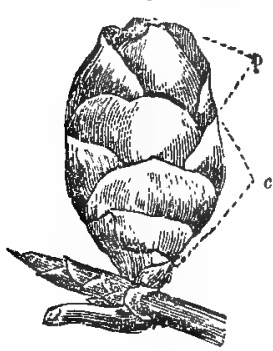

Fig. 289. the calyx of Camellia japonica (fig. 289 c), which cover each other partially like tiles on a a house. This æstivation is imbricate. At other times, as in the petals of Camellia (fig. $289 p$ ), the parts envelop each other completely, so as to become convolute. This is also seen in a transverse section of the calyx of Magnolia grandiflora (fig. 291), where each of the three leaves embraces that within it. When the parts of $a$ whorl are five, as occurs in many Dicotyledons, and the imbrication is such that there are two parts external, two internal, and a fifth which partially covers one of the internal parts by its margin, and is in its turn partially covered by one of the external parts, the rstivation is quincuncial (fig. 290). This quincunx is common in the corolla of Rosaceæ. Fig. 290 is a transverse section of the calyx in the flower-bud of Convolvulus sepium, in which the parts are numbered according to their arrangement in the spiral cycle, and the course of the spiral is indicated by dotted lines. In fig. 292, a section is given of the bud of Antirrhinum majus, showing the imbricate spiral arrangement. In this case it will be seen, when contrasted

Fig. 285. Diagram of calyx, $c$, and corolla, $p$, in the bud of Guazuma ulmifolia, Astivetion of calyx valvate, of petals induplicate. Fig. 286. Diagram of calyx, $c$, and corolla, $p$, in the flower-bud of Althwa rosea. Estivation of calyx reduplicate, of petals contortive or twisted. Fig. 287. Flower-bud of Althea rosea in a young state, showing calyx, $c$, still completely enveloping the other parts, and the edges of its divisions touching each other. Fig. 288. The same in a more advanced state, where the calycine divisions, $c$, are separated so as to allow the expansion of the corolla, the petals of which, $p$, are contortive in xstivation. Fig. 289. Flower-bud of Camellia japonica. c, Imbricated sepals of the calyx. p, Petals with convolute astivation. 
with fig. 290 that the part marked 2 has, by a slight change in position, become overlapped by 4 . In flowers, such as those of the Pea (p. 205, fig. 316), one of the parts, the vexillum, is often large and folded over the others, giving rise to vexillary æstivation, or the carina may perform a similar office, and then the rstivation is carinal.

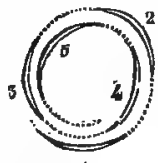

Fig. 290.

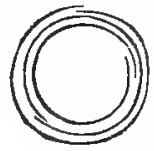

Fig. 291.

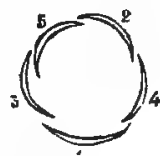

Fig. 292.

The several verticils often differ in their mode of æstivation. Thus, in Malvacex, the corolla is contortive and the calyx valvate, or reduplicate (fig. 288); in St. Johns-wort the calyx is imbricate, and the corolla contortive. In Convolvulacer, while the corolla is twisted, and has its parts arranged in a circle, the calyx is imbricate and exhibits a spiral arrangement (fig. 290). In Guazuma (fig. 285), the calyx is valvate, and the corolla induplicate. The circular æstivation is generally associated with a regular calyx and corolla ; while the spiral æstivations are connected with irregular as well as regular forms.

The different parts of the flower, besides having a certain position as regards each other, bear also definite relations to the floral axis whence they arise. An individual part of a flower may be turned to one or other side of the axis, to the right or to the left. This law often holds good with whole groups of plants, and a means is thus given of characterising them. If a whorl of the flower consists of fourl parts, that which is turned towards the floral axis is called superior or posterior, that next the bract whence the pedicel arises is inferior or anterior, while the other two are lateral. If, again, there are five parts of the whorl, then two may be inferior, two lateral, and one superior, as in the corolla of the Pea tribe; or one may be inferior and two superior, as in the corolla of the Rose tribe. In plants having blossoms like the Pea, the vexillum, or odd petal, is the superior part; whilst in the calyx the odd part, by the law of alternation, is inferior. Sometimes the twisting of a part makes a change in the position of other parts, as in orchids, where the twisting of the ovary changes the position of the labellum.

\section{External Floral Whorls, or Floral Envelopes.}

CALYX.- The calyx is the external envelope of the flower, and consists of verticillate leaves, called sepals, foliola or phylla (folium,

Fig. 290. Transverse section of calyx in flower-bud of Convolvulus sepium. Calyx consists of five sepals corresponding to the numbers in the figure, and the dotted lines indicate the direction of the spiral according to which they are arranged. Fig. 291. Transverse section of the bud of Magnolia grandiflora, showing the convolute astivation of the three outer leaflets (calyx). Fig. 292. Arrangement of the parts of the calyx in the flower of Frogsmouth (Antirrhinum majus). The arrangement differs from that in fig. 290, on account of a slight twisting and overlapping of the parts. 
and $\varphi^{\prime} \lambda \lambda o v$, a leaf). These calycine leaves are sometimes separate from each other, at other times they are united to a greater or less extent; in the former case, the calyx is dialysepalous (dra $\lambda \dot{u} \varepsilon s$, to divide),

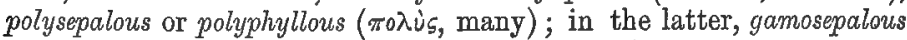

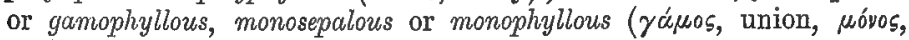
one). The divisions of the calyx present usually all the characters of leaves, and in some cases of monstrosity they are converted into the ordinary leaves of the plant. This is frequently seen in the Rose (fig. 247 c, p. 172), Pæony, etc. Their structure consists of cellular tissue or parenchyma, traversed by vascular bundles, in the form of ribs and veins, containing spiral vessels, which can be unrolled, delicate woody fibres, and other vessels, - the whole being enclosed in an epidermal covering, having stomata and often hairs on its outer surface, which corresponds to the under side of the leaf.

In the great divisions of the vegetable kingdom, the venation of the calyx is similar to that of the leaves; parallel in Monocotyledons, reticulated in Dicotyledons. The leaves of the calyx are usually entire (fig. 293), but occasionally they are cut in various ways, as in the Rose (fig. $294 \mathrm{cf}$ ), and they are sometimes hooked at the margin, as in Rumex uncatus (fig. $295 \mathrm{ci}$ ). In the last-named plant there

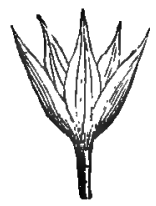

Fig. 293.

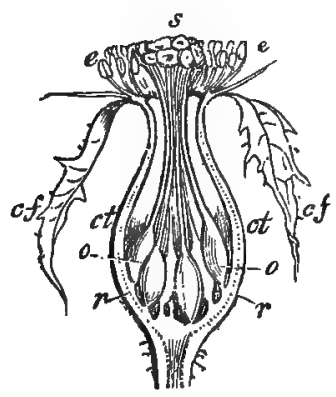

Fig. 294.

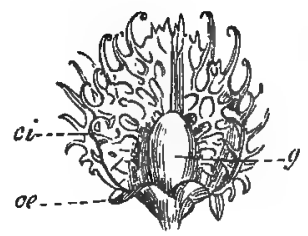

Fig. 295.

are two whorls of calycine leaves, the outer of which, ce, are entire, while the sepals of the inner whorl have hooked margins and have also swellings, $g$, in the form of grains or tubercles on the back. The outer leaves, ce, may be looked upon in this case as bracts, occupying an intermediate place between leaves and sepals. It is rare to find

Fig. 293. Pentaphyllous or pentasepalous calyx of Stellaria Holostea; sepals entire. Fig. 294. Flower of Rose, cut vertically, ot, Tube of the calyx of, Limb of calyx divided into leafiets. ee, Stamens. 0 o, Ovaries, each having a style which reaches beyond the tube of the calyx, and ends in a stigma, s. $r$, Receptacle. Fig. 295. Calyx of Rumex uncatus, composed of two verticils or whorls; the outer, ce, having short and entire divisions; the inner, oi, having larger divisions, which exhibit at the margin narrow hooked projections, and have on the back a tubercular swelling, $g$. 
the leaves of the calyx stalked. They are usually sessile leaves, in which the laminar portion is only slightly developed, and frequently the vaginal part is alone present. Sepals are generally of a more or less oval, elliptical, or oblong form, with the extremity either blunt or acute. In their direction they are erect or reflexed (with their apices downwards), spreading outwards (divergent or patulous), or arched inwards (connivent). They are usually of a greenish colour, and are called foliaceous or herbaceous; but sometimes they are coloured, as in the Fuchsia, Tropæolum, Globe-flower, and Pomegranate, and are then called petaloid. Whatever be its colour, the external envelope of the flower must be considered as the calyx.

The nature of the hairs on the calyx gives rise to terms similar to those already mentioned as applied to the surfaces of other parts of plants (p. 33). The vascular bundles sometimes have a prominent rib (figs. 296, 297), which indicates the middle of the sepal, at other times they have several ribs (fig. 298). The venation is useful as pointing out the number of leaves which form a gamosepalous calyx. At the part where two sepals unite, there is occasionally a prominent line, formed by the

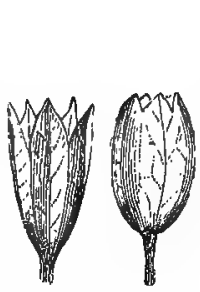

Fig. 296. Fig. 297.

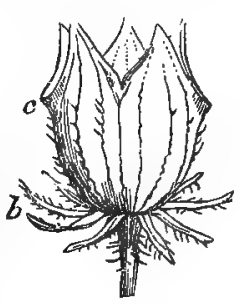

Fig. 298. union of the vessels of each (fig. 298), which divides near the apex into two branches, each following the course of their respective sepals.

In a polysepalous calyx, the number of the parts is marked by Greek numerals prefixed. Thus, a trisepalous calyx has three sepals, pentasepalous or pentaphyllous, five, as in Stellaria Holostea (fig. 293), and so on. The sepals occasionally are of different forms and sizes. In Aconite, one of them is shaped like a helmet, and has been called galeate (galea, a helmet). In Calcophyllum one of the sepals enlarges after the corolla falls, and assumes a pink colour. In Clerodendron Thomsonæ the white calyx becomes pinkish after the scarlet corolla withers.

In a gamosepalous calyx the sepals adhere in various ways, sometimes very slightly, as in CEnothera; and their number is marked by the divisions at the apex. These divisions are either simple projections in the form of acute or obtuse teeth (fig. 297); or they extend down the calyx as fissures about half-way, the calyx being trifid (three-cleft), quinquefid (five-cleft), as in Primula elatior (fig. 296), according to their number; or they reach to near the base in the form of partitions,

Fig. 296. Quinquefid or five-cleft calyx of Primula elatior, the oxlip. Fig. 297. Fivetoothed inflated calyx of Silene inflata. Fig. 298. Calyx, c, of Hibiscus, with its caliculus or epicalyx, $b$. 
the calyx being tripartite, quadripartite, quinquepartite, etc. The adhesion or union of the parts may be complete, and the calyz may be quite entire or truncate, as in some Correas, the venation being the chief indication of the different parts. The adhesion is sometimes irregular, some parts uniting to a greater extent than others; thus a two-lipped or labiate calyx is formed, which, when the upper or posterior lip is arched, becomes ringent. The upper lip is often composed of three parts, which are thus posterior or next the axis, while the lower has two, which are anterior. The part formed by the union of the sepals is called the tube of the calyx; the portion where the sepals are free is the limb. Sometimes a gamosepalous calyx assumes an angular or prismatic form, as in Lamium and Primula, and then the angles are marked by the midribs of the sepals which form it. Occasionally the calyx has a globular form, as in the globeflower, at other times it is bell-shaped, funnel-shaped, turbinate (like a top), or inflated as in Silene inflata (fig. 297).

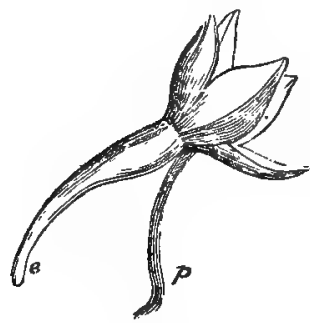

Fig. 299.

Occasionally, certain parts of the sepals undergo marked enlargement. In the Violet, the calycine segments (lacinice) are prolonged downwards beyond their insertions, and in the Indian Cress (Tropæolum) this prolongation is in the form of a spur (calcar), formed by three sepals (fig. 299 e); in Delphinium it is formed by one. When one or more sepals are thus enlarged, the calyx is calcarate or spurred. In Pelargonium the spur from one of the sepals is adherent to the flower-stalk.

In some plants, as in the Mallow tribe, the flower appears to be provided with a double calyx, which has been denominated caliculate, the outer calyx being the epicalyx. In fig. 298, c represents the calyx of Hibiscus, and $b$ the smaller calyx or epicalyx outside; and in fig. 300, the same thing is shown in Potentilla verna. Many authors look upon this epicalyx as a collection of whorled bractlets, forming an involucre immediately below the flower. In some cases the projecting teeth between the divisions of the calyx, as in Rosaceæ, are to be traced to the transformed stipules of the calycine leaves. Degenerations take place in the calyx, so that it becomes dry, scaly, and glumaceous (like the glumes of grasses), as in

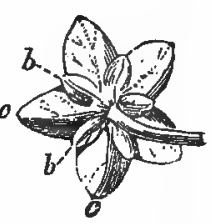

Fig. 300. the Rush tribe; hairy, as in Compositæ; or a mere rim, as in some Umbelliferæ and Acanthaceæ, when it is called obsolete or marginate.

Fig. 299. Calcarate calyx of Tropæolum, Indian cress. e, Spur or calcar. p, Pedicel. Fig. 300. Calyx, $c$ c, of Potentilla verna, with its epicalyx or caliculus, $b$ b. 
In Compositæ, Dipsacaceæ, and Valerianaceæ, the calyx is attached to the pistil, and its limb is developed in the form of hairs, called pappus. This pappus is either simple (pilose) (fig. 302), or feathery (plumose) (fig. 303). In cases where, to the naked eye, the hairs appear to be simple, the examination by a lens sometimes exhibits distinct tooth-like projections often irregularly scattered. In figs. 301, 302, 303, there are examples of calyces, $c$, which are attached to the pistil, while their limbs, $l$, show the transition from the narrowed thread-like form in Catananche cærulea, (fig. 301) to the pilose in Scabiosa atro-purpurea (fig. 302), and thence to the plumose in Pterocephalus palæstinus (fig. 303). In Valeriana the superior calyx is at first an obsolete rim, but as the fruit ripens, it is shown to consist of hairs rolled inwards, which expand so as to waft the fruit.

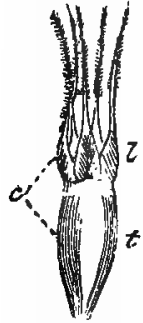

Fig. 301.

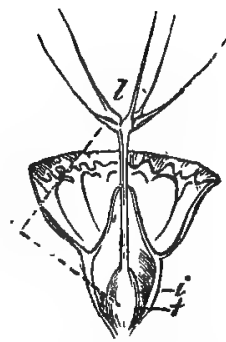

Fig. 302.

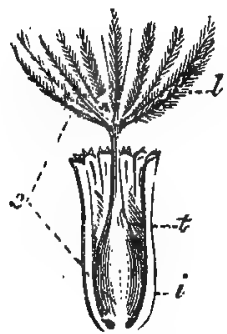

Fig. 303 ,

The calyx sometimes falls off before the flower expands, as in Poppies, and is caducous; or along with the corolla, as in Ranunculus, and is deciduous; or it remains after flowering, as in Labiatæ, Scrophulariaceæ, and Boraginaceæ ; or its base only is persistent, as in Datura Stramonium. In Eschscholtzia and Eucalyptus the sepals remain united at the upper part, and become disarticulated at the base or middle, so as to come off in the form of a lid or funnel. Such a calyx is operculate (operculum, a lid), or calyptrate ( $\alpha \alpha \lambda$ úrrg $\alpha$, a covering). The existence or non-existence of an articulation determines the deciduous or persistent nature of the calyx. In the case of Eschscholtzia the axis seems to be prolonged so as to form a sort of tube, from which the calyx separates. In Eucalyptus the calyx consists of leaves, the laminæe or petioles of which are articulated like those of

Figs. 301-303. Examples of calyces, the limbs of which, $l$, gradually pass into the state of hairs or pappus. $c t$, Calyx, united to the ovary, and forming a narrow column above it; in figs. 302,303 , the calyx ends in numerous simple or feathery hairs, $l$. $i$, Involucre or gamosepalous bracts cut vertically. Fig. 301. Calyx of Catananche cærulea. Fig. 302. Calyx of Scabiosa atro-purpurea. Fig. 303. Calyx of Pterocephalus palæstinns. 
the Orange, and the separation between the parts occurs at this articulation.

The receptacle bearing the calyx is sometimes united to the pistil, and enlarges, so as to form a part of the fruit, as in the Apple, Pear, Pomegranate, Gooseberry, etc. In these fruits the withered calyx is seen at the apex. Sometimes a persistent calyx increases much after flowering, and encloses the fruit, without being incorporated with it, becoming accrescent (accresco, I increase), as in various species of Physalis (fig. 304); at other times it remains in a withered or

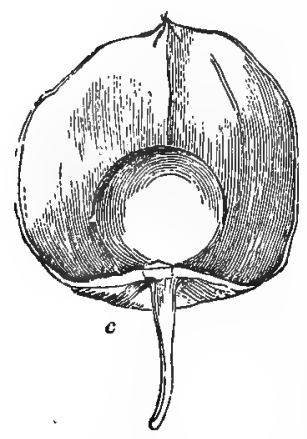

Fig. 304. marcescent (marcesco, I decay) form, as in Erica; sometimes it becomes inflated or vesicular, as in sea campion. In Trifolium fragiferum the union of the inflated calyces produces the strawberry-like appearance of the head of flowers when in fruit.

CorolLA. - The corolla is the more or less coloured inner floral envelope, forming the whorl of leaves between the calyx and the stamens. It is generally the most conspicuous whorl. The gay colours and fragrant odours of flowers are resident in it. It is present in the greater number of Dicotyledons. It is composed of parts which are usually disposed in one or more verticillate rows, and which are called petals ( $\pi_{\varepsilon}^{\prime} r \alpha \lambda \circ v$, a leaf). The petals sometimes form a continuous spiral with the calycine segments, but in general they are disposed in a circle, and alternate with the sepals.

Petals differ more from leaves than sepals do, and are much more nearly allied to the staminal whorl. In some cases, however, they are transformed into leaves, like the calyx, and occasionally leaf-buds are developed in their axil. They are seldom green, although occasionally this colour is met with, as in some Cobæas, Hoya viridiflora, Gonolobus viridiflorus, and Pentatropis spiralis. As a rule they are highly coloured, the colouring matter being contained in cells, and differing in its nature from the chlorophyll of the leaves. As regards their structure, petals consist of cellular tissue traversed by true spiral vessels, and thin-walled tubes. In delicate flowers, as Convolvulus and Anagallis, these vessels are easily seen under the microscope. Petals do not usually present numerous layers of cells like the leaves, neither is the epidermis always distinct, although in some instances it may be detached, especially from the surface next the calyx. The cuticle of the petal of a Pelargonium, when viewed with a $\frac{1}{2}$ or $\frac{1}{4}$ inch object glass, shows beautiful hexagons, the boundaries of which are ornamented with several inflected loops in the sides of the cells.

Fig. 304. Accrescent calyx, c, connected with the fruit of Physalis Alkekengi. 
On the outer surface of petals, corresponding to the lower side of leaves, stomata are sometimes found. Petals are generally glabrous or smooth ; but, in some instances, hairs are produced on their surface. Petaline hairs, though sparse and scattered, present occasionally the same arrangement as those which occur on the leaves: thus in Bombacere they are stellate. Coloured hairs are seen on the petals of Menyanthes, and on the segments of the perianth of the Iris. Although petals are usually very thin and delicate in their texture, they occasionally become thick and fleshy, as in Stapelia and Rafflesia; or dry, as in Heaths ; or hard and stiff, as in Xylopia. A petal often consists of two portions-the lower narrow, resembling the petiole of a leaf, and called the unguis or claw; the upper broader, like the blade of a leaf, and called the lamina or limb. These parts are seen in the petals of the Pink (fig. 305), where $o$ is the claw, and $l$

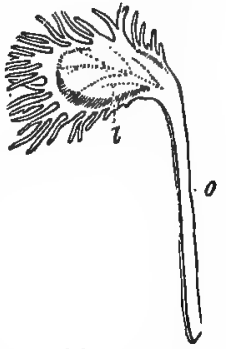

Fig. 305 . the limb. The claw is often wanting, as in the Rose, and the petals are then sessile. Petals having a claw are unguiculate.

Petals, properly so called, belong to Dicotyledonous plants, for in Monocotyledonous the flowers consist of a perianth or perigone, which is referred to the calycine envelope. Hence the venation of petals resembles that of the leaves of Dicotyledons. In the claw the vessels are approximated, as in the petiole, and in the limb they expand. There may be a median vein whence lateral veins go off, at the same or different heights, forming reticulations; or there may be several primary veins diverging from the base of the limb, and forming a sort of fan-shaped venation. At other times the median vein divides into two.

According to the development of veins, and the growth of cellular tissue, petals present varieties similar to those already noticed in the

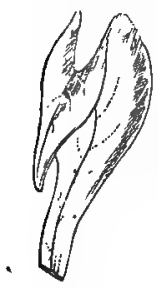

Fig. 306.

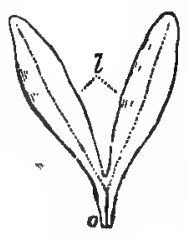

Fig. 307. case of leaves. Thus the margin is either entire or divided into lobes or teeth. These teeth sometimes form a regular fringe round the margin, and the petal becomes fimbriated (fimbria, a fringe), as in the Pink (fig. 305); or laciniated, as in Lychnis Flos-cuculi ; or crested, as in Polygala. Sometimes the petal becomes pinna tifid, as in Schizopetalum. The median vein is occasionally prolonged beyond the

Fig. 305. An unguiculate petal of Dianthus monspessulanus. 0 , Unguis or claw. $l$, Limb, which is fimbriated, or hes a fringed margin. Fig. 306. A petal of Eryngium campestre, with the apex inflexed or turned down towards the base. . Fig. 807. A bipartite petal of Stellaria media, or common Chickweed. $l$, The limb split into two, $o$, The claw. 
summit of the petals in the form of a long process, as in Strophanthus hispidus, where it extends for seven inches; and at other times it ends in a free point or cuspis, and the petal becomes cuspidate; or the prolonged extremity is folded downwards or inflexed, as in Umbelliferæ (fig. 306), so that the apex approaches the base. If the median vein divides into two, the space between the divisions may be filled up so as to leave only a slight deficiency, and thus the petal becomes emarginate; or the deficiency may be greater, while the limb gradually expands from below upwards, and its extremity becomes two-lobed, so that the petal is obcordate. If the separation extends to the middle, it is bifid; if to near the base, bipartite, as in Chickweed (fig. $307 \mathrm{l}$ ). In the same way as in leaves, the venation of the petals is sometimes unequal, and the cellular tissue is developed more on one side than on the other, thus giving rise to an oblique petal.

The limb of the petal may be flat or concave, or hollowed like a boat, cymbiform, or navicular (cymba, a boat, navis, a ship), or like a spoon, cochleariform (cochleare, a spoon). In the case of the navicular petal, the median vein forms a marked keel. In Hellebore the petals

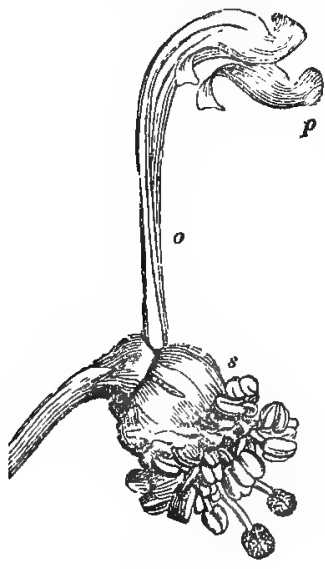

Fig. 308 ,

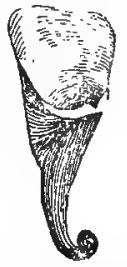

Fig. 309.

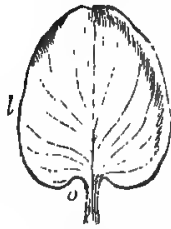

Fig. 310. become folded in a tubular form, resembling a horn; in Aconite (fig. 308) some of the petals, $p$, resemble a hollow curved horn, supported on a grooved stalk; while in Columbine (fig. 309) Violet, Snapdragon, and Centranthus, one or all of them are prolonged in the form of a spur, and are calcarate (calcar, a spur). In Valeriana, Antirrhinum, and Corydalis, the spur is very short, and the corolla or petal is said to be gibbous (gibbus, a bunch or swelling), or saccate at the base. In some Boraginaceæ (fig. 322) there are foldings at the upper part of the tube of the corolla, $r$, forming projections concave outwardly, which might be considered as small internal spurs.

When a petal is narrow throughout, as if formed by a prolongation

Fig. 308. Part of the flower of Aconitum Napellus, showing two irregular horn-like petals, $p$, supported on grooved stalks, $o$. These used to be called nectaries. $s$, The whorl of stamens inserted on the thalamus, and surrounding the pistil. Fig. 309. Single spurred petal of Aquilegia vulgaris, common Columbine, formed by a foiding of the margins. Fig. 310. Cordate or cordiform petal of Genista candicans, J, The claw. $l$, The limb. 
of the claw, it is called linear; when the limb is prolonged at the base, so as to form two rounded lobes, it is cordate, as in the petal of Genista candicans (fig. 310); and when the lobes are acute, it may be sagittate or hastate. The meaning of the terms indicating the forms of petals will be understood by considering those applied to leaves. As a rule, the terms refer to the limb of the petal, which is frequently the only portion developed. In the Poppy, the petals have a puckered or corrugated appearance, arising from their delicacy, and the mode in which they are folded in æastivation. Other petals have a crisp or wavy margin.

A corolla rarely consists of one petal, and when this occurs, as in Amorpha, it depends on the abortion or non-development of others. Such a corolla is unipetalous (unus, one), a term quite distinct from monopetalous. In general, the corolla consists of several petals, equalling the sepals in number, or being some multiple of them. When this is the case, the floral envelopes are said to be symmetrical; when, however, by the abortion of some of the petals the numbers do not correspond, then the flower becomes unsymmetrical. Under the head of floral symmetry the various changes consequent on non-development of petals will be noticed. A corolla is dipetalous, tripetalous, tetrapetalous, or pentapetalous, according as it has two, three, four, or five separate petals.

The general name of polypetalous (roגis, many), or dialypetalous ( $\delta r \alpha \lambda \dot{U} \varepsilon N$, to divide), is given to corollas having separate petals, while monopetalous or gamopetalous ( $\mu$ óvos, one, and rápros, union) is applied to those in which the petals are united. This union generally takes place at the base, and extends more or less towards the apex; in Phyteuma the petals are united at their apices also. In some polypetalous corollas, as that of the Vine, the petals are separate at the base, and adhere by their apices. That a monopetalous corolla consists of several petals united is shown in such plants as Phlox amona, where some specimens have petals more or less completely disunited, while others exhibit the normal form of coherent petals. When the petals are equal as regards their development and size, the corolla is regular; when unequal it is irregular. Even although

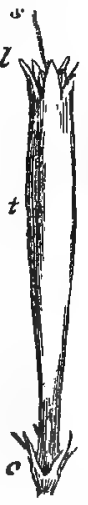

Fig. 311.

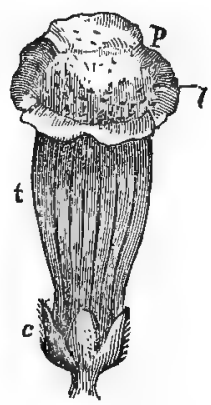

Fig. 312. the separate petals are oblique, still, if they are all equally so, as in

Fig. 811. Regular monopetalous or gamopetalous tubular corolla of Spigelia marylandica. c, Calyx. t, Tube of the corolla. l, Limb of the corolla. s, Stigma at the summit of style. Fig. 812. Irregular gamopetalous or monopetalous corolla of Digitalis purpurea, Foxglove. e, Calyx. $p$, Corolla. $t$, Tube. $l$, Limb. 
many Malvaceæ with twisted æstivation, the corolla is regular. The size of the corolla as compared with the calyx, the number, direction, and form of its parts, and their relation to the axis of the plant, require attention.

When a corolla is gamopetalous, it usually happens that the claws are united into a tube (figs. $311 t, 312 t$ ), while the upper parts are either free or partially united, so as to form a common limb (fig. $311 l$ ), the two portions being separated by the faux or throat, which often exhibits a distinct constriction or dilatation. The number of parts forming such a corolla can be determined by the divisions, whether existing as teeth, crenations, fissures, or partitions; or if, as rarely

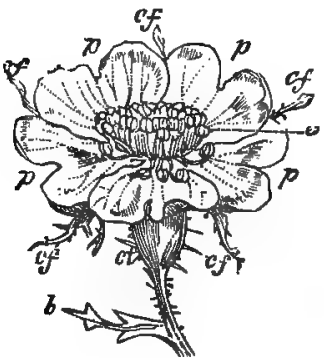

Fig. 313.

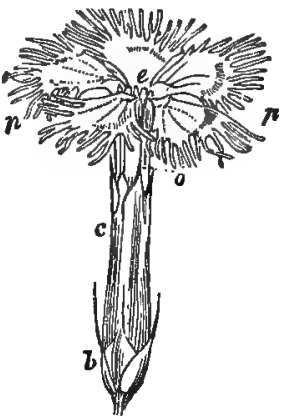

Fig. 314.

happens, the corolla is entire, by the venation. The union may be equal among the parts, or some may unite more than others. Some-

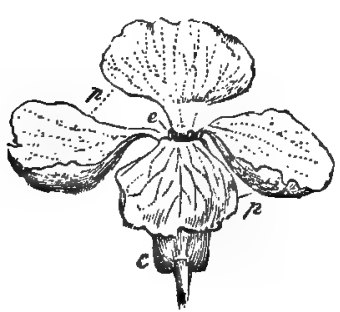

Fig. 315. times the tubular portion is bent, as in Lycopsis; at other times the limb is curved at its apex, as in Lamium.

Regular Polypetalous Corollas. -Among them may be noticed the rosaceous corolla, in which there are five spreading petals, having no claws, and arranged as in the single Rose (fig. 313) and Potentilla; the caryophyllaceous corolla, in which there are five petals with long narrow tapering claws, as in many

Fig. 313. Polypetalous flower of Rosa rubiginosa, the Sweet-brier. $b$, Bract or floral leaf. $c t$, Hollow torus, which forms the conspicuous part of what is commonly called the fruit. $c f, c f, c f, c f, c f$, Sepals or foliola of the calyx, $p p p p$, Petals without a claw. $e$, Stamens attached to the calyx. Fig. 314. Polypetalous flower of Dianthus monspessuIanus. $b$, Bracts. $c$, Calyx. $p p$, Petals with their claws, $o$, approximated so as to form a tabe. Fig. 315. Cruciferous flower of Cheiranthus Cheiri, Wallflower. c, Lobes of the sepals; the two external sepals being prolonged at the base, so as to form a sort of spur or swelling (gibbous or saccate). $p p$, The four petals arranged like a cross. $e$, The four longer stamens, the summits of the anthers being visible. 
of the Pink tribe (figs. 305, 314); the alsinaceous, where the claw is less narrow, and there are distinct spaces between the petals, as in some species of Chickweed ; cruciform, having four petals, often unguiculate, placed opposite in the form of a cross, as seen in Wallflower (fig. 315), and in other plants called cruciferous (crux, a cross, and fero, I bear):

IrRegular Polypetalous Corollas. -The most marked of these is the papilionaceous (fig. 316), in which there are five petals; one superior (posterior), $e$, placed next to the axis, usually larger than the rest, and folded over them in restivation, called the vexillum or standard; two lateral, $a$, the alce or wings; two inferior (anterior), partially or completely covered by the alæ, and often united slightly by their lower margins, so as to form a single keel-like piece, $b$, called carin $a$, or keel, which embraces the essential organs. This

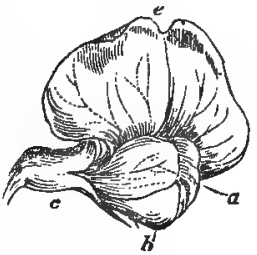

Fig. 316. corolla occurs in the Leguminous plants of Britain, or those plants which have flowers like the pea. Among the irregular polypetalous corollas might be included the orchideous (fig. 317), although it is really the perianth of a Monocotyledon. This perianth consists of three outer portions equivalent to the calyx, and three inner parts alternating with them, constituting the petals. The latter are often very irregular, some being spurred, others hooded, etc.; and there is always one, called the labellum or lip (Fig. 317 l), which presents a remarkable development, and gives rise to many of the anomalous forms exhibited by these flowers.

Regular Monopetalous or Gamopetalods Corollas.-These are sometimes campanulate or bell-shaped, as in Campanula rotundifolia (fig. 318); infundibuliform or funnel-shaped, when the tube is like an inverted cone, and

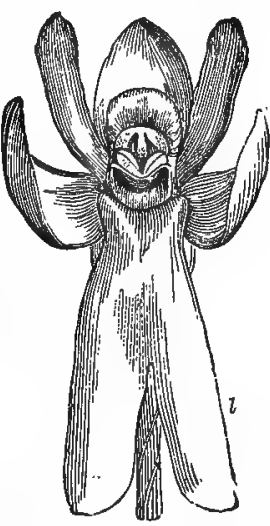

Fig. 317. the limb becomes more expanded at the apex, as in Tobacco (fig. 319); hypocrateriform or salver-shaped, when there is a straight tube surmounted by a flat spreading limb, as in Primula (fig.

Fig. 316. Irregular polypetalous corolla in the papilionaceous flower of Lathyrus odoratus, Sweet-pea. e, Calyx. $e$, Vexillum or standard. $a$, Two alæ or wings. $b$, Carina or keel, formed of two petals. Fig. 317. Flower of Twayblade (Listera ovata), seen in front, showing a large bifid labellum, $l$, which is different from the other five divisions of the perianth. The divisions of the perianth are in two rows of three each. The essential organs of reproduction are placed on a column opposite the labellum. The perianth is irregular polyphyllous, and is denominated Orchideous. 
$320)$; tubular, having a long cylindrical tube, appearing continuous with the limb, as in Spigelia (fig. 311), and Comfrey (fig. 321); rotate or wheel-shaped, when the tube is very short, and the limb flat and spreading, as in Myosotis (fig. 322); when the divisions of the rotate corolla are very acute, as in Galium, it is sometimes called stellate or star-like; urceolate or urn-shaped, when there is scarcely any limb, and the tube is narrow at both ends, and expanded in the middle,

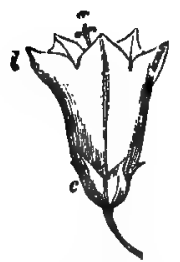

Fig. 318.

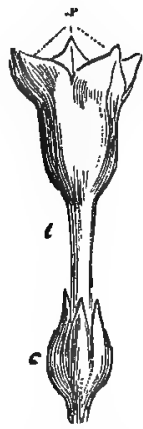

Fig. 319.

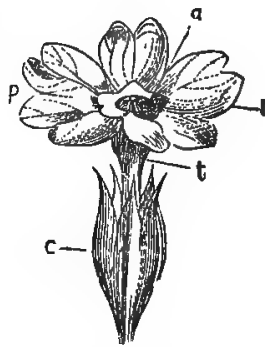

Fig. 320.

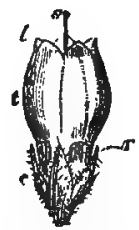

Fig. 321.

as in Bell-heath (Erica cinerea) (fig. 323). Some of these forms may become irregular in consequence of certain parts being more developed than others. Thus, in Veronica, the rotate corolla has one division much smaller than the rest, and in Digitalis there is a slightly irregular campanulate corolla (fig. 312), which some have called digitaliform.

Irregular Monopetalous or Gamopetalous Corollas.Among these may be remarked the labiate or lipped (fig. 324), having two divisions of the limb in the form of what are called labia or lips (the upper one composed usually of two united petals, and the lower of three), separated by a hiatus or gap, $l$. In such cases the tube varies in length, and the parts of the calyx follow the reverse order in their union, two sepals being united in the lower lip, and three in the upper. When the upper lip of a labiate corolla is much arched, and the lips separated by a distinct gap, it is called ringent (ringens, grinning). The labiate corolla characterises the natural order Labiatæ. In Lobelia

Fig. 318. Regular monopetalous or gamopetalous eampanulate or bell-shaped corolla of Campanula rotundifolia. $c$, Calyx. $l$, Limb of corolla. $s$, Stigma. Fig. 319. Regular monopetalous or gamopetalous infundibuliform corolla of Nicotiana Tabacum, Tobacco. c, Calyx. $l$, Limb of corolla. s, Stigma. Fig. 320. Regular monopetalous or gamopetalous hypocrateriform corolla of Primula elatior, Oxlip. c, Calyx. p, Corolla. $t$, Tube. $l$, Limb. $a$, Anthers. Fig. 321. Regular gamopetalous tubular and somewhat bellshaped corolla of Symphytum officinale, Comfrey. $e$, Calyz. $t$, Tube of corolla. $l$, Limb. s, Stigma. $r$, External depressed surface of folds, which project into the trube of the corolla. 
there is a labiate corolla, the upper lip of which becomes convex superiorly, and is split to near the base. When the lower lip is

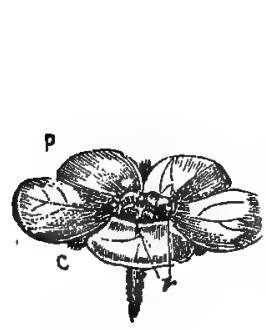

Fig. 322.

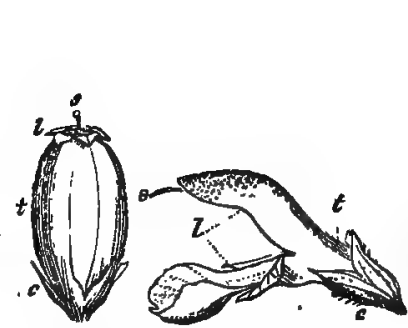

Fig. 324.

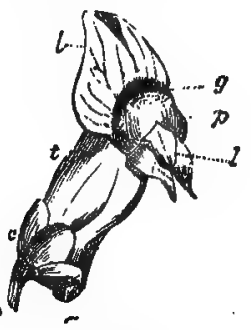

Fig. 325.

pressed against the upper, so as to leave only a chink or rictus between them, the corolla is said to be personate or mask-like (persona, a mask), as in Frogsmouth (fig. 325), Snapdragon, and some other Scrophulariaceæ, and the projecting portion, $p$, of the lower lip is called the palate. In some corollas the two lips become hollowed out in a remarkable manner, as in Calceolaria, assuming a slipper-like appearance, similar to what occurs in the labellum of some Orchids, as Cypripedium. The calceolate (calceolus, a slipper) corolla of Calceolaria may be considered as consisting of two slipper-like lips.

When a tubular corolla is split in such a way as to form a strap-like process on one side with several tooth-like projections at its apex, it becomes ligulate (ligula, a little tongue), or strap-shaped (fig. 326). This corolla occurs in many composite plants, as in the florets of Dandelion, Daisy, and Chicory. The number of divisions at the apex indicates the number of united petals, some of which, however, may be abortive. Occasionally some of the petals become more united than others,

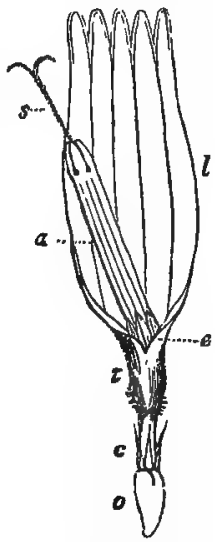

Fig. 326.

Fig. 322. Regular gamopetalous rotate corolla of Myosotis palustris, or Forget-me-not. $c$, Calyx, $p$, Corolla. $r$, Folds of the corolla, forming projections at the upper part of the , tube, which are opposite to the lobes of the corolla. Fig. 323. Regular gamopetalous urceolate or urn-shaped corolla of Erica einerea, or cross-leaved Heath. $c$, Calyx. $t$, Tube of corolla. $l$, Limb of corolla. \&, Stigma. Fig. 324. Irregular gamopetalous labiate or lipped corolla of Salvia pratensis. $c$, Calyx. $t$, Tube of corolla. $l$, Limb, forming two lips, having a gap or hiatus between them. s, Summit of style. Fig. 325. Irregular gamopetalous personate or mask-like corolla of Antirrhinum majus, or Frogsmouth. c, Calyx. $t$, Tube of corolla, having a gibbosity or swelling, $u$, at its base. $l$, Limb of corolla. $g$, The faux or mouth closed by a projection of the lower lip, $p$. Fig. 326. Irregular gamopetalous ligulate floret of Catananehe cærulea. o, Calyx, with a quinquefid limb united inferiorly with the ovary, 0 . $e$, Stamens with united anthers, a (synantherous or syngenesious), surrounding the style, $s$, with its bifid stigma. 
and then this corolla assumes a bilabiate or two-lipped form, as seen in the division of Compositæ called Labiatifloræ. In Compositæ there are often two kinds of florets associated in the same head. Thus, in the Daisy there are irregular ligulate white florets on the outside or in the ray, while there are regular tubular yellow florets in the centre or disc. In Scævola and in Honeysuckle the corolla is split down to its base, so as to resemble somewhat the ligulate form.

Flowers of Grasses and Sedges.-In these plants, in place of verticillate leaves forming the flower, there are alternate scales or glumes. The flowers of grasses usually occur in spikelets (fig. 327 ), which consist of one or two glumes, $a$, covering several flowers, b. The spikelets are associated in spikes or panicles. In Wheat

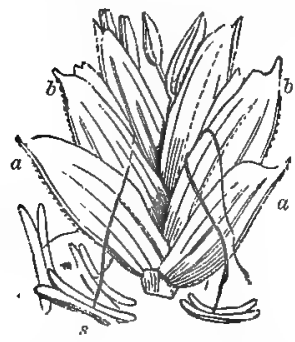

[Fig. 327.

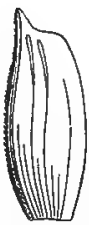

Fig. 328.

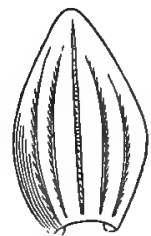

Fig. 329.

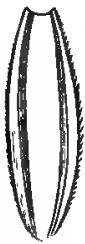

Fig. 330 .

these spikelets are arranged alternately along a common rachis. Each spikelet (fig. 327) consists of two empty glumes, $a$ a, having the form represented in figure 328, and enclosing flowers which are composed of scales (paleæ or glumellæ), delineated in figures 329 and 330 - the former being the outer, and the latter the inner pale or glumella-which are placed at different heights in an alternate manner. In the flower of the Oat (fig. 331), after removing the outer pale or glumella, the inner one, $p i$, is seen with two scales (lodiculæ. or squamæ), $s q$, at the base, enclosing the essential organs of reproduction. The palex of grasses are called by some flowering glumes, while hypogynous scales (lodiculæ) within this are considered as the rudimentary perianth. In Wheat (Triticum) there are two empty glumes, and

Fig. 327. A spikelet of Wheat (Triticum), consisting of two glumes, $a \alpha$, enclosing several flowers, $b b$, which are composed of two pales (paleæ) covering the essential organs of reproduction. The stamens, $s$, hang out by long slender thread-like flaments. The individual glumes and palex are placed alternately on the floral axis. Fig. 328 . One of the glumes of Wheat (Triticum), seen in profile. These glumes are bracts or floral leaves which constitute the outer covering of the spikelet. They are placed at different levels, following the law of alternation. The glume is marked with three ribs. Fig. 329. External (outer) palea or glumella of the flower of Wheat. It is a glumaceous seale marked with two ribs on èch side of the midrib. Fig. 330. Internal (inner) palea or glumella of the flower of Wheat. It is thinner and more membranous than the outer glumella (flowering glume), its edges are folded inwards and its apex is bifid. 
two flowering glumes. In the Oat (Avena) there are two empty glumes (ghuma, a husk), usually three flowering glumes with awns, and two lodicules (lodicula, a coverlet), representing the perianth. In Sedges (Carices) the male flowers are borne on scales, and so are the female, as shown in figure 332, in which the scale, $s$, is placed on one side. Within the scale the female flower is situated, having a peculiar bag-like covering, $u$, termed perigynium.

Nectartes and ANomalies IN PeTals. - Certain abnormal appearances occur in the petals of some flowers, which received in former days the name of nectaries. The term nectary was very vaguely applied by Linnæus to any part of the flower which presented an un-

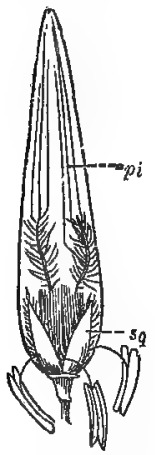

Fig. 331.

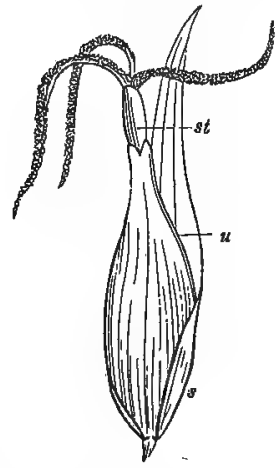

Fig. 332.

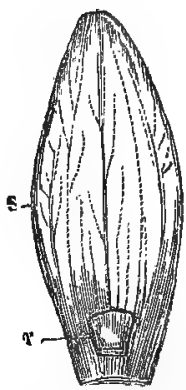

Fig. 383.

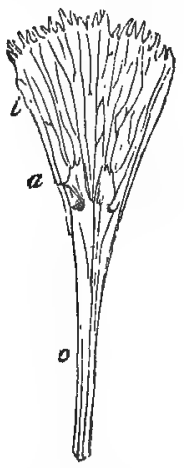

Fig. 334.

usual aspect, as the crown (corona) of Narcissus, the fringes of the Passion-flower, etc. If the name is retained, it ought properly to include only those parts which secrete a honey-like matter, as the glandular depression at the base of the perianth of the Fritillary (fig. $333 r$ ), or on the petal of Ranunculus, or on the stamens of Rutacer. The honey secreted by flowers attracts insects, which, by conveying the pollen to the stigma, effect fertilisation. What have usually, however,

Fig. 331. Flower of Oat (Avena sativa), with the two empty glumes, and the outer flowerglume removed. The inner glumella or palea, $p i$, is seen of a lanceolate form, and bidentate at the apex. The outer glumella has a long twisted genioulate dorsal awn, with two points or bristles at the summit. By removing this glumella there are seen two seales (lodicula, squamæ), sq, with the three stamens and two feathery styles. Fig. 332. Female (pistilliferous or pistillate) flower of a Sedge (Carex), with a single glume or scale, $s$. The pistil is covered by an urceolate glumaceous bag, $u$, called perigynium. There is one style, st, with three stigmas at its summit. Fig. 333. One of the segments, $s$, of the perianth of Fritillaria imperialis, or Crown Imperial, with a pit or depression, $r$, at its base, containing honey-like matter. The cavity is coloured differently from the rest of the segment, and it is often called a nectary, or a nectariferous gland. Fig. 334. Petal of Lychnis fulgens, seen on its inner side. 0 , Claw. $l$, Limb. $a, \Delta n$ appendage supposed to be formed by chorisis. This appendage was called a nectary by old authors. 
been called nectaries, are mere modifications of some part of the flower, especially of the corolla and stamens, produced either by degeneration or outgrowth, or by a process of dilamination (dis, separate, and lamina, a blade), or chorisis ( $\chi \omega$ gif $^{\prime} \omega$, I separate). This process, called also deduplication, consists in the separation of a layer from the inner side of a petal, either presenting a peculiar form, or resembling the part from which it is derived. The parts thus produced are not alternate with the petals or the segments of the corolla, but opposite to them. In these cases, the petals at the lower part consist of one piece, but where the limb and claw separate, or where the tube ends, the vascular layer splits into two, and thus two laminæ are formed, one posteriorly and the other anteriorly. These scales are well seen in Lychnis (fig. 334 a), Silene, Cynoglossum, and Ranunculus, and may be considered as formed in the same way as the ligule of grasses (fig. 210, p. 99). Corollas having these scaly appendages are sometimes denominated appendiculate. In other cases, as in Cuscuta and Samolus, the scales are alternate with the petals, and may represent altered stamens. The formation of these scales is referred to under the section of Morphology and Symmetry.

The parts formerly called nectaries are mere modifications of the corolla or stamens. Thus the so-called horn-like nectaries under the galeate sepal of Aconite (fig. 308, p. 202), are modified petals, so also are the tubular nectaries of Hellebore. The nectaries of Menyanthes and of Iris consist of hairs developed on the petals. Those

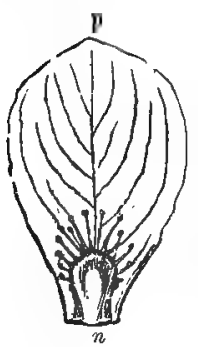

Fig. 335. of Parnassia (fig. $335 \mathrm{n}$ ), and of the Passion-flower, Stapelia, Asclepias, and Canna, are fringes, rays, and processes, which are probably modifications of stamens; and some consider the crown of Narcissus as consisting of a membrane similar to that which unites the stamens in Pancratium. It is sometimes difficult to say whether these nectaries are to be referred to the corolline or to the staminal row. The paraphyses of the Passion-flower, the crown of Narcissus, and the coronet of Stapelia, are referred sometimes to the one and sometimes to the other. In general, they may be said to belong to that series with which they are immediately connected. Some have given names indicating the parts of which they are modifications, by prefixing the term para ( $\pi \alpha \rho \alpha$, beside, or close to), using such terms as paracorolla and parastemones.

Petals are attached to the axis usually by a narrow base, but

Fig. 335. Petal, $p$, of Parnassia paiustris, or grass of Parnassus, with a so-called nectary, 7h, which may be an abortive state of some of the stamens, or a process from the petals, surmounted by stalked glands. 
occasionally the base is larger than the limb, as in the Orange flower. When this attachment takes place by an articulation, the petals fall off either immediately after expansion (caducous), or after fertilisation (deciduous). A corolla which is continuous with the axis and not articulated to it, as in Campanula, Heaths, etc., may be persistent, and remain in a withered or marcescent state while the fruit is ripening. A gamopetalous corolla falls off in one piece; but sometimes the base of the corolla remains persistent, as in Rhinanthus and Orobanche.

Development of Floral Envelopes. - The floral envelopes, when gamosepalous and gamopetalous, first appear in the form of a ring, whence various cellular projections arise, representing the sepals and petals; when they are polysepalous and polypetalous, the ring is wanting. Even when the parts become ultimately unequal, as in Digitalis (fig. 309), they form equal cellular papillæ when first developed (fig. 336).

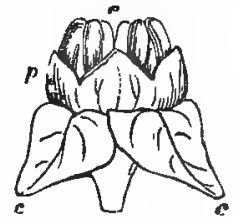

Fig. 336.

Irregular flowers may be referred to regular types, from which they seem to have degenerated. There appear to be three principal kinds of irregularity among corollas:-1. Irregularity by simple inequality in the development of the several segments, often along with adhesion or atrophy, or arrest of growth : this is the most common kind. 2. Irregularity of deviation, when the segments, though equal, turn all to the same side, as in ligulate florets. 3. Irregularity by simple metamorphosis of stamens, as in Canna. The irregular corollas of Acanthaceæ, Bignoniaceæ, Gesneraceæ, Lobeliaceæ, and Scrophulariaceæ, are formed at first in a regular manner, by equal projections from a sort of cup or ring. In Calceolaria, there is at first a scooped-out cup, with four regular and very minute teeth, which are ultimately developed as" the corolla; the nascent calyx has also four divisions. In Begoniacex the floral envelope at first appears as a continuous ring, having five equal small segments; some of these, especially in the male flowers, disappear entirely or become atrophied.

\section{Inner Floral Whorls, or the Essential Organs of Reproduction.}

These organs are the stamens and the pistil, the latter containing the seeds or germs of young plants, and corresponding to the female, while the former produces a powder necessary for fecundation, and is looked upon as performing the part of the male. The presence of both is required in order that perfect seed may be produced. A flower may have a calyx and corolla, and yet be imperfect if the essential

Fig. 336. Bud of the irregular gamopetalous flower of Digitalis purpurea. o c, Calyx. $p$, Corolla, which in its early development is regular. $e$, The stamens, at first projecting beyond the corolla. 
organs are not present. The name of hermaphrodite or bisexual is given to flowers in which both these organs are found; that of unisexual (one sex), or diclinous ( $\delta i s$, twice, and $x \lambda i v \eta$, a bed), to those in which only one of these organs appears, - those bearing stamens only being staminiferous (stamen, a stamen, fero, I bear), or male; those having the pistil only, pistilliferous (pistillum, a pistil, fero, I bear), or female.

The absence of one of the organs is due to abortion or non-development. When in the same plant there are unisexual flowers, both male and female, the plant is said to be monocious or monoicous ( $\mu$ óvos, one, and oixiov, habitation), as in the Hazel and Castor-oil plant; when the male and female flowers of a species are found on separate plants, the term diccious or dioicous ( $\delta i_{5}$, twice) is' applied, as in Mercurialis and Hemp; and when a species has male, female, and hermaphrodite flowers on the same or different plants, as in Parietaria, it is polygamous ( $\pi 0 \lambda_{i} \varsigma$, many, and $\gamma \dot{\alpha} \mu \omega \varsigma$, marriage). The term agamous ( $\alpha$, privative, and $\gamma^{\alpha} \mu_{0 \varsigma}$, marriage) has sometimes been applied to Cryptogamic plants, from the supposed absence of any bodies truly representing the stamens and pistil.

Flowers of the same species of plant sometimes present different forms as regards stamens and pistil. Thus, in the same species of Primula and Linum there are differences in the size and development of the stamens and pistil, one flower having long stamens and a pistil with a short style, the other having short stamens and a pistil with a long style. The former occur in what are called thumb-eyed primroses, the latter in those called pin-eyed. Such plants are called

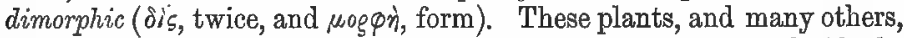
have thus two kinds of hermaphrodite flowers on distinct individuals. In some plants the stamens are perfected before the pistil; these are

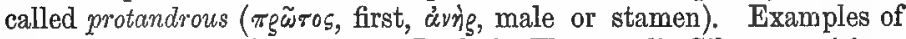
these are Ranunculus repens, Lychnis Flos-cuculi, Silene maritima, Geranium pratense and sylvaticum, Digitalis purpurea, Campanula rotundifolia, and Zea Mais. In other plants the pistil is perfected before the stamens, as in Potentilla argentea, Plantago major, lanceolata, and maritima, Lonicera Periclymenum, and Coix Lachryma. 'These are called protogynous plants ( $\pi \rho \tilde{\omega} \tau 0 \varsigma$, first, yuvì, female or pistil).

STAMENs. - The stamens (stamina) arise from the thalamus or torus within the petals, with which they alternate, forming one or more verticils or whorls which collectively constitute the androcium (ávrig, male, oixion, habitation), or the male organs of the plant, as distinguished from the gynocium ( or female organs of the plant. Their normal position is below the inner whorl or the pistil, and when they are so placed (fig. $337 \mathrm{e}$ ), they are hypogynous (i $i \pi \dot{d}$ under, yuvh, female or pistil). Sometimes they become united to the petals, or are epipetalous (s $\pi i$, upon, and 
$\pi$ Ér $\alpha \lambda \circ$, a leaf), and the insertion of both is looked upon as similar, so that they, are still hypogynous, provided they are independent of the calyx and the pistil. In fig. 338, the stamens, $e$, and the petals, $p$, are below the pistil or ovary, $o$, and both are separate from it and from the calyx, c, and are therefore hypogynous. When the stamens are inserted on the calyx, that is, are united to it to a greater or less height above the base of the pistil, then they become lateral as it were in regard to the latter, and are perigynous ( $\pi \varepsilon g i$, around). This is shown in the flower of the almond (fig. 339), in which the petals, $p$, and the stamens, e, are united to the calyx, $c$, while the pistil is free.

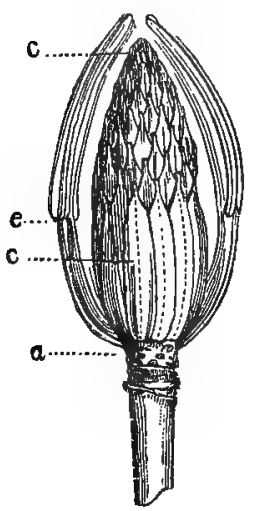

Fig. 337.

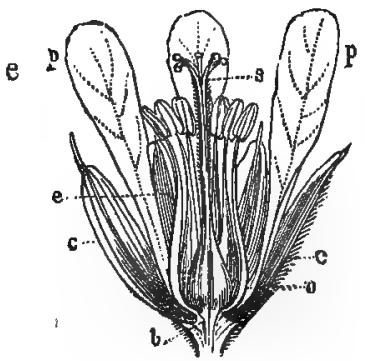

Fig. 338.

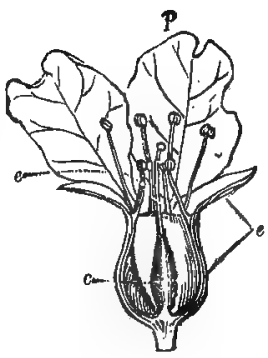

Fig. 389.

When the union of the parts of the flower is such that the stamens are inserted on the top of the ovary, they are epigynous $(\dot{\varepsilon} ;)$, upon or above). In this case the torus is supposed to be united to the ovary, while the calyx is above it, and bears the stamens. In the Orchis tribe, where the stamens and pistil are united so as to form a column, the flowers are said to be gynandrous. In Aralia spinosa (fig. 340), all the whorls, calyx, $c$, petals, $p$, and stamens, $e$, are united by the torus to the pistil, and the two latter whorls appear to rise from the point where the calyx joins the upper part of the pistil. These arrangements of parts have given rise to certain divisions in classification,

Fig. 337. Central part of the flower of Liriodendron tulipifera, the tulip-tree, composed of earpels, $c c$, which together form the pistil. They cover the upper part of the axis, $a$, and below them are inserted numerous stamens, some of which are seen, $e$ e. These stamens are hypogynous and extrorse. Fig. 338. Section of a flower of Geranium Robertianum. $c c$, Calyx. p, Petals, e, Stamens. Pistil composed of ovary, $o$, and style and stigmata, $s$. $t$, Torus or Thalamus. The petals and stamens are hypogynous, and the latter are monadelphous. Fig. 339. Section of the flower of the Almond-tree. The letters indieate the same parts as in the last figure. The petals and stamens are perigynous. The pistil is free. 
to be afterwards particularly noticed. For instance, the term tha-

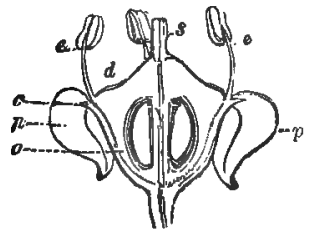

Fig. 340 . lamifloral is applied to plants having a polypetalous corolla and all the whorls inserted immediately into the torus or thalamus; calycifloral to those where the petals are separate or united, and the stamens are inserted directly on the calyx; corollifloral to those in which the united petals are placed under the ovary, and the stamens are either borne by them, or are inserted inde-

pendently into the torus.

The stamens vary in number, from one to many hundred. Like the other parts of the flower, they are modified leaves, resembling them in their structure, development, and arrangement. They consist of cellular and vascular tissue. They appear at first in the form of cellular projections, and are arranged in a more or less spiral form. In their general aspect they have a greater resemblance to petals than to the leaves, and there is often seen a gradual transition from petals

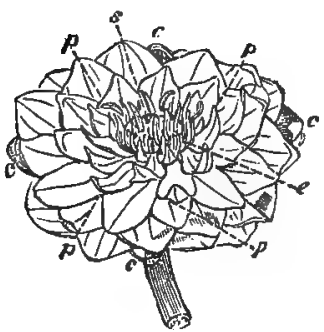

Fig. 341.

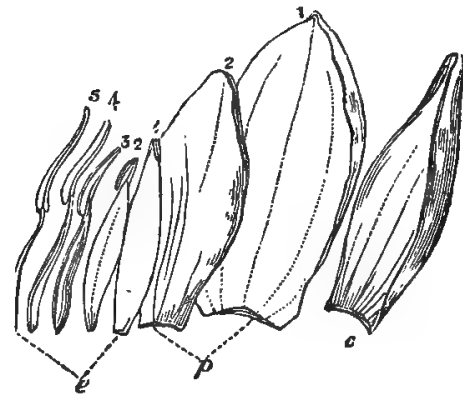

Fig. 342.

to stamens. Thus, in Nymphæa alba, the White Water-lily (figs. 341, 342 ), c represents a sepal, which gradually passes into the petals, $p$, and these in their turn become modified so as to form the stamens, $e$, which are more or less perfect as we proceed from without inwards, or from 1 to 5 . When flowers become double by cultivation, the stamens are converted into petals, as in the Pæony, Camellia, Rose,

Fig. 340. Section of the flower of Aralia spinosa. Letters as in last figure. The petals and stamens are epigynous, attached to the torus, $d$, which covers the summit of the ovary. The ovary is adherent to the torus, and has been laid open to show its loculaments and pendulous ovules.

Fig. 341. Flower of Nymphea, alba, White Water-lily. $c c c c$, The four foliola of the calyx or sepals. $p p p p$, Petals. $e$, Stamens. $s$, Pistil. Fig. 342 . Parts of the flower separated to show the transition from the green sepals of the calyx, $c$, and the white petals of the corolla, $p$, to the stamens, $e$. The latter present changes from their perfect state, 5 , through intermediate forms, $4,3,2$, and 1 , which gradually resemble the petals. 
Anemone, and Tulip; and, in these instances, the changes from one to the other may be traced in the same way as in the Water-lily.

When there is only one whorl, the stamens are usually equal in number to the sepals or petals, and are arranged opposite to the former, and alternate with the latter. The flower is then isostemonous (ioos, equal, and $\sigma \dot{y}_{\mu \omega \nu}$, a stamen). When the stamens are not equal in number to the sepals or petals, the flower is anisostemonous ("̈wross, unequal). When there is more than one whorl of stamens, then the parts of each successive whorl alternate with those of the whorl preceding it. The staminal row is more liable to multiplication of parts than the outer whorls. A flower with a single row of stamens is aplostemonous ( $\ddot{\alpha} \pi \lambda \lambda_{0} 0 \varsigma$, single). If the stamens are double the sepals or petals as regards number, the flower is diplostemonous ( $\delta \cdot \pi \lambda_{00} \varsigma_{\text {, }}$, double); if more than

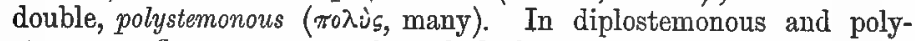
stemonous flowers we sometimes find that the inner stamens are the younger, and thus alternate with the carpels, as in Cerastium and Lilium. In this case the development is centripetal. At other times the external are the younger, and the carpels alternate with the older stamens, as in Geranium and Heath. In this case the development is centrifugal. The outer stamens in the latter case may represent interstaminal parts analogous to interpetiolar stipules. In general, when the stamens are normally developed, and are more numerous than the sepals and petals, they will be found arranged in several whorls, and their parts multiples of the floral envelopes. Thus, if a flower has five sepals, five petals, and twenty stamens, the latter are arranged in four alternate rows, having five in each. Although this is the usual law, yet various changes take place by abortion, arrestment of development, and other circumstances leading to abnormal growth. In this way the stamens may neither be equal to, nor a multiple of, the floral envelopes, and they may even be less numerous, so that the flower is miostemonous ( $\mu$ zicuv, less). In Cruciferous plants, while the petals and sepals are equal in number (four), and alternate in arrangement, the stamens are six in number, four long and two short; this imparity of numbers has been supposed to result from the splitting of the long stamens by lateral chorisis, a presumption favoured by the fact that partial union frequently exists between the two long stamens placed next each other (and superposed to the antero-posterior petals), that teeth are found only on the outer side of these long stamens, and that in many cruciferæ only four stamens exist. In the case of Gloxinia, where the parts of the flower are arranged in fives, there are only four perfect stamens, but the fifth one is seen in the form of a small conical projection from the base of the corolla, and by cultivation the fifth stamen is sometimes fully developed, while the flowers assume a regular form, and have an erect in place of an inclined position on the peduncle. 
In certain cases, as in Primula, the row of stamens is opposite to the petals forming the gamopetalous corolla. This opposition is by many looked upon as caused by the non-appearance of an outer row of stamens; by others it is considered as produced by chorisis or separation of laming from the petals, which become altered so as to form stamens, a view which is thought to be confirmed by their development taking place before the petals ; by a third party, each petal is looked upon when fully developed as formed by the halves of two contiguous petals, and thus the stamens are considered as being really alternate with the original petals.

When the stamens are under twenty they are called definite, and the flower is oligandrous (óíryos, few, and àvì, male or stamen); when above twenty they are indefinite or polyandrous ( $\pi 0 \lambda i \mathrm{~s}$, many), and are represented by the symbol $\infty$. The number of stamens is indicated by the Greek numerals prefixed to the term androus; a flower with one stamen being monandrous ( $\mu$ óvos, one); with two, diandrous ( $\delta i \varsigma$, twice); with three, triandrous (rgsis, three); with four, tetrandrous

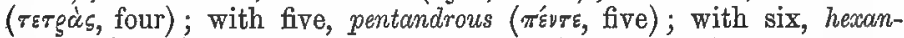

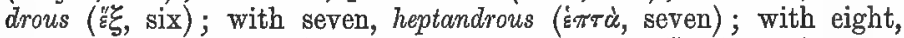

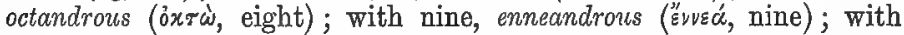

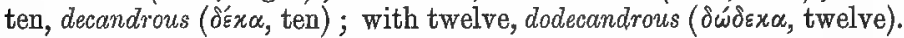
These terms will be referred to when treating of the Linnæan system of classification.

A stamen consists of two parts - a contracted portion, usually thread-like, equivalent to the petiole of the leaf, and termed the filament (filum, a thread); and a broader portion, representing the folded blade of the leaf, termed the anther (ânongos, belonging to a flower), which contains a powdery matter, called pollen. The filament is no more essential to the stamen than the petiole is to the leaf, or the claw to the petal. If the anther is absent, the stamen is abortive, and cannot perform its functions. The anther is developed before the filament, and when the latter is not produced the anther is sessile (sessilis, sitting), or has no stalk, as in the Mistleto.

The Filament, when structurally considered, is found to consist of a thin epidermis, on which occasionally stomata and hairs occur, and of a layer of cellular tissue enclosing a bundle of spiral vessels, which traverses its whole length, and terminates at the union between the filament and the anther. The filaments of Callitriche verna are said to have no vessels. The filament is usually, as its name imports, filiform or thread-like, cylindrical, or slightly tapering towards its summit. It is often, however, thickened, compressed, and flattened in various ways. It sometimes assumes the appearance of a petal, or becomes petaloid ( $\pi \dot{\varepsilon} r \alpha \lambda \omega v$, a leaf or petal, $\varepsilon \tilde{\delta} \delta 0 \varsigma$, form), as in Canna, Maranta, Nymphæa alba (fig. 342) ; occasionally it is subulate (subula, an awl), or slightly broadened at the base, and drawn out 
into a point like an awl, as in Butomus umbellatus; and at other times it is clavate (clava, a club), or narrow below and broad above, like the club of Hercules, as in Thalictrum. In place of tapering, it happens, in some instances, as in Tamarix gallica (fig. 343), Peganum Harmala, and Campanula, that the base of the filament is dilated much, and ends suddenly in a narrow thread-like portion. In these cases the base may represent the sheath or vagina of the petiole, and, like it, may give off stipulary processes in a lateral direction. Sometimes the filament is forked, or divided at the apex into branches or teeth. In Allium and Alyssum calycinum there are three teeth, the central one of which bears the anther. In the common garlic one of the lateral teeth is somewhat cirrose.

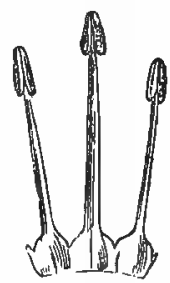

Fig. 343.

The filament varies much in length and in firmness. The length sometimes bears a relation to that of the pistil, and to the position of the flower, whether erect or drooping. The filament is usually of sufficient solidity to support the anther in an erect position; but sometimes, as in Grasses, Littorella, and Plantago, it is very delicate and capillary (capillus, a hair), or hair-like, so that the anther is pendulous. The filament is usually continuous from one end to the other, but in some cases it is bent or jointed, becoming geniculate (genu, a knee) ; at other times, as in the Pellitory, it is spiral. It is frequently colourless ; but, in many instances, it exhibits different colours. In Fuchsia and Poinciana, it is red; in Adamia and Tradescantia virginica, blue; in Enothera and Ranunculus acris, yellow.

Hairs, scales, teeth, or processes of different kinds are sometimes developed on the filament. In Tradescantia virginica, or Spiderwort, the hairs are beautifully coloured, and moniliform (monile, a necklace) or neclilace-like. These hairs exhibit movements of rotation (p. 153). Such a filament is bearded or stupose (stupa, tow). At the base of the filament certain glandular or scaly appendages are occasionally produced, either on its internal or external surface. These may be either parts of a whorl, to be afterwards noticed under the name of the Disk, or separate prolongations from the filament itself. In fig. $345, a$ represents such a staminiferous appendage found on the

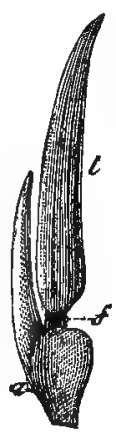

Fig. 344.

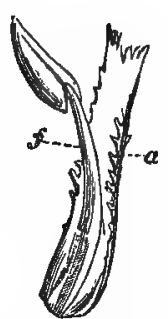

Fig. 345.

Fig. 343. Three out of ten stamens of Tamarix gallica, united together by the dilated bases of their filaments. Fig. 344. Stamen of Borago officinalis. $f$, Appendiculate filament. $\alpha$, Appendage prolonged in the form of a horn-like process. $l$, Lobes of the anther. Fig. 345. Stamen of Zygophyllum Fabago. $f$, Filament, connected with a broad scaly appendage, $a$. 
inner side of the base of the filament, $f$, which is hence called appendiculate, or sometimes strumose (struma, a swelling). The processes noticed in the Boraginacer as modified petals (fig. $344 a$ ) may be considered external appendages of the filaments, the stamen being regarded as the lamina of a petal.

Filaments are usually articulated to the thalamus or torus, and the stamen falls off after fertilisation; but in Campanula and other plants they are continuous with the torus, and the stamen remains persistent, although in a withered state. Certain changes are produced in the whorl of stamens by adhesion of the filaments to a greater or less extent, while the anthers remain free; thus, all the filaments of the androcium may unite, forming a tube round the pistil (fig. 338 $e$ ), or a central bundle when the pistil is abortive (fig. 346,1 ), the
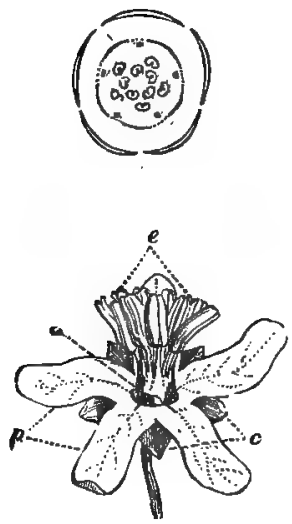

Fig. 346, 1.
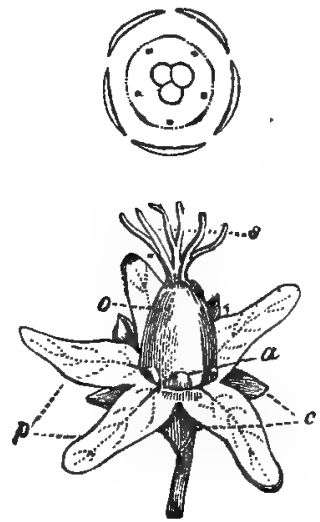

Fig. 346, 2.

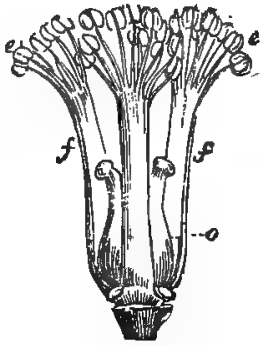

Fig. 347 .

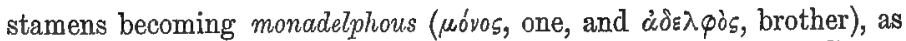
occurs in Geranium (fig. 338), Malva, Hibiscus, and Jatropha Curcas (fig. 346,1 ); or they may unite so as to form two bundles, the stamens being diadelphous (dis, twice), as in Polygala, Funaria, and

Fig. 346. Male or staminiferous flower (1), and female or pistilliferous flower (2), of Jatropha Curcas. $c$, Calyx. $p$, Corolla. $e$, Stamens united by filaments occupying the centre in flower 1, in consequence of the suppression of the pistil. $p$, Pistil in lower 2, composed of ovary, $o$, with three bifid styles at its summit. $a$, Small glandular appendages alternating with the divisions of the corolla. Above each of the flowers is a diagram representing the order in which the different parts of the flower are arranged. In diggram 1 are represented five parts of the calyx, five of the corolla, two rows of stamens, five in each. In diagram 2, the staminal rows are abortive, and there are three carpels forming the pistil, in the centre. Fig. 347. Triadelphous stamens of Hypericun regyptiacum surrounding the pistil, 0 . $f f$, United filaments forming columns. e e, Anthers free. The outer envelope of the flower has been removed, the essential organs alone being left. 
Pea; in this case the bundles may be equal or unequal. It frequently happens, especially in Papilionaceous flowers, that out of ten stamens nine are united by their filaments, while one (the posterior one) is free. When the filaments are united in three or more bundles, the stamens

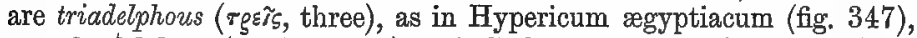
or polyadelphous ( $\pi 0 \lambda$ is, many), as in Luhea paniculata (fig. 348,1 ), or in Ricinus communis (fig. 349,1). These staminal bundles may be supposed to be a compound stamen divided, or they may be looked upon as resembling digitately-divided leaves. When there are three stamens in a bundle we may conceive the bundle as representing a leaf, with two stipules united at its base. In Lauraceæ there are perfect stamens, each having at the base of the filament two abortive stamens or staminodes (fig. 357), which may be analogous to stipules. The union of the filaments takes place sometimes at the base only, as in Tamarix gallica (fig. 343); at other times it extends throughout their whole length, so

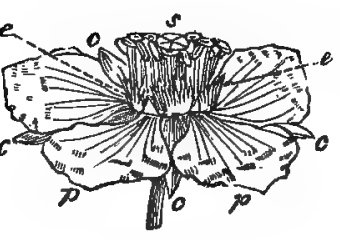

Fig. 348,1 .

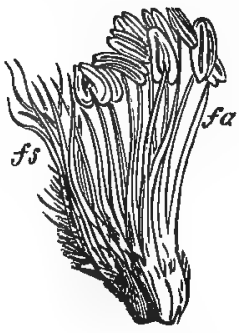

Fig. 348,2 .

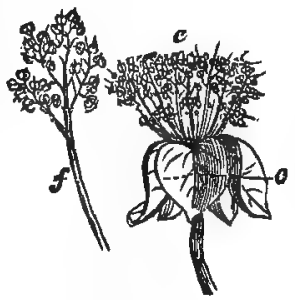

Fig. 349 , 2. Fig. $349,1$.

that the bundles assume a columnar form. In certain cases, the cohesion extends to near the apex, forming what Mirbel calls an androphore (ảvrìe, male or stamen, 申ogśw, I bear); or a column which divides into terminal branches, each bearing an anther $(347, f e)$. Occasionally some filaments are united higher up than others, and thus a kind of compound branching is produced (fig. 349,2). In Pancratium, the filaments are united by a membrane, which may be considered as corresponding to the crown of Narcissus.

Filaments sometimes are united with the pistil, forming a columna or column, as in Stylidium, Asclepiadacex, Rafflesia, and

Fig. 348, 1. Flower of Luhea paniculata. $c$ c $<c$, Segments of calyx. $p p$, Petals. e e, Stamens grouped in bundles, which alternate with the petals. $s$, Stigma, composed of five parts, indicating the union of five carpels. 2. One of the staminal bundles magnified, showing all the filaments united in a single mass at the base, but separating superiorly. $f a$, The larger internal filaments, each ending in an anther. $f s$, The shorter outer ones, sterile and abortive. Fig. 349, 1. Male flower of Ricinus communis, or Castor-oil plant, consisting of a calyx, $c$, composed of five reflexed sepals, and of stamens, $e$, united by their filaments so as to form many bundles, thus being polyadelphous. 2. One of the staminal bundles, $f$, branching above so as to leave the anthers free and separate. 
Orchidaceæ. The column is called gynostemium ( $\gamma u \dot{\eta}$, pistil, and $\sigma \tau \dot{n} \mu \omega \nu$, stamen), and the flowers are denominated gynandrous ( $\gamma$ uviे, pistil, ávìg, male or stamen).

In the case of certain Achlamydeous (p. 192) flowers, as Euphorbia, with only one stamen developed, there is the appearance of a jointed filament bearing one anther. This, however, is not a true filament, but a peduncle with a single stamen attached to it, as proved by the fact, that in some species of Euphorbia one or more verticils are produced at the joint. In this case the apparent anther represents a single flower supported on a stalk, all the parts being abortive except a solitary stamen.

The ANTher corresponds to the blade of the leaf, and consists of lobes or cavities containing minute powdery matter, called pollen, which, when mature, is discharged by a fissure or opening of some sort. The anther-lobes may be considered as formed by the two halves of the lamina, their back corresponding to the under surface, and their face to the upper surface, united by the midrib, the pollen being cellular tissue, and the fissure of the anther taking place at the margin, which, however, is often turned towards the face. In this view, the two cavities which are found to exist in each lobe may correspond with the upper and under layer of cells, separated by a septum equivalent to the fibro-vascular layer of the leaf. Others view the anther as formed by each half of the lamina being folded upon itself, so that the outer surface of both face and back corresponds to the lower side of the leaf, and the septum dividing each cavity into two is formed by the united upper surfaces of the folded half.

There is a double covering of the anther-the outer, or exothecium (" ${ }^{\prime \prime} \xi \omega$, outwards, $\theta$ nxiov, a covering), resembles the epidermis, and often presents stomata and projections of different kinds (fig. $350 \mathrm{ce}$ ); the inner, or endothecium (z"voov, within), is

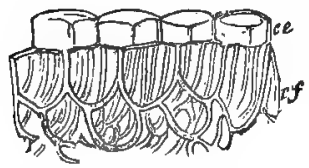

Fig. 350. formed by a layer or layer's of fibro-cellular tissue (fig. $350 \mathrm{cf}$ ), the cells of which have a spiral (fig. 23), annular (fig. 24), or reticulated (fig. 25) fibre in their interior. This internal lining varies in thickness, generally becoming thinner towards the part where the anther opens, and there disappears entirely. The membrane of the cells is frequently absorbed, so that when the anther attains maturity the fibres are alone left, and these by their elasticity assist in discharging the pollen. The cells in the endothecium of Armeria maritima and Pinguicula vulgaris are reticulated, while annular cells occur in the endothecium of Cardamine pratensis.

Fig. 350. Transverse section of a portion of the covering of the anther of Cobæa scandens at the period of dehiscence. ce, Exothecium, or external layer, consisting of epidermal cells. $c f$, Endothecium, or inner layer, composed of spiral cells or inenchyma. 
The anther is developed before the filament, and is always sessile in the first instance. In many examples it continues permanently so.

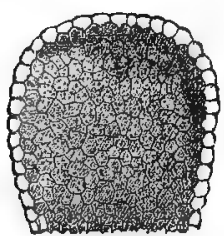

Fig. 351.

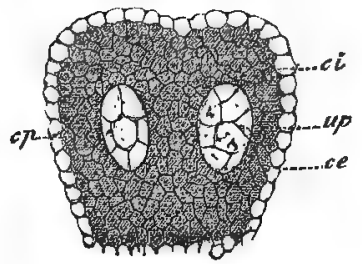

Fig. 352.

It appears in the form of a small cellular projection, containing a mass of mucilaginous cells (fig. 351). In the progress of growth, certain grooves and markings appear on its surface, and its interior becomes

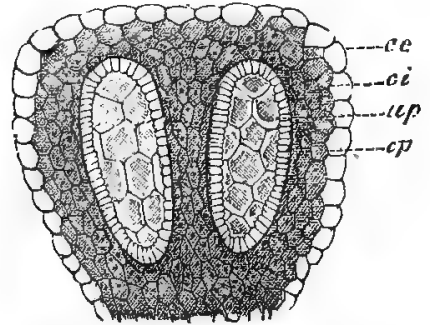

Fig. 353.

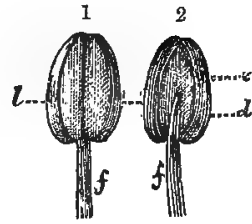

Fig. 354.

hollowed out into two marked cavities, containing a mucilaginous matter (figs. 352, 353). In these cavities cells make their appearance - the outer small (figs. 352, 353, $c p$ ), forming ultimately the endothecium (fig. $350 \mathrm{cf}$ ); the interior layer forming cells in which the pollen is produced (figs. 352, 353, up). As the cavities become larger, the layer of cells (figs. 352, 353, ci) between the endothecium, $c p$, and exothecium, $c e$, is gradually absorbed more or less completely, forming at first septa in the cavities; and ultimately the anther assumes its mature form, consisting of two lobes with their membranous coverings (fig. $354 l$ ).

In the young state there are usually four cavities produced, two for each anther-lobe, separated by the connective, and each divided by

Fig. 351. Transverse section of an anther of Cucurbita Pepo, or Gourd, taken from a bud about two millimetres, or 1-12th of an English inch, in length.

Fig. 352. Similar horizontal section from a bud in a more advanced state. ce, Outer layer of cellules (Exothecinm) forming the epidermis, ci, Intermediate layer of cellules in several layers, most of which are ultimately absorbed. $c p$, Internal layer of cells (Endothecium). $w_{p}$, Anther-cavities flled with large cells, which constitute the first state of the pollen-utrieles, or pollinic cells. Fig. 353. Similar section in a still more advanced state. The letters as in the last figure. Fig. 354. Anther of the Almond-tree. 1. Seen in front. :2. Seen behind. $f f$, Filament attached to the connective, $c$, by a point. $l l$, Anther-lobes containing pollen. 
the septum, which sometimes remains permanently complete, and thus forms a quadrilocular (quatuor, four, loculus, a pouch or box) or

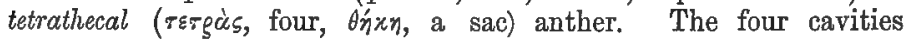
are sometimes placed in apposition, as in Poranthera (fig. 355) and Tetratheca juncea (fig. 356), and at other times two are placed above and two below, as in Persea gratissima (fig. $357 \quad l$ l). In general, however, only two cavities remain in the anther, in consequence of the more or less complete removal of the septum, in which case the anther is said to be bilocular (bis, twice), or dithecal ( $\delta i s$, twice) as seen in figs. 354,358 . Sometimes the anther has a single cavity, and be-

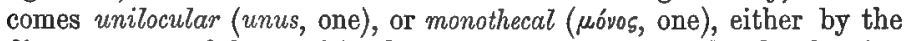
disappearance of the partition between the two lobes, or by the abortion of one of its lobes, as in Styphelia læta (fig. 359) and Althæa officinalis (fig. 360). Occasionally there are numerous cavities in the anther, as in Viscum and Rafflesia. The number of loculi or cavities is only seen when the anther opens.

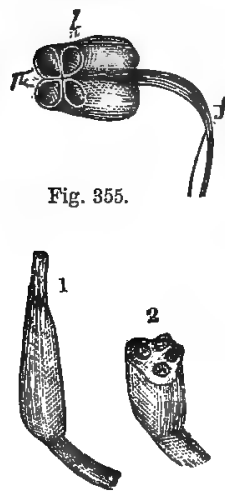

Fig. 356.

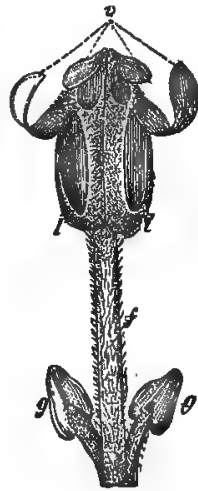

Fig. 357 .

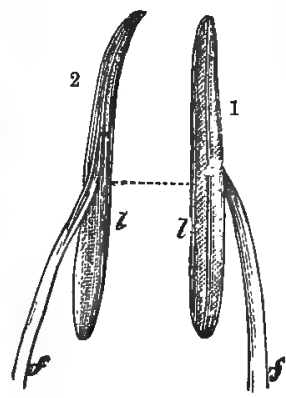

Fig. 359 ,

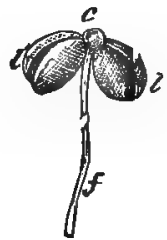

Fig. 358. ,

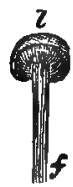

Fig. 360 .

The form of the anther-lobes varies. They are generally of a more or less oval or elliptical form (figs. 354, $361 l$ ). Sometimes

Fig. 355. Quadrilocular anther, $l$, of Poranthera, attached to the filament, $f$, and opening at the summit by four pores, $p$.

Fig. 356. Quadrilocular anther of Tetratheca juncea. 1. The anther entire, with its four loculaments ending in one opening. 2. Anther cut transversely, showing the four loculaments. Fig. 357. Anther of the Avocado pear (Persea gratissima), composed of four cavities or loculaments, $l \quad l$, united in pairs, one above the other, and opening each by a valve, $v$. At the base of the filament, $f$, are two glands, $g g$, which seem to be abortive stamens or staminodes, and which may represent stipules. Fig. 358. Pendulous anther lobes, $l l$, of Mercurialis annua, supported on the filament, $f$, and united by the connective, c. Fig. 359. Unilocular or monotheeal anther of styphelia lreta, one of the Epacridaceæ, seen in front, 1 , and behind, 2. $f$, Filament. $l$, Anther. Fig. 360. Unilocular anther of Althæa officinalis, or Marsh mallow. One of the lobes of the anther, $l$, abortive. $f$, Filament. 
they are globular, as in Mercurialis annua (fig. 358); at other times linear or clavate (fig. 362), curved (fig. 363), flexuose, sinuose, or anfractuose (anfractus, winding), as in Bryony and Gourd (fig. 364). The lobes of the anther are sometimes in contact throughout their whole length (fig. 361), at other times they are separate (figs. 358,

Fig. 361. Fig. 362. Fig. $363 . \quad$ Fig. 364.
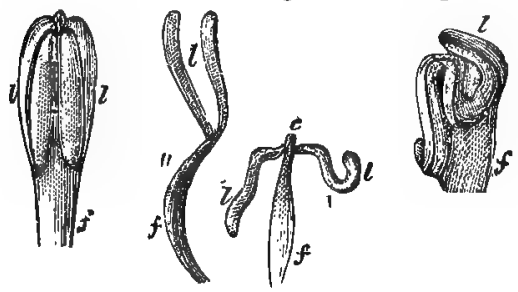

Fig. 365 .

Fig. 366.

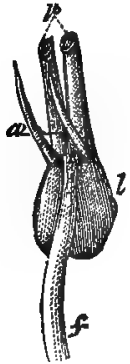

Fig. 367 .

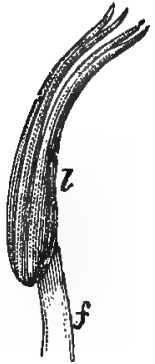

Fig. 368 .

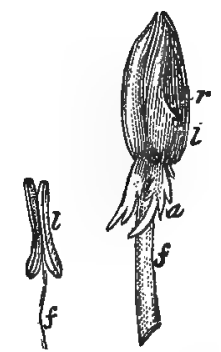

Fig. 369. Fig. 370 .

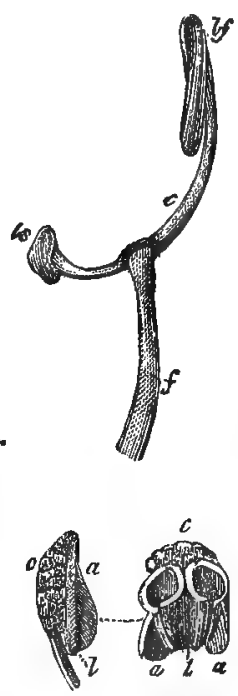

Fig. 371.

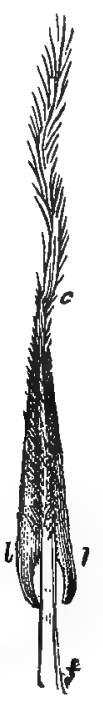

$365)$. In the former case their extremities may be rounded, forming a cordate anther (fig. 354), or the apex may be acute (figs. 344, 345); in the latter case the lobes may divide at the base only, and end in a sagittate or arrow-like manner (fig. $366 l$ ); or at the apex, so as to be bifurcate or forked (fig. $367 p$ ) ; or quadrifurcate, doubly forked

Fig. 361. Adnate or adherent anther of Begonia manicata, opening by longitudinal dehiscence. $l$, Anther-lobes. $f$, Filament: Fig. 362. Forked or bifureate anther, $l$, of Acalypha alopecuroiclea, in the expanded flower. Fig. 363. Same anther in the bud, exhibiting $a$ curved form. Fig. 364. Sinuous anther, $l$, of Bryonia dioica. $f$, Filament. Fig. 365. Anther of Salvia officinalis. $l f$, Fertile lobe full of pollen. $l s$, Barren lobe without pollen. c, Distractile connective. Fig. 366. Anther of Nerium Oleander, with its lobes, $l l$, sagittate at the base, and ending at the apex in a long feathery prolongation. Fig. 367. Anther, $l$, of Vaccinium uliginosum. $l$, Lobes ending in two pointed extremities, which open by pores. $a$, Appendages to the lobes. Fig. 368. Quadrifurcate anther of Gualtheria procumbens. $l$, Lobes ending in four points. Fig. 369. Versatile anther of Poa compressa, f, Filament, $l$, Lobes separating at each end. Fig. 370. Anther, $l$, of Erica cinerea. $f$, Filament. $r$, Lobes split partially downwards. a, Scale-like prolongations at the base. Fig. 371. Anther of Pterandra pyroidea. 1. Entire anther, seen laterally. 2. Lower half after having been cut transversely. $a \alpha a$, Antherine appendages. $l l$, Anther-lobes. $c c$, Connective. 
(fig. $368 l$ ); or at both base and apex, so as to be forked at each extremity, as in Grasses (fig. 369). The cavities of the anther are occasionally elongated so as to end in points (fig. 368 l). Sometimes the lower part of the antherine cavities is obliterated, and they degenerate into flattened appendages (fig. $370 \mathrm{a}$ ). It happens at times that the surface of the anther presents excrescences in the form of warts, awl-shaped pointed bodies (fig. 367 a), or crests (fig. 371 a).

That part of the anther to which the filament is attached, and which is generally towards the petals, is the back, the opposite being the face. The division between the lobes is marked on the face of the anther by a groove or furrow, and there is usually on the face a suture, indicating the line where the membranous coverings open to discharge the pollen. The suture is often towards one side in consequence of the valves being unequal.

The anther-lobes are united either by a direct prolongation of the filament, or more generally by a body called the connective, consisting of a mass of cellular tissue different from that contained in the filament. In this tissue the spiral vessels of the latter terminate: From the connective a partition or septum extends across each antherine loculus, dividing it either partially or completely. The septum sometimes reaches the suture. When the filament is continuous with the connective, and is prolonged so that the anther-lobes appear to be united to it throughout their whole length, and lie in apposition and on either side of it, the anther is said to be adnate or adherent (fig. 361); when the filament ends at the base of the anther, then the latter is innate or erect. In these cases the anther is to a greater or less degree fixed. When, however, the attachment is very narrow, and an articulation exists, the anthers are then movable, and easily turned by the wind. This is well seen in what are called versatile (verto, I turn) anthers, as in Tritonia, Grasses, etc. (figs. 327, 369), where the filament is attached only to the middle of the connective; and it may occur also in cases where it is attached to the apex, as in pendulous anthers (fig. 372).

The connective may unite the anther-lobes completely, or only partially. It is sometimes very short, and is reduced to a mere point, (fig. 358), so that the lobes are separate or free. At other times it is prolonged upwards beyond the lobes in the form of a point, as in Acalypha (fig. $363 \mathrm{c}$ ); or of a feathery awn, as in Nerium Oleander (fig. 366 ); or of a conical or tongue-like process (figs. $373,374 \mathrm{c}$ ); or of a membranous expansion (fig. $375 \mathrm{c}$ ); or it is extended backwards and downwards, in the form of a spur, as in fig. $375 a$; or downwards, as in the case of the flaky appendage in Ticorea febrifuga. In Salvia officinalis (fig. 365 ), the connective is attached to the filament in a horizontal manner, so as to separate the two anther-lobes, and then it is called distractile (dis, separate, traho, I draw). In Stachys, 
the connective is expanded laterally, so as to unite the bases of the antherine lobes, and bring them into a horizontal line.

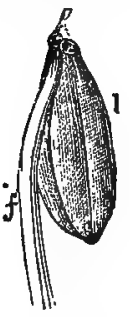

Fig. 372 .

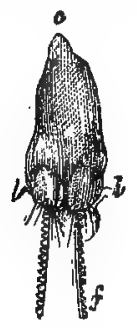

Fig. 373.

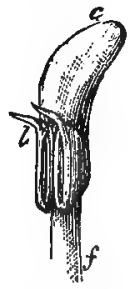

Fig. 374.

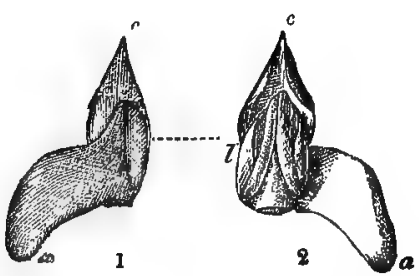

Fig. 375.

The opening of the anthers to discharge their contents is denoninated dehiscence (dehisco, I open). This takes place either by clefts, by hinges, or by pores. When the anther-lobes are erect, the cleft takes place lengthwise along the line of the suture, constituting longitudinal dehiscence (figs. 354, 361, 374). At other times, the slit takes place in a horizontal manner, from the connective to the 'side, as in Alchemilla arvensis, and in Lemna, where the dehiscence is transverse. When the anther-lobes are rendered horizontal by the enlargement of the connective (figs. $360,376, a q$ ), then what is really longitudinal dehiscence may appear to be transverse. In other cases (fig. $376 \mathrm{ag}$ ), when the lobes are united at the base, the fissure in each of them

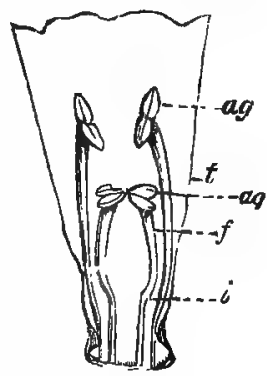

Fig. 376. may be continuous, and the two lobes may appear as one.

The cleft does not always proceed the whole length of the antherlobe at once, but often for a time it extends only partially (figs. 375, 2; 370). In other instances the opening is confined to the base or apex, each loculament.(loculus) opening by a single pore, as in Pyrola (fig. 372), Vaccinium (fig. 367), also in Solanum, where there are

Fig. 372. Pendulous Anther, $l$, of Pyrola rotundifolia. The Anther is suspended from the summit of the filament, $f$, and opens at its apex by two pores, $p$. Fig. 373. Anther of Humiria balsamifera. $l l$, Anther lobes. $f$, Filament, ciliated or fringed with glandular teeth. ¿, Conical appendage, which seems to be a prolongation of the connective. Fig. 374. Anther of Byrsonima bicorniculata. $f$, Filament. $l$, Anther-lobes. The empty lobes at the sumnit are detached in the form of two small horn-like projections. c, A linguiform or tongue-like appendage prolonged from the connective. Fig. 375. Sessile anther of Viola odorata, or sweet violet. 1, Seen in front. 2, Seen behind. $l$, Anther-lobes. $a$, Spur-like appendage from the connective. c, Membranous expansion at the apex of anther-lobes. Fig. 376 . Corolla of Digitalis purpurea, eut in order 'to show the didynamous stamens (two long and two short) which are attached to it. $t$, Tube, f, Filaments which are united to the corolla at $i$, and run along its inner surface, having formed a marked adhesion. ag, Anthers of the long stamens. aq, Anthers of the short stamens. 
two, and Poranthera (fig. 355), where there are four. In Tetratheca juncea the four cavities (fig. 356,2 ) open into a single pore at the apex (fig. 356,1 ); and in the Mistleto the anther has numerous pores for the discharge of the pollen. Another mode of dehiscence is called hinged. In the Barberry each lobe opens by a valve on the outer side of the suture, separately rolling up from base to apex; while in some of the Laurel tribe (fig. $357 v$ ) there are two such separating valves for each lobe, or four in all. This may be called a combination of transverse and hinged dehiscence. In some Guttiferæ, as Hebradendron cambogioides (the Ceylon Gamboge plant), the anther opens by a lid separating from the apex, or as it is called circumscissile (circum, around, scindo, I cut) dehiscence. In the last-mentioned dehiscence the anther may be considered as formed of jointed leaves like those of the Orange, the blades of which separate at the joint.

The anthers open at different periods during the process of flowering; sometimes in the bud, but more commonly when the pistil is fully developed, and the flower is expanded. They either open simultaneously or in succession. In the latter case, individual stamens may move in succession towards the pistil and discharge their contents, as in Parnassia palustris, or the outer or the inner stamens may open first, following thus a centripetal or centrifugal order. The anthers

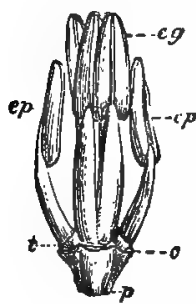

Fig. 377. are called introrse (introrsum, inwardly), or antice (anticus, the fore part), when they open on the surface next to the centre of the flower (fig. 377); they are extrorse (extrorsum, outwardly), or posticae (posticus, behind), when they open on the outer surface ; when they open on the sides, as in Iris, and some grasses, they are' called laterally dehiscent (fig. 369). Sometimes anthers, originally introrse, from their versatile nature become extrorse, as in the Passion-flower and Oxalis. The attachment of the filament either on the outer or inner side, and the position of the anther in the young state, assist in determining the direction of the dehiscence when the anthers open by pores, or are versatile.

The usual colour of anthers is yellow, but they present a great variety in this respect. The are red in the Peach, dark purple in the Poppy and Tulip, orange in Eschscholtzia, etc. The colour and appearance of the anthers often change after they have discharged their functions.

Sometimes a flower consists of a single stamen, as already stated in regard to Euphorbia. It is said, also, that in the Coniferæ, as in

Fig. 377. Tetradynamous stamens (two long and two short) of Cheiranthus Cheiri. p, Top of the peduncle. c, Cicatrices left by the sepals of calyz which have been removed. eg, Two pairs of long stamens. ep, The short stamens. t, Torus or thalamus to which the stamens are attached. 
the Fir, and in the Cycadaceæ, the stamens are to be regarded as single male flowers, supported on scales; being either a single stamen with bilocular anthers, as in Pinus, or unilocular, as in Abies, or several stamens united in an androphore, as in Taxus. In the genus Pinus there are male cones composed of bract-like processes, bearing on their lower side two parallel anther-lobes, beyond which a scale-like connective extends. In the Yew and Cypress there is a peltate connective overhanging the anthers. In Cycads there are numerous anthers on the lower surface of the scales of the male cones.

Stamens occasionally become sterile by the degeneration or nondevelopment of the anthers, which, in consequence of containing pollen, are essential for fertilisation; such stamens receive the name of staminodia, or rudimentary stamens. In Scrophularia (fig. 378) the fifth stamen, $s$, appears in the form of a scale; and in many Pentstemons it is reduced to a filament with hairs, or a shrivelled membrane at the apex. In other cases, as in double flowers, the stamens are converted into petals; this is also probably the case with such plants as Mesembryanthemum, where there is a multiplication of petals in several rows. In Persea gratissima (fig. 357), two glands, $g$, are produced at the base of the filament in the form of stamens, the anthers of which are abortive; the same thing is seen in other Lauraceæ. In these cases the central perfect stamen may be considered as representing the true leaf, and the two staminodes or glandular bodies, the stipules. Sometimes only one of the anther-lobes becomes abortive. In many unilocular anthers, the nondevelopment of one lobe is indicated by the lateral production of a cellular mass resembling the connective.

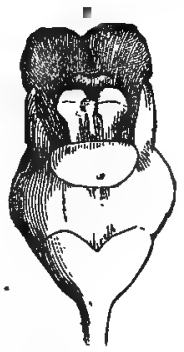

Fig. 378. In Salvias, where the connective is distractile, one of the lobes only is perfect or fertile (fig. 365, lf), containing pollen, the other (fig. $365, l s)$ is imperfectly developed and sterile. In Canna, in place of one of the lobes, a petaloid appendage is produced.

The stamens, in place of being free and separate, may become united by their filaments (pp. 218, 219). They may also unite by their

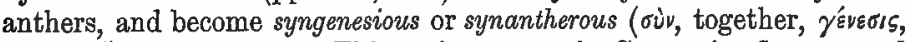

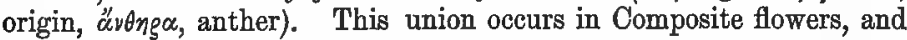
in Lobelia, Jasione, Viola, etc.

Stamens vary in length as regards the corolla. Some are enclosed within the tube of the flower, as in Cinchona, and are called included (figs. 311, 312,376) ; others are exserted, or extend beyond the flower, as in Littorella, Plantago, and Exostemma. Sometimes the stamens in the early state of the flower project beyond the petals,

Fig. 378. Irregular corolla of Serophularia, with a staminodium, $s$, or abortive stamen, in the form of a scale. 
and in the progress of growth become included, as in Geranium striatum (fig. 379). Stamens also vary in their relative

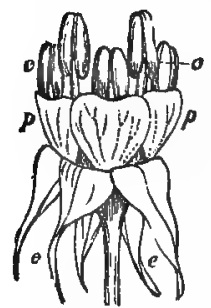

Fig. 379 . lengths as respects each other. When there is more than one row or whorl in a flower, those on the outside are sometimes longest, as in Rosaceæ (fig. 339); at other times those in the interior are longest, as in Luhea (fig. 348, 2, $f a$ ). When the stamens are in two rows, those opposite the petals are usually shorter than those which alternate with the petals.

It sometimes happens that a single stamen is longer than all the rest. In some cases there exists a definite relation, as, regards number, between the long and the short stamens. Thus, some flowers

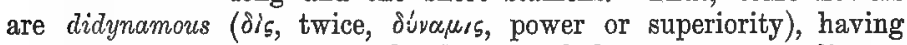
only four out of five stamens developed, and the two corresponding to the upper part of the flower longer than the two lateral ones. This occurs in Labiatæe and Scrophulariaceæ (figs. 376, 378). Again, in other cases, there are six stamens, whereof four long ones are arranged in pairs opposite to each other, and alternate with two isolated short ones (fig. 377), and give rise to tetradynamous (rergàs, four, divveus, power or superiority) flowers, as in Cruciferæ.

Stamens, as regards their direction, may be erect, turned inwards, outwards, or to one side. In the last-mentioned case they are called declinate (declino, I bend to one side), as in Amaryllis, Horse-chestnut, and Fraxinella.

ThE PoLiten.-The pollen or powdery matter contained in the anther consists of small cells developed in the interior of other cells. The cavities formed in the anther (fig. 353) are surrounded by a fibro-cellular envelope, $c p$, and within this are produced large cells, up, containing a granular mass (fig. 380, 1), which divides into four minute cells (fig. 380,2), around which a membrane is developed, so that the original cell, or the parent pollen-utricle, becomes resolved by a merismatic division (p. 14) into four parts (fig. 380,3), each of which forms a granule of pollen. The four cells continue to increase (fig. $380,4)$, distending the parent cell, and ultimately causing its absorption and disappearance. They then assume the form of perfect pollengrains, and either remain united in fours, or multiples of four, as in some Acacias, Periploca græea (fig. 381), and Inga anomala (fig. 382), or separate into individual grains (fig. 380,5 ), which by degrees become mature pollen (figs. 380,$6 ; 383,384$ ). In Acacia ringens, there are eight pollen-grains united; in Acacia decipiens, twelve; and in Acacia linearis, sixteen. Occasionally the membrane of the parent pollen-cell is not completely absorbed, and traces of it are detected in

Fig. 379. Bud of polypetalous corolla of Geranium striatum, exhibiting the stamens, $e e$, at first longer than the petals, $p p$. 
a viscous matter, surrounding the pollen-grains, as in Onagracer. In Orchideous plants the pollen-grains are united into masses or pollinia (fig. 387), by means of viscid matter. In Asclepiadacese (fig. 385) the pollinia are usually united in pairs (fig. 386 b), belonging to two contiguous antherine cavities;- each pollen-mass having a caudicular appendage, ending in a common gland, by means of which they are attached to a process of the stigma (figs. $385 \mathrm{p}$, and $386 p$ ). The pollinia are also provided with an appendieular stami-

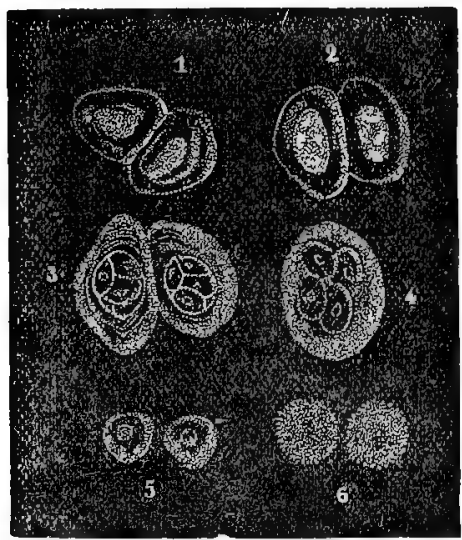

Fig. 380 .

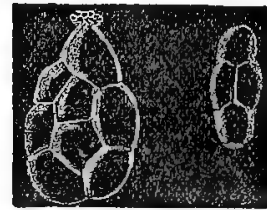

Fig. 381 .

Fig. 382.

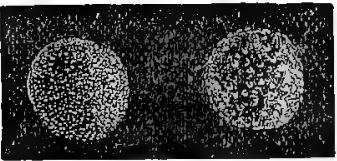

Fig. 383.

Fig, 384.

nal covering (fig. $385 \mathrm{p}$ ). Pollinia in different plants vary from two to eight. Thus, there are usually two in Orchis, four in Cattleya, and eight in Lælia. The two pollinia in Orchis Morio, according to Amici, contain each about 200 secondary smaller masses. These small masses, when bruised, divide into grains which are united in fours. In Orchids each of the pollen-masses (fig. 387) has a prolongation or stalk, called a caudicle (cauda, a tail), which adheres to a prolongation at the base of the anther, called rostellum (rostellum, a beak), by means of a viscous gland (fig. $387 \mathrm{~g}$ ), called retinaculum (retinacutum, a band or rein). The gland is either naked or covered.

Fig. 380. Development of the pollen of Visenm album, or the Mistleto. 1. Two pollencells or pollinie utricles filled with granular matter. 2. Four nuclei produced in this matter. 3. Separation into four masses, each corresponding to a nucleus or a new utricle. 4. Pollinic utricle containing three separate vesicles in its anterior. 5. Two of the latter, or the young pollen-grains, removed from the mother-cell or utricle. 6. The grains of pollen in their perfect state. Fig. 381. Pollen of Periploca græeca, showing four grains agglutinated together. Fig. 382. Pollen of Inga anomala. The grains united in multiples of four. Fig. 383. Pollen-grain showing the extine covered with small punctations. Fig. 384. Pollen-grain with the extine covered with granulations. 
The term clinandrium ( $x \lambda i v \eta$, a bed, and ḋvì, a stamen) is sometimes applied to the part of the column in Orchids where the stamens are - situated.

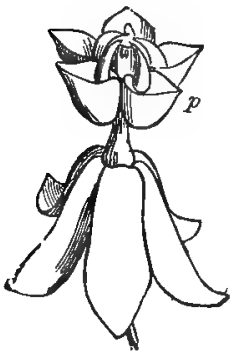

Fig. 385 .

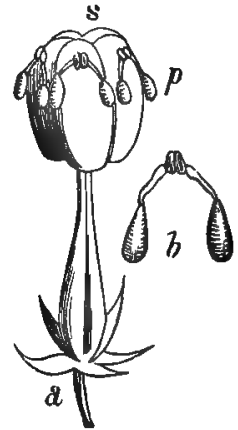

Fig, 386.

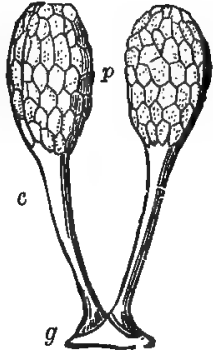

Fig. 387.

When mature, the pollen-grain is a cellular body having an external covering, extine (exto, I stand out, or on the outside), and an internal, intine (intus, within). Fritzsche states that he has detected, in some cases, other two coverings, which he calls intextine and exintine. They occur between the extine and intine, and are probably formed

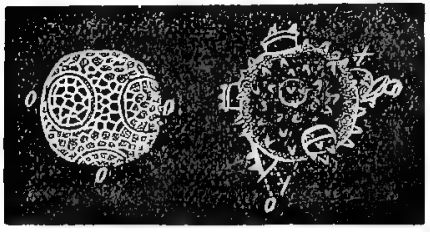

Fig. 388.

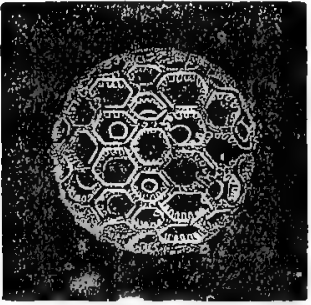

Fig. 390 .

by foldings of these membranes. In some aquatics, as Zostera marina, Zannichellia pedunculata, Naias minor, etc., only one covering exists,

Fig. 385. Flower of Asclepias, showing the pollinia or pollen-masses, $p$, attached to the stigma, and covered by appendages. Fig. 386. Pistil of Asclepias, $a$, with pollen-masses, $p$, adhering to the stigua, s. Pollen-masses, removed from the stigma, $b$, united by a gland-like body. Fig. 387. Pollinia or pollen-masses of orchis, separated from the point above the stigma, with their retinacula or viscid matter attaching them at the base. The pollenmasses, $p$, are supported on stalks or caudicles, $c$, with glands at base, $g$. These masses are easily detached by the agency of insects. Fig. 388. Pollen-grain of Passiflora before bursting. 000 , Opereula or lids formed by the extine, which open to allow the protrusion of the intine in the form of pollen-tubes. Fig. 389. Pollen-grain of Cucurbita Pepo, or Gourd, at the moment of its dehiscence or rupture. 00 , Opercula or lids separated from the extine by the protrusion of the pollen-tubes, $t t$. Fig. 390. Pollen-grain of Ipomoea, with a reticulated extine. 
and that is said to be the intine. The extine is a firm membrane, which defines the figure of the pollen-grain, and gives colour to it. It is either smooth, or covered with numerous projections, granules, points, minute hairs, or crested reticulations (fig. 390). The colour is generally yellow, and the surface is often covered with a viscid or oily matter. The intine is uniform in different kinds of pollen, thin and transparent, and possesses great power of extension. It is said to be the first envelope formed, the other being subsequently deposited while enclosed in the parent cell.

Within these coverings a granular semifluid matter called fovilla is contained, along with some oily particles, and occasionally starch. The fovilla contains small spherical granules, sometimes the $\frac{1}{8000}$ of an inch in diameter (fig. 391), and larger ellipsoidal or elongated corpuscles (fig. 392), which

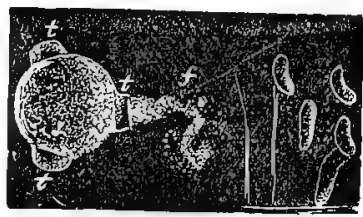

Fig. 391.

Fig. 392. exhibit molecular movements under the microscope.

Pollen-grains vary from $\frac{1}{300}$ to $\frac{1}{700}$ of an inch or less in diameter. Their forms are various. The most common form of grain is ellipsoidal (figs. 392, 393), more or less narrow at the extremities, which are called its poles, in contradistinction to a line equidistant from

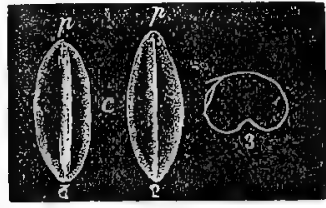

Fig. 393.

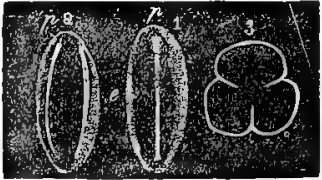

Fig. 394 .

either extremity, and which is its equator. In figs. 393, 394, 1 and 2 , the two surfaces of the pollen-grains of Allium fistulosum and Convolvulus tricolor are represented with their poles, $p$, their equator, $e$, and the longitudinal folds in their membrane; while at 3 are shown transverse sections at the equators, with a single fold in one case, and three folds in the other. Pollen-grains are also of a spherical, triangular, trigonal (fig. 396), or polyhedral figure (fig. 398). In the latter case, when there are markings on their surface, those at the

Fig. 391. Pollen-grain of Amygdalus nana, the intine or internal membrane of which is protruding at three pores, under the form of as many ampullæ ог sacs, $t t t$. One of these is open at the extremity, and from it is discharged the fovilla, $f$, composed of variously-sized granules. Fig. 392. Large granules of fovilla of Hibiscus palustris. Fig. 393. Pollen of Allium fistulosum. $p$, Pole. e, Equator. 1. Pollen-grain seen on the face. 2. On the opposite side or back. 3. Transverse section through its equatorial line. Fig. 394. Pollen of Convolvulus tricolor. The letters and numbers have the same signification as in fig. 393. 
poles, $p$, sometimes differ from those at the equator, $e$. In Tradescantia virginica the pollen is cylindrical, and becomes curved; it is polyhedral in Dipsacaceæ and Compositæ; nearly triangular in Proteaceæ and Onagraceæ (fig. 396). The surface of the pollen-grain is either uniform

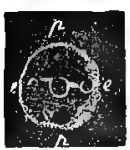

Fig. 395.

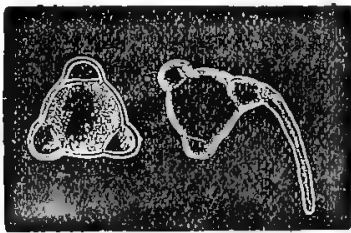

Fig. 396. Fig. 397.

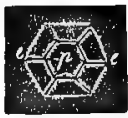

Fig. 398.

and homogeneous, or it is marked by folds dipping in towards the centre, and formed by thinnings of the membrane. In Monocotyledonous plants there is usually a single fold (fig. 393); in Dicotyledons, often. three (fig. 394). Two, four, six, and even twelve folds are also met with.

There are also pores or rounded portions of the membrane visible

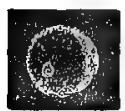

Fig. 399.

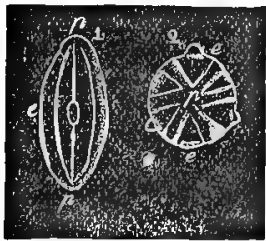

Fig. 401.

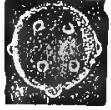

Fig. 400. in the pollen-grain. These vary in number from one to fifty. In Monocotyledons, as in Grasses, there is often only one (fig. 399); while in Dicotyledons, they number from three upwards. When numerous, the pores are either scattered irregularly (fig. 400 ), or in a regular order, frequently forming a circle round the equatorial surface (fig. 395). Sometimes at the place where the pores exist, the outer membrane, in place of being thin and transparent, is separated in the form of a lid, thus becoming operculate (operculum, a lid), as in the Passion-flower (fig. 388) and Gourd (fig. 389). Grains of pollen have sometimes both folds and pores. There may be a single pore in each fold, either in the middle (fig. 401) or at the extremities; or

Fig. 395. Grain of pollen of Cannabis sativa, or common Hemp. e, Equator. $p p$, Poles. Fig. 396. Pollen-grain of Enothere biennis, entire, with three angles, where tubes are proruced. Fig. 397. The same, with one of its angles giving origin to a pollen-tube, which is formed by the intine. When the tube protrudes, the extine is ruptured. Fig. 398. Polyhedral pollen-grain of Cichorium Intybus, or Chicory. Fig. 399. Pollen-grain of Dactylis glomerata, or Cocks-foot grass. Fig. 400. Pollen-grain of Fumaria capreolata. Fig. 401. Grain of pollen of Lythrum Salicaria, showing six folds, three of which are perforated by a pore in their middle, and three alternating with them have no pores ; $p p$, poles; $e$, equator. 1. The grain in a diy stato. 2. The grain swollen in water, so as to take a globular form and display its folds. The intine or internal membrane begins to protrude through the pores. 
folds with pores may alternate with others without pores; or finally, the pores and folds may be separate.

The form of the pollen-grains is much altered by the application of moisture. Thus, in fig. 401, 1, the pollen-grain of Lythrum Salicaria, when, dry, has an ellipsoidal form, but when swollen by the application of water it assumes a globular form (fig. 401, 2). This change of form is due to endosmose, and depends on the fovilla being denser than the water. If the grains are retained in water the distension becomes so great as to rupture the extine irregularly if it is homogeneous, or to cause projections and final rupture at the folds or pores when they exist. The intine, from its distensibility, is not so liable to rupture, and it is often forced through the ruptured extine, or through the pores, in the form of small sac-like projections (figs. $396,401,2)$. This effect is produced more fully by adding a little nitric acid to the water. The internal membrane ultimately gives way, and allows the granular fovilla to escape (fig. $391 \mathrm{f}$ ). If the fluid is applied only to one side of the pollen-grain, as when the pollen is applied to the pistil, the distension goes on more slowly, and the intine is prolonged outwards like a hernia, and forms an elongated tube called a pollen-tube (fig. 397). This tube, at its base, is often covered by the ruptured extine, and probably also by some of the coverings mentioned by Fritzsche as intervening between it and the intine. It contains in its interior fovilla-granules, and its functions will be particularly noticed under fertilisation. The number of pollentubes which may be produced depends on the number of pores. In some pollinia the number of tubes which are found is enormous. Thus, Amici calculates that the two pollen-masses of Orchis Morio may give out 120,000 tubes.

In CRyptogamic Plants there are organs equivalent to stamens, and denominated antheridia. They consist of closed sacs of different forms, rounded, ovate, oblong, clavate, flask-like, etc., developed in different parts of the plants, containing a number of corpuscles immersed in a mucilaginous fluid, which at a certain period of growth are discharged through an opening at the surface. Sometimes the antheridium is a simple cell, at other times it is composed of a number of cells, as in Hypnum triquetrum (fig. 402, 1). Antheridia are sometimes confined to particular parts

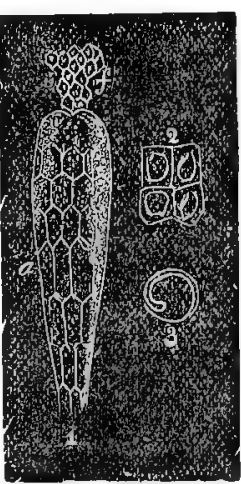

Fig. 402. of the plant, at other times they are more generally diffused. Their

Fig. 402. 1, Antheridium, $a$, of a moss called Hypnum triquetrum, at the moment when its apex is rupturing to discharge the contents, $f$. 2, Four utricles of the contents containing each a spermatozoid or moving corpuscle rolled up in a circular manner. 3 , Single spermatozoid separated. 
contents are small utricles or cellules, varying, like pollen-grains, in the

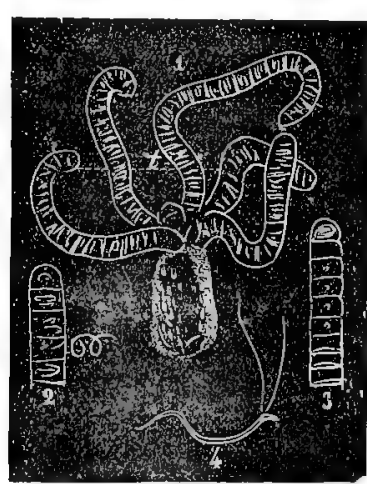

Fig. 403. different orders of cryptogamic plants, and enclosing peculiar bodies called phytozoids ( $\varphi$ us $\delta$, a plant, and $\xi \tilde{\omega} o v$,

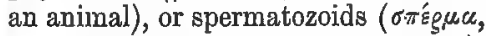
a seed), or antherozoids (fig. 402,2), which are rolled up in a circular or spiral manner, as in Hepaticæ and Mosses (fig. 402, 3). These exhibit active movements at certain periods of their existence, and resemble in this respect animalcules, In Chara vulgaris (fig. 403), the antheridium or globule, as it is called, contains cells, 1 , from which proceed numerous septate (septum, a division) tubes, $t$. In each of the divisions of these tubes, 2 , there is a spermatozoid of a spiral form, which escapes, leaving the division empty, 3 , and ultimately becomes unrolled, 4, exhibiting two vibratile cilia (cilium, an eyelash), to which its movements are referred.

THE DISK. - The term disk is applied to whatever intervenes

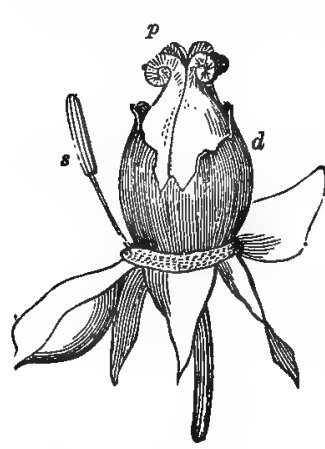
between the stamens and the pistil, and is one of those organs to which the name of nectary was applied by old authors. It presents great varieties of form, such as a ring, scales, glands, hairs, petaloid appendages, etc., and in the progress of growth it often contains saccharine matter, thus becoming truly nectariferous. The disk is frequently formed by degeneration or transformation of the staminal row. It may consist of processes rising from the torus, alternating with the stamens, and thus representing an abortive whorl; or it may be opposite to the stamens, as in Crassula

Fig. 404. rubens (fig. $282 a$ ). In some flowers, as Jatropha Curcas, in which the stamens are not developed, their

Fig. 403. 1, Portion of antheridium or globule of Chara vulgaris. Several septate or partitioned tubes, $t$, attached to a utricle or vesicle. A mass of similar utricles, forming the bases of a large number of tubes, fills the cavity of the antheridium. 2, Extremity of one of these tubes, composed of several cellules, in each of which is a phytozoid or spermatozoid. One of the spermatozoids is represented half detached from the cellule. 3, Extremity of a tube from which the spermatozoids have escaped, with the exception of the terminal celiule. 4, One of the spermatozoids separated. Fig. 404. Disk, $d$, of Pæonia Moutan, or Tree Prony, covering the ovary, and interposed between the whorl of stamens, $d$, and the pistil, $p$. 
place is occupied by glandular bodies forming the disk (fig. 346, 2,a). In Gesneraceæ and Cruciferæ the disk consists of tooth-like scales at the base of the stamens (fig. 377, t). The parts forming the disk sometimes unite and form a glandular ring, as in the Orange; or a dark-red lamina covering the pistil, as in Pæonia Moutan (fig. 404, d) ; or a waxy lining of the calyx tube or hollow receptacle, as in the Rose (fig. 294, $c t$ ) ; or a swelling at the top of the ovary, as in Umbelliferæ, in which the disk is said to be epigynous. The enlarged torus covering the ovary in Nymphæa and Nelumbium may be regarded as a form of disk.

The PistiL.--The pistil occupies the centre or axis of the flower, and is surrounded by the stamens and floral envelopes, when these are present. It constitutes the innermost whorl, and is the female organ of the plant, which after flowering is changed into the fruit, and contains the seeds. It sometimes receives the name of gynocium (ruvin, pistil, oixioy, habitation). It consists essentially of two parts, the ovary or germen, containing ovules or young seeds, and the stigma, a cellular secreting body, which is either seated on the ovary, and is then called sessile, as in the Tulip and Poppy (fig. 444), or is elevated on a stalk called the style, interposed between the ovary and stigma. The style is not necessary for the perfection of the pistil. Sometimes it becomes blended with other parts, as with the filaments of the anthers in the column of Orchidaceæ.

Like the other organs, the pistil consists of one or more modified leaves, which in this instance are called carpels (nagmòs, fruit). The analogy of carpels to leaves may be deduced from their similarity in texture and in venation; from the presence of stomata, hairs, and glands ; from their resemblance to leaves in their nascent state; from their occasional conversion into true leaves, as in Lathyrus latifolius; and from the ovules corresponding in situation to the germs or buds found on some leaves, as those of Bryophyllum calycinum. When a pistil consists of a single carpel it is simple, a state usually depending on the non-development of other carpels; when it is composed of several carpels, more or less united, it is compound. In the first-mentioned case the terms carpel and pistil are synonymons. Each carpel has its own ovary, style (when present), and stigma, and is formed by a folded leaf, the upper surface of which is turned inwards towards the axis, and the lower outwards; while from its margins are

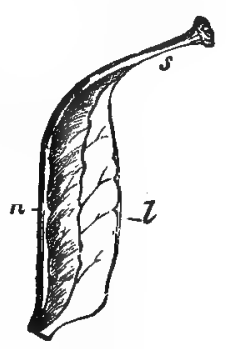

Fig. 405. developed one or more buds called ovules. That this is the true nature

Fig. 405. Carpellary leaf of the double-flowering Cherry. In this plant the pistil is combosed distinctly of one or more leaves folded inwards. $l$, Lamina or blade of the leaf or carpel. $s$, Prolongation of the midrib, $n$, representing the style, and ending in a circular thickened portion equivalent to the stigma. 
of the pistil may be seen by examining the flower of the double-flowering Cherry. In it no fruit is produced, and the pistil consists of sessile leaves (fig. 405), the limb of each being green and folded, with a

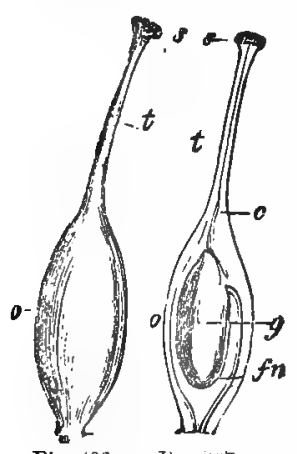

Fig. 406. Fig. 407. narrow prolongation upwards, $s$, as if from the midrib, n, and ending in a thickened portion. When the single-flowering Cherry is examined, it is found that, in place of folded leaves, there is a single body (figs. 406,407 ), the lower part of which is enlarged, forming the ovary, 0 , and containing a single ovule, $g$, attached to its walls, with a bundle of vessels, $f n$, entering it, a cylindrical prolongation, $t$, forming the style, and a terminal expansion, $s$, the stigma. It will be seen that in this case two carpellary leaves have become succulent, and have united together so as to form a compound pistil, with a single cavity containing one seed.

The Ovary then represents the limb or lamina of the leaf, and is composed of cellular tissue with fibro-vascular bundles, and an epidermal covering. The cellular tissue, or parenchyma, often becomes much developed, as will be seen particularly when fleshy fruits are considered. The outer epidermis corresponds to the lower side of the leaf, exhibiting stomata, and sometimes hairs; the inner surface represents the upper side of the leaf, being usually very delicate and pale, and forming a layer called sometimes epithelium, which does not exhibit stomata. The vascular bundles correspond with the veins of the leaf, and consist of spiral, annular, and other vessels.

The Style has usually a cylindrical form, consists of cellular and vascular tissue, and when carefully examined is found to be traversed by a narrow canal (fig. $407 \mathrm{c}$ ), in which there are some loose projecting cells (figs. 408, 409), forming what is called the conducting tissue. A transverse section of the style of Crown Imperial (fig. 408) shows three vascular bundles, $v v v$, corresponding to three styles which are united into one, and loose cells, $p$, in the canal of the style. This canal is bounded by cellular tissue (fig. 409, cc), traversed by spiral vessels, $v v$, and in its interior, besides the loose cells, $p p$, there are, especially at the period of fecundation, elongated tubes, $f f$, which in part fill up the canal. The name, conducting tissue, is given to that found in the canal of the style, on account of the part which it plays in conveying the influence of the pollen to the ovules, as will be ex-

Fig. 406. Pistil or earpel of the single-flowering Cherry in its normal state. o, Ovary. $t$, Style. $s$, Stigma. Fig. 407. The same, cut vertically, to show the central cavity of the ovary, 0 , with the ovule, $g$, suspended from its wall, at a point where a bundle of nourishing vessels, $f n$, terminates. $t$, Style traversed by a canal, $c$, which runs from the stigma, $s$, to the cavity of the ovary. 
plained under fertilisation. Lindley has shown that in some instances the style seems to derive its origin from the placenta. The presence of the style is by no means essential to the perfection of the pistil. It

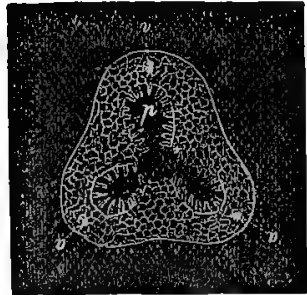

Fig. 408.

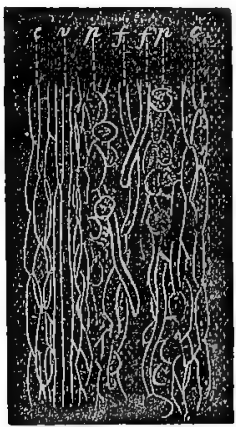

Fig. 409.

varies in its shape and position, being usually apicilar, but from alteration in the direction of the central axis it occasionally seems to be' lateral. Its form and appearance also vary; under ordinary circumstances it is rounded in shape, but occasionally becomes flattened, as in the Iris. In Clematis it is furnished with hairs ; in Euphorbia it is forked.

The Stigma is a continuation of the cellular tissue in the centre of the style, and it may be either terminal, when the canal opens at the top only (figs. $407 s, 410,1$ ), or lateral, when the splitting of the canal takes place on one side (fig.

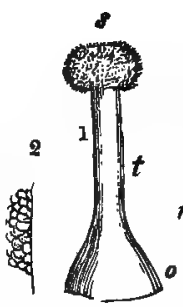

Fis 410

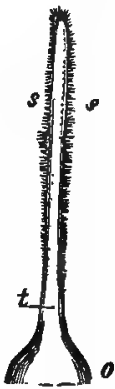

Fig. 412. $411 s$ ), or on both sides (fig. $412 s s$ ). The stigma sometimes extends along the whole length of the style. In other instances the style is absent, and then the stigma is said to be sessile. In Orchideous plants

Fig. 408. Transverse section of the style of Fritillaria imperialis, or Crown Imperial. The style is composed of three united together. $v v v$, Three vascular bundles, each corresponding to one of the three styles. $p$, Papillx or cellular bodies projecting into the cavity of the canal. Fig. 409. Structure of the canal in the centre of the style of a Campanula. $c c$, Cellular tissue forming its parietes traversed by tracheæ, v. $p p$, Variously formed cells, displaced as it were, and along with other elongated and flamentous ones, $f f$, obstructing the canal. Fig. 410. 1, Stigma, $s$, of Daphne Laureola, terminating the style, $t$. o, Summit of the ovary. 2. A small portion of the surface of the stigma, much magnified to show its papillæ. Fig. 411. Unilateral stigma, 8, of Asimina triloba. $t$, style. Fig. 412. Bilateral stigma, $s s$, of Plantago saxatilis. 0 , Ovary. $t$, Style. 
it is placed on a part of the column called the gynizus ( $\gamma$ vrì, pistil, and $"(\%, \mathrm{\omega}$, sit). It is composed of cellular tissue more or less lax, often having projecting cellules in the form of papillæ (fig. 410,2), or of hairs (figs. 413,$3 ; 446 \mathrm{~s}$ ), and at the period of fertilisation exuding a viscous fluid, which retains the grains of pollen, and causes the protrusion of tubes.

A pistil is usually formed by more than one carpel. The carpels may be arranged like leaves, either at the same or nearly the same height in a verticil (figs. 414,415 ), or at different heights in a spiral cycle (fig. $337 \mathrm{c}$ ). When they remain separate and distinct, thus showing at once the composition of the pistil, as in Caltha, Ranunculus, Hellebore, and Butomus (fig. 415), the term apocarpous (àmò, separate, and $x \alpha \rho \pi t \delta$, fruit) is applied. Thus, in Crassula rubens (fig. 414), the pistil consists of five verticillate carpels, 0 , alternating with the stamens, $e$; and the same arrangement is seen in Xanthoxylon fraxineum (fig. 414). In the Tulip-tree (fig. 337) the separate carpels, $c$, are numerous, and arranged in a spiral cycle upon an elongated axis or receptacle. In the Raspberry the carpels are on a conical receptacle ; in the Strawberry, on a swollen succulent one; and in the Rose (fig. $294 \circ$ o), on a hollow one, $r r$, ct, which is probably a prolongation of the torus.

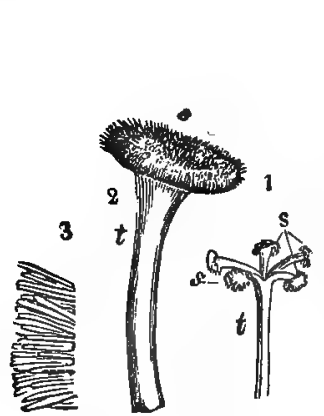

Fig. 413.

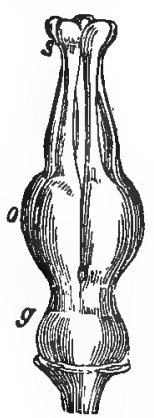

Fig. 414 .

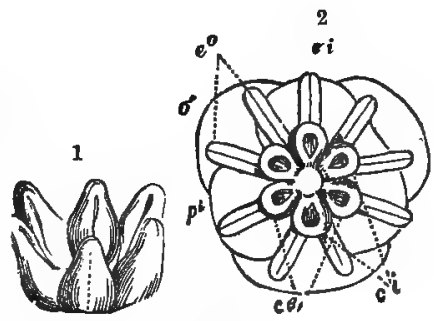

Fig. 415.

When the fruit consists of several rows of carpels on a flat receptacle, the innermost bave their margins directed to the centre,

Fig. 413, 1, Summit of the style, $t$, of Hibiscus palustris, dividing into five branches, which are each terminated by a stigma, $s$. 2, One of these branches highly magnified. 3 , Portion of the surface of the stigma still more magnified, to show its papillæ, which are elongated like hairs. Fig. 414. Pistil of Xanthoxylon fraxineum, consisting of five distinct carpels, supported on a gynophore, $g$. Each of the ovaries, $o$, bears a terminal style dilated at its extremity into a stigma, $s$. The five stigmata remain for a long time adherent by their sides. Fig. 415. 1, Carpels of Butomus umbellatus, consisting of folded leaves arranged in different verticils. 2, Section of the same, showing the alternation of the parts of the flower. Three outer leaves of the perianth, $o^{\prime}$, alternating with three inner ones, $p i$, three rows of stamens, $e 0$ and $e i$, and the carpels, ce and $e i$. 
while the margins of the outer rows are arranged on the back of the inner ones; if the receptacle is convex, the outer carpels are lowest, as in the Strawberry; if concave, the outer ones are uppermost, as in the Rose. At other times the carpels are united, as in the Pear, Arbutus, and Chickweed, so that the pistil becomes syncarpous (oùv, together or united). In Dictamnus Fraxinella (fig. 416) five carpels unite to form a compound pistil. In Scilla italica (fig. 283) the three carpels form apparently only one ; but on examination it will be found that the pistil consists of three carpels alternating with the three inner stamens. The union, however, is not always complete; it may take place by the ovaries alone, while the styles and

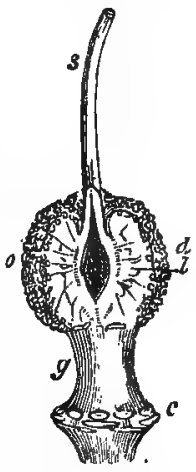

Fig. 416.

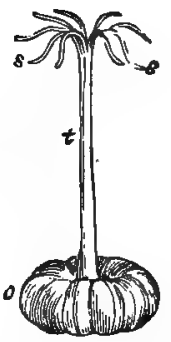

Fig. 417.

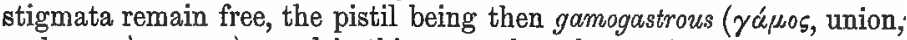
and yootrig, ovary); and in this case, when the ovaries form apparently a single body, this organ receives the name of compound ovary; or the union may take place by the ovaries and styles, while the stigmata are disunited; or by the stigmata and the summit of the style only (fig. 414). Various intermediate states exist, such as partial union of the ovaries, as in the Rue, where they coalesce at their base; and partial union of the styles, as in Malvaceæ (fig. 417). The union is usually most complete at the

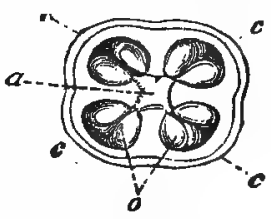

Fig. 418. base; but in Labiatæ the styles are united throughout their length, and in Apocynaceæ and Asclepiadacer the stigmata only.

When the union is incomplete, the number of the parts of a compound pistil may be determined by the number of styles and stigmata (fig. $417 \mathrm{~s}$ ); when complete, the external venation, the grooves on the surface, and the internal divisions of the ovary, indicate the number. When the grooves between the carpels are deep, the ovary

Fig. 416. Portion of the pistil of Dictamnus Fraxinella. Two of the five carpels have been removed in order to show how the styles, s, produced on the inner side of the carpels, and at first distinct, approximate and become united into one. o, Ovaries, two of which in front show their dorsal surface, $d$, and their lateral surface, $l$. At the base of the gynophore, $g$, are seen the cicatrices, $c$, marking the insertion of the calyx, the petals, and the stamens. Fig. 417. Pistil of Malva Alcea. o, Nine ovaries, united so as to form one. $t$, Column formed by nine styles united to near their summit, where they diverge and separate. Each of the divisions of the style is terminated by a stigma, $s$. Fig. 418. Horizontal section of the four-celled (qucadrilocular or tetrathecal) ovary of Fuchsia coccinea, c c c c, Wall of the ovary, which is formed by four carpellary leaves. $a$, Quadrangular axis to which the carpels are united. 0 , Ovules attached to the inner margin of the carpels. 
is denominated lobed, being one, two, three, four, or five lobed, according to circumstances. In fig. 417 the nine carpels forming the ovary, o, are divided by grooves; and in fig. 418 a transverse section of the ovary of Fuchsia coccinea shows the four carpels which form it. The changes which take place in the pistil by adhesion, degeneration, and abortion, are frequently so great as to obscure its composition, and to lead to anomalies in the alternation of parts. The pistil is more liable to changes of this kind than any other part of the flower.

The carpels are usually sessile leaves, but sometimes they are

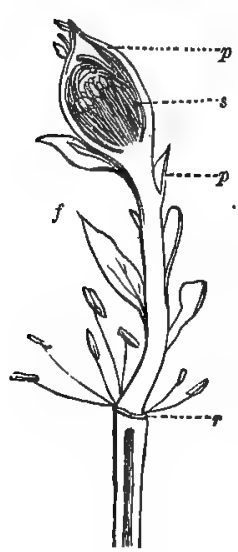

Fig. 419 . petiolate, and then are elevated above the external whorls. This elevation of the pistil may in general, however, be traced to an elongation of the axis itself, in such a way that the carpels, in place of being dispersed over it, arise only from its summit. A monstrosity often occurs in the Rose (fig; 419), by which the axis is prolonged, and bears the carpels, $f$, in the form of alternate leaves. Thus, by the union of the petioles of the carpels, or by lengthening of the axis, the pistil becomes stipitate (stipes, a trunk), or supported, as in the Passion-flower, on a stalk (figs.

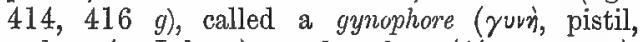

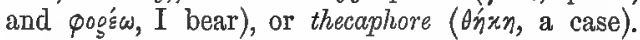
Sometimes the axis is produced beyond the ovaries, and the styles become united to it, as in Geraniacer and Unbelliferæ. In this case fruit, and $\emptyset \circ \rho^{\varepsilon} \omega$, I bear).

the prolongation is called a carpophore (xagrobs,

The ovules are developed on the inner side of the carpel where the two edges of the carpellary leaves unite, and they are connected to it by vascular bundles which proceed from below upwards, traverse the carpel, and send a branch to each of the ovules. At the same place there is a development of cellular tissue in connection with the conducting tissue of the style and with the stigma. By the union of these tissues is formed the placenta, a cellular projection to which the ovules are attached. Some restrict the term placenta to the point of attachment of a single ovule, and call the union of placentas, bearing several ovules, placentaries or pistillary cords. The part of the carpel where the placenta is formed is the inner or ventral suture, corresponding to the margin of the folded carpellary leaf, while the outer or dorsal suture corresponds to the midrib of the carpellary leaf. The placenta

Fig. 419. Section of monstrous Rose, as figured at page 172, the axis of which is prolonged beyond the flower, and the envelopes removed to show the abortive stamens, $r$. The carpels, $f$, are attached alternately along the axis in the form of leaves, $p$, Abortive floral envelopes. s, Stamens in imperfect flower at the apex. 
is hence sometimes called marginal. The placenta is formed on each margin of the carpel, and hence is essentially double. This is seen in cases where the margins of the carpel do not unite, but remain separate, and consequently two placentas are formed in place of one. In fig. 420 the two carpels are folded, so that their margins meet, and the placenta is apparently single; whereas in fig. 421 the margins of each carpel do not meet, and the placenta of each is double. Again, in fig. 422, the two carpels, after meeting in the centre or axis, $a$, are reflected outwards towards the dorsal suture, $s d$, and their margins separate slightly, each being placentiferous, and bearing ovules, $o$.

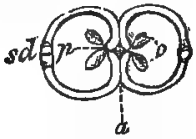

Fig. 420.

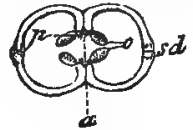

Fig. 421,

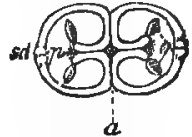

Fig. 422 .

When the pistil is formed by one carpel, the inner margins unite in the axis, and form usually a common marginal placenta. This placenta may extend along the whole margin of the ovary as far as the base of the style, or it may be confined to the base or apex only. When the pistil is composed of several separate carpels, or, in other words, is apocarpous, there are generally separate placentas at each of their margins. In a syncarpous pistil, on the other hand, the carpels are so united that the edges of each of the contiguous ones, by their union, form a septum (septum, a fence or enclosure), or dissepiment (dissepio, I separate), and the number of these septa consequently indicates the number of carpels in the compound pistil. It is obvious then that each dissepiment is formed by a double wall or two laminæ; that the presence of a septum implies the presence of more than one carpel; and that, when carpels are placed side by side, true dissepiments must be vertical, and not horizontal.

When the dissepiments extend to the centre or axis, the ovary is divided into cavities, cells, or loculaments (loculus, a box), and it may be bilocular, trilocular, quadrilocular, quinquelocular, or multilocular, according as it is formed by two, three, four, five, or many carpels, each corresponding to a single cell or loculament (fig. $415,2, c e, c i$ ). In these cases the marginal placentas meet in the axis, and unite so as to form a single central one (fig. 420 a). The number of loculaments is equal to that of the dissepiments. In fig. 418 there is shown a transverse section of the ovary of Fuchsia coccinea, $c c c c$ being its parietes formed by the union of four carpellary leaves, $a$ the axis united to the parietes by dissepiments, and $o$ the ovules attached

Figs. 420,42I, 422. Horizontal sections of ovaries, composed of two carpellary leaves, the edges of which are folded so as to meet in the axis, $a$, in fig. 420 ; are turned inwards into the loculaments after meeting in the axis in fig. 422 ; and do not reach the axis in fig. 421. 
to the placentas at the margin of each carpel. When the carpels in a syncarpous pistil do not fold inwards completely so as to meet in the centre, but only partially, so that the dissepiments appear as projections on the walls of the ovary, then the ovary is unilocular

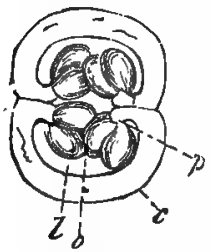

Fig. 423 . (fig. 421), and the placentas are parietal (paries, a wall). A horizontal section of the ovary of Erythræa Centaurium (fig. 423) exhibits a unilocular ovary with parietal placentas, $p$, formed at the inner margins of each of the carpels, which do not meet in the centre. In these instances the placentas may be formed at the margin of the united contiguous leaves, so as to appear single, or the margins may not be united, each developing a placenta. From this it will be seen that dissepiments are opposite to placentas, formed by the union of the margins of two contiguous carpels, but alternate with those formed by the margins of the same carpel.

The carpellary leaves may fold inwards very slightly, or they may be applied in a valvate manner, merely touching at their margins, the placentas then being parietal, and appearing as lines or thickenings along the walls. In fig. 424 the pistil of Viola tricolor is represented, 1 , cut vertically, and, 2, cut transversely, the ovules being attached

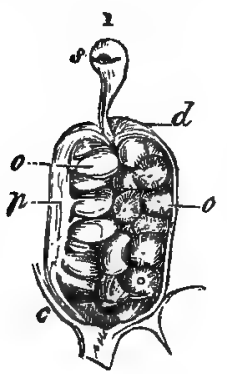

Fig. 424,

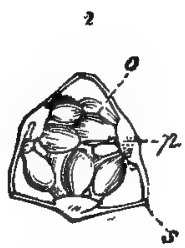

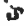

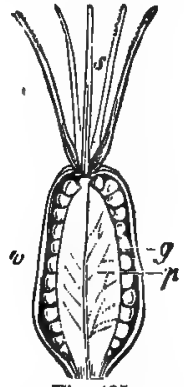

Fig. 425.

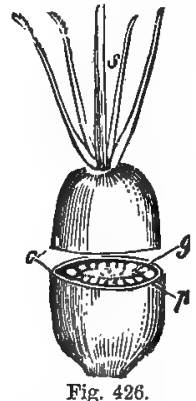

Fig. 426.

to the walls of the ovary, and the placentas, $p$, being merely thickened portions of the walls. Cases occur, however, in which the placentas

Fig. 423. Horizontal section of the ovary of Erythræa Centaurium. c, Wall or paries of the ovary or carpellary leaf. $p$, The edge on which the placenta is formed, bearing the ovules, o. $\quad l$, Cell or loculament. Fig. 424. Pistil of Viola tricolor, or Pansy. 1, Vertical section to show the ovules, $v$, attached to the parietes. Two rows of ovules are seen, one in front, and the other in profile. $p$, A thickened line on the walls forming the placenta. c, Calyx $d$, Ovary. $s$, Hooded stigma terminating the short style. 2, Horizontal section of the same. $p$, Placenta. 0, Ovules. s, Suture. Fig. 425. Pistil of Cerastium hirsutum cut vertically. o, Unilocular or monothecal ovary. $p$, Free central placenta. $g$, Ovules. $s$, Styles. - Fig. 428. The same cut horizontally, and the halves separated so as to show the interior of the cavity of the ovary 0 , with the free central placenta, $p$, covered with ovules, $g$. 
are not connected with the walls of the ovary, and form what is called a free central placenta. This is seen in many of the Caryo phyllaceæ. Thus, in Cerastium hirsutum (figs. 425, 426), the ovary, o, is composed of five carpels, indicated by the styles, $s$, but there is only one loculament, the placenta, $p$, being free in the centre, and the ovules, $g$, attached to it.

In Caryophyllacex, however, while the placenta is free in the centre, there are often traces found at the base of the ovary of the remains of septa, as if rupture had taken place ; and, in rare instances, ovules are found on the margins. But examples occur of this kind of placentation, as in Primulaceæ, Myrsinaceæ, and Santalaceæ, in which no vestiges of septa or marginal ovules can be perceived at any period of growth. The free placenta of Primulacer is different from that of Caryophyllacer. It is always free, and rises in the centre of the ovary, and the part uncovered by ovules gradually extends into the style. It is not first continuous with the style, and then free; neither is it originally marginal and then free; but it is, throughout its

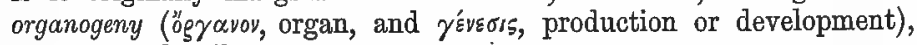
separate and axile.

Free central placentation, therefore, has been accounted for in two ways: either by supposing that the placentas in the early state were formed on the margins of carpellary leaves, and that in the progress of development these leaves separated from them, leaving the placentas and ovules free in the centre; or by supposing that the placentas are not marginal but axile formations, produced by an elongation of the axis, the ovules being lateral buds, and the carpels verticillate leaves, united together around the axis. The latter view has been supported by many botanists, and is confirmed by the fact that in some cases the placenta is actually prolonged beyond the carpels. The first of these views would apply well to Caryophyllaceæ, the second to Primulaceæ. The latter case has been explained, on the marginal hypothesis, by considering the placentas as formed from the carpels by a process of chorisis, and united together in the centre.

Some consider the axile view of placentation as applicable to all cases, the axis in some cases remaining free and independent, at other times sending prolongations along the margins of the carpellary leaves, and thus forming the marginal placentas. The oc-

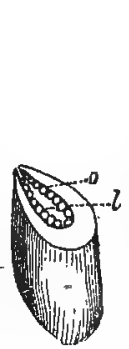

Fig. 427.

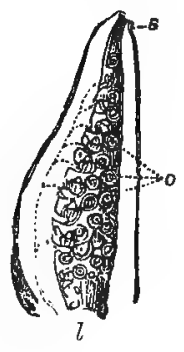

Fig. 428. currence of placentas over the whole inner surface of the carpels or of

Figs. 427, 428. One of the carpels of Butomus umbellatus, or flowering Rush, cut transversely in 427 , and longitudinally in $428 . \quad l$, Loculament or cavity of the carpel. 0 , Ovules. s, Stigmata. 
the dissepiments, as in Nymphæa and in Butomus umbellatus (figs. 427,428 ); also, though very rarely, along the dorsal suture, as in Cabomba, or on lines within the margin, as in Orobanche, has been supposed to confirm this view. Schleiden argues in favour of it, from the case of Armeria, where there are five carpels and a single ovule attached to a cord, which arises from the axis, and becomes curved at the apex, so as to suspend the ovule; also, from cases, such as Taxus, where the ovule appears to be naked and terminates a branch.

This theory of placentation, however, cannot be easily applied to all cases; and Gray says that it is disproved in cases of monstrosity, in which the anther is changed into a carpel, or where one part of the anther is thus transformed and bears ovules, while the other, as well as the filament, remain unchanged. In the case of Luffa foetida, the entangled fibres of the carpellary leaves, even in the young state, seem to be connected with perpendicular lines forming the placenta. Brongniart mentions a case where the marginal placenta was entire, while the axis was prolonged separately, and totally unconnected with the placenta; he also notices peculiar monstrosities, which seem to prove that, in some cases at least, marginal placentation must take place.

Upon the whole, then, it appears that marginal, or, as it is often called, carpellary placentation, generally prevails ; that axile placentation explains easily cases such as Primulaceæ; while such instances as Caryophyllaceæ are explicable on either view.

Occasionally, divisions take place in ovaries which are not formed by the edges of contiguous carpels. These are called spurious dissepiments. They are often horizontal, and are then called

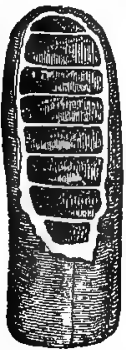

Fig. 429. plragmata ( $\varphi$ gú $\gamma \mu \alpha$, a separation), as in Cathartocarpus Fistula (fig. 429), where they consist of transverse cellular prolongations from the walls of the ovary, only developed after fertilisation, and therefore more properly noticed under fruit. At other times they are vertical, as in Datura, where the ovary, in place of being two-celled, is rendered four-celled; in Cruciferæ, where the prolongation of the placentas forms a replum (replum, leaf of a door) or partition; in Astragalus and Thespesia, where the dorsal suture is folded inwards; in Oxytropis where the ventral suture is folded inwards; and in Diplophractum, where the inner margin of the carpels is inflexed (fig. 422). In Cucurbitaceæ, divisions are formed in the ovary, apparently by peculiar projections inwards from curved parietal placentas. In some cases horizontal dissepiments are supposed to be formed by the union of carpels

Fig. 429. Pistil of Cassia or Cathartocarpus Fistula, in an adranced state, cut longitudinally, to show the spurious transverse dissepiments, or phragmata. 
situated at different heights, so that the base of one becomes united to the apex of another. In such cases the divisions are true dissepiments formed by carpellary leaves. The anomalous divisions in the ovary of the Pomegranate have been thus explained.

The ovary is usually of a more or less spherical or curved form, sometimes smooth and uniform on its surface, at other times hairy

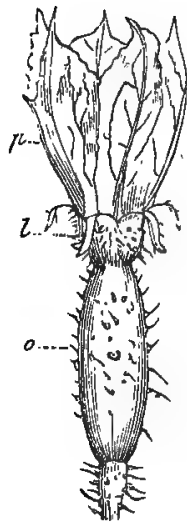

Fig. 430 .

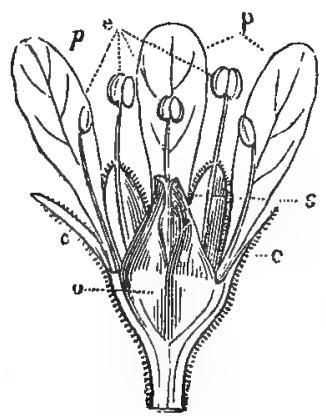

Fig. 431.

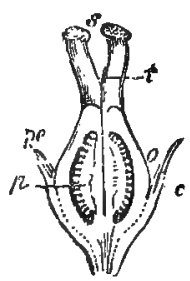

Fig. 432.

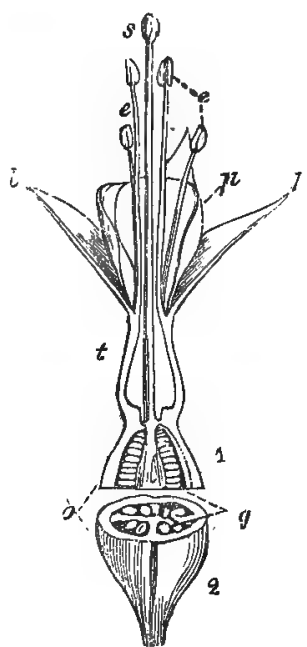

Fig. 433.

and grooved. The grooves, especially when deep, indicate the divisions between the carpels, and correspond to the dissepiments.

Fig. 430. Flower of Cucumis Melo, or Melon. o, Inferior ovary covered by the adherent torus. Calyx, $l$, and Corolla, $p$, being above the ovary. Fig- 431. Flower of Saxifraga Geum, cut vertically to show the ovary, $a$, adherent for half its height to the torus. $c$, The calyx, which is called half-superior. $p$, Petals. $\varepsilon$, Stamens. s, Styles and stigmas. Fig. 432. Pistil of Hoteia japonica, one of the Saxifragacez, cut vertically, in order to show the interior of its two cavities or loculaments. It is a bilocular or dithecal ovary. 0 , Two ovaries consolidated into one, and adherent for balf their height to the torus, $c$. $t$, Styles. s, Stigmas, p, Placentas covered with ovules. pe, Base of the petals. Fig. 433. Flower of Fuchsia coccinea divided horizontally into two halves, through the middle of the ovary, 0 . The lower half, 2, of the ovary has been left untouched, to show its four cavities or loculi, with the ovules attached to their internal angles. (Fig. 418 shows the same section more highly magnified.) The upper half, I, has been cut vertically, to show the ovules, $g$, arranged in a row in each loculament. The torus incorporated with the ovary below bears the calyx, t $l . p$, Petals inserted on the calyx. $e$, Stamens inserted also on the tube, alternately large and small. The style rising from the summit of the ovary, and terminated by an ovoid stigma, s. 
The dorsal suture may be marked by a slight projection, or by a superficial groove.

The ovary, as a rule, is free, in the centre of the flower, and not adherent to any of the surrounding organs. It is then termed superior, as in Lychnis, Primula, and Geranium (fig. 338). In many cases, however, it is united with surrounding parts,--most usually with the torus (receptacle), which, being prolonged into a cup-shaped expansion, becomes adherent to the ovary, and the floral whorls (calyx, corolla, stamens), proceeding from it are thus carried upwards, and rise from a plane, level with the summit of the ovary,- which is thus beneath their point of origin, and is therefore inferior, whilst they are superior. This is well seen in Rose, Almond (fig. 339), Aralia (fig. 340), Melon (fig. 430), Pomegranate, Apple, Pear, Gooseberry, and Fuchsia (fig. 433). A transverse section of the ovary of Fuchsia (figs. 418, 433) shows several closed loculaments containing ovules; while the pistil of the Rose when cut vertically exhibits a receptacular cup or hollow torus, open at the top, and covering numerous separate carpels, arranged on its concave surface, each of the carpels consisting of ovary, style, and stigma (fig. 294, p. 196). In these examples the torus is adherent to the ovary throughout its entire extent; but in some plants, as Saxifragaceæ (figs. 431,432 ), the union is only partial, and the term half inferior is applied to the ovary, whilst the floral whorls are half superior.

These appearances were formerly explained by supposing an adhesion between the calyx tube of the ovary; and the term adherent was applied to the calyx in cases where the ovary is inferior, and the corolla and stamens were considered to be attached to and carried upwards by the adherent calyx. But this view has been superseded by the one already explained. These adhesions between the torus and the ovary will be found to be of importance, as determining the epigynous and perigynous condition of the stamens.

THE STYLE proceeds from the summit of the carpel, and may be

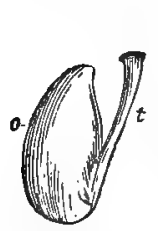

Fig. 434 .

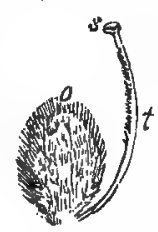

Fig. 435 . looked upon as a prolongation of it in an upward direction (fig. $406 \mathrm{t}$ ). It is hence called apicilar (apex, top). It consists not merely of the midrib, but of the vascular and cellular tissue of the carpel, along with a continuation of the placenta constituting what is called conducting tissue, which ends in the stigma. In some cases the carpellary leaf is folded from above downwards, in a hooded

Fig. 434. Carpel of Strawberry. o, Ovary. $t$, Style arising from near the base, and becoming basilar by the mode in which the ovary is developed; the style, however, still indicating the organic apex of the ovury. Fig. 435. Carpel of Chrysobalanus Leaco. o, Ovary. $t$, Basilar style. $s$, Stigma. 
manner, so that its apex (as in reclinate vernation, fig. 222 a) approaches more or less the base. When the folding is slight, the style becomes lateral (fig. 416); when to a greater extent, the style appears to arise from near the base, as in the Strawberry (fig. 434), or from the base, as in Chrysobalanus Icaco (fig. 435), when it is called basilar. In all these cases the style still indicates the organic apex of the ovary, although it may not be the apparent apex.

The carpel sometimes becomes imbedded in the torus, which consequently forms an elevated margin round it; and then, if the style is basilar or lateral, it may adhere to a portion of the torus, on one side of the carpel, and appear to arise from it. This is seen in Labiatæ (fig. 436) and Boraginaceæ (fig. 437), where the four carpels, $o$, are sunk in the torus, $r$, in such a way that the common style, $s_{f}$ formed by the union of four basilar styles, seems to be actually a prolongation of the torus. When carpels are arranged round a central prolongation of the torus, with which their united style is continuous, the arrangement is called a gynobase ( $\gamma$ uviे, pistil, Báros, base). It is well developed in Ochnaceæ. In Ge-

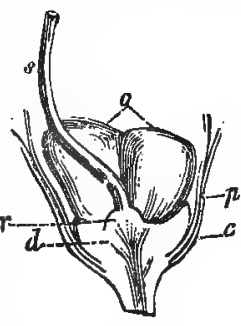

Fig. 436.

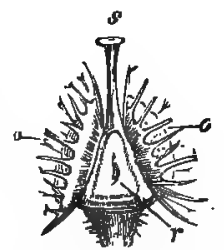

Fig, 437.

raniaceæ there is a carpophore or prolongation of the torus in the form of a long beak, to which the styles are attached.

The form of the style is usually cylindrical, more or less filiform and simple; sometimes it is grooved on one side, at other times it is flat, thick, angular, compressed, and even petaloid, as in Iriș and Canna. In Goodeniaceæ it ends in a cup-like expansion, enclosing the stigma. It may be smooth and covered with glands and hairs. These hairs occasionally aid in the application of the pollen to the stigma, and are called collecting hairs, as in Goldfussia; in Campanula they appear double and retractile. In Aster and other Compositæ (fig. 438) hairs are produced on parts of the style, $p c$, prolonged be-

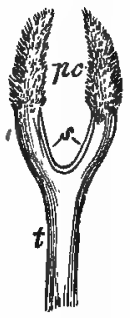

Fig. 438 . yond the stigma, $s$; these hairs, during the upward development of

Fig. 436. Pistil of Laminm album, shown by a vertical section of part of the flower. Two of the four ovaries have been removed to exhibit the connection of the style with the torus, $r$, by adhesion. u, The two remaining ovaries. d, Glandular disk placed below the pistil. c, Part of calyx. p, Corolla. Fig. 437. Pistil of Eritrichium Jacquemontianuru with one of the ovaries removed in front, to show the manner in which the ovaries are inserted obliquely on a pyramidal torus, $r$, whence the style appears to arise, ending in a stigma, s. Big. 438. Summit of the style, $t$, of an Aster, separating into two branches, $s$, each terminated by an inverted cone of collecting hairs, po. The stigma, $s$, is seen below as a band or line on the inner curvature of the branches. 
the style, come into contact with the already ripened pollen, and carry it up along with them, ready to be applied by insects to the mature stigma of other flowers. In Vicia and Lobelia the hairs frequently form a tuft below the stigma.

The styles of a syncarpous pistil may be either separate or united; when separate, they alternate with the septa. When united completely, it is usual to call the style simple (fig. 433); when the union is partial, then the style is said to be bifid, trifid, multifid, according as it is two-cleft, three-cleft, many-cleft; or, to speak more correctly, according to the mode and extent of the union of two, three, or many styles. The style is said to be bipartite, tripartite, or multipartite, when the union of two, three, or many styles only extends a short way above the apex of the ovary. The style of a single carpel, or of each carpel of a compound pistil, may also be divided. In fig. 346 , 2, each division of the tricarpellary ovary of Jatropha Curcas has a bifurcate or forked style, $s$, and in fig. 439 the ovary of Emblica officinalis has three styles, each of which is divided twice in a bifurcate manner, exhibiting thus a dichotomous division.

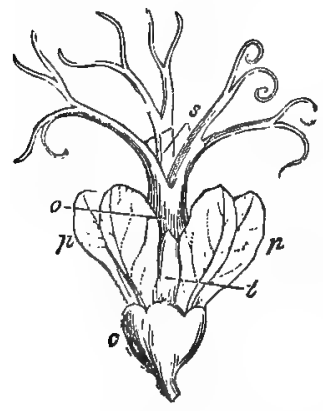

Fig. 439.

The length of the style is determined by the relation which ought to subsist between the position of the stigma and that of the anthers, so as to allow the proper application of the pollen. In some cases the ovary passes insensibly into the style, as in Digitalis, in other instances there is a marked transition from one to the other. The style may remain persistent, or it may fall off after fertilisation is accomplished, and thus be deciduous.

The STIGMA is the termination of the conducting tissue of the style, and is usually in direct communication with the placenta.

It may, therefore, in most instances, be considered as the placental portion of the carpel, prolonged upwards. In Armeria, and some other plants, this connection with the placenta cannot be traced. Its position may be either terminal or lateral. The latter is seen in some cases, as Asimina triloba, where it is unilateral (fig. 411), and in Plantago saxatilis (fig. 412), where it is bilateral. Occasionally, as in Tasmannia, it is prolonged along the whole inner surface of the style. In Iris it is situated on a cleft on the back of the petaloid divisions of the style. Some stigmata, as those of the Mimulus, present sensitive flattened laminæ, which close when touched. The

Fig. 439. Female flower of Emblica officinalis, one of the Enphorbiacez. c, Calyx. $p p$, Petals. $t$, Membranous tube surrounding the ovary. o, Ovary, crowned by three styles, $s$, each being twice bifurcate. 
stigma consists of loose cellular tissue, and secretes a viscid matter which detains the pollen, and causes it to protrude tubes. This secreting portion is, strictly speaking, the true stigma, but the name is generally applied to all the divisions of the style on which the stigmatic apparatus is situated, as in Labiatæ. The stigma alternates with the dissepiments of a syncarpous pistil, or, in other words, corresponds with the back of the loculaments; but in some cases it would appear that half the stigma of one carpel unites with half that of the contiguous carpel, and thus the stigma is opposite the dissepiments, that is, alternates with the loculaments. This appears to be the case in the Poppy, where the stigma of a single carpel is two-lobed, and the lobes are opposite the septa.

If the stigma is viewed as essentially a prolongation of the placenta, then there is no necessary alternation between it and the placenta, both being formed by the margins of carpellary leaves, which in the one case are ovuliferous, in the other stigmatiferous. There is often a notch in one side of a stigma (as in some Rosacer), indicating apparently that it is a double organ like the placenta. To the division of a compound stigma the terms bifid, trifid, etc., are applied, according to the number of the divisions. Thus, in Labiatæ (fig. 324), and in Compositæ (figs. 326,438 s), the stigma is bifid ; in Polemonium, trifid. When the divisions are large, they are called lobes, and when flattened like bands, lamellos; so that stigmas may be bilobate, trilobate, bilamellar, trilamellar, etc.

It has already been stated that the divisions of the stigma mark the number of carpels which are united together. Thus, in Campanula (fig. 440), the quinquefid or five-cleft stigma indicates

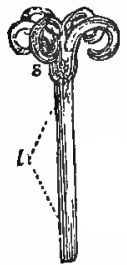

Fig. 440.

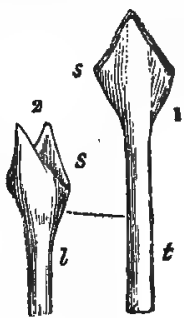

Fig. 441.

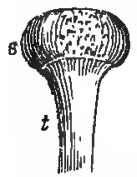

Fig. 442.

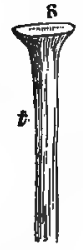

Fig. 443.

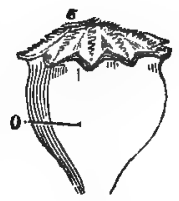

Fig. 444.

five carpels, the stigmata of which are separate, although the other parts are united. In Bignoniaceæ (fig. 441), as well as in Scrophu-

Fig. 440. Stigmas, $s$, of Campanula rotundifolia. $l$, Style. Fig. 441, Bilamellar stigmas of-Bignonia pandorea. The two lamellæ are applied naturally against each other in 1, while in 2 they are artificially separated. Fig. 442. Globular stigma of Mirabilis Jalapa $t$, Style. $s$, Stigma. Fig. 443. Circular stigma, $s$, and $t$, style of Arbutus Andrachne. Fig. 444. Pistil of Papaver somniferum, or opium Poppy. o, Ovary. $s$, Radiating stigmas on its summit. 
lariaceæ and Acanthaceæ, the two-lobed or bilamellar stigma indicates a bilocular ovary. Sometimes, however, as in the case of the styles, the stigma of a single carpel may divide. It is probable that in many instances what is called bifurcation of the style is only the division of the stigma. In Graminex and Compositæ (figs. 331, 438) there is a bifid stigma, and only one cavity in the ovary. This, however, may be probably traced to subsequent abortion in the ovary of one of the carpels. The stigma presents various forms. It may be globular, as in Mirabilis Jalapa (figs. 410, 442) ; orbicular, as in Arbutus Andrachne (fig. 443); umbrella-like, as in Sarracenia, where, however, the proper stigmatic surface is beneath the angles of the large expansion of the apex of the style; ovoid, as in Fucbsia (fig.

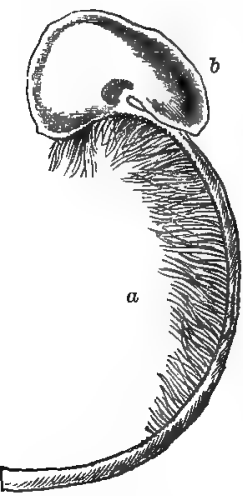

Fig. 445. 433) ; hemispherical ; polyhedral; radiating, as in the Poppy (fig. 444), where the true stigmatic rays are attached to a sort of peltate or shield-like body, which may represent depressed or flattened styles; cucullate - i.e. covered by a hood, in Calabar Bean (fig. 445 a), where it is situated on the apex of a declinate style, bearded (hairy) on its concave surface (fig. $445 \mathrm{~b}$ ). The lobes of a stigma may be flat and pointed, as in Mimulus and Bignonia (fig. 441 ; fleshy and blunt, smooth or granular, or they may be feathery, as in many Grasses (fig. 446). In Orchidaceæ the stigma is situated on the anterior surface of the column formed by the union of the styles and filaments; the point where it occurs being called gynizus ( $p$. 238). In Asclepiadaceæ the stigmas are united to the face of the anthers, and along with them form a solid mass (fig. 386).

In Cryptogamtc Plants there exist organs called pistillidia, which have been supposed to perform the function of pistils. They are hollow flask-shaped organs, like ovaries, to which the names of

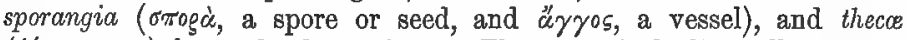
( $\dot{n}$ ' $\eta$, a sac), have also been given. They contain bodies called spores, equivalent to ovules. These spores being capable of germination, and being devoid of cotyledons, have been termed leafless phytons. The sporangia, or spore-cases, are sometimes immersed in the substance of the plant, as in Riccia glauca (fig. 447, 1); at other times they are supported on stalks, or setce (seta, a bristle), as in Mosses. In Marchantia polymorpha they consist of distinct and separate expansions, having $a$ flask-shaped appearance (fig. 448), the lower enlarged part, o, contain-

Fig. 445. Style and stigma of the Calabar Bean (Physostigma venenosum), showing the curved barbate style with hairs, $a$, on its concave surface, and a hooded (cucullate) stigma, $b$. 
ing the spores, and surrounded by a cellular coat resembling a calyx, $c$. From this ovary-like body there is a prolongation which may be con-

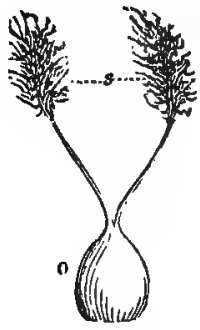

Fig. 446.

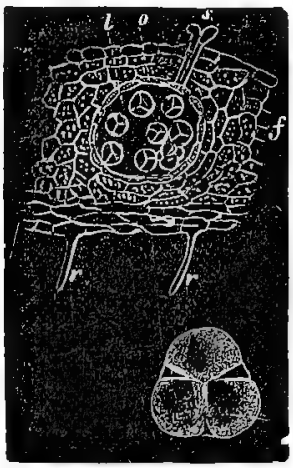

Fig. 447 .

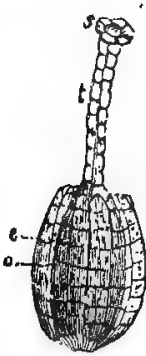

Fig. 448 .

sidered as a style, $t$, terminated by a cellular enlargement, $s$, which has been compared to a stigma. The styloid prolongation withers and disappears when the spores are mature. Sometimes the thecæ, as in Lichens, consist of a club-shaped elongated cell or ascus (fig. 449,1 ), containing nuclei or cells in its interior, which form the spores. Sometimes these are single, at other times united in sets of two (fig. 449,2 ), or of four (fig. 447,2 ), or of some multiple of four. There are various modifications of sporangia in other Cryptogamic tribes. In Ferns, they are often surrounded by an annular ring, or by elastic bands, which cause their dehiscence; while in Chara they are called nucules,

1 2

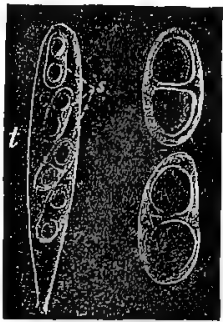

Fig. 449 . and present an oval form with a spiral arrangement of tubes.

THE OvULE.-The ovule is the body attached to the placenta,

Fig. 446. Pistil of Cynodon Dactylon, a Grass. o, Ovary. s, Feathery stigmas. Fig. 447. 1, Perpendicular section of the frond, $f$, of Riccia glauca, and of the sporangium or sporecase, 0 , which is imbedded in it. s, Narrow process or style by which the sporangium communicates with the external surface. $l$, Its cavity or loculus. s, Young spores still united in sets of four in the parent cells. $r$, Cells elongated like roots. 2, One of the cells more highly raggnified, with the four spores which it contrins. Three of the spores are seen, the fourth being concealed by them. Fig. 448. Sporangium or spore-ease of Marchantia polymorpha. o, Hollow swelling containing spores, and which has been compared to the ovary. $t$, Narrow process prolonged upwards; and resembling a style. s, Termination of this cellular process, compared to the stigma. c, Cellular covering of the sporangium, or spore-case, surrounding it like a calyx. Fig. 449. 1, Theca or ascus of Solarina saccata, a species of Lichen, containing eight spores, nnited in sets of two. 2, Two of these double spores, highly magnified. 
and destined to become the seed. It bears the same relation to the carpel that marginal buds do to leaves, and when produced on a free central placenta, it may be considered as a bud developed on a branch formed by the elongated axis. The single ovule contained in the ovaries of Compositæ and Grasses may be called a terminal bud surrounded by a whorl of adhering leaves or carpels, in the axil of one of which it is produced. In Delphinium elatum ovules sometimes appear as mere lobes of the carpellary leaf; in Aquilegia ovules transformed into true leaves are occasionally produced on either margin of the carpel; and the ovules of Mignonette sometimes assume the form of leaves. In such cases the vascular bundles of the placenta (pistillary cords) are formed by the lateral veins of the carpellary leaf. These veins pass into the marginal lobes or leaflets which represent ovules, and seem to prove that the placenta, in such cases, must be truly a carpellary, and not an axile, formation.

The ovule is usually contained in an ovary, but in Coniferæ and Cycadaceæ it is generally considered as having no proper ovarian covering, and is called naked, these orders being denominated gymno-

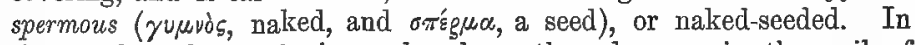
these orders the ovule is produced on the edges, or in the axil of altered leaves, which form no evident style or stigma. The scales of the cones in Coniferæ are by some looked upon as the homologue of opened-out carpels bearing exposed ovules. In the common Fir there are usually two ovules at the base of the upper surface of each scale. In the Juniper each scale bears one ovule. In the Cypress the scales are peltate, and cover numerous ovules; while in the Yew there is a solitary ovule at the apex of a cone-like organ formed by numerous barren scales. In Gnetaceæ there is also a solitary ovule, the secundine of which is pushed out into a long tube-like process. In Cycadaceæ the ovules are either produced on the edge of altered leaves, which some have called leaf-like carpels, as seen in Cycas, or, as in Zamia, they are covered by peltate scales, from the summit of which they are suspended. The Gymnospermal view is not supported by all botanists; some maintain that there is a true ovarian covering independent of the scales, and others think that the outer coat is of the nature of a disk. The subject is still under discussion. The carpellary leaves are sometimes united in such a way as to leave an opening at the apex of the pistil, so that the ovules are exposed or semi-nude, as in Mignonette. In Leontice thalictroides (blue cohosh) the ovary ruptures immediately after flowering, and the ovules are exposed. So also in species of Ophiopogon, Peliosanthes, and Stateria. In the species of Cuphea the placenta ultimately bursts through the ovary and corolla, becoming erect, and bearing the exposed ovules.

The ovule is attached to the placenta either directly, when it is called sessile, or by means of a prolongation called a funiculus 
(funis, a cord), umbilical cord, or podosperm (тойs, a foot, and $\sigma \pi \varepsilon \varepsilon_{\mu \alpha}$, a seed). This cord sometimes becomes much elongated after

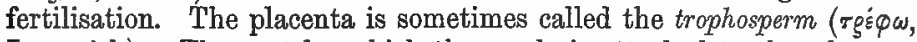
I nourish). The part by which the ovule is attached to the placenta or cord is its base or hilum, the opposite extremity being its apex. The latter is frequently turned round in such a way as to approach the base. The ovule is sometimes imbedded in the placenta.

In its simplest form, as in the Mistleto, the ovule appears as a small cellular projection. The cells multiply until they assume a more or less enlarged ovate form, constituting what has been called the nucleus (figs. $450,451 \mathrm{~m}$ ), or central cellular mass of the ovule. The ovular nucleus alters in the progress of growth so as to be prepared for the development of the embryo plant in its interior. At the apex of the cellular nucleus, an absorption or obliteration of cells takes place, by which a hollow cavity is formed (fig. $451 \mathrm{c}$ ), which in some plants becomes lined by a thin layer of cells or epithelium (p. 236), whilst in others the cells of the nucleus alone form its walls.

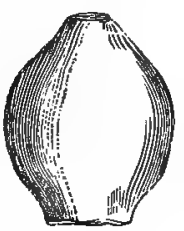

Fig. 450.

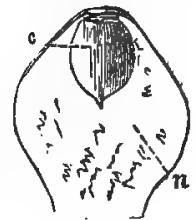

Fig. 451 . This cavity is the embryo-sac, and contains amnios or mucilaginous fluid, in which, after fertilisation has been completed, the embryo plant is formed, being attached to the apex of the sac by a threadlike cellular process called the suspensor.

The nucleus (fig. $457 n$ ) may remain naked, and alone form the ovule, as in the Mistleto, and a few other plants; but in most plants it becomes surrounded by certain coverings during its development. These appear first in the form of cellular rings at the base of the nucleus, which gradually spread over its surface. In some cases only one covering is formed, as in Compositæ, Campanulaceæ, Walnut, etc. Thus, in the latter (fig. 452), the nucleus, $n$, is covered by a single envelope, $t$, which, in the first instance, extends over the base, and then spreads over the whole surface (fig. 453), leaving only an opening at the apex. In other instances (fig. 454), the nucleus, $n$,

Fig. 450. Ovule of the Mistleto entire. embryo-sac, $c$, and the whole of the rest of the mass, $n$, composed of uniform tissue, and forming a nucleus without integuments. Fig. 452. Ovule of Juglans regia, the Walnut. $t$, Simple integument. $n$, Nucleus, the base of which only is covered with integument at the early period of development. Fig. 453 . The same ovule more advanced, in which the nucleus is nearly completely covered.

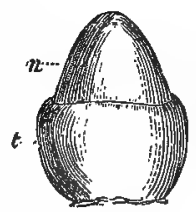

Fig. 452.

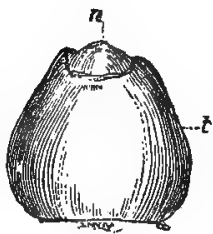

Fig. 453. 
besides the single covering (fig. $454,2, t i$ ), has another developed subsequently (fig. 454,3, te), which gradually extends over that first formed, and ultimately covers it completely, except at the opening at the apex. There are thus two integuments to the nucleus, an outer and an inner, called respectively primine, te, and secundine, $t i$. The name tercine has been given to the cells of the nucleus which surround the embryo-sac (fig. $451 n$ ). These names are applied to the coverings of the ovule without reference to their order of development. At the

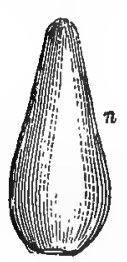

1.

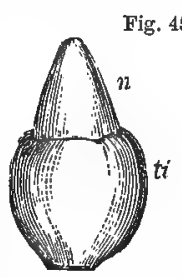

2.

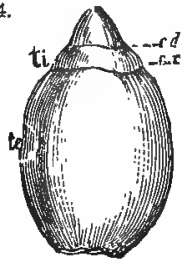

3. apex of the ovule the primine and secundine leave an opening termed the foramen or micropyle (uirgos, small, and $\pi i \lambda_{\eta}$, a gate). This foramen extends through both coats, the opening in the primine (fig. 454, 3, ex), being the exo-

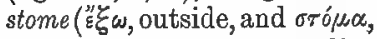
mouth, that in the secundine (fig. 454, 3,ed), being the endostome (Evoov, within). The micropyle indicates the organic apex of the ovule, while the part united directly or by the funiculus to the placenta is the base or hilum. The name micropyle is sometimes restricted to the foramen in the perfect seed. The length of the canal of the foramen depends on the development of the nucleus, as well as on the thickness of the integuments. The embryosac is sometimes prolonged beyond the apex of the nucleus, as noticed by Meyen in Phaseolus and Alsine media, and by Griffith in Santalum album and Loranthus. Some authors, as Mirbel, considering the ovule in reference to the embryo, speak of five coverings of the latterviz. 1 , primine; 2 , secundine; 3 , tercine, or the covering of the nucleus lining the secundine; 4, quartine, a temporary cellular layer, which is occasionally formed at an after period in the form of perisperm around 5, quintine, or the embryo-sac. By most botanists the nucleus and sac, with its two integuments (primine and secundine), are mentioned as the ordinary structure of the ovule. Occasionally, as in Mistleto, there are two or three embryo-sacs formed. In Veronica and Euphrasia the neck of the embryo-sac becomes elongated and swollen, and from it are developed certain cellular or filamentous appendages, which are probably connected with the nutrition of the embryo.

All these parts are originally cellular. The nucleus and integu-

Fig. 454. Ovule of Polygonum cymosum at various ages. n, Nucleus. te, The outer integument or primine. $t i$, The inner integument or secundine. ex, Exostome or opening in the primine. ed, Endostome or opening in the secundine. 1, Onule in the early state, when the nucleus is still naked. 2, Orule in second stage, when the nucleus is covered at its base by the internel integument or secundine only. 3 , Orule in the third stage, when the two integuments, primine and secundine, form a double covering, at the apex of which the nucleus still appears. 
ments are united at the base of the ovule by a cellulo-vascular process called the chalaza (fig. $458 \mathrm{ch}$ ). This is often coloured, of a denser texture than the surrounding tissue, and is traversed by fibrovascular bundles, which come from the placenta, to nourish the ovule. When the ovule is so developed that the union between the primine, secundine, and nucleus, with the chalaza, is at the hilum or base (next the placenta), and the foramen is at the opposite extremity (figs. 453 , 454), the ovule is orthotropal, orthotropous, or atropous (ogtos, straight,

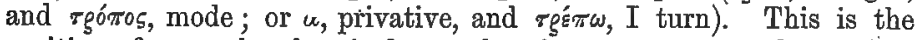
position of an ovule when it first makes its appearance, and occasionally, as in Polygonacer, it remains as the permanent condition. In such an ovule a straight line drawn from the hilum to the foramen passes along the axis of the ovule.

In general, however, changes take place in the ovule, so that it assumes a different form. Thus it may be curved upon itself, so that the foramen approaches the bilum or placenta, and ultimately is placed close to it, while the chalaza is only slightly removed from the hilum. This change depends apparently on the ovule increasing more on one side than on the other, and as it were drawing the chalaza slightly to the side of the hilum opposite to that to which the foramen is inclined.

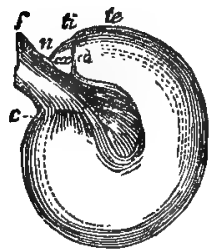

1

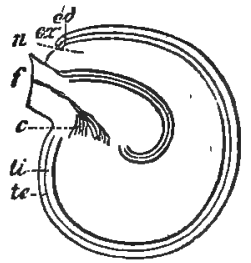

2

Fig. 455.

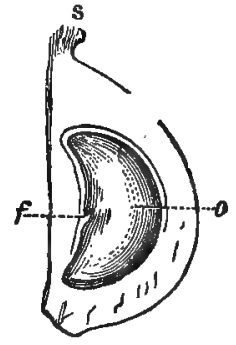

Fig. 456 .

Such ovules are called campylotropal or campylotropous ( $\kappa \alpha \mu \pi \dot{\lambda} \omega_{\Delta}$, curved), when the portions on either side of the line of curvation are unequal (fig. 455); or camptotropal ( $x \alpha \mu \pi r \dot{s} s$, curved), when they are equal (fig. 456). Curved ovules are found in Leguminosæ, Cruciferæ, and Caryophyllaceæ. The union between the parts of the curved portion usually becomes complete, but in some cases there is no union, and the ovules are licotropal, or horse-shoe shaped ( $\lambda$ '́xos, a hollow disk, and réótros, mode or form).

Fig. 455. Campylotropal or Campylotropus ovule of the Stock. 1, Ovule entire, 2, Ovule cut lengthwise. $f$, Funiculus or umbilicad cord. c, Chalaza. $n$, Nucleus, te, Primine or outer covering. $t i$, Secundine or inner covering. ex, Exostome. ed, Endostome. Fig. 456. Carpel of Menispermum canadense, with a curved or camptotropal ovule, $u$. $f$, Funiculus. $s$, The base of the style. 
When, in consequence of the development on one side, the orule is so changed that its apex or foramen (fig. $457,4, n$ ) is brought into close apposition with the hilum (fig. $457,5, h$ ), and the chalaza is also

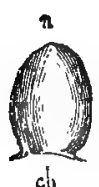

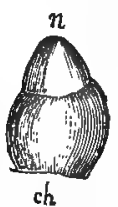

2
Fig. 457.

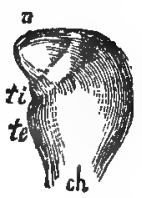

B

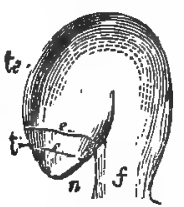

4

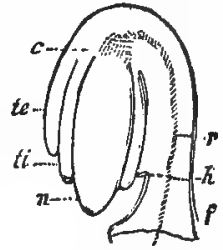

5

carried round so as to be at the opposite extremity (fig. $457,5, c$ ),

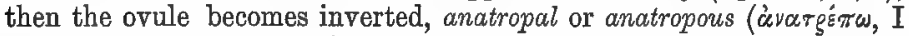
subvert). In this case (fig. 458 ) the union of the chalaza, ch, with the nucleus, $n$, is removed from the hilum, and the connection between the chalaza and placenta is kept up by a vascular

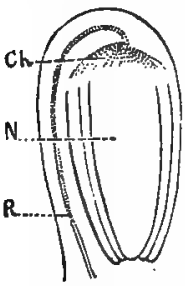

Fig. 458. cord, $r$, passing through the funiculus, and called the raphe ( $\dot{\rho} \propto \varphi \dot{y}$, a line). The raphe often forms a ridge along one side of the ovule, and it is usually on the side of the ovule next the placenta. Some look upon this kind of ovule as formed by an elongated funiculus (fig. $457,5, f$ ) folded along the side of the ovule, and becoming adherent to it completely; and support this view by the case of semi-anatropal ovules, where the funiculus is only, as it were, partially attached along one side, becoming free in the middle; and also by cases where an anatropal ovule, by the separation of the funiculus from its side, becomes an orthotropal seed.

The anatropous form of ovule is of very common occurrence, and may probably aid in the process of fertilisation. Ovules which are at first orthotropous, as in Chelidonium majus (fig. 457, 2), sometimes become anatropous in the progress of development (fig. 457, 4). When the ovule is attached to the placenta, so that the hilum is in the middle, and the foramen and chalaza at opposite ends, it becomes

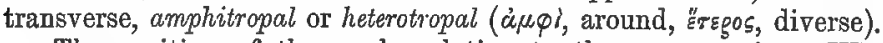

The position of the ovule relative to the ovary varies. When there is a single ovule, and with its axis vertical, it may be attached

Fig. 457. Ovule of Chelidonium majus at different stages of development. $h$, Hilum or umbilicus. ch, Chalaza. $f$, Funiculus or umbilical cord. $r$, Raphe. $n$, Nucleus. $t i$, Secundine. te, Primine. ed, Endostome. ex, Exostome. 1, Tirst stage : nucleus still naked. 2, Second stage: nucleus covered at its base by the secundine. 3, Third stage: the primine developed and covering the seeundine at its base. 4, Fourth stage: the ovule completely reflected, and its point turned downwards. 5, The same cut longitudinally, to show the relation of its different parts. Fig. 458. Anatropous ovule of Dandelion, cut vertically. ch, Chalaza. $r$, Raphe. $n$, Nucleus. 
to the placenta at the base of the ovary (basal placenta), and it is then erect, as in Polygonacere and Compositæ (fig. 459); or it may be inserted a little above the base, on a parietal placenta, with its apex upwards (fig. 460), and then is ascending, as in Parietaria. It may hang from an apicilar placenta at the summit of the ovary, its apex being directed downwards, and is inverted or pendulous, as in Hippuris vulgaris (461), or from a parietal placenta near the summit, and then is suspended, as in Daphne Mezereum (fig. 462), Polygalaceæ, and

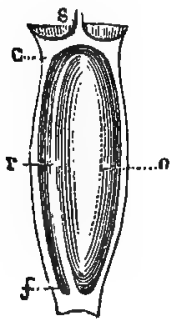

Fig. 459.

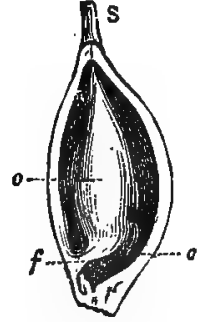

Fig. 460 .

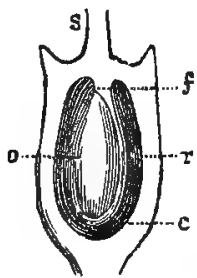

Fig. 461.

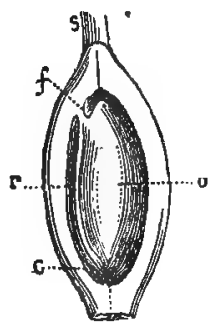

Fig. 462.

Euphorbiaceæ. Sometimeśs a long funiculus arises from a basal placenta, reaches the summit of the ovary, and there bending over suspends the ovule, as in Armeria; at other times the hilum or organic base appears to be in the middle, and the ovule becomes horizontal, peltate (pelta, a shield), or peritropous (тEg', around, and ге́є $\pi \omega$, I turn). All these modifications are determined by the relative position of the hilum and foramen, the length of the funiculus, and its adhesion, as well as the position of the placenta.

When there are two ovules in the same cell, they may be either collateral, that is, placed side by side (fig. 463), or the one may be erect and the other inverted, as in some species of Spiræa and Assculus (fig. 464), or they may be placed one above another, each directed similarly. Such is also the case with ovaries containing a moderate or definite number of ovules. Thus, in the ovary of Leguminous plants (fig. 465), the ovules, o, are attached to the extended marginal placenta, one above the other, forming usually two parallel rows corresponding to each margin of the carpel. When the ovules are definite (uniform, and can be counted), it is usual to find their attach-

Figs. 459-462. Carpels belonging to different flowers, cut vertically to show the various directions of the solitary ovule, 0 , contained in them. $f$, Funieulus. $r$, Raphe. $\&$, Chalaza. $s$, Base of the style. Fig. 459. Carpel of Senecio vulgaris, with a straight or ereet anatropous ovule. Fig. 460. Carpel of Parietaria officinalis (pellitory), with an ascending orthotropous ovule. Fig. 461. Carpel of Hippuris vulgaris (mare's-tail), with a reversed or pendulous anatropous ovule. Fig. 462. Carpel of Daphne Mezereum, with a suspended anatropous ovule. 
ment so constant as to afford good characters for classification. When the ovules are very numerous or indefinite, while at the same time the placenta is not much developed, their position exhibits great variation, some being directed upwards, others downwards, others transversely

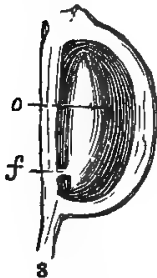

Fig. 469 .

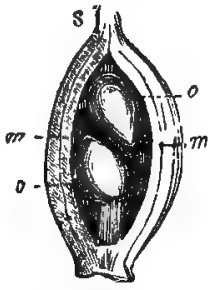

Fig. 464,

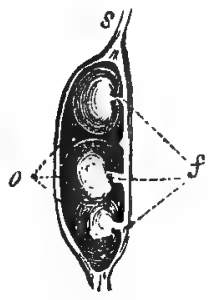

Fig. 465.

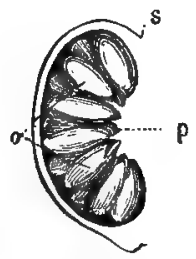

Fig. 466 .

(fig. 466), and their form is altered by pressure into various polyhedral shapes. In such cases it frequently happens that some of the ovules are arrested in their development and become abortive. In Cryptogamous plants, in place of ovules there are cellular bodies called spores, to which allusion will be made when the seed is considered.

\section{4.-Functions of the Floral Envelopes.}

The bracts and calyx, when of a green colour, perform the same functions as leaves, giving off oxygen under the influence of light, and producing the substance called chlorophyll or phytochlor. They are consequently concerned in the assimilation of matters fitted for the nutrition of the flower, and they aid in protecting the central organs. The corolla does not in general produce chlorophyll, nor does it give off oxygen. On the contrary, it absorbs oxygen from the air. At the same time there is a conversion of starch into grape sugar, an evolution of carbonic acid gas, and in many instances a very marked elevation of temperature, caused by the combination between the carbon of the flower and the oxygen of the air. The starch, which is stored up in the receptacle and at the base of the petals, by passing into the state of dextrin and grape sugar, becomes fitted for vegetable nutrition. Important purposes are thus served in the economy of the plant. The saccharine or honey-like matter which often collects in

Fig. 463. Carpel of Nuttallia cerasoides, with two suspended collateral ovales. o, One of the ovules. $f$, Funiculus. $s$, The base of the style. Fig. 464. One of the loculaments of the ovary of Essculus hybrida, laid open to show two ovules, oo, inserted at the same height, but turned in different directions. $m m$, Micropyle indicating their apex. $s$, Base of the style. Fig. 465. Carpel or legume of Ononis rotundifolia, with several campylotropons ovules, o, placed one above the other. $f$, Funiculi. s, Bese of the style. Fig. 466. Loculament of the ovary of Peganum Harmala, with numerous ovules, $v$, attached to a projecting placenta, $p$, and pointing in different directions. $s$, Base of style. 
the cup of the flower, and sometimes in special pits or depressions, as in Crown Imperial, and Asarabacca,"attracts bees and various insects, which are instrumental in disseminating the pollen. The quantity of oxygen absorbed was determined by Saussure. He found that double flowers absorbed less in proportion to their volume than single flowers ; that the essential organs absorbed more oxygen than the floral envelopes ; and that the greatest absorption took place when the stamens and pistil were mature.

The following are the results of some of Saussure's experiments :-

Name. Duration of By Flowers entire. By essential Organs

Stock, single . . 24 hours. $11 \cdot 5$ times their vol. $18^{\circ}$ times their vol.

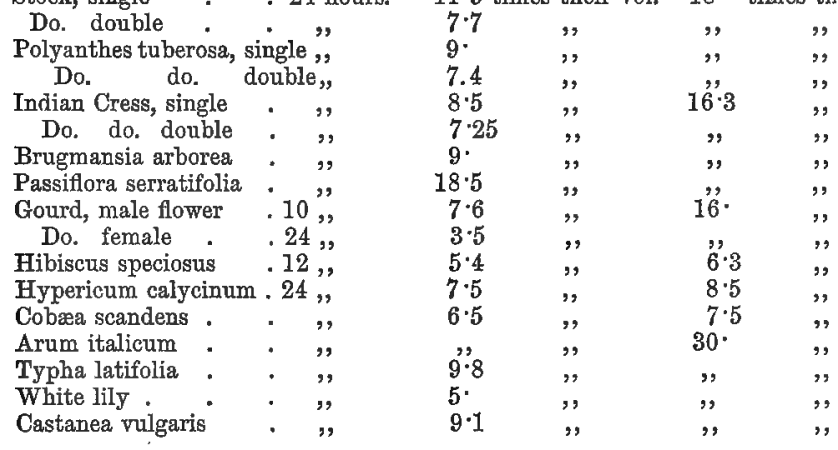

While this oxidation is going on, carbon is given off in the form of carbonic acid, and heat is evolved by the combination between the oxygen and carbon. The quantity of carbonic acid evolved is in a ratio corresponding to the amount of oxygen absorbed, and the degree of heat present is proportionate to the activity of the chemical and vital changes taking place. Experiments have been made as to the amount of heat produced during flowering, especially by species of Arum, Caladium, and Colocasia. These are plants in which the floral envelopes are nearly absent, while the torus and growing point, and the essential organs, attain a high degree of development, forming a spadix enclosed in a large spathe. No heat could be detected when the contact of oxygen was prevented, either by putting the plants into other gases, or by covering the surface of the spadix with oil. The surface of the spadix is the part whence the heat is chiefly evolved. Arum cordifolium occasionally had a temperature $20^{\circ}$ or $30^{\circ}$ above that of the surrounding air; Arum maculatum $17^{\circ}$ to $20^{\circ}$; and Arum Dracunculus and other species still higher. The following observations were made by Brongniart on the spadix of Colocasia odora. The spathe 
opened on the 14th of March; the discharge of pollen commenced on the 16th, and continued till the 18th. The maximum temperature occurred at a different hour on each day.

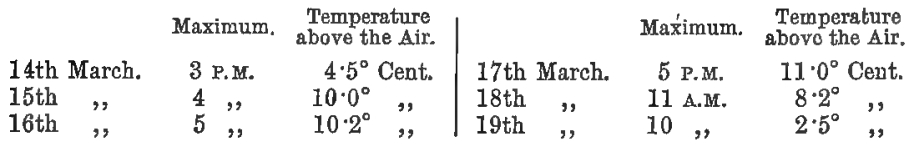

Vrolik and De Vriese made a series of observations on the same plant, and have given the results for every half-hour of the day. The following are some of these results :-

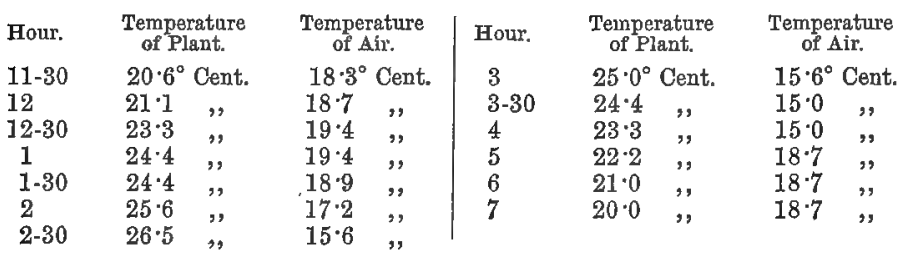

The greatest amount of heat observed was at 2-30 P.M., when it was $10.9^{\circ}$ above the temperature of the air. On the previous day the maximum occurred at 3 P.M., and on the following day at 1 , but then it was only $8.2^{\circ}$ above that of the air. Decandolle states that at Montpellier, Arum italicum attained the maximum of temperature about 5 P.M. Saussure observed similar phenomena, but to a less extent, in the Gourd, where the temperature varied from $1.8^{\circ}$ to $3.6^{\circ}$; also in Bignonia radicans, from $0.9^{\circ}$ to $3^{\circ}$. From all these experiments it would appear that in the Araceæ and some other plants, especially at the period when the essential organs reach maturity, there is a production of heat, which increases during the performance of their functions, attaining a daily maximum, and ultimately declining.

While these changes are taking place the starch is converted into dextrin, and ultimately into grape-sugar, which, being soluble, can be immediately applied to the purposes of the plant.

Flowering takes place usually at a definite period of the plant's existence. The process requires a considerable amount of nutrient matter, and its occurrence is accompanied by a greater or less exhaustion of the assimilated products. A certain degree of accumulation of sap seems necessary in order that flowering may proceed. Annual plants are so exhausted after flowering as to die; but, by retarding the epoch for two or more years, as by nipping off the flower-buds, time is allowed for accumulating sap, the stems, from being herbaceous, become shrubby, and sometimes, as in the Tree-Mignonette, they may live and flower for several years. Perennial plants, by the retardation 
of flowering, are enabled to accumulate a greater amount of nutritive matter, and thus to withstand the exhaustion. Many cultivated plants which lay up a large store of nutriment in the form of starch, lose it when the plants shoot out a flowering stem. This is seen in the case of Carrots and Turnips, in which the succulent roots become fibrous and unfit for food when the plants are allowed to run to seed. The receptacle of the Artichoke and many Compositre, which is succulent before the expansion of the flowers, becomes dry as the process of flowering proceeds. The juices of plants, when required for the purpose either of food or medicine, ought in general to be collected immediately before the flowering of the plant.

By cutting a ring out of the bark of trees, and thus retarding the descent of the sap, the period of flowering is sometimes hastened. Again, when the period of flowering is long delayed, either naturally, as in Agave and several palms, or artificially, the process, when it does begin, proceeds with amazing rapidity and vigour. Richard mentions that a plant of Agave, which had not flowered for nearly a century, sent out a flowering stem of $22 \frac{1}{2}$ feet in 87 days, increasing at one period at the rate of one foot a day. In such cases this vigorous flowering is often followed by the death of the plant. Common fruit trees, when they begin to flower, often do so luxuriantly; but if, from the season being bad, there is a deficiency in flowering, it frequently happens that, from the accumulation of nourishment, the next year's produce is abundant.

If plants are allowed to send out their roots very extensively in highly nutritive soil, the tendency is to produce branches and leaves rather than flowers. In such cases, cutting the roots or pruning the young twigs may act beneficially in checking the vegetative functions. In pruning, the young shoot is removed, and the buds connected with the branch of the previous year are left, which thus receive accumulated nourishment. Grafting, by giving an increase of assimilated matter to the scion or graft (see remarks on Fruiting), and at the same time checking luxuriant branching, contributes to the hastening of the period of flowering.

The period of flowering of the same plant varies at different seasons, and in different countries. During the winter, in temperate climates, and during the dry season in the tropics, the vegetative process is checked, more especially by the diminished supply of moisture, and the arrestment of the circulation of the sap. The assimilated matter remains in a state of repose, ready to be applied to the purposes of the plant when the moisture and heat again stimulate the vegetable functions. This stimulation occurs at different periods of the year, according to the nature of the climate. By observing the mode of flowering of the same species of plant in successive years, conclusions may be drawn as to the nature of the seasons in a 
country; and by contrasting these periods in different countries, comparisons may be instituted as to the nature of their climate. Thus valuable floral calendars may be constructed.

Plants are accommodated to the climate in which they grow, and flower at certain seasons, and even when transferred to other climates where the seasons are reversed, they still have a tendency to flower at their accustomed period of the year. Again, in the same climate, some individuals of a species, from a peculiar idiosyncrasy, regularly flower earlier than others. Decandolle mentions a horse-chestnut at Geneva, which flowered always a month before the rest in the neighbourhood. From such individuals, by propagation, gardeners are able to produce early-flowering varieties.

There is a periodicity as to the hours of the day at which some species open their flowers. Some expand early, some at mid-day, others in the evening. The flowers of Succory open at 8 A.M., and close at 4 P.M. ; those of Tragopogon porrifolius, or Salsafy, close about mid-day. Linnæus constructed a floral clock or watch, in which the different hours were marked by the expansion of certain flowers. The periods, however, do not seem to be always so regular as he remarked them at Upsal. The following are a few of these horological flowers, with their hours of opening:-

\begin{tabular}{|c|c|c|c|c|c|c|c|c|c|}
\hline \multirow{2}{*}{\multicolumn{10}{|c|}{$\begin{array}{l}\text { Ipomoa Nil . } \\
\text { Tragopogon pratense }\end{array}$}} \\
\hline & & & $\cdot$ & & & & 4 to & $\mathbf{5}$ & \\
\hline Papaver nudicaule & * & ${ }^{\circ}$ & . & & ${ }^{\prime}$ & & & & \\
\hline Hypochæris maculata & & & & & & & & & \\
\hline \multicolumn{10}{|c|}{ Various species of Sonchus and Hieracium } \\
\hline Lactuca sativa & - & . & - & - & . & & 7 & & \\
\hline Specularia Speculum & . & . & & - & . & & & & \\
\hline Calendula pluvialis & . & . & $\bullet$ & • & . & & & 8 & \\
\hline Anagallis arvensis & • & - & $\cdot$ & * & . & & 8 & & \\
\hline Nolana prostrata. & - & - & $\cdot$ & " & . & & 8 to & 9 & \\
\hline Calendula arvensis & . & . & $\bullet^{\circ}$ & " & . & & 9 & & \\
\hline Arenaria rubra. & . & . & . & $\cdot$ & - & & 9 to & 10 & \\
\hline Mesembryanthemum n & odifl & rum & & & & & 10 to & 11 & \\
\hline \multicolumn{10}{|c|}{ Ornithogalum umbellatum (Dame d'onze heures) } \\
\hline Various Ficoideous pla & nts & - & . & 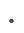 & . & & 12 & & \\
\hline Scilla pomeridiana & - & . & & & . & & 2 & & P. M. \\
\hline Silene noctiflora. & - & . & - & , & - & & 5 to & 6 & \\
\hline Gnothera biennis & . & . & & & & & 6 & & \\
\hline Mirabilis Jalapa . & • & . & • & & . & & 6 to & 7 & \\
\hline Cereus grandiflorus & . & . & & . & - & & 7 to & 8 & \\
\hline
\end{tabular}

Plants which expand their flowers in the evening, as some species of Hesperis, Pelargonium, etc., were called by Linnæus plantoe tristes on that account. Several species of Cooperia, and of Cereus, also Sceptranthus Drummondii, are nocturnal flowers. Some flowers open and decay in a day, and are called ephemeral, others continue to open and close for several days before withering. The corolla usually 
begins to fade after fecundation has been effected. Many flowers, or heads of flowers, do not open during cloudy or rainy weather, and have been called meteoric. Composite plants frequently exhibit this phenomenon, and it has been remarked in Anagallis arvensis, which has hence been denominated the "poor man's weather-glass." The closing of many flowers in such circumstances protects the pollen from the injurious effects of moisture.

The opening and closing of flowers is regulated by light and moisture, and also by a certain law of periodicity. A plant accustomed to flower in daylight at a certain time, will continue to expand its flowers at the wonted period, even when kept in a dark room. Decandolle made a series of experiments on the flowering of plants kept in darkness, and in a cellar lighted by lamps. He found that the law of periodicity continued to operate for a considerable time, and that in artificial light some flowers opened, while others, such as species of Convolvulus, still followed the clock hours in their opening and closing.

Light has been said also to have an effect on the position which flowers assume. Some Compositæ as Hypochwris radicata and Apargia autumnalis, are stated by Henslow to have been seen in meadows, where they abound, inclining their flowers towards the quarter of the heavens in which the sun is shining. A similar statement has been made regarding the Sunflower, but it has not been confirmed in this country at least. Perhaps in its native clime, where the effect of the sun's rays is greater, the phenomenon alluded to may be observable. The effects of light on the direction of the flowers has been noticed in many plants, as Narcissus and certain species of Melampyrum.

It is of importance, both as regards meteorology and botanical geography, that observations should be made carefully on what are called the annual and diurnal periods of plants: the former being the space of time computed between two successive returns of the leaves, the flowers, and the fruit; and the latter, the return of the hour of the day at which the flowers of certain species open. The same species should be selected in different localities, and care should be taken that the plants are such as have determinate periods of flowering. Rules as to the mode of observing periodical phenomena in plants have been drawn up by a committee of the British Association, and they have published (1.) a list of plants to be observed for the periods of foliation and defoliation; (2.) a list of plants to be noticed for flowering and ripening of the fruit; (3.) a list of plants to be observed at the vernal and autumnal equinoxes, and summer solstice, for the hours of opening and closing their flowers. 


\section{5.-Functions of the Organs of Reproduction-Fertilisation or Fecundation.}

The stamens and pistil are called the Essential Organs of flowering plants, inasmuch as without them reproduction cannot be effected. In plants which do not flower, this function is performed either by special organs, which have been termed antheridia and archegonia, or it is accomplished by a process of conjugation or union of cells. The stamens, considered as the male organs, prepare the pollen, which is discharged by the dehiscence of the anther. The pistil, or the female organ, is provided with a secreting surface or stigma, to which the pollen is applied in order that the ovules contained in the ovary may be fertilised.

The existence of separate sexes in plants appears to have been conjectured in early times, as shown by the means taken for perfecting the fruit of the Date Palm. In this palm, the stamens and pistils are on separate plants; and the Egyptians were in the habit of applying the sterile flowers to those in which the rudiments of the fruit appeared, in order that perfect dates might be produced. This practice appears to have been empirical, and not founded on correct notions as to the parts of the plant concerned in the process. In the case of the Fig, they were in the habit of bringing wild figs in contact with the cultivated ones, on the erroneous supposition that a similar result was produced as in the case of the Date, proving that they were not aware of the fact that in the Fig there are stamens and pistils present on the same receptacle. The effect produced by the wild figs, or the process of caprification (caprificus, a wild fig-tree), as it was called, seems to depend on the presence of a species of Cynips, which punctures the fruit, and causes an acceleration in ripening. The presence of sexual organs in plants was first shown in 1676, by Sir Thomas Millington, Savilian Professor at Oxford, and by Grew. The opinions of these naturalists were subsequently confirmed by Malpighi, Ray, Morland, Geoffrey, and others. Linnæus made these organs the basis of his artificial system of classification.

Numerous proofs have been given of the functions of the stamens and pistils, especially in the case of plants where these organs are in separate flowers, either on the same or on different plants. Thus, a pistilliferous specimen of Palm (Chamærops humilis), in the Leyden Botanic Garden, which had long been unproductive, was made to produce fruit by shaking over it the pollen from a staminiferous specimen. The same experiment has on several occasions been performed in the Botanic Garden at Edinburgh, and the fruit thus ripened has furnished seeds which have germinated. Similar results were observed in the case of the Pitcher plant. In Cucumbers, when the staminiferous flowers are removed, no perfect fruit is formed. Removing the 
stamens in the very early state of the flower, before the pollen is perfectly formed, prevents fertilisation. Care must be taken, in all such experiments, that pollen is not. wafted by the wind or carried by insects to the pistil from other plants in the neighbourhood, and the result must be put to the test by the germination of the seed. In some instances the fruit enlarges independently of the application of the pollen, without, however, containing perfect seed. Thus, a species of Carica was fertilised by the application of pollen, and produced perfect fruit and seed, and it continued for at least one year afterwards to have large and apparently perfect fruit, but the ovules were abortive.

Some authors maintain that in the case of Hemp, Spinach, Lychnis dioica, Coelebogyne ilicifolia, Aberia Caffra, and some other plants, perfect seeds have been produced without the influence of pollen, but these statements have not been confirmed. Such cases

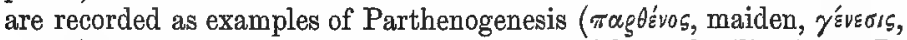
origin), or the production of perfect seeds without fertilisation. In Phanerogamous or flowering plants all experiments lead to the conclusion that there are distinct sexual organs, the presence of which is required for the production of the embryo.

In Cryptogamous or flowerless plants there are also organs of reproduction, although they are not always very conspicuous. In the simplest form of Cryptogamic plants, reproduction and nutrition progress within the same cell. As we ascend in the scale of vegetation, and the plant becomes more complex, there are cells of different kinds, which require to be brought into contact in order that spores (which are equivalent to seeds) may be produced. These reproductive cells are of two kinds, and they are situated either together or apart, on the same or on different individuals, one representing the male and the other the female. One of these is the Antheridium (avengoss, flowery, हiं 05 , form), a cellular body, containing free cells, in which are enclosed Phytozoa ( $\varnothing$ uròv, a plant, and $\zeta$ wos, living), (Antherozoids), minute bodies which exhibit movements; the other is the Pistillidium or Archegonium (ügxǹ, beginning, and yóvos, offspring), containing cells which, after contact with phytozoa, are able to germinate, and which are sometimes provided Fig. 467. Fig. 468.

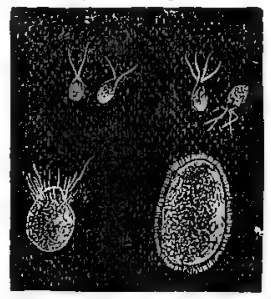

Fig. $469 . \quad$ Fig. 470. with cilia (figs. 467-470), and then are called Zoospores ( $\zeta$ wos; living, and бrogú, a seed or spore), or moving spores. The phytozoa are regarded as exercising a function similar to that of the spermatozoa in animals, and hence they are sometimes called Spermatozoids ( $\sigma \pi \dot{\varepsilon} g \mu \alpha$,

Figs. 467-470. Spores of different fresh-water Algæ. Fig. 467. Spores of Conferva, with two vibratile cilia. Fig. 468. Spore of Chætophore, with four cilia. Fig. 469. Spore of Prolifera, with a circle of cilia. Fig. 470. Spore of Vaucheria, covered with cilia. 
seed). A cessation of their active movements has been observed coincident with the earliest formation of the embryo. When the contents of the antheridia and archegonia are brought into contact, a cellular body is produced in the latter. This cell or germ, when mature, may either be discharged, or may remain in connection with the plant until further developed.

\section{Fertilisation or Fecundation in Cryptogamous or Flowerless Plants.}

In the simplest Cryptogamic plants, composed of a single rounded cell, as the Yeast plant, the Red-snow plant, and Palmella cruenta

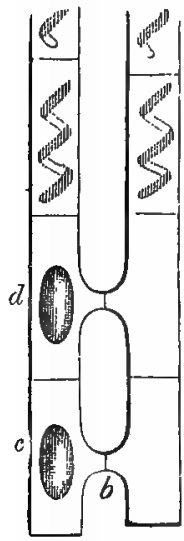

Fig. 471.

(fig. 44, p. 14), the processes of reproduction and nutrition cannot be separated. The same cell appears to perform both functions. At a certain period of growth divisions take place in the cellcontents, and by the bursting of the parent cell germs are discharged which are capable of producing new individuals. As we ascend in the scale the plants become more complex. In place of one cell they consist of several, united together either in a single or branched linear series, and combined both end to end and laterally, so as to form cellular expansions. In this state the nutritive and reproductive cells are often separate and distinct, as may be seen in common Mould, and in Fungi generally. In Confervæ (fig. 45, p. 14), and in Diatomaceæ (fig. 472), reproductive cells are observed with distinct functions. In many of them we perceive at certain stages of growth cells uniting by a process of conjugation, the result of this union being the production of a cellular embryo or spore. This conjugation is a very interesting process, and tends to throw light on the subject of reproduction throughout the whole vegetable kingdom. It is well seen in species of Zygnema, Spirogyra, Tyndaridea, Mougeotia, and Staurospermum, which are called Conjugatce on this account. The cells in these plants have in their interior a granular endochrome, which appears to have different functions in the different cells. When certain cells are brought into contact, tubes are emitted which unite the two (fig. $471 \mathrm{~b}$ ), the endochromes come into contact and the result is the formation of a spore, the mixed endochromes being surrounded with a proper membrane. Sometimes the contents of

Fig. 471. Filaments of Zyguema, with conjugating cells. The tubes uniting two cells are seen at $b$, and similar tubes connect two upper cells, $a$ and $d$. The contents of the cells intermingle, and spores or sporofd embryos, $c$ and $d$, are produced. The upper cells, in which there is no conjugation, retain their usual contents; while some of the lower cells. have lost their contents, and spores are produced in others. 
one cell, considered as the male, pass into the other in which the spore is produced, as in Zygnema (fig. 471), and sometimes the contents of both cells unite, and the spore is produced in the tube between them. Besides this process of conjugation, by means of which a cellular embryo is formed, some of these plants have a power of merismatic or fissiparous division (fig. 472), by which cells are separated, capable of independent existence. This may be compared to the process of budding;

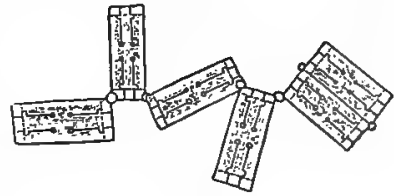

Fig. 472. and is thus distinct from fecundation.

In many of the Confervæ, however, spores appear to be produced without the conjugation of separate filaments. In such instances it is conjectured that different cells in the same filament perform different functions, and are so placed that at a certain period their contents by coming into contact develop a fertile germ. The same filament may thus contain both. male and female cells; although botanists as yet have not been able to show the difference between them. In some species of Meloseira the endochrome at each end of the cell appears to have a different property, and mixture takes place in the cavity of a single frustule. In this case there is a movement towards the centre of the cell where the spore is formed.

Proceeding to other divisions of Acotyledons, we find different kinds of reproductive organs, which can, however, only be observed at certain periods of development, and frequently cannot be seen after the embryo has been fully formed. In the same way as in flowering plants, when the seed has been ripened the stamens have generally withered and fallen off, and sometimes also the style and stigma. It is of importance, therefore, in all investigations into Cryptogamic reproduction, to examine the plants at an early period of their growth. The reproductive organs have received different names in the several orders of Cryptogams. The usual name applied to the male organs is antheridia, containing sperm-cells with phytozoa; and to the female organs, archegonia, containing germ-cells.

We shall now proceed to examine the reproductive organs and their functions in various divisions of flowerless or Cryptogamous plants.

In the case of Fungi (the mushroom order), reproductive bodies called spores are produced, either naked (often stalked) or contained in sacs called theca ( $\dot{y}_{1} x \eta$, a box) or asci (ascus, a bag). Many of the spores, such as those called conidia (róv/s, dust), are rather of the nature of buds. In some fungi, as Peronospora, a conjugation of cells has been

Fig. 472. Diatomaceous Alga (Diatoma marinum), the cells of which are increased by a constant process of fissiparous or merismatic division. The plant increases by abscission of segments. 
observed, and in Zyzygites megalocarpus as well as in species of Rhizopus ( $R$. nigricans), the formation of a compound spore by the complete amalgamation of two cells has occasionally been noticed. This compound spore is termed a zygospore ( $\zeta u$ ubv, a yoke). The bodies called cystidia (xurrı, a bladder), seen in Fungi, are supposed

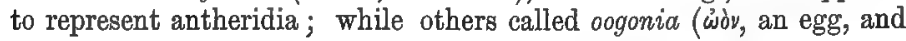
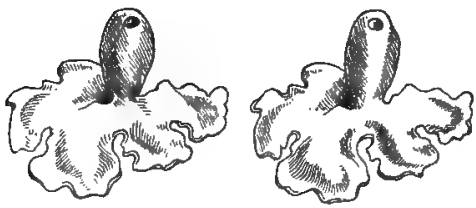

Fig. 473.

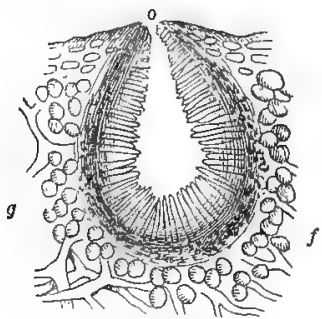

Fig. 474.

yóvos, offspring), are reckoned as equivalent to archegonia or sporangia, in which, after the action of the antheridia, a fertilised spore is formed, which is denominated an oospore.

In Lichens, which are Thallogens, reproductive bodies called spores

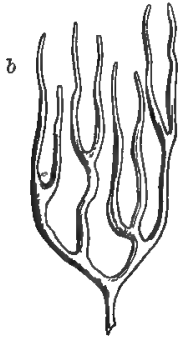

Fig. 475.

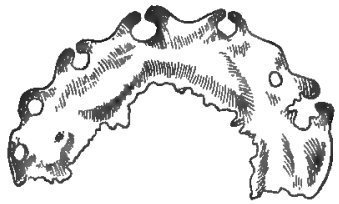

Fig. 476.

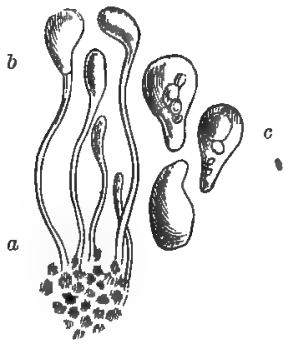

Fig. 4 i个?

occur in thecæ or asci, which are united in the form of open discs or apothecia ( $\dot{\alpha} \pi \dot{b}$, from, Ańx $\eta$, box), and in hollow conceptacles called perithecia ( $\pi \varepsilon \rho i$, around). On the thallus of lichens smaller hollow saes,

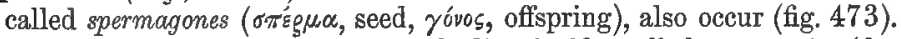
These when cut through show bodies inside called spermatia (fig. 474 ), which some consider as representing antherozoa or sperma-

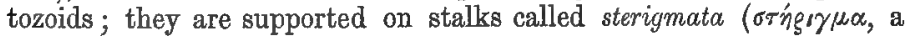

Fig. 473. Two Spermagones on thalli of Lichens. Fig. 474. Spermagones of a Lichen cat through, showing outer filaments, $f$ (hypha), with rounded green cells, $g$ (gonidia); in the interior sterigmata and spermatia; opening at top, o. Fig. 475. Sterigmata, $a$, and spermatia, $b$, of Cladonia fimbriata. Fig. 476. Pycnides of a parasitic Lecidia on thallus of a Cladonia. Fig. 477. Basidia, $a$; stylospores, $b$; free stylospores, $c$, from pyenides of same Lecidia. 
support), (fig. 475). Besides the spermagones, other externally similar reproductive bodies, called pycnides ( $\pi u x v \delta 5$, crowded) (fig. 476), are, though less regularly, produced on the thallus, containing minute bodies denominated stylospores (fig. $477 \mathrm{~b}$ ), which are either attached to style-like stalks (basidia), $a$, or are found free, $c$.

The fertilisation of Lichens is still very obscure, and the functions of their several reproductive organs require further examination. In the thallus of lichens there are interlaced filaments or threads, forming what is called the hypha (fig. $474 f$ ), (i $\varphi \eta^{\prime}$, weaving), in the midst of which are peculiar green-coloured rounded bodies, called gonidia. (fig.

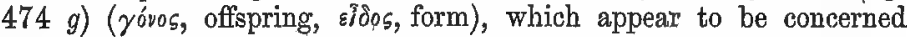
in vegetative propagation, like the zoospores of Algæ. These gonidia have been shown in some cases, as in Parmelia parietina, to contain corpuscles capable of development into zoospores.

In the division of Thallogens called Algæ, embracing Cryptogams, which inhabit salt and fresh water, there are more evident organs of fecundation. We have already noticed these in the case of the conjugation of confervæ (fig. 471), when two cells being different, the contents unite to form a spore or germinating body. This process is seen also in Diatoms and Desmidiex. In the minute Closterium Lunula there is a fissiparous division of the plant, and the contents of the two ruptured cells unite to form a rounded body, containing a spore. Besides the process of conjugation, there are also other modes of reproduction in Algæ; the same plant is seen forming cells which separate as independent plants, and also antheridia and archegonia which give rise to spores. In Vaucheria there is a multiplication by zoospores or moving cells, which are discharged from the extremity of a filament (fig. $478 a$ and $b$ ). This zoospore (fig. 478 $b$ ) is a vegetative reproductive body, independent of fertilisation. The plant also produces a recurved horn-like organ, which performs the part of an antheridium, and a slightly recurved organ close beside it, which represents the sporangium, from which a beak-like process is turned in the direction of the antheridium. These two organs are then in direct communication by their bases with the tube of the Vaucheria, but they are afterwards separated from

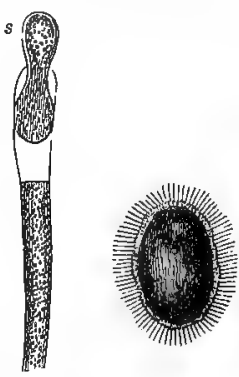

a. Fig. 478 , b. it, each forming a septum. Spermatozoids, contained in the antheridium, afterwards penetrate the beak-like process of the spo-

Fig. $478 \alpha$. Clavate cellular filament of an Alga (Vaucheria ovoidea). The terminal portion becomes separated from the rest by a partition. In this portion the single spore, $s$, is developed, which is discharged through an opening, as seen in the figure. The spore has cilia, by means of which it moves about for some time in water after being separated from the parent cell. The lower part of the filament contains green endochrome. The spore is of a very dark greeen colour. $b$, Zoospore of an Alga ( $\nabla$ aucheria), surrounded by moving cilie. 
rangium, and thus fertilisation is effected, and the true spore is formed in the interior.

In Vaucheria there are thus three reproductive organs:-

1. Zoospores, which are vegetative or bud-like reproductive organs (moving spores).

2. Antheridia, with sperm-cells containing fusiform corpuscles, which move by means of two cilia.

3. Sporangia, with germ-cells, which are fertilised by the ciliated corpuscles and form resting spores, whence the new plants arise.

Pringsheim has examined the reproduction in two minute Algæ, Edogonium and Bulbochæte. The greater part of the cells of CEdogonium contain each à zoospore (fig. 479, 1, a), provided anteriorly with a complete crown of cilia. This body (zoospore) is produced without sexual intercourse; it germinates and gives rise to a new plant in the same way as a bud does. Between the common cells of the cellular plants occur other utricles, usually more swollen, (fig. $479,1,2, b b$ ), either isolated or in groups. In these are formed. motionless spores (or resting spores), which are the female sexual organs. In the individuals which produce these female cells, as well as in others which have no such cells, there occurs a third kind of cell, shorter than the common cell of the plant, and forming often irregular groups. The third kind gives birth to spermatozoids, either at once or after the appearance of an intermediate production of a special nature, which becomes detached from the primordial filament, and contains the male sexual apparatus. In Edogonium ciliatum, a small species, found attached to the leaves of aquatic mosses, the cells containing the male organs are formed towards the anterior extremity of the filament, between the setiform terminal cells (fig. $479,1,2, d$ ) and the upper female organ. In each of these cellules there is formed, at the expense of the contained plastic materials, a single small zoospore called microgonidium (usxgds, small). This, according to Pringsheim, is the antecedent or generator of the male organs. These male organs have been called androspores (ávìg, male). These androspores, furnished with a circle of cilia at their anterior and transparent part, after quitting their mother-cells, move about at first, and then become fixed (in a determinate manner in each species) either to the female organ itself or in its neighbourbood. Pringsheim has seen in Edogonium ciliatum several androspores fix themselves on the surface of the female organ (fig. 479, 1, 2,c c c ). The latter organ continues to be developed, while each androspore becomes a sort of compound cellular plant. In one part of this the spermatozoids are formed, and hence it is called the antheridium. The fixed androspore acts like a mother-cell. The antheridium, properly so called, represents the secondary utricle produced at the upper part of the androspore, and the stalk of the antheridium is formed by the secondary inferior utricle. The antheridium bears at its summit a small lid, formed 
from the upper part of the membrane of the androspore. This antheridium, at first unicellular, divides into two cells, which become the mother-cells of the spermatozoids. The whole plastic contents of each mother-cell are employed in the formation of a single spermatozoid of considerable size. When the spermatozoids are mature then the upper spermatozoid raises slightly the lid of the antheridium (fig. $479,1,2, c)$. In the meantime the female organ is going through a process of development. When its contents are mature, the membrane of the female organ is ruptured all at once a little below its summit, the upper part forming a sort of lid, and the filaments which surmount it are turned to the side by the swelling of the plastic contents (fig. 479, 1, 2, d). There is thus a space on one side between the lid and the lower part of the female organ. Then the mucous colourless portion of the endochrome protrudes from theaperture, and its colourless cellular membrane presents a distinct lateral opening turned towards the antheridium. When the female organ has undergone these further changes in its contents, the lid of the antheridium is completely detached, and allows the upper cuneiform ciliated spermatozoid to escape. This spermatozoid, after moving around the female organ for some time, enters the opening. The spermatozoid reaches the female globule, which is then fertilised, and seems to 1 be absorbed in its substance.

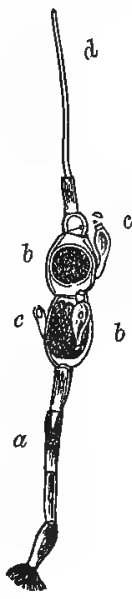

After this the female globular body becomes more and more definite, and finally is surrounded by a double membrane.

In the cells of another Alga, called Sphæroplea annulina (fig. 480 $a b)$, there are produced stellate spores, very like the reproductive bodies of Volvox stellatus. In spring the contents of these spores divide into two, then into four or eight parts, which become zoospores.

Fig. 479,1 . Entire plant of $\dot{E}$ dogonium ciliatum. a, Ordinary cells containing zoospores, which ultimately escape and form new plants. $b$, Sporangium, containing spores. $c$, Androspore fixed on the sporangium, bearing at its summit an antheridium with a lid. $d$, Setiform prolongation of the plant. Fig. 479, $\{2$. Sporangium, with spores. $b$, Magnified. c, Androspores bearing antheridium, with the lid at the top. d, Filament bending to the side, so as to expose an opening into the spore-case, by which the spermatozoids enter. 
These zoospores swim about, and then fix themselves, giving rise to young Confervæ. This is a first asexual generation. The young Conferva is a sort of prothallium, for it bears certain sexual organs. One kind of organ presents itself in the form of cells covered by a membrane, pierced with a certain number of apertures, and having contents which become converted into spores. These are the archegonia (fig. $480 \mathrm{~b}$ ). A second kind has a membrane also pierced with several apertures, and contains small mobile baculiform (rod-shaped) bodies. These are the antheridia, with their spermatozoids (fig. $480 a$ ). The spermatozoids come out from the cells, and enter the openings in the spore-bearing cells, and thus fertilise the spores.

Saprolegnieæ, including the genera Achlya, Saprolegnia, and Pythium, are cellular plants which grow on dead and living animals.

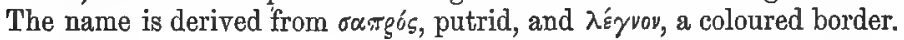

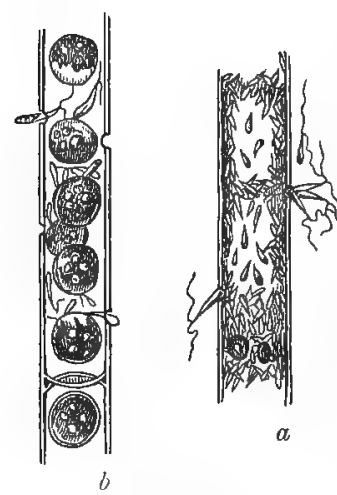

Fig. 480 . The bodies of flies thrown into water often become covered with these minute threadlike organisms. Gold fish in tanks have their gills sometimes covered with Achlya prolifera. They resemble in appearance the mucors or moulds, and some have placed them amongst the Fungi. They seem, however, to be more nearly allied to filamentous Algæ, such as Vaucheria. At the end of the filaments a cell is formed, which becomes separated from the rest of the filament by a septum. Zoospores (fig. 481 a a) are developed, which escape by the bursting of the cell. The filaments of Saprolegniere also produce lateral branches, at the ends of which are swellings, which are divided from the rest of the tissue. In them sacs called oosporangia are formed (fig. 481 b). These are fertilised by the union of cells containing spermatozoids, in the same way as Vaucheria, and oogones ( $\dot{\omega} \delta$, an egg) are formed. Thus there are two modes of reproduction-one by asexual zoospores (fig. 481 $a b$ ), and the other by sexual antheridia and oosporangia (fig. $481 c d$ ).

In the red sea-weeds, called Rhodospermeæ or Florideæ, fecundation is effected by antheridia, containing motionless corpuscles, and a

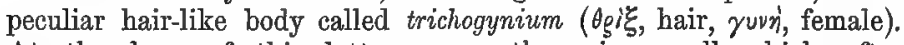
At the base of this latter organ there is a cell which, after fertilisation, is transformed into the cystocarp (xuor/s, a bladder

Fig. 480 a b. Spharoplea annulina. Male flament, $a$, consisting of cells with vacuoles, and with spermatozoids which are passing out of the cells by openings in the walls. Female filament, $b$, formed by cells containing spores, which are being fertilised by the spermatozoids, which enter the cells by openings in the walls, and come in contact with the cellular spores. 
and $x \alpha \rho \pi \sigma_{5}$, fruit), which is sometimes supported on a cellular body

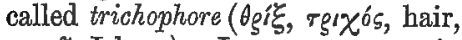
фoge $\tilde{\omega}$, I bear). In some cases, as in Nemalion, the fertilisation is direct, the influence of the antheridian corpuscle being at once conveyed by the trichogynium to the rudimentary cell of the cystocarp. In other cases, as in Dudresnaya, the action is less direct-the influence of the antheridian corpuscles being conveyed by connecting tubes which pass laterally from the base of the trichogynium to numerous fructiferous filaments, on which the cystocarps are finally developed.

In Florideæ there are also bodies called tetraspores (rergás, four), on account of their being divided into

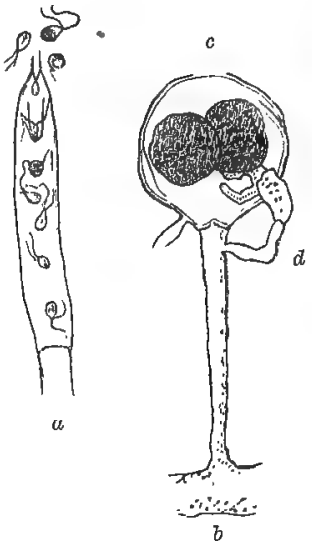

Fig. 481, four spore-like organs. These are contained in a distinct sac (fig. 482). They are probably concerned in vegetative and not in sexual reproduction. In the brown seaweeds (Fucaceæ) there are concep-

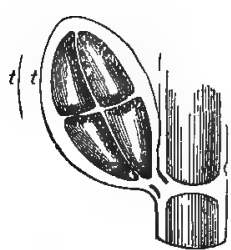

Fig. 482

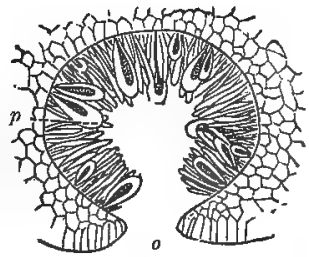

Fig. 483.

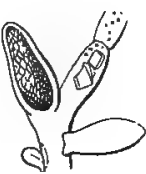

Fig. $484 a$.

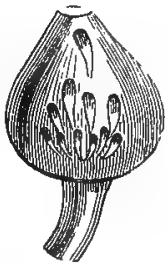

Fig. 485 .

tacles (fig. 483) containing antheridia (fig. 484, $a$ and $b$ ) and archegonia (fig. 485), either separate or combined, the plants thus being monœecious or dicecious.

Fig. 481. Saprolegnia showing organs of reproduction. a'a, Filaments containing asexual zoospores, some of which are being emitted from the end of the cell. $b$, Stalked sporangium (oosporangium) ending in a rounded cell $c$, containing in its interior cells called oogones ready to be fertilised. $d$, Antheridium coming into contact with the female cell, and sending tubes to the oogonia so as to fecundate them. Fig. 4S2. Tetraspore, $t$, of one of the rosecoloured Seaweeds (Callithamnion cruciatum). It is a sac formed by the metamorphosis of the lowermost pinnule of the frond, and contains four germinating spores. Fig. 483. Cell of a conceptacle of Fucus containing spores and abortive filaments. The spores escape at the opening, 0 ; other conceptacles contain antheridia. Fig. 484. Antheridia of a Seaweed (Fucus serratus). a, Antheridium, containing spermatozoids. b, Antheridium with two spermatozoids having vibratile cilia attached. Fig. 485. Archegonium (sporangium) of a seaweed containing pear-shaped spores which germinate. 
In Characeæ, which are aquatic cryptogamic plants found in ponds, there are two fertilising organs, one called, from its rounded form, the globule (fig. $486 \mathrm{~g}$ ), corresponding to the antheridium; and another (fig. $486 n$ ), the nucule (nucula, a small

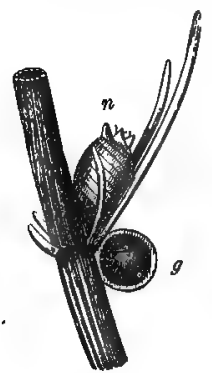

Fig. 486. nut), representing the archegonium. The globule contains a definite number of cells, which meet in the centre and form a round mass, whence jointed filaments containing spermatozoids arise (fig. 487). The colour of the globule is red. The nucule is a large oval cell (archegonium), round which five

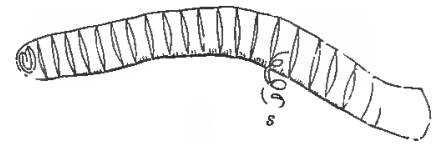

Fig. 487.

filaments are spirally twisted, ending at the summit in five or ten tooth-like processes. The central oval cell in the nucule is fertilised by spermatozoids from the jointed filaments of the globule coming into contact with it. After fertilisation the nucule drops off and ultimately forms a new plant. While the nucule may be considered as equivalent to the archegonium, it is in reality a combination of that organ and a spore.

In Hepaticæ (Liverworts), including Marchantiæ and Jungermannix, the reproductive organs consist of antheridia and archegonia. The antheridia are small cellular sacs of a globular, ovoid, or flasklike form. They have a single or double cellular covering, enclosing viscid matter, in which are developed four-sided cells, in each of which is a small filiform spermatozoid (phytozoon), rolled up in a circular manner, and displaying rapid movements. The spermatozoids are finally liberated, and unrol themselves, appearing as filaments swollen at one extremity, and gradually tapering to the other. In Marchantia (fig. 488) the antheridia occur in the upper side of an elevated disk or receptacle, $r$. When this disk is cut vertically, as in fig. 489 , they are seen at $a$ a, as flask-like cellular sacs separated by air-cavities, $c c$, which communicate with stomata, $s s$. In fig. 490 an antheridium is shown discharging its minute cells containing spermatozoids. In some Hepaticæ the antheridia occur in the substance of the thallus, while in others (as in some Jungermannix) they appear in the axil of the leaves.

Fig. 486. Cellular tubes of Chara, with verticillate branches, from the axil of which proceeds the 'nucule, $n$, containing a germinating spore, while below the branch is placed the red globule, $g$, containing antheridian cells and spermatozoids. Fig. 487. Filament from the globule of Chare, consisting of numerous sperm-cells (phytozoary cells). A spermatozoid, $s$, is seen escaping from one of them. 
The archegonia of Hepaticæ are either situated in the substance of the thallus, as in Riccia and Anthoceros, or they are raised upon

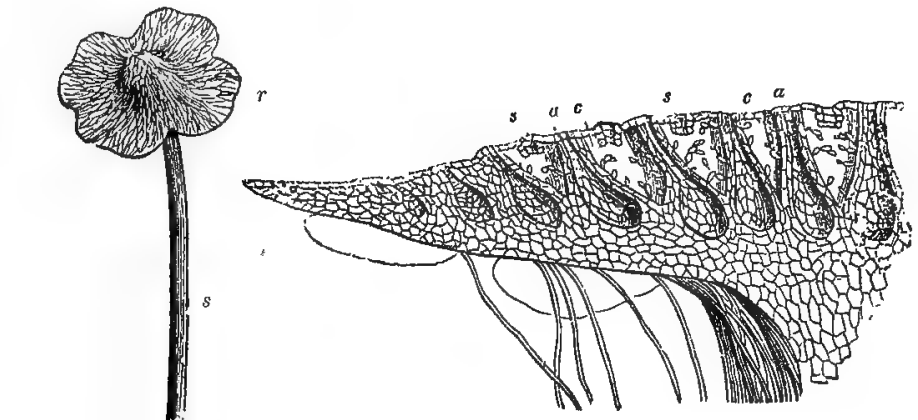

Fig. 489.

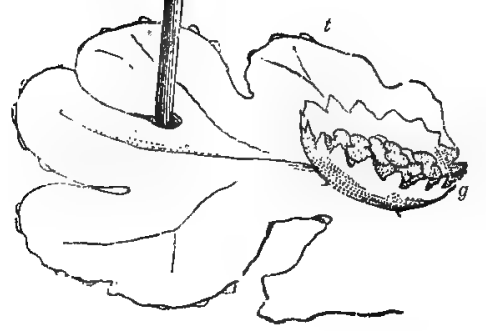

Fig. 488 .

stalks, as in Marchantia (fig. 491) and Jungermanniæ. In Marchantia these stalks bear radiated receptacles, $r$, on the under surface of which the sporangia are placed, which are peculiar bottle-shaped bodies (fig. 492) containing germ-cells.

The spermatozoids enter the archegonia, and thus a cell is fertilised, from which the sporangium or spore-capsule, a distinct body, is produced (fig. 491 s), constituting the second generation. In Jungermannia bicuspidata (fig. 493) there is represented at $a$ an archegonium containing an unimpregnated germ-cell, and at $b$ an archegonium containing an impregnated germ-cell, which is the rudimentary spore-capsule. The germ-cell, after fertilisation, shows two nucleated cells, $c$, and from it, as a second generation, the fruit-

Fig. 488. A species of Liverwort (Marchantia polymorpha), with its green thallus, $t$, bearing a cup-like body, $g$, in which minute cells or free buds (sporules of some) are seen, and a stalked receptacle, $s r$. In the substance of the disk-like receptacle, $r$, cells are produced containing spermatozoids. These are considered antheridia. Fig. 489. Vertical section of the disk-like receptacle of Liverwort (Marohantia), showing the antheridia, $a$ a, in its substance. These antheridia are flask-shaped sacs containing phytozoary cells. They communicate with the upper surface, and their contents are discharged through it. Between the antheridia there are air cavities, $c$ c, connected with stomata, $s$. 
bearing stalk is produced. Around the orifice of the canal leading to the germ-cell and rudimentary spore-capsule are seen numerous spermatozoids, $s s$, which have been discharged from the antheridia.

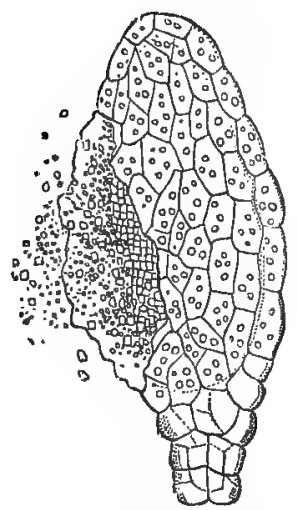

Fig. 490.

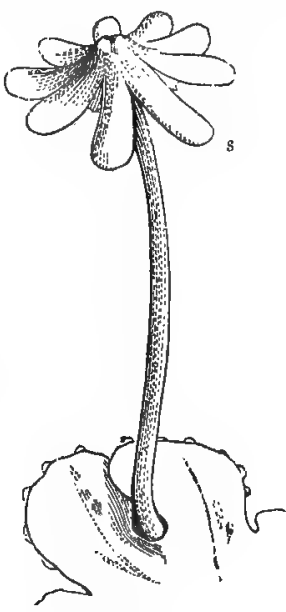

Fig. 491 .

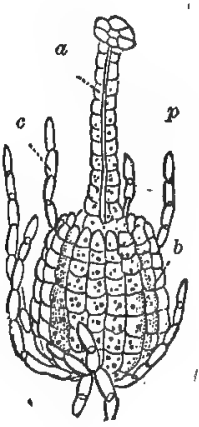

Fig. 492.

In Mosses there is a free germ-cell (embryonal cell) at the base of the archegonium. Spermatozoids, from the sperm-cells of the antheridium (fig. 494), reach it, and then it is developed into the sporangium or spore-case (fig. 495), which is the second generation of the plant. The spores produce the leafy plant, bearing antheridia and archegonia. In fig. 496 is shown the confervoid prothallium, $p$, of a Moss produced from the spore, and bearing buds, $a b$, which produce leafy individuals with organs of reproduction. After the contact of these organs, a single cell of the archegonium is developed into the complete fruit (theca or sporangium), which is often borne upon a stalk (fig. 495). The complete fruit contains spores, which, when discharged, again develop the foliaceous plant.

In leafy Mosses and in Jungermanniæ there is also an increase by buds. The confervoid filament produced by the spore gives origin to a number of buds (fig. 496), whence leafy stems proceed, and

Fig. 490. Antheridium of Liverwort (Marchantia) discharging its eperm-cells, that is, cells containing spermatozoids. Fig. 491. Thallus of Liverwort (Marchantia polymorpha), bearing a stalked fruit, $s$, which is the product of the impregnated cell of the archegonium. The receptacle at the apex of the stalk bears on its under surface sporangia containing spores and elaters. The spores, when germinating, produee a thallus, on which antheridia and archegonia are formed. Fig. 492. Pistillidium or archegonium of Liverwort (Marchantia), containing in its interior a cell, which is impregnated by the spermatozoids of the antheridium. 
these leafy stems also produce buds or gemmæ, called innovations. There is thus a multiplication by sexual reproduction and by gemmation, as in higher plants.

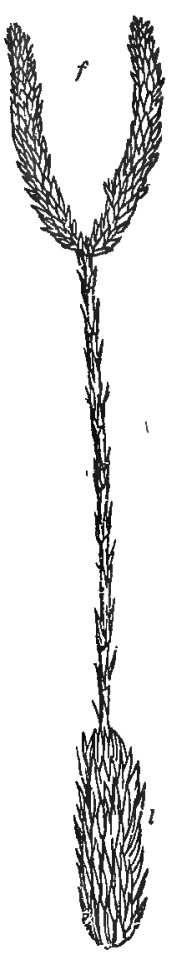

Fig. 497.

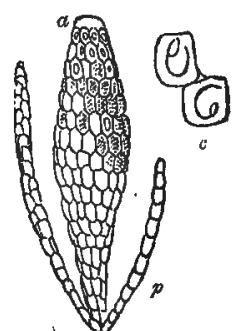

Fig. 494.

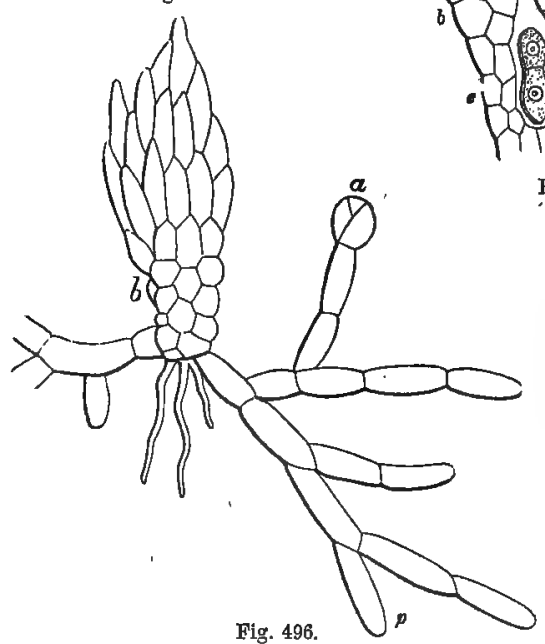

Fig. 496.

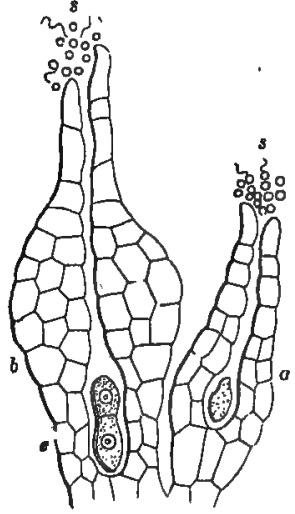

Fig. 493.

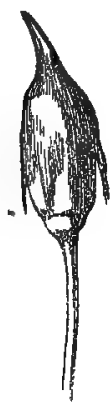

Fig. 495 .

Fig. 493. Archegonia of Jungermannia bicuspidata. $a$, Unimpregnated archegonium, with a tube leading to a cavity, near the base of which is a cell. $b$, Archegonium after impregnation, with the cell divided into two nucleated portions. This double nucleated body is the rudiment of the fruit-bearing stalk. At the apex of the canal leading to the cell are seen spermatozoids, $s$. Fig. 494. The male organs of a Moss (Polytrichum). a, Antheridium containing sperm-cells, two of which are seen at $c$. These sperm-cells contain spermatozoids, which are discharged so as to impregnate the archegonium. Surrounding the antheridium there are flaments or paraphyses, $p$. Fig. 495. Sporangium of a Moss (Polytrichum), supported on a stalk. This stalked sporangium is produced by the impregnated cell of the archegonium. It constitutes the second generation. Fig. 496. Confervoid filament forming the prothallium, p (exothallium), of a Moss (Funaria hygrometrica), consisting of a congeries of cells arranged in a filiform manner. This prothallium originates from the spore, and bears a bud, $a$, and a young stem, $b$, from the base of which roots proceed. Fig. 497. End of fructiferous branch of Lycopodium clavatum, common Clubmoss. The leafy branch, $l$, ends in a stalk bearing two spikes of fructification, $f$. 
Lycopodiaceæ, Club Mosses (fig. 497), have sporangia which are either all alike as in Lycopodium, or of two forms as in Selaginella. The dimorphic sporangia consist of micro-sporangia (fig. 498), (usxgós, small), containing numerous granules (microspores or antheridia), (fig. 499), and macrosporangia (fig. 500), ( called by some megasporangia ( $\mu^{\prime} \varepsilon \alpha \varsigma$, great), or oophoridia ( an egg, $\operatorname{oog}^{\varepsilon} \omega$, I bear), of a large size containing often four macrospores or megaspores, in the interior of which a cellular prothallus is formed (fig. 501, p), on which archegonia are developed (fig.

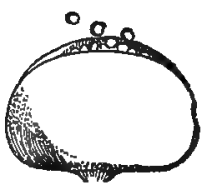

Fig. 498.

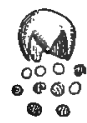

Fig. 499.

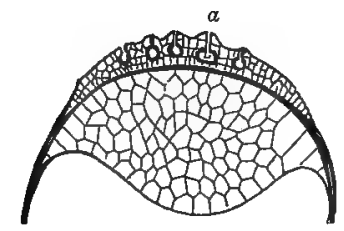

Fig. 502.

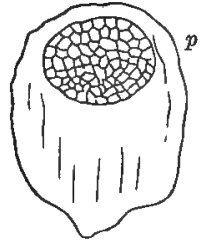

Fig. 500 .

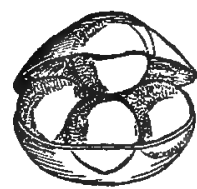

Fig. 501.

$a$

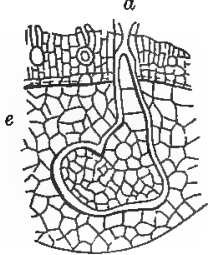

Fig. 503.

502 a). In the microspores of Isoetes and Lycopodium there is a sort of male prothallium bearing antheridia with spermatozoids. No germination has been observed in the microspores of the genus Lycopodium. The process of impregnation in Lycopodiacer is supposed

Fig. 498. Antheridium of a Club-Moss (Lycopodinu), containing microspores, which are cells containing spermatozoidal cellules, as seen in fig. 499 . Fig. 499. Small spore (pollinic spore) of a Lycopod (Selaginella helvetica), bursting and discharging cellules, containing spermatozoids. Fig. 500. Oophoridium or macro-sporangium of a Club-Moss (Lyeopodium), opening and showing four large spores in its interior. These macrospores or megaspores contain a cellalar prothallium or endothallium in their interior, bearing archegonia. Fig. 501. Macrospore discharged from the oophoridium of a Lycopod (Selaginella Mertensii), with the outer coat removed to show the young cellular prothallium, $p$, at the upper end. Fig. 502. Vertical section of the prothallium and upper half of a large spore of a Lycopod (Selryinella dentioulata). There are several archegonia, and in one of them, at $a$, there is a central fres cell, whence the leafy frond ultimately proceeds. Fig. 503. Vertical section of a small portion of the prothallium and upper part of the large spore of a Lycopod (Selaginella denticulata), showing the embryo, $e$, developed from a central cell of one of the archegonia, $a$, carried down by the growth of the suspensor, so as to be imbedded in the cellular tissue at the upper part of the spore. 
to take place by the spermatozoids of the small spores coming into contact with the large spore after the coat of the large spore has burst at its apex, so as to expose the cellular prothallium and its archegonia (fig. 502 a). The free central cell of the archegonium then enlarges, divides, and elongates into a fllament, which growis down into the prothallium (fig. - 503). A suspensor is thus formed, at the end of which is the embryo, $e$, imbedded in the cellular tissue at the upper part of the large spore. The embryo finally produces its radicle and its bud, which is developed as the leafy frond.

In Rhizocarps (Marsileaceæ) there are also antheridia and archegonia. The former are sacs containing small spores, which produce inside a small prothallium, on which are borne antheridia containing spermatozoids. The latter are sporangia containing large spores

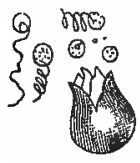

Fig. 504.

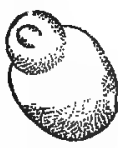

Fig. 505 .

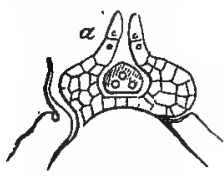

Fig. 506.

which produce a prothallium like that of Lycopods, on which archegonia appear. The prothallium usually produces only one central archegonium, the spermatozoids get access to the archegonia, and thus the young plant is produced.

In Ferns there is a prothallus bearing antheridia and archegonia at the same epoch. It is produced by the spore during its gêrmination, and consists of cells, as shown in fig. 507. The antheridia occur on the under surface of the prothallus, and they consist of a cellular papilla having a central cavity (fig. 508). This cavity contains free cellules, which are discharged by a rupture at the apex, $b$, and each of these little cellules, in bursting, gives exit to a ciliated spiral filament (spermatozoid), (fig. 509), which swims actively in water, advancing with a rotatory motion through the water when seen under the microscope. The archegonia (fig. 510) exist on the under side of the prothallus, near the notch of the border. They are less numerous than the antheridia (varying from three to eight), and consist of cellular papillæ formed by ten or twelve cells. They are larger than

Fig. 504. The small apore of a Rhizocarp (Pilularia globulifera, Pillwort). The inner coat is protruded, and the outer coat has burst, so as to discharge cellules containing spermatozoids. Some of the spermatozoids are separate, and are seen coiled up in a spiral form. Fig. 505. Large spore of a Rhizocarp (Marsilea, Pepperwort), which contains a cellular prothallium bearing archegonia. The mammillary projection is the point whence the gemmation of the embryo proceeds after impregnation. Fig. 506. Vertical section of prothallium of a Rhizocarp (Pilularia globulifera), containing a central archegonium, $u$, before impregnation. 
the antheridia, and have a central canal, a, leading down to a large globular cell, c, imbedded in the substance of the prothallus, and containing the embryo-germ, $e$. The canal is closed at first, and then opens. The spermatozoids enter the archegonial canal and fertilise the germ-cell. After a time this cell divides and gives rise to the
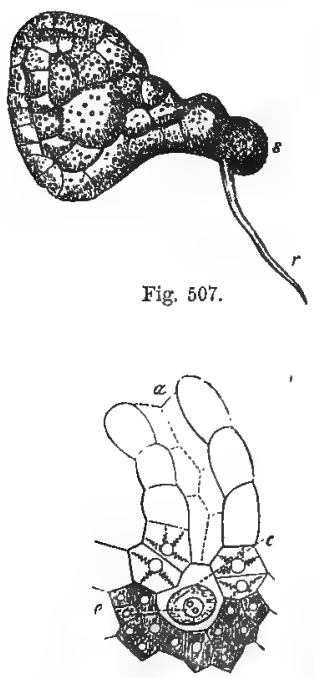

Fig. s10.

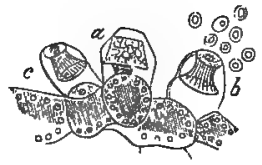

Fig. 508.

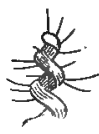

Fig. 509.

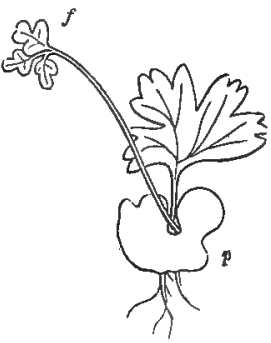

Fig. 511.

embryonic body, whence the stem of the Fern arises (fig. $511 f$ ). The life of the sporangiferous plant is indefinite, as seen in Tree Ferns, while the prothallus is of very short duration. Thus in Ferns the spores contained in the sporangium form the prothallus without impregnation, while this latter process is necessary for the development of the germ, which gives rise to the leafy sporangiferous

Fig. 507. Cellular prothallium (exothallium) of a Fern (Pteris longifolia), produced by a spore, $s$, and giving off a root, $r$, at one end. It consists of numerous cells, and it gives origin to antheridia, and pistillidia or archegonia. Fig. 508. Antheridia from the prothallium of the Common Brake (Pteris aquilina). $a$, An nnopened antheridium; $b$, antheridium borsting at the apex, and discharging free cellules, each containing a spermatozoid; $c$, antheridium after the discharge of the cellules. Fig. 509. A spermatozoid with cilia, discharged from a cellule in the antheridium of the Forked Spleenwort (Asplenium septentrionale). Fig. 510. Archegonium of the Forked Spleenwort (Asplenium septentrionale) immediately after impregnation. a, Canal leading to the ovule or large cell, $b$, at the base of the archegonium; $e$, nucleated embryonic cell, whence the sporangiferoug frond proceeds. Spermatozoida from the antheridium reach the canal of the arehegonium, and impregnate the ovule. Fig. 511. Young plant of a Fern (Pteris paleacea), showing the commencement of the sporangiferous frond, $f$, arising from the impregnated ovule in the archegonium; the prothallium, $p$, being still attached. 
frond; while in Mosses the spore forms the prothallus and the leafy stem without impregnation, and this operation gives rise to the formation of the stalked theca.

The reproduction of Equisetaceæ (fig. 512), Horsetails, resembles much that of ferns. Their spores, which are surrounded by hygrometric filaments, called elaters, germinate and form a lobed prothallus bearing antheridia at the top of its lobes and archegonia at its base. The antheridia appear as ovoid swellings containing at first globules, which ultimately are developed as spermatozoids (antherozoids). The archegonia consist of globular bodies, terminated by a long neck with a four-lobed opening at the top. The spermatozoids enter by the opening and fertilise a cell in the archegonium, which ultimately constitutes the germ of the new plant.

Ferns, Ophioglossaceæ and Equisetaceæ, are called isosporece (" $\% 0 \mathrm{~s}$, equal), because they produce a single kind of spore, which in its turn gives origin to a prothallus furnished with chlorophyll and roots, and capable of independent existence. On the same prothallus, or on two neighbouring ones, antheridia first of all originate, and when mature emit spermatozoids, then follow archegonia generally formed of a central cell, to which access is gained by a canal opening outwards. Fecundation heing effected by the entrance of spermatozoids into the archegonium, the first period is closed, and then commences the asexual generation. The embryo is developed at first in the substance of the prothallus, but afterwards becomes disengaged from it, and passes through the different phases of its development. Finally, the second generation terminates its evolution

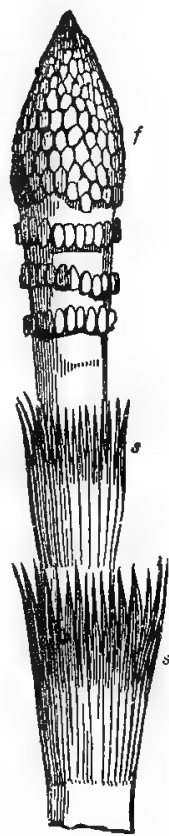

Fig. 512. by the development of the organs of multiplication as spores, which always originate from a normal or modified leaf.

\section{Fertilisation or Fecundation in Phanerogamous or Flowering Plants.}

In flowering plants the organs of reproduction are stamens andpistils, the former representing the male element, and the latter the female. The cellular pollen (sperm-cells) produced by the former must be applied to the cells contained in the latter (germ-cells), in order that the embryo plant may be formed in the seed.

Fig. 512. Fructification of Equisetum maximum, Great Water Horsetail, showing the stalk surrounded by membranous sheaths, $s$, , which are fringed by numerous processes or teeth. The Iructification, $f$, at the extremity, is in the form of a cone bearing polygonal scales, under which are spore-cases containing spores with clavate filaments. 
In flowering plants various provisions are made for insuring the application of the pollen to the stigma. The saccharine secretions of the flower, the comparative length of the stamens and pistils, their position, and the dehiscence of the anthers, are all regulated with this view. The existence of spiral cells in the endothecium has reference apparently to the bursting of the anther and the scattering of the pollen. The number of pollen-grains produced is also very great. In a floret of wheat Wilson reckoned about 7000 pollen-grains. Hassall says that a single head of Dandelion produces upwards of 240,000 , each stamen of a Pæony 21,000, a Bulrush 144 grains by weight. It has been stated that a single plant of Wistaria sinensis produced $5,750,000$ stamens, and these, if perfect, would have contained 27,000,000,000 pollen-grains.* In a single flower of Maxillaria F. Müller estimated the pollen-grains at 34,000,000. This same flower produces $1,756,000$ seeds. In Orchis mascula the pollen-grains in a single flower have been estimated at 120,000 . In the case of Evergreens, such as Firs, the quantity of pollen is enormous, apparently to insure its application notwithstanding the presence of leaves. The pollen from pine forests has been wafted by the winds to a great distance, and sometimes falls on the ground like a shower of sulphur. It is thus that some kinds of coloured rain, occasionally witnessed, may be accounted for. The pollen powder transmitted to considerable distances remains floating in the air till carried down by a passing shower.

The quantity of pollen required for impregnation varies. Koelreuter says, that from fifty to sixty grains of the pollen of Hibiscus Trionum are required to fecundate the fruit completely, containing about thirty ovules. The ovary of Nicotiana, Datura, Lychnis, and Dianthus, according to Grortner, may be completely fertilised by the pollen of a single perfect anther. In Geum, from eight to ten anthers, out of eighty-four to ninety-six contained in each flower, are sufficient to fertilise from eighty to one hundred and thirty ovules contained in the ovaries.

In many trees in which the organs of reproduction are in separate flowers (as in Hazel and Willow), the leaves are not produced until fertilisation has been effected. The protection of the pollen from the direct influence of moisture is effected by the closing of the flowers, by the elasticity of the anther-coat only coming into play in dry

* The following estimate was made of the amount of flowers, stamens, ete., in a single specimen of Wistaria sinensis :-

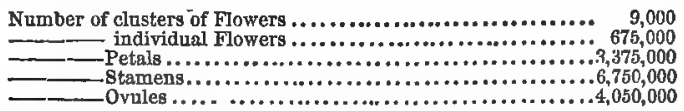

For the purpose of fertilising these ovules, the anthers, if perfect, would have contained about $27,000,000,000$ pollen-grains, or about 7000 grains to each ovule. 
weather ; and in aquatics, either by a peculiar covering and structure as in Zostera, or by the flowers being developed above water, as in Nymphæa, Lobelia, Stratiotes, and Hottonia. In Vallisneria spiralis (fig. 513), a plant growing in ditches in the south of Europe, the staminiferous flowers are detached from the male plant, float on the surface of the water, and scatter their pollen; while the pistilliferous plant, $b$, sends up a long peduncle, which accommodates itself to the depth of the water by being spiral, and bears on its summit the flower with the pistil. By this means the two organs are brought into contact, and fertilisation is effected. Lagarosiphon muscoides, an aquatic plant from Africa, shows similar phenomena in regard to impregnation

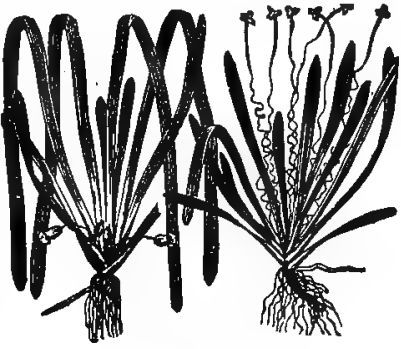

Fig. 513. $\quad b$ as are seen in Vallisneria. When continued wet weather comes on after the pollen has been matured, and has begun to be discharged, it often happens that little or no fruit is produced. In flowers where the anthers burst in succession, the injury done by moisture is less likely to extend to all. Stamens are protected in various ways from wind and moisture. In Iris by the petaloid divisions of the style, in Phyteuma by the upper united part of the corolla, in Trollius by the sepals turned inwards, so as to form a ball (hence the name globeflower), and in Arum by the spathe (fig. 260, p. 178). In many flowers the perianth gives shelter to the stamens. In Orchids the pollen is well protected.

In some plants the stamens, at a certain period of their development, move towards the pistil, before the contents of the anther are discharged. In Parnassia palustris (fig. 514) and Rue they do so in succession. In Kalmia the anthers are contained in little sacs or pouches of the corolla, until the pollen is mature, and when the expansion of the corolla and the elasticity of the filament combine to liberate them, they spring towards the pistil with a jerk. In Parietaria officinalis, and in the Nettle, the spiral filament is kept in a folded state until the perianth expands, and then it rises with elastic force and scatters the pollen. Similar phenomena are observed in the Cornus canadensis. In the various species of Barberry the inner and lower part of the filament, is irritable, and when touched it canses the stamen to move towards the pistil. The anther opens by recurved

Fig. 513. Male and female plants of Vallisneria spiralis. $\alpha$, The male plant, the flowers of which are detached, and rise to the surface of the water so as to mature its pollen and scatter it; $b$, the female plant, which remains fixed in the mud, and sends up a spiral peduncle, which uncoils according to the depth of the water, and bears the pistilliferous flowers above the water, so as to allow the pollen to be wafted upon them. 
valves, which are covered with pollen-grains. The species of Stylidium have their anthers and stigma seated on a column, the base of which is slightly swollen and irritable. When a stimulus is applied, this column passes with considerable force from one side of the flower to the other, rupturing the anther-lobes, and thus aiding in fertilisation. In some plants the pollen is scattered by the wind, and they are

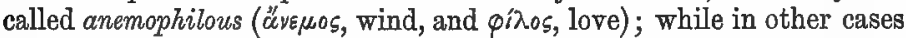
animals are the agents employed in its distribution, and the plants are called zoophilous ('wov, animal). It has been ascertained that self-fertilisation is by no means common in flowers, that is to say, the pollen is not always applied to the pistil of the flower in which it is produced. We constantly find that pollen produced by the anther of one flower is applied by the medium of wind or insects to the pistil of another flower on the same plant, or on different plants. This is seen very evidently in monœcious and dicecious plants. It also occurs in dimorphic plants where there is a difference in the development of the stamens and pistil in the case of individual flowers; as is well seen in some species of Primula, and of Linum. Flowers visited by insects are often highly coloured and odoriferous, and secrete honey-like matter. Night-flowering and night-smelling plants attract crepuscular insects. These may be illustrated by Pelargonium triste, Hesperis tristis, and Nyctanthus Arbor-tristis. Stapelias (carrion flowers) by the fetid odour of their flowers attract blow-flies, which deposit their eggs amongst the hairs of the flower. The eggs in due time are hatched, and then the maggots in search of food press the pollen masses downwards to the stigma and so cause fertilisation. In Oxalis Acetosella the flower is erect during the day, and is open to the visits of insects; it describes an arc of more than 100 degrees when the sun sets, and finally has its opening directed to the ground.

The pollen in the case of plants fertilised by insects is sometimes elliptical with three or more longitudinal furrows, as in Ranunculus Ficaria, Aucuba japonica, and Bryonia dioica; at other times it is spherical or elliptical, and covered with projecting processes (echinate), as in many Compositæ, Malvaceæ, and Cucurbitaceæ; or, thirdly, the pollen grains are attached together by threads or a viscid secretion, as in Richardia Rhododendron and Enothera. In plants fertilised by the wind, as in most grasses, Hazel and Populus balsamifera, the pollen is almost perfectly spherical, and has no processes, and is generally light and dry. Dr. Dyer remarks that while in Cruciferæ fertilisation is generally effected by insects, in Pringlea antiscorbutica (Kerguelen Island Cabbage), which differs from the plants of the order in having no petals, no honey glands, an exserted style and papillose stigma, fertilisation is effected by the wind. It has been stated by some authors that in the case of the cereal grains impregnation is effected before the flowers are open, and that thus self-fertilisation takes place. 
This has been specially noticed by Hildebrand in the case of barley, and Mr. Stephen Wilson states that the same thing occurs in wheat and oats. Delpino remarks that in an ear of barley there are certain flowers differently constructed from the rest, in which cross-fertilisation is possible, and that in the oat the process varies according to the weather. In fine warm weather the flowers open freely, and crossfertilisation is favoured; while in cold wet weather they remain closed, and self-fertilisation is inevitable. In rye, fertilisation from the pollen of other flowers is provided for.*

Certain flowers of Primrose are called pin-eyed, having a long style with the rounded stigma projecting beyond the tube of the corolla, and standing high above the anthers, which are situated half-way down the tube; others are called thumb-eyed, having a short style, with the anthers attached at the mouth of the tube, and therefore high above the stigma. These flowers occur on distinct plants. Such species are dimorphic, and may be conveniently called dioeciouslyhermaphrodite-that is, having two kinds of hermaphrodite flowers on distinct plants. Efficient fertilisation is only attained by the application of the pollen from stamens of a given length to styles of a corresponding length. The short styles are of the same length as the short stamens, and the long styles as the long stamens, and it appears that the best fertilisation and the greatest number of seeds are produced by the application of the pollen of the short-styled flowers to the long-styled. This is called heteromorphic fertilisation, in contradistinction to homomorphic where the pistil is fertilised by the pollen of its own flower. In the Ipecacuan plant (Cephaelis Ipecacuanha) dimorphic flowers occur of a similar kind. Lythrum Salicaria is trimorphic; that is, it presents three forms of flowers. Each of these has stamens and pistils, each is distinct in its pistil from the other two forms, and each is furnished with two sets of stamens differing from each other in appearance and function. There are three lengths of stamens - long, medium, and short-but. two lengths only occur in the same plant; and there are also three lengths of styles, but they are not associated with stamens of corresponding length. There are then three forms of flowers-1. With short and medium stamens, and long style; 2. With short and long stamens, and medium style; 3. With medium and long stamens, and short style. The stigma is best fertilised by pollen from stamens of lengths corresponding to the styles. Two of the three hermaphrodite forms must co-exist, and the pollen must be conveyed reciprocally from one to the other, in order that either of the two may be fully fertile; but unless all three forms co-exist there will be waste of two sets of stamens, and the organisation of the species as a whole will be imperfect. On the other hand, when all three hermaphrodites co-exist,

* See Stephen Wilson's paper in Trans. Bot. Soc., Edin., 1874. 
and the pollen is carried from the one to the other, the scheme is perfect. The three forms are divided according to their styles into long-styled, mid-styled, and short-styled. Such plants may be called triociously hermaphrodite. The fertilisation is effected by the agency of insects. The insect in passing from flower to flower will brush against a stigma at a given level with the same part of its head or body which has brushed off the pollen from an anther at a corresponding level. The object of all these arrangements is the prevention of close inter-breeding. Homomorphic unions, where a pistil is supplied with pollen from its own flower, or from a flower of the same form, result either in very diminished fertility, or, as in the dimorphic species of Linum (Flax), in absolute sterility.

The same object-namely, the prevention of close inter-breedingmay be effected by other means; sometimes, as in Orchidaceæ (fig. 317 , p. 205), and Asclepiadacex (figs. 385, 386, p. 230), by the mechanical arrangement of the parts of the flowers, and, more especially, the consistence of the pollen, being such that fertilisation cannot occur without the agency of insects, which carry the pollen masses (pollinia) from one flower to another. In the species of Orchids, such as Orchis mascula, the pollen masses (fig. 387, p. 230) have each a candicle, which is firmly attached to a viscid disk, consisting of a minute oval or rounded piece of membrane, with a ball of viscid matter on its under side. These balls are contained within a cup-like rostellum, the lip of which is easily depressed by contact with a foreign body, such as the proboscis of an insect. The pollinia become thus attached to the proboscis. At first they stand erect, but ultimately, by the contraction of the minute disk, they bend downwards and forwards towards the point of the proboscis. In this way the pollen is in a position to be at once applied to the stigma when the insect visits another flower, and thus fertilisation is effected.

The prevention of close inter-breeding is also accomplished in many cases by the physiological condition of the parts concerned in fertilisa-

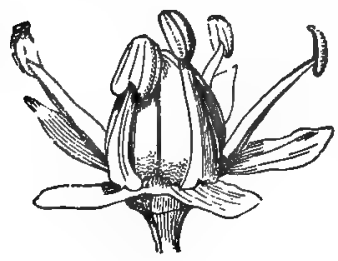

Fig. 514 tion, as occurs in what are called Dichogamous plants - that is, plants in which the stamens and stigmas of the same flower do not reach maturity at the same timethe stamens being matured first in what are called protandrous plants, and the stigmas first in protogynous plants. (See notice of Protandrous and Protogynous plants, at page 212.) In Parnassia palustris (fig. 514) the stamens move in suc-

Fig. 514. Flower of the Grass of Parnassus (Parnassia palustris), the stamens of which move in succession towards the pistil, and discharge their pollen. In the figure some stamens are seen applied to the pistil, and others removed from it. 
cession towards the pistil, and after the pollen has been discharged they curve back to the petals. But the stigma is not perfect at that time. It becomes developed after the pollen has been discharged and the anthers have retired. It requires the agency of insects to effect complete fertilisation. The pollen is discharged on the part visited by insects, and they take it up on that part of their bodies which touches the perfect stigma in other flowers, and thus fertilisation is effected. In Lobelia we have an instance of the stamens being complete and the pollen discharged before the stigma is perfect. After the pollen has been discharged, the style elongates and carries the stigma upwards beyond the syngenesious anthers, and then the stigma becomes perfect, so as to be ready for the pollen applied by insects. Both these flowers are Protandrous.

In Euphorbia jacquiniflora, several days before the stamens burst through the involucre which closely invests them, the pistil with its ovary on the long pedicel has protruded itself beyond, expanded its stigma, and received pollen from neighbouring flowers. It is therefore Protogynous,

In the case of Aristolochia Clematitis (fig. 515), the flowers, as long as the essential organs are in a state fit for fertilisation, stand erect, with their oblique mouth turned outwards, by which an insect can enter easily, and pass down the tube till it comes to the column bearing the stamens and stigma. It is prevented from returning by inverted hairs in the tube. It is detained in the tube till the pollen is fully matured, and then the hairs collapse so as to permit its escape. It carries with it pollen grains. It then visits a flower where the stigma is matured, and which presents the open

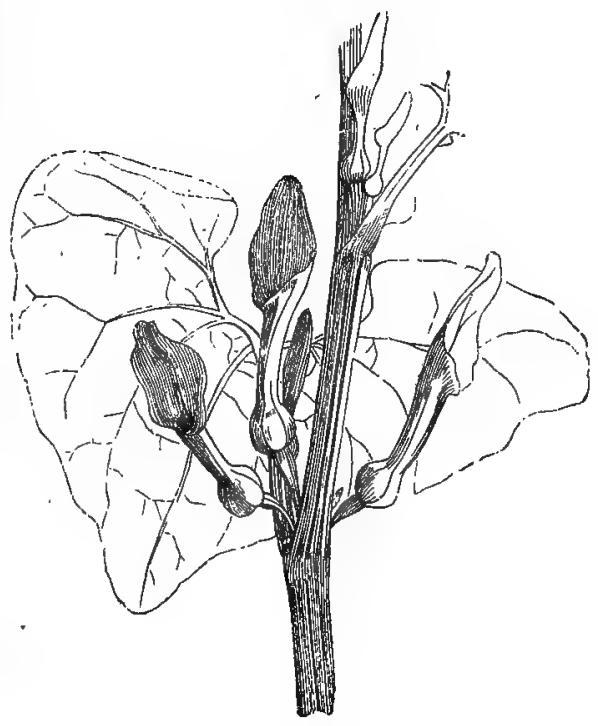

Fig. 515 . mouth of the tube in an erect condition, and on reaching the cavity

Fig. 515. Flowering stalk of Common Birthwort (Aristolochia Clematitis). Fertilisation is effected by insects. 
at the bottom of the tube, fertilises the pistil with the pollen which it has carried with it from another flower. This plant is protogynous, the stigma being matured before the stamens. When the flower is duly fertilised it sinks down, no longer presenting a tempting orifice for the entrance of insects. If no insect visits the chamber, then the stigma passes its maturity before the pollen of its own flower is ripened, and no fertilisation takes place.

Orchids with very long nectaries, such as Anacamptis, Gymnadenia, and Platanthera, are habitually fertilised by Lepidoptera, while those with only moderately long nectaries are fertilised by bees and Diptera. The length of the nectary is correlated with that of the proboscis of the insect which visits the plant. Orchis Morio has been seen fertilised by the hive-bee (Apis mellifica), to sorne of which 10 or 16 pollen-masses were attached; by Bombus muscorum, with several pollinia attached to the bare surface close above the mandibles; by Eucera longicornis, with 11 pollinia attached to the head, and by Osmia rufa. Empis livida has been seen fertilising Orchis maculata.

In Listera (fig. 317, p. 205) the viscid mass of the rostellum bursts with force, and then allows the pollinia to escape. The nectar in some species of Orchids is secreted between the outer and inner membrane of the nectary, and bees puncture the inner lining of the nectary and suck the fluid contained between the coats. In some Orchids, as in Neotinea intacta, there is evident self-fertilisation, although there is also provision for fertilisation by insects. So also in Ophrys apifera, Gymnadenia, Platanthera, Epipactus, Cephalanthera, Neottia, Epidendrum, Dendrobium. In Disa grandiflora the weight of the pollen masses bends the caudicle. In this plant the posterior sepal secretes nectar. In Coryanthes, Gongora, Catasetum, Stanhopea, etc., the extraordinary crests and projections on the labellum are gnawed by insects, and while doing so they are sure to touch the viscid disk of the pollinia and remove them. The flowers of these plants exhibit remarkable animal forms, probably with the view of attracting insects. It has been remarked that in Orchids the forms of the perianth resemble those of the insects belonging to the native country of the plant. The flowers also secrete a large amount of saccharine matter, and are odoriferous; their pollen masses are very easily detached, and are very adhesive. All these circumstances seem to be connected with their mode of impregnation. In Asclepiadaceæ, which have also peculiar pollinia (fig. 386, p. 230), insects are attracted by the odour of the flowers (sometimes very fetid, as in Stapelia), as well as by saccharine matter.

Darwin states that bees always alight on the left wing petal (ala) of the scarlet kidney-bean, and in doing so depress it; and this acts on the tubular and spiral keel petal (carina), which causes the pistil to protrude. On the pistil there is a brush of hairs, and by the 
repeated movement of the keel petal the hairs brush the pollen beyond the anthers on to the stigmatic surface. He found, in many instances, that if the plants were protected from bees, the number of fertile seeds produced was much smaller than when the bees were freely admitted. In the common bean the bees alight on the wing petals (alæ), and cause the rectangularly-bent pistil and the pollen to protrude through the slit of the carina.

In Erica Tetralix each anther-cell adheres, just in the part where its opening is situated, to the corresponding part of the adjoining cell of the next placed anther in the circlet. Thus the pore of a cell, say the right cell of an anther, is, so to speak, closed by the pore of the left cell of the next adjoining enther, and so on all the way round. A very little power, however, dislocates the chain of anthers; a slight pressure on the antherine processes or spurs effects this. An insect accomplishes this easily, and thus its head becomes covered with pollen and applies it to the stigma of another flower.

Polygala is one of the flowers in which a provision is made for insect fertilising. "The corolla consists of five petals united into one piece and folded in the form of a two-lipped tube. The lower lip has a sort of cup-shaped appendage, with a beard of gland-like bodies; this lip opens in front by a narrow vertical slit. The filaments are united, and the stamens expand within the cup of the lower lip into a two-lobed membrane crowned by the anthers. The pistil has two stigmas, - one is placed at right angles to the upper side of the style and is perfect, the other is transformed into a spoon-shaped petaloid prolongation of the pistil reaching to the opening of the lower lip of the corolla, and dividing the interior of the flower into two chambers, in the lower of which are the stamens, which are thus separated from the true stigma. The entrance to the flower is closed by hairs pointing outwards and meeting in front, on the mouse-trap principle. A narrow passage is left open above the petaloid stigma. On each side of the interior of the tube of the corolla, above the style and just behind the true stigma, is a group of white hairs pointing down. the tube and meeting above the style. An insect lights on the beard, finds a narrow passage leading over the stigma into the upper chamber. It is prevented by hairs on the corolla from returning, and is obliged to crawl out through the lower chamber and over the stamens, and thus carries the pollen to other flowers. The calyx, at first tempting to insects, gradually assumes a green colour, and closes over the ripening seed-vessel." (Hart.)

In Scrophulariaceæ and Labiatæ (figs. 324, 325, p. 207) the axis of the flower is horizontal, and the stamens are approximated beneath the upper lip of the corolla. An insect in passing separates the anthers, and causes the pollen to fall from them, and thus transports it to a more advanced flower. In some Leguminosæ the 
insect touches the back of the keel, which throws itself hastily backward, and the insect receives a few grains of pollen, with which it impregnates a neighbouring flower. In Fumariaceæ the stamens and pistil are enclosed between two petals. At the base of the petals, which is prolonged into a spur, there is a quantity of nectar which attracts insects. To reach this an insect must pass between the two petals, the upper parts of which, being borne upon a sort of hinge, separate easily; then the insect is covered with pollen, which is applied to the stigma.

Hermann Miiller states that there are two forms of Euphrasia officinalis in which the mode of fertilisation is different. In the large form there is provision for insect fertilisation or cross-fertilisation; while in the smaller-flowered form there is regularly self-fertilisation. In Rhinanthus Crista-galli there are also two forms, one small and the other large. In the former there is self-fertilisation, while in the latter this is not the case, as the stigma so far overlaps the anther as to render self-fertilisation impossible.

Other animals, besides insects, are instrumental in distributing pollen. Humming-birds, when inserting their bills into the nectaries of plants in some countries, carry the pollen on their head feathers from one flower to another. They are said to act as pollen-distributors in the case of a species of Erythrina in Nicaragua. In Marcgraavia nepenthoides there are peduncular pitchers below the flowers containing a sweet liquid, attracting insectivorous birds which come and feed on their contents, and in so doing burst the anther and carry the pollen to other plants.

While the pollen is being elaborated, the stigma is also undergoing changes. It becomes enlarged, and secretes a viscid, usually saccharine, matter, ready to detain the pollen-grains when they are discharged. In Goldfussia anisophylla, and in species of Campanula, as C. media, C. Rapunculoides, C. Trachelium, C. rotundifolia, the style is covered with collecting hairs (fig. 516), which appear to aid in the application of the pollen. In the first-mentioned plant a remarkable curvation of the style takes place, so as to make the stigma come into contact with the hairs. In Campanula the style is at first slightly longer than the stamens, but it soon becomes twice their length, and during its elongation the hairs upon it brush the pollen-grains out of the anther-cases. The stigma consists of two branches, which are at first erect and closely applied to each other, but afterwards, by changes in the cells, become revolute. This completely developed state of the stigma does Fig. 516.

Fig. 516. Style of a species of Bellflower (Campanula), covered with hairs, which brush out the pollen from the anthers. 
discharged. The plant is dichogamous and requires the pollen of another flower to fertilise the pistil. In rare instances, as in the Sea-pink (Armeria maritima), the conducting tissue of the style at its lower part becomes elongated so as to pass into the ovary, and ultimately comes in contact with the ovule, when impregnation takes place (fig. 517).

The length of time during which the pollen retains its vitality, or power of effecting fertilisation, varies in different plants. According to Gærtner and others, the pollen of some species of Nicotiana retains its vitality only for forty-eight hours; pollen of various species of Datura, two days; pollen of Dianthus

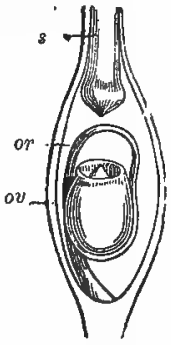

Fig. 517. Caryophyllus, three days; pollen of Lobelia splendens, eight or nine days; pollen of Cheiranthus Cheiri, fourteen days; pollen of Orchis abortiva, two months; pollen of Candollea, one year; pollen of Date Palm, one year or more. Michaux says that in some Palms, as Date and Chamærops humilis, the pollen may be applied successfully after having been carefully kept for eighteen years. The pollen retains its vitality longer when not removed from the anthers; and the finer it is, the more quickly it loses its fecundating property.

In most flowering plants the pollen is applied directly to the stigma, but in some cases when the plants are Gymnospermous, that is, have no proper ovarian covering, and no stigma, the pollen is applied directly to the ovule. The pollen then undergoes changes by the formation of tubes, through which the fovilla passes in order to come in contact with the minute cells in the ovule. The matter called fovilla covered by the intine consists of minute molecules, which often exhibit movements, to which the term moleoular has been applied.

\section{Embryogenic process in Gymnospermous Flowering Plants.}

In Gymnospermous plants, such as Coniferæ (Firs and Pines, fig. 518) and Cycadacer (fig. 519), impregnation is effected by direct contact between the pollen and the ovule. There is no true ovary bearing a stigma. Such is the view taken by many botanists. There are however others of equally high authority who do not adopt this opinion, and who look upon the so-called outer covering as not solely composed of the spermoderm, but as formed partly of it and partly of the ovarian coat. Some speak of the ovuliferous leaves in Cycads as being open carpels, and they also look

Fig. 517. Ovary, ov, nf Sea-pink (Armeria maritima), in which the ovule is suspended by a curved cord, cor, and the conducting tissue, $s$, of the style elongates in a downward direction. 
upon the bracts of Conifers in the same light. In these cases there is no evidence of the presence of a stigma. Gnetaceæ seem to form a link between Cycads and Conifers. They have an open ovary without

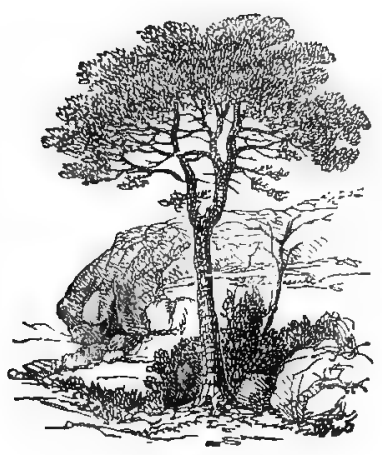

Fig. 518.

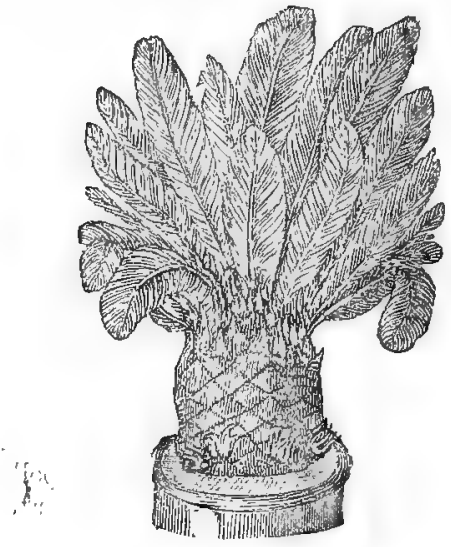

Fig. 519.

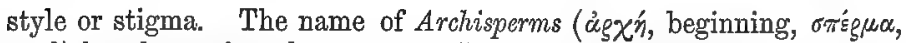
seed) has been given by some to Gymnospermous plants; while the term Metasperms ( $\mu \varepsilon \tau \dot{c}$, after) has been applied to Angiospermous

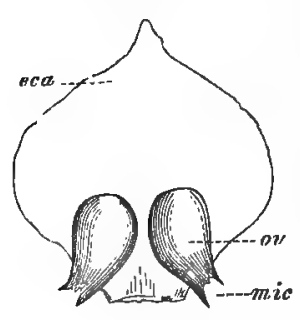

Fig. 520. plants. These views will be noticed when the natural orders are described. In treating of the embryogenic process it is probably not of much importance which view we adopt. The ovules of the so-called Gymnosperms (fig. 520 ov, and fig. 521) consist of a nucleus (fig. 521 a) covered by one or more integuments, and having a large micropyle (fig. $520 \mathrm{mic}$, and fig. $521 \mathrm{~m})$. In the delicate cellular nucleus (fig. $521 \mathrm{a}$ ) there is developed an embryosac, $b$, sometimes more than one, as in the Yew tribe. The pollen-grains enter the large micropyle and come into contact with the nucleus, and then send their tubes into its apex (fig. $522 \mathrm{c}$ ). This process sometimes requires several weeks or months. After this the embryo-sac (fig. 522 b) becomes gradually

Fig. 518. A Coniferous tree, the Stone-pine, which belongs to the Gymnospermous division of Phanerogarns, the seeds being Inaked, that is, not contained in an ovary with a stigma. The sceds are in cones covered by scales. Fig. 519. A Cycadaceous plant (Cycas revoluta), belonging also to the Gymnospermous division. The seeds in Cyeads are produced on the edge of abpormal leaves or on the lower side of scales of cones. Fig. 520. Female Hower of a Pine, consisting of a scale, eca, and two ovules, ov, attached to its base; mic, the foramen of the ovale. The orules are naked, not being contained in a true ovary. 
filled with cellular tissue or endosperm cells, and at the same time enlarges. This development of endosperm cells occupies frequently a long time, especially in the Abietineæ, which require two years to ripen their seeds. After the embryo-sac has become filled with cellular tissue, certain cells at the micropylar end of the sac enlarge and form the corpuscles of Brown, the secondary embryo-sacs of Mirbel and Spach (fig. 523 d). Each corpuscle is at first separated

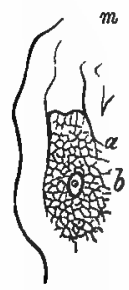

Fig. 521.

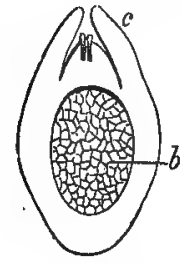

Fig. 522.

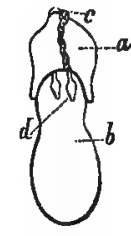

Fig. 523.

from the inner surface of the embryo-sac by a simple cell, which afterwards divides into four by the formation of two septa crossing each other; then a passage is formed between the inner angles of these cells leading to the corpuscle. In the cavity of each corpuscle free cells appear. After the corpuscles become evident, the pollen tubes resume their growth, pass through the tissue of the nucleus, and reach the outside of the embryo-sac, one over each corpusele. The tubes then perforate the membrane of the embryo-sac, reach the canal between the four cells, and come into contact with the corpuscle (fig. 523 d). A cell at the lower end of the corpuscle then enlarges, and forms the embryonal vesicle. A free cell in the vesicle divides into eight cells by vertical and transverse septa, and these together constitute a short cyclindrical cellular body (fig. 524), the pro-embryo, as it is called by Hofmeister. The four lower cells of this pro-embryo, by the elongation 'of the upper ones (fig. 525), are finally pushed

Fig. 521. Vertical section of the ovule of the Austrian Pine (Pinus austriaca), showing the nucleus, $a$, consisting of delicate cellular tissue containing deep in its substance an embryo-sac, $b$, formed before impregnation by the coalescence of a vertical series of a few cells. The micropyle, $m$; is very wide, 'and through it the pollen-grains come into contact with the summit of the nucleus, into the substance of which they send their tubes. Fig. 522. Vertical section' of the ovule of the Scoteh Fir,(Pinus sylvestris) in May of the second year, showing the enlarged embryo-sac, $b$ (full of endospermal cells), and pollen-tubes, $c$, penetrating the summit of the nucleus after the pollen has entered the large mieropyle of the ovule. Fig. 523. Vertical section of the embryo-sac, $b$, and of part of the nucleus, $u$, of the ovule of the Weymouth Pine (Pinus Strobus). At the micropylar end of the embryosac, two cells called corpuscles, $d$, have made their appearance. Each of these is at first separated from the inner surface of the micropylar end of the sac by a single cell, which afterwards divides into four, leaving a passage from the surface of the sac down to the corpuscle. The pollen-grain, $c$, on the summit of the nucleus, then sends down a tube which perforates the embryo-sac, and reaches the corpuscle through the intercellular canal. 
into the substance of the nucleus. The four elongated pro-embryonic cells (fig. 526, 1) now appear as isolated suspensors (fig. 526, 2), and the cell at the end of each suspensor becomes an embryo, $g$. There are thus four times as many rudimentary embryos as there are corpuscles. Usually one of these only becomes developed as the embryo of the ripe seed.

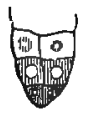

Fig. 524.

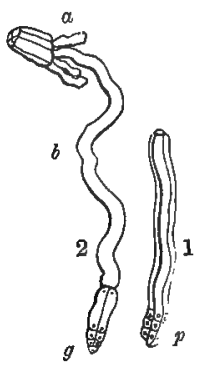

Fig. 526.

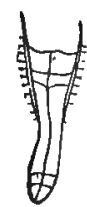

Fig. 525.

In many points this process resembles what takes place in Lycopods. The anthers of Gymnosperms may be considered as corresponding to the microsporangia, and the grains of pollen to the microspores. Certain cells in the anther may represent the prothallus, while a cell forming the pollen-tube may be the antheridium. The embryo-sac in Gymnosperms may be reckoned equivalent to the macrospores, and the endospermal cellular development may be analogous to the prothallus produced in the large spore of Selaginella (see page 278). The prothallus in some Ferns, as Ophioglossaceæ, is produced inside the spore, while in others it grows out from it in the form of a green expansion, bearing both antheridia and archegonia (fig. 507, p. 280).

\section{Embryogenic process in Angiospermous Flowering Plants.}

In the case of Angiospermous Phanerogams, the pollen-grains (fig. $527 \mathrm{gp}$ ) are discharged from the anther, and are applied to the stigmatic surface of the pistil (fig. $527 \mathrm{ps}$ ), either directly or by the

Fig. 524. Nucleated cells of what Hofmeister ealls the pro-embryo, in the ovule of the Weymouth Pine (Pinus Strobus). The cells are pushed downwards into the cellular tissue of the mucleus by the elongation of the upper cells, which finally form the suspensor. Fig. 525. The same pro-embryonic body in the ovule of the Weymouth Pine, with the lower cells pushed farther down by the elongation of the upper suspensory cells. Fig. 526. Suspensors taken from the ovule of the Weymouth Pine (Pinus Strobus). In. No. 1 the four suspensors are united. They form a cylinder composed of four elongated cells, and at the end, $p$, are seen some of the lower nucleated cells of the pro-embryo. In No. 2 the suspensors have separated, three of them, $a$, are cut off, and the remaining one, $b$, is connected with the embryo, $g$, at its extremity. 
agency of wind or insects. The viscid fluid secreted by the stigmatic cells $(p s)$ causes a rupture of the extine, and the intine passes out in the form of a tubular prolongation, which gradually elongates $(t p, t p)$ as it proceeds down the loose conducting tissue $(t c, t c)$ of the style till it reaches the ovule. The length attained by the pollen-tube is sometimes very great. In Cereus grandiflorus, Morren estimated that the tubes, when they reached the ovary, extended as far as 1150 times the diameter of the pollengrain ; in Crinum amabile, Hassall says that they reach 1875 times the diameter of the grain; in Cleome speciosa, 2719 times; in Oxyanthus speciosus, 4489 times; and in Colchicum autumnale, 9000 times. The length of time which the pollen-turbe takes to traverse the conducting tissues of the style in Angiosperms varies.

On reaching the ovule the pollentube enters the foramen, and finally comes into contact with the embryo-sac (fig. $528 \mathrm{e}$ ). In the interior of this

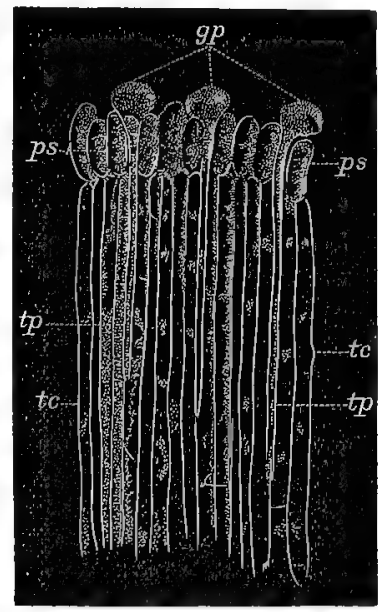

Fìg. 527 . sac one or more nucleated germ-vesicles are produced before impregnation in the midst of the endospermal cells and protoplasmic matter (fig. 530 e). In fig. 529 an anatropal ovule is represented with the raphe $r$, the opening in the primine and secundine $e x, e n$, the nucleus $n$, the embryo-sac es, and the pollen-tube $p t$, in contact with the germ-vesicle $e$.

After the contact of the pollen-tube, one of the embryonal vesicles becomes enlarged, and is then divided by septa into two, the upper division growing out in a filamentous form, constituting the suspensor (fig. $530 \mathrm{~s}, 531 \mathrm{~b}$ ), while the lower portion enlarges and divides repeatedly so as to form a cellular globule-the embryo (fig. $530 \mathrm{~s}$, 531 c). The parts of the embryo being finally differentiated into cotyledonary and radicular portions, as shown in fig. 532, 1-4.

Taking a comprehensive view of the whole subject, it may be said that the union of two kinds of cells appears to be necessary for fertilisation. In Cryptogamic plants this has been traced, particularly

Fig. 527. Portion of the stigna of Antirrhinum majus at the time of fecundation. ps, $p s$, Superficial cells forming the papilly. tc, tc, Deep elongated cylindrical cells forming the conducting tissue. $g p$, Grains of pollen attached to the surface of the stigma, the extine having been ruptured, and the intine protruded in the form of tubes, $t p$, $t p$, which pierce the interstices between the superficial stigmatic cells. 
in certain cases of conjugation; where the two cells come into contact, a tube is formed between them, and the contents of the one unite

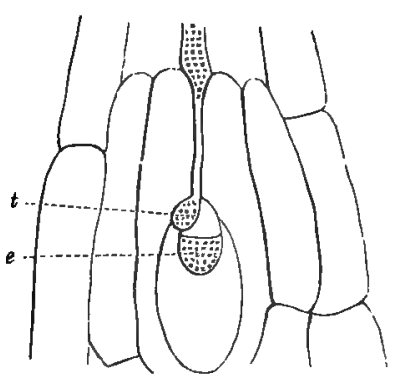

Fig. 528.

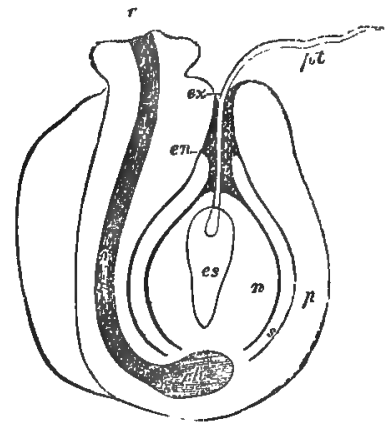

Fig. 529 .

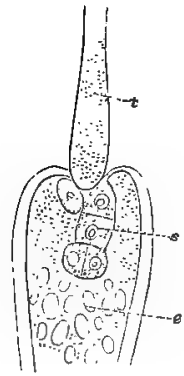

Fig. 530.

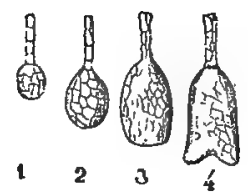

Fig. 532 ,

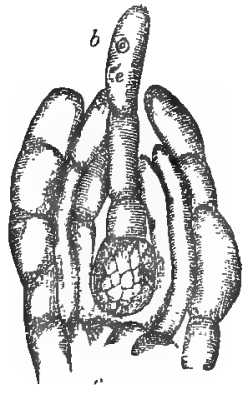

Fig. 531.

Fig. 528. Section of ovule of an Orchis (Orchis Morio), showing the pollen-tube passing through the endostome, and reaching the embryo-sac in the nucleus. The closed and enlarged end of the tube, $t$, is applied to the sac, in which a germ-vesicle had been previously Pormed. Transudation of fluids takes place, and the embryo, $e$, is developed at the lower end of the germinal or embryonal vesicle while the upper part of the vesicle elongates, and forms a confervoid suspensor. Fig. 529. Section of anatropal ovale. $r$, Raphe. ch, Chalaza. $p$, Primine. s, Secundine. ex, Exostome. en, Endostome. $n$, Nucleus. es, Embryo-sac. pt, Pollen-tube. s, The germ-cell which forms the embryo. Fig 530. Section of the ovule of CEnothera, showing the pollen-tabe, $t$, with its enlarged extremity applied to the end of the embryo-8ac, and introverting it slightly; one of the germinal vesicles in the sac has been impregnated, and has divided into two parts, the upper part forming a confervoid septate suspensor, $s$, and the lower dividing into four parts, which form a globular mass - the rudimentary embryo, surrounded by endospermal cells, $e$. Fig. 531. Ovule of Orchis mascula. a, Prinine. b, Secundine, o, Embryo. $e$, Confervoid filament which proceeds from the embryo towards the placenta. Fig. 532. The embryo in different stages of development. 1, Embryo in young state as a globular mass at the end of a suspensor. 2 and 3, Embryo more advanced. 4, Embryo showing the division into two cotyledons. 
with those of the other, giving rise to a germinating body. In Phanerogamic plants, also, there are two cells with different contents - the pollen-grain with its granular fovilla, and the ovule with its protoplasm. These are brought into connection by means of the pollen-tube, formed from the intine, which either enters the embryosac, or comes into contact with it, the union taking place either directly by its extremity, or indirectly by cellular prolongations from the conducting tissue, or from the ovule. By this means the formation of the embryo is determined, which commences as a cellular body or germinal vesicle, in the interior of which other cells are subsequently formed in a definite order of succession.

The Production of Hybrids.- If the pollen of one species is employed to fertilise the ovules of another, the seed will often produce plants intermediate between the two parents. These are termed hybrids, and are analogous to mules in the animal kingdom. As a general rule, hybrids can only be produced between plants which are very nearly allied, as between the different species of the same genus. Thus, different species of Heath, Fuchsia, Cereus, Rhododendron, and Azalea, readily inoculate each other, and produce intermediate forms. It is found, however, that many plants which seem to be nearly related do not hybridise. Thus, hybrids are not met with between the Apple and the Pear, between the Gooseberry and Currant, nor between the Raspberry and Strawberry. The ovules of Fuchsia coccinea, fertilised with the pollen of Fuchsia fulgens, produce plants having intermediate forms between these two species. Some of the seedling plants closely resemble the one parent, and some the other, but they all partake more or less of the characters of each. By the examination of the foliage, conclusions may be drawn as to what will be the character of the flower. Mr. Thwaites mentions a case in which a seed produced two plants extremely different in appearance and character, one partaking rather of the character of Fuchsia fulgens, and the other of Fuchsia coccinea. While hybrids are produced between two species, crosses are produced between two varieties.

In the case of hybridisation, there appears to be a mixture of matters derived from the pollen-grain and the ovule, just like the mixture of two endochromes in flowerless plants; and the nature of the hybrid depends on the preponderance of the one or other. Some have supposed that the pollen-grains require to be of the same form and dimensions in order to admit of artificial union taking place; but this is a mere conjecture. It is, however, requisite for successful hybridising, that the pollen should be in a state of full maturity, and the stigma perfect. Hybrids perform the same functions as their parents, but they do not perpetuate themselves by seed. They must be propagated by offsets or cuttings. If not absolutely sterile at first, 
they usually become so in the course of the second or third generation. Herbert mentions instances of hybrid Narcissi, from which he attempted in vain to obtain seed. The cause of this sterility has not been determined. Some have referred it to an alteration in the pollen. Hybrids may be fertilised, however, by the pollen taken from one of the parents, and then the offspring assumes more or less the characters of that parent.

Hybrids are rarely produced naturally, as the stigma is more likely to be affected by the pollen of plants of its own species than by that of other species. In diœcious plants, however, this is not the case, and hence the reason, probably, of the numerous co-called species of Willows. Hybrids are constantly produced artificially, with the view of obtaining choice flowers and fruits, the plants being propagated afterwards by cuttings. In this way many beautiful Roses, Azaleas, Rhododendrons, Pansies, Cactuses, Pelargoniums, Fuchsias, Calceolarias, Narcissuses, etc., have been obtained. By this process of inoculation, and carefully selecting the parents, gardeners are enabled to increase the size of the flowers, to improve their colour, to render tender plants hardy, and to heighten the flavour of fruits. Herbert thinks, from what he saw in Amaryllides, that in hybrids the flowers and organs of reproduction partake of the characters of the female parent, while the foliage and habit, or the organs of vegetation, resemble the male.

\section{6.-Fruit, or the Pistil arrived at Maturity.}

After fertilisation, various changes take place in the parts of the flower. Those more immediately concerned in the process, the anther and stigma, rapidly wither and decay, while the filaments and style often remain for some time; the floral envelopes also become dry, the petals fall, and the sepals are either deciduous, or remain persistent in an altered form; the ovary becomes enlarged, forming the pericarp ( $\pi \varepsilon g i$, around, and rog $\pi \sigma_{s}$, fruit); and the ovules are developed as the seeds containing the embryo-plant. The term fruit is strictly applied to the mature pistil or ovary, with the seeds in its interior. But it often includes other parts of the flower, such as the bracts and floral envelopes. Thus, the fruit of the Hazel and Oak consists of the ovary and bracts and calyz combined; that of the Apple, Pear, and Gooseberry, of the ovary and calyx; and that of the Pine-apple, of the ovaries and floral envelopes of several flowers combined. Fruits formed by the ovaries alone, as the Plum and the Grape, seem to be more liable to drop off and suffer from unfavourable weather, than those which have the calyx attached, as the Gooseberry, the Melon, and the Apple.

In general, the fruit is not ripened unless fertilisation has been 
effected; but cases occur in which the fruit swells, and becomes to all appearance perfect, while no seeds are produced. Thus, there are seedless Oranges, Grapes, and Pine-Apples. When the seeds are abortive, it is common to see the fruit wither and not come to maturity; but in the case of Bananas, Plantains, and Bread-fruit, the non-development of seeds seems to lead to a larger growth and a greater succulence of fruit.

In order to comprehend the structure of the fruit, it is of great importance to study that of the ovary in the young state. It is in this way only that the changes occurring in the progress of growth can be determined. 'The fruit, like the ovary, may be formed of a single carpel, or of several. It may have one cell or cavity, then being unilocular (unus, one, and loculus, box or cavity) ; or many, multilocular (multus, many), etc. The number and nature of the divisions depend on the number of carpels, and the extent to which their edges are folded inwards. The appearances presented by the ovary do not, however, always remain permanent in the fruit. Great changes are observed to take place, not merely as regards the increased size of the ovary, its softening and hardening, but also in its internal structure, owing to the suppression, enlargement, or union of parts. In this way the parts of the fruit often become unsymmetrical, that is, not equal to, or not a multiple of, the parts of the flower; and at times they are developed more in one -direction than another, so as to assume an irregular appearance. In the Ash (fig. 533) an ovary with two cells, each containing an ovule attached to a central placenta, is changed into a unilocular fruit with one seed; one ovule, $l$, having become abortive, and the other, $g$, gradually extending until the septum is pushed to one side, becoming united to the walls of the cell, and the placenta appearing to be parietal. In the Oak and Hazel, an ovary with three cells, and two ovules in each, changes into a one-celled fruit with one seed. Similar changes take place in the Horse-chestnut, in which the remains of the abortive ovules are often seen in the ripe fruit. In the

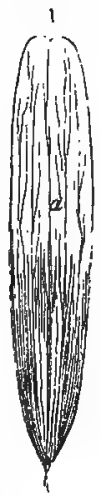

Fig. 533. Coco-nut, a trilocular and triovular ovary is changed into a one-celled, one-seeded fruit. This abortion may depend on the pressure caused by the development of certain ovules, or it may proceed from the influence of the pollen not being communicated to all the ovules. Again, by the growth of the placenta or the folding inwards of parts

Fig. 533. Samara or Samaroid fruit of Fraxinus oxyphylla. 1, Entire, with its wing, $u$. 2, Lower portion cut transversely, to show that it consists of two loculaments; one of which, $l$, is abortive, and is reduced to a very small cavity, while the other is much enlarged, and flled with a seed, $g$. 
of the ovary, divisions may take place in the fruit which did not exist in the ovary. In Pretrea zanzibarica a one-celled ovary is changed into a four-celled fruit by the extension of the placenta. In Cathartocarpus Fistula (fig. 429, p. 244) a one-celled ovary is changed into a fruit having each of its seeds in a separate cell, in consequence of spurious dissepiments being pro-

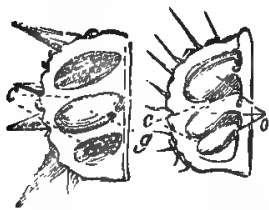

Fig. 534.

Fig. 535. duced in a horizontal manner, from the inner wall of the ovary after fertilisation. In Tribulus terrestris, each cell of the ovary (fig. 534) has slight projections, $c$, on its walls, interposed between the ovules, o, which, when the fruit is ripe, are seen to have formed distinct transverse divisions (fig. $535 \mathrm{c}$ ), or spurious dissepiments, separating the seeds, $g$.

In Astragalus, the folding of the dorsal suture inwards converts a onecelled ovary into a two-celled fruit; and in Oxytropis the folding of the ventral suture gives rise to a similar change in the fruit.

The development of cellular or pulpy matter frequently alters the appearance of the fruit, and renders it difficult to discover its formation. In the Strawberry, the axis becomes succulent, and bears the carpels on its convex surface; in the Rose there is a fleshy hollow torus or disk, which bears the carpels on its concare surface. In the Gooseberry, Grape, Guava, Tomato, and Pomegranate, the seeds nestle in pulp formed apparently by the placentas. In the Orange, the pulpy matter surrounding the seeds is formed by succulent cells, which are produced from the inner partitioned lining of the pericarp.

The pistil, in its simplest state, consists of a carpel or folded leaf, with ovules at its margin; and the same thing will be found in the fruit, where the pericarp, as in the Bean (fig. 536), represents the carpellary leaf, and the seeds correspond to the ovules. The pericarp consists usually of three layers; the external (fig. $536 \mathrm{e}$ ), or epicarp

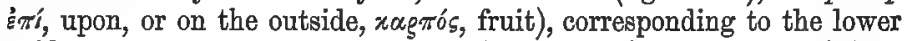
epidermis of the leaf; the middle (fig. $536 \mathrm{~m}$ ), or mesocarp ( $\mu$ śos, middle), representing the parenchyma of the leaf; and the internal (fig. $536 \mathrm{n}$ ), or endocarp ("zyסov, within), equivalent to the upper epidermis of the leaf, or the epithelium of the ovary. In some plants, as Bladder Senna (Colutea arborescens), the pericarp retains its leaflike appearance, but in most cases it becomes altered both in consistence and in colour. Sometimes the three parts become blended together, as in the Nut; at other times, as in the Peach, they remain separable. In the latter fruit, the epicarp is thickened by the addition

Fig. 534, Cell or loculament of the ovary of Tribulus terrestris, cut vertically, to show the commencement of the projections, $c$, from the paries, which are interposed between the ovales, 0 . Fig. 535. The same in a mature state, showing the transverse partitions, $c$, dividing the fruit into cavities, in one of which a seed, $g$, is left. 
of cells, and can be taken off in the form of what is called the skin; the mesocarp becomes much developed, forming the flesh or pulp, and hence has sometimes been called sarcocarp ( $\sigma a ́ g \xi$, flesh), while the endocarp becomes hardened by the production of woody cells, and forms the stone or putamen (putamen, a shell), immediately covering the kernel or the seed. The same arrangement is seen in the fruit of the Cherry, Apricot, and Plum. In these cases, the mesocarp is the part of the fruit which is eaten. In the Almond, on the other hand, the seed is used as food, while the shell or endocarp, with its leathery covering or mesocarp, and its greenish epicarp, are rejected. The pulpy matter found in the interior of fruits, such as the Gooseberry,

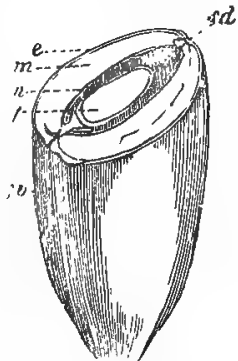

Fig. 536. Grape, and Cathartocarpus Fistula (fig. 429, p. 244), is formed from the placentas, and must not be confounded with the sarcocarp.

In the Date the epicarp is the outer brownish skin, the pulpy matter is the mesocarp or sarcocarp, and the thin papery-like lining is the endocarp covering the hard seed. In the Pear and Apple the outer skin or epicarp is the epidermal covering; the fleshy portion is the mesocarp, formed by the cellular torus; while the scaly layer, forming the walls of the seed-bearing cavities in the centre, is the endocarp. In the Medlar (fig. 568, p. 314) the endocarp becomes of a stony hardness. In the Melon the epicarp and endocarp are very thin, while the mesocarp forms the bulk of the fruit, varying in its texture and taste in the external and internal part. The rind of the Orange consists of epicarp and mesocarp, while the endocarp forms partitions in the interior, filled with pulpy cells.

While normally the divisions of the fruit ought to indicate the number of the carpels composing $\mathrm{it}$, and these carpels should each have three layers forming the walls, it is found that frequently the divisions of a multilocular fruit are atrophied or absorbed, in whole or in part, and the layers become confounded together, so that they appear to be one. Again, in fruits formed of several carpels, the endocarp and mesocarp are occasionally so much developed as to leave the epicarp only on the free dorsal face of the fruit, forming a covering which is wholly external, as in the Castor-oil plant (fig. 543, p. 304), Euphorbia, and Mallow (fig. 548, p. 305). Occasionally, the endocarp remains attached to the centre, forming cells, in which the seeds are placed, while the outer layer separates from it at certain

Fig. 536. Lower portion of the carpel or legume of the Bean, Faba sativa, cut transversely, to show the structure of the pericarp. e, Epicarp, or external epidermis, $m$, Mesocarp. $n$, Endocarp. $s d$, Dorsal suture. $s v$, Ventral suture. $g$, A seed situated at the upper part of the section, and cut also transversely. 
points, and leaves a row of cavities in the substance of the pericarp itself.

In some fruits the calyx is superior, or in other words above the pericarp, while in others it is closely applied to the ovary, but separable from it. Thus in the fruit of Mirabilis Jalapa (fig. 537, 1), when a section is made longitudinally (fig. 537, 2), the hardened calyx (perianth), $c c$, is distinct from the fruit, $f$, which is in this instance incorporated with the seed, but at once distinguished by its style, s. The same thing occurs in Spinach (Spinacia). Again, in the Yew (fig. 538), there is an external succulent covering, $i c$, formed by modified bracts, which here occupy the place of a pericarp, and surround the seed, $g$, which is naked, inasmuch as it is not contained in a true ovary with a stigma.

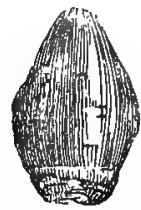

Fig, 537, 1.

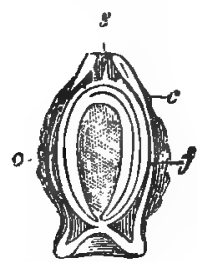

Fig. 537,2 .

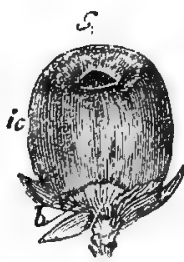

Fig. 538.

The part of the pericarp attached to the peduncle is called its base, and the part where the style or stigma existed is the apex. This latter is not always the mathematical apex. In Alchemilla, Fragaria, Labiatæ, and Boraginaceæ, it is at the base or side (figs. 434, 435, $436, \mathrm{pp} .246,247)$. The style sometimes remains in a hardened form, rendering the fruit apiculate; at other times it falls off, leaving only traces of its existence. The presence of the style or stigma serves to distinguish certain single-seeded pericarps from seeds.

As in the case of the carpel, so in the mature ovary formed of it, the edges unite towards the axis, and constitute the ventral suture (fig. $539 \mathrm{sv}$ ), while the back, corresponding with the midrib, is the dorsal suture (fig. $539 \mathrm{sd}$ ). The inner suture in some fruits formed of a single carpel, as the Apricot and Bladder Senna, is marked by a distinct furrow or depression, consequent on the folding inwards of the carpellary edges; and occasionally the outer or dorsal suture is also

Fig. 537. Fruit of Mirabilis Jalspa. 1, Entire. 2, Cut longitudinally, to show its composition. $c c$, Lower part of perianth hardened, and forming an outer envelope. $f$, The true fruit, covered by the perianth. The integuments of the fruit are incorporated with those of the seed, which has been also ent. The fruit is distinguished by the remains of the style, $s$, at the apiculus or summit. Fig. 538. Fruit of Tasus baccata, the Yew, b, Imbricated bracts at its base. ic, Fleshy envelope taking the place of the pericarp. This envelope covers the seed, $g$, partially, leaving its apex naked. 
thus rendered distinctly visible. When the fruit consists of several mature carpels, all meeting in the centre; and united together, then the dorsal suture is also visible externally; but in cases where the placentation is either parietal or free central, the edges of the separate carpels, being near the surface, may present also externally the marks of the ventral sutures.

Where the sutures are formed, there are usually two bundles of fibro-vascular tissue (fig. 539), one on each edge. The edges of the sutures are often so intimately united as not to give way when the fruit is ripe. In this case it is called indehiscent

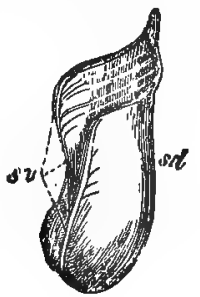

Fig. 539 . (in, used in the sense of not, and dehisco, I open), as in the Acorn and Nut; at other times the fruit opens between the two vascular bundles,

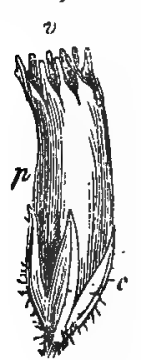

g. 540 . either at the ventral or dorsal suture, or at both, so as to allow the seeds to escape, and then it is dehiscent (dehisco, I open). By this dehiscence the pericarp becomes divided into different pieces, which are denominated valves, the fruit being univalvular, bivalvular, or multivalvular, etc., according as there are one, two, or many valves. These valves separate either completely or partially. In the latter case, the divisions may open in the form of teeth at the apex of the fruit, the dehiscence being apicilar, as in Caryophyllaceæ (fig. $540 v$ ), or as partial slits of the ventral suture, when the carpels are only free at the apex, as in Saxifrages.

Indeniscent Fruits are either dry, as the Nut, or fleshy, as the Cherry and Apple. They may be formed of one or several carpels; and in the former case they usually contain only a single seed, which may become so incorporated with the pericarp as to appear to be naked. Such fruits are called pseudospermous ( $\psi \varepsilon v \delta \eta^{\prime} s$, false, and $\sigma \pi$ '́gpa, seed), or false-seeded, and are well seen in the grain of Wheat. In such cases the presence of the style or stigma determines their true nature.

DEHISCENT FrUITS, when composed of single carpels, may open by the ventral suture only, as in the follicles of Pæony, Hellebore (fig. 539), and Calthea; by the dorsal suture only, as in Magnolias and some Proteacer; or by both together, as in the legume of the Pea and Bean; in which cases the dehiscence is called sutural. When composed of several united carpels, the valves may separate through

Fig. 539. A single carpel of Helleborus fotidus after dehiscence. $s d$, Dorsal suture. $s v$, Ventral suture. The carpel, when mature, opens on the ventral suture, and forms the fruit denominated a follicle. Fig. 540. Capsule or dry seed-vessel of Cerastium triviale after dehiscence. c, Persistent calyx. $p$, Perioarp dividing at the apex, $v$, into ten teeth, which indicate the summits of as many valves united below. 
the dissepiments, so that the fruit will be resolved into its original carpels, as in Rhododendron, Colchicum, etc. This dehiscence, in consequence of taking place through the lamellæ of the septum, is called septicidal (septum and coedo, I cut) (figs. 541, 542). The valves

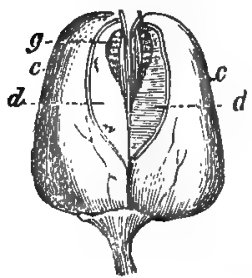

Fig. 541 .

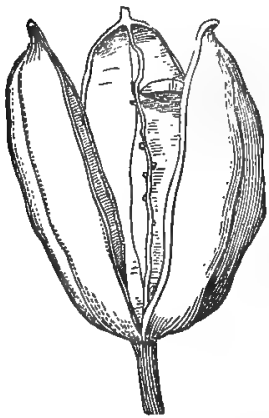

Fig. 544.

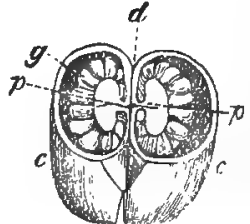

Fig. 542 .

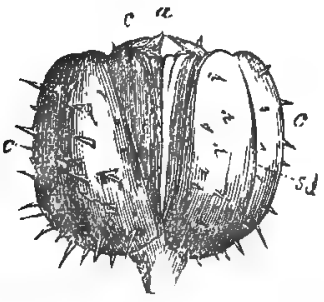

Fig. 543.

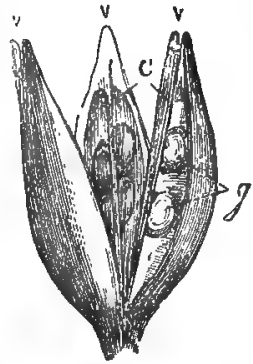

Fig. 545 .

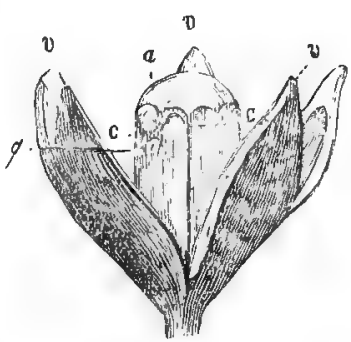

Fig. 646 .

may separate from their commissure, or central line of union, carrying the placentas with them, or they may leave the latter in the centre, so as to form with the axis a column of a cylindrical, conical, or prismatic shape, which has received the designation of columella (fig.

Fig. 541. Capsule of Digitalis purpurea at the moment of dehiscence, when the two cavities, $c c$, separate by division of the septum, $a d$, so as to have"the appearance of distinct carpels. At the apex are seen the seeds, $g$. Fig. 542. Inferior portion of the same capsule cut transversely, to show the formation of the septum, formed by the two inner faces of the carpels, $c c . \quad p p$, Placentaries reflected and projecting into the interior of the cavities. g, Seeds. Fig. 543. Capsule (tricoccous regma) of Ricinus communis, Castor-oil plant, at the moment of dehiscence. The three carpels or cocci, c.c c, are separated from. the axis, $a$, by which they were at first united (see fig. 549), and which remains in a columnar form. These cocei begin to open by their dorsal suture, sd. Fig. 544. Capsule of Iris opening by loculicidal dehiscence. Fig. 545. Capsule of Hibiscus esculentus, showing loculicidal dehiscence. $v v v$, Valves of the seed-vessel. $c$, Septum or partition. $g$, Seeds. Fig. 548. Capoule of Cedrela angustifolia, the valves of which, $v v v$, separate fron the septa, $c c$, by septifragal dehiscence. The separation takes place from above downwards, in such a manner that the axis, $a$, remains in the centre, with five projecting angles, corresponding to the septa. $g$, The seeds contained in the loculaments. 
543 c). The union between the edges of the carpels may be persistent, and they may dehisce by the dorsal suture, or through the back of the loculaments, as in the Lily and Iris (fig. 544). In' this case the valves are formed by the halves of the cells, and the septa either remain united to the axis, or they separate from it, carrying the placentas with them (fig. 545), or leaving them in the centre. This dehiscence is loculicidal (loculus, cell, and coedo, I cut). Sometimes the fruit opens by the dorsal suture, and at the same time the valves or walls of the ovaries separate from the septa (fig. 546), leaving them attached to the centre, as in Thorn Apple (Datura Stramonium). This is called septifragal dehiscence (septum and frango, I break), and may be looked upon as a modification of the loculicidal. The separation of the valves takes place either from above downwards (fig. 546), or from below upwards (fig. 547).

Sometimes the axis is prolonged as far as the base of the styles, as in the Mallow (figs. 548; 417, p. 239), and Castor-oil plant (fig. 549),

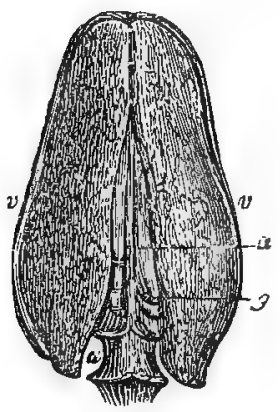

Fig. 547.

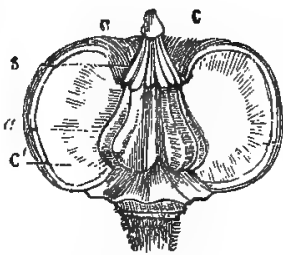

Fig. 548.

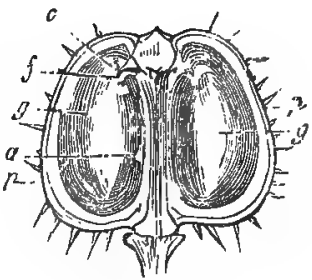

Fig. 549 .

the carpels being united to it by their faces, and separating from it without opening. In the Umbelliferæ (fig. 550) the two carpels separate from the lower part of the axis, and remain attached to a prolongation of it, called a carpophore (xagrós, fruit, and фoǵs, I bear), or -podocarp ( $\pi$ ous, foot, and xagrós, fruit), which splits into two

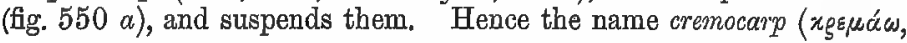

Fig. 547. Capsule of Swietenia Mahagoni, opening by valves from below upwards. The letters have the same signification as in fig. 546. Fig. 548. Fruit of Malva rotundifolia, with half the carpels composing it removed, to show the axis, $a$, to which they are attached. This axis exds at the point where the style, $s$, is produced. $c c$, The carpels, which are left attached to the axis, around which they are arranged in a verticillate manner. The lateral surface of the two carpels in front, $c^{\prime}$, is exposed. Fig. 549. Tricoccous capsule of Ricinus communis, Castor-oil plant, cut vertically, to show the axis, $a$, prolonged between the carpels, and terminating by small cords or funieuli, $f$, which project into the loculaments, and are attached to seeds. $g g$, Seeds exposed, each surmounted by a fleshy caruncula, $c$. $p p$, Pericarp. 
I suspend or hang), applied to this fruit. By some authors the term schizocarp ( $\sigma \chi i \zeta \omega, I$ split) is applied to such dry fruits consisting of one or

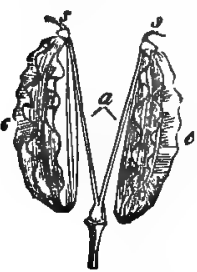

Fig. 550 . more; one-seeded or few-seeded, indehiscent carpels. In Geraniacex the axis is prolonged beyond the carpels, forming a carpophore, to which the styles are attached, and the pericarps separate from below upwards, before dehiscing by their ventral suture (fig. 551). Carpels of this kind are called cocci (xóxxos, kernel), and the fruit is said to be tricoccous, etc., according to the number of separate carpels. In the case of many Euphorbiaceæ, as Hura crepitans, the coeci separate with great force and elasticity, the cells being called dissilient (dissitio, I burst asunder).

In the Siliqua, or fruit of, Cruciferæ, as Wallflower (fig. 552), the valves separate from the base of the fruit, leaving a central replum, or

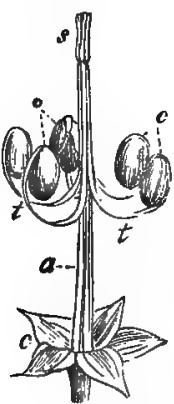

Fig, 551 .

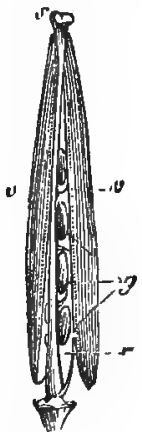

Fig, 552.

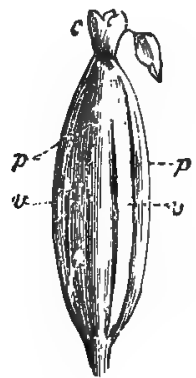

Fig, 553 .

frame, $r$. The replum is considered as being formed by parietal placentas, which remain attached to the fibro-vascular line of the suture, the valves giving way on either side of the suture. In Orchidaceæ (fig. 553) the pericarp, when ripe, separates into three valves,

Fig. 550. Fruit or cremocarp of Prangos uloptera, an umbelliferous plant. Fruit sometimes called sehizocarp. The carpels, mericarps, or achænia, $c c$, separate from the axis, $a$, and are each suspended by a carpophore. $s s$, Persistent styles with swollen bases, formed by an epigynous disk. Fig. 551. Fruit or mature carpel of Geranium sanguineum, c, Persistent calyx. a, Axis prolonged as a beak. $t t$, the styles at first united to the beak, and afterwards separating from below upwards, along with the carpels, 0 o, which dehisce by their ventral suture. s, Stigmas. The fruit is sometimes called gynobasic. Fig. 652. Siliqua of Cheiranthus Cheiri, Wallfower, dehiscing by two valves, $v v$, which separate from a frame or replum, $r$. $g$, Seeds arranged on either margin. 3 , Two-lobed stigma. Fig. 553. Capsule of Orchis maculata at the period of dehiscence. $c$, Remains of the perianth crowning the fruit, $v v$, Segments of the pericarp which are detached in the form of valves. $p p$, Arched repla or placentas which remain persistent, and bear the seeds. 
by giving way only on the margins within the sutures, where the placentas are united; and when the valves fall off, the placentas are left in the form of three arched repla, or frames, to which the seeds are attached. In the case of a free central placenta, when the valves separate, it is sometimes difficult to tell whether the dehiscence is septicidal or loculicidal, inasmuch as there are no dissepiments, and the placentas and seeds form a column in the axis. Their number, as well as their alternation or opposition, as compared with the sepals, will aid in determining whether the valves are the entire carpellary leaves, as in septicidal dehiscence, or only halves united, as in loculicidal dehiscence. In some instances, as in Linum catharticum, the fruit opens

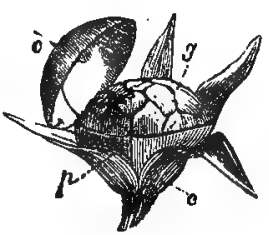

Fig. 554.

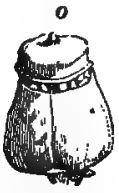

Fig. 555.

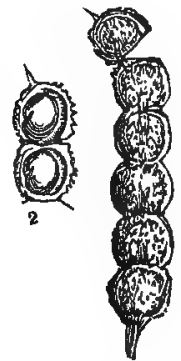

Fig. 556. first by loculicidal dehiscence, and afterwards the carpels separate in a septicidal manner.

Another mode in which fruits open is transversely, the dehiscence in this case being called circumscissile (circum, around, and scindo, I cut). In such cases, the fruit or seed-ressel may be supposed to be formed by a number of articulated leaves like those of the Orange, the division taking place where the laminæ join the petioles. In this dehiscence the upper part of the united valves falls off in the form of a lid or operculum, as in Anagallis (fig. 554), and in Henbane (Hyoscyamus), (fig. 555), and hence the fruit is often denominated operculate (operculum, a lid). In some instances the axis seems to be prolonged in the form of a hollow cup, and the valves appear as leaves united to it by articulation, similar to what occurs in the calyx of Eschscholtzia. In Lecythis (the Monkey-pot) and in Couratari the calyx is superiot, and the lid is formed at the place where the calyx is attached.

Transverse divisions take place occasionally in fruits formed by a single carpel, as in the pods of some leguminous plants. Examples

Fig. 554. Pyxidium or eapsule of Anagallis arvensis, opening by circumscissile dehiscence. $c$, Persistent calyx. $p$, Pericarp divided into two, the upper part, 0 , separating in the form of a lid or operculum. On the capsule are seen three lines passing from the base to the apex, and marking the true valves. $g$, Deeds forming a globular mass round a central placenta. Fig. 555. Operculate capsule or pyxidium of Hyoscyamus niger, Henbane. o, Opereulum or lid separating and allowing the seeds to appear. Fig. 556. Lomentaceous legume or lomentum (transverse schizocarp) of Hedysarum coronarium. 1, Entire, the upper division being nearly detached from the rest. 2, Two of the joints cut longitudinally to show the spurious loculaments, each containing a seed. This seed-vessel divides into separate single-seeded portions by solubility. 
are seen in Ornithopus, Hedysarum (fig. 556), Entada, Coronilla, and the Gum-arabic plant (Acacia arabica), in which each seed is contained in a separate division, the partitions being formed by the folding in of the sides of the pericarp, and distinct separations taking place at these partitions by what has been termed solubility. The name schizocarp has been also applied to such fruits. In Cathartocarpus Fistula transverse partitions occur without exhibiting evident separations of the parts externally. Some look upon these pods as formed by pinnate leaves folded, and the divisions as indicating the points where the different pairs of pinnæ are united. Dehiscence may also be effected by partial openings in the pericarp, called pores, which are situated either at the

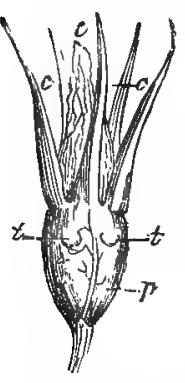

Fig. 557 .

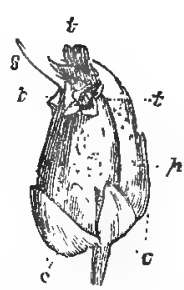

F'ig. 558. apex; base, or side. In the Poppy (fig. 444, p. 249 ) the opening takes place by numerous pores under the peltate processes bearing the stigmas. In Campanulas there are irregular openings towards the middle or base (fig. $557 t$ ), which pierce the pericarp. In Frogsmouth or Snapdragon (fig. 558) the pericarp gives way at certain fixed points, forming two or three orifices, one of which corresponds to the upper carpel, and the other to the lower. These orifices have a ragged appearance at the margins, which has given rise to the name rupturing, as applied to this mode of dehiscence.

CARPologY. - Much has been done of late in the study of car-

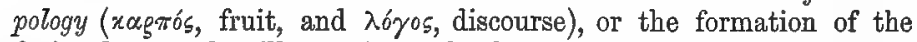
fruit; but much still remains to be done ere the terminology of this department is complete. Many classifications of fruits have been given, but they are confessedly imperfect, and unfortunately much confusion has arisen in consequence of the same names having been applied to different kinds of fruit. In many cases, therefore, it is necessary to give a description of a fruit in place of using any single term. There are, however, some names in general use, and others which have been carefully defined, to which it is necessary to direct attention.

Fruits may be formed by one flower, or they may be the pro-

Fig. 557. Capsule of Campanula persicifolia, opening by holes or pores, $t t$, above the middle. $c$, Persistent calyx, separating above the pericarp, $p$, into five acute segments, in the midst of which is seen the withered and plaited corolla, in the form of induviæ, $e$. The holes perforate the walls of the pericarp. Fig. 558. Capsule of Antirchinum majus, Frogsmouth, after dehiscence. $c c$, Persistent calyz. $p$, Pericarp perforated near the summit by three holes, $t t$, two of which correspond to one of the loculaments, and one to the other. The apex of the capsole is acuminated by the remains of the persistent style, $x$. 
duct of several flowers combined. In the former case they are

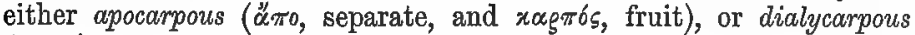

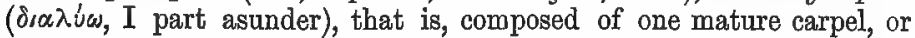
of several separate free carpels; or syncarpous (oiv, together), that is, composed of several carpels, more or less completely united. These different kinds of fruits may be indehiscent (not opening), or dehiscent (opening). When the fruit is composed of the ovaries of several flowers united, it is usual to find the bracts and floral envelopes also joined with them, so as to form one mass; hence such fruits are

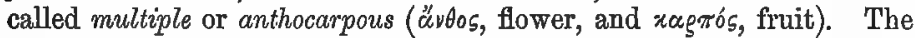
term simple is perhaps properly applied to fruits which are formed by the ovary of a single flower, whether they are composed of one or several carpels, and whether these carpels are separate or combined. Simple fruits are hence sometimes denominated Monogynoecial ( $\mu$ óvos, one, zuvì, pistil, and oixuv, habitation), as being formed by one gynoecium; while multiple fruits are called polygyncecial ( $\pi 0 \lambda$ ú being formed by many gyncecia.

\section{Simple or Monogynocial Fruits which are the produce} of a Single Flower.

Apocarpous Fruits. - These fruits are formed out of one or several free carpels. They are either $d r y$ or succulent; the pericarp, in the former instance, remaining more or less foliaceous in its structure, and sometimes becoming incorporated with the seed; in the latter, becoming thick and fleshy, or pulpy. Some of these do not open when ripe, but fall entire, the pericarp either decaying, and thus allowing the seeds ultimately to escape, as is common in fleshy fruits, or remaining united to the seed, and being ruptured irregularly when the young plant begins to grow; such fruits are indehiscent. Other apocarpous fruits, when mature, open spontaneously to discharge the seeds, and are dehiscent.

INDEHISCENT APOCARPOUs Fridits, when formed of a single mature carpel, frequently contain only one seed, being thus monospermous ( $\mu$ óvos, one, and $\sigma \pi \varepsilon g \mu \alpha$, seed). In some instances there may have been only one ovule originally, in others two, one of which has become abortive.

The Achcenium ( $\alpha$, privative,

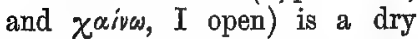
monospermous fruit, the pericarp of which is closely applied to the

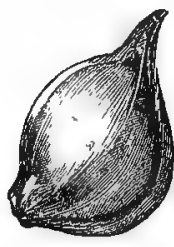

Fig., 559.

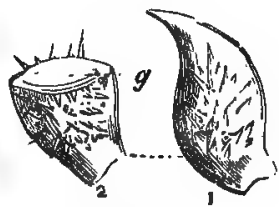

Fig. 560 .

Fig. 559. Achænium or indehiscent monospermous carpel from the pistil of a Ranunculus. Fig. 560. 1, Similar achæniun, with rough points on the pericarp, from the pistil of Ranunculus muricatus. 2, Achænium cut transversely to show the seed, $g$, not adherent to the parietes. 
seed, but separable from it (fig. 559). It may be solitary, forming a single fruit, as in the Cashew (fig. $248 a, p$. 173), where it is supported on a fleshy peduncle, $p$; or aggregate, as in Rununculus (fig. 560), where several achænia are placed on a common elevated receptacle. In the Strawberry the achænia (fig. 434, p. 246) are placed on a convex succulent receptacle. In the Rose they are supported on a concave receptacle (fig. 294, p. 196), and in the Fig they are placed inside the hollow peduncle or receptacle (fig. 267, p. 180), which ultimately forms what is commonly called the fruit. In Dorstenia (fig. 266, p. 180) the achenes are situated on a flat or slightly concave receptacle. In the Rose the aggregate achænia, with their covering, are sometimes collectively called Cynarrhodum ( $x \dot{v} \omega v$, a dog, and góóov, a rose, seen in the dog-rose). It will thus be remarked that what in common language are called the seeds of the Strawberry, Rose, and Fig, are in reality carpels, which. are distinguished from seeds by the presence of styles and stigmas. The styles occasionally remain attached to the achænia, in the form of feathery appendages, as in Clematis, where they are called caudate (cauda, a tail).

In Compositæ the fruit, which is sometimes called Cypsela ( $u \cup \psi^{\prime} \dot{\varepsilon} \lambda \eta$, a box), when ripe, is an achænium (fig. $301 t, \mathrm{p} .199$ ). The calyx in the

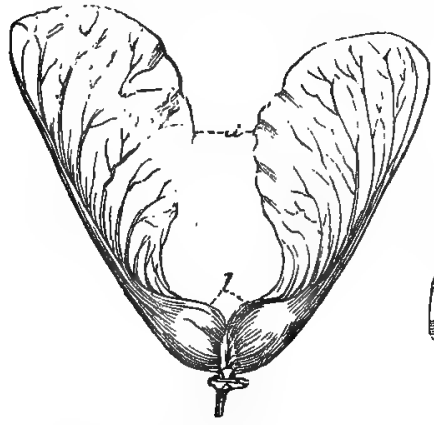

Fig. 561.

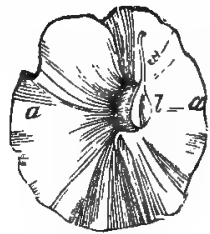

Fig. 562.

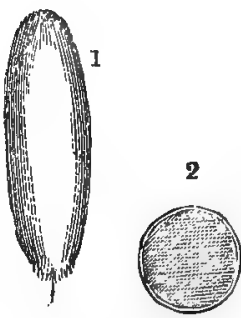

Fig. 563.

Compositæ sometimes becomes pappose, and remains attached to the fruit (fig. 303, p. 199), as in Dandelion and Thistles. A pappose calyx occurs also in some Dipsacaceæ (fig. 302, p. 199). When the pericarp is thin, and appears like a bladder surrounding the seed, the achænium becomes a Utricle, as in Amarantaceæ. This name is often

Fig. 561. Seed-vessel of Acer Pseudo-platanus (Sycamore, called in Scotland Plane), composed of two samaras or winged monospernous carpels united. $\dot{a}$, Upper part forming a dorsal wing. $l$, Lower portion corresponding to the loculaments. Fig. 562. Samara taken from the fruit of Hirea. $s$, Persistent style. $l$, Part corresponding to the loculament. a a, Marginal wing or ala. Fig. 563. Caryopsis of Secale cereale, Rye. 1, Entire. 2, Cut tramsversely to show the seed adherent to the parietes of the pericarp. 
given to fruits which differ from the achænium in being composed of more than one carpel. When the pericarp is extended in the form of a winged appendage, a samara (samera, seed of EIm) or samaroid achoenium is produced, as in the Ash (fig; 533, p. 299), common Sycamore (fig. 561), and Hiræa (fig. 562). In these cases there are usually two achenia united, one of which, however, as in Fraxinus oxyphylla (fig. 533), may be abortive. The Wing (fig. 561 a) is formed by the carpel, and is either dorsal, i.e. a prolongation from the median vein (fig. $561 \mathrm{a}$ ), or marginal, that is, formed by the lateral veins (fig. $562 a)$. It surrounds the fruit longitudinally in the Elm. When the pericarp becomes so incorporated with the seed as to be inseparable from it, as in grains of Wheat, Maize, Rye (fig. 563), and other

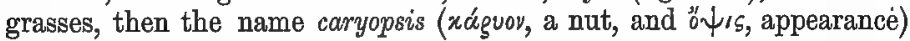
is given.

There are some fruits which consist of two or more achænia, at first - united together, but which separate when ripe. Of this nature is the fruit of the Tropæolum or Indian Cress, also that of Labiatæ and Boraginaceæ, which is formed of four achænia attached to the axis (fig. 436, p. 247), whence the common style appears to proceed. Some of these are occasionally abortive. In the ripe state the pericarp separates from the seed in these cases; and thus there is a transition from indehiscent achænia to single-seeded dehiscent pericarps. The cremocarp (ugsuciw, I hang), or the fruit of Umbelliferæ (fig. 550, p. 306), is composed of two achænia united by a commissure to a common axis or carpophore ( $x a g \pi t o s$, fruit, and $\varphi \circ g^{\prime} \varepsilon \omega$, I bear), from which they are suspended at maturity. It is sometimes denominated diachonium ( $\delta i s$, twice), from the union of two achænia, which in this instance receive the name of mericarps ( $\mu$ Égos, part), or

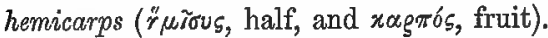

The Nut or Glans.-This is a one-celled fruit with a hardened pericarp, surrounded by bracts at the base, and, when mature, containing only one seed. In the young state the ovary contains two or more ovules, but only one comes to maturity. It is illustrated by the fruit of the Hazel and Chestnut, which are covered by leafy appendages, in the form of a huste, and by the Acorn, in which the leaves or bracts are united so as to form a cupula or cup (fig. 281, p. 191). The parts of the pericarp of the Nut are united so as to appear one. In Sagus, or the Sago Palm, the nut is covered by peculiar tesselated epicarp, giving the appearance of a cone.

The Drupe (drupce, unripe olives).-This is a succulent fruit covered by a pericarp, consisting of epicarp, mesocarp, and endocarp; and when mature containing a single seed. This term is applied to such fruits as the Cherry, Peach, Plum, Apricot, Mango, Walnut, Nutmeg, and Date. The endocarp is usually hard, forming the stone of the fruit, which encloses the kernel or seed. The mesocarp is 
generally pulpy and succulent, so as to be truly a sarcocarp (óag flesh), as in the Peach, but it is sometimes of a tough texture, as in the Almond, and at other times more or less fibrous. There is thus a transition from the Drupe to the Nut. Moreover, in the Almond, there are often two ovules formed, only one of which comes to perfection. In the Walnut, the endocarp, which is easily separable into two, forms prolongations which enter into the interior, and cause the brain-like divisions in the seed. It has been sometimes called Tryma. In the Raspberry and Bramble several drupes or drupels are aggregated so as to constitute an Etcerio (Eraígos, a companion). This name is also given by some to the aggregate achenes of the Strawberry and Rose.

DeHISCENT Apocarpous Fruits.-These open in various ways, and usually contain more than one seed, being either few-seeded,

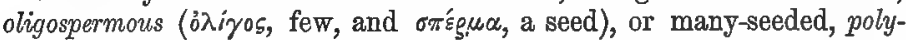
spermous ( $\pi 0 \lambda$ is, many).

Follicle (folliculus, a fittle bag).- This is a mature carpel, containing several seeds, and opening by the ventral suture (figs. 539, p. $303 ; 564$ ). It is rare to meet with a solitary follicle forming the fruit. There are usually several aggregated together, either in a circular manner on a shortened receptacle, as in Hellebore, Aconite, Delphinium, Crassulaceæ (fig. 282, p. 191), Butomus (fig. 415, p. 238), and Asclepiadaceæ; or in a spiral manner on an elongated receptacle, as in Magnolias, Banksias, and Liriodendron (fig.

Fig. 564. 337, p. 213). Occasionally, some of the follicles open by the dorsal suture, as in Magnolia grandiflora and Banksia.

The Legume or Pod (legumen, pulse) is a solitary, simple, mature carpel, dehiscing by the ventral and dorsal suture, and bearing seeds on the former. It characterises leguminous plants, and is seen in the Bean and Pea (fig. 565). In the Bladder-senna (fig. 566) it retains its leaf-like appearance, and forms an inflated legume. In some Leguminosæ, as Arachis and Cathartocarpus Fistula (fig. 429, p. 244), and the Tamarind, the fruit must be considered a legume, although it does not dehisce. The first of these plants produces its fruit underground, and is called earth-nut; the second has a partitioned legume; and both the second and third have pulpy matter surrounding the seeds. In place of opening at the sutures, some legumes are contracted at intervals so as to include each seed in a separate cell, and when ripe, the different divisions of the pod separate from each other. This constitutes the Lomentum (lomentum, bean-meal) or lomentaceous legume of Hedysarum coronarium (fig. 556, p. 307), Coronillas, Ornithopus, Entada, and some Acacias. In Medicago the legume is twisted like a snail (fig. 567), and in Cæsalpinia coriaria, or Divi-divi, it is ver-

Fig. 564. Follicle or dehiscent many-seeded carpel of Aquilegia vulgaris, Columbine. The follicle dehisces by the ventral suture only. 
miform or curved like a worm; in Carmichaelia the valves give way close to the suture, and separate from it, leaving a division.

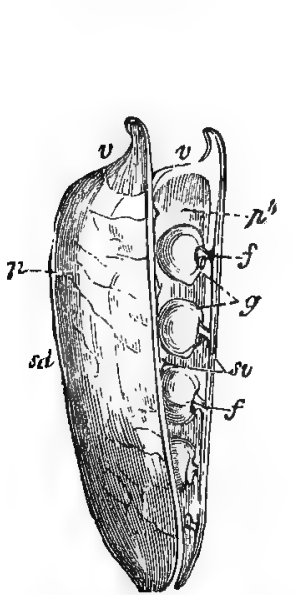

Fig. 565.

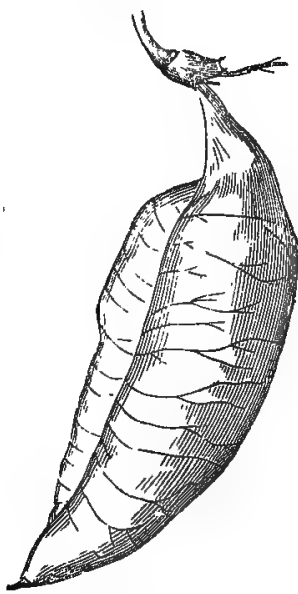

Fig. 566,

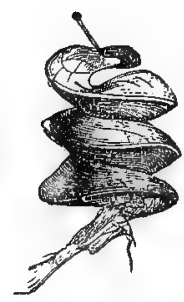

Fig. 567.

SYNCARPous Frutis are formed by several carpels, which are so united together as to appear one in their mature state. These fruits are either dry or succulent; in the former case being usually dehiscent, in the latter indehiscent.

INDEHISCENT SYNCARPOUS FrUITS.-The Berry (bacea) is a succulent fruit, in which the seeds are immersed in a pulpy mass, formed by the placentas. The name is usually given to such fruits as the Gooseberry and Currant, in which the ovary is inferior, and the placentas are parietal, the seeds being ultimately detached from the placenta, and lying loose in the pulp. Others have applied it also to those in which the ovary is superior, as in the Grape, Potato, and Ardisia, and the placentas are central or free central. The latter might be separated under the name $U_{v a}$ (grape). In general, the name of baccate or berried is applied to all pulpy fruits. In the Pomegranate there is a peculiar baccate many-celled inferior fruit, having a tough rind, enclosing two rows of carpels placed above

Fig. 565. Legume of Pisum sativum, common Pea, opened. It is formed by a single carpel, and dehisces by the ventral and dorsal suture. $v v$, Valves formed by the two parts of the pericarp. $\quad p$, The epicarp or external layer of the pericarp. $\quad p^{\prime}$, Endocarp or internal layer. Between these the mesocarp is situated. $g$, Seeds placed one over the other, attached to the placenta by short funiculi or cords, $f f$. The placenta forms a narrow line along the ventral suture, $s v$. sd, The dorsal suture corresponding to the midrib of the carpellary leap. Fig. 566. Legume of Bladder-senna (Coluted arborescens), showing an inflated, foliaceous pericarp. Fig. 567. Twisted or spiral legume of Medicago. 
each other. The seeds are immersed in pulp, and are attached irregularly to the parietes, base, and centre. The fruit has been called Balausta (balaustium, flower of pomegranate), and the tough rind is called malicorium (a name applied to it by Pliny).

The Pepo or Peponida ( $\pi^{\prime} \dot{\epsilon} \omega v$, a pumpkin) is illustrated by the fruit of the Gourd, Melon (fig. 430, p. 245), and other Cucurbitaceæ, where the callyx is superior, the rind is thick and fleshy, and there are three or more seed-bearing parietal placentas, either surrounding a central cavity, or sending prolongations inwards. The fruit of the Papaw resembles the Pepo, but the calyx is not superior.

The Hesperidium (golden fruit in the garden of Hesperides) is the name given to such fruits as the Orange, Lemon, and Shaddock, in which the epicarp and mesocarp form a separable rind, and the endocarp sends prolongations inwards, forming triangular divisions, in which pulpy cells are developed so as to surround the seeds which are attached to the inner angle. Both Pepo and Hesperidium may be considered as modifications of the Berry.

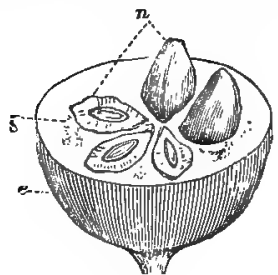

Fig. 568 .
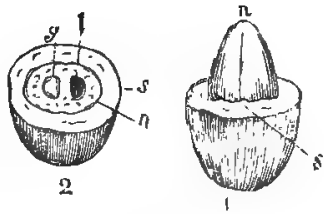

Fig. 569.

The Pome (pomum, an apple), seen in the Apple, Pear, Quince, Medlar, and Hawthorn, is a fleshy fruit with the calyx attached, and has an outer skin or epicarp, a fleshy mesocarp, and a scaly or horny endocarp, the core enclosing the seeds. Some look upon the so-called epicarp and mesocarp as formed by the prolonged receptacle or torus with a fleshy lining; while the endocarp represents the true carpels. In this view the endocarp might be regarded as consisting of a number of indehiscent follicles (usually five) surrounded by a pulpy torus. In the Medlar the endocarp (or what may be called the true pericarp) is of a

Fig. 568. Fruit of common Medlar (Mespilus germanica). Transverse section showing, $e$, epicarp; $s$, Sarcocarp; $n$, Endocarp, forming stony coverings of the seeds. The fruit has been called nucrlanium, and the hard central cells pyrenæ. In the Medlar, as well as in the Apple, Pear, and Quince, the fruit may be considered as composed of stony or parchment-like follicles, covered by a pulpy disk. Fig. 569. Fruit of Cornus mascula, common Cornel. 1, Transverse section detaching the upper half of the fleshy portion, s, so as to show the central kerne1, $n$. 2, Transverse section of the fruit through the central portion, $n$, showing that it consisted of two loculaments. $l$, One of the loculaments empty, the other containing a seed, $g$. 
stony hardness, while the outer pulpy covering is open at the summit. The stones of the Medlar are called pyrence ( $\pi \tilde{u} g \tilde{\eta}$, the stone of fruit); some apply the term nuculanium (nucula, a nut) to the Medlar. Taking this view of the Pome it may be said to resemble the fruit" of the Rose, with this difference, that the Rose produces achenes, and the Pome closed follicles. In Cornus mascula (fig. 569, 1, 2) there are two stony cells, $n$, surrounded by the fleshy epicarp and mesocarp, and as they are close together, and one is often abortive (fig. 569, 2, l), there is a direct transition to the Drupe.

Dehiscent Syncarpods Frorts. - The Capsule (capsula, a little chest). This name is applied generally to all dry syncarpous fruits, which open by valves or pores. The valvular capsule is observed in Digitalis (fig. 541, p. 304), Hibiscus esculentus (fig. 545, p. 304), Cedrela angustifolia (fig. 546, p. 304), Mahogany (fig. 547, p. 305), and Cerastium triviale (fig. 540, p. 303). The porose capsule is seen in the Poppy (fig. 444, p. 249), Antirrhinum majus (fig. 558, p. 308), and Campanula persicifolia (fig. 557, p. 308). Sometimes the capsule opens by a lid, or by circumscissile dehiscence, and it is then called a Pyxidium (pyxis, a box), as in Anagallis arvensis (fig. 554, p. 307), Henbane (fig. 555, p. 307), and Monkey-pot (Lecythis). The capsule assumes a screw-like form in Helicteres, and a star-like or stellate form in Illicium anisatum. In certain instances the cells of the capsule separate from each other, and open with elasticity to scatter the seeds. This kind of capsule is met with in the Sandbox tree (Hura crepitans), and other Euphorbiaceæ, where the cocci, containing - each a single seed, burst asunder with force (fig. 549, p. 305); and in Geraniaceæ, where the cocci, each containing, when mature, usually one seed, separate from the carpophore, and become curved upwards by their adberent styles (fig. 551, p. 306). In the former case, the fruit collectively has been called Regma (éñ $\gamma \mu \alpha$, a rupture).

The Siliqua (siliqua, a husk or pod) (fig. 552, p. 306) may be considered as a variety of the capsule, opening by two valves; these are detached from below upwards, close to the sutures, bearing thin parietal placentas, which are united together by a prolongation called a replum, or spurious dissepiment dividing the fruit into two. The seeds are attached on either side of the replum, either in one row or in two. When the fruit is long and narrow, it is called siliqua; when broad and short, it is called silicula. It occurs in cruciferous plants, as Wallflower, Cabbage, and Cress. The siliqua may be considered as formed of two carpels and two parietal placentas united together so as to form a two-celled seed-vessel. Some say that in its normal state it consists of four carpels, and that two of these are abortive. There are four bundles of vessels in it, one corresponding to each valve, which may be called valvular or pericarpial, and others running along the edge called placental. The replum consists of two lamellæ. 
It sometimes exhibits perforations, becoming fenestrate (fenestra, a window). At other times its central portion is absorbed, so that the fruit becomes one-celled.

\section{Multiple or Polygyncecial Fruits which are the produce of several Flowers united.}

It sometimes happens that the ovaries of two flowers unite so as to form a double fruit. This may be seen in many species of Honeysuckle. But the fruits which are now to be considered consist usually of the floral envelopes, as well as the ovaries of several flowers united into one, and are called Multiple, Confluent, or Polygynocial. The

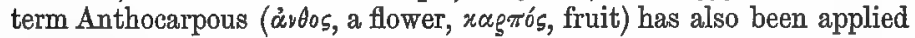
as indicating that the floral envelopes as well as the carpels are concerned in the formation of the fruit.

The Sorosis (owgós, a congeries or cluster) is a confluent fruit

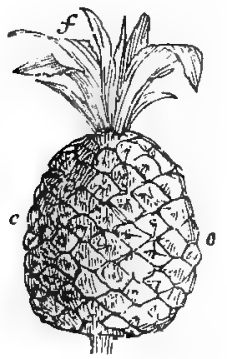

Fig. 570. formed by a united spike of flowers, which becomes succulent. The fruit of the Pine-apple (fig. 570 ) is composed of numerous ovaries, floral envelopes, and bracts, combined so as to form a succulent mass. The scales outside, $c c$, are the modified bracts and floral leaves, which, when the development of the fruit-bearing spike terminates, appear in the form of ordinary leaves, and constitute the crown, $f$. Other instances of a sorosis are the Breadfruit and Jack-fruit. Sometimes a fruit of this kind resembles that formed by a single flower, and a superficial observer might have some difficulty in marking the difference. Thus, the Strawberry, Raspberry, and Mulberry appear to be very like each other, but they differ totally in their structure. The Strawberry and Raspberry are each the produce of a single flower, the former being a succulent edible receptacle bearing achænia on its convex surface; the latter being a collection of drupes placed on a conical unpalatable receptacle; while the Mulberry (fig. 571) is a sorosis formed by numerous flowers united together, the calyces becoming succulent and investing the pericarps.

Syconus (oũxov, a fig) is a confluent anthocarpous fruit, in which the axis, or the extremity of the peduncle, is

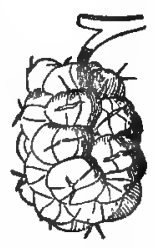

Fig. 571.

Fig. 570. Polygynocial or confluent fruit of Ananassa sativa, Pine-apple. Axis bearing numerous flowers, the ovaries of which are combined with the bracts, $c c$, to form the fruit. $f$, Crown of the Pine-apple, consisting of empty bracts or floral leaves. Fig. 571. Anthocarpous fruit of the Mulberry, forned by the union of several flowers. The floral envelopes become succulent, and cover the pistil. 
hollowed, so as to bear numerous flowers, all of which are united in one mass to form the fruit. The Fig (fig. 267, p. 180) is of this nature, and what are called its seeds are the achænia or monospermal seedvessels of the numerous flowers scattered through the pulpy hollowed axis. In Dorstenia (fig. 266, p. 180) the axis is less deeply hollowed, and of a barder texture, the fruit exhibiting often very anomalous forms.

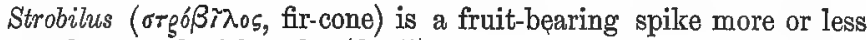
elongated, covered with scales (fig. 572), each of which represents a separate flower, and has often two seeds at its base. The scales may be considered as bracts, or as flattened carpellary leaves or branches, and the seeds are naked, as there is no true ovary present with its style or stigma. This fruit is seen in the cones of Firs, Spruces, Larches, and Cedars, which have received the name of Conifere, or cone-bearers, on this account. The scales of the strobilus are sometimes thick and closely united, so as to form a more or less angular and rounded mass, as in the Oypress (fig. 573); while in the Juniper they become fleshy, and are so incorporated as to form a globular fruit like a berry (fig.

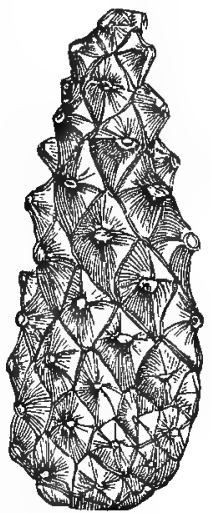

Fig. 572.

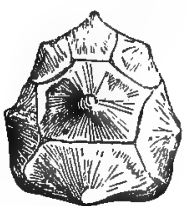

Fig. 573.

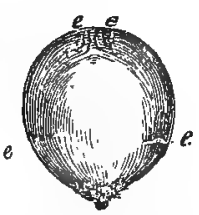

Fig. 574 . 574). The dry fruit of the Cypress, and the succulent fruit of the Juniper, have received the name of Galbulus (galbulus, nut of the cypress). The fruit of the Yew (Taxcus baccata) is regarded as a cone reduced to a single naked seed, covered by succulent scales, which unite to form a scarlet fleshy envelope. In the Hop the fruit is called also a strobilus, but in it the scales are thin and membranous, and the seeds are not naked but are contained in pericarps.

Fig. 572. Cone of Pinus sylvestris, Scotch Fir, consisting of numerous bracts or floral leaves, each of which covers two winged seeds. These seeds are called naked, in consequence of not being contained in an ovary, with a style or stigma. Fig. 573. Cone of Cupressus sempervirens, Cypress; one of the Gymnospermous or naked-seeded plants, like the Pine. Fig. 574. Succulent cone or Galbulus of Juniperus macrocarpa. e e e e, The different scales or bracts united so as to enclose the seeds. 


\section{Tabular Arrangement of Fruits.}

A. Simple or Monogynœcial Fruits formed by the gynocium of a single flower, and consisting of one or more Carpels either separate or combined; thus including Apocarpous, Aggregate, and Syncarpous Fruits.

\section{Indehiscent Pericarps.}

1. Monospermal - usually containing a single seed :

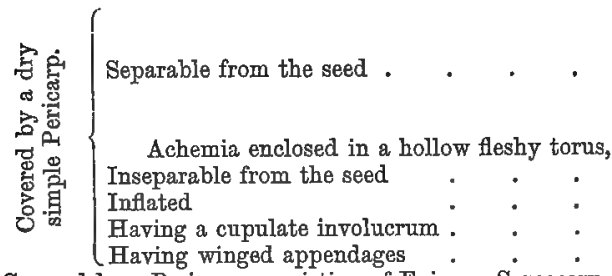

Covered by a Pericarp, consisting of Epicarp, Sarcocarp, and Endocarp.

Drupe, with a two-valved Endocarp, having divisions extending from its inner surface, Tryma (Walnut).

Aggregate Drupes, Etcerio (Raspberry).

2. Polyspermal-containing two or more seeds :

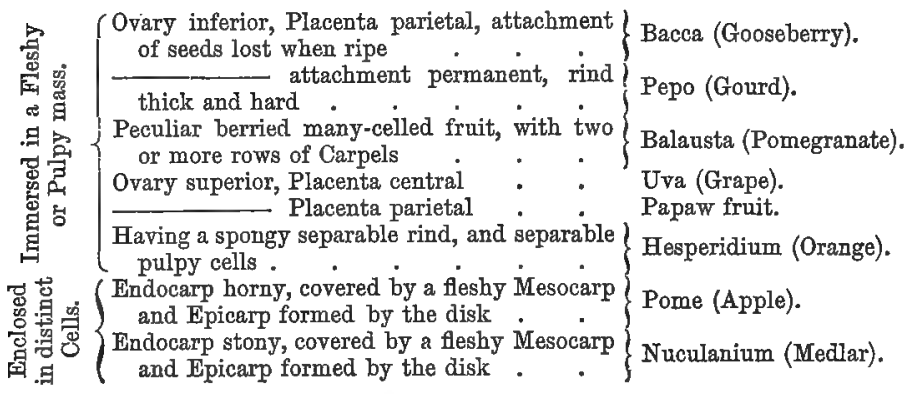

II. Dehiscent Pericarps.
Achanium (Lithospermum).

Mericarp and Cremocarp Cypsela in Compositæ. Cynarrhodum (Rose). Caryopsis (Grasses). Utricle (Chenopodium). Glans (Acorn). Samara (Sycamore). Drupe (Cherry). in Umbelliferæ, and 
B. Polygncecial or Multiple Fruits formed by the union of several Flowers, and consisting of Floral Envelopes, as well as Ovaries ; these are Anthocarpous.

Hollow Anthocarpous Fruit. -Syconus (Fig).

Convex Anthocarpous Fruit. $\left\{\begin{array}{c}\text { formed by Indurated or Scaly Catkin.-Stro- } \\ \text { bilus (Fir Cone and Hop). } \\ \text { formed by Succulent Spike.-Sorosis (Bread- } \\ \text { fruit, Mulberry, Pine-apple), Galbulus } \\ \text { (Juniper). }\end{array}\right.$

Professor Dickson gives the following classification of Fruits (mature pistils).

1. Capsule. Dry, dehiscent, allowing the seeds to escape-Capsule, Siliqua, Follicle, Legume, Regma, Diplotegia, Pyxidium, etc., of authors.

2. Schizocarp. Dry, breaking up into two or more, one- or few-seeded indehiscent pieces-Carcerulus (Malva, Tropuelum, Lamium, ete.), Samara (Acer), Lomentum, Cremocarp, of authors.

3. Achene. Dry, indehiscent, one- or few-seeded, not breaking up as the last . -Achene, Caryopsis, Samara (Fraxinus, etc.), Cypsela, Glans, of authors.

4. Berry. Indehiscent. Seeds imbedded in pulp. Outer portion of variable consistence-Uva, Hesperidium, Amphisarca, Pepo, Balausta, Bacca, of authors.

5. Drupe. Indehiscent. Seed or seeds inclosed by the distinctly defined and indurated endocarp. Outer portion of variable consistence (fleshy, fibrous, etc.) Drupe, Tryma, Pome, of authors.*

Where several distinct (apocarpous) fruits are produced from one flower; the term Etcerio designates a collection of Achenes, Drupes or Follicles (?), upon a more or less convex receptacle; and Cynarrhodum a collection of Achenes upon the inmer surface of a hollow succulent receptacle.

Where the fruits from an inflorescence are massed together the whole forms a "confluent fruit." (a) Syconus-Achenes, upon a flat or hollow, dry or succulent axis of inflorescence. (b) Sorosis-Achenes, Drupes, or Berries, with succulent perianths, or succulent bracts, or both, upon a more or less elongated axis of inflorescence;-Sorosis and Galbulus of authors. (c) Strobilus-Achenes, with dry bracts, and sometimes scale-like secondary peduncles, upon a more or less elongated axis of inflorescence.

\section{Maturation of the Pericarp.}

After fertilisation, the parts of the ovary begin to swell, the foramen of the ovule is more or less closed, the stigma becomes dry, and the style either withers and falls off, or remains attached as a hardened process or apiculum; while the embryo plant is developed in the ovule. Certain fruits, such as Oranges and Grapes, are sometimes produced without seeds. It does not appear, therefore, necessary for the production of fruit in all cases, that the process of fertilisation

* The above classification is founded upon the idea that the definition or description of a fruit, as such, should involve the structural modification undergone by the pistil in ripening, rather than the origin of the fruit from superior to inferior ovary, etc., which is to be understood or taken for granted, from the deseription of the immature pistil. From such a principle not being recognised, the terms indicating different fruits have been needlessly multiplied. 
should be complete. In speaking of seedless Oranges, Dr. Bullar states that the thinness of the rind of a St. Michael Orange, and its freedom from pips, depend on the age of the tree. The young trees, when in full vigour, bear fruit with a thick pulpy rind and abundance of seeds; but as the vigour of the plant declines, the peel becomes thinner, and the seeds gradually diminish in number, till they disappear altogether.

While the fruit enlarges, the sap is drawn towards it, and a great exhaustion of the juices of the plant takes place. In Annuals this exhaustion is such as to destroy the plants; but if they are prevented from bearing fruit, they may be made to live for two or more years. Perennials, by acquiring increased vigour, are able better to bear the demand made upon them during fruiting. If large and highlyflavoured fruit is desired, it is of importance to allow an accumulation of sap to take place before the plant flowers. The wood should be well ripened. When a very young plant is permitted to bear fruit, it seldom brings it to perfection. When a plant produces fruit in very large quantity, gardeners are in the habit of thinning it early, in order that there may be an increased supply of sap to that which remains. In this way, Peaches, Nectarines, and Apricots, are rendered larger and better flavoured. When the fruiting is checked for one season, there is an accumulation of nutritive matter, which has a beneficial effect on the subsequent crop.

The pericarp is at first of a green colour, and performs the same functions as the other green parts of plants, decomposing carbonic acid under the agency of light, and liberating oxygen. Saussure found by experiments that all fruits in a green state perform this process of deoxidation. As the pericarp advances to maturity, it either becomes dry or succulent. In the former case, it changes into a brown or a white colour, and has a quantity of ligneous matter deposited in its substance, so as to acquire sometimes great hardness, when it is incapable of performing any active process of vegetable life; in the latter it becomes fleshy in its texture, and assumes various bright tints, as red, yellow, etc. In fleshy fruits, however, there is frequently a deposition of ligneous cells in the endocarp, forming the stone of the fruit; and even in the substance of the pulpy matter or sarcocarp there are found isolated cells of a similar nature, as in some varieties of Pear, where they cause a peculiar grittiness. The contents of the cells near the circumference of succulent fruits are thickened by exhalation, and a process of endosmose goes on, by which the thinner contents of the inner cells pass outwards, and thus cause swelling of the fruit. As the fruit advances to maturity, however, this exhalation diminishes. In all pulpy fruits which are not green there are changes going on by which carbon is separated in combination with oxygen. 
Dry fruits may remain attached to the tree for some time before they are fully ripe, and ultimately separate by disarticulation. Occasionally, when the pericarp is thick, it separates in layers like the bark. Succulent fruits contain a large quantity of water, along with cellulose, lignine, sugar, gummy matter or dextrine, albumen, colouring matter, various organic acids, as citric, malic, and tartaric, combined with lime and alkaline substances, besides a pulpy gelatinous matter, containing pectose, the characteristic constituent of unripe fruits. This substance is quite insoluble in water, but during the ripening of the fruit it is converted by the vegetable acids into pectine, which is soluble in water, and exists in the pulp of fruits, as Apples, Pears, Gooseberries, Currants, Raspberries, Strawberries, etc. This substance undergoes a further change, being converted into pectic acid $\left(\mathrm{C}^{16} \mathrm{H}^{22} \mathrm{O}^{15}\right)$ and pectosic acid $\left(\mathrm{C}^{82} \mathrm{H}^{46} \mathrm{O}^{31}\right)$. These are easily soluble in boiling water and gelatinise on cooling ( $\pi \eta x \tau o ́ s$, congealed); hence their use in making preserves. Each kind of fruit is flavoured with a peculiar aromatic substance. Starch is rarely present in the pericarp of the fruit, although it occurs commonly in the seed. In Plantains, Bananas, and Bread-fruit, however, especially when seedless, there is a considerable quantity of starchy matter, giving rise to mealiness. Oily matters are also found in the cellular tissue of many fruits. Thus, a fixed oil occurs in the Olive, and essential oils in the Orange, Lemon, Lime, Rue, Dictamnus, etc.

During ripening much of the water disappears, while the cellulose, lignine, and the dextrine, are converted into sugar. Berard is of opinion that the changes in fruits are caused by the action of the oxygen of the air. Fremy found that fruits covered with varnish did not ripen. As the process of ripening becomes perfected the acids combine with alkalies, and thus the acidity of the fruit diminishes, while its sweetness increases. The formation of sugar is by some attributed to the action of organic acids on the vegetable constituents, gum, dextrine, and starch; others think that the cellulose and lignine are similarly changed by the action of acids. The sugar of fruits is grape or starch sugar, called also Glucose. Its formula is $\mathrm{C}^{6} \mathrm{H}^{14} \mathrm{O}^{7}$. In the Grape, when young, there is abundance of tartaric acid; but as the fruit advances to maturity this combines with potash, so as to diminish the acidity. Certain fruits owe their aperient qualities to the saline matter which they contain. In seasons when there is little sun, and a great abundance of moisture, succulent fruits become watery, and lose their flavour. The same thing frequently takes place in young trees with abundance of sap, and in cases where a large supply of water has been given artificially.

The following analysis of the Cherry in its unripe and ripe state, as given by Berard, exhibits generally the chemical composition of succulent fruits :- 


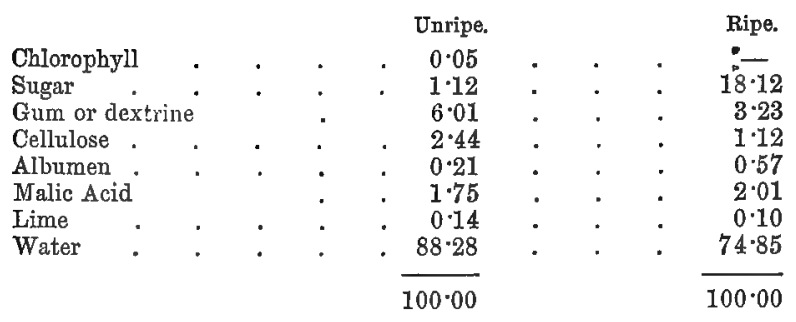

The following table shows the changes produced on the water, sugar, and cellulose, in 100 parts of unripe and ripe fruits :-

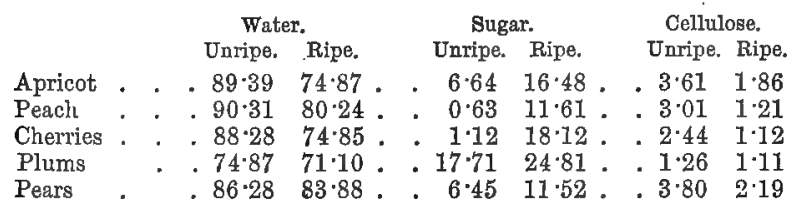

It is not easy in all cases to determine the exact time when the fruit is ripe. In dry fruits, the period immediately before dehiscence is considered as that of maturation; but, in pulpy fruits, there is much uncertainty. It is usual to say that edible fruits are ripe when their ingredients are in such a state of combination as to give the most agreeable flavour. This occurs at different periods in different fruits. After succulent fruits are ripe, in the ordinary sense, so as to be capable of being used for food, they undergo further changes, by the oxidation of their tissues, even after being separated from the plant. In some cases these changes improve the quality of the fruit, as in the case of the Medlar, the austerity of which is thus still further diminished. In the Pear, this process, called by Lindley bletting (from the French, blessi), renders it soft, but still fit for food; while in the Apple it causes a decay which acts injuriously on its qualities. By this process of oxidation the whole fruit is ultimately reduced to a putrefactive mass, which probably acts beneficially in promoting the germination of the seeds when the fruit drops on the ground.

The period of time required for ripening the fruit varies in different plants. Most plants ripen their fruit within a year from the time of the expansion of the flower. Some come to maturity in a few days, others require some months. Certain plants, as some Coniferæ, require more than a year, and in the Metrosideros the fruit remains attached to the branch for several years. The following is a general statement of the usual time required for the maturation of different linds of fruit :- 


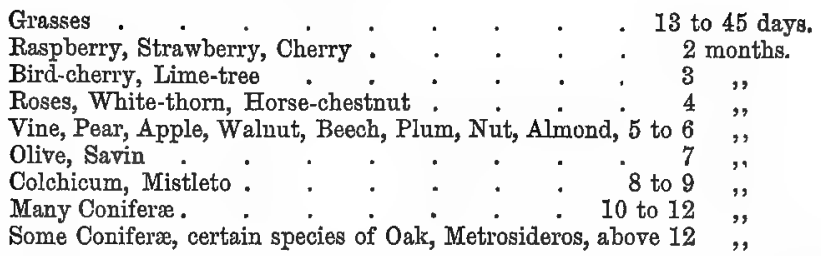

The ripening of fruit may be accelerated by the application of heat, by placing dark-coloured bricks below it, and by removing a ring of bark so as to lead to an accumulation of sap. It has been observed that plants subjected to a high temperature not unfrequently prove abortive, which seems to result from the over-stimulation causing the production of unisexual flowers alone. Trees are sometimes made to produce fruit by checking their roots when too luxuriant, and by preventing the excessive development of branches.

GRAFTING. -A very important benefit is producéd, both as regards the period of fruiting and the quality of the fruit, by the process of grafting. This is accomplished by taking a young twig or scion, called a graft, and causing it to unite to a vigorous stem or stock, thus enabling it to derive a larger supply of nutritive matter than it could otherwise obtain, and checking its vegetative powers. In place of a slip or cutting, a bud is sometimes taken. In order that grafting may be successfully performed, there must be an affinity between the graft and the stock as regards their sap, etc. It has often been supposed that any kinds of plants may be grafted together, and instances are mentioned by Virgil and Pliny, where different fruits are said to have been borne on the same stock. This was probably produced by what the French call greffe des charlatans, - cutting down a tree within a short distance of the ground, and then hollowing out the stump, and planting within it several young trees of different species; in a few years they grow up together so as to fill up the cavity, and appear to be one. The deception is kept up better if some buds of the parent stock have been kept alive. Fortune gives an instance in the Punjaub of a Peach growing out of an old Mango tree about six or eight feet from the ground. In this case the Peach had its roots in the ground, and had grown through the hollow stem of the Mango. In India the Peepul tree (Ficus religiosa) occasionally grows on the stumps of other trees, and sends its roots down so as to cover the stump completely, and thus presents the appearance of two kinds of trees growing from one root. By grafting the branches of hedge plants together good fences are occasionally formed (see drawing of such hedges and trees, Trans. Bot. Soc. Edin., vol. x. p. 452).

The object which gardeners wish to secure by grafting, is the improvement of the kinds of fruit, the perpetuation of good varieties, 
which could not be procured from seed, and the hastening of the period of fruit-bearing. Grafting a young twig on an older stock has the effect of making it flower earlier than it would otherwise do. The accumulation of sap in the old stock is made beneficial to the twig, and a check is given at the same time to its tendency to produce leaves. Although the general law is, that grafting can only take place between plants, especially trees, of the same family, there are certain exceptions. Loranthaceous parasites can form a union with genera in different orders.

Mr. Knight did much to improve fruits by grafting. He believed, however, that a graft would not live longer than the natural limit of life allowed to the tree from which it had been taken. In this way he endeavoured to account for the supposed extinction of some valuable varieties of fruit, such as the Golden pippin, and many cider apples of the seventeenth century. He conceived that the only natural method of propagating plants was by seed. His views have not been confirmed by physiologists. Many plants are undoubtedly propagated naturally by shoots, buds, and tubers, as well as by seed; and it is certain that the life of slips may be prolonged by various means, much beyond the usual limit of the life of the parent stock. The Sugar-cane is propagated naturally by the stem, the Strawberry by runners, the Couch-grass by creeping stems, Potatoes and Jerusalem Artichokes by tubers, the Tiger lily by bulblets, and Achimenes by scaly bodies like tubers. The fruits, moreover, which Mr. Knight thought had disappeared, such as Red streak, Golden pippin, and Golden Harvey, still exist, and any feebleness exhibited by them does not appear to proceed from old age, but seems to be owing to other causes, such as the nature of the soil, cold, violence, and mutilation. Vines have been transmitted by perpetual division from the time of the Romans. A slip taken from a Willow in Mr. Knight's garden, pronounced by him as dying from old age, was planted in the Edinburgh Botanic Garden many years ago, and is now a vigorous tree, although the original stock has long since undergone decay. It is true, however, that a cutting taken from a specimen already exhausted by excessive development of its parts will partake of the impaired vigour of its parent, and will possess less constitutional energy than that taken from a vigorous stock.

In grafting, varions methods have been adopted. One of these is grafting by approach, or inarching, when two growing plants are united together, and after adhesion one is severed from its own stock, and left to grow on the other. This kind of adhesion sometimes takes place naturally in trees growing close together. The branch of the same tree may also be bent, so as to become united to the stem at two points. This is often seen in the Iry. The roots of contiguous trees occasionally unite by a process of grafting, and to this is attributed the continued vigour of the stump of Spruce-trees cut down on the Swiss mountains. This natural grafting of roots has been observed in the 
White Pine (Abies pectinata), and sometimes in the Red Pine (Abies excelsa), as well as in the Scotch Fir (Pinus sylvestris) and the Larch (Larix europace).

The usual method of grafting is by scions or slips, which are applied to the stock by a sloping surface, or are inserted into slits in it by cleft-grafting, or into perforations by wimble- or peg-grafting. Whipgrafting or tongue-grafting is performed by inserting a tongue or cleftprocess of the stock between the lips of a cut in the scion. Side-grafting resembles whip-grafting, but it is performed on the side of the stock without heading it down. Sometimes several slips are placed in a circular manner round the inside of the bark of the stock by crowngrafting; or the bark of a portion of the stock is removed, and that of the scion is hollowed out, so as to be applied over it like the parts of a flute, hence called fute-grafting. Budding is practised by the removal of a bud from one plant, along with the portion of the bark and new wood, and applying it to another plant, in which a similar wound has been made. . Grafting is usually performed between the woody parts of the plants, but herbaceous parts may also be united in this way. The graft and stock are secured by clay, or by bees'-wax and tallow, or by Indian rubber, gutta percha, or collodion.

By grafting, all our good varieties of apples have been produced from the Crab Apple. The seeds of the cultivated apples, when sown, produce plants which have a tendency to revert to the original sour Crab. Grafted varieties can only be propagated by cuttings. The influence exercised by the stock is very marked, and it is of great importance to select good stocks on which to graft slips. In this way the fruit is often much improved by a process of ennobling, as it is called. The scion also seems in some cases to exercise a remarkable effect on the stock. Slips taken from plants with variegated leaves, and grafted on others with non-variegated leaves, have sometimes caused the leaves of the latter to assume variegation, and the effect, when once established, has continued even after the slip was removed. The effects of grafting are well seen in the case of the Red Laburnum, when united to the Yellow species. The Red Laburnum is a hybrid between the common Yellow Laburnum and Cytisus purpureus (the Purple Laburnum). The branches below the graft produce the ordinary Yellow Laburnum flowers of large size; those above exhibit often the small Purple Laburnum flowers, as well as reddish flowers, intermediate between the two in size and colour. Occasionally, the same cluster has some flowers yellow and some purplish.

\section{8.-Seed or Fertilised Ovule arrived at Maturity.}

While the pistil undergoes changes consequent on the discharge of the pollen on the stigma, and ultimately becomes the fruit, the 
ovule also is transformed, and, when fully developed, constitutes the seed. After fertilisation, the foramen of the ovule contracts, the young plant gradually increases in its interior, by the absorption of the fluid matter contained in the sac of the amnios (embryo-sac), solid nutritive matter is deposited, and a greater or less degree of hardness is acquired. The seed then is the fecundated mature ovule containing the embryo, with certain nutritive and protective appendages. When ripe, the seed contains usually a quantity of starchy and ligneous matter, azotised compounds, as caseine and regetable albumen, oily and saline matters. It sometimes acquires a stony hardness, as in the case of the seed of Phytelephas macrocarpa, which yields vegetable ivory. Care "must be taken not to confound seeds with single-seeded pericarps, such as the Achænium and Caryopsis, in which a style and stigma are present; nor with bulbils or bulblets, as in Lilium bulbiferum and Dentaria bulbifera, which are germs or separable buds developed without fecundation.

Seeds are usually enclosed in a seed-vessel or pericarp, and hence the great mass of flowering plants are called angiospermous ( $\ddot{a} \gamma \gamma \circ 5$, or

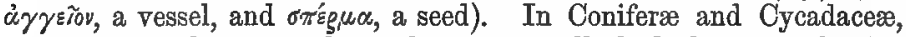
however, the seeds are generally looked upon as having no true pericarpial covering, and fertilisation therefore takes place by the direct application of the pollen to the seed, without the intervention of stigma or style. Hence the seeds, although sometimes protected by scales, are truly naked, and the plants are called gymnospermous Fig. 575. ( the early rupture of the pericarp, seeds originally covered become exposed. This is seen in Leontice and Cuphea. In Mignonette, the seed-vessel (fig. 575) opens early, so as to expose the seeds, which are called seminude.

Besides being contained in a pericarp, the seed has its own peculiar coverings. Like the ovule, it consists of a nucleus or kernel, and integuments. In some instances, although rarely, all the parts of the ovule are visible in the seed-viz., the embryo-sac or quintine, the quartine, the tercine or covering of the nucleus, the secundine, and the primine. In fig. 576 there is a representation of the seed of Nymphæa alba, in which se indicates the embryo-sac, containing the embryo, $e$; $n$, the cellular farinaceous covering (quartine), formed round the embryo-sac; $m t$, membrane formed round the nucleus (tercine); $m i$, the secundine; $t$, the primine. In general, however, great changes take place by the development of the embryo; the embryo-sac is often absorbed, or becomes incorporated with the cellular tissue of the nucleus; the same thing occasionally takes place

: Fig. 575. Fruit or capsule of Mignonette (Reseda odorata), opening early, so that the ovules become seminude. 
in the secundine, so that in the ripe seed, all that can be detected is the embryo with two coverings. The general covering of the seed is called spermoderm ( $\sigma \pi \varepsilon g \mu \alpha$, seed, and $\delta \varepsilon^{\prime} \xi \mu \alpha$, covering). In order to correspond with the name applied to the covering of the fruit, it ought more properly to be denominated perisperm ( $\pi \varepsilon \varepsilon^{\prime}$, around, and $\sigma \pi^{\prime} \varepsilon \rho \alpha \alpha$, seed). This latter term, however, has been appropriated to a certain portion of the seed, to be afterwards noticed under the name of albumen.

The SPERMODERM usually consists of two parts an external membrane, called the

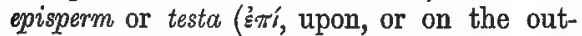
side, and $\sigma \pi \dot{\varepsilon} g \mu c$, a seed ; testa, a shell), and an internal membrane, called endopleura ("zvovov, within, and $\pi \lambda \varepsilon u g \dot{\alpha}$, side or rib). The former may consist of a union of the primine and secundine, or of the primine only, when, as occasionally happens, the secundine is absorbed; the latter, of a combination between the membrane of the nucleus and the embryo-sac, or of one of these parts alone. Sometimes the secundine remains distinct in the seed, forming what has been called a mesosperm

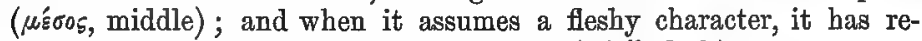

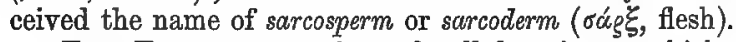

THE EPISPERM consists of cellular tissue, which often assumes various colours, and becomes more or less hardened by depositions in its interior. In Abrus precatorius and Adenanthera pavonina it is of a bright red colour; in French beans it is beautifully mottled; in the Almond it is veined; in the Tulip and Primrose it is rough; in the Snapdragon it is marked with depressions; in Cotton and Asclepias it has hairs attached to it; and in Mahogany and Bignonia it is expanded in the form of wing-like appendages. In Collomia, Acanthodium, and other seeds, it contains spiral cells, from which, when moistened with water, the fibres uncoil in a beautiful manner. Spiral cells are also seen in the episperm of the seeds of Cobra and Calempelis scaber. In the episperm of the seed of Ulmus campestris the cells are compressed, and their sinuous boundaries are traced out by minute rectangular crystals adhering to their walls.

Fig. 576. Young seed of Nymphæa alba cut vertically. $f$, Funiculus or umbilical cord. $a$, Arillus derived from the placenta. $r$, Raphe. c, Chalaza or eotyledonary end of the seed. $h$, Hilum or base of the seed. $m$, Micropyle or foramen. $t$, Testa or primine. $m i$, Secundine. $m t$, Tercine or membrane of the nucleus. n, Farinaceous external perisperm or albumen formed by the nucleus, and probably constituting the quartine of Mirbel. se, se, Internal perisperm or endosperm formed by the embryo-sac. e, The embryo. 
The Endopleura is also cellular. It is often thin and transparent, but it sometimes becomes thickened. It is applied more or less closely to the embryo, and sometimes follows a sinuous course, forming folds on its internal surface, and separating from the episperm.

When the embryo-sac remains distinct from the nucleus in the seeds, as in Nymphæa, Zingiber, Piper, etc., it forms a covering to which the name of vitellus (vitellus, yolk of an egg) was given by Gærtner.

ARILLus. Sometimes there is an additional covering to the seed, derived from an expansion of the funiculus or placenta after fertilisation, to which the name arillus has been given. This is seen in the

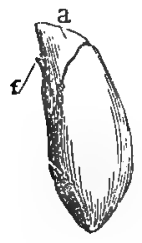

1

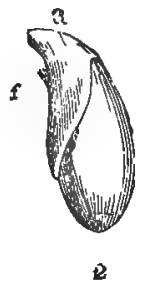

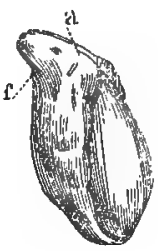

3

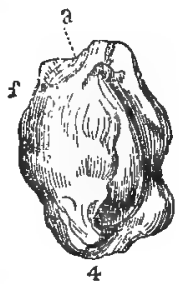

Fig. 577.

Passion-flower, where the covering commences at the base, and proceeds towards the apex, leaving the foramen uncovered. In the Nutmeg and Spindle-tree this additional coat is said to commence at the side of the exostome, and to proceed from above downwards, constituting, in the former case, the substancc called mace; and, in the latter, the

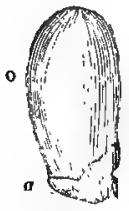

I

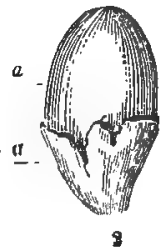

8

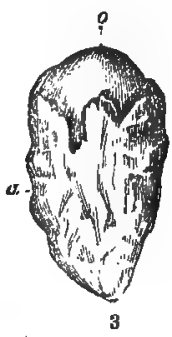

Fig. 578.

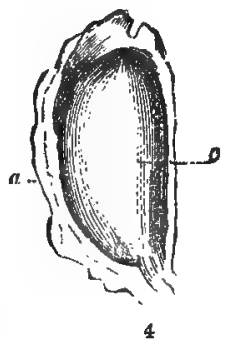

4

bright scarlet covering of the seeds (figs. 577, 578). In such instances

Fig. 577, 1, 2, 3, 4, Various states of the arillus of the spindle-tree (Enonymus). The figures show the mode in which it is developed from the edges of the foramen. a a a a, Arillode. fff $f$, Foramen or Exostome.

Fig. 578. Development of the same arillus, $a$, around the ovule, 0 , exhibited in a different position. 1, 2, 3, 4, are four successive stages of development. In fig. 4 the arillus has been cut vertically to show its relation to the ovule, which it surrounds completely. 
it has been called by some an arillode. This arillode, after growing downwards, may be reflected upwards, so as to cover the foramen.

On the testa, at various points, there are produced at times cellular bodies, which are not dependent on fertilisation, to which the name of strophioles (strophiolum, a little garland), or caruncules (caruncula, a little piece of flesh), has been given, the seeds being strophiolate or carunculate. These tumours may occur near the base or apex of the seed, they may be swellings of the exostome, as in Ricinus (fig. $579 \mathrm{c}$ ), or they may occur in the course of the raphe.

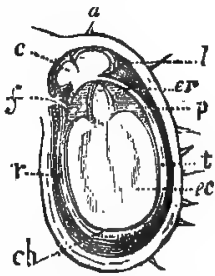

Fig. 579.

Seeds are attached to the placenta by means of a funiculus or umbilical cord, which varies much in length. In Magnolias it attains a great length, and when the seed is ripe it appears like a cord suspending it from the follicle. The point of the seed by which it is united to the cord, or the scar left on its separation, is called the hilum or umbilicus, and represents its base. The hilum frequently exhibits marked colours, being black in the Bean, white in many species of Phaseolus, etc. It may occupy a small or large surface, according to the nature of the attachment. In the Calabar bean and in some species of Mucuna and Dolichos it extends along a large portion of the edge of the seed. The part called the foramen in the ovule becomes the micropyle ( $\mu \iota x g o s$, small, and $\pi \dot{i} \lambda \eta$, gate) of the seed, with its exostome and endostome. This may be recognisable by the naked eye, as in the Pea and Bean tribe, Iris, etc., or it may be very minute and microscopic. It indicates the true apex of the seed, and is important as marking the part to which the root of the embryo is directed. At the micropyle in the Bean is observed a small process of integument, which, when the young plant sprouts, is pushed up like a lid, and is called embryotega (tego, I cover). The fibro-vascular bundles, from the placenta pass through the funiculus and reach the seed, either entering it directly at a point called the omphalode (o $\mu \varphi \alpha \lambda$ ós, navel), which forms part of the hilum, or being prolonged between the outer and inner integument in the form of a raphe (乌̧ắn, a seam), and reaching the chalaza ( $\chi^{\prime} \hat{\lambda}_{\alpha} \zeta \breve{\alpha}$, a pimple or tubercle), or organic base of the nucleus, where a swelling or peculiar expansion may often be detected, as in Crocus. In fig. 576 the spiral vessels, $r$, are seen entering the cord, $f$, passing through the hilum, $h$, forming the raphe, $r$ ', between the testa, $t$, and endopleura, $m i$, and ending in the chalazal expansion, c. So also

Fig. 579. Vertical section of a carpel of Ricinus communis, and of the seed which it contains. $a$, Pericarp. $l$, Loculament. $f$, Funiculus or umbilical cord. $t$, Integuments of the seed, having at their apex a caruncula, 0 , which is traversed by the small canal of the exostome. The exostome does not correspond exactly with the endostome, which is immediately above the radicle. $r$, Raphe. ch, Chalaza. p. Perisperm or albumen, the upper portion of which only is seen. $e$, Embryo, with its radicle, er, and its cotyledons, ec. 
in fig. 577, where $f$ is the funiculus, $r$ the raphe united to the hilum, and chalaza, $c$, whence vessels, $n$, penetrate the seed. In some seeds, as Narthecium ossifragum, the vessels are said not to appear till after fertilisation, and in Habenaria viridis none have been detected. The

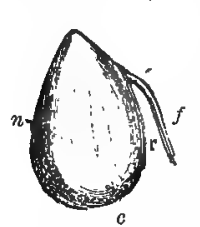

Fig. 580 . chalaza is often of a different colour from the rest of the integuments. In the Orange it is of a reddishbrown colour, and is easily recognised at one end of the seed when the integuments are carefully removed. Sometimes, however, its structure can only be recognised by careful dissection. It indicates the cotyledonary extremity of the embryo. The hilum and chalaza may correspond, or they may be separated from each other and united by the raphe (fig. 580). The raphe is generally on the side of the seed next the ventral suture.

The positions of the hilum, micropyle, and chalaza, are of importance in determining the nature of the seed. The hilum is the base of the seed, and the micropyle its apex, while the chalaza is the organic base of the nucleus. The hilum and chalaza may correspond, the micropyle being at the opposite extremity, and then the seed is orthotropal (opeos, straight). The seed may be curved so that the micropyle is close to the bilum, and the chalaza, by the growth of the seed on one side, may be slightly removed from the hilum, then the seed is campylotropal ( $x \alpha \mu \pi$ ínos, curved). The micropyle may be close to the hilum, and the chalaza in the progress of development may be removed to the opposite end, then the seed is anatropal (ávargér $\pi \omega$, I reverse).*

The position of the seed as regards the pericarp resembles that of the ovule in the ovary, and the same terms are applied-erect, ascending, pendulous, suspended, curved, etc. (figs. 459, 460, 461, 462, 456, pp. 257, 255). These terms have no reference to the mode in which the fruit is attached to the axis. Thus the seed may be erect while the fruit itself is pendent, in the ordinary meaning of that term. The part of the seed next the axis or the ventral suture is its face, the opposite side being the back. Seeds exhibit great varieties of forms. They may be flattened laterally, compressed; or from above downwards, depressed. They may be round, oval, triangular, polygonal, rolled up like a snail, as in Physostemon; or coiled up like a snake, as in Ophiocaryon paradoxum.

The object of fertilisation is the formation of the embryo in the interior of the seed. In general, one embryo is produced, constituting what is denominated monembryony ( $\mu$ óvos, one); but in Coniferæ, Cycadaceæ, Mistleto, etc., there are frequently several embryos, giving

Fig, 580. Seed of the Bazel. $f$, Funiculus. $r$, Raphe. $c$, Chalaza. $n$, Veins spreading in a radiating manner over the integuments of the seed.

\footnotetext{
* See pp. 255, 256, where these terms are more fully explained when treating of the ovule.
} 
rise to what is called polyembryony ( $\pi 0 \lambda i^{\prime} \varsigma$, many). Sometimes two embryos become united together in the same seed. In the coniferous seeds numerous corpuscles are seen, whence the embryos proceed. The process of fertilisation has already been traced until the embryo appears as a rounded cellular body, enclosed in the embryo-sac, and attached to a suspensor. In fig. 576, $e$ is the embryo, and se the embryo-sac. In this sac there is at first a protoplasm, in which cells are developed. The embryonic cell (fig. 581 v), still attached to the sac by its suspensor, $s$, contains distinet nucleated cells (fig. 581, $2 e$ ). These gradually multiply, and form at length a cellular mass, at first undivided (fig. 581, $3 e$ ), but afterwards showing a separation of parts, so that the axis and lateral projections or rudiments of leaves can be distinguished.

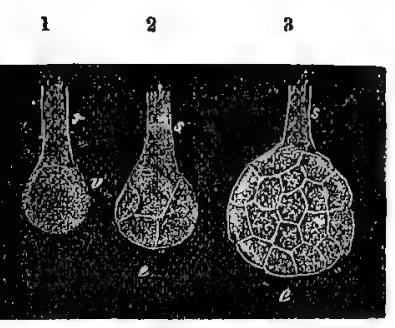

Fig. 581.

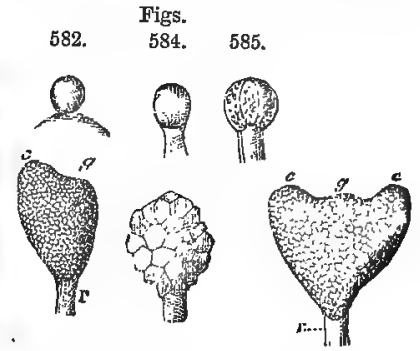

Fig. 583, Fig. 586. Fig. 587.

In figs. 582 to 587 all the stages of the formation of embryo can be traced; appearing first as a simple cell (figs. 582, 584), forming others in its interior (figs. 585, 586); and finally, the parts of the embryo becoming visible, figs. 583, 587, where $g r$ is the axis representing the stem and roots, and $c^{\prime} c$ are the lateral projections, which are developed as leaf-like bodies, called cotyledons (xorĩ $\lambda \eta \delta \tilde{\omega}$, the name of a plant having leaves like seed-lobes).

Perisperm or Albumen.-As the embryo increases in size it gradually causes absorption of the cellular tissue in the embryo-sac, and it is sometimes developed to such a degree as to reduce the nucleus and embryo-sac to a thin integument. In such a case the seed consists of

Fig. 581. First development of the embryo of Draba verna. o, Suspensor, which in this plant is very long. $v$, Embryonic or germinal vesicle. e, Embryo. 1, First stage, in which the embryonic vesicle only is seen. 2, Second stage, showing several cells formed in the embryonic vesicle. 3, Third stage, in which the embryo becomes more conspicuous in consequence of the formation of numerous small cells. Fig. 582. Monocotyledonous embryo of Potamogeton perfoliatus in its early stage, appearing as a vesicle or simple cell. Fig. 583. The same, further advanced, showing radicle, $r$, gemmule or plumale, $g$, and the cotyledon, c. Fig. 584. Dicotyledonous embryo of CEnothera crassipes in its early stage, appearing as a vesicle or cell. Fig. 585 . The same, further advanced, showing three united utricles or cells. Fig. 586. The same, more developed, showing numerous cells. Fig. 587. The same in a more developed state, showing radicle, $r$, gemmule, $g$, and cotyledons, $c$ c. 
integuments and embryo alone. In Santalum, Osyris, and Loranthus, Griffith says the ovule is sometimes reduced entirely to a sort of embryonary sac. In Avicennia the embryo, at its maturity, is on the outside of the nucleus and body of the ovule. In other cases it enlarges to a certain extent, filling the embryo-sac completely or partially, and . only encroaching slightly on the cells of the nucleus. The cells surrounding the embryo then become filled with a solid deposit called albumen, consisting of starchy, oily matter, and nitrogenous compounds. To this some have applied the term perisperm ( $\pi \varepsilon g^{\prime}$, around, and $\sigma \pi^{\prime} \varepsilon \mu \alpha$, seed); others, that of endosperm (Evơov, within). The name, perispermic albumen, or perisperm, is often restricted to that found in the cells of the nucleus alone, outside the embryo-sac (fig. $576 n$ ); endospermic albumen, or endosperm, to that found within the embryo-sac alone (fig. $576 \mathrm{se}$ ), as in Chelidonium majus, Ranunculaceæ, Umbelliferæ, and in many Endogens, etc. Sometimes both kinds of albumen occur

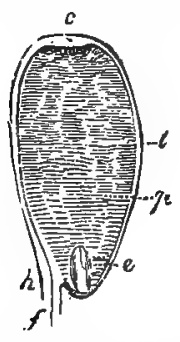

Fig. 588.

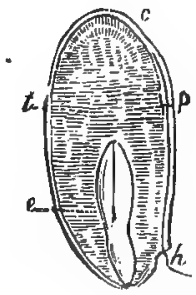

Fig. 589.

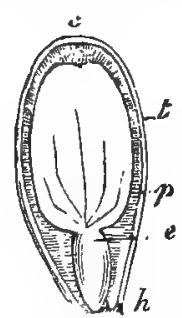

Fig. 590 .

in the same seed, as in Nymphæaceæ and Piperaceæ. In some instances the albumen is produced in the region of the chalaza. In some ScrophuIarias the embryo-sac forms little cavities or bags, which in the ripe seed remain as appendages to the albumen. Seeds in which the embryo occupies the entire seed, are called exalbuminous (ex, without), as Compositæ, Cruciferæ, and most Leguminosæ, while others having separate albumen are albuminous. The larger the quantity of albumen in a seed the smaller the embryo. In figs. 588 to 590 the relative proportion which the embryo bears to the albumen or perisperm in different seeds is shown; $e$ being the embryo with its cotyledons and young root, $p$ the perisperm, $t$ the coverings of the seed, $f$ the funiculus or cord, $h$ the hilum, and $c$ the chalaza. In fig. 588 the embryo is

Fig. 588. Anatropal mature seed of Helleborus niger, cut vertically. The embryo,e, is small, as compared with the perisperm or albumen, $p$. $t$, Spermoderm or coverings of the seed. $f$, Funiculus. $h$, Hilum. c, Chalaza. Fig. 589. Mature seed of Diphylleia peltata, showing an embryo, $e$, which occupies a Iarger portion of the seed than in fig. 588 . Letters indicate the same parts as in the previous figure. Fig. 590. Ripe seed of Berberis vulgaris, exhibiting a larger embryo, $e$, as compared with the perisperm, $p$. Letters as in figs. 588 and 589. 
minute, and occupies only a small part of the apex of the albumen; in fig. 589 it is larger, and has encroached on the perisperm; while in fig. 590 it is still more developed, much of the albumen having been absorbed.

The albumen varies much in its nature and consistence, and furnishes important characters. It may be farinaceous or mealy, consisting chiefly of cells filled with starch (fig. 591), as in Cereal grains, where it is abundant ; fleshy or cartilaginous, consisting of thicker cells which are still soft, as in the Coco-nut, and which sometimes contain oil, as in the oily albumen of Croton (fig. 592), Ricinus, and Poppy; horny, when the matter in the cells is of a hard consistence, and often arranged in a concentric manner, so as nearly to fill the entire cavity, as in Date, Irory-Palm, and Coffee. The albumen may be uniform throughout, or it may present a mottled appearance, as in the Nutmeg, the seeds of Anonaceæ, and some Palms (fig. 593), where it is called ruminated. This mottled appearance depends often on the endopleura

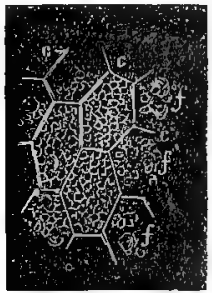

Fig. 591.

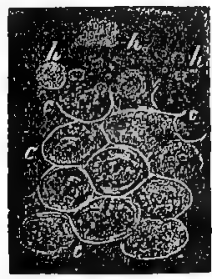

Fig. 592.

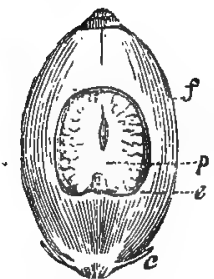

Fig. 593.

or inner integument forming folds on which the albumen is deposited, and when the seed is ripe these foldings of the membrane divide the albumen in a sinuous or convoluted manner.

The albumen is a store of matter laid up for the nourishment of the embryo. In the Coco-nut and double Coco-nut it forms the great bulk of the seed, weighing many ounces, while the embryo is minute, weighing a few grains, and lies in a cavity at one extremity. In Coffee the albumen is the horny portion, the infusion of which is used for a beverage. In Phytelephas it is called vegetable ivory from its hardness, and is used for the same purposes as ivory. In the horny albumen of this Palm, as well as in that of the Attalea funifera, the Date, and the Doom Palm, the concentric deposition of secondary layers, leaving a

Fig. 591. Section of a small portion of the farinaceous perisperm or albumen of Zea Mais, Indian corn. $c e c$, Cells. $f f f$, Grains of starch in the cells. Fig. 592. Section of a small portion of the oily perisperm or albumen of Croton Tiglium. e c c $e$, Cells. $h h h$, Drops of oil contained in the cells. Fig. 593. Vertical section of the fruit of Areca Catechu. c, Perianth. $f$, Pericarp. $p$, Ruminated perisperm or albumen. e, Bmbryo. 
small cavity in the centre of the cells, and radiating spaces uncovered with thickening matter, is well seen under the microscope.

The embryo consists of cotyledons or rudimentary leaves, the plumule (plumula, a little feather), or gemmule (gemma, a bud), representing the ascending axis, radicle (radix, root), or the descending axis, and their point of union the collum, collar or neck; that part of the axis which intervenes between the collar and cotyledons being the caulicule (cauliculus, a little stalk), or tigelle (tigellus, a little stalk). The embryo varies in its structure in the difFig. 594. ferent divisions of the vegetable kingdom. In acrogenous and thallogenous plants it continues as a cell or spore, with granular matter in its interior (fig. 594), without any separation of parts or the produc-

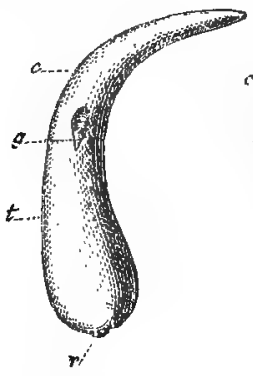

Fig. 595.

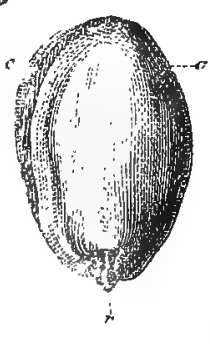

Fig. 596.

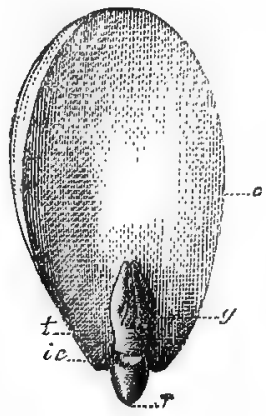

Fig. 597.

tion of cotyledons. Hence these plants are called acotyledonous ( $\alpha$ privative, $\left.x_{0 \tau} \tilde{u} \lambda \eta \delta \dot{\omega}\right)$. Endogenous and Exogenous plants, on the other hand, exhibit a marked separation of parts in their embryo, the former having one cotyledon, and hence being monocotyledonous ( $\mu$ óvos, one); the latter two, and hence dicotyledonous (dis, twice). Thus, the whole vegetable kingdom is divided into three Classes by the nature of the embryo, the first of which classes corresponds with the cryptogamic division of plants, the second with the endogenous division of phanerogamous or flowering plants, the third with the exogenous division of the same. Fig. 595 represents a monocotyledonous embryo, with its cotyledon, $c$; while figs, 596 and 597 exhibit a dicotyledonous embryo, with its cotyledons, c c c.

THE SPORE of acotyledonous plants (fig. 591) is a cellular body,

Fig. 594. Acotyledonous embryo of Marchantia polymorpha. Such embryos bear the name of spores. Fig. 595. Monocotyledonous embryo of Potamogeton perfoliatus nearly mature. $r$, Radicle. $t$, Caulicule or tigellus, $c$, Cotyledon. $g$, Gemmule or plumule. Fig. 596. Mature dicotyledonous embryo of the common Almond. $r$, Radicle or young root. Fig. 597. The same, with one of the cotyledons removed. $r$, Radicle. $t$, Tigelle or caluicule. $c$, One of the cotyledons left. $i c$, Cicatrix left at the place where the other cotyledon was attached. $g$, Gemmule composed of several small leaves. 
from which a new plant is produced. Germination takes place in any part of its surface, and not from fixed points. It sometimes presents filaments or vibratile cilia on its surface (figs. 467-470, p. $265)$, by means of which it moves about in fluids, like some of the Infusoria. When it germinates, these cilia disappear. Sometimes spores are united in definite numbers, as in fours, surrounded by a cellular covering, or perispore ( $\pi \varepsilon e^{i}$, around, and $\sigma \pi \circ \rho \dot{\alpha}$, offspring), or sporidium, and thus forming the reproductive body called a tetraspore (rergás, four), which is common in Algæ (fig. 482, p. 273).

EMBRYo. - In the embryo or corculum (corculum, a little heart), the first part formed is the axis, having one of its extremities turned towards the suspensor, and the other in the opposite direction; the former indicating the point whence the young root or radicle is to proceed, and the latter that whence the leafy stem is to arise. The part which produces the first leaves or cotyledons is called the cotyledonary extremity of the embryo, while the other is the radicutar extremity. The radicular extremity is thus continuous with the suspensor, and consequently points towards the micropyle (fig. $590 h$ ), or the summit of the nucleus, an important fact in practical botany; while the cotyledonary, being opposite, is pointed towards the base of the nucleus or the chalaza (fig. $590 \mathrm{c}$ ). Hence, by ascertaining the position of the micropyle and chalaza, the two extremities of the embryo can in general be discovered. In some rare instances, in consequence of a thickening in the coats of the seed, as in Ricinus (fig. 579, p. 329), and some other Euphorbiaceæ, there is an alteration in the micropyle, so that the radicle does not point directly to it.

The part of the axis which unites the radicle and the cotyledon or cotyledons is denominated caulicule or tigelle (figs. $595 t, 597 t$ ). This is sometimes very short. From the point where the cotyledons are united to the axis a bud is developed (in the same way as from the axil of leares); this bud contains the rudiments of the true or primordial (primus, first, and ordo, rank) leaves of the plant, and has been called plumule or gemmule. This bud may be seen usually lying within the cotyledons. Thus in fig. 597 the embryo of the Almond exhibits the gemmule, $g$, lying on one of the cotyledons, the other having been removed and leaving a cicatrix, ic; while in fig. 595 the gemmule, $g$, of Potamogeton perfoliatus is covered by the single cotyledon, $c$.

The gemmule as well as the cotyledon are sometimes obscurely seen. Thus in

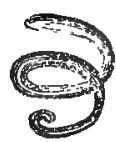

Fig. 598.

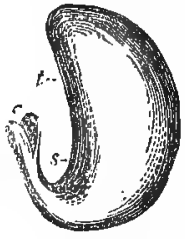

Fig. 599.

Fig. 598. Spiral embryo of Cuscuta or Dodder. Fig. 599. Embryo of Caryocar butyrosum. $t$, Thick tigelle or caulicule, forming nearly the whole mass, becoming narrowed and curved at its extremity, and applied to the groove, $s$. In the figure this narrowed portion is slightly separated from the groove. c, Two rudimentary cotyledons. 
Cuscuta (fig. 598) the embryo appears as an elongated axis without divisions ; and in Caryocar butyrosum (fig. 599) the mass of the embryo is made up by the radicular extremity and tigelle, $t$, in a groove of which, $s$, the cotyledonary extremity lies embedded, which when separated, as in the figure, shows only very small cotyledons. In some monocotyledonous embryos, as in Orchidaceæ, it requires a microscopic examination to detect the cotyledonary leaf.

Monocotyledonous Embryo.-In this embryo the single cotyledon in general encloses the gemmule at its lower portion, and exhibits on one side a small slit (fig. $600 \mathrm{f}$ ), which indicates the edges of the vaginal or sheathing portion of the cotyledonary

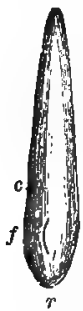
leaf. The embryo presents commonly a cylindrical form, rounded at the extremities, or a more or less elongated ovoid (fig. 600). At first sight there seems to be no distinction of parts ; but on careful examination, by moistening the embryo, and making a vertical section, there will be detected, at a variable height, a small projecting mammilla, buried a little below the surface. This is the gemmule which marks the termination of the axis. From the lower extremity proceeds the radicular portion (figs. $595 \mathrm{t} r$, $600 \mathrm{r}$ ), which may be said to represent both the tigelle

Fig. 600 .

and radicle. The upper portion or chalazal end of the embryo is the cotyledon (figs. 595, 600 c), which is sheathing at its base, so as to enclose the gemmule. In some cases, as in the common oat (Avena sativa), there is a peculiar process which covers the plumule, and which is considered by some as an axillary stipule of the cotyledon. The length of the radicular portion, or that below the gemmule, varies. It is usually shorter than the cotyledon, and is denser in structure; but in some instances it becomes much larger, giving rise to what has been called a macropodous embryo ( $\mu \alpha$ «ós, long, and $\pi 0 u$, a foot). Thus, in fig. $601, t$ represents the long radicular portion in the young state, whence ultimately the root, $r$, proceeds. Occasionally, the radicular portion becomes very thick and large, so as to form a considerable portion of the embryo; and in all monocotyledons it may be considered as an enlarged mammillary projection, whence the rootlets (adventitious roots) proceed, by bursting through it, and carrying with them a covering or sheath, coleorhiza (fig. 105, p. 42).

When considering endogenous or monocotyledonous stems, it was shown that the leaves are produced singly and alternately, in a sheathing manner, each embracing the subsequently developed bud. So it is in the monocotyledonous embryo. There is a single leaf or cotyledon produced, and if in any instance there is more than one, it

Fig. 600. Embryo of Triglochin Barrelieri. $r$, Radicle. $f$, slit corresponding to the gemmule. $c$, Cotyledon. 
is alternate, with the first formed. In the Oat an abortive organ called the epiblast ( $\beta \lambda \alpha \sigma \sigma^{\circ} 5$, a shoot) is produced, which may be considered a rudimentary second cotyledon. The cotyledon (fig. $600 \mathrm{c}$ ) is folded either partially, as in Dioscorea, or completely. Its sheathing portion (vagina) embraces the bud or gemmule, which appears as a mammillary projection; its position being indicated by a cleft or slit (fig. $600 f$, p. 336), where the edges of the sheath unite. All the portion of the embryo above the gemmule is the cotyledon; all below, the radicle.

Dicotyledonods EmbRyo.-The form of this embryo varies much; and although sometimes resembling in its general aspect that of monocotyledons, yet it is always distinguished by a division taking place at the cotyledonary extremity, by which it is separated into two, more or less evident, lobes. The parts of this embryo are easily traced in the Bean, Pea, Acorn, and Almond. In the latter (fig. 596) the embryo has an oval form, consisting of two thick cotyledons, $c c$, and a radicle, $r$. When one of the cotyledons is removed (fig. 597), leaving scars, $i c$, the genamule or plumule, $g$, is seen included between them, with its caulicule or tigelle, $t$.

The cotyledons are not always, however, of the same size. Thus, in a species of Hiræa (fig. 602), one of them, $c^{\prime}$, is smaller than the other; and in Carapa guianensis (fig. 603) there appears to be only one, in consequence of the intimate union which takes place between the two, as indicated by the dotted line, $c$. The union between the cotyledonary leaves may continue after the young plant begins to germinate. Such embryos have been called pseudo-monocotyledonous ( $\psi$ rudins, false). When there are two cotyledons, they are opposite to each

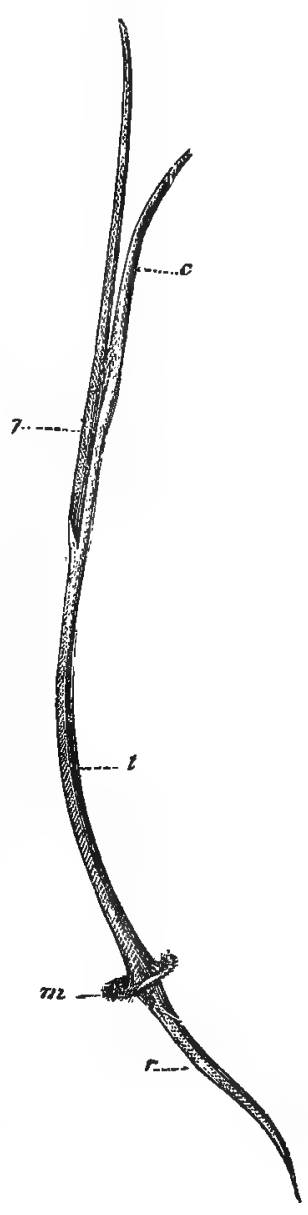

Fig. 601. 造 other. In some cases there are more than two present, and then

Fig. 601. Monocotyledonous embryo of Zannichellia palustris germinating. $m$, Collum or neck, the point intermediate between the stem or tigelle, $t$, and the radicle or root, $r$. $c$, Cotyleđon. $g$, Gemmule or plumule. : 
they become verticillate. This occurs in Coniferæ, especially in the Fir (fig. 604), Spruce, and Larch, in which six, nine, twelve, and even fifteen have been observed. In such cases it is probable that the cotyledons are split by collateral chorisis, and thus divided into several. They are linear, and resemble in their form and mode of development the clustered or fasciculated leaves of the Larch. Plants having numerous cotyledons are occasionally denominated polycotyledonous. Duchartre thinks that the multiple cotyledons of the Firs

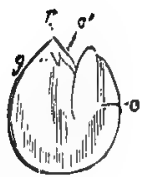

Fig. 602.

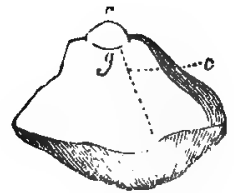

Fig. 603.
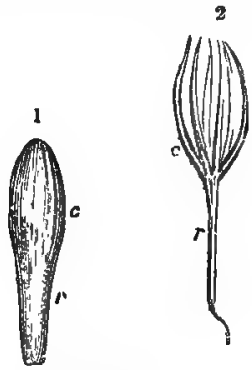

Fig. 604.

are not verticillate, but occur in two opposite groups, placed like two ordinary cotyledons. Hence he considers the plants to be truly dicotyledonous, with the cotyledons deeply divided into a number of segments. Between the two cotyledons there is a slit which is well seen in Pinus Pinaster and excelsa. Thus, the arrangement of the cotyledons follows the same law as that of the leaves in dicotyledonous or exogenous plants, being opposite or verticillate according to the mode of formation of the axis. In Welwitschia there are two cotyledons which last throughout its life (more than a century), and in the course of time they grow to an enormous size, being sometimes six feet long and two or three in breadth. They constitute the only leaves of the plant. In species of Streptocarpus the cotyledons are also permanent and act the part of leaves. One of them is frequently largely developed, while the other is small or abortive.

The texture of the cotyledons varies. They may be thick, as in the Bean, exhibiting only slight traces of venation, with their flat internal surfaces in contact, and their backs more or less convex; or they may be in the form of thin and delicate laminæ, flattened on both

Fig. 602. Embryo of Hiræa Salzmanniana, cut vertically, to show'the inequality of the two cotyledons, one of which, $c$, forms almost the whole mass of the embryo. $c^{\prime}$, The small cotyIedon. $g$, Gemmule or plumule. $r$, Radicle. Fig. 603. Embryo of Carapa guianensis, cut vertically to show the union of the cotyledons, the distinction between which is only indicated by a faint line, c. $r$, Radicle, g, Gemmule. Fig. 604. Embryo of Fir. 1, Taken from the seed. 2, Beginning to germinate. $r$, Radicle. $c$, Cotyledons, which are numerous; the plant being polycotyledonous. 
sides, and having distinct venation, as in Ricinus (fig. 605), Jatropha, Euonymus, etc. In the former case they are called fleshy, or seminal lobes; in the latter, foliaceous, or seminal leaves.

Cotyledons are usually entire and sessile. But they occasionally become lobed, as in the Walnut and the Lime (fig. 606), where the cotyledon, $c$, has five lobes; or petiolate, as in Geranium molle (fig. $607 \mathrm{p}$ ); or auriculate, as in the Ash (fig. 608 o). Like leaves in the bud (see Vernation, p. 110), cotyledons may be either applied directly to each other (fig. 605), or may be folded in various ways. In the

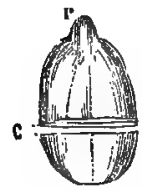

Fig. 605.

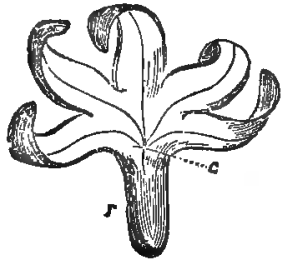

Fig. 606 .

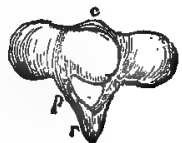

Fig. 607 .

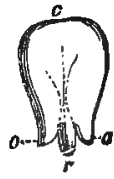

Fig. 608.

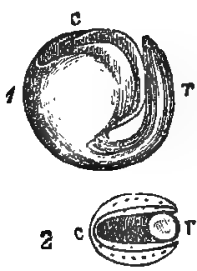

Fig. 609.

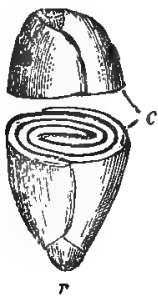

Fig. 610.

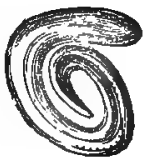

Fig. 611.

Almond (fig. 596) they lie in the direction of the axis. In other cases they are folded laterally, conduplicate (fig. 609) ; or from apex to base, reclinate (fig. $222 a$, p. 111 ); or rolled up laterally, so as partially to embrace each other, convolute (fig. 610); or rolled up like the young fronds of ferns, circinate (fig. 611). In these cases, both cotyledons follow the same direction in their foldings or convolutions, but, in other instances, they are folded in opposite directions, resembling the

Fig. 605. Embryo of Ricinus communis taken out of the seed (see fig. 579, p.'329), and cut transversely. The two halves are separated so as to show the two cotyledons, $c$, applied to each other. r, Radicle. Fig. 606. Embryo of the Lime. $r$, Radicle. $c$, One of the divided or palmate cotyledons. Fig. 607. Embryo of Geranium molle. r, Radicle. c, Cotyledons attached to the collar by a stalk or petiole, $p$. Fig. 608. Embryo of the Ash. $r$, Radicle. $c$, one of the cotyledons. 0 o, Auricular appendages to the cotyledon. Fig. 609. Embryo of Brassica oleracea, Cabbage. $r$, Radicle. c, Cotyledon. 1, Entire embryo. 2, Embryo cut transversely, showing the cotyledons folded on the radicle or conduplicate. The radicle is dorsal, or on the back of the cotyledons.

Fig. 610. Embryo of Punica Granatum, Pomegxanate, cut into two balves. The upper half removed to show the convolute cotyledons. c, Radicle. Fig. 611. Circinate embryo (spirolobex) of Bunias orientalis. 
equitant (fig. $222 \mathrm{~m}$, p. 111) and semi-equitant (fig. $222 n$, p. 111) vernation.

The radicle may be either straight or curved, and, in particular instances, it gives a marked character to the seed. Thus, divisions of the order Cruciferæ are founded on the relative position and folding of the radicle and cotyledons. In the division Pleurorhizece ( $\pi \lambda$ svequ, side, and $\dot{\xi}, \zeta \alpha$, root), the cotyledons are applied by their faces, and the radicle (figs. 612,613 r) is folded on their edges, so as to be lateral, while the cotyledons, $c$, are accumbent (accumbo, I lie at the

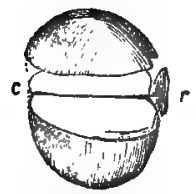

Fig. 612 .

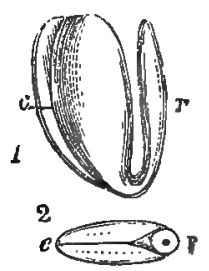

Fig. 613 .

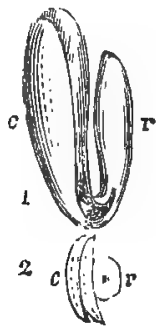

Fig. 614.

side). In Notorhizece (vwros, the back) the cotyledons (fig. $614^{\circ} \mathrm{c}$ ) are applied to each other by their faces, and the radicle, $r$, is folded on their back, so as to be dorsal, and the cotyledons are incumbent (incumbo, I lie upon, or on the back). In Orthoplocece (ogpós, straight, and $\pi \lambda_{0 x \dot{n}}$, a plait) the cotyledons are conduplicate (fig. $609,1,2, c$ ), while the radicle, $r$, is dorsal, and enclosed between their folds. In other divisions, the radicle is folded in a spiral manner (fig. 611), and the cotyledons follow the same course. In the Dodder (fig. 598) the embryo appears as an axis without divisions, having several turns of the spiral on different planes.

The seed sometimes is composed of the embryo and integuments alone, the former being either straight or folded in various ways, as already shown. In other cases there is an addition of perisperm or nutritive matter, in greater or less quantity, according to the state of development which the embryo attains (figs. 588, 589, 590). When the embryo is surrounded by the perisperrn on all sides except its radicular extremity (fig. 590, p. 332), it becomes internal or intrarius (intra, within); when lying outside the perisperm, and only coming into contact with it at certain points, it is external or extrarius (extra,

Fig. 612. Embryo of a Pea, cut transversely. Upper half separated to show the fieshy accumbent cotyledons, $c$, r, Radicle applied laterally. Fig. 613. Embryo of Isatis tinctoria. c, Accumbent cotyledons. $r$, Radicle. 1, Embryo entire. 2, Transverse section of the embryo, Fig. 614. Embryo of Cheiranthus Cheiri, Wallflower. c, Ineumbent cotyledons. $r$, Radicle. 1, Embryo entire. 2, Transverse section of the embryo. 
without). When the embryo follows the direction of the axis of the seed, it is axile or axial, and it may be either external, so as to come into contact with the perisperm only by its cotyledonary apex (fig. 615 ), or internal (figs. 588, 589, 590, see p. 332). In the latter case, the radicular extremity may, as in some Coniferæ, become incorporated with the perisperm apparently by means of a thickened suspensor.

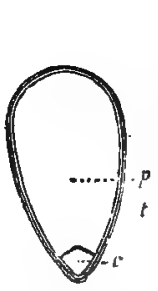

Fig. 615 .

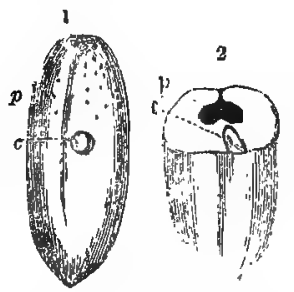

Fig. 616 .

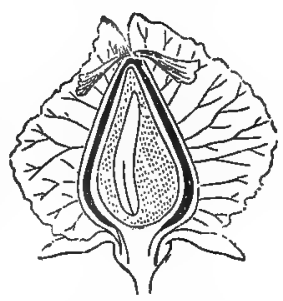

Fig. 617.

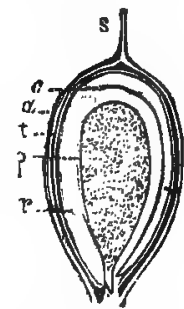

Fig. 618,

When the embryo is not in the direction of the axis, it becomes abaxile or abaxial (fig. $616 e$ ); and in this case it may be either straight or curved, internal or -external. In the straight seed of Grasses the perisperm is abundant, and the embryo lies at a point on its surface immediately below the integuments, being straight and external. In Campylotropous ovules the embryo is curved, and in place of being embedded in perisperm, is frequently external to it, following the concavity of the seed (fig. 618), and becoming peripheri-

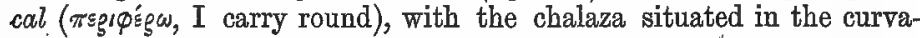
ture of the embryo.

It has been already stated that the radicle of the embryo is directed to the micropyle, and the cotyledons to the chalaza. In some cases, by the growth of the integuments, the former is turned round so as not to correspond with the apex of the nucleus, and then the embryo has the radicle directed to one side, and is called excentric, as is seen in Primulaceæ, Plantaginaceæ, and many Palms, especially the Date (fig. 616). The position of the embryo in different kinds of seeds varies. In an orthotropal seed the embryo is inverted or antitropal (ávri, opposite, $\tau g^{\dot{\varepsilon} \pi \omega \omega}$, I turn), the radicle pointing to the apex of the seed, or to the part opposite the hilum (fig. 617). Thus, fig. 619 represents an orthotropal seed of Sterculia Balanghas, at-

Fig. 615. Grain of Carex depauperata, cut vertically. $t$, Integuments. p, Perisperm. c, Embryo. Fig. 616. Seed or kernel of the Date. p, Perisperm or horny albumen. $e$, Embryo. 1, Entire seed. 2, Seed cut transversely at the point where the embryo, $e$, is situated. Fig. 617. Winged fruit of Rumex, cut vertically to show the abaxile or abaxial lightly curved embryo. Fig. 618. Carpel of Mirabilis Jalapa, cut vertically, with the seed which it contains. $a$, Pericarp erowned with the remains of the style, s. $t$, Integuments of the seed or spermoderm. e, Peripherical embryo, with its radicle, $r$, and its cotyledons, c. $p$, Perisperm or albamen surrounded by the embryo. 
tached to the pericarp, $p c$, by the funiculus, $f$. The chalaza and hilum are confounded together at $c h$, the micropyle being at the opposite end. The integuments of the seed, $t$, cover the embryo with

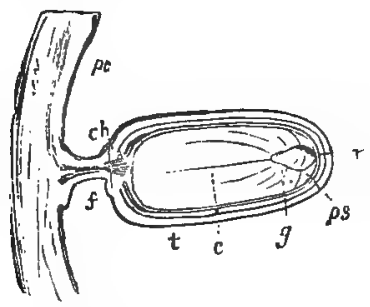

Fig. 619 .

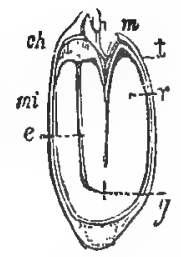

Fig. 620. its perisperm, $p s$; the cotyledons, $c$, point to the hilum and chalaza; while the radicle, $r$, points to the micropyle, and the embryo is thus reversed or inverted. Again, in an anatropal seed (figs. 589, 590, p. 332), where the micropyle is close to the hilum, and the chalaza at the opposite extremity, the embryo is erect or homotropal (o ${ }^{\circ} \mu 0105$, like, and rรś $\pi \omega$, I turn), the radicle or base of the embryo being directed to the base of the seed. In some anatropal ovules, as in Castor oil (fig. 579, p. 329), the exostome is thickened or carunculate, $c$, and the endostome does not correspond exactly to it, so that the radicle, $e r$, of the embryo is directed to a point a little removed from the exostome. In curved or campylotropal seeds (fig. 455, p. 255) the embryo is folded so that its radicular and cotyledonary extremities are approximated, and it becomes amphitropal ( $\dot{\alpha} \mu \varphi \hat{\prime}$, around, г $g^{\prime} \varepsilon \omega$, I turn). In this instance the seed may be exalbuminous, and the embryo may be folded on itself (fig. 620), or albuminous, the embryo surrounding more or less completely the perisperm, and being peripherical (fig. 618). In fig. 620 the seed of Erysimum cheiranthoides is shown, with the chalaza, $c h$, and the hilum, $h$, nearly confounded together, the micropyle, $m$, the embryo

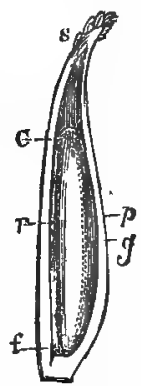

Fig. 621. occupying the entire seed, with the radicle, $r$, folded on the cotyledons, $c$, which enclose the plumule, $g$. Thus, by determining the position of the hilum, chalaza, and micropyle, the direction of the embryo may be known.

\section{According to the mode in which the seed is attached to the}

Fig. 619. Orthotropal seed of Sterculia Balanghas, cut longitudinally, with the portion of the pericarp, $p c$, to which it is attached. $f$, Funiculus. ch, Chalaza and hilum confounded together. $t$, Integuments of the seed, or spermoderm. $p s$, Perisperm, the summit of which only is seen. $c_{z}$ One of the cotyledons. The other cotyledon has been removed to show the gemmule, $g$. $r$, Radicle which is directed to the foramen at the aper of the seed. The embryo is antitropal or inverted. Fig. 620. Campylotropal seed of Erysimum cheiranthoides, cut longitudinally. $m$, Micropyle. ch, Chalaza not far removed from the hilum, $h$. $t$, Testa or episperm. mi, Inner covering of the seed or endopleura. $r$, Radicle. c, Cotyledons. $g$, Gemmule. The embryo is curved or amphitropal, Fig. 621. Vertical section of the carpel of Triglochin Barrelieri. p, Pericarp crowned by the sessile stigma, $s . g$, Seed. $f$, Funiculus. $r$, Raphe. $c$, Chalaza. 
pericarp, the radicle may be directed upwards or downwards, or laterally, as regards the ovary. In an orthotropal ovule, attached to the base of the pericarp, it is superior (fig. 617). So also in a suspended anatropal ovule, as in fig. 579, p. 329 . In other anatropal ovules, as in figs. 588, 600, 621, the radicle is inferior. When the ovule is horizontal as regards the pericarp (fig. 619), the radicle, $r$, is either centrifugal, when it points to the outer wall of the ovary; or centripetal, when it points to the axis or inner wall of the ovary.

\section{9.-Functions of the Seed.}

The seed contains the embryo or germ, which, when placed in favourable circumstances, is developed as a new plant. The embryo is usually of a whitish or pale colour, resenbling the perisperm when present, and sometimes scarcely distinguishable from it at first sight. Occasionally, however, it is of a greenish or yellow hue. Instances of this occurs in the perispermic or albuminous seed of Euonymus, and the aperispermic or exalbuminous seeds of most Cruciferæ. The changes which take place in the composition of the seed, and in its coats, are with the view of protecting the embryo from vicissitudes of temperature, moisture, etc., and of laying up a store of nourishment for its after growth. The coats become thickened and hardened by the deposition of lignine; and in its interior, starch, nitrogenous compounds, phosphates, and sulphates, besides oily and fatty matters, various organic acids, tannin, and resins, are found. The specific gravity of the seed is much increased, so that it usually sinks in water, and it becomes more capable of resisting decomposition, and preserving the vitality of the embryo. In some instances where air is contained in their envelopes seeds float in water.

When seeds are matured, they are detached from the plant in various ways. They separate from the funiculus at the hilum, and remain free in the cavity of the pericarp, which either falls along with them, or opens in various ways so as to scatter them. The elasticity with which some seed-vessels open during the process of desiccation is very great. It may be seen in Hura crepitans, Common Broom, and Cardaninine. In the Geranium (fig. 551, p. 306) the seed-vessels are coiled upwards on the elongated beak, and in this way the seeds are dropped. In the Cyclamen the peduncle curves towards the earth so as to place the seed-vessels in a position suitable for germination. In the succulent fruit of Ecballium Elaterium, or squirting Cucumber, the cells vary in their size and contents in different parts ; and by the force of endosmose a rupture of the valves takes place at their weakest points-viz., where they are united to the peduncle. By the elasticity of the valves the seeds and fluid contents are sent out with great force through the opening left by the separation of the 
peduncle. In the Balsam (Impatiens noli-me-tangere) the seed-vessel opens with force by a similar process, the five valves curving inwards in a spiral manner, in consequence of the distension of the outer large cells. The seeds are discharged before they are dry. In the Mig. nonette (fig. 575, p. 326) the seed-vessel opens early, so as to expose the seeds; and in Cuphea the placenta bearing the seeds pierces the ovary and floral coverings, and is raised above them. Fleshy fruits, which fall to the ground when ripe, supply by their succulent portion the most suitable nutriment for the young embryo in its earliest stages of growth.

Wind, water, animals, and man, are instrumental in the dissemination of seeds. Some seeds, as those of Mahogany, Bignonia, Tecoma, Pine, Asclepias, Epilobium, and the Cotton plant, have winged or hairy appendages, by means of which they are wafted to a distance. The same thing occurs in some indehiscent seed-vessels, as the samara of the Sycamore and Ash, and the achænia of Dandelion, Thistles, etc. Moisture, as well as dryness, operates in the bursting of seed-vessels. The pod of the Rose of Jericho (Anastatica hierochuntina), and the capsule of some Fig-marigolds (Mesembryanthemum Tripolium) exhibit the effects of moisture in a remarkable degree. Animals, by feeding on fleshy fruits, the kernels of which resist the action of the juice of the stomach, disseminate seeds; and man has been the means of transporting seeds from one country to another. In some cases the pericarps ripen their seeds under ground,

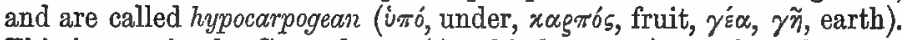
This is seen in the Ground nut (Arachis hypogæa). Other plants, as Vicia amphicarpos, have both aerial and subterranean fruit. Many seeds are used for food by animals, and a great destruction of them takes place from decay ; but this is compensated for by the vast number produced, so as to secure the continuance of the species. The quantity of seeds produced by many plants is very great. In single capsules of Poppy and Tobacco upwards of 40,000 have been counted.

GERmination. - The act by which the embryo of a seed leaves its state of torpidity, and becomes developed as a new plant, is called germination (germinatio, springing). In order that this process may go on, a certain combination of circumstances is necessary. The chief requisites are moisture, air, and a certain temperature. Exclusion from light is also beneficial. In Cotyledonous plants germination may be defined as the act by which the fecundated embryo of a seed leaves the state of torpor in which it has remained for a longer or shorter period, starts into life, as it were, comes out from its envelope, and sustains its existence until such time as the nutritive organs are developed.

Moisture is necessary in order that the nutritive matters may be taken up in a state of solution, and that certain changes may take 
place in the seed. Dry seeds will not germinate. Until water be absorbed no circulation of fluids in the seed can take place. The quantity of water absorbed by seeds is often very large. Decandolle found that a French bean, weighing 544 millegrammes, absorbed 756 of water. The swelling of Peas by absorption of water is familiar to all. The-kernels or seeds of stone-fruits by this means are enabled to burst their hard coverings.

The temperature required for germination varies in different seeds. Some demand a tropical heat, others are satisfied with the warmth of our spring. In general, the requisite temperature may be said to vary from $60^{\circ}$ to $80^{\circ} \mathrm{F}$. Some seeds can bear a temperature which would kill others. Some have been known to germinate after exposure for a short time to the heat of boiling syrup; others after exposure to a cold of $-39^{\circ} \mathrm{F}$. Cereals and beans can only bear immersion in water at $110^{\circ} \mathrm{F}$. for a few minutes. In steam they will bear $140^{\circ} \mathrm{F}$. ; and in dry air $170^{\circ} \mathrm{F}$. Many plants grow in the immediate vicinity of very hot springs, others in cold regions. Edwards and Colin, from their experiments, were led to fix $95^{\circ} \mathrm{F}$. as the highest limit of prolonged temperature which cereal grains can bear in water; and $113^{\circ} \mathrm{F}$. as the highest they can bear in sand or earth. Vegetable life has been observed progressing under much higher temperatures. In the Manilla Islands, a hot spring, which raised the thermometer to $187^{\circ}$, had plants flourishing in it and on its borders. A species of Chara grows in the hot springs of Iceland, and various Confervæ in the boiling springs of Arabia and of the Cape of Good Hope. Dr. Hooker states that on the edge of hot springs in the valley of the Soane in India, the temperature of which was sufficient to boil eggs, there occurred sixteen species of flowering plantș,-Desmodium, Oldenlandia, Boerhaavia, some Compositæ, Grasses, and Cyperaceæ. Moseley noticed specimens of Botryococcus, Braunia, Diatoms, and other Alga, in the hot springs of Furnas in the Azores. Hooker found Confervæ in the hot springs of Belcuppee on the Behar Hills, at $168^{\circ} \mathrm{F}$. Cyperaces grew in water of $100^{\circ} \mathrm{F}$. Dr. Wood of California found Nostoc calidarium and Chrysococcus thermophilus in the hot springs of Benton, at $160^{\circ} \mathrm{F}$. Abel mentions an Arenaria growing in soil at a temperature of $110^{\circ} \mathrm{F}$. Cyperus polystachius and Pteris longifolia were found by Schouw in very hot soil which burnt the hand. Wheat, Oats, and Barley, are said to thrive in any country where the mean temperature exceeds $65^{\circ} \mathrm{F}$. The spores of certain cryptogamic plants are especially fitted for cold countries. Edwards and Colin found that seeds in a dry air bore a higher temperature than in water or steam.

Air, or rather oxygen, was shown by Scheele to be necessary for germination. Seeds deeply buried in the soil, and excluded from air, do not spring. The depth at which seeds should be sown varies 
from half-an-inch to two inches, according to the nature of the soil. The following experiments were made by Petri :-

Seed sown to the depth of

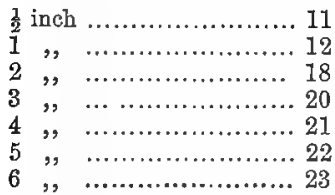

No. of plants that came up. in 7-8ths.

all.

7-8ths.

6-8ths.

4-8ths.

3-8ths

1-8th.

Shallow sowing is thus proved to be the best.

Seeds, when buried deep in the soil, sometimes lie dormant for a long time, and only germinate when the air is admitted by the process of subsoil ploughing, or other agricultural operations. When ground is turned up for the first time it is common to see a crop of white clover and other plants spring up, which had not been previously seen in the locality. After the great fire in London, plants sprang up, the seeds of which must have long lain dormant; and the same thing is observed after the burning of forests and the draining of marshes. Gardner says that the name capoeira is given in Brazil to the trees which spring up after the burning of the virgin forests (matos virgens), and that they are always very distinct from those which constituted the original vegetation. Mr. Vernon Harcourt mentions a case where turnip seeds lay in a dormant state for seven or eight years, in consequence of being carried down to a great depth in the soil. On the Calton Hill, at Edinburgh, when new soil was turned up some years ago for building, a large crop of Fumaria micrantha sprang up ; and seeds gathered from under six feet of peatmoss in Stirlingshire have been known to germinate. A weak solution of chlorine is said to accelerate germination, probably by the decomposition of water, and the liberation of oxygen. Weak solutions of chlorate of potash, of nitric acid, and of oxalic acid, are also said to accelerate the sprouting of seeds.

Darlaness is favourable to germination. Seeds germinate best when excluded from light. M. Boitard showed this by experiments on Auricula seeds, some of which were covered by a transparent belljar, others by a jar of ground glass, and a third set by a jar enveloped in black cloth. The last germinated most rapidly. Senebier concluded that the height and size of a plant were proportionate to the intensity of the illumination, its verdure dependent on the quality of the rays. Mr. Hunt says that the luminous or light-giving rays, and those nearest the yellow, have a marked effect in impeding germination; the red or heat-giving rays are favourable to the process, if abundance of water is present; while the blue rays, or those concerned 
in chemical action or actinism, accelerate the process and cause rapid growth. His experiments were performed by making the sun's rays pass through different kinds of coloured glass. He believes that the scorching effect of the sun on leaves may be prevented by the use of blue glass, and that a high temperature might be obtained by red glass. He has suggested a pale-green glass made with oxide of copper, as that best fitted for conservatories. By this means he expects that the scorching rays of light will be excluded, while no hindrance is given to the passage of the others; the green colour being a compound of yellow or luminous, and of blue or chemical rays. A delicate emerald-green glass has been employed, at his suggestion, in glazing the large Palm-house at Kew.

In order that plants may germinate vigorously, moisture, heat, and air must be supplied in due proportion. If any of them are deficient, or in excess, injury may be done. It is of great importance, therefore, in agricultural operations, that the ground should be well pulverised, the seeds regularly sown at a proper and equal depth, and the soil drained. Pulverised soil, when examined, is found to consist of small particles having cavities in their interior, and separated from each other by interstitial spaces. In a very dry soil, all these cavities are full of air; in a very wet undrained soil, they are full of moisture; in a properly drained soil, the interstices are full of air, while the particles themselves are moist. The seed in such a soil is under the influence of heat, air, and moisture, and is excluded from light. Hence it is in very favourable circumstances for germination. Great attention should be paid to the temperature of the soil in which seeds are sown. Frost has an important effect in pulverising the soil, by the expansion of the water contained in the particles, when it is converted into ice. Snow, again, acts in giving a covering to the young plant, protecting it from intense frost and sudden alternations of temperature, and by its slow melting allows the plant to accommodate itself to the mild atmosphere. Snow contains often much oxygen.

If a field is not equally planted, the seeds will sink to different depths, and will spring up very irregularly. In ordinary productive soils seeds should be placed at a depth not greater than two inches. Draining acts not merely in removing superfluous moisture, but in allowing a constant renewal of nutritive matter, more especially of ammonia and carbonic acid from the atmosphere, in giving a supply of air, and in keeping up a proper temperature in the soil. In an undrained soil the water is stagnant, and there is little supply of fresh nutriment, and much cold is produced. There has been a discussion as to whether shallow or deep draining is the best. Much depends on the nature of the soil, and it is impossible to lay down any fixed rule applicable to all cases. Mr. Smith says that drains in 
very stiff soils should be fifteen feet apart, and in very light soils thirty or forty; the depth being from thirty to thirty-six inches, and the main drains six inches deeper than the parallel ones. In extremely stiff clays he makes drains two and a half feet deep. He was the first to advocate the system of parallel drains, or what is called thorough-draining.

Vitality of SEeDs.-Some seeds lose their vitality soon, others retain it for a long time. Coffee seeds, in order to grow, require to be sown immediately after ripening. On the other hand, Melon seeds have been known to retain their vitality for upwards of forty years, and those of the Sensitive plant for more than sixty years. Oily seeds in general lose their vitality quickly, probably from their power of absorbing oxygen, and the chemical changes thus induced. Considerable discussions have taken place as to the length of time during which seeds will retain their germinating powers. Lindley mentions a case in which young plants were raised from seeds found in an ancient barrow in Devonshire, along with some coins of the Emperor Hadrian; and M. des Moulins relates an instance of seeds capable of germinating, which were discovered in a Roman tomb, supposed to be fifteen or sixteen centuries old. In these instances, it is to be remarked that the seeds were protected from the influences required for growth, and were preserved in circumstances which cannot be easily imitated. The statements relative to the germination of Mummy Wheat, that is to say, grain actually deposited in the case along with the mummy, have not been confirmed, and there are many sources of fallacy.

With the view of preserving seeds, it is of importance that they should be thoroughly ripened, kept in a uniform temperature, and in a dry state, and not directly exposed to the oxygen of the air. They are often best kept in their seed-vessels. The hard coverings of many foreign legumes, and of the cones of Firs, etc., seem to be of importance in preserving the germinating power of seeds. Seeds not fully ripened are very apt to decay, and are easily affected by moisture. Seeds, although fit for food, may have lost their germinating power. Corn, pulse, and farinaceous seeds generally, will live for a long time if gathered ripe, and preserved quite dry. In sending seeds from foreign countries; they should be put up into dry papers and exposed to free ventilation in a cool place; as, for instance, in a coarse bag suspended in a cabin. Oily seeds, and' those containing much tannin, as beechmast, acorns, and nuts, must not only be ripe and dry, but also must be excluded from the air. When transported they are often put into dry earth and sand, and pressed hard, the whole being covered with tin, and put into a stout box. Some have suggested their preservation in hermetically-sealed bottles full of carbonic acid gas. Earthenware bottles, containing ordinary soil, moderately dry, are useful for the conveyance of seeds. A common wooden box, about 10 inches square, with 
the sides $\frac{3}{4}$ of an inch thick, is also suitable for the purpose. In the box may be put alternate layers of earth and seeds, the whole being pressed firmly together. Seeds enveloped in wax sent from India germinated well. They had been kept for three months, and were quite firm and fresh. Spanish Chestnuts and Filberts have been sent enveloped in wax to the Himalaya, and are now growing there. Cuttings of fruittrees, with their ends enveloped in wax, were also sent, and arrived in a living state. In this way also, apples, pears, and plums have been sent. Living plants are best transported in Wardian Cases (fig. 622), and seeds and fruits may also be put in the earth of the Cases. When plants are sent in pots the Case may be divided into separate compartments, as shown in fig. 623, each compartment containing only

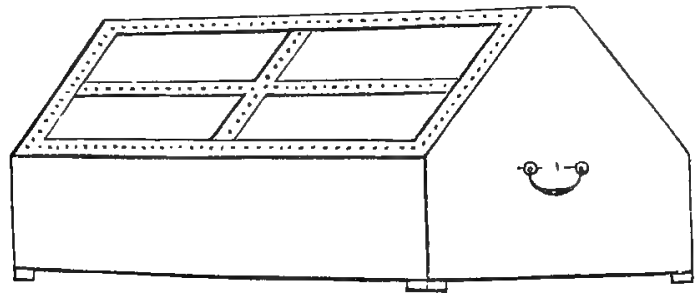

Fig. 622.

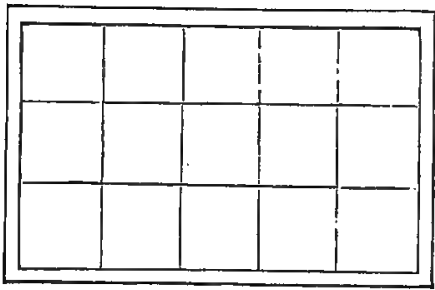

Fig. 623.

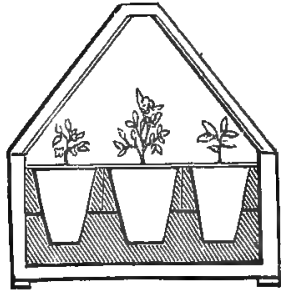

Fig. 624

one pot (fig. 624). The pots should be enveloped in moss, and they should be kept in their place by means of fine galvanised iron-wire. The bottom of the Case should be perforated with six or eight holes, in order to allow the escape of superfluous moisture. Strong white cotton may be used in some instances for covering the Case in place of glass; the cotton to be moistened from time to time during transit.

M. Alphonse Decandolle made experiments on the vitality of seeds.

Fig. 622. Wardian Case, used for transporting living plants and germinating seeds. The top may be glazed with thick glass, or strong white cotton may be firmly stretehed over it. Fig. 623. Wooden partitions, which may be inserted in the Case to hold pots, which must be carefully fastened to prevent injury during transit. Fig. 624. Section of the Case, showing the separate pots, with plants, in the interior. 
He took 368 species of seed, fifteen years old, collected in the same garden, and sowed them at the same time, and in the same circumstances as nearly as possible. Of the 368 only 17 germinated, and comparatively few of the species came up. The following are the results :-

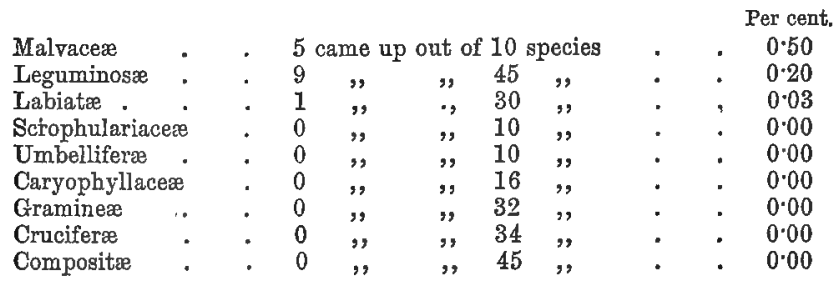

In 357 species, of which the duration of life was known, the results were :-

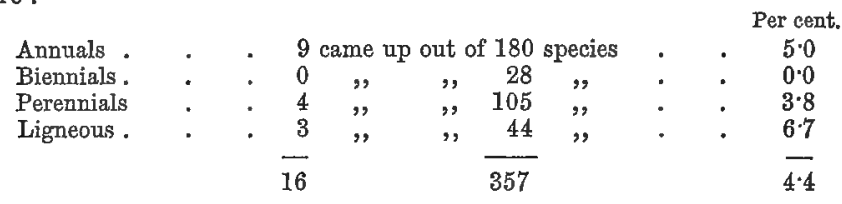

Ligneous species thus seem to preserve the power of germinating longer than others, while biennials are at the opposite end of the scale; perennials would appear to lose their vitality sooner than annuals. Large seeds were found to retain the germinating power longer than small ones, and the presence or absence of separate albumen or perisperm did not seem to make any difference. Compositæ and Umbelliferæ lost their germinating power very early. From these experiments Decandolle concludes that the duration of vitality is frequently in an inverse proportion to the rapidity of the germination.

Chemical Changes duRing Germination.-During the process of germination certain changes take place in the contents of the seed, by which they are rendered fit for the nourishment of the embryo. In exalbuminous or aperispermic seeds, where the embryo alone occupies the interior, these changes are effected principally in the matters stored up in the cotyledons. In albuminous or perispermic seeds, on the other hand, the changes occur in the substance of the perisperm. One of the most remarkable of these changes is the conversion of starch into dextrine and grape sugar by a process of oxidation, the object being the conversion of an insoluble into a soluble substance. While this conversion of starch into sugar proceeds, oxygen is absorbed, carbonic acid is given off, and heat is produced. It is probable that at this period there is a certain amount of electric disturbance. Carpenter states that the conversion of the starch of the seed into sugar involves 
the liberation of carbonic acid, with a small quantity of acetic acid; and as all acids are negative, and like electricities repel each other, it is probable that the seed is at the time in an electro-negative condition. The phenomena of germination are well seen in the malting of barley, which consists in the sprouting of the embryo and the formation of sugar. The changes produced in the air by germinating seeds have been investigated by Saussure, who showed that in all cases carbonic acid was evolved at the expense of the carbon of the seed. During growth and evolution it would appear that all living beings, whether plants or animals, give out carbonic acid (carbon dioxide), whilst oxygen or some oxidising substance is absorbed. Growth and evolution must be considered in a different way from the decomposition of $\mathrm{CO}_{2}$ by leaves, under the influence of light, to provide the starch, gum, sugar, and other materials that are to be organised.

When all the requisites for germination are supplied, the seed, by the absorption of moisture, becomes softened and swollen. When albumen or the perisperm is present, it undergoes certain chemical changes by the action of the air and water, so as to be rendered fit for the nutrition of the embryo. These changes consist partly in the conversion of starch into sugar, and are accompanied with the evolution of carbonic acid, and the production of heat. As the fluid matters are absorbed by the cells of the embryo, the latter continues to increase until it fills the cavity of the seed, and ultimately bursts through the softened integuments. In cases where there is no perisperm, the exalbuninous embryo occupies the entire seed, and the process of germination goes on with greater rapidity. The embryo speedily swells, ruptures the integument, and is nourished at the .expense of the cotyledons, which are often fleshy, containing much starchy matter, as in the Bean and Pea, along with oily matter, as in the Nut and Rape seed. There are thus two stages of germinationthat in which the embryo undergoes certain changes within the seed itself, and that in which it protrudes through the integuments and becomes an independent plant.

The embryo, nourished at the expense of its perisperm and cotyledons, continues to grow, and usually protrudes its radicular extremity (fig. 625,1 ) in the first instance, which is nearest the surface, and next the micropyle. This, which in the embryo is very short, and -confounded with the cauliculus so as to form the first internode, becomes thickened by addition to its extremity (fig. 625, 2), and the -division between the ascending 'and descending axis becomes more marked. The caulicule or axis also elongates, bearing at its summit the plumule, which now appears outside the integuments' (fig. 625, $3 \mathrm{~g}$ ), forming the second internode, either accompanied by the cotyledons, or leaving them still within the seed coats. In the latter case, the .cotyledons are usually fleshy and of a pale colour, and become 
gradually absorbed like the perisperm. In the former they assume a more or less leafy aspect, exercising the functions of leaves for a

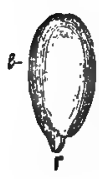

J

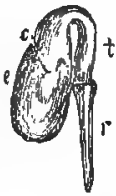

2

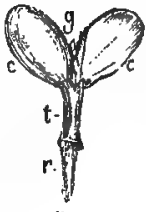

3
Fig. 625 . certain period, and ultimately decaying. While the radicle descends towards the centre of the earth, producing roots of a pale colour, the plumule has a tendency to ascend, forming the leafy axis, and assuming a green colour under the influence of light and air.

Direction of Plumule and Radicle.-Various attempts have been made to explain the ascent of the plumule and the descent of the radicle, but none of them are satisfactory. Physiologists have not been able to detect any law to which they can refer the phenomena, although certain agencies are obviously concerned in the effects. Some have said that the root is especially influenced by the attraction of the earth, while the stem is influenced by light. Experiments have shown that the direction of the root is not owing, to the moisture of the soil, and that the ascent of the stem is not due to the action of light and air; for roots descend, and stems ascend, even when the latter are placed in contact with the earth, and the former submitted to the action of light. Knight thinks that the direction of stem and roots may be traced to gravitation, and the state of the tissues. When a branch is horizontal, the fluids gravitate towards the lower side; a vigorous growth takes place there; the tissues enlarge, and, by increasing more than those on the upper side, an incurvation is produced, the convexity of which looks downwards, and thus the extremity of the branch is directed upwards. Again, in the root the increase takes place by the extremity, and the fluids by their gravity cause this to retain always a descending direction. A similar explanation is given by Dodart. Dutrochet refers the phenomena to endosmose, which varies in its effects according to the comparative size of the cells in the centre and circumference of an axis. In young stems with large pith, the central cells are larger, and they diminish towards the circumference; whereas in roots, according to him, the diminution takes place in the reverse manner. Large cells distend more rapidly than small ones; and, according to their position in the axis, will

Fig. 625. Germination of the dicotyledonous aperispermic seed of Acacia Julibrissin. $e$, Spermoderm or testa. $r$, Radicle of the embryo. $t$, Tigellus or cauliculus. $c$, Cotyledons. $g$, Gemmule or plumule. 1, First stage: in which the radicle ruptures the envelope or spermoderm, and appears externally at the micropyle. 2, Second stage: where the parts of the embryo are further disengaged from the covering, the summit of the cotyledons only being retained by the spermoderm. 3, Third stage: where the embryo is entirely disengaged from the envelope or spermoderm, and the cotyledons, $c c$, are separated so as to exhibit the plumule, $g$. 
thus cause curvature outwards or inwards, the largest occupying the convexity of the arch, the smallest the concavity. When a branch or root is laid horizontally, the force of endosmose is weakened on the lower side, and, consequently, will cease to neutralise the tendency to incurvation on the upper side, which will therefore be directed either upwards or downwards, according to the position of its layers of small cells, - in the case of a branch with large central cells, curving upwards; and in the case of a root with larger hemispherical cells, downwards.

These explanations do not appear, however, to be altogether satisfactory. It is known that the stem is directed upwards, the root downwards, but, as yet, physiologists have not been able to ascertain the laws which regulate them. The tendencies of the root and stem are not easily counteracted. When a seed is planted in moist earth, and suspended in the air, the root will, in the progress of growth, leave the earth and descend into the air in a perpendicular direction, while the stem will pass through a quantity of moist earth in an upward direction. If their positions are reversed they will become twisted, so as to recover their natural positions. Henfrey remarks that "so far as we are in a position to tell, there is some definite, and as yet unknown, cause which makes the radicle first grow towards the earth or other source of nourishment, which it penetrates by elongation, a resisting point being offered by the weight of the seed or the earth covering it; and then, in its further growth downward, it requires a point of resistance to be afforded by the adhesion of the earth around the collar, ring, or neck of the root, since the elongation takes place in the structures just above the point of the root, thus exerting a pressure upwards and downwards, which if the upper part of the root be kept free, and the weight of the plant balanced, will cause the whole to rise bodily upwards. Thus, when seeds germinate in damp moss lying upon a hard surface, the elongation of the root will push the stem up through the moss, unless the root branches so as to get fixed down by entanglement among the loose matter. We may admit, therefore, that we are at present totally ignorant of the cause of the direction taken by roots. All the notions hitherto advanced having been purely speculative."

The effect of light on the stem may be illustrated by the growth of plants in circumstances where a pencil of light only is admitted on one. side. Dr.'Poggioli of Bologna was the first who observed the influence exercised by the rays of the spectrum in causing flection of plants. Experiments on this subject have been made by Payen, Dutrochet, and Gardner. They consider the blue rays as those which have the greatest effect on the plumule. Hunter observed, that if a barrel filled.with earth, in the centre of which are some beans, was rotated for several days horizontally, the roots pointed in a direction $2 \mathrm{~A}$ 
parallel to the axis of rotation. Knight* put Mustard seeds and French beans on the circumference of two wheels, which were put in rapid motion, the one in a horizontal, and the other in a vertical manner; and he found that in the former the roots took a direction intermediate between that impressed by gravitation and by the centrifugal force-viz., downwards and outwards, while the stems were inclined upwards and inwards. In the latter, where the force of gravitation was neutralised by the constant change of position, the centrifugal force acted alone, by which the roots were directed outwards, at the same time that the stem grew inwards. To explain these results, there must be allowed-1. A more or less liquid condition of the new parts of the young plant. 2. A different density in the different parts of the latter. 3. A tendency of the denser parts of new plants, during germination, towards the root. On the vertical wheel, the parts of the young plants submitted to the centrifugal force only, had their roots or densest parts at the circumference. On the horizontal wheel the effect was intermediate between centrifugal force and gravity. The upper side of leaves is under the influence of light in a marked degree, for, when placed in the reverse position by the turning of a branch, they twist round so as to resume their natural exposure. During darkness, on the contrary, many leaves fold in such a way that their lower surface is exposed. Some plants grow indifferently in all directions at the period of germination. The Mistleto and other parasites direct their radicles towards the centre of the plants to which they are attached, while the plumule grows perpendicularly to the surface.

Monocotyledonous Germination.-In Monocotyledons there is generally a perisperm present, often in large quantity, and in them the cotyledon remains more or less within the seed at the period of germination. The intra-seminal portion of the cotyledons, as in Canna (fig. 626), and especially in the Coco-nut, becomes developed as a pale cellular mass, which increases much, and absorbs the nutriment required for the embryo. In some Monocotyledons the perisperm disappears entirely; in others, as in the Phytelephas or Ivory PaIm, while certain soluble matters are removed, the perisperm still retains its original form. The intra-seminal part may be said to correspond to the limb or lamina of the cotyledonary leaf. The extra-seminal portion, corresponding to the petiole, becomes often much elongated, as in the double Coco-nut, and ends in a sheath which envelopes the axis or cauliculus, and the plumule. Sometimes, however, there is no marked elongation of the cotyledon, the sheath being at once formed on the outside of the seed, so that the plumule and radicle are, as it were, sessile on its surface. These phenomena are well seen in Canna indica (fig. 626), where $e$ is the envelope of the seed; $p$, the peri-

* See Kright's Horticultural Papers, London, 184i, p. 124. 
sperm or albumen ; $c$, the intra-seminal portion of the cotyledon, which absorbs the nourishment; $p c$, the petiolary or extra-seminal portion of the cotyledon, which varies in length, and may be wanting; $v$, the sheathing portion of the cotyledon, from a slit in which, $f$, the plumule, $g$, protrudes, supported on the axis or cauliculus, $t$; while the

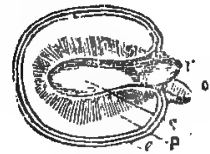

1

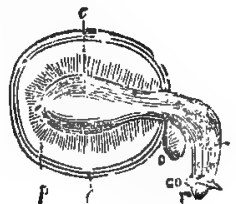

2

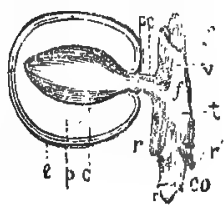

3

Fig. 626 .

radicles, $r$ and $r^{\prime}$, pierce the integument at the base, and are each covered with a separate sheath, co, called coleorhiza (fig. 105, p. 42). In aperispermic Monocotyledons, as Alismaceæ and Potameæ (fig. 595, p. 334), the cotyledon does not remain within the seed, but is raised above the ground, $c$, giving origin to the plumule, $g$, which is at first enclosed in its sheath.

Thus the cotyledon follows the development of leaves. Its limb is first produced, and is either pushed above ground, or is confined within the seed. In the latter case it is arrested in its progress; subsequently, a sheath is formed which may either be a direct continuation of the limb, or may be separated from it by a petiolary portion. When the limb is confined in the seed, and ceases to be developed, the sheath often continues to grow, forming a marked covering of the axis. The rootlets in Monocotyledons during germination (fig. $105 r r, \mathrm{p} .42$ ) pierce the radicular extremity of the embryo, and become covered with sheaths or coleorhizas, $c c$, formed by a superficial layer of cellular tissue. As the radicular extremity

Fig. 626. Germination of the monocotyledonous perispermic seed of Canna indica. The seed is cut to show the relation between the perisperm and the embryo at different stages, the former diminishing, whifie the latter increases. e, Envelope or spermoderm. $o$, Its upper part, which is separated like a lid or operculum, to allow the passage of the radicle. $p$, Perisperm or albumen. c, Cotyledon. $r$, Radicle or young root. $r^{\prime} r^{\prime}$, Secondary radicles. co, Coleorhiza or sheath of the roots. $f$, Slit indicating the position of the gemmule ; at this slit an elongated sheath, $v$, is protruded. o c, Narrow portion of the cotyledon (corresponding to the petiolary portion), intermediate between its enlarged portion, $c$ (corresponding to the Iamina or limb of the leaf), and its sheathing or vaginal portion, $v$. $t$, Tigellus or cauliculus. $g$, Gemmule or plumule. 1, First stage, in which the radicle, $r$, begins to appear through the integuments or spermoderm. 2, Second stage, where the slit, $f$, is seen also on the outer surface, indieating the situation of the gemmule. The true radicle, $r$, has pierced the envelope of the seed, and at its base shows a small sheath or coleorhiza. One of the small radicles, $r^{\prime}$, is also seen with a coleorhiza. 3, Third stage, when all the parts are more developed, and the gemmule, $g$, appears on the outside of the slit, $f$, the edges of which are prolonged in the form of a sheath or vagina, $v$. 
thus remains within the embryo, and sends out radicles (adventitious or secondary rootlets) from its surface, the plants are said to be endo-

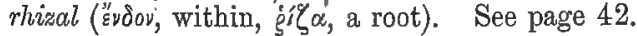

Dicotyledonous Germina tion.- In Dicotyledons, the cotyledons generally separate from the integuments, and either appear above ground in the form of temporary leaves (figs. 627, $628 \mathrm{c} c$ ), which differ in form from the permanent leaves of the plant (fig. $628 \mathrm{~g}$ ), or

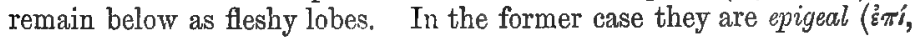

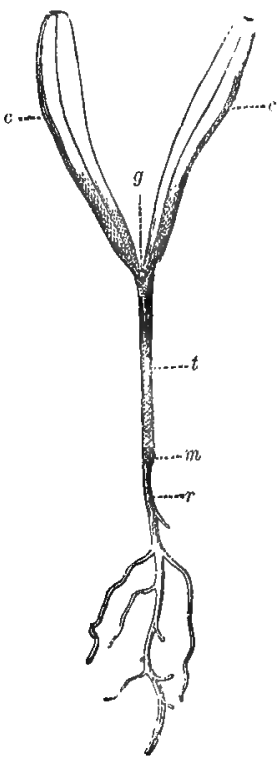

Fig. 627 .

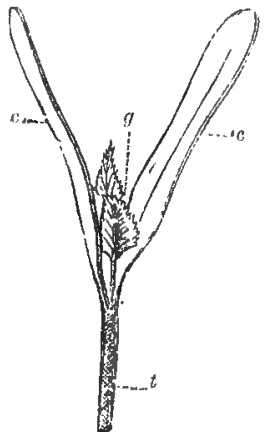

Fig. 628 .

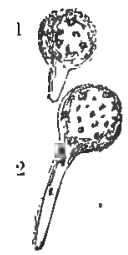

Fig. 629.

upon or above, $\gamma^{\prime} \alpha, \gamma_{\tilde{n}}$, the earth), in the latter case (as in Beans, Arachis, etc.), they are hypogeal (irró, under). The cotyledons usually separate, but sometimes they are united, and appear as one. In all cases, the plumule (figs. $627,628 \mathrm{~g}$ ) proceeds from between the two cotyledons, and does not pierce through a sheath as in monocotyle-

Fig. 627. Germination of the dicotyledonous embryo of Acer Negundo. m, Collum, collar or neck. $r$, Root. $t$, Caulicule or stem. $c c$, Cotyledons. $g$, Gemmule or plumule. Fig. 628. Upper part of the same embryo more developed. $c$ c Cotyledons. g, Gemmule, the first leaves of which are already expanded. $t$, Caulicule or stern. Fig. 629. Acotyledonous embryos or spores of Marchantia polymorpha, germinating. 1, Spore in the early stage of germination. 2, In a more advanced stage. The spores are simple cells, which elongate during germination at some point of their surface. They are heterorhizal. They may be compared to naked embryos rather than to seeds. 
dons. The root (fig. $627 r$ ) is a direct prolongation of the axis, $t$, in a downward direction, separating from it at the collar, $m$, and the embryo is here exorhizal (" $\xi \omega$, outwards). See page 41.

Acotruedonods Germination.-In Acotyledons the spore (fig. 629) has no separate embryo in its interior. It may be considered rather as a cellular embryo than a seed. It germinates by sending off cellular root-like prolongations from all parts of its surface, hence it is called heterorhizal ("זrgos, diverse) (see p. 43). These cellular processes may be formed either from the entire wall of the spore or from its inner covering. In fungi the spore give's origin to a cellular axis called spawn (mycelium), on which ultimately the fructification is developed. The spores of Fungi often germinate in anomalous positions, such as the organs of other plants, and the bodies of animals and man. Much injury is often occasioned in crops by the attacks of these spores. In the higher acotyledons the spores form in the first instance a cellular prothallus, in which the organs of reproduction ultimately are developed (see p. 279). In speaking of the germination of Hyphomycetous Fungi, Lister states that these spores (conidia) germinate in three ways. 1. They may form their sprouts, which become plants like the parent. 2. They may multiply by pullulation, like the yeast plant, and, under some circumstances, this toruloid growth may continue for an indefinite period, though the resulting progeny will, under favouring conditions, reproduce a fungus like the original. 3. The conidia may shoot out sprouts of exquisite delicacy, which break up into Bacteria. These Bacteria, like the fungi whence they are derived, are of various totally distinct kinds, both morphologically and physiologically. They give rise to different fermentative changes, and some refuse to grow in media in which others thrive. Bacteria cannot be classified merely by forms, we must take into account their physiological peculiarities.

Some seeds commence the process of germination before being detached from the plant. This occurs in a remarkable degree in the Mangrove tree, Rhizophora Mangle, which grows at the muddy mouths of rivers in warm climates. Coco-nuts often begin to germinate during a voyage from the tropics to Britain, and germinating seeds have been found in the interior of Gourds, as well as in the fruit of Carica Papaya, the Papaw. The seeds of the Banyan, or Bo-tree (Ficus indica), seldom germinate on the ground. The fig-like fruit of the tree is eaten by birds, and the seeds are deposited in the crown of Palms, where they grow, sending down roots which embrace and generally kill the Palm.

Proliferous Plants. - In place of seeds, some plants produce buds, which can be detached, and produce separate individuals. Flowers which are thus changed into separable buds are called proliferous (proles, offspring, and fero, I bear), or viviparous (vivus, alive, and pario, I produce). They are met with in many alpine grasses, as 
Festuca ovina, var. vivipara, Aira cæspitosa, var. alpina, Poa alpina, etc., as well as in Alliums, Trifoliums, and Ferns. Buds of a similar kind may be produced on the edges, or in the axil of leaves, as in Bryophyllum calycinum, Malaxis paludosa (fig. 231, p. 118), many species of Gesnera, Gloxinia, and Achimenes; and the bulbils of Lilium (fig. 230, p. 117), Ixia, Dentaria, Ornithogalum (fig. 232, p. 118), some Saxifrages (S. cernua and S. foliolosa), seem to be peculiar forms of buds, capable of being detached, and of assuming independent growth. Buds, however, differ from true embryos in the direction of the roots being towards the axis of the plant. In unicellular plants, and others of the lowest class, it is common to find each cell possessing the power of producing a new individual, either by simple division or by the formation of a cellular bud. In higher plants this mode of propagation is carried out by means of an assemblage of cells, which are developed into an organ or bud of a more complicated nature, before it is detached. Multiplication by division of cells is very common among the lowest Algæ, such as Desmidiaceæ and Diatomacer (fig. 472, p. 267). In the case of Lichens, the thallus produces gonidia (p. 269), which appear to be a collection of cellular buds capable of producing independent individuals. On the thallus of Liverworts (Marchantia) cup-like bodies are produced containing gemmæ (fig. $488 \mathrm{~g}$, p. 275). In Mosses the power of reproduction by gemmæ is very marked. Almost every cell of the surface of Mosses, according to Schimper, is capable of giving origin to a leafy plant or innovation. Ferns are propagated by buds, and gemmæ occasionally occur on their prothallium. The higher classes of plants may be considered as consisting of numerous buds united on a common axis (fig. 219, p. 109). These possess a certain amount of independent vitality, and they may be separated from the parent stem in such a way as to give origin to new individuals. In some instances buds are produced which are detached spontaneously at a certain period of a plant's life. The cloves formed in the axils of the scales of bulbs are gemmæ or buds, which can be detached so as to form new plants.

The length of time required for the protrusion of the radicle varies in different plants. Some seeds, as garden cresses, germinate in the course of twenty-four hours, others require many days or many months. Seeds with hard coverings, or a stony perisperm, may lie dormant in the soil for a year or more. The following experiments were made in the Geneva garden, on seeds similarly watered, and exposed to a medium temperature of $53^{\circ} \mathrm{F}$. It was ascertained that one-half of the species of the following families germinated after the lapse of the number of days here mentioned :-

Amarantacex

Cruciferæ

Boraginaceæ, Caryophyllaceæ, Chenopodiaceæ, Malvaceæ . 
Compositæ, Convolvulaceæ, Plantaginaceæ

Polygonaceæ.

Campanulaceæ, Leguninosæ, Valerianaceæ

Graminex, Labiatæ, Solanaceæ

Rosacex

Ranunculace

Antirrhinums, Onagraceæ

Umbelliferæ .

Temperature has a great effect in accelerating germination. Thus, Erigeron caucasicum, at a temperature varying from $49^{\circ}$ to $53^{\circ}$, germinated in ten days; at a temperature from $66^{\circ}$ to $72^{\circ}$, in two days; Dolichos abyssinicus, at the former temperature, in ten days, at the latter, in three; Zinnia coccinea, in twenty-two and five days respectively.

Duration of the Life of Plants.-Plants, according to the duration of their existence, have been divided into annual, biennial, and perennical. - The first of these terms imports that the seed germinates, and that the plant produces leaves and flowers, ripens its seed, and perishes within the year; the second, that a plant germinates and produces leaves the first year, but does not produce a flowering stem, nor ripen its seed, till the second, after which it perishes; while the third intimates that the process of flowering and fruiting may be postponed till the third year, or any indefinite period. The first two exercise the function of flowering in general only once, while the last may do so several times before dying. Under different climates, however, and under different modes of management, the same species may be annual, biennial, or even perennial. Thus, Wheat in this country is annual if sown early in spring, but biennial if sown in autumn; in hot climates Lolium perenne proves annual; the Castor-oil plant in "this country is annual, while in Italy it is a shrub of several years' duration; the annual Mignonette, by removing its flower-buds the first year, and keeping it in a proper temperature during the winter, may be rendered perennial and shrubby. Many flowering garden plants, as Neapolitan Violet and Lily of the Valley, may be brought into flower at a late period of the year, by pinching. off the blossoms in the early part of the season.

Plants, as regards their flowering and fruiting, have also been

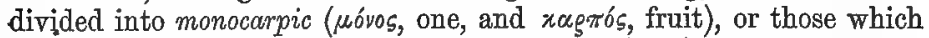
flower once only and then die; and polycarpic ( $\pi 0 \lambda . \epsilon_{\xi}$, many), or those which flower and fruit several times before the entire plant dies. Thus, annuals and biennials, which flower the first or second year and die, as well as the Agave, and some Palms which flower only once in forty or fifty years, and perish, are monocarpic; while perennials are polycarpic. Some perennial woody plants live to a great age. The Baobab of Senegal, the Wellingtonia, the Dragon-tree, the Yew, the Oak, the Lime, the Cypress, the Eucalyptus, the Olive, the Orange, Banyan, and Chestnut, often attain great longevity. 
The following is a notice of the size and age of some trees:-

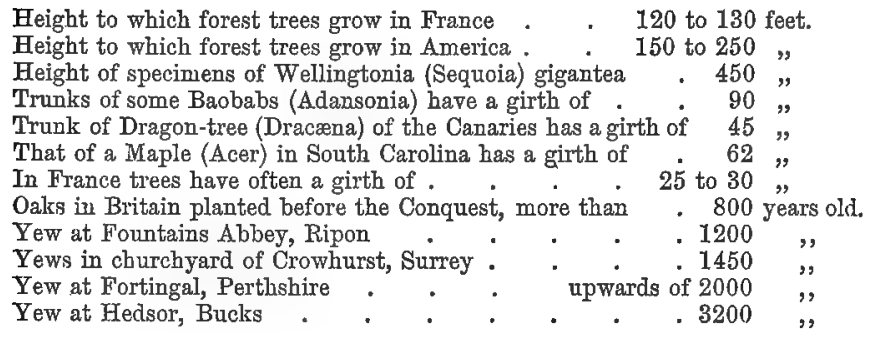

A specimen of the Banyan (Ficus indica), which grew till recently on an island in the river Nerbudda, was believed to be identical with one that existed in the time of Alexander the Great, and which, according to Nearchus, was then capable of overshadowing 10,000 men. The chief trunks of this tree greatly exceeded our English Oaks and Elms in thickness, and were above 350 in number. The smaller stems were more than 3000 in number. The Maronites believe that some Cedars near the village of Eden in Lebanon are the remains of the forest which furnished Solomon with timber for the temple, full 3000 years ago. They must be of great antiquity, seeing they were counted old 300 years ago. Maundrell mentions the size of some of the Cedars. The largest he measured was 36 feet 6 inches in circumference, and 117 feet in the spread of its boughs.

Decandolle has given a list of the ascertained ages of certain trees :-

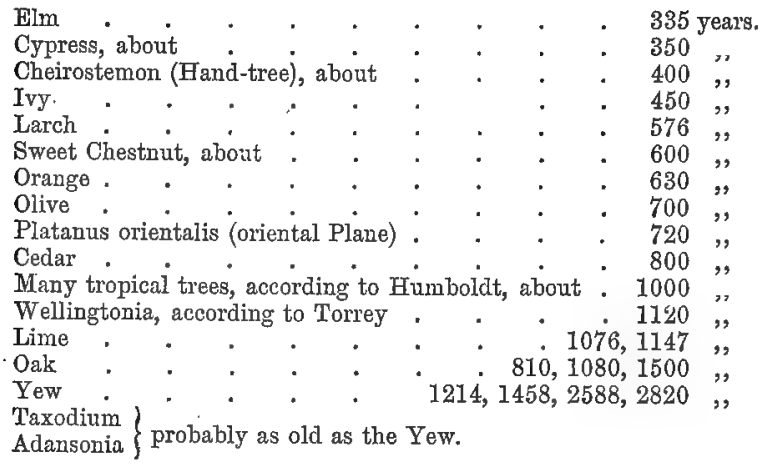

Decandolle states that the Yew increases little more than one line in diameter annually, cturing the first hundred and fifty years, and a little more than one line afterwards, and in very old specimens he con- 
siders their age to be at least equal to the number of lines in their diameter. This average, however, is probably too high for young trees, and too low for old ones. In 1836, Mr. Bowman measured the trunks of eighteen Yews in the churchyard of Gresford, near Wrexham, in North Wales, which were planted out in 1726, and found their average diameter to be 20 inches, or 240 lines. Comparing them with the dimensions of other trees whose ages are known, he came to the conclusion, that for Yews of moderate age, and where the circumference is less than 6 feet, at least two lines, or $\frac{1}{6}$ of an inch of their diameter, should be allowed for annual increase, and even three lines or more if growing in favourable cireumstances. He states that a Yew in the same churchyard, whose mean diameter is 8 feet 6 inches, or 1224 lines, and whose age, by Decandolle's method, would be as many years, was in reality 1419 years old. Sections taken from different sides of the trunk contained as follows :-

$\begin{gathered}\text { Average number of annual rings per inch, } \\ \text { counted on the horizontal plane }\end{gathered} .\left\{\begin{array}{l}\text { On the north side } 43 . \\ \text { On the south side } 46 . \\ \text { On the south-west side } 15 .\end{array}\right.$

giving a general average of $34 \frac{2}{3}$ rings in an inch of the diameter. Supposing that this tree, when 150 years old, had a diameter equal to that of the eighteen already mentioned, and among which it grows, and had continued to increase in the same ratio up to 150 years, and also making additional allowance for an intermediate rate of increase between 150 and 250 years, Mr. Bowman arrives at the following result :-At 150 years old, its diameter would be 25 inches; at 246 years old, 33 inches, leaving 5 feet 9 inches of the diameter for subsequent increase, the radius of which, at 34 rings to the inch, would contain 1173 rings, or years of growth; to this add 246 , and its present age would be 1419 years.

Another Yew in Darley churchyard, Derbyshire, is mentioned by Mr. Bowman, in which sections taken from its north and south sides gave 44 annual rings in the inch, so that its radius would contain 286 such rings, supposing them to be of equal thickness throughout, but making the same deductions as before, its present age may be estimated at about 2006 years. This examination shows the Gresford Yew to be about 200, and that at Darley about 650 years older than Decandolle's standard of one line per annum of the diameter would indicate, and consequently, that for old trees his average is too low. It also shows that the Darley tree, with a greater diameter than the other of only 11 inches, is 587 years older, the excess arising from the extreme thinness of its annual deposits. No precise rule can therefore be laid down, and actual sections must be resorted to if anything like accuracy be required. 


\section{0.-General Observations on the Organs of Plants, and on the}

Mode in which they are arranged.

Plants may be said to be composed of numerous individuals, each having a sort of independent existence, and all contributing to the general growth of the compound individual formed by their union. In the case of a tree there are a vast number of buds, each of which is capable of being removed, and of being made to grow on another tree by grafting; and although each has thus a vitality of its own, it is nevertheless dependent on the general vitality of the tree, so long as it is attached to it. The same thing is seen in Sertularian Zoophytes. Each of the individuals forming a compound plant is called by Gaudichaud a phyton (申uróv, a plant), and in it he recognises three parts or merithalli ( $\mu \dot{s}$ gos, a part, and $\theta \alpha \lambda \lambda \sigma^{\prime} s$, a young shoot), the radicular merithal corresponding to the root, the cauline to the stem, and the foliar to the leaf. In Acotyledonous plants the embryo or spore consists of united cells, and it is only after germination that it exhibits these different parts. In Monocotyledons, the embryo consists of a single phyton, with a radicular merithal or radicle, a cauline or tigellus, and a foliar or cotyledon. In Dicotyledons the embryo consists of two or more phytons united, with their foliar merithals (cotyledons) distinct, while their cauline and radicular merithals form each a single organ.

In tracing the various parts of plants, it has been shown that all may be referred to the leaf as a type. This morphological law was propounded by Linnæus and Wolff, but it is to Goethe we owe the full enunciation of it. Vegetable morphology, the study of forms, or the reference of the forms of the parts of plants to the leaf, is now the basis of organography, and it will be observed that in considering the various organs this has been kept constantly in view. The calyz, corolla, stamens, and pistil, are only modifications of the leaf adapted for peculiar functions. It is not meant that they were originally leaves, and were afterwards transformed; but that they are formed of the same elements, and arranged upon the same plan, and that in the changes which they undergo, and the relation which they bear to each other, they follow the same laws as leaves do. The different parts of the flower may be changed into each other, as into true leaves; or, in other words, the cellular papillæ from which they are formed are capable of being developed in different ways, according to laws which are still unknown. These changes may take place from without inwards, by an ascending or direct metamorphosis, as in the case of petals becoming stamens; or from within outwards, by descending or retrograde metamorphosis, as when stamens become petals.

Bracts are very evidently allied to leaves, both in their colour and 
form. Like leaves, too, they produce buds in their axil. - The monstrosity called Hen and Chickens Daisy depends on the development of buds in the axil of the leaves of the involucre. The sepals frequently present the appearance of true leaves, as in the Rose. The petals sometimes become green like leaves, as in a variety of Ranunculus Pbilonotis mentioned. by Decandolle, and in a variety of Campanula rapunculoides noticed by Dumas. At other times they are changed into stamens. Decandolle mentions a variety of Capsella Bursa-pastoris, in which there were ten stamens produced in consequence of a transformation of petals. The stamens in double flowers are changed into petals, and in Nymphra alba there is a gradual transition from the one to the other. Sometimes the stamens are changed into carpels, and bear ovules. This has been seen in Wallflower, some Willows, Poppy, etc. Petit-Thouars noticed a plant of House-leek, in which the one-half of the anthers bore ovules, and the other half pollen. The carpels, as in the double Cherry, may be seen in the form of folded leaves; in double flowers they are transformed into petals, and in other cases they are developed as stamens. In a monstrosity of Wallfower the placenta gave origin to flowers. It is said that increase of temperature and luxuriance of growth sometimes make flowers produce stamens only. In plants having unisexual flowers this is more liable to take place, as in Melon, Cucumber, etc. Increased vigour seems to be required for the development of stamens. Some fir trees in their young state bear cones, and produce male flowers only when they reach the prime of life.

SYMMETRY OF ORGANS.-In the progress of growth the plants belonging to the different divisions of the vegetable kingdom follow

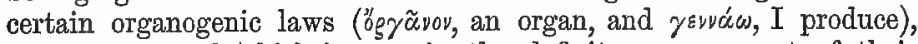
the operation of which is seen in the definite arrangement of their organs. The flower consists sometimes of three, at other times of four or five equal sets of organs, similarly and regularly disposed. Thus, the Iris has three straight parts of its perianth, and three reflexed ones alternately disposed, while the Fuchsia has four parts of the calyx alternating with four petals, and the Rose has five alternating portions. This orderly and similar distribution of a certain number of parts is called symmetry, and flowers are thus said to be symmetrical with various numbers of members. When the number of parts is two the flower is dimerous. (dis, twice, $\mu^{\prime}$ gegos, a part) (fig. 630 ), and the symmetry two-membered. When the number of parts is three the flower is trimerous ( $\varepsilon_{\varepsilon} \varepsilon \tilde{r}$, three), and when the parts are arranged in an alternating manner (fig. 631) the symmetry is trigonal or triangular (regřs, three, yavía, an angle), as in the Lily.

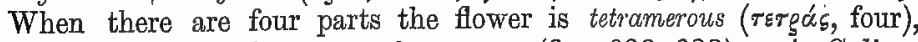
and the symmetry is tetragonal or square (figs. 632,633), as in Galium and Paris. When there are five parts the flower is pentamerous 
( $\pi \dot{\varepsilon} y r \varepsilon$, five), and the symmetry pentagonal (fig. 634), as in Ranunculus. The number of parts in the flower is indicated by the following symbols :-Dimerous $\sqrt[2]{ }$, Trimerous $\sqrt[8]{ }$, Tetramerous $\sqrt[4]{ }$, Pentamerous $\sqrt[5]{ }$.

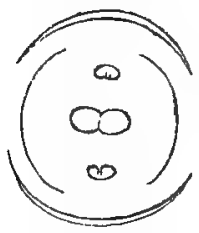

Fig. 630.

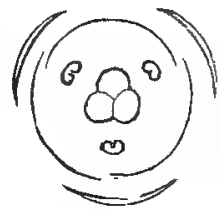

Fig. 631 .

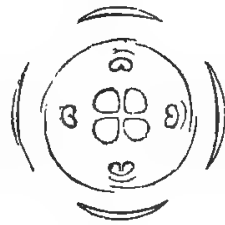

Fig. 632 .

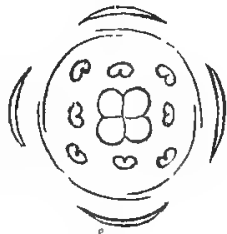

Fig. 633 .

There are also other kinds of arrangements in flowers, which may be referred to certain modifications in the organogenic law. Thus, what is called oblong or two and two-membered symmetry, occurs in cases where the opposite ends are similar, and the opposite sides, as in the arrangement of the stamens of Cruciferæ. The term symmetry, however, is properly confined to cases where the parts are arranged alternately, and are either equal or some multiple of each other, and has no reference to the forms of the different parts. In the very young state, the parts of the flower appear as a shallow rim, from which the petals and sepals arise as mammillæ, in a symmetrical manner. In the case of irregular corollas the parts at first appear regular. In speaking of flowers it is usual to call them symmetrical when the sepals, petals, and stamens follow the law mentioned, even although the pistil may be abnormal. Thus, many Solanaceæ are pentamerous, and have a dimerous ovary, yet they are called symmetrical. In Cruciferæ the flowers are, properly speaking, unsymmetrical, for while there are four sepals and four petals, there are six stamens in place of four. This condition of the stamens depends probably on deduplication (p. 210). In Papilionaceous flowers the parts are usually symmetrical, there being five divisions of the calyx, five petals, and ten stamens in two rows. In these flowers there should normally be five carpels, but there are very rarely more than one.

In Dicotyledonons plants it is common to meet with pentagonal (figs. 634, 635, 636) and tetragonal (figs. 632, 633) symmetry, the parts being arranged in fives and fours, or in multiples of these num-

Fig. 630. Diagram of the dimerous flower of Circæa Lutetiana, Enchanter's Nightshade. There are two carpels, two stamens, two divisions of the corolla, and two of the ealyx. The flower is Isostemonous. Fig. 631. Diagram of the trimerous Isostemonous flower of Cneorum tricoccum. The floral envelopes are arranged in sets of three, and so are the essential organs. Fig. 632. Diagram of the tetramerous Isostemonous flower of Zieria. The organs are arranged in verticils of four parts each. Fig. 633. Diagram of the tetramerous Diplostemonous flower of Ruta graveolens. There are four carpels, eight stamens, or four in each verticil, four folioles of the calyx, and four petals. 
bers. The stamens are often more numerous than the petals, and in that case they are arranged in different verticils, each alternating with that next it. Thus, if there are five sepals, five petals, and twenty stamens, the latter are considered as forming four verticils. No doubt the verticils are often traced with difficulty, more especially when

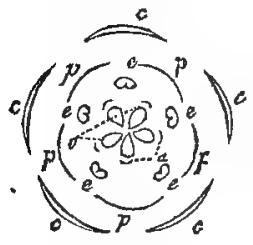

Fig. 634 .

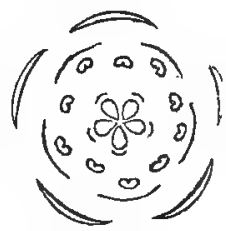

Fig. 635.

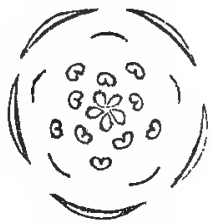

Eig. 636 .

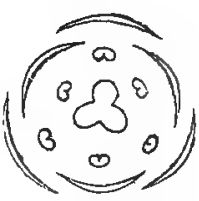

Fig. 637.

cohesions or adhesions take place. In Monocotyledons (fig. 637) the parts are usually in sets of three, or in some multiple of that number, exhibiting trigonal symmetry. In Acotyledons, when any definite number can be traced, it is found to be two, or some multiple of two. The teeth of Mosses are in sets of four, or some multiple of four. The spores of many Acotyledons are also arranged in fours (fig. 482, p. 273).

TERAToLOGY.--There has thus been traced a tendency to symmetrical arrangement. But the parts of plants are often modified by natural causes which cannot be explained. It is assumed that each of the :similar members of a flower have the same organisation, and a similar power of development; and henee, if among these similar parts some are less developed than others, they are considered as abortive, and these abnormal states are traced to changes which take place in the earlier stages of growth. Such changes often interfere with the symmetry of the flower. Alteration in the symmetrical arrangement, as well as in the forms of the different parts of plants, have been traced to suppression or the non-development of organs, degeneration or imperfect formation, colesion or union of parts of the same whorl, adhesion or union of the parts of different whorls, multiplication of parts, and deduplication (sometimes called chorisis). The study of Teratology (r'şas, a monstrosity, and $\lambda o$ ó 0 , treatise), or of the monstrosities occurring in plants,

Fig. 634. Diagram of the pentamerous Isostemonous flower of Crassula rubens. c c c f $c$, Parts of the calyx. $p p p p p$, Petals alternating with the leaves of the calyx. $\quad$ e $e$ e $e$, Stamens alternating with the petals. $\quad$, Accessory bodies in the form of scales, or a disk alternating with the stamens. These scales are often an abortive row of stamens. 0 , Carpels alternating with the stamens, and opposite to the scales. Fig. 635. Diagram of the pentamerous flower of Sedum Telephium. The stamens are ten, arranged in two alternating verticils. The flower is Diplostemonous. Fig. 636. Diagram of the pentamerous Diplostemonous flower of Coriaria myrtifolia ; the parts of the four whorls alternating, the verticil of stamens being double. Fig. 637. Diagram of the trimerous Diplostemonous flower of Ornithogalum pyrenaicum. Stamens six, in two alternating verticils. 
has led to many important conclusions relative to the development of organs, and it is only by tracing the parts of plants through all their stages and transformations that correct ideas can be formed as to their relations and forms.*

By suppression is meant the non-appearance of an organ at the place where it ought to appear if the structure was normal, the organ being wanting to complete the symmetry. This suppression is liable to occur in all the parts of plants, and gives rise to various abnormalities. Suppression may consist in the non-appearance of one or more parts of certain verticils, or of one or more entire verticils. In the flowers of Staphylea (fig. 638) there are five parts of the calyx, five petals, five stamens, and only two carpels; in many Caryophyllaceæ, as Polycarpon and Holosteum (fig. 639), while the calyx and corolla are pentamerous, there are only three or four stamens and three carpels ; in Impatiens noli-me-tangere (fig. 640) the caiyx is composed of three parts, while the other verticils have five ; in Labiate flowers there are five parts of the calyx and corolla, and only four stamens; and in Tropæolum pentaphyllum (fig. 641) there are five sepals, two

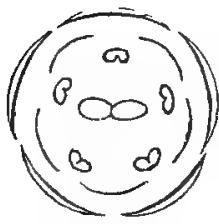

Fig. 638 .

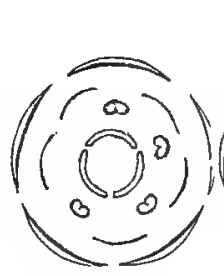

Fig. 639 .

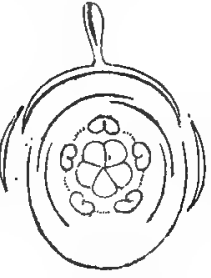

Fig. 640.

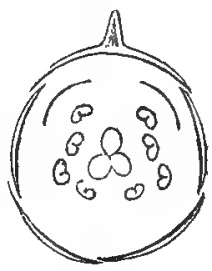

Fig. 641 .

petals, eight stamens, and three carpels. In all these cases the want of symmetry is traced to the suppression of certain parts. In the lastmentioned plant the normal number is five, hence it is said that there are three petals suppressed, as shown by the position of the two remaining ones (fig. 641); there are two rows of stamens, in each of which one is wanting, and there are two carpels suppressed. In many

Fig. 638. Diagram of the flower of Staphylea pinnata. The parts of the caiyx, corolla, and stamens are pentamerous, while the pistil, in consequence of the suppression of three carpels, is dimerous. Fig. 639. Diagram of the flower of Holosteum umbellatum. There are five calycine divisions, and five petals ; but the stamens, by the suppression of one, are only four in number; while the carpels are, by suppression, reduced to three. Thus the flower is unsymmetrical. Fig. 640. Diagram of the flower of Impatiens parviflora, with one of the calycine leaves spurred. There are five carpels, five stamens, five petals, one of which is larger than the rest, but only three parts of the calyx, in consequence of suppression. Fig. 641. Diagram of the flower of Troprelum pentaplayllum, with a spurred or calcarate calycine leaf. The petals, by suppression, are reduced to two; the stamens are eight in place of ten, and the carpels three in place of five.

* For a complete treatise on this subject, see Vegetable Teratology, by Dr. M. T. Masters. 
instances the parts which are afterwards suppressed can be seen in the early stages of growth, and occasionally some vestiges of them remain in the fully developed flower. Sometimes the whorl of the petals is wanting, the flowers being apetalous ( $\alpha$, privative, and $\pi_{\dot{\varepsilon}} \dot{\text { c̆ }} \lambda$ ov, a leaf) (fig. 642), and in such cases it is common to see the stamens opposite to the segments of the calyx which is the whorl (verticil) next to them, as in Chenopodiacer

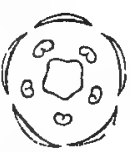

Fig. 642.

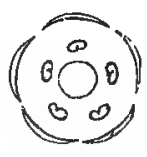

Fig. 643 .

(fig. 643). That this suppression of the petals takes place is shown in the case of certain allied plants, as in the natural orders Caryophyllaceæ and Paronychiaceæ, where some species have petals and others want them.

By the suppression of the verticil of the stamens, or of the carpels, flowers become unisexual (unus, one, and sexus, sex), or diclinous (dís, twice, and $\left.x \lambda_{-i}^{\prime} v x_{i}\right)$, a bed, and are marked thus, $\delta$ q ; the first of these symbols indicating the male, and the second the female flower. Thus, in Jatropha Curcas (fig. 346, p. 218), the flowers have five segments of the calyx, and five petals, while in some (fig. 346,1 ) the pistil is wanting; in others (fig. 346,2), the stamens. In the genus Lychnis there are tisually stamens and pistil present, or the flower is hermaphrodite, or monoclinous ( $\mu$ óvos, one, and xגivn, a bed); but in Lychnis dioica some flowers have stamens only; others pistils only. Thus it is that moncecious or monoicous and diocious or dioicous ( $\mu$ óvos, one, dis, twice, and oixiov, a habitation) plants are produced by the suppression of the essential organs of the flowers, either in the same or in different individuals of the same species; while polygamous ( $\pi 0 \lambda_{u} u_{5}$, many, and

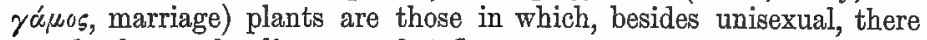
are also hermaphrodite or perfect flowers.

Some parts of the pistil are generally suppressed in the progress of growth, and hence it is rare to find it symmetrical with the other whorls. When the fruit was treated of (p. 299) it was shown that carpels and ovules often become abortive by pressure and absorption, so that the pericarp and seeds differ in their divisions and numbers from the ovary and oviules. If the whorls of the calyx and corolla are wanting the flower becomes naked or achlamydeous (p. 177). It may still, however, be fitted for the functions of producing seed; but if the essential organs-viz. the verticils of stamens and pistils-are suppressed, then the flower, however showy as regards its envelopes, is

Fig. 642. Diagram of the flower of Glaux maritima, showing the suppression of the verticil of the corolla. There are five divisions of the calyx, five stamens alternating with them, and five divisions of the ovary, with a central placentation. Fig. 643. Diagram of the flower 'of Chenopodium album, showing the suppression of the verticil of the corolla. The five stamens, in this ease, are opposite to the divisions of the calyx, thus exhibiting the arrangement which might be expeeted from a non-development of the corolla. The divisions of the ovary are not easily seen, the placentation being central. 
unfit for its functions, and is called neuter. Flowers having stamens only are staminiferous, staminal, sterile; those having pistils only are pistilliferous, pistillate, or fertile. The suppression of various verticils,

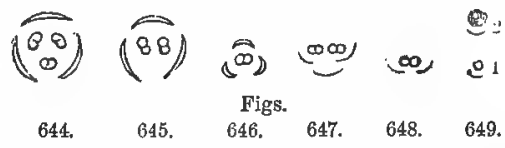

and parts of them, is well seen in the family of the Euphorbiacer (figs. 644-649). Thus, in fig. 644 is delineated an apetalous trimerous staminal flower; in fig. 645 one of the stamens is suppressed, and in fig. 646 two of them are wanting. Again, in figs. 647, 648, 649, the calyx is suppressed, and its place occupied by one, two, or three bracts (so that the flower is, properly speaking, achlamydeous), and only one or two stamens are produced. In fig. 649,1 , there is a sterile flower, consisting of a single stamen with a bract; and in fig. 649, 2, a fertile flower,"consisting of a single carpel with a bract. There is

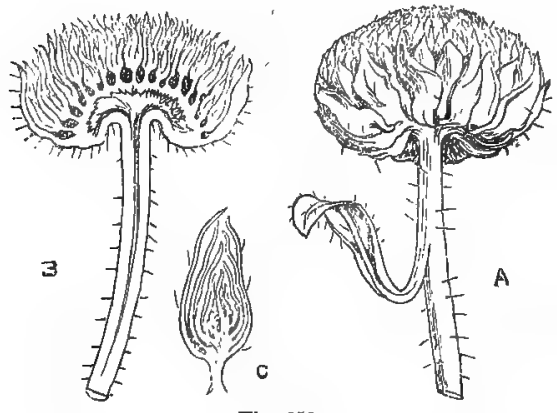

Fig. 650 . thus traced a degradation, as it is called, from a flower with three stamens and three divisions of the calyx, to one with a single bract and a single stamen or carpel.

It is common to find some of the buds of a plant suppressed, thus altering the spiral arrangement. Such buds, however, are often capable of being developed, if any accident occurs, or if the plant is pruned. Deficiency of light and of air, and

Figs. 644-649. Diagrams of flowers of Euphorbiaceous plants, becoming more and more simple. (1.) The calyx is the only envelope, and consists of three parts, in figs. 644,645 , and 646. It is completely suppressed in figs. 647,648 , and 649 , and its place is occupied by a brast, in the axil of which the flower is produced; this bract being accompanied in figs. 647 and 648 with two small bractlets. (2.) The male flowers in fig. 644 have three stamens, in figs. 645 and 646 they have two, in figs. 646 and 648 one stamen only is developed, and in fig. 649,1 , the solitary stamen has only one anther-lobe. (3.) The female flower in fig. 649,2 , is reduced to a single carpel, with a bract in the axil of which it is produced. Fig. 644. Diagram of a staminiferous flower of Tragia cannabina. Fig. 645. Diagram of a staminiferous flower of Tragia volubilis. Fig. 646. Diagram of a staminiferous flower of Anthostema senegalense. Fig. 647. Diagram of a staminiferous flower of Adenopeltis colliguaya. Fig. 648. Diagram of a staminiferous flower of a Euphorbia. Eig. 649. 1, Diagram of a staminiferous flower of Naias minor. 2, of a pistiliferous flower of Naias major. Fig. 650. Capitula of Daisy, in which small tufts of greenish leafy scales occupy the place of the flowers. A represents the Capitulum of the Daisy with tufts of leaves in place of flowers, and a leaf on the scape. B, Section of the Capitulum. C, Section through one of the leafy tufts. 
want of proper nourishment, are capable of producing abortions of various kinds. The non-development of a branch gives rise to clustered or fascicled (fascis, a bundle of twigs) leaves, as in the Larch, and to fascieled twigs, as in a common bird-nest-like monstrosity of the Birch. When the true leaves of a plant are suppressed, their place may be occupied by a tendril, as in Lathyrus Aphaca, in which the stipules perform the functions of leaves (p. 120); or the petiole may be developed in a peculiar way, as in the phyllodia (p. 96) of some Acacias.

Degeneration, or the transformation of parts, often gives rise either to an apparent want of symmetry or to irregularity in form. Branches, when not properly developed, may assume the form of thorns or spines (p. 119), as in the Hawthorn and Wild-plum; and by culture these spines may be converted into leaf-bearing branches. Leaves often become mere 'scales, as in Lathræa, Orobanche, and in Bulbs. The limb of the calyx may appear as a rim, as in some Umbelliferæ; or as pappus, in Compositæ and Valeriana. In Scrophularia the fifth stamen appears as a scale-like body, called staminodium (fig. 378, p. 227); in other Scrophulariaceæ, as in Pentstemon, it assumes the form of a filament, with hairs at its apex in place of an anther. In unisexual flowers it is not uncommon to find vestiges of the undeveloped stamens in the form of filiform bodies or scales. To many of these staminal degenerations Linnæus gave the name of nectaries. In double flowers transformations of the stamens and pistils take place, so that they appear as petals. In Canna, what are called petals are in reality metamorphosed stamens. In the capitula of Compositæ we sometimes find the florets converted into green leaves (fig. 650). Allusion has already been made to the various changes which the different parts of the flower thus undergo. The object of the florist is to produce such monstrosities; and flowers, which by him are considered perfect, are looked upon by the botanist as imperfect, from the want of the essential organs.

Cohesion, or the union of parts of the same whorl, and Adhesion, or the growing together of parts of different whorls, are very common causes of changes both as regards form and symmetry. The union of stems gives rise occasionally to anomalies, as in the fasciated stalk of Cockscomb (fig. 251, p. 174), and the flattened stems of some Coniferæ (p. 117), and probably also the peculiar stems of certain Sapindaceæ and Menispermaceæ of Brazil (p. 62). Some of these, however, may perhaps be traced not to union, but to an abnormal development of buds, producing wood only in one direction, in place of all round. Natural grafts occasionally occur from one branch of a tree uniting to another. Roots also sometimes become grafted, and to this has been attributed the vitality occasionally preserved by the stumps of Spruce-firs which have been felled on the Swiss Alps. The 
cohesion of two leaves by their bases forms a connate leaf, and the union of the lobes of a single leaf on the opposite side of the stalk gives rise to perfoliate leaves (fig. 171, p. 89 ). The union of the edges of a folded leaf forms Ascidia, or pitchers (figs. 200, 203, pp. 95, 96). The different parts of the same verticil of the flower unite often more or less completely, giving rise to a monophyllous or gamophyllous involucre (p. 190); a monosepalous or gamosepalous calyx (fig. 297, p. 197 ; a monopetalous or gamopetalous corolla (figs. 318, 319 , p. 206); monadelphous (figs. 338, p. 213 ; 346, 1, p. 218), diadelphous (p. 218), and polyadelphous (figs. 347, p. 218; 651) stamens; syngenesious anthers (p. 227); a gynandrous column ( $\mathrm{p}$. 220 ), and a syncarpous ovary (fig. 417, p. 239). The different verticils of the flower are frequently adherent. The calyx is often united

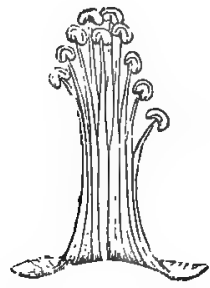

Fig. 651.

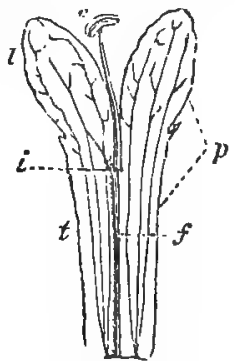

Fig. 652 .

to the corolla or to the stamens, or both (fig. 339, p. 213); the stamens may adhere to the corolla (fig. 652); or there may be a union of the torus with the ovary, so that the calyx becomes superior (fig. 340, p. 214). In some instances, when the axis is elongated, adhesions take place between it and certain whorls of the flower. Thus, in some Caryophyllaceæ (fig. 653), the calyx, c, bearing the stamens, $e$, and petals, $p$, becomes united to the axis, $g$, which supports the ovary, $o$. In Capparidacer (fig. 654), the calyx, $c$, and petals, $p$, occupy their usual position, but the axis is prolonged in the form of a gynophore, $a g$, to which the stamens, $e$, are united. Occasionally, contiguous flowers may unite, giving rise to double fruits, as is sometimes seen in Apples, Grapes, and Cucumbers.

Multiplication, or an increase of the number of parts, gives rise to changes in plants. It is often found that in plants belonging to

Fig. 651. One of the five bundles of stamens taken from the polyadelphous flower of Malva miniata. Stamens are united by their filaments. Fig. 652. Portion of the gamopetalous or monopetalous corolla, $p$, of a Collomia, showing part of the tube, $t$, terminated by two lobes of the limb, $l$, and having the stamen, $e$, inserted into it, and united to it, so that the upper part of the filament, $i$, only is free. 
the same natural order the number of stamens in one is greater than that in another, either in consequence of additional stamens being developed in the verticil, or on account of the production of additional

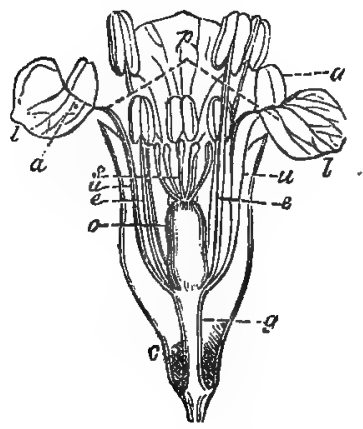

Fig. 653 .

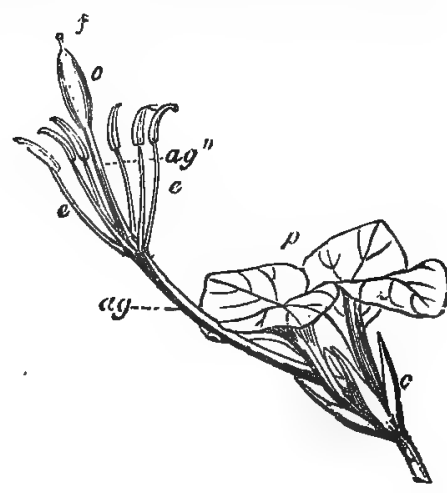

Fig. 654 .

verticils. The same thing is met with in the case of the other whorls, and is well illustrated in the formation of the disk (p. 234). Multiplication causes a repetition of successive whorls, which still follow the law of alternation.

Parts of the flower are often increased by a process of deduplication, unlining, dilamination, or chorization, i.e. the separation of a lamina from organs already formed (p. 210). This is believed to take place in a remarkable degree in the case of appendages to petals. Thus, in Ranunculus, the petal (fig. 655) has a scale at its base, a, which is looked upon as a mere fold of it. This fold may in some cases be more highly developed, as in Caryophyllacew, and in Crassula rubens (fig. $282 a$ ), and it may even assume the characters of a stamen, which will therefore be opposite the petal, as in Primulace». Some do not consider the production of scales or stamens opposite to the petals as the result of chorization. Lindley argues against it from what is observed in Camellia japonica, in which the petals are usually alternate; but, by cultivation, the law of alternation is interfered with, and the parts are so developed that the petals are opposite, and

Fig. 653. Flower of Lychnis Viscaria, one of the Caryophyllaceæ, eut lengthwise, to show the relation of its different parts. i, Gamosepalous calyx. p, Petals with their elongated unguis or claw, $u v$, their limb, $l l$, and the appendages, $a a$, in the form of dilaminated scales of the petals. e e, Stamens. Pistil consists of the ovary, o, and five styles, $s$. Prolongation of the axis $g$, in the form of a gynophore or anthophore, bearing the petals, the stamens, and the pistil. Fig. 654. Flower of Gynandropsis palmipes, one of the Capparidacex. c, Calyx. $p$, Petals. e, Stamens. ag, Gynophore or elongated internode or axis bearing the stamens. $a g^{\prime \prime}$, Gynophore or elongated internode bearing the pistil. of, Pistil composed of an ovary, 0 , a style and a stigma, $f$. 
run in several regular lines from the centre to the circumference. Again, by this process of deduplication it is supposed one stamen may give rise to several. Thus, in Luhea paniculata (fig. 348,

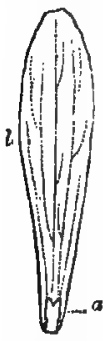

Fig. 655. p. 219), in place of five stamens there are five bundles, composed partly of sterile filaments $f s$, and partly of filaments bearing anthers, $f a$; and each of these bundles is traced to a deduplication of a single stamen, inasmuch as they arise from one point, and do not follow the law of alternation. This process, therefore, repeats the single organs, and causes opposition of parts. Such cases may be explained by supposing each stamen to represent a compound leaf, or a single leaf divided in a digitately-partite manner (p. 219). In the case of the four long stamens of Cruciferæ (p. 364), chorization is said to take place by a splitting of the filaments of two stamens; and thus the two stamens on each side are, by gemination (gemini, twins), normally one. This view is supported by cases in which the filaments of the long stamens are more or less united; also by cases in which the shorter filaments exhibit tooth-like processes on either side, while the longer ones have them only on the outer side. In such cases the two long filaments, if united, would present the same appearance as the shorter ones, and occupy their usual position of alternation with the petals. In some instances, by pelorization ( $\pi \varepsilon \lambda$ wgsos, monstrous), it is found that tetradynamous plants become tetrandrous, with stamens of equal length alternating with the petals.

The mode of explaining anomalies is well illustrated by Darwin's view of the formation of the flower of an Orchid (fig. 656). According to him "An Orchid flower consists of five simple parts-namely, three sepals and two petals; and of two compounded parts-namely, the column and labellum. The column is formed of three pistils, and generally of four stamens, all completely confluent. The labellum is formed of one petal and two petaloid stamens of the outer whorl, likewise completely confluent." This view of the nature of the labellum explains its large size, its frequently tripartite form, and especially its manner of coherence to the column, unlike that of the other petals. As rudimentary organs vary much, we can thus also probably understand the variability of the excrescences on the labellum. With respect to the six stamens or anthers which ought to be represented in every Orchid, the three belonging to the outer whorl are always present, with the upper one generally fertile, and the two lower ones invariably petaloid and forming part of the labellum; the three stamens of the inner whorl are less plainly developed, especially the lower one, which, when it can be detected, serves only to strengthen

Fig. 655. Petal of Ranunculus Ficaria, viewed on the inside. $l$, The limb. a, Small scaly appendage at its base, formed by chorization or dilamination. 
the columan, and, in some rare cases, according to Brown, forms a separate projection or filament. The upper two anthers of this inner: whorl are fertile in Cypripedium, and in other cases are generally represented either by membranous expansions or by minute auricles without spiral vessels. These auricles, however, are sometimes quite absent, as in some cases of Ophrys." On this view of the homologies of Orchid flowers, Darwin further remarks-"We can understand the existence of the conspicuous central column,- - the large size, generally tripartite form, and peculiar manner of attachment of the labellum,the origin of the clinandrium,- - the relative position of the single fertile anther in most Orchids, and of the two fertile stamens in Oypripedium, - the position of the rostellum, as well as of all the other organs, - and, lastly, the frequent occurrence of a bilobed stigma, and the occasional occurrence of two distinct stigmas."

Upper or posterior sepal.

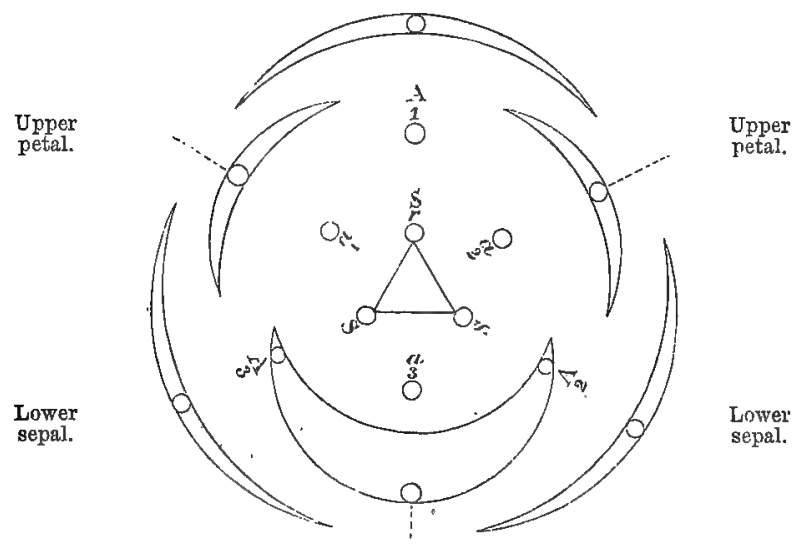

Labellum.

Fig. 656.

SeCtron of the Flower of an OrChID (Darvin).

Fig. 656. The little circles show the position of the spiral vessels, which alternate in five whorls, the three central groups running to the three petals are connected by a triangle.

$\mathrm{S}$ S. Stigmas ; $\mathrm{S}_{r}$, stigma modified into the rostellum.

$A_{1}$. Fertile anther of the outer whorl; $A_{2}, A_{3}$, anthers of the same whorl combined with the lower petal, forming the labellum.

$a_{1} \alpha_{2}$. Rudimentary anthers of the inner whorl (fertile in Cypripedium), generally forming the clinandrium; $a_{3}$ third anther of the same whorl, when present, forming the front of the column. 
Cultivation has a great effect in causing changes in the various parts of plants. Many alterations in form, size, number, and adhesion of parts, are due to the art of the horticulturist. The development of cellular tissue and of starchy matter is often thus much increased, as may be seen in the case of Turnips, Carrots, and Potato. The succulence of the leaves of the Cabbage and Lettuce, and the formation of a heart, as it is called, is due to cultivation; so also the curled leaves of Savoys, Cress, Endive, etc. The changes in the colour and forms of flowers thus produced are endless. In the Dahlia, the florets are rendered quilled, and are made to assume many glowing colours. In Pelargonium the flowers have been rendered larger and more showy; and such is also the case with the Ranunculus, the Auricula, and the Carnation. Some flowers, with spurred petals in their usual state, as Columbine, are changed so that the spurs disappear; and others, as Linaria, in which one petal only is usually spurred, are altered so as to have all the petals spurred, and to present what arecalled pelorian varieties.

Section IV.-Some General Phenomena connected with Vegetation.

\section{1.-Vegetable Irritability.}

Under this head are included certain sensible movements of living plants not referable to mere elasticity, or to the hygroscopic nature of the tissues. These motions are influenced chiefly by light and heat, and, like many phenomena occurring in organised beings, they cannot at present be fully explained by chemical or mere mechanical laws. They may, however, be excited by stimuli of a chemical or mechanical nature. Although the cause of them is obscure, still, in some instances, their use is obvious.

Among the lowest classes of plants there are some peculiar movements of this kind. The simplest members of the sea-weed tribe occasionally move throughout their whole substance. Oscillatorias, which are filaments composed of cells placed end to end, containing fluid and granular matter, have an undulating movement, by means of which they advance. When placed in fluids under the field of the microscope, some of them may thus be seen to pass from one side to the other. The filaments sometimes twist up in a spiral manner, and then project themselves forward by straightening again. The motions are influenced by temperature and light. The spores of many Cryptogamic plants, especially species of Vaucheria, and Conferva, and 
Prolifera, exhibit motions which depend on the presence of cellular hair-like processes called cilia. These mobile organs are in a state of constant agitation, which lasts for some hours, becoming slower, and finally ceasing after germination has commenced. In the spores of Conferva glomerata and rivularis (fig. 467, p. 265) there are two of these cilia or filiform tenţacula, which project from a colourless rostrum. In Chætophora elegans, var. fusiformis, four have been seen (fig. 468, p. 265); in Prolifera (fig. 469, p. 265) there is a circle of cilia, and in Vaucheria (fig. 478, p. 269) the spore is entirely covered with very short cilia, the vibration of which determines their forward movement. These spores, from their movements, have received the name of Zoospores (p. 265). Mr. Thwaites accounts for the rhythmical movements of cilia by electrical currents. In certain cells of Cryptogamic plants,'especially in what are called Antheridia, bodies are met with called Phytozoa or Spermatozoids (p. 265), which also exhibit movements during a part of their existence. They are well seen in Edogonium (p. 271), Sphæroplea (p. 272), Saprolegnia (p. 273), Fucus (p. 273), Hepaticæ (p. 276), Mosses (p. 277), and Ferns and their allies (pp. 279, 280).

Remarkable movements have also been observed in the higher classes of plants. The fovilla contained in the pollen-grain in a young state, when moistened with water, exhibits movements when viewed under the microscope. These movements have by some been referred to irritability, but by Brown and other accurate observers they are considered as merely molecular, and similar to what takes place between the minute particles of inorganic matter-as, for instance, finely powdered Gamboge suspended in water. These fovilla movements are easily seen in the very young pollen of Antirrhinum majus. Certain movements also take place in the floral envelopes. Thus many flowers open and close at particular, periods (p. 262); these phenomena depending on light, temperature, and moisture. Leaves also, especially those which are compound, are folded at certain periods in a distinct and uniform manner. What was called by Linnæus the sleep of plants is the change produced on leaves by the absence of light. It is by no means analogous to the sleep of animals. During: darkness some are slightly twisted and hang down; others, such as pinnate and ternate leaves, have the leaflets folded together, and frequently the common petiole depressed. The youngest leaflets first exhibit these changes; and when the plants becomé old, and their tissues are hardened, the irritability is often much diminished, as is seen in Oxalises. The folding of the leaflets of compound leaves usually takes place from below upwards, but sometimes in the reverse manner, as in Tephrosia Caribæa; so also with the common petiole, which is directed upwards during sleep in the Cassias and downwards in Amorpha. When, besides the common petiole, there are partial 
petioles, as in the Sensitive plant, they may be bent inwards towards each other, while the common petiole is bent downwards.

Mimosa sensitiva and pudica (fig. 657), commonly called sensitive plants, display these morements of their leaves in a remarkable degree,

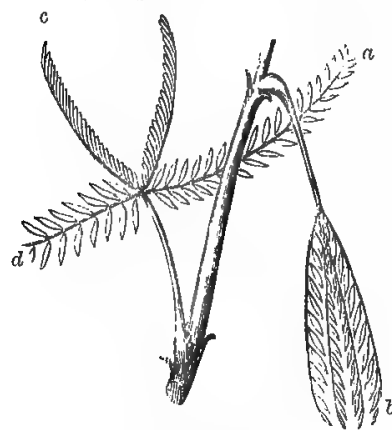

Fig. 657 . not only under the influence of light and darkness, but also under mechanical and other stimuli. They have bipinnate leaves with four partial petioles proceeding from a conmon rachis, and each of the petioles is furnished with numerous pairs of leaflets (about twenty), which are expanded horizontally during the day. During darkness, or when touched or irritated in any way, each leaflet moves upwards towards its fellow of the opposite side, which in its turn rises up, so that their upper surfaces come into contact. When the movement commences at the apex of the leaf it usually proceeds downwards to the base, and thence may be communicated to the leaflets of the next partial petiole, and ultimately to the common petiole, which falls down towards the stem. The partial petioles then converge towards each other, and have a tendency to become parallel to the common petiole, at the extremity of which they are suspended. When the plant is shaken, as by the wind, all the leaflets close simultaneously, and the petioles drop together. If, however, the agitation is long continued, the plant seems as it were to become accustomed to the shock, and the leaflets will expand again. The stem itself is not concerned in the movements. It may be cut and wounded cautiously without causing any change in the leaves, and a portion of it may be removed with a leaf attached and still remaining expanded. If, however, a mineral acid is applied to the stem, after some time the petioles will fall and the leaflets collapse-the leaves perishing with the stem which has been moistened. The chemical action of the acid and absorption cause these phenomena. When a sensitive plant is exposed to artificial light during the night, it is found that its leaves expand, and that they close when put into a dark room during the day, showing the influence which light has on these

Fig. 657. Branch and leaves of Sensitive plant (Mimosa pudica), showing the petiole in its erect state, $a$, and in its depressed state, $b$; also the leaflets closed, $c$, and the leaflets expanded, $d$. At the base of the petiole a swelling or intumescence (pudvinus) is observed, and smaller swellings exist at the base of each partial petiole, and at the base of each leaflet. During darkness the leafstalks hang down, and the leaflets are elosed, while the reverse is the case during light. The cellular swellings at the base of the petioles and leaves are concerned in the movements. Protoplasmic contractions probably take place in the cells. 
phenomena. It is to be remarked, however, that if the plant is kept for a long period of time in darliness, it will ultimately expand its leaves, and the phenomena of folding and opening will go on, although at very irregular intervals.

The leaf of the Mimosa is sensitive of various kinds of stimuli, such as shaking, wounding, burning, contact of irritating fluids, electric and galvanic shocks. Many chemical stimuli cause the leaves to fold. Thus the vapour of prussic acid, of chloroform, and of ether, is found to produce this effect; and in such cases the irritability of the leaves is either destroyed, or, at all events, a considerable period of time elapses before it is restored. One or two drops of chloroform placed on the base of the petiole make it droop, and cause the leaflets to close in succession from apex to base. The influence extends to the other partial petioles and their leaflets. Although the leaflets expand afterwards, yet they are nearly insensible to the excitement produced by touch. When chloroformised several times they at length lose their contractility. Professor Simpson found that the vapour of chloroform affected the sensitive plant. If the vapour was either too strong or too long continued, the plant was destroyed. When it was weak, and applied only for a few minutes, the leaflets in some plants closed, as when irritated, and did not expand again for an unusual length of time. In other plants under exposure to chloroform, no closure of the leaflets took place, and in a few minutes the plant became so anrsthetised that the mechanical and other irritations of the leaflets and petiole did not produce the common movements, nor did the irritability become restored for a considerable time afterwards. The Yellow Water Sensitive plant (Neptunia plena), found in the East and West Indies and in South America, exhibits irritability in its petioles and leaflets.

The ternate leaves of many species of Oxalis (fig. 658) fold not merely during darkness, but also when agitated or struck lightly and repeatedly. Each of the leaflets folds upon itself, and then bends downwards upon the common petiole. The plant called Desmodium gyrans of the East Indies (fig. 659), the Gorachand of Bengal, or Telegraph plant, has compound leaves, consisting of a large terminal leaflet, and usually two smaller lateral ones. The latter are in constant movement, being elevated by a succession of little jerks, until they come into contact, and sometimes even slightly cross each other; after remaining in this position for a short time they separate from each other, and move downwards by rapid jerks on opposite sides of the petiole. This process is constantly repeated, and goes on in a greater or less degree, both during day and night, but is most vigorous during warm moist weather. The large terminal leaflet undergoes movements also, oscillating very gradually from one side to the other, and becoming horizontal or depressed. By the lateral 
oscillatory movement the leaf becomes inclined in various ways, often assuming a remarkably oblique direction. The upward and downward movements seem to depend on the influence of light and darkness.

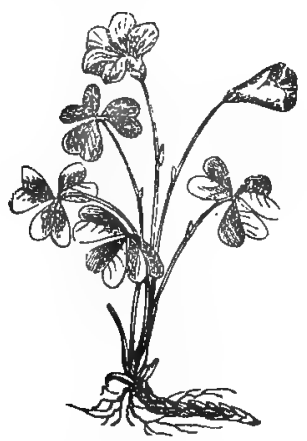

Fig. 658 .

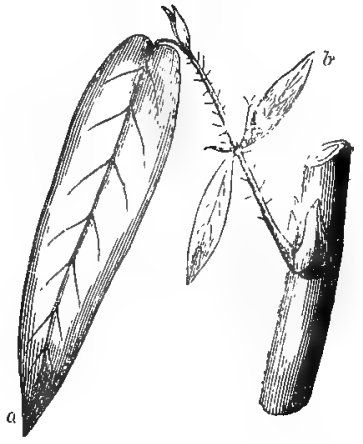

Fig. 659.

During the day the leaf becomes more or less horizontal, while during darkness it hangs down. Similar movements are seen in other species of Desmodium, as D. gyroides and vespertilionis.

The movements in these cases have been referred to certain changes in the organs, causing distension or contraction of the tissues. Dutrochet and Morren refer them to alterations in the circulation of fluids and air in the vessels and cells. In plants: there are frequently swellings where the leaflets join the stalk, as well as where the stalk joins the stem. These swellings contain cells which differ in their dimensions and their contents, and the movements are considered as being produced by changes in the contents of the cells, some of which become more distended than others, and thus cause incurvation or folding. In these swellings the vascular bundles are disposed in a circle near the periphery, and may be concerned in the movements. The contraction of the protoplasm in the cells may also be concerned in the leaf movements. Mechanical and chemical

Fig. 65s. Wood-Sorrel (Oxalis Acetosella), with its ternate leaves, which are said to display a certain amount of irritability when exposed to bright sunshine. During the night each of the three leaflets, forming the compound leaf, fold on their midrib, and then fall down towards the common petiole. Some say that this plant is the true Trish Shamrock. Fig. 659. A portion of the branch and leaf of the moving plant of India (Hedysarum or Desmodium gyrans). The leaf is impari-pinnate, and often piznately-trifoliolate. The large odd leaflet, $a$, becomes more or less horizontal, under the influence of light and heat, and is depressed during darkness or cold. Besides the movement of rising and falling, it has also a lateral oseillatory motion, so that it often becomes oblique in its position relative to the leaf-stalk. At its base there is a cellular intumescence. The smaller leaflets, $b$, of which there are either one or two pairs, have also swellings at their base. They exhibit constant jerking movements, by which they approach and retire from each other, and these motions go on to a certain extent during darkness. 
stimuli are supposed to act by inducing alterations in the contents of the vessels and cells.

In the case of the sensitive plant, if the swelling at the base of the common petiole is touched even slightly on its lower side, it is followed by instant depression of the whole leaf, but no such effect is produced if the upper portion of the swelling is lightly touched. Again, touching the little swelling at the base of each leaflet on its upper side, causes the upward movement of the leaflet, but no such effect follows cautious touching of the lower part of the swelling only. If a pair of leaflets is touched at the extremity of a petiole, the irritation is usually continued downwards from apex to base; but if a pair at the base are touched, the progress of folding is reversed. Clear warm weather, with a certain degree of moisture, seem to be the conditions most favourable for these movements. They are seen best in young plants. The leaves of the sensitive plant contract under the action of electricity and galvanism. Some suppose that in the sensitive plant there are two kinds of cells connected with the upper and lower sides of the leaves and petioles; the one set being contractile, and causing the closing of the leaflet and the fall of the petiole, the other being acted on chiefly through the circulation. In the case of the petiole, it is conceived that the tissue on the lower side of the swellings is contractile, while that in the upper is distensible. The turgescence of the latter, which is kept up by light, counteracts the contractility of the former, and maintains an equilibrium, so as to keep the petiole erect; but when acted on by cold, mechanical irritation, etc., the equilibrium is disturbed, and the contractility operates in depressing the petiole. A careful microscopic dissection of the swellings, shows peculiar cells in some parts, which seem to differ in their contents from others in their vicinity.

In the sensitive species of the Desmodium and Oxalis, the movements are not so evidently influenced by mechanical irritation. In the former, the little leaflets are supported on swollen petiolules, and it is to the curvation and twisting of these in different directions that the movements seem to be owing. The leaflets remain flat and do not fold on themselves. It is said that by arresting the vital actions going on in the leaflets, by giving them a coating of gum, and thus preventing transpiration and respiration, the movements are stopped, and that they recommence when the gum is removed by water. Cutting a leaflet across, and only leaving a small portion of its lamina attached to the petiolule, does not immediately stop the movement of gyration. In such a case, however, the motion ultimately ceases, while it continues in the uncut leaflet, So also, if a leaflet is divided longitudinally into two parts, each of them continues to move for a time, but the motions cease as the process of desiccation goes on.

The leaves of plants belonging to the natural order Droseraceæ 
(Sundews) show marked irritability. The leaf of Dionæa muscipula (Venus's Fly-trap), a plant of that order, exhibits movements when touched. The leaf represented in figure 660 is composed of a pylloid

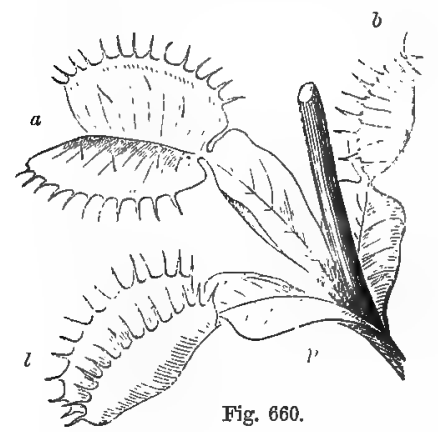
petiole, $p$, and a lamina, $l$, consisting of two movable halves uniterl by a strong midrib. The lobes when open are placed at right angles to each other. Along the edge of each of them there are about twenty spiny hairs; on the reddish upper surface there are numerous glands and three stiff hairs, $a$, with glandular bases on each division of the lamina. These, when touched, cause the leaf to close with considerable force. An insect alighting on these hairs is instantly entrapped. If it is very small it may escape through the grating formed by the crossing of the teeth, and the leaf will soon open again; but if it is large it cannot get out, as the two halves of the lamina close firmly on it, and the spines at this edge interlace more and more completely, like the teeth of a rat-trap, the irritation being kept up by the struggles of the insect. If the hairs are touched with a camel-hair pencil the leaf closes, and may remain so for twentyfour hours. Such is also the case if a small piece of any mineral and indigestible matter is placed in the leaf. But if a fly is caught"then the closure continues for a week or more. During the progress of the pressure the spiny hairs at the margin lose their interlacing position and become more or less exect, and finally the lamina opens. There is often a bulging on the outside of the lobes caused by the body of the insect contained within them.

During the time of closure the glands pour forth a peculiar secretion of an acid nature, as shown by the effect on litmus paper. This secretion acts upon the insect, which is gradually digested, nothing being left ultimately but the dry outer covering of the animal. The same thing occurs when a very small piece of flesh is grasped by the leaf. The leaf closes on it, and it is so completely digested that when the leaf opens there is nothing left. If too large a quantity of flesh is inserted digestion is not carried on properly, and the lamina

Fig 660. Leaves of Venus's Fly-trap (Dioncea muscipula), which exhibit evident irritability. The leaf consists of two parts, a lamina or blade, $l$, and a petiole or leafstalk, $p$. The two halves of the blade are united by a sort of hinge, $a$, and there are on each of them three hairs, which, when touched, cause the folding of the lamina in the way represented at $l$ and $b$. At the base of each of the hairs there is a swelling. The irritation seems to be communicated by means of the vessels to the midrib, and the folding is owing to the turgescence of the lower cells of the midrib. The motion is of the nature of a hinge-joint. 
shows symptoms of decay. The phenomena seem to resemble very much those which take place in animals in whom food is subjected to the action of ptyaline in the mouth and of pepsine in the stomach, along with the formation of hydrochloric acid. Both in the leaf and in the animal stomach an acid is formed with the view of promoting digestion. The plant has therefore been called insectivorous and carnivorous, as requiring the presence of albuminous animal food for its growth and nutrition. There is marked irrito-contractility ; first irritation and then contraction. Every living substance is capable of being excited into action-that is, of having its stored-up force discharged. There is a change of form, seen usually in some mechanical work. There seems, as Dr. Burdon Sanderson remarks, to be a resemblance between the contraction of muscle and the contraction of a leaf. The muscle exhibits chemical changes, consisting in disintegration of chemical compounds and dissipation of force stored up in these compounds. These phenomena are more especially seen when muscle contracts and when heat is developed.

The muscle in its living state is electro-motive, and the force depends on the vigour of the muscle. When the muscle and the leaf contract, electro-motive force disappears and work is done. There is, however, no conversion of the one into the other, and there is no evidence that the force is electrical.

Dr. Burdon Sanderson gives the following account of the electrical phenomena which accompany irritation of the leaf of Dionæa :-

"1. When the opposite ends of a living leaf of Dionæa are placed on non-polarisable electrodes in metallic connection with each other, and a Thomson's reflecting galvanometer of high resistance is introduced into the circuit thus formed, a deflection is observed, which indicates the existence of a current from the proximal to the distal end of the leaf. This current I call the normal leaf-current. If, instead of the leaf, the leaf-stalk is placed on the electrodes (the leaf remaining united to it) in such a way that the extreme end of the stalk rests on one electrode; and a part of the stalk at a certain distance from the leaf on the other, a current is indicated, which is opposed to that in the leaf. This I call the stalk-current. To demonstrate these two currents, it is not necessary to expose any cut surface to the electrodes.

"2. In a leaf with the petiole attached, the strength of the current is determined by the length of the petiole cut off with the leaf, in such a way that the shorter the petiole the greater is the deflection. Thus, in a leaf with a petiole an inch long, I observed a deflection of 40 . I then cut off half, then half the remainder, and so on. After these successive amputations, the deflections were respectively $50,65,90,120$. If in this experiment, instead of completely severing the leaf at each time, it is merely all but divided with a sharp knife, the cut surfaces remaining in accurate apposition, the result is 
exactly the same as if the severance were complete; no further effect is obtained on separating the parts.

" 3. Effect of constant current directed through the petiole on the leaf-current.-If the leaf is placed on the galvanometer electrodes as before, and the petiole introduced into the circuit of a small Daniell, a commutator being interposed, it is found that on directing the battery-current down the petiole (i.e. from the leaf), the normal deflection is increased; on directing the current towards the leaf, the deflection is diminished.

"4. Negative variation.- $a$. If, the leaf being so placed on the electrodes that the normal leaf-current is indicated by a deflection leftwards, a fly is allowed to creep into it, it is observed that the moment the fiy reaches the interior (so as to touch the sensitive hairs on the upper surface of the lamina), the needle swings to the right, the leaf at the same time closing on the fly.

" $b$. The fly having been caught does not remain quiet in the leaf; each time it moves the needle again swings to the right, always coming to rest in a position somewhat farther to the left than before, and then slowly resuming its previous position.

" $c$. The same series of phenomena present themselves if the sensitive hairs of a still expanded leaf are touched with a camel-hair pencil.

" $d$. If the closed leaf is gently pinched with a pair of forceps with cork points, the effect is the same.

" $e$. If the leaf-stalk is placed on the electrodes as before, with the leaf attached to it, the deflection of the needle due to the stalk-current is increased whenever the leaf is irritated in any of the ways above described.

" $f$. If half the lamina is cut off, and the remainder placed on the electrodes, and that part of the concave surface at which the sensitive hairs are situated is touched with a camel-hair pencil, the needle swings to the right as before." *

Species of the genus Drosera (Sundew) exhibit excitability in the leaves, with a certain amount of contractility. The leaves are of various forms, some narrow and elongated, others spathulate or rounded, all bearing on their surface and at their edges beautiful glandular hairs, with a spiral coil in their interior, and a globular apex containing peculiar secretions (fig. 661). They are also insectivorous. When insects alight on the leaves they are entangled by the viscid matter of the glandular hairs, which gradually close upon them, and prevent their escape. The apex of the leaf turns inwards, so as more effectually to secure the prey. This is well seen in some Australian and African species. Droseras are by no means so excitable as the Dionæa, but they seem to act in a similar manner upon insects. Small portions of flesh placed upon the leaves induce movements of the hairs;

* Proceedings of the Royal Society of London, Nov. 20, 1873. 
and it would appear that albuminous food is thus taken up by the plant for its nourishment.

The species of Drosera are widely distributed; three species and some varieties being found in Britain, and numerous species occurring in Australia (fig. 88, p. 32), Equatorial America, and South Africa. Experiments have been made upon the British species, as well as upon Drosera Whittakeri of Australia, D. filiformis of North America, and on some African species. In all these, leaf movements, of the nature described, have been observed in a greater or less degree.

The species of the genus Pinguicula appear also to secrete a viscid fluid, which detains insects. The leaves curl in at the margin, but the presence of irritability is doubtful.

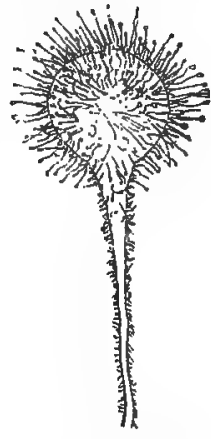

Fig. 661 .

We may here make some remarks on plants which seem also to be insectivorous, although not displaying excitability and contractility. We may specially notice the species of Sarracenia (Trumpet-leaf). The leaves of these plants are all radical, with a more or less tubular petiole, the blade being small, and often lying over the orifice of the tube (fig. 203, p. 96). In some of the tubular petioles honey-like matter is secreted, and this attracts insects, and a secretion collects at the bottom of the tube, which seems to have the power of destroying them. In the case of Sarracenia variolaris (Spotted trumpet-leaf) the inner surface of the tube or pitcher, from the mouth to midway down, is smooth and velvety to the touch, as the finger is passed downwards ; from midway there are retrorse bristles, increasing in size downwards, and ceasing near the base. Insects are attracted by a viscid, honey-like substance, secreted from the internal surface of the pitcher, and extending a short way from the margin, and in passing downwards they slip down into the secretion at the bottom, and are prevented from getting out by the hairs. The fluid in this sppecies seems to destroy insects, but it has not yet been proved that it feeds upon them.

Hooker says that there are two types of pitchers in Sarracenia; first, those with the mouth open and lid erect, into which rain-water enters easily; and secondly, those with the mouth closed by the lid, into which rain can hardly obtain ingress. To the first belong such species as Sarracenia purpurea, S. flava, S. rubra, and S. Drummondii. To the second belong Sarracenia variolaris and S. psittacina. In these pitchers he describes four surfaces:-1. An attractive surface on the inner part of the lid, with minute honey-secreting glands;

Fig. 661. Leaf of a species of Sundew (Drosera rotundifolia), covered with glandular hairs. These hairs secrete a viscid fluid, which often detains insects. The leaves are sometimes seen partially folded. This folding is supposed to be due to irritability. 
2. A conducting surface, formed of glassy cells, with deflexed processes overlapping like tiles of a house, forming a surface down which the insect slips, and affording no foothold to an insect attempting to crawl up again; 3. Below this a glandular surface (seen in S. purpurea), which is smooth and polished, and is formed of sinuous cells, studded with glands; 4 . A detentive surface occupying the lower part of the pitcher. This last, in some cases, extends nearly the whole length of the pitcher. It has no cuticle, and is studded with deflexed rigid hairs, which effectually detain insects. It is probable that these pitchers, which are so variously constructed, may act in different ways. Numerous insects, such as ants, hymenoptera, heteroptera, coleoptera, flies, cockroaches, moths, butterflies, arachnida, and myriapoda, have been observed in a dead state in the fluid at the bottom of the pitcher.

There are some insects which are not destroyed by the plant, but which make use of it. Xanthoptera semicrocea (Guen.), a small glossy moth, walks with impunity over the inuer surface of the pitcher. The female lays eggs near the mouth of the pitcher, and the young larva, by weaving a thin gossamer-like web, closes up the mouth, and feeds on the substance of the tube. Another insect, which feeds on S. variolaris and $\mathrm{S}$. flava, is a fleshy fly, called Sarcophage sarraceniæ. Insects accumulate in large quantities at the bottom of the pitchers, and seem to be far in excess of what the plant requires for digestion. They become decomposed, and other insects, which are not entrapped, drop their eggs into the open mouths of the pitchers, to take advantage of the accumulation of food. Old pitchers are consequently sometimes found full of living larvæ and maggots, showing that the fluid had become exhausted and could not injure them; and insectivorous birds slit open the pitchers with their beaks in order to get at the contents.

In the pitcher of Darlingtonia saccharine matter is formed, and its pitchers become crammed with large moths. Hooker has examined the pitchers of Nepenthes (the true Pitcher Plant), (fig. 200, p. 95), of which there are above 30 known species, inhabiting chiefly the hotter parts of the Asiatic' Archipelago. He finds in these pitchers also an attractive, conductive, and secreting surface. There is also a glandular surface secreting a fluid which appears to act on nitrogenous substances. He found that fragments of meat rapidly dissolved when placed in the fluid. Pieces of fibrine disappeared in two or three days; cartilage was reduced to a clear transparent jelly. He thinks it probable that a substance acting as pepsine is given off from the inner walls of the pitchers, but chiefly after placing animal matter in the fluid. Voelcker found that the fluid in the pitchers of Nepenthes distillatoria, in the Edinburgh Botanic Garden, consisted of water, containing in solution malic acid and a little citric acid, chloride of potassium, carbonate of soda, lime, and magnesia. The fluid was col- 
lected from the pitcher before the lid opened. It is probable that the pitchers of Dischidia and Cephalotus may contain similar fluids, and may act in the same manner on insects.

Irritability exists in the stems of twining plants and in tendrils. The coiling of tendrils seems to be due to the same cause as the closing of the leaves of the sensitive plant on being touched. Hofmeister says that the shoots and leaves of all plants, while young, move after being shaken; and it is almost invariably young petioles and young tendrils, whether formed of modified leaves or flower-peduncles, which move on being touched. The young flower-peduncles of Maurandia semperflorens spontaneously revolve in very small circles and bend themselves, when gently rubbed, to the touched side. Asa Gray found that the tendrils of many common plants coiled up more or less promptly after being touched or brought with a slight force into contact with a foreign body. In some plants the coiling is rapid enough to be directly seen by the eye. The tendril of Sicyos angulatus, one of the Cucurbitacer, when touched, will uncoil into a straight position in the course of an hour, and will again coil up at the second touch. This may be repeated three or four times in the course of six or seven hours. A certain temperature seems to be necessary. Gray experimented at $77^{\circ} \mathrm{F}$. A tendril that was straight, except a slight hook at the top, on being gently touched once or twice with a piece of wood on the upper side, coiled at the end into $2 \frac{1}{2}$ or 3 turns within a minute and a half. The motion began after an interval of several seconds, and fully half of the coiling was quick enough to be very distinctly seen. After little more than an hour had elapsed, it was found to be straight again. The contact was repeated, timing the result by the secondhand of a watch. The coiling began in four seconds, and made one circle and a quarter in four seconds. It had straightened again in an hour and five minutes, and it coiled the third time, on being touched rather firmly, but not so quickly as before - viz. $1 \frac{1}{2}$ turn in half-aminute. The same movements have been observed in the tendrils of the grape-vine and of other plants. The coiling is perhaps caused by the contraction of the cells on the concave side of the coil.(Gray, Proc. Amer. Acad. of Arts and Sciences, iv. Aug. 12, 1858, p. 88.)

Darwin has given a valuable paper on climbing plants in the Journal of Proceedings of the Linnean Society, ix. p. 1.

Climbing plants are thus divided by him :-

1st. Those which twine spirally round a support.

$2 \mathrm{~d}$. Those which ascend by the movement of the foot-stalks or tips of their leaves.

3d. Those ascending by true tendrils, which are either modified leaves or flower-peduncles, or perhaps branches or stipules.

4th. Those furnished with hooks or rootlets for climbing. 
There are thus spiral-twiners, leaf-climbers, tendril-bearers, and hook and root climbers. The most interesting point in the natural history of climbing plants is their diverse powers of movement. The young shoots of the hop revolve during the day and in hot weather, at the rate of two hours and eight minutes for each revolution. The greater number of twiners revolve in a course opposed to that of the sun, or the bands of a watch. The majority therefore ascend the supports from right to left.

Plants belonging to eight families have clasping petioles, and piants belonging to four families climb by the tips of their leaves. As regards tendrils, they place themselves in the proper position for action, standing, for instance in Cobæa, vertically upwards, and with their branches divergent, and their hooks turned outwards; or, as in Clematis, the young leaves temporarily curve themselves downwards so as to serve as grapnels. If the young shoot of a twining plant or of a tendril be placed in an inclined position it soon bends upwards, though completely secluded from the light, the guiding stimulus in this case being the attraction of gravity. Climbing plants bend towards the light by a process closely analogous to that incurvation which causes them to revolve. In some cases the spontaneous revolving movement depends on no outward stimulus, but is contingent on the youth of the part, and on its vigorous health. Sometimes the movement depends orr contact with any body. After clasping a support tendrils contract spirally.

Blondeau and others have shown that ether acts as an anæsthetic on sensitive plants. A current of electricity causes the leaves to fold and the petioles to droop. If too long continued the plant is destroyed. The current could be passed for five or ten minutes without destroying the plant, but when the current lasted for twenty-five minutes the plant was killed. For the effects of anæsthetic agents (such as chloroform) on plants, see Livingstone's paper in Edin. N. Phil. Journal, $2 d$ ser. xi. 333 ; and Mr. W. Coldstream's paper in the same Journal, xiii. 87 .

Movements take place in some parts of the flower, occasionally with the view of scattering the pollen. The stamens of various species of Berberis and Mahonia are articulated to the torus or thalamus, and when touched at their inner and lower part, move towards the pistil. In Parnassia palustris the stamens move towards the pistil in succession to discharge their contents (fig. 514, p. 286). The common Rock-rose (Helianthemum vulgare) exhibits staminal movements also connected with the bursting of the anthers. Morren has noticed sensitiveness in the androcium of Sparmannia africana and Cereus grandiflorus. In the Nettle, Pellitory, Pilea serpyllifolia (the artillery plant), and Kalmia, the flaments are confined by the perianth, and are afterwards released so as to allow their elasticity to come into 
play, by means of which the pollen is forcibly scattered (p. 283). In Ruellia anisophylla the style has a curved stigmatic apex, which gradually becomes straightened, so as to come into contact with the hairs of the corolla, upon which the pollen has been scattered; and in Mimulus and Bignonia (fig. 441, p. 249) the stigma has two expanded lobes which close when touched, a movement apparently in some way connected with fertilisation. In the Passion-flower, and some Cacti, the styles move towards the stamens. The species of Stylidium (fig. 662) have the filaments and styles united in. a common column, at the upper part of which the anther-lobes and stigma are placed. The column often projects beyond the flower, and is jointed. At the articulation an irritable swelling occurs, which, when touched, or acted upon by heat and light, causes a sudden incurvation by which the column is thrown to the opposite side of the flower, bursting the anthers and scattering the pollen on the central stigma. After a time the column recovers its position. These movements take place in the flower for some time after it has been removed from the plant and kept in water (p.

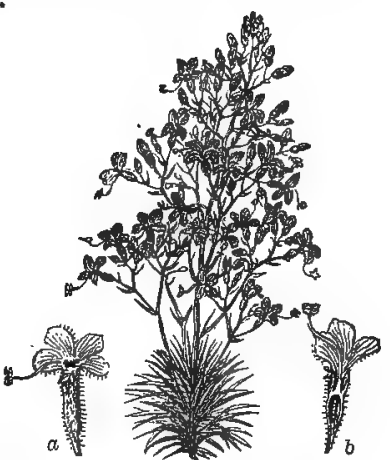

Fig. 662 .

284). Certain petals in some flowers, as in Orchidaceæ, are said to move. Morren notices this in the case of species of Megaclinium and Pterostylis. Drakæa elastica, a Swan River terrestrial Orchid, shows irritability in the stalk of the labellum. This stalk has a movable joint like an elbow. Bolbophyllum barbigerum has a movable bearded labellum. Gentiana sedifolia closes its flowers when tonched.

Chemical agents have an effect on the movements of plants. Some act by causing irritation, others by destroying irritability. Narcotic poisons, as opium, belladonna, and hydrocyanic acid, either taken up by the roots or applied externally, destroy the irritability of plants. They cause closure of the leaves of the sensitive plant, and render it insensible to the action of stimuli. Their prolonged action causes death, but if they are applied in moderate quantity, the plant may recover, and again unfold its leaflets. It frequently happens, however, that the irritability continues for some time much impaired; so that merhanical stimuli do not act in the same rapid and energetic manner as at first. Similar effects (as already noticed) are produced by ether and chloroform when sensitive plants are introduced into an atmosphere through which these substances are diffused. The effects may be

Fig. 662. Stylidium tenuifolium. $a$ and $b$, Separate flowers, showing the irritable column which bears anthers and stigma at its summit. 
produced locally by applying the vapour only to certain parts of the plant. For remarks on the effects of gases on living plants, see pp. $159-161$.

\section{2.-Temperature of Plants.}

The heat developed during the expansion of flowers and the preparation of the pollen, especially in the case of Aroidex, and also at the period of germination, has been already considered (pp, 259 and 260). These phenomena appear to be strictly of a chemical nature, and may be traced to the absorption of oxygen, and its combination with the carbon of the starch, the latter being converted into dextrine and grape sugar. It is now proposed to consider the observations which have been made relative to the general temperature of plants.

Great differences of opinion have prevailed as to the existence of a proper heat in plants. Hunter examined the heat of the internal parts of the trunks of trees by boring holes of different depths in them, and inserting thermometers ; and similar experiments were made by Schubler at Tübingen. The results of these experiments were, 1st, That the temperature of trees is higher than that of the air in winter, and lower in summer; $2 \mathrm{~d}$, That the temperature corresponds to the depth in the soil to which the roots penetrate; and $3 d$, That it depends on the temperature of the fluid matters taken up by the roots, as well as the bad conducting power of the wood of the trees. Dr. Hooker found that the temperature of the juices of plants in India depended materially on that of the soil at their spongioles. Dutrochet made experiments to determine the temperature of the growing parts of plants. He found, by means of a thermo-electric apparatus, that this varied from two or three tenths of a degree to one degree above that of the air. This generation of heat only talses place when the plant is active and vigorous, and seems to be connected with processes going on in the interior of the cells. When the cells cease to be actively engaged in the processes of vegetable life, they cease to manifest this vital heat. It reaches a daily maximum, the period of which varies in different plants, according to their vigour. Rameaux has confirmed Dutrochet's observations. He observed that during the day the temperature of the various layers diminished from the surface to the centre, while during the night the reverse took place, and that both of these processes were materially influenced by the nature of the surrounding temperature and the diameter of the tree. There appear, therefore, to be two sources of heat in plants, one depending on organic actions carried on in the growing parts, and the other on meteorological influences, which either act directly through the air, or indirectly through the fluid matters brought up from a certain depth in the earth. 


\section{3.-Luminosity of Plants.}

Luminous appearances have been observed in certain plants. These have been long noticed in the lower classes of plants, such as Fungi. Decaying wood, in which Fungi are developed, is sometimes luminous. Mr. James Drummond describes some species of Agaric, near the Swan River, growing on the trunks of Banksias and other trees, which emitted at night a phosphorescent light sufficient to enable him to read. A phosphorescent Agaric, with the upper surface of the pileus black, while the centre and gills were white, was noticed by him on the trunk of a dead Eucalyptus occidentalis. The Agaricus Gardneri, found in Brazil, gives out a light of a pale greenish hue, similar to that of fireflies. It is found growing on a Palm, and is called Flor de Coco. Delile found luminosity in the Agaricus olearius, near Montpellier. Agaricus igneus is another luminous species; and a luminous fungus, probably a species of Didymium, has been noticed on the leaves of a Spermacoce in the West Indies. Mr. Worthington G. Smith mentions the occurrence of luminous fungi and mycelia in the coal-mines of Glamorganshire and Carmarthenshire. One of these, Polyporus annosus, gave out a phosphorescent light, which was visible at twenty yards' distance. Mr. Smith also mentions Polyporus sulfureus and Corticium cœruleum, as well as a species of Collybia or Lentinus, as being luminous. In the coal-mines of Dresden certain Rhizomorphous fungi have long been celebrated for the light which they emit. The spawn of the Truffle (Tuber æestivum) is said to present similar appearances. The Mycelia of fungi are sometimes luminous. Temperature has an influence on the intensity of the phosphorescence. The luminosity increases up to $25^{\circ}$ or $30^{\circ}$ C. ; whilst at higher temperature it decreases, and is destroyed at $50^{\circ}$ C. A low temperature stops the luminosity, the lower limit of phosphoresence being near the freezing point. A certain amount of moisture and contact with the atmosphere are said to be essential to phosphorescence. (For notice of luminous fungi see paper by Mr. M. C. Cooke in the Gardeners' Chronicle for 1871, p. 405.) It has been said that the luminosity of these fungi, as well as of decaying wood, is increased by exposure to oyxgen gas. Some consider it as connected with the absorption of oxygen, being in reality a slow spontaneous combustion; while, according to others, it is referable to the liberation of phosphorus from some of its combinations in the plant.

These luminous appearances are said not to be confined to fungi. The younger Linnæus states that the flowers of Nasturtium, Orange Lily, and African Marigold, at the end of a hot summer day give out intermittent light. Mr. Dowden and Mr. James confirmed this by observations on the common Marigold and Papayer pilosum; while 
other observers have noticed the phenomena in the Sun-flower, French Marigold, species of Enothera, and Arum. It is to be remarked that the flowers said to be thus luminous are all of a more or less orange colour, and that the phenomenon takes place in still warm summer evenings, towards twilight. Hence, Professor Allman is disposed to attribute them to optical illusions, depending on a peculiar intermittent effect on the retina. Some authors mention the occurrence of luminous sap in plants with milky juices, as the Euphorbia phosphorea of Brazil. A rhizome of an endogenous plant from India, is said, when moistened, to acquire a phosphorescent appearance, and to lose this property when dry.

\section{4.-Colours of Plants.}

Colour is not of much importance in Botany as regards classification and arrangement. It is chiefly in the case of Fungi that it is employed as a means of diagnosis. Perhaps the want of an accurate nomenclature of colours in Botany may have in part led to this. Mirbel and Henslow have proposed a nomenclature, which consists in referring all natural colours to certain absolute tints and shades, determined according to fixed rules. Thus, the latter assumes three primaries, as red, blue, and yellow, which together give white light, and derives all others from admixtures of these in definite proportions. On this principle he has constructed a chromatometer ( $\chi \rho \tilde{\omega} \mu \alpha$, colour,

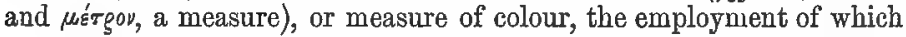
would lead to an accurate nomenclature.

It has already been remarked that the green colour of the leaves, young bark, calyx, and carpels, depends on the presence of chlorophyll (p. 12). This substance is contained in the deep cells or mesophyllum of leaves, and depends on the action of light for its elaboration. When leaves are grown in darkness they become colourless from the absence of chlorophyll. Light acts by the fixation of carbon. The different rays of the spectrum appear to vary in their power of developing the green colour. Senebier performed experiments on the subject, by making the light pass through coloured media, and he was led to the conclusion that while the yellow rays had the greatest effect on the growth of the plant, the blue and chemical rays were those chiefly concerned in the production of the green colour. Hunt seems to agree with Senebier. Other experimenters, however, as Morren, Daubeny, Draper, and Gardner, think the yellow rays are the most active in producing the green colour. The following table shows the result of some of Gardner's experiments. The rays are denominated active or inactive in relation to their power of producing a green colour, and the figures under each of them show their power in this 
respect, 1 being the highest value. The sign - indicates that the effect was not satisfactorily tested:-

\begin{tabular}{|c|c|c|c|c|c|c|c|c|c|c|c|c|}
\hline Plants. & & & Total & & & Acti & e Rays & & & & ive & \\
\hline & 2 & & 109 & & 4 & 8 & t & Gr. & & B. & in. & \\
\hline & & . & 95 & & 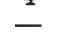 & & & & & & - & \\
\hline & & $\ldots$ & 69 & . & 4 & 2 & & & & - & - & \\
\hline & .2 & $\ldots$ & 10 & $\ldots$ & - & - & & & $\ldots$ & & 0 & \\
\hline & . 17.5 & $\ldots$ & 52 & $\ldots$ & - & 2 & 1 & 3 & $\ldots$ & & 0 & \\
\hline urnips & & & & & & & & & & & & \\
\hline
\end{tabular}

The ray producing the green colour is found to be that which acts most efficiently in the decomposition of carbonic acid, as shown by the following table:-

\begin{tabular}{|c|c|c|c|c|c|c|c|}
\hline $\begin{array}{l}\text { Places of spectrum } \\
\text { examined. }\end{array}$ & , & & $\begin{array}{l}\text { Production } \\
\text { chlorophy }\end{array}$ & & $\begin{array}{l}\text { Decomp. of } \\
\text { COE. }\end{array}$ & & $\begin{array}{l}\text { Illuminatix } \\
\text { power. }\end{array}$ \\
\hline Extreme Red . & & • & .0000 & $\ldots$ & 0.0000 & $\cdots$ & 0.0000 \\
\hline Commencement of & Drange. & - & & $\ldots$ & .5500 & $\cdots$ & \\
\hline Centre of Orange & . & •" & . .777 & $\ldots$ & & $\ldots$ & \\
\hline Centre of Yellow & - & • & . $1 \cdot 000$ & $\ldots$ & $1 \cdot 0000$ & $\ldots$ & $1 \cdot 0000$ \\
\hline Centre of Green & • & & 583 & $\cdots$ & & $\cdots$ & 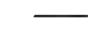 \\
\hline Centre of Blue & - & • &.$\quad \cdot 100$ & $\ldots$ & & ... & 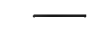 \\
\hline
\end{tabular}

The green colour becomes lighter or deeper according to the quantity of chlorophyll and the aggregation of the cells. It is usually paler on the lower sides of leaves. The dark shades of green in the Yew, Bay, and Holly, are the effect of an immense crowding together of green cells.

As light decreases in autumn, the chlorophyll, in many cases, diminishes, and is probably altered by the loss of a portion of carbon. Thus, Evergreen leaves become of ra paler colour, and deciduous leaves assume various hues, commonly called autumnal tints. The leaves of the Poplar, Ash, and Beech, before falling, become yellow; those of some species of Rhus, bright red; those of Cornus sanguinea, dull red; those of the Vine, yellow and purple. Berzelius states that the leaves become red in plants having red fruits. Robinet and Guibourt maintain that the Vines which produce bluish grapes have red leaves in autumn, while such as produce white grapes have yellow leaves. These yellow and red colours by some are said to depend on changes in the state of oxidation of the chlorophyll, and have been traced by others to the production of peculiar substances, one red, called erythrophyll, the other yellow, xanthophyll. Marquart believes that the action of water on chlorophyll, in different proportions, gives rise to jellow and blue matters. Ellis supposed the change of hues to be due to the prevalence of acid and alkaline matters.

Martens says that the colour of chlorophyll depends on the mixture of anthocyane, blue colouring ( $x$ ícvos, blue), and anthoxanthine,

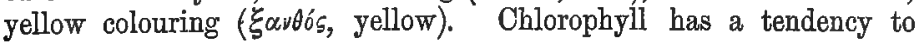


become yellow in consequence of the great alterability of the blue colouring principle, unless the latter is rendered more stable by union with an acid which reddens it. In this case the leaf becomes red. In Selaginella mutabilis the colouring matter becomes aggregated in balls at certain times, while at other times it is diffused. This accounts for the change of colour in bright and in diffused light. In this plant the leaves are pale milk-white in the evening or in cloudy weather, and bright green in sunshine.

Sorby classifies the colouring matter of leaves as follows :--

1. Chlorophyll ( $\chi \lambda \omega \rho b s$, green, $\phi u ́ \lambda \lambda$ ov, a leaf), a green colouring matter, rarely found pure, insoluble in water, but soluble in alcohol or bisulphide of carbon. Spectral tint more or less green.

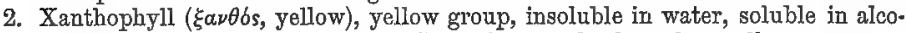
hol and bisulphide of carbon. General spectral colour clear yellow or orange.

3. Erythroplyyll ( $e^{2} \rho u \theta \rho \delta s$, red), red colouring matter, soluble in water and aqueous alcohol, insoluble in bisulphide of carbon. Strong absorption in the green part of the spectrum.

4. Chrysophyll ( $\chi \rho \nu \sigma \delta s$, gold), golden yellow group, soluble in water and in aqueous alcohol, insoluble in bisulphide of carbon. Varying spectra.

5: Phaiophyll ( $\phi$ alos, brown), group comprising various browns, soluble in watet, but not in bisulphide of carbon. No well-defined absorption-bands in the spectrum.

Groups of colours as leaves advance to decay :-

Complete vitality and growth $\left\{\begin{array}{l}\text { Chrysophyll } \\ \text { Chlorophyll } \\ \text { Low vitality and change. } .\end{array}\right.$
Death and decomposition $\cdot\left\{\begin{array}{l}\text { Erythrophyll } \\ \text { Xanthophyll } \\ \text { Phaiophyll } \\ \text { Humus }\end{array}\right\}\left\{\begin{array}{l}\text { More or less bright green. } \\ \text { More or less green-brown. } \\ \text { More or less red-scarlet. } \\ \text { More or less bright orange-brown. } \\ \text { Less or more dull brown. }\end{array}\right.$

(Nakure, Jan. '19, 1871, p. 237.)

Dr. Hope endeavoured to show that there is in plants a colourable

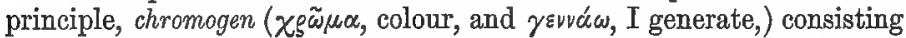
of two separate principles, one of which forms a red compound with acids, while the other forms a yellow with alkalies, and he attributes the green colour produced by the latter to the mixture of the yellow matter with the blue infusion. The two principles, according to him, may exist together, or separate, in different parts of the same plant.

In some very fleshy leaves, as Agave, the central cells are pale, while those of the cuticle are coloured and much thickened. Although leaves are usually of a green colour, still they frequently assume various tints. In certain varieties of Beech and Beet they become of a uniform red or copper colour. In some cases only one of the surfaces of the leaf is coloured, as in many species of Begonia, Saxifraga, Cyclamen, and Tradescantia, in which they are green above and red or brown below; while in others there is a variation of colour, giving rise to variegation, as in Aucuba japonica, Carduus marianus, 
and Calathea zebrina, where there are yellowish spots; or in many Arums, where the spots are of a red colour. The whitish or brown spots which occur on leaves are often produced by thickened cells containing peculiar colouring matter, underlying the chlorophyll cells. In such cases variegation might be traced to an alteration in the epidermal cells ; and the same is true of certain bright colours assumed by the surfaces of some leaves. The juices of many plants are colourless when contained in the vessels, but become milky or coloured by exposure to the air. Thus, the'sap of Finanthe crocata becomes yellow, that of Chelidonium becomes orange, that of Madder changes from yellow to red, and that of some Boletuses becomes blue or bluishgreen. In some instances the changes have been prevented by keeping the cut or broken surfaces in nitrogen, or hydrogen, or carbonic acid, and thus preventing their exposure to oxygen. It is said, however, that the change of colour in the Madder does not take place in pure oxygen.

The bark, at first green, becomes often of a brown colour from the thickening of the cell-walls; as well as the deposition of brown matter. Similar changes take place in the woody tissue, giving rise to the coloured duramen of many trees, as the Laburnum, Guaiac, Ebony, etc. Such changes, however, depend on chemical actions going on in the interior of stems, and are not due to the direct influence of the air. The colour of wood, however, is generally deepened when exposed to the atmosphere.

The red, blue, and yellow colours of flowers depend on fluid or semifluid matters contained in superficial cells, which can be detached with the cuticle. In petals, different cells frequently contain different kinds of colouring matter, thus giving rise to variegation. By the juxtaposition and mechanical mixture of various cells different tints are produced; and the colours are also modified by the nature of the cuticle through which they are seen. In the interior of petals the colour is generally more or less yellow, but it is modified when seen through superficial cells. Along with the colouring matter there is a colourless substance present, the relative quantity of which varies, and hence the colour may be deeper or fainter. In flowers, as well as in leaves, the colours appear to depend on the action of light. It has been said, however, that the powerful action of solar light, in some cases, tends to decolorise flowers. Hence, tulips are screened by floriculturists from the direct rays of the sun. The leaves of herbaceous plants also, when exposed to the direct rays of the sun, do not acquire so deep a green as when they are subjected merely to a bright daylight.

The colours of flowers have been arranged in two series:-1st,

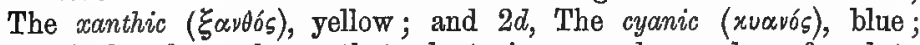
and it has been shown that plants in general may be referred to one or other of these series, while red is common to both series, 
and green, as composed of blue and yellow, is intermediate between them. White is considered as depending on absence or extreme dilution of the colouring principles, while brown or black depends on their accumulation or concentration. Even in white flowers there will be seen a slight admixture of a yellowish or bluish tint.

\section{Green.}

Cyanic $\left\{\begin{array}{l}\text { Greenish-blue. } \\ \text { Blue. } \\ \text { Violet-blue. } \\ \text { Violet. } \\ \text { Violet-red. } \\ \text { Red. }\end{array}\right.$

Some, starting from greenness, as a state of equilibrium between the two series, pass through the blue and violet to red, by a process of oxidation, while the transition from red to orange and yellow has been traced to deoxidation. As illustrations of the cyanic series may be mentioned all, or nearly all, the species of Campanula, Phlox, Epilobium, Hyacinth, Geranium, Anagallis ; of the xanthic series, Cactus, Aloe, Cytisus, Oxalis, Rose, Verbascum, Potentilla, Enothera, Ranunculus, Adonis, Tulip, Dahlia.

Plants belonging to either series vary in colour usually by rising or falling in the series to which they belong, and not by passing from one to the other. Thus, a plant belonging to the blue series does not usually become yellow, nor does one in the yellow series change into a pure blue. This remark will not apply in all cases, although it is generally true. It cannot be said to hold good in regard to genera, as at present determined; thus in the genus Gentian there are blue and yellow species. It seems, however, to be applicable to individual species; thus the Dahlia, belonging to the yellow series, may pass through all the varieties of that series, but has never been produced of a blue colour; so also with the Tulip, the Rose, etc. Even in the case of species, however, there are anomalies. Thus the rule does not apply to such plants as Myosotis versicolor and Dendrobium sanguinolentum, where there are different yellow and blue colours on the corolla. Notwithstanding, however, all the exceptions, the general law already mentioned as to the variation of colour in flowers seems to be founded on correct observations.

Changes are produced in the colour of flowers by bruising and injuring the petals. The pure white flowers of Camellia easily become brown, while those of Calanthe veratrifolia and Bletia Tankervillæ assume a deep blue. By drying many flowers become of a brown or black colour; this is particularly the case with Orchidacer, Melampyrum, and Lathyrus niger. It would appear to depend on the combination between the colouring principle and the oxygen of the air, 
and may in some cases be traced to the existence of tannin, gallic acid, and iron. Blue flowers, under the process of desiccation, are often whitened. Ipomcea Learii, in drying, changes from blue to red.

Remarkable changes take place in the colour of some flowers during the course of the day. The flowers of the common pink Phlox, early in the morning, have a lightish blue colour, which alters as the sun advances, and becomes bright pink. Enothera tetraflora has white flowers which change to red. Hibiscus variabilis has its flowers white in the morning, pink at noon, and bright red at sunset. The colour of many flowers of Boraginaceæ, before expansion, are red; after expansion, blue. The bracts of Hakea Victoria are yellowishwhite in the centre the first year; the second year, what was white becomes a rich golden yellow; the third year, the yellow becomes rich orange ; the fourth year, the colour becomes blood-red; the green portion of the bracts becomes annually darker. It has been stated that soils have an effect on the colour of flowers. The flower of the common Hydrangea hortensis may be changed from pink and rosecoloured to blue, by growing the plant in certain kinds of loam and peat earth. Alum in the soil is said to produce a similar effect.

Köhler and Schubler have endeavoured to determine the relative proportions between the different colours met with in flowers. They examined upwards of 4000 species, belonging to twenty-seven natural orders, of which twenty were dicotyledonous and seven monocotyledonous. The following are some of their conclusions :-

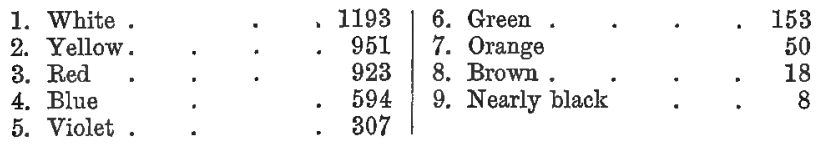

The proportion of white, cyanic, and xanthic flowers varies in different quarters of the globe, and at different elevations. The following are the proportions of colour in different natural orders, deduced from the examination of about 120 species of each :-

\begin{tabular}{|c|c|c|c|c|c|c|c|c|}
\hline & & Red. & Violet. & Blue. & Green. & Yel. & Orange. & White. \\
\hline Nymphæaceæ & . & 11 & - & 14 & - & 28 & - & 46 \\
\hline Rosaceæ & & 32 & 1 & 一 & - & 52 & 一 & 40 \\
\hline Primulaceæ. & & 41 & 7 & 6 & 2 & 15 & 10 & 27 \\
\hline Boraginaceæ & & 10 & 9 & 28 & 3 & 13 & 1 & 35 \\
\hline Convolvulaceæ & . & 39 & 10 & 12 & 一 & 7 & 2 & 27 \\
\hline Ranunculaceæ & • & 16 & 4 & 15 & 2 & 42 & 1 & 19 \\
\hline Papaveraceæ & & - 38 & 9 & - & - & 36 & 7 & 7 \\
\hline Campanulaceæ & " & 5 & 21 & 58 & - & 3 & 1 & 10 \\
\hline
\end{tabular}

Thus, Nymphæaceæ and Rosaceæ, according to Schubler and Köhler's observations, contain a large number of white flowering species ; Primu- 
laceæ and Convolvulaceæ, red; Campanulaceæ, blue; Ranunculaceæ, yellow.

In arranging flowers in a garden it is of importance to place the complementary colours together, in order to produce the best effect. The complementary colour of red, or that which is required to make white light, is green; of orange, blue; of yellow, violet; consequently blue and orange-coloured flowers, yellow and violet, may be placed together; while red and rose-coloured flowers harmonise well with their own green leaves. When the colours do not harmonise, the interposition of white or of black often restores harmony.

\section{5.-Odours of Flowers.}

The peculiar odours of plants depend on various secreted volatile matters, which are often so subtle as to be incapable of detection by ordinary chemical means. Nothing is known of the causes which render one flower odoriferous and another scentless. In some cases the odours of plants remain after being dried, but in general they disappear. Some leaves, as of the Woodruff, become scented only after drying; and certain woods, as Teneriffe rosewood, give out their odour only when heated by friction. Meteorological causes have a great influence on the odours of living plants. Dew, or gentle rain with intervals of sunshine, seem to be the circumstances best fitted for eliciting vegetable perfumes. Light has a powerful effect on the odour as well as the colour of flowers. Plants, when etiolated by being kept in darkness, generally lose their odour. In certain cases the perfumes of flowers are developed in the evening. Some of these plants were called tristes by Linnæus, as Hesperis tristis, or nightscented stock. Many orchidaceous plants are fragrant at night only, as some Catasetums and Cymbidiums. Cestrum nocturnum and the white flowers of Lychnis vespertina are also night-scented. The odours of some plants are peculiarly offensive. This is the case with Phallus impudicus, and with the flowers of many Stapelias.

Schubler and Köhler, whose investigations in regard to colour have been noticed, have also made observations on the odours of plants in the same monocotyledonous and dicotyledonous orders. The following tables show some of their results:-

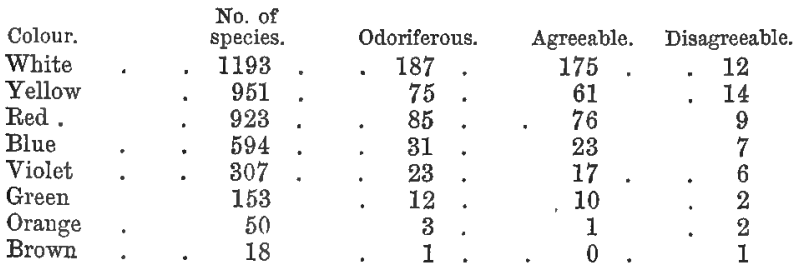


Thus, of the plants examined, those having white flowers presented the larger proportion of odoriferous species. The orange and brown coloured flowers often gave a disagreeable odour. In examining numerous species from various natural orders, they found that out of 100 species of

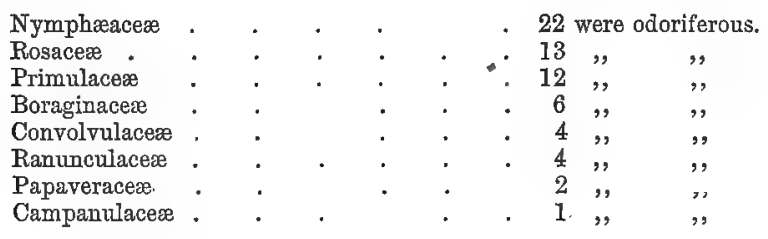

\section{6.-Diseases of Plants.}

Great obscurity attends this department of botany, and much remains to be done ere a system of vegetable nosology (vó́cos, disease) can be completed. It is, however, of great importance, whether we regard its bearing on the productions of the garden or the field. Some have divided the diseases of plants into general, or those affecting the whole plant, and local, or those affecting a part only. A better arrangement seems to be founded on their apparent causes, and in this way they have been divided by Lankester into four groups. 1 . Diseases produced by changes in the external conditions of life; as by redundancy or deficiency of the ingredients of the soil, of light, heat, air, and moisture. 2. Diseases produced by poisonous agents, as by injurious gases, or miasmata in the atmosphere, or poisonous matter in the soil. 3. Diseases arising from the growth of parasitic plants, as Fungi, Dodder, etc. 4. Diseases arising from mechanical injuries, as wounds and attacks of insects.

Plants are often rendered liable to the attacks of disease by the state of their growth. Thus, cultivated plants, especially such as become succulent by the increase of cellular tissue, appear to be more predisposed to certain diseases than others. Concerning the first two causes of disease wery little is known. Absence of light causes blanching, which may be looked upon as a diseased state of the tissues. Excess of light may cause disease in plants whose natural habitat is shady places. Excess of heat is sometimes the occasion of a barren or diseased state of some of the organs of the flowers, and frost acts prejudicially on the leaves, stem, and flowers. By excess of moisture a dropsical state of the tissue is induced. A curious instance of mechanical injury acting on plants is given by Mr. Berkeley. He states that the injury to the tops of the branches of Araucaria imbricata is caused by the shoots coming in contact with their neigh- 
bours, and the leaves being punctured by the rigid points, so that there is an extravasation of resinous juices; when this is often repeated the terminal bud at length dies. Some coniferous trees imported into Britain are suffering from the nature of the climate and soil. This is especially seen in the case of the Larch. Some have supposed that the destruction of the Larch is owing to dryness of the soil in consequence of draining; while others attribute it to the propagation of the tree by means of badly matured seeds, taken from specimens grown in Britain,

Concerning the influence of atmospheric changes on plants, very little has been determined. Many extensive epidemics seem to depend on this cause. By some the late potato-disease has been referred to an unknown miasma conveyed hy the air, and operating over large tracts of country; the disease probably affecting some plants more than others, according to their state of predisposition, and in its progress leading to disorganisation of the textures, alteration in the contents of the cells and ressels, and the formation of a nidus for the spores of Fungi. In the early stage of the disease, as witnessed in 1845, Harting observed that a brown granular matter was deposited in the interior of the cells, beginning with those near the surface. For some time the cell-walls and starch-grains remained uninjured, but were ultimately attacked, the former losing their transparency, and the latter becoming agglomerated in masses. Subsequently to this, parasitic organisms of various kinds made their appearance, cavities were formed, and rapid decay took place. Among the vegetable parasites were detected species of Fusisporium, Oidium, Botrytis, Uapillaria, Polyactis. Berkeley supports the Fungus-theory of Potatodisease, while Solly thinks that the development of parasites is a secondary step in the morbid process. The prevalence of hot or cold weather, the amount of light and moisture, changes in the atmosphere, and electrical conditions of the air and earth, are in all probability connected with epidemic diseases. Some, with Liebig, attribute the late potato-disease to suppressed evaporation and transpiration, depending on the hygrometric state of the atmosphere. The vessels and cells are said to become charged with fiuids, stagnation of the circulation takes place, and thus disease and death are induced.

Balfour Stewart remarks that the researches of Baxendell, Meldrum, Smyth, and others, go to show that the convection-currents of the earth are influenced by the state of the solar surface. Anything that influences the motions of our atmosphere may readily be supposed to influence the distribution and activity of those diseasegerms that are now believed to be present in the atmosphere. Some kinds of blight seem to be associated with the prevalence of certain winds. The maximum of sun-spots may be connected also with the state of the atmosphere; and great auroral outbursts are connected 
with the epochs of maximum sun-spots. When we arrive at an explanation of the sun-spots we may be able to prove some connection.

Gangrene in plants is caused by alterations in the contents of the cells, leading to the death of a part. In succulent plants, as Cactuses, this disease is apt to occur. It is capable of extension by contact of the diseased cells. Sometimes excision of the diseased part checks the progress of the gangrene. Canker, which attacks Apple and Pear trees, is a kind of gangrene.

Some of the most important diseases of corn and other agricultural crops are owing to the production of Fungi. These have been divided into 1. Those attacking the grain, as Uredo fœtida, pepperbrand. 2. Those attacking the flower, as Uredo segetum, smut. 3. Those attacking the leaves and chaff, as Uredo Rubigo, rust. 4. Those attacking the straw, as Puccinia graminis, corn mildew.

Bunt, smut-balls, pepper-brand, or blight, is a powdery matter, occupying the interior of the grain of wheat, etc. When examined under the microscope it consists of minute balls, four millions of which may exist in a single grain, and each of these contains numerous excessively minute sporules. It is caused by the attack of Uredo Caries or foetida. In this disease the seed retains its form and appearance, and the parasitic fungus has a peculiarly fetid odour, hence called stinking rust.

Smut or dust-brand is a sooty powder, having no odour, found in Oats and Barley, and produced by Uredo segetum. The disease shows itself conspicuously before the ripening of the crop. Bauer says that in $\frac{1}{1 \sigma 000}$ part of a square inch he; counted 49 spores of the uredo.

Rust is an orange powder, exuding from the inner chaff scales, and forming yellow or brown spots and blotches in various parts of corn plants. It owes its presence to the attack of Uredo Rubigo. It is sometimes called red gum, red robin, red rust, and red rag. Some consider Uredo linearis as another state of the same disease.

Mildew is a disease caused by a Fungus denominated Puccinia graminis. The ripe spore-cases of this plant are small dark-brown club-shaped bodies, their thicker end being divided into two chambers, each filled with minute spores, and their lower end tapering into a fine stalk. The sori or clusters of spore-cases burst through the epidermis, sometimes in vast numbers. The minute spores seem to enter the plant by the stomata. Some think that they, as well as other minute spores, are absorbed by the roots. The disease attacks Wheat. Spring Wheat is less liable to this disease than winter Wheat, and heavy soils are less subject to it than light ones. Many have supposed that the Barberry is in some way connected with the production of Mildew. It has been ascertained that there is a curious connection beween them. It has been shown that the Fungus called 
Puccinia graminis will not reproduce itself, but if its spopes are sown on the leaves of the Barberry they will give rise to the Fungus called Acidium Berberidis. On the other hand, it has also been proved that the spores of the Alcidium will not reproduce itself, but will give rise to Puccinia graminis. There is thus an alternation of generation in this case, which is remarkable, and in some measure explains the old idea as to the injury caused to Wheat by the Barberry.

Those Fungi which are developed in the interior of plants, and appear afterwards on the surface, are called entophytic ('́vтós, within, and $\varphi$ ur $6 v$, a plant). Their minute sporules are either directly applied to the plants, entering by their stomata, or they are taken up from the soil. Many other Fungi grow parasitically on plants, and either give rise to disease, or modify it in a peculiar way. Among them may be mentioned species of Ustilago, Botrytis, Fusisporium, Depazea, Claviceps, Fusarium, and Erysiphe. Puccinia malvacearum makes great havoc among Mallows and Hollyhocks. Fusisporium solani is considered by Martius as the cause of a certain disease in the Potato. In the recent potato-disease Peronospora infestans, and other Fungi, committed great ravages, spreading their mycelium or spawn through the cells of the leaves and the tuber, and thus accelerating their destruction. Berkeley, Morren, and Townley, consider the Fungus as the cause of the disease. Others think that there exists, in the first instance, a diseased condition of the cells of the potato, caused by meteorological influences, in connection with high cultivation, and that the subsequent attack of the fungus aggravates the disease and causes rapid decay. Various species of Botrytis also attack the Tomato, Beet, Turnip, and Carrot. A species of Depazea sometimes causes disease in the knots of Wheat. A diseased state of Rye and other grasses, called ergot, owes its production to the presence of Claviceps purpurea. By the action of the fungus the ovary becomes diseased and altered in its appearance, so as to be dark-coloured, and project from the chaff in the form of a spur. Hence the name spurred rye (secale cornutum). The nutritious part of the grain is destroyed, and it acquires certain qualities of an injurious nature. Spontaneous gangrene is the consequence of living for some time on diseased rye. Ergot has been seen in Lolium perenne and arvense, Festuca pratensis, Phleum pratense, Dactylis glomerata, Anthoxanthum odoratum, Phalaris arundinacea, etc. Quekett found that he could propagate the ergot by mixing the sportes with water and applying this to the roots.

Extensive disease has been caused to vineyards by the attack of a Fungus called Oidium Tuckeri. The remedy which seemed the most effectual was sulphur. Coffee leaves in Ceylon have suffered from the attack of a Fungus called Hemileia vastatrix.

Fruits when over-ripe are liable to attacks of Fungi, which cause 
rapid decay. Wood also, especially alburnum or sapwood, is injured by the production of Fungi. Dry rot is the result of the attack of Meruleus lacrymans, which in the progress of growth destroys the texture of the wood, and makes it crumble to pieces. Some kinds of wood are much more liable to decay than others. Peziza æruginosa, which grows on the dead branches of oak and larch, imparts a verdigris colour to the wood.

The diseases caused by attacks of Fungi may be propagated by direct contact, or by the diffusion of their minute spores through the atmosphere. When we reflect on the smallness of the spores, the millions produced by a single plant, and the facility with which they are wafted by the wind in the form of the most impalpable powder, we can easily understand that they may be universally diffused and ready to be developed in any place where a nidus is afforded. Perhaps some of the diseases affecting man and animals may be traced to such a source. Diseases of the skin are often aggravated by attacks of Fungi. This is the case in the disease called Porrigo. Diseases in animals, such as the silkworm and polistes, are caused by Fungi.

Mr. Lawes observed a luxuriant growth of Fungi on unmanured plots of ground, and in plots receiving mineral without nitrogenous manure; and by far the most vigorous growth of grass on "fairy rings" was on superphosphated plots, and those receiving superphosphate with salts of soda and magnesia, without potash. Ammonia salts seem to prevent the growth of Fungi. Fairy rings occur most abundantly in poor pastures, and one mode of extirpating them is the application of nitrogenous manures.

In order to prevent fungoid diseases, it has been proposed to steep grains in various solutions previously to being sown. For this purpose alkaline matters and sulphate of copper have been used. In all cases the seed should be thoroughly cleansed. Smut and pepperbrand have been averted by these means. Diseased grains may be removed by being floated off in water, and the grains that remain may be washed with a solution of lime, common potash, or substances containing ammonia. A weak solution of sulphate of copper acts by destroying the fungus. To preserve wood from dry rot, the processes of Kyanizing and Burnetizing have been adopted: the former consists in making a solution of corrosive sublimate enter into the cells and vessels; the latter, in impregnating the wood with a solution of chloride of zinc. Creasote has also been used to preserve wood. Boucherie proposed that a solution of pyrolignite of iron should be introduced into trees before being felled, by making perforations at the base of the trunk, and allowing the absorbing power of the cells and vessels to operate. This plan does not appear to have been successful, although it was reported on favourably to the French Academy. 
The following is the substance of some remarks on the Potato-disease by Dr. Alfred Carpenter :-

"Resting-spores of Fungi are very abundant in places where potatoes are usually stored. They do not produce mycelia until the proper juices are ready for their development, and they also require certain physical agencies, such as moisture, heat, and the proper kind of exhalations from damp unventilated ground, with a disturbed state of the earth and air. The Tuber is planted with the resting-spore in the eye. The haulm is sent up with the spore in its tissues. About the time of flowering the juices in the plant are matured sufficiently for the development of the resting-spore. If at that time we have moisture, undrained ground, and electric disturbance, with luxuriant tops to the plants, the fungus is developed most rapidly. Millions of spores are wafted over the field, and,these are not resting, but developing spores. They send out the mycelia through the stomata, and in a few hours the whole crop is poisoned. Every potato receiving juice from the haulm becomes diseased. These fungus-spores abstract the juice of the plant, and destroy the character of its circulating fluid. Highly manured land and crops make the disease spread more rapidly.

"We must destroy the germ before planting, by using a pound of quick-lime stirred into a bucket-full of water, with an ounce of carbolic acid of commerce added. This quantity will serve for the dressing of a sack of potatoes.

"Potatoes require to be kept dry; exposure to the sun helps to preserve them.

"After the attack of Peronospora infestans, another fungus generally appears, called Fusisporium Solani. This acts on the starch, and destroys it; so that, if you wish to use the starch, it must be done before the appearance of Fusisporium.

"In preservation from potato-disease three things have to be attended to:-1st, Choice of seed (tubers). 2 $d$, Removal of mycelia and restingspores from the seed chosen. Spread seed potatoes out in the sun, and let them dry and become somewhat green. $3 d$, The preservation of the seed itself. Keep it in a temperature to prevent growth of mycelia or the development of the Entophyte, which will not grow below $48^{\circ} \mathrm{F}$. Tubers should be kept in an outhouse where the temperature will not rise above that, nor sink below $35^{\circ} \mathrm{F}$."

In the case of the potato-disease the spores may perhaps follow the same course as that mentioned as occurring in the barley and the wheat fungus. The spores may be produced in one species of plant in the first instance, and then complete their development in another; the fungus may thus pass part of its life upon some other host than the potato. This process has received the name of Hetercecium ("̈rggos, diverse, and oixiov, habitation).

Other diseases in plants owe their origin to insects. Earcockles, 
purples, or pepper-corn, is a disease affecting especially the grains of wheat. The infected grains become first of a dark green, and ultimately of a black colour. They become rounded like a small peppercorn, but with one or more deep furrows on their surface. The glumes spread.open, and the awns become twisted. The blighted grains are full of a fine white cottony matter, which, when moistened and put under the microscope, is seen to consist of a multitude of minute individuals of the Vibrio tritici, or eel of the wheat. The animalcules deposit their eggs in the ovary, and their young are hatched in eight or ten days. Henslow calculates that 50,000 of the young might be packed in a moderately sized grain of wheat. The Vibrio retains its vitality long. It will remain in a dry state for six or seven years, and when moistened with water will revive. The wheat-fly, or Cecidomyia tritici, is another destructive insect. It deposits its eggs by means of a very loug retractile ovipositor, and is seen abundantly in warm evenings. The Cecidomyia destructor, or Hessian fly, also causes injury, and is said to be very destructive to wheat in America. These insects are destroyed in numbers by the Ichneumons, which deposit their ova in their bodies. The Apple-tree mussel, or dry-scale Aspidotus conchiformis, attacks the bark of Apples, Pears, Plums, Apricots, and Peaches. Many of the Coccus tribe are highly injurious to plants. One of this tribe, in 1843 , destroyed the whole orange trees in the island of Fayal, one of the Azores. Many insects cause the rolling up of leaves. Tortricida viridana acts thus on the leaves of the Oak, and various species of Losotænia do so with other trees. Adelges abietis is the aphis which causes the leaves of the Spruce-fir to be united together, so as to have the appearance of a cone.

The insect called the Coffee-borer (Xylotrichus quadrupes) perforates the wood of the Coffee-tree and destroys the plant. The recent Vinedisease has been caused by Phylloxera vastatrix, a very minute Homopterous insect, not more than $\frac{1}{55}$ inch in length. It has a proboscis lying in a groove on its under side, and with this it pierces the roots on which it feeds. It draws nourishment by means of a sucker. The insect is yellow in summer, but in autumn it turns to a copper-brown. Its active life is from the beginning of April to about the month of October; it hibernates during the other months.

Many insects, called miners, make their way into the interior of leaves, and hollow out tortuous galleries, sometimes causing an alteration in the colour of the leaves. Galls are caused by the attacks of species of Cynips, which are provided with ovipositors, by means of which they pierce the bark or leaves, with the view of having a nidus for their ova. These galls are very common on the Oak, and are called oak-apples. Sometimes they have one cavity, at other times they are divided into numerous chambers, each containing a grub, pupa, or perfect fly, according to the season. Galls are produced on 
the twigs, catkins, and leaves of the Oak. The artichoke gall of the Oak depends on an irregular development of a bud, caused by the attack of insects, and consists of a number of leafy imbricated scales, resembling a young cone. A cone-like gall has also been observed in a species of Pernettia. On examining the galls of commerce, the produce of the Quercus infectoria, some are of a blue colour, containing the larva of the insect; others are pale, and are marked with a perforation by which the insect has escaped. Extensive ravages are committed in Elms and other trees by the attacks of Scolyti. The presence of much moisture, such as the rapid flow of sap, destroys them. Mr. Robert found that the flow might be promoted by taking off the suberous layer of the bark, and he proposes this as a method of getting rid of the insects. Some galls are formed in the substance of leaves, and burst through the cuticle in the form of ovate bodies, with crenate borders and opercula, which are perforated in the centre. These galls resemble parasitic fungi. Oak-spangles are galls of this nature. They are attached by a central point to the outer surface of the leaf, the inner side being smooth-the outer red, hairy, and fringed. Each contains a single insect, which retains its habitation till March, long after the leaves have fallen to the ground.

It is impossible in this place to enumerate all the insects which attack plants. Almost every species has certain insects peculiar to it, which feed on its leaves, juices, etc., and often cause great injury. Those which are common to hot-houses and green-houses have called for the special attention of horticulturists, and various means have been suggested for their removal or prevention. Among them may be enumerated vapour of tobacco and ammoniacal liquor of gasworks to kill aphides; vapour of sulphur for the red spider; sulphur for the vine-disease; vapour of turpentine for the wasp; vapour of crushed laurel leaves for the white bug; coal tar for the wire-worm. Carbolic acid, and sulphur mixed with soft soap, are also used. 


\title{
PART II.
}

\section{SYSTEMATIC BOTANY, TAXONOMY, OR THE CLASSIFICATION OF PLANTS.}

\author{
$\longrightarrow$ \\ CHAPTER I. \\ SYSTEMS OF CLASSIFICATION.
}

THIs department of Botany may be considered as a combination of all the observations made on the structure and physiology of plants, with the view of forming a scientific arrangement. It can only, therefore, be prosecuted successfully after the student has acquired a complete knowledge of Organography. In every branch of science arrangement is necessary in order that the facts may be rendered available, and this is more especially the case when a knowledge of species is to be acquired. When it is considered that there are upwards of 150,000 known species of plants, it is obvious that there must be a definite nomenclature and classification, were it only to facilitate reference and communication. Taxonomy has sometimes been pursued with no higher aim than that of knowing the names of plants. When prosecuted in such a spirit, it does not lead to an enlarged and philosophical view of the vegetable kingdom. In all truly scientific systems regard is paid not merely to the determination of the names of the species, but to their relations and affinities, so as to give some conception of the order which has been followed in the plan of creation.

In Classifactory Sciences the arrangements are founded upon an idea of likeness - an idea, however, which is applied in a more exact and rigorous manner than in its common and popular employment. The resemblances of the objects must rest-not on vague generalities, but upon an accurate scientific basis. In order that an arrangement may be constructed on philosophical principles, and that it may be rendered useful for the purpose of science, the following steps are required:-1. A Technical ( $\tau \varepsilon \chi^{y \prime \varkappa o ́ s, ~ a r t i s t i c) ~ l a n g u a g e, ~ r i g o r o u s l y ~ d e-~}$ 
fined, or what is termed Glossology ( $\gamma \lambda \tilde{\omega} \sigma \sigma \alpha$, a tongue or language, and $\lambda \hat{o} \gamma \circ \varsigma$, a discourse), and Terminology ( $\tau_{\varepsilon}^{\prime} \rho \alpha \alpha$, a boundary ; Latin, terminus). The meaning of the terms in this descriptive language must not depend on fancied resemblances, but must have a precise definition, and be constant. In acquiring a knowledge of the conventional terms, or of the vocabulary of the science, the student at the same time fixes in his mind the perceptions and notions which these terms convey, and thus, in reality, becomes acquainted with important elementary facts. 2. A plan of the system, or the principles on which the divisions and subdivisions of the system are made, Diataxis ( $\delta a \alpha^{\prime} \alpha \xi \xi$, orderly arrangement), or what is properly called Taxonomy

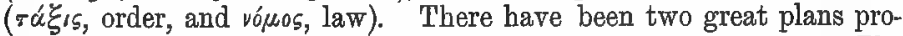
posed in Botany, one denominated artificial, the other natural. The first is founded on characters taken from certain parts of plants only, without reference to others; while the second takes into account all the parts of plants, and involves the idea of affinity in essential organs. 3. There must be also the means of detecting the position of a plant in a system, by short diagnostic marks. In doing so, a few essential characters are selected in accordance with natural affinities. The division into genera is a most valuable help in determining plants. Linnæus did great service to science by his generic divisions, and by adopting a binomial (bis, twice, and nomen, a name) system of nomenclature, in which the genus and species are included in the name of the plant.

Species.-Plants as they occur in nature are viewed as individuals resembling or differing from each other. Some individuals are so decidedly alike that we at once give them the same names. Thus, a field of wheat is composed of numerous similar individuals, which can be separated from each other, but cannot be distinguished by any permanent or marked difference. Although there may be some difference in size and other minor points, still we at once say they are stalks of Wheat. Every grain of Wheat, when sown, produces a stalk of Wheat; these stalks yield grains, which produce individuals like their parents. The shoots or buds given off from the base of Wheat by tillering also produce stalks of Wheat. On such universal and inevitable conceptions as these our idea of species is founded. No classification can be made unless the meaning of the term species is defined. By species (as regards the present epoch of the earth's history) we mean an assemblage of individuals having characters in common, and coming from an original Stock or Protoplast. They resemble each other more closely than they do any other plant, so that they are considered as originating from a common parent, and their seeds produce similar individuals. There may be differences in size, colour, and other unimportant respects; and thus varieties may exist, exhibiting minor differences, which are not, however, incompatible with a common 
origin. Varieties owe their origin to soil, exposure, and other causes, and have a constant tendency to return to their original type. They are rarely propagated by seed, but can be perpetuated by cuttings and grafts. By cultivation, as well as by natural causes, permanent varieties or races are produced, the seeds of which give rise to individuals, varying much from the original specific type. Such races are kept up entirely by the art of the gardener, and may be illustrated in the case of the Cereal grains, and of culinary vegetables, such as Cabbages, Cauliflower, Brocoli, Turnips, Radishes, Peas. It is only after a series of years that these permanent varieties have been established, and there is still a tendency in their seeds, when sown in poor soil and neglected, to produce the original wild form. Permanent varieties in the animal kingdom may be illustrated by the different races of mankind.

Such are the definitions of species, varieties, and races, which were generally adopted by all naturalists. But of late years theories have been propounded in regard to the origin of species which are not in accordance with those views, and which have given rise to new definitions, founded on the supposed derivation of species from others previously existing.

The tendency to variation which exists among the descendants of the same original is not considered as being restrained within fixed limits, but, after the lapse of long periods of time, and under the influence of varying external conditions, the descendants from a common stock may exhibit the differences which characterise distinct species. At the present time aggregates of individuals are seen, forming species. These are supposed by some to have originated from pre-existing species by derivation, and these again from others, and so on, till at last we come to a very few primordial forms (perhaps only one). On this supposition it is necessary to account for the various modifications which these primordial forms have undergone in the production of the present species of the globe. According to Darwin, these primordial forms had a tendency to variations in structure, some of which were favourable, and others unfavourable, for 'the continuance and development of the species. There would then be a struggle for existence, and, by a method which he calls natural selection, the fittest would be preserved, while the weakest would be destroyed. He therefore does not look upon species as fixed and unchangeable, but as transition forms. Species would thus from time to time be formed, fitted for the circumstances in which they were placed. This hypothesis proposes to explain the various phenomena connected with the evolution of species. It does not look upon each species as a direct individual creation, but as produced from previous forms by a law of selection. This law, however, must indicate the acting of a Creator who knows the end from the beginning, and overrules all things for his own 
wondrous designs. Those, however, who adopt this theory, too often appear to put the Creator out of the question, and to subject the whole of the process to an inexorable law, - how enacted they cannot tell. The theory affiliates species of the present day with those of former epochs, and attempts to show a natural connection between them by genealogical descent. This is no doubt important in the view of what is called the natural system of classification, where a law of affinity comes into play. At the present day we see the agriculturist and horticulturist selecting seeds from vigorous plants, planting them in favourable circumstances, improving them by various physiological methods, preserving the forms best fitted for their purpose, and uItimately establishing races which continue to propagate themselves by seed when cultivated in favourable circumstances. Something of this sort may be supposed to occur in the case of natural selection, under the guidance and direction of Him who works by means of instruments, and who carries out His mighty plans in an orderly and systematic manner.

There are numerous variations in species, some of them being of a more permanent character than others. Some species vary in a remarkable manner, without any external influences to account for it. Thus, a plant of Fuchsia has produced, in successive years, flowers differing so much in form and shape, that, if they had not been known to be produced by the same plant, they would have been considered as belonging to distinct species. Such is also the case with Calceolarias, some species of Amaryllis, and many Orchids. Hence there is sometimes considerable difficulty in determining what are true species and what are only varieties, more especially when these varieties are permanent and reproduce themselves. To this must in part be attributed the disputes which have arisen among botanists as to the species of many British genera, such as Roses, Rubi, Salices, and Hieracia.

Mr. John Ball remarks "that most widely diffused plants give rise to numerous varieties, "which reproduce themselves by hereditary descent, forming what are called races. In the case of wild plants we have, in most cases, no positive proof that such races are descended from the family stock, but we draw that inference from observing that the differences by which they are distinguished are not greater than what we observe among the descendants of plants submitted to cultivation, with one important difference-viz, that the wild races, having been for a long period subject to the same external conditions, usually show greater constancy in their characters than cultivated varieties, developed under conditions of a less permanent kind. The varieties enumerated in the works of systematic Botany are almost invariably races, such as those above referred to, and under this head many botanists are disposed to rank a large portion of the so-called species described of late years in France and Germany." 
Sub-species are forms more widely different from recognised species than varieties usually are, distinguished by well-marked characters affecting several organs, and occupying a definite geographical area, but which probably spring from other and more widely diffused species. Ball gives Euphrasia officinalis, and all its varieties, as an example of a species ; while the small alpine yellow-flowered Euphrasia minima is considered by him as a sub-species.

Dr. Boswell Syme, in his preface to English Botany, remarks,"It is often extremely difficult to decide whether a certain form ought to be regarded as a species or a sub-species. Occasionally, in a work on descriptive botany, what are admitted as true species will be found to be quite as closely allied to each other as two other forms which the same author regards as mere varieties, or it may be as sub-species. In fact, all botanists are guided in this matter by an imperfect kind of judgment, which is sometimes not far removed from caprice." He recognises as sub-species those plants which have less strongly-marked differences between them than are found between generally received species, but which are nevertheless too constant in their characters to be considered mere varieties.

The term variety is applied by him to forms which are, or are supposed to be, confined to individuals, and which may revert to the original type in a single or a few generations; while a sub-species transmits its peculiarities for an indefinite period. Many mistales, no doubt, occur respecting variety and sub-species, which better observation and long-continued cultivation may in time meet. "A state" is even less permanent than a variety, for it may be removed in the same individual by altering the external circumstances, such as soil, elimate, place of growth, etc.

By scattering the pollen of one plant on the pistil of an allied species, seeds are formed, which, when sown, produce intermediate forms or hybrids (p. 297). Hybrids, however, are rarely perpetuated by seed. While many hybrids are produced artificially, some are also produced naturally. In giving names to hybrids, those of the two parent species are often given. Thus, a hybrid between Verbascum nigrum and Verbascum Lychnitis is called Verbascum nigroLychnitis. In the case of the genus Rhododendron many hybrid forms have been produced by applying the pollen of the Rhododendron arboreum to the pistil of other more hardy species, such as R. ponticum, R. caucasicum, $R$. catawbiense, and these are indicated by such names as R. arboreo-ponticum, etc. Gardeners very often give special names to these hybrids, and thus confusion is introduced into nomenclature. For instance, Rhododendron arboreo-caucasicum has been called $R$. Nobleanum, and Rhododendron arboreo-catawbiense has received the names of R. alta-clerense and R. Russellianum, etc. Sometimes hybrids are produced between species of different genera, as between Rhodo- 
thamnus Chamæcistus and Phyllodoce cærulea, to which the name of Bryanthus erectus has been erroneously given. These hybrids are propagated chiefly by layering and grafting. Cultivators sometimes mark these named hybrids with a cross (X), to indicate their nature.

Genera.-Certain species are more nearly allied than others, and are conveniently grouped together so as to form a distinct kind or genus. A genus, then, is an assemblage of nearly related species, agreeing with one another in general structure and appearance more closely than they accord with any other species. Thus, the various species of Roses compose one genus, which is distinguished by marked charactersmore especially by the fruit. Occasionally a sub-genus is formed by grouping certain species, which agree more nearly with each other in some important particulars than the other species of the genus. The characters of the genera are taken exclusively from the parts of fructification, while all parts of the plant furnish specific characters. In designating a plant the name of the genus is given as well as that of the species. The latter was called by Linnæus the trivial name. -Thus, a particular species of Rose is called Rosa spinosissima; the first being the genus, and the second the specific or trivial name. As regards the definition of genera and species, and the binomial nomenclature, no one has conferred so much benefit on science as the great Linnæeus. This may be considered as among his highest titles to fame.

The division of a genus may be illustrated from Hooker's Student's Flora of the British Islands, as follows:-

\section{Genus-Thaliotrum of Linnæus, Meadow-rue,}

includes the following British species, sub-species, and varieties :-

1. Thalictrum alpinum of Linnæus.

2. Thalictrum minus of Linnæus.

Sub-species minus (proper).

Variety 1. maritimum.

,2. montanum, a species of Wallroth.

Synonym. T. calcareum of Jordan.

Sub-species, majus of Jacquin.

Synonym. T. flexuosum of Bernhardi.

Sub-species, Kochii, a species of Fries.

Sub-species, saxatile, a species of Schleicher.

3. Thalictrum flavum of Linnæus.

Variety 1. sphærocarpum of Boswell Syme.

"2. riparium, a species of Jordan.

"3. Morisonia, a species of Gmelin.

Orders. - Several genera agreeing in more general characters, although differing in their special conformation, are grouped together so as to form an order or family. As genera include allied species, so orders embrace allied genera. Subdivisions are also made to facilitate 
reference, so that sub-orders and tribes are formed, consisting of certain genera, more nearly related in particular characters than others. Thus, the order Rosacep, or the Rose family, includes the genera Rosa, Rubus, Potentilla, Fragaria, Prunus, etc., which all agree in certain general characters ; and the order is divided into various sub-orders, such as the true Roses, with aohenes contained in a hollow torus; the Amygdaleæ, with drupaceous fruit, comprehending the plum, almond, peach, etc.; the Potentillex, with achenes on a convex receptacle, embracing the Cinquefoil, Strawberry, etc.

Classes.-Orders having some general characters in common are united together in classes; and sub-classes are formed in the same way as sub-orders. This is the general plan upon which botanical classification proceeds. The object of the enlightened botanist is to follow what he considers to be the natural affinities, and thus to trace, as far as possible, the order which pervades the vegetable creation.

Essentiar Characters. - Each of the divisions of a system is accurately defined, the characters being as short as is consistent with precise diagnosis. Such characters are called essential, and they embrace only those points by which the group is distinguished from the others in the same section. The complete description of an individual species, from the root to the flower and fruit, is called the natural character, and embraces many particulars which are not requisite for the purpose of diagnosis. The essential characters of genera, when in Latin, are put in the nominative case, while those of species are in the ablative. Professor Henslow was instrumental in introducing into schools an excellent method of teaching the young to notice and describe the parts of plants. His method has been very generally adopted, and with the best results. For describing the parts of a plant tables are constructed with the names of the organs, and blank spaces are left for the student to fill in the characters in methodical order-1. Root; its form and structure; 2. Stem; its form and structure; 3. Leaves, simple or compound, petiole, and lamina, venation, form, margin and apex, stipules. 4. Inflorescence; indefinite or definite; peduncle, pedicels, bract. 5. Parts of the flower; calyx, corolla, stamen, pistil ; number of parts in each whorl ; their insertion and relative position; separation or cohesion ; adhesion ; the parts of which each organ in a whorl is composed.

Nomenctature.-The names of genera are variously derived, from the structure or qualities of the group, from the name of some eminent botanist, from the classical name of the plant, from old mythological names, and from English names which are Latinised, etc. ; while specific names have reference also to the country where the plant is found, the locality in which it grows, the form of the leaves, root, stem, or the colour of the flowers, etc. The general rule is, that the name shall consist of a substantive and an adjective, the 
former indicating the genus and the latter the species. Sometimes, in place of an adjective, there is a substantive used adjectively. When a species is named in honour of its discoverer or describer, his name is put in the genitive, as Carex Vahlii, or the species of the genus Carex detected by Vahl; but if it is merely in compliment to a botanist, his name is added in an adjective form, as Jungermannia Doniana, or a Jungermannia named in honour of Don, as a botanist. Sometimes two nouns are united in a specific name, as Dictamnus Fraxinella. In such cases the specific name is often an old generic one, has a capital letter prefixed, and does not necessarily agree in gender with the name of the genus. The names of the orders in what is called the natural system are derived from one of the typical genera included under them.

AbBReviations aND SYmBols.-It is of great importance that correct descriptions should be given of species, for without them it is impossible to form the groups accurately. The difficulties of the taxonomist are often greatly increased by imperfect and careless descriptions. Valuable directions are given in Lindley's Introduction to Botany, as to the proper method of describing plants. There are certain abbreviations in constant use among botanists, which it may be of importance to notice here. The authorities for genera and species are given by adding the abbreviated name of the botanist who described them. Thus, Veronica $L$. is the genus Veronica as defined by Linnæus ; Veronica arvensis $L$. is a certain species of Veronica, defined by the same author; Oxytropis DC. is the genus as defined by $\mathrm{De}$ Candolle. It is usual in descriptive works to give a list of the authors, and the symbols for their names. The abbreviation $\nabla$. s. sp., means vidi siccam spontaneam, or that the author has seen a dried wild specimen of the plant; v. s. c., means vidi siccam cultam, or that he has seen a dried cultivated specimen; $\nabla$. $\nabla$. s. means vidi vivam spontaneam, or that he has seen a living wild specimen; while v. v. c., means vidi vivam cultam, or that the author has seen a living cultivated specimen. The asterisk prefixed to a name $\left({ }^{*} \mathrm{~L}\right.$.) indicates that there is a good description at the reference given to the work; while the dagger (tL.) implies some doubt or uncertainty. The point of admiration (IDC.) marks that an authentic specimen has been seen, from the author named; and the point of interrogation (?) indicates doubts as to the correctness of genus, species, etc., according as it is placed after the name of the one or other. $\odot$ (symbol for the Sun), $\mathrm{O}$, (1), or A, annual; of (symbol for Mars); $\odot$, (2), or B, biennial; 4 (symbol for Jupiter), $\Delta$, or P, perennial; $h$ (symbol for Saturn), 5 , or Sh, shrub; ( twining to the right; ), twining to the left; hermaphrodite; $t$, male; $o$ (symbol for Venus), female; $t-q$, monœcious, or the male and female on one plant; $t: 0+$, diœcious, or the male and female on different plants; 00 or $\infty$, means inde- 
finite in number. After the description of a plant, its habitat, or the country and locality in which it grows, is given. If the plant has been described by others, reference is given to the work in which the description may be found. If it has received different names, the synonyms must be carefully detailed, and ought to be arranged in chronological order. Condensed analyses of orders, genera, and species are often given in botanical works, and are very useful for students. Dichotomous keys are also used, a series of characters being given in the form of two contradictory propositions, so that the one being granted, the other must be rejected. In this way the student is led to the order, genus, or species.

Systems.-Various attempts have been made at different times to classify plants. One of the earliest methodical arrangements was that of Cresalpinus, in 1583. It was entirely artificial ; and the same thing may be affirmed of those of Gesner, Morison, Rivinus, and Tournefort. The system propounded by Tournefort was for a long time adopted by the French school, but was ultimately displaced by that of Linnæus, who must be looked upon as the great promulgator of the artificial method. In 1682, Ray published a system which laid the foundation of the natural method of classification. It was long neglected, and did not receive the attention it deserved, until Jussieu entered the field, and developed his views. Since that time the natural method has been advanced by the labours of De Candolle, Brown, Endlicher, Lindley, and many others.

LiNNAfaN System.-Although the Linnæan system is not in conformity with natural affinities, and does not tend to comprehensive views of structure, still it is useful to the student as an index. næus himself did not consider it as occupying a higher position, and he stated distinctly that a natural method was the great object of scientific inquiry. When not elevated to a rank which its author never meant it to occupy, this system may, with all its imperfections, be employed as a useful artificial key, and as such may be combined with the natural system. In many works of the present day, as in Babington's Manual of British Botany, the Linnæan system is used as an index to the genera. In the Linnæan or sexual system, twentythree classes are founded on the number, position, relative lengths, and connection of the stamens; while the orders in these classes depend on the number of the styles, the nature of the fruit, the number of stamens in the classes where this character is not used for distinguishing them, and the perfection of the flowers. The twentyfourth class includes plants having inconspicuous flowers, and in it the orders are formed according to natural affinities. Under these classes and orders all the known genera aud species were arranged. It is in the higher divisions that the system is artificial, for, as regards genera, the Linnæan rules are followed even in the natural systems of the present day. 
Tabular View of the Classes of the Linnaran System,

A. Flowers present (Phanerogamia).

I. Stamens and Pistil in every flower.

1. Stamens Free.

a. Stamens of equal length, or not differing in certain proportions ; in number 1

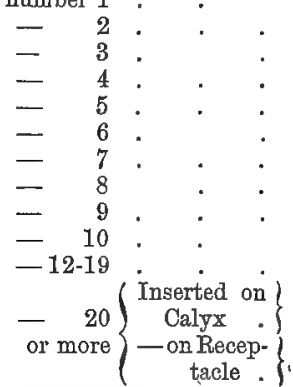

b. Stamens of different lengths;

two long and two short four long and two short

2. Stamens united; by Filaments in one bundle

-

- in more than two bundles

by Anthers (Compoind flowers)

with Pistil on a column.

II. Stamens and Pistil in different flowers on the same Plant. on different Plants

III. Stamens and Pistil in the

same or in different flowers on the same or
on different plants.

B. Flowers Absent
Class I. Monandria. . $\mu b \nu o s$, one.

II. Diandria . . $\delta / s$, two. .

III. Triandria . . т $\rho \in \hat{i}$, three.

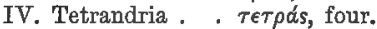

V. Pentandria . . $\pi \dot{v} \nu \tau \in$, five.

VI. Hexandria . . $\dot{\boldsymbol{\epsilon}} \boldsymbol{\xi}$, six.

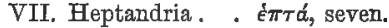

VIII. Octandria . ókrú, eight.

IX. Enneandria . évpéa, nine.

X. Decandria. . Jékâ, ten.

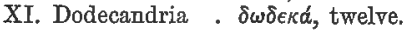

XII. Icosandria . . $\epsilon \ell \kappa o \sigma l$, twenty.

XIII. Polyandria - $\pi 0 \lambda$ śs, many. $\left.\begin{array}{c}\text { XIV. Didynamia } \\ \text { XV. Tetradynamia }\end{array}\right\} \begin{gathered}\delta v^{\prime} \nu \check{c} \mu s, \text { power, } \\ \text { superiority. }\end{gathered}$

XVI. Monadelphia

XVII. Diadelphia.

XVIII. Polyadelphia

XIX. Syngenesia .

XX. Gynandria

XXI. Moncecia

XXII. Diøecia .

XXIII. Polygamia

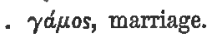

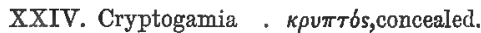

Tabular View of the Orders of the Linnean System.

\begin{tabular}{r|l} 
Class I. & Monogynia \\
II. & Digynia. \\
III. & Trigynia. \\
IV. & Tetragynia \\
V. & Pentagynia \\
VI. & Hexagynia \\
VII. & Heptagynia \\
VIII. & Octogynia \\
IX. & Enneagynia : \\
$X$. & Decagynia \\
XI. & Dodecagynia : \\
XII. & Polygnia \\
XIII.
\end{tabular}

$\gamma v v \eta^{\prime}$, female or pistil.

- $\mu b y$ os, one.

- $\delta i s$, two.

- $\tau \rho \in \hat{\imath} \mathbf{s}$, three.

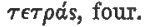
$\pi \dot{\epsilon} \tau \epsilon$, five. $\dot{\epsilon} \xi$, six. $\dot{\epsilon} \pi \tau \dot{d}$, seven.

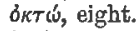
Évvéa, nine. $\delta \in \kappa a \hat{a}$, ten. $\delta \omega \delta \in \kappa d$, twelve.

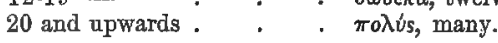




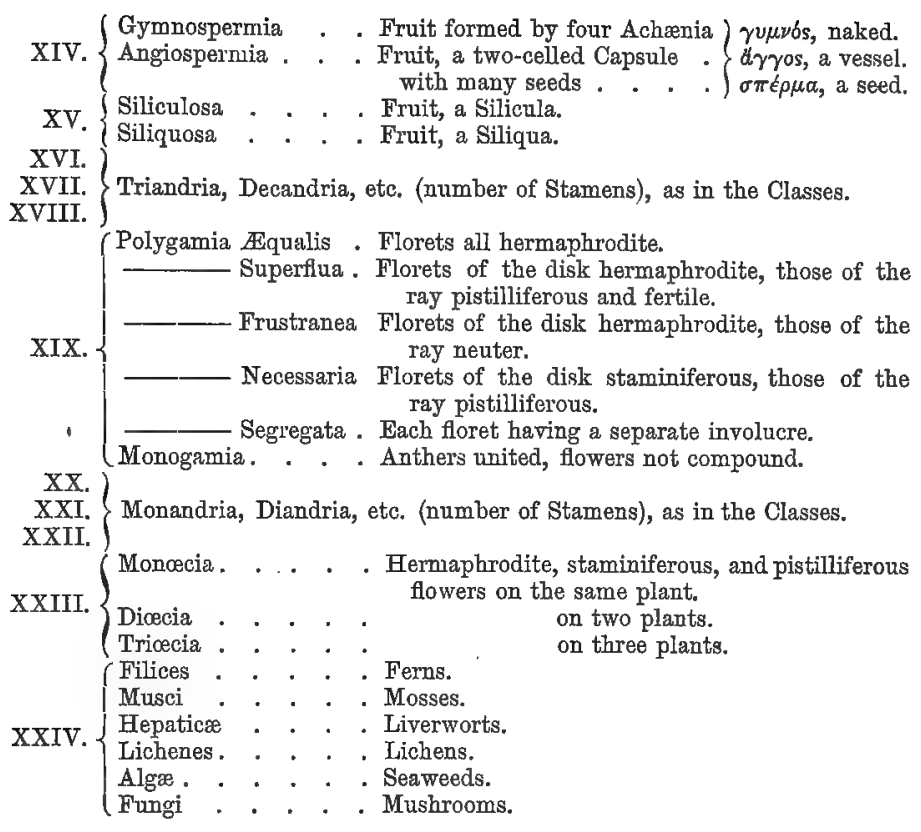

Even as an artificial method, this system has many imperfections. If plants are not in full flower, with all the stamens and styles perfect, it is impossible to determine their class and order. In many instances the different flowers on the same plant vary as regards the number of the stamens. Again, if carried out rigidly, it would separ rate in many instances the species of the same genus; but as Linnæus did not wish to breals up his genera, which were founded on natural affinities, he adopted an artifice by which he kept all the species of a genus together. Thus, if in a genus nearly all the species had both stamens and pistils in every flower, while one or two were moncecious or diocious, he put the names of the latter in italics, in the classes and orders to which they belonged according to his method, and referred the student to the proper genus for the description.

Naturad System. - It has been already stated that a natural system endeavours to bring together plants which are allied in all essential points of structure. It purposes to ascertain the system of nature, and the affinities of plants; and, in doing so, it takes into account all their organs. Every natural method, however, is, to a certain extent, artificial, and is likely to be so. It is impossible to show the affinities of plants in a lineal series ; many orders pass insen- 
sibly into others, so that their limits cannot be accurately defined; and no perfect system can be constituted until all the plants of the globe are known. Moreover, many artificial means are avowedly used in all natural systems to aid the student.

The early natural systems were very imperfect, being founded on comparatively vague views of structure and affinity. Such were the systems of Magnol and Adanson. The sketch of a natural system by Linnæus was very incomplete, and even that of the celebrated Ray was imperfect. It was not until the knowledge of structural botany had advanced, that the affinities of plants were ascertained, and the relative importance of the different characters discovered. The natural systems of the present day recognise a certain subordination of characters, founded on the fact that some organs are of more importance to the life of plants than others. The relative values of these characters are determined by the study of organisation, and are not fixed by arbitrary rules. The following table will illustrate this subordination of character :-

\section{Subordination in Value of the Organs of the same Class.}

Relative Values. Elementary.

Nutritive.

Reproductive.

1. Cellular Tissue.

(Vascular Tissue : ' Embryo.

2.

a. Spiral Vessels . a. Cotyledon.

b. Pitted Vessels . c. Scalariform

Vessels : :
Stomata . .
Prothallus

3.

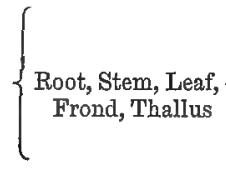

1. Stamens and Pistil.

2. Antheridia and Arche-

3.

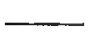

3. Fruit. gonia.

Pericarp.
Theca.

4.

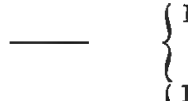

Perianth.

a. Corolla.

b. Calyx.

Inflorescence.

5.

$\left\{\begin{array}{l}\text { Torus, Nectary. } \\ \text { Bract, Involucre. }\end{array}\right.$

Thus, cellular tissue occupies the highest place, as being most universally diffused, and capable of carrying on all the functions; next comes vascular tissue. By the consideration of these, the two great divisions of cellular and vascular plants are determined. There is nothing in the nutritive and reproductive systems of the same value as cellular tissue. The embryo and its parts are reckoned as occupying the highest place in the nutritive system, and as corresponding in value with the vascular among the elementary tissues. In the same 
way the other values are determined. In examining organs it is essential to compare those which belong to the same series; for an organ which occupies the highest place in one series may be inferior in value to a second-rate organ in another. The comparative importance of the different series must be taken into account also. Thus, the nutritive may be considered as of more importance than the reproductive function, as being more essential for the life of the individual; and an organ of first-rate value in the one will therefore assume a higher function than one of the same value in the other. The changes which take place in any one set of organs are often accompanied with changes in others; and thus it is found that natural divisions may be arrived at by different routes - for instance, by the elementary, nutritive, and reproductive functions. This gives the true notion of affinity; and classifications founded on such principles will obviously be more valuable, in a practical and physiological point of view, than those which adopt characters in an arbitrary manner.

Primary Divisions of the Vegetable Kingdom.-In taking a survey of the Vegetable Kingdom, some plants are found to be composed of cells only, and are called Cellular (p. 5) ; while others consist of cells and vessels, especially spiral vessels, and are denominated Vascular (p. 16). If the embryo is examined, it is found in some cases to have cotyledons or seed-lobes, in other cases to want them; and thus some plants are cotyledonous, others acotyledonous (p. 334); the former being divisible into monocotyledonous, having one cotyledon ; and dicotyledonous, having two cotyledons. The radicle, or young root of acotyledons, is heterorhizal (p. 357), that of monocotyledons is endorhizal (p. 356), that of dicotyledons excorhizal (p. 357). When the stems are taken into consideration, it is seen that marked differences occur here also,-acotyledons being acrogenous, monocotyledons endogenous, and dicotyledons exogenous (p. 75). The venation of leaves, parallel, reticulated, or forked (p. 84), establishes the same great natural divisions; and similar results are obtained from a consideration of the flowers, - monocotyledons and dicotyledons being phanerogamous, and acotyledons cryptogamous (j. 171).

Thus, the following natural divisions are arrived at :-

1. Cellular . Acotyledonous. Heterorhizal, Acrogenous. Crypotogamous.

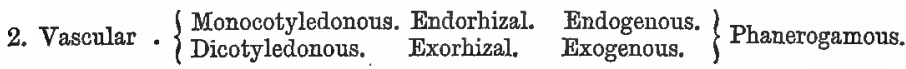

These larger groups are, on similar principles, subdivided, until at length genera and species are reached by a process of analysis. Similar results will be obtained by a synthetical process, conducted on the same principles, and proceeding from species upwards.

Henslow illustrates the divisions and subdivisions of a natural system by reference to Anthyllis Vulneraria, thus:- 


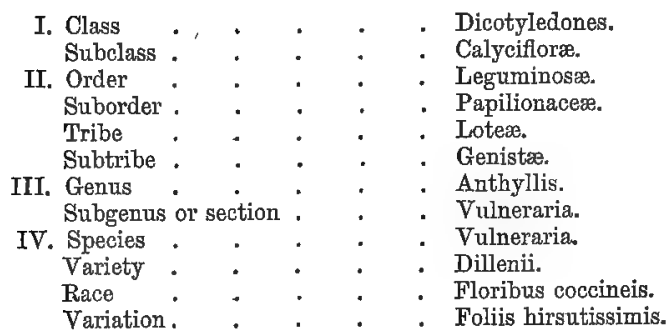

The most important natural systems are those of Jussieu, De Candolle, Endlicher, and Lindley. The larger divisions of each of these systems are given in a tabular form.

\section{Classes of Jussieu's System.}

Acotyledones

Monocotyledones

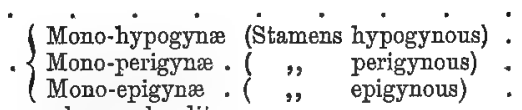

Class I.

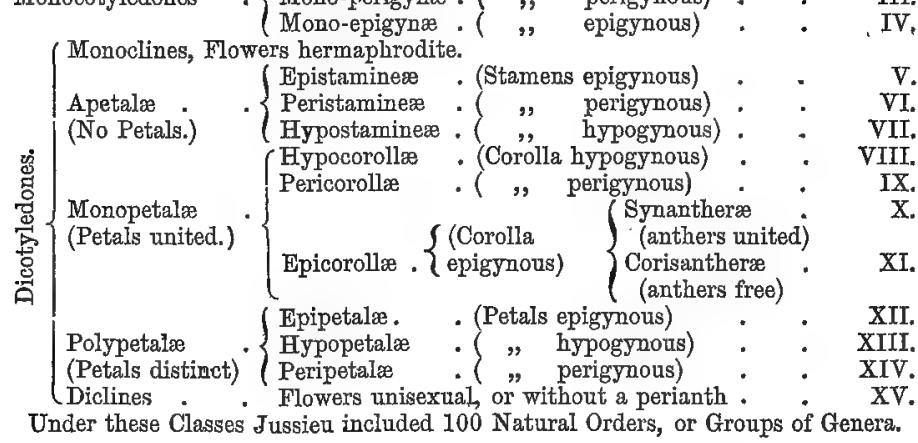

\section{Classes of the Natural System of De Candolle.}

\section{A. Vasculores or Cotyledonece.}

Class I. Dicotyledones or Exogenæ.

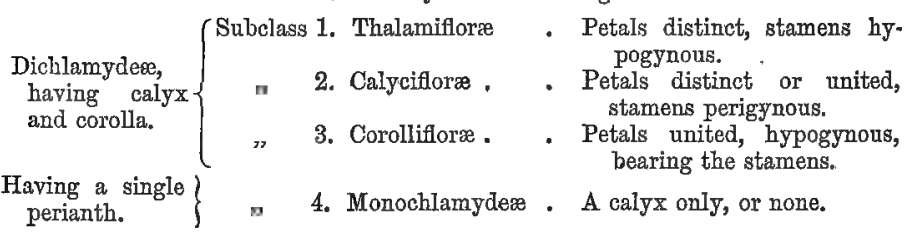

Class II. Monocotyledones or Endogenæ.

Subclass 1. Mon-Phanerogamæ . . . Having floral envelopes. "2. Mon-Cryptogamæ . . Having no floral envelopes. 


\section{B. Cellulares or Acotyledonede.}

Class III. Acotyledones.

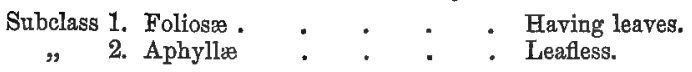

By some recent authors this system has been modified, so as to include, under Corollifloræ, all Dicotyledons with united petals, whether hypogynous or not, and to exclude from Class II. all plants without flowers. It is then presented in the following form :-

\section{Modification of De Candolle's System.}

Class I. Dicotyledones or Exogenæ.

Dichlamydeæ, (Subclass 1. Thalamifloræ . Petals distinct, stamens hypogynous.

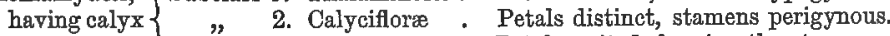
and corolla. $" 3$. Corollifloræ : Petals united, bearing the stamens.

Having asingle \} perianth.

4. Monochlamydex A calyx only, or none.

Class II. Monocotyledones or Endo'genæ.

Subclass 1. Petaloideæ or Floridæ . Floral envelopes verticillate. " 2. Glumaceæ . . . Floral envelopes imbricated.

Class III. Acotyledones or Acrogenæ.

Subclass 1. Atheogarmæ . . Having vascular tissue.

"2. Amphigamæ or Cellulares . Entirely cellular.

\section{System of Enalicher.}

REGTON I.-THALLOPHYTA ( $\theta a \lambda \lambda d s$, frond, $\phi v \tau^{\prime} v$, a plant). No opposition of stem and root. No spiral vessels, and no sexual organs. Propagated by spores.

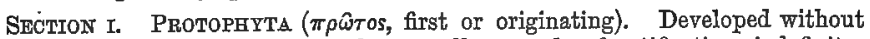
soil; deriving nourishment all around; fructification indefinite. Algæ, Lichenes.

SeCtion II. Hysterophyta ( $\delta \sigma \tau \epsilon \rho$ os, posterior or derivative). Developed on decaying organisms; nourished internally from a matrix ; all the organs appearing at once, and perishing in a definite manner. Fungi.

REGION II.-CORMOPHYTA (кop $\mu \delta$ s, a stalk or trunk). Opposition of stem and root. Spiral vessels and sexual organs distinct in the more perfect.

SeCtion II. ACRobrya ( ${ }^{\prime} k \rho \alpha$, summit, and $\beta \rho u ́ w$, to germinate). Stem increasing by the apex, the lower part being unchanged, and only conveying fluids.

Cohort 1. Anophyta (duw, above). No spiral vessels. Both sexes present. Spores freo within spore-cases. Hepaticx, Musci.

Cohort 2. Protophyta. Bundles of vessels more or less perfect. Both sexes present. Spores free within one- or many-celled spore-cases. Filices, Equisetaceæ, etc.

Cohort 3. Hysterophyta, Both sexes perfect. Seeds without a true embryo, consisting of many spores. Parasitic. Balanophoreæ, Cytineæ, etc. 
SECTION IV. AMPHLBRY ( $\dot{\alpha} \mu \phi \ell$, around). Stem increasing at the circumfer* ence. Vegetation peripherical.

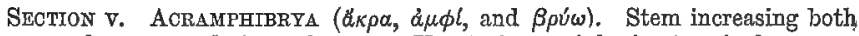
by apex and circumference. Vegetation peripherico-terminal.

Cohort 1. Gymnospermæ ( $\gamma \nu \mu \nu b s$, naked, and $\sigma \pi t \rho \mu a$, seed). Ovules naked, receiving the fecundating matter directly at the micropyle. Coniferæ.

Cohort 2. Apetalæ ( $a$, privative or without, and $\pi \epsilon \tau a \breve{\lambda} \lambda o v$, a petal. Perigone either wanting or rudimentary or single, green or coloured, free or adherent to the ovary.

Cohort 3. Gamopetalæ ( $\gamma$ ámos, union). Perigone double : outer calycine, inner corolline; gamopetalous, rarely wanting by abortion. Monopetalæ of Jussieu.

Cohort 4. Dialypetalæ ( $\delta \iota \alpha \lambda v ́ \omega$, I separate). Perigone double; outer calycine, parts distinct or united, free or attached to the ovary; inner corolline, parts distinct or very rarely cohering by means of the base of the stamens; insertion hypogynous, perigynous, or epigynous; sometimes abortive. Polypetalæ of Jussieu.

Under these sections Endlicher enumerates 279 natural orders, which are grouped under 61 classes.

\section{Division of the Vegetable Kingdom by Lindley. 1839.}

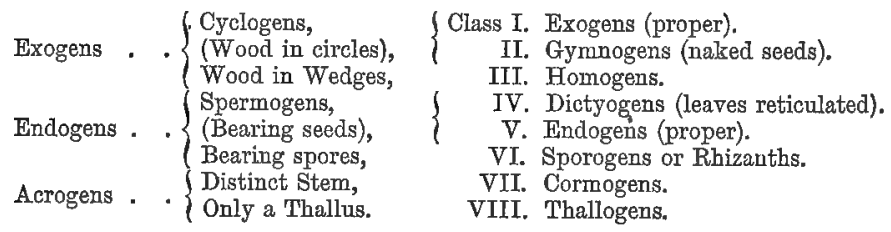

In the Exogens and Endogens the following subordinate series of subclasses are formed:-

1. Consolidated. Floral envelopes are united both with each other and the stamens, and are attached to the ovary.

2. Separated. Floral envelopes and stamens are united to each other, but the ovary is consolidated and free.

3. Adherent. Petals and sepals adhere to each other and the stamens, and are attached to ovary, but have their parts disunited.

4. Disunited. Petals and sepals adhere to each other and the stamens, but have their parts disunited, and are not attached to the consolidated ovary.

5. Dissulved. Petals and sepals are distinct from the stamens, and also from the ovary, whose carpels are disunited, either wholly or by the styles.

In each of these subdivisions the orders are arranged in two series, the one Albuminous, the other Exalbuminous.

\section{Lindley's Division of the Vegetable Kingdom. 1846. A sexual or Flowerless Plants.}

Stem and leaves undistinguishable Stem and leaves distinguishable. Class I. Thallogens. II. Acrogens. 


\section{Sexual or Flowering Plants.}

Wood of stem youngest in the centre, cotyledon single.

Leaves parallel-veined, permanent, wood of stem always confused . . . . . .

Leaves net-veined, deciduous, wood of stem, when perennial, arranged in a circle with a central pith

Wood of stem youngest at the circumference, always

III. Endogens.

IV. Dictyogens.

V. Gymnogens.

VI. Exogens.

The following are the sub-classes of Endogens and Exogens adopted by Lindley :-

\section{Endogens.}

Sub-class 1. Glumaceous. - Floral envelopes imbricated.

2. Petaloid.-Floral envelopes verticillate.

a. Unisexual, often achlamydeous.

b. Hermaphrodite, ovary inferior.

c. Hermaphrodite, ovary superior.

Exogens.

Sub-class 1. Diclinous. - Flowers unisexual.

2. Hypogynous.-Flowers usually herraphrodite, stamens completely hypogynous, free from the calyx or corolla.

3. Perigynous,-Flowers usually hermaphrodite, stamens growing to the side of either the calyx or corolla ; ovary superior, or nearly so.

4. Epigynous. - Flowers usually hermaphrodite, stamens growing to the side of either the calyx or corolla ; ovary inferior or nearly so.

Under the classes Lindley enumerates 303 natural orders, which are grouped together under 56 alliances. In this system of Lindley the divisions of Asexual and Sexual plants correspond to Endlicher's 2 Regions; the 7 classes represent Endlicher's 5 sections ; and the 56 alliances are equivalent to the 61 classes in Endlicher's system.

This division may be presented thus :-

Classes. Wood. Leaves. Envelopes. Sexes. Embryo.

1. Exogenæ . Exogenous Netted 5 or 4-nary Perfect . Dicotyledonous.

2. Gymnospermæ Exogenous $\left\{\begin{array}{c}\text { Parallel } \\ \text { or } \\ \text { forked }\end{array}\right\}$ None . Seed naked Dicotyledonous.

3. Endogenæ . Endogenpus Parallel Ternary Perfect . Monocotyledonous.

4. Dictyogenæ . Endogenous Netted . Ternary Perfect . Monocotyledonous.

5. Acrogenæ. Acrogenous $\left\{\begin{array}{c}\text { Forked } \\ \text { or None }\end{array}\right\}$ None . None . Acotyledonous.

6. Thallogenæ . None. . . None. . None . None . Acotyledonous.

Henslow has given a comparative view of all these systems, pointing out, in a tabular form, the corresponding divisions in each of them :- 


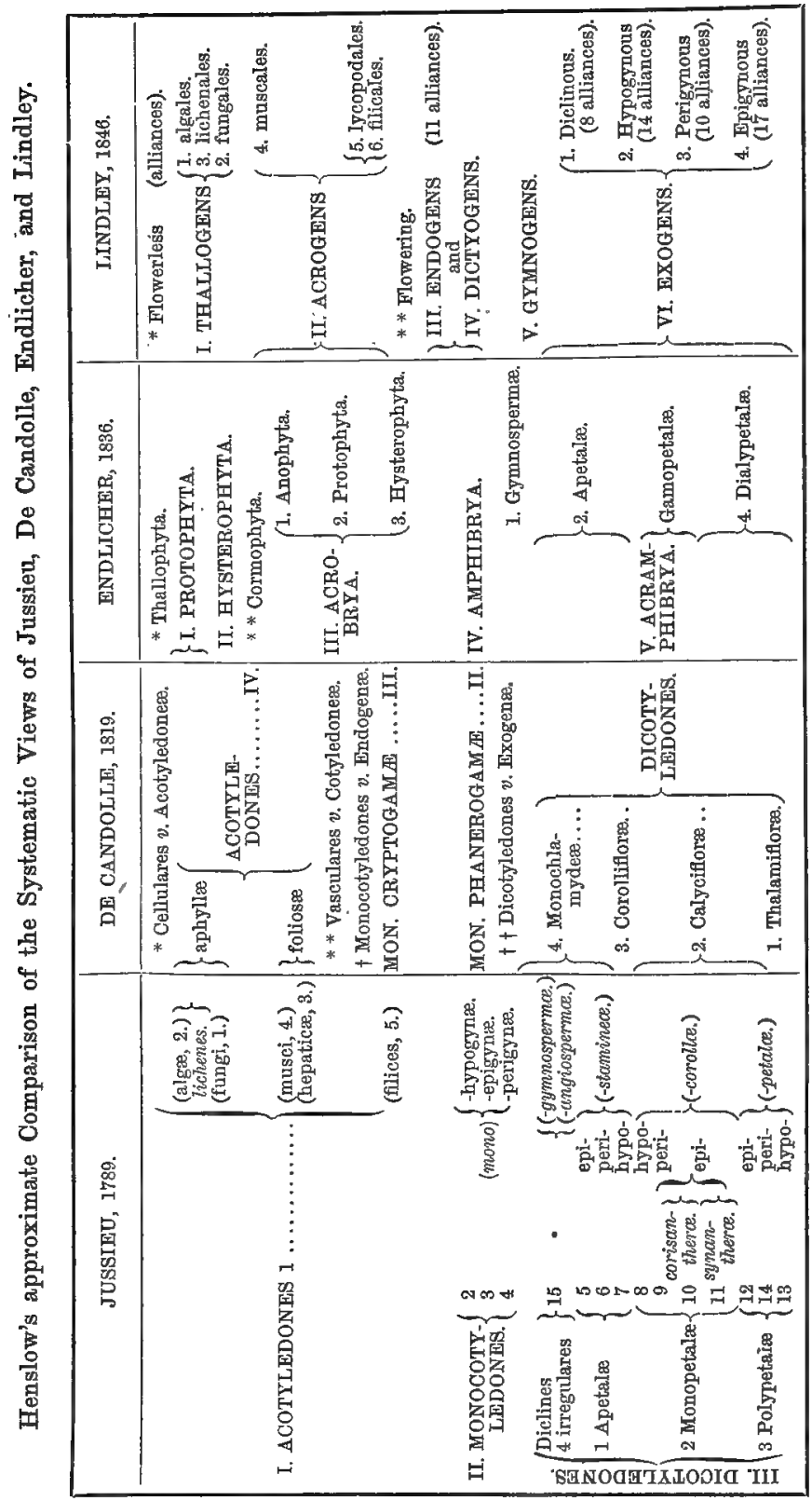


The following is Dr. Hooker's synopsis of classes, sub-classes, and cohorts :-

\section{Stb-Kingdom I. -Phanogamous, Cotrledonods, or Flowering} Plants.

\section{Class I. Dicotyledons.}

Sub-class I. Angiospermous.

Ovules prodnced in a closed ovary, fertilised by the pollen-tube traversing a stigmatic tissue to reach the cavity of the ovary, and hence the embryo-sac of the ovule.

Division"I. Polypetalous.

Flowers with both a calyx and a corolla, the latter of separate petals.

Series I. Thalamifloral.

Sepals usually distinct and separate, free from the ovary. Petals 1-2- $\infty$-seriate, hypogynous. Stamens hypogynous, rarely inserted on a short or long torus, or on a disk. Ovary superior.

Cohorts. -1, Ranales ; 2, Parietales; 3, Polygalales ; 4, Caryophyllales ; 5, Guttiferales ; 6, Malvales.

Series II. Discifloral.

Sepals distinct or connate, free or adnate to the ovary. Disk usually conspicuous, as a ring or cushion, or spread over the base of the calyx-tube, or confluent with the base of the ovary, or broken up into glands. Stamens usually definite, inserted upon or at the outer or imner base of the disk. Ovary superior.

Cohorts. -7, Geraniales ; 8, Olacales ; 9, Celastrales ; 10, Sapindales.

Series III. Calycifloral.

Sepals connate (rarely free), often adnate to the ovary. Petals 1seriate, perigynous or epigynous. Disk adnate to the base of the calyx, rarely tumid or raised into a torus or gynophore. Stamens perigynous, usually inserted on or beneath the outer margin of the disk. Ovary frequently inferior.

Cohorts._11, Rosales ; 12, Myrtales ; 13, Passiflorales ; 14, Ficoidales ; 15 , Umbellales.

Division II. Monopetalous.

Flowers furnished with both sepals and petals, the latter connate.

Series I. Epigynous. Ovary inferior.

Cohorts.-16, Caprifoliales; 17, Asterales ; 18, Campanales.

Series II. Hypogynous or Perigynous. Ovary superior.

Cohorts.-19, Ericales ; 20, Primulales ; 21, Ebenales ; 22, Gentianales ; 23, Polemoniales ; 24, Solanales ; 25, Personales ; 26, Lamiales.

Division III. Apetalous or incomplete-flowered. Flowers with a single floral envelope (the calyx) or none.

Subdivision I. Ovary superior-perianth usually distinct.

Cohorts.-27, Chenopodiales; 28, Laurales; 29, Daphnales ; 30, Urticales ; 31, Amentales ; 32, Euphorbiales ; 33, Piperales.; 34, Nepenthales. 
Subdivision II. Ovary inferior - Perianth more or less distinct in the f, or $q$, or both.

Cohorts. -35, Asarales ; 36, Quernales ; 37, Santalales.

Sub-class II. Gymnospermous.

Ovules produced superficially on a scale (bract or bpen ovary); fertilised by the direct application of the pollen to the apex of the nucleus, which the pollen-tube penetrates. Flowers unisexual (except in Welwitschia.)

Class II. Monocotyledons.

Division I. Ovary inferior-Perianth usually distinct; 2-seriate and coloured.

Cohorts.-1, Hydrales ; 2 , Amomales ; 3, Orchidales ; 4, Taccales ; 5, Narcissales ; 6, Dioscorales.

Division II. Ovary superior.

Subdivision I. Ovary apocarpous.

Cohorts.-7, Triurales ; 8, Potamales.

Subdivision II. Ovary syncarpous.

Cohorts.-9, Palmales; 10, Arales; 11, Liliales ; 12, Pontederales; 13, Commelynales ; 14, Restiales; 15, Glumales.

Sub-Kingdom II.-Cryptogamous, Aootylmdonods, on Flowerless

\section{Plants.}

Class III. Acrogens.

Cohorts.-1, Filicales ; 2, Muscales.

Class IV. Thallogens.

In the succeeding pages the natural orders will be grouped under the following divisions :-

A. Phanerogamous, Cotruedonous, or F'lowering Plants.

Class I. Dicotyledones or Exogenæ.

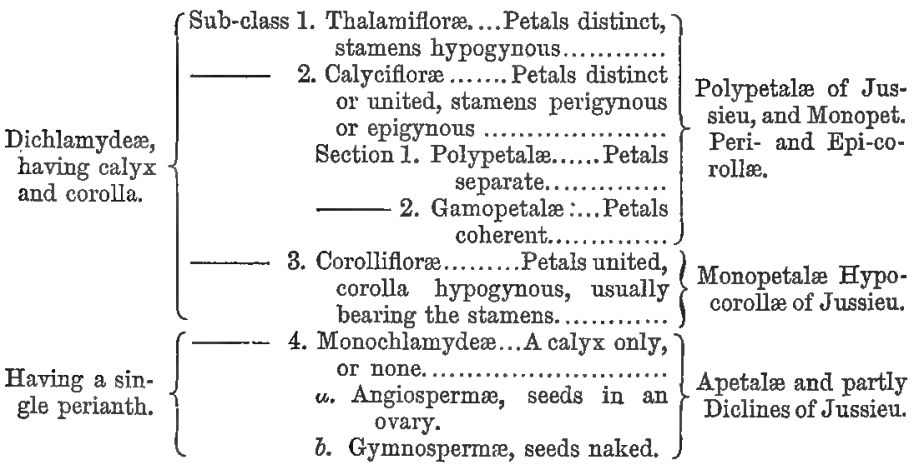


Class II. Monocotyledones or Endogenæ.

Sub-class 1. Petaloideæ or Floridæ, Floral envelopes verticillate.

a. Hermaphrodite, ovary inferior.

b. Hermaphrodite, ovary superior.

c. Unisexual, often achlamydeous.

2. Glumiferæ, Floral envelopes imbricated.

B. Cryptogamods, or acotruedonods Flowerlegs Plants.

Class III. Acotyledones or Acrogenæ.

Sub-class 1. Atheogamæ or Cormogenæ..................... Having vascular tissue.

2. Amphigamæ, Thallogenæ, or Cellulares.........Entirely cellular.

\section{CHAPTER II.}

\section{ARRANGEMENT AND CHARACTERS OF THE CLASSES AND}

NATURAL ORDERS.

\section{Sub-Kingdom I.-Phanerogamous Plants. \\ Plants producing Stamens and Pistils.}

Class I.-DTCOTXLmDONES AND EXOGEN W, Juss. and DC.; ACRAMPHIBRYA, Endl.

This is the largest class in the vegetable kingdom. The plants included under it have a cellular and vascular system, the latter consisting partly of elastic spiral vessels (Fig. 51, p. 17). The stem is more or less conical, and exhibits wood and true bark. The wood is exogenous, i.e. increases by additions at the periphery, the hardest part being internal (p. 49, et seq.). It is arranged in concentric circles. Pith exists in the centre, and from it diverge medullary rays. The bark is separable, and increases by additions on the inside. The epidermis is furnished with stomata (p. 28). The leaves are reticulated (p. 84), usually articulated to the stem. The flowers are formed upon a quinary or quaternary type, and have stamens and pistils. "The ovules are either enclosed in a pericarp, and fertilised by the application of the pollen to the stigma, or they are naked and fertilised by the direct action of the pollen. The embryo has two or more opposite cotyledons, and is exorhizal in germination (p. 41).

\section{Sub-class 1.-ThaLAMIFLORE.*}

Calyx and corolla present; petals distinct, $\uparrow$ inserted into the

* Thalamus, receptacle, and jos, flower.

† Sometimes the petals are abortive, and it is then difficult to determine whether the plant belongs to this sub-class or to Monochlamydex. 
thalamus (receptacle); stamens hypogynous. This includes the hypogynous polypetalous orders of Jussieu, and a diclinous order (Menispermacex).

Order 1.-Randnculacese, the Crowfoot Family. (Polypetalce Hypogynoe.) Sepals 3-6, frequently 5, deciduous (fig. 663 c). Petals

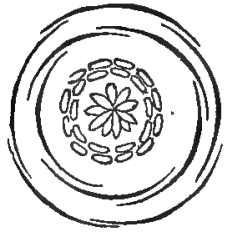

Fig. 664 . 5-15 (fig. $663 \mathrm{pe}$ ), rarely abortive, sometimes anomalous in form (fig, 308, p. 202), occasionally with scales at the base (fig. 662 a). Stamens usually indefinite, hypogynous (fig. 663 e); anthers adnate (figs. 665, 666); carpels numerous, 1-celled (fig. $663 \mathrm{pi}$ ), distinct or united into a single many-celled pistil; ovary containing one anatropal ovule (figs. 588, p. $332 ; 667 \mathrm{~g}$ ), ог several united to the inner edge. Fruit various, either dry achænia (figs. 559, p. $309 ; 668$ ), or baccate, or follicular (figs. 539 , p. 303 ; 564, p. 312 ). Seeds albuminous, erect, or pen-

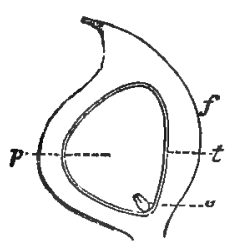

Fig. 668 .

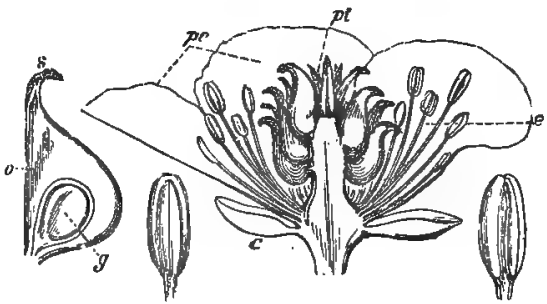

Fig. 663.
Fig. 665 .

dulous ; albumen, horny (fig. 668 p) ; embryo minute (fig. 668 e).Herbaceous, suffruticose, or rarely shrubby plants, having alternate or opposite, simple, much-divided leaves, with dilated sheathing petioles (fig. 254, p. 176). Juice watery. Hairs, if present, simple.

The plants of the order are found in cold damp climates, and in the elevated regions of warm countries. Europe contains one-fifth of the order, and North America about one-seventh. The order is divided into five tribes:-1. Clematideæ; 2. Anemoneæ (fig. 268, p.

Figs. 663-668 exhibit the organs of fructification of Ranunculus acris, to illustrate the natural order Ranunculaceæ. Fig. 663. Flower cut vertically. c, Calyx. pe, Petals. e, Stamens, pi, Pistil composed of several carpels on an elongated receptacle or axis. Fig. 664. Diagram of the flower, showing 5 inbricated sepals, 5 petals alternating with the sepals, indefinite stamens in several whorls, multiples of the petals, and numerous carpels or achænia in the centre. Fig. 665. Adnate anther seen on the outer side. The anther is in this instance extrorse. In Pæonia and some other Ranunculaceæ it is introrse. Fig. 666. Adnate anther viewed on the inside. Fig. 667. Verlical section of the ovary, 0 , showing the ovale, $g$. s, Stigma. Fig. 668. Fruit, an achænium cut vertically. $f$, Pericarp. $t$, Spermoderm or integument of the anatropal seed. $p$, Perisperm or albumen, between fleshy and horny. $e$, Minute embryo. 
181) ; Ranunculeæ (fig. 254, p. 176) ; 4. Helleboreæ (fig. 539, p. 303), 5. Pæoniæ (fig. 404, p. 234), according to the æstivation of the calyx, the nature of the fruit, etc. The following is an analysis of these sub-orders, with the number of British species in each :-

\begin{tabular}{|c|c|c|c|c|c|}
\hline & Spec. $\mathrm{Br}$ & it. Anther. & Carpel. & Seed. & \#istiv. \\
\hline 1. Clematideæ & 1) & & & $*$ & valvate \\
\hline 2. Ane & 11 & & mono- & pendulous & imbricate. \\
\hline 3. Ranu & 19 & extrorse & & erect. & $*$ \\
\hline 4. Hellebore & 10 & & polysper & * & $*$ \\
\hline Pæoniæ & 1 & introrse & $*$ & * & * \\
\hline
\end{tabular}

Authors enumerate 32 known genera, comprising 1290 species. $E_{x-}$ amples of the genera-Clematis, Anemone, Ranunculus, Helleborus, Aquilegia (fig. 309, p. 202), Delphinium, Aconitum, Actæa, Pæonia, Podophyllum.

The order has narcotico-acrid properties, and the plants are usually more or less poisonous. The acridity is frequently volatile, and disappears when the plants are dried or heated. It varies in different parts of the plants, and at different seasons. Ranunculus (the genus whence the order is named) contains many acrid species, such as $R$. sceleratus, alpestris, bulbosus (fig. 254, p. 176), gramineus, acris, and Flammula; while others, such as $R$. repens, aquatilis, Lingua, and Ficaria, are bland. The acridity is entirely lost by drying, and it disappears in the pericarps as the seeds (which are themselves bland) ripen. The leaves of Aconitum Napellus, Monkshood, Friar'scap, or Helmet-flower (fig. 308, p. 202), contain a narcotic alkaloid, called aconitine. They are used as an anodyne in neuralgic affections, in the form of extract and tincture. The root or rhizome has sometimes been mistaken for Horse-radish. The root of Aconitum ferox furnishes the powerful East Indian poison, called Bikh, Bish, or Nabee. The root or rhizome of Aconitum heterophyllum, atis or atees, is used as a remedy for intermittent fever in India. The leaves of Clematis recta and Flammula have been used as vesicants. The seeds of Delphinium Staphysagria, Stavesacre, are irritant and narcotic, and are used for destroying vermin. They owe their activity to an alkaloid principle, called delphinia. Delphinium glaciale grows at the height of 16,000 feet on the Himalayas. The Hellebores have been long noted for their irritant qualities. Helleborus officinalis, niger (Christmas-rose), fretidus, and viridis, act as drastic purgatives; hence the use of some of them in ancient times in cases of mania. Actrea spicata, baneberry, has a single succulent carpel, containing many ovules. The rhizome has some resemblance to that of black Hellebore. The fruit is poisonous. The rhizome of Actrea (Oimicifuga) racemosa, black snake-root, black cohosh or bugbane, is used in rheumatic affections. The rhizome of Coptis Teetoe is used in India as a bitter tonic. Nigella sativa is supposed to be the fitches of Scripture (חצP, 
ketzach), called also black cummin and Fennel-flower. The roots of Hydrastis canadensis, yellow-root, are used as a tonic. The rhizome of Podophyllum peltatum, May-apple, is employed in America as a purgative. Some of the Ranunculaceæ are chiefly marked by bitter tonic properties. This order, in the position, number, and structure of its parts of fructification generally, presents a resemblance to several widely differing families. It differs from Dilleniaceæ in the want of an aril, in its deciduous calyx, and in its whole habit; from Magnoliaceæ, in the want of true stipules; from Papaveraceæ and Nymphæaceæ, in the distinct not united carpels, watery not milky juice, and acrid properties. It closely approaches the Berberidaceæ, especially in Podophyllum (which some authors look upon as a Berberid), but differs in its stamens not bursting by recurved valves. In its numerous carpels, floral divisions, and indefinite stamens, it agrees with the Rosaceæ, but differs in its stamens being hypogynous instead of perigynous, in the large quantity of albumen surrounding the minute embryo, in the want of true stipules, and in its acrid properties. Crowfoots and Umbellifers agree in some particulars; the latter, however, have their ovary inferior, and their stamens always definite.

Order 2.-Dilleniaceses, the Dillenia Family. (Polypet. Hypog.) Sepals 5, persistent. Petals 5, deciduous, in a single row. Stamens indefinite, hypogynous, either distinct or combined into bundles; filaments dilated at the base or apex; anthers adnate, introrse, with longitudinal dehiscence. Ovaries definite, more or less distinct, with a terminal style and simple stigma; ovules anatropous. Fruit of 2-5 capsular or baccate unilocular carpels, which are either distinct or coherent. Seeds erect or ascending, usually arillate, several in each carpel, or only two, or one by abortion; testa crustaceous; embryo straight, minute, axile, at the base of fleshy albumen.-The plants of the order are trees, shrubs, or under-shrubs, having alternate, exstipulate, coriaceous, or rough leaves. They are found chiefly in Australia, Asia, and the warm parts of America. The Indian species are remarkable for their beauty, the grandeur of their foliage, and the magnificence of their flowers. They have astringent properties, and some of the species afford excellent timber. Authors enumerate 30 genera, including 230 species. Examples-Dillenia, Delima, Hibbertia, Candollea, Tetracera.

Order 3.-MaGnoliaCes, the Magnolia Family. (Polypet. Hypog.) Sepals 2-6, usually deciduous. Petals 2-30, hypogynous; often in several rows. Stamens indefinite, distinct, hypogynous; anthers adnate, long, dehiscing longitudinally. Carpels numerous, 1-celled, arranged upon a more or less elevated receptacle; ovules anatropal, suspended or ascending; styles short. Fruit consisting of numerous distinct or partially coherent carpels, which are either dehiscent or 
indehiscent, sometimes samaroid. Seeds, when ripe, often hang suspended from the carpels by a long slender cord; embryo minute, at the base of a fleshy, not ruminate, perisperm.- Trees and shrubs, with alternate coriaceous leaves, and deciduous convolute stipules. They abound in North America, and species occur in India, South America, China, Japan, New Holland, and New Zealand. The order has been divided into-1. Wintereæ; aromatic plants, in which the leaves are dotted, the carpels are in a single verticil, and the wood is often marked. with punctations or dots. 2. Magnolieæ; bitter plants with fragrant flowers, in which the carpels are arranged in several rows on an elevated receptacle (fig. 337, p. 213), and the leaves are not dotted. The Indian mountains and islands are the great centres of Magnolias. 3. Schizandreæ; usually climbing shrubs, with unisexnal flowers, numerous baccate carpels, arranged in heads or spikes, no stipules. Authors mention 10 or 12 known genera, comprising 70 species. ExamplesIllicium, Drimys, Magnolia, Liriodendron, Schizandra, Trochodendron.

The properties of the order are bitter, tonic, and often aromatic. Illicium anisatum, Star-anise, is so called from its carpels being arranged in a star-like manner, and having the taste and odour of anise. It is also called Badiane. Its fruit is employed as a carminative. Drymis Winteri or aromatica, brought by Captain Winter from the Straits of Magellan (Magulhaens) in 1578, yields Winter's bark, which has been employed medicinally as an aromatic stimulant. It somewhat resembles Canella bark. Magnolias are remarkable for their large odoriferous flowers, and their tonic aromatic qualities. The bark of Magnolia glauca, Swamp Sassafras or Beaver-tree, is used as a substitute for Peruvian bark. The seeds of Magnolia Yulan, a species with deciduous leaves, are used in China as aj febrifuge. Liviodendron tulipifera, the tulip-tree (fig. 337, p. 213), marked by its truncate leaves, has similar properties. Talauma fragrantissima supplies the Organ-nut of Brazil.

Order 4.-Anonacese, the Oustard Apple Fanily. (Polypet. Hypog.) Sepals 3-4, persistent, often partially cohering. Petals 6, hypogynous, in two rows, coriaceous, with a valvate æstivation. Stamens indefinite (very rarely definite) on a large torus; anthers adnate, extrorse, with a large 4-cornered connective. Carpels usually numerous, separate or cohering slightly, rarely definite; ovules anatropal, solitary or several, erect or ascending. Fruit succulent or dry, very rarely capsular, the carpels being one- or many-seeded, and either distinct or united into a fleshy mass; spermoderm brittle; embryo minute, at the base of a ruminated or mottled perisperm or albumen, which constitutes an important character of the order.-Trees or shrubs, with alternate, simple, exstipulate leaves, found usually in tropical countries. Authors enumerate 50 genera, including about 300 species. Examples-Bocagea, Anona, Uvaria, Guatteria, Xylopia, Duguetia, Asimina. 
Their properties are generally aromatic and fragrant. Some of the plants are bitter and tonic, others yield edible fruits. The custard-apples, Sweetsops, and Soursops of the East and West Indies, are furnished by various species of Anona, such as A. muricata, squamosa, and reticulata. Anona Cherimolia furnishes the Cherimoyer, a wellknown Peruvian fruit. The fruit of Xylopia aromatica is commonly called Ethiopian pepper, from being used as pepper in Africa. Xylopia glabra is called Bitter-wood in the West Indies. The Lancewood of coachmakers appears to be furnished by a plant belonging to this order, called by Schomburgk Duguetia quitarensis.

Order 5.-Menispermaces, the Moon-seed Family. (Polypet. Hypog.) Flowers usually unisexual (often diccious), generally of a pale-greenish hue. Sepals and petals similar in appearance, in two rows, usually 3 in each row, hypogynous, deciduous, Stamens monadelphous, or occasionally free; anthers adnate, extrorse. Carpels solitary or numerous, distinct or partially coherent, unilocular; ovule solitary, curved (fig. 456, p. 255). Fruit a succulent 1-seeded oblique or lunate drupe. Embryo curved or perpherical; radicle superior; albumen fleshy, sometimes wanting.-The plants of this order are sarmentaceous or twining shrubs, with alternate leaves, and very small flowers. The wood is frequently arranged in wedges. The order is common in the tropical parts of Asia and America. There are about 36 known genera, including about 300 species. Examples -Menispermum, Cissampelos, Cocculus.

The species are bitter and narcotic. Some are employed as tonics, others have poisonous properties. The root of Jateorhiza palmata, a plant of east Africa, is known as Calumba-root, and is used as a pure bitter tonic in cases of dyspepsia, in the form of infusion or tincture. It contains a bitter crystallisable principle called Calumbin. Cocculus indicus is the fruit of Anamirta Cocculus. It is extremely bitter. The seed contains a crystalline poisonous narcotic principle, Picrotoxin, which is its active ingredient; while the pericarp yields a nonpoisonous substance called Menispermin. The seeds have been used externally in some cutaneous affections. At one time they were employed, most prejudicially, to give bitterness to porter. Tinospora cordifolia, called Gulancha, is used as a tonic. The stem and root of Chondodendron tomentosum, found in Peru and Brazil, furnish Pareirabrava, which is tonic and diuretic, and is used in chronic inflammation of the bladder. Cissampelos ovalifolia and C. Mauritiana are tonic and diuretic. Coscinium (Menispermum) fenestratum supplies a false Calumba-root, which contains much Berberine, the same yellow bitter crystalline substance which is found in the Barberry.

Order 6.-BerberIdacese, the Barberry Family. (Polypet. Hypog.) Sepals 3-4-6, deciduous, in a double row. Petals hypogynous, equal in number to the sepals, and opposite to them, or twice as many, 
often having an appendage at the base on the inside. Stamens equal in number to the petals, and opposite to them; anthers adnate, bilocular (dithecal), each of the loculi opening by a valve from-the bottom to the top. Carpel solitary, unilocular, containing 2-12 anatropal ovules; style sometimes lateral; stigma orbicular. Fruit baccate or capsular, indehiscent. Albumen fleshy or horny; embryo straight, sometimes large (figs. 589, 590, p. 332). - Shrubs or herbaceous perennial plants, with alternate, compound, exstipulate leaves and flowers often in racemes (fig. 252, p. 175). The true leaves are often changed into spines, by non-development of parenchyma and induration of the veins (fig. $236 f, \mathrm{p}$. 119). Found chiefly in the mountainous parts of the temperate regions of the northern hemisphere. The plants of the order have bitter and acid properties. The bark and stem of Berberis vulgaris, common Barberry, are astringent, and yield a yellow dye and a crystalline matter called Berberine; the fruit contains oxalic acid, and is used as a preserve. Berberis Lycium is used in India for ophthalmia. The genus Podophyllum is placed in this order by some botanists (see Ranunculaceæ). Lindley enumerates 12 genera, including 109 species. Examples-Berberis, Mahonia, Epimedium, Diphylleia, Leontice, Lardizabala.

Order 7.- N YMPHARACE $\mathbb{E}$, the Water-lily family (figs. 341, 342, p. 214 ; fig. 669). (Polypet. Hypog.) Sepals 3 to 5, sometimes confounded with the petals. Petals numerous, often passing gradually into stamens (fig. 342, 2, p. 214), inserted at different heights in a torus. Stamens indefinite, inserted above the petals into the torus (fig. $669 \mathrm{c})$; filaments petaloid ; anthers adnate, introrse, opening by two longitudinal clefts. Torus large, fleshy, surrounding the ovary more or less (fig. $669 t$ ). Ovary multilocular, many-seeded, with radiating stigmas (fig. $669 \mathrm{~s}$ ) ; numerous anatropal ovules. Fruit many-celled, indehiscent. Seeds very numerous, attached to spongy dissepiments ; albumen farinaceous ; embryo small, enclosed in a fleshy vitellus, and situated at the base of the perisperm (fig. 576, p. 327).-Aquatic

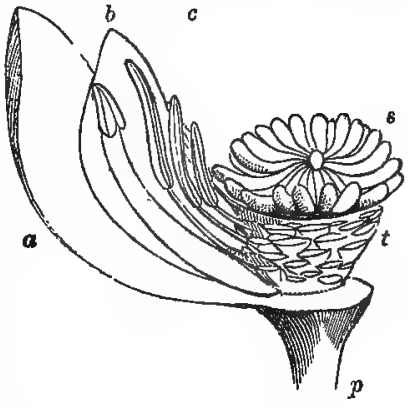

Fig. 669. plants, with peltate or cordate fleshy leaves, and a rootstock or stem which extends itself into the mud at the bottom of the water. There are 3 sub-orders :-1. Nymphææ, water-lilies; sepals 4-6, petals and

Fig. 669.-Section of a flower of Nymphrea alba, white Water-lily, showing the pistils, and the receptacle or torus bearing the stamens and petals. $p$, Peduncle or flower-stalk. $t$, Elevated torus or receptacle. s, Radiating stigmas. $u$, Sepal. b. Petal. c, Stamens, 
stamens $\infty$, carpels united, ovules $\infty$, flowers large and showy. 2. Cabomber, water-shields; sepals and petals 3 , carpels few, placed in the torus, ovules three, flowers small. 3. Nelumboneæ, water beans; sepals $4-5$, petals and stamens $\infty$, carpels inserted in the top of a large flattened torus, ovules 1-2, seeds exalbuminous, flowers showy, and leaves rising above the water. Authors enumerate 8 genera, comprehending about 30 species. Examples-Nymphæa, Nuphar, Victoria, Euryale, Cabomba, Hydropeltis, Nelumbium.

Little is known in regard to the properties of the plants of this order. Some of them are astringent and bitter, while others are said to be sedative. They have usually showy flowers, and their petioles and peduncles contain numerous air-tubes. Victoria regia is one of the largest known aquatics. It is found in the waters of South America, and is said to range over 35 degrees of longitude. The flowers have a fine odour. When expanded they are a foot in diameter. The leaves are from four to six and a half feet in diameter. The seeds and rootstocks of many plants of this order contain much starch, and are used for food. It has been said that the rhizomes of Nymphoea alba are better than Oak-galls for dyeing grey; they have been long employed advantageously for tanning leather. Nymphoea Lotus, Lotus Water Lily, is supposed by some to be the lily ("שE, sheshan or shushan) of the Old Testament. The stems of Nuphar luteum, yellow pond lily, are reported to be astringent. Cabomber have peltate floating leaves; some of them have astringent properties. The flower of Nelumbium speciosum is supposed to be the Lotus figured on Egyptian and Indian monuments, and the fruit is said to be the Pythagorean Bean (xúčmos). It is the sacred bean of India. The plant is said to have disappeared from the Nile, where it used to abound. The petioles and peduncles contain numerous spiral vessels, which have been used for wicks of candles. Dr. Wight states that those wicks on great and solemn occasions are burnt in the lamps of the Hindoos, placed before the "shrines of their gods. Nelumbium Leichardti is the sacred bean of N.E. Australia.

Order 8.-SARRACENIACE a, the Sidesaddle-flower, Water-pitcher, or Trumpet-leaf Family. (Polypet. Hypog.) Sepals 5, persistent, imbricated in æstivation, often with coherent bracts outside. Petals 5, hypogynous, concave; occasionally the corolla is absent (Heliamphora), and the calyx consists of 4-6 segments. Stamens 00 ; anthers adnate, dithecal, introrse, with longitudinal dehiscence. Ovary free, triquinquelocular ; style single, sometimes dilated at the top into a 5angled or 5-lobed parasol-like expansion, the deflexed points of which are stigmatiferous ; stigma persistent, sometimes truncated, at other times divided; ovules anatropal. Capsule 3-5 celled, with loculicidal dehiscence. Seeds very numerous, small, attached to large placentas, which project from the axis into the cavity of the cells; albumen 
copious; embryo cylindrical, lying at the base of the seed; radicle pointing to the hilum.-Herbaceous plants, found in boggy places, having radical leaves, the petioles of which are folded, and cohere at the edges, so as to form ascidia or hollow tubes, which are lined with hairs, and act as secreting organs (fig. 203, p. 96). Scapes one or more flowered. (See remarks on the physiology of these ascidia at p. 383.) The plants are found chiefly in North America. Darlingtonia grows on the Rocky Mountains, Heliamphora on Roraima Mountain in Venezuela. Their properties are not known. There are 3 genera, including 8 species. Examples-Sarracenia, Heliamphora, Darlingtonia.

Order 9.-PAPaveracem, the Poppy Family. (Polypet. Hypog.) Sepals 2, rarely 3, caducous.' Petals hypogynous, usually 4, cruciate, sometimes a multiple of 4, regular, rarely wanting. Stamens hypogynous, usually 00 , sometimes a multiple of 4 ; anthers dithecal, innate. Ovary solitary; style short or none; stigmas 2, or many and radiating (fig. 444 , p. 249 ) ; ovules 00, anatropal (fig. 457, p. 256). Fruit unilocular, either siliquxform with two, or capsular with several parietal placentas. Seeds numerous; albumen between fleshy and oily; embryo minute, at the base of the albumen, with plano-convex cotyledons.-Herbs or shrubs, usually with milky or coloured juice, having alternate exstipulate leaves, and long one-flowered peduncles. The plants belonging to this order are chiefly European. The species, however, are found scattered over tropical America, Asia, China, Australia, Cape of Good Hope, etc. Lindley mentions 20 known genera, and 140 species. Examples-Papaver, Meconopsis, Eschscholtzia, Sanguinaria, Glaucium, Chelidonium, Platystemon.

The order possesses well-marked narcotic properties. Opium is the concrete milky juice procured from the nearly ripe capsules of Papaver somniferum, and its varieties. The plant is a native of Western Asia, and probably also of the south of Europe; but it has been distributed over various countries. There are four kinds of opium known in commerce, viz. Turkey, Egyptian, East Indian, and Persian; of which the first is the kind chiefly used in Britain. The most important active principle in opium is the alkaloid called morphia. There are other crystalline principles found in it, such as codeia, narcotine, thebaia, meconine, and an acid called meconic acid, which constitutes with sulphuric acid the solvent of the active principles. Opium is administered so as to act as a stimulant, a narcotic, anodyne, or diaphoretic. The seeds of the Opium Poppy yield a bland, wholesome oil. The petals of Papaver Rhceas, red corn poppy, or corn-rose, are used in pharmacy chiefiy for their colouring matter. Chelidonium majus, Celandine, yields an orange-coloured juice, which is said to have acrid properties. In this plant, observations were made by Schultz on Cyclosis (fig. 241, p. 146). Eschscholtzia is remarkable for the dilated apex of the peduncle, from which the 
calyx separates in the form of a calyptra, resembling an extinguisher of a candle. Sanguinaria canadensis, Blood-root, or Puccoon, has emetic and purgative properties.

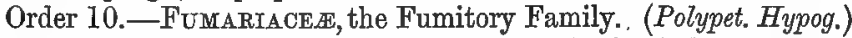
Sepals 2, caducous. Petals 4, cruciate; one or both of the two outer gibbous at the base, the two inner cohering at the apex. Stamens hypogynous, usually 6 , diadelphous; anther of middle stamen of each parcel bilocular, outer ones unilocular. Ovary free, 1-celled; style filiform; stigma with 2 or more points; ovules amphitropal. Fruit either an achænium, or a 1-celled 2-seeded, or 2-valved many-seeded pod. Seeds crested; albumen fleshy; embryo minute, eccentric.-Herbaceous plants, with a watery juice, and alternate multifid leaves. Although at first sight very unlike the Poppy family, the Fumitories resemble this order in their decidnous sepals, in their seeds, and, in many cases, in their fruit. The two outer unilocular stamens of each parcel may be considered as forming one perfect stamen, thus making the whole number four. They are found chiefly in northern temperate latitudes. Two are found at the Cape of Good Hope. They are usually scentless, and are said to be bitter and diaphoretic in their properties. The tuber of Corydalis bulbosa has been used as a substitute for Birthworts in expelling intestinal worms, and as an emmenagogue. Authors notice 18 genera, including 134 species. ExamplesFumaria, Corydalis, Dicentra (Dielytra), Hypecoum.

Order 11. - Cruciferes, the Cruciferous or Cresswort Family, Brassicacere of Lindley. (Polypet. Hypog.) Sepals 4, deciduous, the

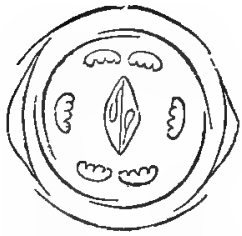

Fig. 670 .

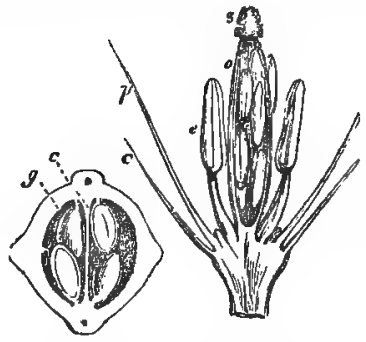

Fig. 673,

Fig. 671.

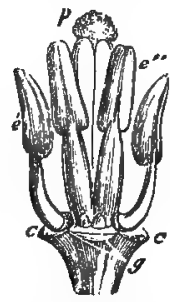

Fig. 672.

two lateral ones gibbous at the base. Petals 4 rarely wanting (as in Pringlea), hypogynous, alternating with the sepals, deciduous, cruciate

Figs. 670-677. Organs of fruetification of Erysimum lanceolatum, one of the Cruciferæ. Fig. 670, Diagram of the flower, showisg the arrangement of four sepals, four petals alternating with them, six tetradynamous stamens, and a siliqua with replum. Fig. 671. Vertical section of the flower. c, Calyx. $p$, Petals. \&, Stamens. o, Ovary laid open. $s$, Stigma. Fig. 672. Flower deprived of its envelopes. c, c, Cicatrices left by the fall of the sepals. $g$, Glands which are situated at the base of the stamens, $e^{\prime}$, Two short stamens opposite lateral sepals. $e^{\prime \prime}$, Four long stamens opposite anterior and posterior sepals. $p$, Pistil Fig. 673. Horizontal section of the ovary. g, Ovules. c, Spurious dissepiment or replum, which divides the ovary into two eavities. This replum is formed by the placentas. 
(fig. 315, p. 204). Stamens 6, tetradynamous (figs. 372, p. 226; 672); two shorter solitary (fig. $672 e^{\prime}$ ) opposite the lateral sepals, occasionally toothed ; four longer (fig. $672 e^{\prime \prime}$ ), opposite the anterior and posterior sepals, generally free, sometimes partially united and furnished with a tooth on the inside; anthers bilocular, introrse (fig. 671); (in Megacarpocea polyandra the stamens are numerous). Torus with green glands between the petals and stamens and ovary (fig. $672 g$ ). Ovary superior, with parietal placentas, which meet in the middle, forming a spurious dissepiment or replum (fig. $673 \mathrm{c}$ ); stigmas 2, opposite the placentas, or anterior and posterior (fig. 552 s, p. 306). Fruit a siliqua (figs. 674,675), or a silicula, rarely 1-celled and indehiscent, usually spuriously 2-celled and dehiscing by two valves, which separate from the replum (figs. $552 r$, p. $306 ; 675$ ), one- or many-seeded. Seeds campylotropous (figs. 455, p. 255; Fig. 676. 620 , p. 342 ), pendulous, attached in a single row by a funiculus to each side of the placentas (fig. 676); perisperm none; embryo with the radicle folded upon the cotyledons which are next the placenta (figs. 620 , p. 342 ; $677 r)$.-Herbaceous plants seldom undershrubs, with alternate leaves, and yellow or white, rarely purple, flowers, without bracts. This order is well distinguished by having tetradynamous stamens. Most of the plants belonging to the order are European. The species, however, are found scattered all over the world. Authors enumerate 172 genera,

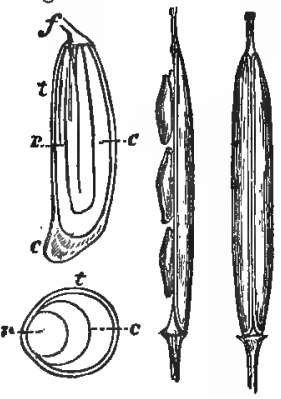

Fig. 677. Fig. 675. Fig. 674. including 1700 species. Examples-Draba, Lepidium, Isatis, Brassica, Sinapis, Bunias, Senebiera, Schizopetalon, Pringlea, Megacarpæa.

The order has been subdivided into sections, aceording to the mode in which the radicle of the embryo is folded on the cotyledons, as well as according to the nature of the fruit. The sub-orders founded on the embryo are-1. Pleurorhizex ( $\pi \lambda \varepsilon v_{g} \alpha \dot{,}$ side, and $\dot{\xi} i \zeta \alpha$, root), $0=$ cotyledons accumbent, radicle lateral, i.e. applied to their edge, as in Stock,

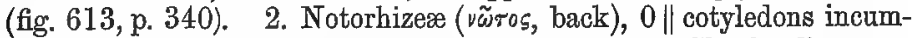
bent, radicle dorsal, i.e. applied to their back, as in Shepherd's purse, (fig. 614, p. 340). 3. Orthoploceæ ỏetós, straight, and $\pi \lambda \lambda^{\prime} x o s$, a plait or fold, 077 cotyledons conduplicate (folded), radicle dorsal, as in Mustard (figs. 609 , p. 339;677). 4. Spirolobeæ ( $\sigma \pi \varepsilon \tilde{e} \alpha \alpha$, a coil, and 入oßós, a lobe), 0\|\|$\|$ cotyledons folded spirally, radicle dorsal as in

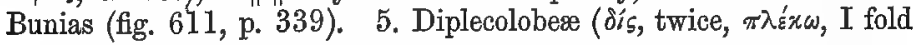

Fig. 674. Siliqua or long pod. Fig. 675. Siliqua with one of its valves removed, in order to show the seeds attached to the replum. - Fig. 676. Vertical section of the seed. $f$, Funiculus or umbilical cord. $t$, Spermoderm or testa swollen at the chalaza, $c$. $r$, Radicle. $c$, Cotyledons. Fig. 677. Horizontal section of the seed. $t$, Spermoderm or testa. $r$, Radicle. c, Incumbent cotyledons. 
or plait, and $\lambda_{0} \beta_{\circ} \varsigma$, a lobe), 0\|\|\|\| cotyledons twice folded, in a spiral, radicle dorsal, as in Subularia. The tribes Pleurorhizeæ and Notorhizeæ are sometimes included under the name Platylobeæ, meaning that the cotyledons are plane or flat ( $\pi \lambda \alpha \tau \dot{v} \xi$, broad).

The divisions founded on the seed-vessel are-1. Siliquosæa, a siliqua, linear or linear-lanceolate, valves opening longitudinally, as in Wallflower. 2. Siliculosæ Latiseptæ (latus, broad, and septum, partition), a silicula, partition in its broadest diameter, oval or oblong, valves flat or convex, opening longitudinally, as in Thlaspi. 3. Siliculosæ angustiseptæ (angustus, narrow), a silicula, partition in its narrow diameter, linear or lanceolate, valves opening longitudinally, folded and keeled as in Capsella. 4. Nucumentaceæ (nucumentum, a nut), silicula, valves indistinct or indehiscent, often 1-celled, from the absence of the replum or partition, as in Isatis. 5. Septulatæ (septa, partitions), valves opening longitudinally, furnished with transverse partitions in their interior, as in Anastatica. 6. Lomentaceæ (lomentum, an articulate legume), siliqua or silicula, dividing transversely into single-seeded cells, the true siliqua being often barren, and all the seeds placed in the beak, as in Sea-kale.

In this order there is a want of symmetry as regards the number of stamens, compared with the floral envelopes. The two long stamens placed close together may, however, be looked upon as one divided by a process of deduplication, so that the actual number will thus be reduced to four. This view is confirmed by the shorter stamens having teeth on each side, while the longer ones are toothed on one side only. By pelorization, too, some Cruciferæ become tetrandrous. While there is a splitting of the filaments, there is also the production of two additional anther-lobes. Others think that the androcium of Cruciferæ is composed of two quaternary whorls, the lower one being composed of the two lateral short stamens only, the other two, which should be developed in front of the antero-posterior sepals, being abortive; while the upper whorl is composed of the four long stamens which approach each other and form two pairs. In regard to the fruit, it has been stated that normally there are four carpidia or carpels, two of which are constantly abortive. In some species of Iberis there have been seen four sepals, four petals, four stamens, and four carpels. Thus the floral type of Cruciferæ is quaternary: calyz having four sepals, corolla four petals, receptacle four staminiferous glands, androecium four stamens, gynœecium four phyllidia, fruit four carpidia.

There are no truly poisonous plants in the 'order. In general, it possesses antiscorbutic and stimulant qualities, with a certain degree of acridity. Many of the most common culinary vegetables belong to the order, such as Cabbages, Cauliflower, Turnip, Radish, Cress, Horseradish, etc. They contain much sulphur and nitrogen, and on this account, when decaying, give off a disagreeable odour. Many garden 
flowers, such as Wallflower, Stock, Rocket, and Honesty, are found in this order. Brassica oleracea is the original species whence all the varieties of Cabbage, Cauliflower, Brocoli, and Savoys, have been obtained by the art of the gardener. The part of the Cauliflower used as food is the deformed flower-stalks. Brassica Rapa is the common Turnip, while Brassica campestris is the source of the Swedish turnip. Brassica Napus, Rape or Coleseed, yields Colza and Carcel oils. Some consider Brassica campestris, Rapa, and Napus, as sub-species. Brassica chinensis yields Shanghae oil. Lepidium sativum is the common Cress, and Raphanus sativus the Radish. Crambe maritima is the Seakale. The seeds of Sinapis nigra (Brassica nigra of some) furnish table mustard. These contain a bland fixed oil, a peculiar bitter principle, myronic acid, and another principle analogous to albumen or emulsin, called myrosine. When water is added, the myronic acid and myrosine, by their combination, form a pungent volatile oil, containing sulphur and nitrogen, which gives to mustard its peculiar properties; a crystallisable substance called myronate of potassium, now called sinigrin, is found in Mustard. Sinapis alba furnishes white Mustard, which contains more fixed oil than black mustard. It does not, however, contain myronic acid, but an analogous principle called sinapin, or sinapisin, which, by combination with another principle, forms an acrid compound, but not a volatile oil. The mustard of Scripture, according to Royle, is not a species of Sinapis, but Salvadora persica, belonging to the natural order Chenopodiacea. This view is not confirmed by Dr. Tristram, who says that the mustard plant of Scripture ( $\sigma_{i v \bar{a}} \pi l$ ) is Sinapis nigra, Black Mustard, while Salvadora is a tropical plant, growing on the north of the Dead Sea, and not found generally in Palestine. Many other Cruciferous plants yield volatile oils containing sulphur, and the seeds of many yield by expression a bland fixed oil, such as Rape-seed oil. Cochlearia officinalis, common Scurvygrass, is used as a stimulant. Cochlearia Armoracia, or Armoracia rusticana, the Horse-Radish, has irritant and even vesicant qualities. Anastatica hierochuntina, Rose of Jericho, is remarkable for the hygrometric property of the old withered annual stems, which are rolled up like a ball in dry weather, and drifted about by the winds in the deserts of Syria and Egypt. If rain falls, they resume their original position. They thus continue for many years to curl up and expand, according to the state of the atmosphere. The genus Schizopetalon is remarkable on account of its tetracotyledonous (having four cotyledons) embryo. Isatis tinctoria, Woad, when treated like Indigo, yields a blue dye. Isatis indigotica is the Tein-Ching, or Chinese Indigo. Pringlea antiscorbutica, Kerguelen Island Cabbage, is found in that island, as well as in Tristan d'Acunha, Marion Island, and Heard Island. It has no petals, no glands, and the stigma is hairy.

Order 12.-CAPPARIDaCe $\approx$, the Caper Family. (Polypet. Hypog.) 
Sepals 4-12, often more or less cohering (fig. 654, p. 371). Petals $4-8$, sometimes 0 , cruciate (fig. $654, p$ ), usually unguiculate and unequal. Stamens hypogynous, 4-6 (fig. $654 e$ ), or 00, but in general some high multiple of four, placed on an elongated hemispherical and often glandular torus (fig. $654 a g^{\prime}$ ). Ovary usually stalked (fig. 654 o) ; styles filiform, sometimes 0 ; ovules curved. Fruit unilocular, siliquæform and dehiscent, or fleshy and indehiscent, rarely monospermous, usually with two polyspermous parietal placentas. Seeds generally reniform and exalbuminous; embryo curved ; cotyledons foliaceous, flattish.-Herbs, shrubs, sometimes trees, with alternate, stalked, undivided, or palmate leaves, which are either exstipulate or have spines at their base. Capparids may be distinguished from Crucifers by their stamens being often indefinite, or, if definite, scarcely ever tetradynamous, while their ovary is usually stipitate, their fruit often succulent, and their seeds generally reniform. They are found chiefly in warm countries, and are abundant in Africa. There are 23 genera, and 300 species. The order is divided into two suborders :-1. Cleomeæ, with capsular fruit. 2. Cappareæ, with baccate fruit: Examples-Cleome, Capparis.

The plants of this order have stimulant qualities. The flowerbuds of Capparis spinosa furnish capers. The plant is a native of the south of Europe. It, or C. ogyptiaca, is supposed to be the Hyssop (IוM) of Scripture; but there is a difficulty in deciding the point. Some species of Cleome and Polanisia are very pungent, and are used as substitutes for mustard. The pungency of some is so great that they act as blisters. The root of Cleome dodecandra is used as an anthelmintic. Order 13.- Resedace 8 , the Mignonette Family. (Polypet. Hypog.) Calyx many-parted. Petals 4-6, unequal, entire, or lacerated, in the latter case consisting of a broad scale-like claw with a much-divided limb. Stamens 3-40, hypogynous, attached to a glandular torus; filaments variously united; anthers bilocular, innate, with longitudinal dehiscence. Ovary sessile, 3-lobed, 1-celled, multiovular, with 3-6 parietal placentas; stigmas 3. Fruit either a unilocular many-seeded capsule, opening at the apex so as to render the seeds seminude (fig. 575, p. 326), or 3-6 few-seeded follicles. Seeds reniform, usually exalbuminous ; embryo curved ; radicle superior ; cotyledons fleshy.-Herbaceous plants, rarely shrubs, with alternate, entire, or divided leaves, having gland-like stipules. They inhabit chiefly Europe and the adjoining parts of Asia. A few are found in the north of India and south of Africa. The uses of the order are unimportant. Reseda Luteola, Weld, yields a yellow dye. Reseda odorata is the fragrant Mignonette. The Mignonette is rendered suffruticose by preventing the development of its blossoms. This is the origin of the tree Mignonette, which is much cultivated in France. There are 6 known genera, and 30 species. Example-Reseda. 
Order 14.-Cistacee, the Rock-Rose Family. (Polypet. Hypog.) Sepals usually 5, persistent, unequal, the three inner with contorted æstivation. Petals 5, caducous, hypogynous, æstivation corrugated, and twisted in an opposite direction to that of the sepals. Stamens usually 00 , free, hypogynous; anthers 2-celled, adnate. Ovary syncarpous, 1- or many-celled; style single ; stigma simple. Fruit capsular, 3-5-10-valved, either 1-celled or imperfectly 5-10-celled, with loculicidal dehiscence. Seeds usually indefinite; embryo inverted, either spiral or eurved, in the midst of mealy albumen ; radicle remote from the hilum.--Shrubs or herbaceous plants with entire, opposite, or alternate, stipulate or exstipulate leaves. They inhabit chiefly the southern regions of Europe, and the north of Africa. Some of the species are remarkable for the irritability of their stamens (p. 386). Many of them yield a resinous balsamic juice, which imparts viscidity to the branches. The resinous matter called ladanum or labdanum is yielded by Cistus creticus and other species. There are 4 known genera, and 100 species, according to authors. Examples-Cistus, Helianthemum, Hudsonia, Lechea.

Order 15. - CaneldaCE phrodite, with imbricated bracteoles (sepals of some authors). Sepals (petals of some) 4-5. Petals (petaloid scales of some) 4-5, sometimes 0 . Stamens 20, hypogynous, with connate filaments. Disk 0. Ovary free, unilocular; placentas 2-5 parietal; style short; stigmas 2-5; ovules ascending or horizontal. Fruit baccate, 2- or many-seeded. Seeds with a shining testa ; albumen fleshy and oily ; embryo straight or curved.Glabrous aromatic trees, with alternate exstipulate leaves and cymose flowers. Natives of tropical America. There are 3 known genera and 5 species. Examples-Canella, Cinnamodendron.

Canelle alba, a tree 30-50 feet in height, a native of the West Indies, yields the canella bark, called also White Cinnamon, which is imported from the Bahamas. It yields several kinds of oils, and is an aromatic stimulant. Cinnamodendron corticosum yields an aromatic bark in the West Indies.

Order 16.-BIXACEA, the Arnatto or Annatto Family. (Polypet. Hypog.) Sepals 4-7, slightly colrering. Petals equal to and alternating with the sepals, or wanting. Stamens hypogynous, equal in number to the petals, or some multiple of them. Ovary roundish, sessile or slightly stalked; style either none or filiform; stigmas several, more or less distinct; ovules attached to parietal placentas, which sometimes branch all over the inner surface of the valves. Fruit 1-celled, containing a thin pulp, either fleshy and indebiscent, or capsular, with 4 or 5 valves. Seeds numerous, enveloped in a covering formed by the withered pulp; albumen fleshy, somewhat oily; embryo axile, straight; radicle turned towards the hilum; cotyledons flat, foliaceous. - Shrubs or small trees, with alternate, 
simple, usually exstipulate leaves, which are often dotted. The plants are chiefly natives of the warmest parts of the East and West Indies, and of Africa. The order is divided into 4 tribes:-1. Bixeæ. 2. Oncober. 3. Flacourtieæ. 4. Pangieæ.

Many of the plants yield edible fruits. The pulp is often sweet and wholesome. Some are astringent, others purgative. The reddish pulp surrounding the seeds of Bixa orellana supplies the substance called arnatto, which is used for yielding a red colour, and for staining cheese. The seeds are cordial, astringent and febrifugal. The seeds of Trichadenia zeylanica, a large tree of Ceylon, called Tettigaha or Tettigass, yield an oil used for burning. The oil expressed from the seeds of Gynocardia odorata (called chalmugra seeds) is used in India for the cure of leprosy, and for various cutaneous diseases. The tree is poisonous, but the seeds yield by expression a bland fixed oil having a peculiar smell and taste. The surface of the leprous ulcers is dressed with the oil, while a six-grain pill of the seed is given three times a day. The seeds are prescribed in cases of scrofula, skin diseases, and rheumatism. The fruit of Hydnocarpis venenatus and $H$. Toon is used to poison fish. There are 30 genera, and 160 species, according to authors. Examples-Bixa, Oncoba, Flacourtia, Aberia, Gynocardia, Pangium.

Order 17.-VIOLACEA, the Violet Family. (Polypet. Hypog.) Sepals 5, persistent usually elongated at the base, æstivation imbricated. Petals 5, hypogynous, equal or unequal, generally withering, æstivation obliquely convolute. Stamens 5, alternate with the petals, sometimes opposite to them, inserted on a hypogynous torus ; anthers dithecal, introrse, often cohering, with a prolonged connective sometimes spurred (fig. 375, p. 225); filaments dilated, two of them in the irregular flowers having an appendige at their base. Ovary unilocular, with many anatropal ovules, rarely one; style single, usually declinate, with an oblique hooded stigma (fig. 424, 1. s, p. 242). Fruit a 3-valved capsule, dehiscence loculicidal, placentas on the middle of the valves (fig. 424, p. 242). Seeds 00 or definite; embryo straight, erect, in the axis of a fleshy perisperm.-Herbs or shrubs, with alternate, rarely opposite, leaves, having persistent stipules, and an involute vernation. They are natives of Europe, Asia, and America. The herbaceous species inhabit chiefly the temperate parts of the northern hemisphere, while the shrubby species are found in South America and India. They have been divided into three tribes :-1. Violeæ, with irregular flowers. 2. Papayroleæ, with irregular corolla, and slightly coherent claws. 3. Alsodeæ, with regular flowers. To these some authors add a fourth tribe, Sauvagesieæ, having anthers without appendages, and septicidal dehiscence. Their distinctive peculiarity may be regarded as resting in their definite stamens, whose anthers burn inwards, and extend their connective into 
a crest. There are 21 known genera, and about 300 species. Examples-Viola, Ionidium, Papayrola, Alsodeia.

They are distinguished by the emetic properties of their roots, which contain an active principle called violin, similar in its qualities to emetin. Some species of Ionidium are used in South America as substitutes for Ipecacuan. The roots of Viola odorata, the Sweet or March Violet, the \%ov of the Greeks, have been used medicinally as an emetic; the petals are laxative, and are used in the form of infusion mixed with sugar; and a violet or purple colouring matter is procured from them, which is employed as a test for acids and alkalies, being changed into red by the former, and into green by the latter. Viola tricolor, Heart's ease, and other species, have been used as demulcent expectorants. $V$. tricolor is the origin of all the cultivated varieties of pansy.

Order 18.-Droserace ex, the Sundew Family. (Polypet. Hypog.) Sepals 5, persistent, equal; æstivation imbricated. Petals 5, hypogynous. Stamens free, withering, alternate with the petals, or 10 or more; anthers bilocular, with longitudinal dehiscence. Ovary single; styles usually 3-5; sometimes 1 or wanting. Fruit, a unilocular or spuriously trilocular capsule, 3-5-valved, with loculicidal dehiscence, occasionally indehiscent. Seeds numerous, either albuminous or exalbuminous; embryo minute and erect. - Herbaceous plants with alternate leaves, usually inhabiting marshy places. They are found in various parts of the world, in Europe, Australia, North and South America, South Africa, China, East Indies, etc. The order is considered by some as allied to Saxifragaceæ. There are 6 known genera, and about 110 species. Examples-Drosera, Drosophyllum, Aldrovanda, Dionæa.

The Droseras have a more or less acid taste, combined with slight acridity. Some of them are said to be poisonous to cattle. Their leaves are furnished with glandular capitate hairs (fig. 88, p. 32 ; fig. 661, p. 383), which are covered with drops of fluid in sunshine; hence the name Sundew or Ros solis. An Italian liquetur, called Rossoli, derives its name from a Drosera used in its manufacture. Some of the Droseras have dyeing properties. The hairs of Drosera have a spiral coil in their interior. They fold upon insects. (For a full account of the phenomena connected with the irritability of these plants, see pages 380-383). Dioncea muscipula, Venus's fly-trap, is a North American plant, having the laminæ of the leaves in two halves, each furnished with three irritable hairs, which, on being touched, cause the folding of the divisions in an upward direction (fig. 660, p. 380). It is insectivorous. Aldrovandra vesiculosa, an aquatic found in the south of Europe, is distinguished by its whorled cellular leaves, or floating bladders.

Order 19. - Polygalace 
Hypog.) Sepals 5; very irregular, distinct; 3 exterior, of which 1 is superior, and 2 inferior; 2 interior, usually petaloid, lateral; æstivation imbricated. Petals hypogynous, unequal, usually 3 , of which 1 is anterior, and larger than the rest, and 2 are alternate with the upper and lateral sepals; sometimes there are 5 petals, 2 of them very minute; the anterior petal, called the keel, is often crested. Stamens hypogynous, 8, monadelphous or diadelphous ; anthers clavate, usually 1-celled, and having porous dehiscence. Ovary mostly bilocular; ovules solitary, rarely 2 ; style simple, curved; stigma simple. Fruit dehiscing in a loculicidal manner, or indehiscent. Seeds pendulous, anatropal, strophiolate at the hilum ; albumen fleshy, embryo straight. - Shrubs or herbs with alternate or opposite exstipulate leaves. They are found in all quarters of the globe. Authors mention 15 genera, including 400 species. Examples-Polygala, Securidaca, Krameria.

In the appearance of their flowers the plants of this order have a resemblance to Papilionaceæ. They are distinguished, however, by the odd petal being inferior, and the sepal superior. They are generally bitter, and their roots yield a milky juice. Polygala Senega, Senega or Seneka root, called also Snake-root, is a North American species, the root of which is used medicinally, in large doses, as emetic and cathartic; and in small doses as a stimulant, sudorific, expectorant, and sialagogue. It contains an acrid principle called senegin, and polygalic acid. The name of Snake-root was given from its supposed use as an antidote to the bite of the rattlesnake. Irameria triandra, a Peruvian plant, furnishes Rhatany-root, which is employed as a powerful and pure astringent in cases of hæmorrhage and chronic mucous discharges. Its infusion is of a blood-red colour, and has been employed to adulterate port wine. A Chilian plant, Krameria cistoidea, also yields a kind of rhatany.

Order 20. - Tremandraces, the Porewort Family. (Polypet. Hypog.) Sepals 4-5, slightly coherent, deciduous, with a valvate rstivation. Petals 4-5, deciduous, with an involute rstivation. Stamens hypogynous, distinct, 8-10, 2 before each petal; anther dior tetra-thecal, with porous dehiscence (fig. 356, p. 222). Ovary bilocular, with 1-3 pendulous ovules in each cell; style, 1 ; stigmas, 1-2. Fruit a 2-celled, 2-valved capsule, with loculicidal dehiscence. Seeds anatropal, pendulous, with a caruncula at the apex; embryo cylindrical, straight, in the axis of fleshy albumen. - Heath-like shrubs, with hairs usually glandular, alternate or verticillate exstipulate leaves, and solitary axillary 1 -flowered pedicels. They are natives of extratropical Australia. Nothing is known regarding their properties. Authors mention 3 genera, including 24 species. Examples-Tetratheca, Tremandra.

Order 21. - Tamaricacede, the Tamarisk Family.

(Polypet. 
Hypog.). Calyx 4-5 partite, persistent, with imbricated æestivation. Petals 4-5, hypogynous, or perhaps inserted at the base of the calyx, marcescent, with imbricated æstivation. Stamens hypogynous, free or monadelphous (fig. 343, p. 217), equal to the petals in number, or twice as many; anthers dithecal, introrse, with longitudinal dehiscence. Ovary unilocular; styles, 3. Fruit a 3-valved, 1-celled capsule, with loculicidal dehiscence. Seeds numerous, anatropal, erect or ascending, comose; albumen 0 ; embryo straight, with the radicle next the hilum.- Shrubs or herbs, with alternate scale-like leaves, and racemose or spiked flowers. They abound in the Mediterranean region, and are confined chiefly to the eastern half of the northern hemisphere. Many are found in the vicinity of the sea. They have a bitter astringent bark, and some of them yield a quantity of sulphate of soda when burned. The saccharine substance called Tamarisk or Mount Sinai Manna, is yielded by Tamarix gallica, var. mannifera, as the result of puncture by an insect called Coccus manniparus. The plant grows in the valleys of the peninsula of Sinai. Tamarix orientalis of North Western India furnishes galls, which are used in place of oak-galls. Authors mention 5 genera, comprising 40 species. Examples-Tamarix, Myricaria, Reaumuria.

Order 22.-Frankeniacese, the Frankenia Family. (Polypet. Hypog.) Sepals 4-5, cohering into a tube, persistent. Petals 4-5, alternate with the sepals, hypogynous. Stamens hypogynous, equal in number to the petals, and alternate with them, sometimes more numerous; anthers bilocular, with longitudinal dehiscence. Ovary unilocular, with parietal placentas ; style filiform, often trifid. Fruit a 1-celled, usually 3-valved capsule, with septicidal dehiscence. This latter distinguishes them from the Violet-worts to which they are allied. Seeds very minute, numerous, anatropal ; embryo straight, in the axis of fleshy albumen.-Herbs or undershrubs, with opposite exstipulate leaves. They are found chiefly on extratropical maritime shores. They are said to have mucilaginous and slightly aromatic properties. Genera, 3 ; species, 30. Example-Frankenia.

Order 23.-Elatrinacese, the Water-pepper Family. (Polypet. Hypog.) Sepals 3-5, free, or slightly coherent at the base. Petals alternate with the sepals, hypogynous. Stamens hypogynous, equal to, or twice as many as, the petals. Ovary tri-quinquelocular ; styles 3-5 ; stigmas, capitate. Fruit capsular, 3-5 celled, 3-5 valved, loculicidal; placenta central. Seeds 00, exalbuminous, anatropal; embryo cylindrical and slightly curved.-Annual marsh plants, with hollow creeping stems, and opposite stipulate leaves. They are found in all parts of the globe. Some of them have acridity, and hence the name Water-pepper. Genera 2, and species 20. The Elatines are natives of Europe and Asia, Bergias of the Cape of Good Hope. Examples-Elatine, Bergia. 
Order 24.-CARYophyluacez, the Chickweed Family. (Polypet. Hypog.) Sepals 4-5 (fig. 678), free (fig. 293, p. 136), or united in a tube (figs. 297 c, p. $197 ; 653$ c, p. 371), persistent. Petals 4-5 (fig. 678 ), hypogynous, unguiculate (fig. 305, p. 201), often bifid or bipartite (fig. 307, p. 201), occasionally 0. Stamens (fig, 679 e) usually double the number of the petals, or, if equal, usually alternate with them ; filaments subulate, sometimes united ; anthers innate, bilocular, dehiscence longitudinal. Ovary single, often stalked or supported on a gynophore (fig. $653 \mathrm{~g}, \mathrm{p} .371$ ), composed of 2 to 5 carpels, which are usually united by their edges, but sometimes the edges are turned in-

Fig. 678.

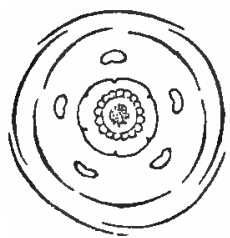

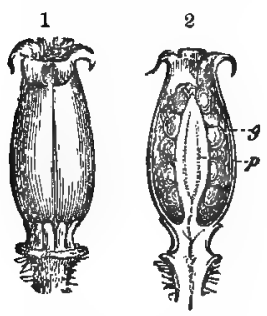

Fig. 681.

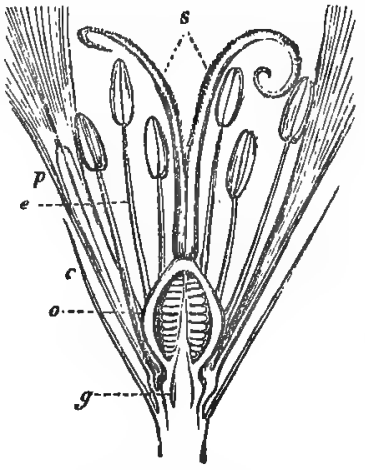

Fig. 679 .

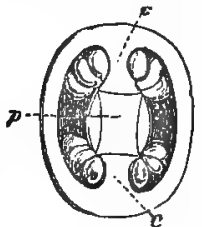

Fig. 680 .

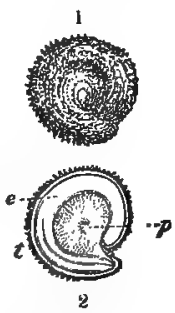

Fig. 682.

wards, so as to form partial dissepiments ; stigmas 2-5 (figs. 425, 426 s, p. 242), with papillæe on their inner surface (fig. $679 \mathrm{~s}$ ). Capsule unilocular (figs. 425 , p. $242 ; 681,2$ ), or imperfectly bi-quinquelocular

Fig. 678-682. Illustrations of the natural order Caryophyllaceæ. Fig. 678. Diagram of the flower of Alsine media, common Chickweed, belonging to the natural order Caryophyllaceæ, tribe Alsinex. The flower consists of five imbricate sepals, five alternate petals, five stamens, a unilocular ovary, with a free central placenta, and numerous ovules. Fig. 679. Section of the flower of Dianthus Caryophyllus, Carnation. $c$, Calyx; $p$, petals, cohering with the stamens at the base; $e$, stamens; $g$, gynophore or thecaphore, i.e. the stalk supporting the ovary; o, ovary with central placenta and ovules; $s$, two stigmas, which are papillose all along their inner surface. Fig. 680. Horizontal section of the ovary in a very young state, showing the partitions $c c$, which divide the ovary into two cavities. These divisions ultimately disappear, leaving the placenta, $p$, bearing the ovules free in the centre. Fig. 681. Capsule of Lychnis Githago at the period of dehiscence, when the periearp separates into five valves at the sunmit. 1, The capoule entire. 2, Capsule cut vertically, to show the seeds, $g$, grouped in a mass, on a free central placenta, $\ddot{p}$. Fig. 682. Seeds. 1, Entire seed. 2, Seed cut vertically. $t$, Spermoderm. e, Peripherical embryo, surrounding the mealy perisperm, $p$. 
(fig. 680), 2-5 valved, opening either by valves, or more commonly by twice as many teeth as stigmas (figs. 540, p. $303 ; 681$ ), placenta in the axis of the fruit (figs. 425, p. $242 ; 681,2, p$ ). Seeds usually 00 , amphitropal with mealy a oumen, and a peripherical embryo (fig. 682).-Herbs, sometimes suffruticose plants, with opposite, entire, exstipulate, sometimes 'connate leaves, and usually cymose inflorescence (figs. 270,271, p. 183). They inhabit chiefly temperate and cold regions. According to the calculation of Humboldt, Cloveworts constitute $\frac{1}{2}$ of the flowering plents of France, $\frac{1}{27}$ of Germany, $\frac{1}{17}$ of Lapland, and $\frac{1}{7^{2}}$ of North America. Those found within the tropics are usually met with on high elevations and mountainous tracts, many of them exclusively vegetate in regions of the lowest temperature. The order has been divided into two tribes :-1. Alsineæ, sepals distinct (fig. 293, p. 136). 2. Silener, sepals cohering in a tube (fig. 297, p. 197). Authors mention 35 genera, and 1000 species. $E x-$ amples-Alsine, Cerastium, Dianthus, Silene, Polycarpon.

The plants of this order are usually insipid, but some are said to be poisonous. The poisonous quality is attributed to Saponine, which exists in many of the species of Saponaria, Silene, Lychnis, and Dianthus. To saponine, also, is due the saponaceous or soap-like properties of the plants. Honkeneja peploides has been used as a pickle. In Iceland it serves as an article of food. The greater part of the plants of the order are weeds, but some are showy garden flowers. To the latter may be referred all the varieties of Dianthus Caryophyllus, Clove-pink or Carnation, Picotees, Bizarres, and Flakes, numerous species of Pink, Campion, etc. The varieties of Carnation depend on the mode in which the coloured stripes or dots are arranged on the petals, and the entire or serrated appearance of their edges. The formation of the placenta in the Caryophyllacer has given rise to discussion, some looking upon it as a marginal, others as an axile formation (p. 243).

Order 25.-Pontulacacese, the Purslane Family. (Polypet. Hypo-Perigyn.) Sepals 2, cohering at the base. Petals usually 5, rarely wanting, distinct or cohering at the base, sometimes hypogynous. Stamens perigynous or hypogynous, variable in number, all fertile, sometimes opposite the petals; filaments distinct; anthers versatile, bilocular, with longitudinal dehiscence. Ovary free or partially adherent, 1-celled, formed by 3 united carpels; style single or 0 ; stigmas several. Fruit capsular, 1-celled, opening by circumscissile dehiscence, or by 3 valves, occasionally monospermous and indehiscent. Seeds numerous or definite, or solitary, attached to a central placenta; albumen farinaceous ; embryo peripherical ; radicle long.-Succulent shrubs or herbs, with alternate, seldom opposite, entire, exstipulate leaves, often having hairs in their axils. They are found in various parts of the world, chiefly, however, in South America and at the Cape of Good Hope. They always inhabit dry parched places. They 
have a great affinity to Caryophyllaceæ, from which they are chiefly distinguished by their bisepalous calyx, their stamens being often perigynous, and their transversely dehiscent capsule. The plants belonging to the order have few properties of importance. They are insipid and destitute of odour. Portulaca oleracea, comnoon Purslane, is used as a potherb on account of its cooling and antiscorbutic qualities; the ancients thought the seeds, steeped in wine, to be an emmenagogue. The tuberous roots of Claytonia tuberosa, a Siberian plant, are eaten; and those of Melloca (Ullucus) tuberosa, a native of Peru, have been recommended as a substitute for the potato. In Portulaca oleracea and grandiflora the stamens, if brushed lightly in any direction, will immediately, with a strong impulse, bend over to the point from which they were brushed. There are 15 known genera, and 125 species. Examples-Portulaca, Talinum, Calandrinia, Claytonia, Montia,

Order 26.-Malvacea, the Mallow Family. (Polypet. Hypog.) Sepals 5 (fig. 683), rarely 3 or 4 , more or less cohering at the base (fig. 298 c, p. 197), with a valvate æestivation (fig. 287, p. 194), often bearing an external calyx (epicalyx) or involucre (fig. $298 \mathrm{~b}, \mathrm{p} .197$ ). Petals equal in number to the sepals; æstivation twisted (fig. 286, p. 194). Stamens 00 (fig. 685 a), hypogynous, all perfect; filaments

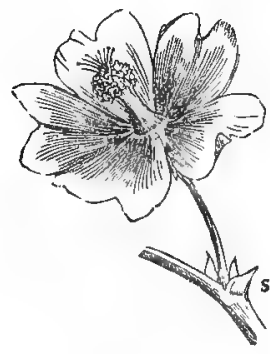

Fig. 683 .

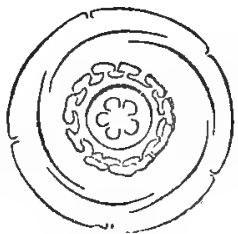

Fig, 684 .

monadelphous (fig. 685 t), or polyadelphous (fig. 651, p. 370) ; anthers monothecal (fig. 360, p. 222), reniform (fig. 686), with transverse dehiscence. Ovary formed by the uuion of several carpels round a common axis (figs. 417, p. 239 ; 548, p. 305 ; 687), either distinct or cohering; styles as many as the carpels (fig. $685 \mathrm{~s}$ ), united or free. Fruit capsular or baccate; carpels one- or many-seeded, sometimes closely united, at other times separate or separable (figs.

Figs. 683-691. Organs of fructification of MaIva sylvestris, to illustrate the natural order Malvacex. Fig 683. Flower viewed from above, with its five petals, monadelphous stamens, peduncle or flower-stalk, and two stipules, s. Fig. 684. Diagram of the flower, showing the different whorls or verticils; five valvate or induplicate sepals, five twisted petals, indefinite monadelphous stamens, and united carpels. 
687,413, p. 238) ; dehiscence loculicidal (fig. 543, p. 304), or septicidal. Seeds amphitropal or semi-anatropal; albumen 0 , or in very small quantity; embryo curved (fig. 690); cotyledons twisted or doubled (fig. 691).-Herbaceous plants, trees or shrubs, with alternate stipulate leaves (fig. $683 \mathrm{~s}$ ), more or less divided, and often with

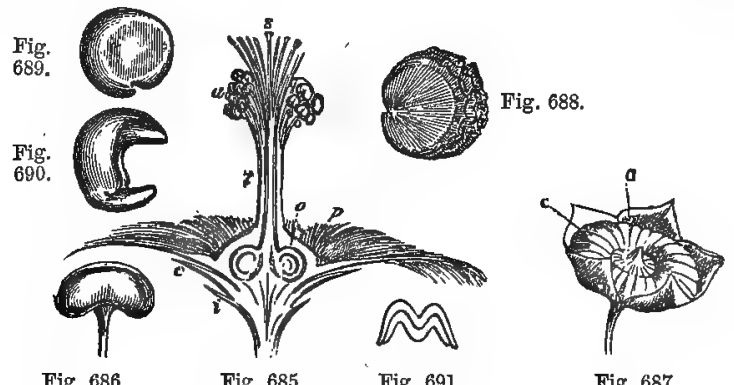

Fig. 686.

Fig. 685 .

Fig. 691.

Fig. 687.

stellate hairs (fig. 86, p. 31). They are dispersed over all parts of the world, with the exception of the Arctic regions. They abound in tropical countries and in the warm parts of the temperate zone. Authors enumerate 40 genera, including about 700 species. The order has been divided into three tribes:-1. Malveæ, calyx with an involucel, carpels 5 or many, whorled, separating from the axis when ripe. 2. Hibisceæ, calyx with an involucel; carpels 3-5-10, united into a loculicidal capsule. 3. Sideæ, calyx naked; fruit syncarpous. Examples-Lavatera, Malva, Hibiscus, Sida.

The plants of the order are all wholesome, and yield mucilage in large quantity. Some furnish materials for cordage, others supply cotton. Malva sylvestris, Common Mallow, and Althoea officinalis, Marsh Mallow, are employed medicinally, as demulcents and emollients. The latter is the Guimauve of the French. The flowers of Althcea rosea, the Hollyhock, are officinal in Greece for similar purposes; the plant also yields fibres and a blue dye. The petals of Malva Alcea and Hibiscus Rosa-sinensis possess astringent properties ; the Chinese make use of them to blacken their eyebrows and the leather of their shoes. The flowers of Abutilon esculentum, and the

Fig. 685. Vertical section of the flower. $i$, Caliculus, epicalyx, or involuere; $c$, calyx; $p$, petals; $t$, tube of monadelphous stamens, forming an arch above the ovary, 0 , and united at the base to the petals; $\alpha$, anthers at the summit of the filaments, free; $s$, styles free at the summit, united below. Fig. 686. A reniform monothecal anther, dehiscing transversely, separated with the upper part of the filament. Fig. 687. Fruit, surrounded by the persistent calyx, c, consisting of whorled carpels united together by the axis, $a$. Fig. 688. A separate carpel viewed laterally. Fig. 689. Exalbuminous amphitropal seed. Fig. 690. Curved embryo. Fig. 691. Section of the embryo, to show the doubled cotyledons. 
fruit of Abelmoschus esculentus (Hibiscus esculentus), called Ochro and Gombo, are used as articles of food. Hibiscus cannabinus is the source whence sunnee-hemp is procured in India. Hibiscus mutabilis receives its name from the changing colour of its flowers, varying from a pale rose to a rich pink colour. Other species of Hibiscus as well as Paritium tiliaceum yield useful fibres. The bark of Paritium elatum furnishes Cuba Bast. Cotton is composed of the hairs surrounding the seeds of various species of Gossypium. These hairs, when dry, exhibit under the microscope a peculiar twisted appearance. Gossypium barbadense seems to be the species which yields the best cotton; the Sea-Island, New Orleans, and Georgian cotton being produced by varieties of it. Gossypium peruvianum or acuminatum furnishes the South American cotton; Gossypium herbaceum, the common cotton of India. G. arboreum is the Indian-tree cotton. The Chinese Nankin cotton is furnished by a variety of $G$. herbaceum. The quality of cotton-wool depends on the length, strength, and firmness of the tissue, or, as it is called, the staple. These essential attributes are modified by the cleanliness and the colour. Long-stapled cottons are generally used for the twist or warp, and short-stapled for the weft. The value of cotton varies not only according to the species, but also according to the nature of the climate in which it grows. The total import of raw Cotton into Britain in 1874 was upwards of $12 \frac{1}{2}$ millions of cwts. The seeds of the cotton-plants yield oil which has 'been used for lamps; when bruised they are employed for oil-cake. Cotton is used in the preparation of gun-cotton and of collodion.

Order 27.-SterCULIACE (Polypet. Hypog.) Calyx of 5, more or less united, sepals, often surrounded by an involucre; restivation usually valvate. Petals 5 or none, hypogynous, æstivation twisted. Stamens usually $\infty$; their filaments variously united; anthers 2-celled, extrorse. Pistil of 5 (rarely 3) carpels, either distinct or cohering; styles equal in number to the carpels, free or cohering; ovules orthotropal (fig. 619, p. 342) or anatropal. Fruit capsular, usually with 5 cells, or follicular or succulent. Seeds often with a woolly covering; with a fleshy or oily perisperm (rarely 0), and either a straight or a curved embryo; cotyledons leafy or thick, plaited or rolled round the plumule.-Trees or shrubs, with alternate leaves, which are either simple or compound, deciduous stipules, and often a stellate pubescence. They are distinguished from Malvacere by their dithecal extrorse anthers. They inhabit warm climates. The order has been divided into the following tribes:-1. Bombaceæ, with hermaphrodite flowers and palmate or digitate leaves; found most abundantly in America. 2. Helictereæ, with hermaphrodite flowers and simple leaves; apparently unknown in Africa. 3. Sterculieæ, with unisexual flowers, and either simple or palmate leaves,; chiefly in India and Africa. Authors men- 
tion 30 genera, including 130 species. Examples-Bombax, Helicteres, Sterculia.

The plants are mucilaginous and demulcent; many are used for food, others supply a material like cotton. The silky hairs surrounding the seeds of Bombax Ceiba, the Silk-cotton tree, are used for stuffing eushions and chairs, and for various other domestic purposes. They cannot be manufactured, in consequence of want of adhesion between the hairs. The trunk of the tree is made into canoes. Adansonia digitata, the Baobab tree of Senegal, or monkey-bread, is one of the largest known trees. Its trunk sometimes attains a diameter of thirty feet, while its height is by no means in proportion. The pulp of its fruit (amphisarca) is used as an article of food. It is emollient and mucilaginous in all its parts. The dried leaves when powdered constitute lalo, a favourite article with the Africans, which they mix with their food for the purpose of diminishing the excessive perspiration to which in those climates they are subject. It is found by Europeans to be most serviceable in cases of diarrhœa, fevers, and other maladies. Adansonia Gregorii is the Gouty-stem tree of Australia. Durio zibethinus furnishes the fruit called Durian in the Indian Arohipelago. The fruit is much prized, although it has a fetid odour, which has given rise to the name Civet Durian. The moment the fruit is ripe, it falls of itself, and the way to eat it in perfection is to get it as it falls. Brachychiton populnerum is the Poplar Bottle-tree of Australia. Cheirostemon platanoides is called the Hand-plant of Mexico, on account of its five peculiarly curved anthers, which resemble a claw. Helicteres (from helix, a snail) is so named on account of its twisted fruit. The Kola, mentioned by African travellers as being used to sweeten water, is the seed of Steraulia tomentosa or acuminata.

Order 28.-Byttneriacese, the Byttneria and Chocolate Family. (Polypet. Hypog.) Calyx 4-5 lobed, valvate in æstivation (fig. 285 c, p. 194). Petals 4-5 or 0, often elongated at the apex, with a twisted or induplicate æstivation (fig. 285 p p. 194). Stamens hypogynous, either equal in number to the petals, or some multiple of them, more. or less monadelphous, some of them sterile ; anthers bilocular, introrse. Ovary free, composed usually of 4-10 carpels arranged round a central column; styles terminal, as many as the carpels, free or united; ovules 2 in each loculament. Fruit capsular, either with loculicidal dehiscence, or the carpels separating from each other. Seeds anatropal, often winged; embryo straight or curved, lying usually in fleshy albumen; cotyledons either plaited or rolled up spirally.-Trees, shrubs; or undershrubs, with alternate leaves, having either deciduous stipules or 0 , and stellate or forked hairs. They abound in tropical climates. Authors enumerate 30 genera, embracing about 400 species. Byttneriads are often united with Sterculiads, from which they are distinguished by their slightly monadelphous stamens, and anthers turned 
inwards. Their two-celled anthers and non-columnar stamens distinguish them from Mallow-worts. The order has been divided into six tribes, founded on the following genera: Examples - Lasiopetalum, Byttneria or Buttneria, Hermannia, Dombeya, Eriolæna, and Philippodendron.

The plants abound in mucilage, and many yield cordage. The seeds of Theobroma Cacao are called Cacao beans, and are the chief ingredient in chocolate, which contains also sugar, arnatto, vanilla, and cinnamon. The seeds by pressure yield a fatty oil, called Butter of Cacao, which has but little tendency to rancidity. They contain a crystalline principle analogous to caffeine called Theobromine. Other species of Theobroma also furnish Cacao-seeds. The Cocoa of the shops consists generally of the roasted beans, and sometimes of the roasted integuments of the beans, ground to powder.

Order 29.-Tiliaces, the Lime-tree Family. (Polypet. Hypog.) Sepals 4-5, often with a valvate æstivation. Petals 4-5, entire, rarely wanting. Stamens hypogynous, free, or united by the enlarged border of the stalk of the pistil (fig. $348,1,2$, p. 219), usually $\infty$; anthers 2 -celled, dehiscing longitudinally or by pores; occasionally some abortive (fig. 348, 2, p. 219). Disk often large and glandular. Ovary solitary, formed by the union of 2-10 carpels ; style 1 ; stigmas as many as the carpels. Fruit dry or pulpy, either multilocular with numerous seeds, or by abortion unilocular and I-seeded. Seeds anatropal; embryo erect in the axis of fleshy albumen, with flat, leafy cotyledons (fig. 606, p. 339).-Trees or shrubs, rarely herbaceous plants, with alternate stipulate leaves (fig. 211, p. 102). The principal part of the order is found within the tropics, forming weed-like plants, or shrubs, or trees, with handsome, usually white or pink flowers. A small number are peculiar to the northern parts of either hemisphere, where they form timber trees. The order has been divided into two sections: -1. Tilier, with entire petals or 0 , and anthers dehiscing longitudinally. 2. Elæocarpeæ, with lacerated petals, and anthers opening at the apex. Authors enumerate 40 genera, including 330 species. Examples-Tilia, Corchorus, Grewia, Aristotelia, Elæocarpus.

The plants possess mucilaginous properties, and many of them furnish excellent materials for cordage. The fruit of some is edible. From the gummy matter they contain some have been employed as demulcents. The inner bark, the bast or bass, of the Linden or Lime-tree (Tilia Europoea) is tough and fibrous, and from it are manufactured Russian mats. The lime-trees of Europe are Tilia Europoea, grandifolia, and parvifolia. The bark of Luthea grandiflora is used in Brazil for tanning leather. An infusion of the flowers is used on the continent as an antispasmodic and expectorant. Corchorus capsularis in India furnishes the Jute used for coarse carpets and gunny bags. The leaves of Corchorus olitorius, Jew's-mallow, are used as a culinary 
vegetable. C. pyriformis supplies fibres in Japan. The bark of Elæocarpus is used as a tonic. The fruits of Grewia microcos and asiatica are agreeable, and are used for sherbet in N.W. India. Other species of Grewia yield cordage, and the fibres of $G$. oppositifolia are used for making paper.

Order 30.-DipterocarPace 4 , the Sumatra-Camphor Family. (Polpet. Hypog.) Calyz tubular, 5-lobed, unequal, naked, persistent, and afterwards enlarged, with an imbricated æstivation. Petals hypogynous, sessile, often combined at the base, with a twisted æestivation. Stamens indefinite, hypogynous ; filaments dilated at the base, either distinct or irregularly cohering; anthers innate, bilocular, subulate, opening by terminal fissures. Torus not enlarged in a disk-like manner. Ovary superior, 3-celled; ovules in pairs, pendulous; style and stigma simple. Fruit coriaceous, unilocular by abortion, 3-valved or indehiscent, surrounded by the calyx, which is prolonged in the form of long wing-like lobes. Seed solitary, exalbuminous; cotyledons often twisted and crumpled; radicle superior.-Trees with alternate leaves, having an involute vernation, and deciduous convolute stipules. They are found in India, and especially in the eastern islands of the Indian Archipelago, where, according to Blume, they form the largest trees of the forest. There are about 10 known genera, including 100 species. Examples-Dipterocarpus, Vateria, Dryobalanops.

The trees belonging to this order are handsome and ornamental, and they abound in resinous juice. A kind of Camphor is procured in Sumatra from Dryobalanops Camphora or aromatica. It is secreted in crystalline masses in cavities of the wood. It is less volatile than the common camphor of commerce. It supplies this camphor only after attaining a considerable age. In its young state it yields on incision a pale yellow liquid, called the liquid camphor of Borneo and Sumatra, which consists of resin and a volatile oil having a camphoraceous odour. Vateria Indica yields an oleo-resinous substance called white Dammar or Piney resin (called also Indian copal or gum animi), used in India as a varnish. From this resin a concrete oil is obtained, called Piney-tallow, or vegetable butter of Canara. The fruit of this tree yields to boiling water the celebrated butter of Canara, or Piney tallow. Various species of Dipterocarpus yield a substance like Balsam of Copaiva. D. loevis, angustifolius, turbinatus, hispidus, zeylanicus, yield wood-oil. Shorea robusta, a native of India, supplies the valuable timber called Sal. It yields the Dhoom or Dammar pitch, used for incense in India.

Order 31.-ChuderaCes, the Chlænad Family. (Polypet. Hypog.) A small order, allied to Malvaceæ in having a 1-2-flowered involucre, and in having the stamens cohering at the base; while the restivation is imbricate and resembles that of Ternstrcmiaceæ.-Trees or shrubs, with alternate stipulate leaves, found in Madagascar. Their proper- 
ties are unknown. There are four genera enumerated, including probably about 8 or 10 species. Examples-Sarcolæna, Leptolæna, Schizolæna, Rhodolæna.

Order 32.-Ternstremaces, the Tea Family. (Polypet. Hypog.) Sepals 5 or 7 , concave, coriaceous, deciduous, the innermost often the largest; æstivation imbricated (fig. 289 c, p. 194). Petals 5, 6, or 9 , often combined at the base. Stamens indefinite, hypogynous; filaments free, or united at the base into one or more parcels; anthers versatile, or adnate, dehiscing longitudinally. Ovary multilocular; styles 2-7. Fruit either a capsule, 2-7 celled, opening by valves, or coriaceous and indehiscent. Seeds attached to the axis, few and large; albumen 0 , or in very small quantity; embryo straight or bent, or folded back; radicle next the hilum; cotyledons very large (fig. 599, p. 335), often containing oil.-Trees or shrubs, with alternate coriaceous, exstipulate leaves, which are sometimes dotted. They abound in South America, and many occur in India, while others inhabit China and North America. They do not occur in Australia and New Zealand. There are 32 genera and 260 species enumerated. The order has been divided into six tribes, founded on the following genera: Examples-1. Rhizobola. 2. Marcgravia. 3. Ternstromia. 4. Saurauja. 5. Gordonia. 6. Bonnetia.

The most important plants of this order are those which yield Tea. Considerable discussion has taken place regarding the Tea plants; some say that there is only one species; others, two; others, three. Fortune visited the black and green tea districts of Canton, Fokien, and Chekiang, and he says that the black and green teas of the northern districts of China are obtained from the same species or variety, viz. that cultivated in Britain under the name of Thea viridis; while the black and green teas from the neighbourhood of Canton are made from the species or variety cultivated in this country under the name of Thea Bohea. Some make the Assam plant a different species, and thus recognise three, Thea Cantoniensis or Bohea, Thea viridis, and Thea Assamica. The quality of the tea depends much on the season when the leaves are picked, the mode in which they are prepared, as well as the district in which the plant grows. Green Tea contains more essential oil and tannin than Black Tea. The Green Teas include Twankay, Young Hyson, Hyson, Gunpowder, and Imperial; while the black include Bohea, Congou, Souchong, Oolong, and Pekoe. The teas of certain districts, such as Ankoi, have peculiar characters. In some instances teas are dyed by means of Isatis indigotica; in other cases by Prussian blue, turmeric, and gypsum. Perfume is communicated to teas by means of Olea fragrans, Chloranthus inconspicuus, and Aglaia odorata. There is a bitter principle in tea called theine, which may be procured by adding a slight excess of acetate of lead to a decoction of tea, filtering hot, evaporating, and subliming. According to Dr. Stenhouse, 
$1 \mathrm{lb}$. of Green Hyson Tea gave 72 grains pure white Theine, and 2 coloured $=74$ grains or 1.05 p.c.

8 oz. Black Congou gave 34.5 gr. pure, and 1.5 impure $=36$ gr. or 1.02 p.c.

$6 \mathrm{oz}$. of Black Assam Tea yielded 36 gr. or 1.37 p.c.

$1 \mathrm{lb}$. of a cheap Green Tea, called Twankay, gave 69 gr. or 0.98 p.c.

In 1874, the imports of tea into the United Kingdom amounted to $142,068,524$ lbs., of which $127,323,630$ lbs. were retained for home consumption. The tea plant is now largely cultivated in India, especially at Darjeeling and Saharumpore. The genus Camellia is prized on account of its showy flowers. There are numerous cultivated varieties of Camellia japonica, many of which can endure the climate of Britain when trained on a wall with a southern exposure, or slightly protected. In China, Camellia Sasanqua, or Sasanqua tea, is cultivated on account of its flowers, which are said to impart frar grance and flavour to other teas. Camellia oleifera yields a valuable oil. Sotari or Butter Nuts are the produce of Caryocar butyrosum. The flowers of Morcgravia are occasionally furnished with bracts, which are folded, and united so as to form ascidia. The stem, root, and leaves of Marcgravia umbellata are regarded in the West Indies as diuretic. The leaves of Freziera theoides are used as tea in Panama.

Order 33.-OlaCACE, the Olax Family. (Polypet. Hypog.) Calyx small, gamosepalous, entire or toothed, often becoming finally large and fleshy; xstivation imbricated. Petals 3-6, hypogynous, free, or adhering in pairs by means of the stamens; æstivation valvate. Stamens hypogynous, some fertile, others sterile; the former $3-10$, alternate with the petals, the latter opposite to the petals; filaments compressed; anthers innate, bilocular, with longitudinal dehiscence. Ovary 1.3-4 celled; ovules 1-3, pendulous from a central placenta; style filiform; stigma simple. Fruit fleshy, indehiscent, often surrounded by the enlarged calyx, unilocular, monospermal. Seed anatropal, pendulous; albumen copious, fleshy; embryo small, at the base of the albumen. - Trees or shrubs, with simple, alternate, exstipulate leaves, which are, however, sometimes abortive. They are chiefly tropical or subtropical-being found in the East Indies, New Holland, and Africa. One only is known in the West Indies. A few are from the Cape of Good Hope. Little is known in regard to their properties. Olax zeylanica has a fetid wood with a saline taste, and is employed in putrid fevers; its leaves are used as a salad. There are 36 genera and 170 species enumerated. Examples-Olax, Opilia, Icacina.

Order 34.-AURantiace ex, the Orange Family. (Polypet. Hypog.) Calyx urceolate or campanulate, short, 3-5 toothed, withering. Petals 3-5, broad at the base, sometimes slightly coherent; æstivation imbricated. Stamens equal in number to, or a multiple of, the petals ; filaments flattened at the base, distinct or combined into one or more parcels ; anthers erect. Thalamus enlarged in the form of a 
hypogynous disk, to which the petals and stamens are attached. Ovary free, multilocular; style 1 ; stigma thickish, somewhat divided. Fruit a hesperidium, having a spongy separable rind, and pulpy separable cells (p. 314). Seeds anatropal, attached to the axis, solitary or several, usually pendulous, having the chalaza and raphe usually well marked; perisperm 0 ; embryo straight; cotyledons thick and fleshy.-Trees or shrubs, usually conspicuous for their beauty, with alternate, often compound leaves, which are articulated with a petiole, usually winged (fig. 201, p. 85). They abound in the East Indies. Limonia Laureola is remarkable as the only plant of this family found near the summit of lofty mountains, where it is for some months of the year covered with snow. Some include this order in Rutacea, to which in many points it is allied. There are 13 genera and nearly 80 species enumerated. Examples-Citrus, Limonia, Triphasia.

The plants exhibit in every part receptacles of volatile oil. The oil abounds in the leaves and in the rind of the fruit. It is fragrant and bitter. The fruit has a more or less acid pulp, and the wood is generally compact. The Orange, Lemon, Lime, Citron, Shaddock, and Forbidden Fruit belong to this order. Citrus vulgaris yields the Bitter or Seville Orange, from the flowers of which an essential oil, called Neroli-oil, is procured, in the proportion of an ounce from 550 pounds of flowers. A similar oil is got from the flower of the Sweet Orange, Citrus Aurantium. The rind of the Bitter Orange is used in conserves. In the young state the fruit is sold under the name of Orangettes or Curaçoa oranges. Orange-flower-water, as obtained from the flowers of the Bitter Orange, is employed as an anodyne. The chief kinds of Sweet Orange are the Common Orange, the Chinese or Mandarin Orange, the Maltese, and St. Michael's. The last are the finest imported into Britain, and are distinguished by their smooth, thin rind. A single tree, it is said, will produce 20,000 good oranges. Their fruit is used medicinally, on account of the pulp, which contains sugar, mucilage, and citric acid. From the rind of the Sweet Orange, an oil, called Oil of Orange, is procured, which differs from Neroli-oil. A similar oil, but of inferior quality, is procured from the rind of the Seville Orange. Many look on the Bitter and Sweet Oranges as produced by varieties of one species. The Bitter Orange tree is less than that yielding the Sweet Orange; the petioles are more distinctly foliaceous; the flowers have a sweeter fragrance; the rind of the fruit is darker and more bitter; and its pulp more bitter and less saccharine. The Lemon, Lime, and Citron, are distinguished from oranges by their oblong form, their adherent rind, and a protuberance at the apex. Citrus Limonum yields the Lemon, the juice of which is antiscorbutic, and is used for cooling drinks and effervescing draughts, while the peel or rind, on account of the oil it contains, is employed as an aromatic and anthelmintic. A single tree will produce 8000 lemons. 
Citrus medica furnishes the Citron, which is larger than the Lemon, has a thicker and tuberculated rind, and a less acid pulp. The rind and juice may be applied to the same purposes as those of the Lemon. C. Bergamia is the Mellarosa or Bergamot, which is a variety of $C$. Limetta, the Lime. The Bergamot is less than the Lemon in size, and is more pyriform, while its colour is golden. The Lime is about half the size of the Lemon; its rind is thin, dense, and of a greenish-yellow colour, and its taste is more bitter. Oil of Bergamot is the volatile oil of the rind, and 100 fruits are said to yield $2 \frac{1}{2}$ ounces. Citrus acida is the East Indian Lime. Citrus Decumana furnishes the Shaddock; C. paradisi, the Forbidden Fruit; C. olivorformis, the Kumquat; and C. Pompelnos, the Pompelmoose fruit: What are called horned oranges and fingered citrons are produced ${ }^{4}$ by a separation or multiplication of the carpels. Sometimes small fruits are enclosed within the large one. In the navel-orange of Pernambuco abortive carpels are seen at the apex. Figle Marmelos (Indian Bael) yields an excellent fruit. The half-ripe fruit is used as a remedy for dysentery. From Feronia elephantum, a gum, like gum-arabic, is procured.

Order 35. - HyPericace Family. (Polypet. Hypog.) Sepals 4-5, separate or united, persistent, usually with glandular dots, unequal; æstivation imbricated. Petals 4-5, oblique, often with black dots; æstivation contorted. Stamens hypogynous, $\infty$; generally polyadelphous (fig. 347, p. 218), very rarely 10 , and monadelphous or distinct; filaments filiform; anthers bilocular, with longitudinal dehiscence. Carpels 2-5, united round a central or basal placenta; styles the same number as the carpels, usually separate; stigmas capitate or simple. Fruit either fleshy or capsular, multilocular, and multivalvular, rarely unilocular. Seeds usually 00, minute, anatropal, usually exalbuminous; embryo usually straight.-Herbaceous plants, shrubs or trees, with exstipulate entire leaves, which are usually opposite and dotted. Flowers often yellow. They are distributed very generally over all parts of the globe, are found in elevated and low, dry and damp situations. They yield a resinous coloured juice which has purgative properties, and resembles gamboge. In the European species this yellow juice is in small proportion to the essential oil and the rest of the vegetable matter; they have been used as tonics and astringents. Hypericum hircinum is fetid. A gargle for sore throats is prepared in Brazil from Hypericum connatum. A decoction of the leaves of Hypericum laxiusculum, or Allecrim brabo, is reputed in the same country to be a specific against the bite of serpents. Parnassia palustris, Grass of Parnassus, has remarkable gland-like bodies between the stamens (fig. 335 , p. 210). These are probably an abortive state of the staminal organs. Lindley looks upon them as bundles of stamens, and hence 
places the genus among Hypericaceæ, while others refer the plant to the natural order Crassulaceæ. The stamens of Parnassia are irritable, and move towards the pistil in succession (p. 386). There are 17 known genera, and about 281 species. Examples-Hypericum, Elodea, Vismia, Parnassia.

Order 36.-Gutriferes or Clusiace, the Gamboge Family. (Polypet. Hypog.) Sepals 2-6-8, usually persistent, round, frequently unequal and coloured; æstivation imbricated. Petals hypogynous, equal to, or a multiple of, the sepals. Stamens hypogynous, usually 00 , rarely definite, free or variously united at the base; filaments unequal in length; anthers adnate, introrse or extrorse, sometimes very small, occasionally unilocular, and sometimes with porous or circumscissile dehiscence. Thalamus forming a fleshy, sometimes 5-lobed disk. Ovary solitary, 1- or many-celled; ovules either solitary and erect or ascending, or numerous and attached to central placentas ; style 0 or very short; stigmas peltate or radiate. Fruit dry or fleshy, 1- or many-celled, 1- or many-seeded, either with septicidal dehiscence or indehiscent. Seeds definite, anatropal, or orthotropal, in a pulp, apterous and often arillate, with a thin and membranous spermoderm; albumen 0 ; embryo straight; cotyledons usually cohering.-Trees or shrubs, sometimes parasitical, with exstipulate, opposite, coriaceous, entire leaves, having a strong midrib, and lateral veins running directly to the margin. Filowers articulated with the peduncle, often unisexual by abortion. They are natives of tropical regions, more especially of South America; a few are from Madagascar and the continent of Africa. They generally require situations combining excessive heat and humidity. Authors enumerate 30 genera, including about 230 species. Examples-Clusia, Garcinia, Cambogia, and Calophyllum.

The plants of this order yield a resinous juice, which is acrid, purgative, and has a yellow colour. Gamboge is one of the most important products. It is procured from Garcinia Morella, var. pedicellata (G. Hanburyi of Hooker), a diœcious tree, with laurel-like foliage and small yellow flowers, found in Camboja, Siam, and in the southern parts of Cochin-China. Garcinia pictoria and Travancorica also furnish Gamboge. In commerce this drug occurs in the form of Pipe or Roll Gamboge, and of Lump or Cake Gamboge. Another kind of gamboge, called Coorg or Wynaad Gamboge, seems to be the produce of Garcinia elliptica. Gamboge is a powerful irritant, and in large doses acts as a poison, causing inflammation of the mucous membrane. It is employed medicinally as a drastic and hydragogue cathartic. It is an excellent pigment. The resin of Tacamahaca is yielded by Calophyllum Calaba. An oil is obtained from the seeds of Calophyllum Inophyllum. Pentadesma butyracea is the Butter and Tallow-tree of Sierra Leone, so called on account of the solid oil which is furnished by the fruit. While an acrid resin is the product of 
most of the plants of the order, there are some parts in which the resin is either absent or elaborated in small quantity. Thus some of them produce fruits which are used as articles of diet. Garcinia Mangostana supplies the East Indian Mangosteen, which is said to be one of the finest known fruits; it resembles a middle-sized Orange, and is filled with a sweet and highly-flavoured pulp. Mammea americana gives a drupaceous fruit, called Mammee Apple, or Wild Apricot of South America. Its seeds are anthelmintic; its flowers yield by distillation a stomachic spirit called Eau de Créole; and a wine is obtained by fermenting its sap. Mesua ferrea yields a hard and durable timber. The Clusias are handsome trees, remarkable for the mode in which they send out adventitious roots. The fruit of Clusia flava, sometimes called Wild Mango, or Balsam-tree, yields a yellow juice like gamboge.

Order 37.-Erythroxylacees, the Erythroxylon Family. (Polypet. Hypog.) Sepals 5, united at the base, persistent; rstivation imbricated. Petals 5, hypogynous, broad and with a small scale at the base, slightly contorted in rstivation. Stamens 10, monadelphous ; anthers erect, bilocular, with longitudinal dehiscence. Ovary 3-celled, two cells sometimes abortive; styles 3 , distinct or united; stigmas 3 ; ovule single, pendulous. Fruit a 1-seeded drupe. Seed angular, anatropal; embryo in the axis of firm albumen, rarely exalbuminous; cotyledons linear, flat, and leafy.-Shrubs or trees with alternate stipulate leaves. Flowers arising from numerous, imbricated, scale-like bracts. Found chiefly in the West Indies and South America. The plants of the order have tonic, purgative, and narcotic qualities. The leaves of Erythroxylon Coca are used by the miners of Peru as a stimulant, like opium. They receive the name of Coca or Ipadu. They are chewed with a small mixture of finelypowdered chalk. The wood of some is of a bright red colour, and yields a dye. There are 3 known genera, and about 60 species. Example-Erythroxylon.

Order 38.-MatpighiaCee, the Malpighia Family. (Polypet. Hypog.) Sepals 5, base; restivation imbricated. Petals 5, unguiculate, with convolute æstivation. Stamens usually 10, often monadelphous; anthers roundish, with a projecting process from the connective (fig. 371, p. 223 ; 374 , p. 225). Ovary formed by 3 (rarely 2 or 4 ) carpels, more or less combined; ovules solitary, with a long pendulous cord ; styles 3, distinct or united. Fruit dry or fleshy, sometimes winged (fig. 562, p. 310). Seeds solitary, orthotropal, suspended, exalbuminous ; embryo straight or curved in various ways ; cotyledons foliaceous or thickish (fig. 602, p. 338).-Trees or shrubs, sometimes climbing, with simple, opposite, or very rarely alternate, stipulate leaves, without dots. Hairs, when present, peltate (fig. 89, p. 33). 
Flowers either perfect or unisexual. They are inhabitants of tropical countries chiefly, and a great number of them are found in South America. Authors notice 50 genera, including 589 species. Examples -Malpighia, Banisteria, Hiptage, Hiræa, Gaudichaudia.

Some of the woody plants of this order exhibit an anomalous formation of the stem, from the absence of annular rings and medullary rays, and the peculiar mode in which the bark is produced. This is shown in figs. 123, p. $61 ; 126$, and 127, p. 62 . Many of the plants are astringent. Some have stinging hairs (fig. 89, p. 33). The fruit of Malpighia glabro and of $M$. punicifolia is called Barbados Cherry, and is used as an article of dessert. Nitraria is a genus doubtfully referred to this order; by some it is placed under the order Zygophyllacece. N. tridentata, found in the desert of Soussa, near Tunis, is said by some to be the true Lotus-tree of the ancient Lotophagi.

Order 39.-ACERACEx, the Maple Family. (Polypet. Hypog.) Calyx divided into 5, rarely into 4 or 9 parts, with an imbricated astivation. Petals equal in number to the lobes of the calyx, with which they alternate, rarely wanting. Stamens generally 8 , inserted on a hypogynous disk. Ovary free, 2-lobed, 2-celled; ovules in pairs ; amphitropal, pendulous; style 1 ; stigmas 2 . Fruit, a samara (fig. 561 , p. 310 ), composed of two winged carpels, each 1-celled with 1-2 seeds. Seeds erect, exalbuminous ; embryo curved, with foliaceous cotyledons, and the radicle next the hilum.-Trees with opposite, simple, lobed or palmate, exstipulate leaves. Flowers often polygamous. They are confined chiefly to the temperate parts of Europe, Asia, and North America. They yield a saccharine sap, from which sugar is sometimes manufactured. It is said that their juices become acrid as the season advances. The bark is astringent, and yields reddish-brown and yellow-coloured dyes. Acer saccharinum is the Sugar Maple of America. Acer Pseudo-platanus, the Sycamore or Great Maple (the Plane-tree of Scotland), acts well as a shelter in exposed places, as near the sea. Its sap is slightly saccharine. Its wood is used in machinery and for charcoal. The leaves are often covered with black spots, caused by the attack of a fungus, Rhytisma acerinum. There are 3 known genera, and 60 species. ExamplesAcer, Negundo, Dobinea.

Order 40.-SaPindaCe Sepals 4-5, distinct or cohering at the base; æstivation imbricated. Petals 4-5, occasionally absent, hypogynous, sometimes naked, sometimes with a glandular or scaly appendage inside; restivation imbricated. Stamens usually $8-10$, sometimes 5-6-7, very rarely 20 ; filaments free, or combined just at the base; anthers introrse. Thalamus forming a fleshy or glandular disc, into which the stamens are often inserted. Ovary trilocular, rarely bi- or quadri-locular ; ovules anatropal, definite; style either undivided or 2-3 cleft. Fruit either 
fleshy and indehiscent, or samaroid, or capsular, and 2-3 valved. Seeds solitary, often arillate, exalbuminous ; embryo straight, curved, or spiral; cotyledons incumbent; radicle next the hilum.-Trees or shrubs, sometimes climbing herbaceous plants, with alternate, sometimes opposite, compound, rarely simple leaves, often marked with lines or pellucid dots. They are natives principally of South America and India. Africa contains many of them; they are wanting in the cold regions of the north. None are found wild in Europe. (In this order some include the Hippocastaneæ or Horse-chestnuts, which are distinguished by their opposite leaves, and their two ovules in each cell, one ascending, the other suspended) (fig. 464, p. 258). Authors give 70 genera, including 600 species. Examples-Sapindus, Paullinia, Nephelium, Dodonæa, Meliosma, Assculus, Pavia.

In this order are included many plants which yield edible fruits, and others which are poisonous. A saponaceous principle exists in certain species. The fruit of Sapindus Saponaria, under the name of Soap-berries, is used as a substitute for soap in the West Indies. The Longan and Litchi are excellent Chinese fruits, the produce of Nephelium Longan and N. Litchi. The kernel of the Longan powdered is sometimes made into paper. Blighia or Cupania sapida yields the Akee fruit, the succulent arillus of which is used as food. Many of the Paullinias are poisonous. From the seeds of Paullinia sorbilis, however, the Guarana bread or Brazilian cocoa is prepared in Brazil. The seeds, after being dried and deprived of their white aril, are pounded and kneaded into a dough, which is afterwards made up into cakes or balls. This guarana contains a bitter crystalline matter called Gugranine, identical with Caffeine. The bark of Assculus Hippocastanum, Horse-chestnut, has been recommended as a febrifuge, and its seeds have been used as a substitute for coffee. The fruit and leaves of Assculus ohiotensis, the Buck-eye or American Horse-chestnut, are said to be poisonous. Paullinia pinnata, and some other Sapindaceæ of Brazil, exhibit anomalous exogenous stems (fig. 124, p. 62). Ophiocaryon paradoxum is the Snake-nut-tree of Demerara, and is so called on account of the embryo resembling a coiled-up snake.

Order 41.-Mediaces, the Melia Family. (Polypet. Hypog.) Sepals 4-5, more or less united, with an imbricated æestivation. Petals 4-5, hypogynous, sometimes cohering at the base, with a valvate or imbricated æstivation. Stamens equal in number to the petals, or 2, 3 , or 4 times as many; filaments combined in a long tube; anthers sessile within the orifice of the tube. Disk often large and cup-shaped. Ovary single, multilocular, the cells often equal in number to the petals; ovules usually anatropal, 1-2 in each cell ; style 1 ; stigmas distinct or united. Fruit baccate, drupaceous or capsular, multilocular, or by abortion unilocular; when valves are present opening by loculicidal dehiscence. Seeds not winged; albumen usually absent; 
embryo straight, with leafy cotyledons.-Trees or shrubs with alternate (occasionally opposite); exstipulate, simple, or pinnate leaves. They are chiefly found in the tropical parts of America and Asia. Under this order some include Humiriaceæ, which are distinguished by a prolonged fleshy connective (fig. 373, p. 225), albuminous seeds, and a slender embryo. Arnott includes Cedrelacem also under this order. There are about 29 known genera, and upwards of 240 species. Examples-Melia, Trichilia, Humiria.

The plants of this order are bitter, tonic, and astringent. Melia Indica, or Azadirachta, is used in India as a febrifuge, and its fruit yields an oil which is employed for domestic purposes, and as an antispasmodic. It is an ornamental tree, 40 or 50 feet high. Its Hindustanee name is Nim, and its Portuguese name is Margosa. Its bark is used as a tonic, under the name of Margosa bark. The root of Melia Azedarach, a native of China, is bitter and nauseous, and is used in North America as an anthelmintic. Oils are procured also from species of Trichilia and Carapa (fig. 603, p. 338). A warm pleasantsmelling oil is prepared from the fruit of Trichilia speciosa, which in India is considered as a valuable external remedy in chronic rheumatism and paralytic affections. The bark of Carapa guineensis has reputation as an anthelmintic. The fruit called in the Indian Archipelago Langsat, is the produce of a species of Lansium. A fragrant balsam, called balsam of Umiri, is got from the trunk of Humiria floribunda.

Order 42.- Cedretaces, the Mahogany Family. (Polypet. Hypog.) Calyx 4-5-cleft, with imbricated æstivation. Petals 4-5, with imbricated æstivation. Stamens 8-10, united below into a tube, sometimes distinct, inserted into a hypogynous annular disc; anthers bilocular, acuminated, with longitudinal dehiscence. Ovary usually 4- or 5-celled; ovules anatropal, pendulous; style simple; stigma peltate. Fruit a capsule opening septifragally (fig. 546, p. 304; 547 , p. 305). Seeds winged; albumen thin or 0 ; embryo straight, erect; cotyledons fleshy.-Trees with alternate, pinnate, exstipulate leaves. They are found in the tropical parts of America and Asia. Authors enumerate 8 genera, including 24 species. ExamplesCedrela, Swietenia.

The plants of this order are bitter, and have an aromatic fragrance. Srwietenia Mahagoni supplies the well-known mahogany wood. Its bark, as well as that of Soymida febrifuga, called Rohun bark, and of Cedrela febrifuga, are used for the cure of intermittenits. The wood of the tree is sometimes called.Bastard Cedar. Chloroxylon Swietenia produces satin wood, and also yields a kind of wood-oil.

Order 43.-Ampelides or Vitace 692.) (Polypet. Hypog.) Calyx small, nearly entire (fig. 693 c). Petals 4-5, sometimes cohering above (fig. 693 p), inserted outside an annular hypogynous disk (figs. $693,694 \mathrm{~g}$ ); æstivation valvate. 
Stamens 4-5, opposite to the petals (figs. 693, 694 e), inserted on the disk; filaments free, or united at the base; anthers ovate, versatile (fig. 694). Ovary 2-6-celled; ovules erect, anatropal (fig. 695 o); style 1 , very short; stigma simple $(695 \mathrm{~s})$. Fruit pulpy and globular, not united to the calyx (fig. 696), sometimes 1-celled by abortion. Seeds 1 to 4 or 5, erect (fig. 697), with an osseous spermoderm, horny

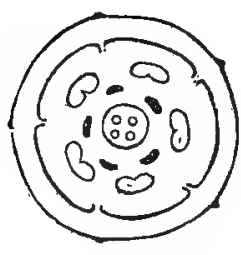

Fig. 692.

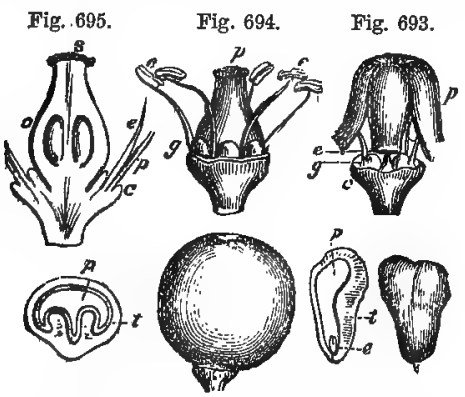

Fig. 699.

Fig. 696. Fig. 698, Fig. 697.

albumen (figs. 698, 699 p), and an erect embryo (fig. 698 e).-Climbing shrubs, having the lower leaves opposite, the upper ones alternate (fig. 239, p. 120). Flowers in racemes, which are often opposite the leaves ; floral peduncles sometimes becoming cirrhose. They inhabit the milder as well as the hotter parts of both hemispheres, and abound in the West Indies. There are 4 genera and 250 species. Examples -Vitis, Cissus, Leea.

The plants of this order have generally acid leaves, and their fruit when ripe is saccharine. Vitis vinifera, the Grape Vine, belongs to this order. It is said to be a native of the shores of the Caspian, whence it was imported into Europe. The unripe fruit contains a harsh acid juice, called verjuice. It contains free citric, malic, and tartaric acids, along with bitartrate of potass. As grapes ripen, sugar,

Fig. 692-699. Organs of fructification of Vitis vinifera, to illustrate the natural order Vitacex or Ampelidex. Fig. 692. Diagram of the flower, showing 5 sepals, 5 petals, 5 stamens opposite the petals on account of the non-development of one staminal row, a disk, and the ovary. Fig. 693. Flower showing the petals, $p$, detached at the base, and remaining united above in a calyptra-like manner. c, Calyx, g, Glands forming a disk, $e$, Stamens, the filaments of which only are seen. Fig. 694. Flower after the petals have fallen. $g$, Glands of the disk. e, Stamens with versatile anthers. $p$, Pistil. Fig. 695. Vertical section of the flower. c, Calyx. p, Petals. e, Filaments. o, Ovary, with 2 cells and their erect anatropal ovules. $s$, Stigma. Fig. 696. Globular pulpy fruit, uva, or grape, differing from a berry, in the calyx not forming part of the pericarp. It is by some calied nuculanium. Fig. 697. The seed of the grape, with its osseous spermoderm enclosing a hard perisperm. Fig. 698. The seed cut vertically. $t$, The integument or spermoderm. $p$, Perisperm, or albumen, which is horny. $e$, Erect embryo, with lanceolate cotyledons. Fig. 699. Horizontal section of the seed of the grape, about the middle. $t$, Integument or spermoderm. $p$, Perisperm or albumen. 
called Grape-sugar, is formed at the expense of the acids (pp. 164, 165). The vessels of the vine are large (fig. 63 , p. 19), and the sap passes through them with great force and rapidity. When cut in spring the plant bleeds freely. The leaves of the vine, on account of their astringency, have been used in diarrhœea. In France its sap is a popular remedy for chronic ophthalmia. Raisins (uvæ passæ), as found in the shops, are the produce of Spain and Asia Minor. Muscatel raisins are imported from Malaga, and are used for dessert; Valencia raisins from Spain. The stoneless Sultana raisins, from Smyrna, are used for culinary purposes. In pharmacy Valencia raisins are used. In 1872, the consumption of raisins in Great Britain amounted to 617,418 cwt., value $£ 1,149,337$. The currants of the shops are the dried fruit of the Corinthian vine. The name currant in this case is a corruption of Corinth. Vitis vulpina yields the Fox-grapes of Rhode Island. The leaves of $C$ issus cordata and $C$. setosa are said to possess acrid properties. The berries of the latter are acrid. Both leaves and fruit of Cissus tinctoria abound in a green colouring matter, which on exposure to air and light becomes blue, and is highly esteemed as a dye for cotton fabrics. Ampelopsis virginica, the Virginian creeper, is commonly cultivated as a climbing plant.

Order 44.-Geraniaces, the Cranesbill Family. (Polypet. Hypog.) Sepals 5, persistent, more or less unequal (figs. 338, p. 213 ; $351 \mathrm{c} c$, p. 306), one sometimes spurred at the base (Pelargonium); æstivation imbricated. Petals 5 (or by abortion 4), unguiculate, with contorted æstivation (figs. 338, p. 213; $379 p p$, p. 228). Stamens monadelphous, hypogynous (figs. 338, p. $213 ; 379$ e, p. 228), twice or thrice as many as the petals, some occasionally abortive. Ovary of 5 carpels, placed round an elongated axis (fig. $338 t$, p. 213); ovules pendulous, solitary; styles 5, cohering round the axis or carpophore (fig. 338, p. 213). Fruit formed of 5 one-seeded coccoons, terminated each by an indurated style, which curls upwards, carrying the coccus or pericarp with it (fig. 551, p. 306). Seeds exalbuminous, solitary, with a curved folded embryo, and leafy, convolute, and plaited cotyledons (fig. 607, p. 339).--Herbs or shrubs, with simple, stipulate leaves, which are either opposite, or alternate with peduncles opposite to them. They are distributed over various parts of the world. The species of Pelargonium abound at the Cape of Good Hope. The species of Geranium proper have regular flowers without spurs. Authors mention 7 genera, including, after separating hybrids, about 300 species. ExamplesGeranium, Pelargonium.

The name Cranesbill is derived from the long beak-like prolongation of the axis, or what is called the carpophore (p. 240). The plants of this order are astringent and aromatic. The root of Geranium maculatum receives the name Alum root, in consequence of being a very powerful astringent. The tuberous or moniliform roots of some, such 
as Pelargonium triste (fig. 103, p. 41) are eatable. The root-stock of Geranium oblongatum, called the yellow geranium, is used by the natives of Namaqualand as an article of food. The species of Pelargonium are remarkable for the beauty of their flowers. By the art of the gardener, and by hybridisation, many fine varieties of Pelargonium have been produced.

Order 45.-Vivianiaces, the Viviania Family. (Polypet. Hypog.) Sepals 5, united. Petals 5, hypogynous, unguiculate, persistent, with twisted æstivation. Stamens 10, hypogynous ; filaments free ; anthers bilocular, opening longitudinally. Ovary free, 3-celled; stigmas 3. Capsule 3-celled, 3-valved, loculicidal; seeds, 2 in each cell, with a curved embryo lying among fleshy albumen.-Herbaceous or suffruticose plants, with opposite or verticillate exstipulate leaves. All the members of this order which have yet been discovered inhabit Chili and South Brazil. They have no properties of importance. Genera 2 ; species 8. Examples-Viviania, Cresarea.

Order 46.-Linace m, the Flax Family. (Polypet. Hypog.) Sepals 3,4 , or 5, persistent, with an imbricated æstivation. Petals 3, 4, or 5 , fugitive, unguiculate, hypogynous, with a twisted æestivation. Stamens equal to the petals and alternate with them (with intermediate teeth or abortive stamens), arising from a hypogynous annular disk; anthers ovate, erect. Ovary with as many cells and styles as sepals, seldom fewer; stigmas capitate; ovules anatropal, pendulous. Fruit a multilocular capsule, pointed generally with the indurated base of the styles; each loculament or cell more or less completely divided by a spurious dissepiment, arising from the dorsal suture, and opening by two valves at the apex. Seeds solitary in each spurious cell, compressed, pendulous; albumen usually in small quantity, sometimes 0 ; embryo straight; cotyledons flat; radicle next the hilum.-Annual and perennial plants, with exstipulate, simple, entire leaves, which are usually alternate. Many species, of Linum have showy flowers, the colours being blue, yellow, and crimson. Linum grandiflorum, from the north of Africa, has a beautiful crimson flower. They are scattered over the globe, but are said to be most abundant in Europe and in the north of Africa. By some authors the order is associated with Geraniacer, from which it differs in its unbeaked fruit and exstipulate leaves, as well as the absence of joints in the stem. There are 4 genera, comprising about 90 species. Examples-Linum, Radiola.

The plants yield mucilage and fibre. Flax, which consists of xylem or bast fibre, is procured from the inner bark of the stalk of Linum usitatissimum, by the process of steeping and stripping off the bark. Linen and cambric are prepared from it. The flax plant is supposed to have been originally a native of Egypt, and mummy. cloth has been shown to be formed of linen. The integument of the seeds is mucilaginous, and an infusion of them in boiling water is used 
as a demulcent and diuretic. The cotyledons of the seeds are oleaginous, and by expression yield Linseed oil, which has the property of drying and hardening into an elastic varnish on exposure to the air. It is used medicinally for burns, mixed with lime water. After expressing the oil a cake remains, called oil-cake, which is used for fattening cattle. The powdered cake receives the name of linseed meal, and is commonly used for poultices. Another species of Linum, called $L$. catharticum, has purgative properties, which seem to depend on the presence of an acrid bitter matter, called Linin. Linum selaginoides is considered in Peru bitter and aperient.

Order 47.-Balsaminacese, the Balsam Family. (Polypet. Hypog.) Sepals 5, irregular, deciduous, the two inner and upper connate, coloured, the lower (odd) sepal spurred (fig. 640, p. 366); æestivation imbricated. Petals alternate with the sepals, usually 4 , in consequence of 1 being abortive, often more or less irregularly united; æstivation convolute. Stamens 5. Ovary 5-celled; ovules usually numerous, stigma sessile, more or less 5-lobed. Fruit a 5-celled capsule, opening septifragally, by 5 elastic valves. Seeds usually numerous, suspended, exalbuminous, with a straight embryo, and radicle next the hilum.- Succulent herbaceous plants with watery juice, having simple, opposite, or alternate, exstipulate leaves, and axillary irregular flowers. They inhabit chiefly the East Indies, and are remarkable for the force with which the seed-vessels open when ripe. The valves give way on account of the osmose which goes on in the cells, and they then curl up in a peculiar manner (pp. 15, 344). They have usually showy flowers, but their properties are unimportant. Lindley mentions 2 genera, including 136 species. Examples-Impatiens, Hydrocera.

Order 48. - Oxalidaces, the Wood-sorrel Family. (Polypet. Hypog.) Sepals 5, equal, sometimes cohering slightly at the base, persistent, imbricate in æastivation. Petals 5, equal, unguiculate, hypogynous, with a twisted æstivation. Stamens 10 , more or less monadelphous, in 2 rows; those opposite the petals being longer than those in the outer row; anthers erect, bilocular. Ovary usually quinquelocular ; styles filiform, distinct; stigmas capitate or slightly bifid. Fruit capsular, membranous or fleshy, usually 5-celled, and when dehiscent 5-10 valved. Seeds few, anatropal, albuminous, attached to a central placenta, sometimes with a peculiar elastic integument; embryo straight, as long as the fleshy albumen, with a long radicle and leafy cotyledons.-Herbs, undershrubs, or trees, with alternate, rarely opposite compound (occasionally simple) leaves, which are generally without stipules. They are found in the hot as well as the temperate parts of the world, and are abundant in North America and at the Cape of Good Hope. The shrubby species are confined to the hotter parts of the world. In some cases phyllodia, or winged petioles, occupy 
the place of leaves. The genus Hugonia is placed by some in the order Linacer, along with Roucheria. There are about 6 known genera, and upwards of 230 species. Examples-Oxalis, Averrhoa, Hugonia.

They are often acid in their properties. Some of them yield esculent roots. Oxalis Acetosella, common Wood-sorrel, receives its name from its acid taste. It contains binoxalate of potash, which is sometimes called the salt of sorrel, and at other times the essential salt of lemons. The plant has been used as a refrigerant and antiscorbutic. Its leaves are trifoliate, and some have considered it to be the true Shamrock, in consequence of being in flower about the period of the year when St. Patrick's day occurs. Some of the oxalises, as 0 . sensitiva, have sensitive leaves, and experiments have been made in regard to their closing and opening by Morren ( $p .377$ ). Oxalis crenata, esculenta, and Deppei, yield tubers, which have been used as a substitute for potatoes. The acid fruits of Averrhoa Bilimbi and Carambola are used in the East Indies as food.

Order 49.-TroparolaCEAr, the Indian Cress Family. (Polypet. Hypog.) Sepals usually 5, the upper spurred (fig. 299, p. 198); astivation slightly imbricate. Petals often 5, hypogynous, more or less unequal, sometimes abortive (fig. 641, p. 366); rstivation convolute. Stamens 8 or 10 , seldom fewer, free, almost perigynous; anthers bilocular, innate. Ovary triquetrous, composed of 3-5 carpels, with a single style, and 3-5 acute stigmas ; ovules solitary, often pendulous. Fruit indehiscent, usually composed of 3 pieces. Seeds exalbuminous, with a large embryo, which has thick, often united, cotyledons, and a radicle next the hilum. - Herbaceous trailing or twining plants, having a delicate texture, with alternate exstipulate leaves, and axillary, often gay, flowers. They are natives of the temperate parts of America, and are extensively cultivated on account of their showy yellow, orange, scarlet, and occasionally blue flowers. The free spur of Tropæolum represents the adherent spur of Pelargonium. They have more or less pungency in their fruit, which is used as a cress. The unripe fruit of Tropocolum majus, common Indian Cress, or Garden Nasturtium, has been pickled, and used as capers. LIMNANTHACEA are included by some in this order. They are characterised by regular flowers, valvate sepals, glands alternating with the petals, stamens double the number of the petals, carpels not bealed, indehiscent, separating from the axis, ovules solitary, with an inferior micropyle. The species are found in North American Limnanthes is a Californian genus, with showy flowers. Their roots are sometimes eaten. Genera 4, including 40 species. Example, Tropæolum, Flœrkea, Limnanthes.

Order 50.-Pittosporaces, the Pittosporum Family. (Polypet. Hypog.) Sepals 4 or 5, deciduous; distinct or partially united; æstivation imbricated. Petals 4 or 5 , sometimes slightly cohering, with 
imbricated restivation. Stamens 5, distinct, alternate with the petals. Ovary single, 2-5-celled; style 1 ; stigmas $2-5$, equal in number to the placentas. Fruit capsular or berried, with many-seeded cells, which are sometimes incomplete; dehiscence loculicidal. Seeds often enveloped in a glutinous or resinous pulp, anatropal, with a minute embryo lying in fleshy albumen; radicle long; cotyledons very short. -Trees or shrubs, with simple, alternate, exstipulate leaves, and flowers occasionally polygamous. Some place the order next Tremandraceæ and Bixaceæ. They are found chiefly in Australia. Many of them are resinous, and, in some instances, the berries are eaten. Bursaria spinosa is called native Box and native Myrtle in Van Diemen's Land. Authors mention 9 genera, including 90 species. ExamplesPittosporum, Billardiera, Sollya, Bursaria.

Order 51.-Zrgophrluaces, the Guaiacum Family. (Polypet. Hypog.) Calyx 4-5-parted, with convolute æstivation. Petals alternate with the calycine segments, æstivation imbricated. Stamens twice as many as the petals ; filaments dilated at the base, usually arising from scales (fig. 345, p. 217). Ovary simple, 4-5-celled; divisions occasionally formed by spurious dissepiments (figs. 534, 535, p. 300). Ovules 2 or more in each cell, usually pendulous; style simple, 4-5-furrowed; stigma simple, or 4-5-lobed. Fruit capsular or rarely fleshy, with 4-5 angles or wings, 4-5-valved, either opening by loculicidal dehiscence, or indehiscent. Seeds few, usually with whitish albumen, sometimes exalbuminous; embryo green, with foliaceous cotyledons and a superior radicle.-Herbs, shrubs, or trees, with opposite, stipulate, usually compound leaves, which are not dotted, and hermaphrodite flowers. They occur in various parts of the world, chiefly in warm extra-tropical regions, as in the south of Europe, America, Africa, and India. The order has been divided into two sections:-1. Zygophylleæ, having albuminous seeds. 2. Tribuleæ, having exalbuminous seeds. Authors mention 10 genera, comprising 60 species. Examples-Zygophyllum, Guaiacum, Tribulus.

Some of the plants abound in a stimulant resin, which pervades the wood and bark; others are bitter and acrid. The medicinal species are used as sudorifics. Zygophyllum Fabago is called the Beancaper, on account of its flowers being used as a substitute for capers. The plant is said to act as a vermifuge. Guaiacum officinale is a beautiful West Indian tree, the wood of which, commonly called lignum-vitæ, is prized for its hardness. The alburnum is of a greyishyellow colour, while the duramen is greenish-black. The fibres of the wood are remarkable for their direction, being cross-grained, in consequence of one layer crossing another diagonally. It yields a resinous matter known as the resin of Guaiac, or Gum-guaiac. This resin exudes spontaneously, or it may be procured by incisions, or by the application of heat. A solution of the resin in alcohol, when applied 
to the fresh cut surface of a potato, gives rise to a blue colour. Both the wood and the resin are used medicinally on account of their stimulant diaphoretic properties. In decoction and tincture they are administered in cutaneous and syphilitic diseases. Guaiacum sanctum from Mexico and the Bahamas also supplies Guaiac resin, and is sometimes used medicinally on the continent. Tribulus terrestris is a prickly plant which grows in the East, and is found in Palestine. Some suppose that the Hebrew word דרדר, dardar, translated thistle in the Old Testament, and refBod.os, translated thistle in the New Testament, refers to this plant (figs. 534, 535, p. 300).

Order 52.--RuTaces, the Rue F'amily. (Polypet. Hypog.) See figs. 632,633 , p. 364 . Calyx having $4-5$ segments, with an imbricated æstivation. Petals alternate with the divisions of the calyx, distinct, or cohering below into a spurious gamopetalous corolla, rarely wanting; astivation either contorted or valvate. Stamens equal in number to the petals (fig. 632, p. 364), or twice or thrice as many (rarely fewer by abortion or non-development) (fig. 633, p. 364), usually hypogynous, but in some instances perigynous. Between the stamens and ovary there is a more or less complete cup-shaped disk, which is either free or united to the calyx. Ovary sessile or supported on a gynophore (fig. 416, p. 239), its carpels equal to the petals in number or fewer; ovules 2 , rarely 4 or more in each carpel; styles adherent above (fig. 416 , p. 239 ) ; stigma simple or dilated. Fruit capsular, its parts either combined completely or partially; seeds solitary or in pairs, albuminous or exalbuminous; embryo with a superior radicle. -Trees or shrubs, with exstipulate, opposite, or alternate leaves, usually covered with pellucid resinous dots (figs. 92, p. 35; 95, p. 36), and hermaphrodite flowers. The order has been subdivided into two sub-orders :- - 1. Ruteæ, with albuminous seeds, and the fruit with sarcocarp and endocarp combined. 2. Diosmeæ, with exalbuminous seeds, and a 2-valived endocarp, which dehisces at the base, and when the fruit is ripe separates from a 2-valved sarcocarp. Ruteæ are found chiefly in the southern part of the temperate zone, as in the south of Europe, while Diosmeæ abound at the Cape of Good Hope and in Australia. Authors mention 44 genera and 430 species. ExamplesRuta, Dictamnus, Diosma, Barosma, Correa, Boronia, Zieria, Pilocarpus.

The plants are remarkable for their peculiar odour, which is very powerful and penetrating. Many have antispasmodic properties, while others are bitter, and act as febrifuges and tonics. The leaves and unripe fruit of Ruta graveolens, common or garden Rue, are used in medicine as stimulant, antispasmodic, anthelmintic, and emmenagogue. They emit when bruised a strong and peculiar oppressive odour, and have a bitter and acrid taste. By distillation with water they yield a yellow acrid volatile oil, which is their active constituent. The leaves of various species of Barosma, especially $B$. crenulata, 
serratifolia, and betulina, are used in medicine under the name of Buchu. They contain a yellowish volatile oil, having a powerful odour, and they have been used as stimulants and antispasmodics. They are prescribed in catarrh of the bladder. Jaborandi, a sudorific and sialagogue from Pernambuco, appears to be the produce of a species of Pilocarpus. Galipea Cusparia (G. officinalis, or Bonplandia trifoliata), a plant found in Venezuela, supplies the Angostura bark, which is used as a tonic and febrifuge. The bark is imported by way of Trinidad. On the continent Angostura bark is sometimes adulterated with the poisonous bark of Strychnos Nuxvomica. Some of the species of Dictamnus, such as D. Fraxinella, False Dittany, abound in volatile oil to such a degree that the atmosphere around them becomes inflammable in hot, dry, and calm weather. The Correas are remarkable for their gamopetalous corolla. The leaves of some of the species have been used for tea in Australia.

Order 53.-XANTHOXYLACEA or ZANTHOXYLACE lon Family. (Polypet. Hypog.) Flowers unisexual. Calyz in 3, 4, or 5 segments, with imbricated æstivation. Petals the same number, rarely 0 , usually larger than the calyx; æstivation imbricated or convolute. Stamens as many, or twice as many, as the petals, not developed in the female flowers. Ovary consisting of as many carpels as there are petals (sometimes fewer), the carpels being either completely or partially united (fig. 414, p. 238); ovules 2, rarely 4, in each carpel; styles more or less combined (fig. $414 \mathrm{~s}, \mathrm{p} .238$ ). Fruit baccate or membranous, sometimes of $2-5$ cells, sometimes of several drupes, or 2-valved capsules, the fleshy sarcocarp of which is partially separable from the endocarp. Seeds solitary or in pairs, pendulous; embryo lying within fleshy albumen; radicle superior; cotyledons ovate, flat.--Trees or shrubs, with exstipulate, alternate, or opposite leaves, having pellucid dots. They exist chiefly in the tropical parts of America. Authors enumerate. 24 genera, including 160 species. Examples - Xanthoxylon, Toddalia, Ptelea.

The plants yield a volatile oil, which is aromatic and pungent. Some are diaphoretic in their properties, others are febrifugal and tonic. The pungency of species of Xanthoxylon has caused them sometimes to be denominated peppers. Xanthoxylon fraxineum, or prickly ash, acts as a sialagogue. $X$. cariboum has a bitter and febrifugal bark. The bitter principle secreted by many of the plants of this order is called Xanthopicrine. Toddalia aculeata, a prickly climbing plant of the Indian Peninsula, the Mauritius, and Southern China, furnishes a pungent aromatic root. The bark of the root is used in India as a stimulating tonic. It was formerly known in Europe as Radix indica Lopeziana.

Order 54.-Simarubacese, the Quassia and Simaruba Family. (Polypet. Hypog.) Flowers usually hermaphrodite. Calyx in 4 or 5 
divisions; æstivation imbricated. Petals 4 or 5 , spreading or connivent into a kind of tube; rstivation twisted. Stamens twice as many as the petals; filaments arising from scales. Ovary 4-5-lobed, 4-5-celled, supported on a gynophore; ovules solitary ; styles simple; stigma 4-5-lobed. Fruit indehiscent, consisting of 4 or 5 drupes arranged round a common receptacle. Seeds anatropal, pendulous; embryo exalbuminous. - Trees or shrubs, with exstipulate, alternate, usually compound leaves without dots.' They are found in the tropical parts of America, Asia, and Africa. Authors give 30 genera, and 112 species. Examples-Simaruba, Quassia, Picræna.

All the plants of the order are intensely bitter. Quassia wood was originally the product of Quassia amara, a tall shrub, never above 15 feet in height, inhabiting Surinam, Guiana, and Colombia. It is a very ornamental plant, and has remarkable pinnate leaves, with winged petioles. In their early state the leaves seem to be simple, but in the progress of growth two or more contractions take place, at each of which two leaflets appear, the pairs being separated by a winged midrib, - a continuation of the petiole. This Surinam Quassia does not appear to be exported now, and it is not met with in English trade. The Quassia of the shops is the wood of Picrcena excelsa, a very large forest tree, attaining a height of nearly 100 feet, growing in Jamaica and other West Indian islands, where it is called Bitter Ash, and Bitter Wood. The quantity shipped from Jamaica in 1871 was 56 tons. Quassia is used medicinally, in the form of infusion and tincture as a tonic and anthelmintic. It acts as a narcotic poison on flies and other insects. Although prohibited by law, it is frequently employed by brewers as a substitute for hops. The bitterness of Quassia is said to be owing to a crystalline principle called Quassin. The bark of the root of Simaruba amara or offcinalis, a tree found in Cayenne and in the West Indies, is used as a bitter tonic and astringent, more especially in the advanced stages of diarrhoea and dysentery. Brucea antidysenterica was at one time erroneously supposed to furnish false Angostura bark. It has properties similar to those of Quassia. The bark of Samadera indica is bitter and tonic, and contains a principle like Quassia.

Order 55.-OcHNACEA, the Ochna Family. (Polypet. Hypog.) Sepals 5, persistent, imbricated in æstivation. Petals equal to, or twice as many as the sepals, deciduous, spreading, imbricated in æstivation. Stamens 5, opposite the sepals, or 10, or indefinite ; filaments persistent, attached to a hypogynous disk; anthers bilocular, innate, opening by pores, or longitudinally. Carpels as many as the petals, seated on an enlarged gynobase (thecaphore) ; ovules erect or pendulous, styles united into one. Fruit gynobasic, consisting of several succulent, indehiscent, monospermous carpels. Seeds anatropal, usually exalbuminous; embryo straight; radicle short; cotyledons thick.- 
Undershrubs or trees, with alternate, simple, stipulate leaves, and pedicels articulated in the middle. They grow in tropical countries, and are remarkable for the large succulent prolongation of the receptacle to which the carpels are attached. They lare generally bitter, and some of them are used as tonics. Genera, 12 ; species, 140. Examples-Ochna, Gomphia, Godoya.

Order 56.-Corrariaces, the Coriaria Family. (Polypet. Hypog.) Flowers unisexual. Calyx campanulate, 5-parted ; æstivation imbricate. Petals alternate with the calycine segments, very small, fleshy, with a keel on the internal surface. Stamens 10 (fig. 636, p. 365); filaments filiform, distinct; anthers dithecal, oblong. Ovary composed usually of 5 carpels, attached to a thickened receptacle or gynobase, 5-celled; ovules solitary, pendulous; style 0 ; stigmas 5 , long and glandular. Fruit, consisting fof 5 monospermous, indehiscent crustaceous carpels, enclosed by the enlarged petals. Seeds pendulous, anatropal, exalbuminous; embryo nearly straight; cotyledons fleshy; radicle short and blunt. - Shrubs with opposite square branches, opposite, simple, ribbed leaves, and scaly buds. They are found in small numbers'in the south of Europe, South America, India, and New Zealand. Some of them are poisonous. The leaves of Coriaria myrtifolia have been employed to adulterate Alexandrian Senna on the Continent. The leaves are known from those of true Senna by being 3 -ribbed, and by wanting the inequality at their base which characterises true Senna. The leaves are used for dyeing black, and an infusion of them gives a dark-blue with sulphate of iron. Coriaria ruscifolia is the Toot or Tutu plant of New Zealand, the seeds and young shoots of which are narcotico-acrid poisons. Genus, 1 ; species, 5. Example-Coriaria.

\section{Sub-class II.-CALYCIFLOR.e.}

In this Sub-class are included the polypetalous orders of Jussieu, in which the stamens are not hypogynous, as well as some monopetalous and diclinous orders. A calyx and corolla are present, in other words, the plants are dichlamydeous ; the petals are distinct or united, and the stamens are either attached to the calyx, and free from the ovary, or they are placed above the ovary,-being perigynous or epigynous. This sub-class, along with Thalamifloræ, comprises the dialypetalre of Endlicher. There are also included in it gamopetalous plants in which the ovary is inferior.

Section I.-PoLYPeтALAs. Petals separate, stamens perigynous or epigynous.

Order 57.-Stackhousiacere, the Stackhousia Family. (Polypet. Perigyn.) Calyx, 5-cleft, equal, with an inflated tube. Petals 5 , equal, inserted at the top of the tube of the calyx, claws of the 
petals united, limb narrow and stellate. Stamens 5, unequal, attached to the tube of the calyx. Ovary superior, 3-5-celled, cells partially distinct; ovules solitary, erect; styles $3-5$, sometimes united at the base; stigmas simple. Fruit consisting of 3-5 indehiscent pieces, which are sometimes winged, and are attached to a central persistent column. Seeds anatropal; embryo long, erect, in the axis of fleshy albumen.-Shrubs with simple, entire, alternate, stipulate leaves, found chiefly in Australia, and not possessing any marked properties. Genus, 1 ; species, 20 . Example-Stackhousia.

Order 58. - Celdastracese, the Spindle-tree Family. (Polypet. Perigyn.) Sepals $4-5$ imbricated in æstivation. Petals $4-5$ on a fleshy disk surrounding the ovary, æstivation imbricated. Stamens alternate with the petals; anthers erect. Disk large, flat, and expanded, surrounding the ovary to which it adheres. Ovary superior, 2-5-celled; ovules ascending, one or numerous, attached to the axis by a short funiculus. Fruit either a 2-5-celled capsule, with loculicidal dehiscence, or drupaceous. Seeds one or many in each cell, anatropal, usually ascending, and sometimes arillate (figs. 577, 578, p. 328); albumen fleshy; embryo straight, with flat cotyledons and a short radicle.-Small trees or shrubs, with simple, alternate, rarely opposite leaves, and small deciduous stipules. They inhabit the warm parts of Europe, North America, and Asia, and many are found at the Cape of Good Hope. Hippocrateæ are arborescent or climbing shrubs, found chiefly in South America. The order contains 39 known genera and 400 species. It has been divided into two tribes :-1. Celastreæ, with 4-5 stamens inserted on the margin of the disk, filaments subulate, seeds albuminous. 2. Hippocrateæ with, usually, 3 stamens inserted on the face of the disk, filaments flattened, seeds exalbuminous. Examples-Celastrus, Euonymus, Catha, Elæodendron, Hippocratea.

The plants of the order have subacrid properties, and the seeds of some yield a useful oil. Those of Celastrus nutans or paniculatus are said in India to be of a stimulant nature, and to be used as a remedy in the disease called Beriberi. Some of the species of Celastrus, as $C$. venenatus, are reckoned poisonous. The seeds of Euonymus, Spindletree, are surrounded by an aril, or rather arillode, which is considered as a prolongation from the exostome (figs. 577, 578, p. 328). In some of the species the capsules are crimson; and with the bright scarlet arillodes, they present a very showy appearance when the fruit is ripe. The bark of Eunymus tingens furnishes a yellow dye, which is used for marking the tika on the forehead of the Hindoos. It is also considered useful in diseases of the eye. The young shoots of Eunymus europoeus, when charred, are used to form a particular kind of drawingpencil ; its fruit and inner bark are said to be purgative and emetic. The young shoots of Catha edulis furnish the Arabian drug called Kât, which is used as a stimulant. The fruit of Salacia pyriformis, a native 
of Sierra Leone, is about the size of a Bergamot Pear: its flavour is rich and sweet. The nuts of Hippocratea comosa are oily and sweet; it is called, in the French West Indian Islands, Amandier du Bois.

Order 59.-STAPHYLeaces, the Bladder-nut Family. (Polypet. Perigyn.) (Fig. 638, p. 366.) Sepals 5, united at the base, coloured. imbricated in æstivation. Petals 5, alternate, with an imbricated rstivation. Stamens 5, alternate with the petals. Disk large and urceolate. Ovary 2-3-celled, superior; ovules usually ascending; styles, 2-3, cohering at the base. Fruit membranous or fleshy, indehiscent or opening internally, often partly abortive. Seeds anatropal, roundish, truncate at the hilum, with a bony testa; albumen generally 0 ; embryo straight, with thick cotyledons and a small inferior radicle. - Shrubs with opposite, pinnate leaves, having stipules and stipels. By many authors they are included under the last order. The plants are found in Europe, America, and Asia. Some are subacrid, while others are bitter and astringent. The species of Staphylea receive the name of bladder-nut, on account of their inflated bladder-like pericarp. They are cultivated as handsome shrubs. Three known genera are enumerated and 14 species. Example-Staphylea.

Order 60. - RHamnace出, the Buckthorn Family. (Polypet. Perigyn.) Calyx 4-5-cleft, valvate in æstivation. Petals distinct, hooded or convolute, inserted into the throat of the calyx, sometimes 0 . Stamens definite, opposite the petals. Disk large, fleshy, flat or urceolate. Ovary superior or half superior, 2-3- or 4-celled; ovules solitary, erect, anatropal. Fruit fleshy and indehiscent, or dry and separating into three parts. Seeds erect; albumen fleshy, rarely 0 ; embryo about as long as the seed, with a short inferior radicle and large flat cotyledons; raphe dorsal or lateral.-Trees or shrubs, often spiny, with simple, alternate, rarely opposite leaves, and minute stipules. They are generally distributed over the globe, and are found both in temperate and tropical regions. There are 37 genera, and 430 species enumerated. Examples-Rhamnus, Ceanothus, Phylica, Pomaderris.

Many of the plants of the order have active cathartic properties. Some, however, yield edible fruit, and others are tonic and febrifugal. Rhamnus catharticus, common or purging Buckthorn, is a European shrub, the black succulent fruits or berries of which are used as a hydragogue cathartic in cases of dropsy. The greenish juice becomes gradually red by the formation of acetic acid in it. It may be preserved unchanged in the form of syrup. When mixed with lime and evaporated to dryness, it forms the colour called sap-green. The fruit of Rhamnus Frangula, Black Alder, is emetic and purgative. The wood supplies charcoal for gunpowder, and crayons for artists. The berries of Rhamnus infectorius, as well as those of other species, are known by the name of French berries. They have been used for 
dyeing yellow. The fruit of many species of Zizyphus is used for food; Zizyphus Jujuba supplies the fruit called Jujube; and the Lotus, or Lote-bush of the classics, whence the Lotophagi were named, is Zizyphus Lotus. A kind of Scinde lac is found on Zizyphus Jujuba. Paliurus aculeatus, Christ's-thorn, is common in the hedges of Judea. Ceanothus Americanus is used in America as an astringent, and its leaves, under the name of New Jersey Tea, have been used as a substitute for tea. The leaves of Sageretia theezans are used for the same purpose by the poorer classes in China. Phylica arborea is a tree found in the island of Tristan d'Acunha, and also on Amsterdam Island in the South Indian Ocean, the two islands being separated by 5000 miles of ocean, and being nearly in the same latitude.

Order 61.-Anacardiaces, the Cashew-nut Family. (Polypet. Perigyn.) Flowers usually unisexual. Calyx usually small and persistent, with 5, or sometimes 3-4-7 divisions. Petals equal in number to the calycine divisions, perigynous, sometimes 0 ; imbricated in restivation. Stamens either equal to the petals in number and alternate with them, or twice as many or more; filaments distinct or cohering at the base, usually perigynous. Disk fleshy, annular or cup-shaped, sometimes inconspicuous. Ovary single, rarely 5 or 6 , free or adhering to the calyx, 1-celled; ovule solitary, attached by a funiculus to the bottom or along the side of the cell; styles 1-3, occasionally 4 ; sigmas 1-3 or 4. Fruit usually drupaceous and indehiscent. Seed ascending or frequently pendulous, from the adherence of the funiculus to the angle of the cell, exalbuminous ; radicle inferior or superior, sometimes curved suddenly back ; cotyledons thick, fleshy, or leafy.-Trees or shrubs, with a resinous, often caustic juice, and alternate leaves without dots. The order is a subdivision of the Terebinthaceæ of Jussieu. The natural order SABIACE em, embracing East Indian plants, is considered by some as a tribe of Terebinthaceæ. The plants inhabit chiefly the tropical parts of America, Africa, and India; some, however, are found in Europe. The order is unknown in Australia. There are 46 known genera and 450 species. Examples -Anacardium, Rhus, Mangifera, Spondias.

The order is characterised by the presence of an acrid resinous juice. In some cases, however, the fruit of the plants is edible. Many of them supply varnishes. Anacardium occidentale furnishes the Cashew-nut, which is remarkable for its large succulent peduncle supporting the fruit or nut (fig. 248, p. 173). The pericarp has the acrid properties which pervade the order, while the seed is eatable. A vesicating oil is procured from the pericarp, and is called cardole in the East Indies. The fleshy peduncle is acid and edible, and a bland gum exudes from the bark. Pistacia vera is the Pistacia or Pistachio nuttree, which extends from Syria to Bokhara and Caubul, and is cultivated in the south of Europe. It has green-coloured oily kernels, 
which are used as articles of diet. The Hebrew word (botnim), translated nuts in Gen. xliii. 11, is supposed to refer to the fruit of this plant. R. Terebinthus is a native of the southern part of Europe, and the northern part of Africa, and yields a liquid resinous exudation, known as the Chian or Cyprian turpentine. The turpentine receives its name on account of being collected in the island of Chio or Scio, where the plant thrives. The plant is common on the islands and shores of the Mediterranean, and is found in Asia Minor, Syria, and Palestine. The tree attains a height of 30 or 35 feet, and one tree will yield ten ounces of the liquid resinous matter, which thickens on exposure to air, by the loss of volatile oil. Like other turpentines, it has diuretic and excitant properties. Pistacia Lentiscus, the Lentisk, a native of the coasts and islands of the Mediterranean, furnishes the concrete resinous exudation called Mastich or Mastic. It is a bush of about 10 or 12 feet in height, which is cultivated abundantly in the island of Chios. Mastich is used as a masticatory for consolidating the gums and cleansing the teeth. It has also been employed as an antispasmodic, and it enters into the composition of varnishes. Rhus Toxicodendron, Poison-oak, is a shrub found in Canada and the United States, the leaves of which have been used as stimulants in cases of palsy. Like the other species of this genus, it yields an acrid milky juice, which becomes black on exposure to the air. Rhus radicans, Poison-ivy, or Poison-vine, is probably another name of the same species. Rhus venenata, Poison-sumach, or Poison-elder, has acrid, poisonous properties, and contact with it, in some instances, gives rise to inflammation of the skin. Cases are related of persons who are peculiarly liable to be thus affected, and in whom the irritation caused by the juice of the poisonous species of Rhus is very great, and even alarming. Rhus coriaria, $R$. typhina, and $R$. glabra, are used for tanning, and their fruit is acid. Rhus Cotinus is called Arbre d perruque (Wig-tree) in France, on account of the hairy appearance of its abortive pedicels. Many of the plants in this order furnish varnishes and marking ink. Semecarpus Anacardium, commonly called the Marking-nut tree, supplies the Sylhet varnish, while Melanorrhoea usitatissima furnishes that of Martaban. Stagmaria verniciflua is the source of the hard black varnish called Japan Lacquer. The leaves of many of the species of Schinus, as S. Molle, when torn and thrown on the surface of water, send out a resinous matter with great force, so as to cause a sort of spontaneous motion by the recoil. Although a resinous principle pervades the plants of this order, yet in some cases it is not developed in the fruit, which becomes eatable. Of this an illustration is furnished by the Mango, the produce of Mangifera indica. The Hog-plums of the West Indies are furnished by various species of Spondias, as S. purpurea and Mombin. Spondias dulcis yields the fruit called $W i$ in the Fiji islands. 
Order 62.-Burseracez, " the Myrrh and Frankincense Family. (Polypet. Perigyn.) Flowers usually bisexual, sometimes unisexual by abortion. Calyx persistent, regular or nearly so, with 2 to 5 divisions. Petals 3-5, inserted at the base of the calyx; æstivation valvate or imbricated. Stamens twice or four times as many as the petals, perigynous. Disk covering the base of the calyx often in a ring-like manner. Ovary superior, sessile, 1-5 celled; ovules in pairs, anatropal, pendulous or suspended; style 1 or none ; stigma simple or lobed, sometimes capitate. Fruit dry, 1-5-celled, indehiscent, or its epicarp splitting into valves. Seeds solitary, exalbuminous, with a superior radicle next the hilum, and cotyledons, which are fleshy or wrinkled. -Trees or shrubs, abounding in resin, with opposite or alternate compound leaves, which are frequently stipulate and dotted. They are natives of tropical regions. There are two tribes :- -1 . Burserex, with a 2-5-celled ovary ; 2 . Amyridex, with an unilocular ovary. Some look upon the stamens of Amyrideæ as truly hypogynous, and consider the order as allied to Aurantiaceæ. Authors give 26 genera and 56 species. Examples-Amyris, Boswellia, Bursera, Balsamodendron.

The plants yield a fragrant balsamic and resinous juice, which, in a dry state, is often used as frankincense, and is employed medicinally as a stimulant or expectorant. The resin called Elemi is supposed to be produced by species of Canarium (C. commune and balsamiferum. The resin contains a stimulant volatile oil. Olibanum (Frankincense), the לבנה (Lebonah) of the Scriptures, is procured from the stem of several species of Boswellia which inhabit the hot and arid regions of eastern Africa near Cape Gardafui, and of the southern coast of Arabia. Among these may be mentioned Boswellia Carterii of Birdwood, including several varieties, B. Bhau-Dajiana of Birdwood, and $B$. Frereana. The two latter are natives of the Somali country. The last mentioned yields a resin called Lubân Matti, which Hanbury considers to be the substance originally known as Elemi. The quantity of olibanum exported from Bombay in 1872-73 was 25,100 cwt. It is used for incense in the Roman Catholic and Greek churches. Boswellia thurifera, the Salai tree of India, produces an odoriferous resin. It contains a volatile oil, and has been used as a stimulant, and as a material for fumigation. Balsamodendron (Protium ?) Myrrha, a shrub growing in Abyssinia, appears to be the source of the officinal myrrh, the רip (mor) of the Bible. It is a bitter aromatic gum-resin, containing volatile oil, and was used in ancient times as frankincense. It is a heating stimulant, and is employed medicinally as an emmenagogue and diaphoretic, as well as for arresting various mucous discharges. The resin called Bdellium is procured from various species of Balsamodendron, as B. africanum and Roxburghii. The bdellium of Scripture צירי (בדלה) is not known. The celebrated balsam called Balm of Gilead, (tzori) is an exudation from Balsamodendron gileadense. Tacamahac 
is procured from Elaphrium tomentosum: Various other balsams and resins are yielded by plants of this order. Amyris toxifera is said to be poisonous.

Order 63.- Connaracee, the Connarus Family. (Polypet. Perigyn.) Flowers bisexual, rarely unisexual. Calyx 5-partite, regular, persistent; æstivation imbricate or valvate. Petals 5, inserted at the base of the calyx. Stamens twice as many as the petals, inserted with them, and doubtfully hypogynous; filaments united at the base. Ovary consisting of one or more separate carpels, each having a terminal style and a dilated stigma; ovules in pairs, collateral, ascending, orthotropal. Fruit follicular, dehiscing along the ventral suture. Seeds solitary or in pairs, erect, with or without albumen, sometimes arillate; embryo with a superior radicle, remote from the hilum, and cotyledons, which are either fleshy or leafy.-Trees or shrubs, with compound, alternate, exstipulate leaves, which are not dotted. They are tropical plants, and according to Endlicher are common in America. Some of them have febrifugal properties. Omphalobium (Agelaca) Lamberti is said to furnish Zebra-wood. This order, as well as the orders Anacardiaceæ and Amyridaceæ, are by many considered truly hypo-, gynous, and as belonging to Thalamifloræ. Lindley includes them in his Rutal alliance. Genera 12, species 140. Examples-Connarus, Omphalobium, Cnestis.

Order 64. - Leguminosa (Fabaceæ of Lindley), the Pea and Bean Tribe. (Polypet. Perigyn.) Calyz 5-partite, toothed, or cleft (figs. $700,701 c c$ ), with the odd segment anterior; segments often unequal and variously combined. Petals 5 (figs. 700, 701), or by abortion, 4, 3, 2, 1, or 0 , inserted into the base of the calyz, sometimes equal, but usually unequal, often papilionaceous, with the odd petal superior (fig. $701 \mathrm{e}$ ). Stamens definite or indefinite, usually perigynous, distinct, or monadelphous or diadelphous (fig. 701, $t$ ) or rarely triadelphous; anthers bilocular, versatile. Ovary superior, 1-celled, consisting usually of a solitary carpel (fig. 701 o), sometimes of $2-5$; ovules 1 or many; style simple, proceeding from the upper or ventral suture; stigma simple (fig. $701 \mathrm{~s}$ ). Fruit a legume (figs. 536, p. $301 ; 565$, p. $313 ; 702$ ), or a drupe. Seeds solitary or several (fig. 702), sometimes arillate, often curved (fig. 703); embryo usually exalbuminous, straight, or with the radicle bent upon the edges of the cotyledons (figs. 465, p. $258 ; 612$, p. 340), which are either epigeal or hypogeal (p. 536) in germination (fig. 704), and leafy (Phyllolobex), or fleshy (Sarcolobeæ).-Herbaceous plants, shrubs, or trees, with alternate usually compound leaves, having two stipules at the base of the petiole (fig. 209, p. 98), and two at the base of each leaflet in the pinnate leaves. Pedicels usually articulated. The flowers are frequently papilionaceous (fig. 316, p. 205), and the fruit is commonly leguminous (figs. 556, p. $307 ; 565,566,567$, p. 313 ), and by the 
presence of one or other of these characters the order may be recognised. It is remarkable that one or other of these distinctions disappears in a great number of cases. Cæsalpinieæ have irregular flowers, with spreading petals and stamens adhering to the calyx;

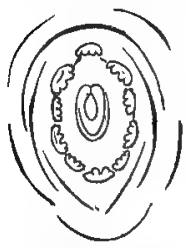

Fig. 700 .

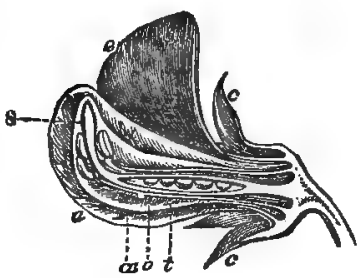

Fig. 701.*

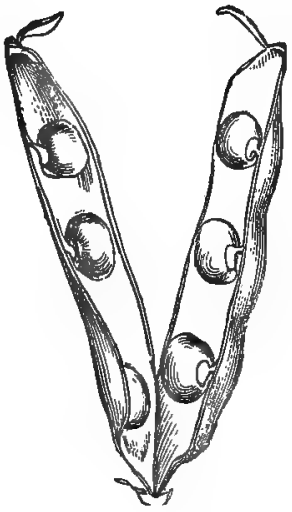

Fig. 702.

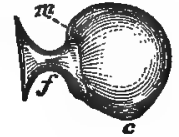

Fig. 703 .

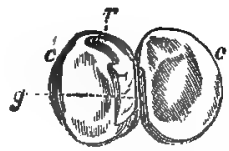

Fig. 704.

others have no petals at all, or some number less than five; while Mimoseæ have perfectly regular flowers and indefinite hypogynous stamens. Detarium and other plants of this family bear fruits not to be distinguished from a drupe. Leguminous plants and Roseworts have so many features in common that it may be affirmed that no positive character has been discovered to distinguish the one order from the other, except the inferior position of the odd calycine lobe.

Figs. 700-704. Organs of fructification of Lathyrus odoratus, Sweat-pea, a papilionaceous flower, showing the structure of the natural order Leguminosw. Fig. 700. Diagram of the flower, showing five divisions of the calyx, 5 petals, consisting of 2 parts forming the carina, 2 alæ, and the vexillum, which is superior, 10 stamens in 2 rows, diadelphous; ovary 1 celled, formed by a single carpel; one of the ovales shown with its funiculus attached to the ventral suture. Fig. 701. Longitudinal section of the flower of Lathyrus odoratus. c c , Calyx, with five segments. e, Vexillum or standard, being the superior or posterior odd petal. $a$, One of the alæ, or wings. c a, One-half of the carina, or keel. $t$, Tube of the stamens, the filaments being united in two bundles, or diadelphous. o, Ovary laid open, showing the ovules attached to the placenta, on the ventral or upper suture. s, Stigma, at the apex of the style, which is continuous with the ventral suture. Fig. 702. Fruit, a Legume or Pod, opening by two valves, and dehiscing by the ventral and dorsal suture. Seeds attached on each side of the ventral suture, curved upon themselves, having a marked bilum and funiculus (podosperm or umbilical cord). Fig. 703. A Seed separated. $f$, Funiculus. $c$, Hilum, which is united to the funiculns. $m$, Micropyle or foramen. Fig. 704. Embryo, which occupies the entire seed after the spermoderm is removed. oc, Two cotyledons separated: they are fleshy and hypogeal-i.e. remain under ground doring germination. g, Gemmule or plumule. $r$, Radicle. 
The plants of the order are very generally distributed over the globe, but many genera are very limited in their range. De Candolle gives the following geographical distribution of the 3600 species known in his day :-

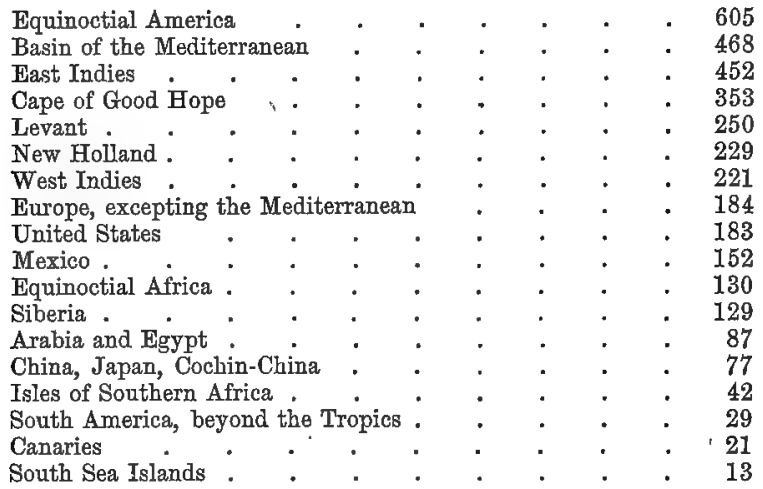

No native species occur in the island of Tristan d'Acunha, nor in the cold Antarctic islands.

The order has been divided into three sub-orders:-1. Papilionaceæ; papilionaceous flowers, petals imbricated in æstivation, and upper one exterior. This sub-order is subdivided into the tribes Podalyrieæ, Loteæ, Vicieæ, Hedysareæ, Phaseoleæ, Dalbergieæ, Sophoreæ; according to the nature of the filaments, whether free or variously united, the form and dehiscence of the legume, the cotyledons whether fleshy or leafy, and the simple or compound nature of the leaves. Examples-Podalyria, Lotus, Cytisus, Pisum, Hedysarum, Phaseolus, Dalbergia. 2. Cæsalpinieæ; flowers irregular, sub-papilionaceous, petals spreading, imbricated in æstivation, upper one interior, stamens often free. Examples-Hæmatoxylon, Cæsalpinia, Cassia, Swartzia, Amherstia, Bauhinia, Copaifera, and Ceratonia. 3. Mimoseæ; flowers regular, petals valvate in æestivation, stamens free or monadelphous. Examples-Parkia, Mimosa, Acacia.

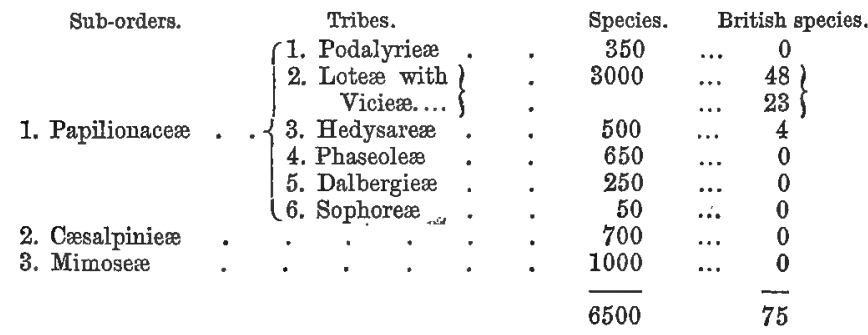


The preceding is the estimate of species in the different sub-orders and tribes, considered in reference to the flora of the globe and the flora of Britain (Bentham and Henslow). The number of known genera at the present day is about 400 , including about 6500 species.

This is a very extensive and a very important natural order. It embraces many valuable medicinal plants, such as those yielding Senna, Gum-arabic, Tragacanth, Catechu, and Kino; important dyes, as Indigo and Logwood ; many valuable timber-trees, as Locusttree and Rosewood; plants furnishing nutritious food, such as the Bean and Pea, Haricots, Kidney-beans, Lentils, Pigeon-peas, Chickpea. The properties of the order may be considered in general as wholesome, although it contains some poisonous plants. Lindley, however, says that the order must be considered upon the whole as poisonous, and that the plants used for food are exceptions to the general rule; the injurious juices of the order not being in such instances sufficiently concentrated to prove injurious, being replaced to a considerable extent by either sugar or starch.

Sub-order Papilionacece. The plants in this section have frequently beautiful showy flowers; for example, Robinia, Laburnum, Wistaria, Lupinus, Clianthus, Erythrina (Coral-flower), Hovea. They are often nutritious. The various kinds of Clover, Beans, Peas, and Pulse belong to it. The common red Clover is Trifolium pratense. White or Dutch Clover (T. repens) springs up frequently on ground recently cleared. The Shamrock is generally considered as a species of Trefoil. Various species of Medick and Lucerne (Medicago, fig. 567, p. 313), of Saintfoin (Onobrychis), and Melilot (Melilotus), are cultivated as food for cattle. Several species of Medicago are called Calvary Plants, on account of dark, blood-like spots on their leaflets. Medicago Echinus is one of the symbolic plants of the East. Many are used for their medicinal qualities. Glycyrrhiza glabra. (Liquiritia offcinalis) is the plant which yields liquorice-root. This plant is a native of the southern part of Europe, and it has been occasionally cultivated with success in Britain, especially at Pontefract in Yorkshire, and at Mitcham in Surrey. An extract is prepared from the root or underground stem by decoction in water, and subsequent inspissation. It owes its sweetness to a peculiar principle called Glycion, or Glycyrrhizin, which appears also to be present in the root and leaves of other papilionaceous plants, as Glycyrrhiza echinata and glandulifera, Trifolium alpinum, and Abrus precatorïus. Liquorice is used medicinally as a demulcent. A sweet secretion (a kind of Manna) is produced by Alhagi Maurorum (Camel's-thorn). Astragalus verus, creticus, aristatus, gummifer, and other species, yield an exudation known by the name of Gum Tragacanth. A. verus seems to be the chief source of the European tragacanth. It is a shrub found in Asia Minor and Persia, and the gum is procured by exudation or incision. Tragacanth forms, 
with cold water, a bulky jelly, while it is soluble in boiling water. It contains both Arabin and Bassorin in its composition, and is used as a demulcent. Myrospermum (Myroxylon) Pereirce yields the Balsam of Peru, while Myrospermum (Myroxylon) toluiferum is the source of the Balsam of Tolu. These balsams are procured chiefly by making incisions in the trees. They consist of resinous and oily matter, with cinnamic acid, and they are used as stimulant expectorants. Pterocarpus Marsupium, a tree of the Indian forests, furnishes the concrete exudation called Kino. Butea frondosa, the Dhak tree of the East Indies, yields a similar product; it has bright orange-red petals, and a black calyx. African Kino is procured from Pterocarpus erinaceus. Kino is used as a powerful astringent, and is administered in the form of powder and tincture. Broom-tops, procured from Cytisus (Sarothamnus) Scoparius, are used as a diuretic. The hairs from the legumes of Mucuna pruriens in the West Indies, and of M. Prurita in the East, under the name of Cowhage, or Cowitch, have irritating properties, and, mixed with syrup, they are used in the treatment of intestinal worms. The leaves of Colutea arborescens, Bladder-Senna (fig. 566, p. 313), are purgative, and are used abroad to adulterate the obovate or blunt-pointed Senna. The leaves of Tephrosia apollinea are also purgative, and are occasionally mixed with Alexandrian Senna. The bark of Andira inermis, the Cabbage-tree of the West-Indies, acts as a purgative and anthelmintic. The fruit of Geoffroya superba, Umari, is much used by the inhabitants of Brazil on the banks of the Rio San Francisco; the fruit is a drupe.

Besides the plants which have active medicinal qualities, there are others which are valuable in commerce and the arts, as furnishing food, dyes, fibres, timber. Various species of Indigofera, as I. tinctoria and carulea, furnish the Indigo of commerce. Pterocarpus santalinus yields red Sandal-wood, which is uised as a dye. It is probably the אלמוים Almug or Algum-trees, of Scripture. P. Draco yields GumDragon, and $P$. Dalbergioides is said to yield Andaman redwood, and to be valuable both as a dye and as timber. Baptisia tinctoria gives a blue dye, and is the wild Indigo of the United States. Dalbergia Sissoo is an Indian forest tree, which is valued on account of its wood. Crotalaria juncea supplies fibres, which are known as Sun or Bengal Hemp. The fragrant seeds of Dipterix odorata are known as Tonkabeans. A similar fragrance is given out by some species of Melilot, the flowers and seeds of which are employed to give the peculiar odour to Gruyere cheese. Arachis hypogoea produces its legumes under ground, and receives the name of underground Kidney-bean, or Ground-nut. Erythrina monosperma yields Gum lac. The roots of Glycine Apios, or Apios tuberosa, are used as an article of food in America. Robinia pseudo-acacia is often cultivated in Britain as the Locusttree. The tree attains in England a height varying from forty-five to 
eighty feet, and sometimes has a diameter of three feet. Its wood is durable. According to Bertoloni, a kind of Ebony is the produce of Fornasinia ebenifera, a papilionaceous plant, found in Oaffraria, near Mozambique. Rosewood is said to be the timber of two or three species of Triptolomea. It is rare to find papilionaceous plants producing double flowers. The Whin is one of the plants which exhibits this monstrosity. Desmodium or Hedysarum gyrans (the Gorachand of Bengal) exhibits a remarkable irritability in its leaves (p. 378). There are certain poisonous plants in this sub-order. The seeds and bark of Cytisus Laburnum are narcotic; such is said also to be the case with those of Lathyrus Cicera and L. Aphaca. The roots of many species of Phaseolus, as $P$. multiflorus, the Scarlet-runner, and $P$. radiatus, are poisonous. The branches and leaves of Tephrosia toxicaria, and the bark of the root of Piscidia erythrina, Jamaica Dogwood, are employed as fish poisons. Physostigma venenosum yields the Calabar ordeal-bean (see figure Trans, $R$. Soc. $E d$., vol. zxii.) It causes contraction of the pupil. The plant has a remarkable hooded stigma (fig. 445 ; p. 250). Gompholobium uncinatum has poisoned sheep in the Swan River colony. Coronilla varia acts as a narcotic poison. The leaves of it and of Coronilla Emerus are sometimes used to adulterate Senna.

Sub-order Ccesalpiniece. In this section there are many plants which furnish purgative remedies. Among these may be noticed various species of Cassia. C. lanceolata, acutifolia, elongata, obtusata, and obovata, supply the various kinds of Senna known as Alexandrian or Egyptian, Tripoli, and East Indian Senna. Other species also, as Cassia marilandica, Absus, corymbosa, biflora, tomentosa, alata, and Porturegalis, have purgative leaves. Cassia Fistula, called also Cathartocarpus Fistula, has an indehiscent pod, divided by numerous transverse phragmata (fig. 429, p. 244), and containing a laxative pulp, which is a secretion from the endocarp. A pulp having similar properties is procured from the pericarp of Tamarindus indica, the Tamarind-tree. The pod of Ceratonia Siliqua is known as the Algaroba-bean, and is used occasionally for feeding horses. The tree is denominated Carobtree, and sometimes Locust-tree, or St. John's Bread, from an erroneous idea that the pods supplied food to John the Baptist in the wilderness. The pods of Hymenoed Courbaril, the West Indian Locust-tree, supply a nutritious matter; its inner bark is anthelmintic, and the plant yields a kind of resin called Anime. The bark of Guitandina Bonducella, the Nicker-tree, is bitter, tonic, and its seeds are said to be emetic. The curved pods of Casalpinia coriaria, under the name of Divi-divi, are used for tanning. Coesalpinia brasiliensis yields the Brazil-wood of commerce ; and the Mora-wood of Guiana is yielded by a large tree called Mora excelsa. Many dyes are furnished by the plants of this sub-order. Homatoxylon campechianum gives Logwood 
or Campeachy-wood, which is employed both as a dye and as an astringent. The inner wood is the part employed both in the arts and officinally. The alburnum is of a yellowish colour, and is not imported. The red colouring principle is Hæmatoxylin. Coesalpinia echinata furnishes Pernambuco-wood; C. Sappan, Sappan-wood, the Wukkum or Bukkum-wood of Scinde; Baphia nitida, Camwood. Various species of Copaifera, as C. Jacquinii, Langsdorffi, bijuga, multijuga, Martii, guianensis, coriacea, etc., furnish the balsam of Copaiva, of which two kinds are distinguished-the West Indian and Brazilian. The balsam contains a resin and volatile oil. It is used in medicine as a stimulant, cathartic, and diuretic, and is especially employed in the treatment of mucous inflammations. Cassia Chamocrista, marilandica, and nictitans, all exhibit, according to Bromfield, a high degree of irritability; the leaflets close together when gathered, and when rudely handled, or brushed by the feet in walking through the herbage. Trachylobium mossambicense yields Zanzibar copal.

Sub-order Mimosece. The plants of this section yield Gum in quantity, and their bark is frequently astringent. Acacia Ehrenbergii, tortilis, Seyal, arabica, vera, gummifera, Adansonii, Verek, albida, and various other species, yield the gummy substances known as Gum Arabic, Gum Senegal, Barbary Gum, and East Indian Gum. A kind of gum is procured at the Cape of Good Hope from Acacia Karroo; and in Australia, A. decurrens yields another variety. A variety of Indian gum procured from $A$. arabica is called Babul, or BaboolGum; Babul-bark is used for tanning in Scinde. These gums are all more or less nutritive and demulcent, and are administered in the form of mucilage, emulsion, or lozenges. The Wattles of Australia are species of Acacia, which furnish astringent barks. An extract made from them has been imported for the purpose of tanning. The duramen of Acacia Catechu, an Indian shrub, furnishes a kind of Catechu, or Cutch, which contains much tannin, and is used for tanning, and as a powerful astringent. Some of the New Holland Acacias are remarkable for the peculiar development of the petiole, which assumes the form of a phyllodium (fig. 204, p. 96). The large seeds of Entada scandens are sometimes carried by the winds and tides from the West Indies to the shores of the outer Hebrides. Acacia Seyal is supposed to be the Shittah Tree, הטש, of Scripture, which furnished Shittim wood. A. formosa supplies the Cuba timber called Sabicu. Some of the plants in this sub-order display peculiar irritability in their pinnate leaves. This is particularly the case with Mimosa sensitiva and pudica, which are commonly called sensitive plants (p. 376). Almost all of the pinnate-leaved Leguminous plants close their leaves in a marked way during darkness.

Order 65.-Moringacese, the Moringa Family. (Polypet. Perigyn.) Calyx 5-partite; æstivation slightily imbricated. Petals 5, 
rather unequal, upper one ascending. Stamens 8 or 10, perigynous ; filaments slightly petaloid, callous, and hairy at the base; anthers simple, 1-celled, with a thick convex connective. Disk lining the tube of the calyx. Ovary superior, stipitate, 1-celled; ovules anatropal, attached to parietal placentas; style filiform; stigma simple. Fruit a pod-like capsule, 1-celled, 3-valved, opening by loculicidal dehiscence. Seeds numerous, half buried in the spongy substance of the valves, sometimes winged, exalbuminous; embryo with a superior, straight, small radicle, and fleshy cotyledons.-Trees, with bi- or tri-pinnate, stipulate leaves, natives of the East Indies and Arabia. Some of them are pungent and aromatic. The seeds of Moringa pterygosperma, Horse-radish tree, are winged, and are called Ben-nuts. From them is procured a fluid oil, used by watchmakers, and called Ben Oil. The root is pungent and stimulant, and resembles Horseradish in its taste. It is used as a stimulant in paralytic affections and intermittent fever. It is also a rubefacient. Some place this order near Violaceæ, others near Capparidaceæ. Genus, 1 ; species, 3. Example-Moringa.

Order 66.-Rosace $\approx$, the Rose Family. (Polypet. Perigyn.) (Figs. 247 , p. 172 ; 256,257 , p. 177 ; 300, p. 198 ; 313, p. 204 ; 419 , p. 240 ; 705). Calyx 4-5-lobed (fig. $706 \mathrm{cc}$ ), the fifth lobe superior. Petals as many as the divisions of the calyx, often 5 (fig. $706 \mathrm{pe}$ ), sometimes wanting, perigynous, generally regular ; æstivation quincuncial (fig. 705). Stamens inserted with the petals (fig. $706 e$ ), definite or indefinite ; filaments incurved in æstivation : anthers bilocular (fig. 707), dehiscing longitudinally (fig. 354, p. 221). Ovaries superior, either solitary or several, unilocular (fig. 708), sometimes uniting so as to form a many-celled pistil ; ovules, 1, 2, or more, anatropal, suspended (figs. $407 \mathrm{~g}$, p. 236 ; $708 \mathrm{~g}$ ), rarely erect; styles lateral (figs. 434 , p. $246 ; 708,710$ ); stigmas usually simple. Fruit either achænia (fig. 294, p. 196), or drupes (figs. 407, p. 236 ; 709), or follicles or pomes (fig. 568, p. 314). Seeds erect or inverted, usually exalbuminous; embryo straight, with the radicle next the hilum (figs. 710, 712), and leafy or fleshy cotyledons (figs. 597, p. 334 ; 711). -Herbaceous plants, or shrubs, or trees, with simple or compound, alternate, stipulate leaves (fig. 207, p. 98), and the flowers sometimes unisexual. They are found chiefly in the cold and temperate climates of the northern hemisphere. Some are found on high mountains within the tropics, and a few occur in warm regions. The superior odd lobe of the calyx distinguishes this order from Leguminosæ.

The order has been divided into the following sub-orders:-1. Chrysobalaneæ, petals and stamens more or less irregular ; ovary stipitate, its stalk adhering on one side to the calyx, style basilar (fig. 435, p. 246), fruit a 1-2-celled drupe. 2. Amygdaleæ or Pruneæ (Drupaceæ of Lindley), tube of calyx lined with a disk, styles terminal, fruit 
a drupe (figs. 339 , p. $213 ; 405$, p. $235 ; 406-7$, p. 236). 3. Spiræeæ (fig. 102, p. 41), calyx-tube herbaceous, lined with a disk, fruit consisting of numerous follicles, seeds apterous. 4. Quillaiere, flowers unisexual, calyx-tube herbaceous, fruit capsular, seeds winged at the apex. 5. Sanguisorbex, or Poterieæ, petals 0 , tube of calyx thickened and indurated, lined with a disk, stamens definite; nut solitary, enclosed in the calycine tube. 6. Potentilleæ (including Rubeæ) (fig. 300, p. 198), calyx-tube herbaceous, lined with a disk which some-

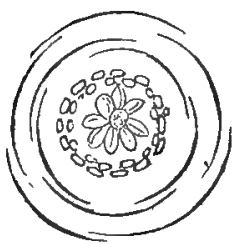

Fig. 705.

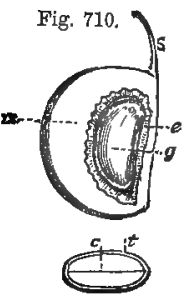

Fig. 711.
Fig. 706,
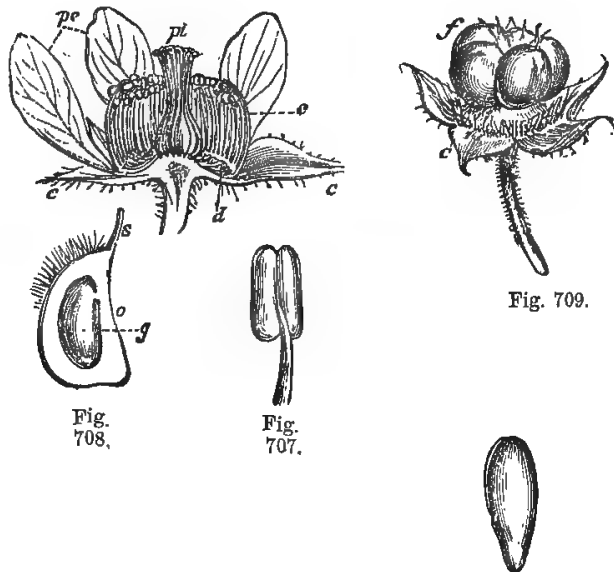

Fig. 709.

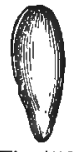

Fig. 712.

times becomes fleshy, fruit consisting of numerous achænia. 7. Roseæ, calyx-tube contracted at the mouth, becoming fleshy, lined with a disk, and covering numerous hairy achænia (figs. 294, p. $196 ; 313$, p. 204). 8. Neuradeæ, calyx-lobes, with or without bracts, petals 5 , carpels 5 or 10, uniovulate, fruit 5-10 valved. 9. Pomeæ (Pomaceæ of Lindley), tube of calyx more or less globose, lined with a fleshy and juicy

Figs. 705-712. Organs of fructification of Rubus strigosus, illustrating the natural order Rosacew. Fig. 705. Diagram of the flower, with five divisions of the calyx, 5 quincuncial petals, indefunite perigynous stamens, and numerous succulent carpels. Fig. 706. The flower cut vertically. $c c$, Calyx. pe, Petals. $e$, Stamens. $d$, Disk, lining the base of the calyx, upon which the stamens are inserted. pi, Pistil, composed of several carpels. Fig. 707. Bilocular anther separated, with the upper part of the filament seen on the outside. Fig. 708. Ovary, 0 , cut vertically. $g$, Exalbuminous, suspended seed. $s$, Lateral style. Fig. 709. Fruit. f, Fleshy oarpels accompanied with the persistent calyx, $a$, connected with which the withered filaments are seen. Fig. 710. Vertical section of a carpel, $s$, Lateral style. $m$, Fleshy mesocarp or sarcocarp. e, Endocarp. $g$, Seed. Fig. 711. Horizontal section of the exalbuminous seed. $t$, Integument (spermoderm). $c$, Cotyledons of the embryo. Fig. 712. Embryo isolated. It fills the entire seed. 
disk, fruit a 1-5-celled (fig. 568, p. 314) or spuriously 10-celled pomum. There are 71 known genera, and about 1000 species. ExamplesChrysobalanus, Amygdalus, Prunus, Spiræa, Quillaia, Sanguisorba, Poterium, Potentilla, Rubus, Fragaria, Rosa, Neurada, Pyrus.

Many of the plants of the order yield edible fruits, such as Raspberries, Strawberries, Brambles, Plums, Apples, Pears, Quinces, Cherries, Almonds, Peaches, Nectarines, and Apricots. Some are astringent, others yield hydrocyanic acid. Those belonging to the sub-order Chrysobalanece are principally natives of the tropical parts of Africa and America. Many of them furnish edible fruits. The drupes of Chrysobalanus Icaco are eaten in the West Indies under the name of cocoa-plums. The root and bark are used as astringents.

The plants in the tribe Amygdalece are chiefly remarkable on account of the presence of hydrocyanic acid in their kernels, leaves, or flowers. Amygdalus communis, the Almond-tree, grows naturally in Barbary and in Asia, from Syria to Affghanistan. It is extensively cultivated in the south of Europe. It is the Shaked, of the Old Testament. There are two varieties of the tree,- - $\alpha$, duccis, yielding the sweet Almond, and $\beta$. amara, yielding the bitter Almond. In the former the style is much longer than the stamens, and there are glands on the base of the leaf; while in the latter the style is equal in length to the stamens, and the glands are situated on the petioles. The chief kinds of sweet Almonds are the Valentia, the Italian, and the Jordan Almonds; the latter come from Malaga. Under the name of shell Almonds, they are often sold with the brittle endocarps on them. They consist chemically of a bland fixed oil, and a kind of vegetable albumen called Emulsin or Synaptase. Bitter Almonds are imported from Mogadore. Besides a fixed oil and synaptase, they contain a bitter azotised principle called Amygdalin, which, when brought into contact with a solution of Emulsin, produces a volatile oil containing hydrocyanic acid. This gives rise to the peculiar aroma of bitter Almonds when mixed with water. Sweet Almonds are used medicinally, in the form of Emulsion, as demulcents. The hydrocyanated essential oil of bitter Almonds is sedative, and has been used as a substitute for Prussic acid. They sometimes produce derangement of the digestive functions, and give rise to nettle-rash. The leaves of Amygdalus persica (Persica vulgaris of some), the Peach, contain a similar oil, and have been employed as sedative and vermifuge. The flowers of the Peach exhale the odour of bitter Almonds. Peaches are divided into Freestone and Clingstone, according as the pulp (sarcocarp) separates easily from the endocarp or adheres to it. The fruit of Prunus domestica, the Plum-tree and its varieties, when dried, constitute Prunes, which are used medicinally, on account of their nutritive and laxative qualities. Some think that the Bullace, Damson, Orleans Plum, and the Quetches, are all derived from the common 
Sloe. They differ much, however, in the form of the stone. The leaves of Prunus or Cerasus Laurocerasus, Cherry Laurel, or 'Common Bay Laurel, have been used medicinally, as anodyne and hypnotic remedies. The water distilled from them has poisonous properties, owing to the presence of a hydrocyanated oil, which seems to be developed in a similar manner as in the case of bitter Almonds. The oil exists in large quantity in the young leaves. Prunus Lusitanica is the Portugal Laurel, which is extensively cultivated in Britain as an evergreen. The leaves of Prunus spinosa, the Sloe, have been used as a substitute for as well as an adulteration of Tea. The fruit of a variety of Cerasus avium, the Cherry, is used in the manufacture of Kirschenwasser. The kernel of Cerasus occidentalis is used for flavouring Noyau. The flavour of Ratafia, Cherry-brandy, and Maraschino, is due to the kernels of Cerasus.

The tribe Pomeos (fig. 257, p. 177) supplies many edible fruits, as Apples, Pears, Medlars (fig. 568, p. 314), and Quinces. The seeds, and occasionally the flowers and bark of some, yield hydrocyanic acid. All the cultivated varieties of Apple are derived by grafting from the native species, Pyrus Malus; while Pears have their origin in Pyrus communis. The seeds or pips of Cydonia vulgaris (Pyrus Cydonia), the Quince, when boiled in water, yield a mucilaginous decoction, which has been used as a demulcent. Malic acid is found in some of the fruits of this sub-order. Eriobotrya japonica yields the Loquat, a Japan fruit.

The other tribes contain plants which are distinguished by astringent and tonic qualities. Geum urbanum and rivale (Avens) have been employed as tonics and astringents, as also the root of Potentilla Tormentilla (Tormentil). Brayera anthelmintica (Hagenia abyssinica), Cusso or Kousso, an Abyssinian tree growing to a height of 60 feet, has been used as a vermifuge in cases of Tænia. The varieties of Scotch Roses are derived from Rosa spinosissima. The fruit (hips) of Rosa canina, the Dog-rose, which consists of the enlarged calyx and disk enclosing numerous achænia (fig. 294, p. 196), is beat into a pulp with sugar, after the hairy achenes have been removed, and used as an acidulous refrigerant and astringent. The petals of Rosa gallica, Red, French, and Provins Rose, are employed in the form of infusion, as a tonic and slightly astringent remedy. The petals of Rosa centifolia, the Hundred-leaved or Cabbage-rose (fig. 93,-p. 35), and its varieties, $R$. damascena, Damask-rose, $R$. moschata, Musk-rose, etc., are employed in the preparation of Rose-water, and of the oil or attar of Roses. It is stated by Sir R. Christison that 100,000 roses, the produce of 10,000 bushes of Rosa damascena, yield at Ghazeepore, near Benares, only 180 grains of attar. The finest Rose perfume is said to be prepared at Grasse, in France. Oil of Roses is adulterated with sandal-wood oil. The bark of many species of Quillaia, as Q. saponaria, is used as a substitute for soap. 
Order 67.-Calycanthaces, the Calycanthus Family. (Polypet. Perigyn.) Sepals and petals confounded, indefinite, combined in a fleshy receptacle; æstivation imbricated. Stamens $\infty$, perigynous; anthers adnate, extrorse, with longitudinal dehiscence. Ovaries several, 1-celled, adhering to the tube of the calyx; ovules solitary or two, one above the other, anatropal ; style terminal. Fruit consisting of achænia enclosed in the fleshy receptacle. Seed exalbuminous; embryo straight; cotyledons convolute ; radicle inferior. - Shrubs, with square stems, consisting of a central woody mass, with four smaller ones around (p. 61); leaves opposite, simple, scabrouts, exstipulate. By many authors this order is placed between Dilleniaceæ and Magnoliaceæ. The plants are natives of North America and Japan. Their flowers are aromatic; the bark of some is used as a carminative. Calycanthus floridus is called Carolina or common American Allspice. The order includes 2 genera and 3 species. Examples-Calycanthus, Chimonanthus.

Order 68.-Lythraces, the Loosestrife Family. (Polypet. Perigyn.) Calyx tubular, lobed, the lobes sometimes with intermediate lobes or teeth; æstivation valvate. Petals alternate with the primary lobes of the calyx, very deciduous, sometimes 0 . Stamens inserted into the tube of the calyx a little below the petals, equal in number to them, or two, three, or four times as many; anthers adnate, dithecal, introrse, with longitudinal dehiscence. Ovary superior, 2-6-celled; ovules numerous, anatropal ; style filiform; stigma usually capitate. Fruit a dehiscent membranous capsule, surrounded by the calyx, but not adherent to it, sometimes 1-celled by the obliteration of the dissepiments. Seeds numerous, small, apterous, or winged, exalbuminous, attached to a central placenta; embryo straight; cotyledons flat and foliaceous ; radicle next the hilum.-Herbs and shrubs, with branches which are usually tetragonal, and with opposite, rarely alternate, entire, exstipulate leaves without glands. They are natives of Europe, North and South America, and India. Authors give 30 genera, including about 250 species. Examples-Lythrum, Cuphea, Lagerströmia.

Many of the plants of the order are distinguished by astringent properties, and some are used for dyeing. Lythrum Salicaria, Purple Loosestrife, or Willowstrife, a European plant, found also in Australia, has been used in cases of diarrhoea, on account of the tannin in its composition. Its flowers are trimorphic (p. 285). The flowers of Grislea tomentosa are employed in India, mixed with Morinda, for dyeing, under the name of Dhaee. Heimia salicifolia is said to possess diaphoretic properties, and is considered by the Mexicans as a potent remedy for venereal diseases. The Henna, or Alhenna of the Arabs, which is used in Egypt for dyeing orange, is the product of Lawsonia inermis. The Cupheas are remarkable for the mode in which the pla- 
centa bursts through the ovary and floral envelopes, so as to expose the seeds.

Order 69.-RhizophoRacess, the Mangrove Family. (Polypet. Epigyn.) Calyx adherent, 4-12-lobed; æstivation valvate, or sometimes calyptriforn. Petals arising from the calyx, alternate with the lobes, and equal to them in number. Stamens inserted with the petals, twice or thrice their number; filaments distinct, subulate; anthers erect. Ovary 2-3-4-celled; ovules 2 or more in each cell, anatropal. Fruit indehiscent, crowned by calyx, unilocular, monospermous. Seed solitary, pendulous, exalbuminous; cotyledons flat; radicle long, piercing the fruit.-Trees or shrubs, with simple opposite leaves, and deciduous interpetiolary stipules. They are found on the muddy shores of the tropics. There are 17 genera and about 50 species known. Examples-Rhizophora, Kandelia, Cassipourea.

The plants of the order have frequently an astringent bark, which is in some cases used for dyeing black. Rhizophora Mangle, the Mangrove, forms thickets at the muddy mouths of rivers in tropical countries, and sends out adventitious roots, which often raise the main trunk much above its original level, and give the tree the appearance of being supported upon stalks (fig. 99, p. 39). The fruit is sweet and eatable. The embryo germinates before the fruit falls, and the radicle is much elongated before the seed drops into the mud. The anther consists of numerous cells containing pollen.

Order 70.-VochYsiace,e, the Vochysia Family. (Polypet. Perigyn.) -Sepals 4-5, united at the base, unequal, the upper one largest and spurred; æstivation imbricated. Petals 1, 2, 3, or 5, alternate with the divisions of the calyx, and inserted into its base, unequal. Stamens 1-5, opposite to or alternate with the petals, perigynous, one having an ovate, fertile, 4-celled anther, the rest being sterile. Ovary free, or partially so, 3-celled; ovules solitary or in pairs, rarely numerous, amphitropal or anatropal ; style and stigma one. Fruit a triquetrous, 3-celled and 3-valved capsule, usually with loculicidal dehiscence. Seeds usually 1-2 in each cell, erect, exalbuminous, attached to a central placenta ; embryo straight; cotyledons large and leafy; radicle short and superior.-Trees or shrubs, with opposite, entire, stipulate leaves. They inhabit the warmer parts of America. Their properties are little known. Their flowers are reputed to be very sweet, and some are said to have a resinous juice. The order is by some placed near Polygalaceæ. There are 7 genera enumerated, including 100 species. Examples-Vochysia, Qualea.

Order 71.-Combretaces, the Myrobalan Family. (Polypet. Epigyn.) Calyx 4-5-lobed, lobes deciduous. Petals arising from the orifice of the calyz, alternate with the lobes, or wanting. Stamens epigynous, twice as many as the lobes of the calyx, rarely equal in number, or thrice as many; filaments distinct, subulate; anthers 
dithecal, dehiscing longitudinally or by recurved valves. Ovary adherent to the tube of the calyx, unilocular ; ovules 2-4, pendulous; style 1 ; stigma simple. Fruit succulent or nut-like, inferior, unilocular, indehiscent, often winged. Seed solitary, pendulous, exalbuminous ; cotyledons leafy, usually convolute, sometimes plicate; radicle turned towards the hilum.- Trees or shrubs, with alternate or opposite, exstipulate, entire leaves. They are natives of the tropical regions of Asia, Africa, and America. The general property of the order is astringency. Many are used for tanning, and some for dyeing. The fruit of Terminalia Belerica, and of T. Chebula, under the name of Myrobalans, is used as an astringent. The seeds of Terminalia Catappa are eaten like almonds. The order has been divided into three tribes :1. Terminalieæ, petals 0 , cotyledons convolute. 2. Combreteæ, petals present, cotyledons plicate. 3. Gyrocarpe», petals 0 , cotyledons convolute, anthers, dehiscing by recurved valves. There are 15 genera, including 240 species. Exarnples-Terminalia, Combretum, Quisqualis, Gyrocarpus.

Order 72.-Melastomacex, the Melastoma Family. (Polypet. Perigyn. or Epigyn.) Calyx with 4, 5, or 6 divisions, which are more or less deep, or are sometimes united and separate from the tube like a lid. Petals equal to the segments of the calyx, perigynous, æstivation twisted. Stamens equal in number to the petals and alternate with them, usually with intermediate sterile ones; filaments curved downwards in the young state ; anthers long, often beaked, bilocular, dehiscing by two terminal pores or longitudinally. Ovary more or less adherent to the calyx, mutilocular; ovules usually 00 ; style 1 ; stigma simple, either capitate or minute. Fruit multilocular, either capsular, with loculicidal dehiscence, or succulent and indehiscent, with calyx attached. Seeds $\infty$, minute, attached to central placentas, exalbuminous; embryo straight or curved; cotyledons sometimes unequal, flat, or convolute.-Trees, shrubs, or herbs, with opposite, undivided, usually entire, often 3-9-ribbed leaves, not dotted. They are found chiefly in warm climates. Many are natives of America and India. There are no unwholesome plants in the order, and the succulent fruit of several is edible. A slight degree of astringency pervades all the plants of the order, and hence some are used medicinally in cases of diarrhoa. The name Melastoma ( $\mu$ 's $\lambda \alpha 5$, black, and бró $\mu \alpha$, mouth) is derived from the circumstance that the fruit of some dyes the lips black. There are two sub-orders:-1. Melastomem, with ribbed leaves and flat cotyledons. 2. Memecylex, with ribless leaves and convolute cotyledons. Authors notice 134 genera, comprising 1800 species. Eixamples-Melastoma, Osbeckia, Lasiandra, Rhexia, Lavoisiera, Miconia, Charianthus, Memecylon, Mouriria.

Order 73.-PhiladelPhaces, the Syringa Family. (Polypet. Epigyn.) Calyx with a 4-10-divided, persistent limb. Petals alter- 
nate with the divisions of the calyx, and equal to them in number ; æstivation convolute, imbricate. Stamens $\infty$ (rarely 10), in one or two rows, arising from the orifice of the calyx. Ovary adherent to the tube of the calyx; styles distinct, or united into one; stigmas $4-10$; ovules $\infty$, attached to a central placenta. Fruit a 4-10-celled capsule, free above. Seeds $\infty$, scobiform, subulate, smooth, pendulous, with a loose membranous arillus; albumen fleshy; embryo straight, about as long as the albumen; cotyledons flat; radicle next the hilum, obtuse.-Shrubs with deciduous, opposite, exstipulate leaves without dots ; flowers usually in trichotomous cymes. They are natives of the South of Europe, of North America, Japan, and India. They have no marked properties. The flowers of Philadelphus coronarius, Syringa or mock-orange, have a peculiar odour, which to some persons is overpowering and disagreeable. The smell is due to the presence of an oil. Deutaia scabra has a scurfy matter on its leaves, 'which, under the microscope, is seen to consist of beautiful stellate hairs. The leaves are in conséquence used in Japan by polishers. Its inner bark is.used for poultices. The order is included by some in the tribe Hydrangieæ, of the natural order Saxifragaceæ. There are 5 genera enumerated, including 22 species. Examples-Philadelphus, Deutzia, Decumaria.

Order 74.-MYrTaces, the Myrtle Family. (Polypet. Epigyn.) Calyx 4-5-6-8-cleft, the limb sometimes cohering at the apex, and falling off like a lid; æstivation valvate. Petals attached to the calyx, alternating with its segments, and equal to them in number, with a quincuncial restivation, rarely 0 . Stamens inserted with the petals, twice as many as the petals, or $\infty$; filaments distinct, or united in one or more pareels, curved inwards in the bud; anthers ovate, dithecal, with longitudinal dehiscence. Ovary inferior, 1-6-celled; style and stigma simple; ovules anatropal, pendulous or erect. Fruit dry or fleshy, dehiscent or indehiscent. Seeds usually $\infty$, attached to a central placenta; mostly exalbuminous; embryo straight or curved ; cotyledons distinct (fig. 610 , p. 339 ), or consolidated with the radicle, which is next the hilum.-Trees or shrubs, with opposite, rarely alternate leaves, which are usually entire and dotted, and frequently have an intramarginal vein. They are natives chiefly of warm countries, as South America and the East Indies. Many, however, are found in more temperate regions. Some of the genera are peculiar to Australia. The order has been divided into the following tribes :-1. Chamælaucieæ, heath-like plants, with a 1-celled ovary, indehiscent capsule, and opposite dotted leaves. 2. Leptospermer, having a multilocular capsule with loculicidal dehiscence, and opposite or alternate, usually dotted leaves. 3. Myrteæ, having a baccate fruit, distinct stamens, opposite dotted leaves. 4. Barringtonieæ, having a fleshy 1-celled fruit, monadelphous stamens, albuminous seeds, opposite or 
verticillate leaves, not dotted. 5. Lecythideæ, having a multilocular woody capsule, which either remains closed or opens by a lid, monadelphous stamens, alternate, not dotted leaves; the stamens form a cup, which often grows out on one side, with a curious hooded appendage. Several of these tribes are made separate orders by Lindley, Miers, and others. There are 75 known genera, and upwards of 1800 species. Examples-Chamælaucium, Calytrix, Leptospermum, Melaleuca, Metrosideros, Eucalyptus, Myrtus, Psidium, Eugenia, Caryophyllus, Barringtonia, Gustavia, Lecythis, Bertholletia, Napoleona (Belvisia), Asteranthus.

Many of the plants of the order yield an aromatic volatile oil. This is particularly the case with those having pellucid dots in their leaves. Some yield edible fruits, others furnish astringent and saccharine substances. The leaves of species of Leptospermum and Melaleuca are used as tea in Anstralia. The leaves of Melaleuca Leucadendron, a tree of the Indian Archipelago, Malayan Peninsula, and Australia, yield the volatile oil of Cajuput. It is a very liquid oil, of a grass-green colour, having a pungent camphoraceous odour, and capable of dissolving caoutchouc. It is used medicinally as a stimulant and antispasmodic. Species of Eucalyptus constitute the gigantic gum-trees of Australia, some of which attain a height of 2-300 feet. Baron Mueller mentions specimens of Eucalyptus amygdalinus 400 feet high. They are remarkable for their operculate calyx, which may be considered as formed by several jointed leaves (like those of the orange), united throughout, and separating at the articulation in the form of a lid (p. 199). Their bark also separates remarkably in layers. They yield an astringent matter, which has been used for tanning. Eucalyptrus resinifera, Brown Gum-tree of New Holland, furnishes Botany-Bay Kino, an astringent, resinous-like substance, which exudes in the form of red juice from incisions in the bark. A single tree will yield sixty gallons. $E$. mannifera gives a saccharine exudation resembling manna. A saccharine substance, mixed with cellular hairs, which arise from a cup-like body, is found upon the leaves of $E$. dumosa. It is called Lurp by the natives, and is produced by the attack of a species of insect belonging to the genus Psylla. Eucalyptus globulus, Blue Gum-tree or Fever Gum-tree, is said to take up moisture , largely from marshy lands. It furnishes good timber, and has an astringent bark. It yields a fragrant oil, which is used as an embrocation. The wood of many species of Metrosideros is hard and dark-coloured. The flower-buds of Caryophyllus aromaticus (Eugenia caryophyllata), a tree which was originally a native of the Moluccas, but is now cultivated in the East and West Indies, constitute the Cloves of commerce. They have the form of a nail (French clou), and, when examined, are seen to consist of the tubular calyx with a roundish projection formed by the unopened petals. They 
contain a volatile oil, associated with resinous, gummy, and astringent matter. The oil is aromatic and acrid, and has been used as a condiment and a stimulant carminative. Some suppose that the name is derived from

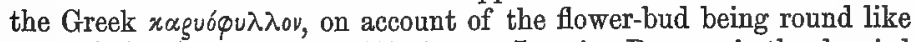
a nut (xáguov). Pimento, Allspice, or Jamaica Pepper, is the berried fruit of Pimenta officinalis (Eugenia Pimenta, Myrtus Pimenta), a tree which is a native of the West Indies and Mexico. The fruit has an aromatic odour, and its taste combines that of cinnamon, nutmeg, and cloves; hence the name Allspice. It contains an acrid volatile oil, to which its properties are due. Medicinally Pimento is sometimes employed as a stimulant and carminative. The fruit of Eugenia acris is used for Pimento. Among the pulpy edible fruits of the order may be noticed Guavas and Rose-apples. The former are the produce of various species of $P$ sidium, such as $P$. pyriferum, pomiferum, and Cattleyanum; the latter are procured from species of Eugenia as $E$. Jambos and malaccensis. The fruit of Eugenia cauliflora is eaten in Brazil, and that of $E$. Ugni in Chili. The berries of the common Myrtle (Myrtus communis) are also used as food. Punica Granatum, the Pomegranate-tree, is a native of the warmer parts of Asia and Northern Africa, whence it was introduced into Europe. It is the (Rimmôn) of Scripture. It produces dark scarlet flowers, formerly called Balaustia, which have been used as an astringent. The fruit of the Pomegranate has given rise to much difference of opinion among botanists. It is composed, in the young state, of two rows of carpels, some of which are placed round the axis, and adhering to the bottom of the calycine tube, while others are placed outside, and adhere to the upper part of the tube. The subsequent contraction of the tube of the calyx, and the peculiar adhesion of the placentas, according to Lindley, account for the anomaly in the fruit (Balausta, p. 314). The rind of the fruit (malicorium) and the bark of the root are used as anthelmintics, especially in cases of tapeworm. Lecythis ollaria, a large Brazilian tree, yields the woody capsules called Monkey-pots, which open by circumscissile dehiscence. These seed-vessels seem to be formed in the same way as the calyx of Eucalyptus, the part where the lid separates indicating the articulations of the carpellary leaves. The seeds are eatable, and are relished by monkeys. The bark of the tree may be separated into numerous thin layers. Bertholletia excelsa, or, according to Miers, Bertholletia nobilis, is the source of the Brazil nuts. The amount exported from Para, and from Manáos on the Rio Negro, in six months in 1865, was about $2,500,000$ of the fruits, or 50,000,000 of the seeds, occupying the bulk of 60,000 bushels. The seeds retain vitality long. Sapucaia nuts are the produce of Lecythis usitata of Miers.

Order 75. - Onagrace 4 (Onagrarieæ), the Evening-Primrose Family. (Rolypet. Epigyn.) Calyx tubular, the limb having usually 
4 (fig. 433 l, p. 245 ), sometimes 2, 3 , or 6 divisions (fig. 630 , p. 364 ), which cohere in various ways; æstivation valvate. Petals usually equal in number to the calycine segments, regular (rarely irregular), inserted into the tube of the calyx (fig. $433 p$, p. 245); æstivation twisted. Stamens usually 4 or 8 (rarely 1 or 2 , fig. 630 , p. 364), epigynous (fig. 433 e, p. 245); filaments distinct; pollen triangular, usually cohering by threads (fig. 396, p. 252). Ovary 2-4-celled (fig. 630 , p. 364), adherent (fig. 433 o, p. 245), usually with an epigynous disk ; style filiform ; stigma capitate (fig. $433 s$, p. 245 ) or 4-lobed ; ovules (figs. 418 o, p. $239 ; 433$ g, p. 245 ) indefinite, rarely definite, anatropal. Fruit succulent or capsular, dehiscent or indehiscent, 1-2-4-celled. Seeds usually $\infty$, exalbuminous; embryo straight, with a long slender radicle pointing to the hilum, and short cotyledons (figs. 530, p. 296 ; 584, 585, 586, p. 331).-Herbs or shrubs, with alternate or opposite, simple, not dotted leaves, and with the parts of the flower usually tetramerous. They inhabit chiefly temperate regions, and are found abundantly in Europe, Asia, and America, and sparingly in Africa. Some yield edible fruits, as Fuchsia, others furnish edible roots, as Einothera biennis. Many of them have mucilaginous properties, while a few are astringent. Trapa has unequal cotyledons. T. natans, Water Chestnut, and T. bicornis, remarkable for its horned fruit, both supply edible seeds. There are about 22 known genera, and upwards of 300 species. ExamplesEnothera, Epilobium, Jussiæa, Montinia, Fuchsia, Circæa, Gaura, Trapa.

Order 76.-Hatorageaces, the Mare's-Tail Family. (Polypet. Epigyn.) Calyx with a minute limb, which is either 3-4-divided, or entire ; it is sometimes reduced to a mere rim. Petals epigynous or 0 . Stamens epigynous, equal in number to the petals, or twice as many, rarely fewer; when the petals are wanting, stamens often 1 or 2. Ovary cohering with the tube of the calyx, with 1 or more cells, sometimes tetragonal or compressed. Style 0 , what is frequently called the styles being the papillose stigmas, which are equal in number to the cells; ovules pendulous, anatropal. Fruit dry, indehiscent, membranous or bony, with 1 or more cells. Seed solitary or in pairs, pendulous ; albumen fleshy or thin ; embryo straight, or slightly curved, in the axis of the albumen ; cotyledons minute ; radicle superior, long. - Herbs or undershrubs, often aquatic, with large air cavities, having alternate, opposite, or whorled leaves, and axillary, sessile flowers, which are occasionally unisexual. They are found in ditches and lakes in various parts of the world. They have no properties of importance. There are 9 known genera and about 80 species. Examples-Hippuris, Myriophyllum, Haloragis, Callitriche, Gunnera.

Order 77.-LoASACEA, the Chili-Nettle Family. (Polypet. Eprigyn.) Calyx 4-5-parted, persistent, spreading in æstivation. Petals 5, 
cucullate, epigynous, alternate with the segments of the calyx, sometimes with an inner row of 5, which are either similar to the outer or dissimilar ; æstivation inflexed, valvate, or twisted. Stamens $\infty$, in several rows, distinct, or polyadelphous, each parcel being opposite the outer petals ; filaments subulate, unequal, the outer ones often sterile. Ovary inferior, 1-celled, with parietal placentas; ovules anatropal; styles combined into 1 ; stigma 1 or several. Fruit capsular or succulent, 1-celled. Seeds without an arillus; embryo straight, in the axis of fleshy albumen; cotyledons small, flat; embryo pointing to the hilum.-Herbaceous plants, hispid with stinging hairs, having opposite or alternate exstipulate leaves, and axillary 1-flowered peduncles. They are American plants, chiefly distinguished for their stinging qualities, and hence the name of Chili-Nettle. The roots of Mentzelia hispida, a Mexican herb, are said to possess purgative qualities. There are 10 genera enumerated by authors, including 100 species. $E x$ amples-Loasa, Mentzelia, Blumenbachia.

Order 78. C Cucurbitaces, the Cucumber Family. (Polypet. or Monopet. Epigyn. and Diclines.) Calyx 5-toothed (figs. 430 l, p. 245; 713 c), sometimes obsolete. Petals 5, distinct, or more or less united, sometimes scarcely distinguishable from the calyx, strongly marked with reticulated veins (fig. $430 p$, p. 245 ), sometimes fringed. Stamens 5, distinct or united in one or three pareels, attached to the petals (fig. 713 e), anthers bilocular, sinuous (figs. 364, p. $223 ; 714 a ; 389$, p. 230 ), ovary (figs. 430 o, p. $245 ; 715 \mathrm{co}$ ), adhering to the tube of the calyx, 1-celled, formed by 3 carpels, and having 3 parietal placentas (fig. 716, p. 495), which sometimes project so as to join in the centre, the ovules remaining attached to the curved free edges; ovules solitary or indefinite (fig. 716), anatropal; styles short; stigmas very thick, velvety or fringed (fig. 715 s). Fruit a pepo (p. 314). Seeds flat and ovate (fig. 717), enveloped in a juicy or dry and membranous covering; testa coriaceous ; albumen 0 ; embryo straight (figs. 717, e; 718); cotyledons leafy and veined; radicle next the hilum.-Herbaceous plants, with succulent stems, climbing by means of lateral tendrils, which are transformed stipules; leaves alternate and palmate, covered with asperities ; flowers generally unisexual. They are natives of warm climates chiefly, and abound in India. A few are found towards the north, in Europe and North America, and several are natives of the Cape of Good Hope. Those which are annuals readily submit to the climate of northern latitudes during the summer, and thus, though of tropical origin, they grow well in European gardens. There are nearly 70 known genera and about 470 species. Examples-Cucurbita, Cucumis, Momordica, Bryonia, Telfairia, Fevillea.

A certain degree of acridity pervades the order, and many of the plants are drastic purgatives. In some cases, however, more espe- 
cially under cultivation, the fruits are eatable. Instances of edible fruits are seen in Cucumis Melo, common Melons; Abbattichim of Scripture; Cucumis sativus, Cucumbers, משים, Kishuim, of the Bible; Cucurbita Citrullus, Water Melon; Cucurbita Pepo, White Gourd; Cucurbita maxima, the Pumpkin; Cucurbita Melo-pepo, the Squash; Cucurbita ovifera, the Egg-gourd. The genus Cucumis contains the Melon and Cucumber, with edible fruits,

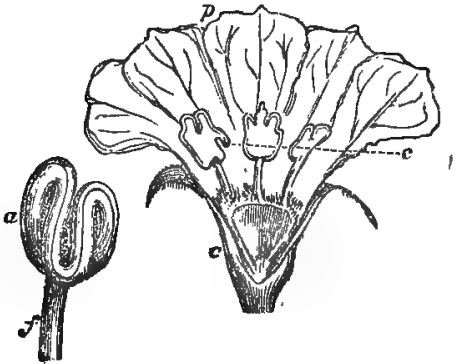

Fig. 714.
Fig. 713.

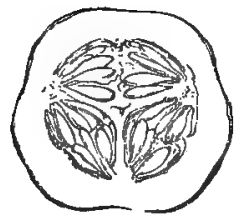

Fig. 716.

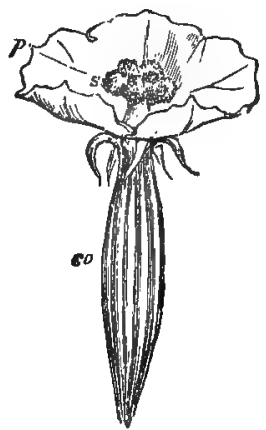

Fig. 715.

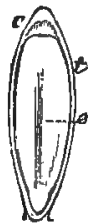

Fig. 717.

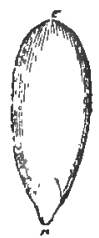

Fig. 718.

and the Colocynth, with purgative fruit. Much discussion has taken place in regard to the structure of the fruit in this genus, and in Cucurbitaceæ in general. Some have considered it an anomaly in vegetable structure, from the apparent formation of the placenta and ventral suture, externally, as if the usual position of the carpels were reversed. It would appear, however, as shown by Lindley, that the placentas follow the ordinary law. They are parietal; and curve in a

Figs. 713-718. Organs of fructification of Cucurbitaceæ. Fig. 713. Male flower of Cucumis sativus, Common Cucumber, Iaid open to show the interior of it. c, 5-divided calyx. p, United petals, by some considered as being an internal coloured calyx. \&, Epigynous stamens. Fig. 714. Stamen separated. $f$, Filament. $a$, Long sinuous anther. Fig. 715. Female flower. co, Calyx attached to the ovary. $p$, United petals. $s$, Thick velvety stigmas. Fig. 716. Horizontal section of the ovary, showing its division into three, by projections from the parietal placentas, to which the indefinite ovules are attached. Fig. 717. Anatropal seed cut vertically. $t$, Spermoderm swollen at the ehalaza, $c$. e, Embryo. Fig. 718. Embryo separated. r, Radicle. c, Cotyledons. 
peculiar way, bearing the seeds on their curvature; at the same time prolongations are sent inwards, which often meet in the centre. Stocks and others consider the carpels as being involute, and they trace this involution particularly in Luffa pentandra. Luffa agyptiaca is called the Towel-gourd, as its split fruit is used as a flesh-brush. Sooly Qua is the fruit of this species of Luffa. Cucumis Colocynthis, or Citrullus Colocynthis, yields a globular fruit called Coloquintida, or Bitter Apple, the pulp of which constitutes the medicinal Colocynth. It is imported from the Levant and the coasts of the Mediterranean. It is used in the form of powder and extract as an irritant cathartic. The plant is supposed to be the פקעת (Pakyoth), or Wild Gourd of Scripture. Mnmordica Elateriun or Ecballium agreste (' $\varepsilon \beta \alpha$ á $\lambda \lambda \omega$, I expel, in allusion to the expulsion of the seeds), the Wild or Squirting Cucumber, is so called on account of the force with which its seeds are expelled when ripe. The fruit, by a process of Endosmose going on in the cells, becomes distended, and ultimately gives way at the weakest part, where the peduncle is united to it. In separating from the stalk, the elasticity of the parietes comes into play, so as to discharge the brown seeds and slimy juice through the aperture at the base of the fruit. The feculence which subsides from the juice constitutes the medicinal Elaterium, which is used in small doses of $\frac{1}{8}-\frac{1}{2}$ a grain, as a violent cathartic, especially in dropsical cases. The active principle is Elaterin. The roots of Bryonia alba and dioica are also powerful purgatives. The fruit of various species of Gourd, as Cucurbita Pepo, the White Gourd, and C. maxima the Red Gourd, O. ovifera succada, Vegetable Marrow, are used as potherbs; while $C$. Citrullus, the Water Melon, is prized for its cool refreshing juice. The fruit of Echinocystis lobata is the Mock-apple of Canada. Trichosanthes anguina, the Snake-gourd, is eaten in India. The fruit of Lagenaria vulgaris, in consequence of having a hard outer covering, is used as a vessel for containing fluid, after the pulp and seeds are removed. It is hence called Bottle Gourd. It is stated that poisoning has followed on the drinking of beer that had been standing in a flask made of one of those Gourds. Dr. Royle mentions that symptoms of cholera have been induced by eating the bitter pulp. The seeds of the plants in this order frequently supply a bland oil. The seeds of Telfairia pedata (Africa) are as large as Chestnuts, and are used as food.

Order 79.-Papayadese, the Papaw Family. (Monopet. Polypet. Epigyn. and Diclines.) Calyz minute, 5-toothed. Corolla monopetalous, inserted into the base of the calyx ; in the male, tubular and 5 lobed; in the female, divided nearly to the base into 5 segments. Stamens 10, inserted into the throat of the corolla ; anthers bilocular, introrse, innate, dehiscing longitudinally. Ovary free, 1-celled; ovules indefinite, attached to 5 parietal placentas; stigma 5-lobed, lacerated. Fruit usually succulent and indehiscent, sometimes capsular and dehi- 
scent, 1-celled. Seeds $\infty$, enveloped in a loose mucous coat, parietal ; spermoderm brittle, pitted; embryo in the axis of fleshy albumen; cotyledons flat; radicle slender, turned towards the hilum. Trees or shrubs, not branching, with alternate lobed leaves, supported on long slender petioles, and with unisexual flowers. They are found in South America, and in other warm countries. One of the most important plants of the order is Carica Papaya, the Papaw-tree, which yields an acrid milky juice and an edible fruit. The juice of the unripe fruit and the seeds are said to act as anthelmintics. The juice is said to have the property of rendering meat tender. The order is by some considered to be a tribe of Passifloraceæ. The order has been divided into two tribes:-1. Caricere, corolla monopetalous, fruit succulent and indehiscent. 2. Modecceæ, corolla monopetalous, fruit capsular and dehiscent. There are 6 known genera, including about 40 species. Examples-Carica, Modecca.

Order 80.-Passifloracex, the Passion-flower Family. (Polypet. Perigyn.) Sepals 5, combined below into a more or less elongated tube. Petals 5, perigynous, often with filamentous or annular processes on their inside, which appear to be an altered whorl or whorls of petals, occasionally wanting, imbricated in æstivation. Stamens 5, monadelphous, surrounding the gynandrophore when present, rarely $\infty$; usually with processes from the thalamus, interposed between them and the petals; anthers dithecal, extrorse, versatile, dehiscing longitudinally; pollen-grains sometimes bursting by opercula (fig. 388, p. 230). Ovary 1-celled, often with a gynophore (p. 240); orules, anatropal, $\infty$; styles 3 ; stigmas dilated. Fruit often stipitate, 1-celled, sometimes 3-valved, opening by loculicidal dehiscence, or succulent and indehiscent. Seeds $\infty$, attached to parietal placentas, arillate, or strophiolate; spermoderm brittle and sculptured; embryo straight in the midst of thin fleshy albumen; radicle pointing to the hilum.-Herbs or shrubs, often climbing, with alternate stipulate or exstipulate leaves. The order has been divided into three tribes :1. Paropsieæ, plants not climbing, with a sessile ovary, arillate seeds, and exstipulate leaves. 2. Passifloreæ, climbing plants with a stalked ovary, arillate seeds, stipulate leaves, and glandular petioles. 3. Malesherbieæ, plants not climbing, with a stalked ovary, style below the apex of the ovary, strophiolate seeds, and exstipulate leaves. They are natives chiefly of warm climates, and are found in America, the East and West Indies. There are 12 known genera, and about 210 species. Examples - Paropsia, Smeathmannia, Passiflora, Tacsonia, Malesherbia.

Considerable discussion has taken place as to the true nature of the calyx and corolla in Passifloracer. Lindley supports the view here given. Others consider the calyx as consisting of ten sepals in two rows, the inner more or less petaloid, and they look on the petals 
as either wanting, or existing in the form of filamentous or annular processes. The name Passion-flower was given on account of a fancied resemblance in the flowers to the appearances presented at Calvary. In the five anthers the superstitious monks saw a resemblance to the wounds of Christ; in the triple style, the three nails on the cross ; in the central gynandrophore, the pillar of the cross ; and in the filamentous processes, the rays of light round the Saviour, or the crown of thorns. Many of the plants, such as Passiftora quadrangularis and edulis (Grenadillas), Paropsia edulis, and species of Tacsonia, yield edible fruits, the pulp or succulent arillus being fragrant and cooling. The root of Passiflora quadrangularis is said to be emetic and powerfully narcotic, on which account it is cultivated in several French settlements. It seems to owe its activity to a peculiar principle called Passiflorin. Other plants of the order are bitter and astringent.

Order 81.-Turneracese, the Turnera Family. (Polypet. Perigyn.) Calyx with 5 equal lobes; rstivation imbricated. Petals 5, perigynous, equal; æstivation twisted. Stamens 5, perigynous, alternating with the petals ; filaments distinct; anthers dithecal, innate, oblong. Ovary free, 1-celled, with 3 parietal placentas; ovules $\infty$, anatropal ; styles more or less cohering, or forked; stigmas multifid. Fruit a 1-celled, 3-valved capsule, dehiscing only half-way down, in a loculicidal manner. Seeds crustaceons, reticulated, arillate on one side; embryo slightly curved, in the midst of fleshy albumen; cotyledons plano-convex; radicle pointing to the hilum.-Herbaceous or somewhat shrubby plants, occasionally with stellate pubescence, having alternate, stipulate leaves, and frequently two glands at the apex of the petiole. Seemann states that Turneraceæ ought to be included in Passifloracer. They are natives of the West Indies and South America. They are not put to any important use. Turnera opifera is astringent, and is employed in Brazil against dyspepsia. Turnera ulmifolia is considered tonic and expectorant. Genera, 3 ; species, 76 . Examplés -Turnera, Wormskioldia.

Order 82. - Paronychiace淈, the Knotwort Family. (Polypet. Perigyn.) Sepals 4-5, distinct or cohering. Petals perigynous, between the divisions of the calyx, usually inconspicuous, sometimes 0 . Stamens usually perigynous, sometimes hypogynous, opposite to the sepals when equal to them in number, some of them occasionally wanting ; filaments distinct, rarely united; anthers bilocular. Ovary superior, with one or more ovules; styles 2-3, distinct or combined. Fruit unilocular, either a utricle covered by the calyx, or a 3-valved capsule. Seeds either numerous, attached to a free central placenta, or solitary and pendulous from a long funiculus arising from the base of the fruit. Embryo more or less curved, lying on one side of the farinaceous albumen, of surrounding it.-Herbaceous or somewhat 
shrubby plants, with opposite or alternate, sometimes setaceous and clustered leaves, which are either exstipulate or have scarious stipules. Found in barren places in various parts of Europe, Asia, and North America. A slight degree of astringency pervades this order, and is the only sensible property that it is known to possess. This order is allied to Caryophyllacer in many respects. It is placed by some among the Monochlamydeous orders, as being allied to Chenopodiacer. The order has been divided into two sections:-1. Illecebreæ, with the embryo lying on one side of the albumen, and stipulate leaves. 2. Scleranther, with a peripherical embryo and exstipulate, leaves. There are 30 known genera, and nearly 120 species. ExamplesParonychia, Illecebrum, Polycarpon, Corrigiola, Scleranthus.

Order 83.-CrassuLaCEm, the Houseleek or Stonecrop Family (figs. 634, 635, p. 365). (Polypet. Perigyn.) Sepals 3-20, more or less united at the base (fig. $282 \mathrm{cc}$, p. 191). Petals equal to the sepals in number, inserted in the bottom of the calyx (fig. $282 \mathrm{pp}$, p. 191), either distinct or cohering in a gamopetalous corolla. Stamens inserted with the petals, either equal to them in number, and alternate with them (fig. $282 e e$, p. 191), or twice as many, those opposite the petals being shortest ; sometimes one or two rows of abortive stamens ; filaments distinct, or united, subulate, anthers bilocular, dehiscing longitudinally or transversely. Abortive stamens or scales (sometimes obsolete), at the base of each carpel (fig. $282 a a, \mathrm{p} .191$ ). Carpels equal in number to the petals and opposite to them, 1-celled (fig. 282 o o, p. 191), sometimes consolidated; styles several or combined; stigmas pointed or 4-cornered; ovules 00, or definite, anatropal. Fruit consisting of several follicles, dehiscing by the ventral suture, sometimes by the dorsal suture. Seeds variable in number; embryo straight in the midst of fleshy albumen; radicle pointing to the hilum.--Herbaceous plants or shrubs, often succulent, with simple, entire, or pinnatifid, exstipulate leaves. They are found in the driest situations, as on rocks, walls, and sandy plains, in various parts of the world. Some of them are acrid, as Sedum acre, Biting Stonecrop; others are refrigerant, from the presence of an acid, such as malic acid. Sempervivum tectorum is commonly known as the Houseleek. The fishermen of Madeira rub their nets with the fresh leaves of the Sempervivum glutinosum, by which the nets are rendered as durable as if tanned, provided they are steeped in some alkaline liquor. Bryophyllum calycinum is remarkable for the property of producing germinating buds at the edges of its leaves (p. 118). In the leaves of some of the species, as Crassula profusa, C. lactea, and C. marginata, there are two kinds of stomata; one kind being of the ordinary size, and scattered over the leaves, the other being very minute, and raised on orbicular slightly convex punctiform disks, arranged in a row within the margin of the leaf. These disks consist of dense cellular tissue which 
terminates downwards in a conical form, and communicates with the peripheral ends of the veins, or the loose parenchymatous substance of the leaf. There are two tribes:-1. Sempervivex, with numerous separate carpels. 2. Penthoreæ, with pistil consolidated. There are 14 genera and about 400 species. Examples-Crassula, Sempervivum, Cotyledon, Sedum, Penthorum.

Order 84.-FrCoIDEA or Mesembryacear, the Fig-marigold and Ice-plant Family. (Polypet. Perigyn.) Sepals definite, usually 5, but varying from 4-8, more or less combined at the base, adherent to the ovary or distinct from it, equal or unequal; æstivation valvate or imbricate. Petals indefinite, coloured, sometimes 0 . Stamens perigynous, distinct, definite or indefinite; anthers oblong, incumbent. Ovary usually many-celied; stigmas several, distinct; ovules 00 , anatropal or amphitropal, attached by cords to the placenta, wbich is either central or parietal. Fruit a many-celled capsule, opening in a stellate or circumscissile manner at the apex, or an indehiscent nut. Seeds 00, rarely definite or even solitary; embryo curved or spiral, on the outside of mealy albumen; radicle next the hilum.-Herbaceous or shrubby succulent plants, with opposite or alternate simple leaves. They are found in warm regions chiefly. The greater part of them grow at the Cape of Good Hope. The order has been divided into three tribes:-1. Mesembryeæ, numerous conspicuous petals, manycelled capsule, with stellate dehiscence. 2. Tetragonieæ, petals 0 , fruit woody and indehiscent. 3. Sesurem, petals 0, capsule with circumscissile dehiscence. 4. Mollugine», calyx 5-partite, petals 3-5 or 0, stamens sub-perigynous, fruit capsular, or with 2-5 cocci. There are 22 known genera and 450 species. Examples-Mesembryanthemum, Tetragonia, Aizoon, Sesuvium, Mollugo.

Some of them are used as articles of diet, as the leares of Mesembryanthemum edule, Hottentot's Fig, and Tetragonia expansa, New Zealand Spinach. Others yield soda, and have been employed in the manufacture of glass. Mesembryanthemum erystallinum, the Ice-plant, is remarkable for the watery vesicles which cover its surface, and which have the appearance of pieces of ice. Its.juice is said to be diuretic, and has been prescribed in dropsy and liver complaints. The seedvessels of some species of Mesembryanthemum, as $M$. Tripotium, have the property of expanding in a star-like manner when put into water, and closing when dry. The flowers of many of the plants of the order exhibit the phenomenon of opening only under the influence of sunshine, and closing in dull weather (p. 262). Leaves of Mesembryanthemum, called Pigs'-faces, are eaten with Kangaroo flesh in some parts, of Australia, as a substitute for salt.

Order 85.-CACTACE 2 , the Cactus or Indian Fig Family. (Polypet. Epigyn.) Sepals numerous, usually $\infty$, and confounded with the petals, adherent to the ovary. Petals numerous, usually indefinite, 
sometimes irregular, inserted at the orifice of the calyx. Stamens indefinite, cohering more or less with the petals and sepals ; filaments long, filiform ; anthers ovate, versatile. Ovary fleshy, inferior, unilocular ; style filiform ; stigmas numerous ; ovules $\infty$, attached to parietal placentas, equal in number to the stigmas. Fruit succulent, 1celled. Seeds $\infty$, parietal, or, after losing their adhesion to the placenta, nestling in pulp, ovate or obovate; albumen 0 ; embryo straight, curved, or spiral ; cotyledons thick, leafy, sometimes nearly obsolete; radicle thick, obtuse, next the hilum.- Succulent shrubs, with peculiar angular or flattened stems, having the woody matter often arranged in wedges. Leaves usually absent; when present, fleshy, smooth, entire or spinous. Flowers sessile, sometimes showy. They grow in hot, dry, and exposed places, and are natives chiefly of the tropical parts of America. Some grow rapidly on the lava in volcanic countries. There are two tribes:-1. Echinocacteæ, calyx tube produced beyond the ovary, stem with tuberculated ribs, or with elongated aculei. 2. Opuntiex, calyx tube not produced beyond the ovary, stem branching, articulated. There are 13 known genera and about 1000 species. Examples-Opuntia, Melocactus, Mammillaria, Echinocactus, Cereus, Epiphyllum, Pereskia, Rhipsalis.

The plants of this order are remarkable for their succulence, for the great development of their cellular tissue, and the anomalous forms of their stems, some of which attain a great size. In their structure numerous spiral cells are met with, and in many cases the fibre in these cells is interrupted so as to present thickened rings united by membrane. These rings, when the cells are macerated, can be obtained in a free state. Many of the plants in this order show a remarkable tendency to spiral development. The setæ, spines, and hairs, are sometimes arranged spirally, and in Cereus flagelliformis the cells of the setæ have this tendency. Many of them yield an edible fruit, which is sometimes refreshing and agreeable, at other times insipid. The fruit of Pereskia aculeata, under the name of Barbados Gooseberry, is used in the West Indies as an article of diet. That of Opuntia vulgaris is known under the name of Prickly Pear. The juice of the fruit of some species is subacid, and has sometimes been used as a refrigerant. Cattle sometimes feed on the succulent stems in dry seasons. Some of the plants are noted as nightflowering (p. 262). Cereus grandiflorus expands its large white blossoms about 10 P.M. in our hothouses, and their beauty lasts only for the night. Such is also the case with O. MacDonaldice and C.nycticalus. A plant of the latter species, in the Glasgow Botanic Garden, began. to open its flowers between 7 and 8 P.M., and they were fully opened at 10. The follow. ing were the numbers and sizes of the various parts :-

Length of the tube of the calyx

7 inches.

Length of the petals

$4 \frac{1}{2}$, 
Length of the style.

Breadth of flower when fully expanded

Number of long sepals

Number of short sepals

Number of petals

Number of stamens .

Number of stigmas.
10 inches.

11,

75
.$\quad 20$
.$\quad 25$
.$\quad 400$
.$\quad 15$

The size to which some of the Cactus family grow may be illustrated by a specimen of Echinocactus Viznaga, imported into Kew gardens from the mountains of San Luis, Potosi :-

Weight of the plant

Height from surface of the earth

Measured over the top from the ground on each side

Circumference at 1 foot front the ground

Number of deep angles or costæ

Number of spines.
713 lbs.

$4 \frac{1}{2}$ feet.

10 feet 9 inches.

8 feet 7 inches. 44

8800

In Brazil, some epiphytic Cactuses are met with; and there are some species described by Gardner as attaining a height of thirty feet, with a circumference of three feet. Opuntia cochinellifera, and other species, are infested by the Coccus Cacti, or the cochineal insect, which feeds upon them. The plants are cultivated in what are called nopaleries, for the sake of the insect, the females of which, when dried, constitute the cochineal of commerce.

Order 86.-Grossulariace开 or Ribesiace 4 , the Gooseberry and Currant Family. (Polypet. Epigyn.) Calyx 4-5 cleft, regular, coloured. Petals minute, perigynous, equal in number to the segments of the calyx, and alternate with them. Stamens 4-5, alternate with the petals, and inserted into the throat of the calyx ; filaments short; anthers dithecal. Ovary unilocular, adherent to the tube of the calyx; ovules $\infty$, anatropal, attached to two opposite parietal placentas; style single, 2-4 cleft. Fruit a 1-celled berry, crowned with the remains of the flower. Seeds $\infty$, immersed in pulp, and attached to the placentas by long thread-like funiculi; spermoderm gelatinous externally; albumen horny; embryo straight, minute; radicle pointing to the hilum.-Shrubs, with alternate lobed leaves, having a plicate vernation. They are natives of temperate regions, and are found in Europe, Asia, and America. Many yield edible fruits, which sometimes contain malic acid. The various kinds of Gooseberry (Ribes Grossularia) and Currant (Ribes rubrum and nigrum) belong to this order. The black currant possesses tonic and stimulant properties. On the under surface of its leaves and flowers fragrant glands may be perceived. The order is considered by some as a tribe of Saxifragaceæ. It contains 2 or 3 genera, and nearly 60 species. Example-Ribes.

Order 87.-Saxifragacea, the Saxifrage Family. Perigyn.) Calyx superior, or more or less inferior (fig. $431 \mathrm{c} c$, p. $245)$; sepals usually 5, more or less cohering at the base. Petals 
usually 5 , perigynous, alternate with the lobes of the calyx (fig. 431, $p p$, p. 245), rarely 0. Stamens perigynous (fig. 431 e, p. 245), 5-10 or $\infty$, in 1 or more rows; anthers bilocular, with longitudinal or porous dehiscence. Disk often present, either annular or scaly. Ovary more or less completely united to the tube of the calyx, consisting usually of two carpels, cohering by their face (figs. 431; $432 o$, p. 245), but distinct and diverging at the apex; styles as many as the carpels, distinct (fig. $432 t$, p. 245) or combined ; stigmas capitate (fig. 432 s, p. 245) or clavate. Placentas (fig. 432 p, p. 245) marginal (basal or apicilar), rarely central. Fruit generally a 1-2-celled capsule, the cells dehiscing at the ventral suture, and often divaricating when ripe, sometines baccate. Seeds usually $\infty$, rarely definite ; spermoderm often reticulated ; embryo small, in the axis of fleshy albumen; radicle pointing to the hilum.-Shrubs or trees, or herbs, with alternate or opposite, usually exstipulate leaves. They are generally natives of temperate climates, and some of them characterise alpine districts. The order has been divided into the following sub-orders:-1. Escallonieæ, petals and stamens 5; ovary inferior; style simple ; albumen oily ; evergreen shrubs, with alternate, simple, exstipulate leaves, found in the temperate regions of Sonth America, often at a great elevation. 2. Cunoniex, petals 4-5 or 0 ; stamens $8-10$ or $\infty$; ovary half inferior; styles 2 , distinct or combined; trees or shrubs, with opposite leaves, having interpetiolary stipules; found in South America, the East Indies, south of Africa, and Australia. 3. Hydrangex, petals $4-6$; stamens $8-12$ or $\infty$; anthers sometimes biporose; ovary more or less inferior; styles 2-5, usually distinct; shrubs with opposite, sometimes whorled, exstipulate leaves, and inflorescence frequently cymose, with the exterior flowers sterile and dilated; found chiefly in the temperate parts of Asia and America. 4. Saxifragex, petals 5 or 0 ; stamens 5 -10; ovary more or less adherent; styles usually 2, and distinct; herbs, with alternate, usually exstipulate leaves, found in the mountainous regions of Europe, etc. Few of the plants are put to any use. Some of them are astringent, and used for tanning; others have bitter tonic properties. The glutinous exudation of a few of them is acrid. Escallonias may be said to represent shrubby Saxifrages. They inhabit chiefly the mountainous districts of Chili and the southern part of South America. Escallonia macrantha and rubra are grown in the milder parts of Great Britain. The leaves of Hydrangea Thunbergii furnish tea of a very recherché character, bearing the name of Ama-tsja in Japan. In the entire order there are 60 known genera, and upwards of 500 species. Some include Philadelphaceæ and Francoaceæ in this order.

Cephalotus is considered as an anomalous apetalous genus of the order. It is allied also to Crassulacex, and by some authors it is included in a separate order-CEPHALOTEE. There is only one species, 
C. follicularis, which inhabits S.W. Australia. Its leaves are arranged in a rosette at the top of the rhizome. They are of two kinds, one flat, with a somewhat cylindrical dilated petiole, and the other true ascidia (pitchers) formed by the petiole, which is dilated at the top into two lips, the lower being larger and cup-like, and opening by a circular orifice, the upper being smaller, and acting as a lid to the cup. The pitchers contain a secretion. Examples-Escallonia, Brexia, Itea, Cunonia, Weinmannia, Hydrangea, Bauera, Saxifraga, Astilbe, Chrysosplenium, Heuchera.

Order 88.-BRuniace $\mathbb{E}$, the Brunia Family. (Polypet. Epigyn.) Calyx 5-cleft; æstivation imbricated. Petals inserted in the throat of the calyx, and alternate with its segments. Stamens alternate with the petals, arising from them, or from a disk surrounding the ovary; anthers introrse, 2-celled, with longitudinal dehiscence. Ovary usually adherent to the tube of the calyx, and 1-3-celled; ovules anatropal, suspended, 1 or 2 in each cell ; style simple or bifid; stigmas 1-3. Fruit either bicoccous and 2-celled, or indehiscent and 1-celled, crowned by the persistent calyz. Seeds solitary or in pairs, suspended, sometimes with a short arillus; embryo minute, at the base of fleshy albumen; cotyledons short and fleshy; radicle conical, next the hilum.-Branched heath-like shrubs, with small, imbricated, rigid, and entire leaves, and small, often capitate flowers. They are natives principally of the Cape of Good Hope, and have no important properties. There are 10 known genera and about 40 species. Examples-Brunia, Staavia, Berzelia.

Order 89.-Hamamelidaces, the Witch-hazel Family. (Polypet. Epigyn.) Calyx 4-5-lobed or truncate. Petals 4-5 or 0, inserted on the calyx, alternating with the calycine segments. Stamens twice as many as the petals, in two rows, one of which alternates with the petals and is fertile, the other is opposite to them and sterile; anthers bilocular, introrse. Ovary adherent, 2-celled; ovules solitary, or several (in Bucklandia and Sedgwickia), pendulous or suspended; styles 2. Fruit a 2-celled, 2-valved capsule, opening by loculicidal dehiscence. Seeds pendulous; embryo straight, in the axis of fleshy albumen; cotyledons leafy ; radicle superior.- - Shrubs or small trees, with alternate, petiolate, feather-veined, and stipulate leaves, and small axillary, bracteated, often unisexual flowers. They are found in various parts of Asia, Africa, and America. The seeds of Hamamelis virginica are used as food, while its leaves and bark are astringent and acrid. Liquidambar orientalis yields liquid storax, which is used as a cure for scabies. The resins yielded by Liquidambar styraciflua, Formosana, and altingiana, are also used as fragrant balsams. By some authors these plants are placed in a Monochlamydeous order, Balsamifluæ or Altingiaceæ. Authors notice 15 genera, including 30 species. $E x-$ amples-Hamamelis, Fothergilla, Bucklandia, Rhodoleia, Liquidambar. 
Order 90.-UMBELIIFERAs, the Umbelliferous Family (figs. 719. 725), Apiaceæ of Lindley. (Polypet. Epigyn.) Calyx superior, 5-

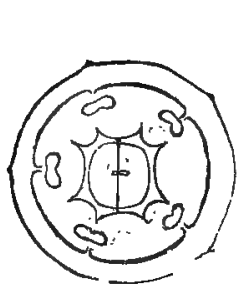

Fig. 719.

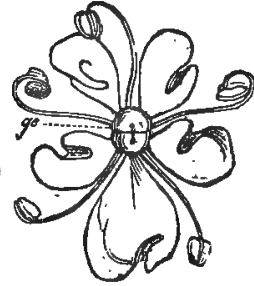

Fig. 720.

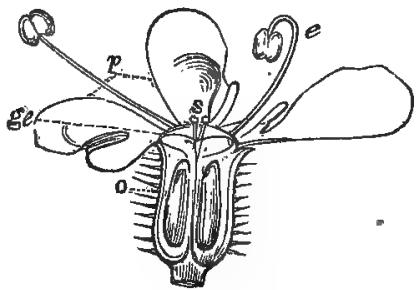

Fig. 721.

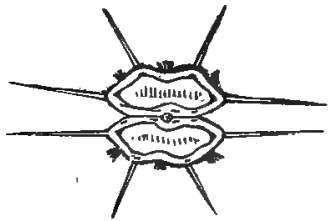

Fig. 722.

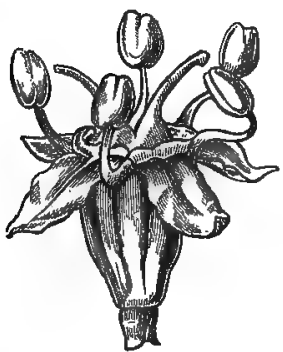

ф

Fig. 724.

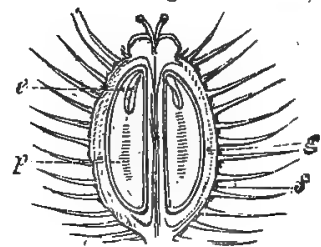

Fig. 723 .

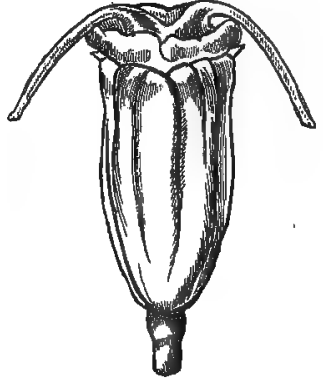

$q$

Fig. 725 .

Figs. 719-723. Organs of fructification of Darucus Carota, common Carrot, to illustrate the natural order Umbelliferæ. Fig. 719. Diagram of the flower, with a 5-toothed calyz, 5 inflexed petals, 5 stamens, and fruit formed by 2 carpels, with primary and secondary ridges, valleculx, commissure, and flat albumen. Fig. 720. The flower viewed from above, showing the petals with inflexed points and 5 stamens. ge, Epigynous disk or stylopod. Fig. 721. Vertical section of the flower. $p$, Petals with inflexed points. $e$, Stamens, one incurved at the apex. u, Ovary formed by two carpels, adherent to the calyx throughout. $s$, Styles aud stigmas. ge, Epigynous disk or stylopod. Fig. 722. Horizontal section of the fruit (cremocarp) with bristly ridges. Fig.723. Vertical section of the cremocarp. $f$, Pericarp. $g$, Seed. $\quad$, Flat perisperm. e, Embryo. Fig. 724. Perfect flower of Narthex Asafoetida, with obsolete 5-toothed calyx, 5 oblong petals, one showiug inflexed point, 5 staraens, epigynous disk, and 2 slightly-eurved styles. Fig. 725. Pistillate flower of ditto, with obsolete-1obed calyx, 2 deflexed styles surmounting the cremocarp. 
toothed or entire. Petals 5, inserted on the outside of a fleshy epigynous disk, often with inflexed points (figs. 306, p. $201 ; 720$ ). Stamens 5, alternate with the petals, incurved in astivation (figs. 720, $721,723)$. Ovary inferior, 2-celled, crowned with a double disk or stylopod (fig. 721 ge); ovules solitary, pendulous; styles 2, distinct (fig. $550 \mathrm{~s} \mathrm{~s}$, p. 306); stigma simple. Fruit (figs. 722, 723) a cremocarp (p. 311), consisting of two achænia (mericarps or hemicarps), which adhere by their face (commissure) to a common axis (carpophore), from which they separate, and are suspended when ripe (figs. $550 a$, p. $306 ; 725)$; each mericarp is traversed by five primary longitudinal ridges (juga), and often by four alternating secondary ones, the ridges being separated by channels (valleculx). In the substance of the pericarp there are frequently vittæ containing oil, which are usually opposite the channels. Seeds pendulous (fig. $723 \mathrm{~g}$ ), usually adherent to the pericarp, rarely loose; embryo minute, at the base of abundant horny albumen (fig. $723 \mathrm{e}$ ); radicle pointing to the hilum.-Herbaceous plants, often with hollow and furrowed stems, with alternate, rarely opposite, variously divided, sheathing leaves (which sometimes assume the appearance of phyllodia), and with umbellate, involucrate flowers (fig. 262, p. 179). They are found chiefly in the northern parts of the northern hemisphere. In warm countries they occur at high elevations. The order has been divided according to the number and size of the pericarpial ridges, the presence or absence of vittæ, and the form of the albumen. The following sections are given by old authors, but they are not sufficiently definite for the purpose of classification :-1. Orthospermæ (óg $\theta 0 s$, straight, and $\sigma \pi^{\prime} \varepsilon \mu \alpha$, seed), albumen flat on the inner face, neither involute nor convolute. 2. Campylospermæ ( $\chi \alpha \mu \pi u$ ì ${ }_{0}$, inflected), albumen curved at the margins, so as to form a longitudinal furrow. 3. Cœlospermæ (xos̀os, concave), albumen curved at the ends (from base to apex). The following are the sections now adopted:-1. Heterosciadeæ, umbels simple, vittæ in valleculæ 0. 2. Haplozygiæ; umbels compound, primary ridges of the fruit alone conspicuous; vittæ in valleculæ very rarely absent. 3. Diplozygiæ; umbels compound, primary and secondary ridges on the fruit, valleculæ thickened above the vittæ. Authors enumerate 160 genera, including about 1300 species. Examples-1. Heterosciadece

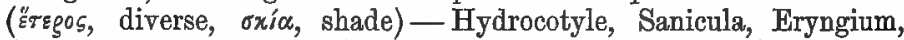

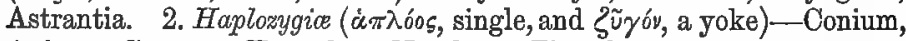
Apium, Carum, Enanthe, Narthex, Heracleum. 3. Diplowygiae

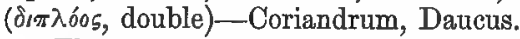

The properties of the plants of this order are various. Some yield articles of diet, others gum-resinous and oily substances, while others are highly poisonous. According to their qualities, the species have been divided into-1. Those which are harmless, and are used as esculent vegetables. 2. Those producing a gum-resin, often having a 
fetid odour from the presence of a sulphur-oil, and which are used as antispasmodics and stimulants. 3. Those yielding a volatile oil, which renders them carminative and aromatic. 4. Those which are poisonous, in consequence of the presence of an acrid and narcotic juice.

Among esculent species may be noticed-Daucus Carota (Carrot), Pastinaca sativa (Parsnip), Apium graveolens (Celery), Foniculum vulgare (Fennel), Petroselinum sativum (Parsley), Anthriscus Cerefolium (Chervil), Sium Sisarum (Skirret), and Archangelica officinalis (Angelica). Crithmum maritimum is the Samphire, which grows abundantly on rocks near the sea, and is used as a pickle. The roots of Arracacha esculenta, a native of Grenada, have been recommended as a substitute for the potato; they are large and esculent, resembling a Parsnip in quality. The roots of Choerophyllum bulbosum (bulbous Chervil) are used like carrots. A dwarf kind of Fennel, called Finochio, is used in Italy as a salad. The roots of Eryngium campestre and maritimum, or Eryngo, are sweet, aromatic, tonic, and diuretic. The tubers of Bunium Bulbocastanum and flexuosum are eaten under the name of Pig-nuts or Earth-nuts. Prangos pabularia, a plant of Southern Tartary, is highly recommended as fodder for cattle.

Many species yield inilky juices, which concrete into a fetid gumresin. Asafœtida is procured from Narthex Asafoetida (F'erula Narthex). The plant is found in Persia and Affghanistan, and seeds of it were sent to this country by Dr. Falconer, some of which germinated in the Edinburgh Botanic Garden, and produced abundance of flowers and fruit.-(Trans. R. S. Edin., xxii., with figures.) The fruit of the plant is distinguished by divided and interrupted vittæ, which form a network on the surface, and its leaves have a resemblance to those of a Prony. It would appear that Ferula persica, a plant with very much divided leaves, yields an inferior sort of asafotida. The asafoetida is procured by taking successive slices off the top of the root, and collecting the milky juice which is allowed to concrete in masses. It consists of resinous and gummy matter, with a sulphur-oil similar to that of Garlic, which is probably its active ingredient. It is employed medicinally in substance or tincture, as a stimulant, antispasmodic, and anthelmintic. Scorodosna foetidum, found in the east of the Sea of Aral, also yields a substance similar to asafoetida. Ammoniac, another fetid gum-resin, is the produce of Dorema Ammoniacum (Diserneston gunmiferum), a native of Persia. It contains resin, gum, and volatile oil, and is used medicinally as a stimulant, antispasmodic, and expectorant. Galbanum, which seems to be the תלבגה (Chelbenah) of Scripture, is procured, in all probability, from Ferula galbaniflua and rubricaulis, found in northern Persia. It consists of resin, gum, and volatile oil, and is used as an antispasmodic and emmenagogue. Opoponax is another gum-resin, procured from Opoponax Chironum (Pastinaca Opoponax), a native of the southern parts of Europe. Sagapenum seems 
to be the produce of a species of Ferula. Sumbul root, used as a stimulant tonic in Russia, is the produce of Euryangium Sumbul.

There are other species which supply a carminative and aromatic oil. From the fruits of Carum Carni, which are commonly called Caraway seeds, a volatile oil of this nature is procured. Similar oils are obtained from the fruit of Pimpinella Anisum (Anise); from that of Feniculum vulgare, or $F$. dulce (common Fennel); Anethum graveolens (common Dill), «ungov, Anise of the Bible; Coriandrum sativum (Coriander), 7., Gad of the Bible; Cuminum Cyminum (Cumin), כמן (Kammon) xíuñov; Archangelica officinalis (Garden Angelica), and Daucus Carota (Carrot). Ammi copticum (Ptychotes Ajowan) is the Ajowan or Omam, a condiment of India.

In regard to the poisonous species of this order there is still much to be learned. They appear to vary according to the soil and climate in which they grow. Some species, generally reputed poisonous, have been found by $\mathrm{Sir}$ Robert Christison to be quite innocuous when gathered from localities in the neighbourhood of Edinburgh. The most important plant of this section is Conium maculatum (Hemlock), the $x$ wrvsov of the Greeks, and probably cicuta of the Romans. It is a biennial plant, found abundantly in Britain, and distinguished by its undulated ridges, smooth purple-spotted stem, and the peculiar mouse-like odour of its leaves, when being dried. Every part of the plant, especially the fresh leaves and green fruit, contain a volatile oleaginous alkali, called Conia, which acts as an energetic poison. To this substance the effects of hemlock on the animal frame are due, and care is required in the preparation of the leaves and fruit in order to retain this active principle. A few drops of Conia will kill a small animal. It acts on the spinal cord, producing paralysis with slight convulsive twitches, and its fatal effects are attributed to asphyxia, produced by palsy of the muscles of respiration, without convulsions or coma. Hemlock has been employed medicinally to allay pain, more especially in cancerous and neuralgic affections. Enanthe crocata (Hemlock-Dropwort, or Dead-tongue), and a variety called apiifolia, have been long looked upon as poisonous. The roots have been mistaken for parsnips, and fatal effects have been thus produced. It would appear, however, that these poisonous qualities are not invariably present, for Sir Robert Christison found that the roots of this plant, when growing in a sea-side locality, near Edinburgh, were innocuous. It remains to be determined if the climate and locality have any effect in modifying the properties of the plant. The same remarks may be made in regard to EEnanthe Phellandrium (Water Dropwort), and Cicuta virosa (Water Hemlock or Cowbane), which seem to vary as regards their poisonous properties. AEthusa Cynapium (Fool's Parsley) is another plant of the order reputed poisonous. It has been stated that the roots of Parsnip, during the spring of the second year, on the 
approach of the flowering season, occasionally produce a poisonous matter.

Azorella Selago, an umbelliferous plant, forms great green cushions in Kerguelen's Island, and seems to take the place of Bolax glebaria, Balsam-bog, an umbellifer of the Falkland Islands. A species of Dichopetalum in Victoria has 5 petaloid sepals.

Order 91.-ARAdiaces, the Ivy Family. (Polypet. Epigyn.) Calyx entire or toothed (fig. $340 c$, p. 214). Petals definite (fig. 340 p, p. 214), 2, 5, 10, deciduous, occasionally 0 ; æstivation valvate. Stamens as many as the petals, or twice as many, inserted below the margin of an epigynous disk (fig. $340, e$ e, p. 214). Ovary adherent to the tube of the calyx, 2 or more celled (fig. $340 \mathrm{o}, \mathrm{p} .214$ ); ovules solitary, pendulous (fig. 340, p. 214), anatropal ; styles 2 or more, distinct or connate (fig. $340 \mathrm{~s}, \mathrm{p} .214$ ) ; stigmas simple. Fruit usually succulent, 2-15-celled, covered by the calycine limb. Seeds solitary, pendulous, adhering to the endocarp ; albumen fleshy ; embryo small ; radicle pointing to the hilum.-Trees, shrubs, or herbaceous plants, with alternate exstipulate leaves, and umbellate (fig. 261, p. 179) or capitate flowers. They are found both in tropical and in cold regions. There are 5 series or sub-orders:-1. Aralieæ, petals more or less imbricated, fixed by a broad base. 2. Mackinlayieæ, petals involute, contracted into a very short claw. 3. Panaceæ, petals valvate, stamens equal in number to the petals, albumen uniform. 4. Hedereæ, petals valvate, stamens and petals isomerous, albumen ruminate. 5 . Plerandreæ, petals valvate or connate, stamens $\infty$, styles 0 , or cohering in a cone. Authors enumerate 38 genera, including 340 species. Examples-Aralia, Mackinlaya, Panax, Fatsia, Hedera, Helwingia, Plerandra.

They have generally aromatic and stimulant properties. They are allied to Umbelliferæ, but do not possess poisonous qualities in a marked degree, nor does their fruit usually yield volatile oil. A species of Panax yields the famous Ginseng root of the Chinese, which is used as a stimulant. Panax quinquefolium possesses qualities resembling those of ginseng. The celebrated Rice Paper of the Chinese is ascertained to be prepared from the pith of Fatsia papyrifera. Some species of Aralia yield an aromatic gum-resin. Aralia nudicaulis, a native of North America, has fragrant and aromatic roots, which are used as a substitute for sarsaparilla. A. spinosa, called toothache-tree in North America, is a stimulant diaphoretic. Aralia japonica (canescens), racemosa, spinosa, hispida, etc., are commonly grown in drawing-rooms in Britain. The succulent fruit of Hedera Helix, the Ivy, is emetic and purgative.

Order 92.-Cornace 4 , the Cornel Family. (Polypet. Epigyn.) Calyx 4-lobed. Petals 4, oblong, broad at the base, regular, inserted into the upper part of the calycine tube ; æstivation valvate. Stamens 
4, inserted along with the petals, and alternate with them; anthers dithecal. Ovary adherent to the tube of the calyx, 2-celled, crowned by a disk ; ovules solitary, pendulous, anatropal ; style filiform ; stigma simple. Fruit fleshy, crowned by the limb of the calyx, 2-celled, rarely 1-celled by abortion'; endocarp bony (fig. 569, p. 314). Seeds solitary, pendulous; embryo straight, long, in the axis of fleshy albumen; radicle superior, shorter than the oblong cotyledons.-Trees, shrubs, or herbs, with opposite, very rarely alternate, exstipulate leaves, and capitate, umbellate, or corymbose, or amentiferous flowers. They inhabit the temperate climates of Europe, Asia, and America; also met with in Australia and New Zealand, and in Africa. The orders Alangiaces and Garryaces are included in this order. The bark of Cornus florida and sericea is used in America as a tonic and febrifuge. The fruit of Cornus mascula has been used as food, and the seeds of Cornus sanguinea furnish oil. From the wood of Cornus mascula, or Akenia of the Greeks, the Kizziljiek or Redwood of Turkey, the Turks obtain the dye for their red fez. The fruit stewed and mixed with water forms a good drink in hot weather, and from its astringency it is useful in diarrhœa. The fruit of Comes suecica, a species found on the Scotch mountains, is reputed tonic. Aucuba japonica has leaves which exhibit a variegated aspect. Garrya elliptica is prized for its peculiar silky catkins. It has unisexual flowers. Some species of Alangium yield edible fruits, others are purgative. Authors give 12 genera and 75 species. Examples-Cornus, Alangium, Aucuba, Garrya, Nyssa.

Section II.-Gamopetaldr-Petals united; stamens usually epigynous.

This section includes the Monopetalous orders of Jussieu, and the Gamopetalæ of Endlicher, in which the ovary is inferior; or, in other words, in which the calyx is superior. Many authors put this section as an epigynous division of the sub-class Corolliflorce. Decandolle's arrangement is followed in this Work.

Order 93.-CaPRIFoliaces, the Honeysuckle Family. (Monopet. Epigyn.) Calyx with its limb 4-5 lobed, usually bracteated. Corolla superior, lobed, usually regular and gamopetalous, sometimes irregular. Stamens epicorolline, equal in number to the lobes of the corolla, and alternate with them. Ovary adherent to the tube of the calyx, usually 3-celled, rarely 4-5-celled; ovules few in each cell, pendulous; style one or none; stigmas 3-5. Fruit fleshy or dry, crowned by the limb of the calyx, indehiscent, uni- or multi-locular; endocarp sometimes bony. Seeds solitary, or several in each cell, pendulous; spermoderm often bony; embryo small in the centre of fleshy albumen; radicle next the hilum. - Shrubs or herbs, with opposite exstipulate leaves, and corymbose flowers. Chiefly found in the northern parts of 
Europe, Asia, and America ; found very sparingly in northern Africa, and little known in the southern hemisphere. The order has been divided into two sub-orders:-1. Lonicereæ, the true Honeysuckles, with a regular rotate or tubular corolla, three sessile stigmas, and a raphe on the inner side of the ovule. 1. Sambuceæ, the Elder Tribe, with a corolla more or less tubular, often irregular, a filiform style, and a raphe on the outside of the ovule. Genera, 14 ; species, 200. Examples-Lonicera, Diervilla, Leycesteria, Linnæa, Adoxa, Sambucus, Viburnum.

Many of the plants, such as the Honeysuckle and Elder, have odoriferous flowers. Some possess emetic and purgative properties. The fruit of Sambucus nigra, the Common Elder, is used in the manufacture of a kind of wine. The flowers contain a concrete volatile oil, and a minute portion of a volatile odoriferous oil. They are used for making an aromatic distilled water. The inspissated juice of the fruit, and the inner bark, possess purgative qualities. Viburnum Opulus, the Gueldres Rose, often cultivated in gardens, is called snowball, from its globular head of abortive flowers. Viburnum Lantana has an acrid bark. Viburnum Tinus is the Laurustinus of gardeners. Linnoea borealis (two-flowered Linnæa) is a northern plant, named after Linnæus. Symphoricarpus racemosus yields the Snowberry, which is a dipyrenous drupe.

Order 94.-RUBIAcese, the Madder and Peruvian Bark Family. (Monopet. Epigyn.) (Figs. 726-732.) Calyx superior, the limb with

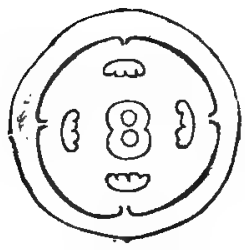

Fig. 726.

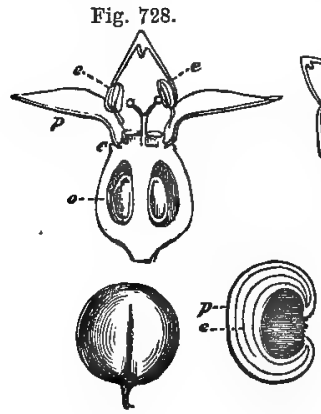

Fig. 729.
Fig. 727.

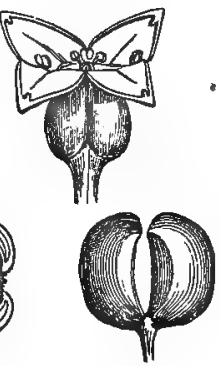

Fig. 730.

a definite number of divisions (usually 4-5), sometimes obsolete (fig. 728 c). Corolla gamopetalous, regular, tubular, or rotate (fig. $728 \mathrm{p}$ ),

Figs. 726-731. Illustrations of the natural order Rubincer. Fig. 726. Diagram of the flower of Galium Mollugo, belonging to the section Stellatæ. Calyx nearly obsolete, corolla rotate, 4-lobed, 4 stamens, and didymous ovary. Fig. 727. Flower entire. Fig. 728. Flower cut vertically. c, Calyx adherent to the ovary, o, which is 2-celled. $p$, Corolla. $e$ e, Stamens surrounding the style and stigmas. Fig. 729. Fruit of Rubia tinctoria, Madder. Fig. 730. The same, showing the separation of the two carpels. Fig. 731. The seed cut vertically. $p$, Perisperm. e, Curved embryo. 
superior, usually with $4-5$ divisions (fig. 727); æstivation valvate or imbricate. Stamens more or less adherent to the corolline tube, as many as the lobes of the corolla, and alternate with them (fig. 726).

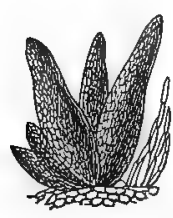

Fig. 732. Ovary inferior, usually bilocular (fig. 728 o), sometimes multilocular, crowned with a fleshy $;$ disk; ovules numerous or solitary, anatropal or amphitropal; style single, sometimes partly divided; stigmas usually 2, more or less distinct (fig. 728). Fruit inferior, 2- or many-celled, dry or succulent, either indehiscent or splitting into two mericarps (figs. 729, 730). Seeds 1 or many in each cell, in the former case erect or ascending (fig. 728), in the latter attached to a central placenta; albumen copious, horny or fleshy (fig. $731 \mathrm{p}$ ) ; embryo small, straight, or slightly curved (fig. $731 \mathrm{e}$ ); cotyledons leafy; radicle turned to the hilum.-Trees, shrubs, or herbs, with simple, entire, opposite, or verticillate leaves, which have either interpetiolary stipules (fig. 206, p. 98), or are exstipulate, sometimes with glands at the base of the stipules, as in Cinchona and Ipecacuan (fig. 732). The order has been divided into three series:-1. Galieæ or Stellatæ, with square stems, verticillate leaves, and no true stipules (as the leaves in the verticil are alike), ovary with 1 seed in each cell. 2. Coffeæ, distinct stipules, ovary with 1-2 seeds in a cell. 3. Cinchoneæ, with distinct stipules, ovary having numerous seeds. The plants in the first series are natives of temperate and cold climates. Those in the other two are natives of warm climates. The order has been divided into 25 tribes by Hooker and Bentham. Some authors think that the verticillate leaves of Stellatæ consist partly of true leaves, and partly of stipules. The order includes nearly 340 genera and upwards of 4000 known species. Examples-Galium, Rubia, Asperula, Nestera, Coffea, Cephaelis, Psychotria, Spermacoce, Cephalanthus, Cinchona, Gardenia, Hedyotis, Isertia, Hamelia, Guettarda, Pæderia.

The properties of the order, in general, are tonic, febrifuge, and astringent. Important articles of materia medica are furnished by the plants in the sub-orders Coffeæ and Cinchoneæ. Peruvian or Jesuits' Bark, Quinquina of the French, China of the Germans, known under the vague and ill-defined names of Pale, Yellow, and Red Bark, is procured from various species of Cinchona, which grow abundantly in the district of Upper Peru. The Cinchona trees seem to be confined exclusively to the Andes, within the boundaries of Peru, Columbia, and Bolivia, from $11^{\circ}$ north lat. to $20^{\circ}$ south lat., chiefly growing at elevations varying from 5000 to 8000 feet above the level of the sea, and in a dry rocky soil ; the highest limit is 11,000 feet. The barks are met with either in thick, large, flat pieces, or in thinner pieces, which curl inwards during drying, and are called quilled. At least

Fig. 732. Glands at the base of the stipules of Cephaelis Ipecacuanha. 
twelve species are supposed to furnish commercial barks. The greater number of these barks are used in the manufacture of Quinine. Those which are used pharmaceutically are-1. Cinchona officinalis (Hook.), a native of Ecuador and Peru; 2. C. Calisaya (Wedd.), from the valleys of Bolivia and south-eastern Peru; 3. C. succirrbra (Pavon.), found in the valleys of the Andes which open into the plain of Guayaquil. Of the other species, the following may be mentioned:-Cinchona lanceolata, pahudiana, pitayensis, purpurea, ovalifolia, ovata, cordifolia. (See Hanbury's Pharmacographia, p. 318.) The most important principles procured from Cinchona bark are the alkaloids of Cinchonine, Cinchonidine, Quinine, Quinidine, and Quinamine, combined with Kinic, Cincho-tannic, and Quinovic acids. The chief officinal kinds are1. Crown-bark, China-loxa, a pale bark in quills 6 to 15 inches long. 2. Gray bark, Silver bark, or Huanuco bark, China-Huanuco, another variety of quilled pale bark. 3. Yellow bark, China-regia, or Calisaya bark, partly flat, partly quilled. 4. Red bark, China-rubra, partly flat and partly quilled. Besides these, there are various inferior kinds of bark met with in commerce, such as Ash bark, China-Jaen, hard Carthagena bark, China-flava-dura, Rusty bark, China-Huamalies, Orangebark, and, Red bark of Santa Fé. Cinchona bark is used medicinally as a tonic and antiperiodic, in cases of dyspepsia, neuralgia, and intermittent fever. It has been administered in the form of infusion and tincture, but at present the disulphate of Quinine is the chief preparation used. The genus Exostemma yields various kinds of false Cinchona bark, which do not contain the Cinchona alkalis. In this genus the stamens are exserted, whereas in Cinchona they are included. Pinckneya pubens yields the fever-bark of Carolina.

Some of the plants of this order have emetic and purgative qualities. Cephäelis Ipecacuanha (see Trans, R. S. Ed., xxvi., with figures) yields the Ipecacuanha of the Pharmacopoeia (figs. 104, p. 41 ; 233, p. 118). The plant is found in the woods of several Brazilian provinces, as Pernambuco, Bahia, and Rio Janeiro. The flowers are dimorphic. The fruit is a succulent, dark purple, 2-seeded drupe. The roots, which are the officinal part, are contorted, knotty, and annulated, and about the thickness of a goose-quill. They are used as emetic and diaphoretic remedies, in the form of powder or wine. Their active ingredient is an alkaloid called Emetine. The plant can be propagated by making sections of the rhizome, as well as by means of the leaves. Ipecacuan and Cinchona are now largely cultivated in India. The import of Ipecacuan into Britain in 1870 was $62,952 \mathrm{lbs}$. Besides this brown or gray annulated Ipecacuanha, there are spurious kinds, such as large black striated Ipecacuanha, the produce of Psychotria emetica, and small striated Ipecacuanha, from a species of Richardsonia, and white undulated Ipecacuanha, furnished by Richardsonia scabra or brasitiensis, a native of the provinces of Rio Janeiro 
and Minas Geräes. Some of the species of Psychotria, Cephöelis, and Randia, are said to act so violently as to produce poisonous effects.

Among the astringent plants of the order may be noticed Uncaria Gambier, which supplies a kind of Catechu, known by the name of Gambier. Of the plants furnishing articles of diet, the most important is Coffea arabica, a native of Arabia and of the borders of Abyssinia, which furnishes the Coffee of commerce. The fruit is succulent, and the horny albumen of the seed is the part used as a beverage. It contains a bitter principle, denominated Caffein, which is identical with that got from Tea. The import of Coffee into the United Kingdom, in 1870 , was $179,901,864$ lbs. The seeds of some other plants of the order, as species of Galium, have been used as substitutes for Coffee. Among the plants yielding dyes, the most interesting is Rubia tinctoria, the root of which is the Madder of commerce. It contains three volatile colouring matters - madder purple, orange, and red. The latter is in the form of crystals, having a fine orange-red colour, and called Alizarine. This is the substance which yields the turkeyred dye. Rubia Munjista (cordifolia), Munjeet, is also used for a similar purpose. The import of Madder into Britain in 1870 was $37,820 \mathrm{cwts}$. ; of madder root $132,749 \mathrm{cwts}$; and of munjeet 2749 cwts. Oldenlandia umbellata is employed in the East Indies as a substitute for Madder, and so is the root of Morinda citrifolia, under the name of Sooranjee. The latter yields a peculiar colouring matter, called Morindine. It is extracted from the bark of the root, and is procured in the form of minute acicular crystals of a fine yellow colour. It is incapable of producing colours with alum and iron mordants, but with turkey-red mordant it produces a dark red. Many of the plants of this order, especially in the section Cinchoneæ, have very showy and fragrant flowers. The species of Musscenda and Calcophyllum are remarkable on account of one of their sepals becoming large and showy, Asperula odorata, Woodruff, gives out its fragrance when dried.

Order 95. - Valerianaces, the Valerian Family. (Monopet. Epigyn.) Calyx superior, its limb being either membranous or pappose. Corolla gamopetalous, inserted into the top of the ovary, tubular, 3-4-5-lobed, sometimes gibbous or spurred at the base. Stamens 1-5, adherent to the corolla and alternate with its lobes. Ovary inferior, 1-3-celled; ovule solitary, pendulous, style filiform; stigmas 1-3. Fruit dry, indehiscent, crowned by the limb of the calyx, 1-celled, in consequence of 2 cells being abortive. Seed solitary, pendulous, exalbuminous ; embryo straight ; radicle superior.-Hérbs, with opposite exstipulate leaves, and cymose inflorescence. They are found in temperate climates. Authors give 9 genera and 300 species. $E x-$ amples-Patrinia, Valeriana, Centranthus, Valerianella, Fedia.

The plants belonging to the order are strong-scented or aromatic, and some of them have been used as bitter tonics, anthelmintics, 
and antispasmodics. The root of Valeriana officinalis is the common medicinal Valerian. It has a bitter acrid taste, and a peculiar odour, which is fetid and disagreeable in the dry state. In the form of tincture and infusion it is prescribed in cases of hysteria. Other species of Valerian, as $V$. celtica, Phu, sitchensis, and Saliunca, have similar properties. Valerian is known to have a peculiar effect on cats, causing a species of intoxication. Nardostachys Jatamansi is the נרד (nerd), vágoos, or spikenard of the ancients, which was highly prized on account of its perfume. Valerianella olitoria, Lamb's lettuce, is used as a salad. Many of the plants in the order secrete a peculiar volatile oil, to which these properties are due.

Order 96.--DIPSACACEæ, the Teazel Family. (Monopet. Epigyn.) Calyx superior ; entire, or toothed, or pappose (figs. 302, 303, p. 199). Corolla gamopetalous, superior, with an oblique 4-5-lobed limb; æstivation imbricated. Stamens 4, attached to the tube of the corolla, and alternate with its lobes; anthers dithecal, distinct. Ovary inferior, unilocular ; ovule solitary, pendulous, anatropal ; style filiform ; stigma simple. Fruit dry, indehiscent, crowned by the limb of the calyx, covered by an epicalyx or involucellum, 1-celled. Seed solitary, pendulous, albuminous; embryo straight; radicle superior.-Herbs or undershrubs, with opposite or verticillate leaves, and capitate or verticillate flowers, surrounded by a many-leaved involucre (figs. 253, p. $175 ; 265$, p. 180). They are found in the south of Europe, the Levant, and at the Cape of Good Hope. The properties of the order are unimportant. The name Dipsacus is derived from si $\psi \alpha$, thirst, in consequence of the bases of the leaves of some of the species being connate, in such a way as to enclose a cavity which contains water ready to allay thirst. D. sylvestris is hence called Venus's Bath; the water contained in which was considered good for bleared eyes. The heads of Dipsacus fullonum, Fullers' Teazel, on account of their spiny bracts, are used in dressing cloth. Some of the species are reputed febrifugal. Scabiosa succisa is said to yield a green dye, and has from its astringent qualities attracted the attention of tanners. It has a premorse rhizome. Genera, 5 ; species, 120 . ExamplesMorina, Scabiosa, Dipsacus.

Order 97. - Caryceraces, the Calycera Family. (Monopet. Eprigyn.) Calyx superior, with a limb of 5 unequal segments. Corolla regular, infundibuliform, with a long slender tube, and a 5-lobed limb, the lobes having each three principal veins. Stamens 5, attached to the tube of the corolla, with as many alternating glands below them; filaments monadelphous; anthers partially united. Ovary inferior, I-celled; ovule solitary, pendulous; style single, smooth; stigma capitate. Fruit an achænium, crowned by the rigid spiny segments of the calyx, sometimes covered with papillæ, which emit spiral tubes when placed in water. Seed solitary, pendulous; embryo 


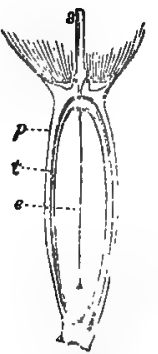

Fig. 744.

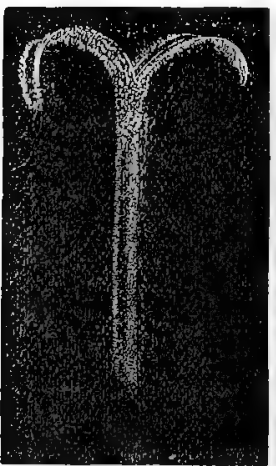

Fig. 743 .

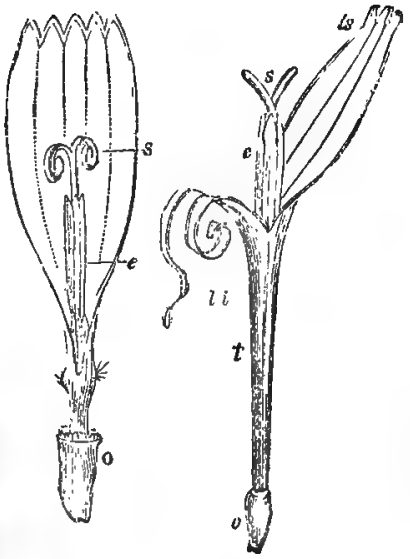

Fig. 734.
Fig. 785 .

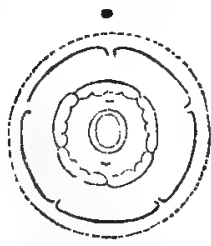

Fig. 733.

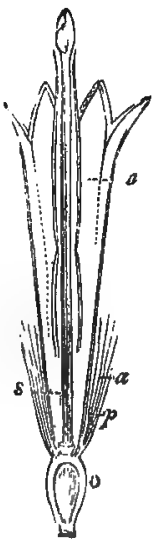

Fig. 736 .

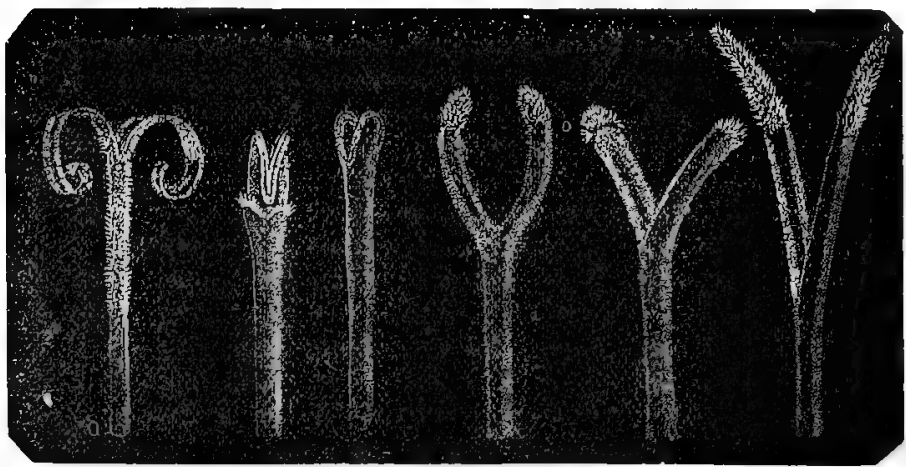

Fig. 737. Fig. 739. Fig. 738. Fig. 741. Fig. 740. Fig. 742 . 
in the axis of fleshy albumen; radicle superior.-Herlaceous plants, with alternate, exstipulate leaves, and sessile capitate flowers, surrounded by an involucre. They inhabit South America, rarely occurring in the tropical districts, but more plentiful in South Chili. Their properties are unknown. There are 3 known genera and 20 species. Examples-Calycera, Boopis.

Order 98.-Composite (Asteraceæ of Lindley, and Synantheræ of other authors), the Composite Family. (Monopet. Epigyn.) (Figs. 733-744). Calyz superior, its limb either wanting or membranous, or divided into bristles, paleæ, or hairs, and called pappus (figs. 301, p. $199 ; 736$ a). Corolla gamopetalous, ligulate (figs. 326, p. 207; 734 ), or tubular (fig. $736 p$ ), in the latter case usually 5 -toothed, ssometimes bilabiate (fig. 735); two marginal veins, containing spiral cells, run along each of the corolline divisions, and afterwards proceed along the axis of these divisions; æstivation valvate. Stanens usually 5 , alternate with the teeth of the corolla (fig. $736 \mathrm{e}$ ); filaments distinct; anthers (figs. 326 a, p. $207 ; 734,735,736$ e) cohering into a cylinder (synantherous or syngenesions). Ovary inferior, closely adherent to the tube of the calyx (figs. 734, 735, 7360,744 ), and undistinguishable from it, 1-celled; ovule solitary, erect (figs. 458, 459, p. $257 ; 736,744)$; style simple, sometimes with collecting hairs (fig. 737 ) ; stigmas two, distinct (figs. 438, p. $247 ; 637,643$ ) or united. Fruit, an achænium (Cypsela, p. 310), crowned with the limb of the calyx (fig. 744). Seed solitary, erect, exalbuminous (fig. 744); radicle inferior. - Herbs or shrubs, with alternate or opposite, exstipulate leaves, and capitula of flowers (called florets), which are either hermaphrodite or unisexual, and are surrounded by bracts in the form of an involucre (figs. 263 , p. $179 ; 264$, p. 180). Bractlets are sometimes interspersed with the flowers on the receptacle, and are then called paleæ. Some of the flowers belong to the cyanic, others to the xanthic series (p. 393). In the same head the flowers are sometimes homochromous ( $0 \mu \rho \varsigma$, similar, and $\chi \rho \tilde{\omega} \mu \alpha$, colour), belonging to the same

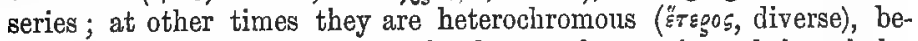
longing to different series, - the ligulate to the cyanic, and the tubular to the xanthic.

This is one of the largest, and, at the same time, one of the most important natural families in the vegetable kingdom. The plants were all included by Linnæus in the class Syngenesia, and were divided into five orders according to the sexes of the florets and the nature of the involucre. These divisions are given at page 415 , under the names Polygamia Aqualis, Superflua, Frustranea, Necessaria, and Segregata. The following series of terms have also been employed to express the nature of the capitula, as regards stamens and pistils :- 
1. Homogamous ( $8 \mu o s$, alike, the same, and $\gamma \alpha \alpha^{\prime} \circ$, marriage), flowers all hermaphrodite $(\not)$.

2. Heterogamous (Etcpos, diverse), the flowers of the disk (centre) hermaphrodite, those of the ray (circumference) either pistillate (female) only, or neutral, i.e. destitute both of stamens and pistils.

3. Monocious, $t-q$, male and female flowers in the same capitulum.

4. Heterocephalous (" $\tau \epsilon \rho \rho s$, diverse, and $\kappa \epsilon \phi a \lambda \dot{\eta}$, a head), some capitula entirely male, others entirely female, in the same plant.

5. Dicecious, $t: q$, some plants with male capitula only, others with female capitula only.

The following series of terms have been used to express the nature of the capitula, as regards the form and arrangement of the flowers:-

1. Discoid or Flosculous, corollas all tubular.

2. Ligulate or Semiflosculous, corollas all ligulate.

3. Radiate, corollas of the margin or ray ligulate, those of the centre or disk tubular.

4. Falsely-discoid, corollas all bilabiate.

5. Falsely-radiate, or radiatiform, corollas of the margin ligulate, those of the centre bilabiate.

Jussieu divided the order into three sections:- -1 . Cynarocephalæ (cynara, the artichoke), having the flowers all flosculous (tubular); involucre hard, conical, and often spiny. 2. Corymbiferæ (corymbus, a corymb, and fero, I bear), having flosculous (tubular) florets in the

Figs, 733-744. Organs of fructification of Compositx. Fig. 733. Diagram of the flower of a Senecio. The outer dotted circle indicates the pappose limb of the calyx; within it is the tubular corolla with five divisions, next five stamens with united anthers, and in the centre the 1-celled, 1-seeded ovary. Fig. 734. One of the ligulate flowers or florets of Cichorium Intybus, Succory or Chicory, belonging to the section Cichoracex. U, Ovary completely adherent to the tube of the calyx, the limb of the calyx forming a crown surrounding the base of the ligulate (strap-shaped) corolla, which has five apicilar divisions. $e$, Cylinder formed by the anthers (synantherous), traversed by the style with its bifid stigma, $s$. Fig. 735. Flower of Chætanthera linearis, belonging to the section Labiatitloræw. 0 , Ovary, with adherent calycine tube. $t$, Tube of the gamopetalous bilabiate corolla. $l s$, Upper lip of the corolla. $l i$, Lower lip of the corolla. $e$, Tube of the anthers. $s$, The bifid stigma at the apex of the style. Fig. 736. Tubular (flosculous) flower of Aster rubricaulis, belonging to the section Corymbiferæ, cut longitudinally, to show the erect orule, 0 , enclosed in the pericarp, consisting of the walls of the ovary, and the calycine tube incorporated. $\quad p$, United petals. a, Pappus, consisting of the altered limb of the calyx. e, Strmens with their united anthers, attached to the corolla. $s$, Style traversing the antherine tube. Fig. 737-743. Summits of the styles of plants belonging to different tribes of Compositæ. Two stigmatic bands are seen bordering the internal surface of the two branches which terminate each of these styles. Several have collecting hairs at different parts. Fig. 737. Summit of the style of Cichorium Intybus, one of the Cichoraces. Fig. 738. Summit of the style of Chætanthera linearis, one of the Labiatiflore. Fig. 739. Summit of the style of Thevenotia, one of the Cynarew. Fig. 740. Suromit of the style of Senecio Doria, one of the Senecionidex. Fig. 741. Summit of the style of Aster adulterinus, one of the Asteroider. Fig. 742. Summit of the style of Stevia purpurea, one of the Irupatoriaces. Fig. 743. Summit of the style of Vermonia angustifolia, one of the Vernoniacex. Fig. 744. Ripe fruit (Cypsela) of a Senecio, cut vertically. e, Exalbuminous embryo, with inferior radicle. $t$, Spermoderm or covering of the erect seed. $p$, Pericarp consisting of ovarian parietes with the closely-adherent calycine tube. $s$, Style. 
disk (centre), and ligulate (semiflosculous) in the ray (circumference); involucre hemispherical, leafy, or scaly, seldom spiny. 3. Cichoracea (cichorium, succory), having the florets all ligulate. Another section was subsequently added, 4. Lahiatifloræ, containing bilabiate flowers.

De Candolle made the following divisions, which are now pretty generally adopted:--1. Tubulifloræ, hermaphrodite flowers tubular, regularly 5-rarely 4-toothed. Under this section he included several tribes, in which the distinctions are founded on the nature of the style and stigma in the hermaphrodite flowers. These characters are shown in figs. 739-743, which illustrate the tribes Vernoniaceæ (fig. 743), Eupatoriaceæ (fig. 742), Asteroideæ (figs. 736, 741), Senecionideæ (figs. 733, 740), and Cynareæ (fig. 739). 2. Labiatifloræ, hermaphrodite flowers, or at least the unisexual ones, divided into two lips (fig. 735). The subdivisions of this section are also founded on the style and stigma (fig: 738). 3. Ligulifloræ (Cichoraceæ), all the flowers hermaphrodite and ligulate (fig. 734). The form of the style and stigma is seen in fig. 73.7.

Henslow gives the following tabular view of these various divisions - the letter $l$ meaning ligulate flowers ; $f$, flosculous ; H, hermaphrodite; $F$, female ; $N$, neuter; $M$, male; the relative position of the letters indicating the nature of the florets in the circumference and in the centre of the same capitulum; and in the last three divisions the letters having reference to the nature of the separate capitula :-

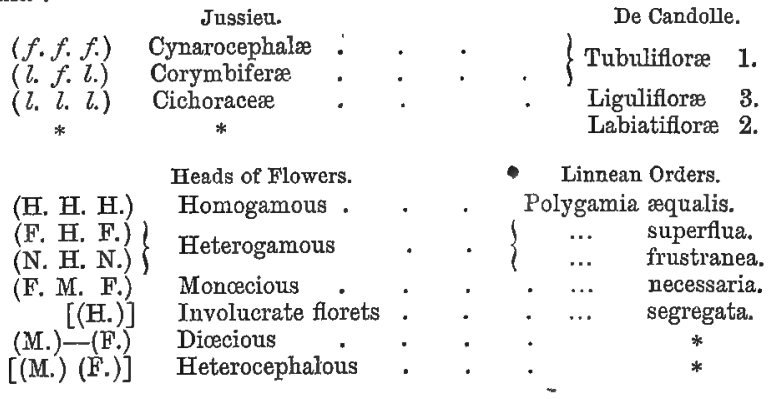

The plants of this order are variously distributed over all quarters of the world. According to the calculations of Humboldt, they constitute $\frac{1}{7}$ of the phanerogamous plants of France, $\frac{1}{8}$ of Germany, $\frac{1}{15}$ of Lapland ; in North America $\frac{1}{6}$, within the tropics of America $\frac{1}{2 .}$. Upon the authority of Brown they only form $\frac{1}{15}$ of the Flora of the north of New Holland, and did not exceed $\frac{1}{23}$ in the collection of plants formed by Smith upon the western coast of Africa in Congo. In northern regions they are generally herbaceous, while in warm climates they sometimes become shrubby, or even arborescent. Cichoraceæ 
abound in cold regions, while Corymbiferæ are common in hot climates. The number of known genera amounts to 766, comprehending 9800 species. They are considered as forming $\frac{1}{10}$ of the known species of plants, and this seems to have been the proportion at different periods. Examples-Vernonia, Eupatorium, Aster, Bellis, Anthemis, Senecio, Centaurea, Carduus, Triptilion, Trixis, Cichorium, Hieracium, Sonchus.

The plants belonging to this vast order have all more or less bitterness, which is sometimes associated with astringent, acrid, and narcotic qualities.

Sub-order Cynarocephalce.-The plants of this sub-order are usually tonic and stimulant. The bitterness of the plants of this section is often much lessened by cultivation, so that they become esculent. The root of Arctium Lappa (majus and minus), Burdock, is bitterish, and has been used in the form of infusion as a substitute for sarsaparilla. The root, leaves, and fruits (often called seeds), are diaphoretic, diuretic, and alterative. Aplotaxis Lappa (Auchlandia Costus), found in Cashmere, is said to be the ancient costus, the root of which was celebrated for its virtues. It has an aromatic, pungent odour, and is used for incense. In northern India it is called Koosht; in Bengal, Puchak. The leaves of Carduus Benedictus, Blessed Thistle, were formerly used in medicine as a stomachic and diaphoretic. The blanched stems and leaf-stalks of Cynara Cardunculus, Cardoon, are eaten, and so are the young'succulent receptacles of Cynara Scolymus, the Artichoke. Scolymus hispanicus is the Spanish oyster-plant. Its tubers are used like potatoes. The dried flowers of Carthamus tinctorius constitute safflower, which yields a pink dye. The genus Cardurs includes the various species of Thistle. What is denominated by gardeners the Scotch Thistle is Onopordon Acanthium, a doubtful native of Scotland, but not uncommon in England.

Sub-order Corymbiferce. - The plants of this section have the general bitterness of the order, and some of them have an aromatic odour, from the presence of volatile oil. The flowers of Anthemis nobilis, Chamomile, are odoriferous, and yield a volatile oil, which is at first greenish, or bluish, but afterwards yellowish brown. They are used as materials for fomentation, and an infusion of them acts as a diaphoretic and emetic. An extract is made from them, having bitter tonic qualities. The essential oil is an excellent carminative. Anthemis tinctoria supplies a yellow colour used for dyeing. Pyrethrum Parthenium, common Feverfew, is aromatic and stimulant. The root of Anacyclus Pyrethrum (Anthemis Pyrethrum), Pellitory of Spain, is an irritant and sialogogue; its properties depending on the presence of a volatile oil. Tussilago Farfara, Coltsfoot, has been used as a demulcent. The root of Inula Helenium, Elecampane, has stimu- 
lant and expectorant qualities. It contains a white amylaceous matter called Inulin. The species of Artemisia are remarkable for their strong odour and bitter taste. The heads of flowers of Artemisia Absinthium (Absinthium officinale), or Wormwood, and those of Artemisia santonica (A. maritima var.), and of other species, under the name of Wormseed, are used as anthelmintics and tonics. Several of these species contain a crystalline bitter principle. Artemisia mutellina and spicata are used in the preparation of a tincture or distilled spirit, called.in France Eau or Crême d'Absinthe, which is in request among those who are addicted to the pleasures of the table. The woolly leaves of Artemisia Moxa are used in China to form the inflammable cones or cylinders called Moxas, which are employed as counter-irritants. Artemisia Dracunculus, Tarragon, is used in pickles and salads, and in the medication of vinegar. A. Abrotanum is commonly called Southernwood, and is used on the continent in the preparation of beer. Artemisia indica, Sikkim-wormseed, grows 12 feet high, at elevations varying from 2000 to 6000 feet. The flowers of Chrysanthemum (Pyrethrum) carneum are said to destroy fleas. Senecio cruenta is the origin of the cultivated Cinerarias. The leaves of Tanacetum vulgare, Tansy, have stimulant antispasmodic properties. They contain a bitter resin, and an aromatic volatile oil. Arnica montana, Mountain Tobacco, or Leopard's-bane, is an acrid stimulant. Its flowers, leaves, and rootstock, are administered in nervous diseases, as well as in gout and rheumatism. The seeds (properly fruits) of Helianthus annuus, common Sunflower, contain a bland oil, and when roasted they have been used as a substitute for Coffee. The name Helianthus ("risos, the sun, $\ddot{\alpha} \nu 0 s$, a flower) is derived from the popular supposition that its large heads of flowers follow the sun in its course (p. 263). The roots of Helianthus tuberosus, Jerusalem, or more properly, Girasole Artichoke, are used as substitutes for potatoes. Eupatorium Ayapana, and Mikania Guaco, have been used to cure the bites of snakes. Ceradia furcata is a peculiar branching coral-like plant, which grows in dry sterile places in the south and west of Africa, and yields a resinoid substance, called by some African bdellium. Madia sativa has been cultivated on account of its bland oil. The species of Lychnophora give a peculiar feature to the mountains of Minas Geräes in Brazil. They grow like Vellozias, and they are covered with a dense coat of long brownishcoloured wool, which is often used for beds and pillows.

Sub-order Cichoracece.-Most of the plants of this section .yield a milky juice, which is bitter, astringent; and sometimes narcotic. By cultivation some of them are rendered esculent. Cichorium Intybus, Wild Succory, or Chicory, is cultivated for the sake of its root, which is used as a substitute for and as an addition to Coffee. The blanched leaves of Cichorium Endivia constitute Endive. Taraxacum Dens Leonis (Leontodon Taraxacum), Dandelion, yields a milky juice, which, in the 
form of extract, has been used medicinally as a diuretic and alterative. It contains a bitter crystalline principle called Taraxacine. Its root is mixed with Coffee in the same way as Chicory. The inspissated juice of Lactuca sativa, common Lettuce, and of $L$. virosa, wild or strongscented Lettuce, receives the name of Lactucarium, or Lettuce-opium, and is used medicinally for allaying pain and inducing sleep. It contains a neutral active principle called Lactucin. Other species of Lactuca yield an inspissated juice having similar qualities. Scorzonera is the esculent root of Scortonera hispanica, while Salsafy is the root of Tragopogon porrifolius, which is called the Oyster-plant in America. Many of the plants of the Cichoraceous section, such as Hieracium, Sonchus, and Tragopogon, act as horological and meteorological flowers (pp. 262, 263), their capitula opening and closing at certain periods of the day, and in different states of the weather.

Order 99.-Brunoniaces, the Brunonia Family. (Monopet. Perigyn.) Calyx persistent, 5-partite, with bracts at the base. Corolla inserted at the base of the calyx, monopetalous, nearly regular, withering; limb 5-parted, having central veins in its segunents, which divide at the top into two recurrent marginal veins; æstivation valvate. Stamens 5, inserted with, but free from, the corolla, alternating with its segments; anthers articulated with the short filaments, dithecal, introrse, dehiscing longitudinally. Ovary free, unilocular; ovule solitary, erect, anatropal; style single; stigma enclosed in a 2-valved cup or indusium. Fruit a utricle, enclosed in the hardened calycine tube. Seed solitary, erect, exalbuminous; embryo straight; cotyledons fleshy, plano-conyex; radicle minute, inferior.-Stemless berbaceous plants, with radical, exstipulate leaves, and capitate flowers, supported on scapes, and surrounded by an involucre of enlarged bracts. Natives of Australia. Their properties are unknown. The order contains as yet only 1 genus and 2 species. Example-Brunonia.

Order 100.-Goodeniacese, the Goodenia Family. (Monopet. Epigyn. and Perigyn.) Calyx persistent, usually equal, with 3-5 divisions, sometimes obsolete. Corolla inserted into the calyx, monopetalous, more or less irregular, marcescent or deciduous; its tube split at the back, and sometimes separable into five pieces, when the calyx only coheres with the base of the ovary ; its limb 5-partite, unior bilabiate, the thin part of the segments being at the edges, which are folded inwards in æestivation. Stamens 5, distinct, inserted with, but free from, the corolla, and alternate with its segments; anthers not articulated with the filaments, distinct or cohering, bilocular, with longitudinal dehiscence; pollen-grains either separate or united in fours. Ovary more or less united to the calycine tube, 1-2- or 4celled, sometimes with a gland at its base; ovules definite or 00 , attached to a central, often free, placenta; style 1 , simple, rarely divided ; stigma fleshy, undivided or 2-lobed, surrounded by a cup- 
like indusium. Fruit a 1-2- or 4-celled capsule, or drupaceous or nut-like. Seeds definite or indefinite, with a thickened, often hard testa ; embryo straight, in fleshy albumen; cotyledons leafy; radicle inferior.-Herbs, rarely shrubs, not lactescent, with scattered, exstipulate, usually alternate leaves, and distinct, never capitate flowers. They are found chiefly in Australia and in the South Sea Islands. The leaves of Scoevola Taccada are eaten as potherbs. Some superstitious qualities are ascribed to its berries. The pith, which is soft and spongy, is fashioned by the Malays into artificial flowers. Sccevola Bela-Modogam appears to be emollient, and is used in India to bring tumours to a head. The order is divided into two sub-orders :- 1 . Goodenieæ, with dehiscent capsular fruit, and numerous seeds. 2. Scævoleæ, with indehiscent, drupaceous, or nut-like fruit, and seeds solitary, or two in each cell. There are 23 known genera, according to authors, and about 200 species. Examples-Goodenia, Velleia, Leschenaultia, Scævola, Dampiera.

Order 101.-STYLIDIACEx, the Stylidium or Stylewort Family. (Monopet. Epigyn.) Calyx adherent, persistent, with 2-6 divisions, bilabiate, or regular. Corolla gamopetalous, falling off late, limb usually irregular, 5-6-partite, segments with a central vein ; æstivation imbricated. Stamens 2 ; filaments united with the style into a longitudinal column; anthers didymous, rarely simple, lying over the stigma; pollen simple, globose, or angular. Ovary cohering with the calyx, bilocular, or by contraction of the dissepiment unilocular, often surmounted by one gland in front, or by two opposite ones; ovules anatropal; style 1 ; stigma entire or bifid. Fruit a bivalvular, bilocular, or spuriously unilocular capsule, with septicidal dehiscence. Seeds 00, small, erect; embryo minute, enclosed in fleshy, somewhat oily albumen.- Non-lactescent herbs or undershrubs, with alternate, scattered, or somewhat verticillate, entire, exstipulate leaves. They are well distinguished by their gynandrous structure. The column formed by the union of the filaments and style, possesses, in the species of the genus Stylidium, a peculiar irritability. It hangs down on one side of the flower, and when touched at the point of flexure, it springs over with considerable force from one side to the other. If not too far advanced to maturity, the column will recover its former position in the course of time. The flower may be cut off carefully without disturbing the colvmn, and the irritability continues for a considerable length of time if the flower is put into water. The movement is said to be connected with the bursting of the anthers, and the discharge of the pollen on the stigma. The cause of this movement is very obscure, but it seems to depend on some changes in the cells (pp. 284, 387). The plants are principally natives of marshy places in Australia. Some are found at the southern point of South America. There are 5 known genera and 123 species. Examples-Stylidium, Forstera. 
Order 102.-CampandLacese, the Harebell Family. (Monopet. Epigyn.) (Fig. 745.) Calyx superior, usually 5-lobed (figs. 746, $747 \mathrm{c}$ ), sometimes 3-8-lobed, persistent. Corolla gamopetalous, inserted into the top of the calyx, usually 5-lobed (fig. 276, p. 186), sometimes 3-8-lobed, regular, marcescent (fig. 557 e, p. 308) ; æstivation valvate (figs. $746,747 p$ ). Stamens inserted into the calyx, alternating with the corolline lobes, and equal to them in number; anthers bilocular, free (fig. $747 \mathrm{e}$ ); pollen spherical. Ovary more or less completely inferior, composed of two or more carpels ; ovules indefinite (fig. 748); style simple, covered with collecting hairs (fig. 747); stigma naked, simple, or with as many lobes as there are ovarian cells (figs. 318 s, p. $206 ; 440$, p. $249 ; 747$ s). Fruit capsular, crowned

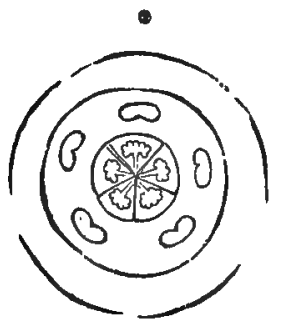

Fig. 745 .

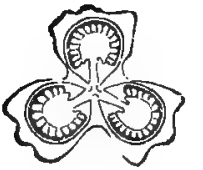

Fig. 748.

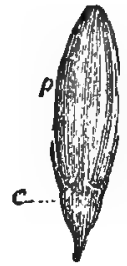

Fig. 746 .

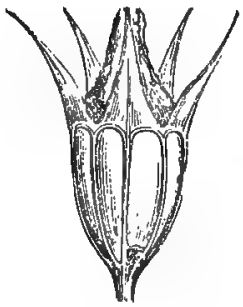

Fig. $\$ 49$.

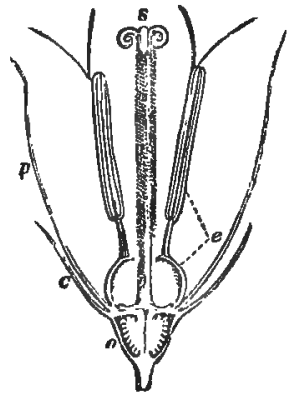

Fig. 74 .

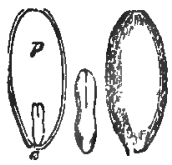

Figs. $751,752,750$.

with the withered calyx and corolla, dehiscing in a loculicidal manner by lateral apertures (figs. $557 t t$, p. $308 ; 749$ ), or by valves at the

Figs. 745-752, Organs of Fructification of Campanula Rapunculus, Rampion, to illustrate the natural order Campanulacexe. Fig. 745. Diagram of the flower, showing five divisions of the calyx, five divisions of the corolla alternating with them, five alternating stamens, and five cells of the ovary. Fig. 746. Flower-bud. $\dot{c}$, Calyx adherent to the ovary. $p$, Corolla, with valvate æstivation. Fig. 747. Vertical section of the flower. $c$, Calyx colering with the ovary, o. $p$, Gamopetalous corolla. e, Stamens with bilocular anthers. $s$, Lobed stigma at the apex of the style, which is eovered with collecting hairs. $\checkmark$, Ovary containing numerous ovules attached to a central placenta.

Fig. 748. Horizonal section of the ovary. Fig. 749. Fruit crowned by the limb of the calyx, dehiscing by openings at the base. Fig. 750. Seed in an entire state. Fig. 751. Seed cut vertically. $p$, Perisperm (albumen). e, Straight embryo in the axis of the albumen, with the radicle pointing to the hilum. Fig. 752. Emabryo detached, showing its form, the cotyledons and radicle. 
apex. Seeds 00, attached to a central placenta; embryo straight, in the axis of fleshy albumen; radicle pointing to the hilum (figs. 750752). - Lactescent herbs or undershrubs, with alternate, rarely opposite, exstipulate leaves. The hairs on the style are said to be retractile, and seem to be connected with the application of the pollen (fig. $516, \mathrm{p} .290$ ). The flowers in most instances belong to the cyanic series. They are natives chiefly of northern and temperate regions. They abound in the alpine regions of Europe and Asia, and are also frequent in North America. It is stated that the species whose capsule dehisces by lateral fissures are natives of the northern hemisphere, while those with apicilar dehiscence are principally found in the southern hemisphere. The milky juice found in the plants of this order has acrid properties. The roots and young shoots of Campanula Rapunculus, Rampion, are used as articles of diet. Authors enumerate 29 genera, including 536 species. Examples-Campanula, Phyteuma, Jasione.

Order 103.-Lobeurace es, the Lobelia Family. (Monopet. Epigyn.) Calyx superior, 5-lobed or entire. Corolla gamopetalous, inserted on the calyx, irregular, more or less deeply 5-cleft. Stamens 5 , attached to the calyx, alternate with the segments of the corolla; anthers cohering; pollen oval. Ovary inferior, 1-3-celled ; ovules 00, attached either to central or parietal placentas ; style glabrous, with a fringe of hairs below the stigma. Fruit a 1 - or many-celled capsule, with apicilar dehiscence. Seeds numerous; embryo straight, in the axis of fleshy albumen; radicle pointing to the hilum.-Lactescent herbs or shrubs, with alternate, exstipulate leaves. They are found both in temperate and warm countries. There are 29 known genera and 386 species. Examples-Lobelia, Siphocampylus, Clintonia.

Acridity prevails more or less in the order. The milky juice of some, such as Lobelia urens, is said to be vesicant. Lobelia inflata, Indian Tobacco, a native of North America, is used medicinally as a sedative, expectorant, and antispasmodic. It is chiefly administered in cases of asthma. The whole plant is active, but the root and capsules are said to be most powerful. In large doses the plant acts as a narcotico-acrid poison. It owes its properties to a volatile alkaloid called Lobelina. The root of Lobelia syphilitica is acrid and emetic. The milky juice of some of the plants of the order contains a considerable quantity of caoutchouc.

Order 104. - Vacciniacese, the Cranberry Family. (Monopet. Epigyn.) Calyx superior, entire, 4-6-lobed. Corolla monopetalous, 4-6-lobed; æstivation imbricated. Stamens distinct, 8-12, inserted into an epigynous disk; anthers bilocular, with two horn-like cells, dehiscing by pores (fig. 367, p. 223). Ovary inferior, 4-5-celled; ovules 00 ; style simple; stigma simple. Fruit succulent, crowned by the persistent limb of the calyx. Seeds 1 or many in each cell, minute; 
embryo straight, in the axis of fleshy albumen ; cotyledons very short; radicle long, inferior. - Shrubby plants, with alternate, undivided, exstipulate leaves. They are closely allied to Ericaceæ, and differ from that order chiefly in their inferior ovary. They are natives of temperate regions, and some of them are marsh plants. Some are astringent, others yield subacid edible fruits. Cranberries are produced by Vaccinium Oxycoccus (Oxycoccus palustris) and $V$. macrocarpum. In the common Cranberry there are two forms of fruit, one pyriform, the other round. V. Vitis-idaea, red Whortleberry, or Cowberry, yields a fruit which is often used as a substitute for Cranberries. The leaves of the plant are sometimes used to adulterate Uva-Ursi. $V$. uliginosum, found in alpine countries, produces the black Whortleberry. Vaccinium Myrtillus yields the Bilberry or Blaeberry. There are 28 genera and 200 species. Examples-Vaccinium, Oxycoccus, Thibaudia.

\section{Sub-class III.-CoRoLLIFLoRes.}

Calyx and corolla present. Corolla gamopetalous, hypogynous, usually bearing the stamens. It includes the hypogynous monopetalous and gamopetalous orders of Jussieu and Endlicher.

Order 105.-ERICACE\&, the Heath Family. (Monopet. Hypog.) Calyx 4-5-cleft, nearly equal, persistent. Corolla inserted at the base of the calyx, or hypogynous, monopetalous (fig. 323, p. 207), 4-5-cleft, sometimes tetra- or penta-petalous, regular or irregular, often marcescent; æstivation imbricated. Stamens definite, equal in number to the segments of the corolla, or twice as many, inserted with the corolla, and either free from it or attached to its base ; anthers 2-celled, cells hard and dry, bifid (fig. 368, p. 223), usually having appendages at the base (fig. $370 a$, p. 223) or apex, dehiscing by apicilar pores (fig. 372, p. 225) or clefts. Ovary free, surrounded at the base by a disk or scales, multilocular; ovules 00 , attached to a central placenta ; style 1, straight ; stigma 1, undivided (fig. 443, p. 249) or toothed. Fruit capsular or baccate, many-ceiled, with loculicidal or scepticidal dehiscence. Seeds 00, minute; embryo cylindrical, in the axis of fleshy albumen; radicle next the hilum.-Shrubs, undershrubs, or herbaceous plants, with evergreen, often rigid, entire, verticillate, or opposite, exstipulate leaves. The order contains many beautiful and showy plants, which abound at the Cape of Good Hope, and which are found also in Europe, North and South America, and Asia. The order has been divided into the following sub-orders:-1. Ericeæ, with the testa closely adherent to the kernel, including the true Heaths with naked buds, and the Rhododendron tribe with scaly conical buds. 2. Monotroper, seeds having a loose winged testa, including the true Monotropas or Fir-rapes, scaly plants, with longi- 
tudinally or transversely dehiscent anthers, and Pyroleæ, or the Wintergreen tribe, leafy plants with porous anthers. These plants are usually put in separate orders-Monotropaceæ and Pyrolaceæ. There are 54 known genera and about 900 species. Examples-Erica, Calluna, Menziesia, Andromeda, Arbutus, Rhododendron, Azalea, Dabeocia, Monotropa, Pyrola.

The plants of the order are not distinguished for medicinal virtues. None of the species of Erica are put to any use. There are six species of the genus natives of Britain; two of which, E. cinerea and E. Letra$l i x$, are common ; two are peculiar to Ireland, $E$. Mackaiana and $E$. mediterranea; and two are common to England and Ireland, $E$. ciliaris and $E$. vagans. Culluna vulgaris is Ling, or the common Heather. Its capsule is septicidal, while in Erica the capsule is loculicidal. It has astringent qualities, and has been used for dyeing. It is commonly made into brooms. The leaves of Arbutus or Arctostaphylos Uva-Ursi, Bearberry, are used as astringents, especially in chronic mucous discharges. Its fruit is baccate. Arctostaphylos glauca, Manzanita, covers the mountains of California with a thick brushwood. Many of the species of Rhododendron, Azalea, Kalmia, Andromeda, and Ledrum, have poisonous narcotic qualities. These properties are well marked in Rhododendron Chrysconthum, a Siberian species. It is said that Azalea pontica was the plant the flowers of which yielded the poisonous honey noticed by Xenophon in his account of the retreat of the Ten Thousand. Andromedas have scaly buds and loculicidal capsules; while Rhododendrons have scaly buds and septicidal capsules. A. fastigiata is Himalayan heather. The fruits of many plants belonging to the order are eatable. Gaultheria procumbens and Shallon are American shrubs, which furnish succulent and grateful berries. They yield a volatile oil. In Sikkim the leaves of species of Gualtheria and Andromeda are used for tea. Azalea procumbens grows on the Scottish mountains, also in the arctic regions, and on the Alps of northern and southern Europe, but not on the Himalaya. Arbutus Unedo is called Strawberry-tree, from its fruit resembling a strawberry in aspect. It is, however, by no means agreeable as an article of food, and the specific name may possibly indicate that to eat one is sufficient. The plant grows at the Lakes of Killarney, in a native state. Chimaphila (Pyrola) umbellata, a North American plant, has been employed as a tonic and diuretic. The leaves have a bitter astringent taste, and the fresh plant is irritant.

Order 106.-EPACRIDACEE, the Epacris Family. (Monopet. Hypog.) Calyx 5- rarely 4-parted, often coloured, persistent. Corolla inserted at the base of the calyx, or hypogynous, deciduous or marcescent, monopetalous, sometimes separable into 5 petals; limb with 5 , rarely 4 , equal divisions, sometimes by the cohesion of the segments, bursting transversely; æstivation imbricated or valvate. Stamens inserted with or on the corolla, equal in number to, and alternate with, 
its segments, rarely fewer; anthers 1-celled (fig. 359, p. 222), without appendages, opening longitudinally; pollen round, or formed of three united grains, attached to a single central receptacle. Ovary sessile, free, multilocular, rarely unilocular, surrounded by scales at the base; ovules solitary or 00 ; style 1 ; stigma simple, sometimes toothed. Fruit drupaceous, baccate, or capsular. Seeds albuminous ; embryo slender, in the axis of fleshy albumen, and about half its length. -Shrubs, or small trees, with alternate, rarely opposite, exstipulate leaves, which are sometimes half-amplexicaul at the base. They are allied to Ericaceæ, and may be said to represent the heaths in Australia. They are distinguished from heaths by the structure of their anthers. Some yield edible fruits. One of the plants, called Native Currant in Australia, is Leucopogon Richei. The order has been divided into two tribes:-1. Epacreæ, polyspermous. 2. Styphelieæ, monospermous. There are 32 genera and 336 species. Examples-Epacris, Sprengelia, Styphelia, Leucopogon, Lissanthe.

Order 107.- EBenacese, the Ebony Family.

(Monopet. Hypog.) Flowers hermaphrodite or unisexual. Calyx 3-7-divided, nearly equal, persistent. Corolla gamopetalous, regular, deciduous, somewhat coriaceous; limb with 3-7 divisions; æstivation imbricated. Stamens either attached to the corolla, or hypogynous, 2 or 4 times as many as the corolline segments, rarely equal to them in number, and then alternate with them; filaments usually in two rows, the inner row having smaller anthers; anthers erect, lanceolate, bilocular, with longitudinal dehiscence. Ovary free, sessile, multilocular; ovules 1-2 in each cell, pendulous; style divided, rarely simple; stigmas bifid or simple. Fruit fleshy, round or oval, the pericarp sometimes opening regularly. Seeds few; testa membranous; embryo straight, nearly in the axis of cartilaginous albumen; cotyledons leafy; radiole taper, next the hilum.-Trees or shrubs, not lactescent, with alternate, exstipulate, coriaceous leaves. They are chiefly found in tropical regions, and many species are met with in India. The plants are remarkable for the hardness and durability of their wood. Some yield edible fruit. Diospyros reticulata and Ebenum and other African and Asiatic species, supply Ebony, which is the black duramen of the tree. Other species of Diospyros furnish Ironwond. Diospyros virginiana, the Persimon, yields a fruit (sometimes called the Dateplum) which is austere when green, but becomes sweet and eatable when ripe, especially after being acted on by frost. Its bark has been employed as a febrifuge. D. Kaki is the Keg-fig of Japan, the fruit of which resembles a plum. Diospyros Embryopteris, a native of India and Siam, yields a succulent fruit, the pulp of which is astringent. Diospyros qucesita supplies the Coromandel or Calamander wood of Ceylon. Genera, 12; species, 175. Examples-Diospyros, Royena, Maba. 
Order 108.-STrracadefin (Symplocinew of Don), the Storax Family. (Monopet. Hypog.) Calyx persistent, with an entire or a 5- or 4-divided limb. Corolla gamopetalous, regular, inserted in the calyx; æstivation imbricated or valvate. Stamens definite or 00 , attached to the corolline tube, of unequal length; filaments often slightly united at their base in one or more parcels; anthers innate, dithecal, introrse. Ovary either free or cohering more or less to the calycine tube, 2-5-celled, the septa occasionally deficient towards the centre; ovules $2-4$ in each cell, or 00, pendulous, sometimes the upper ones ascending; style simple; stigma simple. Fruit enclosed in the calyx, drupaceous, usually unilocular by abortion. Seeds usually solitary, erect, or suspended; embryo slender, in the axis of fleshy albumen; cotyledons flat, foliaceous; radicle long, pointing to the hilum.-Trees or shrubs, with alternate, exstipulate leaves, and frequently stellate hairs. They are chiefly natives of warm countries. There are two tribes:-1. Styraceæ, with a more or less valvate astivation of the corolla, and long anthers. 2. Symploceæ, with a quincuncial corolline æstivation, and roundish anthers. Authors give 12 genera, including 130 species. Examples-Styrax, Halesia, Symplocos.

The plants of the order have in general stimulant, aromatic, and fragrant properties. Styrax officinale, a tree inhabiting Syria, Arabia, and the southern parts of Europe, is supposed to be the source of the balsamic resinous substance called Storax. The resinous juice is procured after incisions or punctures by insects. Common Storax is imported into Britain from Trieste, in the form of little cakes, having a balsamic odour. Bessides resin and a little volatile oil, it contains from 1-2 $\frac{1}{2}$ per cent of Benzoic acid. It has been employed medicinally as a pectoral remedy. Styrax Benzoin is a tree 70 or 80 feet high, a native of Sumatra and Borneo, which yields by incisions the concrete balsamic exudation called Benzoin. When fine this substance contains about 80 per cent of resin, and nearly 20 of Benzoic acid. It is used medicinally as a stimulant expectorant, and is one of the ingredients in the celebrated Friar's balsam. It exists also in other empirical remedies, such as Riga balsam and Jesuits' drops. Benzoin is generally used for fumigation and incense. Pastilles are made by mixing it with balsam of tolu, sandal-wood, labdanum, charcoal, nitre, gum, and tragacanth. It is used for incense in the Greek Church. There are two kinds of Benzoin, one from Siam, and the other from Sumatra. Halesias are the Snowdrop trees of Carolina. Some of the species of Symplocos are used for dyeing; others are used as tea.

Order 109.-Aquifoliaces (Ilicineæ of some), the Holly Family. (Monopet. Hypog.) Sepals 4-6 ; æstivation imbricated. Corolla monopetalous, hypogynous, 4-6-parted; æstivation imbricate. Stamens inserted into the corolla, alternate with its segments, and equal to 
them in number; filaments straight; anthers adnate, bilocular, introrse. Disk 0. Ovary free, fleshy, somewhat truncate, 2-6-celled; ovules solitary, anatropal, pendulous from a cup-shaped funiculus; stigma nearly sessile, lobed. Fruit fleshy, indehiscent, with 2-6 monospermous nucules, and hence it is sometimes called a nuculanium. Seed suspended; albumen large, fleshy; embryo sinall, lying next the hilum ; cotyledons small ; radicle superior.-Evergreen trees or shrubs, with alternate or opposite, coriaceous, simple, exstipulate leaves. They are found in various parts of the world, as in Europe, North and South America, and Africa. Lindley enumerates 11 genera, including 110 species. Examples-Tlex, Prinos.

Astringent and tonic properties seem to pervade the order. Ilex Aquifolium, the common Holly, is a native of Europe, and is one of the indigenous plants of Britain. It forms excellent fences and hedges. At Tynninghame, in Scotland, there were 2952 yards of holly hedges, most of them upwards of 140 years old. These hedges vary in height from 10 to 23 feet, and they are 9 to 13 feet wide at the base. The leaves and bark of the Holly are said to possess tonic and febrifuge properties; while its succulent fruit (berries) are emetic and purgative. Haller recommends the juice of the leaves in jaundice. Its wood is white and hard, and is much esteemed in turnery, joinery, and cabinet work, while its bark furnishes bird-lime. Ilex Paraguensis, and other species, furnish Yerba Maté or Paraguay Tea, which is used extensively in some districts of South America. The leaves of the plant yield the bitter principle called Theine, which has been mentioned as existing in Tea and Coffee. Other species of Iles; are employed in Brazil for a similar purpose. The black drink of the Creek Indians is prepared from the leaves of Ilex vomitoria.

Order 110. - SAPotaces, the Sapodilla Family. (Monopet. Hypog.) Flowers hermaphrodite. Calyx regular, with 5, sometimes 4-8 divisions, persistent; æstivation valvate or imbricate. Corolla monopetalous, hypogynous, deciduous, regular, its lobes equal to, rarely twice or thrice as many as, those of the calyx. Stamens inserted on the corolla, definite, distinct ; fertile ones as many as, rarely more than, the segments of the calyx, with which they alternate; sterile ones alternating with the fertile ones, rarely wanting. Disk 0 . Ovary free, multilocular; ovules solitary, anatropal, ascending or pendulous; style 1 ; stigma simple, sometimes lobed. Fruit fleshy, multilocular, or by abortion unilocular. Seeds nut-like, solitary ; testa bony and shining; with a long scar on its inner face ; embryo large, erect, white; albumen usually fleshy, sometimes 0 ; cotyledons in the albuminous seeds, foliaceous, in the exalbuminous, fleshy ; radicle straight or slightly curved, pointing to the hilum.-Lactescent trees or shrubs, with alternate, exstipulate, entire, coriaceous leaves. They are natives chiefly of the tropical parts of India, Africa, and America. A few are found at the 
Cape of Good Hope. The number of known genera noticed by authors is 25 ; species 218. Esamples-Chrysophyllum, Achras, Bassia, Isonandra, Mimusops.

Many of the plants of this order yield edible fruits, while others supply oily matter. Some act as tonics, astringents, and febrifuges ; Achras Sapota and other species furnish the Sapodilla Plum and Naseberry, well known West Indian fruits; while Achras mammosa yields the fruit called Marmalade. The bark of some of the species of Achras is tonic and astringent, and the seeds of several have laxative properties. The fruit of Chrysophyllum Cainito is the Star-apple. Mimusops Elengi, supplies the Surinam Medlar of Europeans. The fruit of Mimusops kaki is eaten in India. Various species of Bassia yield oil. $B$. Parkii is said to be the source of the Shea butter, and hence the tree is called the Butter-tree of Park. B. butyracea, the Madhuca tree, gives a similar product, which is used as butter in Nepaul. The milky juice of some of the plants contains elastic matter. Isonandra Gutta is the source of Gutta Percha, a kind of caoutchouc, which softens at a moderate temperature, and is used for the soles of shoes, ropes, straps, casts, and various articles for domestic use. The kernels of Lucuma mammosa contain prussic acid.

Order 111. - Mrrsinaces, the Myrsine Family. (Monopet. Hypog.) Flowers hermaphrodite or occasionally unisexual. Calyx 4-5-cleft, persistent. Corolla monopetalous, hypogynous, 4-5-cleft, equal. Stamens 4-5, inserted into the corolla, and opposite to its segments ; filaments distinct, rarely united, sometimes 0 , occasionally 5 sterile petaloid alternating ones; anthers sagittate, erect, bilocular, with longitudinal dehiscence. Ovary free or slightly adherent, unilo-' cular ; ovules definite or indefinite, campylotropal, immersed in a free central placenta ; style single; stigma simple or lobed. Fruit fleshy, 1- or many-seeded. Seeds angular or roundish, with a concave hilum, and a membranous spermoderm; albumen horny; embryo usually curved, often heterotropal ; cotyledons short; radicle horizontal when the seed is solitary, inferior when there are several seeds.-Trees, shrubs, or undershrubs, with alternate or opposite, coriaceous, exstipnlate leaves. They are much restricted as regards their geographical limits, and they are said to abound chiefly in islands with an equable temperature. They are found in Africa, Asia, and America. Little is known regarding their properties. Theophrasta Jussioei is a pricklyleaved shrub, which is called Coco in St. Domingo. Its seeds are eatable, and a kind of bread is made from them. The berries of $M y r-$ sine bifaria are said to possess cathartic properties. The Ardisias are prized for the beauty of their foliage. There are 33 known genera and about 300 species. Examples-Myrsine, Ardisia, Mæsa, Jacquinia.

Order 112. - Jasminace $x$, the Jasmine or Jessamine Family. 
(Monopet. Hypog.) Flowers $\nsucceq$. Calyx with 5-8 divisions or teeth, persistent. Corolla monopetalous, hypogynous, regular, salver-shaped, with 5-8 divisions; æstivation twisted or valvate. Stamens 2, inserted on the corolla, included; anthers bilocular, with longitudinal dehiscence. Disk 0. Ovary free, 2-celled; ovules erect, anatropal, 1-4 in each cell ; style 1 ; stigma 2-lobed. Fruit a double berry, or a pyxidium, or a 2-valved capsule. Seeds usually solitary, rarely in pairs, albuminous or exalbuminous; embryo straight; radicle inferior.Shrubs often with twining stems, and opposite or alternate, pinnate leaves. They abound chiefly in the tropical parts of India. They have frequently fragrant flowers which yield oils, and their leaves and roots are sometimes bitter. The essential oil of Jasmine is procured from Jasminum officinale, grandiflorum, odoratissimum, and Sambac. The bitter root of Jasminum angustifolium, ground small and mixed with powdered Acorus Calamus root, is considered in India as a valuable external application in cases of ringworm. In the East Indies the tube of the corolla of Nyctanthes Arbor-tristis is fragrant at night, and its flowers yield an orange dye. There are 6 known genera and 110 species. Examples-Jasminum, Nyctanthes, Bolivaria.

Order 113.-Coldmeldiace , the Columellia Family. (Monopet. Epigyn.) Calyx superior, quinquepartite. Corolla rotate, inserted into the calyx, 5-8 parted; æstivation imbricate. Stamens 2, inserted in the throat of the corolla; anthers roundish, 3-lobed, extrorse, each consisting of six linear sinuous cells, arranged in pairs, dehiscing longitudinally, and attached to a 3-lobed fleshy connective. Disk fleshy, perigynous. Ovary adhering to the calycine tube, 2-celled; ovules 00 ; style simple, smooth ; stigma capitate, 2-lobed. Fruit a bilocular, bivalvular capsule, with both septicidal and loculicidal dehiscence. Seeds 00 ; testa smooth and coriaceous ; embryo straight, in the axis of fleshy albumen; cotyledons oval, obtuse ; radicle long, pointing to the hilum.-Evergreen shrubs or trees, with opposite, entire, exstipulate leaves, and solitary yellow flowers. Natives of Mexico and Peru. Their properties unknown. There is 1 genus mentioned, including 3 species. Example - Columellia.

Order 114.- Oreaceas, the Olive Family. (Fig. 272, p. 184.) Flowers $\not$, sometimes $t$. Calyx gamosepalous, divided, persistent. Corolla gamopetalous, hypogynous, 4-cleft, sometimes of 4 petals, which are connected in pairs by means of the filaments, sometimes 0 , rstivation somewhat valvate. Stamens 2 (rarely 4), alternate with the corolline segments ; anthers dithecal, with longitudinal dehiscence. Disk 0. Ovary free, 2-celled; ovules in pairs, collateral or pendulous; style 1 or 0 ; stigma entire or bifid. Fruit drupaceous, baccate or capsular, sometimes samaroid (fig. 533, p. 299.) Seeds often by abortion solitary; albumen dense, fleshy, abundant; embryo straight, about half the Iength of the albumen; 
cotyledons leafy; radicle superior.-Trees or shrubs, with opposite leaves (fig. 272, p. 184), which are either simple or compound. Found chiefly in temperate regions. They occur in North America, Asia, Europe, and Australia. There are 2 tribes of the order:-1. Oleæ, with a drupaceous or berried fruit. 2. Fraxineæ, with a samaroid (winged) fruit. Lindley mentions 26 genera, including 144 species. Examples - Olea, Ligustrum, Fraxinus, Syringa, Phillyrea, Chionanthus.

The plants of the order are bitter, tonic, and astringent, and some yield fixed oil. Olea europcea is the Olive-tree, the $\pi^{4}$ (zait or sait) of the Old Testament, the 's $\lambda$ cia of the Greeks. It grows naturally on the coast of the Mediterranean, and is cultivated in many parts of the south of Europe. There are several varieties of the plant, two of which have been long distinguished-the wild and cultivated. The former is an evergreen shrub or low tree, with spiny branches and round twigs; the latter is a taller tree, without spines, and with fourangled twigs. The fruit is a drupe, about the size and colour of a damson. Its fleshy pericarp yields by expression olive-oil, of which the finest comes from Provence and Florence. It consists of two oleaginous principles-Margarin and Elain. Olive oil has nutrient, emollient, and laxative properties. It is used in forming ointments, liniments, and plasters. The bark of the Olive-tree has been used as a tonic; and a resinous exudation from it, called Olivile, or Olive-gum, or Lecca-gum, is employed in the same way. Spanish or Castile soap is made by mixing olive oil and soda, while soft soap is made by mixing the oil with potash. The flowers of Olea fragrans, the Kwei-hwa of the Chinese, are used to perfume teas. Several species of Ornus, more particularly $O$. rotundifolia and $O$. europcea, yield a sweet exudation called Manna, not however the p (manna) of the Bible, on which the Israelites fed. The Manna or flowering Ash is a native of southern Europe, and grows abundantly in the south of Italy and in Sicily, whence the Manna of commerce is imported. The tree attains a height of 20 or 30 feet, and it has a fine appearance when its clusters of white flowers are produced. Manna is the concrete juice of the tree, which flows out after incisions or insect-punctures. It contains a peculiar sweet principle called Mannite. Manna is nutritive and lazative, and is sometimes administered to infants and young children, on account of the mildness of its action. Syringa vulgaris, common Lilac, has a febrifuge bark, which is extensively employed by the peasants in Brenne for the cure of the endemic intermittent fever. According to Meillet this quality is owing to a principle which he calls Lilacine. Fraxinus excelsior, the common Ash, is one of the trees which comes late into leaf, and the leaves of which fall off early in autumn. Some specimens attain the height of 70,90 , or 100 feet, with a circumference of 20 or 30 feet. The wood of the tree is tough and elastic, 
and is used for oars, as well as by coachmakers, etc. The wood of its roots is beautifully veined. The pendulous variety, called Weepingash, is often engrafted on the common Ash, so as to produce a better effect. The leaves of Ligustrum vulgare, common Privet (fig. 272, p. 184), are astringent. L. lucidum yields a kind of waxy excretion, which is used in China for economical purposes. L. Ibota is a Japan privet, on which the wax insect (Asicaca cerifera) feeds.

Order 115.-Salvadorace , the Salvadora Family. (Monopet. Hypog.) Calyx of 4 minute sepals; corolla 4-partite; stamens 4; ovary superior. Fruit succulent, 1-celled; seed solitary, exalbuminous.Small trees or shrubs, with opposite leaves and minute panicled flowers. Natives of Syria and India. The plants are acrid and stimulant, and some of them have properties like Mustard. Salvadora persica was considered by Royle to be the Mustard tree of Scripture, but this seems to be an error. (See Mustard, under natural order CRUCIFER s, p. 437.) There are 2 or 3 genera and a small number of species. Examples-Salvadora, Monetia.

Order 116.-Asclepiadaces, the Asclepias Family. (Monopet. Hypog.) (Figs. 385, 386, p. 230; 753-761.) Calyx 5-divided, persistent (fig. $756 \mathrm{c}$ ). Corolla synpetalous (monopetalous), hypogynous, regular, 5-lobed (figs. 754, $755 p p$ ), deciduous ; æstivation imbricate, rarely valvate. Stamens 5 , inserted into the base of the corolla, and alternate with its segments (fig. $756 e$ ) ; filaments usually combined so as to form a tube; staminal tube rarely naked behind, generally furnished with a corona (crown) of variously-formed leaves, which are either distinct or connate. Anthers bilocular, each cell sometimes spuriously divided; pollen, when the anther dehisces, cohering in masses (pollinia), which are either as numerous as the cells, or are confluent in pairs, and adhere to the five stigmatic processes, either in sets of two or four, or singly (figs. 381, p. 229 ; 385, 386, p. $230 ; 757$ ). Ovaries 2 (fig. 756 o); ovules 00 ; styles 2 , closely approaching each other (fig. $756 \mathrm{~s}$ ), often very short; stigma common to both styles, dilated, quinquangular; the angles furnished with cartilaginous corpuscles which retain the pollinia, or with glands (figs. $755,756 \mathrm{~g})$. Fruit consisting of two follicles (sometimes only one by abortion), having a placenta on the ventral suture (fig. 759). Seeds 00 , imbricate, pendulous, usually comose (hairy) at the hilum (fig. 760); albumen thin (fig. $761 p$ ); embryo straight; cotyledons leafy; radicle superior (fig. 761 e).-Shrubs, or occasionally herbs, usually with milky juice, and often twining. The leaves are usually opposite, sometimes alternate or verticillate, with interpetiolary cilia

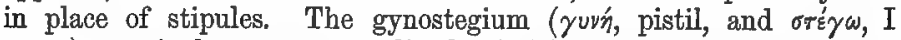
cover), staminal crown, or peculiar-hooded (cucullate) appendages, prolonged from the tube of the filaments, which occur in many of the plants of this order, give a peculiar aspect to their flower (see fig. 385 , 
p. 230). They inhabit chiefly warm and tropical regions, but many species extend to northern climates. Many succulent species are
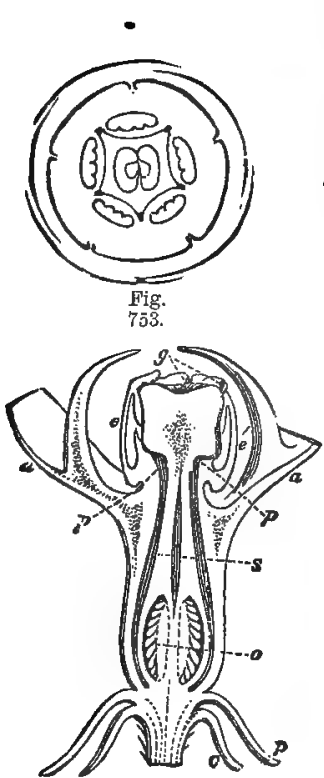

Fig. 756 .

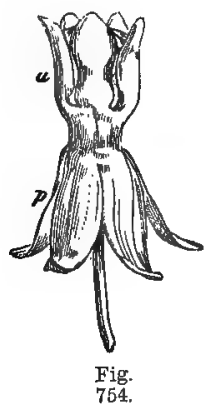

Fig. 755.

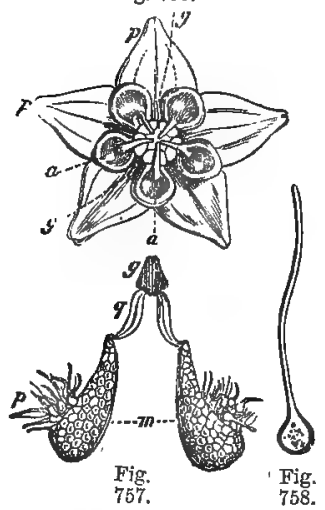

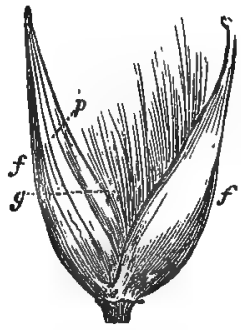

Fig. 759.

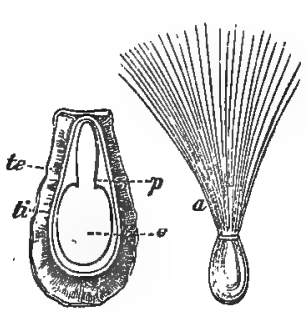

Fig. 761.

Fig. 760 .

found in the south of Africa. In tropical India and Australia, and

Figs. 753-761. Organs of fructification of Asclepias nivea, to illustrate the natural order Asclepiadaceæ. Fig. 753. Diagram of the flower, with five divisions of the calyx, five segments of the corolla, five stamens, and two ovaries.

Fig. 754. The entire flower. $p$, Corolla, with five lobes. a, Appendages forming the staminal crown (corona). Fig. 755. The flower viewed from above. $p p$, Gamopetalous corolla with its five lobes. $a$ a, Appendages forming the corona or crown. $g g$, Glandular bodies attached to the stigma, and bearing the pollen-masses (pollinia). Fig. 756. The flower cut vertically. $c$, Calyx, $p$, Corolla. $a a$, Coronal appendages. e, Stamens. o, Ovary. s, Styles, which are united at the upper part by means of the large stigma, at the base of which, towards the points, $p p$, the pollen tubes enter. Fig. 757. Two pollen-masses, $m$, attached by two prolongations, $q$, in the form of a caudicle or tail, to another body, $g$, formed by the union of two stigmatic glands. $p$, Pollen-grains with tobes beginning to escape from the masses. Fig. 758. One of the pollen-grains, with its tube separated and highly magnified. Fig. 759. Fruit at the period of dehiscence. $f f$, Two follicles. $p$, Placenta, which is detached. $g$, Comose seeds. Fig. 760. One of the comose seeds separated. . $a$, The hairy appendage at the hilum. Fig. 761. Seed separated from the hairs and cut vertically. te, External integument. $t i$, Internal integument. $p$, Perisperm or thin albumen. e, Embryo, with leafy cotyledons and superior radicle. 
in all the equinoctial parts of America, they also abound. Authors enumerate 159 genera, including 958 species. Examples-Periploca, Asclepias, Calotropis, Cynanchum, Gonolobus, Stapelia, Hoya, Dischidia.

The plants of the order have acrid, purgative, emetic, and diaphoretic properties. The milky juice is usually bitter and acrid, but occasionally it is bland, and is used as milk, as in the case of Gymnema lactiferum, the Cow-plant of Ceylon. Asclepias tuberosa, the Butterfly-weed, or Pleurisy-root, is used as a cathartic and diaphoretic in North America. The emetic properties of Asclepias curassavica have secured for it the name of Wild Ipecacuanha in the West Iudies. The leaves of Solenostemma (Cynanchum) Argel are used to adulterate Alexandrian Senna. The fragrant roots of Hemidesmus indicus are used in Madras as a substitute for Sarsaparilla, under the name of Country Sarza. It is also called Nannari, or Ananto-múl. The bark of the root of several species of Calotropis, such as C.procera' (Hamiltonii), and gigantea, furnish the substance called Mudar, which is used as a diaphoretic in India. It contains a principle called Mudarine, which gelatinises on being heated, and becomes fluid on cooling. Cynanchum monspeliacum furnishes Montpellier Scammony, and Periploca mauritiana is the source of Bourbon Scammony. Both of these substances act as purgatives, and are used to adulterate true Scammony. Marsdenia tinctoria and Gymnema tingens are said to yield a dye similar to indigo. The milky juice of many of the plants contains caoutchouc in its composition. The root of Tylophora asthmatica, an Indian plant naturalised in the Mauritius, is used as country or Indian Ipecacuanha. Hoya carnosa receives the name of wax-flower from the peculiar aspect of its blossoms. Dischidia Raftesiana, an Indian climber, has remarkable ascidia (p. 100). The Stapelias are singular plants, resembling some of the Cactuses and Euphorbias. Their blossoms are often very fetid, and hence they are called Carrion flowers. Some of the species of Asclepias receive the name of Wild Cotton, on account of the hairs attached to their seeds. Gomphocarpus fruticosus is the silk plant of Madeira.

Order 117.-APocynaCEse, the Dogbane Family. (Monopet. Hypog.) Calyx usually 5-partite, persistent. Corolla hypogynous, gamopetalous, regular, usually 5-lobed, deciduous; æstivation contorted, twisting in some cases to the right, in others to the left. Stamens 5, inserted on the corolla, alternate with its segments ; filaments distinct; anthers 2-celled, dehiscing longitudinally; pollen granular, globose, or 3-lobed, immediately applied to the stigma. Ovaries 2, and each unilocular, or 1 , and bilocular ; ovules 00 ; styles 2 or 1 ; stigma 1, with a contraction in the middle. Fruit follicular or capsular, or drupaceous or baccate, double or single. Seeds 00 , rarely definite, usually pendulous; albumen cartilaginous or fleshy, 
rarely 0 ; embryo foliaceous ; radicle turned towards the hilum.Trees or shrubs, usually lactescent, with entire, generally opposite, exstipulate leaves, with interpetiolary cilia or glands. They are chiefly found in tropical regions. They appear to be most abundant in the hot parts of Asia, are less common in the tropics of America, and still less abundant in Africa. Authors enumerate 110 genera, including 602 species. Examples-Apocynum, Echites, Strophanthus, Nerium, Balfouria, Vinca, Tanghinia, Plumieria, Carissa.

Many of the plants of this order are poisonous. Some are used medicinally, as cathartics, and there are a few which yield edible fruits. The order is in general to be regarded with suspicion. One of the most deadly plants of the order is Tanghinia venenata (Cerbera Tanghin), the seeds of which, Tangēna nuts, supply the famous Tanghin poison, used formerly in Madagascar as an ordeal in cases of criminals. Strophanthus Kombe furnishes the Kombe arrow-poison of South Africa. S. hispidus seems also to supply an arrow-poison in West Africa. Toxicophloea Thunbergii is used as a fish-poison at the Cape of Good Hope. Nerium Oleander, the common Oleander, is poisonous. The stomata of its leaves are furnished with cellular hair-like processes (fig. 79, p. 29), and the anthers are terminated by feathery appendages (fig. 366, p. 223). Death has ensued from eating the flowers of this plant. Its branches, when divested of their bark and used as skewers, rendered meat roasted on them poisonous. The meat proved fatal to seven out of twelve of those who partook of it. The roots of Apocynum cannabinum and androscemifolium are said to be emetic. The bark of Alstonia (Echites) scholaris is used in India as a tonic. The Vincas, Periwinkles, are astringent and acrid. Allamanda cathartica, a native of Ceylon and Java, is emetic and cathartic. Although the milky juice is generally acrid, still in some instances it is bland. Thus, the juice of Tabernomontana utilis, Hyahya, the Cow-tree or Milk-tree of Demerara, is used as milk. Many of the plants, such as Urceola elastica and Vahea gummifera, supply caoutchouc. Wrightia tinctoria yields a dye like indigo. Aspidosperma excelsum is a Guiana tree, remarkable for the sinuous arrangement of its wood, which gives the stem a deeply-fluted appearance. Beaumontia is a magnificent Indian climber ; it has splendid foliage, and festoons of enormous funnel-shaped white flowers.

Order 118.-Logantacem, the Logania or Nux Vomica Family. (Monopet. Hypog.) Calyx 4-5-partite (fig. 311 c, p. 203); æestivation valvate or imbricate. Corolla hypogynous, regular or irregular, 4-5or 10-divided (fig. $311 t l, \mathrm{p} .203$ ); ;estivation convolute or valvate. Stamens inserted on the corolla, 5 or 1 , not always corresponding with the divisions of the corolla; pollen elliptical or triangular, simple, or marked with three bands. Ovary free, usually 2-celled; ovules 00 or solitary, peltate and amphitropal, or ascending and anatropal. 
Fruit a 2-celled capsule, with placentas finally becoming loose; or a nuculanium with 1- or 2-seeded nucules; or baccate, with seeds immersed in a pulp. Seeds usually peltate, sometimes winged; albumen fleshy or cartilaginous; embryo small; radicle turned towards the hilum, or parallel with it.- Shrubs, herbs, or trees, with opposite entire leaves, and usually with stipules, which adhere to the footstalks, or form interpetiolary sheaths. They inhabit chiefly tropical and warm climates, in Asia, Africa, and America. The order is divided into three sub-orders :- -1 . Loganieæ, æstivation of corolla convolute, fruit a bilocular capsule or nuculanium, seeds peltate, sometimes winged. 2. Strychneæ, æstivation of corolla valvate, fruit a 2-3-celled berry or capsule, seeds peltate, embryo rather large. 3 . Spigelieæ, æstivation of corolla valvate, fruit a didymous capsule, seeds apterous, embryo small, cotyledons inconspicuous. There are about 32 known genera, and nearly 190 species. Examples-Logania, Potalia, Strychnos, Spigelia.

The plants of this order are highly poisonous. They act energetically on the spinal marrow, causing tetanic spasms, or they produce narcotic symptoms by acting on the brain. Many are very bitter and a few are tonic. Strychnos $N u x-$ Vomica, the Poison-nut or Koochla, a tree which abounds on the Malabar and Coromandel coasts, supplies the substance called Nux-Vomica. It yields fruit of the size and appearance of an orange, with a coriaceous reddish integument, enclosing a mucilaginous pulp. The seeds, which are embedded in the pulp, are the officinal part of the plant. They are circular and fiat, umbilicated on one surface, and are thickly covered with brown silky hairs. All parts of the plant, especially the seeds and bark, are intensely bitter. The seeds contain two alkaloids, Strychnia and Brucia, to which they owe their poisonous properties. These alkaloids occur in combination with Igasuric or Strychnic acid. Nux-Vomica and Strychnia, in poisonous doses, cause death by producing tetanic spasms in the muscles of respiration. The bark of the Nux-Vomica tree is the false Angostura bark, and the wood is often called Snakewood. Strychnia exists in other species of Strychnos, as S. Ignatia (Ignatia amara), St. Ignatius's Bean, S. colubrina, S. lagustrina (Snakewood), and S. Tieuté, the source of a Java poison called Upas Tieute. It is also said to exist in the Woorali or Ourari poison of Guiana, which some consider to be the produce of $S$. toxifera or guianensis. The effects of this last-mentioned poison, however, do not seem to agree with those of Strychnia. Strychnia stimulates the spinal cord without affecting the function of the brain. It causes convulsive twitches of the muscles of the arms and legs, and hence it has been recommended in cases of chronic palsy, unconnected with any signs of local irritation or determination of blood to the head. Its administration requires great caution, as $\frac{2}{3}$ of a grain have been known to produce 
alarming lock-jaw, and $\frac{1}{6}$ of a grain has killed a dog. Effects antagonistic to the action of Strychnia are produced by the Calabar bean. Some species of Strychnos seem not to possess a poisonous principle in large quantity, for they are used as tonics and febrifuges. Among them may be noticed strychnos potatorum and pseudoquina. The former is called Clearing-nut, and is used in India for purifying water. The root of Spigelia marilandica, Carolina Pink-root (fig. 311, p. 203) is used as an anthelmintic, more particularly in the United States. $S$. Anthelmia, Guiana Pink-root, is employed in Demerara for a similar purpose. These plants also possess narcotic qualities.

Order 119. - Gentranacese, the Gentian Family. (Monopet. Hypog.) (Fig. 269, p. 182.) Calyx gamosepalous, usually in 5 divisions, sometimes 4-6-8 or 10 divisions, persistent. Corolla gamopetalous, hypogynous, usually regular and marcescent; limb sometimes fringed, divided into as many lobes as the calyx; æstivation plaited or imbricate-twisted. Stamens inserted upon the corolla, alternate with its segments, and equal to them in number, some of them occasionally abortive. Ovary composed of 2 carpels, unilocular or partially bilocular (fig. 423, p. 242); ovules 00 ; anatropal ; style 1 ; continuous ; stigmas 1 or 2 . Fruit capsular or baccate, 1-celled (fig. 423, p. 242), usually bivalvular, with septicidal, or rarely loculicidal dehiscence. Seeds 00, small; erobryo straight, minute, in the axis of soft fleshy albumen; radicle next the hilum.-Herbs, seldom shrubs, with opposite (fig. 269 , p. 182), rarely alternate, entire or divided, exstipulate leaves, which are often 3-5-ribbed. The plants of the order are distributed generally over the globe, inhabiting both cold and warm regions. They are rare in the arctic and antarctic islands. They exhibit great varieties of colours, and many are prized for their beauty. There are two tribes:- 1 . Gentianeæ, æstivation of corolla imbricatetwisted, leaves opposite, simple, and entire. 2. Menyantheæ, æstivation of corolla plaited or induplicate, leaves usually alternate and compound, or divided. Authors mention 67 genera, including 484 species. Examples-Gentiana, Chironia, Agathotes, Erythræa, Chlora, Menyanthes, Villarsia.

The general property of the plants of this order is bitterness, which pervades all their organs. Hence they are used as tonics. The medicinal gentian is the root of Gentiana lutea, a plant which grows abundantly on the Pyrenees, and on the Alps of Switzerland and Austria, usually at an elevation of 3000 to 5000 feet. It produces showy yellow flowers, and its root is yellow internally. It is administered in the form of extract, infusion, tincture, and wine, as a tonic. Its roots are often mixed with the roots of other species, such as Gentiana punctata, purpurea, and pannonica. Gentiana Kurroo of the Himalayas has similar properties. The British species, Gentiana campestris and Amarella, have also been used as bitter tonics. The 
officinal Chiretta is the herb and root of Agathotes Chirayita (Ophelia Chirata), a herbaceous plant found in the Himalayas. The whole plant is bitter, and has been long used in Bengal as a tonic and stomachic. Adenema hyssopifolia is the Chota chirayta. The flowering cymes of Erythrcea Centaurium, common Centaury (fig. 269, p. 182), are used as a substitute for gentian, and so are the leaves of Menyanthes trifoliata, Buck-bean, Marsh-trefoil, or Bogbean. The roots of Frasera Walteri sometimes receive the name of American Calumba. Red-flowered species of Gentian are nearly confined to the Andes and New Zealand. Bluer flowered species on the Himalayas reach to 16,000 feet.

Order 120.-BignoNIACE , the Trumpet-Flower Family. (Monopet. Hypog.) Calyx divided or entire, sometimes spathaceous. Corolla monopetalous, hypogynous, usually irregular, 4-5 lobed. Stamens 5 and unequal, or 4 and didynamous, some of them occasionally sterile; anthers bilocular. Disk annular or glandular. Ovary superior, 1-2celled, each cell being often spuriously divided; ovules indefinite; style 1 ; stigma bilamellar (fig. 441, p. 249), or 2-4-cleft or entire. Fruit a 2-celled (sometimes spuriously 4-celled) and 2-valved capsule, occasionally succulent. Placentas parietal, sometimes extending to the centre, and forming a spurious dissepiment, which finally separates, bearing the seeds. Seeds winged or wingless, often flat and compressed, exalbuminous; embryo straight; radicle next the hilum.Trees, shrubs, or herbs, with opposite, rarely alternate, exstipulate leaves. They abound generally in tropical regions, but some of them are widely distributed. The order has been divided into four suborders:-1. Bignoniex, capsule 2-valved, 2-celled, sometimes spuriously 4-celled, with a dissepiment parallel or contrary to the valves, at length free, bearing the seeds, which are transverse, compressed, and winged. 2. Cyrtandreæ (Didymocarpeæ), fruit succulent or capsular, or siliquose and 2-valved, seeds small, ovate, or cylindrical, suspended, apterous, sometimes comose. 3. Crescentieæ, fruit woody, and melon-shaped, enclosing large seeds, which are immersed in the pulp of the placentas. 4. Pedaliex, fruit dmupaceous, rarely capsular and 2-valved, spuriously many-celled; seeds few, large and apterous, pendulous, erect or transverse. These are reckoned separate orders by many. There are upwards of 100 known genera and about 666 species. Examples-Bignonia, Spathodea, Eccremocarpus, Cyrtandra, Didymocarpus, Crescentia, Pedalium, Sesamum, Kigelia, Tanæcium.

There are many showy plants in this order. Their flowers are frequently large and trumpet-shaped. None of them are noted for marked medicinal properties. Some are timber trees, others furnish dyes and articles of diet, while a few have bitter and astringent qualities. The species of Bignonia are conspicuous objects in tropical forests. Their wood sometimes exhibits a crucial arrangement (fig. 125, p. 62). From Bignonia Chica the Indians extract a red ochreous 
colouring matter, with which they paint their bodies. Crescentia Cujete (C. cuncifolia), the Calabash-tree, is found in the tropical regions of America, and produces a large melon-like fruit, containing a slightly acid pulp, which is sometimes eaten. Its pericarp is hard, and after removal of the pulp it is used as cups and bottles. Calabashes are used in crossing the rivers in Africa; a large Calabash can support two men on the water. These Calabashes are two feet or more in diameter. Teel seeds, the produce of Sesamum orientale, supply a bland oil, called by the Arabs Siritch. It is used, under the name of gingilee oil, to adulterate oil of almonds. Parmentiera cerifera, Palo de Velas, is the candle-tree of the Isthmus of Panama, Kigelia pinnata yields excellent timber in Africa. The bark of $K$. africana is used on the Gold Coast for dysentery. The succulent fruit of Tancecium lilacinum is eaten. The fruit of the species of Martynia, the Unicorn-plant, is furnished with hooked processes. Tecoma radicans and Eccremocarpus scaber are climbing plants often cultivated. In the perfect fruit of Pretrea (Martynia) Zanguebarica there are 6 cells formed by the mode in which the placentas unite, and of these cells two are seedless.

Order 121.-Gesnaracese, the Gesnera Family. (Monopet. Perigyn.) Calyx partially adherent, 5-partite; æstivation valvate. Corolla monopetalous,'tubular, more or less irregular, 5-lobed ; æstivation imbricated. Stamens 4, didynamous, with the rudiment of a 5 th, rarely 2 ; anthers dithecal, with a thick swollen connective. Ovary partly free, unilocular, formed by two carpels with parietal placentas, which are 2-lobed; ovules indefinite, anatropal ; style continuous with the ovary ; stigma capitate, concave, glandular or annular. Disk surrounding the base of the ovary. Fruit capsular or succulent, 1-celled, more or less adherent. Seeds 00, minute; testa thin, finely and obliquely veined; embryo erect in the axis of fleshy albumen; radicle pointing to the hilum. Herbs or shrubs, often springing from scaly tubers, with opposite or whorled, rugose, exstipulate leaves and showy flowers. They are found principally in the warmer regions of America, and are interesting chiefly on account of their beauty, for they do not appear to possess any important qualities. There are 22 known genera and upwards of 120 species. Examples-Gesnera, Columnea, Gloxinia, Achimenes.

Order 122.-Polemoniaces, the Phlox Family. (Monopet. Hypog.) Calyx inferior, in 5 divisions, persistent, sometimes irregular. Corolla regular, rarely irregular, 5-lobed. Stamens 5, inserted on the middle of the tube of the corolla, and alternate with its segments; pollen often blue. Disk lobed. Ovary free, 3-celled; ovules anatropal or amphitropal ; style simple; stigma trifid. Fruit a 3celled, 3-valved capsule, with septifragal dehiscence. Seeds angular or oval, or winged, "often enveloped in mucus, containing spiral threads, 
ascending, in a single or a double row ; embryo straight, in the axis of a fleshy or horny albumen; cotyledons foliaceous, elliptical or cordate ; radicle inferior, next the hilum.-Herbaceous or climbing plants, with opposite or alternate, simple or compound leaves. They inhabit temperate countries chiefly, and they abound in the north-western part of America. There are 17 genera enumerated by Lindley, including 116 species. Examples-Polemonium, Phlox, Cobæa (fig. 350, p. 220), Collomia, Gillia, Leptosiphon, Cantua.

Many of the plants of this order have showy flowers, and are commonly cultivated in flower-borders. Connected with the episperm of various species of Collomia are numerous spiral cells, and when the seeds are moistened with water, the mucus surrounding the cells is dissolved, so that the spiral fibres are uncoiled. The movements of these fibres, when uncoiling, are beautifully seen under the microscope. The fibres carry with them a mucous envelope which has the appearance of a membrane. Polemonium coeruleum, Greek Valerian, or Jacob's ladder, is bitter. In Siberia poultices are prepared from its leaves. The Russians fancy that a decoction of it is useful in hydrophobia.

Order 123. - Hydropirluace.er, the Hydrophyllum Family. (Monepet. Hypog.) Calyx 5-parted, persistent. Corolla monopetalous, hypogynous, regular, 5-cleft; æstivation plicate or imbricate. Stamens 5, inserted upon the corolla, and alternate with its segments; filaments sometimes petaloid; anthers deeply-lobed at the base, often versatile, 2-celled, dehiscing longitudinally or transversely. Disk annular or $0 . \quad$ Ovary free, 1-2-3-celled; ovules definite or indefinite; style 1 or 2 ; stigmas usually $2 . \quad$ Fruit capsular, 2-valved, 1-2-celled, with a parietal or a large central placenta. Seeds with a brittle or reticulated testa; embryo in the midst of fleshy or cartilaginous albumen; radicle next the hilum.-Trees, shrubs, or herbs, with opposite, or alternate, exstipulate, often lobed leaves. They occur both in the northern and southern parts of America chiefly. They have no properties of importance. Many have showy flowers, and some have glandular or stinging hairs. The order has been divided into two tribes:-1. Hydrophylleæ, including Hydroleæ of authors, with the anthers dehiscing longitudinally, disk present, ovary 1-2-celled, styles 2. 2. Diapensieæ, with anthers dehiscing transversely, disk 0 , ovary 3 -celled, style single. There are 20 known genera and 81 species. Examples-Hydrophyllum, Hydrolea, Nemophila, Eutoca, Phacelia, Diapensia.

Order 124.-Convolvulacesi, the Convolvulus or Bindweed Family. (Monopet. Hypog.) Calyx in five divisions, persistent, imbricated, often bracteated (figs. 762-764). Corolla monopetalous, hypogynous, deciduous, regular ; limb 5-lobed, with a plaited or contorted æstivation (fig. $763 p$ ); tube sometimes with scales, alternate with the lobes of the limb. Stamens 5, inserted in the base of the 
corolla, and alternate with its lobes (fig. 764 e); filaments included or exserted, equal or unequal. Disk annular, hypogynous. Ovary free, 2-4-celled, rarely by abortion 1-celled; ovules definite, erect, when more than one, collateral ; style 1 (fig. $764 \mathrm{~s}$ ), usually bifid, rarely 2 ; stigmas obtuse or acute (fig. 765). Fruit succulent or capsular (fig. 766), 1-4-celled, with septifragal and septicidal, or circumscissile dehiscence. Seeds albuminous; embryo curved or spiral (figs. 769 ; 598, p. 335) ; cotyledons corrugated (fig. 768) or inconspicuous ; radicle inferior.-Herbs or shrubs, usually twining, sometimes parasitical, often with a milky juice, and with alternate, un-

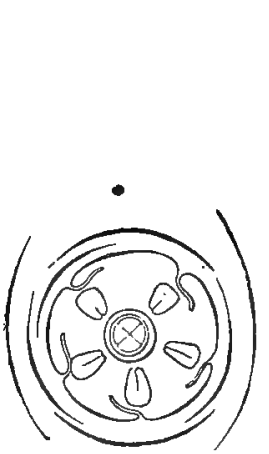

Fig. 762.

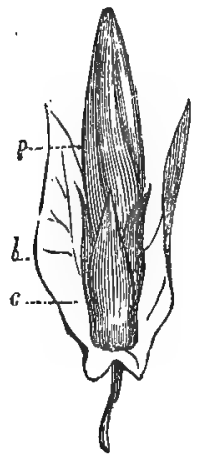

Fig. 763.

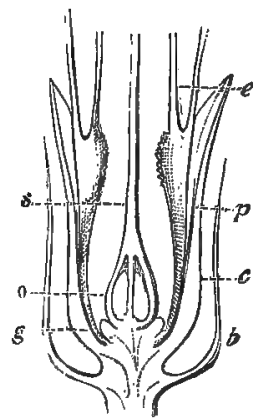

Fig. 764 .

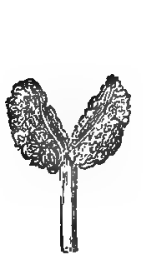

Fig. 765 .

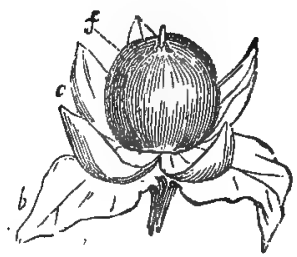

Fig. 766.

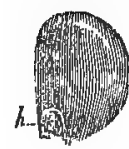

Fig. 767.

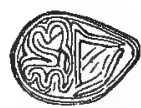

Fig. 768.

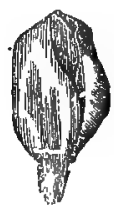

Fig. 769 .

divided or lobed, exstipulate leaves, rarely leafless. They occur chiefly in tropical and temperate regions. A few only are found in cold

Figs. 762-769. Organs of fructification of Convolvuius (Calystegia) sepium, to illustrate the natural order Convolvulacex. Fig. 762. Diagram of the flower, showing two bracts five unequal divisions of the imbricated calyx, five lobes of the plicate contorted corolla, five stamens alternating with the corolline lobes, and a quadrilocular ovary. Fig. 763. Flower bud. b, Large bracts. c, Calyx. p, Corolla. Fig. 764. Vertical section of the lower part of the flower. $b$, Bracts. $c$, Calyx. $p$, Tube of corolla, bearing the filaments of the stamens, e. v, Ovary. $s$ style. Fig. 765. Summit of the style and stigmas. Fig. 766. Fruit, $f$, suirounded by the calyx, $c$, and the bracts, $b$, which are persistent. Fig. 767. Seed. $h$, Hilum. Fig. 768. Section of the seed, showing the corrugated cotyledons. Fig. 769. Embryo separated. 
climates. The order has been divided into two sub-orders:-1. Convolvuleæ, true Bindweeds, leafy plants, with the corolline tube not scaly, embryo curved, cotyledons conspicuous. 2. Cuscuter, Dodders, leafless parasites, having scales on the corolline tube, embryo spiral and filiform (fig. 598, p. 335), cotyledons inconspicuous. There are 51 genera and upwards of 740 species. Examples-Convolvulus, Ipomcea, Exogonium, Dichondra, Cuscuta.

The order is characterised generally by the presence of an acrid juice in the roots, which has purgative properties. On this account several of the plants are used medicinally. The old genus Convolvulus has been split into various genera, such as Ipomoea, Exogonium, Pharbitis, Batatas, Quamoclit, Calonyction, and Lepistemon, according to the form of the corolla, the exsertion or inclusion of the stamens, the form and nature of the stigma, and the structure of the ovary. Exogonium Purga (Ipomcea Purga) is the Jalap plant, a native of the eastern declivities of the Mexican Andes, which grows well in this country, requiring only the protection of a frame during winter. The plant flowered regularly for many years in a cold frame in the Edinburgh Botanic Garden. It has been introduced on the Neilgherry hills, South India. The root-stock is the officinal part. It has a roundish tuberous form, is black externally, white and milky within, and varies in size from that of a walnut to that of a moderate-sized turnip. It contains a resin, in which its active properties reside. It is used in the form of powder and tincture, as an active irritant cathartic. Ipomoea Jalapa yields Mechoacan root, which has purgative properties. I. Orizabensis supplies a kind of Jalap, the Purgo macho of the Mexicans ; 'while $I$. simularis furnishes Tampico Jalap. The root of Convolvulus Scammonia yields a gummy resinous exudation, which constitutes medicinal Scammony. The plant grows abundantly in Greece, the Grecian Islands, and various parts of the Levant. The plant succeeds well in a cold frame in the Edinburgh Botanic Garden. The Jalap and Scammony plants flower in the open border in the garden. Scammony is procured by cutting the root across, and collecting the milky juice, which soon concretes. The drug is imported into this country from Smyrna. Its active principle is a resin. It is used medicinally as a drastic purgative, in the form of powder, pill, and extract. A spurious kind of Scammony has been prepared from the root of Convolvulus (Calystegia) sepium; and several plants belonging to the natural order Asclepiadaceæ yield a purgative exudation, which has been used under the names of Montpellier and Bourbon Scammony. The roots of some of the plants do not possess purgative qualities, and have been used as articles of food. Batatas edulis (Convolvulus Batatas) yields the sweet Potato, which contains much saccharine and amylaceous matter, and is used as food in tropical countries. The plant is reared in Carolina, Japan, and China, and succeeds within an 
annual Isotherm of $59^{\circ} \mathrm{F}$. It is cultivated also in Spainn and Portugal. In the Philippine Islands the Batatas, or Camotas, as they are called, are used for making soup, as well as roasted. Ipomcea macrorhiza also yields farinaceous edible roots. The species of Cuscuta, Dodder, or Scald-weed, have acrid purgative properties. Their seeds germinate in the soil, and the plants afterwards twine round others, and become attached to them by means of suckers. They then lose their connection with the soil, and are supported as true parasites. In this way they often destroy erops of Flax and Clover, Beans and Hops. Calonyction speciosum is a night-flowering plant, with large white blossoms, and has received the name of Moon-plant. Convolvulus scoparius is said to yield the perfume called Oil of Rhodium. Ipomoea Bona-nox is the moon-flower of Ceylon and of other warm countries. Pharbitis Nil, a plant of tropical countries, common in India, and ascending the mountains to 5000 feet, supplies Kaladana seeds, which are used as purgatives.

Order 125.-CORDIACE A, the Cordia Family. (Monopet, Hypog.) Calyx 4-5-toothed, inferior. Corolla monopetalous, 4-5-cleft, regular. Stamens inserted on the corolla, alternate with its segments; usually long, exserted; anthers versatile. Ovary free, 4-8-celled; ovules solitary, pendulous, anatropal ; style continuous; stigma 4-8-cleft. Fruit drupaceous, 4-8-celled. Seed exalbuminous, pendulous from the apex of the cell by a long funiculus, upon which it is turned back; radicle superior; cotyledons plaited longitudinally.-Trees, with alternate, rough, exstipulate leaves, and panicled flowers. They are chiefly natives of warm countries. Some yield edible fruits; their bark is occasionally bitter, tonic, and astringent, and their wood is used for various economical purposes. The succulent, mucilaginous fruits of Cordia Myxa and latifolia receive the name of Sebesten Plums. It is said that mummy cases were made from the wood of this plant. There are 11 genera enumerated by Lindley, including 188 species. Examples-Cordia, Varronia.

Order 126.-Bonaginacese, the Borage or Bugloss Family. (Monopet. Hypog.) Calyx persistent, with 4-5-divisions (figs. 770, 771 c). Corolla gamopetalous, hypogynous, usually regular (figs. 321, p. 206 ; 322, p. 207), 5- rarely 4-cleft; æastivation imbricated (figs. $770,771 p p)$. Stamens inserted on the corolla, equal in number to its segments, and alternate with them (fig. 771 e). Ovary usually 4-lobed, quadrilocular (fig. 7710 ); ovules 4, each attached to the lowest point of the ovary, amphitropal; style simple, basilar (figs. 437, p. $247 ; 771 s$ ), (terminal in Ehretieæ and Heliotropieæ); stigma simple or bifid. Fruit (fig. 772) consisting of 2 to 4 distinct achænia (succulent and consolidated in Ehretieæ). Seed exalbuminous, or with thin albumen; radicle superior; cotyledons plano-convex (fig. 772). - Herbs, shrubs, or trees, with terete stems, alternate, rough, exsti- 
pulate leaves, and flowers generally in scorpioidal (gyrate) cymes (fig. 274, p. 185). On account of the asperities in the leaves, the plants have sometimes been called Asperifolix. The order is divided into three sub-orders :-1. Boragineæ (figs. 770-772), with a basilar style,

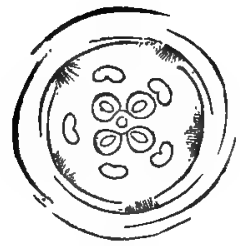

Fig. 770.

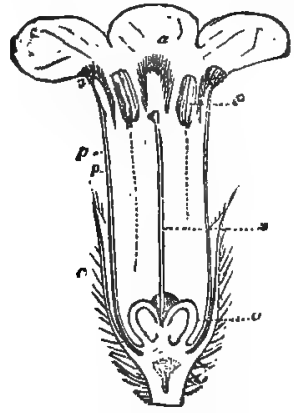

Fig, 771 .

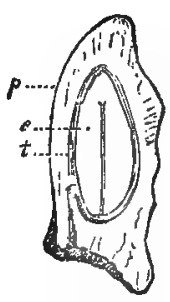

Fig. 772 .

4-lobed ovary, achænium-like fruit, and exalbuminous seeds; natives chiefly of temperate climates. 2. Ehretiex, with a terminal style, a quadrilocular, concrete ovary, a succulent fruit, and usually albuminous seeds; natives of tropical countries. 3. Heliotropieæ, with a terminal style, an entire or 2-lobed ovary, a dry fruit separable into four achænia, and exalbuminous seeds; natives partly of temperate, and partly of warm climates. There are 60 known genera and nearly 650 species. Examples-Borago (or Borrago), Anchusa, Echium, Myosotis, Cynoglossum, Ehretia, Heliotropium.

The plants of the order are generally mucilaginous and emollient. Some are astringent. Nitrate of potash exists in some, and imparts coolness to the water in which they are steeped. Borago officinalis, Borage, has been used for its mucilaginous emollient properties, as a remedy in pectoral affections ; and with wine, water, lemon, and sugar, its leaves form an ingredient in what is called cool-tankard. Attached to the stamens in this plant, and others of the order, are scales, which may be considered as abortive stamens, formed by dilamination (fig. 344, p. 217). Anchusa tinctoria supplies alkanet root, which is used as a reddish-brown dye. Some of the species of Heliotropium (as $H$. peruvianum) are distinguished by their fragrant odour. The leaves of

Figs, 770-772. Organs of fructification of Anchusa italica, to illustrate the natural order Boraginacex. Fig. 770. Diagram of the flower, with five imbricated divisions of the calyx, five imbricated segments of the corolle, five stamens, and a 4-1obed ovary. Fig. 771. Vertical section of the flower. c, Hairy calyx. $p p$, Corolla. $e$, Stamens inserted into the corolla. $\alpha$ a, Staminal appendages or corolline scales. $o, 4$-lobed ovary, two of its divisions cut through vertically. $s$, Basilar style. Fig. 772 . One of the carpels (achænia) cut yertically. $p$, Pericarp separable from the seed. $t$, Spermoderm or integuments of the seed. $e$, Embryo with superior radicle and plano-convex cotyledons. . 
Mertensia (Lithospermum) maritima have the taste of oysters, and hence it is called the Oyster-plant in Scotland. Myosotis palustris (fig. 274, p. 185) is the true Forget-me-not. Miss Strickland remarks that the banished and aspiring Henry of Lancaster appears to have been the person who gave to this plant its emblematical and poetical meaning, by uniting it in his exile with the initial letter of his watchword, 'Souveigne-vous de-moy.'

Order 127. - Solanacese, the Nightshade Family. (Monopet. Hypog.) Calyx inferior, 5- rarely 4-partite, persistent (fig. 774 c). Corolla monopetalous, hypogynous, with the limb 5- rarely 4-cleft, regular, or somewhat unequal, deciduous; æstivation plicate or imbricated (fig. 773). Stamens inserted on the corolla (fig. $774 e$ ), equal in number to the corolline segments, and alternate with them (fig. 773) ; anthers with longitudinal or porous dehiscence (fig. $774 \mathrm{e}$ ). Ovary usually 2-celled (fig. 774 o), sometimes 4-5- or many-celled; ovules indefinite; style continuous ; stigma simple (fig. $774 \mathrm{~s}$ ). . Fruit with 2, 4, or more cells, rarely unilocular ; either a capsule dehiscing
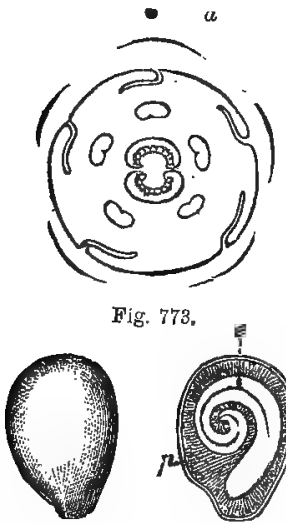

Fig. 777 .
Fig. 773,

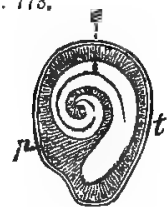

Fig. 778.

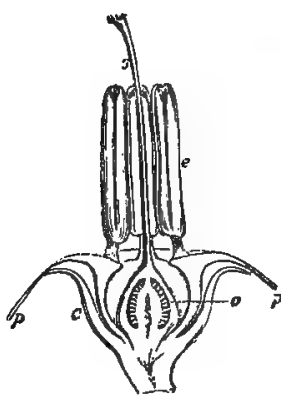

Eig. 774.
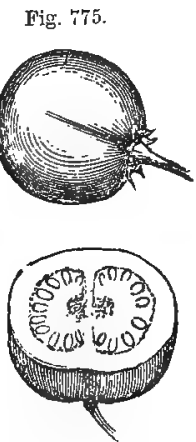

Fig. 776 .

in a septicidal or circumcissile manner, and having a double dissepiment parallel to the valves, or a berry (figs. 775,776 ) with the pla-

Figs. 773-778. Organs of fructification of Solanum tuberosum, the Potato, to illustrate the natural order Solanacex. Fig. 773. Diagram of the flower, with five divisions of the calyx ; five plicate segments of the corolla, five stamens, and a 2-celled ovary with polyspermous placentas. $a$, Axis. Fig. 774. Vertical section of the flower. $e$, Calyx. $p p$, Lower part of the corolla. e, Stamens, with porous dehiscence of the anthers. 0 , Bilocular ovary, polyspermous. s, Style and stigma. Fig- 775. Fruit baccate. Fig. 776. Horizontal section of the fruit, showing the seeds and placenta. Fig. 777. The seed. Fig. 778. Vertical section of the seed. $t$, Integument (spermoderm) of the seed. $p$, Fieshy perisperm (albumen), e, Embryo, which is curved and excentric, with the radicle next the hilum. 
centas adhering to the dissepiment, or a nuculanium with 5 or more nucules. Seeds 00 ; embryo straight ('rectembryece), or curved (curvembryeos) (fig. 778), often excentric, lying in fleshy albumen ; radicle next the hilum. - Herbs or shrubs, with alternate leaves. Natives of most parts of the world, but abundant in the tropics, in which the mass of the order exists, in the form of the genera Solanum and Physalis. There are 69 known genera and 1025 species enumerated. The order has been divided into two sub-orders. 1. Solaneæ; Isomerous flowers with a valvate or induplicato-valvate æstivation; inflorescence extraaxillary; innocuous or doubtfully poisonous. Examples - Solanum, Capsicum, Lycopersicum, Physalis, Cestrum, Habrothamnus, Nolana. 2. Atropeæ; Isomerous flowers or nearly so, with a more or less imbricate æstivation; inflorescence extra-axillary; narcotic poisons causing dilatation of the pupil. Examples-Atropa, Mandragora, Nicotiana, Datura, Hyoscyamus.

The plants of this order often possess narcotic qualities. These are sometimes developed in a great degree, so as to render the plants very poisonous; at other times they are obscured by the prevalence of nutritious and starchy matter. Some of the species are entirely innocuous. In some instances, certain parts of the plant have poisonous narcotic properties, while other parts are innocuous, and are used as articles of diet. These facts will be illustrated by a consideration of different genera and species. We commence with the species in the sub-order Solanece. Solanum Dulcamasa, Bitter-sweet, or woody Nightshade, has diaphoretic properties. A decoction of the twigs is used in various cutaneous diseases. The scarlet berries are not poisonous; five pounds weight given in the course of ten days did not produce poisonous effects. The black berries of Solanum nigrum are used by the garrison in the Island of Ascension to make pies. Solanum tuberosum, the Potato (fig. 109, p. 48), produces nutritious starchy tubers. Solanum Melongena yields the Aubergine or Brinjal, an edible fruit. S. laciniatum, the Kangaroo apple, is eaten in Tasmania. Solanum ovigerum produces the fruit called Egg-apple. Solanum vescum, the Gunyang of Australia, is used as a potato. In the genus Solanum the anthers open by pores. The fruit of different species and varieties of Capsicum supply Cayenne-pepper, and what are called Chillies. Chilli is the Mexican name for all the varieties of Capsicum. They are natives of the East and West Indies, and of other hot climates. Capsicum annurm is the species commonly noticed, but of it there seem to be numerous varieties, which by many are reckoned species. Thus, C. frutescens is a shrubby plant which, along with $C$. fastigicutum, supplies the variety called Bird-pepper; $C$. baccatum has a globular fruit, and furnishes Cherry- or Berry-capsicum. In Capsicums irritant properties prevail, without any narcotic action. Their acridity is owing to an oleaginous substance called Capsicin. Cayenne-pepper is used 
chiefly in the form of tincture as a rubefacient and stimulant, especially in cases of ulcerated sore throat. It acts on the stomach as art aromatic condiment, and, when preserved in acetic acid, it formas Chilli vinegar. The species of Physalis are remarkable for their accrescent calyx (fig. 304, p. 200). The fruit of some, such as $P$. peruviana, Peruvian Winter Cherry, is eaten. P. edulis is the Cape Gooseberry. The fruit of Lycopersicum esculentum is the edible Tomato or Loveapple.

We shall now notice some of the species belonging to the poisonous sub-order Atropece: Atropa Belladonna, Deadly Nightshade or Dwale, is a highly poisonous plant. All parts of the plant are narcotic. The fruit is a dark brownish-black shining berry, which often proves attractive to children. The leaves are the parts used in medicine, and from these an extract is prepared. The watery extract is best made in vacno, but the alcoholic extract is probably the best. Belladonna is one of our most active indigenous poisons. It owes its properties to the presence of an alkaloid called Atropia, which exists in the plant in combination with malic acid. Belladonna is used medicinally to allay pain and spasmodic action, to cause dilatation of the pupil, and as a prophylactic against scarlatina. Mandragora officinalis (Atropa Mandragora), Mandrake, acts as a stimulant on the nervous system, and its forked root was long celebrated for its properties in this respect. It is the דדאים (Dudaim) of the Bible. Its root is easily made to assume the human form, and hence has arisen the stories of the plant shrieking when torn out of the ground. By the Arabs the plant is called Tufah-al-Sheitan, or Devil's Apple. Narcotic properties exist in the species of Hyoscyamus, more especially in $H$. niger, Henbane, a biennial plant, with dingy-yellow flowers, exhibiting beautiful purple reticulations, hairy viscous leaves, and a bilocular operculate capsule (fig. 555, p. 307). The leaves yield by expression a large quantity of juice, whence an extract is prepared. A tincture of Henbane is often used in place of laudanum, on account of not causing constipation. It is employed in medicine to procure sleep and allay pain, and it acts also in dilating the pupil. The narcotic properties seem to be owing to an easily decomposed alkaloid called Hyoscyamia. An empyreumatic oil is obtained from the plant, which is an energetic narcotic poison. The roots of the plant have sometimes caused poisoning by being mistaken for parsnips. Many species of Datura are powerfully narcotic. $D$. Stramonium is the Thorn-apple, so called on account of its prickly capsule. Its leaves and seeds are used medicinally as narcotics, their qualities being due to an alkaloid called Daturine. They are prescribed as anodynes and antispasmodics, in the form of powder, extract, and tincture, and the leaves are smoked in cases of asthma. Datura Tatula and Metel, sanguinea, ferox, and fastiosa, have similar properties. The seeds and leaves of Datura alba, white-flowered 
Datura, are used in India as sedative and narcotic. Several species of Nicotiana furnish Tobacco. That chiefly used in Europe is procured from $N$. Tabacum, a plant naturally inhabiting the hotter parts of North and South America. It is an annual plant, attaining a height of six feet, having dingy-red infundibuliform flowers (fig. 319, p. 206) and viscid leaves. The leaves are the officinal part, and their active properties depend on a peculiar oily-like alkaloid called Nicotina. They are employed in the form of infusion, tincture, and wine. Tobacco is an energetic narcotic poison. Its oil, which is inhaled and swallowed in the process of smoking, is one of the most deadly known poisons. The Hottentots are said to kill snakes by putting a drop of it on their tongues: the death of these reptiles is said to take place instantaneously. It is employed medicinally as a sedative, and its depressing action is useful in cases of hernia. Its depressing action is indicated by its effect on the cerebral functions and on the heart. The flavour and strength of tobacco depend on climate, cultivation, and the mode of manufacture. That most esteemed by the smoker is Havannah tobacco; but the Virginian is the strongest. It is said that small Havannah cigars are prepared from the leaves of Nicotiana repanda; East Iudian, Latakia, and Turkish tobacco, from N. rustica, and fine Shiraz tobacco from $N$. persica.

Order 128.-Orobanchaces, the Broom-rape Family. (Monopet. Hypog.) Calyx divided, persistent, inferior. Corolla monopetalous, hypogynous, irregular, usually bilabiate, persistent; æstivation imbricated. Stamens 4, didynamous. Disk fleshy. Ovary free, 1-celled, composed of two carpels which stand fore and aft (antero-posterior), with 2 or more parietal placentas; ovules 00 ; style 1 ; stigma 2-lobed, each of the lobes belong half to each carpel. Fruit capsular, enclosed within the withered corolla, 1-celled, 2-valved. Seeds 00, minute; embryo very minute, at one lend of fleshy albumen.Herbaceous parasitical plants, having scales in place of leaves. They are natives of Europe, more especially the southern parts, and of Asia, North America, and the Cape of Good Hope. Authors give 14 genera and 125 species. Examples-Orobanche, Lathræa.

The properties of the plants of the order are, in general, astringency and bitterness. Some have been used as tonics, and as applications to indolent ulcers. The species of Orobanche are called Broomrapes, on account of the ravages they are supposed to commit on the Broom tribe. They attach themselves to the roots of various plants, and are hence called Root-parasites. Different species infest and injure different tribes of plants. Thus, Orobanche Rapum is parasitical upon Broom and Furze; O. ramosa, upon Hemp; O. rubra, upon common Thyme; O. minor, upon red Clover; O. Hederce, upon the Ivy; 0 . elatior and arenaria, upon different species of Compositæ, as Centaury and Milfoil. The stems of Orobanches have a large central 
cellular portion, surrounded by numerous fibro-vascular bundles, which are arranged in a circle without any medullary rays. Tubers exist at the lower part, whence subterranean buds are developed. Sometimes the fibro-vascular bundles of the plants, to which the Broom-rapes are attached, are found ramifying in the substance of the parasite. Lathrcea squamaria, Tooth-wort, is parasitical upon the roots of Hazels, Cherry-laurels, and other trees. Epiphegus virginiana, Beech-drops, has been used in powder as an application to cancerous sores. In conjunction with Arsenious acid it is supposed to have constituted the specific lnown in North America under the name of Martin's Cancer Powder.

Order 129.-Scrophulariaces, the Figwort Family. (Monopet. Hypog.) Calyx divided into 4 or 5 parts, unequal, persistent, inferior (fig. 312 c, p. 203). Corolla monopetalous, more or less irregular and bilabiate (fig. 312 p, p. 203), or personate (fig. 325, p. 207), sometimes spurred or saccate at the base; æstivation imbricate. In the bud, the flowers are regular (fig. 336, p. 211). Stamens usually 4 , didynamous (figs. 376, p. $225 ; 378$, p. 227 ), rarely 5 , sometimes 2 ; anthers bilocular, or unilocular by abortion or adhesion. Ovary free, 2-celled; ovules usually 00 ; style simple; stigma 2-lobed, rarely entire. Fruit capsular, rarely fleshy, dicarpellary, 2-celled (cells antero-posterior) (fig. 541, p. 304), 2-4-valved, opening by septicidal or loculicidal dehiscence, rarely by pores (fig. 558, p. 308) or lids, the dissepiments becoming finally loose in the centre (fig. 542, p. 304). Placentas attached to the dissepiment, and sometimes in the mature fruit becoming central. Seeds definite or 00 ; embryo straight or slightly curved, included within fleshy albumen.-Herbs, undershrubs, or shrubs, with opposite, whorled or alternate leaves. They are found generally distributed over the globe, both in cold and warm regions. The order has been divided by Bentham into three sections:-1. Salpiglossideæ, æstivation of corolla plicate or imbricate, 2 posterior lobes outside. 2. Antirrhineæ, corolla bilabiate, æstivation imbricate, the posterior lip outside the anterior one. 3. Rhinantheæ, æstivation of corolla imbricate, the two lateral lobes, or one of them, placed outside. Many of the Rhinantheæ, such as Euphrasia, Rhinanthus, and Melampyrum, are said to be root parasites. There are 183 known genera and about 1800 species. Examples-Schizanthus, Salpiglossis, Calceolaria, Verbascum, Antirrhinum, Scrophularia, Pentstemon, Mimulus, Digitalis, Veronica, Rhinanthus, Melampyrum.

The plants of the order are usually scentless, or at all events not aromatic. They are acrid and slightly bitter, and some of them are sedative and poisonous. Some of the plants of the order belong to the tribe of Root-parasites. This is particularly the case with species of Euphrasia, Rhinanthus, Bartsia, Melampyrum, and Pedicularis. 
These parasites differ from Broom-rapes in having green leaves, and they seem to be apparently independent after they have acquired a certain degree of development. The species of Mimulus have a bilamellate stigma, the two lamellæ of which are irritable, and close when irritated. The movements of the stigma are probably in some way connected with self-fertilisation. One of the species, Mimulus luteus, has become naturalised in many parts of Britain, as in the neighbourhood of Edinburgh, on the shores of the Clyde, the Isle of Slkye, Perthshire, etc. Mimulus moschatus is cultivated on account of its musk-like odour. The most important medicinal plant of the order is Digitalis purpurea, Foxglove, the leaves and seeds of which are employed in the form of powder, tincture, and infusion. The leaves have a bitter taste, which they retain when carefully dried. In large doses they act as a narcotico-irritant poison, and in small doses they are used as sedative of the circulation, and diuretic. Their continued use causes great slowness of the pulse, and hence their employment in diseases of the heart and in hæmorrhages, such as hæmoptysis. In dropsical cases, especially those connected with diseased heart, Digitalis is extensively used. Its active properties are due to the presence of a crystalline principle called Digitalin. Several other species of Digitalis, such as D. lovigata, grandiflora, lutea, and tomentosa, have similar properties. The leaves of Scrophularia nodosa, knotted Figwort, have irritant qualities, and have been used as emetic and cathartic remedies. In the form of ointment and fomentation, they have been applied to diseases of the skin and tumours. The woolly leaves of Verbascum Thapsus, Great Mullein, are emollient and slightly narcotic. They have been used in some pectoral affections. The species of Melampyrum are called Cow-wheat, in consequence of being relished by cows. Euphrasia afficinalis, Eye-bright, or Euphrasy, was formerly used in cases of ophthalmia. Some of the species of Linaria and Calceolaria are used for dyeing. Linaric vulgaris exhibits what Linnæus called Peloria (pp. 369, 374), by the flowers being 5-spurred in place of 1-spurred, and thus becoming symmetrical. Gratiola officinalis, Hedge-hyssop, is bitter and acrid, and is said to enter into the composition of the Eau médicinale, so much vaunted as a remedy for gout. This was formerly called Gratia Dei, on account of its efficiency as a medicine. In over-doses it acts as a poison. According to Haller, it renders by its abundance some of the Swiss meadows useless as pastures. The leaves of Veronica officinalis are bitter and astringent, and are sometimes used as tea.

Order 130.- Labiates (Lamiaceæ of Lindley), the Labiate Family. (Monopet. Hypog.) Calyx tubular inferior, regular or bilabiate, persistent (figs. 780, $782 \mathrm{c}$ ). Corolla monopetalous, hypogynous, bilabiate; upper lip entire or bifid, lower 3-lobed (figs. 324, p. $207 ; 780,781$ ). Stamens 4 (fig. 779), didynamous (fig. $781 \mathrm{e}$ ), 
sometimes 2 by abortion, inserted into the corolla, and alternate with the lobes of the lower lip; anthers 2-celled, or 1-celled by abortion,

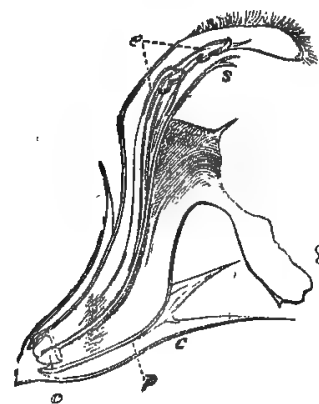

Fig. 781.

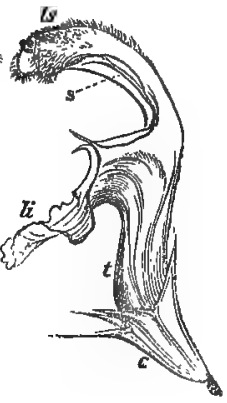

Fig. 780.

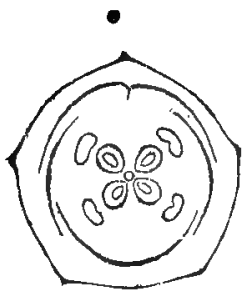

Fig. 779.

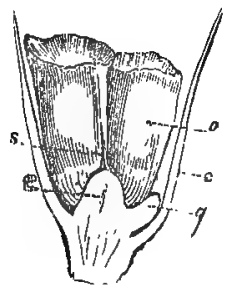

Fig. 782 .

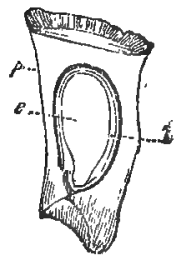

Fig. 783.

or by absorption of the septum (fig. 365, p. 223) ; connective sometimes large and distractile (fig. $365 \mathrm{c}, \mathrm{p} .223$ ). Disk fleshy. Ovary free, deeply 4-lobed (figs. 436, p. 247 ; 779); ovules 4; style 1 , basilar (figs. 436, p. 247 ; $781 \mathrm{~s}$ ); stigma bifid (fig. $781 \mathrm{~s}$ ), usually acute. Fruit consisting of 1-4 achænia, enclosed within the persistent calyx (figs. 436, p. $247 ; 782$ ). Seeds erect (fig. 783); albumen either 0 , or in small quantity; embryo erect (fig. 783 e); cotyledons flat; radicle inferior.-Herbs or undershrubs, with tetragonal stems, opposite exstipulate leaves, and cymose inflorescence, the flowers

Figs. 779-783. Organs of fructification of Lamium album, to illustrate the natural order Labiatæ. Fig. 779. Diagram of the flower, with the pentamerous calyx; pentamerous corolla, having two lips, theipper lip being formed of two united petals, the lower of three; four stamens, in consequence of one being undeveloped, and four divisions of the ovary. Fig. 780. Entire flower viewed laterally. c, Five-cleft calyx. $t$, Tube of the corolla. $l s$, Upper lip of two petals. $l i$, Lower lip of three. 8, Style. Fig. 781. The flower cut vertically, $\quad c$, Calyx. $p$, Corolla. e, Didynamous "stamens. $s$, Style and bifid stigma. $o$, Ovary. Fig. 782. Fruit (a tetrachænium) cut vertically, showing the carpels, two of which have been removed. $c$, Persistent calyx. $g$, Fleshy disk or gland. $r$, Gynobasic receptacle bearing the style, $s$, which is basilar, i.e. arises from the lower;part of the carpels. o, Two carpels, which form achænia when ripe. Fig. 783. A carpel cut vertically. $p$, Pericarp. $t$, Integument of the seed, $e$, Embryo erect with inferior radicle. 
being often in verticillasters. Linnæus looked upon the fruit as naked seeds, and hence included many of the plants in the order Gymnospermia of his Didynamous class. They are natives chiefly of temperate regions. Authors mention 120 genera, including 2500 species. Examples-Mentha, Salvia, Melissa, Lamium, Teucrium, Scutellaria.

The plants of this order are in general fragrant and aromatic, and none of them are poisonous or injurious. Scarcely any are used for ordinary food, although many form grateful condiments. Their leaves contain receptacles of volatile oil, and many of them furnish a stearoptin resembling camphor. Medicinally, many of them are used as carminatives. The species of Mentha yield volatile oils. M. Piperita, Peppermint, is used as a powerful diffusible stimulant in cases of colic and gastrodynia. The oil is procured by distillation with water, and, when dissolved in rectified spirit, it forms the essence of Peppermint. Mentha viridis, Spearmint, is used in the same way as Peppermint; while $M$. Puleginm, Penny-royal, is employed as a pectoral and antispasmodic. Lavandula vera ( $L$. spica, officinalis, and angustifotia of authors) yields the best oil of Lavender; while $L$. latifolia furnishes Spike-oil. Lavandula Stoechas of the south of Europe also supplies oil. Like the other volatile oils of the Labiatæ, oil of Lavender consists of a fluid oil, or Elæoptin, and a solid crystalline substance, or Stearoptin, analogous to camphor. Lavender is a tonic, stimulant, and carminative. The flowering tops of Rosmarinus offcinalis, Rosemary, furnish an oil which has similar properties. It is used much in perfumery, and enters into the composition of Eau de Cologne. It is reputed as possessing efficacy in encouraging the growth of hair and in curing baldness. The admired flavour of Narbonne honey is ascribed to the bees feeding on the flowers of this plant. Oils of the same nature are procured from Origanum vulgare, Wild Marjoram, $O$. Majorana, Sweet Marjoram, Origanum Dictannus, Dittamy of Crete, Melissa officinalis, common Balm, and Marrubium vulgare, white Horehound. Some consider the Hyssop of Scripture, בוז'Esobh, as being Hyssopus orientalis ( $H$. officinalis, var. angustifolius); but Royle looks upon it as one of the Caper plants (Capparis cegyptiaca). Plectranthus graveolens of some, Pogostemon suavis or P. Patchouly of others, is the Patchouli plant of the East Indies, which is used as a perfume. It is called in India puchá pát. It yields a volatile oil of a yellowishgreen colour. Lycopus virginicus, Bugle-weed, and L. europocus, Gipsy-wort, are used as astringents and sedatives. Many Labiates, such as Thyme (Thynus), Mint (Mentha), Sage (Salvia), Basil (Ocymum), Savoury (Satureia), etc., are used as culinary vegetables, more particularly to flavour sauces and dishes. The species of Salvia are distinguished by having only two stamens in consequence of the abortion of the rest, and by their distractile connective, which separates the anther lobes (fig. 365, p. 223). In the outer coat of the achenes 
of the species of Salvia there are spiral cells, the fibres of which, like those of the seeds of Collomia, uncoil when moistened with water, and form an interesting microscopic object. Salvia officinalis, common sage, has been used in the form of tea as a stomachic. What are called Sage-apples, are galls produced, by the puncture of insects, on Salvia pomifera. The roots of Ocymum tuberosum are said to be esculent. Hyptis membranacea, one of the Brazilian Labiates, attains the height of 20 or 30 feet.

Order 131.-VERBENACEA, the Vervain Family. (Monopet. Hypog.) Calyx tubular, persistent, inferior. Corolla monopetalous, tubular, hypogynous, deciduous, limb usually irregular; æstivation imbricated. Stamens usually 4, didynamous, rarely equal, sometimes 2. Ovary free, 2-4-celled; ovules usually 4, erect or pendulous, anatropal or amphitropal; style 1, terminal; stigma bifid or entire. Fruit nucamentaceous or baccate, composed of 2 or 4 achænia united. Seeds 1-4; albumen 0 or fleshy; embryo straight; radicle either inferior or superior.-Trees or shrubs, rarely herbs, with opposite or alternate, exstipulate leaves. The order has been divided into three sub-orders :-1. Myoporinex, anthers 2-celled, seed pendulous, radicle superior, seeds albuminous, leaves alternate; natives of the southern parts of America and Africa, and of Australia. 2. Verbeneæ (fig. 258, p. 178), anthers 2-celled, seed erect, radicle inferior, seeds exalbuminous, leaves opposite; natives both of the tropical and temperate regions of America, and found also in Asia and in Europe. 3. Selagineæ, anthers 1-celled, seed pendulous, radicle superior, seeds albuminous, leaves in alternate fascicles, or sub-opposite, narrow ; natives chiefly of the Cape of Good Hope, but some are European. There are 75 known genera and upwards of 800 species. Examples-Myoporum, Avicennia, Verbena, Vitex, Tectona, Selago, Globularia.

Many of the plants of the order are fragrant and aromatic, some are bitter, tonic, and astringent, others are acrid. None of them occur in the British Pharmacopoeias. Aloysia citriodora, Sweet-scented Verbena or Lemon-plant, is commonly cultivated for its fragrance. In the leaves Dr. Murchison has noticed peculiar glands containing oily matter. The species of Avicennia have adventitious roots like the Mangrove. The bark of Avicennia tomentosa is used in Brazil for tanning. Tectona grandis is the Teak-tree of India, the wood of which is very hard and durable, and is used for shipbuilding. The trunk of the tree in Eastern forests sometimes attains a height of two hundred feet, and its leaves are twenty inches long by sixteen broad. Clerodendron leaves when bruised are employed to kill vermin on cattle in India. The twigs form toothpicks. Clerodendron Thomsonce, and its variety Balfourianum, are beautiful climbing plants in hot-houses, on account of the contrast between their scarlet flowers and white calyx. Myoporum platycarpum of Australia exudes a saccharine matter from its stem. 
The fruit of several species of Vitex is acrid and aromatic. Some species of Lantana and Stachytarpheta are used for tea. The Vervain (Verbena officinalis) was a sacred plant among the Greeks, and received the name of ispoßorárn, holy-wort. It was also looked upon by the Druids with superstitious reverence. The Verbenas of gardens are chiefly varieties of $V$ erbena Chamadrifolia.

Order 132.-ACANTHACE, the Acanthus Family. (Monopet. Hypog.) Calyx with 4-5 divisions, equal or unequal, occasionally multifid, or entire and obsolete, persistent. Corolla monopetalous, hypogynous, usually irregular, with the limb ringent or bilabiate, or rarely unilabiate, sometimes nearly equal, deciduous. Stamens inserted on the corolla, usually 2 , sometimes 4 , didynamous, the shorter ones being occasionally sterile; anthers 1-2-celled, with longitudinal dehiscence. Disk glandular. Ovary free, 2-celled; placentas adhering to the axis; ovules 2 or more in each cell, curved; style 1 ; stigma 2-lobed, rarely entire. Fruit a 2-celled capsule, dehiscing by 2 elastic valves, in a loculicidal manner. Seeds 2 or many in each cell, sometimes solitary, roundish, attached to hard, persistent, hooked or subulate ascending processes of the placenta; testa loose; albumen 0 ; embryo curved or straight; cotyledons large, leafy; radicle cylindrical, next the hilum.-Herbaceous plants or shrubs, with opposite, exstipulate, simple leaves, and bracteated flowers; 2 or 3 large leafy bracts accompanying each flower. They abound in tropical regions. The order has been divided into three tribes :- 1 . Thunbergieæ, with the placental processes in the form of a hard cup, supporting the seed. 2. Nelsonieæ, with the placental processes contracted into a papilla, bearing the seed, which is small and pitted. 3. Acanthieæ, with the placental processes hooked. There are 168 genera, according to authors, and about 1500 species. Examples-Thunbergia, Nelsonia, Acanthus, Justicia, Ruellia.

The plants of the order have mucilaginous and bitter properties in general, but they are not put to important uses. The leaves of Acanthus mollis, with their sinuated lobes, gave origin to the capital of the Corinthian pillar. The plant has emollient qualities. The seeds of Acanthoclium spicatum have beautiful spiral cells in their episperm (page 7). The style of Ruellia (Goldfussia) anisophylla exhibits a peculiar irritability; its curved stigmatic apex becoming gradually straightened, so as to come into contact with the hairs of the corolla upon which the pollen is scattered. A deep-blue dye, called Room, is obtained in Assam from a species of Ruellia. A similar dye in China is procured from a species of Justicia. Many of the species of Justicia, Ruellia, and Aphelandra, are cultivated for their showy flowers. Andrographis paniculata, a native of India, is employed as a pure bitter tonic, under the name of Kariyát or Creyat. Meninia turgida of Cochin-China has febrifuge properties. 
Order 133.-Lentibulariaces, the Butterwort Family. (Monopet. Hypog.) Calyx inferior, divided, persistent. Corolla monopetalous, hypogynous, irregular, bilabiate, usually spurred. Stamens 2, inserted into the base of the corolla, and included; anthers monothecal, sometimes contracted in the middle. Ovary free, composed of 2 carpellary leaves, unilocular; ovules 00, anatropal ; placenta free, central ; style 1, very short; stigma bilamellar. Fruit, a 1-celled capsule, dehiscing transversely, or by an apicilar cleft. Seeds numerous, minute, exalbuminous; embryo sometimes undivided; radicle next the hilum.-Aquatic or marsh herbaceous plants, with radical leaves, which are sometimes compound, and bear little bladders or ampullæ. Flowers often on scapes. They are found in all parts of the world, and abound in the tropics. There are 3 genera, including about 130 species. Examples-Utricularia, Pinguicula.

The plants of the order have no properties of importance. The name of Butterwort, given to the species of Pinguicula, may be derived from the property of giving consistence to milk. Others say that it has reference to the greasy appearance of their foliage. Linnæus declares that the solid milk of the Laplanders is prepared by pouring it warm and fresh from the cow over a strainer on which fresh leaves of Pinguicula have been laid. Of the four British species, one ( $P$. grandiflora) is peculiar to Ireland, and another $(P$. alpina) is peculiar to Scotland. The leaves, of Pinguiculas secrete a viscid fluid, which detains insects. They also curl inwards at the margin (p. 383). Utricularias, Bladderworts, are so called on account of the utricles or bladders connected with the leaves (p. 100). In the interior of these vesicles a mucous fluid is found along with cellular projections in the form of hairs. Utricularia nelumbifolia grows in the water which collects. in the bottom of the leaves of a large Tillandsia in Brazil. It sends out runners and shoots, and often in this way unites several plants of Tillandsia. The leaves are peltate, and more than three inches across, while the flowering stem is two feet long.

Order 134.-PRIMULACE

(Monopet. Hypog.) Calyx 5- rarely 4-cleft (fig. 296, p. 197), inferior or half superior, regular, persistent (figs. $785 \mathrm{c} ; 787$ ). Corolla monopetalous (fig. 320 p, p. 206), hypogynous (fig. 785), rarely perigynous, with the limb 5- rarely 4-cleft, sometimes 0 (fig. 642, p. 367). Stamens inserted on the corolla, equal in number and opposite to its segments (figs. 784, 785). Ovary free (figs. 785, 786 o), rarely adherent to the base of the calyx, 1-celled; ovules 00, usually amphitropal ; style 1 (fig. $785 \mathrm{~s}$ ) ; stigma capitate (fig. 785). Fruit a capsule, opening with valves (fig. 787), or with a lid (fig. 554, p. 307). Seeds numerous, peltate (fig. 788), attached to a free central placenta (fig. 787); embryo straight (fig. 790), enclosed within fleshy albumen, and lying across the hilum (fig. 789). - Herbaceous plants, with leaves usually 
opposite, and frequently radical, exstipulate; flowers on simple or umbellate scapes. They are natives chiefly of temperate and cold regions in the northern hemisphere; some occur in elevated situations in warm countries. Authors notice 20 genera, including 200 species. Examples-Primula, Androsace, Soldanella, Glaux, Trientalis, Anagallis, Samolus.

None of the plants of this order occur in the British Pharmacopoias, but few of them have any important medicinal properties. Acridity prevails more or less in the order. They are cultivated as showy garden

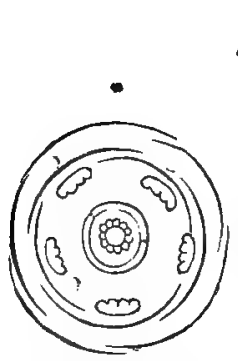

Fig. 784.

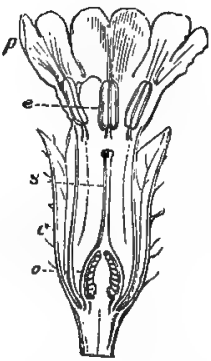

Fig. 785 .

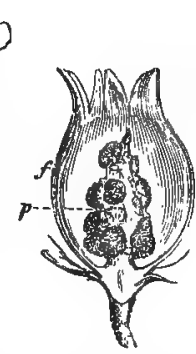

Fig. 787.
Fig. 789.

Fig. 788.

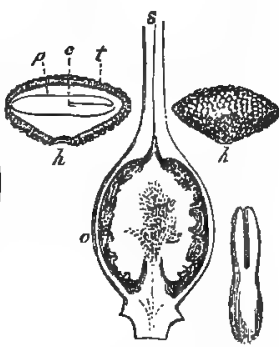

Fig. 786. Fig. 790.

annuals and perennials. All the fine forms of Auricula are derived from the yellow Primula Auricula, a native of the Swiss Alps. The British species of Primula are P. veris, the Cowslip, the flowers of which are said to be narcotic ; $P$. elatior, the Oxlip ; $P$. vulgaris, the Primrose ; $P$. farinosa, the Bird's-eye Primrose; and P. scotica, the Scottish Primrose. The garden Polyanthus is a variety of the Primrose. The species of Cyclamen, or Sowbread, have large tuberous-like partially subterranean stems, with acrid properties, and their English name is derived from the circumstance of their being eaten as food by wild boars. In them, as well as in the species of Dodecatheon, the petals are reflexed. The flowers of the species of Anagallis are meteoric (p. 263), and their seed-vessel is a pyxidium (fig. 554, p. 307). They are said to be acrid, and to cause inflammation of the mucous membrane. Anagallis

Figs. 784-790. Organs of fructification of Primula elatior, illustrating the natural order Primulaceæ. Fig. 784. Diagram of the flower, with five imbricate divisions of the calyz. flve segments of the corolla, five stamens opposite the corolline segments, and five carpellary leaves, surrounding a free central placenta. Fig. 785. Vertical sestion of the flower. c, Inferior calyx. $p$, Monopetalous corolia. e, Stamens attached to the corolla, $o$, Superior ovary. s, Style with capitate stigma. Fig. 786. Ovary cut vertically, to show the free central placenta covered with ovules. s, Base of the style. Fig. 787. Vertical section of the fruit. $f$, Pericarp. $p$, Placenta, with numerous seeds, some of which have been detached. Fig. 788. Peltate amphitropal seed separated. $h$, Hilum. Fig. 789. Seed cut vertically, $t$, Integuments (spermoderm). $h$, Hilum, $p$, Fleshy perisperm (albumen). e, Transverse embryo lying across the bilum. Fig. 790. Embryo with cotyledons and radicle. 
arvensis is called Poor-man's Weather-glass, or Shepherds' Weatherglass. By Lord Bacon it is called Nincopipe. Trientalis europoca is the only British plant belonging to the Linnæan class Heptandria. It is slightly acrid. In Samolus Valerandi, Brook-weed, the calyx is partially adherent to the ovary, and in Glaux maritima the corolla is abortive, and the calyx becomes coloured (fig. 642, p. 367).

Order 135.-Plumbaginaces, the Searpink Family. (Monopet. Hypog.) Calyx tubular,"; persistent, sometimes coloured; æstivation plaited. Corolla monopetalous, or pentapetalous, regular. Stamens 5, hypogynous when the corolla is gamopetalous, attached to the base of the petals when they are separate. Ovary free, 1-celled; ovule solitary, pendulous from a funiculus which arises from the bottom of the cell (fig. 517, p. 291) ; styles 5, seldom 3 or 4, each bearing a subulate stigma. Fruit a utricle. Seed pendulous; spermoderm simple; embryo straight, in the axis of mealy albumen; radicle superior.Herbs or undershrubs, with alternate or fasciculate exstipulate leaves, somewhat sheathing at the base; flowers panicled or capitate. They inhabit the sea-shores and salt marshes chiefly in temperate regions. There are two tribes of this order:-1. Plumbagineæ, with a synpetalous corolla and connate styles. 2. Staticex, with a pentapetalous corolla and distinct styles. Authors mention 10 genera and 200 species. Examples-Plumbago, Statice, Armeria.

Some of the plants are acrid, others have tonic qualities. Armeria maritima, Thrift, or common Sea-pink, grows both on the seashores and on the top of the highest Scottish mountains. Its inorganic chemical ingredients are said to vary in these positions (p. 132). In Armeria the funiculus curves over the foramen of the ovule in a young state, but slips off at the period of fecundation, and allows an ovular process to proceed from the exostome towards the placenta. In this genus also the scaly bracts unite so as to form an inverted cylindrical sheath below the heads or shortened panicles of flowers. The root of Statice caroliniana is said to be one of the most powerful vegetable astringents. Plumbago europcea has been employed for the relief of toothache, and has hence been called Toothwort. Its root is so acrid that it is used in Roumelia for causing issues. Administered internally in small doses it is said to be as effectual an emetic as Ipecacuanha. Some of the species of this genus act as vesicants.

Order 136.-Plantaginacese, the Ribwort Family. (Monopet. Hypog.) Calyx 4-parted, persistent, æestivation imbricate. Corolla monopetalous, hypogynous, scarious, persistent, with a 4-parted limb. Stamens 4, inserted into the corolla, and alternate with its segments; filaments long, filiform, folded inwards in the bud'; anthers dithecal, versatile. Disk inconspicuous. Ovary free, 2-4-celled; ovules solitary, or in pairs, or 00 ; style simple, capillary ; stigma hispid, simple, rarely bifid. Fruit an operculate capsule enclosed within the per- 
sistent corolla. Seeds sessile, peltate, or erect; spermoderm mucilaginous; embryo in the axis of fleshy albumen, transverse; radicle inferior.-Herbs, which are often stemless, with radical ribbed leaves, and spiked hermaphrodite flowers, or solitary unisexual ones. The species are chiefly found in temperate and cool regions. There are 3 genera noticed by Lindley, including about 50 species. Examples - Plantago, Littorella.

The plants of this order are frequently bitter and astringent. Their mucilaginous seeds are sometimes used as demulcents. Plantago maritima is found both on the sea-shores and on the top of the highest mountains in Scotland. Its inorganic constituents are said to differ in these localities (p. 132). Plantago major, Way-bred, is said to follow the footsteps of man in his migrations. Its spikes are used for feeding birds. Sometimes the bractlets become large, and at other times they assume a verticillate appearance. The seeds of Plantago decumbens, a native of Fgypt, N.W. India, and the Canary Islands, are used to form a demulcent drink in diarrhoea. They are called Ispaghúl seeds, or Spogel seeds.

\section{Sub-class IV.-MoNochLAMYDEzA.}

Corolla wanting; a calyx, or what is called a simple perianth, present; flowers sometimes Achlamydeous. This sub-class includes the Apetalous orders of Jussieu, and many of his Diclinous irregular orders. It corresponds to the Apetalæ and Gymnospermæ of Endlicher.

\section{Section A.-ANgiospermar.}

Monochlamydeous or Achlamydeous plants, having their seeds contained in an ovary, and fertilised by the action of the pollen on a stigma. It is the Apetalous division of Endlicher's Acramphibrya.

Order 137.-Nyctaginacese, the Marvel of Peru Family. (Apet. Hypog.) Perianth tubular, coloured, contracted in the middle, becoming indurated at the base (fig. 792); limb entire, or toothed and deciduous; æastivation plicate (fig. 791). Stamens definite, hypogynous (fig. 792 e) ; anthers dithecal (fig. 793). Ovary superior, 1celled; ovule solitary, erect; style 1 ; stigma 1 (figs. 792, 794); Fruit a caryopsis, enclosed within the enlarged persistent tube of the perianth (figs. 537, p. $302 ; 795,796$ ). Embryo peripherical (figs. 618 , p. 341 ; 796 e) ; albumen farinaceous ; cotyledons foliaceous ; radicle inferior (figs. 796, 797).--Herbs, shrubs, or trees, with opposite, often unequal, sometimes alternate leaves, and involucrate flowers (figs. 791, 792). They are natives principally of warm regions. 
Anthors notice 19 genera, including 117 species. Examples-Mirabilis (Nyctago), Boerhaavia, Pisonia.

The plants of the order have in general purgative qualities. Mira-

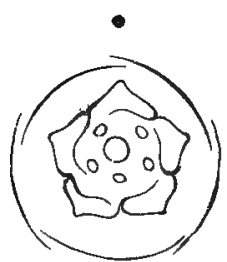

Fig. 791.

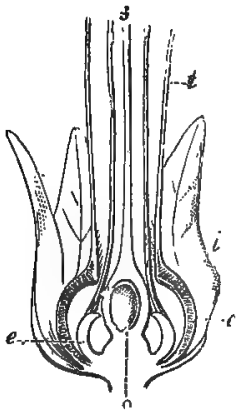

Fig. 792.
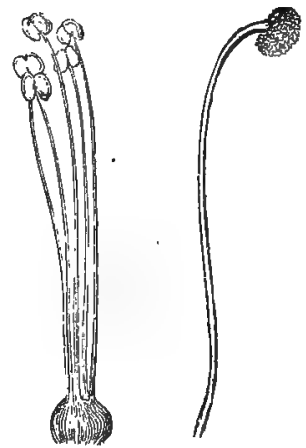

Fig. 793. Fig. 794 .

bilis Jalapa was at one time considered the Jalap-plant, in place of Exogonium Purga, one of the Convolvulacer. $M$. dichotoma is the Marvel of Peru, which is commonly cultivated in gardens. It is

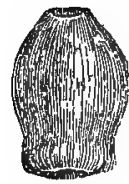

Fig. 795 .

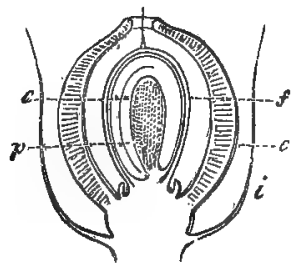

Fig. 796.

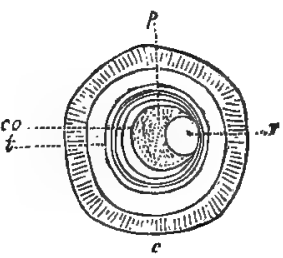

Fig. 797.

called in the West Indies "four o'clock flower," on account of opening its blossoms at that hour in the afternoon. Some of the species of Pisonia present a peculiar arrangement of the vascular bundles of the woody stem, which resembles in appearance that of Endogens.

Figs. 791-797. Organs of fructification of Mirabilis Jalapa, illustrating the natural order Nyetaginacez. Fig. 791. Diagram of the flower, with an imbricated involucre, five divisions of the perianth, five alternate stamens, and a unilocular ovary. Fig. 792. Lower part of the flower eut vertically. i, Involucre. c, Base of the perianth, green and swollen around the ovary. $t$, Part of its coloured tube. $e$, Lower part of the filaments. $s$, Part of the style. 0, Ovary, with its erect ovule. Fig. 793. Stamens, with convex swelling at the base of the tilaments. Fig. 794. Style and stigma. Fig. 795. Fruit enclosed by the persistent and indurated bose of the perianth. Fig. 796. The same cut vertically. $i$, Involucre. c, Perianth. $f$, Pericarp. $p$, Perisperm. e, Curved peripherical embryo, surrounding mealy albumen. Fig. 797. Horizontal section of the fruit. $c$, Perianth. $t$, Integument of the seed with the pericarp. $p$, Perisperm. $r$, Radicle, $c o$, Cotyledons. 
Order 138.-Amaranthace 2 , the Amaranth Family. (Apet. Hypog.) Perianth 3-5-partite, hypogynous, scarious, persistent, usually with two bractlets at the base. Stamens hypogynous, either 5 and opposite the segments of the perianth, or double that number, distinct or united, sometimes partly abortive; anthers either dithecal or monothecal. Ovary superior, single, 1-celled; ovules solitary or several, amphitropal, hanging from a free central funiculus; style 1, or 0 ; stigma simple or compound. Fruit a utricle or a caryopsis, rarely baccate. Seeds lentiform, pendulous ; testa crustaceous ; embryo peripherical; albumen farinaceous; radicle next the hilum.-Herbs and shrubs, with simple, opposite, or alternate exstipulate leaves; flowers in beads or spikes, usually hermaphrodite. They are natives of tropical and temperate regions. There are 45 known genera and 400 species. Examples-Amaranthus, Achyranthes, Celosia, Deeringia, Gomphrena.

The plants are principally mucilaginous and demulcent. Many of them are known in cultivation, such as Amaranthus hypochondriacus, Prince's-feather ; $A$. caudatus, Love-lies-bleeding; Celosia cristata, Cockscomb ; Gomphrena globosa, Globe-amaranth. Amaranthus Blitum, A. oleraceus, Chusan Han-tsi, and other species, are used as pot-herbs. In the Cockscomb the flowers form at the apex a peculiar crest of flattened or fasciated peduncles (fig. 251, p. 174).

Order 139.-Chenopodiaces, the Goosefoot Family. (Apet. Perigyn. and Hypogyn.) Perianth deeply divided, sometimes tubular at the base, persistent, without bracts ; æstivation imbricate. Stamens inserted into the base of the perianth or hypogynous, opposite to its segments, and equal to them in number, or fewer (fig. 643, p. 367). Ovary single, superior, or sometimes cohering to the tube of the perianth, 1-celled; ovule solitary, attached to the base of the cell ; style 2-4-parted; stigmas simple. Fruit membranous, indehiscent, enclosed in the calyx, sometimes fleshy. Seed erect or resupinate; embryo curved around farinaceous albumen, often like a horse-shoe, or spiral or doubled together without albumen; radicle next the hilum.-Herbs or undershrubs, with alternate, sometimes opposite, exstipulate leaves, and hermaphrodite or unisexual flowers. They are found in almost all parts of the world, but do not abound in the tropics. Most of the plants are inconspicuous weeds. There are 70 known genera and 450 species, Examples-Chenopodium, Salicornia, Salsola, Atriplex, Beta, Basella.

Many of the plants of this order are used as esculent pot-herbs, such as Spinacia oleracea, Spinage, Beta vulgaris, Beet, and var. campestris, Field Beet or Mangold Wurzel, Atriplex horternsis, Garden Orach, Chenopodium Bonus Henricus, English Mercury. The seeds of the last are used in the manufacture of shagreen. The seeds of Chenopodium Quinoa are used as food in Peru, under the name of petty rice. 
The plant grows at a great elevation. Its leaves are used for spinage. They contain much starch and oil, combined with a bitter substance which appears to reside in the integuments. Chenopodium erosum is Australian spinach. C. tomentosum is the tea plant of Tristan d'Acunha and Inaccessible Island. Many of the plants of the order grow in salt marshes, and are called Halophytes ("̋ $\lambda s$, salt, and $\varphi$ uróv, a plant). They yield a quantity of soda. Among them may be enumerated species of Salicornia, Salsola, Halimocnemis, and Kochia. Beet-root yields a large quantity of sugar. Ambrina anthelmintica yields a volatile oil, which is used in the cure of worms. Anabasis Ammodendron, Saxaul, is a peculiair leafless shrub of Khiva. Some of the Chenopodiums have a very fetid odour. The genus Atriplex has polygamous flowers, and was placed by Linnæus in his class Polygamia.

Order 140.-Phytolaccaces, the Phytolacca Family. (Apet. Perigyn.) Perianth 4-5-partite. Stamens usually perigynous, indefinite, or equal to the segments of the perianth, and alternate with them. Ovary of 1 or several carpels, distinct or combined; ovule 1 in each carpel, ascending or erect; styles equal to the carpels in number, terminal or lateral ; stigmas simple or divided. Fruit fleshy and dry, indehiscent, sometimes samaroid. Seeds solitary, erect or ascending; embryo straight or curved; albumen mealy or 0 ; radicle next the hilum.-Undershrubs or herbs, with alternate, entire leaves, which are often dotted. They are natives both of tropical and warm countries, and are found in America, Asia, and Africa. The order has been divided into two tribes:-1. Phytolaccer, with ascending seeds, embryo curved round mealy albumen, and exstipulate leaves. 2. Petiverieæ, with an erect seed, exalbuminous straight embryo, and stipulate leaves. There are 20 known genera, including about 84 species. Examples-Phytolacca, Rivina, Petiveria.

There is frequently much acridity in the plants of this order, and some of them act as irritant emetics and purgatives. The succulent fruit of Phytolacca decandra, common Poke, yields a red juice. It has been used as a remedy in cases of chronic syphilitic pains, and it possesses also emetic and purgative qualities. The plant is said to yield much potash. Petiveria alliacea is the Guinea-hen-weed, so called on account of these animals being fond of it.

Order 141. - Polygonaces, the Buckwheat Family. (Apet. Hypog. and Perigyn.) Perianth inferior (fig. $798 c c$ ), divided, often coloured; æstivation imbricate (fig. 799). 'Stamens definite, inserted into the bottom of the perianth (fig. 798,ee, ei) ; anthers with longitudinal dehiscence. Ovary free (fig. 798 o), usually formed by 3 carpels, unilocular; ovule solitary, orthotropal (fig. 454, p. 254); styles and stigmas equal to the carpels in number (fig. $798 \mathrm{~s}$ ). Fruit a nut, usually triangular, naked or covered by the persistent perianth (fig. 295 , p. 196). Seed erect; albumen farinaceous; embryo antitropal, 
generally on one side (fig. 800), sometimes in the axis of the albumen ; radicle superior (fig. 800).-Herbaceous, rarely shrubby plants, with alternate, stipulate, or exstipulate leaves, and often unisexual flowers. They are found in almost all parts of the world, more especially in the temperate regions of the northern hemisphere. They grow in fields, waste-grounds, ditches, mountains, etc. The order has been divided

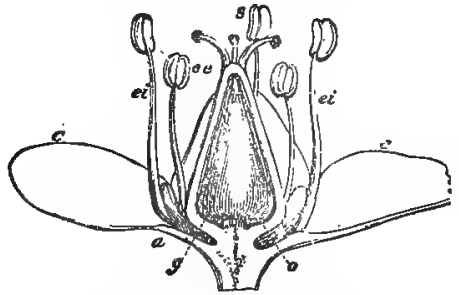

Fig. 798.

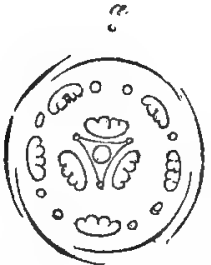

Fig. 799.

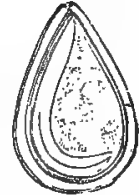

Fig. 800 .

into two tribes:-1. Polygoneæ, with loose flowers, embryo usually abaxial (fig. 617, p. 341), ochreate stipules (fig. 147, p. 82). 2 . Eriogoneæ, with involucrate flowers, embryo axial, leaves generally exstipulate. Authors enumerate 33 genera, including 500 species. Examples-Polygonum, Rumex, Rheum, Eriogonum.

The plants of this order have astringent and acid properties; some of them are purgative, and a few are acrid. Their astringency depends on the presence of tannin, and their acidity chiefly on oxalic acid. The root (or rhizome) of Polygonum Bistorta, Bistort, so called on account of its double twist, contains much tannin, some gallic acid, and starch, and is a powerful astringent. The leaves of $P$. Hydropiper, TVater-pepper, are acrid and vesicant. $P$. tinctorium yields a blue dye. The fruit of $P$. aviculare is emetic and purgative. $P$. cymosum, on the Himalaya, is used as spinach, under the name of Pullop-bi. $P$. Sieboldi, in Japan, supplies a green crop for cattle. The fruit of Fagopyrum esculentum, $F$. tataricum, and other species of Buckwheat, are used as food. The plants are cultivated in some northern countries. The leaves of Rumex acetosa, Common Sorrel, and of R. Acetosella, Sheep's Sorrel, are acid and astringent. The roots of Rumex aquaticus, Water Dock, R. Hydrolapathum, Great Water Dock, and of other species, are used as astringents and alteratives, while those of $R$.

Figs. 798-800. Organs of fructification of Fagopyrum esculentum (Polygonum Fagopyrum), to illustrate the natural order Polygonacere.

Fig. 798. Vertical section of the flower. cc, Perianth. ee, Outex stamens, which are introrse. ei, Inner stamens, which are extrorse. $a$, Glandular appendages. 0, Ovary with its erect ovule, $g$. $s$, Styles and stigmas. Fig. 799. Diagram of the flower, showing five divisions of the imbricate perianth, stamens opposite the divisions, with glands and triangular unilocular ovary. Fig. 800. Seed cut vertically, showing the embryo with its superior radicle curved at one side of mealy albumen. 
alpinus, under the name of Monk's-rhubarb, were formerly employed as purgatives. One of the most important plants of the order is the Rhubarb-plant. The officinal Rhubarb is the root of Rheum officinale of Baillon. It was discovered in south-eastern Thibet, and it is also said to grow in various parts of western and north-western China, whence the supplies of Rhubarb are derived. The extent of country from which Rhubarb of one kind or another is actually collected, according to Christison, stretehes from Ludak, in $77 \frac{1}{2}^{\circ}$ east longitude, to the Chinese province of Shen-si, $29^{\circ}$ farther east, and from the Sue-chan mountains, in north latitude $26^{\circ}$, nearly to the frontiers of Siberia, $24^{\circ}$ northward. The best Rhubarb is said to come from the very heart of Thibet, within $95^{\circ}$ east longitude and $35^{\circ}$ north latitude, five or six hundred miles north of Assam. The following are the species of Rheum said to yield Rhubarb :-

1. Rheum officinale, Baillon, the true officinal rhubarb-plant.

2. Rheum palmatum, L. At one time considered the rhubarb-plant.

3. Rheum undulatum, L., which yields much of the French rhubarb.

4. Rheum compactum, L. Another species yielding French rhubarb, and often cultivated in Britain for its acid petioles.

5. Rheum Emodi, Wall. This species yields a kind of Himalayan rhubarb. Its petioles are used for their acid properties.

6. Rheum rhaponticum, $\mathbf{L}$. Used in France and Britain in the same way as the fourth species.

7. Rheum hybridum, Murr. Much cultivated in Germany for its root, and in Britain for its stalks.

8. Rheum Webbianum, Royle. A Himalayan species.

9. Rheum spiciforme, Royle. Another Himalayan species.

10. Rheum Moorcroftianum, Royle. Another Himalayan species.

11. Rheum crassinervinum, Fisch. A Russian species.

12. Rheum leucorhizum, Pall. A Siberian and Altai species, said to yield imperial or white rhubarb.

13. Rheum Caspicum, Fisch. A Caspian and Altai species.

14. Rheum Ribes, L. An Affghanistan and Persian species.

All these species grow in the cold parts of the world, as on the Altai mountains, in Siberia, Thibet, North of China, and on the Himalayan range. The rhubarb procured from one or more of these species is known in commerce under the names of Russian or Turkey, Chinese or East Indian, and English rhubarb. Rhrbarb contains raphides of oxalate of lime (p. 11), along with tannin, gallic acid, resin, and a peculiar yellow-coloured principle called rhabarberin, which seems to be identical with chrysophanic acid. Raphides form from 35 to 40 per cent of Turkey rhubarb, and give rise to its grittiness. These crystals are less abundant in the other varieties of rhubarb. Rhubarb is employed medicinally as a cathartic, astringent, and tonic, in the form of powder, pill, extract, tincture, wine, and infusion. The stalks of Rheum nobile are eaten in Sikkim. Coccoloba uvifera, Seaside-grape, so called from the appearance of its fruit, yields an astringent substance called Jamaica Kino. 
Order 142.-Begoniadem, the Begonia Family. (Apet. Diclin.) Flowers unisexual. Perianth coloured, having usually 4 divisions in the male flowers, and 5 or 8 in the female, some being smaller than others; æativation imbricate. Stamens 00 , distinct, or united into a solid column ; anthers collected in a head, dithecal, with a thick connective and longitudinal dehiscence. Ovary adherent to the tube of the perianth, winged, 3-celled, with three placentas meeting in the axis ; ovules 00 , anatropal; stigmas 3, sessile, 2-lobed, somewhat spirally twisted. Fruit a membranous, triangular, winged capsule, dehiscing below in a loculicidal manner. Seeds 00 , minute; testa thin and reticulated; albumen 0 ; embryo oblong; radicle next the hilum. -Semi-succulent, herbaceous plants and undershrubs, with alternate oblique leaves, having large scarious stipules. They are sometimes called Elephant's-ear, from the form of the leaves. They are natives of warm countries, as the East and West Indies, and South America. The stomata on the lower side of the leaves of many of the species of Begonia are arranged in clusters, and exhibit a beautiful appearance under the microscope. Their leaves and young stems are acid, and have been used for tarts. Their roots are astringent and slightly bitter. Begonia obliqua is said to have purgative roots, and it is sometimes called wild rhubarb. Begonias have a great tendency to become viviparous. B. gemmipara of the Himalaya has gemma in the axils of the stipules. There are 42 genera and 170 known species. $E x$ amples-Begonia, Casparya.

Order 143. 一 LAURACEA, the Laurel Family. (Apet. Perigyn.) Perianth with 4 or 6 divisions, which are usually in 2 rows (figs. 801, 802), the limb sometimes obsolete ; æstivation imbricate (fig. 802). Stamens perigynous, definite, often twice as many as the divisions of the perianth, and arranged usually in two rows; those of the inner row (often three) being frequently sterile (staminodia), (fig. $803 \mathrm{es}$ ). while those of the outer (often six in number) are fertile (figs. 802, 803 ef); if the inner stamens are fertile they are extrorse, while the outer are introrse; filaments of the inner row often with glands at their base (figs. 357, p. 222; $804 \mathrm{~g}$ ) ; anthers 2-4-celled, cells opening by longitudinal valves (figs. 357 , p. $222 ; 805$ ). Ovary superior, unilocular (fig. 803 o) ; ovule "solitary, pendulous (fig. 803); style simple; stigma obtuse (fig. $803 \mathrm{~s}$ ). Fruit baccate or drupaceous, naked, or covered by the enlarged perianth (fig. 806); peduncle of the fruit sometimes becoming fleshy. Seed solitary, pendulous; albumen 0 ; embryo inverted (fig. 807 e) ; cotyledons large, plano-convex, peltate near the base; radicle very short, superior; plumule conspicuous -Trees, with exstipulate, alternate, rarely opposite leaves; sometimes twining, parasitic, and leafless herbs or undershrubs. They are natives chiefly of the tropical regions of Asia and America. Few are found in Africa. The order has been divided into two sub-orders:-1. 
Laureæ, true Laurels, trees with leaves. 2. Cassytheæ, Dodder-laurels, climbing parasitic plants without leaves. There are 56 known genera and 470 species. Examples-Laurus, Cinnamomum, Persea, Nectandra, Tetranthera, Cassytha.

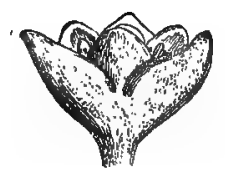

Fig. 801 .

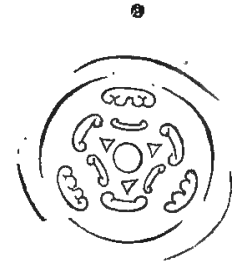

Fig. S02.

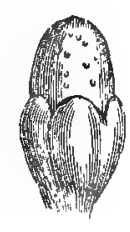

Fig. 806.

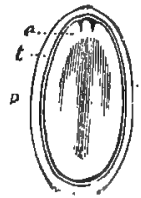

Fig. 80 h.

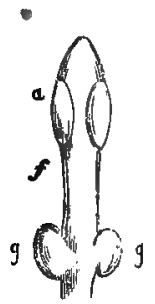

Fig. 804.

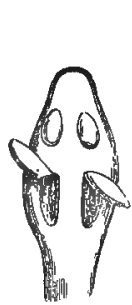

F'ig. 805.

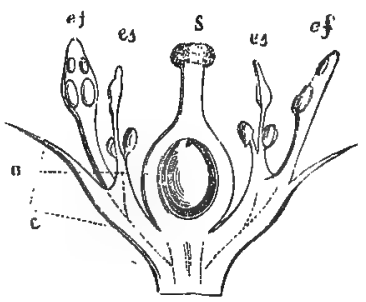

Fig. 803 .

The plants of this order are in general aromatic and fragrant. Many of them yield volatile and fixed oils, others furnish camphor, and others have bitter and tonic barks. Some supply useful timber. Laurus nobilis is the Victor's-laurel, the leaves of which were used to crown the conquerors in battle and in the Olympic games. It is probably the אור Exach, of the Bible. It is often called Sweet-bay, and is quite distinct from the common Bay, or Cherry-laurel (Cerasus Lauro-cerasus), both as regards structure and properties. It does not yield any hydrocyanic acid. The leaves and fruit are used medicinally as aromatic stimulants. The leaves contain a volatile oil, and the darkcoloured fruit yields, by expression, an odoriferous concrete oil of a

Figs. 801-807. Organs of fructification of Cinnamomum zeylanicum (Laurus Cinnamomum), to illustrate the natural order Lauracez.

Fig. 801. Flower entire, with 6-divided perianth. Fig. 802. Diagram of the flower, with six imbricate divisions of the perianth; stamens in two rows, the outer six introrse, the inner three extrorse; glandular disk, and unilocular ovary. Fig. 803. The flower cut vertically. $c$, The perianth. ef, Fertile outer stamens with valvular introrse dehiscence. es, Sterile inner stamens with glandular bodies. o, Monothecal ovary with pendulous ovule. s, Style and obtuse stigma. Fig. 804. Stamen separated. $f$, Filament with two glandular bodies, $g g$, at its base. $a$, Anther with valves. Fig. 805 . Anther viewed separately, showing its mode of dehiscence from below upwards by four longitudinal valves Fig. 806. Fruit, which is sueculent and partially euclosed in the persistent perianth. Fig. 807. The fruit deprived of the perianth, and cut vertically. $p$, Pericarp. $t$, Integument of the seed, $e$, Embryo. 
green colour, called Oil of Bays. It is the only species found in Europe in a wild state. Camphora officinarum (Laurus Camphora), a native of China, Japan, and Cochin-China, is the Camphor-tree. Many plants supply a kind of Camphor, but the common camphor of the shops is the produce chiefly of this tree. All parts of the tree supply it, but it is obtained principally from the wood by distillation and subsequent sublimation. It is used in medicine as a sedative antispasmodic, in the form of mixture and tincture. The Bormeo camphor has been noticed under the natural order Dipterocarpaces (p. 451). Sassafras officinale (Laurus Sassafras) is an American tree, the root, wood, and flowers of which have been used in medicine. The root is prescribed in Britain as an aromatic stimulant and diaphoretic. It contains a volatile oil. A kind of Sassafras oil is procured from Nectandra cymbarum (Ocotea amara) on the Casiquiare river in S. America. Cinnamomum seylanicum (Laurus Cinnamomum) is the true Cinnamon-tree, cultivated in Ceylon. It attains the height of 30 feet. The bark of the tree constitutes the cinnamon of commerce, the pinamon, of the Bible. The young twigs about three years old furnish the best cinnamon, as first noticed by Sir Robert Christison many years ago. The bark yields by distillation an oil, which is at first of a yellow colour, but soon assumes a reddish hue. The ripe fruit yields a concrete oil, called cinnamon-suet. The root yields camphor. Cinnamon is administered as a tonic, stomachic, and carminative. The importation of cimnamon into Britain in 1872 was 1,071,461 lbs. The leaves of the Cinnamon-tree are more or less acuminated; they have three principal ribs, which come into contact at its base, but do not unite; its young twigs are not downy, and its leaves have the taste of cloves. Cinnamomum Cassia or aromaticum (Laurus Cassic) is doubtfully considered to be the chief source of the Cassia lignea, or Cassia-bark of commerce, the קרה, Kiddah, of the Bible. It differs from the true cinnamon in many particulars. Its leaves are oblonglanceolate; they have three ribs, which coalesce into one at the base; its young twigs are downy, and its leaves have the taste of cinnamon. Cassia-bark is imported from Canton through Singapore. In 1872 the shipments were $10,195,200$ lbs., valued at $\$ 267,703$. It yields a yellow volatile oil called Oil of Cassia. Both the bark and oil are administered as aromatic stimulants. It is probable that Cassia buds, which consist of the flower-bud (perianth and ovary), are the produce of the Cassia-bark tree. They are chiefly used in confectionery, and they have the flavour and pungency of Cassia. Malabar Cassia appears to be the produce of another species of Cinnamomum, perhaps C. eucalyptoides. Nectandra Rodicei, a large tree 60 feet high, found in British Guiana, yields a bark known as Bibiru or Bebeeru-bork. The wood of the tree is imported for shipbuilding, under the name of Green-heart. The bark was used by Dr. Rodie, who detected the 
existence of an alkaloid called Bebeerine (Bibirine.) Dr. Douglas Maclagan obtained it pure, and found along with it another alkaloid called Nectandrine. Sulphate of Bebeerine is used as an antiperiodic. The cotyledons of the seed contain much starch, and are used for food. The cotyledons of $N$. Puchury are imported from Brazil under the name of Puchurim beans or Sassafras nuts. Persea gratissima (Laurus Perseu) yields a pear-shaped succulent fruit called Avocado or Alligator-pear, or Subaltern's-butter. It contains a fixed oil. The clove nutmegs of Madagascar are produced by Agathophyllum aromaticum, and Brazilian nutmegs are the produce of Cryptocarya moschata. Bentoin odoriferum is the Spice-wood or Fever-bush of North America. The inner bark of Oreodaphne opifera yields a large quantity of volatile oil.

Order 144.- Mrristicaceses, the Nutmeg Family. (Apet. Diclin.) Flowers unisexual. Perianth trifid, rarely quadrifid, in the female deciduous; æstivation valvate. Stamens $3-12$; filaments combined into a cylinder; anthers united or distinct, dithecal, extrorse, dehiscing longitudinally. Ovary free, composed of one or more carpels, unilocular; ovule solitary, erect, anatropal; style very short; stigma somewhat lobed. Fruit succulent, 1-celled, 2-valved. Seed solitary, usually covered by a laciniated arillus ; embryo small, orthotropal, at the base of ruminate albumen; cotyledons foliaceous; radicle inferior.-Trees with alternate, exstipulate, entire, not dotted leaves. Natives of the tropical regions of Asia and America. There are 5 known genera and between 30 and 40 species. Example-Myristica.

Acridity and aromatic fragrance are the properties of the order. The most important plant is Myristica officinalis ( $M$. moschata, fragrans, or aromatica), a tree attaining a height of 30 feet (50-60 feet in the Banda Islands), found in the Moluccas, and cultivated in many tropical countries. The fruit is drupaceous, and opens by two valves when ripe, displaying the beautiful reticulated scarlet arillus which constitutes mace. Within this is a thin, hard, dark-brown, glossy shell, covering the kernel, which is the nutmeg of the shops. The tree begins to bear when 8 years old, and is in its prime at 25 years, and continues to bear fruit until 60 or even 80 years old. A good tree will yield annually 2000 fruits. In 1871 the produce of the Banda Islands amounted to $1,080,933 \mathrm{Ibs}$. By expression nutmegs yield a concrete oil called Adeps Myristicce, or sometimes erroneously oil of mace. A volatile oil is also procured by distillation. Mace is an arillode or additional covering of the seed commencing at the exostome (p. 328). It has a fine crimson hue, and yields a fatty matter and volatile oil, resembling those of the nutmeg. A variety produces ivory-coloured mace. Nutmeg and mace are used medicinally as aromatic stimulants and condiments. In large doses they have a narcotic effect. The fleshy part of the fruit is used as a preserve. The kernels of Myristica tomentosa are also used as aromaties, under 
the name of wild or male nutmegs. The bark of many plants of the order yields an acrid juice, which is sometimes of a crimson colour. A red pigment is furnished by Pyrrhosa tingens.

Order 145.-Proteaceze, the Protea Family. (Apet. Perigyn.) Perianth more or less deeply 4-divided; rstivation valvate. Stamens perigynous, 4 ( 1 sometimes sterile), opposite the segments of the perianth; anthers dithecal, with longitudinal dehiscence. Ovary single, superior, unilocular; ovules single or in pairs, anatropal or amphitropal; style simple; stigma undivided, discoid. Fruit dehiscent or indehiscent. Seed exalbuminous, sometimes winged; embryo straight; cotyledons 2 or more; radicle inferior, next the hilum.Shrubs or small trees, with hard, dry, opposite or alternate, exstipulate leaves. They are natives principally of Australia and the Cape of Good Hope. In general they occur in land unfit for cultivation, and seldom attain to a large size. The order has been divided into two sections:-1. Nucumentaceæ, with nucumentaceous indehiscent fruit. 2. Folliculares, with follicular dehiscent fruit. Lindley mentions 46 genera, including 654 species. Examples-Protea, Persoonia, Grevillea, Hakea, Banksia, Dryandra.

The plants of this order have no medicinal properties of importance. They present great diversity of appearance, hence the name of the order, and they are cultivated for their handsome habit and the peculiarity of their flowers. The clustered cone-like heads of the flowers of Banksias have a remarkable appearance. In Grevillea the style is at first bent downwards, and the discoid stigma is enclosed within the upper part of the perianth, where the anthers are placed; but after the pollen has been scattered, the stigma is emancipated, and the style rises upwards. The fruit and seeds of a few plants of the order are eaten, and the wood is used for economical purposes. Guevina Avellana yields nuts, which are sold in Chili under the name Avellano. Protea mellifera is called Sugar-bush, on account of the honey furnished by its flowers. Leucadendron argenteum is the Silvertree or Witteboom of the Cape. The bark of Proted grandiflora, called Wagenboom, is used by the Cape settlers in diarrhoea. It attains a height of 8-14 feet, and its wood supplies fuel at Simon's Town. Grevillea robusta is called Silver-oak. Macadamia ternifolia yields an edible fruit.

Order 146.-ELAAGNACEA, the Oleaster Family. (Apet. Diclin. and Perigyn.) Flowers usually unisexual, rarely hermaphrodite. Male flowers amentaceous, with 2-4 leaves forming the perianth; stameus 3,4, or 8 ; anthers nearly sessile, dithecal, introrse, and dehiscing longitudinally. In the female and hermaphrodite flowers, perianth tubular, persistent, with an entire or 2-4-toothed limb. Disk fleshy. Ovary superior, 1-celled; ovule solitary, ascending, on a short funiculus, anatropal; style short; stigma simple, subulate, 
glandular. Fruit a crustaceous achænium, enclosed within the enlarged succulent perianth. Seed ascending; embryo straight, surrounded by thin fleshy albumen; cotyledons fleshy; radicle inferior. -Trees or shrubs, with alternate or opposite, entire, or exstipulate leaves, which are often covered with scurfy scales (fig. 87, p. 32). They are found in all parts of the northern hemisphere. They have no marked medicinal properties. The fruit of some is eaten. Hippophaë rhamnoides, Sea Buckthorn, is furnished with sharp spines, and forms a good hedge near the sea. Its fruit is eaten, and has been used as a preserve, although it is said by some to have narcotic qualities. The plant yields a yellow dye. The fruit of Elosagnus parvifolia is eaten. Its flowers are highly fragrant, and abound in honey, which is esteemed as a remedy for malignant fevers in some parts of Europe. There are four known genera and 20 species. ExamplesElæagnus, Hippophaë.

Order 147.-Penaracese, the Sarcocol Family. (Apet. Perigyn.) Perianth coloured, salver-shaped, with a 4-lobed limb, and with two or more bracts at its base, persistent. Stamens perigynous, either 4 or 8 , alternate with the lobes of the perianth; anthers dithecal, introrse. Ovary superior, 4-celled; ovules usually in pairs, collateral, anatropal, ascending or suspended; style simple; stigmas 4 . Fruit a 4-celled, 4-valved capsule. Seed erect or pendulous; testa brittle ; hilum with a fungus-like aril; nucleus a fleshy mass, without distinction of albumen or embryo.-Shrubs, with opposite, entire, exstipulate leaves. They are found at the Cape of Good Hope. They have no known properties of importance. The gum-resin called Sarcocol is said to be produced on the perianth of Pencea Sarcocolla and other species. There are two sections of this order:-1. Penæeæ, æestivation valvate, stamens 4 , connective fleshy, ovules ascending. 2. Geissolomeæ, æstivation imbricate, stamens 8 , connective not fleshy, ovules suspended. There are 6 known genera and 21 species. Examples-Penæa, Geissoloma.

Order 148.-Thymedarace 2 , the Daphne Family. (Apet. Perigyn.) Perianth tubular, coloured, 4- rarely 5-cleft, inferior; occasionally with scales in its orifice; æstivation imbricate. Stamens perigynous, definite, often 8 , sometimes 4 or 2 , and then opposite the segments of the perianth; anthers dithecal, with longitudinal dehiscence. Ovary free, 1-celled; ovule suspended, anatropal (fig. 462, p. 257); style I; stigma undivided. Fruit either nut-like or drupaceous. Seed solitary, pendulous ; albumen 0 , or thin and fleshy ; embryo straight ; cotyledons plano-convex, or somewhat lobed and shrivelled; radicle superior.-Shrubby, rarely herbaceous plants, with alternate, or opposite, entire, exstipulate leaves. Natives of various parts of the world, both in warm and temperate regions. There are two sections of the order :-1. Daphneæ, with hermaphrodite or rarely unisexual flowers, 
and plano-convex cotyledons. 2. Hernandiex, with polygamous flowers, and lobed and shrivelled cotyledons. Authors enumerate 40 genera, including 300 species. Examples-Daphne (Thymelæa), Edgeworthia, Passerina, Pimelea, Gnidia, Lagetta, Exocarpus, Hernandia, Inocarpus.

The bark of many of the plants is acrid and irritant, the fruit is often narcotic. The bark of 1 ,he root, as well as that of the branches of Daphne Merereum, Mezereon, is used in decoction as a diaphoretic in cutaneous and syphilitic affections. In large doses it acts as an irritant poison, causing hypercatharsis; and, when applied externally, it acts as a vesicant. It contains a neutral crystalline principle called Daphnein. The succulent fruit is also poisonous. The barks of Daphne Gnidium, D. alpina, D. Cneorum, D. pontica, and D. Laureola, Spurge-laurel, have similar properties. The berries of Daphne Laureola are poisonous to animals (except birds). The bark of Dirca palustris, North American Leatherwood, is used for cordage; its young twigs are made into ropes and baskets. It abounds near San Francisco and in the valley of the Mississippi. Its fruit is said to be narcotic. The bark of many of the plants is made into ropes and paper (fig. 119, p. 57). The inner bark of Lagetta lintearia (Daphne Lagetta), when cut into thin pieces after maceration, assumes a beautiful net-like appearance, whence it has received the name of Lace-bark. The bark, young leaves, and seeds of Hernandia, are slightly purgative. The seeds of Inocarpus edulis have the taste of chestnuts, and are eaten when roasted.

Order 149. - Aquilariacese, the Aquilaria Family. (Apet. Periqyn.) Perianth coriaceous, imbricate or tubular, limb 4-5-lobed; æstivation imbricate. Stamens usually 10 fertile, alternating with 10 sterile, in the form of petaloid scales, sometimes 8 or 5 ; filaments inserted into the orifice of the perianth, often united; anthers dithecal, with longitudinal dehiscence. Ovary free, ovate, compressed, 2-celled; ovules 2, suspended, anatropal; stigma usually sessile, large and simple. Fruit a pyriform, sessile, or stipitate 2-valved capsule, or drupaceous and indehiscent. Seeds 2 , one on each placenta, pendulous ; albumen 0 ; cotyledons fleshy, hemispherical ; radicle straight, superior.-Trees, with alternate or opposite, entire, stalked, and exstipulate leaves. They are natives of the tropical regions of Asia. They have no known medical properties. Aquilaria ovata and Agallochum furnish a fragrant wood called Eagle-wood, or Aloes-wood. It

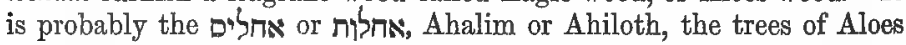
or Lign-Aloes, of the Bible, yielding an aromatic perfume. It has been considered a cordial by some Asiatic nations, and has been prescribed in Europe in gout and rheumatism. There are 7 genera noticed, including 12 species. Examples-Aquilaria, Gyrinopsis.

Order 150. - Chaildetiacese, the Chailletia Family. (Apet. Perigyn.) Perianth 5-parted, with an incurved valvate æstivation. Stamens inserted into the base of the perianth, 5 inner fertile opposite 
the segments of the perianth, 5 outer sterile, petaloid, usually with glands at their base; anthers ovate, versatile, dithecal. Ovary free, 2-3-celled ; ovules twin, pendulous ; styles 2-3, distinct or combined; stigmas capitate or obscurely 2-lobed. Fruit dry, 1-2- or 3-celled. Seeds solitary, pendulous, exalbuminous; embryo thick; cotyledons fleshy; radicle superior.-Trees or shrubs, with alternate, stipulate leaves, and axillary peduncles, often cohering to the petiole. They are natives of the warm parts of Africa and South America. The fruit of Chailletia toxicaria is said to be poisonous; it is called Ratsbane in Sierra Leone. There are 4 genera and 10 species known. Examples-Chailletia, Tapura.

Order 151.-SaMrdaces, the Samyda Family. (Apet. Perigyn.) Perianth 4-5-divided, usually coloured inside; æstivation somewhat imbricate. Stamens inserted into the tube of the perianth, 2, 3, or 4 times as many as its divisions, either all fertile, or the alternate ones sterile, shorter and fringed; filaments monadelphous at the base ; anthers erect, ovate, 2-celled. Ovary free, 1-celled; ovules 00, attached to parietal placentas, semi-anatropal ; style 1, filiform ; stigma capitate or slightly lobed. Fruit a coriaceous, unilocular, 3-5-valved capsule, partially dehiscent. Seeds 00 , fixed irregularly on the pulpy inner surface of the valves, with a fleshy arillus and a hollowed hilum ; embryo large, in the midst of oily or fleshy albumen; cotyledons ovate, foliaceous ; radicle pointing to the extremity remote from the hilum.-Trees or shrubs, with alternate, simple, stipulate leaves, usually having pellucid, round, or linear markings. Natives of tropical regions, chiefly in America. Some of the species of Casearia are bitter and astringent. A decoction of the leaves of Casearia Lingua, called by the Brazilians Cha de Frade and Lingta de Fin, is also used internally in inflammatory disorders and malignant fevers. There are 6 known genera and 82 species. Examples-Samyda, Casearia.

Order 152.-Homadiaceas; the Homalia Family. (Apet. Perigyn.) Perianth funnel-shaped, with 5 to $\mathbf{1 5}$ divisions, and having usually alternating petaloid segments, and glands or scales in front of the outer divisions. Stamens perigynous, either single or in parcels of 3 or 6, alternating with the outer divisions of the perianth; anthers dithecal, with longitudinal dehiscence. Ovary partly adherent to the tube of the perianth, 1-celled ; 'ovules numerous, anatropal, pendulous, attached to 2,3 , or 5 parietal placentas ; styles $3-5$, simple, filiform, or subulate. Fruit either baccate or capsular. Seeds small, ovate; embryo in the axis of fleshy albumen; cotyledons leafy; radicle superior.-Trees or shrubs, with alternate leaves, having deciduous stipules. Many look upon the petaloid divisions of the perianth as true petals. Lindley puts this order in his Cactal alliance, and considers it as allied to Loasaceæ; others include it in Samydaceæ. It contains tropical plants, which do not possess any important properties. 
Authors mention 9 genera, including 32 species. Examples-Homalium, Nisa.

Order 153. - Santadacers, the Sandal-wood Family. (Apet. Epigyn.) Perianth superior, 4-5-cleft; æstivation valvate. Stamens 4-5, opposite the segments of the perianth, and inserted into their bases. Ovary coherent, 1-celled; ovules 1-4, pendulous from the apex of a central placenta; style 1 ; stigma often lobed. Fruit nut-like or drupaceous. Seed solitary; embryo minute, in the axis of fleshy albumen ; radicle superior. - Trees, shrubs, or herbs, with alternate or nearly opposite exstipulate leaves. Found in various parts of the world, as Europe, Asia, America, and New Holland. Authors give 20 genera, including 200 species. Examples-Santalum, Osyris, Thesium.

Some are astringent, others yield fragrant wood. Santalum album, and other Indian and Polynesian species, yield Sandal-wood, which is used both medicinally and as a perfume. Some think the Almug or Algum trees of the Bible are Santalum album, while others refer them to Pterocarpus santalinus, the Red Sandal-wood of India (p. 480). The seeds of some of the plants of the order are eaten. The species of Thesium seem to be root-parasites. The large seeds of Pyrularia oleifera, Buffalo-tree, or Oil-nut, yield a fixed oil. Santalum Persicari is a dwarf kind of Australian Sandal-wood. The bark of the root furnishes an amylaceous food.

Order 154.-Loranteacem, the Mistleto Family. (Apet. or Monopet. Epigyn.) Calyx arising from a tube, or rim, which some regard as an expansion of the pedicel, often bracteated. Petals (or according to others, sepals) 4-8, distinct, or more or less united; æstivation valvate. Stamens equal in number to the petals, and opposite to them; filar ments more or less united to the petals ; anthers 1- 2- or many-celled (p. 222). Ovary unilocular, adherent to the calycine tube or the expanded pedicel ; ovules with a naked nucleus, erect or suspended (figs. 450,451, p. 253 ); style filiform or 0 ; stigma simple. Fruit succulent, crowned by the calyx, 1-celled. Seed solitary, pendulous; embryo straight, in the axis of fleshy albumen ; cotyledons either minute or numerous ; radicle superior.-Shrubs usually parasitical, with opposite or alternate, fleshy exstipulate leaves. Many of the plants have showy flowers, which hang from the trunks and branches of trees in the equinoctial parts of Asia and America. Some occur in temperate regions. Genera, 13; species, about 450. Examples-Loranthus, Viscum, Myzodendron.

Disputes have taken place as to the structure of the flowers in this order, some considering the petals as being in reality sepals, and regarding the calycine rim as being an expansion of the pedicel only. The wood of some of the plants is arranged in separate wedges, and their vessels are either annular or scalariform. The fruit contains a 
viscid matter, like bird-lime, by means of which the seeds adhere to trees. The seeds in germinating send their radicles into the plant to which they are attached, and grow afterwards as true parasites, selecting certain chemical ingredients in preference to others. The bark is usually astringent. Griffith has carefully described the nature of the parasitism of those plants. He states that in Loranthus the ripe seeds adhere firmly to the substance on which they are applied by means of their viscid coating, which hardens into a transparent glue. In two or three days after application, the radicle curves towards its support, and as soon as it reaches it, becomes enlarged and flattened. By degrees a union is established between the woody system of the parasite and stock, after which the former lives exclusively on the latter, the fibres of the sucker-like root of the parasite expanding on the wood of the support. Before this occurs the parasite is nourished by its own albumen, which is gradually absorbed. "As soon as the young parasite has acquired the height of one or two inches, when an additional supply of nourishment is perhaps required, a lateral shoot is sent out, which is, especially towards the point, of a green colour. This at one, or two, and subsequently at various points, adheres to the support by means of sucker-like productions, which are precisely similar in structure and mode of attachment to the original seminal oue." The fibres of the parasite never penetrate beyond their original attachment; in the adult the sucker-bearing shoots frequently run to a considerable distance. "I have seen," says Mr. Griffith, "such shoots which had taken their course along a decayed branch become replaced, and return in quest, as I may express it, of a part capable of affording some nourishment." Viscum album, Mistleto, was called by the Druids the Mistleto of the Oak, on which, however, it is rarely found parasitic. It grows well on the apple-tree. The formation of the ovule in the Mistleto, according to Schleiden, is described at p. 253. Loranthus tetrandrus is used in Chili to dye black.

Order 155.-Aristolochiacede, the Birthwort Family. (Apet. Epigyn.) Perianth adherent, tubular, 3-cleft (fig. 809), regular, or sometimes very irregular (fig. 808); rstivation valvate or induplicate. Stamens 6-12, epigynous, distinct or gynandrous (fig. 811). Ovary inferior, 3-6-celled (figs. 810, 812); ovules 00 (fig. 810), anatropal, horizontal; style simple, short; stigmas radiating, 3-6 (fig. $811 \mathrm{~s}$ ). Fruit dry or succulent, 3-6-celled (fig. 813). Seeds (fig. 814) numerous ; embryo very minute, at the base of fleshy albumen (fig. 815); cotyledons inconspicuous; radicle next the hilum (fig. 816).-Herbs or shrubs, often climbing, with alternate, simple, often stipulate leaves, and solitary axillary flowers. Found in abundance in the warm regions of South America, and growing also in the temperate and cold regions of Europe, Asia, and America. There are 5 known genera and 180 species. Examples-Asarum, Aristolochia. 
The plants of the order are generally bitter, tonic, and stimulant. Some are acrid, and act as emetics. The leaves of Ascrum europoum are used as an acrid emetic under the name of Asarabacca. The roots appear to have greater activity than the leaves. The powdered root

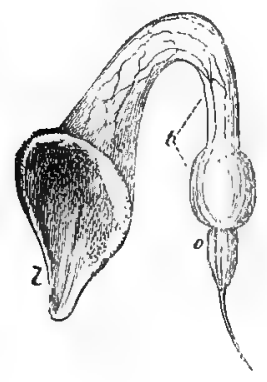

Fig. 80 .

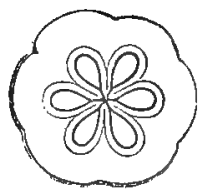

Fig, 512.

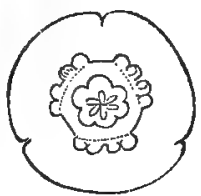

Fig. 809 .

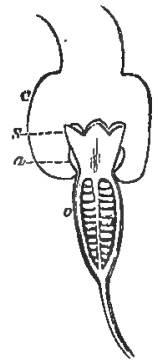

Fig. 810.

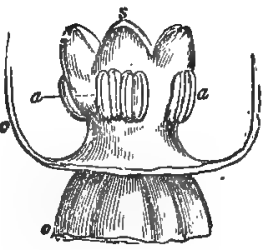

Fig. 811.

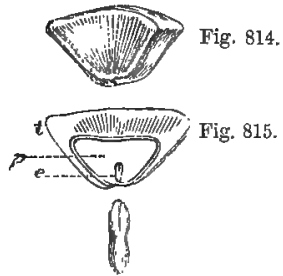

Fig. 816 .

and leaves enter into the composition of cephalic snuffs, which cause sneezing by their irritation, and are used in cases of headache and ophthalmia. An active crystalline substance, called Asarin, exists in the plant. Asarum canadense, Wild Ginger, or Canada Snake-root, is used as a spice in Canada. The shrubby species of Aristolochia have

Figs. 808-816. - Organs of fructification of Aristolochia Clematitis, to illustrate the natural order Aristolochiacere. Fig. 808. Flower entire, consisting of an inferior ovary, and a superior, irregular, funnel-shaped perianth. 0 , Part of the perianth adherent to the ovary. $t$, Part of the tube of the perianth, with a swollen portion at the base, enclosing the anthers and stigma. $l$, Limb of the perianth prolonged laterally in a tongue-like form. Fig. 809. Diagram of the flower, showing three divisions of the perianth, six anthers, and six cells of the ovary. Fig. 810. Lower part of the flower eut vertically. 0, Ovary with numerous ovules. s, Radiating stigma, a, Anthers, $c$, Swollen part of the tube of the jerianth. Fig. 811. $s$, Stigma with the anthers adhering to the column in pairs. 0 , Summit of the ovary. $c$, Swollen part of the tube of the perianth. Fig. 812. Horizontal section of the six.celled ovary. Fig. 813. Ripe fruit. Fig. 814. Angular seed. Fig. 815. Seed cut vertically. $t$, Integument thickened mear the chalaza. $p$, Fleshy perisperm. $\quad$, Minute embryo. Fig. 8I6. Embryo separated, witl cotyledons and radicle. 
a peculiar arrangement of vascular bundles in their wood. There are no concentric zones, but a number of separable wedges (p. 60). The name of Birthwort, given to Aristolochias, depends on their supposed action on the uterus. Some of them are used as emmenagogues. The root of Aristolochia Serpentaria, Virginian Snake-root, is a stimulant tonic. The plant is a native of the United States. It was formerly used as an antidote to snake-poison. It is now employed occasionally as a tonic diaphoretic. Aristolochia longa, rotunda, and Clematitis, were celebrated in ancient times as uterine remedies. The roots of many of the species have a strong aromatic taste. Those of Aristolochia anguicida are said to stupify snakes.

Order 156.-BaLANophoRaces, the Balanophora Order. (Apet. Diclin.) Flowers usually unisexual, male flowers conspicuous, with an entire or 3-5-lobed perianth; æstivation valvate; stamens usually $3-5$, distinct or united. Female flowers minute, with a superior perianth, sometimes bilabiate; ovary 1-celled; styles 2 ; ovule solitary, pendulous. Fruit a 1-celled, 1-seeded nut. Seed albuminous; embryo amorphous and lateral. Root-parasites, without leaves, and having peculiar fungus-like stems, bearing spikes of flowers, which are either on naked or scaly peduncles. Hooker considers the order as allied to Halorageaceæ. - The plants grow on the roots of Dicotyledonous trees, chiefly on the Andes and Himalayas. Some are found in Africa and Australia. Some of the plants are astringent, and have been employed as styptics. Cynomorium coccineum, commonly known as Fungus melitensis, grows in Malta and Sardinia, and was long celebrated for arresting hæmorrhage. Genera, about 15 ; species, 37. Examples-Balanophora, Cynomorium, Sarcophyte, Helosis.

Order 157. - CxTINACE出, the Cistus-rape Family.

(Apet. Diclin.) Flowers perfect, or monœcious ; perianth 3-6-parted, superior; anthers sessile, opening by longitudinal dehiscence; ovary 1celled; ovules numerous, attached to parietal placentas. Fruit succulent, unilocular. Seeds embedded in pulp, with or without albumen ; embryo amorphous.-Root-parasites, having a fụngus-like aspect, with the flowers either solitary or in clusters at the end of scaly peduncles. They are parasitic upon the roots of Cistus, some succulent Euphorbiaceæ, and other plants. They are found in the south of Europe and in Africa. Cytinus hypocistis is said to contain gallic acid. Genera, 4 ; species, 7 . Examples-Cytinus, Hydnora.

Order 158. - RAFFLESIACE. Diclin.) Perianth 5-10-parted with a ring or a circle of scales (calli) on the throat; anthers 2- or many-celled, distinct or united, with porose dehiscence, and supported on a column; ovary 1-celled, with parietal placentas, to which numerous ovules are attached. Fruit indehiscent, Seeds with or without albumen; embryo a uniform undivided body.-Parasitic on species of Cissus, in the East Indies, and on legu- 
minous plants in South America. The species of Rafflesia are gigantic parasites, the perianth being sometimes three feet in diameter, and capable of holding twelve pints of fluid. Raflesia Patma is employed in Java as an astringent and styptic. The flower of $R$. Arnoldi sometimes weighs more than $14 \mathrm{lbs}$. It is parasitic on the roots of Cissus angustifolia. Genera, 4; species, 16. ExamplesRafflesia, Sapria, Brugmansia.

Order 159. NePenthaces, the Pitcher-plant Family. (Apet. Diclin.) Flowers dicecious. Perianth 4-parted, inferior; restivation imbricated. Male flowers : stamens united in a solid central column; anthers about 16, forming a spherical head, extrorse, and with longitudinal dehiscence. Female flowers: ovary free, four-cornered, 4celled; ovules 00 ; stigma sessile. Fruit a 4-celled, 4-valved capsule, with loculicidal dehiscence. Seeds 00 , ascending, very minute, fusiform, with a loose testa; nucleus less than the seed, suspended by the chalaza; embryo in the midst of fleshy albumen; cotyledons plano-convex; radicle pointing to the hilum.-Herbs, or half-shrubby plants, with alternate leaves, slightly sheathing at the base, having a foliaceous petiole, which forms an ascidium at its extremity, with the lamina in the form of a lid (fig. 200, p. 95). Natives of swampy ground in the East Indies and China. The greater part are found in Borneo and the Malay Archipelago, one in India, one in Ceylon, one in Madagascar, one in the Seychelles, one in tropical Australia. $\mathrm{Ne}$ penthes Wardii of Percival Wright is found in the Seychelles, on exposed mountain peaks, at a height of 2500 feet. $N$. Kennedyana is the tropical Australian species. They have no known properties. The pitchers have been found to contain in solution salts of potash, soda, lime, or magnesia, as well as malic and citric acid. Spiral vessels abound in all parts of the pitcher plants; and the woody bundles arewithout concentric zones. Genus, 1; species, 30. ExampleNepenthes.

Order 160.-Datiscaces, the Datisca Family. (Apet. Diclin.) Flowers unisexual. Male flowers: perianth 3-4-divided. Stamens 3-7; anthers linear, membranous, dithecal, with longitudinal dehiscence. Female flowers: perianth adherent, 3-4-toothed. Ovary inferior, unilocular; ovules 00, anatropal, attached to 3 or 4 parietal placentas; styles as many as the placentas. Fruit a 1-celled capsule, opening at the apex. Seeds 00, strophiolate, with a reticulated spermoderm; albumen 0; embryo straight ; cotyledons very short; radicle pointing to the hilum. - Herbaceous branched plants or trees, with alternate exstipulate leaves. They are scattered over North America, various parts of Asia, and the south-eastern part of Europe. Some of the plants are said to be bitter, and others, as Datisca cannabina, have purgative qualities. Lindley mentions 3 genera and 4 species. Examples-Datisca, Tetrameles, Tricerastes. 
Order 161.-Empetracear, the Crowberry Family. (Apet. Diclin.) Flowers unisexual. Perianth bud-like, consisting of persistent imbricated scales, in 2 or 4 alternating rows, the inner row often petaloid. Male flowers: stamens 2-3, equal in number to the scales in each row, and alternating with the innermost, hypogynous; anthers roundish, dithecal, with longitudinal dehiscence, Female flowers : ovary free, seated on a fleshy disk, 3-6- or 9-celled; ovules solitary, anatropal, ascending; style 1 ; stigma with as many radii as there are ovarian cells. Fruit a nuculanium, seated within the persistent perianth, with 2 or more 1 -seeded pyrenes. Seeds solitary in erch nucule, ascending; embryo in the axis of fleshy albumen; radicle inferior.-Heath-like shrubs, with alternate or somewhat verticillate, evergreen, exstipulate leaves. They inhabit chiefly Europe and North America. By some this order is placed in an alliance with Celastraceæ, Aquifoliaceæ, and Olacaceæ. The order has also some affinity with Ericacer. The fruit of some is slightly acid. Empetrum nigrum, the black Crowberry, is common on the mountainous and northern parts of Europe. The fruit is watery, and very slightly. acid and astringent. Genera, 3 ; species, 4 . Examples-Empetrum, Corema.

Order 162.-EuphorbiacEe, the Spurge Family. (Diclin.) Flowers unisexual, sometimes enclosed within an involucre (fig. 817). Perianth lobed, inferior (figs. $346 c$, p. $218 ; 349 c$, p. 219), with various glandular or petaloid, scaly, internal appendages (figs. $346 \mathrm{pa}$, p. $218 ; 439$, p. 248); sometimes the flowers are naked (fig. 818). Male flowers (fig. $817 \mathrm{fm} \mathrm{fm}$ ): stamens definite or 00 , distinct (fig. 818 ) or monadelphous (fig. 346,1, p. 218 ), or polyadelphous (fig. 349 , p. 219); anthers bilocular (fig. 362 , p. 223 ; fig. 358 , p. 222), sometimes with porous dehiscence (fig. 355, p. 222). Female flowers (figs. $439 f f$, p. $248 ; 817$ ): ovary free, sessile or stalked, 1-2-3- or many-celled (fig. 819); ovules solitary or twin, suspended; styles equal in number to the cells (figs. $346,2, \dot{p} .218 ; 819$ s), distinet or combined, sometimes 0 ; stigmas several, or 1 with several lobes. Fruit usually tricoccous (figs. 543, p. $304 ; 549$, p. 305), with the cocci separating in an elastic manner, and opening by 2 valves (figs. 820,821 ), or indehiscent and fleshy. Seeds solitary (fig. 822) or in pairs, suspended, often arillate (fig. $549 \mathrm{~g} g$, p. 305); embryo enclosed in fleshy albumen (fig. 579, p. 329); cotyledons flat (fig. 605, p. 339); radicle superior (fig. 823).- -Trees, shrubs, and herbs, often abounding in acrid milk, with opposite or alternate, often stipulate leaves, sometimes none. Some look on this order as apetalous, with a tendency to develop a corolla, while others consider it polypetalous, with a tendency to have the corolla suppressed. In European plants of the order there are usually no petals present, but in those of tropical countries the corolla is frequently well marked. In the 
Euphorbias of Britain there is an evident involucre, surrounding a number of achlamydeous male and female flowers, which by Linnæus were looked upon as merely stamens and pistils, and hence the plants were put by him in Dodecandria in place of Monœcia (p. 220). The flowers in Euphorbiacer vary much in the number of their parts, as may be seen in figs. $644-649$, p. 368 . Sometimes the general penduncle or rachis becomes flattened and leaf-like (fig. 250, p. 173). The inflorescence is occasionally amentaceous, as in the division

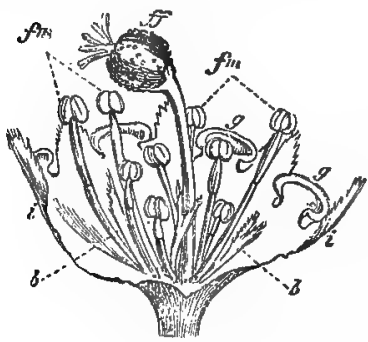

Fig. 817 .

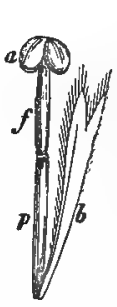

Fig. 818.

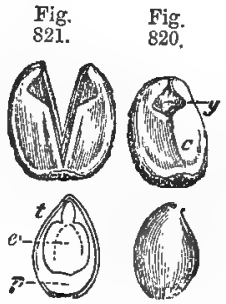

Fig. 823. Fig. 822.

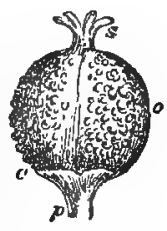

Fig. 819.

Scepacece, which is described by some as a distinct order. The plants of the order abound in warm regions, especially in Equinoctial America, where they occur as trees or bushes, or lactescent herbs, and often present the appearance of Cactacex, from which their milky juice at once distinguishes them. They are also found in North America and in Europe. In Britain there are 3 genera and 17 species. There are about 180 known genera and about 3000 species. ExamplesEuphorbia, Hippomane, Hura, Acalypha, Croton, Jatropha, Ricinus, Phyllanthus, Buxus.

The plants of this order are acrid and poisonous, in some instances furnished with stinging hairs. These properties reside especially in their milky juices, which are contained in laticiferous vessels (fig. 68,

Figs. 817-823. Organs of fructification of Euphorbia palustris, to illustrate the natural order Euphorbiacex. Fig. 817. Inflorescence, with the involucre, $i$, , opened and spread out, to show the position of the male and female flowers, which it encloses, $g g$, Glands (glandular lobes) alternating with'the divisions of the involucre. $b b$, Membranous laminix, or bracts, at the base of the flowers. $f m, f m$, Achlamydeous male flowers, consisting of a single stamen, supported on a pedicel, to which it is attached by an articulation. $f f$, Achilanydeous fenale flower in the centre; the ovary and styles supported on a long pedicel. Fig. 818. Achlamydeous male flower separated. $b$, Bract. $p$, Pedicel. $f$, Filament articulated with the pedicel. $a$, Anther. Fig. 819. Female flower. $p$, Summit of the pedicel which supports it. c, A flattened portion of the pedicel, which some call a perianth. 0, Tricoccous ovary. $s$, Styles and stigmas. Fig. 820. One of the cocei (carpels), $c$, separated, and seen on its inner surface. $g$, The seed seen across the opening by which the nourishing vessels enter. Fig. 821. A coccus separated, after dehiscence and expulsion of the seed. Fig. 822. Seed separated. Fig. 823. Seed cut vertically. $t$, Integument (spermoderm). $p$, Perisperm (fleshy albumen). e. Embryo with flat cotyledons and a superior radicle. 
p. 21), in which the movements of Cyclosis were observed by Schultz (p. 146). In many cases the elaborated sap contains caoutchonc and resin. The acrid 'properties of the order are also found in the seeds, many of which yield oils, both of a bland and of an irritating nature.

The milky juice of many species of Euphorbia is caustic, and has been used for destroying warts and causing vesication. At other times the juice has been used for its purgative and emetic properties. The root of Euphorbia Ipecacuanha has been employed as a substitute for Ipecacuan. The resinous substance called Euphorbium is procured from Euphorbia resinifera, a native of Morocco. It is a leafless plant like a Cactus, attaining a height of six or more feet. The stem is fleshy and quadrangular, and on its angles are produced at intervals spines which represent stipules. The resin is a powerful irritant, and has been used as a vesicant. It causes great irritation of the mucous membrane when applied to the nostrils and eyes, and it acts as a cathartic when taken internally. Many species of Euphorbia yield resins of a similar nature. The juice of Hippomane Mancinella, Manchineel, is very acrid and poisonous. When applied to the skin it excites violent inflammation, followed by ulceration. The juice of Hur'a crepitans, Sand-box-tree, or Monkey's dinner-bell, is also very acrid. The fruit of this tree is composed of numerous 1-seeded cocci, which, when dry, separate from each other with great force. Mercurialis perennis, and annua, produce vomiting and purging.

Many important medicinal oils are furnished by the plants of this order. Castor-oil is expressed from the seeds of Ricinus communis (Palma Christi), a plant with peltate-palmate leaves (fig. 161, p. 88), which is found native in Greece, Africa, and the East Indies, and is cultivated in the West Indies, as well as in North and South America. In the temperate and more northern parts of Europe the plant is a herbaceous annual, of from three to eight feet high; in the more southern parts it becomes shrubby, and even attains a height of twenty feet; while in India it is often a tree thirty or forty feet high. The best oil is got by expression from the seeds, without heat, and is called cold-drawn Castor-oil. It is entirely soluble in alcohol, and, by the action of hyponitrous acid, it is converted into a solid yellow substance called Palmin. The oil acts as a mild laxative. Besides this comparatively bland oil, there exists in the seed a powerfully cathartic constituent, which remains behind when the oil is expressed, and which is destroyed or evaporated under the process of ebullition. Croton-oil is obtained by expression from the seeds of Croton Tiglium (Tiglium officinale), an Indian and Asiatic shrub. It acts as an irritant purgative in the dose of one drop. In large doses it is a dangerous poison. When applied externally it produces pustules. Other species of Croton, as C. Pavana and Roxburghï, yield a purgative oil. 
Croton Malambo yields a tonic bark. The oil procured from the seeds of Euphorbia Lathyris, Caper-spurge, has cathartic properties, and so has that procured from the seeds of Jatropha Curcas (Curcas purgans), Physic or purging-nut, Jatropha multifida, and Hur'a crepitans. The fatty matter obtained from the seeds of Stillingia sebifera, the Tallowtree of China, is used for making candles; the plant also yields a bland oil. The roots of Euphorbia pilosa and palustris are used as purgatives, and are said to have been useful in hydrophobia. Rottlera tinctoria (Mallotus Philippinensis) is a small tree which grows in Abyssinia, the Indian Peninsula, Philippines, and Australia. The ruby-like glands on its tricoccous fruit are brushed off, and constitute the powder known in Bengal as Kamale, which is administered for tape-worm.

Cascarilla is the bark of Croton Eleuteria, and of other species of Croton. It acts as a tonic and stimulant. When burned it gives out a musky odour, and is often used in pastilles. The bark of another species of Croton (C. Pseudo-china, or niveum), a native of the West Indies and Mexico, is known by the name of Copalchi bark, and used as a tonic. The bark of Buxus sempervirens, Box-tree, is said to be alterative, and its leaves have bitter and purgative qualities. Its wood is much used for wood-engraving. The tree is the Hebrew רושיש, Teashur. The hard wood called African Teak or African Oak is the produce of Oldfieldia Africana. In the root of Janipha Manihot (Manihot utilissima), a shrub about six feet high, extensively cultivated in tropical countries, there is much starchy matter deposited, usually along with a poisonous narcotic substance, which is said to be hydrocyanic acid. The latter can be removed by washing, or it can be driven off. by roasting, and then the starch is used in the form of Cassava bread. There are two varieties of the Cassava or Manioc plant; one (called sometimes Janipha Loeflingii) having a. spindle-shaped root, brown externally, about six ounces in weight, which contains amylaceous matter, without any bitterness, and is used as food under the name of Sweet Cassava; another, called Bitter Cassava, having a knotty root, black externally, and sometimes $30 \mathrm{lbs}$. in weight, which is bitter and poisonous, and requires to be rasped and washed thoroughly before the amylaceous matter can be used. From the starch of the bitter Cassava, Tapioca is prepared by elutriation and granulating on hot plates. Manihot starch is sometimes imported into Europe under the name of Brazilian Arrow-root. The milky sap of Euphorbia phosphorea is said to emit a peculiar phosphorescent light. That of Siphonia elastica contains much caoutchouc, and supplies the bottle India-rubber. Hevea brasiliensis is the Para rubber-tree. Aleurites laccifera furnishes gum-lac in Ceylon. The seeds of Aleurites tritoba, the candlenut tree, yield by expression an oil, which is purgative, and is also used 
as artists' oil. Crozophora tinctoria supplies a purple dye called. Turnsole, which becomes blue on the addition of ammonia. The seeds of a few species of Aleurites, Anda, and Omphalea, are edible.

Order 163.-URTicades, the Nettle Family. (Apet. Diclin.) Flowers unisexual (figs. 824, 826), usually in cymes or polygamous, or collected into catkins or heads. Perianth usually divided (fig. 826). Stamens definite, inserted into the perianth ; filaments sometimes curved in æstivation (fig. 825). Ovary superior (figs. 827,

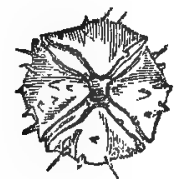

Fig.

824.

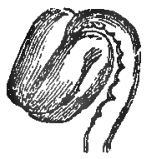

Fig. 825.

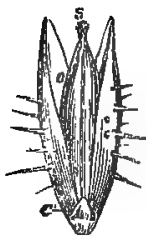

Fig. 827.

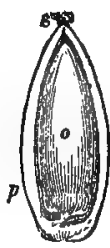

Fig, 828.

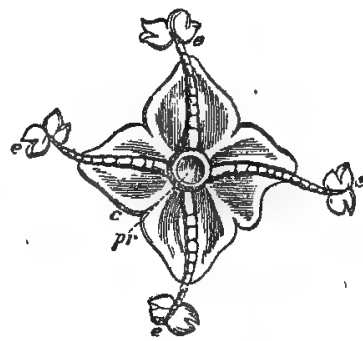

Fig. 826.

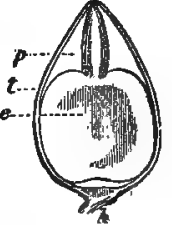

Fig. 829 .

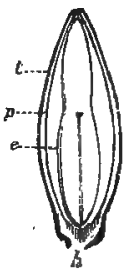

Fig. 830 .

828), 1-celled; ovule solitary, erect (fig. 828), orthotropous; style simple or with a capitate or penicillate stigna (fig. 828). Fruit an achene (fig. 460, p. 257), or a drupe (fig. 460, p. 257), naked or surrounded by the persistent, sometimes accrescent, perianth. Seed soli-

Figs. 824-830. Organs of fructification of Urtica urens, to illustrate the natural order Urticacex. Fig. 824. Bud of the male flower, viewed from above. Fig. 825. Stamen taken from the bud of the male flower, with the elastic. incurved filament, and the anther bent down before dehiscence. Fig. 826. Male flower expanded. c, Perianth with four divisions. eeee, Four hypogynous stamens, thrown back by the elasticity of the filaments, with the anthers burst. $p r$, Abortive rudiment of the central pistil. Fig. 827. Female flower. $c$, Perianth with four unequal segments, the two exterior ones being very small, o, Unilocular ovary. $s$, Sessile stigma. Fig. 828. Pistil cut vertically, to show the direction of the erect ovule, o. $p$, Parietes of the ovary. s, Stigma. Fig. 829. Seed cut vertically, parallel to the cotyledons. $t$, Integument (spermoderm). $h$, Hilum. $p$, Perisperm. $e$, Embryo straight, with the radicle superior. Fig. 830. Seed cut perrenclieularly to the cotyledons. $t$, Integument. $h$, Hilum. $p$, Perisperm. $e$, Embryo, 
tary, erect, suspended, albuminous or exalbuminous ; embryo straight, axile; radicle superior (figs. 829, 830).-Herbs, shrubs, or undershrubs, with stipulate leaves, which are usually hispid or scabrous, sometimes with stinging hairs; juice watery. The plants of this order are found both in temperate and in tropical regions. They belong mainly to the latter. Weddell says that 8 species are common to the Old and New World; 289 are natives of the former, and 187 of the latter. The Malayan Peninsula and Archipelago have the greatest number of species; then come Madagascar, the proximate African islands, Peru, and Bolivia, New Grenada and Ecuador. There is a greater abundance on islands than on continents. Genera, 43 ; species, about 500. Examples-Urtica, Boehmeria, Parietaria.

There are 3 species of British nettles, Urtica dioica, $U$. urens, and $U$. pilulifera. The last has capitate female flowers, hence its specific name. Various species of Urtica, Nettle, such as $U$. dioica, urens, pilulifera, stimulans, urentissima, and Laportea crenulata of Northern India, have stinging hairs (fig. 91, p. 34). The young shoots of the common nettle are sometimes used like spinach or greens. Urtica cannabina and tenacissima furnish fibres fit for cordage. Bohmeria nivea supplies fibre for the Chinese grass-cloth, and the Rheea fibre of Assam ; and Bohmeria Prya gives the Pooah or Puya fibre of Nepaul and Sikkim. In Nettles and Pellitories the elastic filaments turn the anthers back with elasticity, and cause the scattering of the pollen (p. 283). Specimens of tree-nettle were measured by Backhouse in Australia, and found to be 18, 20, and 21 feet in circumference. Their sting is very severe, causing violent inflammation. According to Mr. Macarthur, the stem of a specimen of Urtica (Laportea) gigas, in Australia, was 42 feet in circumference at a foot from the ground. The stem in some cases gradually tapered upwards, without a branch, to 120 or 140 feet, the trunk then dividing into a regularly-formed wide-spreading head.

Order 164.-Cannabinaces, the Hemp and Hop Family. (Apet. Diclin.) Flowers diœcious, males in racemes or panicles. Perianth herbaceous, 5-sepalous'; æstivation imbricate. Stamens 5, opposite the sepals; filaments erect and filiform; anthers dehiscing longitudinally. Female flowers in a strobilus or glomerulus; perianth formed by a bract enclosing the ovary. Ovary 1-celled; style terminal or 0 ; stigmas 2 ; ovules solitary, pendulous; fruit; indehiscerit, seed suspended; embryo exalbuminous, hooked or spiral, cotyledons incumbent, radicle superior.-Herbaceous plants, sometimes. twining, with watery juice, scabrous, stipulate; usually opposite and often glandular leaves. The plants have been long cultivated. They occur chiefly in northern temperate regions. Genera, 2 ; species, 3. Examples-Cannabis, Humulus.

Cannabis sativa, an annual herbaceous plant, native of Western 
and Central Asia, but cultivated in temperate and tropical regions, is the source of the valuable fibre called Hemp; what are usually called Hemp seeds are in reality fruits. A variety, called Cannabis indica, is used in India for producing intoxication. It is also employed medicinally in the form of extract, as an antispasmodic and anodyne, in cases of tetanus and neuralgia. The properties of the hemp plant appear to be much modified by climate. The Indian variety has a marked resinous varnish, called Churrus, on its leaves. What is called Bhang in India consists of the dried larger leaves and fruit, while Gunjah or Ganja is the whole plant dried after flowering, and the Haschisch or Qinnab of the Arabs is composed of the tops and tender parts of the plant dried. Hemp is probably the Hebrew שu, Shesh. The strobili of the female plants of Humulus Lupulus constitute hops, the bitterness of which resides in the resinous glandular scales surrounding the fruit, and to which the name of Lupulinic glands, or Lupulin, has been applied. The latter name is also given to the bitter principle of the hops. Hops are employed as a tonic and narcotic, in the form of extract, infusion, and tincture. Their tonic properties depend on their bitterness. A pillow stuffed with hops is a popular means of procuring sleep. The twigs of hops have been used to adulterate Sarsaparilla.

Order 165.-Ulmace $z$, the Elm Family. (Apet. Diclin.) Flowers hermaphrodite or unisexual, fascicled. Perianth single, inferior; stamens definite, inserted on the perianth; filaments erect; ovary superior, 1-2-celled; styles 2. Ovules solitary, anatropous. Fruit indehiscent, a samara or drupe, 1-2-celled. Seed solitary, pendulous, usually exalbuminous; embryo straight or curved, cotyledons leafy, radicle superior ; juice watery.-Trees or shrubs with alternate rough leaves, and deciduous stipules; chiefly natives of the northern and mountainous parts of Europe, Asia, and America. Genera, 9 ; species, about 60 . There are two sub-orders:-1. Ulmeæ, true Elms, ovary 2-celled, fruit a samara. Examples-Ulmus, Planera, Holoptelea. 2. Celtideæ, Tree-nettles, ovary 1-celled; fruit a drupe. ExamplesCeltis, Sponea, Trema.

Several species of Elm are cultivated for timber. Olmus campestris, English or small-leaved Elm, rarely produces fruit in this country. It often attains a height of 70 to 90 feet, with a diameter of 4 to 5 feet. Its wood is compact and durable under water, and it has been used for sleepers on railways, and for wooden pavements. Its inner bark is bitter, mucilaginous, and astringent. Ulmus montana, the Mountain, Wych, or Scotch Elm, produces fruit freely in this country, but its wood is inferior to that of the English Elm. The bark of Ulmus fulva, the red or slippery Elm, a tree of central. and northern United States, is used as a demulcent. Celtis occidentalis, the Nettle-tree, or Sugar-berry, has a sweet drupaceous fruit. 
Order 166.-Moraces, the Mulberry, Fig, and Bread-fruit Family. (Apet. Diclin.) Flowers unisexual. Male flowers with a 3-4-parted calyx or 0 ; stamens usually isostemonous, opposite the calyx segruents, inserted at the base, usually 4 ; filaments thread-like, often with inflexed rstivation. Female flowers with imbricate persistent perianth, either with 3-4 sepals, or 4-5 cleft, or 0 . Ovary usually 1-celled; styles 1-2; ovule solitary, micropyle superior. Fruit an achene, drupe or utricle; albumen fleshy or 0 ; embryo curved or straight, axile; radicle superior.-Trees, or shrubs, or herbs, sometimes climbing, with milky juice, and alternate stipulate leaves. There are two sub-orders:-1. Morem, the Mulberries and Figs, with flowers in heads, spikes, or catkins; fruit a sorosis or syconus; seed pendulous ; embryo hooked; albumen fleshy; natives both of temperate and tropical climates. Examples-Morus, Ficus, Sycomorus, Dorstenia. 2. Artocarpeæ, Bread-fruits, with flowers in dense heads; fruit usually a sorosis; seed erect or pendulous, with a variable quantity of albumen; embryo straight. Natives of tropical climates. Examples-Artocarpus, Antiaris. Genera, 46 ; species, about 230.

The common Fig is the Fruit of Ficus Carica, the Old Testament, and $\sigma \tilde{v} x \tilde{\eta}$ of the New Testament. It consists of a succulent hollow receptacle, enclosing numerous single-seeded carpels (fig. 267, p. 180), and is called a syconus (p. 316). The fruit is demulcent and laxative, and is used for cataplasms. Many other species of Ficus yield edible fruits. The plants belonging to the Fig tribe are generally remarkable for the adventitious roots which they send out from the stems. One of the most celebrated in this respect is Ficus indica, the Banyan (pp. 39, 360). Many of the species can live suspended in the air for a long time. A specimen of Ficus arstralis grew in this way in the Botanic Garden of Edinburgh for upwards of twenty years (p. 127). Ficus (Urostigma) religiosa is the Pippul-tree, or sacred Fig of India. Ficus (Urostigna) elastica is an Indian tree which supplies a large quantity of caoutchouc; so also do Ficus Radula, elliptica, and prinoides. Peculiar clusters of raphides are found in the cellular tissue of some of them (fig. 39, p. 11). The millyy juice is not in all instances bland and innocuous; it occasionally has acrid qualities. Ficus Sycomorus (Sycomorus antiquorum) is probably the Sycamore of the Bible, the שקמים (shikmim) of the Old Testament, and the ouxounger of the New. The wood of the tree is said to be very durable. Morus nigra supplies the common black Mulberry, which is an anthocarpous fruit, composed of numerous succulent flowers, forming a sorosis (fig. 571, p. 316). The Mulberry is probably the бuxápuvos, or Sycamine-tree of the New Testament. The white Mulberry, a less esteemed fruit, is the produce of Morus alba. Both of these mulberries are sub-acid. Their leaves are the favourite food of silkworms, The root of the white Mulberry is anthelmintic. Dov- 
stenias have a slightly concave broad receptacle, bearing numerous flowers (fig. 266, p. 180). D. Contrayerva, D. Houstoni, and D. brasitiensis furnish the Contrayervarroot of commerce. The officinal part is the root-stock, which is used as a stimulant, tonic, and diaphoretic. Broussonetia papyrifera is the Paper-mulberry, 'so called on account of being used in China and Japan in the manufacture of a kind of paper. It is called Crape-paper, and is prepared by pounding the bark, steeping it in water, then mixing it with glue, and taking it up with a mould of Bamboo-screen of the size required. The yellow dye-wood called Fustic is the produce of Maclura (Broussonetia) tinctoria.

The Artocarpus section is important as regards its uses. Artocarpus incisa, the Bread-fruit tree, supplies an anylaceous fruit, which furnishes an abundant supply of food in tropical countries. The properties of this tree are thus enumerated by Hooker :- The fruit serves for food; clothes are made from the fibres of the inner bark; the wood is used for building houses and making boats ; the male catkius are employed as tinder ; the leaves for table-cloths and for wrapping provisions in ; and the viscid milky juice affords birdlime. $A$. integrifolia is the Jack or Jaca, the fruit of which attains a large size, sometimes weighing thirty pounds, and is inferior in quality to the Breadfruit. In both instances the fruit is a sorosis, consisting of numerous flowers on a common axis, which becomes succulent. The milky juice of many of the Artocarpus tribe supplies caoutchouc, and in some instances it is used as a substitute for milk. This is the case with the juice of Brosimum (Galactodendron) utile, which is called Palo de Vaca, or the Cow-tree, in Demerara. The wood of Brosimum Aubletii (Piratinera guianensis) is called Snake-wood, or Letter-wood, in Demerara, and is used for articles of furniture. Specimens sent by Dr. Campbell from Demerara have been beautifully manufactured in Scotland. The seeds of many of the Artocarpus tribe are eaten. Brosimum Alicastrum yields Bread-nuts, which, when boiled or roasted, are nutritious and agreeable articles of food. While the juice of some is nutritive, that of others is highly poisonous. Thus Antiaris toxicaria is the source of the famous poison called Bohun-Upas or Upas-Antiar, by the Javanese, and which is said to owe its properties to the presence of a peculiar principle called Antiarin, which causes muscular paralysis. Another Upas poison, called Upas-Tieute, has already been noticed under the order Loganiaceæ, as being the produce of a species of Strychnos. The bark of Antiaris saccidora, a gigantic tree, having a trunk 18 feet in circumference at the base, is used for forming sacks. These bags are formed by separating the bark entire from the wood throughout the whole extent, with the exception of a small portion at one end. The wood is then removed from the interior, a part being left with the bark attached to form the bottom of the sack. The tree is common in the jungles near Coorg, and the sacks made from it are 
in general use among the villagers for carrying rice. Cecropia peltata is the Trumpet-wood, so called on account of the hollowness of its stem and branches, which are used for wind instruments. The fibrous bark of the tree is used for cordage.

Order 167.-Ceratophyllacese, the Hornwort Family. (Apet. Diclin.) Flowers unisexual. Perianth inferior, 10-12-parted. Male flowers: stamens, 12-20; anthers sessile, bilocular. Female flowers: ovary free, 1-celled; ovule solitary, pendulous, orthotropal; style filiform, oblique; stigma simple. Fruit a 1-celled indehiscent nut, terminated by the hardened style. Seed solitary, pendulous, exalbuminous; cotyledons 2, but apparently 4 ; radicle inferior.-Aquatic submersed herbs, with verticillate leaves cut into filiform lobes. They are found in ditches in various parts of Europe, Asia, and America. The affinities of the order are still obscure. Some authors consider it as allied to Lythracex, others to Chenopodiacex, while Lindley puts it in his Urtical alliance. Its properties are unimportant. There is only 1 genus, including about 6 species. Example-Ceratophyllum.

Order 168. - Podostemaces, the Podostemon Family. (Apet. Monoclin.) Flowers naked, or with a more or less perfect perianth, bursting through an irregularly lacerated spathe. Stamens hypogynous, definite or indefinite, distinct or monadelphous ; anthers dithecal, with longitudinal dehiscence. Ovary free, 2-3-celled; ovules numerous, anatropal, attached to a fleshy central placenta; styles or stigmas 2 or 3. Fruit slightly pedicellate, capsular, 2-3-valved. Seeds 00 ; embryo exalbuminous, erect.-Herbaceous, branched, floating plants, with capillary, or linear, or lacerated, or minute and imbricated leaves. Natives chiefly of South America, and of the islands to the east of Africa. They flower and ripen seed under water, and their ashes furnish salt. The affinities of the order are uncertain. Some authors put it among the Monocotyledons. Genera, 21 ; species, 100. ExamplesPodostemon, Lacis.

Order 169.-STtlaginace 2 , the Stilago Family. (Apet. Diclin.) Flowers unisexual. Perianth 2-3- or 5- partite. Male flowers: stamens 2 or more, arising from a swollen receptacle; filaments capillary ; anthers innate, 2-lobed, with a fleshy connective and vertical cells opening transversely. Female flowers: ovary free, 1-2-celled; ovules 2, anatropal; stigma sessile, 3-5-toothed. Fruit drupaceous. Seed solitary, suspended; embryo in fleshy albumen; cotyledons leafy ; radicle superior.-Trees or shrubs, with alternate, stipulate leaves. Natives chiefly of the East Indies. Some yield edible fruits, others are used as potherbs. The position of this order in the natural system is obscure. Lindley places it in the Urtical alliance, others consider it as allied to the Amentiferous orders. There are 5 known genera and about 22 species. Examples-Stilago, Antidesma.

Order 170.-Monimiace 
Flowers unisexual. Perianth somewhat globose, in one or more rows; divided at the border. Male flowers : stamens indefinite, covering the whole interior of the perianth; filaments often with 2 scales at the base ; anthers dithecal, with longitudinal dehiscence. Female flowers : ovaries several, superior, enclosed within the tube of the perianth, each with 1 style and 1 stigma; ovule solitary, pendulous, anatropal. Fruit consisting of several achrenia, enclosed within the enlarged perianth. Seeds pendulous; embryo at the end of copious fleshy albumen; radicle superior.-Trees or shrubs, with opposite exstipulate leaves. They are natives chiefly of South America and Australia. The bark and leaves are aromatic and fragrant. The succulent fruit of some is eaten. Boldoa fragrans (Peumos, or Ruizia fragrans) is a branching aromatic tree of Chili, the leaves of which contain an essential oil. The leaves are used as stimulant and tonic. The bark is used by tanners and the fruit is eaten. There are 8 known genera and about 40 species. Examples-Monimia, Boldoa.

Order 171. - Atherospermactes, the Plume-nutmeg Family. (Apet. Diclin.) Flowers unisexual. Perianth tubular, divided at the top into several segnents, "in 2 rows, the inner often petaloid, and accompanied in the female flowers with a few scales. Male flowers: stamens 00 , inserted in the bottom of the perianth; filaments with scales at the base; anthers 2-celled, with valvular dehiscence. Female flowers : ovaries usually 00 ; ovule solitary, erect ; style simple, lateral or basilar; stigmas simple. In some flowers, though rarely, stamens and pistils are found, and in that case the stamens are fewer, and arise from the orifice of the perianth. Fruit consisting of achænia, with persistent, ultimately feathery styles, enclosed within the tube of the perianth. Seed solitary, erect; embryo small, at the base of soft fleshy albumen; radicle inferior.-Trees, with opposite, exstipulate leaves, found in Australia, and in some parts of South America. They are generally fragrant. The bark of Atherosperma moschatum, a native of Australia, resembles Sassafras in flavour. There are 3 known genera and 4 species, according to Lindley. Examples - Atherosperma, Laurelia.

Order: 172. - Lacistemaces, the Lacistema Family. (Apet. Diclin.) Flowers polygamous. Perianth in several narrow divisions, covered by an enlarged bract. Stamen 1, hypogynous ; anther having 2 cells, which are separated by a thick 2-lobed connective, and which dehisce transversely. Disk fleshy. Ovary superior, 1-celled; ovules several, anatropal, attached to 2-3 parietal placentas; stigmas 2-3, nearly sessile. Fruit a unilocular 2-3-valved capsule, with loculicidal dehiscence. Seed usually, by abortion, solitary, suspended, with a fleshy arillus; spermoderm crustaceous; embryo in fleshy albumen; cotyledons flat ; radicle cylindrical, superior.-Small trees or shrubs, with simple, alternate, exstipulate leaves, and amentaceous flowers. 
They are natives of the warm parts of America. Their properties are unknown. There are 2 genera and 6 species. Example-Lacistema. Order 173. - CHLORANTHACEAs, the Chloranthus Family.(Achlamyd, Monoclin, or Diclin.) Flowers bisexual or unisexual, with a. supporting scale. Perianth 0 . Stamens definite, lateral, and if more than 1, connate; anthers monothecal, with longitudinal dehiscence, each adnate to a fleshy connective. Ovary unilocular; ovule solitary, pendulous, orthotropal; stigma sessile, simple. Fruit drupaceous, indehiscent. Seed pendulous; embryo minute, at the apex of fleshy albumen; cotyledons divaricate; radicle inferior, remote from the hilum.-Herbs or undershrubs, with jointed stems, opposite, simple, stipulate leaves, sheathing petioles, and spiked flowers. Natives of the warm regions of India and America. Some of them, as Chloranthus officinclis, are aromatic and fragrant, and have been used as stimulants and tonics. There are 4 known genera and 16 species. Example -Chloranthus.

Order 174.--SAURURACEA, the Lizard's-tail Family. (Achlamyd.) Flowers bisexual. Perianth 0 , a scale or bract supporting the flowers. Stamens 3-6, clavate, hypogynous, persistent; filaments slender; anthers 2-celled, continuous with the filament, with a thick connective separating the lobes, dehiscence longitudinal. Ovaries $3-4$, distinct, with 1 ascending orthotropal ovule, and a sessile recurved stigma, or united so as to form a 3-4-celled pistil, with several ovules and 3-4 stigmas. Fruit either consisting of 4 fleshy indehiscent nuts, or a 1-3-4-celled capsule, dehiscing at the apex, and containing a few ascending seeds. Seeds with a membranous spermoderm; embryo. minute, lying in a fleshy vitellus, outside of hard mealy albumen at the apex of the seed.-Herbs growing in marshy places, with alternate, stipulate leaves, and spiked flowers. Natives of North America, India, and China. Their properties are said to be acrid. There are 4 known genera, according to Lindley, and 7 species. ExamplesSaururus, Houttuynia.

Order 175. - PrPeracex, the Pepper Family. (Achlamyd.), Flowers $\Varangle$. Perianth 0, flowers supported on a bract. Stamens 2$3-6$, arranged on one side or all round the ovary; anthers 1- or 2celled, with or without a fleshy connective; pollen roundish, smooth. Ovary solitary, free, 1-celled ; ovule solitary, erect, orthotropal ; stigma simple, sessile, rather oblique. Fruit somewhat fleshy, indehiscent, unilocular. Seed erect; embryo in a fleshy vitellus outside the albumen, and at the apex of the seed.-Shrubs or herbs, with articulated stems, leaves opposite (sometimes alternate by abortion of one of the pair of leaves), or verticillate, exstipulate or stipulate, and spiked or racemose flowers. Natives of the hottest quarters of the globe. Common in South America and India. The wood is often arranged in wedges, with medullary rays, but without concentric zones. There 
are 21 known genera and upwards of 600 species. ExamplesPiper, Artanthe, Peperomia.

The plants of the order have pungent, acrid, and aromatic properties. Most of them contain an acrid resin, and a crystalline principle called Piperin, in which their active qualities reside. Some are narcotic and astringent. The dried fruiting spikes of Piper (Chavica) officinarum, an Indian creeper, constitute Long-pepper; Chavica Roxburghii, a plant of Malabar, Ceylon, Eastern Bengal, and the Philippines, also supplies Long-pepper. The dried unripe fruit (drupes) of Piper nigrum constitute Black-pepper, a climbing plant common in the East Indies. The ripe fruit, when deprived of its outer fleshy covering by washing, forms the White-pepper of the shops. These peppers are hot aromatic condiments, and they are used medicinally as tonic, stimulant, febrifuge, and stomachic. The fruit of Piper Cubeba (Cubeba offcinalis), a climbing plant of Java and other Indian islands, is the medicinal Cubeb-pepper, which is used extensively in arresting discharges from mucous membranes. It contains a resin, a volatile oil which is very active, and a peculiar principle called Cubebin. African Cubebs, or West African Black-pepper, is the fruit of Piper (Chavica) Clasii. The substance called Matico or Matica consists of the leaves and unripe fruit of Piper angustifotium (Artantive elongata), a shrub which grows in the moist woods of Bolivia, Peru, Brazil, New Grenada, and Venezuela. It possesses aromatic, fragrant, and astringent qualities. It has been particularly recommended for checking hæmorrhage, a property which seems, in part, to be a mechanical one, depending on the structure of the leaf, which abounds in tannin. Piper (Artanthe) lancecefolium also yields Matico. The root of Macropiper methysticum is the Kava of the South Sea Islanders, which is used by them for preparing a stimulating beverage. The leaf of Betel-pepper (Chavica Betle) is chewed with the Areca nut in the East, as a means of intoxication. One of the forms of the aromatic drug called Jaborandi is referred to the genus Piper, while others are said to belong to the genus Pilocarpus, one of the Rutaces. The leaves have sudorific and sialogogue properties, and they appear to be a very active medicine.

Order 176. - Saltcacese, the Willow Family. (Apet. Diclin.) Flowers dicecious, in catkins, each with a membranous bract. Male flowers, with a glandular disk; stamens 2 or many; anthers innate (basifixed), with longitudinal dehiscence; ovary 1-celled; placentas 2 , parietal; ovules many, erect, anatropal. Fruit a capsule, 1-celled, 2-valved. Seeds comose; embryo erect, exalbuminous; radicle inferior.-Found in woods in temperate and cold regions. Willows grow in damp places throughout the northern hemisphere, and also in the temperate parts of South America and South Africa. None are found in Australia or the Pacific islands. Poplars grow in Europe 
as well as in North America and the northern parts of Africa. Genera, 2 ; species, 180 . Examples-Salix, Populus.

The bark of many species of Willow, such as Salix Caprosa, alba, Russelliana, fragilis, pentandra, vitellina, purpurea, and Helix, yields a neutral crystalline bitter substance called Salicin, which is employed as a febrifuge and tonic. The bark also possesses astringent qualities from the presence of tannin. Salicin assumes a carmine-red tint when moistened with a few drops of concentrated sulphuric acid. Salix fragilis yields a saccharine exudation. Various species of Willows (osiers) are used for basket-making, while others are employed in forming charcoal. Salix babylonica is the Weeping-willow. Its specific name is founded on the supposition that it was the species on which the Israelites hanged their harps by the waters of Babylon. The word ערבים, Orebim, in the Bible is doubtfully translated Willows. Populus alba is commonly called the Abele, while $P$. tremula is the Aspen, and $P$. fastigiata and dilatata the Lombardy Poplar. The buds of Populus nigra and balsamifera are covered with a resinous exudation, to which the name of Tacamahac has been given; it is said to be diuretic and antiscorbutic. The leaves and bark of some Poplars secrete a șaccharine substance, which has been termed Populine. Salix arctica and polaris extend to the arctic regions, and form the most northern woody plants. Salix herbacea, a small creeping Willow, occurs abundantly on the Scotch mountains. The downy matter surrounding the seeds of Poplars and Willows is used for.stuffing pillows and cushions, as well as for the manufacture of a kind of paper.

Order 177. - Mrricacese, the Gale Family. (Apet. Diclin.) Flowers monœcious or dicecious, in catkins. Male flowers achlamydeous : stamens $2-16$, sessile, in the axil of a scale; filaments united at the base; anthers innate, extrorse. Female flowers in catkins : ovary 1-celled, with hypogynous scales; ovule solitary, erect, orthotropal. Fruit drupaceous, often with a waxy secretion, and with fleshy adherent scales; embryo exalbuminous ; radicle superior.- Shrubs or trees, with scattered unjointed branches, scaly buds, alternate, simple, often serrated leaves, usually odoriferous. Natives both of tropical and of temperate regions. They are found chiefly in North America, at the Cape of Good Hope, and on the mountains of Asia and Java. Genera, 3 ; species, about 30 . Examples-Myrica, Comptonia.

The species of Myrica are aromatic, and yield resinous and oily matter. Myrica Gale is the Gale, Scotch Myrtle, or Bog-myrtle, which is common in marshy grounds and damp heaths in Britain. The fruit of Myrica cerifera, called Wax Myrtle, or Bay Myrtle, or Candleberry, yields a greenish-coloured wax, which is used for candles. The drupaceous fruit of Myrica sapida, a native of Nepaul and China, is eaten. The leaves of Comptonia asplenifolia, Sweet Fern, contain peculiar glands. 
Order 178. - Casuarinacem, the Beef-wood Family. (Apet. Diclin.) Flowers monœcious or dicecious, bracteated. Males in spikes : stamen 1; filament lengthening; anther dehiseing longitudinally. Females in capitula : ovary 1-celled, ovules 2 ; fruit consisting of winged achænia, collected into a cone; seed erect; radicle superior. -Australian trees or shrubs, with filiform branches, bearing membranous toothed sheaths in place of leaves. They are found also in India, the Indian Archipelago, and Madagascar. Genus, 1 ; species, about 20. Example-Casuarina.

The species of Casuarina (Cassowary-tree) yield excellent timber, called Beef-wood, from its having some resemblance to raw beef. What is called the She-oak in Australia is C. quadrivalvis. In the integument of the seeds of Casuarinas there are numerous spiral cells.

Order 179.-Betulace 2 , the Birch Family. (Apet. Diclin.) Flowers monœcious, in catkins. Male flowers borne on scales, which are sometimes verticillate, so as to form a perianth : stamens 4 or 2 ; anthers innate (basifixed). Female spikes pendulous : ovary 2-celled; ovules solitary, pendulous, anatropal ; fruit membranous, indehiscent, forming a sort of cone; seeds pendulous, exalbuminous; embryo with a supeior radicle.-Amentiferous trees with alternate stipulate leaves, stipules deciduous. Natives of temperate and cold regions in Europe, Asia, and America, and extending to the Arctic and Antarctic regions. Genera, 2 ; species, about 35. Examples-Betula, Alnus.

The species of Betula, Birch, have astringent and resinous barks. The oil from the bark of the common Birch (Betula alba and glutinosa) gives the peculiar odour to Russia leather. In North America the bark of the Canoe Birch (Betula papyracea) is used for making boats. A saccharine matter exists in the sap of the Birch. Betula lenta is the Black Birch of America, and is called Mountain Mahogany on account of the beauty and hardness of its timber. The bark of $B$. Bhajapaltra is used in India to form paper. Alnus glutinosa, common Alder, grows well in muddy ground on the banks of rivers. Its charcoal is used in the manufacture of gunpowder. In Kamtschatka the bark of Alnus incana is used in the preparation of a kind of bread.

Order 180.-Platanacees, the Plane Family. (Apet. Diclin.) Flowers in unisexual globose catkins or capitula. Male flowers covered by scale-like bracts; stamen 1, with scales. Female flowers with a 1-celled ovary: 'style thick and subulate; ovules solitary or in pairs, suspended, orthotropal. Fruit consisting of compressed clavate nuts, terminated by recurved styles; seeds 1-2, pendulous, albuminous; embryo with an inferior radicle.-Trees with alternate, palmate, and stipulate leaves. Natives chiefly of temperate regions, as the Levant and North America. Genus, 1; species, about 6. Example -Platanus. 
Platanus orientalis, the Oriental Plane, has broad palmate leaves, resembling the Sycamore, which is often erroneously called the Plane in Scotland. Some say that this is the Sycamore of the ancients. Platanus occidentalis and $P$. acerifolia are also cultivated as showy trees, under the name of Planes.

Order 181.-Cupuliferex or Corylacea, the Nut Family. (Apet. Diclin.) Flowers amentaceous (fig. 259, p. 178) or aggregate, unisexual. Male flowers, with 5-20 stamens attached to seales (fig. 831). Female flowers geminate on a bract (fig. 832). Ovary surrounded by a coriaceous involucre or cupula (figs. 833, 835), crowned by the remains of a persistent perianth or disk, 3 - or more celled; styles 2 (fig. 835 ) ; ovules 2 or 1, pendulous. Fruit a glans (fig. 281, p. 191 ; 836). Seeds usually solitary (figs. $834 ; 580$, p. 330), exalbuminous ;

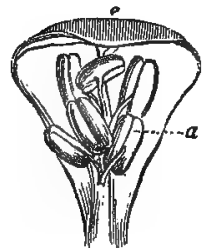

Fig. 831.

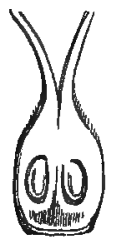

Fig. 834 .

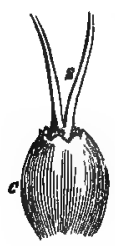

Fig. 885 .

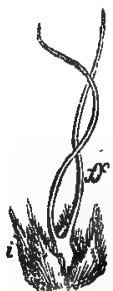

Fig. 832,

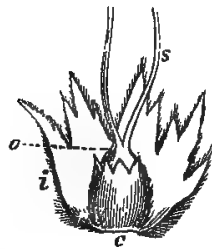

Fig. 833 .

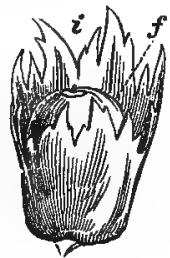

Fig. 886.

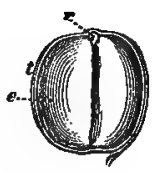

Fig. 837.

embryo with a superior radicle (fig. 837).--Trees or shrubs with alternate, stipulate, and often feather-veined leaves (fig. 149, p. 83), found chiefly in temperate regions; some extend to warm countries. Genera,

Figs. 831-837. Organs of fructification of Corylus Avellana, the Hazel, to illustrate the natural order Cupuliferæ or Corylaces. Fig. 831. Male flower separated from the catkin (amentum). $e$, Scale or bract bearing the stamens, $a$, with their dithecal anthers. Fig. 838. Female flower, ff, in a very young state, with its involucre, $i$. Fig. 833. Female flower more advanced. $i$, involucre opened to show the ovary, $o$, covered by the perianth or disk, c. $s$, Two styles. Fig. 834. Tiemale flower"cut longitudinally, to show the two loculaments with a pendulous ovule in each. Fig. 835 . Female flower more advanced. $c$, Perianth. $s$, Styles. Fig. 836. Ripe fruit, $f$, enveloped in its involucre or bracts, $i$. Fig. 837. Seed separated. $t$, Integument, half of which is removed to show the exalbuminous embryo, e. $r$, superior radicle. 
12 ; species, about 260. Examples-Corylus, Carpinus, Fagus, Castanea, Quercus.

The Hazel-nut, with its involucral appendage, is the produce of Corylus Avellana. The bark of Quercus pedunculata (Robur), the common Oak, contains much tannin, and is used as an astringent. Another British species, Q. sessiliffora, having sessile fruit, is believed to yield the best timber. In the wood of $Q$. pedunculata there are numerous medullary rays (silver-grain), (fig. 117, p. 54), while in that of Q. sessiliflora, entrost, it is said there are scarcely any visible. There is some doubt as to the existence of more than one species in Britain, and no permanent characters have been established. Babington mentions three species. It has been stated that 2000 well-grown oaks, equal to 3000 loads of timber, were required to build a seventyfour gun-ship. The acorn-cups of Quercus ZEgilops, Valonia or Balonia Oak, under the name of Valonia, are used by dyers. Oaks are liable to the attacks of insects, whose punctures give rise to the formation of galls. These excrescences oceur on the buds, bark, and leaves. The medicinal galls are the produce of Quercus infectoria, a native of Asia Minor, and the best are imported from Aleppo. They are caused by punctures from the ovipositor of the Diplolepis (Cynips) Gallæ-tinctoriæ. Blue galls are those which still contain the young insect in their interior, while white galls are those from which it has escaped. In medicine they are employed as powerful astringents, and in the arts they are used for dyeing, tanning, and forming ink. The bark (epiphloeum) of Quercus Suber constitutes cork (fig. 118, p. 54). The bark of Quercus tinctoria is called Quercitron, and yields a yellow dye. Quercus Ilex, Evergreen Oak, is commonly cultivated in gardens. The Oak, אלllon of the Bible, is said by some to be Quercus Afgilops. The Beech-tree (Fagus sylvatica), the Horn-beam (Carpinus Betulus), and the Spanish Chestnut (Castanea vulgaris or vesca), belong to this order. Fagus Forsteri is the Evergreen Beechof South America, found at Tierra del Fuego. A species of Beech ( $F$. antarctica) is found in the antarctic regions.

Order 182.-JuglandaCEe, the Walnut Family. (Apet. Diclin.) Flowers unisexual. Male flowers amentaceous : perianth membranous, dblique, irregularly-lobed, with a scaly bract. Stamens definite or 00 ; filaments short, free; anthers dithecal, erect. Female flowers in terminal clusters, or in loose racemes, with separate or united bracts : perianth single or double, the outer 3-5-parted, inner, when present, in minute separate pieces. Ovary adherent to the perianth, 1-celled; ovule solitary, erect, orthotropal (figs. 452,453, p. 253 ) ; styles 1-2, very short; stigmas 2-4, fringed or sessile, discoid and 4-lobed. Fruit a drupe, sometimes with an adherent involucre; endocarp bony, 2valved or valveless, 2-4-celled at the base, and 1-celled at the apex, with partial dissepiments. Seed exalbuminous, 2-4-lobed, with a 
membranaceous testa; embryo large; cotyledons fleshy, oily, and sinuous; radicle superior.-Trees with alternate, pinnated leaves, having neither dots nor stipules. They are chiefly natives of North America. There are 5 genera, according to authors, and 28 species. Examples-Juglans, Carya.

While the plants belonging to this order yield edible oily nuts, their bark is often acrid, and there is frequently bitterness and astringency in the coverings of their fruit and seed. The seeds of Juglans regia, common Walnut, yield a bland oil, which may be used as a substitute for olive-oil. Carya alba yields the American Hickorynut. Purgative and resinous properties prevail in some of the plants. The timber of many of the trees is valuable. That of the Black Walnut (Juglans nigra) has a fine dark brown colour when polished.

\section{Section B.-Gymnospermes.}

Monochlamydeous or Achlamydeous plants, with an Exogenous structure as regards their stems and organs of vegetation, but differing from Exogens in having naked ovules, which are fertilised by the direct application of the pollen to the foramen, without the intervention of stigma, style, and ovary. Flowers unisexual. Their woody tissue is marked by the presence of disks (figs. 49, 50, p. 17). They are included in Lindley's class of Gymnogens, and Endlicher's Gymnospermous division of Acramphibrya.

Order 183.-ConIFER - Ce the Cone-bearing Family. (Achlamyd. Diclin.) It includes the orders Pinacex, Taxacex, and Gnetaceæ of

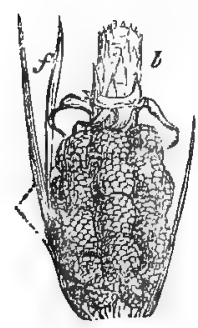

Fig. 838.

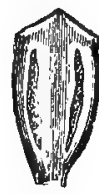

Fig. 839 .

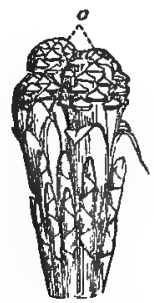

Tig. 840 .

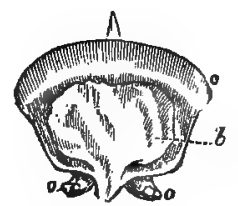

Fig. 841.

Lindley. Flowers unisexual. Male flowers monandrous or monadelphous: stamens collected in a deciduous amentum, about a common

Figs. 838-844. Organs of fructification of Pinus sylvestris, Scotch Fir, to illustrate the natural order Coniferæ. Fig. 838. Collection of male catkins, $c$, clustered round a common axis. $f$, Leaves. $b$, Terminal buds, with young leaves and scaly sheaths. Fig. 839. Male flower, or the two-lobed anther, separated. Fig. 840. Three collections of female flowers, or young cones, $c$, at the extremity of a branch. Fig. 84I. A scale detached from one of these young cones, and seen on the exterior. $b$, Bract. $e$, Scale. o o, Summit of the naked ovules. Fig. 842. Scale of a young cone seen on the inside. $c$, The scale. 
rachis (fig. 838 ) ; anthers $1-2$ or many-lobed, with longitudinal dehiscence, often terminated by a scaly crest (fig. 839). Female flowers in cones (figs. 572 , p. $317 ; 840$ ), sometimes solitary : ovary none, its place being supplied by the flat scales of the cones, arising from the axil of membranous bracts (fig. 841); ovules naked, usually in pairs on the face of the scales (figs. 520, p. $292 ; 841,842$ o o), inverted or erect ; style 0 ; stigma 0 . Fruit a cone (figs. 217 , p. 105; 572, 573, p. 317), or a solitary naked seed (fig. 538, p. 302). Seed with a hard crustaceous integument, sometimes winged (fig. 843); embryo in the midst of fleshy oily albumen (fig. 844); sometimes more than one embryo; cotyledons 2, or many and verticillate (fig. 844);

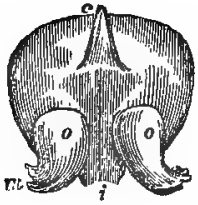

Fig. 842.

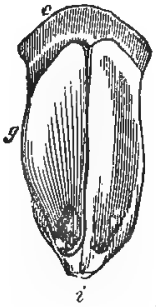

Fig. 843.

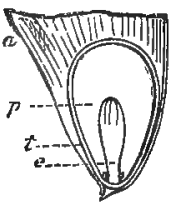

Fig. 844.

radicle next the apex of the seed, organically connected with the albumen.-Trees or shrubs, with branched, usually resinous trunks, the wood marked with circular disks (figs. 49, 50, p. 17), the leaves usually narrow, rigid or acerose, entire (fig. 162, p. 88), sometimes fascicled, and with a scaly sheath at their base (fig. 838 b). They are found in various parts of the world, both in cold and hot regions. They abound in the temperate regions of Europe and America, and many occur in Australia. They also grow on the tropical mountains of Asia and America. Some genera of Coniferæ, as Araucaria, Phyl locladus, Microcachrys, and Arthrotaxis, are peculiar to the southern hemisphere. The following attain their maximum to the south of the tropics:-Callitris, Podocarpus, and Dacrydium. Dammara has one species in each hemisphere.

The order is a very extensive one, and has been divided into the following sub-orders :-

1. Abietineæ, Fir and Spruce: fertile flowers in cones, with 1 or 2 inverted

$i$, The point by which it is attached to the axis of the cone. 00 , The two naked inverted ovules. $m$, Their upper opening or foramen to which the pollen is applied. The foramen was formerly described erroneousiy as a stigma. Fig. 843. A scale from a mature cone. $e$, The scale. $i$, Point of insertion. $g$, One of the winged seeds; the other having been removed. Fig. 844. The seed eut longitudinally. $\quad u$, Base of the wing. $t$, Integument. $p$, Perisperm (albumen). e, Polycotyledonous embryo. Near the radicle are the remains of two other abortive embryos. 
ovules at the base of each scale (fig. 520, p. 292) ; embryo in the axis of fleshy and oily albumen, di- or poly-cotyledonous. The following are divisions of this tribe :-

A. Scales 2-seeded, seeds adnate to the scale, and at length separating from it ; anthers bilocular.

a. Scales with a thickened apophysis, which is either entire or dimidiate. Pinus.-Leaves in twos, threes, fours, or fives.

b. Scales without an apophysis.

* Leaves solitary. Abies, Picea, Tsuga.

* Leaves fasiculated.

Larix, Cedrus.

B. Scales 1-seeded, seed adnate to the scale, and not separating from it, anthers multilocular. Araucaria (Eutassa).

C. Scales 1- or many-seeded, seeds free, anthers bi- tri- or multi-locular. Dammara, Cunninghamia.

2. Cupressineæ, Cypress, and Juniper ; anthers 3-5, rarely 2 ; ovules erect; fruit either an indnrated cone (fig. 573, p. 317 ), with 4 decussate scales, or fleshy with the scales connected and forming a galbulus (fig. 574, p. 317); seeds 2-3-winged, rarely apterous; embryo dicotyledonous ; leaves opposite or whorled. Examples-Cupressus, Juniperus, Thuja, Taxodium, Callitris, Libocedrus, Fitzroya.

3. Taxineæ, Yew (fig. 128, p. 63) ; anthers usually bilocular, with longitudinal dehiscence ; fertile flowers, solitary, ternimal ; ovule solitary, sessile in the centre of a fleshy disk, when in fruit forming a sort of drupe (fig. 538, p. $302)$; testa fleshy ; embryo dicotyledonous. Examples-Taxus, Podocarpus, Dacrydium, Phyllocladus, Salisburya, Torreya, Cephalotaxus.

4. Gnetaceæ, Joint-fir ; male flowers with a perianth, anthers uni- or quadrilocular, opening by a short cleft; ovules with a projecting process formed from the secundine, which is exserted through the open exostoma in the form of a filiform tube, which expands into a stigma-like disk (endostome); seed solitary; embryo at the apex of fleshy albumen; radicle superior; stems jointed ; zones of wood, often separated by marked cellular circles (fig. 122, p. 61). Examples-Gnetum, Ephedra, Welwitschia.

The order embraces about 33 genera and 300 species. Zuccarini enumerates 216 species of Coniferæ-in the northern hemisphere 165 , and in the southern 51, some species being common to both hemispheres.

The plants of this order furnish valuable timber, and yield various important products, such as turpentine, pitch, and resin. The various kinds of Pine, Fir, Spruce, and Cedar, belong to this family. Eutasso (Araucaria) excelsa is the Norfolk-island Pine, famed for its size and for its wood. Sequoia (Wellingtonia) gigantea is another large tree in the order. Its trunk sometimes attains a height of 450 feet. Abies Douglasii, the Douglas-Fir, yields excellent timber. Cedrus Libani is the Cedar of Lebanon, the ins, Eres, of the Bible. Cedrus Deodara is the Deodar or Himalayan Cedar. The name is said to be derived from Deva, a deity, and Dara, timber. Hooker considers the cedar of Lebanon, the Deodar, and the Atlantic cedar to be varieties of 
one species. By exudation, and partly by the aid of heat, the plants of this order yield various kinds of turpentine, resin, tar, and pitch. Common turpentine is procured from Pinus sylvestris, the Scotch Fir, Pinus Pinaster, the Cluster-Pine, and var. maritima, Bourdeaux Pine, Pinus palustris, Swamp Pine, and Pinus Toeda, Loblolly or Frankincense Pine. Oil of turpentine is obtained from it by distillation. Venice turpentine and Strasburg turpentine are the produce of Larix europcea, the Larch, and Abies Picea (Abies or Picea pectinata), the Silver Fir, while Canada Balsam is collected from Abies or Picea balsamea, Balm of Gilead Fir, and $A$. canadensis, Hemlock Spruce. Dammara australis, the-Kawrie-pine of New Zealand, yields a hard resin, and so does D. orientalis, the Amboyna Pitch-tree. Callitris quadrivalvis (Thuja articulata), the Arar-tree, supplies a solid resin called Sandarach or Pounce, which is used to strew over manuscripts. Thus, or Common Frankincense, is yielded by Pinus palustris and Pinus Toeda. Burgundy pitch is procured from Abies excelsa (Pinus $A$ Abies), the Norway Spruce. Pinus Pumilio gives Hungarian balsam. Pinus pinea, the Stone Pine (fig. 518, p. 292), is the source of Carpathian balsam. Essence of Spruce, used in making Spruce-beer, is got by boiling in water the leaves of the Scotch Fir (Pinus sylvestris) (fig. 572, p. 317), the Black Spruce (Abies nigra), and other species. A kind- of Manna is procured from the Larch and from the Cedar of Lebanon. The Bark-bread of the Norwegians is prepared from the inner bark of Pinus sylvestris. The bark of the Larch is astringent, and has been used for tanning, as well as in bronchitic affections. Common tar is procured by the destructive distillation of the stems and roots of coniferous trees. It is used as an ointment in skin diseases, and is largely employed in shipbuilding, and for the preservation of fences. These various kinds of resin and pitch are used for stimulating and healing plasters, while the oil of turpentine (oleum terebinthince) is employed medicinally as a stimulant, diuretic, cathartic, and anthelmintic. The vapour of tar has been recommended in affections of the chest. The succulent cones (fig. 574, p. 317) (commonly called berries) of Juniperus communis, Common Juniper, and the oil procured from them, are used medicinally as diuretics. The oil enters into the composition of the spirituous liquor called Hollands. The young branches and leaves of Juniperus Sabina,' Savin, contain an active volatile oil, which is used as an anthelmintic and emmenagogue. In large doses it acts as a violent irritant poison. The wood of Juniperus Bermudiana furnishes Pencil Cedar. J. Virginiana, the Red Cedar, yields a rubefacient oil. Thuja.occidentalis is the common Arbor-vitæ of gardens. Thuja orientalis is also in cultivation. Cupressus sempervirens, common Cypress, yields a durable wood, which is supposed to be the Gopher-wood, (Gopher) of the Bible. Podocarpus Totarra and Dacrydium taxifolium both supply 
good timber in New Zealand. Taxus baccata, the Yew, is a valuable timber tree. It yields resin, and its leaves and seeds are said to be narcotico-acrid. Salisburya has remarkable cuneate leaves, and the fruit of S. adiantifolia, the Ginko, is said to be eatable. Gnetum urens has singular stinging hairs within the episperm or outer integument of the seed. Welwitschic is a remarkable plant from the West Coast of Africa. It is not more than one foot high, and its stem is often four feet in diameter. The only leaves produced are the two cotyledons, which last during the life of the plant, probably more than 100 years, and they increase so as to become six feet in length and two or three in width. The peduncles are short, and bear terminal catkins with scarlet imbricated bracts, each covering a flower. Dr. W. R. M'Nab considers that in the male flowers of this remarkable plant we have a close approach to the angiosperms, the axis of the flower ending in a mass of tissue, which in the female flower is the terminal ovule; while in the female flower we have the truly gymnospermous condition, there being no carpels, but a terminal ovule, the modified end of the axis of the flower, with a single ovular integument,- - the pollen-grains being applied directly to the naked nucleus.

Order 184.-Cycadaces, the Cycas Family. (Achlamyd. Diclin.) Flowers unisexual. Males collected into cones, the scales bearing on their lower surface 1-celled anthers, which are united often in sets of two, three, or four. Females consisting of naked ovules, placed at the base of flat scales, or beneath peltate ones, or seated on the margins of altered leaves. Seeds hard and nut-like, sometimes with an external spongy coat; embryos 1 or 2 , suspended in a central cavity; albumen fleshy or mealy; cotyledons unequal; radicle superior, having a long cord-lilse prolongation, by which the embryo is suspended. -Trees or shrubs, with cylindrical trunks, usually simple, sometimes dichotomous, marked with the scars of the leaves, and in many respects having the aspect of Palms (fig. 519, p. 292). The internal structure is more or less distinctly that of dicotyledons. Pitted tissue and spiral vessels occur. The leaves are pinnate, and their vernation is sometimes circinate, resembling ferns. The seeds of Macrozamia spiralis, called Burrawary, are considered poisonous, causing vomiting and stupor. The Plant is called in Sydney "Native Palm," and the leaves are used on Palm-Sunday. The seeds, when steeped in water for several days, and then roasted, are said to lose their poisonous qualities. The plants of this order are found in the temperate and warm regions of America and Asia, as well as at the Cape of Good Hope. There are 7 genera, according to authors, and 50 species. Examples-Cycas, Zamia, Dion, Encephalartos, Macrozamia, Stangeria, Bowenia.

The Cycadaceous family yields much starchy matter, along with 
mucilage. From the stems of Cycas revoluta (fig. 519, p. 292) and C. circinalis a kind of Sago is made. A clear insipid mucilage also exudes from them, which hardens into a transparent gum resembling tragacanth. Dion edule yields a kind of arrow-root in Mexico. Zamia pumila, and other species in the West Indies, supply an amylaceous matter, which has been sold as Arrow-root. The Breadtree is a name applied by the Hottentots to various species of Encephalartos.

Class II.-Monodotyledones, Juss. Endogenn, DO. Endogens and DiCTYOGENs, Lindl. AMrPHIBRYA, Endl.

In this great class the plants have a cellular and vascular system, the latter consisting partly of elastic spiral vessels (fig. 53, p. 17). The woody stem (as in Palms, fig. 134, 1, p. 68) is usually more or less cylindrical, simple, and unbranched. There is no true separable bark, no concentric zones, and no true pith (figs. 131, 132, p. 65). The wood is endogenous, i.e. increases by additions, which first tend towards the centre, and then curve outwards in an interlacing manner (fig. 133, 2, p. 66) towards the circumference, where much hard ligneous matter is deposited, so as to make the exterior the hardest part. The development of the stem usually takes place by a single central and terminal bud; occasionally lateral buds are produced (fig. 134, 2, p. 68), and at times the stem is hollow. The leaves are usually parallel-veined (figs. 150, p. $83 ; 188$, p. $90 ; 210$, p. 99). The parts of the flower are arranged in a ternary manner (fig. 637 , p. 365), and they are often petaloid (fig. 284, p. 92), sometimes scaly or glumaceous. The ovules are contained in an ovary, and are fertilised by the application of the pollen to the stigma. The embryo has one cotyledon (fig. 600, p. 336), and the germination is endorhizal (fig. 626, p. 355).

\section{Sub-class I. - Petalordext.}

Flowers having usually a perianth consisting either of verticillate leaves, which may sometimes be separated into calyx and corolla, and are often coloured (petaloid), or of a few whorled scales. Occasionally the perianth is abortive.

\section{a. EPIGYNa.-Ovary inferior, Flowers usually hermaphrodite.}

Order 185.-Hydrocharidaces, the Frog-bit Family. (Mono-

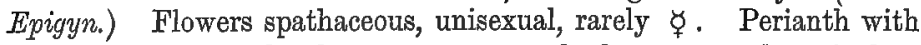
a 6-partite limb, the 3 outer segments herbaceous, and equivalent to the calyx, the 3 inner petaloid, and equivalent to the corolla. Stamens definite or indefinite, epigynous. Ovary inferior, 1- or many- 
celled; ovules 00 , anatropal, frequently attached to parietal placentas; stigmas 3-6. Fruit dry or succulent, indehiscent, uni- or multi-locular. Seeds numerous, exalbuminous; embryo straight, radicle remote from the hilum.-Floating or aquatic plants, with parallel-veined leaves, sometimes spiny. Chiefly found in Europe, Asia, North America, and Australia. The plants of this order are not remarkable for their properties. Some are mucilaginous and astringent. Vallisneria spiralis (figs. 249 , p. $173 ; 513$, p. 283 ) is a diocious plant, the male flowers of which, at the time of flowering, are detached from the mud of the water in which they grow, and float on the surface. At the same time the female flower develops a long spiral peduncle, by means of which it reaches the surface of the water, so as to allow the application of the pollen (p. 283). Vallisneria and Anachas is exhibit under the microscope the rotation of protoplasm in their cells. The order has been divided into two tribes :-1. Vallisneriex, ovary 1-celled. 2. Stratioteæ, ovary manycelled. There are 10 known genera, according to authors, including 20 species. Examples-Vallisneria, Udora, Anacharis (Elodea), Stratiotes, Hydrocharis.

Order 186.-ORCHIDACE 2 , the Orchis Family. (Mono-Epigyn.) Flowers bisexual. Perianth adherent, herbaceous, or coloured, with a 6-partite limb (fig. 846 pe, pi), the segments being arranged in 2 rows; exterior row (fig. $845 \mathrm{ce}$ ), called the calyx (although Lindley says it is more properly the corolla, the true calyx or calyculus being usually abortive), consisting of 3 segments (rarely 2 by adhesion), the odd one of which is often next the axis by a twisting of the ovary; interior row (fig. $845 \mathrm{ci}$ ), called the corolla (regarded by Lindley as petaloid stamens), consisting usually of 3 segments (very rarely 1 ), the odd one of which is called the labellum or lip (fig. 317, p. 205). This labellum (figs. 845, 846, 847 l) frequently differs from the other divisions of the perianth, assuming remarkable forms, being lobed, spurred at the base, or furnished with peculiar appendages, which are sometimes derived from the stigma. It is sometimes divided by contraction, so as to exhibit three distinct portions, the lowest being the

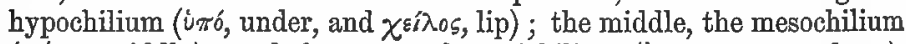
( $\mu \varepsilon^{\prime} \sigma \circ 5$, middle); and the upper, the epichilium (' $\varepsilon \tau^{\prime}$, upon or above). Stamens 3, epigynous, united in a central column along with the style; the two lateral stamens are usually abortive (fig. $846 \mathrm{ss}$ ), the central one opposite the odd exterior segment being fertile (fig. $846 \mathrm{e}$ ); but at times the two lateral are fertile, and the central one is abortive; anthers 1-2-4-celled (fig. 848) ; pollen powdery or cohering in definite (fig. 854) or indefinite waxy masses (pollinia) (figs. 849, 853; 387, p. 230 ), which often adhere by a caudicle (fig. $853 \mathrm{c}$ ) to a gland connected with the beak (rostellum) of the stigma. This gland is sometimes naked, at other times in a sac or pouch (bursicula). Ovary 
inferior, 1-celled (fig. 850), composed of 6 carpels, of which 3 only are placentiferous (Lindley); style incorporated with the column

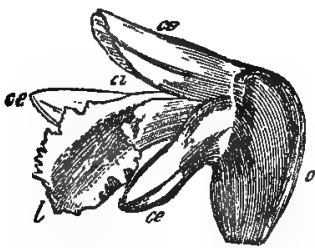

Fig. 845 .

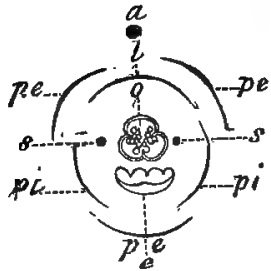

Fig. 846.

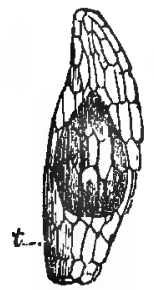

Fig. 851.

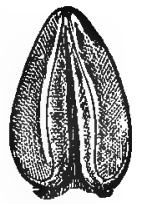

Fig. 848.

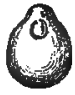

Fig. 852.

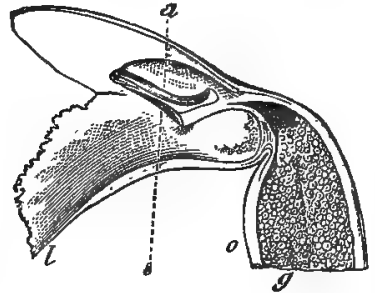

Fig. 847.

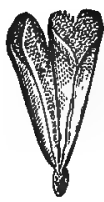

Fig. 849 .

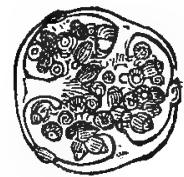

Fig. 850 .

Figs. 845-851. Flower of Spiranthes autumnalis, to illustrate the natural order Orchidacer. Fig. 845. "Flower after the ovary has twisted on itself, seen laterally. o, Ovary with the adherent perianth. ce, Outer divisions of the perianth, called by some calyx, and by Lindley corolla. ei, Inner divisions of the perianth, called by some the corolla, and considered by Lindley as petaloid stamens. $l$, The labellum or lip, being the lower of the three inner segments. Fig. 846. Diagram of the flower in the young state, before the twisting of the ovary has taken place. $a$, The axis of the spike of flowers. pe, pe, pe, Outer perianth. $p i, p i$, Two divisions of the inner perianth. $l$, Third division of the innerperianth, in this state placed next the axis. $e$, Fertile anther. $s s$, Two abortive anthers. or staminodia. o, Ovary. Fig. 847. Summit of the flower cut vertically. o, Inferior ovary with parietal ovules, $g$. $l$, Labellum or lip. $s$, Stigma. $\alpha$, anther. Fig. 848. Anther separated. Its inner surface shown with its two cells. Fig. 849. Granular pollen-masses taken from the anther. Fig. 850. Horizontal section of the ovary, with three parietal placentas bearing numerous ovules. Fig. 851. A seed separated, with its external reticulated integument, $t$. Fig. 852. Embryo of Aceras anthropophora deprived of its integuments. Fig. 853. Pollen-masses (Pollinia) of Orchis maculata, with the grains united in little conical masses. c, Caudicle terminated by the retinaculum and glands. Fig. 854. The conical masses which the pollen-grains form by their cohesion. 


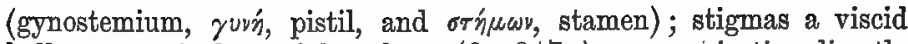
hollow space in front of the column (fig. $847 \mathrm{~s}$ ), communicating directly with the ovary by an open canal. The upper part of the united stigmas is often extended into a beals-like process (rostellum). Placentas 3, parietal (figs. 553 , p. $306 ; 850$ ). Fruit a capsule, opening by 3 or 6 valves, rarely fleshy, and indehiscent. Seeds 00 , very minute, with a loose reticulated spermoderm (fig. 851), exalbuminous; embryo solid, fleshy (fig. 852); large radicle next the hilum. (See a full description of the morphology of the flower of an Orchis at p. 373.)-Perennial herbs or shrubs, with fibrous or tubercular roots (fig: 101, p. 41), either no stem or a pseudo-bulb, entire, parallel-veined often sheathing leaves, and generally showy, attractive flowers. Sometimes buds are produced on the margins of the leaves (fig. 231, p. 118). They are natives of almost all parts of the world, but they abound in moist tropical regions. They are not found in the Arctic regions, nor in very dry climates. Some are terrestrial, and others are epiphytic. The former are commonly seen in temperate climates, the latter in warm regions. Disa grandiflora is found on Table Mountain at an elevation of 3582 feet. The only known locality for it is in a marshy hollow, near the eastern extremity of the summit, where it is abundant, among rushes; on the margins of small pools and streamlets, in a black boggy soil. Two rare species of Disa are also found there, $D$. ferruginea and tennifolia. Oncidium nubigenum grows on the Andes, near Quito, at an elevation of 14,000 feet above the level of the sea. Epidendrum frigidum occurs in Columbia at an elevation of 12,000 to 13,000 feet (mean temperature $46^{\circ}$ ), and is covered with a sort of varnish. Authors enumerate 400 genera, including above 3000 species; of these, 17 genera and 38 species are British. $E x-$ amples - Stelis, Liparis, Dendrobium, Epidendrum, Stanhopea, Vanda, Orchis, Ophrys, Listera, Arethusa, Neottia, and Cypripedium.

The plants of this order are well distinguished by the peculiar forms of their flowers, their remarkable lip, gynandrous stamens, and pollen-masses. Their flowers often resemble insects, as butterflies, moths, bees, flies, and spiders; or birds, as doves and eagles; or reptiles, as snakes, lizards, and frogs. The colours and spots on the perianth sometimes give the appearance of the skins of quadrupeds, as the leopard and tiger. These resemblances are often indicated in the generic and specific names. The labellum, in some instances, displays peculiar irritability (p. 387).

Mucilaginous properties occur in many of the plants of "this order. Some are aromatic and fragrant; others are antispasmodic and tonic. The tuberous roots of some yield a nutritious substance called Salep, which consists chiefly of bassorin, some soluble gum, and a little starch. The following orchids yield Salep :-Orchis mascula, 0. papilionacea, $O$. Morio, O. militaris, $O$. coriophora, and $O$. longicruris, as well 
as Eulophia herbacea and campestris. Salep forms an article of diet fitted for convalescents, when boiled with water or milk. Orchis mascula is supposed to be the "long purples" of Shakspeare. The roots of Aplectrum hyemale contain a very glutinous matter, and hence the plant is called in America Putty-wort. The fleshy pod-like fruit of $V$ anilla planifolia, and $V$. aromatica, and other species, constitutes the substance called Vanilla, which is used in confectionery, and in flavouring chocolate. It contains an oil and much benzoic acid. Vanilla comes into the markets chiefly through France. In 1872 nearly 60,000 lbs. of Vanilla were imported into that country. A kind of Vanille called Chica in Panama is procured from a species of Sobralia. A blue colouring matter has been found in some of the Orchids. The odour of many of them is very fragrant; sornetimes it is oppressive ; at other times, as in Malachadenia clavata, it is very fetid, resembling carrion.

Order 187.-Zingiberacese or Scitaminem, the Ginger Family. (Mono-Epigyn.) Perianth superior, in 2 whorls; outer (calyx) tubular, 3-lobed, short ; inner (corolla) tubular, elongated, 3-parted, segments nearly equal. Stamens in 2 whorls; outer sterile, petaloid, having the appearance of a 3-parted corolline whorl, with the intermediate segment (labellum) larger than the rest, and often 3-lobed, sometimes the lateral segments are inconspicuous or nearly abortive; inner stamens 3 , the two lateral being abortive, the intermediate one opposite the labellum, fertile; filament not petaloid, often prolonged beyond the anther; anther 2-celled, dehiscing longitudinally. Ovary 3-celled, or imperfectly so; oviles several, anatropal, attached to a placenta in the axis; style filiform; stigma dilated, hollow. Fruit usually a 3-celled capsule, sometimes baccate. Seeds roundish or angular, sometimes with an arillus; embryo enclosed in a vitellus. (the remains of the embryo-sac), surrounded by farinaceous albumen, which is deficient near the hilum.-Herbs with a creeping rhizome, and simple sheathing leaves, having parallel veins proceeding from the midrib to the margin. The flowers arise from membranous spathaceous bracts. Natives of tropical countries. By far the greater number inhabit various parts of the East Indies; some are found in Africa, and a few in America. They form a part of the singular Flora of Japan. Authors mention 31 genera and 250 species. Examples -Zingiber, Curcuma, Amomum, Hedychium, Renealmia.

Plants often with showy flowers, having aromatic stimulant properties, which reside chiefly in their rhizome or root, and in their seeds. Some yield starchy matter. The rbizome of Zingiber officinale (Amomum Zingiber) constitutes the Ginger of commerce, which is imported from the East and West Indies. In the young state the rhizomes are fleshy and slightly aromatic, and they are then used as preserves; while in a more advanced state, the aroma is fully deve- 
loped, their texture is more woody, and they are then fit for ordinary ginger. When dried, after immersion in hot water, they form Black ginger; when simply dried in the sun, after being cleaned, they receive the name of White ginger. The rhizome contains an acrid resin and volatile oil, starch and gum. It is used as a tonic and carminative, in the form of powder, syrup, and tincture. The kinds of ginger in the market are Jamaica (the best), Cochin, Bengal, and African. Curcuma longa, a native of Eastern Asia, furnishes Turmeric. This consists of the branches of the rhizome, or root-stock. Its powder is lemon-yellow, and it is used as a dye-stuff. It contains starch, an acrid volatile oil, and a yellow colouring matter called Curcumin. It is employed medicinally as an aromatic carminative, and, as a condiment, it enters into the composition of curry-powder. The root-stock of Alpinia officinarum, a Chinese plant, constitutes the Galangal root of commerce, which has the same properties as ginger. A. Galanga also supplies a similar rhizome. They have been used by the Indian doctors in cases of dyspepsia and in the treatment of coughs. Various "species of Amomum, Elettaria, and Renealmia, appear to furnish the Cardamoms of the shops, which consist of the oval trivalvular capsules containing the seeds. Elettaria Cardamomum is the source of Malabar Cardamoms. The plant grows in the mountain forests of North Canara, Coorg, and the Wynaad, on the Malabar coast, from 2800 to 5000 feet above the level of the sea. The fruit is ovoid and three-sided. The Malabar name for the plant is Elettari. A variety, formerly called $E$. major, grows in Ceylon. Amomum Cardamomum supplies the round Cardamoms of Java, Sumatra, and Siam. A. xanthioides is the wild or bastard Cardamom of Siam; while Amomum aromaticum is the Bengal Cardamom. Amomum maximum, another Java species, furnishes a kind of Cardamom. The seeds of these plants are used as aromatic tonics and carminatives. Their active ingredient is a pungent volatile oil. Grains of Paradise are the seeds of Amomum Melegueta, Melegueta Pepper, and have the same properties as Cardamoms. The plant is widely distributed in tropical West Africa. It is also cultivated in Demerara. East Indian Arrow-root is procured in part from Curcuma angustifolia, and a similar kind of starch is yielded by Curcuma Zerumbet, O. leucorhiza, and Alpinia Galanga.

Order 188.-MARANTACEA or CANNACE 2 , the Arrow-root Family. (Mono-Epigyn.) Perianth superior, in 2 whorls ; outer (calyx) 3-lobed, short; inner (corolla) tubular, elongated, 3-parted, segments nearly equal. Stamens in 2 whorls; outer sterile, petaloid, irregular, resembling a tubular trifid corolla, with one of the lateral segments different from the others; inner petaloid, 2 sterile, and 1 lateral fertile; filament of the latter petaloid, entire, or 2-lobed; anther on the margin of the filament, 1-celled, dehiscing Iongitudinally. Ovary 3-celled, 
rarely 1-celled; ovules solitary and erect, or numerous and attached to the axis; style petaloid or swollen; stigma either the naked apex of the style, or hollow, hooded, and incurved. Fruit a 3-celled capsule, or baccate, 1-celled and 1-seeded. Seeds round, without arillus ; embryo straight, in hard, somewhat floury albumen, without a vitellus; radicle lying against the hilum (fig. 626, p. 355).- - Herbaceous plants. with tuberous rhizomes, and leaves and flowers, similar to those of the Ginger Family. They are natives of tropical America and Africa; several are found in India; none are known in a wild state beyond the tropics. Authors enumerate 9 genera, including 164 species. Examples-Maranta, Canna, Phrynium.

The plants of the order contain much starch in the rhizomes and roots. They are destitute of aroma. Arrow-root is the produce of the tuberous rhizomata of Maranta arundinacea and $M$. indica. The former grows in the tropical parts of America and in the West Indian Islands; the latter in Bengal, Java, and the Philippines. The best West Indian arrow-root comes from Bermuda. Its globules are much smaller and less glistening than those of tous-les-mois or of potato starch. Amylaceous matter of a similar kind is produced from other species of Maranta, as well as from species of Canna. Tous-les-mois is the produce of Canna coccinea, C. Achiras, C. edulis, etc. Hanbury thinks that the name of this kind of starch is a corruption of Touloula, a Carib designation of Canna. The seeds of Cannas are round and black, and are commonly known under the name of Indian shot. They have been used as a substitute for coffee. Calathea zebrina, Zebra plant, is so called from the peculiar variegation of its leaves, which have a velvety aspect. Barnéoud states that the two outer verticils of the flowers in Cannas are always developed, one after the other, precisely like the calyx and corolla; while the verticil, sometimes called petals, is really metamorphosed stamens, and hence its irregular aspect.

Order 189.-Musaces, the Banana Family. (Mono-Epigyn.) Perianth 6-cleft, adherent, petaloid, in 2 whorls, more or less irregular. Stamens 6 , inserted on the middle of the segments of the perianth, some usually abortive; anthers linear, dithecal, introrse, often with a membranous petaloid crest. Ovary inferior, 3-celled; ovules numerous, anatropal ; style simple; stigma usually 3-lobed. Fruit either a 3-celled capsule, with loculicidal dehiscence, or succulent and indehiscent. Seeds sometimes surrounded by hairs; testa usually crustaceous ; embryo erect, in the axis of mealy albumen ; radicle touching the hilum.- Plants without true aerial stems, or nearly so, having shoots proceeding from subterranean root-stocks, which form spurious stems, composed of the sheathing leaf-stalks. Veins in the limb of the leaf parallel, and proceeding in a curved manner from the midrib to the margin (fig. 150, p. 83). Flowers bursting through spathes. 
Natives of warm and tropical regions. Species of Strelitzia are found in $\mathrm{S}$. Africa, and of Ravenala in Madagascar. There are 5 known genera and 21 species. Examples.-Musa, Strelitzia, Ravenala.

The plants of this order furnish a large supply of nutritious fruit, and their leaves afford valuable fibres. Spiral vessels abound in them. Musa sapientum and Cavendishii furnish different kinds of Banana, while $M$. paradisiaca yields the Plantain. These fruits in their ripe state contain much starchy matter. From their spurious stems the fibres of the spiral vessels may be pulled out in such quantity as to be used for tinder. The ribbon-like fibre in these vessels is composed of several threads united together (pleiotrachex) (fig. 53, p. 17). The produce of the Banana is of great value to the inhabitants of warm countries. The same extent of ground which in wheat would only maintain two persons, will yield sustenance under the Banana to fifty. It has been estimated that a Banana plant in one year will produce 3 bunches of fruit, each weighing $44 \mathrm{lbs}$. Musc textitis yields a kind of fibre which is used in India in the manufacture of fine muslins; Manilla Hemp is also the produce of this plant. The woody tissues of many species of Musa is used for manufacture in warm climates. The young shoots of the Banana are used as a culinary vegetable. The juice of the fruit and the lymph of the stem of Musa are slightly astringent and diaphoretic. The succulent interior of the stem of an Abyssinian species, Mrusa Ensete, is eaten; its fruit is dry and full of seeds. Urania or Ravenala speciosa is the Water-tree of the Dutch, or the Traveller's tree of Madagascar, so called on account of the great quantity of water which flows from its stem or leaf-stalk when cut across. The juice of the fruit of Urania is used for dyeing.

Order 190.-IrIdacese, the Iris or Flower de Luce Family. (MonoEpigyn.) Perianth adherent, 6-parted, coloured, in 2, often unequal whorls (figs. 855, 856). Stanens 3 , epigynous, opposite the outer segments of the perianth (figs. $855,856 \mathrm{e} e$ ); filaments distinct or monadelphous; anthers 2-celled, extrorse. Ovary inferior (fig. 856 o), 3-celled; ovules numerous (fig. $856 \mathrm{~g}$ ), anatropal; style 1 ; stigmas 3 , often petaloid (fig. $856 \mathrm{~s}$ ), sometimes bilabiate. Fruit a 3-celled, 3-valved capsule, with loculicidal dehiscence (fig. 544, p. 304). Seeds numerous; embryo enclosed in horny or fleshy albumen; radicle next the hilum (fig. 857).-Herbs, rarely undershrubs, with rhizomes or underground corms, having their leaves often equitant or distichous, and their flowers spathaceous. Natives chiefly of warm and temperate regions. They abound at the Cape of Good Hope. The Crocus occurs only in Europe and Asia. There are 55 known genera and 550 species. Examples -Iris, Sisyrinchium, Witsenia, Gladiolus, Ixia, Crocus.

Some of the plants have fragrant and stimulant, and some acrid, rhizomes and corms; others yield dyes. The root-stock of Iris ger- 
manica, I. pallida, and I. florentina yield orris root, which has a pleasant odour like violets, and an acrid taste, depending on the presence of a volatile oil. It is imported from Leghorn, Trieste, and Mogador. Orris-root is used chiefly for giving a pleasant odour to the breath, and in perfumery and tooth-powder. Orris-root starch is used for hair-powder. Croous sativus, the ברבם (Karcom) of the Old Testament, furnishes the colouring material called Saffron. It consists of the stigmata, which have a fine deep-orange colour. These stigmata are either dried in the loose state, forming Hay Saffron, or compressed

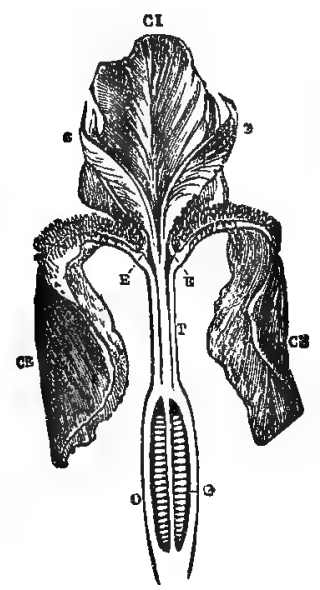

Fig. 856 .

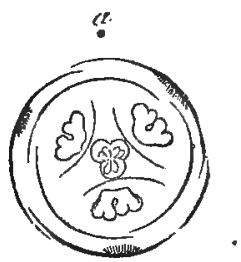

Fig. 855.

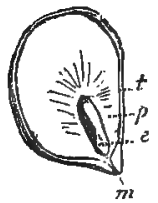

Fig. 857.

into masses, constituting Cake Saffron. The yellow colouring ingredient is Polychroit, which possesses the property of being totally destroyed by the action of the solar rays, and of forming blue tints when treated with sulphuric and nitric acid. Saffron contains an active volatile oil, and it has been used in the form of tincture and syrup, as an emmenagogue and antispasmodic. The stigmata of Crocus autumnalis and $C$. odorus also supply saffron. The roasted seeds of Iris pseudacorus have been used as a substitute for coffee.

Figs. 855-857. Organs of fructification of Iris germanica, to illustrate the natural order Iridacer. Fig. 855. Diagram of the flower, showing six divisions of the perianth in two verticils, three extrorse stamens, and the 3-celled capsule with numerous ovules. $a$, Position of the axis of inflorescence. Fig. 856. Vertical section of the flower. ce, Outer divisions of the coloured perianth. $c i$, Inner divisions of the perianth. $t$, Tube of the perianth attached to the ovary. o, Inferior 3-eelled ovary. $g$, Numerous anatropal ovules. e e, Stamens. $s s$, Petaloid stigmas. Fig. 857. Seed separated and cut longitudinally. $t$, Integuments (spermodertn). $p$, Perisperm. e, Embryo enclosed in the perisperm. $m$, Micropyle (foramen). 
Order 191.-Burmanniaceas, the Burmannia Family. (MonoEpigyn.) Perianth coloured, tubular, 6-cleft, the three outer segments (calyx) often keeled at the back, the three inner (petals) minute. Stamens 3, inserted in the tube of the perianth and opposite its inner segments, sometimes with 3 alternating sterile filaments; anthers dithecal, opening transversely, with a fleshy connective. Ovary inferior, either 1- or 3-celled, in the latter case the cells opposite the outer segments of the perianth; ovules 00 ; style simple; stigmas 3 . Fruit a 1-3-celled, 3-valved capsule, crowned by the persistent perianth. Seeds 00, minute, striated.-Herbs, with radical leaves and bisexual flowers. Natives of moist grassy places in tropical regions. They have no properties of importance. Apostasia is placed by some in this order, while by others it is put in a distinct order-APoSTASIACE Examples-Burmannia, Apteria, Apostasia?

Order 192.-Hemodoraces, the Blood-root Family. (MonoEpigyn.) Perianth petaloid, more or less woolly, 6-cleft. Stamens inserted on the perianth, either 3 , and opposite the inner segments of the perianth, or 6 ; anthers introrse. Ovary inferior, usually 3-celled, rarely 1-celled; ovules 1-2 or numerous; style simple; stigma undivided. Fruit a 3-valved capsule, sometimes indehiscent. Seeds either definite or 00 , sometimes peltate; embryo in cartilaginous albumen.-Herbs with fibrous roots, equitant distichous leaves, and bisexual flowers. They are found in various parts of the world, more especially in the warm parts of South America, at the Cape of Good Hope, as well as in North America and Australia. Lindley mentions 13 genera and 50 species. Examples-Hæmodorum, Anigosanthus, Vellozia, Barbacenia.

The plants receive the name of Blood-root, from the red colour of their roots, which are used for dyeing. Vellozias, Tree Lilies, give a decided feature to the vegetation of the mountains of Minas Geraes in Brazil. Their trunks are covered by the withered remains of the leaves, and their branches are dichotomous, and bear tufts of leaves at the extremities. The outer surface of their stems is covered thickly with numerous adpressed rootlets.

Order 193.-DIosconeacex, the Yam tribe. (Mono-Epigyn.) Flowers unisexual. Perianth in 6 divisions. t. Stamens 6, inserted into the base of the perianth; anthers introrse, with longitudinal dehiscence. $q$. Ovary inferior, 3-celled; ovules 1-2, anatropal; style bifid; stignas undivided. Fruit a compressed trilocular capsule, with 2 cells, sometimes abortive, occasionally fleshy and indehiscent. Seeds compressed, winged or wingless, in the succulent fruit, ovate; embryo small, near the bilum, lying in a large cavity of cartilaginous albumen.-Twining shrubs, with large epigeal or hypogeal tubers, alternate, sometimes opposite, slightly reticulated 
leaves, and small, spiked, bracteated flowers. Natives chiefly of tropical countries; a few only found in temperate regions. There are 6 genera, according to authors, and 100 species. Examples-Dioscorea, Tamus.

Although farinaceous matter exists in the tubers of many species, yet there is a prevalent acridity throughout the order. Various species of Dioscorea, as $D$. alata, sativa, and aculeata, produce the tubers called Yams, which are used in warm countries as a substitute for the potato. The growth of yams is very remarkable. A tuber of $D$. alata, $1 \mathrm{lb}$. in weight, was planted at Madras in June, and lifted at the end of nine months, when the weight was found to be $27 \frac{1}{2}$ Ibs. Testudinaria Elephantipes is the Tortoise plant of the Cape, or Elephant's-foot, so called on account of its peculiar shortened and thickened stem (p. 65). Tamus communis, Black Bryony, is common in hedges in England. It produces red succulent fruit, and has a large root, which is acrid. This acridity does not extend to the young suckers, which may be eaten with impunity. The acridity of the order sometimes manifests itself in purgative qualities.

Order 194.-AMarylidDACE, the Amaryllis Family. (MonoEpigyn.) (Fig. 275, p. 186.) Perianth petaloid, regular, 6-cleft, the outer segments overlapping the inner. Stamens 6, inserted in the perianth, sometimes cohering by the dilated bases, and forming a kind of cup ; occasionally there are additional sterile stamens, which sometimes form a corona above the tube of the perianth; anthers introrse. Ovary inferior, 3 -celled; ovules 00 , anatropal ; style 1 ; stigma 3 lobed. Fruit either a 3-celled, 3-valved capsule, with loculicidal dehiscence, or baccate. Seed with a thin or thick, or black and brittle spermoderm; albumen fleshy ; embryo nearly straight; radicle next the hilum.-Usually bulbous plants, sometimes with fibrous roots; leaves ensiform, with parallel veins; flowers spathaceous ; stem sometimes woody and tall. Natives chiefly of the Cape of Good Hope, but species are found in Europe, East and West Indies, South America, and Australia. Lindley enumerates 68 genera and 400 species, and he divides them-into 4 tribes:-1. Amarylleæ, bulbs, flowers without a corona. 2. Narcisseæ, bulbs, flowers with a corona. 3. Alströmerieæ, fibrous roots, outer segments of the perianth different in form from the inner. 4. Agaveæ, fibrous roots, both segments of the perianth alike. Examples-Amaryllis, Galanthus, Crinum, Narcissus, Alströmeria, Agave.

The bulbs of many plants of this order have narcotic poisonous qualities. Some of them act as emetics, others are used in the preparation of a kind of intoxicating spirit. The tough fibres of some are used for flax. The root of Homanthus toxicarius is poisonous. The flowers of the Daffodil (Narcissus pseudo-narcissus) are also said to be poisonous. The fibres of Agave americana, American Aloe, constitute 
Pita flax. This plant does not flower often, but when flowering begins it proceeds with great rapidity aud vigour. Its roots are sometimes used to adulterate Sarza. Its juice is fermented so as to form an intoxicating beverage. Agave Saponaria is used in Mexico for washing. The bulbs of Narcissus poeticus, $N$. Jonquilla, $N$. odorus, $N$. pseudo-narcissus, N. Tazetta, and of some species of Pancratium, are emetic. The Guernsey Lily is also reputed poisonous. Some Alströmerias are diuretic. In Alströmerias (fig. 275, p. 186) the leaves are twisted, so that what should be the upper surface becomes the lower. In Narcissus the corona or crown of abortive filaments projects ibeyond the flower; while in Pancratium the dilated filaments of the fertile stamens unite together, and are included within the perianth. Many ornamental garden plants belong to the order. Some have supposed that Stembergia lutea is the Lily of the fields referred to by Christ. The snowdrop (Galanthus nivalis) and the snowflake (Leucojum vernum) belong to this order.

Order 195.-Hypoxidace , the Hypoxis Family. (Mono-Epigyn.) Perianth petaloid, superior, usually 6-parted, regular. Stamens 6, inserted into the base of the segments of the perianth, filaments distinct; anthers introrse. Ovary inferior, 3-celled; ovules numerous, amphitropal ; style simple; stigma 3-lobed. Fruit indehiscent, sometimes succulent, 1-2-3-celled. Seeds 00, with a lateral hilum and a beaked caruncle; testa black, and crustaceous; embryo straight, in the axis of fleshy albumen; radicle remote from the hilum.-Herbaceous and usually stemless plants, with tuberous and fibrous roots, radical plaited leaves, and simple or branched scapes. Natives of warm countries. Some have bitter roots, others have edible tubers. There are 5 known genera, including 60 species. Examples-Hypoxis, Curculigo.

Order 196. - Bromeliacede, the Pine-apple Family. (MonoPerigyn.) Perianth tubular, 6-divided, in 2 verticils; outer whorl (calyx) persistent, more or less adherent to the ovary ; inner petaloid, marcescent or deciduous, with imbricated rstivation. Stamens 6, inserted into the base of the segments of the perianth; anthers introrse. Ovary either free or partially adherent, 3-celled; ovules 00 , anatropal; style single; stigma 3-lobed or entire, often twisted. Fruit capsular or succulent (figs. 280, p. $190 ; 570$, p. 316), 3-celled. Seeds 00; embryo minute, curved or straight, lying in the base of mealy albumen; radicle next the hilum. Stemless or short-stemmed plants, with rigid, channelled leaves, which are often spiny at the margin, and are covered with scurfy matter. Natives of the warm parts of America chiefly. There are 30 genera, according to authors, and 170 species. Excamples-Bromelia, Ananassa, Tillandsia, Bonapartea.

The plants of this order are all more or less epiphytic, being able 
to grow without any direct attachment to the soil. In hothouses they are frequently kept suspended in moistened moss. Some of the Tillandsias are hung from balconies in South America as air-plants. Tillandsia usneoides has the appearance of the Beard-moss (Alectoria jubata, a British tree-lichen), and is used for stuffing cushions, etc. The plant has been called Tree-beard, Old-man's-beard, or Black Moss. The leaves of Tillandsias frequently contain much water in their hollowed-out bases. The fruit of Ananassa sativa is well known as the Pine-apple or Ananas (fig. 280, p. 190). It is an anthocarpous fruit, consisting of numerous flowers and bracts united together, and becoming succulent. The fruit is more or less acid in the wild state, but when cultivated it becomes sweet and highly aromatic. The fibres of the leaves are used in the manufacture of fine muslins. The woody fibres of many Bromelias are used in manufactures. Bromelia Pinguin is used as a vermifuge in the West Indies. Its ovaries do not combine into one mass, and therefore illustrate well the formation of the Pine-apple. The crown of the Pine-apple consists of the leaves arising from the prolonged axis (fig. $570, \mathrm{p} .316 \mathrm{f}$.)

\section{b. HYPOGYN \&-Ovary superior, Flowers usually hernaphrodite.}

Order 197.-LILIACE里, the Lily Family. (Mono-Perigyn. and Mono-Hypog.) Flowers usually bisexual. Perianth coloured, in 2 rows, regular, with 6 divisions (figs. 283,284 , p. $192 ; 858,859$ ). Stamens 6 (fig. 637, p. 365), perigynous, inserted into the segments

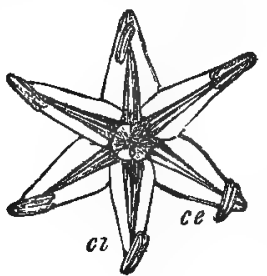

Fig. 858 .

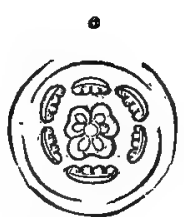

Fig. 859.

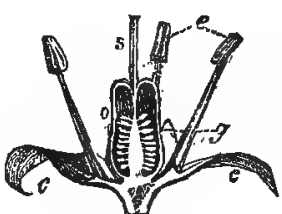

Fig. 860.

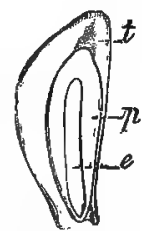

Fig. 861.

of the perianth (figs. 283, p. $192 ; 858,860$ ) ; anthers introrse (fig. 860 e). Ovary free, 3 -celled (fig. 859) ; ovules 00 ; style 1 ; stigma simple or 3-lobed (figs. 283, 284, p. 192; 860 s). Fruit 3-celled,

Figs. 858-861. Organs of fructification of Seilla autumnalis, to illustrate the natural order Lilliaceæ. Fig. 858. Flower seen from above, $c e$, Outer verticil of the perianth (calyx). ci, Inner verticil of the perianth (corolla). Fig. 859. Diagram of the flower, showing three outer and three inner leaves of the pexianth, six alternating stamens in two rows, and three carpels of the ovary with the ovules. Fig. 800. Vertical section of the flower. c c, Perianth. e, Stamens. o, Ovary. s, Style and stigmas. $g$, Ovules attached to a placenta in the axis. Fig. 861 . Seed separated and cut lengthwise. $t$, Integument. $p$, Perisperm. e, Embryo. 
either succulent or dry and capsular. Seeds numerous, packed one above the other in 1 or 2 rows (fig. 860 ); embryo in the axis of fleshy albumen (fig. 861).- - Herbs, shrubs, or trees, with bulbs (figs. 224-226, p. 115), or tubers, or aborescent stems, or rhizomes (fig. 107, p. 47); leaves not articulated, usually narrow, with parallel veins. They are found both in temperate and tropical climates. In warm regions some of them are arborescent, as in the case of Dracænas; others are very succulent, as species of Aloe. The order has not been sufficiently defined, and there are still many differences of opinion as to its limits. Under it are included by some the following tribes :-

1. Tulipex, Tulip tribe: bulbous plants, segments of perianth scarcely adherent in a tube, testa pale and soft.

2. Hemerocallidex, Day-lily tribe : bulbous plants, with a tubular perianth, testa pale and soft.

3. Scilleæ or Allieæ, the Squill and Onion tribe : bulbous (figs. 224-226, p. 115), with the testa black and brittle.

4. Anthericeæ or Asphodelex, Asphodel tribe : not bulbous, roots fascicled (fig. 100, p. 41) or fibrous, leaves not coriaceous nor permanent.

5. Convallarieæ, Lily of the Valley tribe: stem developed as a rhizome or tuber (fig. 107, p. 47).

6. Asparagex, Asparagus tribe: stem usually fully developed, arborescent, in some cases branched, leaves often coriaceous and permanent.

7. Aloinex, Aloe tribe : stem usually developed, arborescent, leaves succulent.

8. Aphyllantheæ, Grass-tree tribe : having a rush-like habit and membranous imbricated bracts.

9. Conantherex, Conanthera tribe: stemless herbs of Peru and Chili, with the perianth more or less adherent, ovary being partially inferior.

10. Wachendorfieæ, Wachendorfia tribe : ovary superior, flowers triandrous, leaves somewhat equitant ; allied to Hæmodora.

11. Eriosperneæ, Eriospermum tribe: stemless plants of South Africa; seeds covered with long silky hairs.

12. Aspidistrex, Aspidistra tribe : Japanese and Asiatic plants; stemless ; leaves radical ; flowers in spikes, resembling Aracex.

13. Ophiopogoneæ, Ophiopogon tribe: Indian and Japanese plants; stemless tufted herbs, sheathing leaves, simple scapes, ovary sub-adherent.

Lindley enumerates 155 genera, including 1250 species. ExamplesTulipa, Lilium ; Hemerocallis, Phormium ; Scilla, Allium; Anthericum, Asphodelus ; Convallaria ; Asparagus, Dracæna ; Aloe ; Aphyllanthes, Xanthorrhæa; Conanthera; Wachendorfia ; Eriospermum; Aspidistra ; Ophiopogon.

Many of the plants of this order are showy garden flowers, such as Tulips, Lilies, Fritillaries, Day-lilies (Hemerocallis), Tuberoses (Polianthes tuberosa), and Dog-tooth-violets (Erythronium Dens-canis), etc. Some of them are used medicinally as purgatives, stimulants, emetics, and diaphoretics. Some yield valuable fibres, others supply resinous matter. The bulb of Scilla or Squilla (Urginea) maritima supplies the officinal squill. The plant grows on the sandy coasts of the Mediterranean. Its bulbs vary in weight from half-a-pound to four or five pounds. In their fresh state they are very acrid. They contain a bitter crystalline 
principle called Scillitina. Squill is used medicinally in the form of powder, vinegar, syrup, and tincture, as an emetic, diaphoretic, expectorant, and diuretic. The drug called Aloes is the inspissated juice of the leaves of various species of Aloe, as $A$. spicata, vulgaris, socotrina, indica, rubescens, arabica, linguceformis, and Commelini. It is inported under the names of Socotrine; East Indian or Hepatic, Barbados, Cape and Caballine Aloes. It contains a substance called Aloin, which some regard as its active principle. Aloes is used medicinally as a cathartic, acting chiefly on the large intestines and on the rectum. Aloe dichotoma is an arborescent species of South Africa, 30 feet high and 12 feet in girth; it is called Kokerboon or Quiver-tree. Baker thinks that the species of Aloe are probably only indigenous in Southern and Eastern Africa. Aloe vulgaris is, however, widely distributed in the East and West Indies, where it is cultivated as the source of Barbados aloes. Aloe Barberce is a tall Kaffiarian species. The bulb of Allium sativum, Garlic, is used as an irritant, stimulant, and diuretic. It is the $\square \cdot E^{\circ}$ (shoom) of the Bible, the oxogodov of the Greeks. The bulb of Allium Cepa, the Onion, the bya (betzal) of the Bible, is used in the same way as garlic, and so is the bulb of Allium Porrum, the Leek, the (chatzir) of the Bible (figs. 224, 225, p. 115). Some suppose that the leek is a cultivated form of Allium Ampeloprasum. Besides the Onion and Leek, several species of Allium, under the names of Chive (A. Schoenoprasum), Shallot (A. ascalonicum), and Rocambole (A. Scorodoprasunz), are used as articles of diet. These plants contain free phosphoric acid, and a sulphuretted oil which is in a great measure dissipated by boiling or roasting. In the Oregon and Missouri districts of North America the bulb of Gamassia esculenta, Gamass or Squamash, is also employed in a similar manner. It is called by the Indians Biscuit-root. The turios or young shoots sent up from the underground stem of Asparagus officinalis (fig. 129, p. 64) are the parts employed in cooking. The bulbs of species of Lilium, found in the east of Siberia, are eaten like potatoes. Fibres are procured from Phorminu tenax, New Zealand Flax, and from the species of Yucca, Adam's Needle (fig. 255, p. 176). Draccena Draco, and other species, yield an astringent resin called Dragon's-blood. The Draccenas often branch in a dichotomous manner, and attain a large size. The Grass-tree of New South Wales, Xanthorrhcea Hastile, gives a peculiar feature to the vegetation of that country. It yields a yellow gum-like substance. The base of the inner leaves of some Grass-trees is used as food. Some of the Lilies have bulbils or bulblets in the axils of their leaves (fig. 230, p. 117). In the Crown-Imperial there is a nectariferous depression in the base of the segments of the perianth (fig. 333, p. 209). Litium chalcedonicum is said to be the Lilies of the field, $\tau \alpha$ xgivo rou árgou, mentioned in Scripture. Dr. Tristram suggests that Anemone coronaria, one of the Ranunculacer, is 
probably the plant referred to. Hyacinthus orientalis is the common cultivated Hyacinth, of which the Haarlem florists had at one time upwards of 2000 varieties. The mania for Tulip bulbs was formerly carried to a great extent, and the price given for approved kinds was enormous. Many hundred varieties of tulips are known. Cordyline australis, the $T i$ of New Zealand, and $C$. Banlsii, yield fibres.

Order 198.-Medanteaces, the Colchicum Family. (MonoPerigyn.) Perianth petaloid, in 6 pieces, which are sometimes slightly coherent, usually involute in æstivation. Stameas 6 ; anthers usually extrorse. Ovary 3-celled; ovules numerous ; style 3-parted ; stigmas, 3, undivided. Fruit a 3-celled capsule, with septicidal or loculicidal dehiscence. Seeds with a membranous spermoderm; albumen dense, fleshy; embryo very minute.-Plants with bulbs, tubers (fig. 110, p. 48), or fibrous roots, having parallel-veined leaves, sheathing at the base. The flowers are sometimes polygamous. They are natives of various parts of the globe, but are most abundant in northern countries. The order has been divided into three sub-orders:-1. Veratreæ or Melantheæ, rhizome fibrous, dehiscence of capsule septicidal, flowers frequently unisexual. 2. Colchiceæ, rhizome bulbous, dehiscence septicidal. 3. Uvularieæ, rhizome bulbous or fibrous, dehiscence loculicidal. There are 34 known genera and 130 species. Examples -Melanthium, Asagræa, Veratrum, Tofieldia, Narthecium; Colchicum ; Uvularia.

The plants of the order have in general poisonous properties. Many are acrid, purgative, and emetic, and some are narcotic. Among the medicinal plants of the order, the most important is Colchicum autumnale, Meadow Saffron, or Autumn Crocus. It is found in England and Ireland, and in the greater part of Middle and Southern Europe. On the Swiss Alps it ascends to 5500 feet. The corm (fig. 110, p. 48) and the seeds are the officinal parts. They contain a peculiar alkaloid called Colchicin, which seems to be analogous to Veratrine. Colchicum in large doses acts as a narcotico-acrid poison. In medicinal doses, in the form of extract, vinegar, tincture, and wine, it is used in the cure of gout and rheumatism. It is sedative, cathartic, and diuretic. Colchicum variegatum, according to Planchon, is probably the true Hermodactyle of the Greek and Arabian physicians, who used it for diseases of the joints. The rhizome of Veratrum album, the White Hellebore of the Greeks, is an irritant narcotic poison, its properties being due to the presence of an alkaloid called Veratrine. It has been used as an emetic and purgative, especially in mania, and it has been administered as a remedy for gout. Cevadilla is the fruit of Asagrcea officinalis, a native of Mexico. The fruit and seeds contain the alkaloid veratrine, in combination with a peculiar fatty acid called cevadic or sabadillic acid. Cevadilla or Cebadilla is used in cases of neuralgia and rheumatism. 
Order 199.-SMILACEe, the Sarsaparilla Family. (Mono-Perigyn.) Flowers bisexual or polygamous. Perianth petaloid, 6-parted. Stamens 6, inserted into the base of the perianth, rarely hypogynous. Ovary free, 3-celled ; cells uni- or multi-ovulate; ovules orthotropal ; styles usually 3-cleft; stignas 3. Fruit globular and succulent. Seeds with fleshy, cartilaginous albumen; embryo very small ; usually distant from the hilum.- - Herbs or undershrubs, often climbing, with netted-veined leares. Natives of the temperate and tropical regions of Asia and America. There are 6 known genera and upwards of 120 species. Examples-Smilax, Philesia.

Mucilaginous and demuleent properties prevail throughout the order. The root of various species of Smilax constitutes the Sarsaparilla or Sarza of the pharmacopœias. Lininæus considered Smilax Sarsaparilla, a native of the United States, as the plant which furnished Sarsaparilla, but recent observers state that this is not the case. The following are enumerated as sources whence Sarsaparilla of various kinds is derived :-

1. Smilax officinalis, found in woods near the Rio Magdalena in Columbia. It furnishes Jamaica Sarza, which is the best in the market.

2. Smilax medica, native of the Mexican Andes. It is thought to furnish Vera Cruz Sarza.

3. Smilax syphilitica, found in Brazilian Guiana. It in part supplies Brazil and Lisbon Sarza.

4. Smilax cordato-ovata, a Brazilian species. Brazil Sarza in part.

5. Smilax papyracea, a Brazilian species. Probably the source of the Pará Sarza.

6. Smilax Brasiliensis, a Brazilian species. Brazil Sarza.

The officinal part is the roots which come off from the rhizomes. The roots are mucilaginous, bitterish, and slightly acrid. They contain mucilage, starch, oil, resin, and a crystalline principle called Pariglin or Smilacin. Sarsaparilla is used in decoction and infusion, as a tonic and alterative, in cachectic and syphilitic cases. Smilax China, a native of China, Japan, and India, yields the Tuber Chinæ or Chinaroot. The tubers are used as a remedy in syphilis. The root of $S$. Pserdo-China, from the United States, is also used. The genus Astelia is by some included in this order, while by others it is put in a separate order,-Astelied. The plants have grass-like leaves, and in habit they resemble Tillandsias. They are found in New Zealand, Tasmania, and South America. They yield fibres. Astelia Solandri is the Tree-flax of New Zealand, A. Banksii, A. Cunninghamii, and A. trinerois, also yield fibres.

Order 200.-Trilliacese, the Trillium Family. (Mono-Perigyn.) Flowers usually bisexual. Perianth in 6, sometimes 8 divisions, coloured or herbaceous. Stamens 6, 8, or 10; filaments subulate; anthers linear, with a prolonged connective. Ovary free, 3- 4- or 5celled ; styles as many, distinet ; ovules 00 , anatropal. Fruit succu- 
lent, 3-4- or 5-celled. Seeds 00 ; embryo minute, in fleshy albumen. The order may be considered as a tribe of Smilaceæ. It sometimes receives the name of Paridea.-Natives of the temperate parts of Europe, Asia, and America. Some of them are more or less acrid, others are narcotic. The rhizome of Trillium cernuum is used as an emetic. The juice of the berries mixed with alum gives a blue colouring matter. Paris quadrifolia, Herb Paris, is narcotic. There are about 10 known genera, and upwards of 30 species. ExamplesTrillium, Paris.

Order 201.-Gilliesiace $\approx$, the Gilliesia Family. (Mono-Perigyn.) Perianth 6-parted, sometimes 5-parted by cohesion of two of the pieces, in a double row; the outer, petaloid or herbaceous; the inner, smaller, and more coloured; æstivation twisted. Stamens in ar double series ; outer whorl sterile, in the form of a 6 -toothed urceolate body, or of scale-like bodies, one of which forms a sort of labellum; inner whorl of six stamens, of which three are sometimes sterile. Ovary superior, 3-celled; style 1 ; stigma simple. Fruit a 3-celled, 3 -valved capsule, with loculicidal dehiscence. Seeds numerous, attached to the axis; spermoderm black and brittle; embryo curved in the midst of fleshy albumen.-Herbs with tunicated bulbs, grasslike leaves, and umbellate spathaceous flowers. Natives of Chili. Their properties unknown. The description of the flower is in accordance with Arnott's view, and differs from that of Lindley, who considers the perianth as bracts, and the outer verticil of stamens as the perianth. There are 2 genera and 5 species. ExamplesGilliesia, Miersia.

Order 202.-Pontederiaces, the Pontederia Family. (MonoPerigyn.) Perianth tubular, coloured, 6-parted, more or less irregular ; æstivation circinate. Stamens 3-6, perigynous; anthers introrse. Ovary free, or slightly adherent, 3-celled; ovules numerous, anatropal ; style 1 ; stigma simple. Fruit a 3-celled, 3-valved.capsule, with loculicidal dehiscence. Seeds 00 , attached to a central axis ; testa membranous; hilum small; embryo straight, in the axis of somewhat mealy albumen; radicle next the hilum.-Aquatic or marsh plants with sheathing, parallel-veined leaves, which are sometimes cordate or sagittate, and have inflated petioles. The flowers are spathaceous. They are natives of North and South America, East Indies, and Africa. Their properties are unimportant. There are 6 genera, according to Lindley, and 30 species. Examples-Pontederia, Leptanthus.

Order 203.-XyRIDaCes, the Xyris Family. (Mono-Perigyn.) Perianth 6-parted, in two verticils; the outer glumaceous, the inner petaloid. Stamens 6, 3 fertile, inserted into the claws of the inner perianth; anthers extrorse. Ovary single, 1-celled; ovules 00 , orthotropal, attached to parietal placentas; style trifid; stigmas 
obtuse, multifid or undivided. Fruit a 1-celled, 3-valved capsule. Seeds numerous; embryo on the outside of mealy albumen, remote from the hilum.-Herbs having a sedge-like aspect, with radical leaves, equitant and sheathing at the base, and scaly heads of flowers. Natives chiefly of tropical regions, having no important properties. There are about 7 genera and 72 species. Examples-Xyris, Abolboda, Philydrum?

Order 204.-JUNCACEA, the Rush Family. (Mono-Hypo-Perigyn.) Perianth 6-parted, more or less glumaceous. Stamens 6, inserted into the base of the segments, sometimes 3 , and opposite the outer segments; anthers 2-celled, introrse. Ovary 1-3-celled; ovules 1,3 , or many in each cell, anatropal; style 1 ; stigmas generally 3 , sometimes 1. Fruit a 3-valved capsule, with loculicidal dehiscence, sometimes indehiscent. Seeds with the testa neither black nor crustaceous ; embryo very minute, near the hilum, within fleshy or cartilaginous albumen.-Herbs with fasciculated or fibrous roots, hollow, grooved, or flat leaves, with parallel veins. In rushes the green shoots which act as leaves are often terete; they are either barren or bear flowers. They often have stellate cellular tissue in their interior, and they are sometimes twisted in a spiral manner (fig. 190, p. 91). They are natives chiefly of the colder regions of the globe. Many species of Juncus are used for making the bottoms of chairs, mats, etc., and the central cellular tissue forms the wicks of rushlights. In Sussex the manufacturers of rush fabrics use Juncus glaucus, hard Rush, $J$. effusus, soft Rush, $J$. conglomeratus, hollow Rush. All the three are used for mats; the last two for chair bottoms. Prionium Palmita, Palmite, is a remarkable aquatic Juncaceous plant of South Africa. It has a very thick stem, and is from 5 to 10 feet long. There are about 8 known genera and upwards of 130 species. Examples-Juncus, Luzula.

Order 205.-PaLMe, the Palm Tribe. (Mono-Perigyn.) Flowers bisexual or unisexual, or polygamous. Perianth 6-parted in a double row (fig. 867) ; 3 outer (calyx) fleshy, or leathery and persistent (figs. $862 \mathrm{ce}, 866 \mathrm{c}$ ), 3 inner (corolla) often larger (figs. $862 \mathrm{ci}$ ), and sometimes deeply connate. Stamens 6 (figs. 863, 867), rarely 3 , sometimes 00 , inserted into the base of the perianth. Ovary free, 1-3-celled, usually composed of 3 carpels, which are more or less completely united (fig. 865) ; ovules 1-3. Fruit drupaceous, or nut-like (fig. 866), or baccate, often with a fibrous covering. Seed with cartilaginous or horny albumen (fig. 616, p. 341 ), which is often ruminate (fig. 593 , p. 333), or furnished with a central or lateral cavity; embryo small, cylindrical, or flat, in a cavity of the albumen, remote from the hilum (figs. ${ }^{\circ} 593$, p. $333 ; 616$, p. 341).-Arborescent plants (fig. 134, 1, p. 68), with simple, rarely branched trunks, marked with the scars of the leaves, which are terminal, pinnate, or fan- 
shaped, with plicate vernation, parallel simple veins, and often spiny petioles. Flowers on a terminal, often branched spadix, enclosed in a 1- or many-valved spatha. A single spadix of Alfonsia amygdalina has been known to produce upwards of 200,000 flowers. Natives of tropical regions chiefly, and imparting to them much of their botanical physiognomy. Most of them have unbranched stems, attaining some-

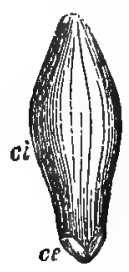

Fig. 862.

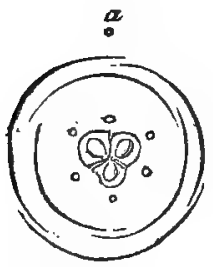

Fig. 865 .

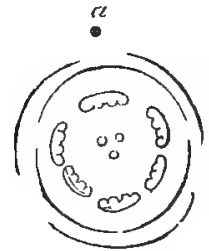

Fig. 863 .

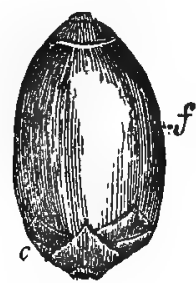

Fig. 866 .

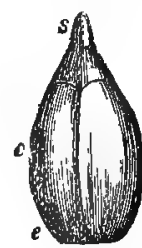

Fig. 864 .

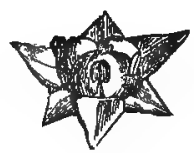

Fig, 807 .

times a height of 250 feet, and sending "out clusters of large leaves, from the axil of which bunches of flowers proceed. Although the flowers are small, still the inflorescence, talien collectively, has often a most imposing aspect. Humboldt describes their effect on the landscape in glowing colours, and Martius has illustrated the order by splendid delineations. Linnæus called them the Princes of the Vegetable Kingdom. There are about 180 known genera and upwards of 500 species. Martius estimates the known species at 582, of which 91 have fan-shaped leaves. They have been divided by him into various tribes, depending chiefly on the nature of the ovary, ovules, and fruit;

Figs. 862-866. Organs of fructification of Areca Catechu, Betel-nut Palm, to illustrate the natural order Palmæ. perianth. $c i$, Inner perianth. Fig. 863. Dingram of the flower, showing the two verticils

Fig. 862. Unexpanded flower-bud. ce, Onter division of the of the perianth, the six stamens, and three abortive carpels. $u$, The position of the axis of inflorescence in reference to the flower. Fig. 864. A flower deprived of its perianth, in which the stamens, $e$, are partly abortive, while the ovary, 0 , is developed. $s$, Stigma. Fig. 865. Diagram of the last flower, showing the double perianth, the partially abortive stamens, and the 3-celled ovary. $a$, Axis of inflorescence. Fig. 836. Fruit, $f$, surrounded at its base by the persistent perianth, $c$. Fig. 867 . Flower of Chamærops humilis, European Fan-Palm, seen from above. There are six divisions of the perianth, six stamens, and the ovary. 
and sections are formed according as the leaves are pinnate or flabelliform, and the stems are spiny or not. The following are the tribes:1. Areciner, the Betel-nut tribe. 2. Lepidocaryinæ, the Sago tribe. 3. Borassinere, the Palmyra Palm tribe. 4. Coryphinem, the Talipot and Date tribe. 5. Cocoineæ, the Coco-nut tribe. Examples-Areca, Euterpe, Caryota ; Lepidocaryum, Calamus, Sagus ; Borassus, Lodoicea; Corypha, Livistona, Phoenix ; Cocos, Elais, Acrocomia; Phytelephas.

The properties of the plants of this order are very various. In the countries in which they grow they are used for supplying food, and for forming habitations. The fruit of some is eatable, while that of others is extremely hard. Many supply oil, wax, starchy matter, and sugar, which is fermented so as to form an intoxicating beverage. Their fibres are employed for ropes, and the reticulum surrounding their leaves is sometimes manufactured into brushes.

The Palm of the Bible, תמת, Tamar, seems to be Phoenix dactylifera, Date, the drupaceous fruit of which supplies food to many of the inhabitants of Arabia and Africa. Cocos nucifera (fig. 134, 1, p. 68), the Coco-nut Palm, is one of the most useful, supplying food, clothing, materials for houses, and utensils of various kinds, ropes and oil. Herbert says, "The Indian nut alone is clothing, meat and trencher, drink and cann, boat, cable, sail and needle, all in one." The sugar procured from it is called Jagery, and is fermented so as to form arrack. The fibrous part of its fruit is manufactured into Coir-rope. The wood of the Coco-nut Palm is known by the name of porcupine wood. The terminal bud of the Coco-nut Palm, as well as that of Euterpe montana, the Cabbage Palm, are used as culinary vegetables. The Double Coco-nut of the Seychelles Islands is produced by Stevensonia Sechellarum. Verschaffeltia splendida is another Palm of these islands. The palm-oil imported from the west coast of Africa is obtained by bruising the fruit of Elais guineensis and melanococca: The oil-bearing palms are in the tribe Cocoiner. The Betel-nut is the produce of Areca Catechu, and from it an extract is prepared of an astringent nature resembling Catechu. This Areca is an elegant palm, 40-50 feet high, and 20 inches in circumference. It grows in the East Indies and in Indo-China. The powdered nut is used for tapeworm. The seeds or nuts form an ingredient in the Eastern masticatory called Pan or Betel, and which seems to owe its stimulating properties to the leaves of the Piper Betle. Sago, and starchy matter allied to it, are obtained from many Palms. It is contained in the cellular tissue of the stem, and is separated by bruising and elutriation. Fine Sago is said to be procured from Metroxylon loeve, a native of Borneo and Sumatra, Sagus Rumphii or farinifera, a native of Malacca, and Saguerus Rumphii or saccharifer, which is found in the eastern islands of the Indian Ocean. After the starchy matter is washed out of the 
stems of these Palms, it is then granulated so as to form sago. A single tree, it is said, will yield 500 to 600 pounds. The last-mentioned Palm also furnishes a large supply of sugar. Sago, as well as sugar and a kind of Palm-wine, are procured from Caryota urens. The date-sugar of Bengal is the produce of Phoenix sylvestris. Ceroxylon Andicola yields wax, which forms a coating over its trunk. Copernicia cerifera, Carnahuba Palm, is another wax palm. Its trunks are imported into Britain, and have been used for veneering. It is much used in the northern parts of Brazil, as at Aracaty, for thatch, hats, packsaddles, stakes, and palisades. The wax is procured by shaking the leaves, which have a glaucous bloom. Each leaf will yield fifty grains. Acrocomia aculeata is called Prickly-pole on account of the large black prickles on its stem. A reddish resinous matter is yielded by Calamus Draco (Dcemonorops Draco), one of the Rattan Palms, which have flexible climbing stems. It grows in Sumatra and Borneo. The resin is one of the substances called Dragon's-blood (the xıvvá $\beta$ aess of Dioscorides), and is used for colouring. The whalebonelike bristles which surround the base of the leaves of some species of Sagus and Saguerus are used for brushes. The thinner stems of Palms, as of Calamus Scipionum and Rotang, are used as canes, under the name of Rattans. Calamus Rudentum, the Cable Cane, a native of the East Indies, Cochin-China, and the Moluccas, grows sometimes to the length of 500 feet. Sabal umbraculifera is the Fan-Palm or Bull-Palm of the West Indies. The fruit of Attalea funifera is known by the name of Coquilla-nuts, and its hard pericarp is used for making umbrella-handles, etc. Leopoldinia Piassaba supplies a fibre used in manufacture under the name of Piassaba. The hard albumen of Phytelephas macrocarpa is used in the same way as ivory. Hence the plant is called the Ivory Palm. The spatha of Manicaria saccifera comes off in the form of a conical cap, and is used as a covering for the head in the West Indies. Chamoerops hamilis is the only European species of Palm. It is able to stand the climate of this country with slight protection during winter. A specimen in the Edinburgh Botanic Garden has lived in the open air for about 50 years. It is covered with matting during winter. The Doom-palm of Egypt (Hyphcene thebaica) has a trunk which divides in a dichotomous manner. Its pericarp is used as food, and has the taste of gingerbread. Acrocomia sclerocarpa is the Macahuba-palm of Brazil. Mauritia vinifera is the Buriti-palm, the stem of which, when perforated, yields a reddish juice, having the taste of sweet wine. Areca sapida is a Palm of New Zealand, and is the most southern representative of the family, extending to $38^{\circ} 22^{\prime \prime} \mathrm{S}$. lat.

Order 206.-Commelynaces, the Spider-wort Family. (MonoHypogyn.) Perianth in 2 verticils; outer (calyx) herbaceous and tripartite; inner (corolla) petaloid, tripartite or trifid. Stamens 6 or 
fewer, hypogynous, some of them occasionally abortive or deformed; anthers introrse. Ovary 3-celled; ovules few in each cell ; style 1 ; stigma 1. Fruit a 2-3-celled, 2-3-valved capsule, with loculicidal dehiscence. Seeds often in pairs, with a lateral and linear hilum; embryo pulley-shaped, antitropal, in a cavity of fleshy albumen, remote from the hilum.-Herbs with flat narrow leaves, which are usually sheathing at the base. Natives chiefly of warm climates. Some have fleshy rhizomes, which are used for food. Tradescantias, Spider-worts, have moniliform staminal hairs, in which a microscopic movement of protoplasmic granules is seen (fig. 246, p. 153). Gezera, 17 ; species, 264. Examples-Commelyna, Tradescantia, Mayaca.

Order 207.-Alismaces, the Water-plantain Family.

(MonoHypog.) Perianth in 6 divisions and 2 verticils; outer whorl usually herbaceous; inner usually petaloid; sometimes the perianth is wanting. Stamens definite or 00, hypogynous ; anthers introrse or extrorse. Ovaries, 3, 6, or more, distinct or united ; ovules erect or ascending, solitary or in pairs; styles and stigmas equal to the number of carpels. Fruit of several dry, indehiscent carpidia. Seeds 1-2 in each carpel, exalbuminous (fig. 621, p. 342) ; embryo straight, or curved like a horse-shoe; radicle next the hilum.-Plants growing in flowing or stagmant water, usually with a creeping rhizome, parallel-veined leaves, and hermaphrodite or unisexual flowers. Natives both of tropical and temperate regions. The limits of the order are not well defined. It has been divided into two sub-orders :-1. Alismeæ, inner perianth petaloid, anthers introrse, embryo curved or hooked. 2. Juncagineæ, inner perianth herbaceous, sometimes perianth 0 , anthers extrorse, embryo straight, plumule coming through a slit in the embryo (fig. 600, p. 336). They have few important properties. Some are acrid, others have, eatable rhizomes. Various Brazilian Sagittarias are very astringent; their expressed juice being employed in the preparation of ink. There are $10 \mathrm{known}$ genera and about 50 species. Examples-Alisma, Sagittaria; Triglochin, Scheuchzeria, Triuris.

Order 208.-Butomaces, the Flowering-rush Family. (MonoHypog.) Perianth of 6 parts, in 2 verticils (fig. 415, 2, p. 238); outer usually herbaceous; inner petaloid. Stamens definite (fig. 415, 2 ,eo, ei, p. 238), or 00, hypogynous. Ovaries, 3, 6, or more, distinct or united, 1-celled (fig. 415); ovules 00 ; stigmas simple, as many as the carpels. Fruit consisting of several follicles, which are either distinct (fig. 427, p. 243) and beaked, or combined. Seeds 00, minute, attached to the whole inner surface of the pericarp (fig. 428, p. 243), exalbuminous; embryo often curved like a horse-shoe; radicle next the hilum.-Aquatic plants, often lactescent, with parallel-veined leaves, and frequently umbellate flowers. They are chiefly found in northern countries, and some of them have acrid and bitter properties. Butomus umbellatus, Flowering-rush, is the only British plant in the 
class Enneandria of Linnæus. Authors give 5 genera, including 8 species. Examples-Butomus, Limnocharis.

c. INCOMPLET perianth, or with a few verticillate scales.

Order 209.-Pandanaces, the Screw-pine Family. (Fig. 98, p. 39.) (Mono-Hypog.) Flowers unisexual or polygamous, coveringthe whole of the spadix. Perianth 0 , or a few scales. Male flowers: stamens numerous ; filaments with single anthers, which are 2-4-celled. Female flowers : ovaries 1-celled, united in parcels; ovules solitary or numerous, anatropal; stigmas sessile, equal to the carpels in number. Fruit either fibrous drupes collected into parcels, or berries. Seeds solitary in the drupes, numerous in the berries; embryo at the base of fleshy albumen ; radicle next the hilum.-Trees or bushes, sometimes with adventitious roots (fig. 134, 2, p. 68), long, imbricated, amplexicaul leaves, usually with spiny margins and backs. Natives of tropical regions. The order is subdivided into two sections :-1. Pandaneæ, undivided leaves and no perianth. 2. Cyclantheæ, fanshaped or pinnate leaves, flowers with a few scales. There are 25 genera, according to authors, and 85 species. Examples-Pandanus, Freycinetia; Cyclanthus, Carludovica, Nipa.

The flowers of some of the plants are fragrant, and their seeds are sometimes used as food. The juice has in some instances astringent properties. In the stem of the Serew-pines fibro-vascular bundles occur, containing woody tubes, scalariform and spiral vessels. Cells are also seen on the outside containing large prismatical crystals. The species of Pandanus are remarkable for their aerial roots, with large cup-like spongioles. These roots are sent out regularly from all parts of their stems, and appear like artificial props (fig. 134, 2, p. 68). Their spermoderm has numerous raphides. Their leaves are arranged in a spiral manner in three rows, and in their aspect they have some resemblance to those of the pine-apple-hence the name Screw-pine. The appearance of the fruit may also have given origin to the name. Pandanus Candelabra is the Chandelier-tree of Guinea, and is so called on account of its mode of branching. The Pandani are called Vacoas in Mauritius and Rodrigues. They abound in these islands. Freycinetia Bantesii is the Kie-Kie, or Screw-pine of New Zealand. The fleshy bracts called Tawhara are eaten by the natives; they are also made by the colonists into a luscious jelly, like strawberries. The leaves are used in basket-making. Panama hats are made from the leaves of Carludovica palmata. In 1869 these were exported from Santa Martha to the value of $£ 34,579$. Some of these hats sell from $£ 4$ to $£ 10$. Species of Nipa yield a kind of wine from their spadices. The Atap of India is the fruit of $N$. fruticans. 
Order 210.-Aracex, the Arum Family. (Mono-Hypog.) Flowers generally unisexual, rarely bisexual, enclosed within a spathe, and usually on a spadix (fig. 260 , p. 178), having male flowers at its upper part, female below, and abortive flowers between them (fig. 260,2 , p. 178). Perianth either 0 , or in the $\Varangle$ flowers rudimentary and scaly. Stamens definite or 00, hypogynous; anthers extrorse. Ovary free, 1-3- or more celled ; ovules solitary or numerous ; style short or 0 ; stigma simple. Fruit succulent or dry, indehiscent, one-celled, very rarely three-celled; seeds one or several ; embryo in the axis of fleshy or mealy albumen, sometimes with a lateral cleft for the plumule; radicle usually next the hilum.-Herbaceous or shrubby plants, often with tubers or creeping rhizomes, leaves sheathing at the base, and having parallel or branching veins (fig. 260, 1, p. 178). They occur in dry and marshy places, and in lakes in various parts of the world, abounding in the tropics. The order has been divided into four sub-orders : - 1. Arineæ, Cuckoo-pint tribe (fig. 260); naked flowers with a spadix and spathe, $t$ o, anthers sessile, ovules several, fruit succulent, seeds pulpy. 2. Typhineæ, Bulrush-tribe ; marsh or ditch plants, with nodeless stems, flowers $t$ o, with a scaly or hairy perianth, arranged on a spadix, without a spathe, anthers wedge-shaped on long filaments, ovule solitary, fruit dry, seed with adherent pericarp. 3. Acoreæ, Sweet-flag tribe; flowers $\Varangle$, having usually a scaly perianth, arranged on a spathaceous spadix, ovules 1 or more, fruit a berry. 4. Pistieæ, or Lemneæ, Duckweed tribe ; flowers to, naked, enclosed in a spathe without a spadix, ovary 1-celled, ovules 2 or more, fruit membranous or capsular. The order includes 60 genera and 286 species. Examples - Arum, Caladium, Colocasia, Calla; Typha, Sparganium; Acorus, Orontium, Pothos; Pistia, Lemna.

The general property of the order is acridity. Sometimes the plants are dangerous irritant poisons. In some instances the rhizomes yield much starchy matter, and when boiled or roasted are used as substitutes for yams, under the name of Coco. The starch may be separated and used as Arrow-root. Thus, Portland Sago is prepared from the rhizoine of Arum maculatum, common Cuckoo-pint, or Wake-Robin. Dieffenbachia seguina (Caladium seguinune) is called Dumb-cane, on account of the swelling of the tongue caused by chewing the plant. Many of the plants of this order give out heat in a marked degree during flowering (p. 259). Some send out aerial roots, by means of which they climb upon trees. Monstera (Tornelia) deliciosa has perforated leaves (p. 81); it yields an edible fruit. Symplocarpus foetidus, Skunk-cabbage, has a very disagreeable odour. Its rhizome and seeds have been used as antispasmodics. Richardia africana, with its white spathe, is commonly cultivated under the name of Athiopian Lily. The root-stock of Acorus Calamus, Sweet- 
flag, has an aromatic odour, combined with a bitterish acrid taste. It has been used as a stimulant and tonic. In Typha latifolia, Great Reed Mace, the pollen is abundant and easily collected, and from its inflammable nature has been used as a substitute for the Lycopodium spores. The rhizomes of Typha Shuttleworthii, called Gortong, is used by the Murray natives near Swanhill, Australia, as food. The young shoots of $T$. latifolia and angustifolia are eaten by the Cossacks like asparagus. The large, fleshy, amylaceous rhizomes are eaten by the Kalmucks. Examples of large Araceæ are seen in Godwinia gigas from Nicaragua, the root-stock of which weighs 5-6 Ibs., the leafstalk being 10 feet high, and the spathe 2 feet long, on a stalk 3 feet high; also in Archemone Hookeri, Dracontium asperum from Brazil, and Corynophallus Afzelii from western tropical Africa. Lemnas, Duckweeds, are common in ditches in temperate regions. Their flowers are very simple, one male, and the other female, without a perianth, enclosed in a membranous bag; their roots are simple, covered with a sheath. Colocasia esculenta, and other species, have edible corms, which are called Eddoes and Cocoes in the West Indies. Pistia Stratiotes floats in lakes in tropical countries.

Order 211. -NAIADACE Family. (Mono-Hypog.) Flowers hermaphrodite or unisexual. $\mathrm{Pe}-$ rianth of two or four herbaceous or scaly pieces, often deciduous, sometimes 0 . Stamens definite, hypogynous. Ovary free, of one or more carpels ; ovule solitary ; style 1 or 0 ; stigma

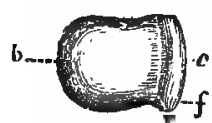

Fig. 868 . entire, rarely 2-3 parted. Fruit dry, 1-celled, usually indehiscent. Seed solitary, erect, or pendulous, exalbuminous ; embryo straight or curved (figs. 582, 583, p. 331), usually with a lateral slit for the plumule (fig. 868) ; radicle large (figs. 595, p. 334 ; 868).Plants living in fresh and in salt water, having cellular leaves with parallel veins and inconspicuous flowers. They are found in various parts of the world. They have no properties of importance. Zostera marina is used in the dried state for stuffing mattresses, and has been recommended for hospitals. Ouvirandra (Hydrogeton) fenestralis has peculiar skeleton-like leaves. It is the lace-plant or lattice-plant of Madagascar. Its rhizome is used for food under the name of wateryam (ouvi, yam, and rano, water). Aponogeton distachyum, a Cape aquatic, has grown well for many years in the open pond of the Edinburgh Royal Botanic Garden. Caulinia fragilis is one of the plants in which Protoplasmic Rotation has been observed. There are 20 known genera and upwards of 90 species. Examples-Naias, Zannichellia (fig. 601, p. 337), Potamogeton (fig. 145, p. 81), Ruppia, Zostera.

Fig. 868. Embryo of Zostera, in the natural order Naiadaceæ. c, Cotyledon. $r$, Radicle. $b$, Lateral swelling connected with the radicle. $f$, Slit for the plumule, which lies in a cavity of the very large radicle. 
Order 212.-Restiacese, the Restio or Cord-rush Family. (Mono-Perigyn). Flowers frequently unisexual. Perianth glumaceous, sometimes 0 . Stamens definite, perigynous, when two or three in number opposite the inner glumes; anthers usually 1celled. Ovary 1- or more celled, sometimes composed of several carpels; ovules solitary, pendulous; styles and stigmas 2 or more. Fruit capsular or nucumentaceous. Seeds pendulous; embryo lenticular, outside mealy albumen, remote from the hilum.-Herbs or undershrubs, with narrow simple leaves or none, naked or sheathed culms, and spiked or capitate, bracteated flowers. They are found chiefly in America and Australia. They have few properties of importance. The tough wiry stems of $W$ illdenovia teres and some Restios are used for making baskets and brooms. Eriocaulon septangulare is a native of Britain, being found in the Isle of Skye, as well as in the West of Ireland. In Brazil there exist branched Eriocanlons six feet high. In 1764, Linnæus described only 5 species of Eriocaulon in all the world, while Gardner collected in Brazil 100 species. The Diamond districts of Brazil are great centres of Eriocaulons. There are, according to Lindley, 36 genera and 372 species: Examples-Restio, Centrolepis, Eriocaulon.

\section{Sub-class II,-GLUMIFERA.}

Flowers glumaceous, consisting of bracts or scales, which are imbricated, and not arranged in true verticils.

Order 213.-CYPERACEA, the Sedge Family. (Mono-Hypog.) Flowers hermaphrodite or unisexual, generally without a perianth. Each flower furnished with a solitary bract (glume or scale). These bracts are imbricated upon a common axis, and the lowermost are often empty. Occasionally they enclose two or three opposite membranous bracts or glumies. In the female flower of Carex the two inner bracts receive the name of Perigynium (fig. 332, p. 209). Stamens hypogynous, definite, 1-12; anthers dithecal, innate. Ovary 1-celled, often surrounded by hypogynous bristles (setæ), which are probably abortive filaments; ovule erect, anatropal; style single, 2-3-cleft; stignas undivided, sometimes bifid. Fruit a crustaceous or bony achænium or nut (fig. 615, p. 341) ; embryo lenticular, enclosed within the base of fleshy or farinaceous albumen (fig. 615 e, p. 341) ; plumule inconspicuous (fig. 869).-

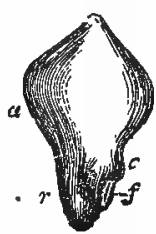

Fig. 869. Grass-like herbs with fibrous roots. Their stems are solid, often without joints, sometimes creeping (fig. 108, p. 48), frequently angular.

Fig. 869. Enbryo of Carex depanperata, separated to show the structure of that body $\mathbf{n}$ the natural order Cyperacex. $r$, Radicle. $c \alpha$, Ootyledon. $f$, Slit for the plumule. 
The leaves are narrow, and their sheaths are entire, not slit. They are found in all quarters of the globe, and in various localities, from the sand on the shore to the tops of the mountains. MIany of them occur in marshy ground. Genera, 110 ; species, 2000. ExamplesCyperus, Eriophorum, Scirpus, Fuirena, Cladium, Schœenus, Scleria, Elyna, Carex.

None of the plants of the order possess important medicinal qualities. The creeping stems of Carex arenaria, disticha, and hirta, are diaphoretic and demulcent, and have been used under the name of German Sarsaparilla. Cyperus Papyrus (Papyrus antiquorum) is the Papyrus of the Nile, the cellular tissue of which was used in the manufacture of paper. Cyperus syriacus, found in Sicily and on the plains of Sharon, etc., differs from $O$. Papyrus in having its leaves and floral clusters drooping all round the top of the stalk, in place of being erect and bending to one side like a plume. Some say that the word (gôme) in the Bible, translated Bulrush, is either the Papyrus or a species of Cyperus. The word ערות (aroth) has been translated PaperReeds. The species of Eriophorum are called Cotton-grass, on account of the woolly-like substance which is attached to the base of the ovary. Some species of Cyperus have tubers at the lower part of their stems, which are used as food. The roots of Cyperus longus have been used as bitter and tonic remedies, while those of $C$. odoratus are aromatic. C. esculentus is probably the אחו (achu) of the Bible, translated flag. Some species of Scirpus are used for making chair-bottoms. In South America Scirpus lacustris is used for making balsas or boats. Isaiah speaks of vessels of bulrushes on the waters. Species of Gahnia yield fibres in New Zealand. Some of the Carices, with their creeping stems, tend to bind together the loose sand on the sea-shore.

Order 214.-Graminew, the Grass Family. (Mono-Hypogyn.) Flowers usually $\Varangle$, sometimes unisexual or polygamous; 1,2 , or more (some occasionally abortive), attached to a common axis, and enclosed within bracts, the whole together forming a locusta or spikelet (figs. $327-330$, p. 208 ; 870-872). The outer imbricated bracts are called glumes (empty glumes); they are usually 2 (figs. 870,871 ge gi), sometimes 1, rarely wanting, and often unequal. They are either awned (aristate) or awnless (muticous). The bracts enclosed within the glumes are called paleæ, glumellæ, or flowering glumes; they immediately enclose the stamens, are usually 2 , the lower being simple, and the upper being formed of 2 united by their margins (fig. 871 pe pi). The innermost set of bracts consists of two or three hypogynous scales (squamulæ, glumellulæ, or lodiculæ), which are either distinct or combined, forming a sort of perianth (fig. $873 p$ ), and are sometimes wanting. Stamens hypogynous, 1-6 or more; anthers dithecal, versatile (figs. 331, p. $209 ; 369$, p. $223 ; 873$ e). Ovary simple (fig. 873 o); ovule ascending, anatropal; styles 2 (fig. 873 ) or 3 , sometimes united; 
stigmas feathery or hairy (fig. 446, p. $251,873 s s$ ). Fruit a caryopsis (fig. 563, p. 310). Seed incorporated with the pericarp; embryo len-

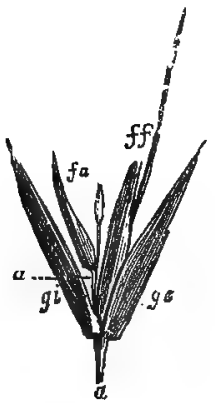

Fig. 870 .

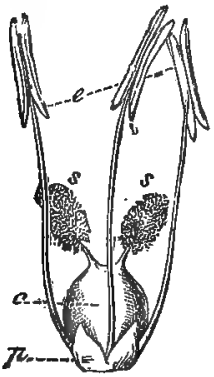

Fig. 873.

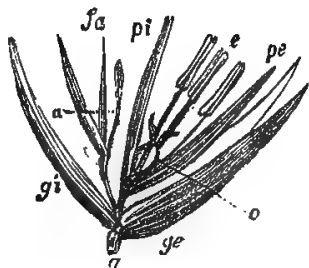

Fig. 871 .

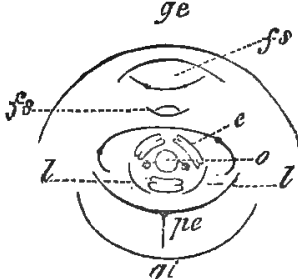

Fig. 872 .

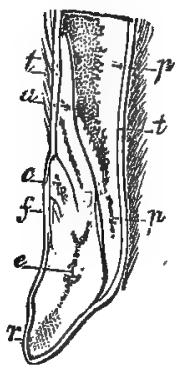

Fig. 874 .

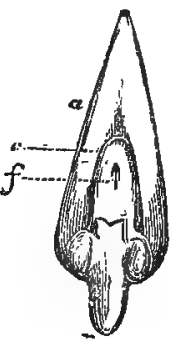

Fig. 875 .

ticular, lying on one side of farinaceous albumen (fig. 591, $\mathrm{p}_{*} 333$ ); near its base (figs. 874, 875) ; endorhizal in germination (fig. 105,

Figs. 870-875. Organs of fructification of Avena sativa, common cultivated Oat, to illustrate the natural order Gramineæ. Fig. 870. Spikelet of the Oat. $a$, Axis of inflorescence or rachis. $g e$, Exterior or lower glume. $\quad g i$, Inner or upper glume. $f f$, Inferior fertile flower. $f a$, Two upper abortive flowers. Fig. 871. The same spikelet with the envelopes separated to show the internal parts. $a d$, Axis of inflorescence. ge, Onter glume. $g i$, Inner glume. pe, Outer palea of the fertile flower with its awn (arista). pi, Inner palea, cleft at the apex, and apparently formed by two united. $e$, Three stamens. $o$, Pistil consisting of the ovary and two styles. fa, Two abortive flawers. Jig. 872. Diagram of the spikelet. ge, Outer glume. gi, Inner glume. pe, Outer palea with awn; the inner palea being opposite. es Stamens. o, Pistil. $l l$, Scales or lodiculæ. $f s, f s$, Barren flowers. Fig. 873. Fertile flower deprived of glumes and palex. $e$, Three stamens with rersatile cleft anthers. $p$, Scales (squamæ or lodiculæ) partially united. o, Ovary ultimately forming the grain, which consists of pericarp and seed combined. $s s$, Two styles with feathery stigmas. Fig. 874. Vertical seetion of the Caryopsis (fruit or grain), with the upper portion cut off. $t t$, Integuments of the caryopsis and of the seed united. $p p$, Perisperm. $\dot{e}$, Embryo. ' $r$, Radicle. $c a$, Cotyledon. $f$, Slit corresponding to the plumule. Fig. 875. Embryo separated. $r$, Radicle. $c a$, Cotyledon. $f$, slit corresponding to the plumule. 
p. 42).-Herbaceous plants, with cylindrical, hollow (fig. 130, p. 64), and jointed stems, called culms; alternate leaves, with a split sheath, and a membranous expansion at the junction of the petiole and blade, called a ligule (fig. 210 , p. 99), the collections of flowers (locustæ) being arranged in spikes, racemes, or panicles.

Discussions have arisen as to the true nature of the palex in grasses. Brown thinks that the upper palea is composed of two parts united, while the inferior palea is the third part. The arrangement is thus trimerous. Mohl, on the other hand, states that the inferior palea is not on a level with the other, and is in fact a bract from which the other is developed. From their alternate position, the parts of the flowers of grasses are in general looked upon as bracts, rather than as parts of a true perianth. The following may be given as a general view of the parts of the flower :-

1. Outer envelope : One or two flowerless or empty glumes, enclosing or subtending one or more flowers, with distinct insertions on a common axis. When one glume is suppressed it is the exterior or lower.

2. Inner envelope: One or two flowering glumes or paleæ, covering a unisexual or bisexual flower. Inner or upper palea sometimes suppressed. This palea (valve) consists usually of two confluent valves, as shown by two ribs equidistant from the axis. Hence this envelope is, according to some, a ternary perianth.

3. Squamulæ (scales," lodiculæ, or glumellulæ) occur within the last envelope, and at the base of the ovary. These are by some considered as the true perianth.

Grasses are found in all quarters of the globe, and are said to form about $\frac{1}{2}$ part of known plants. In tropical regions they sometimes assume the appearance of trees. They generally grow in great quantity together, so as to receive the name of social plants. The order has been divided into numerous sections, founded on the number of flowers in a spikelet, their hermaphrodite, unisexual, or polygamous nature, the number and form of the different sets of bracts, and the nature of the fruit. Genera, 250; species, about 4500. Examples-Oryza, Zea, Phalaris, Panicum, Stipa, Agrostis, Arundo, Echinaria, Chloris, Avena, Bromus, Festuca, Bambusa, Lolium, Triticum, Hordeum, Nardus, Rottboellia, Andropogon, Saccharum.

This is one of the most important orders in the vegetable kingdom, whether we regard it as supplying food for man or herbage for animals : To the former division belong the nutritious cereal grains, as Wheat, Triticum vulgare, and the varieties spring wheat, $F$. castivum, and winter wheat, T. hybernum; Triticum Spelta, spelt, which is בסמת (Kussemeth) of the Bible, translated Rye; T. compositum, Egyptian or mummy wheat (p. 348); Oats, Avena sativa; Barley, Hordeum vulgare, and its variety $H$. hexastichum Bere or Bigg; Rye, Secale cereale; Rice, Oryza sativa; Maize or Indian Corn, Zea Mays; Guinea-corn, Sorghum 
vulgare; and Millet, Panicum miliacenm, דחן, dockhan of Scripture :To the latter division belong pasture grasses, as Rye-grass (Lolium), Timothy-grass (Phleum), Meadow-grass (Poa), Cock's-foot-grass (Dactylis), Sweet-Vernal-grass (Anthoxanthum), Fescue (Festuca), Dog's-tailgrass ( $C$ ynosurus). The grains of many other grasses are used for food. Zizania aquatica supplies a kind of rice in Canada; Setaria germanica yields German millet. The grains of Sorghum vulgare (Andropogon Sorghum) have been sent to this country from India under the name of Durra. Phalaris canariensis is the source of the common Canary seed. The cereal grains have been so extensively distributed by man, that all traces of their native country are lost. They seem to be in many instances examples of permanent varieties or races kept up by cultivation. Their grain or caryopsis contains a large amount of starch (figs. 35, 36) and gluten. The grasses used for fodder in some parts of the world attain a large size, such as Anthistiria australis, the Kangaroo-grass of Australia, called also Satin-grass; Tripsacum dactyloides, the Gama-grass of Mexico; Gynerium argenteum, the Pampas-grass of the Cordilleras, and Festuca flabelloides (Dactylis ccespitosa), the Tussac-grass of the Falkland Islands. Some of these are five or six feet in height, and are, nevertheless, sufficiently delicate to be used for the food of animals. The Tussac has been introduced into this country, and it thrives well in peaty soils within the influence of the sea spray. Elymus condensatus is the Bunchgrass of California, an excellent early fodder plant in Britain. The rhizome of Triticum repens, Couch-grass or Quitch-grass, T. junceum, and Cynodon Dactylon, are used for mucous discharges from the bladder.

Sugar is a valuable product obtained from many grasses. It has been procured in Italy from Sorghum saccharatum, sweet Sorgho; in China, from Saccharum sinense; in Brazil, from Gynerium saccharoides; in the West Indies, from Saccharum violaceum; and in many other parts of the world, from S. officinamum. The last two are commonly known as Sugar-cane, and they are generally considered as varieties of a single species, Saccharum officinarum, which is now widely spread over various parts of the world, and has a stem from 6 to 12 feet high. Six or eight pounds of the saccharine juice of the plant yield one pound of raw sugar. The import of unrefined sugar into Great Britain in 1874 amounted to nearly 14 millions of cwts. Sugar is imported from British West Indies and Guiana, Mauritius, British East Indies, Java and Philippine Islands, Cuba, Porto-Rico, and Brazil, etc.

Some grasses have a very agreeable fragrance. This has been remarked in Anthoxanthum odoratum, which is hence called sweet-scented vernal grass, and is said to impart the odour to new-made hay. This odour has been referred to the presence of benzoic acid. A fragrant oil is procured from some species of Andropogon, as A. citratus, Lemon- 
grass, and $A$. Calamus aromaticus, which seems to be the (kaneh), or קפה בשט (kaneh bosem), the Sweet-cane of the Bible. A. Schenanthr!s yields Rousa oil, called also oil of ginger-grass or of Geranium. A. murcatus, Cuscus or Vetivert, yields a fragrant oil, used medicinally in India. A. Nardus yields citronella oil. Grasses contain a large quantity of siliceous matter in their stalks. This is deposited so as to form part of their structure, and in some cases it accumulates in the joints. The tabasheer in the joints of Bambusa arundinacea, the Bamboo, and of Melocanna bambusoides, is composed of silica. This is one of the tree-like branching grasses, which sometimes attains a height of fifty or sixty feet. It shoots up with great rapidity. In the Edinburgh Botanic Garden the young shoots attain a height of thirty or forty feet in a few months; and the late superintendent (Mr. W. M'Nab) measured, during a long summer day, a growth of the young stem tothe extent of nine inches. In Borneo the Dyaks use Bamboos for floors, beds, temporary houses, bridges, pegs for climbing lofty trees in order to get beeswax, baskets, fish-traps, hencoops, bird-cages, aqueducts, water-vessels, cooking utensils, jars and dishes of various sorts. The leaves and young shoots of the Bamboo are eaten; the leaves serve as fodder for horses, also for covering the tops of houses, and for stuffing cushions; the split stems serve as floor mats; the fibres are used for cordage and paper. Bamboos rarely flower and produce seed. Most of the species of Bamboo have hollow stems, which often attain a diameter of many inches. Gardner mentions a large species of Bamboo (B. Tagoara) having a stem 18 inches in circumference, and attaining a height of 50 to 100 feet. The touchpaper of the Chinese is made from a variety of Bamboo, by beating the young shoots flat, steeping them in a lime-pit for a month, and then washing and drying. A kind of paper is made from the Bamboo in India. Its young shoots are used as pickles. The hollow stems of some reeds in warm climates supply refreshing water to travellers. Dendrocalamus strictus is called the male Bamboo. Lygeum Spartum, Alpha-grass, and Macrochloa tenacissima, Esparto, yield fibres which are used for making paper and mats.

The stems of some grasses run under ground, and form a sort of network, which is useful in consolidating the sand of the sea-shore. Elymus arenarius and Ammophila (Psamma) arenaria constitute the Bent and Marram of the British shores. This tendency to creep under ground renders some grasses, such as Triticum repens, Couch-grass, difficult of extirpation. The grains of some grasses are used for ornaments. Beads are made from those of Coix Lachryma, commonly called Job's-tears, from their form and hardness. A few grasses, as Bromus purgans and catharticus, have purgative properties; and one, Lolium temulentum (infelix lolium), Darnel-grass, is said to be poisonous, but this has not been proved, if we judge by the experiments of 
GRAMINE正.

633
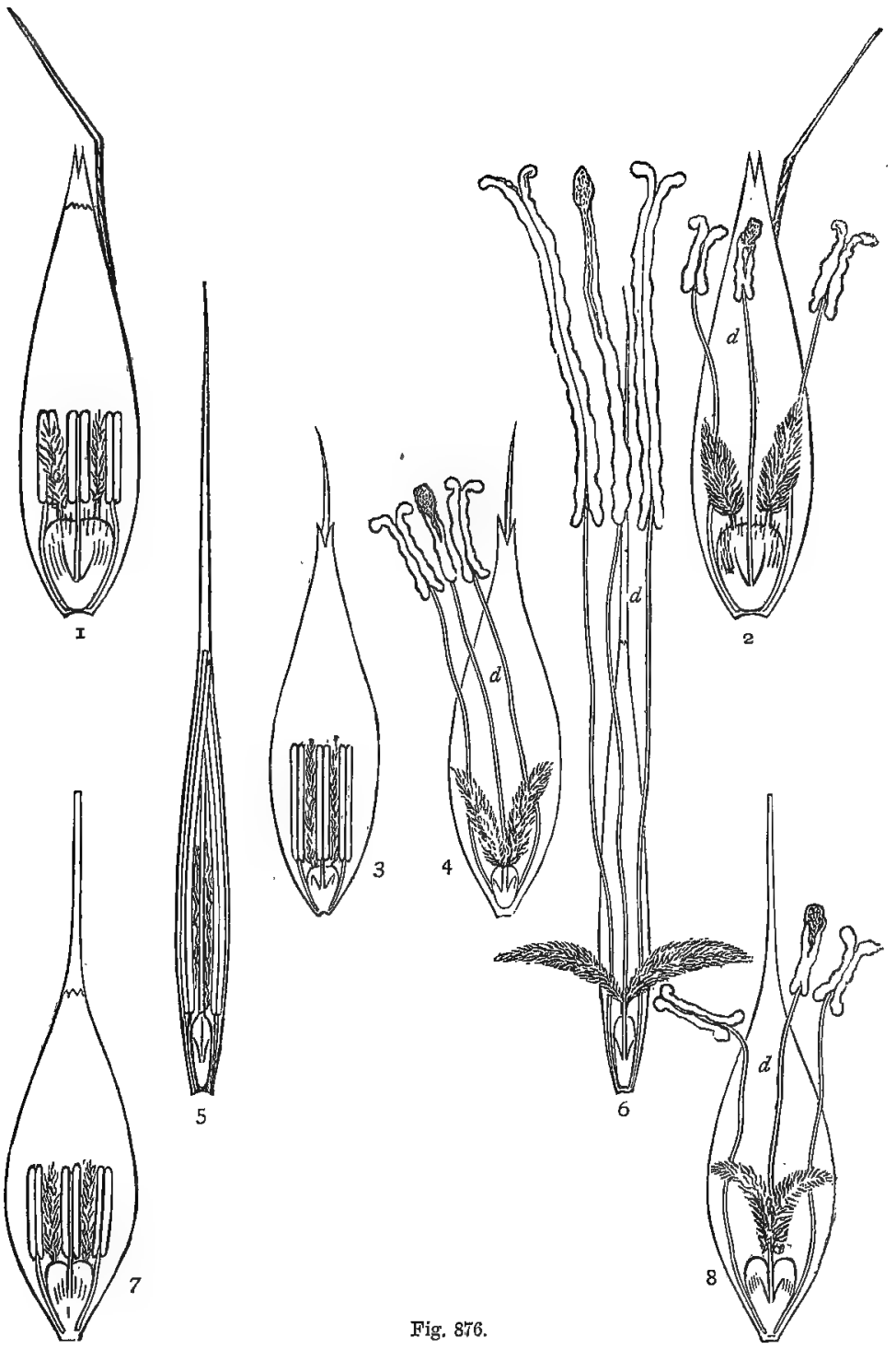
Dr. John Lowe and Mr. Stephen Wilson. Some suppose that it is

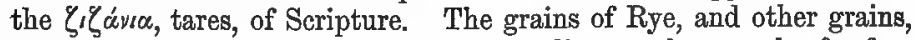
are liable to a disease called Ergot, depending on the attack of a fungus which alters the texture of the ovary, and makes it assume an elongated spurred form. The Ergot of Rye, or spurred Rye, has a peculiar effect in promoting the contraction of the uterus, and is on this account used in medicine. Ergoted rye, when regularly used for food, has the effect of causing what has been called convulsive and gangrenous ergotism, the former disease being distinguished by insensibility and convulsions, ending in death; the latter by dry gangrene, which attacks the fingers and toes, causing sloughing of these parts, and sometimes proving fatal by exhaustion. The poisonous effects of Ergot are attributed to the presence of a fixed oil.

Mr. A. Stephen Wilson states (Trans. Bot. Soc. Edin., 1874) that in the case of Wheat, Barley, and Oats, fertilisation takes place before the anthers are visible outside. After this process has taken place the filaments are rapidly elongated. In the case of Rye, the anther, in its immature state, extends almost the whole length of the palea (flowerglume) before it discharges its pollen.

In figure $876,1,3,7$, are represented the florets of Oats, Wheat, and Barley, before fertilisation with the short stamens, and at 5 , the floret of Rye with elongated stamens; while at 2, 4, 8, are shown the florets of Oats, Wheat, and Barley, after fertilisation, and at 6 that of Rye; $d$ marks the point where the spontaneous discharge of pollen takes place.

Mr. Wilson states that in Wheat, Oats, and Barley, the fertilisation is nore complete than it is in Rye, because in the former the dehiscence of the anther takes place inside the floret, where in general neither wind nor rain can carry away the pollen from the vicinity of the stigma; whereas in Rye the dehiscence takes place after the elongation of the stamens, and thus a quantity of the pollen falls outside the floret.

Fig. 876, illustrating the organs of reproduction of Cereal grains. 1, Floret of Oats, showing a floral glume (palea), bicuspidate at the summit, with a long, bent, and twisted awn arising from below the summit; stamens short, near the base. 2, 8ane, with the 8 stamens elongated, after fertilisation, and 2 feathery styles or stigmas. 3, Floral glume of Wheat before fertilisation. 4, Ditto after fertilisation. 7, Floral glume of Barley before fertilisation. 8, Ditto after fertilisation. 5, Floret of Rye before fertilisation. 6, Ditto after fertilisation. In $2,4,6$, and 8 , $d$ marks the point where spontaneous disoharge of pollen takes place. 


\section{Sub-Kingdom II.-CRyptogamous Plants.}

Flowerless Plants, having sexual organs, and producing spores, but having neither stamens, nor pistils, nor seeds.

Class III.-ACotyledones, Juss. Cellulares and Mono-Cryptogam正, $D C$. Thallophyta and Acrobrya, Endlich. Thallogens and Acrogens, lindl.

The plants belonging to this Class are in some instances composed entirely of cellular tissue; in other instances both cells and vessels are present. The vascular tissue in the higher orders consists partly of closed spiral and scalariform (fig. 64) vessels. Many of them have no true stem nor leaves. The woody stem, when present, consists of simultaneous vascular bundles, which increase in an acrogenous manner (p. 70). The stem of Tree-ferns (which illustrates this class) is unbranched, more or less uniformly cylindrical, hollow in the interior, and marked by the scars of the leaves (fig. 135, p. 71). Stomata occur in the epidermis of the higher divisions. Leaves, when present, have frequently no true venation, at other times the venation is forked. There are no flowers, and no distinct stamens nor pistils. Reproduction takes place by the union of cells of different values, some representing the male element, and called Antheridia, others the female, and called Archegonia (p. 265), by means of which germinating bodies called spores are formed (fig. 594, p. 334). The spore may be considered as a cellular embryo which has no cotyledons, and germinates from any part. of its surface, being heterorhizal (p. 334, fig. 629, p. 356). (For a full account of Oryptogamic reproduction see pages 266-281.)

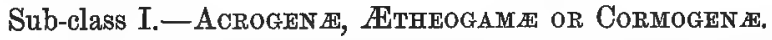

Acotyledons, having usually distinct stems and leaves (fronds), stomata, a certain amount of vascular tissue, and sporangia or thecæ (spore-cases), containing spores. This sub-class corresponds in a great measure with the division of Cormophyta, called Acrobrya by Fndlicher, and with the Foliosæ or Atheogamæ of De Candolle, and Angiosporæ of other authors. The Antheridia contain ciliated antherozoids or spermatozoids, and the spore in germination forms a prothallus on which Archegonia are produced, which are fertilised by the spermatozoids. Equisetums and Ferns have only one kind of spore, and are called Isosporous ("\%os, equal), while Marsileas and Lycopods have two kinds of spores (microspores and macrospores), and are called by some Heterosporous ("זr£gos, diverse). The microspores have a minute imperfect prothallus, with an antheridial cell containing 
numerous spermatozoids; the macrospores form a more or less rudimentary prothallus, with one or more Archegonia. Ferns have a monoicous' prothallus; Equisetums have a dioicous prothallus - a small one forming Antheridia, a larger Archegonia. In Ophioglossums, which some authors put as an order distinct from ferns, the prothallus is not green, is produced under ground, and bears both Antheridia and Archegonia.

Order 215.-Equismacese, the Horse-tail Family. Stem striated, hollow, usually branched, containing much silica in its composition, articulated, the joints being separable, and surrounded by ar membranous toothed sheath, formed by scales, which are equivalent to leaves (fig. 139, p. 73). There are no true leaves, green-coloured branches, having a straight vernation, occupying their place; some stems are barren, others fertile. The cuticle exhibits a longitudinal series of stomata. A spiral structure is observed in some of the vessels. The stems are also traversed by air canals (fig. 140, p. 74). Reproductive organs collected into cones; spore-cases (thecæe or spo-

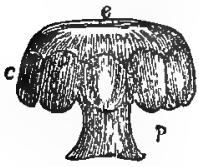

Fig. $87 \pi$.

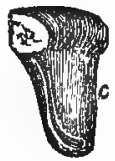

Fig. 878.

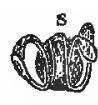

Fig. 879 .

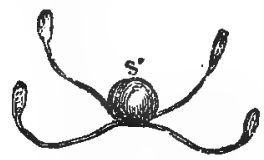

Fig. 880.

rangia) attached to the lower surface of peltate polygonal scales (fig. 877), and opening by an internal longitudinal fissure (fig. 878); spores in the form of rounded cells, surrounded by 4 elastic, clubshaped, hygrometric filaments or elaters (figs. 879, 880), formed by the breaking up of the outer coat of the spore in a spiral manner. The spore in germinating produces a green prothallus, on which Antheridia (containing spermatozoids) and Archegonia are formed, the latter producing the leafy stems.-Plants with simple or branched stems, the branches being jointed and placed in whorls at the articulations of the stem, each whorl consisting of as many branches as there are teeth in the sheath. Found in ditches, lakes, and rivers, in various parts of the world. In South America, Gardner measured

Figs. 877-880. Reproductive organs of Equisetum, to illustrate the natural order Equisetaceæ. Fig. 877. A peltate or polygonal scale, $e$, taken from the terminal cone-like fructification of an Equisetum. c, Thece or spore-cases arranged in a verticil on the under surface of the seale. $p$, Stalk by which the scale is attached to the axis. Fig. $878 . c$, Spore-case seen on ifs inner surface, with the slit or opening by which the spores are discharged. Fig. 879. A spore, $s$, with four clavate filaments rolled up in a spiral manner around it. Fig. 880 . Spore, $s$, with the flaments, which are clavate at their extremities, unrolled. These flaments or elaters are hygrometric, and move about under the influence of moisture. 
an Equisetum fifteen feet high, and three inches in circumference at the lower part of the stem. There is only 1 known genus, comprehending about 25 species. Example-Equisetum.

From the quantity of silicic acid contained in them, some of the species of Equisetum are used in polishing mahogany. An analysis of them is given at page 131. The spiral filaments which surround their spores are interesting objects under the microscope, exhibiting marked movements according to the moisture or dryness of the atmosphere around them. The stomata are arranged in lines on the cuticle. In Equisetum hyemale, often called Dutch Rushes, the siliceous stomatic apparatus is well seen after the action of nitric acid on the stem. There are regular rows of tubercles of a siliceous nature, in each of which is a transverse fissure, and at the bottom of the fissure a stoma is placed, with its opening at right angles to that of the tubercle. Each portion of the stoma has a pectinated (comb-like) appearance. The distinctions between the species of Equisetum are founded on the nature of the fertile and barren stems, the number of striæ or furrows, and the number of teeth at the articulations.

Order 216.-FilicEs, the Fern Family. Stem, a rhizome (fig. 881), which creeps along or under the surface of the ground, emitting descending roots and ascending fronds (leaves), or which rises into the air so as to form an acrogenous trunk (fig. 135, p. 71). This trunk (stipe) is of nearly uniform diameter, often hollow in the interior, marked on the hard outer rind by the scars (cicatrices) of the leaves, and contains vascular bundles of woody, dotted, and scalariform vessels, which are enclosed in hard tissue, and are arranged in an irregular manner (fig، 136, p. 71). Ferns have a continuous woody cylinder in their stem. The stem of many tree-ferns is composed of a mass of parenchyma traversed by vascular bundles of scalariform tissue, which form a closed circle separating the medulla in the interior from the cortex of the exterior. The tissue of this vascular cylinder is entirely destitute of medullary rays, but it is penetrated by large meshes, through which pass the vascular bundles that supply the fronds, and which invariably rise from the inner surface of the cylinder. Sometimes the trunk is dichotomous (fig. 137, p. 72). The outer fibrous covering is formed by the bases of the leaves, and is thicker at the lower than at the upper part of the stem. The leaves (fronds) have a circinate (gyrate) vernation (fig. $881 f^{\prime} f^{\prime \prime}$ ); their veins are generally of "equal thickness, and either simple or dividing in a forked manner (fig. 882), or somewhat reticulated, and occasionally stomata occur. Reproductive organs consist of spore-cases (thecr, sporangia), which arise from the veins on the under surface of the fronds (figs. $881 f^{\prime \prime \prime \prime}, 882 \mathrm{~s}, 883$ ), or from their margin. Spore-cases, either stalked, with the pedicel passing round them in the form of an elastic ring (fig. 884), or sessile and destitute of a ring. The thecæ some- 
times arise from the surface of the frond, while at other times they spring from below, having a cuticular covering in the form of an indusium or involucre (fig. 882). The clusters of thecæ are called

Fig. 882.

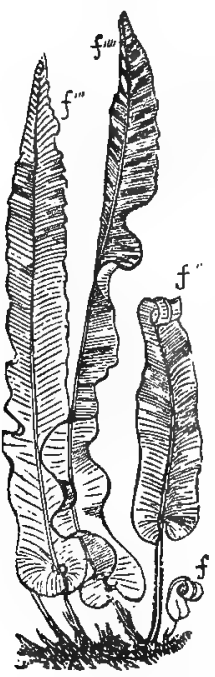

Fig. 881.
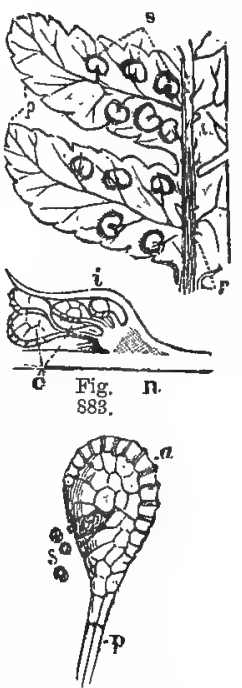

Fig. 884 . sori (fig. 883). The margin of the frond sometimes is folded so as to cover the thecæ, and at times the whole frond is converted into clusters of thecæ. The spores when sown give rise to a prothallus (prothallium), which bears antheridia and archegonia (p. 280). The antheridia are in the under surface of the prothallus, and consist of cellular papillæ, having a central cavity. This cavity contains free cellules, within each of which there is a ciliated spiral filament or spermatozoid. These cellules are discharged by a rupture at the apex of the antheridium. The spiral filaments then burst. the cellules, and being set free reach the cellular body containing the embryo-germ, or archegonial cell, embedded in

the substance of the prothallus. The archegonia are larger than the antheridia, and present a canal leading to the germ-cell, which canal remains closed till the period when the spermatozoid is matured. After fertilisation the archegonial cell enlarges, develops numerous cellules, and forms the true sporangiferous frond of the fern.-Ferns abound in moist insular climates. They characterise the New Zealand Flora. They are elegant leafy plants, occurring chiefly in moist insular climates, and abounding in the tropical islands. In mild and warm climates they occur in the form of large Tree-ferns,

Fig. 881. Rhizome of Scolopendrium vulgare, with several fronds (leaves), $f^{\prime \prime}, f^{\prime \prime}, f^{\prime \prime \prime}, f^{\prime \prime \prime}$, in different degrees of development. In $f^{\prime}$ and $f^{\prime \prime}$, the circinate or gyrate vernation is seen. In $f^{m t r}$, the linear transverse sori or clusters of thecæ are seen, lhaving the appearance of dark lines on the lower surface of the frond. Figs. 882-884. Frond and fructification of Lastrea (Nephrodium), to illustrate the natural order Filices. Fig. 882. Part of the frond seen on the lower surface. $p$, Two pinnæ covered with sori, $s$, having an indusium. $r$, Rachis or central stalk of the frond. Fig. 883 . One of the sori or clusters of thece cut vertically. $n$, The vein bearing it. $i$, Indusium or fold of the frond covering it. $c$, Thecas or sporangia (spore-cases). Fig. 884. One of the theca separated at the period of dehiscence. $a$, Incomplete annulus or ring, which is elastic, and causes transverse dehiscence of the theca. $p$, Stalk of the theca. $s$, Spores discharged. 
fifty to sixty feet high, which give a character to the landscape. The theca of ferns has been looked upon as a modified leaf, having the same gycate or circinate development as the frond. Leaves have occasionally been produced in place of thecæ. The prothallus of Pteris serrulata is said to produce occasionally fronds without the agency of archegonia. This case is similar to the formation of adventitious buds or leaves. Ferns having the thecr on the back of the frond, and furnished with an elastic ring or band, are called dorsiferous and annulate; while those having no thecal ring are exannulate.

The order has been divided into several sub-orders :-

1. Gleichenieæ, Gleichenia tribe.-Sori dorsal, sporangia (thecæ or capsules), opening vertically, surrounded by a broad transverse complete ring (annulus), no indusion (involucre), vernation circinate.

2. Polypodiex, Polypody tribe--Sori dorsal, sporangia pedicellate or sessile, distinct, annulate, ring vertical, usually incomplete, bursting irregularly and transversely, involucre marginal, dorsal, or 0 , vernation circinate.

3. Hymenophyllex, Filmy Fern tribe.-Sori marginal or dorsal, involucre 2-valved, sporangia nearly sessile, distinct, annulate, ring horizontal, complete, occasionally oblique, bursting lengthwise, vernation circinate.

4. Osmundex, Royal or Flowering Fern tribe.-Sporangia 2-valved, dorsal, or forming a separate stalked mass (an altered frond), distinct, with a short horizontal and more or less incomplete ring, opening across the apex, no involucre, vernation circinate.

5. Schizæx, Schizæa tribe. - Sporangia 2-valved, opening along the side, crowned by a complete opercular ring, vernation circinate.

6. Marattiea, Marattia tribe.-Sporangia united in mass (synangia), exannulate, opening irregularly by a cleft on one side or by a pore at the apex, vernation circinate.

7. Ophioglosseæ, Adder's-tongue tribe.- Sporangia collected into a spike, formed at the base of an altered frond, exannulate, 2-valved, vernation straight. They have a pale underground prothallus, bearing antheridia and archegonia.

The generic characters of Ferns are founded on the position and direction, covered or uncovered nature of the sori, as well as on the venation. There are 240 genera, including upwards of 2600 species. Examples - Gleichenia; Polypodium, Aspidium, Lastrea, Asplenium, Adiantum, Pteris, Davallia, Woodsia, Cyathea; Hymenophyllum, Trichomanes; Schizæa, Aneimia, Lygodium; Osmunda; Danæa, Marattia, Angiopteris ; Ophioglossum, Botrychium.

Few of the Ferns are used medicinally. They are in general demulcent and astringent. Some yield food. The rhizome of Lastrea (Aspidium) Fitix-mas, Male shield-fern, has been used as a vermifuge, especially in cases of tapeworm. It contains starch, gum, saccharine matter, tannin, green fixed oil, and resin. Its properties are ascribed to the fixed oil. The rhizome has been used for tanning, and its ashes contain much carbonate of potash. Cyathea medullaris, Ponga of New Zealand, furnishes a gum used as a vermifuge. The syrup called Capillaire, and certain pectoral nixtures, are prepared from Adiantum 
pedatum (Canadian Maiden-hair), and A. Capillus Veneris (true Maiden-hair). The rhizome of Pteris esculenta is used as food in Australia, and that of Marattia alata in the Sandwich Islands. Many other species of Ferns are esculent. The stems and leaf-stalks of Ferns are often covered with scales, and with woolly matter ; Davallia canariensis is called Hare's-foot Fern on this account, and Cibotium Barometz receives the name of Scythian or Tartarian-lamb, because, when prepared in a particular way, it resembles that animal.

Order 217.-MARsilface开, or RHIZOCARPE正, the Pepperwort Family (p. 279). Stem wanting. Leaves often stalked, with the lamina divided into three or more wedge-shaped pieces; sometimes the lamina is abortive; vernation circinate. Reproductive organs near the root or along the petiole, enclosed in an involucre. At the base of the leaves or petioles stalked sporocarps are formed, which are 2-4celled or 2-4-valved; they contain antheridia (microspores) and sporangia in separate cavities (fig. 504, p. 279), or there may be separate sporocarps for antheridia and archegonia (fig. 505, p. 279). The spore forms a prothallus bearing one or more archegonia.-Creeping or floating plants, found in ditches and pools in various parts of the world, more especially in temperate climates. They are not put to any important use. Marsilea Macropus or Salvatvix is the Nardoo plant of Australia, the sporocarps of which have been used as food by travellers in that country. There are 4 genera and upwards of 40 species. Examples-Marsilea, Pilularia, Salvinia, Azolla.

Order 218.-Iroopodiace. , the Club-moss Family (p. 278). Stems creeping or corms; annular vessels in the axis. Leaves imbricated, more or less setaceous, sometimes subulate. Sporangia, axillary and sessile, 1-3-celled, opening by valves or indehiscent; often of two kinds. One, round, reniform or crescentic, consisting of antheridian cells, with spermatozoids; the other, called oophoridium (ふ心ov, an egg, and $\varphi o^{g} \varepsilon$, I bear), of a roundish or tetrahedral form, opening by two valves, and enclosing four large spores capable of germinating; these spores contain an internal prothallus on which archegonia are formed. In Lycopodium we meet with one kind of theca containing numerous small spores; while in Selaginella there are microspores or antheridia (figs. 498,499, p. 278 ) at the upper part of the cone-like fructification (fig. 497, p. 277) ; while at the lower part there is a sporangium containing macróspores (fig. 501, p. 278), producing a prothallus bearing archegonia, which are fertilised by the spermatozoids of the antheridia from the interior of the microspores. The fertilisation of Lycopodium has not been fully ascertained. In Isoetes the two kinds of reproductive bodies are embedded in the substance of the base of the leaf. Isoetes is put by many in a distinct order, IsoETACE\&, Quillwort Family. They differ from Lycopods in their habit, and in their stem, which is a perennial, woody caudex increasing by annual 
growths.-They are moss-like plants, intermediate between ferns and mosses, and in some respects allied to cone-bearing plants. They abound in warm, moist, insular climates. A species of Selaginella from Jamaica has a green hue during the day, and turns white to the eye at night. There are 6 genera and about 200 species. Examples-Lycopodium, Selaginella, Isoetes.

Some of the Lycopodiums are emetic and cathartic. The powdery matter in the thecæ is inflammable, and has been used as a substitute for sulphur, under the name of Lycopod or vegetable brimstone. The minute spores of Lycopodium clavatum, in the form of a yellow powder, are shaken out of the sporangia, and are used externally for dusting excoriated surfaces, and putting in pill-boxes to prevent the mutual adhesion of pills. Church has found Potassium Phosphate in large quantity in the ash of Lycopodium giganterm. Two or three species of Selaginella, as $S$. convoluta and involvens, coil up into a ball during the dry season, and unroll during the wet season. They have been called resurrection plants.

Order 219.-Musci, or Bryaces, the Moss Family. Plants having a distinct axis of growth, often giving off branches or innovations ; no vascular system. Leaves minute and imbricated (fig. $885 \mathrm{f}$ ), entire, or serrated; sometimes with condensed cells in the form of ribs or nerves. Reproductive organs of two kinds :-1. Antheridia (figs. 402 , p. 233 ; 494, p. 277), cylindrical or fusiform stalked bags, containing minute cells with spermatozoids (fig. 402, 3, p. 233), and mixed with empty jointed filaments or paraphyses ( $\pi \alpha \rho \ddot{a} \phi \bar{v} \sigma \iota \zeta$, an offset). 2. Urn-shaped sporangia (figs. $887 ; 495$, p. 277 ), enclosed at

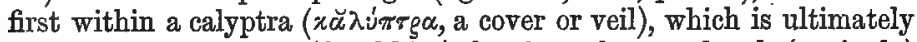
carried up with them (fig. $886 \mathrm{c}$ ), leaving often a sheath (vaginula) round the bottom of the fruit-stalk. These spore-cases (fig. 885) are supported on a stalk or seta, which has leaves at its base, called perichætial leaves ( $\pi \varepsilon g^{i}$, around, and $\chi \alpha i r n$, flowing hair, foliage); on removal of the calyptra, the theca is found to consist of a case with an operculum or lid (fig. 887), which, when it falls off, shows the mouth of the urn either naked or crowned with a peristome ( $\pi \varepsilon g i$, around, and orópa, mouth), consisting of one or more rows of teeth (in number, four, or a multiple of four), distinct, or united in various ways (fig. $887 p$ ). In the centre of the theca is a columella (fig. $888 \mathrm{c}$ ), and the bag formed between it and the parietes of the theca contains spherical cells called spores (fig. $888, \dot{s}$ ). In some cases the operculum remains persistent, and the theca opens by four valves. At the base of the theca there is occasionally a fleshy protuberance at one side, called a struma, or a swelling of the seta, called an apophysis

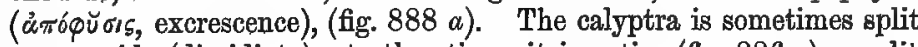
on one side (dimidiate), at other times it is entire (fig. $886 c$ ) or split into short clefts all round its base (mitriform). Between the teeth of 
the peristome and the edge of the theca an elastic ring or annulus is formed; and occasionally a horizontal septum or epiphragm ( $\rho_{g} a^{\prime} \gamma \mu \alpha$, a partition), extends across the mouth of the theca. The setre are sometimes twisted, and so are the teeth of the peristome. The spore of mosses when germinating forms a confervoid prothallus, from which a leafy axis arises bearing antheridia and archegonia, from the latter

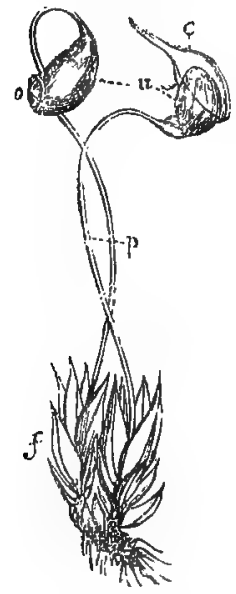

Fig. $885^{\circ}$

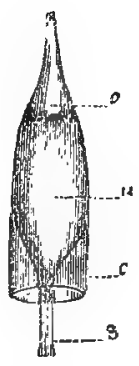

Fig. 886 .

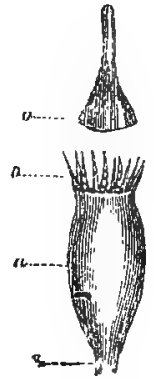

Fig. 887.

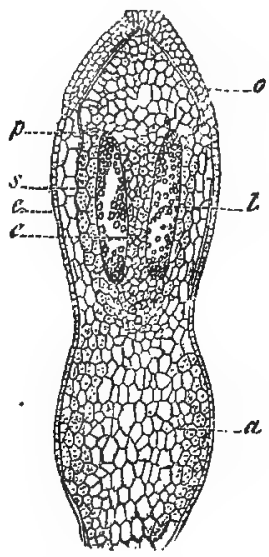

Fig. 888.

of which, after fertilisation, the sporangiferous axis proceeds (figs. 494496 , p. 277).-Mosses are either erect or creeping, terrestrial or aquatic plants, found in all moist countries, extending from the arctic to the antarctic regions. They abound most in temperate climates. Spruce met with few mosses in the Amazon and Rio Negro districts. He did not find Funaria hygrometrica there, although it is a very generally distributed moss. They are among the first plants which

Figs. 885-888. Figures to illustrate the natural order Musei. Fig. 885. Fhnaria hygrometrica slightly magnified. $f$, Leaves, those connected with the seta being called periehretial. $u$, UIn-like theca, sporangium or spore-case supported on a long twisted stalk or seta, p. c, Calyptra, which exists on one of the thecre, and has fallen from the other. v, Operculum or lid. Fig. 886. Theca of Encalypta vulgaris. $u$, Theca or spore-case. c, Mitriform entire calyptra. O, Operculum or lid. $\delta$, Top of the seta. The calyptra is transparent, and the operculum and theca are seen through it. Fig. 887. The same theca, $u$, with the calyptra removed. o, Operculum detached, showing the peristome, $p$, with its sixteen cilia or teeth. Fig. 888. Very young theca of Splachnum cut longitadinally. $a$, Apophysis or swelling of the seta at the base of the theca. $c$, Central columella. s, Cavity or bag between the columella and the walls of the theca, containing spores. The integument of the theca is formed of different cellular layers ; the first, $e$, forms the epidermis, and is thickened at the summit to form the operculum; there are then two intermediate layers, which ultimately form the teeth of the peristome; and lastly, an inner integament, $s$, which forms the parietes of the spore-bearing cavity. 
appear on newly-formed islands. In speaking of the morphology of mosses, Lindley states that the calyptra may be considered as a convolute leaf, the operculum another, the peristome one or more whorls of minute flat leaves, and the theca itself as the excavated distended apex of the seta. In a specimen of Tortula fallax, which I received from the late $\mathrm{Mr}$. E. Quekett, leaves are produced at the top of the seta in place of the spore-case. Dusting-brooms, called silk brooms, are made in Sussex from Polytrichum commune.

Mosses have been divided according as their sporangia are ter-

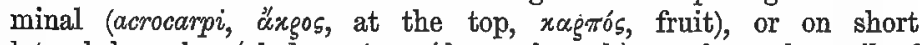
lateral branches (cladocarpi, $x \lambda \alpha_{\alpha} \delta \circ \varsigma$, a branch), or from the axil of leaves (pleurocarpin, $\pi \lambda$ evgóv, side) ; according as the operculum is adherent or not; and according as the mouth of the theca is naked, or has a single or double peristome, aploperistomi ( $\dot{\alpha} \pi \lambda{ }^{\prime} \circ \sigma_{\text {, }}$ single), and diplo-

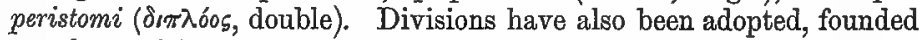
on the position of the antheridia and archegonia, etc. There are 3 sub-orders:-1. Bryeæ, urn mosses; cæspitose mosses, urn-shaped sporangia, with calyptra, usually an operculum; peristome with or without teeth, central columella, no elaters. 2. Sphagneæ, bog-mosses ; aquatic plants, with spirally imbricated leaves, clustered branches, spiral cells, operculum, but no peristome. 3. Andrææ, split-mosses; cæspitose mosses, sporangia bursting vertically into 4 valves, central columella, spores without elaters. Genera, 130; species, 2500. British genera, 110 ; species about 570. Examples - Phascum, Gymnostomum, Splachnum, Orthotrichum, Dicranum, Bryum, Funaria, Polytrichum, Hypnum; Sphagnum; Andræa.

Order 220.- HePATIC 4 , the Liverwort Family. Plants having an axis which either bears cellular leaves (fig. 889) or is leafless, and is bordered by a membranous expansion or thallus. Stomata are found in the epidermis of some. The reproductive organs are-1. Antheridia (fig. 490, p. 276), which are either embedded in the frond (fig. 489, p. 275) or situated on rounded sessile and stalked receptacles (fig. 488, p. 275). 2. Archegonia (fig. 492, p. 276), either inclosed in involucres and solitary (figs. 493, p. $277 ; 889 i i$ ), or occurring at the edge of the frond, or on the lower side of stalked peltate expansions (figs. 448 , p. 251 ; 491, p. 276). Thecæ or sporangia, having no operculum, opening irregularly, or by four valves (fig. 889). Spores (fig. 594; p. 334) often mixed with spiral filaments called Elaters (fig. 890). Heterorhizal in germination (fig. 629, p. 356).-Terrestrial plants, found in damp places, or inhabiting water; some having a moss-like appearance. They are natives both of cold and warm climates, and are generally distributed over the globe.

The order has been divided into three sections :-1. Marchantieæ, Liverworts : thecæ collected in heads, bursting irregularly, no operculum, spores with elaters. 2. Jungermannieæ, Scale-mosses: thecæ 
solitary, opening by four valves, no operculum, spores with elaters.

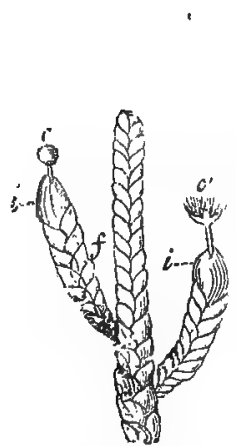

Fig. 889 .

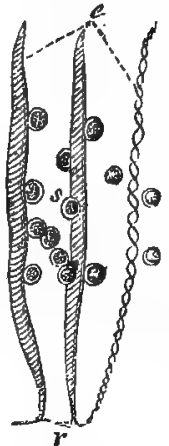

Fig. 890 .

3. Anthoceroteæ: thecæ pod-like, 2-valved, a central columella with elaters. 4. Riccieæ, Crystalworts : thecæ solitary, decaying so as to allow the spores to escape, no operculum, no elaters (fig. 447, p. 251 ). Many of the Hepaticæ producegemmæ or buds (fig. 488, p. 275), which are developed on the frond in the form of cup-shaped receptacles, and ultimately fall off so as to become distinct plants. Marchantia hemispherica has been recommended in dropsical cases. There are, according to Lindley, 73 . genera and about 700 species. Examples-Marchantia; Jungermannia; Anthoceros; Riccia.

\section{Sub-class II.-Amphigame, Thallogen ex, Cellulares.}

Acotyledons composed entirely of cellular tissue, having no distinct axis, nor leaves, nor stomata, propagated by means of spores, which are often enclosed in asci. The sub-class corresponds to Endlicher's division of Thallophyta, and includes the Amphigamæ of De Candolle and the Gymnosporæ of others.

Order 221.-Lichenes, the Lichen Family. Plants forming a thallus, which is either foliaceous, crustaceous (fig. 891), or pulverulent ; these different forms depending on the mode in which the cells are developed and combined. The reproductive organs appear on the frond in the form of protuberances of various kinds (fig. $892 t p$ ), consisting of an outer layer of thick-walled roundish cells, more dense than thetissue of the thallus, and of a different colour (fig. $893 \mathrm{cc}$ ), and of an internal medullary layer (fig. $893 \mathrm{~cm}$ ), with paraphyses and sporangia lying perpendicularly to the outer layer $c c$. The fructification gradually projects more from the surface, and either remains covered with the outer layer, or bursts through it. When it remains closed, there is a nucleus in the centre. When the fructification bursts through the

Figs. 889, 890. Organs of fructification of Jungermannia Tamarisci, to illustrate thenatural order Hepatice. Fig. 889. $f$, Branches covered with imbricated leaves, arranged in a distichous manner. Two of the branches bearing thecæ, supported on stalks which arise from an invohcre at the base. $i i$, Involucres. $c$, Thecæ closed in the young state: $c^{\prime}$, Thecæ opening by four valves to discharge the spores and elaters. Fig. 890. $r$, Receptacle bearing elaters, e, or spiral filaments, one of which shows the double spiral fibre. s, Free spores. 
cortical or outer layer, it expands in the form of shield-like discs, called

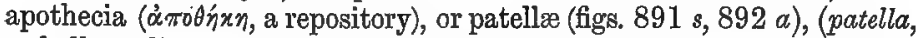
a hollow disk), or linear expansions called lirellæ (lira, a furrow). Sometimes the cortical matter forms a border round the fructification,

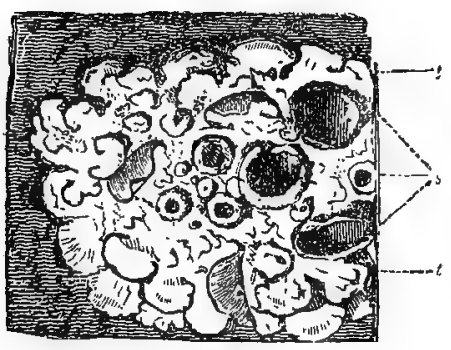

Fig. 891 .

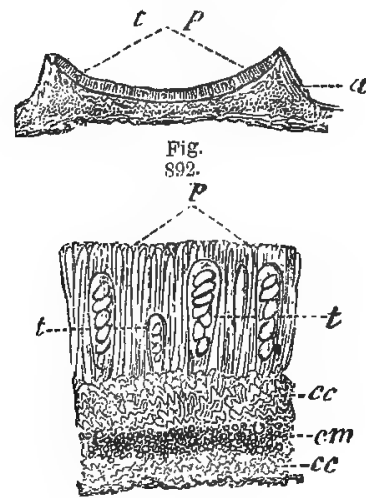

Fig. 893.

at other times it grows up in the form of a stalk, so as to give rise to a podetium (zoṽs, a foot). The young thecæ (asci) contain spores, varying from 4 to 8 (fig. 449, p. 251 ), or from 12 to 16 . Occasionally the spores are in sets of two (fig. 449, 2, p. 251). Separated cells of the medullary layer, of a green colour, called gonidia ( generation, and $\varepsilon^{3} \delta \circ \varsigma_{\text {, }}$ resemblance), or gongyli, are considered as another kind of reproductive organ. There are also capsular bodies called spermogones, containing minute linear cells or spermatia, which are often supported on stalks or sterigmata (fig. 475, p. 268). Besides these, pycnides (fig. 476 , p. 268 ), or bodies like spermogones occur, containing spore-like cells, called stylospores (figs. 473, 474, p. 268). Lichens bearing fructification in cavities of the thallus, and opening by a pore on the surface, are called angiocarpous, while those which have the fructification expanded in the form of a shield-like scutellate, cup-shaped, or linear thallus, are called gymnocarpous. The order has been"divided into four sections:-

1. Hymenothalameæ ( $\dot{u} \mu \dot{\eta} v$, a membrane, $\theta \dot{d} \lambda \check{a} \mu$ os, a receptacle) : shields open, discoid, permanent, nucleus bearing the sporangia on its surface (fig. 891).

Figs. 891-893. Organs of fructification of Parmelia Acetabulum, to illustrate the natural order Lichenes, section Hymenothaiamer. Fig. 891. $t$, Thallus of the Lichen. s, Apothecia in the form of shields in different degrees of development. Fig. 892. Apothecium, $a$, cut vertically and magnified in order to show the layer, $t p$, formed by the union of thecx and paraphyses. Fig. 893. A small portion of the apothecium much more magnified, showing, $c m$, the central medullary layer. $c c$, The cortical layer. $t t$, Thecr in different degrees of development. $p$, Paraphyses. 
2. Gasterothalamex ( $\gamma a \sigma \tau \eta p, a \cdot b e l l y)$ : shields either closed always, or opening by bursting through the cortical layer of the thallus, the nucleus containing the deliquescing or shrivelled sporangia.

3. Idiothalamer ('oı taining free spores in a nucleus composed of the gelatinous remains of the paraphyses and sporangia.

4. Coniothalamex ( $\kappa$ bvts, powder), pulverulent lichens ; shields open, without a nucleus, cavity filled with free spores.

Lichens are found in all quarters of the globe, adhering to stones, rocks, trees, etc. They derive much of their nourishment from the atmosphere. They have the power of acting on hard rocks, so as to disintegrate them; and many of them contain much inorganic matter in their composition. They all grow in the air ; none are found submersed. Genera, 60 ; species, 2400 . Examples-Urceolaria, Umbilicaria, Lecidea, Cladonia, Parmelia, Cetraria, Roccella, Evernia.

The Thallus of Lichens is composed of a filamentous tissue called hypha (i $\varphi \dot{n}$, a weaving), the filaments of which are usually colourless, and of green, yellow, blue, or brown cellules, called gonidia ( $\gamma^{\circ} v o s$, offspring), which vary as regards their character and situation. They contain either chlorophyll or a colouring matter called phycochrome ( $\varphi$ úxos, seaweed, $\chi \rho \tilde{\omega} \mu \alpha$, colour), which distinguishes an entire group of the lower algæ. The hypha forms the principal part of the thallus. It may be in a filamentous form, or it may be developed as fronds of considerable extent. Lichens are connected with Algæ on one hand by means of some of the Collemacere, and with Fungi on the other by the inferior genera of Pyrenocarpei. Of late a singular hypothesis has been brought forward by Schwendener to the effect that Lichens are not autonomous plants, but are composed of a true algal and a parasitic fungus. Each lichen is supposed to be an algal-type, which has become the host of a parasitic fungus growth; the Lichen-gonidia being algæ, and the Lichen-thallus (the hypha), a parasitic fungus. This theory is illustrated by Nostoc, an independent algal, which may either continue so, or it may become the host of a parasitic fungus, and by it be converted into a Collema, or what is usually called Lichen.* This view is not adopted by our best fungologists. (For a detailed account of the reproductive process in Lichens, see p. 268.)

Lichens furnish articles of food and important dyes. Cetraria - islandica, commonly called Iceland Moss, contains a nutritious matter called Lichenin, or Lichen-starch. There exists in it a bitter principle also, to which the name Cetrarin has been given. The plant is used as a demulcent and tonic, in the form of decoction or jelly. This Lichen occurs in northern regions, as Greenland, Iceland, Spitzbergen, and Scandinavia, on the mountains of Britain, and other parts of

* See a paper by Mr. Crombie, in Popular Scicnce Review, July 1874. See also Grevillea, 1873, and Ann. des Sc. Nat. 5 ser. xvii. 
Europe, also North America and the Antarctic regions. It is used as a tonic. By the action of sulphuric or hydrochloric acid on it, 72 per cent of grape sugar is procured. Cladonia rangiferina is a Lichen upon which the Reindeer feeds. Several species of Gyrophora constitute the Tripe de Roche, on which Franklin and his companions subsisted for some time. Many other Lichens, such as Sticta pulmonaria, Lung-wort or oak-lungs, and species of Lecanora, furnish articles of food. Roccella tinctoria from the Canaries, $R$. fuciformis, $R$. hypomecha, furnish valuable dyes, under the name of Orchil or Archil. The dye proeured from them, and from other Lichens, is called Litmus. Lecanora tartarea supplies the dye called Cudbear. Parmelia parietina contains a yellow colouring matter called Parietin or Chrysophanic acid. Some species of Variolaria contain a large quantity. of oxalate of lime. Some plants of the order are aromatic.

Order 222.-Fungr, the Mushroom Family. (Hysterophyta of Endlicher.) The plants belonging to this order consist of cells, sometimes round, sometimes elongated in the form of filaments, either placed closely together or separated. They are variable in their consistence, being soft or hard, fibrous or gelatinous, fleshy or leathery. They never contain green gonidia like Lichens, and they rarely grow in water. There exists a vegetative system called spawn or mycelium ( $\mu$ úrทs, fungus), formed of elongated, simple, or articulated filaments, concealed within the matrix, or expanded over its surface, from which varied forms of fructification proceed. The mycelium occurs in a filamentous, a membranous, a tubercular, or a pulpy form. The reproductive organs consist of spores or spherical cells (usually 4, or some multiple of 4 ), which are either attached to the cellular tissue, and supported often on simple or branched filamentous processes (figs.

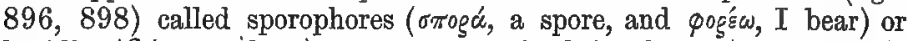
basidia ( $\beta$ áos, a base); or are contained in thecre (theca, a sac),

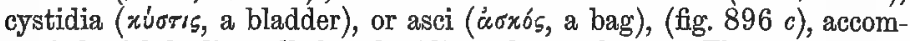
panied with bodies called antheridia and paraphyses. The sporophores sometimes end in delicate cells bearing the spores, and called sterigmata (orńgryuce, a support). In the Agarics or Mushrooms, which are among the best known fungi, there is observed first a roundish protuberance on the mycelium. This swelling is called the volva or wrapper, and it-gradually enlarges, containing in its interior what appears afterwards as the agaric, with its reproductive bodies. When the volva is ruptured, the fully-formed agaric is seen, consisting of an upper rounded portion called the pileus or cap (fig. $894 c c$ ), supported on a stalk or stipes (fig. $894 p$ ). On its under surface is situated the hymenium ( $i \mu n \dot{v}$, membrane), or the part where the spores are produced (fig. $894 h$ ), covered at first by a thin membrane called a veil (indusium or velum), which is ultimately ruptured; and when the rupture takes place at the edge of the pileus, an annulus or ring 
is left on the stipes (fig. $894 a a$ ). The hymenium, or the part on which the organs of reproduction are placed, consists in the agaric of cellular plates, lamellæ, or gills, radiating from the centre (fig. $894 h$ ). In other genera of Fungi (fig. 897) it consists of tubes or solid

Fig. 895.

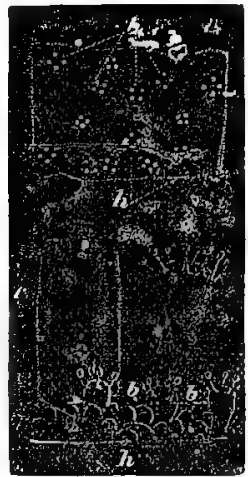

Fig. 896 .
Fig. 897 .
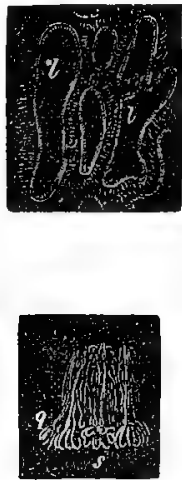

Fig. 898.

columns, or fleshy or gelatinous matter. Sometimes the hymenium is on the upper surface of the fungus.-Cellular plants, often growing on decaying organic matter, generally very fugacious, and presenting various colours. They are found in all parts of the world.

The following are the divisions usually recognised, as defined by Berkeley :-

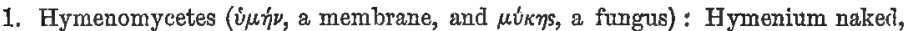
spores in sets of four (fig. $895 \mathrm{~b}$ ), and borne on distinct sporophores (figs. 894, 896), as seen in Mushrooms.

2. Gasteromycetes ( $\gamma a \sigma \tau \eta \dot{\rho}$, a.belly) : Hymenium enclosed in a membrane (peridium), spores as in section 1 (figs. 897, 898); as seen in Puff-balls.

3. Coniomycetes ( $k \delta v \iota s$, powder) : Flocci of the fruit obsolete or mere peduncles,

Figs. 894-898. Figures to illustrate the natural order Fungi. Fig. 894. A cluster of plants of Agaricus campestris, Mushroom in different stages of development. $p$, Stipe or stalk c c c, Pileus, hat or cap. v, Velum or indusium, which unites the pilous and stipe, and when ruptured forms the annulus or ring, $a_{a} a_{n^{*}} h$, Lamellæ or gills radiating from the centre on the under surface of the pileus, and bearing the hymenium or receptacle of the spores. Fig. 895. Hymenium seen from above, the spores, $b$, being scattered over it in sets of four (quaternary). Fig. 896. A small portion of the Hymenium much magnified and viewed laterally. $h$, Its tissue composed of cells. $b$, Basidia or sporophores bearing the spores; one of these is figured separately, bearing a large number of spores. $c$, Cystidia or thecr. Fig. 897. A small portion of the pileus of Clathrus cancellatus, in the form of a sort of network. The Hymenium covers its inner surface, and is seen following the contour of the lacunæ, $l l$, of the network. Fig. 898 . Hymenium much more highly magnified to show the particular form of the basidia, $b$. $s$, Spores. 
spores single, often partitioned, and on more or less distinct sporophores; as seen in the Rust and Bunt of Corn.

4. Hyphomycetes (iфáw, I weave) : Thallus floccose, spores naked, often septate; as in Gymnosporous Moulds, Mildews.

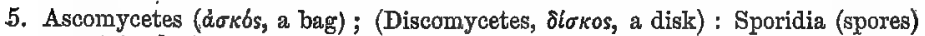
contained often in sets of eight in asci or tubes; as in Morels and Truffles.

6. Physomycetes ( $\phi \dot{\sigma} \sigma a$, a bladder): Thallus floccose, spores surrounded by a vesicular veil or sporangium; as in common bread-mould.

Under these sections Berkeley enumerates about 600 genera, including about 5000 species. Examples-Agaricus, Polyporus, Hydnum, Clavaria; Phallus, Geaster, Bovista, Craterium, Nidularia; Bactridium, Torula, Uredo, Aicidium ; Ceratium, Tubercularia, Botrytis, Penicillium; Helvella, Peziza, Tuber, Erysiphe, Onygena; Phycomyces, Mucor.

The plants of this order deserve attention, whether we regard their esculent or their poisonous qualities, or the destruction which they cause by their parasitic growth. In this country the chief species eaten are Agaricus campestris, the common Mushroom, Agaricus Georgii, Morchella esculenta, and other species of Morel, Tuber cibarium, and cestivum, Truffle. In foreign countries, as in France, Italy, Germany, and Russia, some Fungi are used as food, which have acted as poisons in this country. The process of cooking, as well as the climate, may have some effect in modifying their qualities. Agaricus procerus is eaten abroad; but a case of poisoning from it has been known to occur in Edinburgh. In Rome it is stated that the yearly average of taxed mushrooms, from 1837 to 1847 , was between 60,000 and 80,000 pounds weight. The finest mushroom is said to be the Agaricus Prunulus. Amanita muscaria is a poisonous species, which is used as a means of intoxication in Kamtschatka. It is said to give this property to the urine of those who eat it. It is not easy to distinguish between edible and poisonous Fungi. It has been said that the latter are often highly coloured, have scales or spots on their surface, tough watery flesh, and grow in clusters on wet ground, and often in the shade; while the former are seldom highly coloured, generally white or brownish, rarely show scales or spots, have brittle flesh, and grow solitary in dry pastures, not in the shade. The true field 'mushroom grows in pastures, has dark purple brown spores, has a perfect encircling clothy colour, and gills which do not touch the stem, and a top with an overlapping edge. Berkeley says that, as regards ordinary mushrooms, a good indication is the bright rosy tint of the gills, and the absence of any yellow stain when bruised. In some cases Fungi form a staple article of food. Darwin states that the inhabitants of Tierra del Fuego live upon a globular fungus of a bright yellow colour (Cyttaria Darwini $i$ ), found on the bark of the beech. Many species of Boletus are used as food in Western Aus- 
tralia, according to Drummond. Mylitta australis is known in Australia as Native Bread. Hygrophorus pratensis is the Herefordshire truffle. Fistulina hepatica is called Vegetable Beefsteak. Hirneola (Exidra) Auricula Juda, Jew's-ear, has been used as an astringent. Large quantities of Fungi are eaten by the Chinese under the name of Hiang-Kwan, and have some medicinal or dietetic properties assigned to them. The Polypori or Boleti are generally preferred by them to Agarics.*

Some Fungi are limited to certain kinds of decaying matter. Many species of Onygena are found only on the dung, feathers, and hoofs of particular animals. Peculiar species of Mycoderma are developed in vinegar, in yeast, and in flour. The rapidity with which Fungi sometimes grow is remarkable. Ward noticed Phallus impudicus shoot up three inches in the course of twenty-five minutes, and attain its full elevation of four inches in an hour and a half. Bovista gigantea, in a single night, has increased from the size of a pea to that of a melon. The force also with which they expand has been shown by their raising pavements under which they had been developed. Some 1 Fungi, as Agaricus oreades, coccinens, and personatus, are developed in a centrifugal manner, forming fairy rings. Certain species of Agaricus give out a sort of phosphorescent light. This has been remarked in Agaricus olearius, Agaricus Gurdneri, and some species of Agaric from the Swan River. A similar kind of light is produced by species of Rhizomorpha, which occur in coal-mines (p. 389). Polyporus fomentarius forms amadou, and it, as well as $P$. betulinus, have been made into razor-straps. Caps are also made from Amadou; and this material is used in Hungary for making waistcoats and for caulking boats. Pietra fungaia of Italy is a mass of earth bound together by fungus spawn.

The diseases caused by .Fungi are numerous (pp. 399-402). Blight, mildew, rust, and smut, are diseases of grain due to the attacks of Fungi. Dry-rot is owing to the presence of Merulius lacrymans and vastator, and Potyporus destructor, the mode of preventing which has been already alluded to (p. 401). The disease called ergot, which attacks Rye and other grasses, is produced by Claviceps purpurea. Oidium Tuckeri has caused much destruction in vineyards. The various moulds which occur on bread, cheese, preserves, and fruits, are plants of this extensive order. Penicillium glaucum is one of the most common moulds, occurring on organic substances, on books, etc. A species of Racodium is found in low cellars, as at the London docks. Some Fungi are produced on living animals. Thus, the disease called muscardine in the silkworm is produced by Botrytis Bassiana. Certain wasps in the West Indies are affected by a similar disease. A China. 
disease in silkworms caused by a fungus, Cladosporium (Pleospora) herbarum, is called gattine, being a corruption of catkin, from the appearance presented, in the same way as the name muscardine is given from the fancied resemblance to a little cake, or a kind of pastille, which the dead caterpillars resemble. Spharia sinensis, a celebrated Chinese drug, grows on a caterpillar; Sphoeria Robertsii is developed on the larva of Hepialus virescens in New Zealand; and Sphceria Taylori on an Australian caterpillar. Sphceria sobolifera, entomorhiza, militaris, and others, also grow on auimals. Particular kinds of mould sometimes grow on the mucous membrane of birds. Some mycodermatous Fungi are connected with certain cutaneous and other diseases in the human species. Thus, cellular filaments called Porrigophytes are found in the crusts of Porrigo favosa, Mentagraphytes in those of Mentagra or Sycosis menti, and Aphthaphytes in Aphtha. These are all forms of mould. The following analysis of Puff-balls (Lycoperdon giganteum) is given by Professor Church. Ash contains 46 per cent of Phosphoric acid" and 35 per cent of Potash. These elements exist in small quantities in the soil, but are largely accumulated in plants. It is therefore inferred that the Puff-ball receives its phosphorus and potash from the stores already accumulated in the higher plants. Fresh Puff-balls contain 90 per cent water, $5 \frac{1}{2}$ per cent albuminoids, 2 per cent cellulose, and about $\frac{1}{2}$ per cent ash. When the water is driven off, the nitrogenous elements (albuminoids) constitute 66 per cent of the residue. The spores of the Puff-ball, when swallowed in large quantities, have given rise to severe diarrhœa.

Order 223.-Characes, the Chara Family. Aquatic plants, with tubular jointed stems and verticillate branches. (fig. 244, p. 152); stem formed either by a single tube or by several parallel tubes surrounding a central one. Reproductive organs of two kinds (fig. 486, p. 274):-1. Antheridia of a rounded form called globules, sessile in the branches, consisting of 8 valves, which cover confervoid filaments, each joint of which contains a spermatozoid bearing 2 cilia (fig. 403, p. 234 ; fig. 487 , p. 274). 2. Oval nucules or axillary sporangia, formed by a large central cell (spore) with 5 elongated cells wound spirally round it, surmounted by a corona of 5 teeth. The nucules, after being fertilised by the globules, fall off and germinate, forming new plants. - The plants are found in all parts of the world, especially in temperate regions. Genus, 1 ; species about 40, of which 16 are British. Example-Chara (including Nitella).

The Charæ grow in stagnant water. Some have the stem encrusted with carbonate of lime, which renders them brittle. In the unencrusted Nitellas, the movement of rotation in the protoplasmic contents of the tubes is well seen (fig. 245, p. 152). Some of the calcareous Charas are used for polishing plate. The Charas have frequently a peculiarly fetid odour, especially when decaying, and their 
presence is said to give rise to malaria. Occasionally they communicate their odour to the water of reservoirs, and render it unpleasant. It is of importance for Water Companies to see that Charas do not exist in the streams which supply the water for their reservoirs.

Order 224.-ALG\&, or HYDrophyTA, the Seaweed Family. Cellular plants, found both in salt and in fresh water. Fronds composed of variously formed, often elongated, cells, which are either simple or branched filaments, continuous or articulated, separate, or combined in different ways (fig. 29), so as to constitute fronds of various kinds (fig. 899). Growth takes place by the division of cells, or by cellular prolongations, in the form of lateral branches. Reproductive organs consist of spores (figs. 467-470, p. 265), which are contained in mother-cells or perispores ( $\pi \varepsilon \rho\lrcorner$, around, and $\sigma \pi \circ \rho^{\alpha}$, seed),

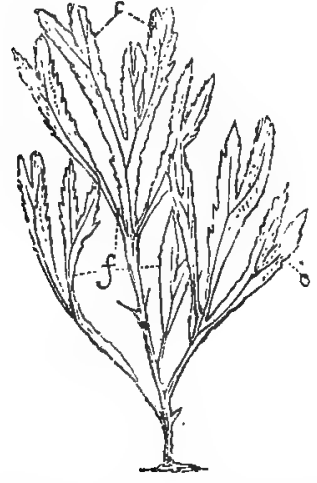

Fig. 899 .

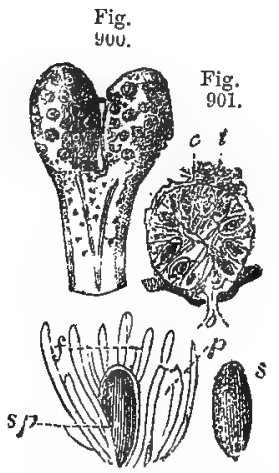

Fig. 902. Fig. 903.

or sporocarps ( $\alpha g_{\pi} o_{5}$, fruit). These are sometimes congregated together in receptacles of different sorts (figs. $899 c c, 900$ ). The spores occasionally divide into 3 or 4 cells, constituting tetraspores (rєrgás, four), (fig. 482, p. 273). In addition to spores or sporocarps (fig. $902 s p$ ), there are antheridia, consisting of minute cells, with spermatozoids in their interior. In some of the simplest Algæ, the whole plant is concerned in producing new individuals by division of

Figs. 899-903. Frond and organs of reproduction of Fucus serratus, to illustrate the natural order Algæ. Fig. 899. The entire plant much diminished in size. f, Frond composed of cells, so united as to form a flat expansion. $c c$, Conceptacles at the extremities of the frond, containing the organs of reproduction. Fig. 900. Extremity of the frond covered with conceptacles. Fig. 901. Vertical section of a conceptrcle, $v$, with its inner surface covered with spores (sporocarps), paraphyses, and antheridia. $t$, The superficial cellular tissue of the frond, in which the conceptacle is buried. o, Foramen by which the conceptacle opens externally. Fig. 902. Spore, $s p$, covered with its perispore or sporocarp, $p$. $f$, Filaments or paraphyses, by some called antheridia. Fig. 903. Spore, s, sep\&rated and deprived of its perispore or outer covering. 
the parent cells into 2 or 4 . In others there is a union of 2 filaments, and a passage of certain granular particles (endochrome) from the one to the other, ending in the formation of the spore. This process is termed conjugation, and is one of great interest. It has been observed in some of the Confervacece and Diatomacece. In certain cases the terminal cell of the filament is that in which a spore is formed without any conjugation, and in these cases the spore is frequently provided with ciliary processes, which exhibit for a time spontaneous movements (figs. $467-470$, p. 265) ; hence called zoospores. In the higher Algæ, the sporocarps containing 2, 4, or more reproductive cellules, are united together in conceptacles along with antheridia containing phytozoa or spermatozoids (figs. 901, 902), and archegonia, containing cells to be fertilised. The antheridia and archegonia are either on the same or on different plants.

In place of a single natural order, Algæ should be looked upon as an alliance of several orders. They have been divided as follows :-

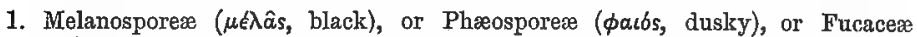
( $\phi \hat{v} \kappa o s$, a seaweed) : plants of an olive-green or olive-brown colour, and cellular or filamentous structure; growing in the sea (sea-wrack); cells often united by gelatinous matter (fig. 29, p. 8 ), and often forming a broad expansion (thallus) supported on a stalk; reproductive organs consisting of sporocarps and antheridia (fig. 484, p. 273), contained in conceptacles opening externally (fig. 483, p. 273 ; 901), which are united on club-shaped expansions or receptacles situated at the end, on margins of the fronds (figs. 899, 900). In germinating, the nucleus bursts the epispore or onter covering of the spore, and sends out filamentous processes. Spores dark coloured.

2. Rhodosporeæ ( $\dot{\phi} \delta \delta \nu^{2}$, the rose), or Choristosporei ( $\chi \omega \rho \omega \tau t \delta s$, separated), or Floridex (flos, a flower, from the fine colour) : rose or purple coloured seaweeds, with fronds formed of a single row of articulated cells, or of several rows of cells combined into a flat expansion ; reproductive organs of 2 kinds, moncecious or diocious; sporangia in the substance of the frond or in conceptacles; spores red or red-brown, rounded and often in fours (tetraspores); antheridia containing motionless antherozoids; a special tube called trichogynium ( $\theta \phi i \xi$, hair), passing from the antheridia to the sporangia, and thus effecting fertilisation (figs. 482, 485, p. 273).

3. Chlorosporea ( $\chi \lambda \omega \rho b$ s, green) : plants growing either in the sea, or in fresh water, or in damp situations ; filamentous or membranaceous, or shapeless ; usually of a grass-green colour; reproductive organs consisting of green moving spores furnished with cilia, or of spores fertilised by antherozoids (figs. 479,480, pp. 271, 272).

In the olive, red, and green Algæ, Sorby found at least 12 different colouring matters diștributed very differently, in such a manner as to connect, and yet to distinguish, the different groups very characteristically. (See Proc. R. Soc. Lond. 1873.)

4. Vaucherieæ (named after Vaucher) : green Algæ, with single filaments not septate, producing 2 kinds of reproductive cells, and ciliated spores, not the result of reproduction (fig. 478, p. 269).

5. Saprolegniex ( $\sigma \alpha \pi \rho \delta s$, putrid) (fig. 481, p. 273 ) : coloturless aquatic filamentous 
plants, growing on decaying organic matter, having moving zoospores, and sporangia, containing round oogonia (see p. 272).

6. Conjugatæ (so called from union of cells), or Synsporeae ( $\sigma \dot{w} w$, together) : fresh-water Algæ, with septate cellnIar tubes containing green matter, foften arranged in spirals, reproduction by union of the contents of 2 cells (fig. 471 , p. 266). It includes the sub-tribe Desmidieæ.

7. Diatomacer ( $\delta\llcorner\alpha$, through, or $\tau \epsilon \mu \nu \omega$, I cut, in allusion to the mode of division): inhabiting still waters and moist places; fronds consisting of frustula or fragments, which are either angular or cylindrical, siliceous and brittle, united by a gelatinous sort of substance; propagated by the division of parent cells into two halves, which become more or less completely detached, and form new individuals (fig. 472, p. 267). Conjugation also takes place in the same way as in the Conjugatæ.

Besides these tribes, there are others specially noted by authors as doubtful; among these are included Oscillatoriece:-aquatic plants with moniliform filaments, which have a wavy motion, propagating by selfdivision ; Nostochinea :-composed of moving filaments, immersed in a gelatinous matter; Palmellacece:-composed of more or less rounded cells in a gelatinous matrix, illustrated by the plant seen in Red-snow; Volvocinece, composed of numerous cells or zoospores, which move about in water. Authors enumerate 350 genera, including above 2500 species. Examples-Fucus, Sargassum, Laminaria, Padina, Ectocarpus; Ceramium, Delesseria, Rhodymenia, Chondrus; Ulva; Vaucheria; Saprolegnia; Conferva, Desmidium; Diatoma; Oscillatoria; Nostoc; Palmella, Protococcus; Volvox.

The plants of the order are widely distributed over the globe, being found in salt and fresh water, in moist places, as on damp rocks and stones, and the glass and pots of hothouses, and even in hot springs. Sometimes they present collectively the appearance of green slime. They derive nourishment chiefly from the medium in which they grow; and the root-like processes with which some of them are provided seem to be merely for the purpose of fixing them. Some of the species are very gigantic, others very minute, requiring the aid of the microscope for their detection. The lowest members of the order approach very nearly to the lowest tribes of animals, and it is difficult to draw a line of demarcation. Many species now considered vegetable, such as Corallina officinalis and many Diatomacea, are figured as animals by Ehrenberg. There are interesting movements connected with the cells of many Algæ, such as Oscillatoria and Nostoc. Some of the species found in the ocean have conspicuous stems, which sometimes present the appearance of zones in their interior (p. 75). Among the large-stemmed species may be noticed Durvillea utilis and Lessonia fuscescens. Scytosiphon (Chorda) Filum attains in the British seas a length of 30 or 40 feet, while Macrocystis pyrifera in the Pacific ocean reaches the length of 500 to 1500 feet. Some of the Laminarias of Britain have stalks of considerable size. Sar- 
gassum bacciferum, the Gulf-weed, is found floating in great quantities on each side of the equator in the Atlantic, Pacific, and Indian oceans. Protococcus nivalis and viridis occur in red and green snow. The red and green colours of certain lakes and seas are attributed to species of Trichodesmium and Sphcerozyga. According to Dr. Hooker, Diatomacece are found in countless numbers between the parallels of $60^{\circ}$ and $80^{\circ} \mathrm{S}$., where they give a colour to the sea, and also to the icebergs floating on it. The death of these bodies in the South Arctic ocean is producing a submarine deposit, consisting entirely of the siliceous particles which entered into the composition of these plants. Conferva crispa, called Water-flannel, forms beds of entangled filaments on the surface of water. Species of Tyndaridea also occur in thick green patches. Hydrodictyon utriculatum, Water-net, has the appearance of a green net, composed of filaments which enclose pentagonal and hexagonal spaces. Achlya prolifera, and other Saprolegnieæ, are developed occasionally on living animals, such as on the gills of the gold-fish and of trout, as well as on dead flies and other organic matter. Certain organisms have been detected in the human stomach which appear to belong to this order. One of these is called Sarcinula ventriculi by Goodsir, and was ejected by romiting in a case of pyrosis. It consists of square cells united together in sets of four, and propagating by division. It is probably an anomalous condition of a mould-fungus.

The plants of this order supply a quantity of gelatinous matter, and many of them are used for food. Kelp is obtained by the burning of Seaweeds, and iodine is procured from them. Spherococcus (Chondrus) crispus, Carrageen or Irish Moss, supplies a nutritious article of diet; so does S. lichenoides, Ceylon Moss. Rhodymenia palmata, Dulse, Alaria esculenta, Iridaca edulis, young plants of Laminaria digitata and saccharina, Tangle, as well as various species of Porphyra, Laver, and Ulva, Green Laver, are esculent. The edible swallows'nests of the East are said to be formed of a species of Galidium. Sphcerococcus cartilagineus, var. setaceus, is used in China as a substitute for these nests. Agar-agar is a seaweed of a similar kind. Nostoc edule is used in China as an article of food. The use of burnt seaweed, in cases of scrofulous swellings, has been superseded by the discovery of iodine, the active ingredient. Plocaria (Gigartina) Helminthocorton, under the name of Corsican Moss, was formerly used as a vermifuge. 
ADDITIONAL REMARKS on the FERTILISATION of GRAMINEA, in continuation of the statements at page $634:-$

Dr. Hermann Müller, in his work entitled "Die Befruchtung der Blumen durch Insekten," has the following remarks :-

"The whole family of Gramineæ consists of plants with very marked wind-flowers. I have repeatedly seen, however, a small dipterous fly, Melanostoma mellina $L$., occupied with its mouth on the anthers of different species (Anthoxanthum odoratum;'Poa annuck, Festuca pratensis), probably consuming pollen grains which had remained sticking in them. Many Graminem are protogynous. For example, Arithoxanthum odoratum, Alopecurus pratensis, Nardus stricta.

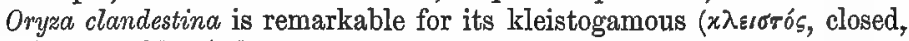

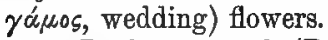

"In Secale cereale (Rye) the flowers have the anthers and stigmas matured simultaneously; they open widely, and allow both sexual organs freely to project. Cross-fertilisation can thus be effected. through the wind on the most extensive scale.

"In Triticum vulgare (Wheat) the flowers, the stamens, and stigmas are likewise simultaneously matured; they only half open themselves, and that for only a quarter of an hour, again hermetically to close. The opening takes place suddenly, with immediate and complete scattering of the pollen, about a third part of which goes into the same flower, and two-thirds are carried out by the emerging anthers. Cross-fertilisation by the wind can thus take place, only to a much more limited extent. Self-fertilisation, according to Delpino's experiments, produces good fruit. Since each flower remains open for only a quarter of an hour, while the blossoming lasts four days, only a very small number of the flowers are open at once.

"In Hordevm vulgare or hexastichum (6-rowed Barley or Bere) the flowers of the two middle rows never open; those of the four outer rows behaving in the same way as the flowers in Wheat.

"While the flowers in $H$. vulgare are all hermaphrodite, in $H$. distichum (2-rowed Barley) only those of the two middle rows are so, and remain closed and fertilise themselves. Among these, however, a few exceptionally occur with slightly open flowers, thus affording the chance of cross-fertilisation by the purely male flowers of the four marginal rows." 


\section{PART III.}

\section{GEOGRAPHICAL BOTANY, OR THE DISTRIBUTION OF PLANTS OVER THE GLOBE.}

IN this department of Botany we treat of the manner in which plants are affected by climate and station, and the mode in which they are distributed over the globe, and we endeavour to investigate the conditions under which particular families, or species of plants, are confined to certain zones of latitude and altitude. It is a subject of great interest, and one which cannot be prosecuted with success until the vegetation of the globe is more fully known. So long as there are vast tracts of continents unexplored by botanical travellers, the facts upon which Botanical Geography is founded must be imperfect.

\section{I.-Epirrheology, or the Influence of Various External Agents on Plants.}

It is a matter of common observation, that the localities and soils in which plants grow vary much. Thus, some species grow in the shade, while others thrive best in full exposure to light; some grow in mountainous or alpine districts, while others prefer the plains; some are found in dry, others in marshy places; some are submersed in lakes or in the sea; while others live on muddy banks, or on sandy shores. The plants growing on a granitic or micaceous soil differ frequently from those found on trap, limestone, or sandstone. It is equally well known that climate exercises a powerful influence on vegetation, modifying the Floras in different regions of the globe. Some plants are fitted to bear the rigour and duration of an arctic winter, with a moderate summer heat, others require the heat and light of the torrid zone; and between these two extremes there are all varieties of gradation. Thus vegetation extends over the whole globe, from one pole to the other-from the summit of the highest mountains to the bosom of the ocean. Notwithstanding this general diffusion of plant-life, there are a few spots in which it has not been detected, such as the hot sands of Africa, and some of the Antarctic Islands. Each zone may be said to have its own peculiar vegetable 
features, the number of species being found to increase as we approach the equator, and to decrease as we retire from it. Palms, Bananas, Tree Ferus, and Orchideous Epiphytes, are chiefly confined to the tropics ; Cruciferous and Umbelliferous plants are found in temperate regions; some Coniferous and Amentiferous plants flourish in more northern countries ; while Saxifrages and Lichens extend to the arctic regions. In warm regions are found those fruits which are so necessary for the well-being of the inhabitants; in temperate climates chiefly, occur the cereal grains for the food of man, and the green pastures for the nourishment of cattle; and in the arctic regions, the Lichen, on which the reindeer feeds, grows luxuriantly.

The number of known species of plants amounts to upwards of 100,000 , including about 10,000 genera. " The following is an estimate of the known species of plants on the globe at different dates:-

\begin{tabular}{|c|c|c|c|c|c|c|c|c|}
\hline Linnæus & & 1753 & & 5,323 & Phanerog. & 615 & Cryptog. & 5,938 \\
\hline Persc & $\ldots$ & 1807 & $\ldots$ & 19,949 & - & 6,000 & - & 25,949 \\
\hline Steude & $\ldots$ & 1824 & ... & 39,684 & - & 10,965 & - & 50,649 \\
\hline Steudel & $\ldots$ & 1841 & .. & 78,000 & - & 13,000 & - & 91,000 \\
\hline Steudel & $\ldots$ & 184 & .. & 80,000 & - & 15,000 & - & 95,000 \\
\hline
\end{tabular}
and species :-

In 1846, Lindley gave the following estimate of known genera

Thallogens

Acrogens

Rhizogens

Endogens

Dictyogens

Gymnogens

Exogens .

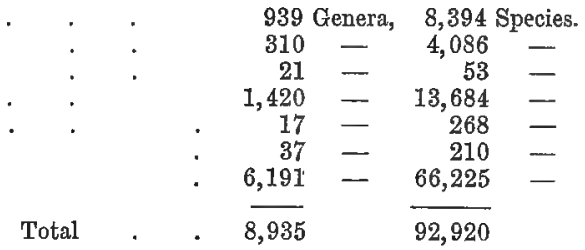

Much yet remains to be done in regard to the Floras of India, China, Africa, Australia, and South America. Meyen conjectures that the total vegetation of the globe may be about 200,000 species.

The distribution of species over different quarters of the globe is regulated by various external agents, the study of which is termed

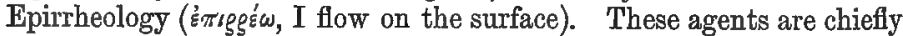
temperature and moisture, and the nature of the soil. The effects produced on plants by increase or decrease of light, and by changes in the state of the atmosphere, have not been sufficiently determined.

\section{1.-Empers of Temperature.}

The effects of this agent must be considered both as regards its latitudinal and its altitudinal ranges. In proceeding from the equator to the poles, or in ascending from the surface of the ocean to the summit of a lofty mountain, there is a gradual decrease of temperature, 
and, at the same time, marked changes in the nature of the vegetation. The scale of atmospherical temperature serves as a scale for the progress of vegetation. As regards the latitudinal distribution of heat, the globe has been divided into eight regions, four northern and four southern-viz., a tropical region, from the equator to the limits of the tropics in each hemisphere ; subtropical, between this and $40^{\circ}$ of latitude ; temperate, between $40^{\circ}$ and $60^{\circ}$ of latitude ; arctic and antarctic, beyond $60^{\circ}$ of latitude.

Each species of plant is adapted to thrive best between certain limits of temperature. These limits do not necessarily coincide with any definite parallels of latitude ; for it is well known that the climate of different places in the same latitude is very different. It is of importance, therefore, to ascertain the mean temperature of the year, but particularly of different seasons. By drawing lines through different places where the mean annual temperature is the same, Humboldt established a series of isothermal ("\%о tersecting the parallels of latitude. These lines run in curves, which rise in their course from the eastern coast of America towards western Europe, and sink towards the south in the interior of the continentand that so quickly, that Scotland lies in the same isothermal line as Poland, and England as Hungary. It is clear, therefore, that the isothermal lines in 'the higher latitudes do not, by any means, correspond with the parallels of latitude. At the equator, however, these lines coincide more nearly. Much depends upon the temperature of the different seasons. Thus, a place which has a very cold winter and a very warm summer, may be in the same isothermal line with one in which the temperature of both these seasons is moderate, and plants which succeed well in the one may not grow in the other. Cherry-laurels and other Evergreens, which grow well in the open air in England, will not stand the winter of places on the continent in the same isothermal line. It is necessary, in determining the geographical distribution of plants, to take into account the mean summer and the mean winter heat, and, better still, the mean monthly temperatures. The distribution of temperature among the different months of the year is of importance, especially in reference to the heat and duration of the summer months; for many plants protected by a covering of snow are enabled to bear rigorous winters, provided the summer be hot enough, and of sufficient duration. Lines passing through places having the same mean summer temperature are called isotheral (" 605 , equal, and $\theta_{z}^{\prime}$ gos, summer); those passing through places with an equal mean winter temperature, are isocheimal ( $\chi$ sinsco, wintercold). The isocheimal lines in the interior of continents bend considerably towards the south. In the interior of continents, the isotheral lines, though doubtless bending considerably to the north, follow more closely the parallels of latitude. Many circumstances 
conspire to influence the temperature of countries. Insular and coast climates are more equable, from the effect of the sea in preventing the atmosphere from being much heated during the day, and much cooled during night. In the interior of vast continents the extremes of temperature are often great. Winds have a powerful effect on climate. In China, the north-east monsoon brings great cold in February. The state of a country as regards forests has a decided effect on the temperature. In different quarters, the nature of the exposure also, whether to the east or west, north or south, and the intervention of elevated ranges of mountains, materially affect the temperature.

In determining the limits of distribution in the vegetable kingdom, we must know the mean monthly and the mean daily temperature during those periods when vegetation is active. We must ascertain the number of days which a plant requires to produce successively its leaves, flowers, and fruit, and we must estimate the mean temperature during that period. The conditions which define the limits of a plant require that we should know at what degree of temperature its vegetation begins and ends, and further, the sum of the mean temperatures during that time. Adanson first stated, that by adding the mean temperature of each day from the commencement of the year, it was found that when the sum reached a certain figure the same phenomena of vegetation were exhibited, such as leafing and flowering. 'Boussingault afterwards promulgated the statement, that if we multiply the number of days (the length of time the culture of a summer plant endures) by the mean temperature of this time, the product will be the same in all countries and in all years. Thus, if a plant, he says, has taken 20 days to ripen its seeds from the period of flowering, and the mean temperature during these 20 days has been $50^{\circ}$, it will be found that the heat received by the plant has been $1000^{\circ}$. The same sum may be given by a greater amount of heat during a smaller number of days. Lucas says that at Arnstadt, which is 897.4 French feet above the level of the sea, and has a mean temperature of $46^{\circ} .6 \mathrm{~F}$., winter Rye requires an average temperature of $48^{\circ} 1 \mathrm{~F}$. during 105 days, in all $5048^{\circ}$, to bring it into flower; from the flowering to the ripening 53 days, with a mean temperature of $63^{\circ} .4$, in all $3360^{\circ} \cdot 2$; altogether the duration of the vegetation of Rye amounts to 158 days, with a mean temperature of $53^{\circ}$, the sum of this being $8466^{\circ} .9$. Again, winter Wheat requires for flowering 129 days, with a mean temperature of $50^{\circ} 6$, in all $6527^{\circ} 4$; from flowering to ripening 53 days, with a mean temperature of $63^{\circ}$, in all $3339^{\circ}$. The total duration of the vegetation of Wheat is thus 182 days at Arnstadt, with a mean temperature of $54^{\circ}$, which makes a total of $9828^{\circ}$. Wheat requires a higher mean temperature than Rye to bring it into flower; it therefore blossoms on an average 24 days later, and consumes $6527^{\circ} 4$ of heat, while Rye only requires $5048^{\circ}$. From the flowering to the 
maturation, Wheat and Rye require nearly the same length of time and the same amount of heat. Boussingault's law has been somewhat modified by Alphonse De Candolle, who has pointed out many sources of error to be avoided. It is difficult to fix the time which is to be taken into account; the temperature of the soil requires to be attended to; low temperatures, and especially all below $32^{\circ}$, or perhaps $35^{\circ}$, which do not excite the phenomena of vegetable life, should be left out of the calculation; and the thermometric measurements should be made by observations on the plants themselves, and not merely on the air. By attention to these points, he thinks that useful and accurate conclusions may ultimately be arrived at relative to the temperature required for the performance of vegetable functions.

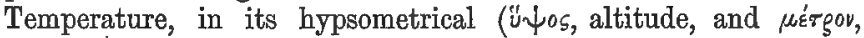
measure) rélation, or as regards its altitudinal range, requires to be considered. In ascending into the atmosphere, a decrease of temperature is observed, which varies in its amount at different stages of ascent. The following table shows the temperature at different heights in the equatorial and temperate zones-

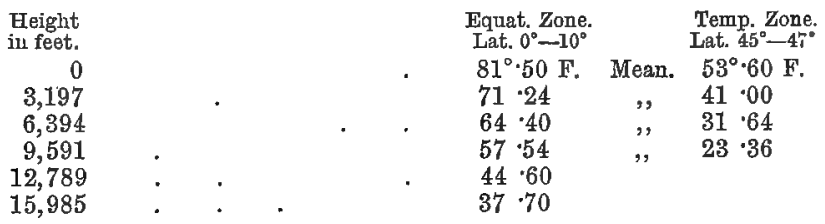

Taking an average, it may be said that there is a fall of $1^{\circ}$ in the thermometer for every 340 feet of ascent. Prof. Forbes states that 543 feet of ascent give a difference of $1^{\circ}$ of the thermometer in the boiling point of water. The elevation at which constant frost takes place is called the snow-line or line of perpetual congelation. Its limit does not exactly correspond with the height at which the temperature is equal to $32^{\circ} \mathrm{F}$. The following table, by Buchan, gives the height of the snow-line above the sea (in feet) at different latitudes :-

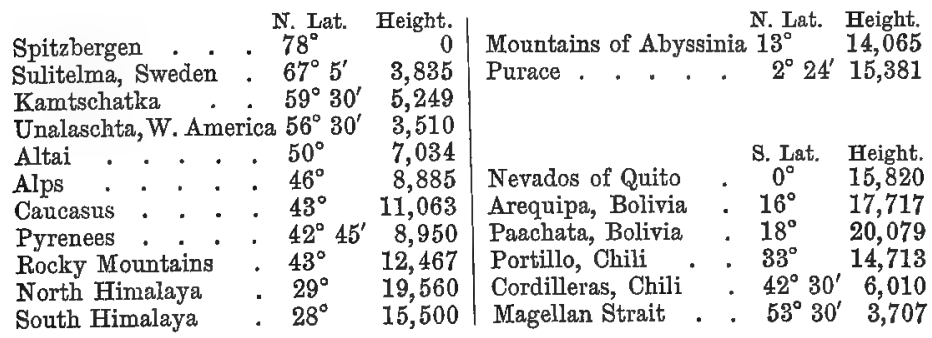

The decrease of temperature on ascending mountains regulates, in a 
great measure, the nature of the plants which grow at different heights. The same changes take place as have been shown to occur in proceeding from the equator to the poles. The following observations made on the growth of certain trees on the Grimsel, show the relation between height and latitude :-

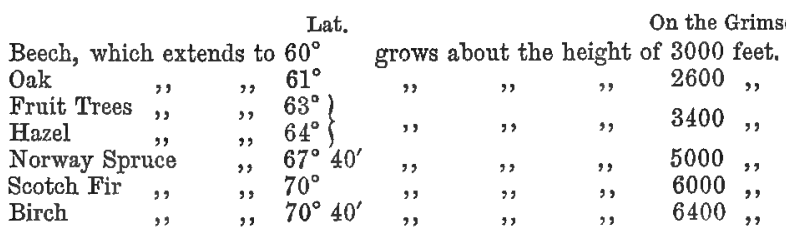

\section{2.-EFFECTS OF MoIstuRE.}

The absolute and relative quantity of moisture in the air has a decided effect on the distribution of plants. Nothing checks vegetation more than extreme dryness. Hence the barrenness of those hot sandy deserts which exhibit only an arid waste, without a single blade of grass to relieve the eye of the weary traveller. In warm and dry climates, succulent plants occur, with hard epidermal coverings, capable of resisting the effects of evaporation and transpiration. Among these may be noticed Cactaceæ, Mesembryaceæ, Euphorbias, and some of the Aloe tribe. In the districts of Australia, where a dry climate prevails, many plants, such as Proteas, Banksias, and leafless Acacias, have hard and dry foliage, capable of enduring much drought without injury. In warm climates the effect of the dry season on vegetation is very remarkable. This season may be said to correspond with our winters. In some parts of South America, where no rain falls for eight months of the year, the leaves during the dry season fall, buds are developed in their axils, and it is only when the wet season arrives that the trees become clothed with verdure, and the herbage appears. Forests appear to keep up the humidity of the atmosphere in a country, and thus have a powerful influence on the climate.

\section{3.-EFFECTS OF SOIL, LIGHT, AND OTHER AGENTS.}

The physical localities in which plants grow vary considerably. These variations are connected with the dryness and moisture of the soil, as well as with its mechanical and chemical composition. Some plants are fitted to grow in water, others in marshes; some grow in peaty soil, others in sandy soil. Thurmann has endeavoured to show that the nature of the soil, whether siliceous, clayey, calcareous, or saline, has an effect in modifying the vegetation. Prof. E. Forbes states that in Lycia he could easily distinguish the serpentine from 
the limestone, not merely by their geological characters, but also by the disposition of the arborescent vegetation. On the serpentine, usually pines only grew, and never in thick forest masses, but scattered; whereas the limestone bore thick clustered oaks and a luxuriant underwood, with now and then clumps of lofty pines. In the low countries near the sea, the serpentine was marked by Senecio squalidus, a little Erophila, and Cheilanthes odora; while on the limestone, Acrostichum lanuginosum was a conspicuous fern. Some of the rare alpine plants of Scotland grow on serpentine. A crumbling micaceous soil favours the growth of alpine species in Britain. Lichens seem to be often associated with special kinds of rocks.

Alphonse De Candolle has recently promulgated the following views in regard to the distribution of plants in connection with heat and moisture:-The present distribution of plants over the globe depends on two principal factors-1. The phenomena of distribution in other geological epochs than our own. 2. The physical condition, temperature, moisture, etc., now existing. The climate in any region now-a-days may be the same as that which prevailed elsewhere at a remote period. The vegetation of the Mediterranean region, as we now know it, once extended as far as Paris, and the present Arctic and Alpine floras were once spread over a large extent of Europe. The flora of the tropics once extended as far as London, as proved by the fossils of the tertiary epoch. De Candolle establishes five groups of plants according to their physical requirements.

1. Megatherms ( $\mu^{\prime} \dot{\varepsilon} \tilde{\alpha} \xi$, great, $\theta^{\prime} g \mu \eta \eta$, heat), plants requiring a large amount of heat and moisture. Megathermal plants at the present day exist in the tropics, in the plains, and in the hot damp valleys, as far as the 30 th parallel. Mean temperature never below $86^{\circ} \mathrm{F}$. , $^{*}$ and moisture never deficient. The fossil predecessors of existing Megatherms are much more widely diffused than their descendants. In a very early period they were distributed all over the globe, but since the commencement of the tertiary epoch they have been concentrated more and more in the equatorial regions. The species of this epoch vary in different regions of the globe. They consist mainly of woody plants and climbers, with persistent leaves. Epiphytes abundant in the forests. Such orders as Anonaceæ, Ternstrœiniaceæ, Guttiferæ, Aristolochiaceæ, and Piperaceæ, are amongst the most characteristic plants.

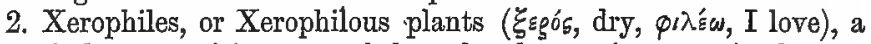
group of plants requiring as much heat, but less moisture. At the present day such plants thrive in the hot and dry regions between 20 th to 25 th and 30 th to 35 th degrees of latitude, i.e. in the dry regions extending from California and Texas to Mexico, from Senegal to Arabia and

\footnotetext{
* Not a few of the temperatures which follow, as given by De Candolle and Schouw, now require revision, and we hope that some meteorologist will soon adequately diseuss the subject from the most recent observations.
} 


\section{DISTRIBUTION AS AFFECTED BY MOISTURE AND HEAT.}

the Indies, in South Australia,"at the Cape of Good Hope, and the dry portions of La Plata, Chili, Peru, and the Andes. Xerophilous plants occur likewise in Brazil, the Mediterranean region, some parts of India, China, etc. At the present day they are more widely distributed than the Megatherms. In this group are included many Compositæ, Labiatæ, Boraginaceæ, Liliaceæ, Palms, Myrtles, Euphorbiacex, etc. The most characteristic orders are-Zygophyllacex, Cactaceæ, Mesembryanthemaceæ, Cycadaceæ, and Proteaceæ. Succulent plants abound-Cacti in America, Euphorbias in Africa, Mesembryanthemums at the Cape. The history of the fossil plants of these districts is very imperfectly known.

3. Mesotherms ( $\mu^{\prime} \varepsilon \sigma \delta \xi$ middle, and $\theta_{\varepsilon}^{\prime} g \mu \eta$, heat), requiring a moderate degree of heat (mean annual temperature $59^{\circ}$ to $68^{\circ} \mathrm{F}$.) with a moderate degree of moisture. This division includes the majority of Mediterranean plants, plants of Northern India at low elevations, plants of China, Japan, California, the Southern States of America, the Azores, and Madeira (including always the mountain plants of those districts), the plains of Chili, Tasmania, and New Zealand. Mesotherms are also met with on the lower slopes of tropical mountains. They include many plants with evergreen foliage, Laurels, Magnolias, Campanulas, Cistuses, many Leguminosæ, Compositæ, Cupuliferæ, Labiatæ, and Cruciferæ. Analogous forms existed in the early tertiary period in Spitzbergen and North America, while the floras of Japan and of the United States were probably nearly identical.

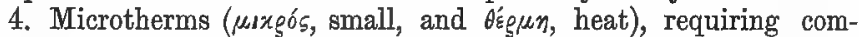
paratively little heat (mean annual temperature, $57^{\circ}$ to $32^{\circ} \mathrm{F}$.) Species of our European plains and of the Alps, those of Asia, between the Caucasus and the Himalayas, those of North America, $38^{\circ}$ and $40^{\circ}$ north, and between $60^{\circ}$ and $66^{\circ}$ of the Southern Hemisphere, plants of Chili, Cape Horn, Kerguelen Land, and the mountains of New Zealand. Herbaceous perennials abound, deciduous trees and conifers. The ground now covered by Microthermal plants was previously occupied by Mesotherms and Megatherms, which were extinguished by the glacial epoch.

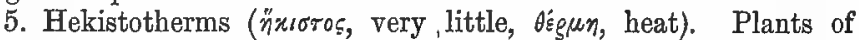
arctic and antaretic regions, and upper portions of mountainous or temperate regions. They can bear a continued period of darkness, either from being covered with snow, or from their nearness to the poles, where daylight is absent for many months. Mosses, Lichens, Coniferæ, Caryophyllaceæ, Rosaceæ, Saxifragaceæ, are well represented.

6. Megistotherms ( $\mu \varepsilon_{\varepsilon}^{\prime} \gamma \sigma \tau 05$, greatest, $\theta_{\varepsilon}^{\prime} \rho \mu \eta$, heat). Plants requiring an extreme degree of heat (more than $86^{\circ} \mathrm{F}$. mean annual temperature). This is not geographical. Algæ, Ferns, and Lycopods of the coal period may have been their representatives in former ages, as the Alge of hot springs are now-a-days. 
The following is a division of plants according to the botanical stations or physical localities in which they grow, whether placed there by nature or by art :-

$$
\text { A.-Plants growing in Water, whether Salt or Fresh. . }
$$

1. Marine plants, such as Seaweeds, Lavers, etc., which are either buried in the ocean, or float on its surface : also, such plants as Ruppia and Zostera, grasswrack. In the Sargasso Sea there are flouting meadows of Sargassum bacciferum, gulf-weed. This sea extends from $22^{\circ}$ to $36^{\circ}$ north lat, and from $25^{\circ}$ to $45^{\circ}$ west long. from Greenwich, and extends over 40,000 square miles.

2. Maritime or saline plants. These are plants which grow on the border of the sea, or of salt lakes, and require salt for nourishment, as Salicornia, glasswort, Salsola, saltwort, Anabasis. Such plants are often called Halophytes (ä $\lambda$, salt, and $\phi u т b \nu$, a plant). Under this head may be included littoral and shore plants, such as Armeria, sea-pink, Glaux, sea-millkwort, and Samolus, brookweed.

3. Aquatic plants, growing in fresh water, either stagnant or running; as Sagittaria, arrowhead, Nymphoed, water-lily, Potamogeton, pondweed, Subularia, awlwort, Utricularia, bladderwort, Stratiotes, water-soldier, Lemna, duckweed, Pistia, Confervoe, Oscillatorioe, and Ranunculus fuitans. Some of these root in the soil, and appear above the surface of the water" ; others root in the soil, and remain submersed, while a few swim freely on the surface without rooting below.

4. Amphibious plants, living in ground which is generally submerged, but occasionally dry, as Ranunculus aquatilis and sceleratus, Polygonum amphibium, Nasturtium amphibium. The form of the plants varies according to the degree of moisture. Some of these, as Limosella aquatica nudwort, grow in places which are inundated at certain periods of the year; others, such as Rhizophoras mangroves, and Avicennicus, form forests at the months of muddy rivers in tropical countries.

\section{B.-Land Plants which Root in the Earth and Grow in the Atmosphere.}

5. Sand plants; as Carex arenaria, Psamma arenaria, Elymus arenarius, and Calamagrostis arenaria, which tend to fix the loose sand, Plantago are naria, Herniaria glabra, Sedum acre, biting stonecrop.

6. Chalk plants; plants growing in calcareous and cretaceous soils, as some species of Ophrys, Orchis, and Cypripedium.

7. Meadow and pasture plants ; as some species of Lotus, bird's-foot trefoil, a great number of grasses and trefoils, the daisy, dandelion, and buttercups.

8. Plants found in cultivated ground. In this division are included many plants which have been introduced by man along with grain; as Centaurea Cyanus, corn blue-bottle, Sinapis arvensis, common wild mustard, Agrostemma, corn-cockle, several species of Veronica and Euphorbia, Lotium temulentum, Convolvulus arvensis, Cichorium Intyous; also plants growing in fallow ground, as Rumex Acetosella, Cardurs nutans, Echinum vulgare, Artemisia campestris, and Androsace septentrionalis. In this division garden weeds are included; such as Groundsel, Chickweed, Lamium amplexicaule, Chenopodium album, and urbicum.

9. Rock or wall plants ; Saxifrages Wall-flower, Linaria Cymbalaria, Draba muralis, species of Hieracium and Sedum, Asplenium Ruta muraria, and some lichens and mosses.

10. Plants found on rubbish heaps, especially connected with old buildings. Some of these seem to select the habitations of man and animals on account of certain nitrogenous and inorganic matters which enter into their composition. 
Among them may be noticed, Nettles, Docks, Borage, Henbane, Xanthium. Here, also, have been placed some plants immediately connected with the habitation of man, such as Racodium cellare, a fungus found on wine casks. Some plants, as Sempervivum tectorum, select the roofs of houses.

11. Plants growing in vegetable mould; such as bog-plants, or those growing on wet soil, so soft that it yields to the foot, but rises again ; and marsh plants, growing in wet soil, which sinles under the foot and does not rise. To the former class belong such plants as Pinguicula alpina and Primula farinosa; to the latter, such as Menyanthes, bogbean, Comarum, Bidens cernuca.

12. Forest plants, including trees which live in society, as the Oak, the Beech, Firs, etc., and the plants which grow under their shelter, as the greater part of the European Orchises, some species of Carex and Orobanche. Some plants especially grow in pine and fir woods, as Linnoea borealis, and some Pyrolas.

13. Plants of sterile places, found in barren tracts, by roadsides. This is a heterogeneous class, and contains many plants of uncertain characters. Under it are included the plants of uncultivated grounds, as those found in moors, where Calluna vulgaris, common heather, and various heaths, Juniper, Andromeda, and some species of Polytrichum occur.

14. Plants of the thickets or hedges, comprehending the small shrubs which constitute the hedge or thiclzet, as the Hawthorn and Sweet-brier; and the herbaceous plants which grow at the foot of these shrubs, as $A$ doxa, Wood-sorrel, Violets; and those which climb among their numerous branches, as Bryony, Black Bryony, Honeysuckle, Traveller's Joy, and some species of Lathyrus.

15. Plants of the mountains, which De Candolle proposes to divide into two sections : 1. Those which grow in alpine mountains, the summits of which are covered with perpetual snow, and where, during the heat of summer, there is a continued and abundant flow of moisture, as numerous Saxifrages, Gentians, Primroses, and Rhododendrons. 2. Those inhabiting mountains on which the snow disappears during summer, as several species of Snap-dragon, among others the Alpine Snap-dragon, Umbelliferous plants, chiefly belonging to the genus Seseli, meadow Sazifrage, Jabiate plants, etc.

\section{C.-Plants Growing in Special Localities.}

16. Parasitic plants, which derive their nourishment from other vegetables, and which, consequently, may be found in all the preceding situations; as the Mistleto, species of Orobanche, Cuscuta (Dodder), Loranthus, Rafflesia, and numerous Fungi.

17. Pseudo-parasitic plants, or Epiphytes, which live upon dead regetables, as Lichens, Mosses, etc., or upon the bark of living vegetables, but do not derive much nourishment from them, as Epidendrum, Aerides, and other Orchids, as well as Tillandsia, Bromelia, Pothos, and other air-plants.

18. Subterranean plants, or those which live under ground, or in mines and caves, almost entirely excluded from the light, as Byssus, Tuber cibarium; Trufles, and some other Cryptogamic plants.

19. Plants which vegetate in thot springs, the temperature of which ranges from $80^{\circ}$ to $150^{\circ}$ of Fahrenheit's thermometer; as Vitex Agnus-castus, and several Cryptogamous plants, as UTva thermalis, the hot-spring Laver.

20. Plants which are developed in artificial infusions or liquors, as various kinds of Mucor, causing mouldiness.

21. Plants growing on living animals ; as species of Sphceria and Sarcinula and various other Fungi and Algæ.

22. Plants growing on certain kinds of decaying animal matter; such as species of Onygena, found on the hoofs of horses, feathers of birds, etc., some species of Fungi, which grow only on the dung of animals, and certain species of Splachnum. 
Light is an agent that has a powerful influence on plants, as regards their vigour, irritability, secretions, and colour. Hence, in those regions where the light is intense, the vegetation presents certain peculiarities. The luxuriance and greenness of the leaves, the nature of the woody matter deposited, of the fruit produced, and of the secretions formed, are all influenced in some degree by the intensity of the sun's rays. Little is known in regard to the effects of increased or diminished atmospheric pressure on plants. Humboldt believed that vegetation was influenced by the amount of atmospheric pressure. Further research has not corroborated his suppositions. The effects of the atmosphere have been studied chiefly as regards dryness and moisture, and the mixture of certain gases with it, especially in the vicinity of manufacturing towns (page 159).

The effects of climate and season on the leafing, flowering, and fruiting of plants, may be seen in the case of some species which are found distributed over various countries in Europe. Berghaus has made an extensive series of observations on the subject. The Lilac (Syringa vulgaris), according to him, unfolds its leaves at Naples, in latitude $41^{\circ}$, during the first half of the month of January; near Paris, in latitude $49^{\circ}$, on the 12 th March. The Elder unfolds its leaves

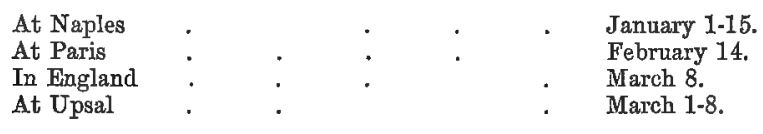

The Beech unfolds its leaves

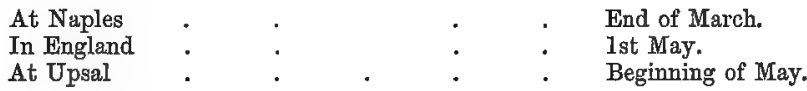

In regard to flowering, Berghaus states that in the middle latitudes of Europe and North America, it is generally four days later for each degree of latitude towards the north. The same plants flower at Zurich 6 days later than at Parma; at Tübingen, 13 days later; at Jena, 17 ; at Berlin, 25 ; at Hamburgh, 33 ; at Greifswald, 36 ; and at Christiania, no less than 52 days later than at Parma. In the Berlin district, an elevation of 1000 feet renders vegetation 10 to 14 days later: so also in regard to fruiting. The wheat harvest begins

At Naples

In Central Germany

In the South of England.

Ripe Cherries are to be had

At Naples

At Paris .

In Central Germany

In the South of England
In June.

July.

August.
First days of May.

End of June.

Do.

22d July. 


\section{II.-Dissemination of Plants.}

\section{1.-Agents miploted in their Dissemination.}

Some plants are disseminated generally over the globe, while others are confined within narrow limits. De Candolle says that no phanerogamous plant is a cosmopolite in an absolute sense. Some extend over more than one-third of the earth's surface, but none appear to compass the whole earth. 'Some of the common weeds in Britain, such as Chickweed, Shepherd's-purse, and Groundsel, are found at the southern extremity of South America. Lemna minor and trisulca, 'Convolvulus sepium, Phragmites communis, Cladium Mariscus, Scirpus lacustris, Juncus effusus, and Solanum nigrum, are stated by Meyen to be common to Great Britain and Australia. Nasturtium officinale, and Samolus Valerandi, are very extensively diffused, and they may be almost reckoned cosmopolites. They are both natives of Europe, and they occur, the former near Rio Janeiro, the latter at St. Vincent. Trisetum subspicatum is a grass having a range from Tierra del Fuego to Greenland; Drimys Winteri, Winter's. bark, extends in South America over 5000 geographical miles. Many European plants are found in the antarctic regions. Potentilla anserina, Epilobium tetragonum, Oxalis corniculata, Hymenophyllum Wilsoni, Galium Aparine, Urtica dioica, Chenopodium album, and Cynodon Dactylon, are very widely distributed. The lower the degree of development the greater seems to be the range. Some Cryptogamic plants, as Lecanora subfusca, are found all over the world. Man has been instrumental in diffusing widely culinary vegetables, such as the potato and the cereal grains, as well as many other plants useful for food and manufacture. Corn plants, such as Barley, Oats, Rye, Wheat, Spelt, Rice, Maize, and Millet, are so generally cultivated over the globe that almost all trace is lost of their native country. They can arrive at perfection in a great variety of circumstances, and they have thus probably a wider geographical range than any other kind of plant. As regards these plants, the globe may be divided into five regions-the region of Rice, which may be said to support the greatest number of the human race; the region of Maize; of Wheat; of Rye; and lastly, of Barley and Oats. The first three are the most extensive, and Maize has the greatest range of temperature. The grains extending farthest north in Europe are Barley and Oats. Rye is the next, and is the prevailing grain in Sweden and Norway, and all the lands bordering on the Baltic, the north of Germany, and part of Siberia. Wheat follows 
Rye; it is cultivated in the middle and south of France, England, part of Scotland, part of Germany, Hungary, Crimea, and the Caucasus. We next come to a district where wheat still abounds, but no longer exclusively furnishes bread,--rice and maize becoming frequent. To this zone belong Portugal, Spain, part of France, Italy and Greece, Persia, Northern India, Arabia, Egypt, the Canary Islands, etc. Wheat can be reared wherever the mean temperature of the summer, for a period of at least three or four months, is above $55^{\circ}$. It succeeds best on the limits of the sub-tropical region. In the Scandinavian Peninsula the cultivation of Bere extends to $70^{\circ}$ north latitude, Rye to $67^{\circ}$, and Oats to $65^{\circ}$. The cultivation of Rice prevails in Eastern and Southern Asia, and it is a common article of subsistence in various countries bordering on the Mediterranean. Maize succeeds best in the hottest and dampest parts of tropical climates. It may be reared as far as $40^{\circ}$ north and south latitude on the American continent on the western side, while in Europe it can grow even to $50^{\circ}$ or $52^{\circ}$ of latitude. It is now cultivated in all regions in the tropical and temperate zones, which are colonised by Europeans. Millet of different kinds is met with in the hottest parts of Africa, in the south of Europe, in Asia Minor, and in the East Indies. Henslow gives the following table to show the range of Wheat and Barley (Bere), and the mean temperature required for them :-

\begin{tabular}{|c|c|c|c|c|c|c|c|c|}
\hline Lat. & & & $\begin{array}{l}\text { Winter } \\
\text { Mean. }\end{array}$ & & $\begin{array}{l}\text { Summe } \\
\text { Mean. }\end{array}$ & & $\begin{array}{l}\text { Annual } \\
\text { Mean. }\end{array}$ & \\
\hline $\begin{array}{l}62 \frac{1}{2} \\
70 \\
67 \frac{1}{2} \\
57 \frac{1}{2}\end{array}$ & $\begin{array}{l}\text { Feroe } \\
\text { Lapland : } \\
\text { Russia } \\
\text { Siberia }\end{array}$ & - & $\begin{array}{r}39^{\circ} \\
22 \\
9 \\
0\end{array}$ & $\dot{*}$ & $\begin{array}{l}. \quad 51^{\circ} \\
. \quad 46 \\
. \quad 46 \\
. \quad 60\end{array}$ & $\dot{.}$ & $\left.\begin{array}{ll}. & 45^{\circ} \\
. & 33 \\
. & 32 \\
\cdot & 32\end{array}\right\}$ & $\begin{array}{l}\text { Barley (includ- } \\
\text { ing Bere ?) }\end{array}$ \\
\hline $\begin{array}{l}58 \\
64 \\
62 \\
60 \frac{1}{2}\end{array}$ & $\begin{array}{l}\text { Scotland } \\
\text { Norway : } \\
\text { Sweden : } \\
\text { Russia }\end{array}$ & • & $\begin{array}{l}36 \\
23 \\
23 \\
15\end{array}$ & . & $\begin{array}{r}57 \\
. \quad 59 \\
59 \\
. \quad 60\end{array}$ & & $\begin{array}{r}46 \\
\cdot \quad 39 \\
39 \\
. \quad 37\end{array}$ & \\
\hline $\begin{array}{l}30 \\
22 \\
22 \\
23 \\
21\end{array}$ & $\begin{array}{l}\text { Cairo } \\
\text { Macao } \\
\text { Rio Janeiro } \\
\text { Havanna } \\
\text { Bourbon }\end{array}$ & • & $\begin{array}{l}57 \\
64 \\
68 \\
71 \\
71\end{array}$ & * & $\begin{array}{r}. \quad 88 \\
\cdot \quad 82 \\
. \quad 78 \\
82 \\
. \quad 80\end{array}$ & - & $\begin{array}{r}72 \\
73 \\
\cdot \quad 74 \\
\cdot \quad 77 \\
77\end{array}$ & heat. \\
\hline
\end{tabular}

Winds, water, and animals are also instrumental in disseminating plants. Many seeds and fruits with winged and feathery appendages are easily wafted about; others are carried by rivers and streams, and some can be transported by the ocean currents to a great distance, with their germinating powers unimpaired. 


\section{2.-General and Endemic Distribution of Plants.}

While some plants are generally diffused, it is found that the different quarters of the globe are each characterised by more or less distinct floras. Europe, Asia, Africa, North America, South America, and Australia, may be regarded as separate provinces of the vegetable kingdom, possessing species, genera, and families of plants, which give to each division its distinctive features. Humboldt and Bonpland, in their travels in equinoctial America, did not see an exogenous plant which was found equally in the New and the Old World; the only plants which they discovered common to both being some grasses and sedges. Among 4160 species met with in New Holland by Brown, 166 only were to be found in Europe.

Some plants live in society, occupying exclusively large tracts of ground, from which they banish all other vegetables. These are called by Humboldt Social plants. They give a peculiar feature to the countries and districts in which they grow. To this class belong many species of Seaweed in the ocean; Cladonias and Mosses in the waste levels of Northern Asia; Grasses (Bamboos), and some Cactuses, Mangroves, and Avicennias in tropical countries; Ferns in the South Sea Islands; Banksia speciosa in Australia; Cinchonas in certain parts of South America; Coniferous trees and Birches in the Baltic and Siberian plains.

Some plants are very much restricted in their distribution over the globe; a few are confined to single localities, while others have a limited latitudinal range. The species of the genus Erica, Heath, which extend from northern regions to the Cape of Good Hope, are scattered over a surface very narrow compared to its length; in other words, while their latitudinal range is great, their longitudinal range is very much restricted. Calceolarias occur chiefly on the western side of the Cordilleras of Ohili. Lobelia Dortmanna is found principally in the western countries of Europe. Camellias are also limited in longitudinal direction, so also Phalangium bicolor and 'Raymondia pyrenaica. Arbutus Unedo, Erica mediterranea, and Dabeocia polifolia, whose chief seat is in the Pyrenees and the mountains of Asturias, migrate in a north-westerly direction, and appear in Ireland. It is said that Azaleas, Rhododendrons, Magnolias, Vacciniums, Actæas, and Oaks, which form prevailing genera on the east of the Rocky Mountains, scarcely appear on the western side. Epacridacer are confined to Australia; Cinnamon, Cloves, and Nutmeg, are the produce of the Indian Archipelago; Gentians and Saxifrages form a characteristic feature of the European Alps; Bejarias and Cinchonas of the Peruvian Cordilleras ; Schizanthuses of Chili ; Polemoniaceæ of California and Oregon; yellow and brown Papilionaceæ of Australia; 
Dionæa muscipula is limited to a small area in Carolina; Cephalotus follicularis is found in the bogs near King George's Sound, Australia ; Lodoicea Seychellarum is found only in the rocky islets of Seychelles; Disa grandiflora is a rare orchid peculiar to Table Mountain at the Cape of Good Hope ; Pringlea antiscorbutica is peculiar to Kerguelen's Land, and a few other antarctic islands; and Phyliea arborea is peculiar to the Tristan d'Acunha group of islands. It is said that Origanum Tournefortii is found only in a small island in the Grecian Archipelago. The vegetation of islands removed from continents presents often peculiar features, the ocean acting as a barrier to the dissemination of plants. The island of St. Helena was originally inhabited by a most peculiar vegetation, although its productions now are completely changed by the destruction occasioned by goats, and by the introduction of European and other plants, especially fruit trees. Such may also be said of the plants found in the Sandwich Islands, the Society Islands, and the Canaries. The island of Madeira has 672 Phanerogamous plants, of which 85 are peculiar to it.

\section{3.-Conjectures as to the Mode in which the EARTh was originallt Clothed with Plants.}

It is an interesting question to determine the mode in which the various species and tribes of plants were originally scattered over the globe. Various hypotheses have been advanced on the subject. Linnæus entertained the opinion that there was at first only one primitive centre of vegetation, from which plants were distributed over the globe. Some, avoiding all discussions and difficulties, suppose that plants were produced at first in the localities where they are now seen vegetating. Others think that each species of plant originated in, and was diffused from, a single primitive centre, and that there were numerous such centres situated in different parts of the world, each centre being the seat of a particular number of species; they thus admit great vegetable migrations, similar to those of the human races. Those who adopt the latter view, recognise in the distribution of plants some of the last revolutions of our planet, and the action of numerous and varied forces which impede or favour the dissemination of vegetables at the present day. They endeavour to ascertain the primitive floras of countries, and to trace the regetable migrations which have taken place. Daubeny says that analogy favours the supposition that each species of plant was originally formed in some particular locality, whence it spread itself gradually over a certain area, rather than that the earth was at once, by the fiat of the Almighty, covered with vegetation in the manner we at present behold it. The human race arose from a single pair, and the distribution of plants and animals over a certain definite area would 
seem to imply that the same was the general law. Analogy would lead us to believe that the extension of species over the earth originally took place on the same plan on which it is"conducted at present when a new island starts up in the midst of the ocean, produced either by a coral reef or a volcano. In these cases the whole surface is not at once overspread with plants, but a gradual progress of vegetation is traced from the accidental introduction of a single seed, perhaps of each species, wafted by winds, or floated by the currents. The remarkable limitation of certain species to single spots on the globe seems to favour the supposition of specific centres. Professor E. Forbes says, the hypothesis of the descent of all the individuals of a species, either from a first pair or from a single individual, and the consequent theory of specific centres being assumed, the isolation of assemblages of individuals from their centres, and the existence of endemic or very local plants, remain to be accounted for. Natural transport, the agency of the sea; rivers, and winds, and carriage by animals, or through the agency of man, are insufficient means in the majority of cases. It is usual to say that the presence of many plants is determined by soil or climate, as the case may be; but if such plants be found in areas disconnected from their centres by considerable intervals, some other cause than the mere influence of soil or climate must be sought to account for their presence. This cause he proposes to seek in an ancient connection of the outposts or isolated areas with the original centres, and the subsequent isolation of the former through geological changes and events, especially those dependent on the elevation and depression of land. Selecting the flora of the British Islands for a first illustration of this view, Professor Forbes calls attention to the fact, well known to botanists, of certain species of flowering plants being found indigenous in portions of that area, at a great distance from the nearest assemblages of individuals of the same species in countries beyond it. Thus, many plants peculiar in the British flora to the west of Ireland, have the nearest portion of their specific centres in the north-west of Spain; others confined with us to the south-west promontory of England, are, beyond our shores, found in the Channel Isles and the opposite coast of France ; the vegetation of the south-east of England is that of the opposite part of the continent; and the Alpine vegetation of Wales and the Scotch Highlands is intimately related to that of the Norwegian Alps. The great mass of the British flora has its most intimate relations with that of Germany. He believes, therefore, that these isolated outposts were formerly connected together by chains of land, and that they have been separated by certain geological convulsions. Islands may be considered as the remains of mountain chains, part of the flora of which they still exhibit, and the farther they are from continents the more likely are the plants to be peculiar. 


\section{In speaking of the floras of comparatively small (and usually volcanic)} islands in the midst of the ocean, and at a distance from continents, Dr. Hooker remarks :- " They are rich in Ferns, Mosses, and other flowerless plants, and they possess many evergreen, but comparatively few herbaceous plants, and fewer or no indigenous annuals. Plants which are herbs on continents often either themselves become shrubby on islets, or are represented by allied species that are shrubby or arborescent. Species are few in proportion to genera, and genera in proportion to orders. The mountains, however lofty, present few alpine or sub-alpine species ; and the total number of species is usually small compared with what continental areas of equal size and similar conditions contain. The floras of islands all display an affinity with one another, or with certain continents ; as is shown by Madeira, the Azores, and Canaries, containing many plants in common that are not found on any continent; by the Canarian flora being in the main a Mediterranean one; the St. Helena being an African, and so on." The conclusions he comes to are as follows :-

1. The Flora of no oceanic island is an independent one; in all cases it is quite manifestly closely allied to some one continental Flora, and however distant it may be from the mother continent, and however much it may approximate to another continent, it never presents more than faint traces of the vegetation of such other continent. Thus the Azores, though 1000 miles nearer to America than Madeira is, has not even so many American types as Madeira has. St. Helena, though 1000 miles nearer to South America than is any part of the African coast, contains scarcely any plants that are even characteristic of America ; and Kerguelen's Land, though far more distant from Tiema del Fuego than it is from Africa, Australia, or New Zealand, is almost purely Fuegian in its Flora.

2. The Floras of all these islands are of a more temperate character than those of the mother continents in the same latitude; thus, Madeira and the Canaries have a Mediterranean Flora, though they are respectively $5^{\circ}$ and $10^{\circ}$ south of the principal parallel of the Mediterranean region; the affinities of the St. Helena Flora are strongly South African; and the Flora of Kerguelen's Land, in lat. $48^{\circ}$, is what we might expect to meet with in Fuegia, were the American continent produced southward to lat. $60^{\circ}$.

3. All contain many and great peculiarities, distinguishing them from the continental Floras ; and these admit of the following classification :-

a. Plants peculiar to the islands and betraying no affinity with those of the mother continent, as the Laurels, etc., of Madeira and the Canaries and Azores; the arborescent Compositæ of St. Helena, and the Kerguelen's Land Cabbage.

$\beta$. They contain certain genera that are very different from those of the mother continent, but are evidently allied to them; and others but slightly different. They contain species that are very different from, but allied to, those of the mother continent; and others that are but slightly different from continental; and they contain varieties in the same categories.

4. As a general rule, the species of the mother continent are proportionally the most abundant, and cover the greatest surface on the isiands. The peculiar species are rarer, the peculiar genera of continental affinity are rarer still ; whilst. the plants having no affinity with those of the mother continent are often very common, in the temperate islands especially - at least under the conditions which the island vegetation now presents. 
5. Indigenous annual plants are extremely rare or absent; but recently introduced annuals are very abundant in those islets that have been frequented by man.

The hypotheses advanced to account for the stocking of an oceanic island with plants from a continent are the transport of seeds by currents, winds, or animal agencies, or that these islands in bygone ages formed a part of the eontinent from which they have now been severed. Hooker looks upon the floras as the remains of plants of an old geological epoch, the congeners of which are seen in the tertiary fossil flora. We have seen that Edward Forbes adopted this view of continental extension and subsequent separation of insular portions. Hooker favours the view of trans-oceanic migration, coupled with Darwin's theory of the derivative origin of species. By this means he accounts for many continental species and genera being represented on an island by similar but not identical species and genera; for the graduated series of forms extending from variety to genus; for the absence of whole tribes from the islands; for the limited floras and the fewness of the species in proportion to the genera.

Important changes have taken place in the Floras of islands by the agency of man. Thus St. Helena, according to Burchell, had 45 indigenous species, of which 40 were peculiar to the island. Now all is changed. The island, when discovered 360 years ago, was wooded. The introduction of goats in 1513 destroyed the vegetation. In 1709 the native ebony (Melhania melanoxylon) still existed, and was used to burn lime. It is now extinct. Plants introduced by General Beatson from Europe, Africa, and Australia, now thrive well. The original native vegetation had its affinity with the Flora of South Africa.

The regions of the globe, as regards their vegetable productions, are related either in the orders, the genera, or the species of plants which they produce. By Orders (Hinds remarks) the most distant or general resemblances are established, constituting analogy. One family may occupy the place of another in certain regions. Thus, the Mesenbryaceæ of South Africa are represented in America by Cactaceæ; and in the south of Europe only by a few species of Sempervivum and Sedum. The Ericaceæ of the Cape are represented in Australia by Epacridaceæ. By Genera, a closer approximation is establishedthat of affnity. The Cistuses of Spain and Portugal are represented by the Helianthemum of the north of Europe; and the genera of Abies and Pinus, in arctic and temperate regions, have their representatives in the genera Arancaria, Ephedra, and Dammara of the south. By Species, the most perfect accordance of characters is established.

Meyen states that the species of a genus, and genera, and natural orders, proceed from a point, and range themselves round it in concentric circles, or spread out from it like rays in all directions; or are 
distributed in belts of greater or less breadth, which are parallel to the meridians, or to the parallels of latitude. A genus or family predominates in certain regions; and attains its maximum there, while in others it is at its minimum. Hence, regions are distinguished by the names of plants which attain their maximum there. Palmæ, Musaceæ, Piperaceæ, and Scitamineæ, attain their maximum in the torrid zone, although representatives of them extend to high latitudes, or to the temperate zone. Thus, the Palm called Chamærops humilis is found in $49^{\circ}$ north latitude. The Ericaceæ of the old world have their inaximum in the south of Africa. A single form, Calluna vulgaris, common Heather, is predominant in the north; and a shrubby species, Erica arborea, represents the order in the south of Europe. Acacias attain their maximum in Australia, while Acacia heterophylla represents the family in the Sandwich Islands. The Lauraceæ of the tropics have Laurus nobilis as their representative in Europe. The Myrtaceæ of the tropics are represented in Europe by Myrtus communis. As regards species, Trientalis europæa has a representative form in America, T. americana; Cornus suecica occurs in Europe, O. canadensis in Canada; Empetrum nigrum, in Arctic regions, has E. rubrum, to take its place in the Antarctic; Pinguicula lusitanica, in the Northern hemisphere, has P. antarctica, resembling it, in the Southern; Aucuba japonica of Japan is represented in the Himalaya iby Aucuba Himalaica.

\section{4.-Distribution of Plants considered Physiognomically and Statisticalliy.}

The distribution of plants over the globe may be considered either Physiognomically, as regards the prevalence of certain vegetable forms which give a general character to the landscape of a country; or Statistically, as regards the numerical proportion which different groups bear to each other, or to the whole known plants.

Physiognomy of Vegetation. - Some families of plants, on account of their form, aspect, and locality, particularly engage the attention not only of the botanist, but of every observer of nature. They are called Physiognomic plants. Their difference is connected with various external circumstances of climate. In prosecuting this department of botanical geography, we shall specify some of those vegetable forms which give a character to the landscape. This has been done more especially by Meyen, who gives the following series :-

1. Gramineous or Grassy Form. This is illustrated in northern countries by meadows and pastures. The cereal grains also have a great influence on the aspect of countries. Under this form are included Cyperaceæ, Restiaceæ, and Juncacea. In the torrid zone some arborescent forms occur, as Bamboo; and along with 
these are associated Sugar-cane and Rice. Barley is an extra-tropical form, while Carex extends to cold regions.

2. Scitamineous Form. This includes the Ginger, Arrow-root, and Plantain families, some of which attain a large size. They contribute to give a character to the torrid zone.

3. Pandanus or Screw-pine Form. A tropical form illustrated by Screw-pines. and Dracæuas.

4. Pine-apple Form. Illustrated by the Bromeliacere of warm climates.

5. The Agave or American Aloe Form. Chiefly tropical and sub-tropical.

- 6. The Palm Form. Under this are included also the Cycadaceous family. They give is character to the hotter regions of the globe. Some of the Palms are social, as the Date and Coco-nut. Chamærops humilis represents this form in Europe.

7. Filical or Fern Form. True Ferns, in an especial manner, affect the landscape in tropical and warm regions.

8. Mimosa Form. This includes Leguminous plants in general. The finelycut foliage of some has a resemblance to Ferns. Modifications of this form occur both in warm and cold regions. Acacias in Australia give a peculiar feature to the landscape.

9. Coniferous Form. The Abietinex are characteristic of northern regions, and the Cupressinex of southern.

10. The Protea, Epacris, and Erica Forms. These forms supply the place of Coniferse in the southern hemisphere. The Protea and Epacris forms occurring in Australia, and the Erica form at the Cape of Good Hope.

11. Myrtle Form. Some of these, such as Melalenca and Eucalyptus, characterise Australian scenery; others, as Guavas, are tropical.

12. Forms of Dicotyledonous trees. Some with broad and thin leaves, as Birch, Alder, Poplar, Oak, Lime, Elm, Beech, and Horse-chestnut, giving a character to the physiognomy of the colder lialf of temperate climates; while others, with thick, leathery, and showy leaves, as Olives and Laurels, are characteristic of warmer climates; and a third division, with large, beautiful leaves, Cecropia, Artocarpus, and Astrapæa, abound in the hottest climates.

13. Cactus Fomn. This form is developer chiefly in America, especially in Brazil.

14. Form of Succulent plants. Seen in the Mesembryacre of South Africa.

15. Lily Form. This includes Liliacere, Amaryllidacex, and Iridaceæ. Modifications of this form occur in warm and temperate climates.

16. Forms of Lianas or Climbing-plants. These forms are chiefly tropical, and are illustrated by Passion-flowers, Paullinias, Aristolochias, and Bauhinias.

17. Pothos Form. This is a tropical form, and is illustrated by varions species of Aracex.

18. Orchideous Form. This is seen in the splendid Epiphytes of warm climates. Terrestrial species chiefly occur in cold zones.

$\left.\begin{array}{l}\text { 19. The Moss Form. } \\ \text { 20. The Lichen Form. }\end{array}\right\}$ Both these forms characterise cold regions chiefly.

Besides the forms of plants, it is found that the prevalent colours sometimes give a character to the vegetation. White or pale-coloured flowers are said to be more abundant in northern latitudes than in the tropics, and in alpine situations they are of more frequent occurrence than on the plains. The xanthic series of colours, Hinds states, is abundant within the tropics in the autumn, on the plains over the mountains. The flowers of the cyanic series, especially intense blues. 
and violets, delight in the clear skies of sub-tropical regions. Hinds gives the following tabular view of the relative proportion of colours:

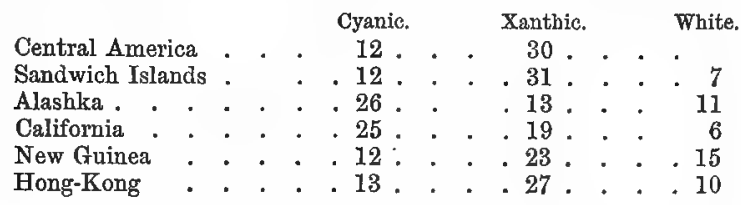

Geyer says that vivid colours mark the basaltic plains of Upper Oregon ; blue and purple, eastward ; scarlet with golden-yellow, westward; glaucous green reigns in the herbage over the plains; deep saturated green in the valleys.

Stratistics of Vegetation.-The number of known vegetable families differs in different latitudes. In examining the distribution of the great classes of the Vegetable Kingdom, it will be found that certain relative numerical proportions have been ascertained. It is not easy to estimate the proportion which Cryptogamous bear to Phanerogamous plants. From data already given it may be estimated that the proportion for the whole world is as 1 to 7 . This proportion varies in different regions; the Cryptogamous plants increasing in their proportion in the northern parts of the temperate zone. Ferns are to known Phanerogamous plants as 1 to 20 . This proportion is least in the middle of the temperate zone, and becomes larger towards the equator, and towards the poles. Ferns, however, attain their absolute maximum at the equator, and their absolute minimum in the arctic zone. At North Cape there are only four species of Ferns found, and yet their proportion to Phanerogamia is 1 to 7 there; and in Greenland 1 to 10 (Meyen). Humboldt says that in the torrid zone Monocotyledons are to Dicotyledons as 1 to 6 ; in the temperate zone, as 1 to 4 ; and in the arctic zorie as 1 to 3 . Monocotyledons increase in proportion to Dicotyledons as the latitude becomes higher. Some natural orders are very generally diffused, as Leguminosæ, Malvaceæ, Ranunculaceæ, Caryophyllaceæ, Cruciferæ, and Umbelliferæ. Cellular plants have also a wide range, and so have aquatics. Juncaceæ, Cyperaceæ, and Gramineæ, increase in proportion to all the Phanerogamous plants, as the latitude becomes higher; while Restiaceæ, Leguminosæ, Euphorbiaceæ, and Malvaceæ, decrease. Cruciferæ, Umbelliferæ, and Compositæ, are highest in their proportion in the temperate zone, diminishing towards the equator and the poles. Hinds gives the following statement as to certain families which are almost exclusively confined to one of the six great divisions of the globe :-

In Europe-Globulariaceæ a section of Selaginaceæ, Ceratophyllaceæ.

In Asia-Dipterocarpaceæ, Aquilariaceæ, Camelliaceæ, Moringacere, Stilaginacex. 
In Africa-Bruniaceæ, Brexiaceæ, Belvisiaceæ, Penæacex.

In North America-Sarraceniaceæ.

In South America-Rhizobolaceæ, Monimiaces, Simarubaceæ, Vochysiaceæ, Calyceraceæ, Escalloniaceæ, Humiriacex, Lacistemaceæ, Papayaceæ, Gilliesiacex, Gesneraceæ.

In Australia - Tremandraceæ, Epacridacex, Goodeniacer, Stackhousiaceæ, Brunoniaceæ:

He also gives the following list of natural orders, as prevailing in the northern hemisphere and southern hemisphere :-

In the northern hemisphere the following natural orders abound or are predolninant :-Aceraceæ, Aurantiaceæ, Artocarpeæ a section of Urticaceæ, Amentiferæ, Berberidaceæ, Boraginaceæ, Caryophyllaceæ, Cistaceæ, Cruciferæ, Coniferæ, Campanulaceæ, Caprifoliaceæ, Dipsacaceæ, Elreagnacex, Fumariaceæ, Grossulariaceæ, Hypericaceæ, Hippocastaneæ a section of Sapindaceæ, Hamamelidacea, Magnoliaceæ, Onagraceæ, Orobanchaceæ, Papaveraceæ, Rosaceæ, Ranunculaceæ, Rutaceæ, Resedaceæ, Saxifragaceæ, Umbelliferæ, Vacciniaceæ, Alismaceæ.

In the southern hemisphere the following natural orders are predominant:Atherospermaceæ, Cactaceæ, Crassulaceæ, Capparidaceæ, Diosmeæ a section of Rutaceæ, Dilleniaceæ, Geraniaceæ, Heliotropeæ a section of Ehretiacere, Myrtaceæ, Melastomacex, Mesenubryaceæ, Myoporineæ a section of Verbenaceæ, Malpighiaceæ, Oxalidacen, Pittosporaceæ, Polygalaceæ, Proteaceæ, Scævoleæ a section of Goodeniaceæ, Spigeleæ a section of Loganiaceæ, Stylidiaceæ, Amaryllidacere, Hæmodoracen, Iridaceæ, Restiaceæ.

It is sometimes difficult to tell in what division of the globe a family may be said to be chiefly represented, inasmuch as the species and genera are nearly equal in different countries. When a group of plants occurs only in one of the six great divisions of the globe, it is said to be monomic ( $\mu$ óvos, one, and vo,uos, a region). Thus, Vochysiacex, being confined to South America, is a monomic family; and Cliffortia, whose shrubby species are all indigenous to South Africa, is a monomic genus. Again, a natural family, common to all the divisions, is polynomic; and so also genera, as Viola or Ranunculus. If restricted to two or more divisions, the groups are dinomic, trinomic, etc. Aceraceæ, found in Europe, Asia, and North America, are trinomic.

\section{5:-Phyto-Geographical Division of the Globe.}

The subject will be considered in two points of view :-1. In respect to the horizontal or latitudinal range of vegetation; and 2. In respect to its vertical or altitudinal range.

\section{LATITUDINAL RANGE OF VEGETATION.}

Various attempts have been made to divide the globe into zones or kingdoms, founded on the characters impressed upon them by the nature of the regetation. Willdenow, Treviranus, De Candolle; Schouw, and Mejen, have each proposed arrangements. Those of Schouw and Meyen chiefly deserve attention.

Schouw, in his divisions, proceeds on the principle of the predomi- 
nance of certain characteristic forms or families of plants. His system is founded on the three following requisites: -1 . That at least one-half of the known species of plants of that part of the earth, constituting a botanical region, should be peculiar to it. 2. That onefourth part of the genera of the region should be peculiar to it, or at least should have so decided a maximum as to be only represented in other regions. 3. That individual families should either be peculiar to the region, or at least reach their maximum in it. The regions are divided into provinces according to minor differences in the vegetation;' one-fourth of peculiar species, or some peculiar genera, being sufficient to form a province.

\section{Schouw's Plyyto-Geographic Regions.}

1. The Region of Saxifragaceæ and Musci, or the Alpine Arctic Flora (Wahlenberg's Region).--This region is characterised by the abundance of Mosses and Lichens, the presence of Saxifragaceæ, Gentianaceæ, Caryophyllaceæ, Cyperaceæ, Salices; the total absence of tropical families; a notable decrease of the forms peculiar to the temperate zone; by forests of Fir and Birch; the small number of annual plants, and the prevalence of perennial species; and finally, a greater liveliness in their simple colours. In this region there is no cultivation. The region is divided into two provinces :- -1 . The province of the Carices, or the Arctic Flora, which comprehends all the countries within the polar circle, with some parts of America, Europe, and Asia, which are to the south of it, more especially Lapland, the north of Russia, Siberia, Kamtschatka, New Britain, Canada, Labrador, Greenland, and the mountains of Scotland and Scandinaria. Kane in his Arctic Explorations gives a list of plants collected on the western coast of Greenland, $73^{\circ}$ to $80^{\circ} \mathrm{N}$. Among the interesting plants may be noted Ranunculus Sabini, Hesperis Pallasii, Vesicaria arctica, Arenaria arctica, Potentilla frigida, Pedicularis Kanei, Diapensia lapponica, and only one fern, Cystopteris fragilis. In latitude $82^{\circ} \mathrm{N}$., on the east side of Smith's Sound, Dr. Bessel gathered Draba alpina, Cerastium alpinum, Leontodon Taraxacum var, and Poa flexuosa. In the Iceland Flora Babington enumerates 467 Phanerogams, the great bulk of the species Scandinavian, and all but 62 British. There are 3 purely Arctic species, Gentiana detonsa, Pleurogyne rotata, and Epilobium latifolium; Bellis perennis (the daisy) is a great rarity; it was only once found. In Spitzbergen there are 117 Phanerogamous plants, and 50 Cryptogamous. In Nova Zembla and Waigatsch Island the Phanerogams amount to 146 , and the Cryptogams to 144 . 2. The province of Primulaceæ and Phyteumæ, or the Alpine Flora of the south of Europe, which embraces the flora of the Pyrenees, Switzerland, the Tyrol, Savoy, the mountains of Greece, the Apennines, and probably the 
mountains of Spain. Polar regions, mean temperature, $2^{\circ}$ to $41^{\circ} \mathrm{F}$.; mountains in the south, $21^{\circ}$ to $37^{\circ} \mathrm{F}$.

2. The Region of Umbelliferæ and Cruciferæ, including the NorthEuropean and North-Asiatic Flora (Linnæus's Region).-These orders are here in much greater number than in any other region. Rosaceæ, Ranunculaceæ, Fungi, Amentiferæ, and Coniferæ, are likewise very numerous; the abundance of Carices, and the fall of the leaves of almost all the trees during winter, form also important features of this division. It may be separated into two distinct provinces:-1. The province of the Cichoraceæ, which embraces all the north of Europe not comprehended in the preceding region, namely, Britain, the North of France, the Netherlands, Germany, Denmark, Poland, Hungary, and the greater part of European Russia. 2. The province of the Astragali, Saline plants, as Salsola and Salicornia, and Cynarocephalæ, which in. cludes a part of Asiatic Russia, and the countries about the Caucasian and Altai mountains. Mean temperature, $29^{\circ}$ to $46^{\circ} \mathrm{F}$. The cultivated plants are-Rye, Barley of different kinds, Oats, Wheat and Spelt, Maize, Millet, the Potato, Buckwheat, Apple and Pear, Quince, Cherry, Plum, Apricot, Peach, Mulberry, Walnut, Vine, Gooseberry and Currant, Strawberry, Cucumber and Melon, Cabbage, Mustard, Pea, Bean, Beet, Spinach, Carrot, Flax, Hemp, Trefoils and Vetches, Rye-grass, etc.

3. The Region of Labiatæe and Caryophyllacex, or the Mediterranean Flora (De Candolle's Region).- It is distinguished by the abundance of the plants belonging to these two orders. Compositæ, Galiaceæ, Boraginaceæ, also occur in considerable quantity. Some tropical families are also met with, such as Palms, Laurels, Araceæ, Anacardiaceæ, grasses belonging to the genus Panicum (millet), and some, as Cyperaceæ, Solanaceæ, Malvaceæ, Leguminosæ, Urticaceæ, and Euphorbiaceæ increase. The forests are composed chiefly of Amentiferæ and Coniferæ, as birches, oaks, firs, etc.; the copses, of Ericaceæ (the heath tribe) and Anacardiaceæ, as the mastich. We meet in this region with a great number of evergreen trees. Vegetation never ceases entirely, but verdant meadows are more rare. Schouw divides this region into five provinces:-1. The province of the Cistuses, including Spain and Portugal. 2. The province of the Salvix and Scabiosæ, the south of France, Italy, and Sicily. 3. The province of the Shrubby Labiatæe, the Levant, Greece, Asia Minor, and the southern part of the Caucasian countries. 4. The Atlantic province, the north of Africa. 5. The province of Semperviva, the Canary Isles, and probably also the Azores, Madeira, and the north-west coast of Africa; many Sempervivums, and some Euphorbias with naked and spiny stems, particularly characterise this province. Erica arborea, Vaccinium maderense, and Pinus 
canariensis, are found here. Among the plants of the Mediterranean flora, requiring both a warm summer and a warm winter, may be enumerated Oleander, Aloe, Chamærops humilis, Phœnix dactylifera, Capparis, Ceratonia Siliqua, Cyclamen Clusii, Ornithogalum arabicum, arborescent species of Dianthus, several Ferns; and of cultivated plants, Ricinus communis, Egg-plant, Hibiscus esculentus, Capsicum, Acacia Farnesiana, Phaseolus Caracalla, Sterculia platanifolia, and Schinus Molle. Of 596 species inhabiting Madeira and Porto Santo, 108 are endemic ; and of the 108, 28 are common to Madeira and the Azores. Of the Azorean species, 4-5ths are European, and may have been carried by man. Of the remaining 5th, nearly the whole are peculiar to the Azores or to the Archipelago of the Atlantic islands, which includes also Madeira and the Canaries. Mean temperature, $55^{\circ}$ to $73^{\circ} \mathrm{F}$. Cultivated plants are the same as in the second region, with the addition of Rice, Guinea Corn, Italian Millet, Fig, Almond, Orange and Lemon, Water Melon, Olive, Cotton. Rye and Buckwheat are only cultivated in the mountainous regions.

4. The region of Asters and Solidagos, or the Flora of the northern part of North America (Michaux's Region). - This is marked by the great number of species belonging to these two genera, by the great variety of Oaks and Firs, the small number of Cruciferæ and Umbelliferæ, Cichoraceæ and Cynarocephalæ, the total absence of the genus Erica, or heath, and the presence of more numerous species of Vaccinium, or whortleberry, than are to be met with in Europe. It comprehends the whole of the eastern part of North America, with the exception of what belongs to the first region. It has been divided into two provinces :1."That of the south, which embraces the Floridas, Alabama, Mississippi, Louisiana, Georgia, and the Carolinas, $54^{\circ}$ to $72^{\circ}$. 2. That of the north, which includes the other States of North America, such as Virginia, Pennsylvania, New York, etc. Mean temperature, $9^{\circ}$ to $59^{\circ} \mathrm{F}$. In the northern districts, down to the parallels of $55^{\circ}$ or $50^{\circ}$, there is no cultivation. South of this line the cultivation is the same as in the second region. Maize is cultivated to a greater extent in North America than in Europe.

5. The region of Magnolias, or the southern North American Flora (Pursh's Region). - This comprises the most southern parts of North America, between $36^{\circ}$ and $30^{\circ}$. The tropical forms which show themselves more frequently than on a similar parallel of the old continent, are the chief feature in the regetation. Thus we meet with Anonaceæ, Sapindaceæ, Melastomaceæ, Cactaceæ, and Zingiberaceæ. This region has fewer Labiatæ and Caryophyllaceæ than occur in corresponding latitudes in the Old World. It presents more trees with fine blossoms, and shining, sometimes pinnated, leaves, as Magnolia, 
Tulip-tree, Horse-chestnut, Robinias or False Acacias. Among other plants may be mentioned the following:-Illicium floridanum, Pavia flava, Cassia Tora and C. Marilandica, Kalmia hirsuta, Opuntia vulgaris, Halesia tetraptera, Laurus caroliniensis, L. Sassafras, Carya aquatica, Liquidambar styraciflua, Carpinus americanus, Castanea americana, Pinus Tæda, Chamærops Palmetto. Mean temperature, $59^{\circ}$ to $73^{\circ}$. The same plants cultivated as in the third region. Rice is much cultivated. In the southern district the Sugar-cane is productive; and in the eastern districts Cotton is grown to a great extent. Dr. Hooker says that the Indian mountains and islands are the true centres of Magnolias.

The Californian and Oregon districts, in the west of North America, and extending farther north than Region 5, have a marked Flora, which requires to be more fully explored. Many showy Polemoniaceæ are found here; also Eschscholtzia californica, species of Platystemon, Nemophila, Gilia, Collinsia, Clarkia, Bartonia, and Eutoca. Many interesting Coniferæ also occur, such as Abies Douglasii, Pattoniana, Picea nobilis, amabilis, grandis, lasiocarpa, Pinus Lambertiana, Sabiniana, insignis, Jeffreyi, ponderosa, monticola, californica, Fremontiana, Coulteri, flexilis, muricata, tuberculata, Libocedrus decurrens, Thuja gigantea, Sequoia gigantea, Juniperus dealbata and occidentalis, Castanea chrysophylla. In the upper Oregon districts Geyer enumerates Umbelliferæ, Scrophulariaceæ, Asphodeleæ, Polemoniaceæ, Boraginaceæ, Vacciniaceæ, Ranunculaceæ, Cruciferæ, Onagraceæ, Rosaceæ, Polygonaceæ, Labiatæ, Caryophyllaceæ, Compositæ, Gramineæ, species of Mahonia, Lewisia, Geranium, Ribes, Lobelia, Clintonia, Pentstemon, Camassa, Horkelia, and Eriogonum. The bulk of the wood in upper Oregon is composed of Pinus ponderosa, and along with it occur Abies balsamea, canadensis, Douglasii, nobilis, and alba. In the basaltic plains of upper Oregon, Geyer says there are no Papaveraceæ, Urticaceæ, Violaceæ, Vitaceæ, Solanaceæ, Jasuninaceæ, Amaranthaceæ, Eleagnaceæ, Oxalidaceæ. In Vancouver's Island there are many interesting Pines and Oaks, also Rhododendron macrophyllum.

6. The Region of Ternstrœmiaceæ and Celastraceæ, or the Chinese Japanese Flora (Kæmpfer's Region). - This region is as yet too little known to enable us to determine accurately its characteristic features. It embraces the eastern temperate part of the old continent, namely, Japan, the north of China, and Chinese Tartary, between lat. $30^{\circ}$ and $40^{\circ}$ north. Its vegetation appears to occupy a middle place between that of Europe and that of North America, approaching more to the tropical than to the European. It has an affinity to the Indian Flora, as shown by the occurrence of Bananas, Palms, Zingiberacer, Anonacex, Sapindacer, and Cycadaceæ. The genera Camellia, Thea 
Citrus, Rhamnus, and Lonicera, are abundant. Among the more characteristic species are Eriobotrya japonica the Loquat, Cryptomeria japonica, Salisburya adiantifolia, Pæonia Moutan, Anemone japonica, Stillingia sebifera the Tallow-tree, Camphora officinalis, Azalea sinensis, Wistaria sinensis, Gossypium religiosum, Enkianthus quinqueflorus, Cymbidium sinense, Pinus sinensis, P. Jezöensis, Juniperus rigida, J. chinensis, Podocarpus Nageia, and species of Biota. Sciadopitys verticillata, Thuiopsis dolabrata, Torreya nucifera, Cephalotaxus drupacea. Mean temperature, $54^{\circ}$ to $68^{\circ}$. The cultivated plants areRice, Wheat, Barley, Oats, Millet, Buckwheat, Apple and Pear, Quince, Plum, Cherry, Apricot, Peach, Loquat, Orange and Shaddock, Melon, Tea, Hemp, Paper-Mulberry, Cotton, and False Sago.

7. The Region of Zingiberaceæ, or the Indian Flora (Roxburgh's Region).--Zingiberaceæ here are much more numerous than in America, as well as Leguminosæ, Cucurbitaceæ, and Tiliaceæ, although in a less degree. It comprehends India east and west of the Ganges, the island of Ceylon and the south-eastern Peninsula, to the height of 4500 to 5500 feet above the level of the sea. The Coco-nut, Mangosteen, Turmeric, Cinnamon, Cotton, Indigo, Clove, and Pepper, are abundant. In the island of Ceylon we meet with Salvadora persica, Feronia Elephantum, Thespesia populnea, Chloroxylon Swietenia, Schleichera trijuga, and Borassus flabelliformis. The south of China and Cochin-China may be considered as a distinct region. It partly resembles that of India, but contains many peculiar plants. In the island of Formosa occurs Fatsia papyrifera, the Rice-paper plant; near Hong Kong are found Chirita sinensis, Rhodoleia Championi, Arundina sinensis, Spathoglottis Fortuni, Cunninghamia sinensis, Olea fragrans, Campanula grandiflora, Brassica chinensis, Enkianthus reticulatus, Litchi and Longan fruits, Ficus nitida, Bamboo, and Orchids. Mean temperature, $66^{\circ}$ to $83^{\circ} \mathrm{F}$. The cultivated plants are-Rice, Coco-nut, Tamarind, Mango, Ginger, Cinnamon, Mangosteen, Peppers, Indigo, Cotton, Coffee, Bananas, Guava, Órange and Shaddock, Sugarcane, Cloves, Turmeric.

8. The Region of Tree Rhododendrons, the Emodic Region, or the Mountains of India (Wallich's Region).-This comprises the Alpine region south of the ridge of the Himalaya. It includes Sirmore, Gurwal, Kamaon, Nepaul, and Bhotan, to a height of from 5000 to 12,000 feet above the level of the sea. Some tropical plants grow in the lower parts of the region. Extra-tropical, more especially European forms, make their appearance. Deodar, Pinus excelsa, P. Webbiana, and other Coniferæ, are met with. Abies Smithiana reaches 10,000 feet on the Himalaya. Some European species occur in these high districts, for instance, Ranunculus sceleratus, Nasturtium officinale, Veronica Anagallis, and Polygonum amphibium. Chamærops Khasyana, 
species of Oak, Dammar, Rhododendron, Berberis, Primula, etc., also occur. Mean temperature, $37^{\circ}$ to $66^{\circ} \mathrm{F}$. Some European grains and fruit are cultivated, along with Mountain Rice.

9. The Region of the Asiatic Islands, Polynesian Flora (Reinwardt's Region).- This includes the mountainous districts of the islands between the south-eastern Peninsula and Australia, to the height of 5500 feet above the level of the sea. Mean temperature, $66^{\circ}$ to $84^{\circ}$. Orchids, Ferns, and species of Ficus abound, along with some Australian forms. In the Flora of Sumatra we meet with Rafflesia Arnoldi, Dryobalanops Camphora, Sagus lævis, Stagmaria verniciflua, Rhododendron Malayanum (top of Sugar-loaf Mountain, Bencoolen, about 3000 feet), Vaccinium Sumatranum, Elodea Sumatrana, Millingtonia Sumatrana, Hedychium Sumatranum, and numerous Begonias. The cultivated plants are those of the Indian region (7); also, Bread-fruit, Cassava, Nutmeg, Camphor, Papaw, Dammar, Paper-Mulberry, and Cotton.

10. The Region of Upper Java (Blume's Region). - This embraces those districts of the island of Java and the islands of the Indian Archipelago which have an elevation of 5000 to 12,000 feet above the level of the sea. Extra-tropical forms ocour, and the Flora has some resemblance to that of the Emodic region. Ternstrœmiaceæ, Thibaudias, and forests of Podocarpus and Oaks characterise the region.

11. The Polynesian or Oceanic Region (Chamisso's Region).This includes all the islands of the Pacific Ocean within the Tropics. The plants are allied to the Asiatic and Australian Floras. Among the plants of this region may be mentioned Artocarpus incisa, Tacca pinnatifida the Pia, which yields a kind of Arrow-root, Cocos nucifera, Lodoicea seychellarum, Jambosa malaccensis the Ohiaai, and many species of Arum, Dioscorea, Musa, and Ficus. The genera Dissochæta, Orophea, Pterisanthes, Arthrophyllum, and Visenia, occur in this region. In the Sandwich Islands, belonging to the Hawaiian group, nearly one-third of the vegetation is composed of Ferns. There are three PaIms, the Coco-nut and two species of Livistona. The rest of the flora consists of Myrtles, Grasses, Sedges, Mimoseæ, and Arums. Acacia heterophylla, called Koa, yields durable timber. The root of Dracæna terminalis, called $\mathrm{Ki}$, is eaten. The fruit of Physalis pubescens is used; also the fruit of Pandanus odoratissimus, called Lahala ; that of Osteomeles anthyllidifolia, the Ulei; that of Morinda citrifolia, the Noni; and that of Morus indica, the Kilica. Colocasia esculenta, the Kalo, is used as a vegetable. Cloth is made from Broussonetia papyrifera and Boehmeria albida, cordage from Paritium tiliaceum, water-flasks from Lagenaria vulgaris; and Macropiper methysticum is the great remedy for diseases. Peculiar Compositæ, 
Lobeliaceæ, Goodeniaceæ, and Cyrtandrex, are met with in those islands. Mean temperature, $73^{\circ}$ to $83^{\circ}$. The cultivated plants areBread-fruit tree, Coco-nut, Double Coco-nut, Yams, Plantain, CabbagePalm, Paper-Mulberry, Taro, Kava.

12. The Region of Amyridaceæ, or of Balsam trees, Arabian flora (Forskäl's Region).-This comprehends the Persian or Arabian Flora, especially the south-western part of the highlands of Arabia or Yemen. In this region are many trees yielding gums and balsamic resins, as species of Mimosa, Acacia, Balsamodendron, Boswellia. There are many Indian forms in this region. Cultivated plants are-Maize, Millet, Date-palm, Coco-nut, Fig, Apricot and Peach, Plum, Apple, Quince, Vine, Coffee-tree, Tamarind, Papaw, Sugar-cane, Ginger, Cotton, and Indigo.

13. The Desert Region (Delile's Region).-This includes Northern Africa, to the south of the mountains of Atlas, between lat. $30^{\circ}$ and $15^{\circ}$ N., and the northern part of Arabia. Phœuix dactylifera, or the Date-palm, and Cucifera thebaica, or Doom palm, are found here. Mean temperature, $73^{\circ}$ to $86^{\circ} \mathrm{F}$. Cultivation is confined to the valley of the Nile and the Oases. We meet with Guinea Corn, Wheat and Barley, and the South European and Indian grains.

14. The Region of Tropical Africa (Adanson's Region).-This includes that part of Africa lying between the parallel of $15^{\circ}$ and the tropic of Capricorn, or between the northern and southern, limits of periodical rains, with the exception of Abyssinia and the unknown countries of the interior. The Flora of the western part of this region is characterised in part by Adansonia, or the Baobab, one of the largest known trees. We also meet with the Elais guineensis, a palm which furnishes oil. Other characteristic plants are Sarcocephalus esculentus and Schmiedelia africana. Vogel noticed, near Cape Coast Castle, Arachis africana, Bignonia tulipifera, Euphorbia drupifera, Hibiscus populneus, and Blighia sapida the Akee. Species of Sorghum, Sterculia acuminata the Kola nut, Physostigma venenosum the Calabar bean, belong to this region. Welwitsch mentions species of Rhipsalis, Monodora, Vellozia, Begonia, Rafflesia parasitic on Cæesalpinieæ, a tree Umbellifer and Welwitschia mirabilis the Toumbo. The vegetation of Guinea and Congo is a mixture of the Floras of Asia and America, though most resembling the former. The eastern part of the region, including Madagascar, has a peculiar Flora, distinguished chiefly by the genera Danais, Ambora, Dombeya, Dufourea, Didymorneles, and Senacea, Tanghinia, Ouvirandra, Urania, and Buddleia. There are many peculiar genera, but few species. Mean temperature, 72. to $86^{\circ}$. Cultivated plants: Maize, Rice, Guinea Corn and Millet, 
Yams, Cassava, Banana, Mango, Papaw, Pine-Apple, Cashew, Tamarind, Coffee, Sugar, Cotton, Ginger, Cardamoms, Earth-nut, Oil-Palm, Tobacco.

15. The Region of Cactaceæ and Piperaceæ (Jacquin's Region).This embraces Mexico, New Grenada, Guiana, and Peru. These natural orders are here predominant, both as regards the number of species and the individual plants. Tropical orders are abundant. Murichi or Ita Palm, Phytelephas or Ivory Palm, and Victoria regia, are found in this region. Seemann states that the Isthmus of Panama is characterised in part by the leaves of the plants being covered with hair and tomentum, by the abundance of greenish, yellow, and white flowers, and by the numerical superiority of Leguminosæ, Melastomaceæ, Compositæ, Cinchonaceæ, Orchids, and Ferns. Anona Cherimolia yields the Cherimoyer, a famous Peruvian fruit. Mean temperature, $68^{\circ}$ to $84^{\circ}$. Cultivated plants : Maize, Guinea Corn, Cassava, Yams, Batatas, Arracacha, Arrow-root, Plantain, Mango, CustardApple, Guava, Coco-nut, Papaw, Avocado-Pear, Pine-Apple, Cashew, Tamarind, Granadilla, Vine, Indian Fig, Jambos, Chocolate, Vanille, Coffee, Sugar, Capsicum, Cochineal-Cactus, Cotton, Earth-nut.

16. The" Region of the highlands of Mexico (Bonpland's Region). -This embraces the districts which have an elevation of more than 5000 feet above the level of the sea. Many European plants are cultivated here, as well as Maize. Picea religiosa, Pinus apulcensis, P. Hartwegii, P. Montezumæ, and Taxodium distichum, are found; also species of Mirabilis, Cheirostemon, Dahlia, Zinnia, and Lopezia. Mean temperature, $67^{\circ}$ to $79^{\circ} \mathrm{F}$.

17. The Region of Cinchonas, or Medicinal Barks, Andes Flora (Humboldt's Region).- This comprises a part of the elevated regions or Cordilleras of South America, included in the torrid zone, the Andes from 5000 to 9000 feet. The Cinchona belongs exclusively to this region, and forms its principal feature. In the higher regions the Potato and Quinoa are cultivated, as well as some European grains and fruits. Ceroxylon Andicola, the Wax-Palm, also occurs in this region of the Andes. In the lower districts Maize and Coffee are still cultivated. Mean temperature, $59^{\circ}$ to $68^{\circ}$.

18. The Region of Escalloniæ and Calceolariæ (Ruiz and Pavon's Region).--It embraces the highest parts of South America, or that portion of the chain of the Andes which extends from 9000 to 18,000 feet of elevation. Besides the plants mentioned, we meet with alpine plants, as Saxifrages and Gentians, and species of Draba, Arenaria, Carex, Lobelia, and Salvia, Espeletia, Aster, also Drimys Winteri, 
Junci, and Carices, besides some European genera belonging to the orders Gramineæ and Cichoraceæ, such as Bromus, Festuca, Poa, Apargia, and Hypochæris. Mean temperature, $34^{\circ}$ to $59^{\circ} \mathrm{F}$.

19. The West "Indian Region (Swartz's Region).-This includes the whole district of the Great and Little Antilles. Bananas, Plantains, Mangos, Guava, Arocado-Pear, Tamarind, and many other useful plants, are met with. The Flora is intermediate between that of Mexico and the northern parts of South America. Ferns and Orchids prevail. Many tropical fruits are met with, such as Mango, Guava, Avocado-Pear, and Custard-Apple. Mean temperature, $59^{\circ}$ to $79^{\circ} \mathrm{F}$. Cultivated plants the same as those in the fifteenth region.

20. Region of Palmæ and Melastomaceæ-It embraces Brazil and that part of South America which lies to the east of the chain of the Andes, between the Equator and the Tropic of Capricorn. The vegetation is very luxuriant. Vellozia and Lichnophora give a decided feature to the vegetation of some of the mountainous parts. Here, also, numerous large peculiar species of Eriocaulon occur. Species of Croton, Dorstenia, and Heliconia, tall grasses, arborescent Solanums, Vernonias, and large Compositæ, species of Ficus, Laurus, Lasiandra, Solandra, and Fuchsia, are also met with. In place of the few mosses and lichens which cover the trunks and branches of forest trees in temperate climes, in Brazil they are bearded from the roots to the very extremities of the smallest branches with Ferns, Aracex, Tillandsias, Cactuses, Orchids, Peperomias, Gesneras, and Bignonias. Mean temperature, $59^{\circ}$ to $84^{\circ} \mathrm{F}$. Same plants cultivated as in the fifteenth region.

21. The Region of Arborescent or Shrubby Compositx, Extratropical South American Flora (St. Hilaire's Region).-The great number of arborescent Compositæ, and of plants belonging to the order Calyceraceæ, forms the chief feature of this Flora, which approaches in a remarkable manner to that of Europe, whilst it differs entirely from the floras of Chili, the Cape, and Australia. This region comprehends the lower part of the basin of La Plata, and the plains which extend to the west of Buenos Ayres and Chili, between the Tropic of Capricorn and latitude $40^{\circ}$ south. The Flora of Chili approaches that of Australia, the Cape of Good Hope, and New Zealand, in Goodenia, Araucaria, Proteacex, Gunnera, Ancistrum. In many respects the flora resembles that of the mountainous districts, in the presence of Calceolarias, Escallonias, species of Weinmannia, Buddlea, and Campanula. Araucaria imbricata, the Banksian or Chili Pine, is a hardy Conifer of this district, extending on the Chilian 
Andes from $37^{\circ}$ to $40^{\circ} \mathrm{S}$. lat. Thuja chilensis occurs on the mountains of south Chili. In this region we also meet with Thuja tetragona the Alerse of Chili, and Podocarpus chiliana. Araucaria braziliana is found on the mountains near Rio Janeiro in the province of St. Pauls. Mean temperature, $59^{\circ}$ to $74^{\circ} \mathrm{F}$. European plants form here objects of culture. Wheat, the Vine, and the Peach are widely extended.

22. The Antarctic Region (D'Urville's Region).-This includes the countries near the Straits of Magalhaens, Tierra del Fuego (Fuegia), and the Falkland Islands. There is a considerable resemblance between the regetation here and what is seen in the north temperate zone. Polar forms display themselves in the species of Saxifrage, Gentian, Arbutus, and Primrose, and other European genera. There is also a resemblance between the plants of this region and those of the mountains of South America, of Chili, the Cape, and Australia. In Fuegia, the Evergteen Beech, Fagus Forsteri, which never sheds its coriaceous foliage, is a very prevalent tree; also the Deciduous Beech, Fagus antarctica, the leaves of which change colour and fall, and Drymis Winteri. These three trees occupy exactly the same position in Fuegia that the Birch, Oak, and Mountain Ash, do in Scotland. The vegetation of Fuegia includes a number of British plants, although 106 degrees of ocean roll between, and some of the species in question inhabit no intermediate latitudes. The genera are in a great measure identical with those of Britain. Fuegia is the native place of the Fuchsia. In the Falkland Isles there are about 120 flowering plants, consisting chiefly of those found on the mountains of Fuegia, and on the arid coast and plains of Patagonia. Grasses and Bolax glebaria, the Balsam-bag (one of the Umbelliferæ), form the chief botanical features. Bolax glebaria forms hard hummocks 4 feet high and the same diameter, which give out a balsamic resinous smell. Their form and occurrence on this barren soil has given rise to the name of Misery-balls. Dactylis cæspitosa, the Tussac-grass, appears, Hooker remarks, like a forest of miniature Palms. It forms hillocks about 6 feet high, and 4-5 in diameter, some of the blades of grass being 6 feet long; and supplies excellent fodder. Among shrubby plants may be noticed Veronica elliptica and decussata, Chiliotrichum amelloides, Empetrum rubrum, and Pernettia empetrifolia. Of Ferns, Lomaria alpina and L. magellanica are found. Lichens abound, and the Usnea melaxantha forms a miniature shrubbery on the rocks. In the islands farther south Mosses and Lichens form the chief flora. Among the plants found on the antarctic islands of Tristan d'Acunha, Inaccessible, and Nightingale Islands, are the following:-Cardamine hirsuta, Sonchus oleraceus, Hypochaeris glabra, and Apium graveolens (European plants), Nertera depressa, Chev- 
reulia stolonifera, Lagenophora Commersoni, Gnaphalium pyramidale, Phylica arborea, the tree of the islands, which sometimes attains a height of 20 feet, with a diameter of 12-18 inches; Chenopodium tomentosum, known as the tea plant, having strongly-scented leaves, of which a decoction is made and drunk with milk and sugar; Pelargonium australe var. acugnaticum, Empetrum medium, Acæna Sanguisorba, Hydrocotyle capitata, Carex insularis, Spartina arundinacea, Dactylis cæspitosa (Tussac-grass), Lomaria magellanica (robusta), L. alpina, L. Boryana, Lycopodium insulare. Mean temperature, $41^{\circ}$ to $46^{\circ} \mathrm{F}$. No cultivation.

23. The Region of Mesembryanthema and Stapeliæ, South African Flora (Thunberg's Region).-These two genera, as well as the Ericeæ (Heaths), are very abundant. The latter family is found in greater quantity here than anywhere else. The region embraces the southern extremity of Africa, from the tropic of Capricorn to the Cape Coast. Iridaceæ, Pelargoniums, Aloineæ, Bruniaceæ, and Selaginaceæ, and various Gnaphaliums and Helichrysums, occur in this region. Pachylepis cupressoides and P. juniperoides are Cape Conifers. Thalictrum caffiorum and Conium africanum are South African species. On Table Mountain at the Cape, peculiar species of Disa are found. Many European grains and fruits are in cultivation along with Sorghum caffrorum and Convolvulus Batatas. In Natal, where the mountains rise to nearly 10,000 feet, Krauss distinguishes a coast or forest region where species of Rhizophora, Avicennia, Ficus, Tabernæmontana, Zygia, and Phœnix reclinata, are found; a hilly pasture region, with species of Acacia, Aloe, Euphorbia, Andropogon, and tropical Leguminosæ, Labiatæ, Acanthaceæ, and Scrophulariaceæ; a mountainous region with species of Podocarpus, Ixia, Hypoxis, Watsonia, also Ferns, Oyperaceæ, Orchids, Proteaceæ, and Geraniaceæ. Mean temperature, $54^{\circ}$ to $73^{\circ} \mathrm{F}$. Cultivated plants : European kinds of grain, fruit, and vegetables; also Batatas, Plantains, Tamarind, Guava, and Shaddock.

24. The Region of Epacridaceæ and Eucalypti, or Australian Flora (R. Brown's Region). - It comprehends the temperate parts of Australia beyond the tropics, with the Island of Tasmania or Van Diemen's Land. Besides the plants whence it receives its name, it is characterised by the orders Stackhousiaces and Tremandraces, and by the presence of a great number of Proteaceæ, Myrtaceæ, Stylidiaceæ, Restiaceæ, Diosmeæ, Casuarineæ, and Acacias. Araucaria (Eutassa) excelsa, the Norfolk Island Pine, forms one of the features of the region. It is one of the most peculiar Floras, but the vegetation is not profuse; the number of Australian species is probably 10,000. Baron von Mueller makes the following observations on the 
flora of Australia:-_" The flora of Australia approaches in its tropical portion to the plants of India, and in its extra-tropical portion to those of South Africa. The flora may be divided into a western, southern, eastern, and Tasmanian flora. In the western districts Leguminosæ and Proteaceæ predominate, forming one-fourth of the entire vegetation. Ferns and Grasses are rare. In the southern flora, Compositæ and Leguminosæ abound along with Salsolas, Myoporaceæ, Halorageaceæ, Caryophyllaceæ, and Cruciferæ. The genus Mesembryanthemum is here seen as a connecting link with the South African flora; Nitraria with the Siberian flora; Crantzia with the North American flora. In the eastern flora, Proteacex and Epacridaceæ are found, with fewer Compositæ than in the south, and a larger number of Ferns and Grasses than in the western district. On Brisbane mountains, near Moreton Bay, we meet with Araucaria (Eutassa) Bidwillii, the Bunya-Bunya, and in the same district Araucaria (Eutassa) Cunninghami, the Moreton Bay Pine. The Tasmanian flora is an insular one. Ferns abound, Goodeniaceæ are scarce, Loranthaceæ and Cæsalpinieæ are wanting. Plants are found belonging to the natural orders Stackhousiaceæ, Tremandraceæ, Proteaceæ, Stylidiaceæ, Myrtaceæ, Restiaceæ, Diosmeæ, Casuarinacer, and Mimoser. In south Australia, Compositæ form 1-8th of the whole vegetation; Compositæ and Leguminosæ form together one-third of the whole of the Dicotyledons. Nearly 100 of the plants now growing wild have been introduced from Europe and the Cape. The introduction of European culture is changing the aspect of Australia as well as its climate. Rain now falls where none did before. The flora of South Australia has been divided into two marked forms, that of the Grass-land and that of the Scrub. Grassland resembles European pastures. Along with it there are associated light park-like forests of Eucalypti, with their smooth stems robbed of their outer bark, standing at regular intervals, and their crowns never in contact with each other. In poorer soil Casuarinas grow, also gummiferous Acacias, as A. retinoides and pycnantha, and species of Bursaria, and Grevillea, along with occasional Melaleucas or Leptospermums, especially in the beds of rivers dried up in summer. The Scrub shows no turf; a few scattered Stipas and Neurachnes constitute the only grasses. There is profusion of bushes and small trees. The plants have a heath-like foliage or vertically-placed leaves, and their colour is of a dead blue-green in general. The Palm forms which occur in Australia are species of Livistona, Seaforthia, and Corypha. In the British colonies of Australia the European grains and fruits are cultivated. In Norfolk Island, which may be connected with the Australian flora, Araucaria (Eutassa) excelsa, the Norfolk Island Pine, grows to a great size. Van Diemen's Land contains 10 Coniferæ endemic to the island, according to Hooker. These are Cal- 
litris australis, Oyster-Bay Pine, 50-70 feet high; C. Gunnii, native Oypress, 6-10 feet; Arthrotaxis selaginoides, A. cupressoides, and A. laxifolia; Microcachrys tetragona, 15-20 feet; Podocarpus alpina, P. Lawrencii ; Phyllocladus asplenifolia, celery-topped or Adventure Bay Pine, 50-60 feet; Dacrydium Franklinii, Huon Pine, 60 to 100 feet high, with a diameter of 2 to 8 feet. The banks of the Huon river are clothed with the loftiest and most valuable timber-trees of the colony. Sir John Ross measured some trees 180 feet high and 28 in circumference. One tree was shown to him which exceeded 200 feet in height, and was 38 feet in circumference about 3 feet from the ground." The European plants of the Australian Alps, according to Mueller, are :-Turritis glabra, Sagina procumbens, Alchemilla vulgaris, Veronica serpyllifolia, Carex pyrenaica, C. echinata, C. canescens, C. Buxbaumii, Botry,chium Lunaria. In the Gipps' Land morasses Lysimachia vulgaris grows. Mean temperature, $53^{\circ}$ to $73^{\circ}$. In the British Colonies the European kinds of grain and fruit are cultivated.

25. The Region of New Zealand (Forster's Region).-This Flora, besides the plants peculiar to New Zealand, as Phormium tenax, New Zealand Flax, comprehends several others which belong to the extremities of America, Africa, and Australia. We find in these islands Corypha australis, the Australian or Southern PaIm, Tree Ferns, and Dracænas, forests of Coniferæ, and many Myrtaceæ.

The New Zealand Coniferæ consist of Dammara australis (Kaudi, Cowdie, or Kauri Pine), Podocarpus spicata (Mai or Matai), P. ferruginea (Miro or Maira), P. Totarra, P. dacrydioides (Kaikatia), P. excelsa (Kahika), and others ; also Dacrydium cupressimum (Rinu or the Dimon Pine), D. Colensoi, D. laxifolium, and Phyllocladus trichomanoides (Tauehaha). Many European plants are cultivated. The known flora of New Zealand amounts to about 1900 or 2000 species, of which 730 are flowering plants, thus making Phanerogams to Cryptogams nearly as 2 to 3 . The Phanerogamous flora of New Zealand shows a large amount of absolutely peculiar or endemic plants, which are said by Hooker to amount to 507 species, and to constitute more than 2-3ds of the whole. Among the orders to which the endemic species belong may be noticed Coniferæ, Scrophulariaceæ, Epacridaceæ, Compositæ, Araliaceæ, Umbelliferæ, Myrtaceæ, and Ranunculaces. The remaining 1-3d of the flora is thus analysed by Hooker:-193 species are Australian, 89 are South American, 77 species common to both these countries, 60 are European, and 50 are species of the Antarctic Islands, Fuegia, etc. Among the peculiar genera of New Zealand are enumerated Anisotome, Hoheria, Phormium, Carmichælia, Tupeia, and Alseuosmia. In New Zealand there are of European species 60 Phanerogams, 50 Mosses, 13 Hepatice, 45 Algæ, 50 Fungi, and 100 Lichens. The species of Veronica form 
an important feature in the flora, from their number, their beauty, and ubiquity, and from many forming large bushes. The flora of the Auckland group and Campbell's Island may be considered as a contimuation of that of New Zealand, differing only in being more typical of the antarctic regions. In the Auckland group the country is generally covered by Pteris esculenta, Leptospermum scoparium (Manuke or Tea-tree), Phormium tenax, and Cordyline stricta. We also meet with Vitex littoralis, Knightia excelsa (Rewa-Rewa), species of Metrosideros (M. robusta, or Rata), the Kauri Pine, Cyathea dealbata, Areca sapida, and numerous Ferns. Some European plants, as Cardamine hirsuta, Montia fontana and Callitriche, are found. The woods consist of 4 or 5 species of trees or large shrubs, which are enumerated by Hooker in the order of their abundance. 1. Metrosideros lucida. 2. Dracophyllum longifolium. 3. Panax simplex. 4. Veronica elliptica. 5. Coprosma foetidissima. Under the shade of these, near the sea-beach, about 15 different Ferns grow abundantly, the most remarkable of which is Aspidium venustum. Mean temperature between latitude $34^{\circ}$ and $36^{\circ}$ south, from $61^{\circ}$ to $63^{\circ}$. Many of the European plants are cultivated.*

Meyen divides the latitudinal range of vegetation into zones, taking for his basis the three ordinary divisions of the torrid, the temperate, and the frigid zone, and subdividing each hemisphere into eight smailler zones.

\section{Meyen's Phyto-Geographical Zones.}

\section{A.-TORRID ZONE.}

1. Equatorial Zone. - This extends $15^{\circ}$ on both sides of the equator, and has a mean annual temperature of $78 \frac{1}{2}^{\circ}$ to $82 \frac{1}{2}^{\circ} \mathrm{F}$. The forms characteristic of this zone are chiefly Palmæ, Musaceæ, arborescent Gramineæ, Pandanus, Scitamineæ, Orchids, and Lianas (gigantic twining plants, such as Aristolochias); besides plants belonging to the orders Malvaceæ, Anonaceæ, Anacardiaceæ, Artocarpeæ a section of Urticaceæ, Lecythidaceæ, Malpighiaceæ, Sapindaceæ, Cæsalpinieæ a section of Leguminosæ, Cedrelacer, and many others.

2. The Tropical Zone.-This reaches from the 15 th degree on each side of the equator to the tropics, in $23^{\circ}$ latitude. Mean temperature $73 \frac{1}{2}$ to $78 \frac{3}{4}^{\circ}$. Summer temperature, $80 \frac{1}{2}^{\circ}$ to $86^{\circ}$; winter temperature in the eastern coast countries, $59^{\circ}$. Besides many equatorial forms, as Palms, Musaceæ, Scitamineæ, Meliaceæ, Anonaceæ, Sapindaceæ, Orchidaceæ, Araceæ, and Lianas, there are in this zone Treeferns, and plants belonging to Convolvulaceæ, Melastomaceæ, and Piperacex.

* Coloured delineations of Schouw's Phyto-Geographic Regions are given in W. and A. K. Johnston's Physical Atlas. 


\section{B. - TEMPERATE ZONE.}

3. Sub-tropical Zone.-This extends from the tropics, $23^{\circ}$ to $34^{\circ}$ of latitude. Mean temperature $62 \frac{1}{2}^{\circ}$ to $71 \frac{1}{2}^{\circ}$; summer temperature, $73 \frac{1}{2}^{\circ}$ to $82 \frac{1}{2}^{\circ}$. There are many tropical fruits in this region. The winters are mild, and vegetation is green throughout the year. In the northern division of the zone, Palms and Bananas grow on the plains. The Date-palm, Doom-palm, Chamærops Palmetto, many succulent Mesembryaces and Crassulaceæ, arborescent Euphorbias, Camellia, Thea, Aucuba, and Magnolias, are met with. In the southern division are Proteaceæ, Myrtaceæ, Epacridaceæ, Ericaceæ, many Compositæ, Diosmer, Zamias, and Cactaceæ.

4. The warmer Temperate Zone.-It embraces the space between $34^{\circ}$ and $45^{\circ}$ of latitude, including the southern part of Europe, Asia Minor, north of China, and Japan. Mean temperature, 531. to $62 \frac{1}{2}^{\circ}$. Summer temperature in North America, ${ }^{\prime} 77^{\circ}$; in Europe, $75 \frac{1}{4}^{\circ}$ to $68^{\circ}$; in Eastern Asia, 821. to $32 \frac{1}{2}^{\circ}$; in Europe, $50^{\circ}$ to $34 \frac{3}{4}^{\circ}$; in Eastern Asia, 261. ${ }^{\circ}$. Many subtropical forms occur. Evergreen Dicotyledonous trees and shrubs, Cistuses, many species of Ericaceæ, Lauraceæ, and Myrtaceæ, and the Vine, are met with. In some parts of the zone, Solidagos and Asters, Magnolias and Smilaceæ, abound; while in others there are representatives of the Mimosa form, Myrtaceæ and Proteaceæ.

5. The cooler Temperate Zone.-This includes a belt from $45^{\circ}$ to $58^{\circ}$ latitude. Mean temperature, $43^{\circ}$ to $53 \frac{1}{2}^{\circ}$. Minimum summer temperature on the West Coast, $567_{4}^{\circ}$; in the interior of the Continent, $68^{\circ}$; minimum winter temperature in the interior of Europe, $14^{\circ}$. England, the north of France, and Germany, supply the characteristics of the vegetation of this zone. It embraces the region of Umbelliferæ, and Cruciferæ of Schouw. Meyen selects plants having a more marked physiognomic effect, such as ordinary Dicotyledonous trees, along with Abietineæ, and heaths covered with Calluna vulgaris.

6. The Subarctic Zone.-This reaches from $58^{\circ}$ latitude to the arctic circle, $66^{\circ}$. Mean temperature, $39 \frac{1}{4}^{\circ}$ to $43^{\circ}$. Summer temperature in the New World, $66 \frac{1}{4}^{\circ}$; in the old World, $60 \frac{3}{4}^{\circ}$ to $68^{\circ}$; Winter temperature of the former, $14^{\circ}$; of the latter (Western Europe), $24 \frac{3}{4}$; of the interior of Russia, $10 \frac{1}{2}^{\circ}$ to $14^{\circ}$. It is characterised by Firs and Willows in the northern hemisphere.

\section{C.-FRIGID ZONE.}

7. The Arctic Zone.-This extends from the Arctic circle, $66^{\circ}$ to $72^{\circ}$. Mean temperature, $28 \frac{1}{2}^{\circ}$ to $32^{\circ}$, and towards the eastern and continental portions, far below the freezing point. The Birch, and some Coniferæ, may be said to characterise this zone. We meet also with representatives of the genera Andromeda, Myrica, Alnus, Rhododendron, and Salix. 
Meyen's Comparative Exhibition of the Different Zones, with the Corresponding Regtons as given by Dr. Masters.

The elevations and temperatures are here given in round numbers.

\begin{tabular}{|c|c|c|c|c|c|c|c|c|c|c|c|}
\hline \multicolumn{3}{|c|}{ 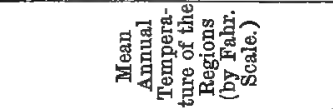 } & & 紫 & 等 & : & 点 & : & 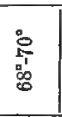 & 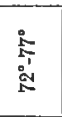 & $\begin{array}{l}\stackrel{\otimes}{0} \\
\stackrel{\leftrightarrow}{\infty} \\
\stackrel{\infty}{\infty}\end{array}$ \\
\hline \multicolumn{4}{|c|}{ 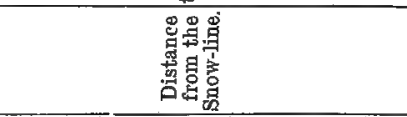 } & ষे & $\begin{array}{l}8 \\
\\
+4\end{array}$ & 8 & $\begin{array}{l}\text { ठ্ } \\
\infty\end{array}$ & $\begin{array}{l}\text { ¿ } \\
\stackrel{0}{0}\end{array}$ & $\begin{array}{l}\text { ठ } \\
\text { ơ }\end{array}$ & 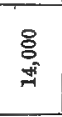 & $\begin{array}{l}\stackrel{8}{8} \\
\text { ئ }\end{array}$ \\
\hline 营 & 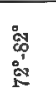 & 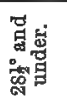 & 응 & & : & : & : & : & : & : & : \\
\hline 鰙 & 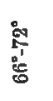 & 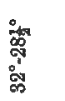 & $\underset{\square}{\circ}$ & $\begin{array}{l}8 \\
\dot{8} \\
\text { जे }\end{array}$ & & : & : & : & : & : & : \\
\hline 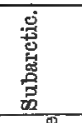 & $\begin{array}{l}\text { : } \\
\stackrel{0}{0} \\
\vdots \\
0 \\
0\end{array}$ & 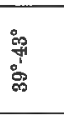 & $\stackrel{8}{0}$ & চ্ & $\begin{array}{l}8 \\
\text { 워 }\end{array}$ & & \multicolumn{5}{|c|}{ : } \\
\hline 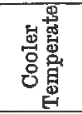 & 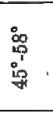 & 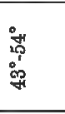 & $\begin{array}{c}8 \\
\vdots \\
\infty\end{array}$ & $\begin{array}{l}\circ \\
\stackrel{8}{0} \\
0^{\circ}\end{array}$ & $\begin{array}{l}8 \\
\\
4\end{array}$ & 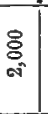 & & \multicolumn{3}{|r|}{ : } & : \\
\hline 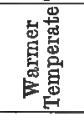 & 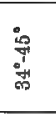 & 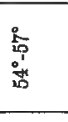 & 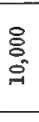 & $\begin{array}{c}8 \\
\\
\infty\end{array}$ & $\begin{array}{l}0 \\
\text { ठ } \\
0\end{array}$ & $\begin{array}{l}8 \\
8 \\
-+i\end{array}$ & 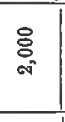 & & \multirow[t]{2}{*}{ : } & : & : \\
\hline 宫总总 & 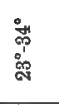 & 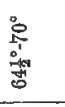 & 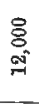 & $\begin{array}{l}8 \\
0 \\
0\end{array}$ & $\begin{array}{l}8 \\
\infty^{\circ}\end{array}$ & $\begin{array}{l}0 \\
0 \\
0 \\
0\end{array}$ & $\underset{8}{\stackrel{8}{\circ}}$ & ఫ্ণ & & \multicolumn{2}{|c|}{$: \quad:$} \\
\hline 宓 & 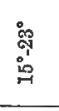 & 党 & $\begin{array}{l}\text { ○ } \\
\text { ơ }\end{array}$ & 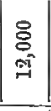 & 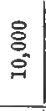 & $\begin{array}{l}8 \\
\\
\infty \\
\infty\end{array}$ & ర్ & $\underset{+}{8}$ & 总 & & : \\
\hline 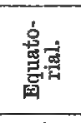 & 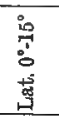 & 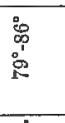 & \multirow[t]{2}{*}{$\begin{array}{l}\text { Oे } \\
0 \\
0 \\
0\end{array}$} & \multirow{2}{*}{ 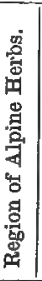 } & \multirow{2}{*}{ 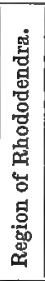 } & \multirow[b]{2}{*}{ 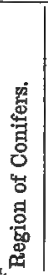 } & \multirow{2}{*}{ 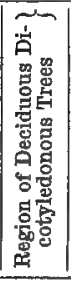 } & \multirow{2}{*}{ 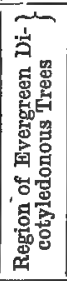 } & \multirow{2}{*}{ 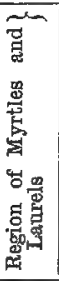 } & \multirow{2}{*}{ 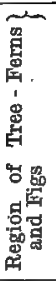 } & \multirow{2}{*}{ 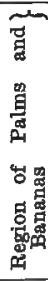 } \\
\hline 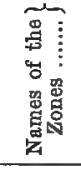 & 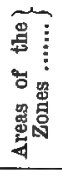 & 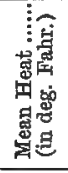 & & & & & & & & & \\
\hline \multicolumn{3}{|c|}{ 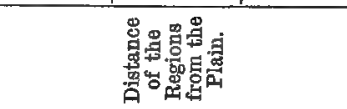 } & ठి & 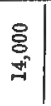 & $\begin{array}{l}\text { ఫ్ } \\
\text { ఫ्ञ }\end{array}$ & $\begin{array}{l}0 \\
\vdots \\
0 \\
0\end{array}$ & $\underset{\infty}{\stackrel{0}{0}}$ & $\underset{0}{8}$ & $\stackrel{8}{\circ}$ & ষ্ণ & $=$ \\
\hline
\end{tabular}


8. The Polar Zone.-This includes all lands from $72^{\circ}$ to $82^{\circ}$ latitude. The mean temperature of one point in this zone, viz Melville Island, is $1 \frac{1}{2}{ }^{\circ}$. In the Old World, the mean temperature is $16 \frac{1}{2}^{\circ}$. Summer temperature of the New World, $37 \frac{1}{2}^{\circ}$, and of the Old, $38 \frac{1}{4}^{\circ}$; Winter temperature, $-28^{\circ}$ in the $\mathrm{New}$, and $-21^{\circ}$ in the Old World. No trees nor bushes in this zone. Some Saxifrages, Ranunculi, Potentillas, species of Draba, Dryas, Parrya, and Phippsia, and numerous Cryptogamic plants, as Lichens, prevail in it.

\section{Altimudinal Range of Vegetation.}

Under this head we consider the changes produced in the physiognomy of vegetation on ascending mountains. It has reference to the distribution of plants in an altitudinal or hypsometrical point of view. This geographical range is best seen in the high mountains of tropical countries, where all gradations are met with, from the heat of the torrid zone to the cold of the frigid zone. Humboldt, in describing South American scenery, remarks :- "In the burning plains, scarce raised above the level of the Southern Ocean, we find Bananas, Cycadaceæ, and Palms in the greatest luxuriance; after them, shaded by the lofty sides of the valleys in the Andes, Tree Ferns; next in succession, bedewed by cool misty clouds, Cinchonas appear. When lofty trees cease, we come to Aralias, Thibaudias, and myrtle-leaved Andromedas; these are succeeded by Bejarias abounding in resin, and forming a purple belt around the mountains. In the stormy regions of the Paramos, the more lofty plants and showy flowering herbs disappear, and are succeeded by large meadows covered with gxasses, on which the Llama feeds. We now reach the bare trachytic rocks, on which the lowest tribes of plants flourish. Parmelias, Lecidias, and Leprarias, with their many-coloured sporules, form the flora of this inhospitable zone. Patches of recently fallen snow now begin to cover the last efforts of vegetable life, and then the line of eternal snow begins."

On the mountains of temperate regions the variety is rather less, but the change is"not less striking. "We begin to ascend the Alps, for instance, in the midst of warm vineyards, and pass through a succession of oaks, sweet-chestnuts, and beeches, till we gain the elevation of the more hardy pines and stunted birches, and tread on pastures fringed by borders of perpetual snow. At the elevation of 1950 feet the vine disappears; and at 1000 feet higher the sweetchestnuts cease to grow ; 1000 feet farther, and the oak is unable to maintain itself; the birch ceases to grow at an elevation of 4680 , and the spruce fir at the height of 5900 feet, beyond which no tree appears. The Rhododendron ferrugineum (the Rose of the Alps) then covers immense tracts, to the height of 7480 feet, and Salix herbacea creeps 200 or 300 feet higher, accompanied by a few Saxifrages, Gentians, 
and Grasses, while Lichens and Mosses struggle up to the imperishable barrier of perpetual snow."

On the Andes, at 13,000 to 15,000 feet, Humboldt found woolly species of Culcitium and Espeletia (C. nivalis, rufescens, reflexum, and E. grandiflora and argentea), Sida pichinchensis, Ranunculus nubigenus, Myrrhis andicola, and Fragaria aretioides ; and at 15,770 he detected Saxifraga Boussingaultii. The late Professor Jameson of Quito also reported on the Flora of the Andes. On the Himalaya of Sikkim Dr. Hooker observed five belts of vegetation :-1. Palms and Plantains; 2. Oaks and Laurels; 3. Pines; 4. Rhododendrons and Grass; 5. Rock and Snow. These belts are seen in proceeding from the bed of the Ratong up to the summit of Mon Lepcha and other mountains. Mr. New has given a notice of the Subalpine flora of Kilima Njaro, a mountain in Eastern Africa, $3^{\circ} .8$ lat., rising to the height of 20,000 feet, or nearly 5000 feet above the snow-line. The Flora is essentially that of the Cameroons. 1. Inhabited district: Plantain, Bananas, and Maize. Thermometer ranges from $59^{\circ} \mathrm{F}$. to $85^{\circ}$ F. 2. Thick Jungle. 3. Gigantic trees covered with moss. Herbaceous vegetation, chiefly European, Docks and Stinging Nettle. Vines abound. Frost at night. 4. Verdant hills with pasturage of clover. 5. Heath. 6. Bare hills. 7. Everlasting snow. Near the snow 20 plants were gathered, including species of Adenocarpus, Helichrysum, Artemisia, Blæria, Ericinella, Bartsia, Protea, and Gladiolus.

Desmouslins, in his Flora of the Pyrenees, mentions the limits of the following Alpine species :-

\begin{tabular}{|c|c|c|c|}
\hline $\mathrm{Coc}$ & $\begin{array}{l}\text { French Feet. } \\
5500 \text { to } 6000\end{array}$ & & French Feet. \\
\hline Herniaria pyrenaica & 3000 to 7500 & a corysoleuc & \\
\hline alus depressus & 7500 to 8400 & "elegans, cinerea, & \\
\hline pyrenaica & 8500 & badia ... & 9000 \\
\hline cularis pyrenaica & 9000 & Lecidea geographica & 9000 \\
\hline nictangium ciliatum & 8400 & Umbilicaria cylindrina & 6000 \\
\hline
\end{tabular}

Massot gives the following limits of ligneous plants on the Canigou in the Pyrenees, which rises to the height of 9136 feet:-

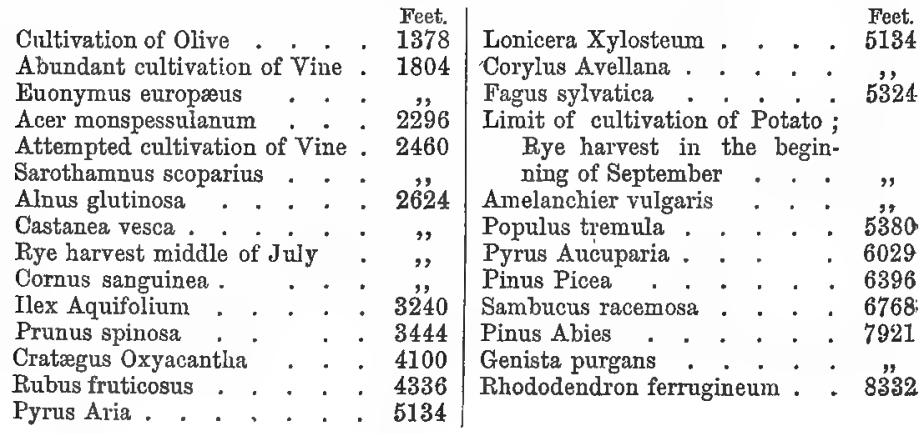


The following table by Mr. Moggridge shows the zones of Coniferæ from the Mediterranean to the crest of the Maritime Alps; the lowest and highest elevations are given in feet :-

\begin{tabular}{|c|c|c|c|}
\hline & & & \\
\hline Pinus Pinea & $\cdot$ & • & - \\
\hline P. maritima & . & . & - \\
\hline P. halepensis & . & & - \\
\hline Cupressus sempervirens & . & . & - \\
\hline Juniperus phoenicea & . & . & - \\
\hline Pinus sylvestris & . & & 1977 \\
\hline Abies excelsa & • & . & 1800 \\
\hline A. pectinata & & 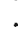 & 1900 \\
\hline Taxus baccata & . & . & - \\
\hline Larix europæa & & 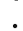 & 3500 \\
\hline Pinus Cembra & . & . & 4500 \\
\hline Juniperus communis & . & : & - \\
\hline
\end{tabular}

The starting points from the coast embraced the line from Monaco to Ventimiglia.

In central and southern Europe the proportion of Monocotyledons to Dicotyledons, which is as 1 to 4 in the 'plains, decreases with the elevation on dry mountain slopes, till at the height of 8526 feet it is as 1 to 7. Moist mountain slopes favour Monocotyledons, the proportion on them being as 1 to 3 .

The following table shows the height at,which corn and trees grow in different quarters of the globe:-

\begin{tabular}{|c|c|c|c|c|c|c|}
\hline \multirow[b]{3}{*}{$\begin{array}{l}\text { Inferior limit of per- } \\
\text { petual snow }\end{array}$} & \multicolumn{2}{|c|}{ Torrid Zone. } & \multicolumn{3}{|c|}{ Temperate Zone. } & \multirow{2}{*}{$\underbrace{\begin{array}{c}\text { Frigid } \\
\text { Zone. }\end{array}}_{\begin{array}{c}\text { Lapland, } \\
677^{\circ}-70^{\circ}\end{array}}$} \\
\hline & $\begin{array}{l}\text { Andes, } \\
0^{\circ} \text { Lat. }\end{array}$ & $\begin{array}{l}\text { Mountains } \\
\text { of Mexico, } \\
20^{\circ} \text { Lat. }\end{array}$ & $\begin{array}{l}\text { Caucasus, } \\
42^{\circ} 30^{\prime}\end{array}$ & $\underset{43^{\circ}}{\text { Pyreeses, }}$ & Alps, & \\
\hline & 15,200 feet. & 13,478 & 9,900 & 8,400 & 8,220 & 3,300 \\
\hline Upper limit of trees & $10,800,$, & 12,000 & 6,700 & 7,020 & 6,000 & 1,500 \\
\hline $\begin{array}{l}\text { Distance between } \\
\text { trees and snow . }\end{array}$ & 4,400 & 1,478 & 3,200 & 1,380 & 2,220 & 1,800 \\
\hline $\begin{array}{l}\text { Distance between } \\
\text { snow and corn. }\end{array}$ & $5,200 \quad$, & $\cdots$ & 3,780 & $\cdots$ & 4,200 & 2,700 \\
\hline
\end{tabular}

In the Himalaya, the upper limit of trees on the south side is marked by Quercus semecarpifolia, at 11,500 feet, and on the north side by Betula alba, at 14,000 feet. The Birch also forms the limit on the Caucasian mountains. On the Pyrenees and Alps, the limit of trees is marked by Coniferæ; on the Pyrenees, by Pinus uncinata; on the south side of the Alps, by Larix europæa, the Larch; and on the north side, by Abies excelsa. In Lapland the Birch forms the upper limit of trees. The upper limit of shrubs is determined by the Rhododendrons in the old World, on the Pyrenees at 8312 feet, and on the Alps at 7480; and by Bejarias on the Andes, at the height of 13,420 feet. On the south side of the Himalaya, Juniperus, Salix, 
and Ribes, form the upper limit of shrubs, at 11,500 feet; on the north, Genista versicolor ascends to 17,000 feet.

The following have been given by some authors as the zones of Alpine vegetation :-

1. Region of Lowland cultivation. Its extent of elevation is at the spot where the prevailing cultivated plants of the latitude cease to be productive. In mount Atna, it rises to 3300 feet; on Teneriffe to nearly 3000 (zone of vines). It embraces two zones of the Cactus and Euphorbia in the Canaries. In Madeira it embraces two regions of Spix and Martius; the region of tropical plants reaching to 700 feet, and the region of the vine, fruit, and corn, to 2300. In Norway, Sweden, and Finmark, it is narrow. In the Carpathians it rises to 1500 feet. Within the tropics it is a broad and important region. On the Andes, at Quito, it only ceases at 5000 or 6000 feet.

2. Region of Woods. A magnificent region in all Alpine districts, and well characterised on the Andes and Himalaya. In the Andes it reaches to 10,800 feet, and is characterised by Escallonia myrtilloides, Aralia avicennifolia, and Drymis Winteri ; on the mountains of Mexico to 12,000 feet, and is marked by Pinus Montezumx. Humboldt notices this region in Teneriffe. In Æstna it extends to 6200 feet; in the Canaries to 4080 ; in Madeira (region of chestrut) to 2950 . In Lapland it extends to 800 feet; in Finmark $70^{\circ}$ north latitude to 730 .

3. Region of Shrubs. Region of Retama (Spartium nubigenum) in Teneriffe. On the Pyrenees and Mont Blanc, it is extensively covered, to about 8500 feet, with Rhododendrons. In the Andes, about Quito, it reaches 13,000, and is conspicuous for its Bejarias and shrubby Compositæ. In Madeira it embraces Kuhl's regions of Spartium and Heath. On the Mountains of Lapland it attains from 2000 to 3000 feet, and is characterised by Betula nana, Vaccinnium, and Salix. In Finmark its limits are 1100. As Rhododendron hirsutum and ferrugineum succeed the arborescent region of the Swiss Alps, and $R$. ferrugineum that of the Pyrenees, so does R. Lapponum succeed the Conifers in Lapland, and $R$. caucasicum on the Caucasus.

4. Region of Grasses. These predominate in certain Alpine situations, and in certain parallels of latitude. In South Shetland, none of the islands exhibit any Phanerogamous vegetation, with the exception of straggling grass. In Melville Island, $75^{\circ}$ north latitude, the proportion of grasses to Phanerogamous plants is 1 to 5 ; in Great Britain, 1 to 121 . In the Andes the region is traced to Paramos, and occupies a space of 13,000 to 14,500 feet; here are large cattle farms. In the'Himalaya a fine greensward is often seen at 14,600 feet. In Teneriffe, it is distinguished by Humboldt. On the Swiss Alps, Poa annua exists at an elevation of 7400 feet.

5. Region of Cryptogamous plants. This is well marked in many places. Colonel Hall, on Chimboraço, under the Equator, at nearly 16,000 feet, found Draba aretoides, and Culcitium rufescens; still higher, a moss, which! may be considered as having attained the highest limit on the globe at wbich vegetable life exists. Lichens are the latest plants met with in ascending Teneriffe, the Himalaya mountains, and the Alps.

In the mountains of the torrid zone, the following regions are described by Meyen, corresponding to the zones given in his latitudinal range of vegetation (page 692):-

1. The region of Palms and Bananas, extending from the level of the sea to 1900 feet of altitude It corresponds to the Equatorial zone.

2. Region of Tree Ferms, and species of Ficus, extending from 1900 feet to 3800. (Tropical zone.) 
3. Region of Myrtaceæ and Lauraceæ, extending from 3800 to $\mathbf{5 7 0 0}$ feet. (Subtropical zone.)

4. Region of Evergreen Dicotyledonous trees, extending from 5700 to 7600 feet. (Warm Temperate zone.)

5. Region of Deciduous Dicotyledonous trees, extending from 7900 to 9500 feet. (Cool Temperate zone.) This is not always well marked in the Tropical and Equatorial zones, owing to want of sun and deficiency in moisture.

6. Region of Coniferæ, the Pine and Fir, extending from 9500 to 11,400 feet. (Sub-arctic zone.) On the Cordilleras of the Andes this zone is naarked by Escallonias. On the Scandinavian mountains and the Himalaya, Birches also occur.

7. Region of Alpine Shrubs or of Rhododendrons, extending from 11,400 to 13,300 feet. (Arctic zone.) On the Andes the zone is characterised by Bejarias, and on the Himalaya by Willows, Junipers, and species of Ribes.

8. Region of Alpine Plants and Lichens, extending from the upper limit of shrubs to the snow-line at $15,200_{k}$ feet. (Polar zone.) Lichens abound in this region. The Alpine herbs are mostly perennial. They are protected during winter by a covering of snow. Their flowers are often large and beautiful.

\section{Zones of Marine Vegetation.}

The ocean, as well as the land, possesses its vegetable forms, which vary according to their position, surrounding medium, relative degrees of pressure, and exposure to light. Harvey has observed that some seaweeds seem to be unaffected by circumstances of this nature, and are found equally abundant under opposed latitudes and in extremes of temperature. The lower we descend in the scale of marine vegetation the better is this illustrated. Some seaweeds, Harvey remarks, are cosmopolitan or pelagic, as species of Ulva and Enteromorpha, which are equally abundant in high northern and southern latitudes, as they are under the equator and in temperate regions. Codium tomentosum, Ceramium rubrum, C. diaphanum, species of Ectocarpus, and several Confervæ, have a range nearly as wide. Plocamium coccineum and Gelidium corneum are common to the Atlantic and Pacific oceans; Rhodymenia palmata, the common Dulse of Britain, is found at the Falkland Islands and Tasmania. Fucus tuberculatus extends from Ireland to the Cape of Good Hope ; Fucus vesiculosus occurs on the north-west coasts of America, and on the shores of Europe; while Desmarestia ligulata is found in the north Atlantic and Pacific oceans, as well as at the Cape of Good Hope and Cape Horn. Many Diatomacex are distributed from pole to pole, and are found in the lowest depths of the ocean. In the antarctic ocean, Hooker found Diatoms constituting a bank which stretched 200 miles north from the base of Victoria Barrier, at an average depth of 1800 feet.

Lamouroux has estimated the marine Algæ as ranging from 5000 to 6000 , which, he has shown, are distributed in various regions. Their distribution is much influenced by the degree of exposure to light, as well as by the motion of the waves. Great depths of the ocean are observed to exercise an influence on marine vegetation, 
similar to that which high mountains have on land plants. Some species, as the Laminariæ, are confined to the colder regions of the sea, while others, as the Sargassa, are only found where the mean temperature is considerable. The colour of Algæ may be regarded as being in a measure indicative of their depth of growth, the Algæ of green colour being generally found either in fresh water or in the shallower parts of the sea; the olive-coloured Algæ abound most between tide-marks; those of a red colour occur chiefly in the deep and dark parts of the sea.

Marine vegetation is found to vary both in its horizontal and vertical range. This difference is less decided than that which is. observable amongst land plants, owing probably to the greater uniformity of the ocean's temperature. The ocean has been divided into the following provinces of marine vegetation:-1. The Northern Ocean, from the Pole to the 60th parallel of north latitude. 2. The North Atlantic, between the 60th and 40th parallels, the province of the species of Fucus proper. 3. The Mediterranean, which is a subregion of the warmer temperate zone of the Atlantic, lying between the 40 th and $23 \mathrm{~d}$ northern parallels. 4. The tropical Atlantic, in which Sargassum abounds. 5. The Antaretic American regions from Chili to Cape Horn, and the whole circum-polar ocean south of $50^{\circ}$ of latitude. 6. The Australian and New Zealand province. 7. The Indian Ocean and Red Sea. 8. The Japan and China seas, besides certain provinces in the Pacific.

Forbes remarks of the vertical range, that one great marine zone lies between high and low water mark, varying in species according to the nature of the coast. This zone is generally uniform throughout the northern hemisphere. A second zone begins at low-water mark, and extends to a depth of 7 to 15 fathoms. The first of these, or the littoral zone, has been divided into sub-regions, in which certain marine species are found to prevail. 1. The sub-region of Fucus canaliculatus. 2. The sub-region of Lichina. 3. The sub-region of Fucus articulatus, F. nodosus, and Corallina officinalis. 4. The sub-region of Fucus serratus. The second or Laminarian zone includes the great Tangle sea-weeds and deep-water Fuci. The lowest forms of marine vegetation are alone met with in the deepest waters.

Marine vegetation is equally various in its latitudinal or horizontal range. In the North Sea and the British Channel Chorda Filum is found to constitute beds of 15 to 20 miles in length, and about 600 feet in breadth. Sargassum bacciferum constitutes the Gulf-weed of the Atlantic. The Sargasso sea occupies the eddy caused by the revolution of the Atlantic current, and extends over a space of 260,000 square miles. There are two principal banks of Gulf-weed ;-one, the largest, extending from $35^{\circ}$ to $36^{\circ}$ of north latitude, and a little west of the meridian of Fayal ; the other, a short way west of the Bahamas, 
between the 22d and 26th degrees of latitude. The Gulf-weed has never been found attached, but always floating. In that state it is healthy, pushing out new fronds, but no fructification has been seen. Harvey conjectures that it may be a pelagic variety of Sargassum vulgare, in the same way as the variety sub-ecostatus of Fucus vesiculosus has never been found attached, but growing in salt marshes. The Macrocystis pyrifera, and the Laminaria radiata are remarkable for the size and extent of their range. Immense green meadows of the Macrocystis are met with in every latitude. It requires a mean depth of 6 or 9 fathoms. Many specimens have been seen 300 feet long. Hooker estimated some, in a strait between the Crozet Islands, at 700 feet. It girds the globe in the southern temperate zone, but not in the tropics nor in the northern hemisphere. The tribe Fucoideæ are met with in abundance towards the poles, in which regions they are observed to attain their greatest bulk, diminishing and ceasing as they approach the Equator. Cystoseiree follow a course in the higher latitudes of the southern hemisphere similar to the Fucoidex. Hooker remarks that throughout all latitudes the two tribes Fucoider and Cystoseires form the prevailing marine vegetation, and that the genera of north cool zones are represented by others. in the south. The genera Fucus and Himanthalia, in the north, are represented by D'Urvillæa and Sarcophycus in the south; so also the genera Oystoseira and Halidrys of the former are represented by Cystophora and Scytothalia in the latter. Laminarias inhabit the antarctic ocean, and stretch northwards to the Cape of Good Hope. The red, green, and purple Lavers of the British seas are found at the Falkland Islands. Lessonia, with a stem 10 feet long and 12 inches in circumference, and its fronds 2-3 feet long and about 3 inches broad, is found in immense masses off the Patagonian regions. D'Urvillæa utilis is another large antarctic Seaweed, whieh, along with Lessonias, is often found at the Falkland Islands, formed by the surf into enormous vegetable cables, several hundred feet long, and thicker than the human body. The stems of Lessonia, when washed ashore, look like dead wood. Of the strictly antarctic marine plants, Hooker has identified 1-5th with those of Britain. In the north-west American Sea we meet with the remarkable Nereocystis, consisting of a very long thread-like stalk bearing a large vesicle and fronds ; while in the Australian and New Zealand regions we have the peculiar genera of Cystophora, Hormosira, Lansburghia, and others. At Vancouver's Island Laminarias occur of large size. Nereocystis Lutkiana has a stipe attaining the length of 300 feet, and Alarix have fronds 20-30 feet long. Georgetown, Tasmania, aecording to Harvey, is a good locality for Algre-all attaining a large size; Dasyas 2-3 feet long; Polysiphonia Hookeri even longer; Griffithsia setacea and G. corallina, nearly 2 feet long: Callithamnions, covering a large sheet of cartridge paper; a single 
plant of Laurencia dasyphylla supplied 20-30 good-sized specimens ; Mertensia and Claudia, large, but rare.

Species which are found abundantly in one sea may be scarcely present in another. This is seen in the difference between the marine vegetation of the Red Sea as compared with that of the Mediterranean, and that of the Mediterranean as contrasted with the Atlantic. The genera Sargassum and Caulerpa of the Red Sea are represented in the Mediterranean by very few, and those distinct, species. The genus Fucus, which is common in the Atlantic, is almost entirely wanting in the Mediterranean. Many Floridex which abound in the open seas do not adorn the rocks in the Mediterranean.

\section{DISTRIBUTION OF PLANTS IN BRITAIN.}

The climate of Britain is influenced by its geographical position, and the form and elevation of its surface. The climate is warmer than that of other places in the same parallel of latitude. Its most striking feature is the absence of extremes, either as regards cold or heat. It is, generally speaking, mild and damp. The eastern coasts partake more of the continental climate, while the western experience the insular or more equable climate. While the winters are mild, the heat of the three summer months, June, July, and August, in which the growth and ripening of crops take place, is by no means great, being very little above that due to the latitude. The heat of these months is most important. It should be noticed that the day and night may be both mild during these months, and thus give rise to a high average temperature. But the important thing is to have high temperature during the day, even although the nights are cool. The mean temperature varies from $46^{\circ}$ to $52^{\circ} \mathrm{F}$. Some of the mountains rise to the height of about 4400 feet, and there is a fall of $1^{\circ}$ of the thermometer for every 250 or 260 feet of ascent. Mr. Alezander Buchan gives the rate of decrease as $1^{\circ}$ for about every 300 feet of ascent. The number of Phanerogamous species of plants amounts to. about 1600 , while the Cryptogamous are probably about 6000 .

In considering the distribution of British plants as regard areas, Watson divides Britain (excluding Ireland and the Channel Islands) into 18 provinces, or groups of counties, which together constitute the basin of a principal river, or have some other physical peculiarity in common. In each of these provinces he notices the heights attained by the loftiest mountains. The details connected with those provinces are given in his Cybele Britannica. Many of the British species appear to have been introduced, and some appear to have 
little elaim to be included in the flora. Hence Mr. Watson distinguishes-

1. Native species, apparently aboriginal, such as Corylus, Calluna, Bellis, Teesdalia.

2. Denizen species, doubtfully native, although maintaining their habitats without the aid of man, as Aconitum, Pronia, Viola odorata, Impatiens noli-metangere.

3. Colonist species, or weeds occurring in cultivated land and about houses, perhaps owing their presence to the operations of man, as Adonis, Papaver, Githago.

4. Alien species, originally introduced, although now more or less naturalised, as Sempervivum, Mimulus, Hesperis, Camelina.

5. Incognitxe, or species reputed British but requiring confirmation, as Ranunculus gramineus, Gentiana acaulis, Tussilago alpina, Echinophora spinosa.

According to the nature of the localities in which British plants grow, they have been thus divided by Watson:-

1. Pratal, plants of meadows or rich and damp grass lands, as Geranium pratense.

2. Pascual, plants of pastures and grassy commons, as Trifolium repens.

3. Ericetal, plants of moors and heaths, as Calluna and Erica.

4. Uliginal, plants of swamps and boggy ground, as Drosera and Pinguicula.

5. Lacustral, immersed or floating plants, as Subularia aud Nymphæa.

6. Paludal, plants of wet marshy ground, as Typha.

7. Inundatal, plants of places liable to be inundated in wet weather, as. Nasturtium terrestre.

8. Viatical, plants of roadsides and rubbish heaps, as Lamium album and Urtica dioica.

9. Agrestal, plants of cultivated ground, as Papaver.

10. Glareal, plants of dry exposed ground, chiefly gravel or sand, as Ornithopus and Sedum acre.

11. Rupestral, rock and wall plants, as Cotyledon and Asplenium Rutamuraria.

12. Septal, hedge plants, as Bryony.

13. Sylvestral, plants of woods, as Paris.

14. Littoral, plants of the sea-shore, as Statice and Convolvulus Soldanella.

Taking a general view of the distribution of British flowering plants and Ferns (excluding the Hibernian and Sarnian species), Watson recognises the following types:-

1. British type-species widely spread over Britain-found in all or nearly all the 18 provinces, and forming more than one-third of the British species, such as Alnus glutinosa, Betula alba, Corylus Avellana, Salix capræa, Rosa canina, Lonicera Periclymenum, Hedera Helix, Sarothamnus scoparius, Calluna vulgaris, Ranunculus acris, Cerastium triviale, Potentilla Tormentilla, Trifolium repens, Stellaria media, Lotus cornieulatus, Bellis perennis, Senecio vulgaris, Carduus palustris, Leontodon Taraxacum, Myosotis arvensis, Prunella vulgaris, PIantago lanceolata, Polygonum aviculare, Urtica dioica, Potanaogeton natans, Lemna minor, Juncus effusus, Carex panicea, Poa annua, Festuca ovina, Anthoxanthum odoratum, Pteris aquilina, Polypodium vulgare, Lastrea Filix-mas.

2. English type-species chiefly or exclusively found in England, and decreasing in frequency northwards, constituting about 1-5th of the whole flora, as 
Rhamnus catharticus, Ulex nanus, Tamus communis, Bryonia dioica, Hottonia palustris, Chlora perfoliata, Sison Amomum, Moenchia erecta, Linaria Elatine, Ranunculus parviflorus, Lamium Galeobdolon, Hordeum pratense, Alopecurus agrestis, Ceterach officinarum, besides very local plants such as Cyperus Iongus and Cicendia filiformis.

3. Scottish type-species chiefly prevalent in Scotland or the north of England, forming about 1-20th of the flora, as Empetrum nigrum, Rubus sazatilis, Trollitus europæus, Geranium sylvaticum, Trientalis europæa, Habenaria albida, Haloscias scoticum, Mertensia maritima; also Primula farinosa, Goodyera repens, Corallorhiza innata, and Saxifraga Hirculus, which are comparatively limited in their distribution and partial in their localities, and which form a sort of intermediate type ; besides some very local plants such as Arenaria norvegica, Primula scotica, and Ajuga pyramidalis.

4. Highland type-species either limited to the Scottish Highlands or extending to the mountains of the north of England and Wales; a more boreal flora than the last, the species being especially limited to the mountains or their immediate vicinity, and forming probably about 1-15th of the flora, as Azalea procumbens, Veronica alpina, Alopecures alpinus, Phleum alpinum, Juncus trifidus, Sibbaldia procumbens, Erigeron alpinus, Gentiana nivalis; to these may added the following, which, however, descend also lower, Salix herbacea, Silene acaulis, Saxifraga stellaris, Oxyria reniformis, Thalictrum alpinum, Luzula spicata, Juncus triglumis, Rubus Chamæmorus, Epilobium alsinifolinm, Draba incana, Dryas octopetala, Alchemilla alpina, Arenaria norvegica, Primula scotica; likewise some very local species, as Lychnis alpina and Oxytropis campestris.

5. Germanic type-species chiefly seen in the east and south-east of England (bounded by the German ocean eastward) - forming about 1-15th or 1-20th of the flora, as Frankenia lævis, Anemone Pulsatilla, Reseda lutea, Silene noctiflora, Silene conica, Bupleurum tenuissimum, Pimpinella magna, Pulicaria vulgaris, Lactuca Scariola, Halimus pedunculatus, Aceras Anthropophora, Ophrys aranifera, Spartina stricta; also very local plants, such as Veronica verna.

6. Atlantic type-species found in the west and south-west of England and Wales, having a tendency to the western or Atlantic parts of the island-forming about 1-15th or 1-20th of the flora, as Sinapis monensis, Matthiola sinuata, Raphanus maritimus, Sedum anglicum, Cotyledon Unabilicus, Eufragia viscosa, Pinguicula lusitanica, Euphorbia Peplis and E. Portlandica, Scirpus Savii ; also more limited species, as Sibthorpia europæa, Erica vagans, E. ciliaris, Physospermum cornubiense, Polycarpum tetraphyllum, Adiantum Capillus-Veneris, Cynodon Dactylon.

7. Local or doubtful type-species which cannot be referred to any of the preceding types, as Potentilla rupestris, Lloydia serotina, confined to peculiar mountains in Wales, Draba aizoides and Cotoneaster vulgaris, found on the rocky coasts of Wales very locally, Draba muralis and Hutchinsia petræa; also Eriocanton septangulare, found in the Isle of Skye, and formerly included under Watson's Hebridean type.

The following are the 18 provinces, with their included counties, into which Britain is divided by Watson :-

1. Peninsula-Cornwall, Devon, Somerset.

2. Channel-Dorset, Wilts, Isle of Wight, Hants, Sussex.

3. Thames-Kent, Surrey, Berks, Oxford, Bucks, Middlesex, Herts, Essex.

4. Ouse-Suffolk, Norfolk, Cambridge, Bedford, Huntingdon, Northampton.

5. Severn-Gloucester, Worcester, Warwick, Stafford, Salop, Hereford, Monmouth.

6. South Wales-Glamorgan, Caermarthen, Pembroke, Cardigan, Brecon, Radnor.

7. North Wales-Montgomery, Merioneth, Caernarvon, Denbigh, Flint, Anglesea. 
8. Trent-Leicester, Rutland, Lincoln, Notts, Derby.

9. Mersey-Cheshire, Lancashire.

10. Humber-York.

11. Tyne-Durhan, Northumberland.

12. Lakes-Westmoreland, Cumberland (Isle of Man).

13. West Lowlands-Dumfries, Kirkcudbright, Wigton, Ayr, Lanark, Renfrew.

14. East Lowlands-Berwick, Roxburgh, Peebles, Selkirk, Haddington, Edinburgh, Linlithgow.

15. East Highlands-Fife, Kinross, Clackmannan, Stirling, 'Perth, Forfar, Kincardine, Aberdeen, Banff, Moray (including Nairn, Elgin, and the north. east of Inverness).

16. West Highlands-Dumbarton, Argyle, Inverness, westward of Loch Ericht, Isles adjacent from Arran to Skye.

17. North Highlands-Ross and Cromarty, Sutherland, Caithness.

18. North Isles-Hebrides, Orkney, Shetland.

Under these are included 38 sub-provinces, of which 18 are in South Britain, 10 in Mid-Britain, and 10 in North Britain.

As Mr. Watson does not include Ireland nor the Channel Islands in his work on the Distribution of British Plants, the following remarks on the Floras of these divisions of the kingdom are added:-

The Flora of Ireland has been specially reported on by Dr. D. Moore and Mr. A. G. More in their Cybele Hibernica. The mean annual temperature of Ireland is $50^{\circ} \mathrm{Fahr}$. The mean summer temperature is $2^{\circ}$ lower than that of Great Britain, while the mean winter temperature is $2^{\circ}$ higher. The Flora is remarkable for the occurrence of plants characteristic of the west and south of Europe, a list of which is given in noticing Forbes's Pyrenean Flora (p. 708). Bésides these there are plants which point to a former connection with North America, such as

Spiranthes gemmipara (Romanzoviana).

Naias flexilis.

Sisyrinchium anceps.

Eriocaulon septangulare.

Of plants belonging to Watson's Atlantic type, the following may be given as examples :-

Matthiola sinuata.

Cotyledon Umbilicus.

Crithmum maritimum.

Rubia peregrina.

Pinguicula lusitanica.

Euphorbia Paralias.
Euphorbia portlandica.

Alisma natans.

Scirpus Savii.

Rhynchospora fusca.

Asplenium lanceolatum.

Adiantum Capillus-veneris.

Of Watson's Germanic type there are few representatives. Among them are :-

Turritis glabra.

Lythrum hyssopifolia.

Monotropa Hypopitys.
Cynoglossum montanum.

Orchis pyramidalis.

Stratiotes aloides.

The mountains in Ireland reach about 3400 feet above the level 
of the sea. Among the plants belonging to Watson's Highland type are the following:-

Thalictrum alpinum.

Draba incana.

Silene acaulis.

Dryas octopetala.

Rubus Chamæmorus.

Alchemilla alpina.

Saxifraga stellaris. aizoides.
Saxifraga nivalis.

-__ oppositifolia.

Saussurea alpina.

Salix herbacea.

Allosorus (Cryptogramme) crispus.

Polystichum (Aspidium) Lonchitis.

Watson's Scottish and intermediate types are represented by such plants as :-

\author{
Trollius europæus. \\ Drosera anglica. \\ Alsine verna. \\ Potentilla fruticosa. \\ Rubus saxatilis. \\ Saxifraga Hirculus.
}

Haloscias (Ligusticum) scoticum. Lobelia Dortmanna.

Andromeda polifolia.

Pyrola secunda.

Carex filiformis.

Polypodium Phegopteris.

Moore estimates the flowering plants and ferns of Ireland at 1000 ; and the following are given as the plants which occur in Ireland without reaching Great Britain :-

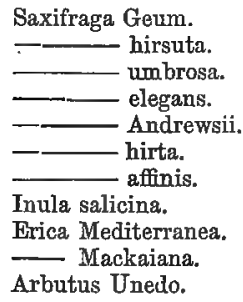

Dabeocia polifolia.

Pinguicula grandiflora.

Spiranthes Romanzoriana (gemmipara).

Neotinea intacta.

Sisyrinchium anceps.

Potamogeton longifolius.

Naias flexilis.

Carex Buxbaumii.

Asplenium acutum.

The Sarnian, or Channel Island Flora, has been examined by Professor C. C. Babington, and described in his Flora Sarnica. In general the flora may be said to resemble more that of the coast of France than that of the southern counties of England. Nearly all the species appear to be natives of the north-western parts of France. Babington enumerates about 850 species of flowering plants and ferns as occurring in the islands. Among the plants rare in England, or specially characteristic of the Channel Islands, the following may be mentioned :-

Ranunculus ophioglossifolius.

Erucastrum incanum.

Sinapis Cheiranthus.

Matthiola sinuata.
Helianthemun polifolium. Erodium moschatum. Hypericum linarifolium. Anthrolobium ebracteatum. 
Lotus angustissimus.

Thispidus.

Polycarpon tetraphyllum.

Bupleurum aristatum.

Centaurea Isnardi.

Cicendia filiformis.
Orobanche cærulea. barbata.

Linaria Pelisseriana.

Salvia clandestina.

Armeria plantaginea.

Spiranthes æstivalis.

Scirpus pungens.

The Alpine vegetation of Great Britain is best illustrated on the Scottish mountains. Among these may be noticed the Breadalbane range, embracing such mountains as Ben Lawers, Craig-Chailleach, Meal Ghyrdy, Ben More; and also the high mountains on the shores of Loch Lomond, such as Ben Lomond and Ben Voirlich. Another rich Alpine district is Clova, in Forfarshire, embracing the mountains which surround Glen Dole and Glen Fee, as well as those around Caenlochan, the highest of which is Glass Meal. The third important Alpine district as regards rare plants is Braemar. In that district occur Ben-muich-dhui, Lochnagar, Cairngorm, Benabourd, Ben Avon, Breriach, Cairntoul, and the mountains around Glen Callater and Glen Ceander.

In visiting these Scottish mountains, we, in the first instance, pass through the region of the common plants of the country, and reach the moorland district, abounding in peat, and where such plants as heather, heath, and Myrica Gale form the characteristic vegetation. The zone of lowland cultivation ends with Pteris aquilina, which extends to $1000-1200$ feet above the level of the sea. Above this we come to the regions of Alpine and Arctic plants. In the ascent we meet with the following plants:-

Malaxis paludosa.

Galium boreale.

Linnæa borealis.

Arctostaphylos Uva-ursi.

Antennaria dioica.

Rubus Chamæmorus.

Cornus suecica.

Tofieldia palustris.

Polygonum viviparum.

Alchemilla alpina.

Saxifraga aizoides.

$\longrightarrow$ hypnoides.

Oxyria reniformis.

Epilobium alpinum.

Saxifraga stellaris.

Juncus triglumis.

Epilobium alsinifolium.

Vaccinium uliginosum.

Potentilla maculata (Salisburgensis).

Pyrola secunda.

- rotundifolia.

Sesleria cærulea.
Betula nana.

Saxifraga oppositifolia.

Asplenium viride.

Polystichum Lonchitis.

Lycopodium annotinum.

Carex aquatilis.

Veronica serpyllifolia, var: humifusa.

Polypodium alpestre.

Sedurn Rhodiola.

Plantago maritima (alpine form).

Thalictrum alpinum.

Dryas octopetala.

Woodsia hyperborea.

Botrychium Lunaria.

Alopecurts alpinus.

Phleum alpinum.

Hieracium alpinum, and varieties.

Draba incana.

Carex atrata.

- capillaris.

Saxifraga nivalis.

Carex pulla (vesicaria, var. alpigena). 
Cerastium alpinum.

Veronica saxatilis.

- - alpina.

Solidago Virgaurea (dwarf form).

Saussurea alpina.

Sonchus alpinus.

Erigeron alpinus.

Poa alpina.

Silene acaulis.

Lychnis alpina.

Bartsia alpina.

Juncus castaneus.

Salix reticulata.

- lapponum.

- Sadleri.

Astragalus alpinus.

Oxytropis campestris.
Cystopteris montana.

Juncus biglumis. trifidus.

Gentiana nivalis.

Cherleria sedoides.

Sibbaldia procumbens.

Myosotis alpestris.

Carex rariflora.

- rupestris.

__ Vahlii (alpina).

- vaginata. frigida.

Cerastium trigynum.

Silena maritima.

Sagina nivalis.

Alsine rubella.

Saxifraga rivularis.

Carex lagopina.

On the summits of some of these mountains the following plants are met with :-

Juzula spicata.

Armeria maritima (alpine form).

Cochlearia officinalis, var. alpina.

Gnaphalium supinum.

Carex rigida.

Draba rupestris.

Salix herbacea.
Luzula arcuata.

Saxifraga cernua.

Andræa (several species).

Trichostomum lanuginosum.

Gyrophora (several species).

Cetraria nivalis.

Lecidea (several species).

Edward Forbes followed Watson in his views of distribution, and promulgated a theory in regard to the origin of the flora of Britain. He considers the vegetation of Great Britain and Ireland as composed of several floras, which are to be reckoned outposts separated by geological changes from more extended areas. The following five floras, according to him, make up the vegetation of Britain and Ireland :-

1. A west Pyrenean flora (Iberian or Asturian type), confined to the mountainous districts of the west and south-west of Ireland, characterised by botanical peculiarities, which depend on the presence of a few prolifie species belonging to the families Saxifragaceæ, Ericaceæ, Lentibulariaceæ, and Cruciferæ. The nearest parts where these plants are native is the north of Spain. The species are Saxifraga umbrosa, S. elegans, S. hirsuta, S. Geum, S. hirta, S. affinis, Erica Mackaiana, E. mediterranea, E. ciliaris, Dabeocia polifolia, Arbutus Unedo, Pinguicula grandiflora, Arabis ciliata, Sibthorpia europæa, Euphorbia hyberna, Simethis bicolor, Triehomanes radicans.

2. A flora in the south-west of England and south-east of Ireland (Armorican type), which is intimately related to that of the Channel Isles and the neighbouring coast of France (Brittany and Normandy). This is Watson's Atlantic type. In the Channel Isles we have such peculiar plants as Ranuuculus ophioglossifolius, Sinapis Cheiranthus, Erucastrum incanum, Arthrolobium ebracteatum, Linaria pelisseriana, Echium violaceum, Orchis laxiflora, Gymnogramme leptophylla, etc. Again, in the south-west of England, we meet with Helianthemum 
polifolium, Tamarix gallica, Hypericum linarifolium, Oxalis corniculata, Corrigiola littoralis, Physospermum cornubiense, Lobelia urens, Scilla autumnalis, Trichonema Columnæ, etc. While in the south-east of Ireland the following plants connect the flora with that of Devonshire and Cornwall :- Matthiola sinuata, Senebiera didyma, Linaria Elatine, Sibthorpia europæa, Erica vagans, Cicendia filiformis, and others.

3. The flora of the south-east of England, where the rocks of the Cretaceous system are chiefly developed, and in which many species occur common to this district and the opposite coast of France. This corresponds nearly to Watson's Germanic type. Among the characteristic plants may be noticed, Thlaspi perfoliatum, Linum perenne, Genista pilosa, Inula Conyza, Centaurea Calcitrapa, Phyteuma orbiculare, Gentiana Pneumonanthe, several species of Verbascum, Salvia pratensis, Ajuga Chamæpitys, and many chalk Orchids.

4. An alpine flora (Boreal or Scandinavian type), developed chiefly on the mountains of Scotland, and also partially on those of Cumberland and Wales. The species found on the latter are all, with the exception of Lloydia serotina, inhabitants also of the Scotch Highlands. The Scotch alpines all occur in Scandinavia, where they are associated with numerous additional species. This flora corresponds nearly to Watson's Highland type. It is represented in Shetland by Arenaria norvegica, and in Orkney by Primula scotica. It is largely developed on the Scottish Alps.

5. The general flora of the British islands, identical with that of central and western Europe, and which is called a Germanic flora. It corresponds to Watson's British, English, and Scottish types. It is a flora which overspreads many local floras throughout Europe, and gives a general character to the vegetation by the presence of such common species as Bellis perennis, Primula valgaris, Ranunculus acris, R. Ficaria, Cardamine hirsuta, and our most common trees and shrubs. Certain species are more limited in their distribution, and characterise particular districts. Some are limited to the eastern counties of England, others occur in Scotland and England, and not in Ireland. Certain species flourish best on limestone, others in sandy soils.

There are in Britain a few sporadic plants, which are met with only in one or two localities. Thus Oxytropis campestris is limited to a single rock in Glen Fee, Clova; Lychnis alpina to a small alpine summit, Little Gilrannoch in Clova, and Hobcarten Fell in Cumberland; Astragalus alpinus to a rock in Glen Dole, Clova, and to Little Craigindal, a mountain in Braemar; Saxifraga cernua to the summit of Ben Lawers; Carex lagopina to the summit of Lochnagar and Cairntoul, Aberdeenshire; Carex Grahami to a rock in Glen Fee, Clova; Carex frigida and Salix Sadleri to rocks above Loch Ceander, at the head of Glen Callater, Braemar; Phyllodoce cærulea to the Sow of Atholl; Saxifraga cæspiton to rocks on Ben Avon, Braemar ; Carex Buxbaumii to Harbour Island, Lough, Neagh; Potentilla rupestris to Craig Breidden, Montgomeryshire; Neotinea intacta, Castle Taylor, Galway; Spiranthes gemmipara, Bantry Bay; Epipogium Gmelini, Todston, Delamere Forest; Oypripodium Calecolus, Castle Eden Dene ; Lloydia serotina, Snowdon; Eriocaulon septangulare to the Isle of Skye in Scotland, and to Connemara in Ireland. The last-mentioned plant belongs to an American genus, and is supposed by some to have migrated from the New World. 
Forbes endeavours to prove that the specific identity, to any extent, of the plants of one area with those of another, depends on both areas forming, or having formed, part of the same specific centre, or on their having derived their vegetable population by transmission, through migration, over continuous or closely contiguous land, aided, in the case of alpine floras, by transportation on floating masses of ice. According to him, "the oldest of the floras now composing the vegetation of the British isles, is that of the mountains of the west of Ireland. Though an alpine flora, it is southernmost in character, and is quite distinct as a system from the floras of the Scottish and Welsh Alps. Its very southern character, its limitation, and its extreme isolation, are evidences of its antiquity, pointing to a period when a great mountain barrier extended across the Atlantic from Ireland to Spain. The distribution of the second flora, next in point of probable date, depended on the extension of a barrier, the traces of which still remain, from the west of France to the south-east of Britain, and thence to Ireland. The distribution of the third flora depended on the connection of the coast of France and England towards the eastern part of the channel. Of the former existence of this union no geologist doubts. The distribution of the fourth, or alpine flora of Scotland and Wales, was effected during the glacial period, when the mountain summits of Britain were low islands, or members of chains of islands, extending to the area of Norway through a glacial sea, and clothed with an arctic vegetation, which in the gradual upheaval of those islands and consequent change of climate, became limited to the summits of the new-formed and still existing mountains. The distribution of the fifth, or Germanic flora, depended on the upheaval of the bed of the glacial sea, and the consequent connection of Ireland with England, and of England with Germany, by great plains, the fragments of which still exist, and upon which lived the great elk, and other quadrupeds now extinct. The breaking up or submergence of the first barrier led to the destruction of the second; that of the second to that of the third; but the well-marked epoch of migration of the Germanic flora indicates the subsequent formation of the straits of Dover and of the Irish Sea, as now existing.

"To determine the probable geological epoch of the first or westIrish flora-a fragment, perhaps with that of north-western Spain, of a vegetation of the true Atlantic-we must seek among fossil plants for a starting-point. This we get in the flora of the London clay, or Eocene, which is tropical in character, and far anterior to the oldest of the existing floras. The geographical relations of the Miocene sea, indicated by the fossils of the crag, give an after-date certainly to the second and third of the above floras, if not to the first. The epoch of the red or middle crag was probably coeval with the second flora; that 
of the mammaliferous crag with the third. The date of the fourth is too evident to be questioned; and the glacial region in which it flourished is to be regarded as a local climate, of which no true traces, as far as animal life is concerned, exist southwards of the second and third barriers. This was the newer Pliocene epoch. The period of the fifth flora was that of the post-tertiary, when the present aspect of things was organised. Adopting such a view of the relations of these floras in time, the greatest difficulties in the way of changes of the earth's surface and destruction of barriers, deep sea being found where land (probably high land) was, are removed when we find that those greater changes must have happened during the epoch immediately subsequent to the Miocene period; for we have undoubted evidence that elsewhere, during that epoch, the Miocene sea-bed was raised 6000 feet in the chain of Taurus, and the barriers forming the westward boundary of the Asiatic Eocene lakes so completely annihilated, that a sea several hundred fathoms deep now takes their probable place. The changes required for the events which are supposed to be connected with the peculiar distribution of the British flora are not greater than these. The distribution of endemic animals, especially that of the terrestrial mollusca, seems to support these views."

D'Archiac says that in a botanical point of view it would perhaps be desirable to determine whether the external circumstances under which these five floras of Great Britain now live, such as latitude, altitude, temperature, winds, humidity or dryness, exposure, nature of the soil, greater or less distance from the coast, etc., are altogether insufficient to explain their different characters. We know that plants have very different geographical limits. Thus there are some which we meet with over an extent of $25^{\circ}$ in latitude, and much more in longitude, while others occupy only zones extremely restricted in both senses; it would therefore be useful to study the fire British floras in this point of view. The radiation of plants from a centre is by no means satisfactorily proved; and it may be asked, for example, What is the original centre from which the species common to North America and southern Europe could have radiated? D'Archiac thinks that inconvenience arises from an attempt to give an account of facts hitherto inexplicable in our science, by drawing from 'another science suppositions made, as it appears, with the sole view of these explanations, and for which there is no sufficient authority. Proofs drawn from geology must rest on more certain data, he thinks, than those which have been adduced by Professor Forbes.

On ascending lofty mountains in Britain, there is a marked variation in the nature of the vegetation. On Ben-muich-dhui, which attains an elevation of upwards of 4296 feet, Watson gives a full list of the species observed in succession. On leaving the plants of the low country we find Myrica Gale, extending on this mountain to 1400 
feet, and in succession we come to the upper limits of the following species :-Erica cinerea, Pinus sylvestris, Carex pauciflora, Pedicularis sylvatica, at 1838 feet; Tofieldia palustris, Erica Tetralix, at 2370 feet; Arctostaphylos Uva-Ursi, Thalictrum alpinum, Vaccinium VitisIdæa, Hieracium alpinum, Juniperus communis var. nana, at 2660 feet; Potentilla Tormentilla, Calluna vulgaris, at 2690 feet; Azalea procumbens, Armeria maritima, Cochlearia grœnlandica, Arabis petræa, Rubus Chamæmorus, Epilobium alpinum, E. angustifolium, Vaccinium uliginosum, Sibbaldia procumbens, Saxifraga stellaris, Alchemilla alpina, Empetrum nigrum, Juncus trifidus, Cnaphalium supinum, and on the summit Silene acaulis, Carex rigida, Luzula arcuata and L. spicata, Salix herbacea. Other lofty mountains, as Ben Lawers, 3984 feet, Ben Nevis, 4406 feet, exhibit similar changes in the vegetation.

Examples of the altitudinal limits of some alpine species are given below :-

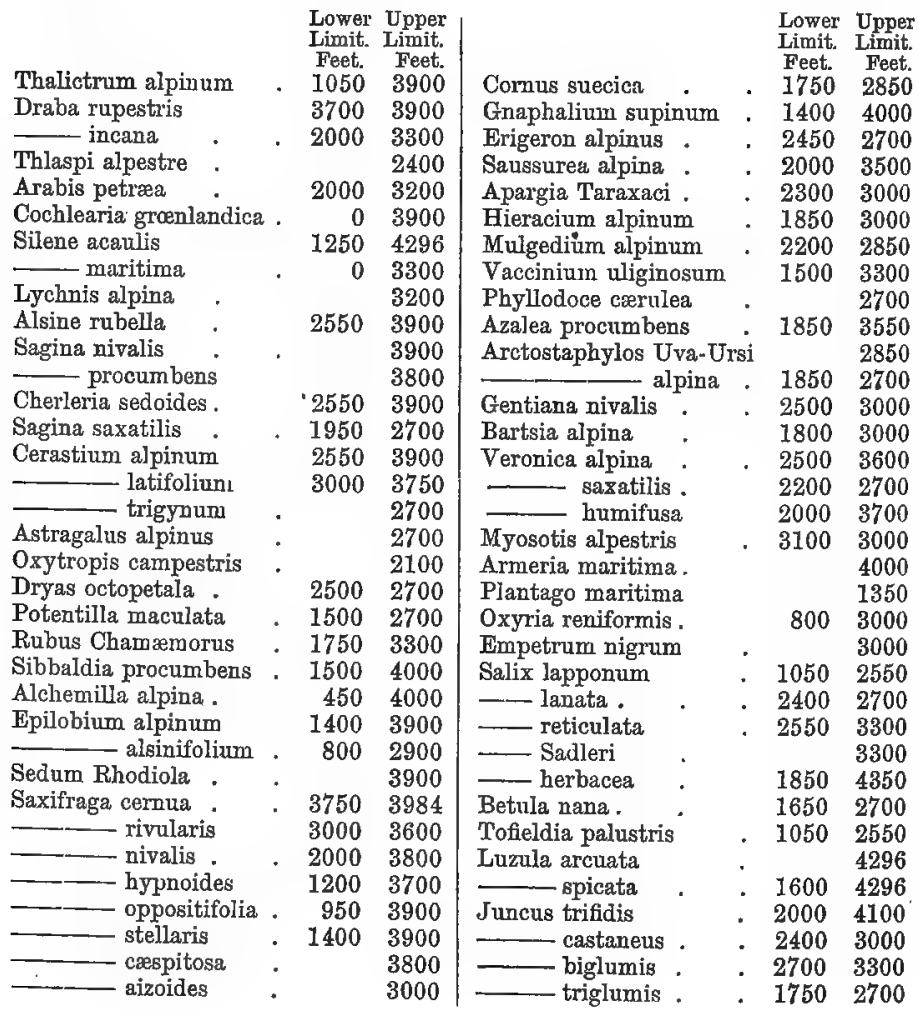




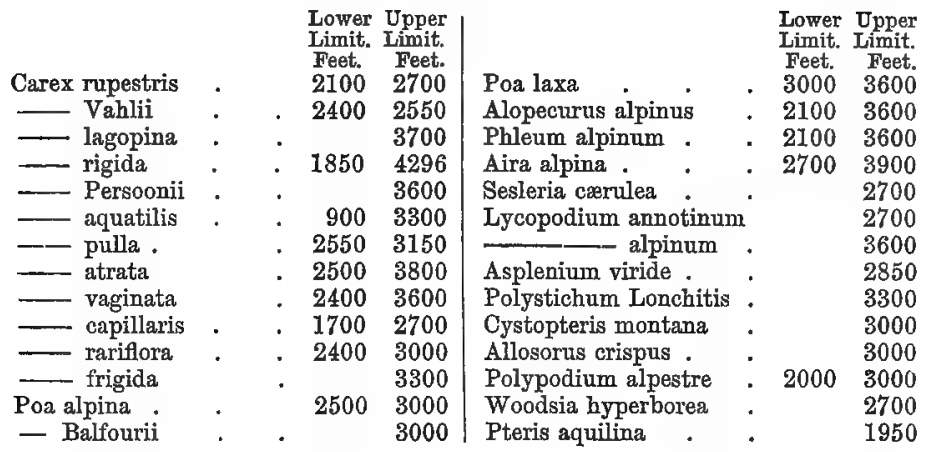

Considering British plants in climatic or ascending zones they are divided by Watson into-

I. Agrarian Region-limited generally by the Pteris aquilina, and indicating the region of Corn cultivation. In the Highlands it may be said to extend as high at least as 1200 feet.

It is subdivided into three zones :-

1. Infer-agrarian Zone-embracing all the country southward from the Dee and Humber, except the mountainous parts of Wales, and the higher hills and moors in the provinces of the Severn and Peninsula (including,Gloucester, Worcester, Warwick, Stafford, Hereford, Monmouth, Cornwall, Devon, and Somerset). Some of the peculiar species are Clematis Vitalba, Rubia peregrina, Cyperus Iongus, Erica ciliaris, Sibthorpia europæa, and Scilla autumnalis.

2. Mid-agrarian Zone-all the low grounds, clear from the mountains, situate between the entrance of the Clyde and ray on the north, and.those of the Humber and Dee on the south, also probably a narrow coast-line of the East Highlands, extending from Perth to Aberdeen, and possibly even to Inverness. Also a narrow belt extending round the hills of Wales. Rhamnus catharticus and Frangula, Tamus commúnis, Bryonia dioica, Acer canpestre, Ulex nanus, Viburnum Lantana, Euonymus europæus, and Cornus sanguinea, occur in this zone, but are not restricted to it. There is no Clematis.

3. Super-agrarian Zone-coast-line and low plains and moors in the north and north-west of Scotland, where alpine plants descend to the sea-shore; sueh as Thalictium alpinum, Draba incana, Saxifraga oppositifolia, Arctostaphylos alpina, and Dryas octopetala. Also other parts where the elevation of the ground leads to the production of the same species, or of such plants as Arctostaphylos Uva-Ursi, Saxifraga stellaris, Alchemilla alpina, Tofieldia palustris, Juncus triglumis, Also tracts of slight elevation in the proximity of high mountains, upon which a corresponding flora prevails. At its lower limits appear Ilex, Corylus, Quercus, Fraxinus, Lonicera, Cratægus and fruticose Rubi. 


\section{ARctic Region-characterised by the absence of Corn cultivation.}

1. Infer-arctic Zone-this has its terminal line at the limit of Erica Tetralix.

2. Mid-arctic Zone-space above the limit of Erica Tetralix, and within or below that of Calluna vulgaris. In this zone most of the rare alpine plants are found, such as Saxifraga nivalis, Gentiana nivalis, Erigeron alpinus, Astragalus alpinus, Veronica alpina, Alopecurus alpinus, etc.

3. Super-arctic Zone-above the limit of Calluna, characterised by Saxifraga cernua and rivularis, and Luzula arcuata.

These six climatic zones are thus presented in a tabular form :--

\section{Agrarian Region.}

1. Infer-agrarian Zone-Glematis, Rubia, Cyperus longus.

2. Mid-agramian Zone-Rhamnus catharticus without Clematis.

3. Super-agrarian Zone-Pteris aquilina without Rhamnus, etc.

\section{Arotio Region.}

4. Infer-arctic Zone-Erica Tetralix without Pteris.

5. Mid-arctic Zone-Calluna vulgaris without Erica.

6. Super-arctic Zone-Salix herbacea without Calluna.

The MARINE FLORA of Britain, with the exception of such plants as Zostera, Zannichellia, and Naias, is Cryptogamic, and does not present very definite zones of distribution. Cryptogamic plants in general can endure great vicissitudes of climatal conditions. Species of Ulva, Enteromorpha, and other genera, seem to be universally distributed from pole to pole. There are, however, Algæ of a higher type which are more limited, and the diffusion of which is determined by lines of coast and depth of water. British marine vegetation presents two well-marked types according to Forbes, a southern and a northern. The genera Padina and Halyseris have their northern limit on the south coast of England, where they are rare. The genera Cystoseira, Sporochnus, Cutleria, and certain species of Sphacelaria, Mesogloia, Rhodymenia, Gigartina, and Dictyota, mark out a southern region, including the British Channel and part of the east coast, the Bristol Channel, and the south and west of Ireland; while the presence of Odonthalia dentata, Rhodymenia cristata, R. lycopodioides, and Fucus Mackaii, characterise a northern flora, on the coasts of Scotland, the north of England and of Ireland.

On the shores of Britain, Dr. Greville remarks, it is easy to perceive that some species, as Gelidium corneum, Phyllophora rubens, and Sphærococcus coronopifolius, become more plentiful and more luxuriant as we travel from north to south; and, on the other hand, that Ptilota plumosa, Rhodomela lycopodioides, Rhodymenia sobolifera, and several others, occur more frequently and in a finer state as we approach the north. Odonthalia dentata and Rhodymenia cristata 
are confined to the northern parts of Great Britain, while the species of Cystoseira, Fucus tuberculatus, Halyseris polypodioides, Rhodymenia jubata, R. Teedii, Microcladia glandulosa, Rhodomela pinastroides, Laurencia tenuissima, Iridæa reniformis, and many others, are confined to the southern parts. The proportion of the different marine plants on the shores of Britain are as follows:-Melanospermeæ 1-5th, Rhodospermeæ 3-8ths, and Chlorospermeæ 1-4th of the whole.

Dickie, in speaking of the British Algæ which have a southern type, says that they may be classed under three heads-1. Those confined to the southern parts of Great Britain and Ireland; 2. Species of a more extensive range, which extend to the north of Ireland and south-west of Scotland; and 3. Those found abundantly in the south of England, and ranging along the western coasts of both islands as far as Orkney and Shetland. The species comprehended under these three heads, and amounting to at least 20, seem to be absent from a certain part of the east coast of Scotland. A considerable portion of them re-appear in Shetland and Orkney. He thinks that the appearance of southern forms of Algæ, at the extreme northern párts, is to be attributed to the influence of the Gulf Stream as regards temperature.

British Algæ are variously distributed, some in deep, others in shallow water. Laminaria digitata only extends to the low line of ebb during stream tides; L. saccharina flourishes along an inner belt, partially uncovered during the ebbs of the larger neaps; Fucus serratus and F. nodosus thrive in a zone still less deeply covered by water, and which even the lower neaps expose; F. vesiculosus occurs in a zone higher still, altering its form as it goes farther inland; $\mathrm{F}$. canaliculatus also rises high on rocky beaches. If land-springs escape from the beach there may be found an upper terminal zone of Confervæ mixed with Ulva latissima, Porphyra laciniata, and Enteromorpha compressa. In the lake of Stennis at Stromness, Orkney, there occur at the part where the sea enters, specimens of Fucus nodosus and vesiculosus in their ordinary form, along with Halidrys siliquosa. A little farther in, where there is more fresh water, Halidrys and Fucus nodosus disappear; F. vesiculosus becomes stunted, its air-bladders being altered or disappearing ; and ultimately it becomes narrowed like the Confervæ, and altogether loses its usual aspect.

The British marine plants, according to Forbes, are distributed in depth or bathymetrically in a series of zones or regions which extend from high-water mark down to the greatest explored depths. The first or littoral zone is that tract which lies between high and low water marks, and therefore is very variable in extent according to the amount of rise and fall of the tides. It has been divided into subregions characterised by the prevalence of certain marine species. 
1. The sub-region of Fucus canaliculatus. 2. The sub-region of Lichina. 3. The sub-region of Fucus vesiculosus, F. nodosus, and Corallina officinalis. 4. The sub-region of Fucus serratus. The littoral zone is succeeded by narrow belts of such Seaweeds as Himanthalia lorea, Conferva rupestris, Laurencia pinnatifida, Chondrus crispus, and C. mammillosus. The second or Laminarian zone commences at lowwater mark, and extends to a depth of from 7 to 15 fathoms. Here we meet with the great Tangle Seaweeds and deep water Fuci. Species of Laminaria, Rhodymenia, and Delesseria, are found in an upper sub-region of this zone. In the lower sub-region they are rare, and are succeeded by the coral-like Nullipore. The zones below them are entitled the Coralline zone, extending from 15 to 50 fathoms, and the region of the deep sea corals from 50 to beyond 100 fathoms. These zones do not exhibit any conspicuous vegetable forms ; they are characterised by the presence of certain animals.

Acclimatising of Puants. - It is commonly supposed that by length of time plants may be rendered fit to endure a climate which they could not stand in the first instance. It has been said that by slow degrees tender plants may become acclimatised to cold climates. Such a view, however, is totally inconsistent with the facts of the case. Each species of plant naturally bears a certain range of temperature, and it is impossible to extend that range. Many plants originally placed in greenhouses, and subsequently planted out, are held up as cases of acclimatisation. Aucuba japonica, coming from a warm climate, was at first treated in this country as a stove-plant, and was afterwards planted out, and was found to endure the climate, but no change was made in the constitution of the plant. It was capable from the first of enduring the cold of this climate. Aponogeton distachyum, an aquatic from the Cape, was cultivated long in the stoves of the Edinburgh Botanic Garden. A specimen was accidentally thrown into the open pond, where it has continued to live and flower for many years. The constitution of the plant is unaltered. It was able to bear a certain range of temperature, but cultivators were not aware of this in the first instance. Its roots are deep in the mud of the pond, which is supplied by springs. Plants sent from warm countries, and supposed to be delicate, are often quite hardy, inasmuch as their native locality has been high on the mountains. Such is the case with Araucaria imbricata from Chili, and with some Nepaul and Japan plants. Again, take the Potato, the Dahlia, Heliotrope, and Marvel of Peru, which have been long cultivated in Britain, and it will be seen that they are not in the slightest degree more hardy than when first introduced; they are injured by the frost just as easily as at first.

It is of importance to define accurately what is meant by saying that a plant suits a particular climate. It is not enough that it lives 
and sends forth leaves; it must be also able to produce flowers and seeds, and to elaborate the peculiar secretions and products on which its qualities depend. The seeds of Indian Hemp have been sent to this country, and the plant has grown well, even to the height of ten feet, with thick stems, vigorous leaves, and abundance of flowers; but they do not produce the churrus, a resinous matter which renders the plant valuable in India as a medicinal agent. Summer heat is wanting to enable the plant to perform all its functions. Such is also the case with Rhubarb, which, as regards the size and vigour of the plant, thrives in the climate of Britain, but the root does not produce a medicinal agent of the same quality as that grown in Chinese Tartary.

Something may be done by the art of the gardener to render halfhardy species of plants less tender. In this climate the great risk in such cases is frequently not so much the degree of cold, as the accession of it at the time when the plants cannot resist it, in consequence of being full of sap. Attention, therefore, should be paid to bringing the plants into as dry a state as possible at the beginning of winter. Lindley remarks that the only means of effecting this consists in thoroughly drained soil and an elevated situation-the first preventing a plant from filling itself with moisture during winter or overgrowing itself in summer, so as to enable it to ripen its wood; and the latter securing it from the action of those early frosts in autumn, or those late frosts in spring, which are so pernicious even to our own wild trees. In an elevated situation, a plant also escapes the risk of being stimulated into growth by a few days' warmth, succeeded by nipping colds, which so often occurs in our variable climate. 


\section{PART IV.}

\section{FOSSIL BOTANY OR VEGETABLE PALAONTOLOGY.}

THE history of vegetation could not be considered complete unless we endeavoured to give some account, however brief, of the plants which existed on the earth in its primeval state, during the extended geological epochs which elapsed before the establishment of the present order of things. This subject is alike interesting to the botanist and the geologist. It has sometimes been called Geo-Botany, and is an important section of Oryctology (óguxrós, dug out), or Palæontology ( $\pi \alpha \lambda \alpha \alpha^{\prime} s$, ancient, ö $v \tau \alpha$, beings). "Geology," Phillips says, "would never, perhaps, have escaped from the domain of empiricism and conjecture, but for the innumerable testimonies of elapsed periods and perished creations, which the stratified rocks of the globe present in the remains of ancient plants and animals. So many important questions concerning their nature, circumstances of existence, and mode of inhumation in the rocks, have been suggested by these interesting reliquiæ, and the natural sciences have received so powerful an impulse, and been directed with such great success to the solution of problems concerning the past history of the earth, that we scarcely feel disposed to dissent from the opinion, that without fossil Zoology and Botany there would have been no true Geology." The stratified crust of the globe is full of these monuments of vanished forms of life. They are of various kinds, are in different states of preservation, and occur very unequally in rocks of different kinds and ages. The remains of ancient vegetation are very abundant in the Coal-measures, the important combustible material derived from them, and which is vegetable matter in an altered form.

The regetation of the globe, during the different stages of its formation, has undergone very evident changes. The farther we recede in geological history from the present day, the greater is the difference between the fossil plants and those which now occupy the surface. At the time when the coal-beds were formed, the plants covering the earth belonged to genera and species not recognised at the present day. As we ascend higher, the similarity between the ancient and the modern flora increases, and in the latest 
stratified rocks we have in certain instances an identity in species and a considerable number of existing genera. At early epochs the flora appears to have been uniform, to have presented less diversity of forms than at present, and to have been similar in the different quarters of the globe. The vegetation also seems to indicate that the nature of the climate was different from that which characterises the countries in which these early fossil plants are now found.

Fossil plants are by no means so easily examined as recent species. They are seldom found in a complete state. It is very rare to find any traces of the flowers. The parts of fossil plants are usually separated from each other, and it is very difficult to ascertain what are the portions which should be associated together so as to complete a specimen. Specimens are sometimes preserved, so that the anatomical structure of the organs, especially of the stem, can be detected by thin microscopic slices placed under the microscope.

The mode in which plants are preserved in a fossil state may be referred to four principal classes:-1. Casts of the plants from which all the original substance and structure have been removed subsequently to the burial of the plants, and the greater or less induration of the rocks in which they are entombed. Such casts are occasionally hollow, but more frequently they are filled with the amorphous substance of the rock which has been forced into the cavity, and which exhibits, often with remarkable minuteness, the external aspects of the original specimen. 2. Carbonisation; in which the original substance of the plant has been chemically altered and converted into coal. All trace of the form of the original plant is generally lost, as is the case with the extensive beds of coal; but frequently, when the organism has been buried in a bed of clay, the external appearance is faithfully preserved, as in the ferns and other foliage found in the shales of the Coal-measures. 3. Infiltration; in which the vegetable tissues, though carbonised, retain their original form from the infiltration of some mineral in solution, chiefly lime or silex, which has filled the empty cells and vessels and preserved their original form. This mode of preservation occurs in the calcareous nodules in coal-beds, in the remarkable ash-beds discovered by $\mathrm{Mr}$. Wünsch in Arran, and generally in the secondary rocks. 4. Petrifaction; in which the structure is preserved, but the whole of the original substance has been replaced, atom for atom, by an inorganic substance, generally lime, silex, or some ore of iron. This is the condition of the beautiful fossils from Antigua, and of many stems and fruits from rocks of all ages in Britain. Silicified stems have been observed in various parts of the world, with the structure well preserved.

It is rare to find the organs of reproduction in such a state of preservation as to furnish distinct characters. It is chiefly from the fragments of stems, and the impressions of leaves, and some fruits, 
that the fossil botanist can draw conclusions. Besides this, fossil vegetables, thus reduced to some of their insulated organs, scarcely ever present them in such a state of preservation as to allow them to be studied in all their constituent parts. Sometimes the internal structure of the stem can be traced, and by examination under the microscope the nature of its woody tissue may be determined. In this way some fossilised woods have been referred to the Coniferous tribe, in consequence of the presence of punctated woody tissue (figs. 904-907). Fossil woods have been shown by chemical"tests to contain portions of vegetable tissue, cemented into a mass by silica. In some cases the vessels and cells are separately silicified without being united into a compact mass. In these instances the wood breaks down easily. At times the internal structure is obliterated, and it is only from the external configuration, the nature of the outer covering, and the scars of the leaves, that any conclusions can be drawn. The leaves often furnish important and valuable characters, and, in the case of fossil ferns, their form, divisions, and venation, supply distinguishing marks. The leaves, however, are generally isolated, and are rarely found in connection with the stems. Thus, the separation of the different parts of the plant, and, in most cases, their imperfect state of preservation, are great obstacles to the determination of fossil plants by, a comparison with those which now exist on the earth. Before, then, endeavouring to compare a fossil vegetable with living vegetables, it is necessary to put together, with as much exactness as possible, according to the parts preserved, and the general data of vegetable anatomy and organography, the portions of the plant under examination; to contrast these portions with the other organs of the same plant, searching for their points of attachment, their forms and vascular connections, being guided generally by traces of structure rather than by exterior form; and by endeavouring to reconstruct a vegetable by bringing together all fragments from the same fossil beds, which may belong to the same plant. The connection of the different parts of the same plant is of the greatest importance in vegetable palæontology, as from their fragmentary nature many difficulties arise. These difficulties are increased as we go back to the earliest geological epochs, for the farther they are removed from the present state of things, the greater are the differences between the fossil and living plants. Dr. Hooker remarks, that the knowledge of recent botany required to throw light upon the study of fossil plants, and the origin of coal, must be both varied and extended. "Some acquaintance with systematic botany is the first requisite; through this alone can any approximation to the living affinities of the fossil be obtained. It should embrace not only a knowledge of the principal groups, or natural orders under which all plants are arranged, but a familiarity with vegetable anatomy; for when the stem or trunk alone is preserved 
which is often the case, a minute examination of its tissues is the sole method of determining its position in the Natural series. There must also be some general ideas of the vegetation both of the tropics and cooler latitndes, of mountain-chains, table-lands, valleys, and estuaries;

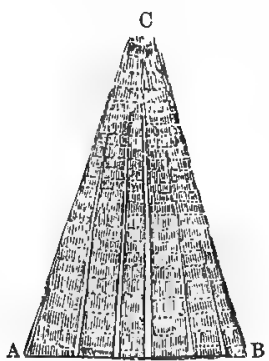

Fig. 904.

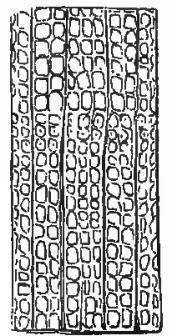

Fig. 905 .

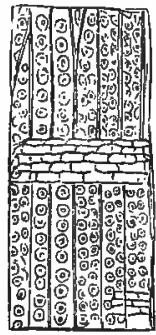

Fig. 906.

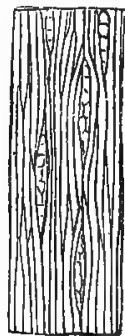

Fig. 907.

more especially of countries characterised by equable, and by excessive or extreme climates, as compared with continents, and of humid and desert districts; in short, of all the complex associations with, or dependence of botanical characters upon, surface, soil, and climate, which the globe presents."

Many of the fossil plants of the tertiary or recent strata may be referred to genera at present existing, and merely present specific differences; such as pines, elms, beeches, maples, etc. Those of the secondary strata may, in general, be referred to known families, but in most instances require the formation of new genera; while those of the older strata, in numerous instances, cannot be classed in existing families, and must constitute new groups. From all the investigations of fossil botanists, however, it appears that the same great types existed in a former state as at the present day, viz. Thallogens, Cellular Cryptogams, Acrogens, Vascular Cryptogams, Monocotyledons, and Dicotyledons (including Angiosperms and Gymnosperms). The relative proportion of these classes, however, has been different from that of the present day, and the predominance of certain forms has given characters to the vegetation of different epochs.

Brongniart gives the following division of fossil plants :-

1. Amphigenous Cryptogamous Plants, Cellular Cryptogams, or Thallogens, which he subdivides into two classes, Fungi and Algæ.

Figs. 904-907. The structure of wood in recent Conifere, to illustrate the appearances presented by some fossil woods. wood, of the natural size, Fig. 905. A section of the same wood seen under the

Fig. 904. Transverse section of a piece of Coniferous microscope. The medullary rays and woody tubes seen without any large porous vessels. Fig. 906. Longitudinal section of the same, in the direction в C, magnified. A medullary ray seen crossing the woody tubes, which are marked by discs, in one or more rows. Fig. 907. Section of the same in the direction A B, perpendicular to the medullary rays, which are seen at intervals between the woody fibres. 
2. Acrogenous Cryptogamous Plants, comprehending two classes, Musci and Filicales ; the latter'being divided into five families-Ferns, Narsileacex, Characeæ, Lycopodiaceæ, and Equisetaceæ.

3. Dicotyledonous Phanerogamous Plants, of which he enumerates the several families, indicating the characters which show their affinity to the same families of living vegetables.

\section{Monocotyledonous Plants.!}

When the analogy between a fossil and a living plant is such that the difference is not greater than occurs among the individuals included in a species of the living genus, then the fossil and living plant may be considered identical, and the epithet of fossil is applied to the name of the plant. If, on the other hand, the fossil presents distinct specific characters, but does not differ more from living species than these species differ among themselves, then it is looked upon as a new species of the genus, as Alnus primæva, Quercus Lignitum, - Ulmus Bronnii, and Pinus Palæostrobus. If the differences are well marked, but at the same time the organ which represents them is not of sufficient importance to induce the belief that the plant differs from others of the genus in all its essential organs, then the termination ites is added to the name of the genus. Thus, Lycopodites is a genus of fossil plants allied to Lycopodium, apparently not differing, so far as known, in essential and important parts; so also Zamites is a genus allied to Zamia, Thuites to Thuia, Taxites to Taxus. If a fossil plant, although presenting several essential characters of a family, yet differs in the fossilised organ from all the known genera of the family, as much or more than these genera do among themselves, then it is to be considered as a new genus different from those actually existing. This will be seen in many of the coal fossils, as Sigillaria and Lepidodendron.

The rocks of which the globe is composed are divided into two great classes, those which contain fossil remains, and which are called Fossiliferous, and those having no such remains, and which are designated Non-fossiliferous or Azoic ( $\alpha$, privative, and 'ऊ'́, life). The igneous unstratified rocks, included under the names of Granitic and Trappean, show no appearance of animal or vegetable remains. Trap rocks, however, have in some cases covered or enclosed vegetable structures, and these are found in an altered condition. Thus, in Antrim, near the Giant's Causeway, deposits containing vegetable remains occur interstratified with basaltic rocks. These remains are of miocene age, and have been referred to coniferous plants, beeches, oaks, plane-trees, etc. Plants of the same kind have been discovered in a similar position by the Duke of Argyll in the island of Mull. In trap rocks near Edinburgh, lignite with distinct structure has also been detected. Several beds of ash formed into solid compact rock by in- 
filtrated carbonate of lime occur in the north-east of Arran, which contain numerous stems, branches, and fruits of carboniferous plants. These represent the remains of successive forests which grew on this locality, and were one after the other destroyed by the ash showers poured forth from a neighbouring volcano during its intermittent periods of aetivity.

Fossil remains are extremely rare in certain rocks, which, from the changes they have undergone, were denominated by Hutton metamorphic. These include Gneiss and Mica-slate, which are stratified rocks subsequently altered by the effects of heat, having been so completely metamorphosed that the traces of organisms have been nearly obliterated. Nevertheless, recognisable traces of plant and animal remains have been found in what were recently thought to be azoic rocks. The absence of organic remains in rocks, however, is not always sufficient to enable us to state that these rocks were formed before animals or vegetables existed.

The stratified rocks which contain fossils have been divided into

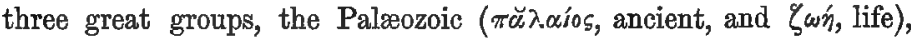
the Secondary, and the Tertiary; or into Palæozoic and Neozoic (vsós,

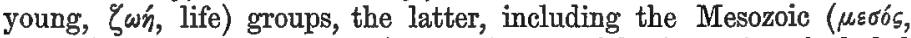
middle) and the Cainozoic (xolvos, fresh). The formations included under these are exhibited in the following table, taken from Lyell's Manual of Geology:-

1. Recent.

2. Post Pliocene.

3. Newer Pliocene.

4. Older Pliocene.

5. Upper Miocene.

6. Lower Miocene.

7. Upper Eocene.

8. Midale Eocene.

9. Lower Eocene.

10. Maestricht Becls.

11. White Chall.

12. Chloritic Series.

13. Gault.

14. Neocomian.

15. Wealden.

16. Purbeck Beds.

17. Portland Stone.

18. Kimmeridge Clay.

19. Coral Rag.

20. Oxford Clay.

21. Great or Bath Oolite.

22. Inferior Oolite.

23. Lias.

24. Upper Trias.

25. Middle Trias.

26. Lower Trias.

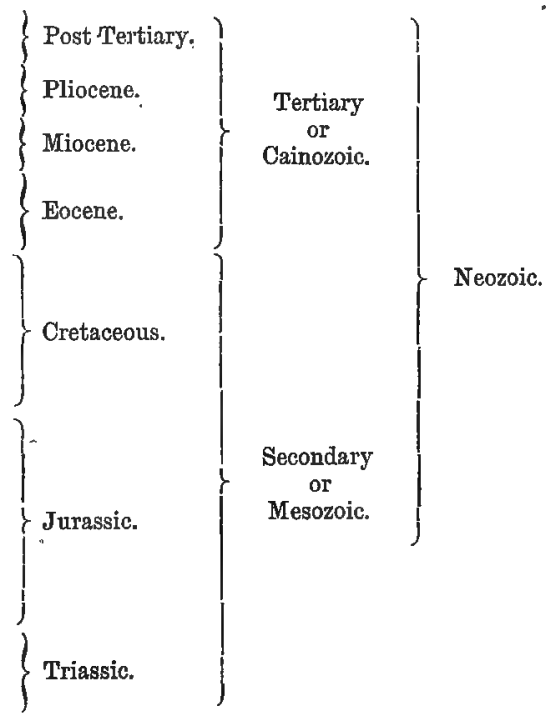


27. Permian.

28. Coal Measures.

30. Upper

31. Middle Devonian.

32. Lower

33. Upper

34. Lower Silurian.

35. Upper

36. Lower Cambrian. . Cambrian.

37. Upper

38. Lower Laurentian.

Devonian.

Silurian.

Laurentian.

The plants found in different strata are either terrestrial or aquatic, and the latter exhibit species allied to the salt and fresh water plants of the present day. Their state of preservation depends much on their structure. Cellular plants have probably in a great measure been destroyed, and hence their rarity; while those having a woody structure have been preserved. The following enumeration has been compiled from Schimper's Traitê de Paténtologie Végétale. It is only an approximation to the number of fossil plants described in the various formations, as it includes many species said to be doubtful, and many which are known merely by fragments of stems, or leaves, fruits, etc.- the affinity of which cannot be accurately determined at present :-

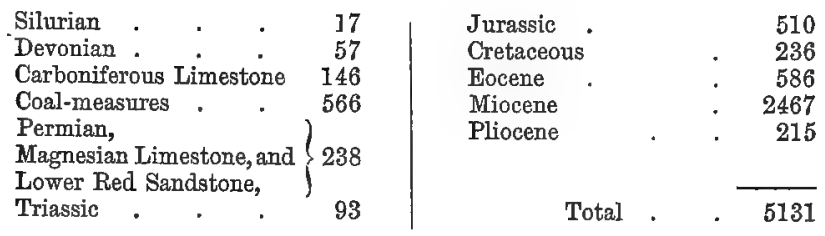

The following is a general statement of the number of fossil genera and species belonging to the different classes and sub-classes of the vegetable kingdom :-

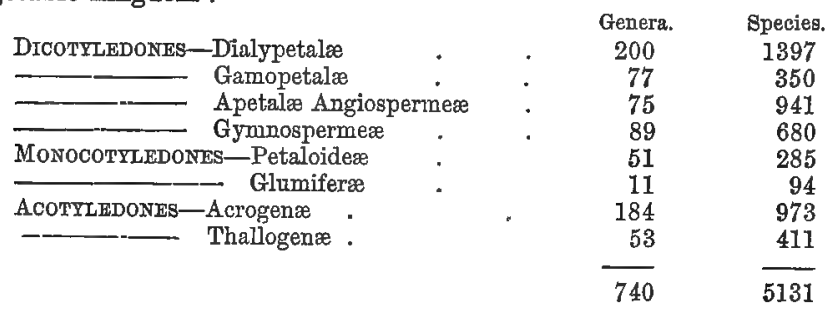


Class I.-Dicotyledones.

1. Thalamifloree.

Ranunculaceæ. Magnoliaceæ.

Anonacer.

Menispermaceæ.

Berberidaceæ.

Celastraceæ. Hippocrateaceæ.

Rhamnaceæ.

Anacardiaceæ.
Nymphæaceæ. Crucifere. Cistaceæ.

Violacer.

Malvaceæ.
Byttneriaceæ.

Tiliaceæ.

Ternstromiaceæ. Malpighiacere. Aceracea.
Sapindaceæ.

Vitaceæ. Pittosporacere. Zygophyllacez. Xanthoxylaceæ.

2. Calyciflora, Polypetala.

\begin{tabular}{l|l|l} 
Burseraceæ. & Melastomaceæ. & Saxifragaceæ. \\
Leguminosæ. & Myrtaceæ. & Hamamelidaceæ. \\
Rosaceæ. & Halorageaceæ. & Umbelliferæ. \\
Combretaceæ. & Crassulaceæ. & Araliaceæ.
\end{tabular}

Cornaceæ.

3. Calyciflorce, Gomopetaloe.

Caprifoliaceæ. | Rubiaceæ. | Valerianaceæ. | Compositæ.

Vacciniaceæ.

4. Corollifloro.

Ericaceæ.

Aquifoliaceæ.

Sapotaceæ.

Myrsinaceæ.

Nyctaginacer.

Chenopodiaceæ.

Polygonacer.

Lauraceæ.

Proteacer.

Elæagnaceæ.

Oleacer.

Asclepiadaceæ.

Apocynaceæ.

Gentianaceæ.

\section{Bignoniaceæ. \\ Convolvalaces. \\ Cordiaceæ. \\ Boraginaceæ.}

Solanaceæ.

Scrophulariacex.

Verbenaceæ.

\section{Monochlamydece, Angiospermece.}

Thymelæaceæ. Samydacer. Homaliaceæ. Santalaceæ. Loranthacer. Aristolochiaceæ.
Euphorbiaceæ. Urticaceæ.

Ulmaceæ.

Moracex.

Monimiaceæ.

Salicacer.
Myricaceæ. Casuarinaceæ.

Betulaceæ.

Platanaceæ.

Corylaceæ.

Juglandacex.

6. Monochlamydea, Gymnospermea.

Coniferæ. | Cycadaceæ.

Class II.-MoNocotruedones.

1. Petaloideo.

Hydrocharidaceæ.

Zingiberaceæ.

Marantaceæ.

Musacere.

\section{Iridaceæ. Amaryllidaceæ. Bromeliaceæ. Liliaceæ.}

Smilaceæ.
Juncaceæ.
Palmæ.
Pandanaceæ.

Typhaceæ. Araceæ. Naiadacex.

2. Glumiferce.

Cyperaceæ. 1 Gramineæ.

Class III.-ACOTYLEDONES.

1. Acrogence.

Equisetaceæ. Filices.

\section{Rhizocarpeæ. Lycopodiaceæ. \\ Musci. \\ Hepaticæ.}

2. Thallogenoe.

Lichenes.

Fungi.

! Characeæ.

Alga. 
Fossil Plants in Different Strata.-The plants in the stratified rocks are either of a marine, fluviatile, lacustrine, or terrestrial nature, according to the state of the globe at the period of their deposition. The condition of the strata as regards fossils may depend in some measure on the depth at which they were deposited under the waters of the globe. The state of preservation depends much on the nature of the plant in regard to its anatomical structure. Cellular plants, which are easily destroyed, have in a great measure disappeared, while plants which resist well the decomposing action of water and other agents, such as ferns, occur in great abundance. In the Silurian system, the fossils consist chiefly of invertebrate animals. Lignite has been detected by Hugh Miller in the Old Red Sandstone of the north, and has been referred to some coniferous plants by Nicol. In the Carboniferous system fossil plants occur in vast quantity. With the Palæozoic series one great epoch in the Rock formations was concluded, and a change took place so as to usher in the Secondary series. In the Triassic system the fossil remains are few and local, while in the Jurassic and Cretaceous systems they are much more numerous. With the Secondary series of strata a general condition of the globe ended, and a new one commenced with the Tertiary strata. In these we meet with fossil remains nearly resembling or identical with the existing races. The names given to the groups indicate this. In the Eocene group (’’ús, dawn, and ravvós, fresh) we meet with a certain proportion of living shells. In the Miocene ( $\mu$ siwn, less) the number of living species increases, although still less in number than the extinct ones; while in the Pliocene ( $\pi \lambda_{\varepsilon} i \omega v$, more) the recent shells outnumber the extinct ones. The differences between the organic contents of one system and another are in proportion to the interval of geological time elapsed between them; and the older the rocks the more are the fossils distinct from the plants of the present day. The systems of organic life have been adjusted to the condition of land and sea.

The number of fossil plants known to M. Adolphe Brongniart, in 1836, was 527. In 1845, Goeppert and Bronn stated the number to be 1792 ; Unger, in 1850, described 2421 ; while Schimper, in 1874 , enumerates upwards of 5000 . When we consider that of the 130,000 plants which may be supposed to constitute the present Flora of the globe, a large proportion consists of cellular plants, which would disappear in the process of fossilisation, it would seem that the total number of known fossil species bears a considerable proportion to those now existing.

It is impossible in a short treatise like this to allude to many of the fossil species of plants. It will be sufficient to indicate some of the more important genera, and to give an account of their structure and conformation. 
Brongniart, from the investigation of the several geological formations, has arrived at the conclusion that three distinct periods of vegetation can be established. In the most ancient periods there is a predominance of acrogenous cryptogamous plants (Ferns, Lycopodiacex, Equisetaceæ, and their allies) ; later, the predominance of gymnospermous dicotyledons (Cycadaceæ and Coniferæ); and, in the last place, the appearance and predominance of angiospermous plants, both dicotyledons and monocotyledons. These differences led Brongniart to recognise three long periods of vegetable growth, which he terms the reign of the Acrogens, the reign of the Gymnosperms, and the reign of the Angiosperms, as indicative of the successive predominance of each of these three great divisions of the vegetable kingdom, rather than the complete exclusion of the others. Each of these three kingdoms is commonly subdivided into many periods, during which traces of the same family and genera are discoverable. These periods comprehend many epochs, during which vegetation does not appear to have undergone any notable changes. Materials are often wanting to establish precisely these subdivisions, either from a want of accuracy in determining the exact geological position of beds enclosing vegetable impressions, or because the division of the various species in the different beds of the same formation has not been carefully established. Brongniart proposes the following general division of the fossil kingdom :-

\section{REjGn of the ACrogens.}

\section{Carboniferous and Permian Pertods.}

During these periods there seems to be a predominance of Ferns, a great development of Lycopodiaceæ, arborescent forms of Lepidodendron and Sigillaria, Gymnosperms allied to Araucaria, and anomalous Gymnosperms, as Nöggerathia.

\section{Reign of the Grmnosperms.}

Triassic and JuRassic Periods.

Here we meet with numerous Coniferæ and Cycadacex, while Ferns are Iess abundant.

\section{ReigN of the ANgiosperms,}

\section{Cretaceods and Tertiary Phriods.}

This is characterised by the predominance of Angiospermous Dicotyledons, a class of plants which constitute more than three-fourths of the present vegetable productions of the globe, and which appear to have acquired a predominance from the commencement of the Tertiary formations. These plants appear sparingly even at the beginning of the chalk formation in Europe, but are more abundant in this formation, as developed in North America.

Schimper divides Brongniart's Reign of Acrogens into two:-1. The Reign of Thallassophytes or of Cellular Cryptogams, especially 
Marine algæ; including the lower Permian, Silurian, and Cambrian rocks. 2. The Reign of Vascular Cryptogams.

Williamson thinks that these divisions of Brongniart cannot be adhered to. He finds that there are fossil plants which show an evident transition from the Vascular Cryptogams to the Gymnospermous Exogens, and that these divisions cannot be separated as regards fossil plants. He suggests the division of Vascular Cryptogams into two :-1. An Exogenous group, including Lycopodiaceæ, Equisetaceæ, and the fossil Calamitacex. 2. An Endogenous group, containing the Ferns. The former uniting the Oryptogams with the Exogens through the Cycadaces and Conifere; and the latter linking them with the Endogens through the Palmæ.

\section{I.-FLORA OF THE PRIMARY OR PAL PERIOD.}

REIGN OF ACROGENS.

(According to BRongNIART.)

In this period Acrogens and Gymnosperms are found to have existed simultaneously, the former predominating over the latter in number and size. The number of the Fern family, the great development of the Lycopodiaceæ and Equisetaceæ, are the most prominent characters of this epoch. Other anomalous families belonging to the Gymnosperms are also met with, which differ from actually existing orders.

Flora of the Silutian and Cambrian Systems,-In the lower Palæozoic strata the plants which have been detected are few. In the Silurian and Cambrian systems we meet with the remains of ancient marine plants, as well as a few terrestrial species. Even in the still older Laurentian rocks, if the remarkable structure known as Eozoon canadense be considered, as it generally is, an animal, the existence of contemporary plants may be inferred, inasmuch as without vegetable life animals could not obtain food. In the Lower Silurian or Grauwacke, near Girvan, Hugh Miller has found a species resembling Zostera in form and appearance. In the Lower Old Red Sandstone of Scotland, he has detected Fucoids, a Lepidodendron, and Lignite with a distinct Coniferous structure resembling that of Araucaria, besides a remarkable pinnate frond. In the middle old Red of Forfarshire, as seen in the Arbroath pavement, he has collected specimens of a peculiar plant, bearing organs which resemble in appearance small receptacles of Nelumbium, besides a Fern with reniform pinnæ and a Lepidodendron; while, in the Upper Old Red, near Dunse, a Neuropteris, like N. gigantea of the Coal-measures, 
and a Calamite have been discovered by him. In the Old Red Sandstone rocks at Oporto, Bunbury detected Pecopteris Cyathea, P. muricata, and Neuropteris tenuifolia-ferns allied to those of the Coal-measures. A still more extensive and varied land flora of Devonian age (or Erian, as he calls it) has been described and illustrated by Principal Dawson from the rocks of that period occurring in Canada; and during a recent visit to Britain he has correlated many of the fragments collected by Miller, Peach, and others; with the American species he has described. The following are some of the fossil plants from beds older than the Carboniferous system :Prototaxites Logani, Dadoxylon ouangondianum, Calamites transitionis, Asterophyllites parvulus, Sphenophyllum antiquum, Lepidodendron Gaspianum, Lepidostrobus Richardsoni, L. Matthewi, Psilophyton princeps, P. robustum, Selaginites formosus, Cordaites Robbii, C. angustifolius, Cyclopteris Jacksoni.

Fossil Flora of the Carboniferous System.-The Carboniferous period is one of the most important as regards fossil plants. The vegetable forms are numerous and uniform throughout the whole system, whether exhibited in the Old or the New World. The important substance called Coal owes its origin to the plants of this epoch. It has been subjected to great pressure, and hence the appearance of the plants has been much altered. It is difficult to give a definition of Coal. The varieties of it are numerous. There is a gradual transition from Anthracite to Household and Parrot Coal, and the limit between Coal and what is called bituminous shale is by no means distinct. Coal may be said to be chemically-altered vegetable matter interstratified with the rocks, and capable of being used as fuel. On examining thin sections of coal under the microscope, we can detect vegetable tissues both of a cellular and vascular nature. In Wigan cannel coal vegetable structure. is seen throughout the whole mass. Such is likewise the case with other cannel, parrot, and gas coals. In common household coal, also, evident traces of organic tissue have been observed. In some kinds of coal punctated woody fibre has been detected, in others scalariform tissue, as well as cells of different kinds. Sporangia are also occasionally found in the substance of coal, as shown by Mr. Daw in that from Fordel; and some beds, like the Better bed of Bradford, are composed almost entirely of these sporangia, embedded in their shed microspores, as has been recently shown by Huxley. The structure of coal in different beds, and in different parts of the same bed, seems to vary according to the nature of the plants by which it has been formed, as well as to metamorphism. Hence the different varieties of coal which are worked. The occurrence of punctated tissue indicates the presence of Coniferæ in the coal bed, while scalariform vessels point to Ferns and their allied forms, such as Sigillaria and Lepidodendron. The ana- 
tomical structure of the stems of these plants may have some effect on the microscopic characters of the coal produced from them. 'In some cannel coals structure resembling that of acrogens has been observed. A brownish-yellow substance is occasionally present, which seems to yield abundance of carburetted hydrogen gas when exposed to heat.

Unger enumerates 683 plants of the Coal-measures, Schimper mentions 566, while Brongniart notices 500. Of the last number there are 6 Thallogens, 346 Acrogens, 135 Gymnosperms, and 13 doubtful plants. This appears to be a very scanty vegetation, as far as regards the number of species. It is only equal to about 1-20th of the number of species now growing on the surface of the soil of Europe. Although, however, the number of species was small, yet it is probable that the individuals of a species were numerous. The proportion of Ferns was very large. There were between 200 and 300 enumerated. The following are some of the Cryptogamous and Phanerogamous genera belonging to the flora of the Carboniferous period:Cyclopteris, Neuropteris, Odontopteris, Sphenopteris, Hymenophyllites, Alethopteris, Pecopteris, Coniopteris, Cladophlebis, Senftenbergia, Lonchopteris, Glossopteris, Caulopteris, Lepidodendron (Lepidostrobus, Lepidophyllum), Lyginodendron (Dictyoxylon), Knorria, Ulodendron, Halonia, Psaronius, Sigillaria and Stigmaria, Calamites, Asterophyllites, Sphenophyllum, Nöggerathia, Peuce, Dadoxylon, Araucarioxylon, Trigonocarpus.

Ferns are the carboniferous fossil group which presents the most obvious and recognisable relationship to an order of the present day. While cellular plants and those with lax tissues lose their characters by the maceration to which they were subjected before fossilisation took place, ferns are more durable, and retain their structure. It is rare, however, to find the stalk of the frond completely preserved down to its base. It is also rare to find fructification present. In this respect, fossil Ferns resemble Tree-ferns of the present day, the fronds of which rarely exhibit fructification. Hooker states that of two or three kinds of New Zealand Tree-ferns, not one specimen in a thousand bears a single fertile frond, though all abound in barren ones. Only one surface of the fossil Fern-frond is exposed, and that generally the least important in a botanical point of view. Fructification is sometimes evidently seen, as figured by Corda in Senftenbergia. Mr. Carruthers has recently detected the separate sporangia of Ferns full of spores in calcareous nodules in coal. These have the elastic ring characteristic of the Polypodiacex, and in their size, form, and method of attachment, they are allied to the group Hymenophyllex. The absence of fructification presents a great obstacle to the determination of fossil Ferns. Circinate vernation, so common in modern Ferns, is rarely seen in the fossil species, and we do not in general 
meet with rhizomes. Characters taken from the venation and forms of the fronds are not always to be depended upon, if we are to judge from the Ferns of the present day. There is a great similarity between the carboniferous Ferns of Britain and America. In the English Coal-measures the species are 140. The preponderance of Ferns over flowering plants is seen at the present day in many tropical islands, such as St. Helena and the Society group, as well as in extra-tropical islands, as New Zealand. In the latter, Hooker picked:36 kinds in an area of a few acres; they gave a luxuriant aspect to the vegetation, which presented scarcely twelve flowering plants and trees besides. An equal area in the neighbourhood of Sidney (in about the same latitude) would have yielded upwards of 100 flowering plants, and only two or three Ferns. This Acrogenous flora, then, seerns to favour the idea of a humid as well as mild and equable climate at the period of the coal formation-the vegetation being that of islands in the midst of a vast ocean.

Among the Ferns found in the clays, ironstones, and sandstones of the Carboniferous period, we shall give the characters of some by way of illustration. Sphenopteris ( $\sigma \varphi \dot{\eta} v$, a wedge, and $\pi \tau^{\prime} \varepsilon s \varsigma$, a fern) has a bi-tripinnatifid frond, pinnæ narrowed at the base (cuneate), not adherent to the rachis, lobed, veins generally arranged as if they radi-

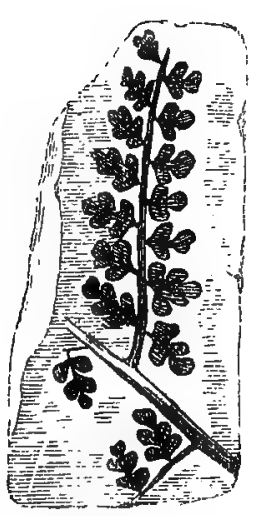

ITig. 908:

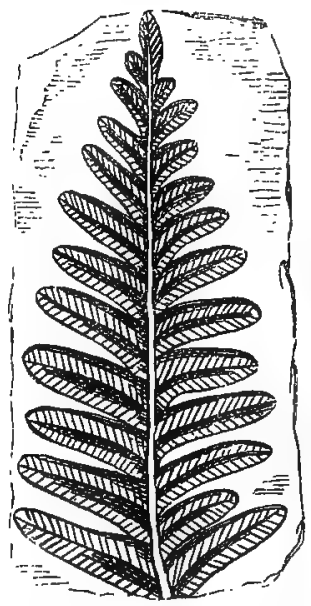

Fig. 909.

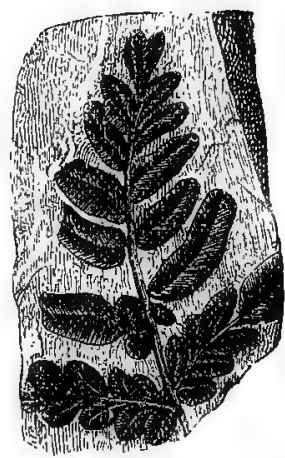

Fig. 910.

ated from the base (fig. 908). In Pecopteris ( $\pi^{\prime} \varepsilon$ ) frond is pinnatifid or bi-tripinnatifid (often pectinate), pinnæ adnate

Fig. 908. Sphenopteris Hoenninghausii, a*fern of the Carboniferous system. Pecopteris aquilina, another fern. Fig. 910. Neuropteris Loshii, another fern.

Fig. 909. 
to the rachis, sometimes confluent, a strong primary vein reaching the apex, the secondary veins being nearly straight, simple, or forked, rarely pinnate, sori rounded at the end of the secondary veins (fig. 909). In Neuropteris (vะũgov, a nerve) the frond is pinnate or bipinnate, pinnæ sub-cordate at the base, distinct from the rachis, strong primary vein vanishing towards the apex, secondary veins oblique, arched, repeatedly dichotomous (fig. 910). Lonchopteris has its frond multi-pinnatifid, and the leaflets more or less united together at the base; midrib is distinct, and the veins are reticulated. Cyclopteris has simple orbicular leaves, undivided or lobed at the margin, the veins radiating from the base, with no midrib. Schizopteris resembles the last, but the frond is deeply divided into numerous unequal segments, which are usually lobed and taper-pointed. Caulopteris and Psaronius are names given to the stems of Tree-ferms found in the coal-fields. Tree-ferns appear to have existed in Britain during the deposit of the coal strata, and to have occupied an important place in the flora. The stems of these ferns are included under the genus Caulopteris. The fronds have not been found attached; but it is probable that some of the fronds found in the Coal-measures have been connected with these stems. Prof. W. C. Williamson says that the number of fossil ferns has been needlessly multiplied, and he includes the entire series of four petioles and stems found in the Coalmeasures under the name Rachiopteris. These petioles belong, no doubt, to the different forms of fronds already described, such as

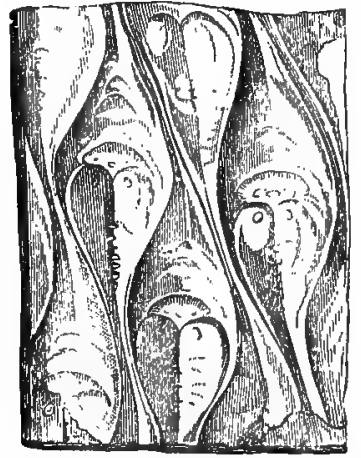

Fig. 911.

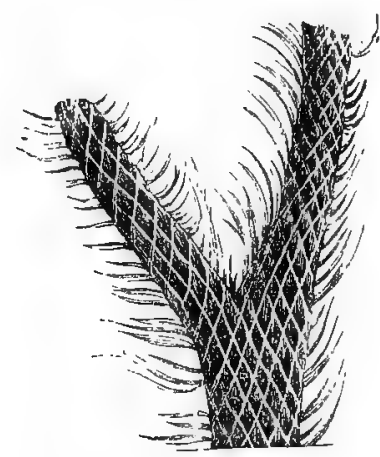

Fig. 912.

Pecopteris, Sphenopteris, etc. The way in which the vascular bundles in the four stems are arranged, are, he says, represented by the letters $\mathrm{H}, \mathrm{T}, \mathrm{V}$, and $\mathrm{X}$. As a general rule the secondary bundles are given

Fig. 911. Lepidodendron crenatum, with the scars of the leaves on its stem. It belongs to a family of plants apparently intermediate between Coniferæe and Lycopodiacez. Fig. 012. Lepidodendron elegans, with its dichotomous trunk and linear acute leaves. 
off from that part of the primary one which happens to be nearest the secondary rachis to be supplied.

Fossil plants, allied to Lycopodiums, also occur in the Coalmeasures. Brongniart believes they are more abundant in the ancient beds than in the superior beds of the greater part of the coal formation. These have been included under the genera Lycopodites, Selaginites, and Lepidodendron ( $\lambda \varepsilon \pi i \zeta$, a scale, and $\delta \varepsilon \nu \delta \rho o v, ~ a ~ t r e e)$, (figs. 911,912). The last mentioned appear to occupy an intermediate place between Coniferæ and Lycopodiaceæ. Their leaves are arranged in the same manner as some of the Coniferæ, and their scars are similar. Their branches bifurcate like Lycopodiaceæ. They occur in the form of dichotomous trunks, 20 to 45 feet high, with linear or lanceolate leaves (fig. 912), like those of some species of Lycopodium and Eutassa. Schimper enumerates 59 species of Lepidodendron, all arborescent and carboniferous. The stem consists of a thin cuticle, a double cellular zone, a vascular cylinder, and a pith. The vascular cylinder consists of polygonal tubes marked with lines, while the pith is composed of fusiform cells. The stems are marked with rhomboid and orbicular scalelike scars (fig. 911). Their cone-like fruit occurs in a fossil form, called Lepidostrobus (fig. 913). It consists of a central axis bearing scales, which cover sporangia. In the interior of these there are spores consisting of 3 or 4 angular sporules. There

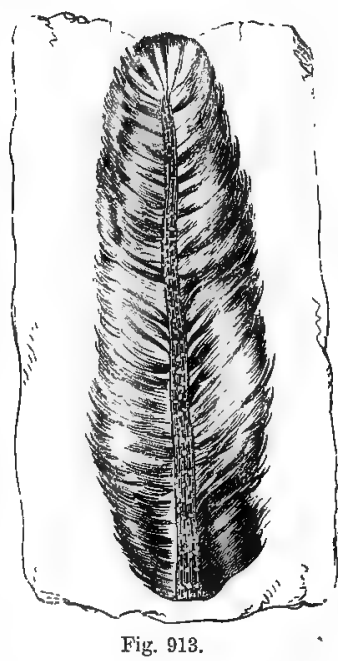
is a single sporangium on each scale, and all the sporangia are filled with microspores. In Lepidostrobus we do not meet with two kinds of spores.

In Triplosporites, another Lycopodiaceous plant, there is a single sporangium on each scale. The sporangia in the upper portion of the cone contain microspores, while those at the lower part have macrospores, in the same way as occurs in the genus Selaginella (p. 278). Flemingites is another fruit of the same kind. It is a cone with a double series of small sporangia on each scale. The sporangia of Flemingites occur sometimes abundantly in coal (Trans. Roy. Soc. Edin., xxi. 187). It is conjectured that in some cases the mass of the coal is formed by sporangia of plants allied to Ferns and Lycopods. The various forms of Lepidophyllum are said to be the leaves of

Fig. 913. Lepidostrobus ornatus, after Lindley and Hutton, from the Bensham coalseam of the Jarrow colliery, showing central axis with leaflets. It is the fructification of a Lepidodendron. 


\section{FOSSIL PLANTS OF THE CAIBONIFEROUS SYSTEM.}

Lepidodendrons. Professor W. C. Williamson, who has examined with great care the fossil carboniferous Flora, has detected in many of the plants an apparent exogenous mode of formation in the s.tem. According to him the stem of a Lepidodendron consists of a central medullary axis containing scalariform vessels and cells. It is surrounded by a narrow ring of a similar nature, but arranged in vertical laminæ radiating from within outwards. The laminæ are separated by cells, arranged like the medullary rays of an Exogen. From the outer cylinder vessels go to the leaves. Outside the woody zone there is a cortical portion, formed by parenchymatous and prosenchymatous cells. The whole is covered by an epidermis, consisting of a cellular layer, then a bast layer, and finally a superficial cellular layer. The outer epidermal covering is often removed, and is sometimes converted into coal. The stem increases in a more or less exogenous manner, while the cortical portion retains all the characters of Lepidodendroid plants. Williamson thinks that there is an evident transition from the vascular Cryptogams to the Gymnospermous Exogens, and that they cannot be separated. There are some difficulties in deciding on the exogenous development of a fossil stem. To determine this properly, we require to demonstrate the existence of Cambium cells, and it is not easy to do so in fossilised plants. Care is also required in pronouncing on the mode of development, seeing that the thick stems of cellular plants, such as seaweeds, sometimes exhibit concentric circles, and the same thing occurs in the succulent roots of some annual and biennial plants. The beautiful microscopical preparations made by Professor Williamson certainly show in many instances marked zones with rays. Full details of his researches are given in the Transactions of the Royal Society of London, illustrated by excellent plates.

The slender terminal branches of Lepidodendron are known under the name of Lycopodites. Ulodendron (i $\lambda_{n} n$, wood, and $\delta^{\varepsilon} \varepsilon \delta \rho o v$, tree) is a genus nearly allied to Lepidodendrons. Hugh Miller states that Ulodendron minus, found in ferruginous shale in the Water of Leith, near Colinton, exhibits beautiful sculptured scars, ranged rectilinearly along the stem. The surface is covered with small, sharply-relieved obovate scales, most of them furnished with an apparent midrib, and with their edges slightly turned up. The circular or oval scars of this genus are probably impressions made by a rectilinear range of aerial roots placed on either side. When decorticated, the stem is mottled over with minute dottings, arranged in a quincuncial manner, and its oval scars are devoid of the ordinary sculpturings. Bothrodendron (Bódgos, a pit or depression) is a decorticated condition of Ulodendron. Halonia appears also to be a species of Lepidodendron. The scars of Ulodendron, and the tubercles of Halonia, are probably the remains of special organs, such as cones. 


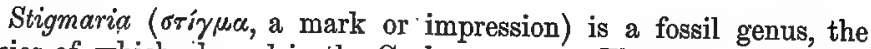
species of which abound in the Coal-measures. They occur generally in the bed called the Underclay. Stigmaria ficoides (fig. 914) is the common species. It sends forth grooved and pitted branches, which divide dichotomously, and extend 20 to 30 feet. Slender processes are given off, which appear to have been hollow (fig. 914). These processes (called fistular roots) form an entangled mass traversing the

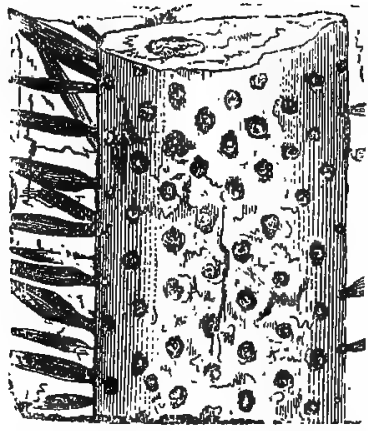

Fig. 914.

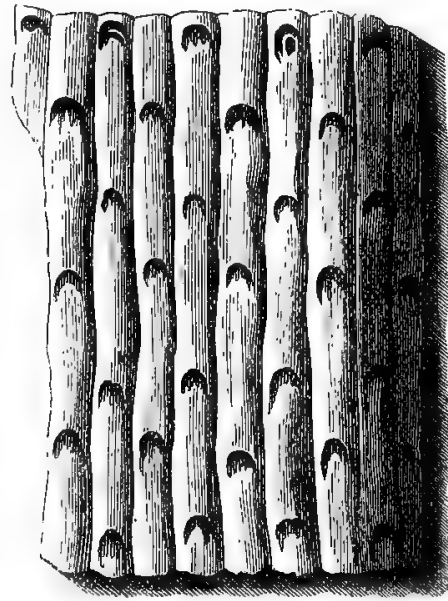

Fig. 915.

argillaceous lower bed in every direction. In Stigmarias three tissues are met with, - vascular tissue forming the inner part of the cylinder, ligneous forming the wood, and cellular tissue forming a broad cortical zone, as well as the central portion or pith. Stigmaria is apparently a thick rhizome, having a large medulla, surrounded by a cylinder of scalariform vessels, and with a mass of cortical parenchyma surrounding the whole. Rootlets proceed from the pits on the sides of the rhizome, each containing a small bundle of scalariform vessels having its origin in the vascular cylinder. In the structure of its stem it agrees, according to some, with Cycads, and with certain fleshy Euphorbiaceæ and Cactaceæ. According to Williamson, Stigmaria has a pith surrounded by a thick woody zone, containing two distinct sets of primary and secondary medullary rays, the former going direct to the bark. In what are called decorticated stems of the Lepidodendroid plants, the more central axial portion (medulla, wood, and thin layers of inner bark) have disappeared through decay; the bast

Fig. 914. Stigmaria ficoides; a branch giving off fistular leaves, which traverse the underclay in all directions. stem, and the scars of the leaves.

Fig. 915. Sigillaria pachyderma; showing fluting of the 
layer of the bark has arrested the destruction of the entire cylinder, and formed the mould into which inorganic materials have been introduced. In Stigmaria, however, the woody cylinder is usually preserved, probably owing to its more tenacious character. Some think that the stores of fossil fuel in England and America are mainly due to the presence of this plant. Stigmaria ficoides has been shown to be the rhizome and roots of a Sigillaria. Specimens of the latter have been discovered standing erect, and connected with Stigmarias. Stigmaria ficoides abounds in the underclay of a coal seam, sending out numerous roots from its tubercles, and pushing up its aerial stem in the form of a fluted Sigillaria.

Sigillaria (sigillum, a seal) is another plant which appears to have aided in the formation of coal. It occurs in the form of compressed stems, attaining a height of 40 to 50 feet, and a breadth of 5 feet. The stems are fluted longitudinally, and marked at regular intervals by single or double scars (hence their name), the remains of the leaf insertions (fig. 815). Some suppose Sigillarias to be allied to Treeferns, others to Coniferæ. Brongniart says they resemble Zamia integrifolia, and appear to predominate in the middle and superior beds of the coal formations. Some consider them as intermediate between Ferns and Cycads. Their foliage has not been accurately determined, some conjecturing that it consisted of Neuropteris, others of long linear leaves, called Oyperites. They have a medullary sheath in the shape of apparently isolated bundles, and vessels intermediate between true spiral and scalariform. The stem of Sigillaria is fluted in a longitudinal manner, like a doric column, and has a succession of single scars, which indicate the points of insertion of the leaves. When the outer part of the stem separates like bark, it is found that the markings presented by the inner surface differ from those seen externally. This has sometimes given rise to the erroneous supposition that they belong to different genera. King says, that if in imagination we delineate a channelled stem of any height between 12 and 100 feet, crowned with a pendent fern-like foliage, furnished with wide-spreading thickly-fibrilled roots, and growing in some densely-wooded swamp of an ancient Mississippi, we will then have formed a tolerably close restoration of a Sigillaria vegetating in its true habitat. The fructification consists of small sporangia, like that of Flemingites, borne on the bases of the leaves, and this indicates an acrogenous plant allied to Lycopods.

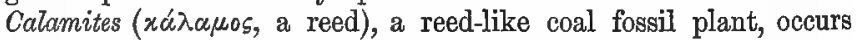
in the form of jointed fragments, originally cylindrical and hollow, but now crushed and flattened (fig. 916). The stem is ribbed and furrowed (fig. 917), articulated and septate. It consisted of a cortical portion now converted into coal, of a medulla, at first solid and then fistular, surrounded by a woody cylinder of scalariform vessels. The 
medulla penetrated this cylinder by a series of wedges, which were continued to the outer portion of the stem by their cellular laminæ. The appendicular organs (leaves) were produced in whorls. Williamson considers the structure of the medullary and ligneous zones as resembling that of the stem of an exogen of the first year. On making a longi-

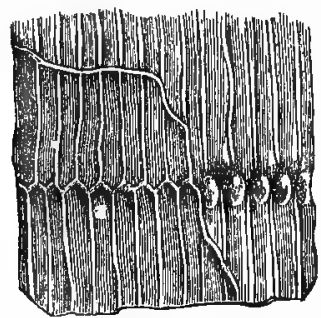

Fig. 916.

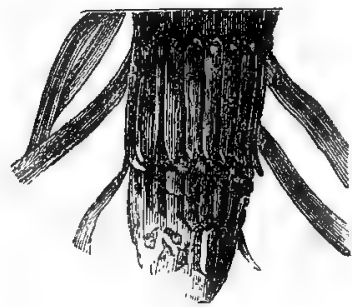

Fig. 91'.

tudinal tangential section of the stem, the woody zones show alternating parallel bands of vascular and cellular tissue. The bark consists of a thin layer of parenchyma. It is smooth outside, and does not present ridges or furrows. The ligneous cylinder of Calamite, as it increases in size and age, exhibits less and less of the Calamitean peculiarities seen in young stems; the external part becoming unsulcated. In a Calamitean plant, called by Williamson Calamopitus, canals pass from the medullary cavity, horizontally to the bark, below the nodes (infra-nodal). Calamites give off subterranean branches from rhizomes as well as slender appendages from the aerial stem, arranged in verticils at the nodes. Williamson puts Calamites in his order Calamitaceæ, allied to Equisetaceæ, but differing in having cryptogamic reproduction connected with an exogenous development of the stem. Schimper considers Calamites as having an analogy with Equisetum in their fructification. He regards them as fossil Equisetaceæ. Annularia and Sphenophyllum are considered as establishing a passage from the Equisetaceæ to the Lycopodiaceæ. Some gigantic fossil Equiseta had a diameter of more than 12 centimetres, and a height of 8 to 10 metres. The branches, which adorned the higher part of them in the form of a crown, are simple, have at their extremity a spike of the size of a pigeon's egg, and are organised exactly like the spikes of living Equiseta. There is also a resemblance between them as regards their rhizomes. Dr. W. R. $\mathbf{M}^{\prime} \mathrm{Nab}$ has examined the Equisetum stem, and contrasted it with that of Calamite, and he has come to the following conclusions:-That the stem of Equisetums differs but little in construction from that of Calamites :

Fig. 916. Calamites Suckovii, composed of jointed striated fragments having a bark. Fig. 917. Calamites cannæeformis, giving off roots. 
that in both Equisetums and Calamites the fibro-vascular bundles are but poorly developed: that the mass of tissue (woody wedges" of Williamson) forming the most important part of the stem consists of the small fibro-vascular bundles, with the addition of a large quantity of thickened parenchyma and prosenchyma (sclerenchyma of Mettenius): that the sclerenchyma is part of the cortical tissues, and not a portion of the fibro-vascular bundles : that there is no evidence of any growth having taken place in the fibro-vascular bundles comparable to that observed in Dicotyledons; but that if the stems of Calamites increased in diameter it was by additions to the cortical tissues, and not to those of the fibro-vascular bundles: that the pointed ends of the Calamite stem (indicating that the embryonic parts did not enlarge) lead to the conclusion that circumferential growth did not take place, but that the stem, when it attained its maximum diameter close to the base, remained cylindrical.

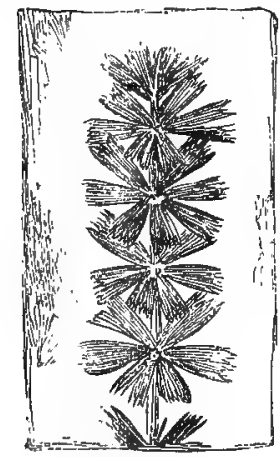

Fig. 918.

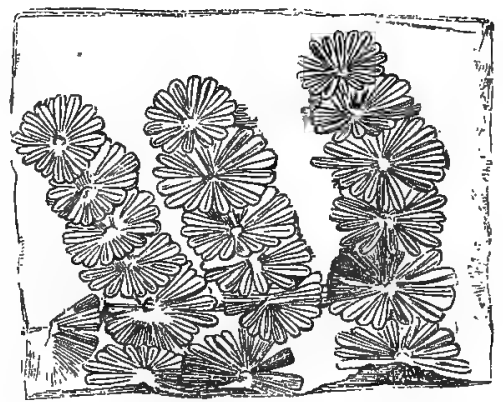

Fig. 919.

In Spitzbergen, in rocks of the Carboniferous epoch, there have been found Calamites radiatus, Lepidodendron Veltheimianum, Sigillaria distans, Stigmaria ficoides, and ferns apparently the same as those found in the Carboniferous epoch in Europe. Some species, as Sigillaria Malmgreni, S. Canneggianna, and Lepidodendron Wilkii, seem to be peculiar to Bear Island.

In the family Calamitaceæ we have the genera Equisetites and Calamites. Some also place in this family the genera Asterophyllites, Sphenophyllum (fig. 918), Annularia (fig. 919), and Volkmannia. Annularia may be a link between Equisetaceæ and Ferns, and Sphenophyllum a link between Lycopodiaceæ and Ferns. Williamson

Fig. 918.' Sphenophyllum dentatum, one of the dubious forms of the Carboniferous system, perhaps allied to Salisburya Fig. 919. Annularia brevifolia, a coal plant of doubtful affinity, placed by some among the Calamitacex. 
considers Asterophyllites as having a general affinity with Lycopodiaceæ and not with Equisetaceæ. He finds its parallel in the present flora in Psilotum triquetrum. It is also allied to the fossil plant called Sphenophyllum (fig. 918). Asterophyllites Dawsoni, formerly called Volkmannia Dawsoni, has a peculiar triquetrous vascular axis.

True Exogenous trees exist in the Coal-fields both of England and Scotland, as at Lennel Braes and Allan Bank, in Berwickshire, HighHeworth, Fellon, Gateshead, and Wide-open, near Newcastle-uponTyne, and in quarries to the west of Durham; also in Craigleith quarry, near Edinburgh, and in the quarry at Granton. In the latter localities they lie diagonally athwart the strata, at an angle of about $30^{\circ}$, with the thicker and heavier part of their trunks below, like suags in the Mississippi. From their direction we infer that they have been drifted by a stream which has flowed from nearly northeast to south-west. At Granton one of the specimens exhibited roots. In other places the specimens are portions of stems, one of them 6 feet in diameter by 61 feet in length, and another 4 feet in diameter by 70 feet in length. These Exogenous trees are Gymnosperms, having woody tissue like that of Coniferæ. We see under the microscope punctated woody tissue, the rows of disks being usually two, three, or more, and alternating (figs. 906, 907). They seem to be allied in these respects to Araucaria and Eutassa of the present flora. Dadoxylon or Pinites (Araucarioxylon) Withami is one of the species found in Craigleith quarry; the concentric layers of the wood are obsolete; there are 2,3 , or 4 rows of discs on the wood, and 2-4 rows of small cells in the medullary rays. Along with it there have also been found Dadoxylon medullare, with inconspicuous zones, 2,3 , and 4 rows of discs, and 2-5 series of rows of cells in the rays. Pissadendron antiquum (Pitus antiqua), having $4-5$ series of cells in the medullary rays, and P. primævum (Pitus primæva), with 10-15 series of cells in the medullary rays, occur at Tweedmill and Lennel Braes in Berwickshire.

Sir Robert Christison states-" Seven fossils, all apparently belonging to the Pine tribe, and either to the same species, or to two closely allied to one another, have been uncovered since 1826 in the sandstone of Craigleith quarry. Six are stems of great trees, and one is a longitudinally split section of a large branch, or possibly of another stem. Portions of all seven have been traced as still preserved in Collections, and have been subjected more or less to examination. Of one, the greatest of all, about 36 continuous feet, from 12 to 14 feet in girth, have been removed in large fragments to the British Museum, and will be pieced and erected there. Another, found in 1830, is now partly in the Botanic Garden, and has been supplemented by other portions from the Museum of Science and Art, so as to make a nearly perfect fossil stem 30 feet in length. A third, nearly 9 feet in girth, has been sliced 
and polished, to show its structure on the great scale, and will be exhibited in the British Museum, the Edinburgh Museum, and the Edinburgh Botanic Garden.

"The composition of all these great fossils is substantially the same. The great mass of each consists of carbonate of lime, carbonate of magnesia, carbonate of protoxide of iron, and free carbon, the proportions varying in different parts of the same fossil. The iron-carbonate and charcoal vary most in their amount. The charcoal, which is left after the action of diluted acids, sometimes without any other insoluble residuum, seems to form three per cent of the mass, unless when collected, as it often is, in cavities. This charcoal contains only about $3 \frac{1}{2}$ per cent of incombustible ash.

"The surface of the fossils is covered with a shining coat of very bituminous caking coal, which, on the principal part of the stem, varies from only a 20th to a 10th of an inch in thickness, but at the lower end of that now at the British Museum, it increases to two inches and a half. This coaly covering contains only 4, 3,2 , and sometimes only $1 \cdot 1$ per cent of mineral matter, which is not the same as the fossilising matter of the included wood, but is chiefly siliceous in nature, being at least insoluble in acids. The crust is not altered bark, for bark could not fail to undergo, in part at least, fossilisation by the material which has fossilised the wood. Moreover, the coaly crust is found round fragments and on broken points where bark could never have existed.

"The rock of the quarry is a very pure quartzy sandstone, hard, tough, and quite free from earthy carbonates or iron. But for some feet around the fossils, and also here and there throughout the quarry, where there is no fossil near, the rock has quite a different appearance, has a higher density, is more sharp-edged, much tougher, and harder to pulverise, and becomes yellow under exposure to the air. These changes are owing to the siliceous particles of the sandstone being bound together by carbonate of lime, carbonate of magnesia, and carbonate of protoxide of iron, forming together from 10 to 38 per cent of the rock, and bearing much the same relation in proportion to each other as in the mineral material of the fossils,-consequently derived from the same fluid which fossilised them.

"Thus the interesting fact is presented of these great trees and the rock in which they are embedded having been both similarly mineralised, so to speak, by the same fossilising fluid, while there is between them a thin uniform coating of bituminous coal, which has refused admission to any of the fossilising agents. After rejecting various theories to account for this exemption, the only one which stands the test of facts is, that a part of the process of fossilisation consists in a slow process, analogous in its results to the destructive distillation of wood, the result of which is charcoal left behind, 
and bitumen gradually forced outwards, and collected on the exterior surface.

"The charcoal which remains in the stems renders their minute internal structure singularly distinct when a thin transparent slice is placed under the microscope. Longitudinal woody bundles, transverse medullary rays, crowded cells of the longitudinal fibres cut crosswise, are all seen most characteristically; and in one specimen two inches in breadth the boundaries and whole structure of five annual layers of wood are displayed characteristically, even to the naked eye. On the polished surface of one of the great stems, too, the eye can easily trace many annual rings for long distances."

Sternbergia is considered by Williamson as a Dadoxylon, with a discoid pith, like that seen now-a-days in the Walnut, Jasmine, and Cecropia peltata, as well as in some species of Euphorbia and in some Conifers. Sternbergia approximata is named by him Dadoxylon approximatum. Hooker has shown from the structure of Trigonocarpus, a not uncommon fruit, that it is a coniferous fruit, nearly allied to Salisburya. Nöggerathia, and a few other plants, such as Flabellaria and Artisia, are referred by Brongniart to Cycadaceæ. Flabellaria borassifolia, according to Peach, has leaves like Yucca. Nöggerathia has pinnate leaves, cuneiform leaflets, sometimes fanshaped; the veins arise from the base of the leaflets, are equal in size,

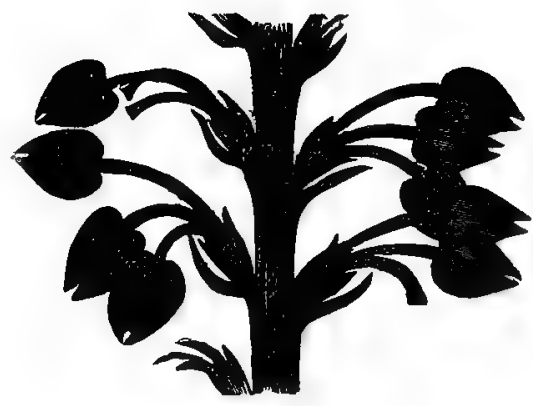

Fig. 920.

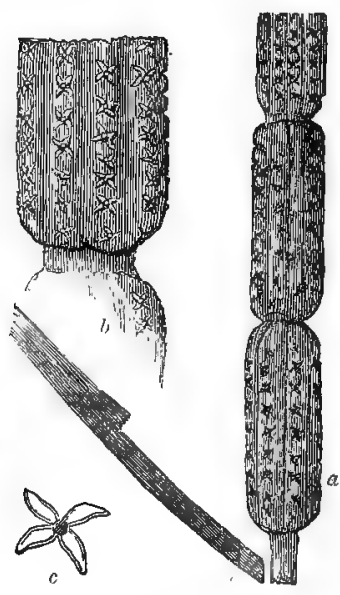

Fig. 921.

Fig. 920. Cardiocarpum Lindleyi,"collected by C. W. Peach, near Falkirk, a peculiar fossil 'of the Coal-measures, supposed to be the fruit of Antholithes.

Fig. 921. Pothocites Grantoni. $a$, Spike natural size. $b$, Portion of the spike magnified, $c$, Perianth 4-cleft. anagnified. 
and either remain simple or bifurcate, the neuration or venation being similar to that of some Zamias.

A fossil plant called Antholites has been found in the coal-measures. It appears to be a spike of flowers, having a calyx and linear petals. Mr. Peach has recently found that the fruit called Cardiocarpum is the produce of this plant (fig. 920). It may possibly be a Monocotyledon. Mr. Peach has also found a peculiar fossil fern near Edinburgh, which presents the characters of the genus Staphylopteris of Lesquereux.

In the bituminous shale at Granton, near Edinburgh, Dr. Robert Paterson discovered in 1840 a peculiar fossil plant, which he called Pothocites Grantoni (fig. 921). It is a spike covered by parallel rows of flowers, each apparently with a 4-cleft perianth. It was supposed to be allied to Potamogeton or Pothos, more probably to the latter. In that case it must be referred to the natural order Aracer. Pothocites has been recently found by Mr. Etheridge near West Calder, and by Mr. Bennie at Corstorphine, near Edinburgh. Lyginodendron ( $\lambda$ úyıos, wicker-work) is a peculiar coal fossil discovered by the Rev. Mr. Landsborough in Ayrshire, and described by Mr. Gourlie. Its impression consists of rounded narrow twigs, which cross each other like the parts of an osier basket. Lyginodendron (called also Dictyoxylon by Williamson) is probably allied to Lycopods. It has a stem composed of pith, wood, and bark. The parenchymatous pith is surrounded by an irregular vascular cylinder, which breaks up into bundles, separated by medullary parenchyma. Before this, however, the true ligneous zone appeared as a narrow vascular ring, with radiating vertical laminæ, separated from each other by large cellular rays. A bark exists in the circumference formed of two cellular layers, and a third composed partly of parenchyma and partly of prosenchyma. Two species are described by Williamson, Lyginodendron Oldhamia and D. Grievii.

It may be remarked, in general, that the Carboniferous flora is uniform, or nearly so, in all parts of the globe where carboniferous. fossils have been obtained-viz. the whole of western, northern, and eastern Europe, North America, from Alabama to Melville Island, various districts of Asia, Eastern Australia, and Van Diemen's Land, and probably the Asiatic Islands.

As fossils in the coal formation consist principally of ferns and their allies, conjectures have been made as to the climate of the globe at that epoch. Ferns of the present day thrive best in a moist insular climate, and many of them occur in tropical climates. Hence Brongniart conjectures that at the coal epoch the surface of the earth consisted of a series of islands in the midst of a vast ocean, and that the temperature was higher generally than that of the present day. In the forests of these islands lofty Lepidodendrons would occur, with their delicate and 
feathery fronds; Sigillarias, with their fluted stems and enormous matted roots; Calamites, with their singular branches; Tree-ferns and Coniferous plants, resembling the Norfolk Island Pine, and towering a hundred feet above the rest of the forest. He also thinks that the immense deposits of carbon at that epoch warrant the conclusion that the air contained a large amount of carbonic acid. These conclusions are, of course, mere hypotheses. In regard to the.temperature, it may be remarked that there is no evidence, from the nature of the flora, of a marked increase of temperature at the coal epoch. In New Zealand, which is in a latitude the same as that of a great part of Europe, a very large proportion of the vegetation consists of Acrogenous plants. Ferns and their allies, in that country, cover immense districts, replacing the grasses of other countries, and giving a marked character to all the open land. Some of the ferns attain a height of 30 or 40 feet, and occur in groups. Hemitelia capensis, a Tree-fern found at the Cape, was also seen by Gardner, at an elevation of 6000 feet, on the Organ mountains, thus showing a capability of enduring a great range of climate, and. warning us against hasty conclusions on the subject of the temperature of the world at the coal epoch.

Dr. Hooker thinks that the prevalence of ferns may be regarded as a probable evidence of the paucity of other plants, and the general poverty of the whole flora which characterised the formation. He is led to these conclusions from observing the mode in which the ferns in Van Diemen's Land and New Zealand monopolise the soil, chokjng plants of a larger growth on the one hand, and admitting no undergrowth of smaller species on the other. In New Zealand he has collected 36 kinds of ferns on an area not exceeding a few acres; they. gave a most luxuriant aspect to the regetation, which presented scarcely a dozen flowering plants and trees besides.

Some have supposed that the plants of the coal-fields have been drifted into basins, others that they grew in the spots where they are now found. Beaumont thinks that all the plants which are now converted into coal grew in swampy islands, covered with a luxuriant vegetation, which accumulated in the manner of peat-bogs ; that those islands having sunk beneath the ocean, were there covered with sand, clay, and shells, till they again became dry land, and that this operation was repeated in the formation of each bed of coal. The occurrence of stems of trees in an erect state (fig. 922) appeared to him to confirm the view that the trees were in situ. Ansted says, that although many trees are found in the Coal-measures in an erect or highly-inclined position, there is no reason for believing that they grew on the spot where they are met with. He rather thinks that they have been caught or stopped in their passage down a rapid stream, and, like the snags in some of the great American rivers, have been 
detained till the lower portion was firmly embedded in the rapidly forming sandstone. The embedding of stems in strata of sandstone is similar to what Gardner saw near the mouth of the Rio San Francisco, where coco-nut trees were found with their stems immersed to the depth of 50 feet or more in the embankment of sand which stretches along the shore. Phillips remarks, that the condition of

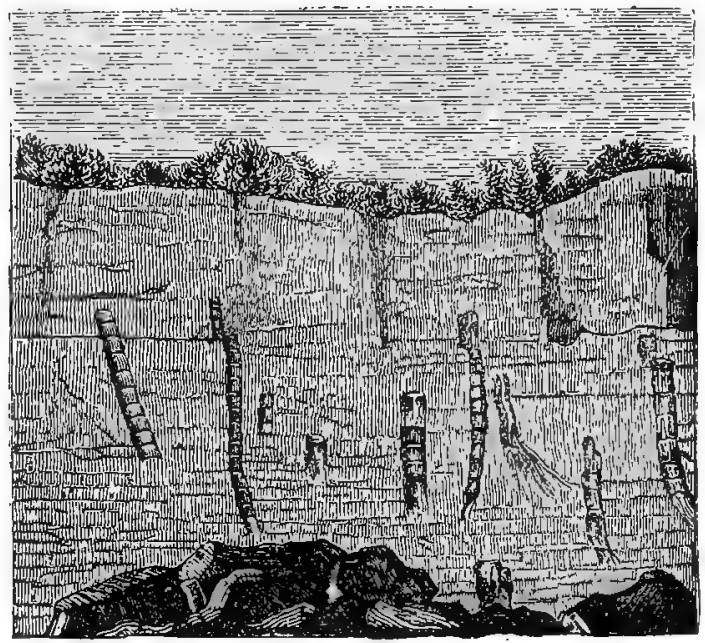

Fig. 922.

the plants which compose the coal, the general absence of roots, the fragmentary state of the stems and branches, the dispersed condition of the separable organs, all confirm the conclusion that the plants have been swept down from the land on which they grew by watery currents, often repeated, and deposited in basins and large estuaries of the sea, or, perhaps rarely, in lakes of fresh water.

Flora of the Perman Epoca.-The nature of the vegetation during the Permian period, which is associated with the Carboniferous, under the reign of Acrogens, has not been positively determined. Brongniart has enumerated the fossils in three different localities, which he refers doubtfully to this period. 1. The flora of the bituminous slates of Thuringia, composed of Algæ, Ferns, and Coniferæ. 2. Flora of the Permian sandstones of Russia, comprehending Ferns, Equisetacex, Lycopodiaceæ, and Nöggerathiæ. 3. Flora of the slaty schists of Lodeve, composed of Ferns,

Fig. 922. Vertical stems of fossil trees, Calamites chiefly, found in the Coal-measures of Treuil, near Saint Etienne. 
Asterophyllites, and Coniferæ. The genera of Ferns here met with are also found in the Carboniferous epoch; the Gymnosperms are chiefly species of Walchia (figs. 923, 924) and Nöggerathia (the latter is supposed by Schimper to be a Oycad) ; Lepidodendron elongatum, Calamites gigas, and Annularia floribunda, are also species of this period. Goeppert has given an account of the plants of the Permian formation. Among other plants he enumerates the following : - Equisetites contractus, Calamites Suckowi, C. leioderma, Astero-

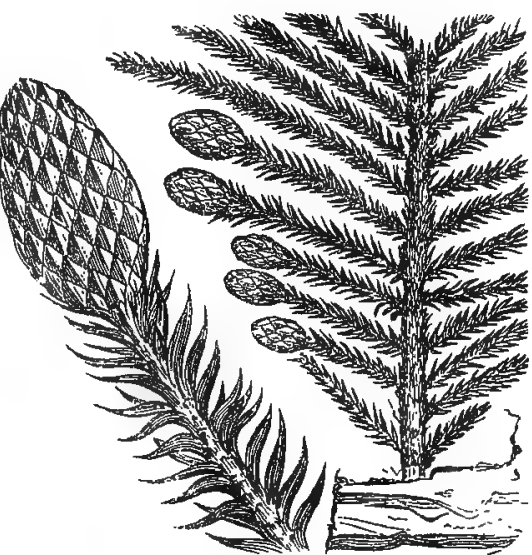

Fig. 923.

Fig. 924.

phyllites equisetiformis, A. elatior, Huttonia truncata, H. equisetiformis, many species of Psaronius one of the filicoid plants, Hymenophyllites complanatus, Sphenopteris crassinervia, Sagenopteris tæniæfolia, Neuropteris imbricata, and many other species of these genera; several species of Odontopteris, Callipteris, Cyclopteris, Dioonopteris, Cyatheites, Alethopteris, Nöggerathia, Cordaites, Anthodiopsis, Dictyothalamus, Calamodendron, Arthropitys ; besides species of Sigillaria, Stigmaria, and Lepidodendron. Various fruits are also mentioned, under the names of Rhabdocarpus, Cardiocarpus, Acanthocarpus, Trigonocarpus, and Lepidostrobus.

\section{II. -FLORA OF THE SECONDARY OR MESOZOIC PERIOD.}

\section{Brongniart's Reign of Gymnosperms.}

In the Carboniferous period the Acrogenous Cryptogams were found to predominate, while the Gymnospermous Dicotyledons were less numerous. In this reign, on the other hand, the Acrogens are less numerous, and the Gymnosperms almost equal them in number, and ordinarily surpass them in frequency.

Figs. 923, 924. Walchia piniformis Sternb., a common species in the Permian rocks of Europe. Fig. 923. Plant with leaves and fruetification. Fig. 924. Fructification, natural size. 
The reign of the Gymnospermous Dicotyledons is divided into two periods: the first, in which the Coniferæ predominate, while the Cycadaceæ scarcely appear; the second, in which the latter family preponderates as regards the number of species, and the frequency and variety of generic forms. Cycadaceæ (figs. 925, 926) occupied a more important place in the ancient than in the present vegetable world. They extend more or less from the Triassic formation up to the

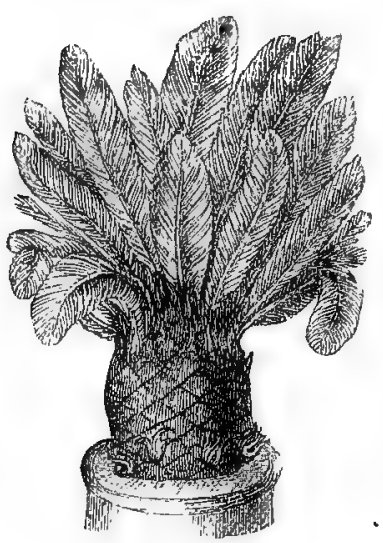

Fig. 925.

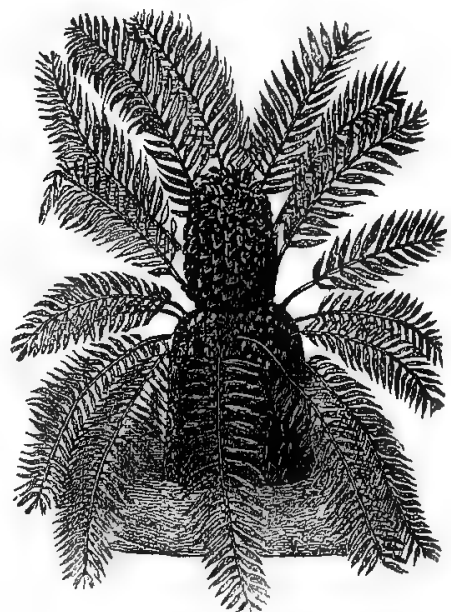

Fig. 926.

Tertiary. They are rare in the Grèsbigarré or lower strata of the Triassic system. They attain their maximum in the Lias and Oolite, in the latter of which 60 species have been enumerated, and they disappear in the Tertiary formations. Schimper thinks that Trigonocarpum (15 species), Rhabdocarpum (24 species), Cardiocarpum (21 species), Carpolithes ( 9 species), and Oycadinocarpus (6 species), are all fruits of Cycader. Many supposed fossil Cycads are probably Conifers. It is important to notice that in an existing Cycad called Stangeria paradoxa the vernation of the leaf-divisions is involute and inflexed, and the veins of the pinnæ rise from a true midrib and fork, characters which are more commonly met with in Ferns.

In Brongniart's Vosgesian period, the Grèsbigarré, or the Red Sandstones and Conglomerates of the Triassic system, there is a change

Fig. 925. Cycas revoluta, one of the species of Cycas of the present flora of the globe, with its scale-like stem and pinnate fronds. Fig. 926. Encephalartos (Zamia) pungens, one of the Cycadacese at present existing on the globe. 
in the flora. Sigillarias and Lepidodendrons disappear, and in their place we meet with Gymnosperms, belonging to the genera Voltzia, Haidingera, Zamites (fig. 927), Ctenis, Ethophyllum, and Schizoneura (fig. 928). Species of Neuropteris, Pecopteris, and other acrogenous coal genera are still found, along with species of Anomopteris and Crematopteris, peculiar F'ernforms, which are not found in later formations. Stems of arborescent Ferns are more frequent than in the next period.

In the Lias the essential characters of the flora are the predominance of Cycadaceæ,

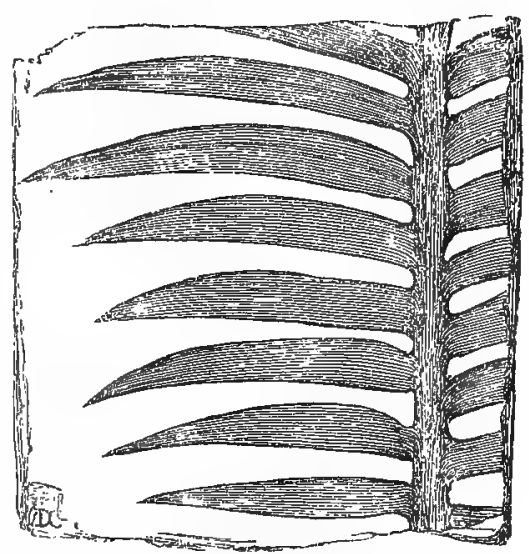

Fig. 927. in the form of species of Cycadites, Otozamites, Zamites, Ctenis, Pterophyllum (figs. 929, 930), and Nilssonia, and the existence

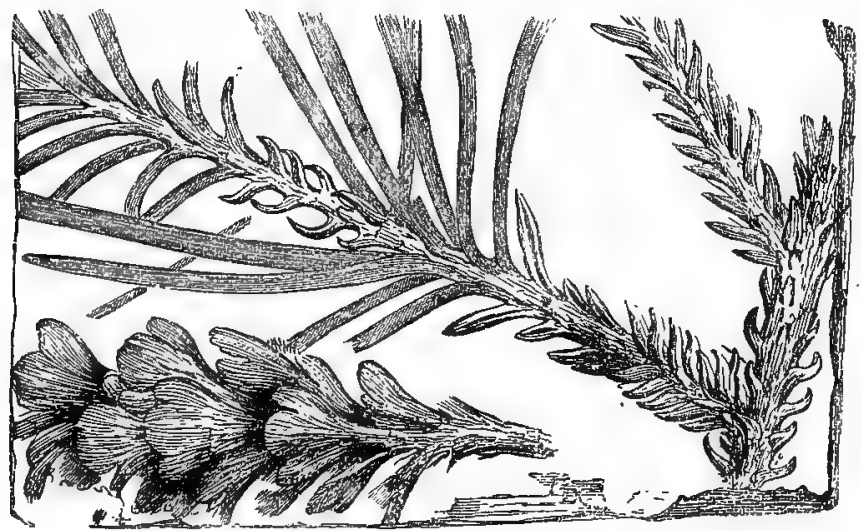

Fig. 928.

among the Ferns of many genera with reticulated vernation, such as Camptopteris and Thaumatopteris, some of which began to appear at

Fig. 927. Zamites. Leaf of a fossil Cycad. Fig 928. Schizoneura heterophylla, one of the fossil coniferæ of the Triassic system. 
the Keupric epoch. Coniferous genera, as Brachyphyllum, Taxodites, Palissya, and Peuce, are found.

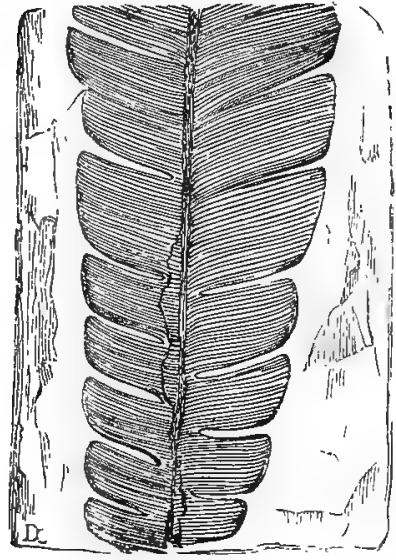

Fig. 929.

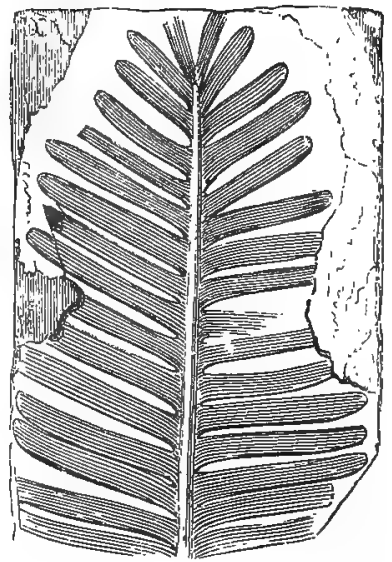

Fig." 930.

In the Oolitic epoch the flora consists of numerous Cycadaceæ and Coniferæ, some of them having peculiar forms. Schimper enumerates

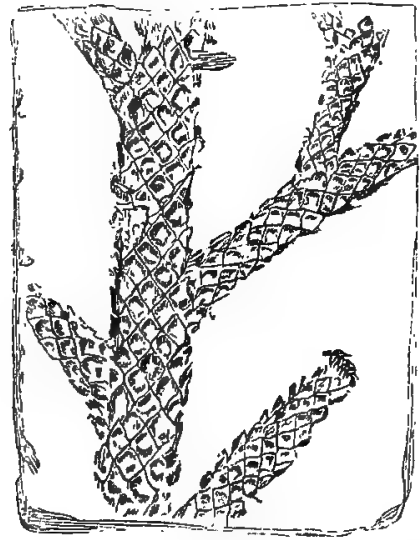

Fig. 931.

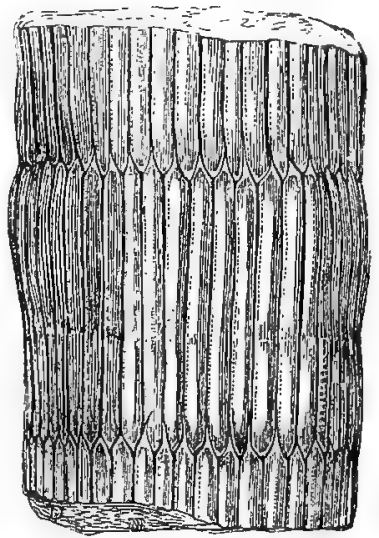

Fig. 932

Fig. 929. Palæozamia pectinata (Zamia pectinata of Brongniart, and of Lindley and Hutton), a pinnati-partite leaf of a fossil Cycad. Fig. 930. Pterophyllum Pleiningerii, leaf of a fossil Cycadaceous plant. Fig. 931. Brachyphyllum!mammillare, a Coniferous genus of the Oolitic System, Yorkshire. Fig. 932. Equisetum columnare, a fossil species of the Oolite of Yorkshire. 
96 Ferns, 61 Cycads, and 14 Conifers. The distinctive characters of this flora are, the rarity of Ferns with reticulated venation, which are so numerous in the Lias, the frequency of the Cycadaceous genera Otozamites and Zamites, which are most analogous to those now existing; of a remarkable group presenting very anomalous structure in their organs of reproduction, to which Mr. Cariruthers has given the name of Williamsonia, and the diminution of Ctenis, Pterophyllum, and Nilssonia, genera far removed from the living kinds; and lastly, the :greater frequency of the coniferous genera, Brachyphyllum (fig. 931), and Thuites, which are much more rare in the Lias. In the Scottish Oolite at Helmsdale Miller has detected about 60 species of plants, including Cycadaceæ and Coniferæ, with detached cones, and Fern forms resembling Scolopendrium. He also discovered a species of Equisetum (fig. 932), and a Calamite which is a connecting link between the Oolitic and Carboniferous epochs.

There is an absence of true coal-fields in the secondary formations generally; but in some of the Oolitic series, as in the lower Oolite at Brora, in Sutherlandshire, and the Kimmeridge clay of the upper Oolite, near Weymouth, there are considerable deposits of carbonaceous matter, but the vegetable remains are only in the state of imperfect lignite; some suppose that the Brora coal was formed chiefly by Calamites columnaris. In the sandstones and shales of the Oolitic series, especially in the lower Oolite of the north of England, as at Whitby and Scarborough, as well as in Stonesfield slate, the Portland Crag of the middle, and the Portland beds of the upper Oolite, nume-

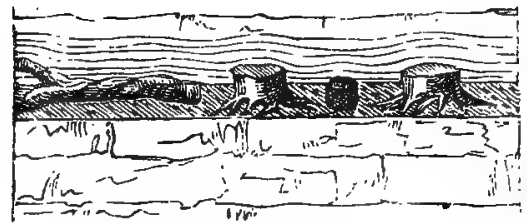

Fig. 933.

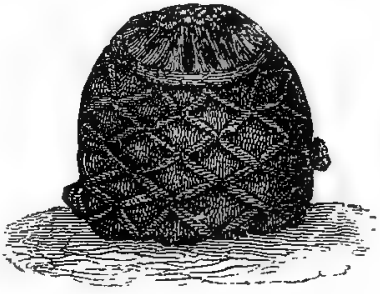

Fig. 934.

rous fossil plants are found. Peuce Lindleyana is one of the Coniferæ of the lower Oolite. Beania is a Cycadaceous fossil from the Oolite of Yorkshire. Araucarites sphærocarpus is found in the inferior Oolite. The upper Oolite at Portland contains an interesting bed, about a foot in thickness, of a dark brown substance, containing much earthy

Fig. 933. The Dirt-bed of the island of Portland, containing stumps of fossil Cycadaceæ in an erect position. Fig. 934. Cycadoidea megalophylla (Mantellia nidiformis of Brongniart), a subglobose depressed trunk, with a concave apex, and with the remains of the petioles disposed in a spiral manner, the markings being.transversely elliptical. It is found in the Oolite of the Island of Portland, in a silicified state. 
lignite. This is the Dirt-bed, made up of black loam, which, at some far distant period, was penetrated by the roots of trees, fragments of whose stems are now found fossilised around it. These consist of an assemblage of silicified stumps or stools of large trees, standing from 1-3 feet from the mould. Most of them are erect, some slightly inclined, and the roots remain attached to the earth in which they grew (fig. 933). They appear to resemble Cycadaceæ. One of these is Mantellia nidiformis (fig. 934). Carpolithes conica and Bucklandia are fruits found in the Oolite. Some look upon them as fruits of palms.

The flora of the Wealden epoch is characterised in the south of England by the abundance of the fern called Lonchopteris Mantellii, and in Germany by the predominance of the Conifer denominated Abietites Linkii, and the presence of Araucarites Pippingfordiensis, as well as by numerous Cycadaceæ, such as species of Cycadites, Zamites, Pterophyllum, Mantellia, Bucklandia, and a remarkable genus having a fleshy fruit, and related to the ordinary Cycadacer as Taxus is to the other Coniferæ, which has been described under the name of Bennettites. In the Wealden at Brook Point, Isle of Wight, Cycads have been detected allied to Encephalartos. Their fruit has been described by Carruthers as Cycadeostrobus. There are several species. Mantell has found 40 or 50 fossil cones in the Wealden of England. The remains are those of land plants. The Wealden fresh-water formation terminates the reign of Gymnosperms.

\section{III.-FLORA OF THE TERTIARY OR CAINOZOIC PERIOD.}

\section{(Including the Cretaceous Epoch.)}

\section{Brongniart's Reign of ANGiosperms.}

This reign is characterised by the appearance of Angiospermous Dicotyledons, plants which constitute more than three-fourths of the present vegetable productions of the globe, and which appear to have acquired the predominance from the commencement of the Tertiary epoch. These plants, however, appear even at the beginning of the Cretaceous period. In this reign, therefore, Brongniart includes the upper secondary period, or the Cretaceous system, and all the Tertiary period. The Cretaceous may be considered as a sort of transition period between the reign of Gymnosperms and Angiosperms.

The CreTaceous (chalk) period is characterised by the Gymnospermous almost equalling the Angiospermous Dicotyledons, and by the existence of a considerable number of Cycadacer, which do not appear in the Tertiary period. The genus Credneria is one of the character- 
istic forms. In this period we find Algæ represented by Cystoseirites, Confervites, Sargassites, and Chondrites ; Ferns by peculiar species of Pecopteris and Protopteris; Naiadaceæ by Zosterites; Palms, by Flabellaria and Palmacites; Cyacadaceæ, by Cycadites, Zamites, Microzamia, Fittonia, and Bennettites; Coniferæ, by Brachyphllum, Widdringtonites, Cryptomeria, Abietites, Pinites, Cunninghamites, Dammarites, Araucarites; and Angiospermous Dicotyledons, by Comptonites, Alnites, Carpinites, Salicites, Acerites, Juglandites, and Credneria. In the Gault of Folkestone a cone allied to that of Sequoia gigantea has been detected. Carruthers thinks that the coniferous vegetation of the highlands of the upper Cretaceous system had a facies similar to that now existing in the mountains in the west of North America, between the 30th and 40th parallel of latitude. With the chalk, Ansted says, we close, as it were, one great volume of the history of animated creation. Everything up to this point belongs to the past; everything on this side of it may be ranked among indications of the present. New forms, new types of organisation, corresponding to different habits and altered circumstances, now replace those which have passed away. The conditions under which animals and vegetables lived were changed, and a new epoch commenced upon the earth. At the base of the Tertiary period, there is a Fucoidean epoch, characterised by deposits rich in Algæ of a very peculiar form, belonging to the genera Chondrites and Munsteria. No land plants have been found mingled with these marine species.

The TerTrary series of Rocks are well seen in the south of Europe, Asia, and America. In Britain the tertiary deposits are met with in the London clay, in Hampshire and the Isle of Wight, the Suffolk and Norfolk Crag, and in the Till of the Clyde. The London clay contains numerous fruits belonging to many hundred species of plants. The first tertiary land of which we have knowledge seems to have been richly clothed with plants. The strata are, generally speaking, rich in fossils. The stems and leaves appear to be those of Dicotyledons, little differing from the plants of the present day (figs. 935-939). In the brown coal of this series, the structure of the wood is evident, and distinctly exogenous (figs. 935-937), and there are often associated with it leaves of Poplars, Elms (fig. 938), Oaks, Beeches, Maples, Hazels, Birches, and other forest trees. The fossil plants of the Isle of Sheppey have been examined by Bowerbank, and have led to the determination of several hundred species of plants, all of them extinct, and all resembling those of warmer climates :- fivits of Nipadites (Pandanocarpum), a fossil plant, allied to Nipa, one of the Pandanaceæ; Hightea, a fiveseeded fruit, probably Malvaceous; also the fruit of a Proteaceous plant, and of species allied to. Canna, Cucumber, and the Leguminosæ and Coniferæ of the present day. To some of them the names of Cupanoides, Wetherellia, Cucumites, and Mimosites, have been given. 
In some of the tertiary formations there occur pieces of wood, which present the structure of that of Pepper-plants and of Palms (figs. 940, 941 ), and there are also leaves which have the flabelliform appearance

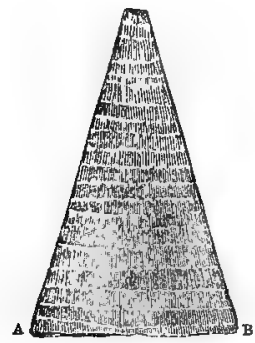

Fig. 985.

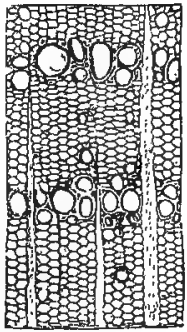

Fig. 936 .

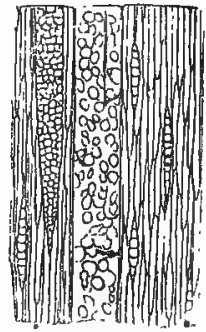

Fig. 937.

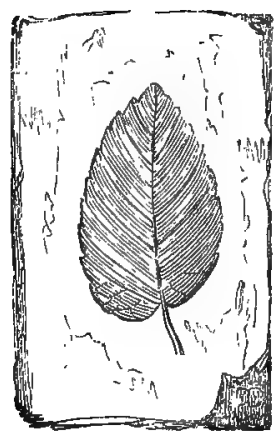

Fig. 988.

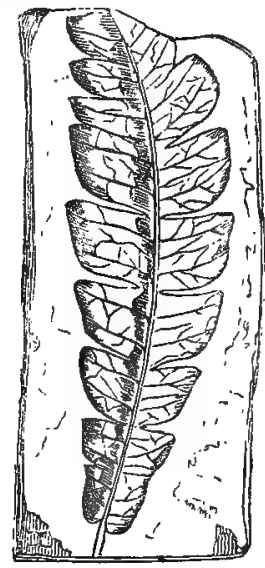

Fig. 939.

of Palm leaves, included under the name of Palmacites (fig. 942). Specimens allied to Chara are also found, with their fructification denominated Gyrogonites.

The Tertiary period is characterised by the abundance of Angio-

Figs, 935-987. Structure of ordinary Dicotyledonous stems, to illustrate the appearances presented by some tertiary fossil woods. Fig. 935. Portion of a Dicotyledonous (Fxogenous) stem cut transversely. Natural size. Fig. 936. Section of the same magnified, to show the occurrence of large porous vessels. The ordinary Dicotyledons differ in this respect from Coniferx. . Tig. 937. Longitudinal section of the same in the line A $\mathrm{B}$, perpendicular to the medullary plates, showing woody tissue and large pitted vessel, and the rays appearing here and there among the woody tissue.

Fig. 938. Leaf of fossil Elm of the middle Tertiary epoch. Fig. 939. Leaf of Comptonia acutilobr, an Amentiferous plant of the same epoch. 
spermous Dicotyledons and of Monocotyledons, more especially of Palms. By this it is distinguished from the more ancient periods. Angiosperms at this period greatly exceed Gymnosperms. Oycadaceæ are very rare, if not completely wanting, in the European Tertiary strata, and the Coniferæ belong to genera of the temperate regions.

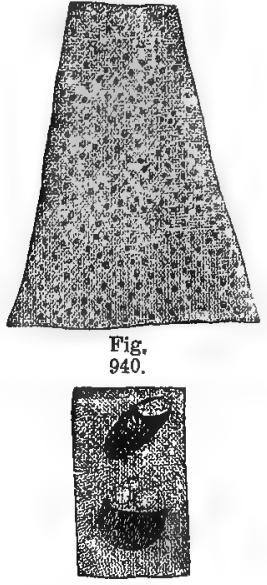

Fig. 941 .

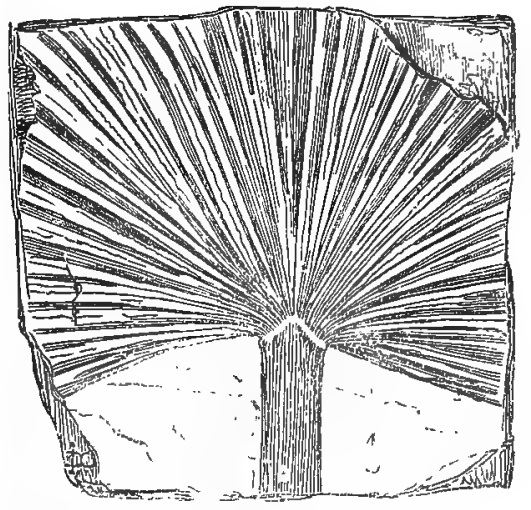

Fig. 942.

In the lower Tertiaries, Carruthers has found a fossil Osmunda. In the Tertiary beds some of the Pineæ are found. The Cupressiner occur in the Tertiary beds only. Taxodieæ are represented by Sequoia in the Cretaceous and Eocene shale. Peuce australis of Van Diemen's Land and P. Pritchardi of Ireland are Tertiary plants. Isoetes is mentioned by Schimper as a Tertiary genus. Although the vegetation throughout the whole of the Tertiary period presents pretty uniform characters, still there are notable differences in the generic and specific forms, and in the predominance of certain orders at different epochs. In the Eocene formation, the fossil fruits of the Isle of Sheppey increase the number of Phanerogamous plants, only a small proportion of which have as yet been described. This is an exceptional locality, and is perhaps an example of the effects of currents in conveying exotic plants from remote climates.

The EOcENE epoch in general is characterised by the predominance of Algæ and marine Naiadaceæ, such as Caulinites and Zosterites;

Fig. 940. Section of a recent Palm stem, to show its structure. The dark dots marking vaseular bundles in the midst of cellular tissue. Fig. 941. A portion of the same magnified, to show the vascular bundles. Fig. 942. Palmacites Lamanonis (Flabellaria litigiosa). Leaf of a Monocotyledon resembling a Palm. 
by numerous Coniferæ, the greater part resembling existing genera among the Cupressineæ, and appearing in the form of Juniperites, Thuites, Cupressites, Callitrites, Frenelites, and Solenostrobus ; by the existence of a number of extra-European forms, especially of fruits, such as Nipadites, Leguminosites, Cucumites, and Hightea; and by the presence of some large species of Palm belonging to the genera Flabellaria and Palmacites. Unger says that the Eocene flora has resembled in many respects that of the present Australian vegetation. He gives the following genera as occurring at the Eocene epoch :Araucaria, Podocarpus, Libocedrus, Callitris, Casuarina, Pterocarpus, Drepanocarpus, Centrolobium, Dalbergia, Cassia, Cæsalpinea, Bauhinia, Copaifera, Entada, Acacia, Mimosa, Inga. Amber is considered to be the produce of many Coniferæ of this epoch, such as Peuce succinifera or Pinites succinifera, and Pinus Rinkianus. It occurs in East Prussia in great quantity, and it is said that many pieces of fossil wood occur there, which, when moderately heated, give out a decided smell of amber. Connected with these beds are found cones belonging to Pinites sylvestrina and P. Pumilio, Miocene species nearly allied to the living Pinus; others to Pinites Thomasianus and P. brachylepis. Goeppert contrasts the present flora of Germany and that of the Amber epoch as follows:-

$\begin{array}{lccc} & & \text { German Flora. } & \text { Amber Flora. } \\ \text { Cryptogameæ } & \cdot & 6800 & 60 \\ \text { Phanerogameæ } & \cdot & 3454 & 102 \\ & & & \\ \text { Cupuliferæ } & & 12 & 10 \\ \text { Ericaceæ } & & 23 & 24\end{array}$

In the Lower Eocene of Herne Bay, Carruthers found Osmundites Bowkeri. Berkeley has detected in amber fossil fungi, which he has named Penicillium curtipes, Brachycladium Thomasinum, and Streptothrix spiralis. Some Characeæ are also met with, as Chara medicaginula and C. prisca, with a fossil called Gyrogonites, the nucule or the fructification of these plants. Carpolithes ovatus, a minute seedvessel, occurs in the Eocene beds of Lewisham. It is probably allied to the sporangium of a ferm. Another small fruit, of a similar nature, called Folliculites minutulus, occurs in the Bovey Tracey coal, which belongs to the Tertiary beds.

The most striking characters of the MIOcENe epoch consist in the mixture of exotic forms of warm regions with those of temperate climates. Unger says that it resembles that of the southern part of North America. Thus we meet with Palms, such as species of Flabellaria and Phcenicites, a kind of Bamboo called Bambusium sepultum, Lauraceæ, as Daphnogene and Laurus ; Combretaceæ, as Getonia and Terminalia; Leguminosæ, as Phaseolites, Desmodophyllum, Doli- 
chites, Erythrina, Bauhinia, Mimosites, and Acacia_all plants having their living representatives in warm climates; Echitonium, Plumiera, and other Apocynacese of equatorial regions, and Steinhauera, a Cinchonaceous genus; mingled with species of Acer (Maple), Ulmus (Elm), (fig. 936), Rhamnus (Buckthorn), and Amentiferous forms, such as Comptonia (fig. 938), Myrica, Betula (Birch), Alnus (Alder), Quercus (Oak), Fagus (Beech), Carpinus (Hornbean), all belonging to temperate and cold climates. The statements as to the occurrence of Pinus sylvestris and Betula alba among the Miocene fossils have not been founded on complete data. It is by no means easy, even in the present day, to distinguish fragments of dried specimens of Pinus Pumilio from those of $P$. sylvestris, and from a great many other Pines. The difficulty is still greater in fossils. There are a very small number of plants belonging to orders with gamopetalous corollas. As connected with the Miocene epoch, we may notice the leafbeds found at Ardtun, in the island of Mull, by the Duke of Argyll. Above and below these beds basalt occurs, and there are peculiar tuffbeds alternating with the leafy deposits. These tuff-beds are either of volcanic origin, or are a conglomerate stratified deposit, altered in a metamorphic manner. The beds are associated with chalk and flints. The leaves are those of plants allied to the Yew, Rhamnus, Maple, Plane, and Alder, along with the fronds of a peculiar Fern, and the stems of an Equisetum. The genera are Taxites or Taxodites, Rhamnites, Platanites, Alnites, Filicites, and Equisetum. In the leaf-beds at Bournemouth $\mathrm{Mr}$. Wanklyn detected several ferns. One is called by him Mertensites, and shows distinct venation and fructification. Fossilised wood was found in the Arctic Regions by Captain $\mathrm{M}^{\prime}$ Clure. At the. N.W. of Banks' Land he found trees with trunks 1 foot 7 inches in diameter.

The Arctic fossil flora (Miocene), according to Heer, amounts to 162 species: Cryptogamia, 18 species, of which 9 are large ferns; Phanerogamia, Coniferæ, 31 ; Monocotyledons, 14 ; Dicotyledons, 99. Among the Coniferæ are-Pinus M'Clurii, Sequoia Langsdorfii, Sternbergii, and Couttsiæ, Taxodium dubium, Glyptostrobus Europæus, Thuiopsis Europæa. Among leafy trees are-Fagus Deucalionis, Quercus Olafsoni, Platanus aceroides, willows, beeches, Acer, Otopteryx, tulip-tree, walnuts, Magnolia Inglefieldi, Prunus Scottii, Tilia Malmgreni, Corylus M'Quarrii, Alnus Kefersteinii, Daphnogene Kannii probably one of the Lauraceæ; and among Proteaceæ? MacClintockia and Hakea. In Greenland are found species of Rhamnus, Paliurus, Cornus, Ilex, Cratægus, Andromeda, Myrica, Iry, and Vine. From the flora of Spitzbergen, in the Miocene epoch, we may conclude that under $79^{\circ} \mathrm{N}$. lat. the mean temperature of the year was $41^{\circ}$ Fahr., while at the same epoch that of Switzerland was $69^{\circ} .8$ Fahr., judging from the analogy of floras. It appears that for each degree of 
latitude the mean temperature has fallen $0^{\circ .9} \mathrm{~F}$. From this it follows that at Spitzbergen, at. $78^{\circ} \mathrm{N}$. lat., the mean temperature was $41^{\circ} .9 \mathrm{Fahr}$; in Greenland, at $70^{\circ}$, it was $49^{\circ} .1 \mathrm{Fahr}$; and in Iceland and on the Mackenzie, in lat. $65^{\circ}$, it was $52^{\circ} .7$ Fahr. At the Miocene epoch the temperature was much more uniform, and the mean heat diminished much more gradually in proportion as the pole was approached. The isothermal line of $32^{\circ}$ Fahr. fell upon the Pole, while now it is situated under $58^{\circ} \mathrm{N}$.

In speaking of the Polar flora of former epochs, Heer says, " Every plant executes a slow and continuous migration. These migrations, the starting-point of which is the distant past, are recorded in the rocks ; and the interweaving of the carpets of flowers which adorn our present creation retraces them for us in its turn. For the vegetation of the present day is closely connected with that of preceding-epochs; and throughout all these regetable creations reigns one thought, which not only reveals itself around us by thousands upon thousands of images, but strikes us everywhere in the icy regions of the extreme north. Organic nature may become impoverished there, and even disappear when a cold mantle of ice extends over the whole earth; but where the flowers die the stones speak, and relate the marvels of creation; they tell us that even in the most distant countries, and in the remotest parts, nature was governed by the same laws and the same harmony as immediately around us."

The flora of the PLIocene epoch has a great analogy to that of the temperate regions of Europe, North America, and Japan.' We meet with Coniferæ, Amentiferæ, Rosaceæ, Leguminosæ, Rhamnaceæ, Aceraceæ, Aquifoliaceæ, Ericaceæ, and many other orders. There is a small number of Dicotyledons with gamopetalous corollas. The twenty species with such corollas recognised by Brongniart are referred to the Hypogynous Gamopetalous group of Exogens, which in the general organisation of the flowers approach nearest to Dialypetalæ. In this flora there is the predominance of Dicotyledons in number and variety; there are few Monocotyledons and no Palms. No species appear to be identical, at least with the plants which now grow in Europe. Thus the flora of Europe, even at the most recent geological epoch of the Tertiary period, was very different from the European flora of the present day.

Taking the natural orders, which have at least four representatives, Raulin gives the following statement as to the Tertiary flora of Central Europe. The Eocene flora of Europe is composed of 128 species, of which 115 belong to Algæ, Characeæ, Pandanaceæ, Palmæ, Naiadaceæ, Malvaceæ, Sapindaceæ, Proteaceæ, Papilionaceæ, and Cupressineæ. The Miocene flora has 112 species, of which 69 belong to Algæ, Palmæ, Naiadaceæ, Apocynaceæ, Aceraceæ, Lauraceæ, Papilionaceæ, Platanaceæ, Quercineæ, Myricaceæ, and Abietineæ. 
The Pliocene flora has 258 species, of which 226 belong to Algæ, Fungi, Musci, Filices, Palmæ, Ericaceæ, Aquifoliaceæ, Aceraceæ, Ulmaceæ, Rhamnaceæ, Papilionaceæ, Juglandaceæ, Salicaceæ, Quercineæ, Betulaceæ, Taxaceæ, Cupressineæ, and Abietineæ. The Eocene species are included in genera which belong at the present day to inter-tropical regions, comprising in them India and the Asiatic islands of Australia. Some are peculiar to the Mediterranean region. The aquatic plants, which form almost one-third of the flora, belong to genera now peculiar to the temperate regions of Europe and of North America, or occurring everywhere. The Miocene species belong to genera, of which several are found in India, tropical America, and the other inter-tropical regions, but which for the most part inhabit the sub-tropical and temperate regions, including the United States. Some of the genera are peculiar to the temperate regions. The aquatic genera, poor in species, occur everywhere, or else solely in the temperate regions. The Pliocene species belong to genera which almost all inhabit the temperate regions either of the old continent or of the United States. A few only are of genera existing in India, Japan, and the north of Africa. These various floras, which present successively the character of those of inter-tropical, sub-tropical, and temperate regions, seem to indicate that central Europe has, since the commencement of the Tertiary period, been subjected, during the succession of time, to the influence of these three different temperatures. It would appear, then, Raulin remarks, that the climate of Europe has during the Tertiary period gradually become more temperate. This may proceed either from a displacement of the earth's axis, or from the gradual cooling of the earth, or from a different proportion of land and water.

Brown coal occurs in the upper Tertiary beds, and in it vegetable structure is easily seen under the microscope. Groeppert, on examining the brown coal deposits of northern Germany and the Rhine, finds that Coniferæ predominate in a remarkable degree. Among 300 specimens of bituminous wood collected in the Silesian brown coal deposits alone, only a very few other kinds of Exogenous wood occur. This seems remarkable, inasmuch as in the clays of the brown coal formation in many other places leaves of deciduous Dicotyledonous trees have been found; and yet the stems on which we may suppose them to have grown are wanting. The leaves have been floated away from the place where they grew by a current of water, which was not powerful enough to transport the stems. The coniferous plants of these brown coal deposits belong to Taxineæ and Cupresșineæ chiefly. Among the plants are Pinites protolarix and Taxites Ayckii. Many Coniferæ exhibit highly compressed very narrow annual rings, such as occur in those of northern latitudes. Goeppert has described a trunk, or rather the lower end of a trunk, of Pinites protolarix, dis- 
covered in 1849 in the brown coal of Laasan in Silesia. It was found in a nearly perpendicular position, and measured more than 32 feet in circumference. Sixteen vast roots ran out almost at right angles from the base of the trunk, of which about four feet stood up perfect in form, but stripped of bark. Unfortunately the interior of the stem was almost entirely filled with structureless brown coal, so that only two cross sections could be obtained from the outer parts, one sixteen inches, the other three feet six inches broad. In the first section Goeppert counted 700, in the second 1300 rings of wood, so that for the halfdiameter of $5 \frac{1}{2}$ feet, at least 2200 rings must have existed. As there is every reason to believe that the rings were formed in earlier ages just as the annual zones are now, this tree would be from 2200 to 2500 years old. Exogenous stems in lignite are often of great size and age. In a trunk near Bonn, Nöggerath counted 792 annual rings. In the turf bogs of the Somme, at Yseux near Abbeville, a trunk of an Oak-tree has been found above 14 feet in diameter.

We have thus seen that the vegetation of the globe is represented by numerous distinct floras connected with the different periods of its history, and that the farther back we go the more are the plants different from those of the present day. There can be no doubt that there have been successive deposits of stratified rocks, and successive creations of living beings. We see that animals and plants have gone through their different phases of existence, and that their remains in all stages of growth and decay have been embedded in rocks superimposed upon each other in regular succession. It is impossible to conceive that these were the result of changes produced within the limits of a few days. Considering the depth of stratification, and the condition and nature of the living beings found in the strata at various depths, we must conclude (unless our senses are mocked by the phenomena presented to our view) that vast periods have elapsed since the Creator in the beginning created the heavens and the earth. How far it may be possible in the future to correlate the history of the earth inscribed on its rocky tablets and deciphered by the geologist, and that short narrative which forms the introduction to the Sacred Volume, it is difficult to say. At present there are no satisfactory materials for such a correlation; but one thing is certain, that both Revelation and Geology testify with one voice to the work of a Divine Creator.

When we find animals and plants of forms unknown at the present day, in all conditions as regards development, we read a lesson in regard to the history of the earth's former state as conclusive as that which is derived from the Nineveh relics (independent of Revelation) in regard to the history of the human race. There is no want of harmony between Scripture and geology. The Word and the Works of 
God must be in unison, and the more we truly study both, the more they will be found to be in accordance. Any apparent want of correspondence proceeds either from imperfect interpretation of Scripture or from incomplete knowledge of science. The changes in the globe have all preceded man's appearance on the scene. He is the characteristic of the present epoch, and he knows by Revelation that the world is to undergo a further transformation, when the elements shall melt with fervent heat, and when all the present state of things shall be dissolved, ere the ushering in of a new earth, wherein righteousness is to dwell. sulted :-

On the subject of Fossil Botany the following works may be con-

Argyll, Duke of, on Tertiary Leaf Beds in the Isle of Mull, Journ. Geol. Soc., May 1851. Balfour, on Vegetable Organisms in Coal; Trans. R.S.E., vol. xxi. ; Palæontological Botany, 1872. Bennett, on the Structure of Torbane Hill Mineral and other Coals, Trans. R. Soc. Ed, vol. xxi. p. 173. Binney, E. W., on Calamites and Calamodendron, Palreontographical Society's Memoirs, 1868. Bowerbank, Fossils of the London Clay. Brongniart, Histoire des Végétaux Fossiles, 1828-1844; Observations sur la Structure interieure du Sigillaria, etc., in Archives du Museum, i. 405; Exposition Chronologique des Periodes de Végétation, in Ann. des Sc. Nat., 3d series, Bot. xi. 285. Carruthers, on Gymnospermatous Fruits from the Secondary Rocks of Britain, Journ. Bot., Jan. 1867 ; on the Structure of the Stems of the Arborescent Lycopodiaceæ of the Cobl Measures, Month. Microsc. Journ. i. 177 ; on The Cryptogamic Forests of the Coal Period, April 1869; on the Structure and Aftinities of Sigillaria and Allied Genera, Quart. Journ. Geol. Soc., Aug. 1869; on some Fossil Coniferous Fruits, Geol. Mag., vols. iii. vi.; On Beania, a new genus of Cycadean Fruit, from the Yorkshire Oolites, Geol. Mag., vol. vi. ; on Plant-remains from the Brazilian Coal-bods, with Remarks on the genus Flemingites, Geol. Mag., vol. vi. ; on the Fossil Cycadaceous Stems from the Secondary Rocks of Britain, Linn. Trans., xxvi. 675. Christison on Fossil Trees of Craigleith, Proc. R.S.E., 1873. Corda, Beiträge zur Flora der Vorwelt, Prag. 1845. Cotta, Dendrolithen. Dawson, on Vegetable Structures in Coal, Quarterly Journal Geological Society, 1860; on the Pre-Carboniferous Flora of New Brunswick and Eastern Canada, Canadian Naturalist, May 1861; on the Flora of the Devonian Period in North-Eastern America, Quart. Journ. Geol. Soc., Nov. 1862 ; on an Erect Sigillaria and a Carnolite from Nova Scotia, Quart. Journ. Geol. Soc. Lond. ; on Calamites, Ann. Nat. Hist., 4th ser., vol. iv. 272; on the Varieties and Mode of Preservation of the Fossils known as Sternbergiæ, Canadian Naturalist; Acadian Geology, 1868. Ettinghausen, Beiträge zur Flora der Vorwelt in Abhandlungen der Geolog. Reichsanstalt, Vienna, 1851. Forbes, on the Vegetable Remains from Ardtun Head, Quart. Journ. Geol. Soc. Lond., vol. vii. Giebel, Palæontologie. Goeppert, Die Gattungen der Fossilen Pflanzen, Bonn, 1841; Monographie des Fossilen Coniferen, 1850; Systema Filicum Fossilium, Nova Acta, xvii. ; Ueber die Fossilen Cycadeen, Breslau, 1844 ; Erläuterung der Steinkohlen-Formation; Die Fossile Flora der Permischen Formation, in Palæontographica, von Meyer, Cassel, 1864 ; Beiträge zur Kenntniss Fossilen Cycadeen, Breslau. Grand d'Eury, on Calamites and Asterophyllites, Ann. Nat. Hist., ser. 4, vol. iv. 124. Harkness, on Coal, Edin. Phil. Jour., July 1854. Heer, Flore Fossile des Regions Polaires, 1869, transl. Ann. Nat. Hist., 4th ser., p. 61. Hooker, on some Minute Seed-ressels (Carpolithes Ovalum, Brongniart) from the Eocene beds of Lewisham, Proceed. 
Geol. Soc., 1855 ; Vegetation of the Carboniferous Period, in Mem. of Geol. Survey, ii. ; on a New Species of Volkmannia, Quart. Journ. Geol. Soc. Lond., May 1854. King, on Sigillaria, etc., in Edin. New Phil. Journal, xxxvi. Lesquereux, on the Coal-Measures of America, Silliman's Journal, 1863. Report of the Trial as to the substance called Torbane Mineral or Torbanite. Lindley and Hutton, Fossil Flora, Our Coalfields, by a Traveller under ground. Lowry, Table of the Characteristic Fossils of Different Formations. Nicholson, on the Occurrence of Plants in the Skiddaw Slates, Geol. Mag., vol. vi. Paterson, Description of Pothocites Grantoni, Trans. Bot. Soc. Edin., vol. i. Penny Cyclopredia, vol. vii,, Coal Plants. Pictet, Manual of Palæontology. Quekett, on the Minute Structure of Torbane Hill Mineral, Journ. Microsc. Sc., 1854. Raulin, Flore de l'Europe pendant la Période Tertiaire, in Ann. des Sc. Nat., 3d ser., x. 193. Redfern, on the Nature of the Torbane Hill and other Varieties of Coal, Brit. Assoc. Liverpool, 1854. Saporta, Études sur la Végétation du Sud-Est de la France à l'Epoque Tertiaire, Annales des. Sciences Naturelles, ser. 4, tome xvi. 309, xvii. 191, xix. 5; ser. 5, tome iii. 5, iv. 5. Schimper, Traité de Paléontologie Végétale, 3 vols. $8 \mathrm{vo}$, with folio plates. Tate, on the Fossil Flora of the Mountain Limestone Formation of the Eastern Borders, in connection with the Natural History of Coal (in Johnston's Eastern Borders). Unger, Genera Plantarum Fossilium; Chloris Protogea; Le Monde Primitive (a work which contains picturesque views of the supposed state of the earth at different geological epochs). Williamson, on the Structure and Affinities of the Plants hitherto known as Sternbergix, Sept. 1851 ; on a New Form of Calamitean Strobilus, from the Lancashire Coal Measures, Mem. Lit. Phil. Soc. Manchester, vol. iv., 3d series; on the Structure of the Woody Zone of an Undescribed Forma of Calamite, Mem. Lit. Phil. Soc. Manchester, vols. iv. and viii., 3d series ; on Zamia gigas (Williamsonia gigas), Linn. Trans. xxvi. 663 ; on the Organisation of Fossil Plants of the Coal-Measures, Phil. Trans. R.S.L., vols. 161-164. Witham, on the Structure of Fossil Vegetables. M'Nab, Dr., on the Structure of Calamites, Ed. Bot. Soc. Trans., vol, xi. p. 437. Yates, on Zamia gigas, Proceed. Yorkshire Phil. Soc., April 1847. Besides geological treatises such as those of Ansted, Beudant, Jukes, Lyell, and others. 


\section{APPENDIX.}

\section{I.-ON the Use of the Microscope in Botanical Researches.}

THE Microscope is a most important instrument in education, and it is essential for the due understanding of the structure and physiology of plants. The study of the microscopical structure of organised bodies is termed Histology (iđrós, a web or tissue, and $\lambda$ ó yos, discourse). Dr. Carpenter remarks :- "The universe which the microscope brings under our ken seems as unbounded in its limit as that whose remotest depths the telescope still vainly attempts to fathom. Wonders as great are disclosed in a speck of whose minuteness the mind can scarcely form any distinct conception, as in the most mysterious of those nebulæ whose incalculable distance baffles our hopes of attaining a more minute knowledge of their constitution. And the general doctrines to which the labours of microscopists are manifestly tending, in regard to the laws of organisation and the nature of vital action, seem fully deserving to take rank in comprehensiveness and importance with the highest principles yet attained in physical or chemical science. It is by pursuing, by the aid which the microscope alone can afford to his visual power, the history of the organic germ, from the simple and homogeneous form which seems common to every kind of living being --either to that complex and most heterogeneous organism which is the mortal tenement of man's immortal spirit, or only to that humble Protophyte or Protozoon, which lives, and grows, and multiplies, without showing any essential advance upon its embryonic type, that the physiologist is led to the grandest conception of the unity and all-comprehensive nature of that creative design, of which the development of every individual organism, from the lowest to the highest, is a separate exemplification, at once perfect in itself and harmonious with every other."

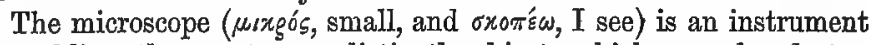
for enabling the eye to see distinctly objects which are placed at a very short distance from it, or to see minute objects that would otherwise be invisible. It has been used with great success in the examination of vegetable structure. To it we are indebted for a knowledge of the various vessels and cells which enter into the com- 
position of the different parts of plants, of the circulation of fluids, and of ciliary movements, as well as for the facts connected with the development of the embryo. It is an instrument, however, which requires to be used cautiously; and the conclusions drawn from it ought to be carefully weighed, more especially when the observations have been made with high magnifying powers.

LENSES.-Before proceeding to notice the construction of simple and compound microscopes, it will be advantageous to notice the different kinds of lenses used, and the sources of error which require to be guarded against in their preparation. The chief forms of lenses used are the double-convex (fig. 943,4), with two convex faces ; plano-

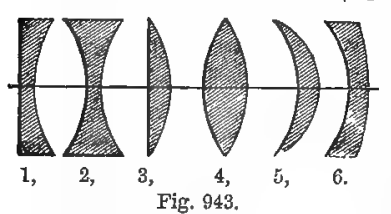
convex (fig. 943,3 ), with one face flat and the other convex; double-concave (fig. 943, 2), with two concave faces; and plano-concave (fig. 943, 1), with one flat and one concave face. Sometimes, also, a meniscus (fig. 943,5) is used, with a concave and a convex face, and a sharp edge, and a concavo-convex (fig. 943,6), with a concave and convex surface and flat edges. Convex lenses with sharp edges cause parallel rays to converge ; while concave lenses with flat edges cause them to diverge. The lenses used in microscopes are chiefly convex-the concave lenses being employed to make certain modifications in the course of the rays passing through convex lenses, whereby their performance is rendered more exact. The magnifying power of a single lens is inversely as its focal length. The principal focus is the point to which parallel rays converge after refraction. The focal distance of a double convex lens is half that of a plano-convex lens, having the same curvature. In the use of ordinary lenses there are sources of error from the form of the lens and the nature of the material of which it is made. When parallel rays fall on a doubleconvex or a plano-convex lens, they are brought to a focus at a certain. distance from the lens; but it is found that no lens with a spherical surface can bring the rays of light to the focus at one point. Hence arises what is called spherical aberration. In this kind of aberration the rays which pass through the lens near its circumference are brought to a focus nearer to the lens than those which pass through near the centre, hence the objects at the circumference of the field of the microscope are not in focus at the same time as those in the centre. Moreover, the different coloured rays of which white light is composed are unequally refrangible, the violet rays having the greatest and the red rays having the least degree of refrangibility; a

Fig. 943. Different kinds of lenses-1, Plano-concave, 2, Double-concave. 3, Planoconvex. 4, Double-convex. 5, Meniscus. 6, Concavo-convex. 3, 4, 5, are sharp-edged lenses, and cause convergence. $1,2,6$, are flat-edged, and cause divergence. 
lens therefore breaks up a ray of white light into its constituent colours, so that a colourless object appears coloured. This is termed chromatic ( $\chi \rho \tilde{\omega} \mu \alpha$, colour) aberration. To remedy these defects certain combinations of glasses have been adopted, so that the light traversing one lens through the centre may pass through near the margin of another. The confusion produced by these aberrations may be greatly lessened by diminishing the pencil of light ; for instance, by employing a stop or diaphragm, which lessens the aperture of the lens and cuts off the peripheral rays. In lenses of low power, such as are used in the simple dissecting microscope, these aberrations do not cause much confusion. It is only when high powers are required that these aberrations must be done away with. The invention of Wollaston's doublet with two lenses, and Holland's triplet with three, was with the view of diminishing, as far as possible, these aberrations. They were aplanatic ( $\alpha$ privative, $\pi \lambda \alpha v \alpha^{\prime} \omega$, I wander), i.e. they remedied spherical aberration, but coloured images were still produced. Their lenses were constructed of the same kind of material; and it was found that in order that lenses might present the object uncoloured, or be what is called achromatic ( $\alpha$, privative, and $\chi \rho \tilde{\omega} \mu \alpha$, colour), it was necessary to use two glasses of different refractive power. Achromatic lenses, or such as are nearly free from chromatic aberration, are constructed by placing together glasses of different dispersive powers, and of different forms. The usual achromatic lens consists of a double-convex lens, made of plate or crown glass, and a plano-concave, made of flint-glass (fig. 944), fitted

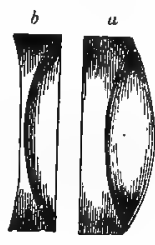

Fig. 944. accurately to it, and cemented by Canada balsam.

Microscopes are of two kinds. Simple and compound. By the Sincple Microscope objects are viewed through a single lens, or through two or three lenses placed together, so as to form doublets or triplets. The glass is arranged so that it can be brought over the object, and adjusted, by means of a rack and pinion, or by some other contrivance, to its exact focal distance-the object, when opaque, being seen by light thrown from above, and when transparent, by light transmitted from below. This instrument, when used with single lenses or doublets, is the best for ordinary botanical investigations, more especially for dissections. The combination of three lenses approaches too near the object to be easily used. A very high power may be obtained by doublets formed of plano-convex glasses, or by means of the lenses termed Coddington's or periscopic, consisting of two hemispherical lenses, cemented together by their plane faces, having a stop between them, or rather having a groove in the whole sphere filled with opaque matter. The chief objections to the simple microscope are

Fig. 944. $u$, An achromatic and aplanatic lens, consisting of a double-convex lens of plate-glass, and a plano-concave of flint-glass. $b$, Section of the plano-concave lens. 
the fatigue attendant on long-continued investigations, and the small field of view. In the simple microscope, glasses of the following focal lengths may be employed-viz, $1 \frac{1}{2}$ inch, $\frac{3}{4}, \frac{1}{2}, \frac{1}{4}$; and, if very minute objects are to be examined, of 1-10th, 1-30th, or 1-40th of an inch.

For examining minute plants, such as Diatomacer and Desmidix, during an excursion, it is useful to have a simple microscope similar to that represented in fig. 945 . It consists of a Wollaston's doublet, fixed in a round plano-concave brass disc (fig. 945, 1, a),

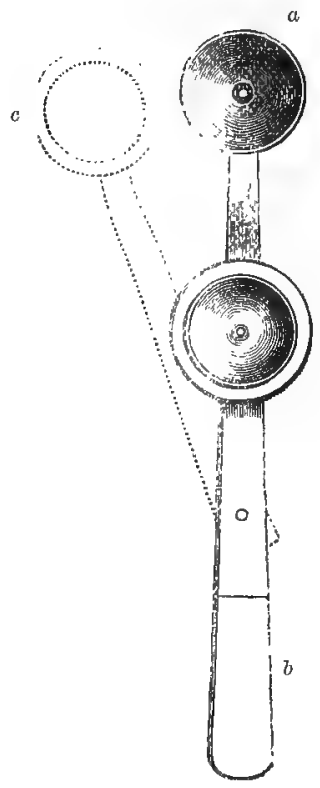

1

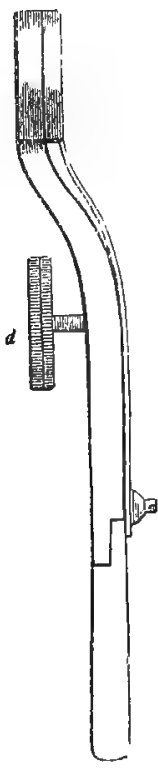

Fig. 945 .

2

attached to a small brass handle (fig. $945,1, b$ ). For ordinary botanical purposes a lens magnifying 65 to 70 diameters is enough; but the lenses may be procured with a power of 150 to 220 diameters. On the plane side of this brass disc there is a ring of silver (fig. $945,1, c$ ), in which a thin piece of glass is fixed, also supported by a brass handle, which acts as a spring, so as to keep the two rings in contact.

Fig. 945 represents Dr. Gairaner's portable simple' microscope. In I there is given a front view of the instrument, showing the posterior silver ring, $c$, enelosing a piece of thin glass, separated and turned aside from the dise, $a$, containing the doublet, to which the eye of the observer is applied. 2 exhibits a lateral view of the instrument, with the screw, $d$, shy means of which the handles are separated or approximated, so as to bring the object into focus. 
In the handle of the first-mentioned disc there is a screw (fig. 945,2 , d), which passes through it, and by the motion of which the two handles can be separated or allowed to come close to each other. By this means an exact focal distance can be obtained. A drop of fluid containing Diatoms, or any minute object, is placed on the outside of the thin glass in the silver ring, and it is then covered by a similar piece of thin glass, which adheres by means of the fluid. The object being brought into focus, as in fig. 945,2 , the observer can distinguish the characters of the microscopic plant, so as to determine whether it is necessary to take specimens home for more careful examination by the compound microscope.

In the Compound microscope there are two sets of lenses-the one called the object-glass or objective, the other the eye-piece or ocular. The first receives the rays from the object, and bringing them to new foci, forms an image, which the second treats as an original object, and magnifies it just as the single microscope magnified the object itself. The image is inverted, but this may be remedied by making the rays pass through another set of lenses in the tube of the microscope, called an erector. In the construction of the object-glasses, great care is taken to render them achromatic. Those made by the most eminent London makers consist of two or three compound lenses, which cannot be used separately, but are fixed together in a tube. In the case of high powers, the object-glasses are also provided with an adjustment for the thickness of the glass covering the object to be viewed. This adjustment makes up for the refraction caused by the passage of light through thin glass of different thickness, and is accomplished by altering the distance between the outer and middle pairs of lenses in the object-glass. This adaptation is especially necessary in the case of a glass with a large angle of aperture. The eye-piece, also, must be so formed as to be free from error. That used is called Huyghens', and consists of two plano-convex lenses with their plane sides towards the eye, and placed at a distance apart equal to half the sum of their focal lengths, with a diaphragm inserted midway between the lenses. In this eye-piece, the lens next the eye is called the eye-glass, the other the field-glass. By the Huyghenian or negative eye-piece the object is seen inverted. The Ramsden or positive eye-piece consists of two plano-convex glasses, with the convex surfaces directed towards each other; by it objects are seen erect, and it is often used as a micrometer eye-piece, that is, for measuring objects. The eye-pieces supplied with the best microscopes are usually three, and they are so constructed, that, with each of the object-glasses, they give a certain amplification of the object, the powers being in the proportion of 1,2 , and 3 , or $1,1 \frac{1}{2}$, and $2 \frac{1}{2}$. In the best microscopes there is also an achromatic condenser or eclairage, through which the light reflected from the mirror passes. The amplification by means of an eye-piece 
in the compound microscope enables us to use an object-glass of a lower power than would otherwise be necessary. The compound microscope, when well constructed, gives a flat and colourless picture of the object, with clearness of definition. The observer can use it for a length of time with less fatigue than when employing the simple microscope. Weak eye-pieces and strong object-glasses are to be recommended. The eye-piece does not add either clearness or distinctness to the object, and when it is very powerful the field of view becomes too small to take in the whole image formed by the object-glass; for the magnitude of the field of view and the strength of the illumination diminishes according to the magnifying power of the eye-piece employed. The lower powers are of use in searching for the object to be examined, which may thus be more easily found by a higher power. For the lower power a linear amplification of from 20 to 50 diameters, and for a higher power a linear amplification of from 300 to 500 diameters at most, will give a sufficiently wide range of powers.

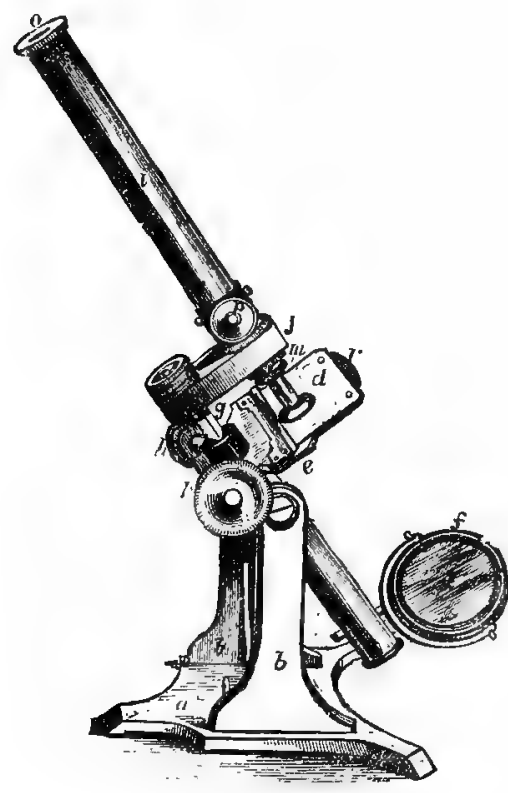

F'ig. 948.

The powers are increased by a more powerful eyepiece or object-glass, or by both, or by lengthening the tube of the microscope.

In examining vegetable structures, an instrument magnifying 150 to 200 diameters is usually suffcient; but in some instances higher powers are required. Achromatic objectlenses of $1 \frac{1}{4}, \frac{2}{3}$, and $\frac{1}{4}$ of an inch focal length are recommended as the most essential; and two eye-pieces should be provided, one of about $1 \frac{1}{2}$ and the other of $2 \frac{1}{2}$ inches in length. The instrument should have both a coarse and a fine adjustment; and it is of importance that it should be made to incline or to stand vertical. A movable stage is also useful, and a spring-holder to fix the objects on the stage, so that the different parts of the object may be viewed without being touched by the fingers.

Fig. 946. Ordinary compound microscope. 
In figure 946 a compound microscope is represented. The stand or base consists of a strong tripod, $a$, supporting two upright pillars, $b \quad b$, between the upper parts of which an axis works. This carries the whole of the optical parts of the instrument, which can be adjusted to any inclination, horizontal, vertical, or intermediate. The stage, $d e$, is firmly attached to the axis, as is also the double mirror, $f$. The triangular bar, $g$, has a rack on its posterior part, which is worked by a pinion, the milled heads of which are seen at $h h$. The body, $i$, screws firmly into the arm, $j$; the achromatic object-glasses are screwed into the body at $m$; the Huyghenian eye-piece slides into the other end of the body. The mirror is plane on one side, and concave on the other, and is fitted with a universal movement, so as to be inclined in any desired position. The milled heads, $h h$, by being revolved, raise or lower the body, $i$, and constitute the coarse adjustment; the fine adjustment is effected by turning the milled head, $p$. The object to be examined is placed on the stage, $d$, and retained in the required position by the sliding piece, $e$. The quantity of light admitted through the instrument may be modified by the diaphragm, $r$, which consists

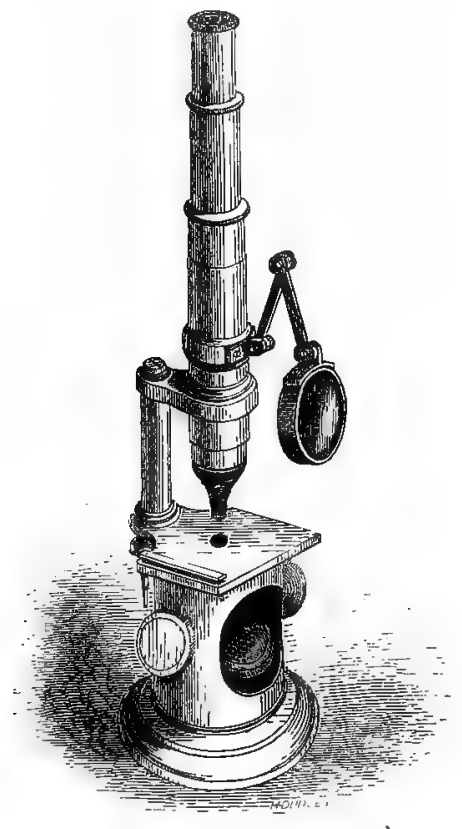

Fig. 947.

Fig. 947. Hartnack's (Oberbäuser's) student's microscope. 
of a plate of brass with four apertures of different diameters, made to

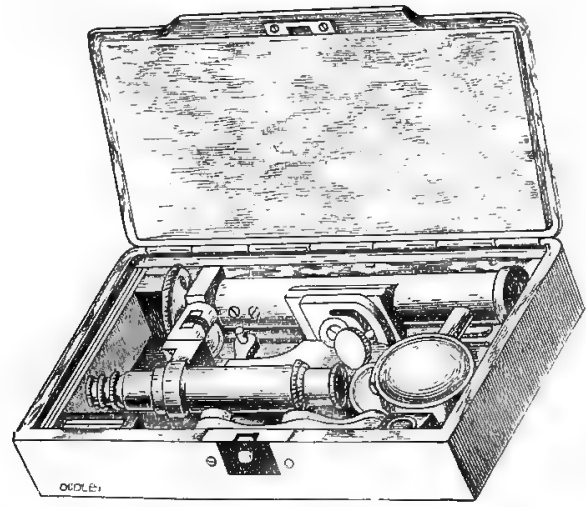

Fig. 948 .

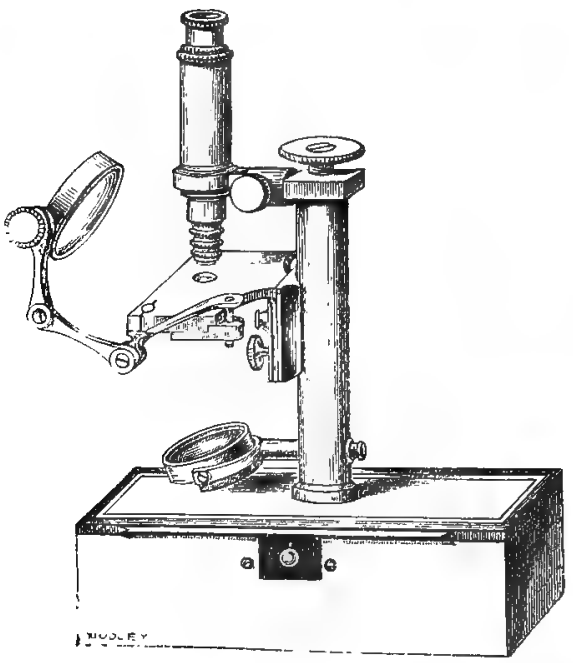

Fig. 949 .

revolve on a central pin or axis fixed to the bottom of the stage.

Figs. 948 and 949 represent Gruby's portable compound microscope one-half its real size. Fig. 948. The instrument in its case. Fig. 949. The instrument mounted. A foll deseription is given by Dr. Bennett in the Edinburgh Monthly Medical Journal for December 1846. 
Provision is also made for adding a polarising apparatus. In addition to the four holes mentioned as needed to admit the requisite amount of light, the diaphragm is furnished with a fifth hole, into which a Nicol's prism may be screwed, forming the polariser; the analyser being serewed into the upper part of an adapter previously to its being attached to the body, $i$. The polariser is mounted on a double tube, so as to be capable of being evolved by turning a large milled head at the bottom. A condensing leas for illuminating opaque objects may be fitted into the hole at the corner of the stage ; it is so arranged that it can be used in any required position or angle. Among the objects often furnished with the microscope is a plate of selenite, which, if laid under many animal and vegetable structures while being examined by polarised light, will cause them to assume beautiful colours. By means of a Binocular microscope objects may be seen in relief.

Very good microscopes for students are made by Smith and Beck in London, and by Nachet and Hartnack in Paris. One of the latter is shown in figure 947. The figure is one-fourth of the real size of the instrument. The body consists of a telescope tube eight inches in length, held by a split tube three inches long. It may be elevated or depressed by the hand by a cork-screw movement, and this constitutes the coarse adjustment. It is attached to a cross-bar and pillar, at the lower portion. of the latter of which there is a fine adjustment screw. The stage is three inches broad and two and a half inches deep, with a circular diaphragm below it. The base of this portable instrument is loaded with lead so as to give it steadiness. A similar instrument is made by Nachet, in which there is a broader stage and a broader base, as well as a means of inclining the body of the instrument. The following are the magnifying powers, in diameters linear, of Nachet's compound achromatic microscope for students :-*

\begin{tabular}{|c|c|c|c|}
\hline $\begin{array}{c}\text { OBJECTIVES } \\
\text { (OBIECT- } \\
\text { GLASSES) }\end{array}$ & \multicolumn{3}{|c|}{ OCULARS (EYE-PIECES). } \\
\cline { 2 - 4 } & $\mathbf{1}$ & $\mathbf{2}$ & $\mathbf{3}$ \\
\hline $\mathbf{1}$ & 70 & 90 & 140 \\
\hline $\mathbf{3}$ & 190 & 250 & 400 \\
\hline $\mathbf{5}$ & 280 & 360 & 600 \\
\hline
\end{tabular}

As a portable compound microscope is sometimes wanted by a student, Dr. Bennett has given the accompanying figures of one recommended by Gruby of Paris. In fig. 948 the instrument is shown in its Case,

* The price of the instrument, with all these powers, is 190 francs, exclusive of duty and carriage; without No. 2 ocular, and No. 5 objective, it is 150 francs. 
and in 949 it is mounted. The woodcuts are exactly one-half the real size, and give a good idea of the instrument, a detailed description of which is not required. In fig. 950 a representation is given of one of Smith and Beck's microscopes for students. $A$ is the brass stand, supported firmly on three feet, and having two upright flat cheeks, to the top of which the stage-plate, $d$, is fixed. Into the stage-plate is

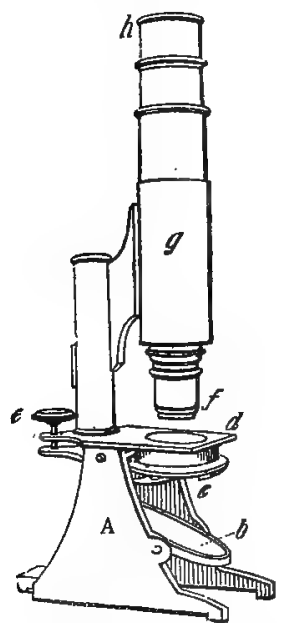

Fig. 950.

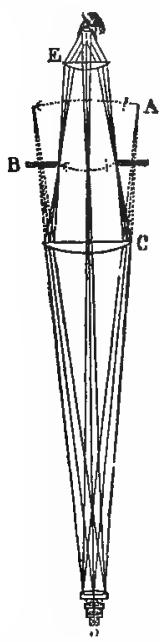

Fig. 951. serewed an upright round tube, to which is attached an open tube, $g$, in which the body of the instrument, $f h$, slides. By moving the body up and down in this tube, the coarse adjustment is effected, and when the instrument is brought near to the object on the stage-plate, $d$, a finer adjustment is made by means of the screw with the milled head, $e$, which either raises or depresses the part by which $g$ is attached to the up-. right tube. The mirror is represented at $b$, supported on trunnions, and capable of motion upwards or downwards, so as to reflect the light on the object placed on the stageplate; $c$ is the diaphragm or stop, or perforated plate attached to the stage, with the view of shutting off the extreme rays of light. The object-glass or objective is placed at the lower end of the instrument, $f$, and the eye-piece or ocular at the upper part, $h$.

In fig. 951 a diagram is given to explain the mode in which the compound microscope acts. In this figure, $O$ is the object, above which is seen the triple achromatic object-glass or objective, consisting of three achromatic lenses, which are combined in one tube; $e c$ is the eye-piece or ocular, consisting of two plano-convex lenses, one at $e$, being the eye-glass, and the other at $c$, the field-glass. Three rays of

Fig. 950. Smith and-Beck's compound microscope for students. A, brass atand, sapported on three feet; $b$, mirror supported on trunnions; $c$, diaphragm; $d$, stage-plate on which the object is placed; $e$, screw with milled head for fine adjustment; $g$, brass tujo in which the body of the instrument is moved, so as to effect the coarse adjustinent; $f$, the object-glass or objective; $h$, the eye-piece or ocular. Fig. 951. Diagram to show the mode in which the compound microscope acts. $O$, an object, with three rays of light from its centre, and three from each of its ends; $e c$, eye-piece, cousisting of two plano-convex lenses-one at $e_{3}$ the eye-glass, the other at $c$, the field-glass; $b$, diaphragm; $a$, the point where an image would be formed if the rays were not made to converge by the lens $c$. 
light are represented as proceeding from the centre of the object, and three from each end of it. These rays, if uninterrupted, would form an image of the object at $a$, but owing to the interposition of the field-glass $c$, they are refracted so as to converge and meet at $b$, where the diaphragm is placed to intercept all light except what is necessary for the formation of a perfect image. The image formed at $b$ is viewed as an original object by the observer through the eyeglass $e$.

Microscopic Apparatus.-In measuring the size of microscopic

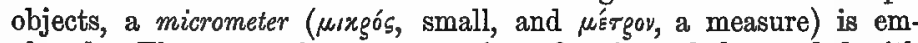
ployed. The stage micrometer consists of a piece of glass, ruled with fine lines by means of a diamond point, at some known distance apart, such as the $\frac{1}{100}$ th, or $\frac{1}{100} \mathrm{th}$, or $\frac{1}{2500 \mathrm{th}}$ of an inch. A mode of ascertaining the magnifying power of the compound microscope is founded on the assumption that the naked eye sees most clearly and distinctly at the distance of ten inches. If a divided scale be placed on the stage, and distinctly seen magnified through the instrument, let a rule be held at ten inches' distance from the right eye, while the observer uses, at the same time, his left eye in looking at the other scale through the microscope, and let the rule be gently moved so that it is seen to overlap or lie by the side of the magnified picture of the other scale,-a comparison as to how many of its known divisions correspond with a number of those on the magnified scale will indicate the magnifying power. Upon a similar principle a pair of compasses may be substituted, whose points being placed on the stage are separated till they cover or mark off so many spaces as magnified by the instrument. If they cover one magnified space, and correspond to 2, 3 , or more, known spaces on the rule, then the instrument is said to magnify 2,3 , or more times linear that known space. If $\frac{1}{10} \sigma$ th of an inch is found to cover 2 inches on the rule, the instrument magnifies 200 times; if 3 inches, 300 times; if 4 inches, 400 times, and so on. In this way is determined the magnifying power of any combination of lenses, and the scale which is magnified is called a stage-micrometer. The size of objects may be measured by placing them directly on this micrometer; but it is obvious that they cannot under high powers be brought into focus at the same time as the lines of the micrometer. An instrument called the eye-piece micrometer is therefore generally used. It consists of a fine scale, ruled on glass, and placed in the focus of the upper glass of the eye-piece. The value of each space of the eye-piece micrometer varies with the magnifying power of the object-glass which is placed on the microscope ; e.g., suppose we look at $\frac{1}{100}$ th inch space of the stage micrometer with a magnifying power of 250 diameters, and find that the space thus magnified extends over 5 spaces of the eye-piece micrometer, the value of each space of the latter will obviously be 
used. If a lower object-glass were taken-e.g., one which magnifies 50 diameters, it would then be found that the $\frac{1}{100}$ th inch space of the stage micrometer is equal to only one space of the eye-piece micrometer, so that, with this magnifying power, each space of the latter indicates $\frac{1}{1000}$ th inch. These calculations have to be made for the magnifying powers of every microscope. When an object is to be measured, the stage micrometer is removed, and the object, placed on a slide and covered in the usual manner, is brought into focus, say, with a power of 250 diameters. If the object extends over 5 spaces of the eye-piece micrometer, its breadth would evidently be $\frac{1}{1000}$ inch. In using the eye-piece micrometer, the marked side of the glass is put undermost. Hartnack's eye-piece micrometer is the best. With this instrument, when using - a magnifying power of 500 or 600 diameters, we can estimate distances from 500 th to $\frac{1}{500}$ th of an inch with tolerable precision. Other kinds of eye-piece micrometers are also employed, such as the cobweb micrometer, where, by the motion of a delicate screw, fine wires, extended across the field of vision, can be separated from each other to known distances.

In delineating minute structures, it is useful to have the inoage thrown on paper by means of a camera-lucida, or small prism, which can be easily attached to the microscope. The microscopist sometimes uses a compressorium, for the purpose of applying pressure to objects whilst they are under examination; troughs for holding such plants as Chara, which are to be seen in water; while various instruments for the dissection and examination both of animal and vegetable structures are indispensable accessories. In testing the power of an instrument, certain objects are used, in which peculiar markings occur, which can only be properly seen by a fine instrument. Either artificial or natural objects may be chosen as test-objects. The former have been prepared by Nobert, a Konigsberg optician, and consist of glass plates, on which are ruled, with a diamond, systems of a hundred lines, which, 10 by 10, approach closer together and are finer, according to a definite standard. With most instruments only the 6 th and 7 th systems can be distinctly made out to be composed of separate lines. Superior instruments reach the 8 th and 9 th. No instrument has yet reached the 10th system, with its component lines. The best testobjects are the natural ones, as being regular and uniform in their markings, such as the scales of Podura plumbea or common Springtail, of Lepisma saccharina or sugar-louse, and the minute markings of the Diatomaceæ, as Pleurosigma Hippocampus. Certain markings occur in these test-objects, which can only be seen properly by good microscopes.

Microscopic Manipulation.-In viewing objects under the microscope they must be placed on slips or slides of glass, which should be of a uniform size, not less than three inches by one; and 
they should be covered with round or square pieces of very thin glass, $\frac{1}{60}$ th to $\frac{1}{100}$ th of an inch thick. The slides ought to be made of thin plate-glass, and the covers of very thin crown or plate glass. In examining recent vegetable structures, it is best to moisten them with water. When the parts are dry, thin sections may be made either by means of slicing instruments or by a sharp lnife. Many dry objects are well seen when immersed in Canada balsam. To preserve objects in a moistened state, the substances used are alcohol, a mixed solution of salt and alum and corrosive sublimate, water containing a small quantity of creasote (five drops to the ounce), and glycerine. The objects, in such instances, are placed in shallow glass cells, or they are laid on the slides and covered with thin glass, which is cemented by means of japanner's gold size, or black japan varnish. The methods of procedure are afterwards described.

In proceeding to use the microscope it is necessary to have a variety of tools and apparatus to aid in preparing objects for investigation. These may be arranged beside the observer in such a way that they shall be always within his reach.* A small tray or box, with divisions, containing a pair of needles in handles (such as are used for crotchet needles), a sharp knife or razor, a section-knife (such as that invented by Valentine, and which bears his name), scissors, and a pair of sharp or fine needle-pointed forceps, about three inches long, are among the most essential instruments required. Glass slides may be arranged also upon the same tray for common use, and the thin glasses for covers should be kept in a small box by themselves. In manipulating the object to be examined certain re-agents are required. These are:-1. Distilled water. 2. Methylated alcohol undiluted, and also diluted in the proportion of about 1 part to 10 of distilled water; it is the best preserving agent; it removes colour and also air. 3. Ether, which dissolves resins, fats, and oils. 4. A solution of liquor potassæ diluted to about 1 to 20 ; it swells up, and sometimes separates membranes of cells and tubes when they exist in condensed layers. 5. A solution of iodine in iodide of potassium of the following strength-namely, 1 grain of iodine to 3 grains of iodide of potassium, and an ounce of distilled water. 6. Chromic acid diluted in the proportion of about 1 to 30 or 40 of distilled water. The last two re-agents chiefly act by colouring the cell-walls or the contents of the cells. 7. Sulphuric acid. 8. Oil, such as the finest of that obtained from coal, and known as mineral oil, is to be recommended for examining and preserving objects. It does not become rancid, nor has it any affinity for oxygen. For the examination of pollen and spores there is nothing better. 9. One part of dry calcium

\footnotetext{
* The following details are partiy condensed from Schacht's Treatise on the Microscope,
} and from the works of Hannover, Quekett, Jabez Hogg, and Beale. 
chloride and 3 of water make also an excellent solution for preserving objects which do not contain starch. 10. Glycerine is the best preservative agent for cells containing starch. 11. Solution of Canada balsam (see Preservation of Microscopic Objects, page 783); and 12. Turpentine, are most useful re-agents and preservative materials for many dry preparations. 13. Nitric acid, used for separating cells. 14. Dilute hydrochloric acid may also be found useful in removing deposits of carbonate of lime. 15. Pyroligneous acetic acid. 16. A solution of carbonate of potass or soda. These sixteen substances should be arranged in stoppered glass bottles (excepting the Canada balsam, which should be placed in a corked bottle), fitting into a stand or box, so as to be of easy access; and small camel's hair brushes, pipettes, and glass rods, should be arranged beside these bottles, in order to apply the fluid to the object. Lastly, the student should provide himself with a small note-book of good drawing-paper, on which he ought constantly to practise the delineation of the forms or outlines of the objects seen, and he should endeavour to colour them also when required.

Numerous other requisites and appliances will suggest themselves during the course of investigations, and especially such as will secure cleanliness of the object, and of everything used in the research. 1 . One who has any regard for his instrument will never suffer it or its lenses to be handled by those unaccustomed to their use. 2. The microscope, when not in use, must be kept under cover, generally under a glass shade. It should never be exposed in a chemical laboratory. 3. Its lenses must be cleansed when necessary by soft wash-leather, or a cloth which is used only for that purpose. The cloth best adapted for this purpose is old and frequently washed linen. 4. A separate cloth of a coarser kind is to be used for drying and wiping the slides and covers. 5. Covers of a middle size, from concave disks, such as watch-glasses, up to the size of a wine-glass without the stem, or other bell-shaped jars, are also required to protect the objects, if it is necessary to leave them for any length of time.

The microscope is used to best advantage in a room which receives its light from the north or west, or both. The light which is reflected from a white and motionless cloud opposite to the sun is the best that can be obtained. If gas-light is to be used, it ought to be softened by passing it through a blue glass shade before reaching the mirror; but for exact observation, daylight is always to be preferred. When observations are made at night a sperm-oil lamp is used, and the light is transmitted to the mirror through a plano-convex lens, called a condenser. To correct the unpleasant glare attendant on the reflected light from an ordinary mirror, Mr. Handford makes a mirror of thin concave glass, three inches in diameter, the back rendered 
white by plaster of Paris. This is mounted on brass, and fitted over the frame of the ordinary silvered mirror, thus not requiring the latter to be removed. The advantage is, that the whole rays reflected from the surface of plaster of Paris are brought into one focus, together with those reflected from the surface of the glass, and thus an equal and brilliant light is produced. In viewing opaque objects, the light is thrown by the condenser directly on the object, and sometimes a metallic speculum, called a Lieberkuhn, is connected with the objectglass, by means of which an additional supply of light is obtained. In conducting microscopic observations great steadiness of the instrument is required, which should accordingly be set upon a very firm and sufficiently large table, so that all the apparatus hitherto mentioned shall be within reach of the observer. It is proper also to begin the examination of objects with the lower magnifying powers, and to pass gradually from them to the use of the higher powers. By such means a far larger portion of the object is seen, and a more correct idea is obtained of the relations of the parts when considered as a whole. Object-glasses, varying from 30 to 50 diameters, are the best to begin with. The eye-glass of lowest power, that is, the longest one of the series, is also the one which ought generally to be used in the first instance, and as long as the power can be increased by object-glasses of greater magnifying power, any more powerful eyepiece should not be used, for it must be remembered that the eyepiece merely magnifies an image produced by the object-glass. If, therefore, there be any defect in the image, it is magnified by the eye-piece.

\section{Directions by Smith and Beck for using the Compound Microscope.}

Before using the microscope, see that the mirror, object-glass, and eye-piece, are free from dust:-a little soft wash-leather should be used in cleaning these. The instrument should be placed on a steady table to avoid vibration. The best position for examination by daylight is with the window to the left hand, and the back partly turned toward the window, so that the light may fall directly upon the mirror, and not upon the observer's face. At night, when a lamp is used, a shade should be placed if possible before the lamp, so as to screen the eyes from its glare. The nearer the observer can approach the window by day, and the closer the lamp can be brought towards the mirror at night (say from fifteen to twenty inches), the better; as all the light that can be obtained is required for high magnifying powers; and if too intense for some objects, can be easily modified by the mirror. When the microscope has a joint to the stand, it should generally be used with the body in an inclined position-at an angle of about $45^{\circ}$, this being much more convenient for the observer, and 
not so liable to injure the eye by overstraining it. The management of light, either natural or artificial, is of the greatest importance in microscopic observations. This may be regulated by altering the position of the mirror under the stage; the proper adjustment of which will soon be acquired by a little practice and observation. In adjusting the microscope for use, first place it in its proper position, and screw or slide on a low-powered object-glass, then look through the tube, and incline the mirror towards the light, moving it about until a clear bright light is seen. The object may then be placed upon the stage and the focus adjusted by the rack movement. In examining any fresh object the lowest magnifying power should be first used, as a larger portion of it can be thus viewed at once, and a better general idea of its form, colour, etc., obtained. Afterward the higher powers may be employed, in order to reveal its minute structure.

In viewing very delicate transparent objects, as fossil infusoria, thin vegetable and animal tissues, blood and milk globules, etc., a good clear light should be used, but the mirror should be inclined on one side more than usual, that the object may appear less brightly illuminated. This is what is termed "oblique illumination"- the rays of light being reflected from the mirror, through the object, in an oblique direction, by which many delicate markings may be observed on some objects which could not be distinguished before, and the outline also rendered more distinct.

In examining opaque objects, a low magnifying power should be used, and the light thrown upon the object by means of the "Condenser," which should be placed within two inches of it, and so arranged that a small circle of bright light may be seen upon the spot to be examined. When viewing objects in a drop of water, or examining a drop of any other liquid, a slip of thin glass should always be laid over it ; otherwise the liquid will evaporate, and condensing on the object-glass, will render it dim.

SoURCes of Errors of OBSERvation.-Extraneous or accidental objects may be present, and may be derived from various sources. Thus, water too long used may bring before the eye both plants and animals of the lowest forms, which otherwise would not have been present. Fresh water is absolutely necessary. Particles of dust, or fibres from the cloths used in cleaning the glasses, may also add to the confusion. These consist, generally, of fibres of paper, linen, woollen, cotton, or silk fabrics, or minute hairs from the brushes used in manipulation. Air-bubbles are almost invariably a source of confusion to the microscopic observer in his first attempts ; but once seen and studied, they no longer distract the attention, and the microscopist soon gets into the habit of disregarding their presence. When seen by transmitted light they generally appear in the form of circles of larger or smaller diameter, with a dark rim surrounding them; while 
with reflected light their rim appears white. Pressure under a glass cover may cause them to assume very irregular shapes, but possessing the same properties in their margin or outline in their behaviour with the light. It is also necessary to become familiar with the appearances of the lowest forms of animal and vegetable life, such, for instance, as the common forms of infusoria ; also the yeast, and such like plants; and the different forms of mould. A peculiar motion, known as "Brownian motion," is also a phenomenon which must be recognised. It is peculiar to all very small particles when they float in a very thin fluid medium. It is well seen in the fine granules of milk when mixed with water, and in the milky juices of plants. A magnifying power of 400 or 500 diameters is the best for this observation. The eye itself is a source of deception, inasmuch as the phenomena known as "muscæ volitantes" appear as if they were objects seen by the microscope. These are described as follows by Dr. W. Mackenzie in his Treatise on the Eye:-

"The vision of objects on the surface or in the interior of the eye has attracted attention, chiefly in relation to a symptom to which the name of musces volitantes has been given. Any spectrum or visual appearance which is apt to impose on the mind, and lead one to think that flies are moving before the eye, is called a musca volitans (fig. 952).

"The condition comprehends those sensations which arise from1. The layer of mucus and tears on the surface of the cornea; 2 . Corpuscles between the external surface of the cornea and the focal centre of the eye; 3 . Corpuscles between the focal centre of the eye and the sensitive layer of the retina.

"In hanging the head over the microscope, especially if one is affected with catarrh at the time, the globules, by gravitating to the centre of the cornea, not unfrequently appear to the observer so as to impede his view of the object, till by the act of nictitation he clears them away. In telescopic observations, also, the muco-lacrymal spectrum is apt to prove a source of annoyance. Thus, in looking at the sun through a tinted glass, the observer may be unable to distinguish the spots on that body, being perplexed by what seems the refiection of some part of his own eye interposed between it and the sun. This is caused by the layer of mucus and tears on the surface of the cornea.

"If one looks at the flame of a candle two or three feet distant, or at the sky, through a hole made in a blackened card with the point of a fine needle, or through a convergent lens of short focus, such as the eye-glass of a compound microscope, on steadily regarding the luminous field presented to view, four sets of spectra will be seen (fig. 952), independent of the muco-lacrymal spectrum. The most remarkable appears nearest to the eye, and consists of twisted strings 
of minute pearly globules, hung across the field of view (fig. $952 a$ ). The second in point of remarkableness, and the farthest of the four from the eye, consists of watery-like threads, destitute of any globular appearance, and depending chiefly from the upper part of the field (fig. $952 b$ ). I call the former the pearly spectrum, and the latter the watery spectrum. In two distinct planes, between those occupied by these two spectra, float two

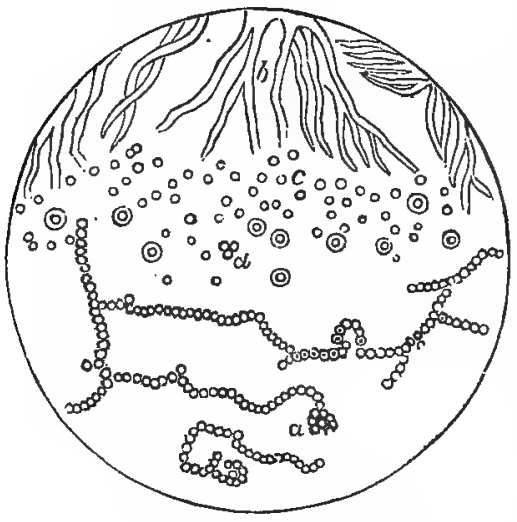

Fig. 952. sets of globules, not aggregated into threads, but insulated. These constitute what I call the insulo-globular spectra. The individual globules of the set farther from the eye, being hazy and illdefined, may be compared in appearance to small grains of sago (fig. $952 \mathrm{c}$ ). The globules of the set nearer to the eye are clear in the centre, exteriorly to which they present a sharp black ring, and still more exteriorly a lucid circumference (fig. 952 d). These four sets of spectra never mingle with one another, so as to change the order in which they stand before the eye; but the pearly spectrum always appears the nearest; then the sharplydefined insulo-globular; then the obscurely defined globules; and farthest away the watery threads.

"Almost every eye, even the most healthy, and which has never attracted the possessor's attention by muscæ volitantes, exhibits the pearly spectrum, on being directed towards a luminous field, through a fine pin-hole, the eye-glass of a compound microscope, or a convex or concave lens of short focus. I have given it the same name of the pearly spectrum, from its resemblance to a string of pearls. Prevost had already called it apparence perlée, or simply perles.

"The lines of the pearly spectrum are hung across the field of vision as often transversely as vertically. On first directing the eye towards the Iuminous field, in one or other of the methods just mentioned, perhaps only a very few small pearly globules are perceived; but after steadily regarding it for a short time, numerous strings of them are discovered, generally twisted in different forms, and presenting a variety of knots, loops, and agglomerations. Sometimes they

\footnotetext{
'Fig. 952. Four sets of spectra, which are apt to cause errors in observations with the microscope.
} 
are so numerous as to form an extensive shower or cloud. The pearly threads are of different lengths; some of them very short, others stretching across the whole field. Not unfrequently some of them end abruptly in a sort of bulb. The globules or pearls forming the threads or rosaries seemed joined together merely by apposition, without being contained in any tube. Sometimes, however, the globules are rather indistinct, and then the threads approach to a tubular appearance. The globules are always in single rows. They appear destitute of any nucleus. They are not all of one diameter, but are all smaller than the globules of the insulo-globular spectra. I have not satisfied myself that all the pearly threads occupy the same plane, although it is very evident that they are behind the insulo-globular spectra.

"That portion of the pearly spectrum which appears in the centre of the field of view has but little real motion, less perhaps than the watery spectrum which is seen beyond it. Both partake, of course, in the motion of the eyeball ; and this gives to both a wide apparent motion. But if the field be examined towards its circumference, or if the eye be suddenly rotated upwards, other pearly spectra appear, which it is difficult or impossible for the observer to bring directly before him; and which, when he succeeds in some measure in doing so, quickly subside again out of view, partly by a real motion of their own, partly by a wide apparent motion, owing to their obliquity in respect to the axis of vision. It is these last spectra, chiefly, which produce the pearly muscæ volitantes."

There are also various optical phenomena caused by refraction, and which are necessary to be attended to. They depend, for the most part, upon a bad adjustment of the focus, or illumination of the object. The appearances are also most frequently associated with an increase of the magnifying power, and especially with the use of powerful eyeglasses. Large grains of potato-starch, pollen-grains, the thickened substance of woody tubes, and the cells of cartilage, are among the most common objects which exhibit such optical phenomena, which consist in a feeble and generally yellowish colouring of the edges of the objects when seen with particular foci.

Focal ADJUSTMENT OF THE MICROSCOPE.-The regulation of this adjustment is based on the fact that the microscope can only afford a view of one surface of an object at any given time, so that nothing is distinctly seen which lies above or below such a focal plane at that time; and the more flat the field of vision, the clearer and better will be the view of objects in that plane if the adjustment is correct. The more perfect the object-glass, and the greater the angle of aperture, ${ }^{*}$ the more exact is this focal plane, and the more sensitive

* The angle of aperture is that made by two lines from opposite ends of the aperture of the object-glass with the point of focus of the lens. A glass with a large angle of aperture shows objects clearly. The angle varies usually from $50^{\circ}$ to $100^{\circ}$. Many glasses, however, are made with a much higher angle. Ross makes glasses of $170^{\circ}$ of angular aperture. These are useful for observing minute organisms, such as Diatoms. 
is the instrument to any small alteration of focus. The focal adjustment is made and varied by what is called a fine adjustment screw; and the accurate adjustment of the object is judged of by the sharpness of the delineation of the image, as well as by the fineness and clearness of the outline. An experienced microscopic observer always uses the instrument with his finger and thumb grasping the fine adjustment screw, and would not be content. with his observation, although it was limited to a mere peep of the object, unless he had made the fine focal adjustment for himself.

Preparation and Selection of ObJects for Examination. -Opaque objects require merely to be made smooth or level on one side, and to be fixed on the other. If the object is to be viewed by transmitted light, a section or slice sufficiently thin must be procured, a common sharp scalpel or razor are the instruments to use. The object must be moistened with water, and sometimes it is advisable to make the section under water. If the object is very small it may be embedded in solid paraffin (an ordinary paraffin candle), by melting it and pouring it over the object, and allowing it to cool; or it may be embedded in gum arabic in the following manner:-Make a cone of blotting paper about the size of the end of the finger, half fill it with a solution of gum as thick as possible, place the piece of tissue in the gum, and then set the cone in a vessel containing three or four times its bulk of rectified spirit for an hour or so, in order that the spirit may remove the water from the gum. Lastly, expose the cone to the air in a warm place, until the gum is hard enough to be cut. In making the sections wet the knife with water, and lay the sections in water to remove the adherent gum. A small piece of tissue may also be supported for the purpose of section between two slices of carrot or cork. Sections should be made in various directions, so that a correct knowledge may be obtained of the relation of the component parts. Maceration in water, and tearing the parts asunder with fine needles, are the best methods for obtaining the ultimate tissues of plants. Thin glass plates to cover the object under the microscope must be invariably used. They keep the object moist, they prevent the object-glass from being covered with vapour, and so rendered obscure; and, lastly, they produce a slight pressure, by which the elementary parts of the substance may become separated from each other, so as to lie on one plane. The thin covers are not absolutely necessary where very low powers are used. In placing the object on the stage care must be taken not to bring it in contact with the object-glass of the instrument. It is also to be remembered that, in a compound microscope, the image is inverted, and that, consequently, the object is moved in a direction contrary to that of the image.

The following list of tissues to be examined by the student of 
Vegetable Histology is talken from the preparations used in the microscopical demonstrations given to the pupils of the Botanical Class in the University of Edinburgh :-

Cellular Tissue.-Seaweeds, Confervæ, Moulds and other Fungi ; Lichens, Liverworts, pith of Elder and of the Rice-paper plants (Fatsia and Æschynomene), outer bark as of the Cork and of Elephantipes, succulent roots, stems, and fruits as Orange and Lemon.

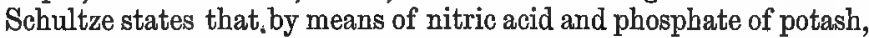
the cells of plants, young or old, hard or soft, may be isolated from one another so as to give single cells, free and distinct, for microscopic examination. Protoplasm in the cellular tissue of young roots is well shown by the action of carmine or magenta.

Nucleated Cells. - Scales of Onion, Vinegar plant, ripe fruit of Strawberry, Smut, ovules or very young seeds ; covering of ovary of Orchis mascula and maculata, shows bi-nucleated cells.

Independent Cells.--Red-snow plant (Protococcus nivalis), Yeast plant (Torula), Chlorococcus vulgaris (yellow powdery matter on trees).

Thickened Cells. - Shell of Coco-nut, stone of Peach, Cherry and Nut, seed of Ivory-Palm and Date, gritty matter of Pear, scales of Cone. The thickening process in cells is seen in the rootlets of Marchantia (Liverwort).

Pitted or Porous Cells.-Pith of Elder, stem of Common Balsam, outer covering of seeds of Gourd and Almond, Pith of Rosa tomentosa.

Spiral Cells.-Leaves, stems, and aerial roots of many Orchids, rootlets of Oncidium, leaves of Pleurothallis ruscifolia and racemiflora, leaf of Sphagnum, episperm of seeds of Collomia, Acanthodium, Calempelis scaber, Lophospermum, and Cobæa, pericarp of Salvia, Isoetes lacustris.

Reticulated Cells.-Inner lining of anthers of Silene maritima and Pinguicula vulgaris; Pith of Rubus odoratus and of Erythrina; leaf of Sphagnum.

Annular Cells.-Inner lining of anther of Cardamine pratensis; stem of Opuntia.

Stellate Cells.-Centre of leaves of Juncus conglomeratus and other rushes, the transverse septa in petiole of Banana and Plantain; petiole of Sparganium ramosum, Potamogeton, stems of many aquatic plants, inner lining of anther of Armeria.

Ciliated Cells.-Spores of Vaucheria and some Fuci.

Filamentous Cells.-The structure of many Fungi.

Pollen Cells.-Anthers of Tulip, Lily, Passion-flower and Mallow (echinated), Acacia (cells united in fours), Zamia, Cycas, Tropæolum, Gloxinia, Colocasia, Sherardia arvensis, Mimulus moschatus, Juncus, Linum, Scorzonera hispanica, Tragopogon porrifolius, pollinia of Asclepias and Orchids. 
Pollen Tubes,-Enothera, Antirrhinum, Hibiscus, Linaria, Gesnera, Crocus.

Embryonic Cells._Orchis, Listera, Hippuris, Euphrasia, Draba.

Spores or Reproductive Cells.-In Cryptogamous plants, Ferns, Mosses, Lichens, Algæ, and Fungi, Zygnema when conjugating.

Cells with Siliceous Covering. - Diatoms, cuticle of grasses, Equisetum.

Cells encrusted with carbonate of Lime.-Chara.

Epidermal Cells.-Leaves of Hyacinth, petals of Pelargonium, Apple, Duckweed, Hellebore, and Digitalis.

Hairs.-On leaves, and in pappus of Compositæ, Cotton (twisted), articulated hairs on leaves of Groldfussia and Alstroemeria ovata, pappus of Trichinium, moniliform hairs on stamens of Tradescantia, stellate hairs of Deutzia, Viburnum Opulus, Ivy, Hollyhocks, and Fatsia papyrifera, peltate hairs of Malpighia urens, glandular hairs of Nettle, Loaza, Chinese Primrose, Drosera, and Dionæa, branched hairs Verbascum, forked Apargia hispida, Alyssum, stalked cruciate hairs Arabis sinensis, clubbed hairs on filament of Verbascum nigrum, capitate hairs of Scrophularia nodosa, beaded hairs Mirabilis Jalapa.

Glandular Cells.-Sweet-Brier, Passiflora lunata, Ice-plant, Lilac, Cinchona, lupuline glands of Hop, Rhamnus, Rottlera, Aloysia, Mentha, in Pitchers of Nepenthes, and Sarracenia.

Scaly Cells.-Ferns, as Polypodium sepultum, Niphobolus, Ceterach, and Nothochlæna lævis, scales of Hippophäe, Begonia, Olive, and Elæagnus.

Starch in Cells.-Potato, Arrow-root, Cereal grains, Bean and Pea, Habenaria bifolia, rhizome of Florentine Iris.

Raphides.-Hyacinth, Rhubarb, Arum, Colocasia, Onion, Squill, Balsam, Cactus, Lemna trisulca, Ficus (cystoliths), Aloe, Banana, petal of Ornithogalum, bark of Salisburya adiantifolia, leaves of Dieffenbachia seguina (biforines), sphæraphides, or globular clusters of raphides, seen in the parenchyma of the leaf of the tea-plant.

Air-Cells and Lacunce. - Rush, Sparganium ramosum, Papyrus, Limnocharis Plumieri, Hippuris (mare's tail), Nymphæa, and other aquatic plants.

Oil-Cells.-Rind of Orange and Lemon, leaves of Hypericum and Myrtacex.

Chlorophyll-Cells.-Mosses, Vallisneria, Anacharis, Chara, Green Seaweeds.

Colour-Cells.-Leaf of Rottlera tinctoria, petals of Pelargonium and Geranium, Strelitzia. One way of preparing the petal of Pelargonium is by immersing it in sulphuric ether for a few seconds, and then allowing the fluid to evaporate. Another mode is simply to dry the petal, immerse it for an hour or two in spirit of turpentine, and then put it up in new Canada balsam. 
Stomata.-Cuticle of Leek, Hyacinth, Begonia, Oleander, Lilium, Equisetum, Box, Gasteria, Marchantia, Crinum, Yucca, Billbergia, Mistleto, Hellebore, Ivy.

Antheridia and Archegonia.-Prothallus of Ferns, Mosses, Fucus, Marchantia, spermatozoids in Ferns and Chara.

Conjugating Cells._Zygnema nitidum, Tyndaridea, Cylindrocystis, Desmidieæ.

Vascular Tissue.-Young stems of herbaceous plants.

Spiral Vessels.-Canna bicolor, Pitcher plant (Nepenthes), Banana and Plantain, Cactus, Hyacinth, Asparagus, Balsam, Strelitzia, branching spirals in Mistleto, Long-leek, and Anagallis. Compound spirals in Water-lily and Lilium candidum; a loose spiral in stalk of Horsetails (Equisetum).

Annular Vessels.-Opuntia vulgaris, Leek, Equisetum maximum.

Dotted or Pitted Vessels.-Sugar-Cane, Nepenthes, Willow, Ash, Bramble, Clematis Vitalba, Papaver somniferum, Balsam. Tylosis in pitted vessels of Walnut, Hazel, Vine, Oak, Bignonia.

Reticulated Vessels.-Garden Balsam.

Scalariform Vessels.-Rhizomes and stalks of fronds of Ferns, Polystichum, Osmunda, Asplenium, Cheilanthes, Pteris.

Laticiferous Vessels. - Ficus elastica, Euphorbia, Tragopogon, Chelidonium, Lactuca, Isonandra Gutta, Dandelion.

Woody Tissue.-Stems of trees, inner bark especially of plants yielding useful fibres, as Flax, Jute, Hemp, Bchmeria, Lace Bark tree, Cuba Bast; root of Elder, Cabbage.

Punctated Woody Tissue.-Stems of Coniferæ when cut parallel to medullary rays, Pinus, Abies, Wellingtonia (Sequoia), Araucaria, fossil stems, Cycas, Illicium, Daphne Mezereum; and with spirals in Yew.

Ovules and Embryo.-Cruciferæ, Chelidonium, Cactus (shows branched funiculus), Passion-flower (dicotyledonous embryo) ; Orchids and Lilium (monocotyledonous).

Seeds.-Papaver somniferum, Gentiana lutea, Eccremocarpus scaber, Lepigonum marinum, Sphænogyne speciosa, Erica cinerea, Calluna vulgaris, Oxalis rosea.

Preservation of Microscopic ObJects.-The following apparatus is required-viz, glass-slides ground at the edges, and of the requisite standard size, 1 by 3 inches, with circular glass covers; preserving agents, cement, and turn-table for mounting and making cells. Among the preserving media for vegetable substances are-a solution of chloride of calcium, glycerine, copal varnish, mineral oil, Canada balsam, Pyroligneous acid. Some recommend the use of arsenic in preserving objects. Make a saturated solution of arsenious acid in boiling water, allow it to cool, and then filter. Then take of this solution one ounce, of glycerine one ounce, and of gum arabic one ounce; allow this to stand for three weeks, and then filter through 
cambric. Among the cements used for vegetable objects are the following:-Asphalte, japanner's gold size, black japan sealing-wax varnish, Robinson's liquid glue, gum mastic and caoutchouc dissolved in chloroform. Objects are put up (i.e. preserved) either as dry or as wet objects. For dry objects, the oils and the Canada balsam are the preservative materials, but they are not suited for wet objects. Before mounting objects in Canada balsam they must be perfectly clean and free from moisture. The moisture is got rid of by immersing them in rectified spirit for an hour or so ; the spirit is then removed by placing the tissue for a few minutes in turpentine or oil of cloves in a watchglass or on a slide. Both of these agents, owing to their high refractive index, render tissues transparent. In this respect clove oil is more powerful than the turpentine, and therefore it is preferred when great transparency is desirable. When the tissue is sufficiently clarified, a drop of Canada balsam solution is placed on a slide, the tissue is transferred to it, the cover-glass applied and gently pressed down in order to flatten the tissue. The balsam soon dries, so that the cover-glass is permanently fixed. The solution of Canada balsam is thus prepared :--Place the ordinary kind obtained from the shops in a saucer, cover it with blotting-paper to protect it from dust, place it near the fire for some days, until the balsam is so dry that it becomes as hard as ice when it cools. Dissolve this perfectly dried balsam in chloroform, or turpentine, or benzole (the latter is to be preferred), and keep it in a corked bottle. The solution ought to be as thin as milk. The mounting of objects in this solution of dried balsam has quite superseded the old method of mounting objects in undried balsam with the aid of heat. The solution of chloride of calcium is adapted for the preservation of wood and leaves, and for most kinds of isolated tissue. The colouring matter in the cells, however, is always more or less altered by it, while grains of starch, if present, swell up and can scarcely be recognised. The strength of the solution is one part of lime to three of water. Glycerine is used in equal parts mixed with camphor water, which prevents the tendency to mildew. The chlorophyll and the grains of starch remain unchanged, and the laminæ of the starch appear more beautifiul after a few hours' immersion in the glycerine solution. Canada balsam and copal varnish are used for the preservation of dry and fossil woods. Thin sections should be made, and treated as above directed. If the entire structure of any exogenous wood is required to be examined, the sections must be made both in the transverse or horizontal, and in the longitudinal or vertical direction. The vertical section, made parallel to the medullary rays, or, in other words, along the course of them, shows the nature of these cellular rays, which proceed horizontally from the centre, enclosed between the layers of woody fibres, and which are known to the cabinetmaker as the silver grain of the wood. In coni- 
ferous trees, as the pine, this section shows also the beautiful punctations on the walls of the fibres. The tangential-vertical section is a slice across the ends of the medullary rays, and exhibits the form and arrangement of the cellular tissue in them. The cells of the rays are seen projecting between the fibres of the wood. These vertical sections show the form, size, and connections of the woody tubes and the spiral, reticulated, and dotted vessels. In endogenous trees horizontal and vertical sections are also required. Peat wood requires to be digested in a strong solution of carbonate of soda, and fossil woods which have been converted into carbonate of lime should be digested in dilute hydrochloric acid ( 1 of acid to 20 of water).

Schleiden gives the following method of preserving minute structures for the microscope. Upon a glass slide of the common form two narrow slips of paper are gummed, of a thickness proportioned to the object, and at a distance which is regulated by its size. Between these the object is laid in a drop of solution of chloride of calcium (60 grains to half-an-ounce of water). A thin slip of glass, sufficient to cover the object and paper slips, is put on ; the slips are gummed, and the thin glass applied to its place, where it is retained by the gum drying. The whole may be secured by pasting a long slip of paper over all, with a hole for the object. The method has the advantage of preventing all running in, which is so apt to happen when asphalte varnish is employed. Chloride of calcium, being deliquescent, never dries up, and, if evaporation takes place, water is easily introduced at the open sides of the thin glass. The points to be attended to are-1, that the paper between the glasses be thick enough to prevent much pressure on the object, and not so thick as to allow it to float about or fall out at the side; 2 , that the drop of solution be not

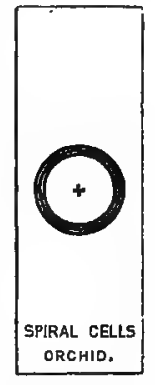

Fig. 953. too large, but covering the object, and yet not reaching the paper. Glycerine may be used in place of chloride of calcium in cases where the objects are very delicate, or contain chlorophyll or albumen.

Small specimens for the microscope, such as Diatoms and Desmidieæ, and many small Seaweeds, as well as vegetable tissues, are put up on slides (fig. 953), in the centre of which there is a circular cavity formed by a layer of asphalte, ${ }^{*}$ and covered by a circular piece of thin glass.

Fig. 953. Glass slide for microsoopie preparations, 3 inches long and 1 inch broad. In the centre is a ring of asphalte, forming a cell to contain fluid ; the object marked by a + in the centre is covered by a circular piece of thin glass fitted to the asphalte rim. The name of the object is often written on the glass, but perhaps it is preferable to write the name on coloured paper, and attach it to the glass by ísinglass or fine bookbinder's glue.

* Prepared asphaite is better than gold size or black japan varnish, as it dries more rapidly, and is less liable to run. It can be procured from opticians. 
The asphalte is applied by means of a hair pencil, the slide being placed on a turn-table (fig. 954), which has circular marks on it corresponding to the required dimensions of the cavity. The depth of the cavity can be varied according to circumstances, by putting one or more layers of asphalte. After the thin glass cover is put on, it is luted carefully with asphalte. The cavity is filled with distilled water, weak

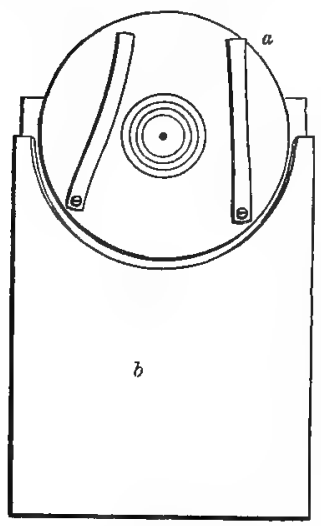

Fig. 954. pyroligneous acid, alcohol, diluted glycerine, a very weak solution of creazote (one drop to the ounce of distilled water), or some other fluid. When specimens are very minute the asphalte cell is not required; the thin glass is applied at once to the slide, a drop or two of the fluid being inserted along with the specimen. In the case of some dry preparations, as pollen-grains and the fine-lined Diatoms, no fluid whatever is required, but precautions must be taken against the access of damp. Canada balsam is useful in some instances. The specimen is laid on a slide,"then a drop of the solution of Canada balsam is put on it, and the thin glass above all. It is then set aside to dry, and ultimately a rim of asphalte is made round the margin of the glass cover. Canada balsam is well fitted for many Diatoms, and for thin sections of woods. In putting up woods, the specimen is placed in the centre of the slide, a drop of turpentine is insinuated below it, with a camelhair pencil, in order to expel the air; a solution of Canada balsam is then applied, and the same procedure is followed as above.

To make Chils, and to fix the thin Glass Covers.-The cells are made either round or square by thin layers of cement, according to the depth required. Perhaps the round ones are neater, but they require circular pieces of glass for covers, and by the aid of the turntable (fig. 954) the roundness of the mounting can be made with perfect accuracy. The cover is laid gently down, so as to float on the solution in which the object lies, and by pressing carefully on the cover, the superabundant fluid is made to pass out by the edges, and may be taken up by blotting paper. A thin layer of asphalte, or gold size, may be placed round the edge, which will gradually harden and completely seal up the preparation.

Fig. 954. Turn-table for making the circular rim of asphalte; $b$, a piece of mahogany; $d, a$ circular piece of brass, which can be moved round by the hand, and has two brass springs on its surface for holding a glass slide firm. In the centre of the brass disc are circular markings fitted for the size of asphalte cells required. These marks being seen through the slide laid above them, guide the hand in making the circular asphalte rim, the brass dise being turned round during the application. 
On preparing fossils for microscopic examination, Mr. Alexander Bryson remarks :-**

The usual mode of proceeding in making a section of fossil wood is simple, though tedious. The first process is to flatten the specimen to be operated on by grinding it on a flat lap made of lead charged with emery or corundum powder. It must now be rendered perfectly flat by hand on a plate of metal or glass, using much finer emery than in the first operation of grinding. The next operation is to cement the object to the glass plate. Both the plate of glass and the fossil to be cemented must be heated to a temperature rather inconvenient for the fingers to bear. By this means moisture and adherent air are driven off, especially from the object to be operated on. Canada balsam is now to be equally spread over both plate and object, and exposed again to heat, until the redundant turpentine in the balsam has been driven off by evaporation. The two surfaces are now to be connected while hot, and a slow circular motion, with pressure, given either to the plate or object, for the purpose of throwing out the superabundant balsam and globules of included air. The object should be below and the glass plate above, as we then can see when all the air is removed, by the pressure and motion indicated. It is proper to mention that too much balsam is more favourable for the expulsion of the air-bubbles than too little. When cold, the Canada balsam will be found hard and adhering, and the specimen fit for slitting. This process has hitherto been performed by using a disc of thin sheet-iron, so much employed by the tinsmith, technically called sheet-tin. The tin coating ought to be partially removed by heating the plate, and when hot rubbing off much of the extraneous tin by a piece of cloth. The plate has now to be planished on the polished stake of the tinsmith, until quite flat. If the plate is to be used in the lathe, and by the usual method, it ought to be planished so as to possess a slight convexity. This gives a certain amount of rigidity to the edge, which is useful in slitting by the hand; while by the method of mechanical slitting, about to be described, this convexity is inadmissible. The tin plate, when mounted on an appropriate chuck in the lathe, must be turned quite true, with its edge slightly rounded and made perfectly smooth by a fine-cut file. The edge of the dise is now to be charged with diamond powder. This is done by mingling the diamond powder with oil, and placing it on a piece of the hardest agate, and then turning the disc slowly round; and holding the agate with the diamond powder under; a moderate pressure against the edge of the disc, it becomes thoroughly charged with a host of diamond points, becoming, as it were, a saw with invisible teeth. In pounding the diamond some care is necessary, as

* On an improved Method of preparing Siliceous "and other Fossils for Microscopic Investigation, with a description of a new Pneumatic Chuck. By Alex. Bryson, in Edin. N. Phil. Journal, N. S., iii. 297. 
also a fitting mortar. The mortar should be made of an old steel die, if accessible; if not, a mass of steel, slightly conical, the base of which ought to be 2 inches in diameter, and the upper part $1 \frac{1}{2}$ inch. A cylindrical hole is now to be turned out in the centre, of $\frac{3}{4}$ ths of an inch diameter, and about 1 inch deep. This, when hardened, is the mortar; for safety it may be annealed to a straw colour. The pestle is merely a cylinder of steel, fitting the hollow mortar but loosely, and having a ledge or edging of an eighth of an inch projecting round it, but sufficiently raised above the upper surface of the mortar, so as not to come in contact while pounding the diamond. The point of the pestle ought only to be hardened and annealed to a straw colour, and should be of course convex, fitting the opposing and equal concavity of the mortar. The purpose of the projecting ledge is to prevent the smaller particles of diamond spurting out when the pestle is struck by the hammer.

Mr. Bryson has contrived an instrument for slitting fossils. The

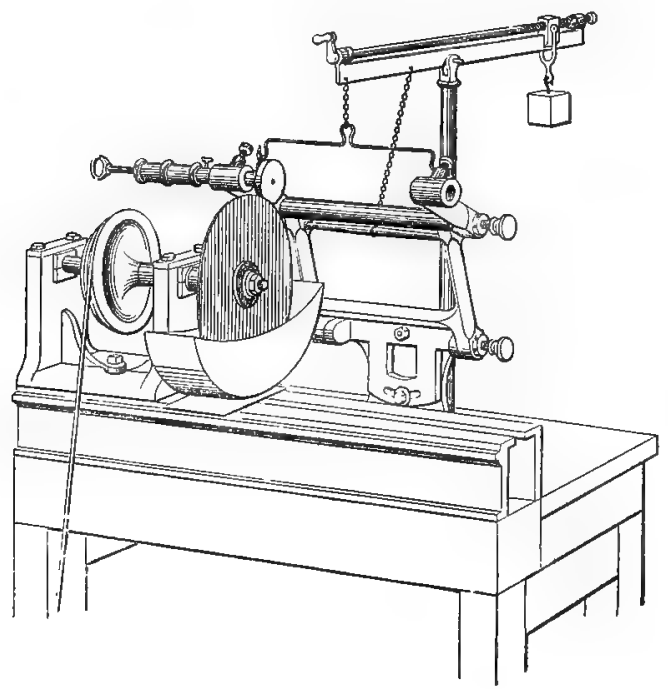

Fig. 955.

instrument is placed on the table of a common lathe, which is, of course, the source of motion. (Fig. 955.) It consists of a Watt's parallel motion, with four joints, attached to a basement fixed to the table of the lathe. This base has a motion (for adjustment only) in a horizontal plane, by which we may be enabled to place the upper

Fig. 955. Mr, Bryson's instrument for slitting fossils. 
joint in a parallel plane with the spindle of the lathe. This may be called the azimuthal adjustment. The adjustment, which in an astronomical instrument is called the plane of right ascension, is given by a pirot in the top of the base, and clamped by a screw below. This motion in right ascension gives us the power of adjusting the perpendicular planes of motion, so that the object to be slit passes down from the circumference of the slitting-plate to nearly its centre, in a perfectly parallel plane. When this adjustment is made accurately, and the slitting-plate well primed and flat, a very thin and parallel slice is obtained. This jointed frame is counterpoised and supported by a lever, the centre of which is movable in a pillar standing perpendicularly from the lathe table. Attached to the lever is a screw of three threads, by which the counterpoise weight is adjusted readily to the varying weight of the object to be slit and the necessary pressure required on the edge of the slitting-plate.

The object is fixed to the machine by a pneumatic chuck. It consists of an iron tube, which passes through an aperture on the upper joint of the guiding-frame, into which is screwed a round piece of gun-metal, slightly hollowed in the centre, but flat towards the edge. This gun-metal dise is perforated by a small hole communicating with the interior of the iron tube. This aperture permits the air between the glass plate and the chuck to be exhausted by a small air syringe at the other end. The face of this chuck is covered with a thin film of soft India-rubber not vulcanised, also perforated with a small central aperture. When the chuck is properly adjusted, and the India-rubber carefully stretched over the face of the gun-metal, one or two pulls of the syringe-piston is sufficient to maintain a very large object under the action of the slitting-plate. By this method no time is lost; the adhesion is made instantaneously, and as quickly broken by opening a small screw, to admit air between the glass plate and the chuck, when the object is immediately released. Care must be taken, in stretching the India-rubber over the face of the chuck, to make it very equal in its distribution, and as thin as consistent with strength. When this material is obtained from the shops, it presents a series of slight grooves, and is rather hard for our purpose. It ought, therefore, to be slightly heated, which renders it soft and pliant, and in this state should now be stretched over the chuck, and a piece of soft copper wire tied round it, a slight groove being cut in the periphery of the chuck, to detain the wire in its place. When by use the surface of the India-rubber becomes flat, smooth, and free from the grooves which at first mar its usefulness, a specimen may be slit of many square inches, without resort being had to another exhaustion by the syringe. But when a large, hard, siliceous object has to be slit, it is well for the sake of safety to try the syringe piston, and observe if it returns forcibly to the bottom 
of the cylinder, which evidences the good condition of the vacuum of the chuck.

After the operation of slitting, the plate must be removed from the spindle of the lathe, and the flat lead lap substituted. The pneumatic chuck is now to be reversed, and the specimen placed in contact with the grinder. By giving a slightly tortuous motion to the specimen, that is, using the motion of the various joints, the object is ground perfectly flat when the length of both arms of the joints is perfectly equal. Should the leg of the first joint on the right hand side be the longer, the specimen will be ground hollow; if shorter, it will be ground convex. But if, as before stated, they are of equal length, a perfectly parallel surface will be obtained.

In operating on siliceous objects, I have found soap and water quite as speedy and efficacious as oil, which is generally used; while calcareous fossils must be slit by a solution of common soda in water. This solution of soda, if made too strong, softens the India-rubber on the face of the pnuematic chuck, and renders a new piece necessary; but if care is taken to keep the solution of moderate strength, one piece of India-rubber may last for six months. The thinner and fiatter it becomes the better hold the glass takes, until a puncture occurs in the outer portion, and a new piece is rendered necessary.

The polishing of the section is the last operation. This is performed in various ways, according to the material of which the organism is composed. If siliceous, a lap of tin is to be used, about the same size as the grinding lap. Having turned the face smooth and flat, a series of very fine notches are to be made all over the surface. This operation is accomplished by holding the edge of an old dinner-knife almost perpendicular to the surface of the lap while rotating; this produces a series of criddles, or slight asperities, which detain the polishing substance. The polishing substance used on the tin lap is technically called lapidaries' rot-stone, and is applied by slightly moistening the mass, and pressing it firmly against the polisher, care being taken to scrape off the outer surface, which often contains grit. The specimen is then to be pressed with some degree of force against the revolving tin lap or polisher, carefully changing the plane of action by moving the specimen. in various directions over the surface.

To polish calcareous objects, another method must be adopted, as follows :-

A lap or disc of willow wood is to be adapted to the spindle of the lathe, 3 inches in thickness, and about the diameter of the other laps (10 inches), the axis of the wood being parallel to the spindle of the lathe, that is, the acting surface of the wood is the end of the fibres, or transverse section.

This polisher must be turned quite flat and smoothed by a plane, 
as the willow, from its softness, is peculiarly difficult to turn. It is also of consequence to remark that both sides be turned so as that the lap, when dry, is quite parallel. This lap is most conveniently adapted to the common face chuck of a lathe with a conical screw, so that either surface may be used. This is made evident when we state that this polisher is always used moist, and, to keep both surfaces parallel, must be entirely plunged in water before using, as both surfaces must be equally moist, otherwise the dry will be concave, and the moist surface convex. The polishing substance used with this lap is putty powder (oxide of tin), which ought to be well washed to free it from grit. The calcareous fossils being finely ground, are speedily polished by this method. To polish softer substances a piece of cloth may be spread over the wooden lap, and finely levigated chalk used as a polishing medium.

In all instances slides should be labelled with the name, locality, and date, and they should be numbered and catalogued, so that they may be easily referred to when put up in cases, such as that shown in fig. 956 , or in cabinets. *

The Diatomaceæ being either free, or attached to Algæ, etc., different modes must be resorted to for collecting them. Those which are attached require only (either at the time or after being dried) to be rinsed gently in fresh water to get rid of the sand or mud, and salt if any; and then placed in a small saucer in boiling water, with a few drops of nitric or muriatic acid. The cuticle being corroded, the 'Diatoms fall to the bottom, the floating Algæ are taken out with a glass rod, and the residue washed. This step is merely preparatory to that of burning or boiling the objects. If the Diatoms be free, they should, as far as possible, be gathered free from sand or mud, by skimming the surface of the pond or pool with an iron spoon; but as much mud and sand may still be mixed with them, they ought to be afterwards placed in a saucer in a little water, and exposed to the sun for a day. or two. A tumbler or hand-glass will prevent too much evaporation. Diatoms, if recently gathered and alive, will come to the surface of the sediment, or water, or both, and this affords an easy mode of separating certain species. They may now be skimmed off with a small spoon, or, what is preferable, a camel's hair pencil, and removed to clean water; and this process is to be repeated till the mud is got rid of entirely. As for preparing the specimens, they may be either burned, or boiled in nitric acid. For the isolated Diatoms, + as Navicula, Pleurosigma, Cocconeis, etc., boiling is preferable; but for the

* In making sections of minute objects, such as Diatoms, they are mixed with. plaster of Paris and mucilage, and then the whole is sliced by means of a sharp razor. Small pieces of wood are sometimes put into a slit in a cork, and then the whole sliced.

$\dagger$ By free Diatoms are meant those that are not parasitical. By isolated or solitary Diatoms are meant those not connected nor coliering together into threads or plates, or by a stipe, tube, or gelatine. 
others, as Synedra, Fragilaria, Melosira, Meridion, etc., if one wishes to have a few frustules cohering together to show their habit, then burning must be adopted, as the acid separates them joint by joint, and valve from valve. This is accomplished by arranging the specimens in the centre of a glass slide, and laying them on a thin iron slide, and placing the whole within a little iron tray, closed in the form of a slipper, to exclude ashes. This is exposed to the fire till the slide is red hot. The slide is now allowed to cool, and the specimen is ready

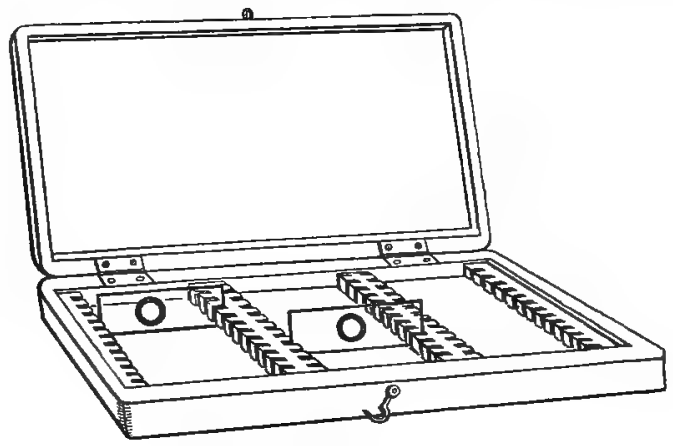

Fig. 956.

for being covered either with or without the intervention of balsam. The latter is called dry mounting, and is best accomplished by making a ring of asphalte, and following the same process as for liquid mounting, but without liquid. When nitric acid is to be used, the cleaned Diatoms are put into a large-sized test tube of German glass, with as little water as possible, and about one part of nitric acid to four of water. After being boiled for two or three minutes over a spirit-lamp, the Diatoms must be allowed to subside, and as much liquor as possible poured off, with any fragments of vegetable matter floating in it. This

Fig. 956. A case for containing slides after being prepared. There are three divisions, each containing twelve slides, two of which are shown projecting above the lower division of the box, the lid being hollowed to receive them. Numbers corresponding to those on the slides are fastened on the partitions at the sides of the grooves which retain the slides. On the front of the box a notice of the numbers contained in it should be fastened. Corresponding numbers, with full particulars as to the preparations, ought to be entered in a book, which serves as a catalogne, in which there should be first a numeral progressive series, and then an alphabetical register for genera. Card boxes for holding 24 slides are made by Smith and Beck, and others, price one shilling each. They are excellent for forming a general collection. Cabinets are also made for slides, consisting of dratwers half-aninch deep (including the bottom) divided so as to hold 30,40 , or 50 slides all on their back ; the drawers being slightly bevelled at their divisions on one side, so that the slides may be tilted up by pressing them down. Cases such as that in Figure 956 may be placed on their ends, like books on a shelf, so as to keep the slides horizontal, and prevent the object from gravitating to one side of the disc. 
boiling sometimes suffices, but it is always preferable to add some of the strong acid, and boil the whole again for a few minutes, so as to dissolve any vegetable or animal substances remaining. As the siliceous covering is very thin, and easily broken by a sudden change of temperature, care must be taken in washing away the acid, either to use boiling water or to allow the Diatoms in the test-tube to cool. When a sufficient supply of pure distilled water can be easily got, it alone ought to be used for washing them; but, when that is not the case, ordinary water may be employed for the first washing, but the after washings must be all made with distilled water until the acid is got rid of. After being thoroughly washed, the Diatoms are kept in a small test-tube with some distilled water. In taking the specimens from the test-tube, in order to put them on the slide, a pipette or dropping-tube is employed, having a bore of about $\frac{1}{80}$ th to $\frac{1}{50}$ th of an inch at its lower end.

Mr. Jackson remarks that it is desirable that no object submitted to higher power than a quarter-inch objective of $75^{\circ}$ aperture should ever be mounted under a cover thicker than $\frac{1}{1} \frac{1}{4}$ th of an inch; if the aperture exceeds $120^{\circ}$, the best thickness for the cover is $\frac{1}{250}$ th of an inch.* Glass of this thickness can easily be cut with a good writing diamond, when laid on a piece of plate glass.t To clean the covers it is recommended to put them in strong sulphuric acid for a day or two, and then wash them repeatedly with water; after that to place them, a few at a time, on a tightly-stretched clean cambric bandkerchief, and to rub them very gently with another handkerchief on the finger. They should then be removed to a clean box, with forceps, and carefully kept from dust and from contact with the fingers. The covers should be sorted according to their thickness, and this is done at once by Ross's "lever of contact," which consists of a long slender index, having a projecting touch near the centre of motion, which is kept in contact with a plane surface by means of a spring. When a piece of glass is inserted under the touch, the index points to the thickness on a graduated arc. The thickness may also be measured in the usual way by placing a fragment in the pliers, with the edge upwards, under the microscope, armed with an inch object-glass and an eye-piece micrometer.

WORKS ON THE MICROSCOPE.-The following works may be consulted by the student :-Carpenter, The Microscope and its Revelations;

* On account of the brittleness of the glass, covers thinner than 1-140th or 1-150th of an inch are, in the hands of most manipulators, practically useless, as they break by the mere wiping or mounting, and glass I-150th of "an inch is not too thick either for Smith and Beck's 1-5th object-glass with $100^{\circ}$ of aperture, or Ross's 1-8th with $156^{\circ}$ of aperture ; but when dry mounting is adopted, the object ought to be arranged on the under side of the cover, thus bringing it as near the lenses as possible.

$\dagger$ Quekett on the Microscope. 2d Edit. p. 265.

$\ddagger$ Quarterly Journal of Microscopical Science, i. 141. 
Schacht, The Microscope and its Application to Vegetable Anatomy and Physiology, translated by Currey; Hannover on the Construction and Use of the Microscope, edited by Professor Goodsir; Beale, How to work with the Microscope ; Hogg on the Microscope ; The Quarterly and Monthly Microscopical Journals; Griffith and Henfrey, Micrographical Dictionary; Pritchard's Microscopic Illustrations; Robin, Du Microscope et des Injections; Dippel, das Mikroscop; Gosse, Evenings at the Microscope ; Lankester's Half-hours at the Microscope, illustrated by Tuffen West; Lewis on Seaside Studies; Prichard on Infusoria ; Woodward on Polarised Light ; Griffith's Elementary Textbook on the Microscope.

Ross's Microscopes in 1855-ObJectives and Prices.

\begin{tabular}{|c|c|c|c|c|c|c|}
\hline $\begin{array}{l}\text { Object Glasses, } \\
\text { Focal Length. }\end{array}$ & $\begin{array}{l}\text { Angle of } \\
\text { Aperture. }\end{array}$ & \multicolumn{4}{|c|}{$\begin{array}{l}\text { Magnifying Powers, with } \\
\text { Four Eye-pieces. }\end{array}$} & Prices. \\
\hline $\begin{array}{l}2 \text { inches } \\
1 \text { inch } \\
11, \\
\frac{1}{2}, " \\
\frac{1}{4}, " \\
\frac{1}{2}, " \\
\frac{1}{8}, " \\
\frac{1}{8}, \\
\frac{1}{8}, \\
\frac{1}{12},\end{array}$ & $\begin{array}{l}12 \text { degs. } \\
15 \text {," } \\
22, " \\
65 \text { ", } \\
85 \text {," } \\
125 \text { ", } \\
135, " \\
130, \\
150 \text { ", } \\
170,\end{array}$ & $\begin{array}{r}\text { A } \\
20 \\
60 \\
60 \\
100 \\
220 \\
220 \\
320 \\
400 \\
400 \\
650\end{array}$ & $\begin{array}{r}\mathrm{B} \\
30 \\
80 \\
80 \\
130 \\
350 \\
350 \\
510 \\
670 \\
670 \\
900\end{array}$ & $\begin{array}{r}\mathrm{C} \\
40 \\
100 \\
100 \\
180 \\
500 \\
500 \\
700 \\
900 \\
900 \\
1250\end{array}$ & $\begin{array}{r}\mathrm{D} \\
60 \\
120 \\
120 \\
220 \\
620 \\
620 \\
910 \\
1200 \\
1200 \\
2000\end{array}$ & $\begin{array}{rr}£ & s . \\
2 & 0 \\
3 & 0 \\
3 & 10 \\
5 & 5 \\
5 & 5 \\
7 & 10 \\
10 & 0 \\
11 & 0 \\
12 & 0 \\
18 & 0\end{array}$ \\
\hline
\end{tabular}

Gundlach's Achromatic ObJect Glasses.

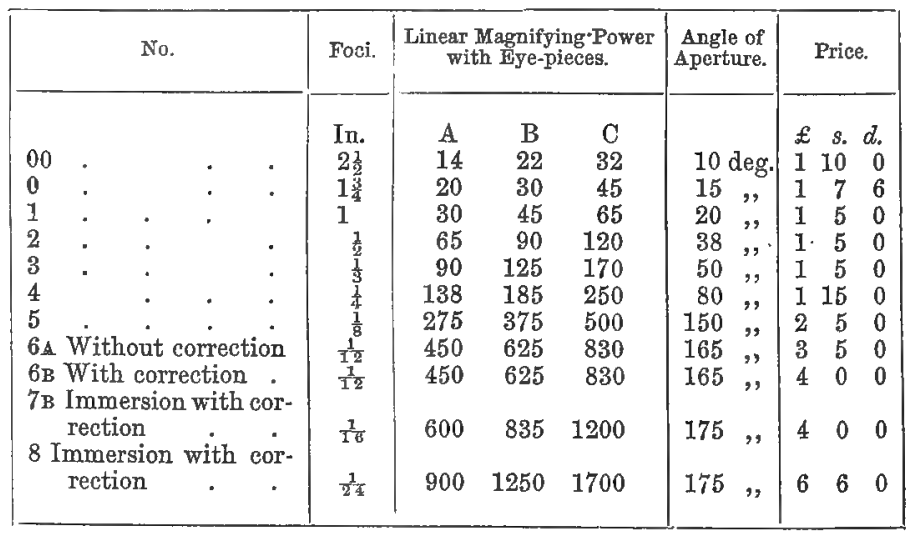


List of the Principal Microscope Makers.--Ross, Powell and Lealand, Smith and Beck, Crouch and Balker, in London; Adie, Bryson, in Edinburgh ; Field, Parkes, in Birmingham; Dancer, in Manchester; King, in Bristol; Nachet, Hartnack, in Paris; Schiek, Pistor, in Berlin : Ploesl, in Vienna.

\section{II.-On Collegoting and Examining Plants, and on the Formation of a Herbaridum.}

INSTRUMENTS AND APPARATUS.-In examining the characters of plants, with a view to classification, the chief instruments required are a lancet-pointed knife, a small pair of forceps, and a lens from $\frac{1}{4}$ to 1 inch focus. With the view of holding the object steadily the blades of the forceps may be made so as to be fastened by a sliding button. In more minute examinations, the simple or compound microscope must be called into requisition. In selecting specimens, care should be taken to have the plants in a perfect state, or with all the characteristic parts present. The entire plant should be taken when practicable ; when that is not the case, then those parts should be taken on which the generic and specific characters are founded. The roots should always be carefully washed at the time the plants are gathered. In most cases, particularly in specimens of Umbelliferæ, Leguminosæ, Compositæ, Rosæ, etc., it is of importance that both flowers and fruit should be preserved. In the case of Willows the young shoot, with its fully developed leaves, as well as the male and female flowers, are requisite. In Rubi, specimens of the young shoots must be taken. When bulbs or tubers exist, they should be preserved, either in an entire or split condition; and when there is much mucilaginous matter in them, they may be enveloped in small pieces of paper, so as to prevent them from adhering to the drying paper. In the case of Ferns, two fronds are necessary to make a perfect specimen, showing both surfaces, along with a portion of the rhizome. Entire specimens of Graminex and Cyperaceæ should be collected; these, when long, may be bent into one or more folds, corresponding to the size of the paper on which they are to be fastened, the folds being temporarily retained by small slips of paper having slits in the centre. No bad specimens ought to be preserved.

In taking up the roots of plants, a small Digger or trowel is used, 7 or 8 inches long (fig. 957 ); the spud $2 \frac{1}{2}$ inches long, $2 \frac{1}{2}$ inches wide at the top, narrowing gradually to 2 inches at the bottom, the lower angles slightly rounded. It should be sufficiently strong to resist considerable force in digging out plants from the erevices of rocks. The iron portion, which unites the spud to the handle, should be particularly attended to in this respect. This spade is put into a leather sheath, and fastened by a strap round the waist, the spade itself being 
attached to the strap by a long string. A japanned tin box or Vasculum is required for the reception of specimens. This should be of sufficient length to receive a plant of the full size of the herbarium paper ; it ought to be convex on both sides (fig. 958); and its capacity

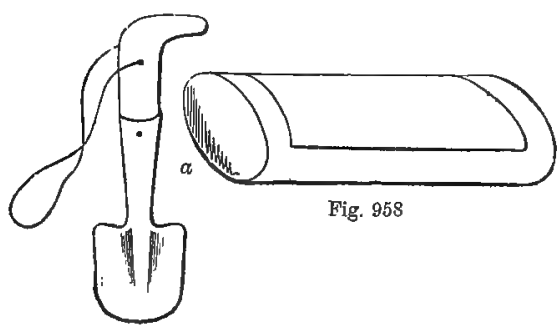

Fig. 957.

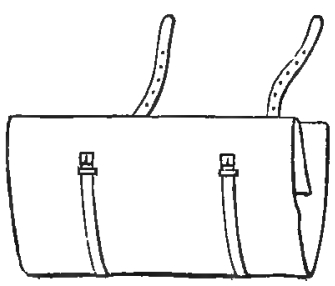

Fig. 959.

may vary according to the wish of the collector. In long excursions where productive localities are visited, it will be found that a vasculum 20 inches long, by 8 or 9 inches wide, and 5 deep, is not too large; and when it is made of thin tin it is by no means heavy. At one

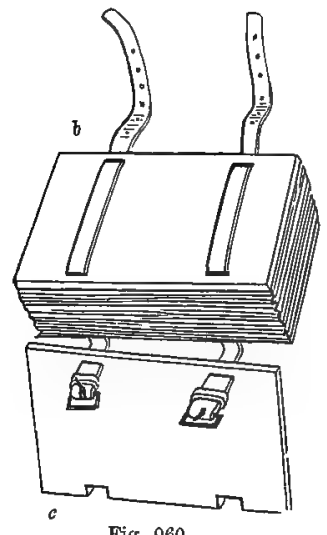

Fig. 960. end a good sized thickish handle should be placed, and it is necessary to have wires fixed at each end $(a)$ so as to receive a strap for fastening the vasculum on the shoulders. The lid of the vasculum should be large, and is best secured by a wire which slips into a tin sheath, and so constructed as not to be liable to slip out when the box is held by the handle. The specimens should be put into the box in a uniform manner-the flower at one end, and the roots at the other; and care should be taken to have the former (which should be the end where the handle is) always kept on the higher position when carried on the shoulders. For mosses and some Alpine species of plants, a small box may also be carried in the pocket. In collecting. minute aquatic plants, as Desmidieæ and Diatomaceæ, it is necessary to have small glass bottles, or test tubes, fitted in a small case. The corks should be numbered to facilitate notes being taken at the time of the locali-

Fig. 957. Form of spade or digger. Fig. 958. Form of Vasculum or botanical box. Fig. 959. Form of Field-book for drying specimens of plants. Fig. 960 . Small field-book with thin mahogany boards outside, which are brought together by leather straps. 
ties in which the specimens were collected. Many plants will not bear transport; their flowers fall off easily, and they are so delicate that their foliage becomes shrivelled. This is the case with the flower of Trientalis europæa, Rubus Chamæmorus, and Veronica saxatilis, and with some delicate Ferns. In such instances it is best to put them at once into paper. This is managed by having a small Fieldbook (fig. 959), which may be put into the pocket or suspended round the neck, secured by straps, so as to give pressure, and with an oilcloth covering which may be used in wet weather. This field-book may be made with two thin mahogany boards on the outside.

A convenient field-book, used by students in Edinburgh, is represented by fig. 960 . It is made of two mahogany boards, about nine inches long by five broad, containing from 12 to 24 parcels of paper, each parcel consisting of four sheets, the back of the parcels being covered with strips of leather or cloth. The boards may be rendered firm by being made each of two thin layers of crossed wood fastened together in the way afterwards noticed when speaking of large boards. Two narrow leather straps pass through two holes in one margin of each of the boards, and also through slits in the leather-covered backs of the parcels of the paper, $a$, so as to prevent them from falling out when the field-book is opened. In the case of one of the boards, the two straps also pass through perforations in its other margin, $b$, and under these another strap is passed for the purpose of suspending the field-book round the neck. The two small straps pass through grooves in the margin of the other board, $c$, and are thus buckled so as to apply pressure.

The Paper for drying should be moderately absorbent, 18 inches long by 11 broad, and arranged in parcels containing not less than four sheets. The paper which is generally used in Scotland is of considerable thickness, absorbs moisture rapidly, but does not become too moist, and dries easily. A very thin kind of paper, called crown teapaper, is used for holding very delicate plants, which cannot be easily transferred from one paper to another during drying. After being carefully laid out in the folds of this paper, they are placed between the sheets of drying paper, and when the paper is changed they are transferred at once in their thin cover without being disturbed. This plan is useful in the case of such plants as Myriophyllum, Callitriche autumnalis, and other aquatics, as well as Viola lutea, whose petals collapse if removed in the ordinary way, after a day's pressure.

In order that pressure may be given, Boards are requisite. These should be exactly the size of the drying paper. Some of them are used for outside boards, and these ought to be from $\frac{1}{2}$ to $\frac{3}{4}$ of an inch thick. Others are inside boards, about $\frac{3}{8}$ of an inch thick. The outside boards are often made double-each double board being composed of two thin ones, the grain of the one crossing that of the other (as in 
the case of the field-boards already mentioned), closely glued together, and firmly secured by small screws along the edge, at intervals of three inches. They may be rounded on their outer margins. For every two reams of drying paper not less than ten boards should be procured; two of which are for the outside and eight for the inside. Sheets of stout pasteboard are also useful for packing up the plants as they become dry. The pressure is best applied, on a botanical excursion, by means of a rope put crosswise round the boards and paper, and tightened by a rack-pin. This is much better than straps, which are apt to give way, and are with difficulty replaced during an excursion. In other circumstances, pressure is best applied by means of heary weighits. 诲 The pressure ought not to be less than $100 \mathrm{lbs}$. This is preferable to a screw-press, in which the pressure is not kept up while the plants are losing their moisture. In order to allow free ventilation, and thus to dry plants more rapidly, Mr. Twining recommends, instead of boards, frames made of crossed bars, with spaces

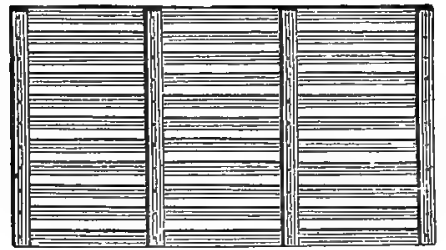

Fig. 961.

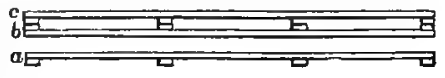

Fig. 962.

between them ; the surface applied to the paper being flat, - the others being ribbed by means of prominent cross bars, so as to leave a ventilating space between the one frame and the other (figs. 961 and 962). By an apparatus consisting of eight of such inner frames, and two outer frames of a stouter nature, so as to bear pressure, the plants as well as the paper may be dried rapidly. The apparatus, with paper and plants firmly strapped, is suspended in a draft of air coming through a partially closed window, or on the branch of a tree in sunshine; and it is said that desiccation of the plants and paper is accomplished in four days. By the use of artificial heat in an open and airy place, as, for instance, by being placed before the fire, the drying may be accomplished in twenty-four or forty-eight hours. Mr. Twining, when in Switzerland, first pressed the plants tightly for twenty-four hours, and then piled them properly in the frame-work apparatus, which was hung up in the hot air of a drying-room, and in twenty-four hours more they were ready for packing, the paper also

Fig. 961. Frames formed of cross-bars, for $_{i}^{-}$pressure and ventilation. IFig. 962. Side view of frames. One of the frames, $a$, seen laterally, with its cross bars forming projections ; two of these frames, $b$ and $c$, appear together, so as to. allow ventilation between them. 
which contained them being perfectly dry and bibulous.* Henslow recommends that, with the view of ventilating plants during drying, holes should be made in the ordinary boards at regular intervals, and that two of the inner boards should always be placed together, separated by flat cross-bars, which may either be fastened to the boards by liquid glue prepared from shell lac, or may be kept loose, and inserted when required. A complicated apparatus is suggested by $\mathbf{M}$. Gannal, the particulars of which are given in the Botanical Gazette, ii. 55; and there also another mode of drying is described, in which plants, after having been kept in a press for a few hours, are exposed to the sun, or placed on a stove or in an oven, in an apparatus called the Coquette. This consists of two open covers made of strong iron-wire network fastened into frames made of light iron rod, pressure being applied by straps or ropes, as already mentioned. The open frames allow the moisture to escape freely. Sheets of tin may be employed to separate the different layers of plants in process of drying, so as to hinder the humidity of one from reaching the other, or the inequalities of the larger from injuring the smaller and more delicate. In the case of plants with strong stems, they must either be split, or a sandbag, of the same size as the boards, used so as to equalise the pressure.

Process of Drying.-The plants when collected are to be placed on the drying paper. In doing this a parcel of not less than four sheets is put on one of the outside boards; then the specimens are laid out carefully, preserving as far as possible their natural habits, and laying out the leaves and other parts. Another parcel of drying paper is then placed above these, and the same process is repeated with other specimens until twelve such parcels have been placed together. Then one of the inner boards is laid down, and other layers of paper and specimens are applied, until the whole parcel is of sufficient size to be subjected to pressure. After twelve hours' pressure, in most instances, the paper is changed, the moist paper being hung up to dry ; and in . transferring the specimens from the wet to the dry paper, a large pair of surgeon's forceps is used. The interval elapsing between the changing of the paper max be increased or diminished according to the nature of the plants and the state of the weather. In the course of eight or ten days, ordinary specimens will be so dry as to require only very slight pressure, with a moderate circulation of air. Some very dry plants, as grasses, may require only one changing. Succulent plants, such as Sedum and Sempervivum, continue to grow, however much submitted to pressure, and the ordinary methods of desiccation already indicated. In order to dry these plants completely and rapidly, it is necessary to kill them, by immersion in boiling water for five or ten minutes-some recommend the use of a solution of arsenic as a means of

* See a description and drawing of this apparatus in Botanical Gazette, ii. 59. See also .drawing of drying apparatus in Gardeners' Chronicle, 1861, p. 76. 
killing them. The plants thus dealt with are then placed upon a cloth and left to drain for some time, after which they must be carefully placed between the folds of the drying paper, not forgetting to lay out properly any of the parts which the water may have disarranged. Orchideous plants are sometimes put into warm paper, and changed frequently, with the view, if possible, of preserving their colours by the rapidity of drying. Scarification has sometimes been adopted with the view of allowing the juice to flow out rapidly. Motley recommends that Orchids should be put into weak spirit for one or two nights, and then dried. In the case of some thick-headed plants, as Thistles, the capitula must either be cut, or they must be crushed between paper, by temporary pressure from the foot; this treatment must also be applied to such plants as Eryngium maritimum and the Holly. Sometimes the flower, or parts of the flower, may be separated advantageously during drying, by the insertion of small pieces of blotting-paper. At the time the specimens are laid out on the drying paper, a label should be inserted with the date of collecting, the name of the station, its elevation above the sea (if it can be ascertained), and any remarks as to soil or geological structure that may be known. In the course of long excursions, it is necessary to devote every now and then some time to the proper arranging and tallying of the specimens. On this subject Greville says, "Half-a-day, therefore, at least, in the middle of the week, say the morning of every Wednesday, till two o'clock, should be appropriated to the preservation and arrangement of your plants; and a part or the whole of every Saturday should invariably be set apart for the same purpose, in order that they may not be injured by remaining untouched on the Lord's Day." With the view of transporting dried plants securely in wet weather, it is useful to have a supply of oil-cloth to cover them.

Mosses may be collected in excursions in tufts, and dried by moderate pressure at first. They can afterwards be separated, moistened, and dried with greater pressure. They ought to be gathered in fructification. In preserving minute Mosses, Dr. C. Miüller takes clear talc, splits it into thin layers, and cuts it into oblong pieces of proper size. Then, with a penknife, he splits one of these pieces, from one of the narrow sides, half-way through, so that it may be opened to admit the object and then close by its elasticity, the unsplit end serving as a holder. A drop of water is introduced into the slit with the object. When laid aside it dries, and may be rendered fit for microscopic examination by dipping in water. Lichens sometimes require to be taken with the rocks or stones to which they are attached, and they may be merely wrapped up in paper. Seaweeds must be washed with fresh water before being laid out. The more delicate kinds are floated out on pieces of stiff paper, and afterwards dried by moderate pressure. In preserving fungi, such as Agarics, 
etc., a thin slice is taken from the centre, extending from the top of the pileus to the base of the stipe. This is dried separately to show the gills or pores, etc. The inner cellular portion of the pileus and stipe is then removed, and these parts are dried so as to give the form. Travellers visiting foreign countries (although not botanists) will find it an easy matter to preserve Mosses, Lichens, and Seaweeds in a state fit for after-examination. In the case of Seaweeds, it is necessary to aroid such specimens as are in a state of decay. Those which are taken should be spread out in the shade to dry, without washing them with fresh water, and when quite dry, packed loosely in a box. Many species are found thrown upon the beach, and the pools in the rocks at low water are often filled with excellent specimens. The stems of the larger Algæ are often covered with parasitic species, which should be dried without separation.

When the specimens (whether Phanerogamous or Cryptogamous) are fully dried, they are then selected for the herbarium, and are fastened upon fine stiff paper, fit for writing upon, 17 inches by $10 \frac{1}{2}$. In large herbaria, which are constantly consulted, the best way of securing the specimens is by means of fine thin glue; the plants, after the glue is put on them, being made to adhere to the paper, by pressure between folds of drying paper. Some use gummed paper, others use thread or narrow ribbon, by means of which the specimens are sewed to the paper. Some put more than one species on a sheet. There may be as many specimens of the species as you choose, more especially from different localities. Put single specimens near one side of the herbarium sheet, and not in the middle; change the side on the alternate sheet. By this means one being on the right side of the sheet, another on the left, a third near the top, and a fourth near the bottom, the whole will be flat and not bulge up in the middle. Fasten any loose parts with the strips of gummed paper; strap down the main stem in all cases, unless it is covered with hair, in which case strips are superfluous. Write the name of the plant near the lower right-hand corner of the half-sheet, and in some convenient spot near the specimen itself, the habitat, etc. If printed or written tickets are put on, let them be pasted (not glued) upon the lower right-hand corner. Plants of certain families, as Compositæ, are more particularly exposed to the ravages of insects. Hence, all plants after being dried should be brushed over with an alcoholic solution of corrosive sublimate.* This treatment has the inconvenience of discolouring

* The solutions recommended are :-

I. Methylated spirit . Corrosive sublimate Carbolic acid

II. Rectified spirit of wine Corrosive sublimate. Creasote

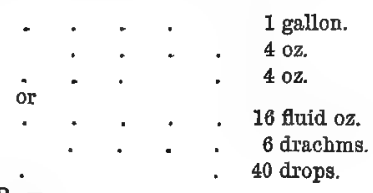


them more or less completely, and making them assume a light brown tint; but there can be no hesitation between the alteration of their colour and the complete destruction with which they are menaced, if not submitted to the above manipulation; some recommend cyanide of potassium to destroy insects. In herbarium-presses camphor is employed to prevent the attack of insects. The specimens must be kept dry, and frequently examined, and when insects are present, they must be retouched with the solution already indicated. Dry fruits, specimens of wood and bark, large roots, lichens and minute Algæ on rocks or stones, or other specimens which cannot be preserved in a herbarium, may be either placed in drawers, in glazed cases, or in glass jars.

The size of the wooden case for the herbarium must of course depend on the extent of the collection. In a private collection it is better to have numerous small cases, which are easily removed at pleasure along with the specimens. This should be particularly attended to by medical students, and others, who have the prospect of going abroad, and who may wish to transport their collections to foreign countries. In such instances the cases should be strongly made, and should be not more than four feet high, with two rows of drawers. These drawers are made open in front, and should slide freely in the case. In the Edinburgh University Herbarium, the size of the drawers or trays is-depth (inside measurement) 4 inches, length 19 inches, and breadth $11 \frac{1}{2}$ inches. The size of the trays should of course correspond to that of the herbarium paper. Some collectors have peculiar fancies in regard to the size of their herbarium. Thus a valuable collection of Cryptogamic plants, grasses, sedges, rushes, etc., left by Menzies to the Edinburgh Botanic Garden has the following:dimensions :- Height of the mahogany cases 30 inches, breadth in front $28 \frac{1}{2}$, from front to back 11 ; depth of the trays (inside measurement) $4 \frac{1}{2}$ inches, length $9 \frac{1}{2}$, breadth 6 .

Specimens in a Moist State.-In preserving fresh specimens of fruits, and the other parts of plants, the best mode is to put them into a saturated solution of salt and water. They can thus be sent home from foreign countries in jars or barrels. In making a museum of such specimens, they are put into glass jars, the sizes of which should be regular-4, 8,12 , and 16 inches bigh, with a diameter varying according to the size of the specimen. The glasses may be filled with the following solution, which is nearly the same as that used by Goadby, and which seems to answer well in most instances :-

\begin{tabular}{|c|c|c|c|c|c|c|}
\hline Bay salt & & & & & & 4 ounces. \\
\hline Burnt alum . & . & - & • & • & & 2 ounces. \\
\hline Corrosive sublimate & 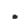 & . & • & • & - & . 5-10 grains. \\
\hline Boiling water & - & . & . & . & . & . 2 quarts. \\
\hline
\end{tabular}


Dissolve and filter the solution. Alcohol is often used, but it usually makes all colours alike brown. It is useful for delicate specimens which are required for dissection. Pyroligneous acetic acid diluted with from 3 to 5 parts of water is also very generally employed. Specimens, however, in the acid are apt to become pulpy and brittle after a few years, so as not to admit of being handled; most colours are altered by it. Before being put in jars, fresh specimens should be kept for a month or more in the solution, so as to allow any colouring matter and other impurities to be separated, otherwise the preparation will become obscure, and require to be re-adjusted. The mouth of the glass jars may be conveniently covered with India rubber, or, in the case of glasses of small diameter, with a watch glass secured by sealing wax, or by circular glass covers cemented by a lute composed of resin 1 part, wax 2 parts, and vermilion 1 part. The glass cover on the top of the jar may be either luted or held in its place by a metallic ring (fig. 963 a), which is fitted carefully to it, and covers a portion of the glass lid. Two grooves may be made on the inner side of the rim at the top of the jar for holding a piece of whalebone, to which

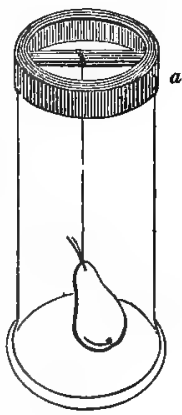

Fig. 963 . the specimen may be attached by means of a thread, as seen in the figure. In the case of dry preparations, the metallic ring answers well.

It is difficult to keep the solution of salt in the preparation jar. Sir Robert Christison says:- " The most effectual method, when the mouth of the jar does not exceed 2 or $2 \frac{1}{2}$ inches in diameter, is to have a space half-an-inch or more at the top of the fluid, to clean and dry the top of the jar thoroughly, to drop melted sealing-wax on the upper surface of the top, so as to form a uniform ring over it, to place over the mouth a watch-glass of such size as to cover the whole lip, and even to overhang it a little, to press this gently down with one finger, and to fuse the wax between the top of the jar and the watch-glass, by moving a large spirit flame around the edge." Where the mouth of the jar is large, then a round flat piece of glass may be used, or sheet eaoutchouc. The latter, after being gently heated, is stretched moderately, not strongly, by one, or still better, by two persons, while a third secures round the neck two or three folds of stout twine as a temporary ligature. A stout thin cord is then drawn steadily and tightly round three or four times above the former, taking care that the caoutchouc is not cut, and that the turns of the twine lie regularly above each other; and finally, that a secure knot is made.

Fig. 963. Jar for holding wet or dry preparations, the glass cover at the top being held in its place by a metallic xing. 
SEEDS, when sent from abroad, should be collected perfectly ripe and dry, and if possible kept in their entire seed-vessels. Small seeds may be folded in cartridge paper, and should be kept in a cool and airy place during transport. Large seeds and oily seeds, which lose their germinating power speedily, are best transported in earth. A box about 10 inches square, with the sides $\frac{3}{4}$ of an inch thick, answers well. In this may be put alternate layers of earth and seeds, the whole being pressed firmly together. Living plants are best transported in Wardian cases, and seeds or fruits may also be scattered in the earth of the cases. Bulbs and rhizomes not in a state of vegetation, cuttings of succulent plants, as aloes and cactuses, and the pseudobulbs of Orchideous plants, may be put into a box or barrel with dry moss, sand, peat, or sawdust.

Hints as to the Preparations to be made for Alpine Travelling, particularly in Switzerland, partly taken from. Wills" "Wanderings on the High Alps."

A botanical trip for six weeks in Switzerland, including the expense of going and coming, need not cost more than twelve shillings a-day. In a pedestrian tour the traveller must be as lightly equipped as possible; at the same time he must so provide as to have a change of dress in case of wet weather. The Botanist must send his heavy portmanteau and his drying paper, with boards, ropes, and rack-pin, to different points by railway or post. During his alpine rambles he will find that he can only carry his box, spade, field-book, alpenstock, and light waterproof. His knapsack, while he is botanising, must be carried by a porter. He should, however, be prepared on an emergency to carry all his alpine baggage with him, more especially when passing from one station to another by some beaten track, where few plants are to be expected. A large party will find it convenient and economical to hire a horse for the conveyance of their knapsacks.

The articles required are as follows:-

A light waterproof knapsack, which will bear rough usage, about 14 inches long, 10 inches broad, and $3 \frac{1}{2}$ inches deep, with two light straps at the top to hold a very light waterproof, and a stout leather handle by which to carry it, if necessary. The straps for the shoulders should be broad. One of the shoulder straps should end in a ring, and a hook should be fastened on the Iower edge of the knapsack to receive it. By this contrivance the knapsack is easily taken off. The whole apparatus ought not to weigh above 2 lbs.

Good shoes, large, so as to allow for the swelling of the feet, the soles from $\frac{5}{8}$ ths to $\frac{3}{4}$ ths of an inch thick, studded with stout nails, not too thickly. They should be worn with gaiters, so as to keep out dust, stones, etc. 
Soft woollen socks, such as those made in Shetland. Of these two or three pairs are required.

A shooting coat, a waistcoat, and trousers of flannel, or of shepherd's plaid, the two former being double-breasted. Flannel should always be worn next the skin on account of rapid changes of temperature on the glaciers and in the valleys.

A light wide-awake hat, with strings or elastic band. In very hot weather the action of the sun on the forehead and temples may be diminished by a thick roll of white muslin round the hat.

A light waterproof of silk; one may be got weighing only six ounces.

The contents of the knapsack should not weigh more than 6 or 7 lbs. They should consist of two spare thin merino shirts, three or four pairs of socks, well run in heels and toes, a very thin pair of trousers or drawers for change, two pocket handkerchiefs, and a pair of light shoes; materials for mending - as needles, thread, worsted, tape, buttons, bits of cloth and flannel; also string, soap, sponge, brush and comb, and tooth-brush; oiled-silk, lint, and bandages; ordinary medicine-as compound rhubarb pills, opium, and sugar of lead and opium pills, tartar emetic, lard and sticking-plaster; a small quantity of note-paper, ink, and pens; a large knife, furnished with a corkscrew, gimlet, and saw; lucifers; a pair of dark spectacles, and a dark veil, and warm gloves and muffitees. There may be also added a journal, a thermometer, compass, clinometer, whistle, and a small telescope. A flask and drinking-cup will also be of service, and a common coarse blouse, which can be procured in Switzerland for two francs. For travelling on glaciers a few screws, about sths of an inch long, with large double-pointed heads, are useful. Wills procured them at Chamouni. These are screwed into the sole, three or four being enough for each shoe.

For glacier work, stout ropes, thicker than a window-sash cord are required, 10 to 15 feet for each person, and an ice hatchet. An alpenstock, 6 feet in length, is of essential service. A good map is also of great value. The botanist must also have a small tin box, 10 or 12 inches in length, and about 4 deep; a small spade, in a leathern case, fastened round his waist, and a small field-book for drying plants, made of thin wooden boards, 8 or 9 inches long, and about 5 inches broad, and containing drying paper, about 1 or $1 \frac{1}{2}$ inch deep. The plants gathered must be transferred to larger drying paper at different stations, and must then either be carried by a porter, or sent by conveyance of some sort.

It is by no means necessary to have guides in every part of the Alps of Switzerland. For instance, Mr. Wills says, that none are required for the Col de Balme, the Tête Noire, the Col de Vose, the Great St. Bernard, the Gemmi, and the Grimsel. In wandering, 
however, among the high mountains, it is always safe to take a guide. Wills suggests that the best way is to secure a good guide at starting, and keep him during the whole tour. He costs about five or six franes a day.

Directions to Collectors visiting Foreign Countries, condensed from Hooker's Kew Miscellany, Vol. IX., pp. 214-219.

A Botanist visiting a foreign country should make as perfect a collection as possible of all the plants, neglecting no species, and preserving specimens of every kind, more especially such as seem to be confined to certain localities. The arborescent plants, trees of every description, are to be sought for and collected in flower and in fruit; cones and larger acorns, and other kinds too large for the hortus siccus, are to be preserved apart from the foliage, and notes made of the locality, height, bulk of the trunk, etc. In proportion as mountains are ascended, the vegetation will be found to change, and to become more interesting and more peculiar. Particular notice should be taken of the heights at which different plants grow, and of those plants which are found nearest to the limit of perpetual snow. Care should be taken to preserve the collections from wet and damp. They may require to be opened occasionally, and exposed to a dry air or artificial heat. Seeds should be collected, and transported in the way already noticed. Objects of interest as regards economic botany should be collected; such as articles of food, clothing, ornament, medicines, resins, dye-stuffs, samples of woods, particularly those good for carpentry and cabinet work. Varieties and abnormal forms of species should be sought for and preserved, attention being paid to differences in habit, and in the form of leaves and flowers in the same species at different periods of growth and in different conditions of growth. A comparison should be instituted between the flowers of different regions, as of the plains, swamps, and of different heights and exposures on the mountains, as well of different geological districts, as granite, limestone, etc. The times of leafing and flowering of bushes and trees, etc., should be noticed. When the vegetation seems unusually retarded or accelerated, the temperature of the surface soil and at three feet deep should be ascertained, wherever possible. The collector should, as soon as possible, make himself acquainted with the names of the more common and conspicuous plants of the district he traverses, by consulting any works which may have been written regarding it. The plants which affect waysides or the tracks of man and animals should be noticed, and the effect of clearing away forests and of burning grass land on the subsequent vegetation should be attended to. The transport of seeds by man and animals is a subject of great interest, which should not be neglected. Care should be taken to ticket the specimens, so 
that there may be no difficulty in determining their localities afterwards. Notes as to elevation (if above 2000 feet of the sea level), dates, name of district, and any other information, should be attached to the specimens to which they refer. A collector cannot be too careful in regard to these matters. Ascertaining the temperature of the trunks of evergreen and deciduous trees, and of the soil at their roots, is a subject of importance. The temperature of the soil at various depths during winter should be recorded; also the temperature of the air and water between the under surface of melting snow-beds and the subjacent dormant vegetation, with the view of determining the causes of the rapidity with which plants germinate and blossom after the disappearance of snow from alpine situations.*

* For fuller details, see instructions by Sir Wm. Hooker and Dr. Hooker, in Kew Miseellany, vol, ix. pp. 214-219. 



\section{GLOSSARY}

OR

\section{EXPLANATION OF SOME OF THE TERMS USED -IN BOTANICAL WORKS.}

A, alpha, privative of the Greek, placed before a Greek or Latin word, indicates the absence of the organ; thus, aphyllus, leafiess, acaulis, stemless.

ABAXIAI or ABAXILE, not in the axis, applied to the embryo when out of the axis of the seed.

ABIogenesis, same as HeTERoGenESIS, aname for so-called spontaneous generation from inorganic matter.

ABNORMAL, deviating from regularity or from the usual form of structure.

ABORTION, suppression of an organ, depending on non-development.

ABRUPT, ending in an abrupt manner, as the truncated leaf of the Tulip tree; $a b r u p t l y-p i n-$ nate, ending in 2 pinna, in other words, paripinnate ; abruptly-acuminate, a leaf with a broad extremity from which a point arises.

ABScission, cutting off, applied to the separation of the segments or frustules of Diatoms.

ACAULIS or ACAULESCENT, without an evident stem.

ACCRESCENT, when parts continue to grow and increase after flowering, as the calyx of Physalis, and the styles of Anemone Pulsatilla.

ACCRETE, grown together.

ACCUMBENT, applied to the embryo of Cruciferz, when the cotyledons have their edges applied to the folded radicle.

ACERose, narrow and slender, with a sharp point.

ACHENE or ACH ENIUM, a monospermal seedvessel which does not open, but the pericarp of which is separable from the seed.

ACHLAMYDEous, having no fioral envelope.

Achromatic, applied to lenses which prevent chromatic aberration, $i, e$. show objects with out any prismatic colours.

Acrcular, like a needle in form.

Acrculus, a strong bristle.

ACINACIFORM, shaped like a sabre or scimitar.

Acrnvs, one of the pulpy drupels forming the fruit of the Raspberry or Bramble.

ActinenChyMA, cellular tissue, having a starlike or stellate form.

ACOTYLEDONous, having no cotyledons.

ACrocarpi, Mosses having their fructification terminating the axis.
ACROGEN and ACRogenous, increasing at the summit, applied to the stems of ferns, which have a vascular cylinder penetrated by bundles of vessels belonging to the fronds ; and stems marked by the scars of the fronds.

ACulEus, a prickle, a process of the bark (not of the wood), as in the Rose; Aculeate, furnished with prickles.

ACUMINATE, drawn out into a long point.

AcuTe, terminating gradually in a sharp point.

ADELPHOUS or ADELPHIA, in composition, means union of filaments.

ADHERENT, united, adhesion of parts that are normally separate and in different verticils, as when the calyx is united to the ovary.

ADNATE, when an organ is united to another throughout its whole length, as the stipules in Rose, and the filament and anther in Ranun. culus.

ADPRESSED or APPRESSED, closely applied to a surface, as some hairs.

ADUnCus, crooked or hooked.

ADVENTITIOUS, organs produced in abnormal positions, as roots arising from aerial stems.

EsTIVAl, produced in summer.

ESTIVATION, the arrangement of the parts of the flower in the flower-bud.

AFFINITY, relation in all essential organs.

Agamous, the same as Cryptogamous.

ALA, a wing, applied to the lateral petals of a papilionaceous flower, and to membranous appendages of the fruit, as in the Elm, or of the seed, as in pines.

AlBUMEN, the nutritious matter stored up with the embryo, called also Perisperm and Endo. sperm.

ALBURNum, the outer young wood of a Dicotyledonous stem.

Algology, the study of Seaweeds.

Alsinacrous, a polypetalous corolla, in which there are intervals between the petals, as in Chickweed.

ALTERNATE, arranged at different heights on the same axis, as when each leaf is separated by internodes from those next to it.

ALVEOLA, regular cavities on a surface, as in the receptacle of the Sunflower, and in that of Nelumbium which is called Alveolate. 
Amentum, a catkin or deciduous unisexual spike; plants having catkins are $A$ mentiferons.

Aminios, the fluid or semi-fluid matter in the embryo-sac.

AMORPHOUs, without definite form.

AMPHISARCA, an indehiscent multilocular fruit with a hard exterior, and pulp round the seeds, as seen in the Baobab.

Amphitropal, an ovule curved on itself, with the hilum in the middle.

AMPLEXICAUL, embracing the stem over a large part of its circumference.

Ampulla, a hollow leaf, as in Utricularia.

AnAlogous, when a plant strikingly resembles one of another genus, so as to represent it.

ANASTOMOSIS, union of vessels; union of the final ramifications of the veins of a leaf.

ANATROPAL or ANATROPOUs, an inverted ovule, the hilum and micropyle being near each other, and the chalaza at the opposite end ; raphe present.

ANCers, two-edged.

ANDRCECIUM, the male organs of the flower.

AnDRogynous, male and female flowers on the same peduncle, as in some species of Carex.

ANDROPHORE, a stalk supporting the stamens, often formed by a union of the filaments.

ANEMophilous, applied to plants fertilised by the agency of wind.

ANER, male or stamen, in composition, Andro and Androus.

ANFRACTUOSE, wavy or sinuous, as the anthers of Cucurbitacea.

ANGrenCHYMA, vascular tissue in general.

ANGIOCARPous, applied to Lichens having fructification in cavities of the thallus and opening by a pore.

ANGIOSPERMOUS, having seeds contained in a seed-vessel.

Anciosporous, Cryptogamic plants having spores contained in a theca or sporangium.

ANisos, in composition, means unequal.

ANisostemonous, stamens not equal in number to the floral envelopes, nor a multiple of them.

ANNOTINUS, a year old.

ANNulus, a ring, applied to the elastic rim surrounding the sporangia of some Ferns, also to a cellular rim on the stalk of the Mushroom, being the remains of the veil.

ANTERIor, same as inferior, when applied to the parts of the flower in their relation to the axis, part of a flower next the bract or in front.

AntHela, the cymose panicle of Juncacer.

ANTHER, the part of the stamen containing pollen.

ANTHERIDIUM, male organ in Cryptogamic plants, frequently containing moving filaments.

AnTHEROzOA, moving filaments in an antheridium.

Anthesis, the opening of the flower.

Anthocarpous, applied to multiple, polygynocial, or confluent fruits, formed by the ovaries of several flowers,

ANTHODIUM, the capitulum or head of flowers of Composite plants.

ANTHOPHORE, a stalk supporting the inner floral envelopes, and separating them from the calyx.

Anthos, a flower, in composition, Antho; in Latin, Flos.
ANTHOTAXIS, the arrangement of the flowers on the axis.

ANTICUs, placed in front of a flower, as the lip of Orchids ; Antherce Antice, anthers which open on the surface next the centre of the flower; same as Introrse.

ANTITROPAL, applied to an embryo whose radicle is diametrically opposite to the hilum.

APERISPERMIC, without separate albumen; same as Exalbuminons.

APETAlous, without petals, in other words, monochlamydeous.

ApHyllous, without leaves.

APICAL, or APICILAR, at the apex; often applied to parts connected with the ovary.

ApICUlate, having an apiculus.

A.PICULUS or Aprculum, a terminal soft point springing abruptly.

Aptanatic, applied to lenses in which spherical aberration is corrected.

Apocarpous, ovary and fruit composed of numerous distinct carpels.

Apophysis, a swelling at the base of the theca in some Mosses.

ApoтHECIUM, the rounded shield-like fructification of Lichens.

Apterous, without wings.

ArACHNOID, applied to fine hairs so entangled as to resemble a cobweb.

ARCHE, in composition, means beginning.

ARCHEGoNIUM, the young female cellular organ in Cryptogamic plants.

ARCHISPERMS, another name for gymnosperms.

ARCUATE, curved in an arched manner like a bow.

AREOLATE, divided into distinct angular spaces, or Areole.

ARILlus and Arillode, an extra covering of the seed, the former proceeding from the placenta, as in Passion-flower, the latter from the exostome, as in the Mace of Nutmeg.

ARISTA, an awn, a long-pointed process, as in Barley and many grasses, which are called Aristate.

ARMature, the hairs, prickles, etc., covering an organ.

ARTICULATED, jointed, separating easily and cleanly at some point.

Ascending, applied to a procumbent-stem, which rises gradually from its base; to ovules attached a little above the base of the ovary; and to hairs directed towards the upper part of their support.

Ascroium, a pitcher or folded leaf, as in $\mathrm{Ne}$ penthes.

Ascus, a bag, applied to the theca of Lichens and other Cryptogams, containing sporidia or spores.

Aspreity, roughness, as on the leaves of Boraginace

ATRACTENCHYMA, tissue composed of spindleshaped cells.

ATropous or ATropal, the same as Orthotropous.

AURICULATE, having appendages, applied to leaves having lobes or leaflets at their base.

AWN and AWNED, see Arista and Aristate.

AxIL, the upper angle where the leaf joins the stem.

AXILE or AxIAL, belonging to the axis.

AXILLARY, arising from the axil of a leaf.

AxIs, is applied to the central portion of the 
young plant, whence the plumule and radicle are given off, and the name is given in general to the central organ bearing buds; in Grasses, the common stern of a locusta.

BACcA, berry, a unilocular fruit, having a soft outer covering, and seeds immersed in pulp. All such fruits are called Baccate.

BACULrForM, applied to rod-like bodies in the reproductive organs of Spharoplea.

BALAUSTA, the fruit of the Pomegranate.

BARBATE, BEARDED, having tufts of hair-like pubescence.

BARK (cortex), the outer cellular and fibrous covering of the stem; separable from the wood in Dicotyledons.

BARREN, not fruitful, applied to male flowers, and to the non-fructifying fronds of ferns.

BASAL or BASILAR, attached to the base of an organ.

Basidium, a cell bearing on its exterior one or more spores in some Fungi, which are hence called Basidiostornus.

BAsT or BAss, the inner fibrous bark of Dicotyledonous trees.

Bathymetrical, measurement of depths at which plants grow in the ocean.

Bedeguar, a hairy excrescence on the branches and leaves of Roses, caused by an attack of a Cynips.

Bidendate, having two tooth-like processes.

Bifarious, in two rows, one on each side of an axis.

BifID, two-cleft, cut down to near the middle into two parts.

Biforine, a raphidian cell with an opening at each end.

Bilamellar, having two lamella or flat divisions, as in some stigmas.

Bilocular, having two loculaments.

Binate, applied to a leaf composed of two leafiets at the extremity of a petiole.

Brogenesis, the production of living cells from previously existing cells of a similar nature.

Brparous, applied to cymose inflorescence when the first axis gives rise to two bracts, from each of which a second axis proceeds, and so on; thus the inflorescence is Dichotornous.

Bipartite, cut down to near the base into two parts.

Bipinnate, a compound leaf divided twice in a pinnate manner.

BipinNatifid, a simple leaf, having lateral lobes with divisions extending to near the middle, the lobes being also similarly divided.

BIPINNATIPARTITE, differing from bipinnatifid in the divisions extending to near the midrib.

Biplicate, doubly folded in a transverse manner.

Brporose, having two rounded openings.

BIS, twice, in composition, $B i$.

BiserRate, or duplicate-serrate, when the serratures are themselves serrate.

BrsexuAt, male and female organs in the same flowers.

Biternate, a compound leaf divided into three, and each division again divided into three.

Bitten, same as Premorse.
BLADE, the Iamina or broad part of a leaf, as distinguished from the petiole or stalk.

Blanching, see Etiolation.

BlETTING, is the change of the pulp from green to brown, as occurs in the Medlar after being pulled and kept for some time; the fruit from being austere thus becomes soft and edible.

BOLE, the trunk of a tree.

BOTHRENCHYMA, dotted or pitted vessels, with depressions on the inside of their walls.

BRACHIATE, with decussate branches.

BRACT, a leaf more or less changed in form, from which a flower or flowers proceed flowers having bracts are called Bracteated.

BRACTEOLE or BRACTLET, a small bract at the base of a separate flower in a multifloral inflorescence.

BRyology, the study of Mosses; same as Muscology.

BuLB, an underground bud covered with fleshy scales.

BulbIL or BuLblet, separable buds in the axil of leaves, as in some Lilies.

Bulbous-BASED, applied to hairs which are tumid at the base.

Byssoid, very slender, like a cobweb.

Caducous, falling off very early, as calyx of Poppy.

Casious, with a fine pale blue bloom.

Caspitose, growing in tufts.

CALATHIFORM, hemispherical or concave, like a bowl or cup.

Calathium, same as Capitulum and Anthodium.

Calcar, a spur, a projecting hollow or solid process from the base of an organ, as in the flowers of Larkspur and Snapdragon; such flowers are called Calcarate or spurred.

Calceolate, slipper-like, applied to the hollow petals of some Orchids, also to the petals of Calceolaria.

Callosity or Callus, a leathery or hardened thickening on a limited portion of an organ.

CalycrFlore, a sub-class of Polypetalous Dicotyledons having the stamens attached to the calyx.

Calyculus or Caliculus, an outer calycine row of leaflets, giving rise to a double or calyculate calyx.

CALYPTRA, the outer covering of the sporangium of Mosses.

CALYPTRIMORPHOUS, applied to pitchers or ascidia having a distinct lid.

Caryx, the outer envelope of the flower; when there is only one envelope, it is the calyx.

CAmBrum, mucilaginous cells between the bark and the young wood, or surrounding the vessels.

Campanulate, shaped like a bell, as the flower of Hare-bell.

Campulttropal or Campylotropal, a curved ovule with the hilum, micropyle, and chalaza near each other; no true raphe.

CAMPYlospermas, seeds with the albumen folded laterally.

Canaliculate, channelled, having a longitudinal groove or furrow.

Cancellate, latticed, composed of veins alone, or lattice-like cells.

CAPILLARY, filiform, thread-like or hair-like. 
CAPITATE, pin-like, having a rounded summit, as some hairs.

Capitulum; head of flowers in Compositz.

CAPREOLATE, having tendrils.

Caprification, the ripening of the Fig, by means of the wild fig or Caprificus.

Capsula Circumscissa, same as Pyxis or Pyxidizm.

CAPSUle, a dry seed-vessel, opening by valves, teeth, pores, or a lid.

CARCERULUS, a fruit consisting of several 1-2seeded indehiscent carpels cohering by a common style round a common axis; as a Mallow and Tropaeolum.

Carina, keel, the two partially united lower petals of papilionaceous flowers.

CARINAL, applied to astivation when the carina embraces the other parts of the flower.

Carnose, fleshy, applied to albumen having a fleshy consistence.

Carpet or Carpidium, the leaf forming the pistil. Several carpels may enter into the composition of one pistil.

- Carpology, the study of fruits.

- Carpophore, a stalk bearing the pistil, and raising it above the whorl of the stamens, as in Lychnis and Capparis.

Carpos, fruit, in composition Carpo.

CARUNCULA, a fleshy or thickened appendage of the seed.

Caryorsis or Cariopsis, the monospermal seed-vessel of Grasses, the pericarp being incorporated with the seed.

Cassmeous, shaped like a helmet.

CATKIN, same as Amentum.

CAUDATE, having a tail or feathery appendage.

CAUDEx, the stem of Palms and of Tree-ferris.

Caudicle, Caumicura, the process supporting a pollen-mass in Orchids.

Caulescent, having an evident stem.

Caulicle, Cauliculus, a stalk connecting the axis of the embryo and the cotyledors.

CAulis, an aerial stem.

Cellulose, the chemical substance of which the cell-wall is composed.

Centimetre, a French measure, equal to o. 3937079 British inch.

Centrifugal, applied to that kind of inflorescence in which the central flower opens first.

CENTRIPETAL, applied to that kind of inflorescence in which the flowers at the circumference or base open furst.

CeramidiuM, an ovate conceptacle having a terminal opening, and with a tuft of spores arising from the base; seen in Alga.

Ceratium, a siliquaform capsule, in which the lobes of the stigma are alternate with the placenta, as in Glaucium and Corydalis.

CEREAL, applied to Wheat, Oats, Barley, and other grains.

Cernuous, pendulous, nodding.

CHAFFY, covered with minute membranous scales.

CHALA2A, the place where the nourishing vessels enter the nucleus of the ovule.

Chlamys, covering, applied to the floral envelope, in composition Chlamydeous.

Chlorophyli, the green colouring matter of leaves.

Chloros, green, in composition Chloro.

CHorisis or CHORIzation, separation of a lamina from one part of an organ, so as to form a scale or a doubling of the organ; it may be either transverse or collateral.

Chroma, colour, in composition, Chrom.

Chromogen and Chromule, the colouring matter of flowers.

Chrysos theans yellow like gold, in composiw tion Chryso,

Cicatricula, the scar left after the falling of a leaf; also applied to the hilum or base of the seed.

Crlia (Cilium), short stiff hairs fringing the margin of a leaf ; also delicate vibratile hairs of zoospores ; ciliate, with cilia.

Crnenchyma, laticiferous tissue, formed by anastomosing vessels.

CiRcrNATE, rolled up like a crozier, as the young fronảs of Ferns.

CIRCUMSCISSILE, cut round in a circular man. ner, such as seed-vessels opening by a lid.

CIRCUMSCRIPTION, the periphery or margin of a leaf.

CirRus, a tendril, or modified leaf in the form of a twining process.

Cistolith, an agglomeration of raphides (Sphreraphides) suspended in a sac by tube, as in Ficus elastica.

CLADENCHYMA, tissue composed of branching cells.

CIADOCARPI, mosses producing sporangia on short lateral branches.

CLAnoptosis, the fall of branches as in Thuja, Taxodium, Glyptostrobus and Tamarisk.

Clados, a branch, in composition Clado.

Clathratus, latticed like a grating.

Clavate, club-shaped, becoming gradually thicker towards the top.

CLAw, the narrow base of some petals, corresponding to the petiole of leaves.

CleFt, divided to about the middle.

Clinandrium, the part of the column of Orchids bearing the anther.

Cinanthium, the common receptacle of the flowers of Composita.

Cling, a bed, in composition Clin, used in reference to parts on which the floral organs are inserted.

Cloves, applied to iyoung bulbs, as in the Onion.

Clypeate, having the shape of a buckler.

Coccrorum, a rounded conceptacle in Alga without pores, and containing a tuft of spores.

Coccus and Coccum, applied to the portions composing the dry elastic fruit of Euphorbiacex.

COCHLEAR, a kind of restivation, in which a helmet-shaped part covers all the others in the bud.

Cochlariform, shaped like a spoon.

CELospermas, seeds with the albumen curved at the ends.

CoHEreNT, cohesion of part in the same verticil, as sepals, petals, or stamens.

CoLEORHIZA, a sheath covering the radicles of a monocotyledonous embryo.

Collateral, placed side by side, as in the case of some ovules.

ColleNCHYMa, the inter-cellular substance which unites cells.

CoLLUM, neck, the part where the plumule and radicle of the embryo unite. 
ColpenchyMA, tissue composed of wavy or sinuous cells.

Cozumella, central column in the sporangia of Mosses; also applied to the carpophore of Umbellifera.

Column, a part in the flower of an Orchid supporting the anthers and stigma, and formed by the union of the styles and filaments.

Coms, applied variously to tufts of hairs, to bracts occurring beyond the inflorescence, and to the general arrangement of the leafbearing branches of a tree, etc.

Commissure, unjon of the faces of the two achenes in the fruit of Umbellifera.

Comose, furnished with hairs, as the seeds of the Willow.

Compoljnd, composed of several parts, as a leaf formed by several separate leaflets, or a pistil formed by several carpels either separate or combined.

COMPRESSED, flattened laterally or lengthwise.

ConcePTACLE, a hollow sac containing a tuft or cluster of spores.

Conducting Tissue, applied to the loose cellular tissue in the interior of the canal of the style.

ConduPlicate, folded upon itself, applied to leaves and cotyledons.

Cone, a dry multiple fruit, formed by bracts covering naked seeds.

ConenCHYMA, conical cells, as hairs.

ConfrRvoID, formed of a single row of cells, or having articulations like a Conferva.

ConfluENT, when parts unite together in the progress of growth.

Conidia, peculiar spores in Fungi, which resemble buds.

Conjugate spirals, when whorled leaves are so arranged as to give two or more generating spirals running parallel to each other; according to the number of leaves in the whorl, the spirals are bijugate, trijugate, quinquejugate, etc.

ConjugAtion, union of two cells, so as to develop a spore.

CONNATE, when parts are united even in the early state of development; applied to two leaves united by their bases.

Connecrivi, the part which connects the anther lobes.

Connrven't, when two organs, as petals, arch over so as to meet above.

CoNToRTED, when the parts in a bud are imbricated and regularly twisted in one direction.

Convolute or Convolutive, when a leaf in the bud is rolled upon itself.

Coralline, like Coral, as the root of Corallorhiza.

Corcuium, a name for the embryo.

Cord, the process which attaches the seed to the placenta.

CORDATE, heart-shaped, a plane body with the division or broad part of the heart-next the stalk or stem.

CORDIFORM, a solid body having the shape of a heart.

Coriaceous, having a leathery consistence.

CoRM, thickened underground stem, as in the Colchicum and Arum.

CoRmogens, having a corm or stem.

CORnU, a horn ; Comeous, having the consist- ence of horn; Bicornis or Bicornute, having two horns.

Corolla, the inner envelope of the flower.

Corolliflor.se, Gamopetalous (Monopetalous)

Exogens, with hypogynous stamens.

Corona, a corolline appendage, as the crown of the Daffodil.

CORRUGATED, wrinkled or shrivelled.

Cortex, the bark; Cortical, belonging to the bark; Corticated, having a bark.

CoRTINA, the remains of the veil which continue attached to the edges of the pileus in Agarics.

ConymB, a raceme in which the lower stalks are longest, and all the flowers come nearly to a level above; Corymbiferons or Corymb. ose, bearing a corymb, or in the form of a corymb.

$\operatorname{Cos} T A$, a rib, applied to the prominent bundles of vessels in the leaves; Costate, provided with ribs.

Cotyledon and Cotyledons, the temporary leaf, leaves, or lobes, of the embryo ; in some cases the Cotyledons are persistent, as in Welwitschia.

CRAMPONS, a name given to adventitious roots which serve as fulcra or supports, as in the Ivy.

Cremocarp, the fruit of Umbelliferæe, composed of two separable achenes or mericarps.

CRENATE, having superficial rounded marginal divisions.

CRenatures, divisions of the margin of a crenate leaf.

CREsT, an appendage to fruits or seeds, having the form of a crest

CRISP, having an undulated margin.

CROWN OF THE ROOT, the short stem which is at the upper part of the root of perennial herbs.

Cruciform and Cruciate, arranged like the parts of a cross, as flowers of Cruciferz.

Crustaceous, hard, thin, and brittle ; applied to those Lichens which are hard and expanded like a crust.

Cryptogamous, organs of reproduction obscure.

Cryptos, inconspicuous or concealed, in composition Crypto.

Cucullate, formed like a hood.

CuLM, stem or stalk of grasses.

CunEIForm or CUNEATE, shaped like a wedge standing upon its point.

Cupula, the cup of the acorn, formed by aggregated bracts.

Curvembrye $\approx$, plants with the embryo curyed.

Cuspis, a long point large at the base, and gradually attenuated; Cuspidate, prolonged into a cuspis, abruptly acuminate.

CuTICLE, the thin layer that covers the epidermis.

CyAThIForM, like a wine-glass; concave, in the form of a reversed cone.

Cyclogens, applied to Dicotyledons with concentric woody circles.

Crclosis, movement of the latex in laticiferous vessels.

CYLINDRENCHYMA, tissue composed of cylindrical cells.

Cymbiform, shaped like a boat.

CYME, a kind of definite inflorescence, in which the flowers are in racemes, corymbs, or umbels, 
the successive central flowers expanding first: Cymose, inflorescence in the form of a cyme.

CYNARRhodum, fruit consisting of a hollow inferior receptacle containing numerous achenes, as in the Rose,

Cypsela, inferior monospermal indehiscent fruit of Compositze.

Cystidia, sacs containing spores; a kind of fructification in Furigi.

CYstocarp, the fully-formed fructification of Floridea, a tribe of Red Seaweeds.

Cystolith, a cell, containing numerous crystals (raphides), as in leaf of Ficus.

CYTOBLAST, the nucleus of a cell.

Cytorlastema, mucilaginous formative matter of cells, called also Protoplism.

Cytogenesis, cell-development.

Cytos, a cell, in composition Cyto.

DRDALENCHYMA, entangled cells.

DECA, ten, in Greek words, same as the Latin Decen; as decandrous, having ten stamens; decagynous, having ten styles.

DEcrouous, falling off after performing its functions for a limited time, as calyx of Ranunculus.

Deciduous Trees, which lose their leaves annually.

Decimetre, the tenth part of a metre, or ten centimetres.

Declinate or Declining, directed downwards from its base ; applied to stamens of Amaryllis.

DEcompound, a leaf cut into numerous compound divisions.

DECORTICATED, deprived of bark.

DECUMBENT, lying flat along the ground, and rising from it at the apex.

DECURRENT, leaves which are attached along the side of a stem below their point of insertion. Such stems are of ten called Winged.

Decussate, opposite leaves crossing each other in pairs at right angles.

DEDUPLICATION, same as Chorisis.

DEFINITE, applied to inflorescence when it ends in a single flower, and the expansion of the flower is centrifugal; also when the number of the parts of an organ is limited, as when the stamens are under twenty.

DEFleXED, bent downwards in a continuous curve.

DEFOLIATION, the fall of the leaves.

DEGENERATION, when an organ is changed from its usual appearance and becomes less highly developed, as when scales take the place of leaves.

DEHISCENCE, mode of opening of an organ, as of the seed-vessel and anther.

DELTOLD, like the Greek $\Delta$ in form, properly applied solely to describe the transverse section of solids.

DENTATE, toothed, having short triangular divisions of the margin. The term is also applied to the superficial divisions of a gamosepalous calyx and a gamopetalous corolla.

DeNTiculate, finely-toothed, having small tooth-like projections along the margin.

Depressed, flattening of a solid organ from above downwards.

Determinate, applied to definite or cymose infiorescence.

DExTrorse, directed towards the right.
DiAChenium, same as Cremocarp, fruit composed of two achenes.

DIACHYMA, the parenchyma of the leaf.

DIADELPHOUS, stamens in two bundles, united by their filaments.

Dialycarpous, pistil or fruit composed of distinct (separate) carpels.

Dialypetalous, corolla composed of separate petals.

Dialysepalous or Dialyphyllous, calyx composed of separate sepals.

Dichlamydeous, having calyx and corolla.

Dichogamous, stamens and stigmas of the same flower, not reaching maturity at the same time.

Dichотомоus, stem dividing by twos.

Dichotomous CYME, a kind of definite inflorescence in which the secondary axes come off in pairs, each ending in a single flower; the same kind of division goes on through the tertiary and yuaternary axes, etc.

Diclinous, unisexual flowers, either monoecious or diaecious.

Dicotyledonous, embryo having two cotyledons.

Dictyogenous, applied to monocotyledons having netted veins.

Didymocs, twin, union of two similar organs.

DiDYNAMOUs, two long and two short stamens.

Drgitare, compound leaf composed of several leaflets attached to one point.

Digynous, having two styles.

Dilamination, same as Deduplication and Chorisis.

Dimerous, composed of two pieces.

Dimidiate, split into two partially, as the calyptra of some Mosses; or completely, as the lobes of the anther in Salvia.

Dimorphic, having two forms of flowers, differing in size and development of the stamens and pistils, as in Primula and Linum.

Dimorrhous, when similar parts of a plant assume different forms.

Dicecious, or Dioicous, staminiferous and pistilliferous flowers on separate plants.

DIGECIOUSLY-HERMA PII RODITE, hermaphrodite flowers having only one of the essential organs perfect in a flower.

DIPLECOLOBEA, cotyledons twice folded transversely.

Diploos, double, in composition Diplo.

Diploperistomi, Mosses with a double peristome.

Diplostemonous, having a double row of stamens, which are thus often double the number of the petals or sepals.

Diplotegia, an inferior, dry, I-many-celled seed-vessel, usually opening by valves or by pores, as in Campanula.

Dipterous, having two wings.

Drs, twice in composition, $D i$, same as Latin $B i s$ or $B i ;$; as disepalous, having two sepals, dispermous, two-seeded.

DISCIFORM, and DiscorD, in the form of a disc or flattened sphere; discoid pith, divided into cavities by discs.

Discord, also applied to the flosculous or tubular flowers of Composita.

Discs, the peculiar rounded and dotted markings on coniferous wood.

Disk, a part intervening between the stamens and the pistil in the form of scales, a ring, 
etc. ; it is connected with the receptacle or torus.

Dispermous, having two seeds.

Dissected, cut into a number of narrow divisions.

Dissepiment, a division in the ovary; true, when formed by edges of the carpels ; false, when formed otherwise.

DissILIENT, applied to fruit which bursts in an elastic manner.

Distichous, in two rows, on opposite sides of a stem.

DISTRACTIIE, separating two parts to a distance from each other.

Dithecal, having two loculaments.

DIVARICATING, branches coming off from the stem at a very wide or obtuse angle.

DoDzcA, twelve; in Latin, Duodecim.

Dodecagynous, having twelve pistils.

DODECANDROUS, having twelve stamens.

DOLABRIFORM, shaped like an axe.

DORSAL, applied to the suture of the carpel which is farthest from the axis.

Dorsiferous, applied to Ferns bearing fructification on the back of their fronds.

DoRsum, the back, the part of the carpel which is farthest from the axis.

DoUBLE Flower, when the organs of reproduction are converted into petals.

Drups, a fleshy fruit like the cherry, having a stony endocarp. Drupels, small drupesaggregated to form a fruit, as in the Raspberry.

Dumose, having a low shrubby aspect.

DURAMEN, heart-wood of Dicotyledonous trees.

Dynamis, power, in composition means superiority in length; as didynamous, two stamens longer than two others.

$\mathrm{E}$ or $\mathrm{Ex}$, in composition corresponds to alpha, privative; as ebracteated, without bracts; exaristate, without awns; edentate, without teeth; ecostate, without ribs.

EсHINATE, covered with straight slender prickles, like an Echinus.

Elaters, spiral fibres in the spore-cases of Hepatica.

ELLIPTICAL, having the form of an ellipse

EMARGINATE, with a superficial portion taken out of the end.

EMBryo, the young plant contained in the seed.

EMBRYo-BUDS, nodules in the bark of the beech and other trees.

Embryogeny, the development of the embryo in the ovule.

EMBRYoLOGy, the study of the formation of the embryo.

EMBRYO-SAC or EMBRYONARY-SAC, the cellular bag in which the embryo is formed.

EMBRyotega, a process raised from the spermoderm by the embryo of some seeds during germination, as in the Bean.

ENDECA, in Greek, eleven; in Latin, Undecim.

Endecagynous, having eleven pistils.

ENDECANDRous, having eleven stamens.

ENDOCARP, the inner layer of the pericarp next the seed.

ENDOCHROME, the colouring matter of cellular plants.

ENDoGEN, an inward grower, having an endogenous stem.

ENDON, within or inwards, in composition Endo.
ENDOPhlaum, the inner bark or liber.

ENDOPLEURA, the inner covering of the seed.

ENDORHIZAL, numerous rootlets arising from a common radicle, and passing through sheaths, as in endogenous germination.

ENDosmose, movement of fluids inwards through a membrane.

ENDOSPERM, albumen formed within the embryo-sac.

Endosporous, Fungi having their spores contained in a case.

ENDOSTOME, the inner foramen of the ovule.

ENDOTHECIUM, the inner coat of the anther.

ENERVIS, without veins.

ENNEA, nine ; in Latin, Novem."

ENNEAGYNOUS, having nine pistils.

ENNEANDROUS, having nine stanens.

ENSIFORM, in the form of a sword, as the leaves of Iris,

ENTIRE (integer), without marginal divisions; (integerrimus), without either lobes or marginal divisions.

ENVELOPES, FloRAL, the calyx and corolla.

$E_{P I}$, upon, in composition means on the outside or above, as epicarp, the outer covering of the fruit; epigynous, above the ovary.

EPIBLA5T, an abortive organ in the Oat, supposed to be the rudiment of a second cotyledon.

EPICALYX, outer calyx, formed either of sepals or bracts, as in Mallow and Potentilla.

EpICARP, the outer covering of the fruit.

EPICHILIUM, the label or terminal portion of the strangulated or articulated lip (labellum) of Orchids.

EPICOROLLINE, inserted upon the corolla.

EPIDERMIs, the cellular layer covering the external surface of plants.

EPIGEAL, above ground, applied to cotyledons.

EPIGONE, the cellular layer which covers the young sporangium in Mosses and Hepatica.

EPIGYNous, above the ovary, and attached to it.

EPIPETALOUS, inserted upon the petals.

EPIPHRAGM, the membrane closing the orifice of the thecz of some Mosses, as Polytrichum.

EPIPHYLLOUS, growing upon a leaf.

EPIPHYTE, attached to another plant and growing suspended in the air.

EPIRRHEOLOGY, the influence of external agents on living plants.

EPISPERM, the external covering of the seed.

EPISPORE, the outer covering of some spores.

EqUiTANT, applied to leaves folded longitudinally, and overlapping each other without any involution.

ERECT, applied to an ovule which rises from the base of the ovary; also applied to innate anthers.

EROSE, irregularly toothed, as if gnawed.

ERUMPENT, prominent, as if bursting through the epidermis, as seen in some tetraspores.

ETARIO, the aggregate drupes forming the fruit of Rubus.

Etiolation, blanching, losing colour in the dark.

Exalbuminous, without a separate store of albumen or perisperm.

Exannulate, without a ring, applied to some Ferns, as Botrychium and Ophioglossum.

EXCENTRIC, removed from the centre or axis; applied to a lateral embryo. 
ExcIPULus, a receptacle containing fructification in Lichens.

EXCURRENT, running out beyond the edge or point.

ExINTINE, one of the inner coverings of the pollen grain.

EXo, in composition, on the outside.

ExoGEN, outside grower, same as Dicotyledon.

EXORHIZAL, radicle proceeding directly from the axis, and afterwards branching, as in Exogens.

ExOSMOSE, the passing outwards of a fluid through a membrane.

Exosporous, Fungi, having naked spores.

Exostome, the outer opening of the foramen of the ovule.

ExoTHECIUM, the outer coat of the anther.

EXSERTED, extending beyond an organ, as stamens beyond the corolla.

EXSTIPULATE, without stipules.

EXTINE, the outer covering of the pollen-grain.

EXTRA-AXILLARY, removed from the axil of the leaf, as in the case of some buds.

EXTRORSE, applied to anthers which dehisce on the side farthest removed from the pistil.

Exutive, applied by Miers to seeds wanting the usual integumentary covering, as in Olacacez.

Falcate or Falciform, bent like a sickle.

FALSE AXES OF INFLORESCENCE, an elongated axis produced by the union of several singleflowered axes, which are joined together by their extremities.

Farinaceous, mealy, containing much starch.

Fasciation, union of branches of stems, so as to present a flattened riband-like form.

FAscicle, a shortened umbellate cyme, as in some species of Dranthus.

Fastigiate, having a pyramidal form, from the branches being parallel and erect, as Lombardy Poplar.

Favella, a kind of conceptacle in Algze.

Favellidia, spherical masses of spores, usually contained in sacs called capsules.

FEATHER-VEINED, a leaf having the veins passing from the midrib at a more or less acute angle, and extending to the margin.

Fenestrate, applied to a replum or leaf with openings in it, compared to windows.

Fertile, applied to pistillate flowers; and to the fruit-bearing frond of Ferns.

FIBRO-CELLULAR tissue, composed of spiral cells.

Fibrous, composed of numerous fibres, as some roots.

Fibro-vascular tissue, composed of vessels containing spiral and other fibres.

Fid, in composition, cleft, cut down to about the middle.

FiLAMENT, stalk supporting the anther.

Filamentous, a string of cells placed end to end.

FILIFORM, like a thread.

Fimbriated, fringed at the margin.

Fissiparous, dividing spontaneously into two parts by means of a septum.

FISSURE, a straight slit in an organ for the discharge of its contents.

Fistulous, hollow, like the stem of Grasses.

Flabelliform, fan-shaped, as the leaves of some Palms.
FLAGELLUM, a runner, a weak creeping stem bearing rooting buds at different points, as in the Strawberry.

Flexuose or Flexuous, having alternate curvations in opposite directions; bent in a zigzag manner.

Fioccr, woolly filaments with sporules in Fung: and Algx.

FLoccose, covered with wool-like tufts.

FLORAL ENVELOPES, the calyx and corolla.

Flosculous, the tubular florets of Compositæ.

Foliation, the development of leaves.

Foliola, same as Phylla and Sepala.

FOLLICIE, a fruit formed by a single carpel, dehiscing by one suture, which is usually the ventral.

Foot, French, equal to $\mathrm{I}$ " 7892 foot British.

FORAMEN, the opening in the coverings of the ovule.

Foveate or Foveolate; having pits or depressions called foveze or foveola.

FoviLla, minute granular matter in the pollengrain.

FROND, the leaf-like organ of Ferns bearing the fructification; also applied to the thallus of many Cryptogams.

Frondose, applied to Cryptogams with foliaceous or leaf-like expansions.

FRUSTULES, the parts or fragments into which Diatomacex separate.

FRUTEX, a shrub ; Fruticose, shrubby.

Fugacrous, evanescent, falling off early, as the petals of Cistus.

Fulvous, tawny-yellow.

Funiculus, the umbilical cord connecting the hilum of the ovule to the placenta.

FurCate, divided into two branches like a twopronged fork.

FURFURACEOUS, scurfy or scaly.

FusIFORM, shaped like a spindle.

GaLbulus, the polygynocial confluent succulent fruit of Juniper.

GALEA, applied to a sepal or petal shaped like a helmet; the part is called Galeate.

GaMo, in composition, means union of parts.

GaMopetalous, same as Monopetalous, petals united.

Gamophyllous and Gamosepalous, same as Monophyllous and Monosepalons, sepals united.

Geminate, twin organs combined in pairs, same as Binate.

Gemma, a leaf-bud ; Gemmation, the development of leaf-buds.

Gemmiferous, bearing buds.

GeMmrparovs, reproduction by buds.

GrMmule, same as Plumule, the first bud of the embryo.

Geniculate, bent like a knee.

GERMEN, a name for the ovary.

Germinal Vesicle, a cell contained in the embryo sac, from which the embryo is developed.

GERMINATION, the sprouting of the young plant.

GiBBOSITY, a swelling at the base of an organ, such as the calyx or corolla, as in Diely tra.

GibBous, swollen at the base, or having a distinct swelling at some part of the surface.

GIABRous, smooth, without hairs.

GLAND, an organ of secretion consisting of cells, 
and generally occurring on the epidermis of plants.

Glandular Hairs, hairs tipped with a gland, as in Drosera and Chinese Primrose.

Glans, nut, applied to the Acorn and Hazelnut, which are enclosed in bracts.

GLaucous, covered with a pale-green bloom.

Globule, male organ of Chara.

Glochidiate, barbed, applied to hairs with two reflexed points at their summit.

GLOMERULUS, a rounded, cymose inflorescence, as in Urtica.

GLOSSOLOGY, explanation of technical terms.

Giumaceous, of the nature of glumes.

GLUME, a bract covering the organs of reproduction in the spikelets of Grasses, which are hence called Gluwriferous.

Glumelle and Glumellule, a name applied to the palea or fertile glume of a Grass.

Gongyli, same as Gonidia.

GoNIDLA, green germinating cells in the thallus of Lichens.

Govos and Gone mean offspring; used in composition.

Gonus or GonUM, in composition, means either kneed or angled; in the former case the $o$ is short, "in the latter long : Polygornum, manykneed; Tetragōntenz, four-angled.

GRAIN, caryopsis, the fruit of Cereal Grasses.

Grains of pollen, minute cells composing the pollen.

GRANULES, minute bodies varying greatly in size, having a distinct external shadowed ring or margin, the external edge of which is abrupt.

GRANULATED, composed of grantles.

GruMous, collected into granular masses.

GYMNOCARPOUS, Lichens having fructifications in the form of a scutellate, cup-shaped, or linear thallus.

Gymnogen, a plant with naked seeds, i.e. seeds not in a true ovary.

Gymnos, naked, in composition Gymno.

GyMNOSPERMOUS, plants with naked seeds, i.e. seeds not in a true ovary, as Conifers.

GYMNOSPORE, a naked spore ; Gymnosporous, having naked spores.

Gxm nostomi, naked-mouthed, Mosses without a peristome.

GYNANDROPHORE, a column bearing stamens and pistil.

Gynandrous, stamen and pistil united in.a common column, as in Orchids.

Gyve, female, and Gyn, Gynous, and Gyvo, in composition, refer to the pistil or the ovary.

Gynizus, the position of the stigma on the column of Orchids.

GYNOBASE, a central axis, to the base of which the carpels are attached.

Gyncerium, the female organs of the flower.

GyNOPHORE, a stalk supporting the ovary.

Gynostegrum, staminal crown of Asclepias.

GynostemiUM, column in Orchids bearing the organs of reproduction.

Gyrate, same as Circinate.

GYRATION, same as Rotation in cells.

HABIT of a plant, its general external appearance.

HALOPHYTES, plants of salt marshes, containing salts of soda in their composition.
H.ASTATE, halbert-shaped, applied to a leaf with two portions at the base projecting more or less completely at right angles to the blade. HAULM, dead stems of herbs, as of the potato.

HAUSTORIUM, the sucker at the extremity of the parasitic root of Dodder.

HEAD. See Capitulum.

HEART-Wood, same as Duramen.

Hekistotherms, plants requiring a very small amount of heat, as arctic and antarctic plants.

Henicoid cyme, in which the flowers are arranged in a continuous helix or spiral, round a false axis.

Helicoidal, having a coiled appearance like the shell of a snail, applied to inflorescence.

HELMET, the upper petaloid sepal of Aconitum.

HEMr, half; same as Latin Semi.

HEmICARP, one of the achenes forming the cremocarp of Umbellifere.

Hepta, seven; same as Latin Septem.

HEPTAGyNous, having seven styles.

HEPTANDROUS, having seven stamens.

HERB, a plant with an annual stem, opposed to a woody plant.

Herbaceous, green succulent plants which die down to the ground in winter ; annual shoots ; green-coloured cellular parts.

HERMAPHRODITE, stamens and pistil in the same flower.

HESPERIDIUM, the fruit of the Orange, and other Aurantiacea.

HETERACMY, another name for Dichogamy.

HeTEROCEPHALOUs, composite plants having male and female capitula on the same plant.

Heterocysts, peculiar cells forming large germs in Nostochinea, differing from sporangia and spores.

HETERODroMous, spirals running in opposite directions.

HETERECIUM, applied to potato fungus, meaning that part of its life is passed on some other host than the potato.

Heterogamous, Compositz having hermaphrodite and unisexual flowers on the same head.

HETERoGenesis, another name for so-called spontaneous generation, in which living cells are supposed to be produced by inorganic matter.

HETEROMORPHIC, having different forms of flowers as regards stamens and pistils, and these forms being necessary for fertilisation, as in Primula.

HETEROPHYLLOUS, presenting two different forms of leaves.

HETERORHIZAL, rootlets proceeding from various points of a spore during germination.

Heteros, dissimilar or diverse ; in composition, Hetero.

Heterosporous, Cryptogamic plants, having both microspores and macrospores on the same individual, as in Selaginella.

Heterotropal, ovule with the hilum in the middle, and the foramen and chalaza at opposite ends.

HEXA, six ; same as Latin Sex.

Hexagyaus, having six styles.

Hexandrous, having six stamens.

HrLUM, the base of the seed to which the placenta is attached, either directly or by means of a cord. The term is also applied to the mark at one end of some grains of starch. 
HIRSUTE, covered with long stiff hairs.

HISPID, covered with long very harsh hairs.

Histogenetic, applied to minute molecules, supposed to be concerned in the formation of celis.

HISTOLOGY, the study of microscopic tissues.

HoLoserickous, covered with minute silky hairs, discovered better by the touch than by sight.

Homodromous, spirals running in the same direction.

Homogamous, Composite plants having the flowers of the capitula all hermaphrodite.

HOMOGENEOUS, having a uniform structure or substance.

HomomorpHic, when the pistil is fertilised by the polien from its own flowers; this is selffertilisation.

Homos and Homoros, similar, in composition Homo.

HOMOTROPAI, when the slightly curved embryo has the same general direction as the seed.

HOROLOGiCAL, flowers opening and closing at certain hours.

HUMifuse, spreading along the ground.

HYaline, transparent or colourless; applied by Barry to the part where the cell-nucleus appears.

HYBRID, a plant resulting from the fecundation of one species by another.

HYMENIUM, the part which bears the fructification in Agarics.

HXPANTHODIUM, the receptacle of Dorstenia, bearing many flowers.

Hypнa, the filamentous tissue in the thallus of lichens.

HYPHASMA, a web-like thallus of Agarics,

HYPO, under or below, in composition $H_{y p}$.

HyPOCARPOGEAN, plants producing their fruit below ground.

HypochILIUM, the lower part of the labellum of Orchids.

HYPOCRATERIFORM, shaped like a salver, as the corolla of Primula.

HyPoGEAL or HYPOGEOUS, under the surface of the soil, applied to cotyledons.

Hypogynous, inserted below the ovary or pistil.

НуротнALLUS, the mycelium of certain Entophytic Fungi, as Uredines.

HYPSOMETRICAL, measurement of altitude.

HySTERANTHOUS, when leaves expand after the flowers have opened.

HYSTEROPHYTA, a name applied to Fung:.

ICOSANDRIA, having twenty stamens or more inserted on the calyx: Icosandrous, having twenty stamens.

Icosr, twenty; in compusition Icos. Same as Latin Viginti.

IMBRICATE or IMBRICATED, parts overlying each other like tiles on a house. Imbricated astivation, the parts of the flower-bud alternately overlapping each other, and arranged in a spiral manner.

IMPARI-PINNATE, unequally-pinnate, pinnate leaf ending in an odd leaflet.

INARCHING, a mode of grafting by bending two growing plants towards each other, and causing a branch of the, one to unite to the otber.
INARTICULATE, without joints or interruption to continuity.

INCH, French, is equal to 1.06578 inch British.

INCISED, cut down deeply.

INCLUDED, applied to the stamens when enclosed within the corolla, and not pushed out beyond its tube.

INCUMBENT, cotyledons with the radicle on their back.

INDEFINITE, applied to inflorescence with centripetal expansion; also to stamens above twenty, and to ovules and seeds when very numerous.

INDEHISCENT, not opening; having no regular line of suture.

INDETERMINATE, applied to indefinite inflorescence.

INDIGENOUS, an aboriginal native in a country.

INDUPLICATE or INDUPLICATIVE, edges: of the sepals or petals turned slightly inwards in zestivation.

INDUSIUM, epidermal covering of the fructification in some Ferns.

INDUTIVE, applied by Miers to seeds having the usual integumentary covering.

INERMIS, unarmed, without prickles or thorns.

INFERIOR, applied to the ovary when it is situated below the calyx; and to the part of a flower farthest from the axis.

INFLORESCENCE, the mode in which the flowers are arranged on the axis.

INFUNDIBULIFORM, in shape like a funnel; as seen in some gamopetalous corollas.

INNATE, applied to anthers when attached to the top of the filament.

InNOVATIONS, buds in Mosses.

InTERCELlular SPACE, same as Lacuna.

INTERFOLIAR, between two opposite leaves.

INTERNODE, the portion of the stem between two nodes or leaf-buds.

INTERPETIOLAR, between the petioles of opposite leaves ; as the stipules of Cinchona.

INTERRUPTEDLY-PINNATE, a pinnate leaf in which pairs of small pinnæ occur between the larger pairs.

INTERSTAMINAL, an organ placed between two stamens.

INTEXTINE, one of the inner coverings of the pollen-grain.

INTINE, the inner covering of the pollen-grain.

INTRORSE, applied to anthers which open on the side next the pistil.

INVERTED, applied to the embryo when the radicle points to the end of the seed opposite the hilum.

INVOLUCEL, bracts surrounding the partial umbel of Umbelliferæe.

INYOLUCRE, bracts surrounding the general umbel in Umbelliferx, the heads of flowers in Compositz, and in general any verticillate bracts surrounding numerous flowers. It is also used in the same sense as the Indusium of Ferns.

InVolute or Involutive, edges of leaves rolled inwards spirally on each side, in astivation.

IRREGULAR, a flower in which the parts of any of the verticils differ in size.

IsOCHEIMAL or ISOCHEIMONAL, lines passing through places which have the same mean winter temperature. 
Isochomous, branches springing from the same plant, and always at the same angle.

ISOMERIC, applied chemically to substances which, though differing in qualities, have the same elements in the same proportions.

Isomerous, when the organs of a flower are composd each of an equal number of parts.

Isos, equal, in composition $/ s$.

IsosPoRous, cryptoganic plants producing a single kind of spore, as ferns.

Isostemonous; when stamens and floral envelopes have the same number of parts or multiples.

ISOTHERAL, lines passing through places which have the same mean summer temperature.

IsoTHERMAL, lines passing through places which have the sarne mean annual temperature.

JoININGs, the places where the parts of the stem are attached to each other; the nodes.

JorNTS, spaces between the knots or nodes or joinings.

JuGA, a name given to the ribs on the fruit of Umbelliferae.

JUGUM, a pair of leaflets : jugate, applied to the pairs of leaflets in compound leaves: unijugate, one pair; bijugate, two pairs; and so on.

KEEL, same as Carina.

KLeistogamous, applied to certain grasses in which fertilisation is effected in closed flowers,

KNOT'TED, when a cylindrical stem is swollen at intervals into knobs.

LABEL, the terminal division of the lip of the flower in Orchids.

LABELLUM, lip, one of the divisions of the inner whorl of the flower of Orchidis. This part is in reality superior as regards the axis, but becomes inferior by the twisting of the ovary.

LABIATE, lipped, applied to irregular gamopetalous flowers, with an upper and under portion separated more or less by a hiatus or gap.

LACINIATED, irregularly cut into narrow segments.

LACINULA, the small inflexed point of the petals of Umbelliferæ.

LACTESCENT, yielding milky juice.

LACUNA, a large space in the midst of a group of cells.

LAEIGATUS, having a smooth polished appearance.

L.svis, even.

LAMELLAE, gills of an Agaric, also applied to flat divisions of the stigma.

LAmina, the blade of the leaf, the broad part of a petal or sepal.

LANCEOLATE, narrowly elliptical, tapering to each end.

LANUGINous, woolly, covered with long flexuous interlaced hairs.

LATERAL, arising from the side of the axis, not terminal.

LATEX, granular fluid contained in laticiferous vessels.

LATICIFEROUS, anastomosing vessels containing latex.

LATISEPTE, Cruciferous plants having a broad replum in their silicula.
Lecotropal, shaped like a horse-shoe, as some ovules.

LEGUME, a pod composed of one carpel, opening usually by ventral and dorsal suture, as in Pea.

LENTICEL, a small process on the bark of the Willow and other plants, whence adventitious roots proceed.

LENTICULAR, in the form of a doubly-convex lens.

LEPIDOTE, covered with scales or scurf; Lepis, a scale.

LIANAS or LIANES, twining woody plants.

LIBER, the fibrous inner bark or endophloum.

LIEBERKUHN, a metallic mirror attached to the objective of a microscope for the purpose of throwing down light on opaque objects.

LIGNINE, woody matter which thickens the cell-walls.

Ligulate, strap-shaped florets, as in Dandelion.

Ligule, a process arising from the petiole of grasses where it joins the blade.

Liguliflore, Composite plants having ligulate fiorets.

LimB, the blade of the leaf; the broad part of a petal or sepal; when sepals or petals are united, the combined broad parts are denominated collectively the limb.

LINE, the Izth part of an inch; Line, French, is equal to 0.0888 I 5 inch British.

LiNEAR, very narrow leaves, in which the length exceeds greatly the breadth.

LIRELLA, sessile linear apothecium of Lichens.

LOBE, large division of a leaf' or any other organ; applied often to the divisions of the anther.

LOCULICIDAI, fruit dehiscing through the back of the carpels.

LOCUluS or LOCULAMENT, a cavity in an ovary, which is called unilocular when it has one cavity, bilocular with two, and so on. The terms are also applied to the anther.

Locusta, a spikelet of grasses formed of one or several flowers.

LODICULE, a scale at the base of the ovary of Grasses.

Lomentum and Lomentaceous, applied to a legume or pod with transverse partitions, each division containing one seed.

LUNATE, crescent-shaped.

LYRATE, a pinnatifid leaf with a large terminal lobe, and smaller ones as we approach the petiole.

MACROPODOUS, applied to the thickened radicle of a monocotyledonous embryo.

MACROS, large, in composition Macro.

Macrosporangia, cells or thecæ containing macrospores.

MACROSPORES, large spores of Lycopods.

MaLPIGHIACEOUS HAIRS, peltate hairs, such as are seen in Malpighiacez.

MANLCATE, applied to scales surrounding a stalk like a frill, and easily removed.

MARCESCENT, withering, but not falling off until the part bearing it is perfecter.

MARginate, applied to calyx, same as Obsolete.

MASKED, same as Personate.

MATH, a term sometimes used for crop; an agricultural term. 
Matrulla, the fibrous matter covering the petioles of Palms.

MEdulla, the cellular pith.

Medullary Rays or Plates, cellular prolongations uniting the pith and the bark.

Medullary Sheatr, sheath containing spiral vessels surrounding the pith in Exogens.

Megasporangia, same as Macrosporangia.

Megatherms, or Macrotherms, plants requiring a high temperature.

Megistotherms, plants requiring extreme heat.

Meiostemonous or Mrostemonous, the stamens less in number than the parts of the corolla.

Membranaceous or Membranous, having the consistence, aspect, and structure of a membrane.

Meniscus, a lens having a concave and a convex face, with a sharp edge.

MERENChYMA, tissue composed of rounded cells.

Mericarp, single-seeded portion of a fruit composed of several monospermal carpels, which separate from each other when ripe; as in Borage, Labiata, and Umbellifera ; also the separate monospermal portion of a Lomentum.

MERITHAL, a term used in place of internode ; applied by Gaudichaud to the different parts of the leaf.

Mesocarp, middle covering of the fruit.

Mesochrifum, middle portion of the labellum of Orchids.

MEsophlqum, middle layer of the bark.

MesophYLLUM, the parenchyma of the leaf.

Mesos, the middle, in composition Meso.

Mesosperm, applied to a covering of the seed derived from the secundine.

Mesotherms, plants requiring a moderate heat,

METASPERMS, another name for Angiosperms.

METRE, equal to 39.37079 inches British.

Micrometer, instrument for measuring microscopic objects.

Micropyle, the opening or foramen of the seed.

Micros, small, in composition Micro.

MicrosporangIA, cells or thecr, containing microspores.

Microspores, small spores of Lycopods, producing antheridia.

Microtherms, plants requiring a small amount of heat.

Millimetre, equal to 0.03937079 English inch, or 25.39954 millimetres equal to an English inch.

MrTriform, shaped like a mitre, as the calyptra of some Mosses.

Molecule, an exceedingly minute body in which there is no obvious determinate external circle or internal centre.

Monadelphous, stamens united into one bundle by union of their filaments,

Monandrous, having one stamen.

Monembryony, having a single embryo.

MoNiliform, beaded, cells united, with interruptions, so as to resemble a string of beads.

MoNOCARPIC, producing flowers and fruit once during life, and then dying.

MONOCHLAMYDEOUS, flower having a single envelope, which is the calyx.
MONOCLINOUS, stamens and pistils in the same flower.

MONOCOTYLEDonous, having one cotyledon in the embryo.

Monocious, or Monorcous, stamens and pistils in different flowers on the same plant.

MONOGYNECIAL, applied to simple fruits, formed by the pistil of one flower.

Monogynous, having one pistil or carpel, also applied to plants having one style.

Monopetalous, same as Gamopetalous.

MONOPHYLlous, same as Gamophyllous.

Monos, one, in composition Mono and Mon, as Monandrozs, one stamen; sometimes applied to the union of parts into one, as Monopetalous, meaning combined petals; same as Latin Unus.

MonosePalous, same as Gamosepalous.

MONOSPERMOUS or MONOSPERMAL, having a single seed.

MONOTHECAL, having a single loculament.

Monstrosity, an abnormal development, applied more especially to double flowers.

MORPHOLOGY, the study of the forms which the different organs assume, and the laws that regulate their metamorphoses.

MUCRO, a stiff point abruptly terminating an organ; Mucronate, having a mucro.

Mucus, definite, peculiar matter forming a covering of certain seaweeds.

Mucticostate, many-ribbed.

MULTIFID, applied to a simple leaf divided laterally to about the middle into numerous portions ; when the divisions extend deeper it is Multipartite.

MULTILOCULAR, having many loculaments.

Multiple, applied to anthocarpous or polygynœcial fruits formed by the union of several flowers.

MURICATE, covered with firm, short points, or excrescences.

MURIFORM, like bricks in a wall ; applied to cells.

MusCology, the study of Mosses.

Muticus, without any pointed process or awn. Mrcelium, the cellular spawn of Fungi.

NAKED, applied to seeds not contained"in a true ovary; also to, flowers without any floral envelopes.

NAPIFORM, shaped like a turnip.

NATURALISED, originally introduced by artificial means, but become apparently wild.

Navicular, hollowed like a boat.

NECTARIFRROUS, having a honey-like secretion ; applied to petals having depressions or furrows at their base, which contain a sweet secretion.

NECTARY, any abnormal part of a flower. It ought to be restricted to organs secreting a honey-like matter, as in Crown Imperial.

NeMEE, from Nema, a thread, applied by Fries to cryptogams in allusion to the germination by a protruded thread, without cotyledons.

NerVation or Neuration, same as Venation.

NETTED, applied to reticulated venation; also covered with raised lines disposed like the threads of a net.

Nitidus, having a smooth and polished surface.

NODE, the part of the stem from which a leaf bud proceeds ; a joining. 
NoDose, having swollen nodes or articulations.

Nodulose, applied to roots with thickened knots at intervals.

Nosologx, vegetable, the study of the diseases of plants.

NotoRHIZE, radicle on the back of the cotyledons, as in some Crucifera.

NuCleus, the body which gives origin to new cells ; also applied to the central cellular portion of the ovule and seed.

Nuculanium, applied to the fruit of the Medlar having nucules; some also apply this term to the Grape.

Nucule, hard carpel in the Medlar, also one of the parts of fructification in Characere.

Nucumentaceous, Crucifera having a dry monospermal fruit.

NuT, properly applied to the glans, but also applied to any hard nut-like fruit, as in Carex and Rumex.

$\mathrm{OB}_{\mathrm{B}}$, in composition, means reversed or contrariwise.

OBCOMPRESSED, flattened in front and behind, not laterally.

OBCORDATE, inversely heart-shaped, with the divisions of the heart at the opposite end from the stalk.

OBLoNG, about $\frac{8}{4}$ as long as broad; elliptical, obtuse at each end.

OBovate, reversely ovate, the broad part of the egg being uppermost.

OBsolete, imperfectly developed or abortive : applied to the calyx when it is in the form of a rim.

OBruse, not pointed, with a rounded or blunt termination.

OBvolute, margins of one leaf alternately overlapping those of the leaf opposite to it.

OCHREA or OCREA, boot, applied to the sheathing stipule of Polygonacea.

OCTANDROUS, having eight stamens.

Oсто, eight, in composition $O c t$.

Octogynous, having eight styles.

CEcrum and Cerous, in composition, have reference to the position of the reproductive organs, as Androcium, the staminal organs; Diacious, stamen and pistil in different flowers.

OfFicinal, sold in the shops.

OFFSET, same as Propagulum.

Oleraceous, used as an esculent potherb.

OLIGANDROUS, stamens under twenty.

Oligos, few or in small number; in composition $O$ ligo and $O$ lig.

Oligospermous, plant having few seeds.

OMPHAzODE, the central point of the hilum, where the nourishing vessels enter.

Oogonia, equivalent to Archegonia in Fungi.

Oophoridium, organ in Lycopodiacea containing large spores.

OOSPORANGIA, spore-cases in some Algæ.

Oospore, a fertilised spore in Fungi.

OPaque, dull, not shining.

Operculum, lid, applied to the separable part of the theca of Mosses; also applied to the lid of certain seed-vessels; Operculate, opening by a lid.

OPPOSITE, applied to leaves placed on opposite sides of a stem at the same level.

ORBICULAR, rounded leaf with petiole attached to the centre of it.
OrGANOGENy, the development of organs, including their primitive condition and their gradual evolution.

ORGANOGRAPHY, the description of the organs of plants.

ORTHOPLOCE , Crucifera having conduplicate cotyledons.

ORTHOS, straight; in composition Ortho, same as Latin Rectus.

ORTHOSPERM its inner face.

ORTHOTROPAL and ORTHOTROPOUS, ovule with foramen opposite to the hilum; embryo with radicle next the foramen, and hence inverted.

Osmose, the force with which fluids pass through membranes in experiments on exos. mose and endosmose.

OVAL, elliptical, blunt at each end.

OVARY, the part of the pistil which contains the ovules.

Ovate, shaped like an egg, applied to a leaf with the broader end of the egg next the petiole or axis ; Ovate-lanceolate, a lanceolate leaf, which is somewhat ovate.

OVENCHYMA, tissue composed of oval cells.

OvuLE, the young seed contained in the ovary.

Pagina, applied to the surface of the leaf, or any fiat surface.

Palmontology, the study of Fossils,

PALEOPHYTOLOGY, the study of Fossil plants.

PaLATE, the projecting portion of the under lip of personate flowers.

PaLeA or PALE, the part of the flower of Grasses within the glume : also applied to the small scaly laminge which occur in the receptacle of some Composita.

PALEACEous, chaffy, covered with small erect membranous scales.

PALMATE and PALMATIFid, applied to a leaf with radiating venation, divided into lobes to about the middle.

Palmatipartite, applied to a leaf with radiating venation, cut nearly to the base in a palmate manner.

PANDURIForm, shaped like a fiddle, applied to an oblong leaf, with a sinus on each side about the middle.

PANICLE, inflorescence of Grasses, consisting of spikelets on long peduncles coming off in a racemose mannex.

Paniculate, forming a panicle.

PANSPERMISM, development of cells from germs introduced from the atmosphere.

PAPILIONACEOUS, corolla composed of vexillum, two ala, and carina, as in the Pea.

PAPILIATED and PAPILlose, covered with small nipple-like prominences.

Pappus, the hairs at the summit of the ovary or achene in Composita. They consist of the altered calyx. Pappose, provided with pappus.

Para, beside or in place of; often used in composition.

Paraphyses, filaments, sometimes articulated, occurring in the fructification of Mosses and other Cryptogams; also applied by some authors to abortive petals or stamens.

Parasite, attached to another plant, and deriving nourishment from it.

Parenchyma, cellular tissue. 
Parietal, applied to placentas on the wall of the ovary.

Pari-PinNate, a compound pinnate leaf, ending in two leaflets.

Parthenogrnesis, production of perfect seed with embryo, without the application of pollen.

Partite or Parted, cut down to near the base, the divisions being called Partitions.

Patella, rounded sessile apothecium of Lichens.

Patent, spreading widely.

PathologY, Vegetable, same as Nosology.

PATuLous, spreading less than when patent.

Pectinate, divided laterally into narrow segments, like the teeth of a comb.

Pedate and Pedatifid, a palmate leaf of three lobes, the lateral lobes bearing other equally large lobes on the edges next the middle lobe.

Pedicel, the stalk supporting a single flower; such a flower is Pedicellate.

$P$ EDUNCLe, the general flower-stalk or floral axis. Sometimes it bears one flower, at other times it bears several sessile or pediceilate flowers.

PrLagic, growing in many distant parts of the ocean.

Pellicle, the outer cuticular covering of plants.

PELoria, a name given to a teratological phenomenon, which consists in a flower, which is usually irregular, becoming regular; for instance, when Linaria, in place of one spur, produces five.

Pestate, shield-like, fixed to the stalk by a point within the margin; peltate hairs, attached by their middle.

Pendulous, applied to ovules which are hung from the upper part of the ovary.

Penicrllate, pencilled, applied to a tufted stigma resembling a camel-hair pencil, as in the Nettle.

Penni-nerved and Penni-veined, the veins disposed like the parts of a feather, running from the midrib of the leaf to the margin.

Penta, Pente, five; same as Quinque in Latin.

Pentagonal, with five angles having convex spaces between them.

Pentagynous, having five styles.

Pentamerous, composed of five parts ; a pentamerous flower has its different whorls in five, or multiples of that number.

Pentandrous, having five stamens.

Pentangular, with five angles and five flat faces between them.

Pero and Peponida, the fruit of the Melon, Cucumber, and other Cucurbitacez.

PrR, when placed before an adjective, sometimes gives it the value of a superlative, as perpusillzu, very weak; at other times it means through, as perfoliate, through the leaf.

Prrcurrent, running through from top to bottom.

Perennial, living, or rather flowering, for several years.

Perfoliatr, a leaf with the lobes at the base, united on the side of the stem opposite the blade, so that the stalk appears to pass through the leaf.
Peri, around ; in Latin, Circa.

Perianth, a general name for the floral envelope; applied in cases where there is only a calyx, or where the calyx and corolla are alike.

PERICARP, the covering of the fruit.

PERICHATIAL, applied to the leaves surrounding the fruit stalk or seta of Mosses.

Pericladium, the large sheathing petiole of Umbelliferæe.

Periclinium and Periphoranthium, the involucre of Compositz.

Periderm, a name applied to the outer layer of bark.

PERIDIUM, the envelope of the fructification in Gasteromycetous Fungi.

Perigone, same as Perianth. Some restrict the term to cases in which the flower is female or pistilliferous. It has also been applied to the involucre of Jungermanniex.

PERIGYNIUM, applied to the covering of the pistil in the genus Carex.

Perigvanous, applied to corolla and stamens when attached to the calyx.

Peripherical, applied to an embryo curved so as to surround the albumen, following the inner part of the covering of the seed.

PERISPERM, the albumen or nourishing matter stored up with the embryo in the seed.

PERISPORE, the outer covering of a spore; the mother-cell of spores in Algax.

Peristomatic, cells surrounding a stoma, as in Ceratopteris.

PERISTOME, the opening of the sporangium of Mosses after the removal of the calyptra and operculum.

Perithecium, a hollow conceptacle in Lichens, containing spores, and having an opening at one end.

Persistent; not falling off, remaining attached to the axis until the part which bears it is matured.

Personate, a gamopetalous irregular corolla having the lower lip pushed upwards, so as to close the hiatus between the two lips.

PERTUSE, having slits or holes.

PERUL Fe, the scales of the leaf bud.

Petaloid, like a petal.

Petals, the leaves forming the corolline whorl.

Petiolate, having a stalk or petiole.

Petrole, a leaf-stalk; Petiolule, the stalk of a leaflet in a compound leaf.

Phalanges, applied to stamens divided into lobes, like a partite or compound leaf.

Phanerogamous, having conspicuous fiowers.

Phaneros and PhenNos, conspicuous; in composition, Phanero and Phano.

Phenogamous, same as Phanerogamous.

PHLEBOIDAL, applied to moniliform vessels.

PhLeum, a name applied in composition to the bark.

Phoranthium, applied to the receptacle of Compositx.

PhORUS, PHORUM, and PhORE, in words derived from the Greek, are used as terminations, meaning, that which bears; equivalent to the Latin Ferus and Fer.

Phragma, transverse division or false dissepiment in fruits.

Phycochrome, colouring matter in Lichens and in the lower Alga.

Phycology, the study of Algz or Seaweeds. 
Phyllaries, the leaflets forming the involucre of Composite flowers.

Pryclodium, leaf-stalk enlarged so as to have the appearance of a leaf.

Phyllody, change of an organ into true leaves.

Phyllorv, like a leaf.

Phyllolobes, cotyledons green and leafy.

Phylzoptosis, the fall of the leaf.

Phyllotaxis, the arrangement of the leaves on the axis.

Phyllum, leaf, in composition Phyllo and Phyllous; in Latin Folium.

Physiognomy, general appearance, without reference to botanical characters.

PHYsiology, Vegetable, the study of the functions of plants.

Phytogenesis, the development of the plant.

Phytography, the description of plants.

Phytology, the study of plants.

Phyton, a name given by Gaudichaud to the simple individual plant, as represented by a leaf. In words derived from the Greek, Phyton and Phyto mean plant.

PrytozoA, moving filaments in the antheridia of Cryptogams.

Pileorhiza, a covering of the root, as in Lemna.

Pileus, the cap-like portion of the Mushroom, bearing the hymenium on its under side.

Pilose, provicled with hairs; applied to pappus composed of simple hairs.

Pinakenchyma, tissue composed of tabular cells.

Pin-eyed, applied to the flower of Primula, having long styles with stigma visible at the top of the floral tube.

PinNa, the leaflet of a pinnate leaf.

Pinnate, a compound leaf having leaflets arranged on each side of a central rib.

Pinnatifid, a simple leaf cut into lateral segments to about the middle.

Pinnatipartite, a simple leaf cut into lateral segments, the divisions extending nearly to the central rib.

Pinnules, the small pinna of a bipinnate or tripinnate leaf.

Pistil, the female organ of the flower, composed of one or more carpels; each carpel being composed of ovary, style, and stigma.

Pistillate, and Pistilliferous, applied to a female flower or a female plant.

Pistillidium, the female organ in Cryptogams.

PLACENTA, the cellular part of the carpel bearing the ovule.

Placentary, a placenta bearing numerous ovules.

Placentation, the formation and arrangement of the placenta.

Platys, large or broad; in composition Platy; in Latin Latzs and Late.

Pleion, several, in composition Pleio; in Latin Pluri.

Pleiotrachex, spiral vessels with several fibres united.

Plenus, when applied to the flower, means double.

Pleurenchyma, woody tissue.

Pleurocarpi, Mosses with the fructification proceeding laterally from the axils of the leaves.

Pleurorhize.te, Cruciferous plants having the radicle of the embryo applied to the edges of the cotyledons, which are called Accumbent.

Plicate and Plicative, plaited or folded like a fan.

Plumose, feathery, applied to hairs having two longitudinal rows of minute cellular processes.

Plumule, the first bud of the embryo, usually enclosed by the cotyledons.

PLURI in Latin words means several.

Plurilocular, having many loculaments.

PODETIUM, a stalk bearing the fructification in some Lichens.

PODOCARP, a stalk supporting the fruit.

PODOGYNiUm, a stalk supporting an ovary.

PoDOSPERm, the cord attaching the seed to the placenta.

POGON, beard; in Latin Barba.

POLlard-TREEs, cut down so as to leave only the lower part of the trunk, which gives off numerous buds and branches.

POLLEN, the powdery matter contained in the anther.

POLLEN-TUBE, the tube emitted by the pollengrain after it is applied to the stigma.

Pollinia, masses of pollen found in Orchids and Asclepiads.

Polyadelphous, stamens united by their filaments so as to form more than two bundles.

POLYANDROUS, stamens above twenty.

POLYCARPIC, plants which flower and fruit many times in the course of their life.

POLYCOTYLEDONOUS, an embryo having many cotyledons, as in Firs.

Polyembryony, having more than one embryo.

POL VGAMOUS, plants bearing hermaphrodite as well as male and female flowers.

PolygYNacial, applied to multiple fruits formed by the united pistils of many flowers.

Polygynous, having many pistils or styles.

POLYMORPHous, assuming many shapes.

Polvpetalous, a corolla composed of separate petals.

PoLYPHYLLOUS, a calyx or involucre composed of separate leaflets.

Polys, many, in composition Poly; in Latin Multus.

PolysEpalous, a calyx composed of separate sepals.

POLYSPERMAL, containing many seeds.

POME, a fruit like the Apple and Pear.

Pores of the leaf, same as Stomata.

Porous vessels, same as Pitted or Dotted vessels.

PORRECT, extended forwards.

Posterior, applied to the part of the flower placed next the axis; same as Superior.

Posticus, same as Extrorse; applied to anthers.

Poucr, the short pod or silicle of some Cruciferæ.

Pous, PoDos, a foot or stalk, in composition Podo; in Latin Pes, Pedis.

Preffloration, same as Atstivation.

PRferoliation, same as Vernation.

PREMORSE, bitten, applied to a root or rhizome terminating abruptly, as if bitten off.

PRICK LES, hardened epidermal appendages, of a nature similar to hairs.

PRIMINE, the outer coat of the ovule.

PRIMordial, the first true leaves given off by 
the young plant; also the first fruit produced on a raceme or spike.

Primordial UTRICLE, the lining membrane of cells in their early state.

Prismenchyma, tissue composed of prismatical cells.

Process, any prominence or projecting part, or small lobe.

Procumbent; lying on the ground.

Pro-EMbryo, cellular body in ovary, from which the embryo and its suspensor are formed. Sometimes Pro-embryo is used for Prothallus.

Proliferous, bearing abnormal buds.

Prolification, axis prolonged beyond the flower, bearing leaves, and ending in an abortive flower-bud; seen in Rose and Geum.

Prone, prostrate, lying flat on the earth.

Propagulum, an offshoot, or germinating bud attached by a thickish stalk to the parent plant.

ProsenCHYMA, fusiform tissue forming wood.

ProtandRous, or PROTERANDROUs, stamens reaching maturity before the pistil.

Prothallium, or Prothallus, names given to the first part produced by the spore of an acrogen in germinating.

Protogynous, or Proterogynous, pistil reaching maturity before the stamens.

Protoplasm, the matter which seems to be concerned in the early formation of nuclei and cells.

Pruinose, covered with a coarse granular secretion, as if dusted.

Pseudo, false; in Iatin, Spurius.

Pseudo-BuLB, the peculiar aerial stem of many epiphytic Orchids.

PseUdosPermous, applied to plants bearing single-seeded seed-vessels, such as Achenes, resembling seeds.

Pteridographia, a treatise on Ferns.

Pterocarpous, having winged fruit.

Pubescence, short and soft hairs covering a surface, which is hence called Pubescent.

Pulverulent, covered with fine powdery matter.

Pulvinate, shaped like a cushion or pillow.

Pulvinus, cellular swelling at the point where the leaf-stalk joins the axis.

Punctated, applied to the peculiar dotted woody fibres of Conifera.

Putamen, the hard endocarp of some fruits.

PYCNIDE, a papillaform or wart-like minute cellular reproductive body in the thallus of Lichens.

PYREN F, stony coverings of the seeds in the Medlar.

Pyridium, same as Pome.

Pyriform, pear-shaped.

Prxis and PYXIDIuM, a capsule opening by a lid.

QUADRT, in composition. means four times.

QUADRIFARIOUS, in four rows.

QUADRIFID, four-cleft, cut down into four parts to about the middle.

QUADRIJUGATE, having four pairs of leaflets.

QUADRILOCULAR, having four loculaments.

QUADRIPARTITE, divided deeply into four parts.

QUARTINE, the fourth coat of the ovule, which often is changed into albumen.
QUATERNATE, leaves coming off in fours from one point.

QUINARY, composed of five parts, or of a multiple of five.

QUINATE, five leaves coming off from one point.

Quincunx, when the leaves in the bud are five, of which two are exterior, two interior, and the fifth covers the interior with one margin, and has its other margin covered by the ex terior. Quincuncial, arranged in a quincunx.

QUINQUE, in compound words means five.

QUINQUEFID, five-cleft, cut into five parts as far as the middle.

QUINQUELOCULAR, having five loculaments.

QUINQUEPARTITE, divided deeply into five parts.

Quintine, the fifth coat of the ovule, otherwise called the embryo-sac.

RACE, a permanent variety.

RACEME, cluster, inflorescence in which there is a primary axis bearing stalked flowers.

RACEMOSE, flowering in racemes.

RACHIS, the axis of inflorescence; also applied to the stalk of the frond in Ferns, and to the common stalk bearing. the alternate spikelets in some Grasses.

RADIANT, applied to flowers which form a raylike appearance, as seen in Umbellifere and in Viburnum, etc.

RADIATE, disposed like the spokes of a wheel : also applied to the florets of the ray or circumference of the capitula of Compositx.

RADICAL, belonging to the root, applied to leaves close to the ground, clustered at the base of a flower stalk.

RADICLE, the young root of the embryo.

RADIUS, the ray or outer part of the heads of Composite flowers.

RAMAL, belonging to the branches.

RAMENTA, the scales or chaff of Ferns.

RAMOSE and RAMOUS, branched.

RAPHE, the line which connects the hilum and the chalaza in anatropal ovules.

RAPHIDES, crystals found in cells, which are hence called Raphizias.

RECEPTACLE, the flattened end of the peduncle or rachis, bearing numerous flowers in a head ; applied also generally to the extremity of the peduncle-or pedicel.

RECLINATE, curved downwards from the horzontal, bent back up.

RECTEMBRYEE, the embryo straight in the axis of the seed.

RECTINERVIS and RECTIVENIUS, straight and parallel veined.

RECTISERLAL, leaves disposed in a rectilinear series.

RECURVED, bent backwards.

REDUPLICATE, edges of the sepals or petals turned outwards in astivation.

REgMA, seed-vessel composed of elastic cocci, as in Euphorbia.

REGULAR, applied to an organ the parts of which are of similar form and size.

RELIQUIA, remains of withered leaves attached to the plant.

RENIFORM, in shape like a kidney. .

REPA ND, having a slightly undulated or sinuous margin. 
Replum, a longitudinal division in a pod, formed by the placenta, as in Crucifera.

Resupinate, inverted by a twisting of the stalk.

RETiculated, netted, applied to leaves having a network of anastomosing veins.

ReTiForm, like network.

ReTrinaculum, the glandular viscid portion at the extremity of the caudicle in some pollinia.

RETINERYIS and RETIVENIUs, having reticulated veins.

RETRORSE, turned backwards.

RexUSE, when the extremity is broad, blunt, and slightly depressed.

Revolute and Revolutive, leaf with its edges rolled backwards in vernation.

RHrza, in words derived from the Greek, means root.

RHıANTH, same as Rhizogen.

RHIzOCARP, applied̦ to Marsilea, as producing spore-cases on root-like processes.

RHIzOGEN, a name applied to such plants as Rafflesia, which consist of a flower and root only.

RHizome, a stem creeping horizontally, more or less covered by the soil, giving off buds above and roots below.

RHizoTAXis, the arrangement of the roots.

RHomвoID, quadrangular form, not square, with equal sides.

RICTUS, the throat or chink in personate flowers.

RINGENT, a labiate flower, in which the upper lip is much arched.

ROOT-5TOCK, same as Rhizome.

RosAcEous, applied to corollas having separate sessile petals like the Rose.

RosetTE, leaves disposed in close circles forming a cluster.

Rostellum, a peculiar body in Orchids, often cup-shaped, bearing the glands of the pollenmass, with its viscid balls attached.

ROSTRATE, beaked, having a long sharp point.

Rotate, a regular gamopetalous corolla with a short tube, the limb spreading out more or less at right angles.

Rotation or GYration, a peculiar circulation of the cell sap, seen in Hydrocharidacea, Characex, etc.

RUDIMENTARY, an organ in an abortive state, arrested in its development.

Rugose, wrinkled.

RUMiNATE, applied to mottled albumen.

Runcinate, a pinnatifid leaf with a triangular termination and sharp divisions pointing downwards, as in Dandelion.

RunNer, a prostrate shoot rooting at the end; a stoton.

SACCATE, forming a sack or bag, seen in some petals.

SaGitTATE, like an arrow, a leaf having two prolonged sharp-pointed lobes projecting downwards beyond the insertion of the petiole.

SAIVER-SHAPED. See Hypocrateriform.

SAMARA, a winged dry fruit, as in the Elm.

SARCOCARP and SARCODERM, the mesocarp of the fruit, having become succulent.

SARCoLOBEA, cotyledons thick and fieshy, as in Bean and Pea.

SARMENTUM, sometimes meaning the same as
Flagellum, or runner, at other times applied to a climbing stem which supports itself by means of others, as in Vine.

SCABROUS, rough, covered with yery stiff short hairs; Scabrizsculus, somewhat rough.

SCALARIFORM, vessels having bars like a ladder, seen in Ferns.

Scandent, climbing by means of supports, as on a wall or rock.

SCAPE, a naked flower-stalk, bearing one or more flowers arising from a short axis, and usually with radical leaves at its base.

Scarious, having the consistence of a dry scale, membranous, dry, and shrivelled.

SCHIzocaRP, dry seed-ressel splitting into two or more I-seeded mericarps.

ScIon, the young twig used as a graft.

SCLEROGEN, the thickening matter of woody cells.

SCOBIFORM, in the form of filings, or like fine sawdust.

SconinA, the flexuose rachis of some Grasses.

SCORPIOIDAL, like the tail of a scorpion, a peculiar twisted cymose inflorescence, as in Boraginacea.

SCORPIOID CYME, flowers arranged alternately or in a double row along one side of a false axis, the bracts forming a double row on the other side; bracts often wanting.

SCROBICULATE, pitted, having small !depressions.

Scutellate, like a shield.

Scutelum, a sort of apothecium in Lichens.

SECUND, turned to one side.

SECUNDINE, the second coat of the ovule within the primine.

SEGREGATE, separated from each other.

Self-Fertilisation, pistil fertilised by the pollen of the stamens in the same flower.

SEMI, half, same as the Greek Hemi.

Semiflosculous, same as Ligulate.

SEMINAL, applied to the cotyledons, or seedleaves.

SEPAL, one of the leaflets forming the calyx.

SEPTATE, divided by septa or partitions.

SEPTEM, seven, in Greek Heptr.

SEPTENATE, organs approaching in sevens; a compound leaf with seven leaflets coming off from one point.

SEPTICIDAL, dehiscence of a seed-vessel through the septa or edges of the carpels.

SEPTIFRAGal, dehiscence of a sseed-vessel through the back of the loculaments, the valves also separating from the septa.

SEPTULATE, having spurious transverse dissepiments.

SEPTUM, a division in an ovary formed by the sides of the carpels.

Sericeous, silky, covered with fine, closepressed hairs.

SERRATE or SERRATEd, having sharp processes arranged like the teeth of a saw. Biserrate, when these are alternately large and small, or where the teeth are themselves serrated.

Serratures, pointed marginal divisions arranged like the teeth of a saw.

SERRULATE, with very fine serratures.

SESQU, in composition, means one and a half.

SESsILE, without a stalk, as a Ieaf without a petiole.

SETA, a bristle or sharp hair ; also applied to the gland-tipped hairs of Rosacere and 
Hieracia; and to the stalk bearing the theca in Mosses.

Setaceous and Setiform, in the form of bristles,

Setigerous, bearing seta.

Setose, covered with setr.

SEx, in Latin, six ; same as Greek Hexa.

Sheatr. See Vagina.

Silicula or Silicie, a short pod with a double placenta and replum, as in some Crucifera.

Siliculose, bearing a silicula.

Siliqua, a long pod similar in structure to the sílicula.

Siliquaform, fruit like a siliqua in form.

Siziquos.e, bearing a siliqua.

Simple, not branching, not divided into separate parts; Simple fruits are those formed by one flower.

Sinistrorse, directed towards the left.

SINUATED, the margin having numerous large obtuse indentations.

Sinuous, with a wavy or flexuous margin.

SIASHED, divided by deep and very acute incisions.

SOBOLES, a creeping underground stem.

Social Plants, such as grow naturally in groups or masses.

Soredia, powdery cells on the surface of the thallus of some Lichens.

Sorosis, a compound or polygynocial succulent fruit, such as Breadfruit and Mulberry; also applied by some to the fructification in Alaria, containing pyriform stipitate spores.

SoRUS, a cluster of sporangia in Ferns ; applied also to fructification in Alaria, containing pyriform stipitate spores.

SPADIX, a succulent spike bearing male and female flowers, as in Arum.

SPATHACEOUS, having the aspect and membranous consistence of a spathe.

SPATHE, large membranous bract covering numerous flowers.

SPATHELlfe, another name for the glumella of Grasses.

Spathulate, shaped like a spathula, applied to a leaf having a linear form, enlarging suddenly in to a rounded extremity.

Spawn, same as Mycelizum.

SPeCific Character, the essential character of a species.

Spermatia, motionless spermatozoids in the spermogones of Lichens and Fungi.

SPERMATozolds, moving filaments contained in the antheridia of Cryptogams; called also phytozoa and antherozoids.

Spermoderm, the general covering of the seed. Sometimes applied to the episperm or outer covering.

SPERMOgOne, a microscopic conceptacle in Lichens, containing reproductive bodies called Spermatia; also a conceptacle containing fructification in Fungi.

SPHAERAPHIDES, globular clusters of raphides, as in Ficus.

SPHARENCHYMA, tissue composed of spherical cells.

SPIKE, inflorescence consisting of numerous flowers sessile on an elongated axis.

SPIKELET, small cluster of flowers in Grasses.

SPINE or THORN, an abortive branch with a hard sharp point.

SPIN ESCENT or SpINOSE, bearing spines.
Spiral Vessels or Spiroidea, having a spiral fibre coiled up inside a tube.

SPIRILlum, same as Spermatozoid.

SPIROLOBEA, Crucifera having the cotyledons folded transversely, the radicle being dorsal.

SPONGIOLE or SPONGELET, the cellular extremity of a young root.

Sporadic Plants, confined to limited localities.

SPORANGIUM, a case containing spores.

SPORE, a cellular germinating body in Cryptogamic plants.

SPORIDIUM, a cellular germinating body in Cryptogamics containing two or more cells in its interior.

SPOROCARP, the involucre or ovoid-sac containing the organs of reproduction in Marsileacea.

SPOROPHORE, a stalk supporting a spore.

SPOROPHORES, filamentous, processes supporting spores in Fungi.

SPOROZOID, a moving spore furnished with cilia or vibratile processes.

Spur, same as Calcar.

SQUAMA, a scale ; also applied to bracts on the receptacle of Compositæ, to bracts in the inflorescence of Amentiferæ, and to the lodicula of Grasses.

SouAmose, covered with scales.

SQUARROSE, covered with processes spreading at right angles or in a greater degree.

STACHYS and STACHYA, in Greek words signify a spike.

STAMEN, the male organ of the flower, formed by a stalk or filament and the anther containing pollen.

Staminate and Staminiferous, applied to a male flower, or to plants bearing male flowers.

Staminodium, an abortive stamen.

STAMINODY, change of an organ into stamens.

STANDARD, same as Vexillum.

STELlATE or STElifForM, arranged like a star.

STERIGMATA, cells bearing naked spores; also cellular filaments bearıng spermatia and stylospores, in the Spermogones and Pycnides of Lichens.

STERILE, male flowers not bearing fruit.

STICHIDIA, pod-like receptacles containing spores.

STICHOUs at the termination of words means a row, as distichous, in two rows.

STIGMA, the upper cellular secreting portion of the pistil, uncovered with epidermis; Stigmatic, belonging to the stigma.

STIMULUs, a sting, applied to stinging hairs with an irritating secretion at the base.

STipe, the stem of Palms and of Tree-ferns ; also applied to the stalk of Fern-fronds, and to the stalk bearing the pileus in Agarics.

STIPEL, a small leaflet at the base, of the pinnæ or pinnules of compound leaves.

Stipitate, supported on a stalk.

STIPUlary, applied to organs occupying the place of stipules, such as tendrils.

STIPUlate, fumished with stipules.

STIPULE, leaflet at the base of other leaves, having a lateral position, and more or less changed either in form or texture.

STOLON, a sucker, at first aerial, and then turning downwards and rooting. 
Stolonifarous, having creeping runners which root at the joints.

STOoL, a plant from which layers are propagated, by bending down the branches so as to root in the soil.

Stomates and Stomata, openings in the epidermis of plants, especially in the leaves.

Strangulated, contracted and expanded irregularly.

STRAP-SHAPED, same as Ligulate; linear, or about six times as long as broad.

STRIA, a narrow line or mark.

STRIATEd, marked by streaks or stria.

STRIgosE, covered with rough, strong, adpressed hairs.

STRIPES, a name given to the Vitta of Unbelliferz.

STrobilus, a cone, applied to the fruit of Firs as well as to that of the Hop.

STROPHIOLE, a sort of aril or swelling on the surface of a seed.

STRUMA, a cellular swelling at the point where a leaflet joins the midrib; also a swelling below the sporangium of Mosses.

STUPOSE, having a tuft of hairs.

STYLE, the stalk interposed between the ovary and the stigma.

STylopoD, an epigynous disk seen at the base of the styles of Umbelliferz.

STYLOSPORE, a spore-like body borne on a sterigma or cellular stalk, in the Pycnides of Lichens.

SuB, in composition, means a near approach to, as sub-rotund means nearly round.

Suberous, having a corky texture.

Subiculum, same as Hypothallis.

Subterranean, underground, same as $\mathrm{Hy}$ pogeal.

Subulate, shaped like a cobbler's awl.

Succisus, abrupt, as it were cut off, same as Premorse.

Suffruticose, having the characters of an undershrub.

SulCaTE, furrowed or grooved.

Superior, applied to the ovary when free from the calyx; to the calyx when it is attached to the ovary; to the part of a flower placed next the axis.

Supervolute or Supervolutive, a leaf rolled upon itself in vernation.

Surculus, a sucker, a shoot thrown off underground, and only rooting at its base.

SUSPENDED, applied to an ovule which hangs from a point a little below the apex of the ovary.

SusPENSOR, the cord which suspends the embryo, and is attached to the radicle in the young state.

Sutural, applied to that kind of dehiscence which takes place at the sutures of the fruit.

Suture, the part where separate organs unite, or where the edges of a folded organ adhere; the ventral suture of the ovary is that next the centre of the flower; the dorsal suture corresponds to the midrib.

Syconus, a multiple or polygynocial succulent hollow fruit, as in the Fig.

SymBols. Seep. 412.

SYMmetRy, applied to the flower, has reference to the parts being of the same number, or multiples of each other.

SYN, in composition, means united.
SYNACME, stamens and pistils reaching maturity at the same time.

Syna N THERous, anthers united.

SYNanthos, flowers united together.

SYNCARPoUs, carpels united so as to form one ovary or pistil.

SYNGENESIOUS, same as Synantherous.

SYNOCHREATE, stipules uniting together on the opposite side of the axis from the leaf.

SYNSPOROUs, applied to Algæ which propagate by conjugation of cells.

TAPHRENCHYMA, pitted vessels, same as $B$ othrenchyma.

TAP-ROOT, root descending deeply in a tapering undivided manner.

TAXONOMY, principles of the classification of plants.

TEGMEN, the second covering of the seed, called also Endopleura.

Tegmenta, scales protecting buds. .

Tendril. See Cirrus.

TERATOLOGY, study of monstrosities and peculiar morphological changes.

Tercine, the third coat of the ovule, forming the covering of the central nucleus.

TERETE, nearly cylindrical, somewhat tapering into a very elongated cone, the transyerse section nearly circular.

TERNARY, parts arranged in threes.

TERnate, compound leaves composed of three leaflets.

TESTA, the outer covering of the seed; some apply it to the coverings taken collectively.

TESTICULATE, root having two oblong tubercules.

TETRA, in Greek words four ; in Latin Quater or Quadri.

Tetradynamous, four long stamens and two short, as in Crucifera.

Tetragonous, or Tetragonal, having four angles, the faces being convex.

Tetragynous, having four carpels or four styles.

Tetramerous, composed of four parts; a flower is tetramerous when its envelopes are in fours, or multiples of that number.

TETRANDRous, having fout stamens.

TETRAPTEROUS, having four wings.

TETRAqueTrous, having four angles, the faces being concave.

Tetraspore, a germinating body in Alga composed of four spore-like cells; but also applied to those of three cells.

TETRATHECAL, having four loculaments.

Thalamifloral, parts of the floral envelope inserted separately into the receptacle of thalamus.

Thalamus, the receptacle of the flower, or the part of the peduncle into which the floral organs are inserted.

Thallogens or Thallophytes, plants producing a thallus.

Trallus, cellular expansion in Lichens and other Cryptogams, bearing the fructification.

THECA, sporangium or spore-case containing spores.

THECAPHORE, a stalk supporting the ovary.

ThECASPOROUS, applied to Fungi which have the spores in thecr.

THORN, an abortive branch with a sharp point.

THROAT, the orifice of a gamopetalous flower. 
THRUM-Eyed or THumb-EYED, flowers having short styles, where the stigma does not appear at the upper part of the tube of the corolla, as in Primula.

THYrsus, a sort of panicle, in form like a bunch of grapes, the inflorescence being definite.

TIGellus, the young embryonic axis.

ToIse is equal to 1.94904 metres or 6.39459 English feet.

Tomkntose, covered with cottony, entangled pubescence, called tomentzm.

TORULOSE, presenting successive rotinded swellings, as in the moniliform pods of some Cruciferze.

Torus, another name for thalamus ; sometimes applied to a much-developed thalamus, as in Nelumbium.

TRACHE.E, a name for spiral vessels.

Trachenchyma, tissue composed of spiral vessels.

Transpiration, the exhalation of fluids by leaves, etc.

Trers, three ; Tris, thrice, in composition Tri.

TRIADELPHOUS, stamens united in three bundles by their filaments.

TRIANDROUS, having three stamens.

TRIANGULAR, having three angles, the faces being flat.

TrichOHHORE, cellular body supporting the Cystocarp in some Floridex.

Trichogynum, a hair-like process in Floridere, surmounting a cell, which after fertilisation becomes a cystocarp.

TRICHотоMоUS, divided successively into three branches.

Tricoccous, formed by three elastic monospermal carpels.

TricostaTE, three-ribbed, ribs from the base.

Tricuspidate, having three long points or cuspides.

Tridentate, having three teeth.

TRIFarious, in three rows, looking in three directions.

TRIFID, three-cleft, a leaf divided into three segments which reach to the middle.

TRIFOLIATE or TRIFOLIOLATE, same as Ternate. When the three leaves come off at one point the leaf is ternately-trifoliolate; when there is a terminal stalked leaflet and two lateral ones it is pinnately-trifoliolate.

Trigonous, having three angles, the faces being convex.

TRIGXNous, having three carpels or three styles.

TRIJUGATE, having three pairs of leaflets.

Trilocular, having three loculaments.

Trimerous, composed of three parts ; a trimerous flower has its envelopes in three or multiples of three.

TrimorpHIC, three forms of flowers in one species, each on a different plant, and having stamens and pistil ; there are three lengths of stamens, of which two lengths are in each flower; and there are three lengths of styles differing in each form of flower, not associated with stamens of corresponding length.

Trinervis, having three ribs springing together from the hase.

Triacious, or Triolcous, a species producing

" hermaphrodite, staminate, and pistillate flowers on three separate individuals.

Trideciousl $y$-Hermaphrodite, same as Trimorphic.
Tripartitr, deeply divided into three

TRIPINNATE, a compound leaf three times divided in a pinnate manner.

Tripinnatifid, a pinnatifid leaf with the segments twice divided; in a pinnatifid manner.

Triplicostate, three ribs proceeding from above the base of the leaf.

Triquetrous, having three angles, the faces being concave.

TRISTICHOUs, in three rows.

TRITERNATE, three times divided in a ternate manner.

Trophosperm, a name for the placenta.

TrunCATE, terminating abruptly, as if cut off at the end.

TrYMA, drupaceous fruit like the Walnut; a superior $x$-celled $\mathbf{r}$-seeded fruit, with a coriaceous or fleshy epi- and mesocarp; a stony 2-valved endocarp with partitions on inner concave surface, as in Walnut.

Tuber, a thickened underground stem or branch, as the potato.

TuBERCULE, the swollen root of some terrestrial Orchids.

TUBerous, applied to roots in the form of tubercules.

TUBULAR, applied to the regular florets of the Compositz.

TubUlar-BELL-Shaped, applied to a campanulate corolla, which is somewhat tubular in its form.

TUNrCATED, applied to a bulb covered by thin external scales, as the Onion.

TURBINATE, in the form of a top.

Turio, a young shoot covered with scales sent up from an underground stem, as in Asparagus.

TYLOSIS, development of irregular cells in the interior of pitted vessels, seen in many exogenous trees, as Walnut, Oak, and Elm.

TyPE, the perfect representation or idea of any" thing.

TYPICAL, applied to a specimen which has eminently the characteristics of the species, or to a species or genus characteristic of an order.

UMBEL, inflorescence in which numerous stalked flowers arise from one point.

UMBELLULE, a small umbel, seen in the compound umbellate flowers of many Umbellifere:

UMBILICATE, fixed to a staik by a point in the centre.

Umarlcus, the hilum or base of a seed.

UMBO, a conical protuberance on a surface.

UMBONATE, round, with a projecting point in the centre, like the boss of an ancient shield.

UMBRACULIFEROUS, in the form of an expanded umbrella.

UNCINATE, provided with an uncus or hooked process.

UNDECIM, eleven; in Greek, Endeca.

UNGUIS, claw, the narrowed part of a petal ; such a petal is called Unguiculate.

UNI, in composition, one, same as Greek $M o n o$.

UNICELLULAR, composed of a single cell, as some Alga.

UNILATERAL, arranged on one side, or turned to one side.

UNILOCULAR, having a single loculus or cavity.

UNIPAROUS, a cymose inflorescence in which the primary axis produces one bract, and 
from the axil of this a second axis arises, and so on in succession; a false axis is thus formed.

UnIPARous, scorpioidal cyme. See Scorpioid.

UNISEXUAL, of a single sex, applied to plants having separate male and female flowers.

URCEOLATE, urn-shaped, applied to a gamopetalous globular corolla, with a narrow opening.

Ustulate, blackened.

UTRICLE, a name for a thin-walled cell, or for a bladder-like covering.

UTRICULUS, applied to a kind of fruit like the achene, but with an inflated covering; also to the persistent confluent perigone of Carex: in Algae applied to a loose cellular envelope containing spores.

VAGrNA, sheath, lower sheathing portion of some leaves.

VALLECULA, an interval between the ribs on the fruit of Umbellifera.

VALVATE, opening by valves, like the parts of certain seed-vessels, which separate at the edges of the carpels.

VALVATE Astivation, when leaves in the flower-bud are applied to each other by their margins only.

Valvate Vernation, when leaves in the Jeaf-bud are applied to each other by their margins only.

VALves, the portions which separate in some dehiscent capsules. A name also given to the parts of the flower of grasses.

VASCULAR IISSUE, composed of spiral vessels and their modifications.

VASIFORM Tissue, same as Dotted vessels.

VErNs, bundles of yessels in leaves.

VELUM, veil, the cellular covering of the gills of an Agaric in its early state.

VELUTINOUS, having a velvety appearance.

VENATION, the arrangement of the veins.

VENTRAL, applied to the part of the carpel which is next the axis.

VENTRICOSE, swelling unequally on one side.

VERMICULAR, shaped like a worm, or having worm-like movements.

VERNATION, the arrangement of the leaves in the bud.

VERRUCOSE, covered with wart-like excrescences.

VERSATILE, applied to an anther which is at- tached by one point of its back to the filament, and hence is very easily turned about.

VERTICLL, a whorl, parts arranged opposite to each other at the same level, or, in other words, in a circle round an axis. The parts are said to be Verticillate.

VERTICILLASTER, a false whorl, formed of two nearly sessile cymes placed in the axils of opposite leaves, as in Dead-nettle.

VESICLE, another name for a cell or utricle.

Vessels, tubes with closed extremities.

VEXILLARX, applied to astivation when the vexillum is folded over the other parts of the flower.

VEXILIUM, standard, the upper or posterior petal of a papilionaceous flower.

VigINTI, twenty, same as Greek Icosi.

VILLOUS, covered with long soft hairs, and having a woolly appearance.

VIRGATE, long and straight like a wand.

Viscous, clammy, like bird-lime.

VITelies, the embryo-sac when persistent in the seed.

VIITA, cells or clavate tubes containing oil in the pericarp of Umbelliferæ.

VIviparous, plants producing leaf-buds in place of fruit.

VoLUBILE, twining, a stem or tendril twining round other plants.

Volva, wrapper, the organ which encloses the parts of fructification in some Fungi in their young state.

WhoRLED, same as Verticillate.

WINGS, the two lateral petals of a papilionaceous flower, or the broad flat edge of any organ.

XANTHOPHYLL, yellow colouring matter in plants.

XANTHos, yellow, in composition Xantho.

Xerophllovis, plants requiring a hot and dry climate.

XYLEM, woody tissue.

XYLOCARPOUS, fruit which becomes hard and woody.

Zoophilous, applied to plants which are fertilised by the agency of insects.

ZOOSPORE, a moving spore provided with cilia ; called also Zoosperm and Sporozoid.

ZYGOSPORE, compound spore formed by conjugating cells in Fungi.

ZoothecA, a cell containing a spermatozoid. 


\section{ABBREVIATIONS AND SYMBOLS.*}

THE names of Authors are abridged in Botanical works by giving the first letter or syllable, etc.-Thus, L. stands for Linneus ; DC. for De Candolle; Br, for Brown; Lam. and Lmk. for Lamarck ; Hook. for Hooker ; Hook. fll. for Hooker junior ; Lindl. for Lindley; Arn. for Arnott; H. and B. for Humboldt and Bonpland; H. B. and K. for Humboldt, Bonpland, and Kunth; W. and A. for Wight and Arnott; Benth. for Bentham; Berk. for Berkeley; Bab. for Babington, etc.

The Symbol 00 or 00 means an indefinite number; in the case of stamens it means above 20 .

$\odot$ means Monocarpic, flowering and fruiting once during life; duration uncertain.

(1) or A. means a Monocarpic annual plant; flowering and fruiting within the year and then dying.

$\delta \odot \odot \odot(2)$ or $B$. means a biennial plant; flowering and fruiting in the second year.

If $\triangle$ or P. means a perennial plant; Rhizocarpic.

5 means a woody plant. $\overline{5}$ means an undershrub.

$\mathbf{b} 5$ or Sh. means a shrub; 5 means a Tree under 25 feet; T. or 5 a Tree above 25 feet.

- means a climber;) turning to the left; (turning to the right.

$0=$ Cotyledons accumbent, radicle lateral ; Pleurorhizex.

O $\|$ Cotyledons incumbent, radicle dorsal; Notorhizex.

$O \gg$ Cotyledons conduplicute, radicle dorsal ; Orthoploceæ.

O \| \| Cotyledons plicate or folded, radicle dorsal; Spirolobeæ.

O || || || Cotyledons biplicate or twice folded, radicle dorsal; Diplecolobeæ.

$\Varangle$ Hermaphrodite flower, having both stamens and pistil.

† Male, staminiferous, staminate, or sterile flower.

ㅇ Fernale, pistilliferous, pistillate, or fertile flower.

$\delta$ o Unisexual species, having separate male and female flowers.

t-o Moncecious species, having male and female flowers on the same plant.

む: 9 Diccious species, having male and female flowers on different plants.

$\not \nmid \delta$ ㅇ Polyganous species, having hermaphrodite and unisexual flowers on the same or different plants.

! Indicates certainty as to a genus or species described by the author quoted.

$?$ Indicates doubt as to the genus or species.

O Indicates absence of a part.

v. $v . s p$. or $v . v$. Vidi vivam spontaneam, indicates that the author has seen a living native specimen of the plant described by him.

v. v. . Vidi vivam cultam, indicates that he has seen a living cultivated specimen.

v. $s . s p$. or $v$. s. Vidi siccam spontaneam, indicates that he has seen a dried native specinen.

v. s. v. Vidi siccam cultarn, indicates that he has seen a dried cultivated specimen.

$v$, in $h$. Vidi in Herbario; seen in Herbarium.

* For further remarks on Abbreviations and Symbols, see page 412. 


\section{IN D E.X.}

Abaxile or abaxial, |Acotyledons, root of, Agathotes, $54^{\circ}$ 34I

Abbattichim, 495

Abbreviations and symbols, 4I2, 830

Abele, 592

Aberia, $44^{\circ}$

Abies, 599

Abietinea, 597 region of, 676

Abietites, $75^{\circ}$

Abiogenesis, 15

Abnormal roots, 39

Abolboda, 619

Abruptly pinnate, 93

Abrus, 479

Absinthium, 52T

Absorption of fluids, I2I, I24, 142

Acacia, 96,482

Acalypha, 580

Acanthacea, 556

Acanthodium, 556

Acanthus, $55^{6}$

Acaules, 44

Acclimatising, 7 I 6

Accrescent, 200

Accumbent, II2, 340

Aceracez, 458

Achanium, 309

Achimenes, 54

Achlamydea, 560

Achlamydeous or naked flowers, Ig2, $3^{6} 7$

Achlya, 272, 655

Achras, 53I

Achromatic, 763

Achu, 628

Acicular, 88

Acids, Organic, I7o

Acinaciform, go

Aconite, fruit of, $3^{\text {I2 }}$

Aconitum, 427

Acorex, 625

Acorn, 3 II

Acorus, 625

Acotyledonous, 334

Acotyledonous germination, 357

embryo, 265, 335, 362

Acotyledons, 635

- leaves of, IOI

- phyllotaxis of, 107
43 spore of, 334 symmetry in, $3^{6} 5$

Acrobrya, 70,635

Acrocarpi, 643

Acrocomia, 62a

Acrogenous or Acoty

ledonous stem, 70

Acrogens, 635

- course of sap in, $\mathrm{I}_{4} 8$

Actæa, 427

Actinenchyma, 4

Aculei, 32

Acuminate, 89

Adam's Necdle, 6r5

Adansonia, 449

Adanson's floral region, 685

Adder's Tongue, $6_{39}$

Adherent, $98,224,246$

Adhesion, 98, I73, $365,3^{6} 9$

Adiantum, 639

Adnate, 98, 224

Adoxa, 5 I

Adventitious, II6

Adventitious root, 39 , 336

Acrdium, 649

Egle, 455

Aerial leaf-buds, 1 I 4

Aerial root, $3^{8}$

Asculus, 459

Astivation, 193

Atheogame, $6_{35}$

Athiopian Lily, 625 Pepper, $43^{\circ}$

Ethophyllum, 747

Ethusa, 508

Affinity, 674

Africa Northern, flora of, $68_{5}$

South, flora of, 689

- Tropical, fora of, 685

Agallochum, 572

Agamous, 2 22

Agar-agar, 655 scent, $3^{8} \mathrm{~g}$

Agaricus, 649

Agathophyllum, 569
Agarics, phosphore-

Alhenna, 487
Agave, 6r I

Agavex, 6rx

Age of trees, 360

Agelaea, 476

Aggregate fruits, 3 Io

Agrarian region in Britain, $7 \pi_{3}$

Ahalim and Ahaloth, 572

Air-cells, I3

Air in germination, 345

Air-plants, I27, I4I, 613

Aizoon, 500

Ajowan, 508 .

Alabastrus, I93

lae or wings, 205

Alangiacex, 510

Alaria, 655

Albumen, 327, 33 I

Albumin, vegetable, I66

Albuminous, 332

Alburnum, 55

Alder, 593

Aldrovanda, 44I

Alethopteris, 745

Aleurites, 582

Alfonsia, 626

Alga, 652

Algae of the chalk, 75 I

A. ga, reproduction of, 269

Algaroba Bean, $48 \mathrm{I}$

Algum - trees, 480 , 574 .

Alhagi, 470

Alismacez, 623

Alkaloids, I7o

Allamanda, 537

Alliea, $6 r_{4}$

Alligator pear, 569

Allium, 6I5

Allon, 595

Allspice, 487,492

Almond, 312, 485

Almug-tree, 480,574

Alnus, 593

Aloes, 6 r 5

Aloes-wood, $57^{2}$

Aloinea, 6x4

Aloysia, 555

Alpine-Arctic flora,
Alpine plants of Britain, their limits, 712 vegetation of Great Britain, 707

- travelling, preparation for, 804

- vegetation, zones of $6 g^{8}$

Alpinia, $6 \circ 6$

Alps, Maritime, range of trees on, 697

Alsinaceous corolla, 205

Alsinea, 445

Alsodea, 440

Alsodeia, 44 I

Alstonia, 537

Alströmeria, 6r I

Alternate, $\mathrm{IO}_{3}$

Alternately-pinnate, 93

Alternation of parts of flowers, 192

Altingiacea, 504

Altitudinal range of vegetation, 698

Alumina in soils, 135

Amadou, 650

Amanita, 649

$\Lambda$ marautacea, fruit of $3 \mathrm{TO}$

Amaranthacea, 562

Amaranthus, 562

Anaryllidacea, 6 I I

Amber, 754

Amboyna Pitch-tree, 599

Ambrina, 563

Amenta, Igo

Amentifera, fossil, $75^{8}$

Amentum, I78

American Aloe, 6 ri

Amherstia, $47^{8}$

Ammi, 508

Ammonia, source of nitrogen, I27

Ammoniac, 507

Ammoniacal manures, I37

Ammophila, 632

Amnios, 253, 326

Amomum, 605

Ampelidea, 460

Ampelopsis, 462

Amphigamz, 644

Amphitropal, 256, 342 
Ampulla, 38, 100 Amygdalea, 483

Amygdalin, $x 67$

Amygdalus, 485 .

Amyridacer, region of, 685

Amyridea, 475

Anabasis, 563

Anacardiacea, 473

Anacharis, 602 .

- rotation in cells of, 153

Anacyclus, 520

Anagallis, 3x 5, 558

- fruit of, dehiscence of, 307

Analogy, 674

Anamirta, 430

Ananassa, 6r3

Anastatica, 437

Anastomosis of vessels, $2 \mathrm{I}$

Anatropal, or Anatropous, 256, 330

Anchusa, 546

Anda, 583

Andes fora, 686, 696

Andira, 480

Andraea, 643

Androecium, 2I2

Andrographis, 556

Andromeda, 527

Androphore, 219

Andropogon, 631

Androsace, $55^{\circ}$

Androspores, $27^{\circ}$

Anemia, 639

Anemonea, 426

Anemophilous, 284

Anethum, 508

Anfractuose, 223

Angelica, 507

Angienchyma, I6

Angiopteris, 639

Angiospermous, 326

Angiospermous dicotyledons of the chalk, 75 I

Angiospermous flowering plants, fertilisation in, 294

Angiosperms, fossil, reign of, 750

Angiosporæ, 635

Angostura, 469 . - false, $53^{8}$

Angustiseptre, 436

Anigosanthus, 6ro

Anise, 508

Anisostemonous, 215

Annual plants, 359

Annular rings, 251, 36I - vessels, Ig

Annularia, 738

Annulate ferns, 639

Annulated root, 40

Anomopteris, 747

Anonacea, 429

Antarctic region, 688

Anterior, applied to the parts of a flower, 195
Anthemis, 520

Anther, 216, 220 - abnormalities, 226

-- appendages, 224 colour of, 226 coverings of, 220 dehiscence of, 225 lobes, form of, 222

Anthericex, 614

Anthericum, 6r4

Antheridia, 234, 263, $267,27^{8}$

Antherozoids, 234, 265

Anthemis, 520

Anthesis, 193

Anthistiria, $63 x$

Anthocarpous, 309,316

Anthocerotese, 644

Anthocyane, 39I

Anthodium, I80

Antholites, 742

Anthotaxis, 172

Anthoxanthine, 39I

Anthoxanthum, $63 \mathbf{r}$

Anthriscus, 507

Antiaris, 587

Antica, 226

Antidesma, 588

Antilles, flora of, 687

Antirrhinea, 55I

Antirrhinum, capsule of, 3 I 5

Antitropal, 34I

Aperispermic, 343

Apetalæe, 560

Apetalous, 367

Apex of fruit, 302

- of ovule, 253

Aphelandra, 556

Aphthaphytes, 651

Aphyllanthea, $6 \mathrm{I}_{4}$

Apiaceæ, 505

Apicilar, 246, 303

Apiculate, 302

Apios, 480

Aplanatic, 762

Aplectrum, 605

Aploperistomi, 643

Aplostemonous, 2I5

Aplotaxis, 520

Apocarpous, 238, 309

- dehiscent fruits, 312 indehiscent fruits, 309

Apocynacex, 536

- fossil, 755

Apocynum, 537

Aponogeton, 626

Apophysis, 64I

Apostasia, 610

Apostasiacea, 6ro

Apothecia, 268

Apparatus for drying plants, 795

Appendicular organs, 30

Appendiculate, 2ro, 218

Apple, 314, 485, 486

Appressed, III
Apricot, 3I I, 485

Apteria, 6ro

Aquatic plants, 655

Aquifoliacea, 599

Aquilaria, 572

Aquilariacez, 572

Arabian flora, 685

Arabin, 163

Aracea, 625

Arachis, 480

Araliacex, 509

Arar-tree, 599

Araucaria, 598

Araucarioxylon, 739

Araucarites, 749

Arborescent, 46

Arbor-vitæ, 599

Arbutus, 527

Archangelica, 507

Archegonium, 265, 267

Archemone, 626

Archil, 647

Archisperms, 292

Arctic fossil flora, 755

Arctic Region in Britain, 7I4

Arctic zone, plants of, 693

Arctium, 520

Arctostaphylos, 527

Ardisia, $3^{1} 3,53$ I

Ardtun Leaf-beds, 755

Areca, 62I

Arecinea, 62I

Arethusa, 604

Argel, 536

Arillode, 329

Arillus, 328

Arinea, 625

Arista, 629

Aristolochia, 577 fertilisation of, 287

Aristolochiàcea, $\mathbf{5 7 5}$

Aristotelia, 450

Armeria, 550

Armorican flora of Britain, 708

Arnatto or Annatto, 439

Arnica, 52I

Aroth, 628

Arracacha, 507

Arrow-root, 607

- starch, 263

Artanthe, 59I

Artemisia, 52I

Arthrotaxis, 597

Artichoke, 520

Artificial system, 406

Artisia, 74I

Artocarpus, $5^{87}$

Asafoetida, 507

Asagraea, 616

Asarabacca, 576

Asarum, 576

Ascending axis, 44, 334

Ascending sap, I44

Asci, 267

Ascidia, 100

Asclepias, 536

Asclepiadaceæ, 534

- fertilisation of, 286
Asclepiadacea, fruit of, 3 I 2

Ascomycetes, 649

Ascus, 25I

Ash, 533

$\longrightarrow$ fruit of, 3 II

Ash of plants, 129,167

Asimina, 429

Asperula, 5ז2

Asphodelex, 6r4

Aspidium, 639

Aspidosperma, 537

Asplenium, 639

Assimilation, 124

Astelia, 6r7

Asteliez, 617

Aster, 520

Asteracea, 517

Asterophyllites, 738

Asters, Region of, $68 \mathrm{I}$

Astilbe, 504

Astragalus, 479

Asturian type in Irish flora, 708

Atap, 624

Atherospermacea, 580

Atlantic province, 680

Atractenchyma, 4

Atriplex, 562

Atropa, 549

Atropea, $54^{8}$

A tropous, 255

Attalea, 622

Attar of Roses, ${ }_{4} 86$

Aubergine, 548

Autcklandia, 520

Aucuba, 5Io

Aurantiaceæ, 453

Auricula, $55^{\circ}$

Auriculate, 89, 339

Australian flora, 689

Australian Spinach, 56

Autumn Crocus, 616

Avena, 630

Avenia, 83

Averrhoa, 465

Avicennia, 555

Avocado Pear, 569

Awn, 224

Axil, I08, 335

Axil of leaf, 82

Axile, or Axial, 34I

Axile placentation, 243

Axillary, $82,98,108$, I74

Axis, ascending, 44,334

- , descending, 37 , 334

arrangement of flowers on, I72

Azalea, 527

Azolla, 640

Azorella, 509

Azores, plants of, 680

Azotised products, 166

BABUL bark, 482

Bacca, $3 r_{3}$

Baccate, 3 r 3

Bactridium, 649

Baculiform, 272

Bael, 455 
Balanophoraceæ, 577

Balausta, 3×4, 492

Balm, 554

Balm of Gilead, 475, 599.

Balonia, 595

Balsam, bursting of seed-vessel of, I5 of Peru, 480

of Tolu, 480

of Umiri, $46 a$

trees, Region of, 685

Balsam, bog, 509

Balsamilluze, 504

Balsaminaceæ, 464

Balsamodendron, 475

Bamboo, $6_{32}$

Bambusa, 632

Bambusium, 754

Banana, 608

Baneberry, 427

Banisteria, $45^{8}$

Banksia, 570

- fruit of, 152,312

Banyan, age and size of, 360

Baobab, 449

Baphia, 482

Baptisia, 480

Barbacenia, 6ro

Barbadoes Cheny, $45^{8}$

- Gooseberry, 501

Barbed hairs, 32

Barberry, $43^{\circ}$

- fertilisation of, 83

Bark, 50, 56, 76, 512

Bark-bread, 599

- false, in endogens, 65

Barley, 630

Barosma, 467

Barringtonieæ, 490

Bartsia, 55x

Basal placenta, 257

Base of fruit, 302

Base of ovule, 253

Basella, $5^{62}$

Bases, organic, r7o

Basidia, 269

Basil, 554

Basilar, 247

Bassia, 53r

Bassorin, I6 3

Bast or Bass, $45^{\circ}$

Bastard-Cedar, 460

Bast-layer, 57

Batatas, 544

Bauera, 504

Bauhinia, 478

Bay, 567

- laurel, 486

Bay-Myrtle, 592

Bdellium, 475

Bean, 479

Bean-caper, 466

Beania, 749

Bearded, 33

Bearded filament, 2I7

Beaumontia, 537

Beaver-tree, $4^{29}$
Bebeeru, 568

Beech, 595

Beech-drops, 55 I

Beet, 562

Beet-sugar, $x 6_{4}$

Begass, 164

Begonia, 566

Begoniaceæ, 566

Belladonna, 549

Bellis, 520

Bell-shaped, I98, 205

Bengal hemp, 480

Bennettites, $75^{\circ}$

Ben-nuts, 483

Ben-oil, 483

Bent or marram, 632

Benzoin, 529, 569

Berberidaceæ, $43^{\circ}$

Berberin, $43 \circ$

Bere or Bigg, 630

Bergamot, 455

Bergia, 443

Berried, 3 I3

Berry, $31_{3}$

Bertholletia, 492

Berzelia, 504

Beta, 562

Betel-nut palm, 62I

Betel-pepper, 591

Betula, 593

Betulacea, 593

Betzal, 6I 5

Bhang, 585

Biennial, 359

Bifid, 202, 248

Bifurcate, 223, 248

Bignoniaceze, 540

Bijugate, 92, 104

Bikh or Bish, 427

Bilabiate, 207

Bilateral, 248

Bilamellar, 249

Bilberry, 526

Billardiera, 466

Bilobate, 249

Bilocular, 222, $24 \mathrm{I}$

Bindweed, 544

Binomial system of nomenclature, 406

Biogenesis, I5

Biparous cyme, $18_{3}$

Bipartite; 87, 202, 248

Bipinnate, 92

Bipinnatifid, 87

Bipinnatipartite, 87

Birch, 593

Bird lime, 530

Birds, agency in fer-

tilisation, 290

Birthwort, 577

Biscuit-root, 6r5

Bisexual, 2I2

Bistort, 564

Biternate, 93

Bitter almond, 485

- apple, 496

- sweet, $54^{8}$

wood, $43^{\circ}$

Bivalvular, 303

Bixacex, 439

Bizarres, 445

Black Alder, 472
Black Birch, 593

- Bryony, 6ri
- Cummin, 428

- Whortleberry, 526

Bladder-nut, 472

- Senna, 480

- wort, 557

Blade of leaf, $8 z$

Blaeberry, 526

Blanching, 397

Bleeding, or flow of sap, I 44

Blessed Thistle, 520

Bletting, 322

Blighia, 459

Blight, 399

Blood-root, 434, 6ro

Bloom of Grapes, I68

Blume's Floral Region, 684

Boards for pressing plants, 798

Bocagea, 429

Boehmeria, 584

Boerhaavia, 56 I

Bog-bean, 540

- mosses, 643

myrtle, 592

Bolax, 509

Boldoa, 589

Boletus, 649

Bolivaria, $53^{2}$

Bombace $2,4{ }^{8}$

Bombax, 449

Bonapartea, 6 62

Bone-earth, 138

Bones as a manure, $x_{39}$

Bonnetia, 452

Bonpland's Floral Region, 686

Boopis, 5 I7

Borage, 546

Boraginaceæ, 545

- fruit of, 3 II

Borassinez, 621

Boronia, 467

Boswellia, 475

Botanical box, 796

— spade, 796

- terms explained, 809

Botany Bay Kino, $49 \mathrm{r}$

Bothrenchyma, or

Taphrenchyma, 6, zo

Bothrodendron, 734

Botnim, 474

Botrychium, 639

Botrytis, 650

Bottle Gourd, 496

Bourdeaux Pine, 599

Bovista, $65^{\circ}$

Bowenia, 6oo

Box-tree, 582

Brachychiton, 449

Brachyphyllum, $74^{8}$

Bracteæ, 189

Bracteoles, 177,189

Bractlets, $177, x 89$

Bracts, or floral leaves, I72, 189

Ig0 arrangement of, - flower, I93 Igo
Bracts, coloured, $x 89$

I89 phyllotaxis of,

viviparous, or

proliferous, rgr

Bramble, 3 I2, 485

Branches, 112

- arrested, II

Branching of trees, 45

Branchlets, $\mathrm{Ir} 2$

Brassica, 437

Brassicaceæ, 434

Brayera, 486

Brazil-nuts, 492

Brazilian flora, 687

Bread-fruit, 316,587 nuts, 587

- tree, 6oI

Brexia, 504

Brinjal, 548

Britain, distribution of plants in, 702

British plants, local. ities of, $7 \circ 3$

- sporadic species 709

Brocoli, 437

Bromelia, 6ra

Bromeliacers, 612

Bromus, 632

Brongniart's division of fossil plants, $72 \mathrm{r}$, 727

Brookweed, 559

Broom, 480

Broom-rape, 550

Brosimum, $5^{8} 7$

Broussonetia, $5^{8} 7$

Brown coal, 757

Brown's floral Region, 689

Brownian corpuscles, 293

Brucea, 469

Bruniacea, 504

Brunoniaceæ, 522

Bryacex, 64I

Bryonia, 494

Bryony, 496

Bryophyllum, 499

Bryson's instrument for slicing fossils, 788

Bryum, 643

Buchu, 468

Buck-bean, 540

- eye, 459

Bucklandia, 504, 750

Buckthorn, 472

Buckwheat, 564

Bud, arrangement of leaves in the, III

-Budding, rog, 325

Buds, leaf, ro8

—abnormal, 40

- adventitious, I 7 embryo, I I6 wood, $48 \mathrm{x}$

- 
Buds, on grasses, $35^{8}$ |Calcar, r98 $35^{8}$ 368

Buffilo-tree, 574

Bugle-weed, 554

Bugloss, 545

Bukkum-wood, $4^{82}$

Bulb, II4

—_ pseudo, 47

- naked, II5 scaly, ir 5 solid, II6 tunicated, II 5

Bulblets or bulbils, II7

Bulbochate, z7o

Bull-palm, 622

Bulrush, 625

Bunch-grass, 63 r

Bunias, 435

Bunium, 507

Bunt, 399

Burdock, 520

Burgundy pitch, 599

Buriti-palm, 622

Burmanniacea, 6ro

Bursaria, 466

Burserace $æ$, 475

Bush, 46

Butea, $480^{\circ}$

Butter of Cacao, 450

- of Canara, 457

- tree of Park, 531

Butomacea, 623

Butomus, 623

- fruit of, $3 \mathrm{x}_{2}$

Butterfly-weed, 536

Butter-nuts, 453

- of plants, 168

- tree, $53 \mathrm{I}$

Butterwort, 557

Buxus, 582

Byttneriaceæ, 449

Cabbage, 437 fruit of, 3 I 5 palm, 621 tree, 480

Cable-cane, 622

Cabomba, 432

Cabomber, 432

Cacao, $45^{\circ}$

Cactacea, 500

- Region of, 686

Caducous, Igg, 2 II

Casalpinia, 478, 481

Casalpiniex, $48 \mathrm{I}$

Casarea, 463

Caffein, $5 I_{4}$

Cajuput, $49 x$

Calabar bean, 329, 48I

Calabash-tree, 54I

Caladium, 625

Calamander wood, 528

Calamites, 736

Calamodendron, 745

Calamiss, 622

Calandrinia, 446

Calathea, 607

Calathium, I8I
Calcarate, 198,202

Calceolaria, 551 Region of, 686

Calceolate, 207

Calcophyllum, 5 I4 $_{4}$

Caliculate, 190, 198

California and Oregon flora, 682

Calla, 625

Callitriche, 493

Callitris, 599

Calluna, 527

Calonyction, 545

Calophyllum, $45^{6}$

Calotropis, 536

Calumba, $43^{\circ}$

Calvary plants, 479

Calycanthace 2,487

Calyceracea, 515

Calycifloræ, 214

Calyciflorze Gamopetale, 510

Calyciflora Polypeta$12 x, 470$

Calycine hairs, I97

Calyptra, 641

Calyptrate, I99

Calyptrimorphous, too

Calystegia, 544

Calytrix, 491

Calyx, I9I, 195, 198 .

- degenerations in, 196, 198

Cambium, 56, 75

Cambogia, 456

Camellia, 4.53

Camel's-thorn, 479

Camera-lucida, $77^{2}$

Campanula, style of, 290

Campanulacea, 524

Campanulate, 205

Campeachy-wood, 482

Camphor, 169

Camphora, 568

Campion, 445

Camptopteris, 747

Camptotropal, 255

Campylosperma, 506

Campylotropal, 255, 330

Camwood, 482

Canada Balsam, 599

- R Rice, 631

Canarium, 475

Canary Islands, flora of, 680

Canary-seed, 63 工

Candleberry, 592

Candle-nut-tree, 582

Candle-tree, 54 I

Candollea, 428

Cane-sugar, 164

Canella-bark, 439

Canellacex, 439

Canker, 399

Canna, 607

Cannabis, 584

Cannabinacea, $5^{8} 4$

Cannacer, 606

Canoe-birch, 593
Caoutchouc, I70, 537

Cape Gooseberry, 549

Caper-spurge, $5^{82}$

Capers, $43^{8}$

Capillaire, 639

Capitate hairs, 32

Capitula, 182 , I9I

Capitulum, I8o, 182

Capoeira, 346

Capparidacea, 437

Caprification, 264

Caprifoliacea, 5 Io

Capsicum, $54^{8}$

Capsule, $3{ }^{15}$

Carapa, 460

Caraway, 508

Carbon in plants, I26

Carbonate of potash and soda as a manure, I39

Carbonic acid decomposed by aquatics, 158

Carbonic acid given off by flowers, 259

Carboniferous fossils, 729

Cardamoms, 606

Cardiocarpum, 746

Cardoon, 520

Carduus, 520

Carex, 628

Carica, 497

Carices, province of, 679

Carina or Keel,205, 506

Carinal, I95

Carludovica, 624

Carnahuba palm, 622

Carnation, 445

Carob-tree, 481

Carpel, 235, 238, 239, 303

Carpels, number and position of, 238

— analogy to leaves, 235

Carpolithes, 746, 750

Carpology, 308

Carpophore, 240, 305, 3 II

Carrageen, 655

Carrion flowers, 536

Carrot, 507

Carthamus, 520

Cartilaginous albumen, 333

Carya, 596

Caryocar, 453

Caryophyllace $x, 444$

- Region of, 680

Caryophyllaceous corolla, 204

Caryophyllus, 49I

Caryopsis, 3 II

Caryota, 622

Caruncules, 329

Cascarilla bark, 582

Casearia, 573

Case for microscopic slides, $79^{2}$

Casein, vegetable, $x 66$
Cashew, fruit of, 3ro, 473

Casparya, 566

Cassava, 582

Cassia, $47^{8}, 4^{8 \pi}$

- bark and buds, 568

Cassipourea, 488

Cassowary-tree, 593

Cassytha, 567

Cassythex, ${ }^{6} 7$

Castanea, 595

Castor-oil, $58 \mathrm{I}$

Casuarina, 593

Casuarinacea, 593

Catechu, 482

Catha, 471

Cathartocarpus, 48r - Fistula, fruit of 308

Catingas in Brazil, I23

Catkin, I78, Igo

Caudate, 310

Caudex, 44

Caudicle, 229

Caulescent, 44

Caulicle, 334

Cauliflower, 437

Caulinary, 97

Cauline, 362

Cauline leaves, ror

Caulinia, 626

Caulis, 44

Caulopteris, $73^{2}$

Cavernous tissue, $8 \mathrm{I}$

Cayenne-pepper, $54^{8}$

Ceanothus, 472

Cecropia, 588

Cedar, $59^{8}$

Cedars, age and size of, 360

- - cone of, 317

Cedrelacez, 460

Cedrus, $59^{8}$

Celandine, 433

Celastracea, $47 \mathrm{r}$

- - Region of, 682

Celery, 507

Cell development, I3 $_{3}$ germ, 275 nucleus, 9

Cells, 3, 7, 24I

- contents of, 8 endosperm, 293 epidermal, 27 functions of, I3 movements in, I $5 \mathrm{I}$ of ovary, 299 prepared for microscopic preparations, 786

Cellular, 3

Cellular plants, propagation of, $x 4$

Cellular tissue, 3

Cellulares, 638,644

Cellulose, r, 8

Celosia, 562

Celtideæ, $5^{8} 5$

Celtis, 585

Centaurea, 520 
Centrifugal, I75

Centripetal, I75

Centrolepis, 627

Cephaelis, $5 \mathrm{I} 3$

Cephalanthus, 5 x2

Cephalotaxus, 598

Cephalotex, 503

Cephalotus, 503

Ceradia, 521

Ceramium, 654

Cerasin, $I 63$

Cerastium, 445

Cerasus, 486

Ceratium, 649

Ceratonia, 478

Ceratophyllaceæ, 588

Cerbera, 537

Cereal grains, distribution of, 668

- - fertilisation in, II3, 284

Cereals, albumen of, 333

Cereus, $50 \mathrm{r}$

Ceroxylon, 622

Cestrum, 548

Cetraria, 646

Cevadilla, 6 r6

Ceylon flora, 683

Ceylon moss, 655

Chaerophyllum, 507

Chailletiacea, 572

Chalaza, 25. 329

Chalk fossils, 750

Chalmugra or Chaulmugra, $44^{\circ}$

Chamalauciex, 490

Chamarops, 622

Chamisso's floral $\mathrm{Re}$ gion, 684

Chamomile, 520

Chandelier-tree, 624

Channel Island flora, 706

Chara, 65I

Chara, carbonate of lime in, $x_{3}$ I

- rotation in, 152

Characex, 652

- fossil, 754

- reproduction in, 274

Charcoal as a manure, I39

Charianthus, 489

Chatzir, 6r 5

Chavica, 59x

Cheirostemon, 449

Chelbenah, 507

Chelidonum, 433

Chemical agents, effects on movements of plants, $3^{87}$

Chemical composition of plants, 124 composition of soils, $x_{34}$

elements, 124

Chenopodiacea, 562

Chenopodium, 562

Cherimoyer, 430

Cherry, 3II, 486
Cherry, double flowering, 236

-laurel, 486

Chervil, 507

Chestnut, 595

Chestnut, fruit of, 3 rI

Chian Turpentine, 474

Chick-pea, 479

Chickweed, 444

Chicory, 522

Chili-nettle, 493

Chillies, $54^{8}$

Chimaphila, 527

Chimonanthus, 487

China bark, 513

- root, 6I7

Chinese flora, 682

- grass-cloth, 584

Chinanthus, 533

Chiretta, $54^{\circ}$

Chironia, 539

Chive, 6I5

Chlæenacea, 45 I

Chloranthacex, 590

Chloranthus, 590

Chlorophyll, I2, I68, 258,390

Chlorosporea, 653

Chloroxylon, 460

Chocolate, 450

Chondodendron, $43^{\circ}$

Chondrites, 75r

Chorda, 654

Chorisation, $37 \mathbf{r}$

Chorisis, 210,365

Choristosporei, 653

Christison on fossil trees, 789

Christmas rose, 427

Christ's-thorn, 473

Chromatic aberration, 763

Chromatometer, 390

Chromogen, 392

Chrysanthemum, 521

Chrysobalanea, 483

Chrysophanic acid, 647

Chrysophyll, 392

Chrysophyllum, $53 \mathrm{I}$

Chrysosplenium, 504

Churrus, 585

Chusan Han-tsi, 562

Cibotium, 640

Cicatrices on ferns, $7^{2}$

Cicatricula, 82

Cicatrix, 95

Cichoracex, 5 I9

- province of, 680

Cicuta, 508

Cilia, 204, 205, 235, 265

Ciliated hairs, 33

Cimicifuga, 427

Cinchona, 512

- glands, 35

Cinchonacea fossil, 755

Cinchonas, or Medicinal barks, Region of, 686

Cinenchyma, 21
Cinenchymatous, $x_{4} 6$

Cinnamodendron, 439

Cinnamomum, 568

Cinnamon, 568

Circaea, 493

Circinate, x ro, 339

Circular, I94

Circulation of fiuids in plants, 124, 142, 147

Circumscissile, 226, 307

Circumscription of leaf, 82

Cirrus, 97, 120

Cissampelos, $43^{\circ}$

Cissus, $46 \mathrm{I}$

Cistacez, 439

Cistuses, province of, 680

Cistus-rape, 577

Citron, 454

Citrus, 454

Cladenchyma, 4

Cladium, 628

Cladocarpi, 643

Cladonia, 647

Cladosporium, $65 \mathrm{x}$

Classes, essential character and nomenclature, 4 I I of plants, 405

Classification, artificial and natural, 406

- systems of, 405 , 418,422

Clavaria, 649

Clavate, 217

- hairs, 32

Claviceps, 650

Claw, 201

Claytonia, 446

Clearing-nut, 539

Cleft-grafting, 325

Clematidea, 426

Clematis, 427

Cleome, $43^{8}$

Clerodendron, 555

Clianthus, 479

Climate, effect of, on flowering, 667

Climbing plants, 385

Clinandrium, z30

Clinanthium, I73

Clintonia, 525

Close interbreeding, prevention of, 286

Ciosing of flowers, 262

Clove, 49r

Clove pink, 445

Clover, 479

Cloves, II 4, 358

Club-moss, $64^{\circ}$

Club-mosses, embryogeny in, 278

Clusiacea, 456

Cluster-pine, 599

Cnestis, 476

Coal epoch, climate of, 742

- flora of, 743

Coal-measures, plants of, $73^{\circ}$

Coal of Humus, 134
Coal, sporangia in, 729

Cobza, 542

Coca, 457

Cocci, 306

Coccoloba, 565

Cocculus, 430

Cochlearia, 437

Cochleariform, 202

Cochineal-Cactus, 502

Cockscomb, 173,562

Cocksfoot-grass, 631

Cocoa, $45^{\circ}$

Cocoa-plums, 485

Cocoinea, 62I

Coco, 621, 625.

Coco-nut, 62r, $29 r$

333

Coelospermx, 506

Coffea, 514

Cohesion, $3^{65}, 3^{69}$

Coiling of tendrils, 385

Coir-rope, 6zI

Coix, 632

Colchicea, $6 \mathbf{1} 6$

Colchicum, 616

Coleorhiza, 42, $33^{6}$

Coleseed, 437

Collateral, 257

Collecting hairs, 33

Collectors in foreign countries, directions to, 806

Collemacea, 646

Collenchyma, 8

Collomia, 542

- spiral cells in seeds of, $3^{27}$

Collum, 38, 334

Colocasia, 625

Colocynth, 496

Coloquintida, 496

Colouring matters, I 7 I

Colours, complementary, 396 of flowers, 393

- in natural orders, 395

Colpenchyma, 4

Colt's foot, 520

Columbine, 202

Columella, 304

Columelliacex, 532

Columna, 2I9

Columnea, $54 \mathrm{I}$

Colutea, 480

Colza, 437

Combretacex, 488

- fossil, 754

Commelynaceæ, 622

Commissure, 3 II

Compositæ, $5 \mathrm{I} 7$

- fruit of, 3 Io arborescent, $\mathbf{R e}$ -

gion 687

Compound, 235, 239

C... leaves, 85 , 91

Compressed, $33^{\circ}$

Compressorium, $77^{2}$

Comptonia, 592

Conanthereæ, 6I4

Conceptacles, 268 
Concrete oils, $x 6_{7}$

Condenser, 765

Conducting tissue, 236

Conduplicate, III, I93, 339

Conenchyma, 4

Cones, I79, rgo

- spirals in, I05

Conferva, conjugation of, 269

- reproduction of, 272

Confervæ, 655

Conia, 508

Conidia, 267

Coniferæe, 596

- fertilisation 291

fossil, 746

fruit of, 317

of chalk, $75 \mathrm{r}$

Coniomycetes, 648

Coniothalamea, 646

Conium, 508

Conjugatx, 266, 654

Conjugation, 653

Connarace 4,476

Connate, roo

Connective, 22I, 224

Connivent, I97

Conservatory, 349

Conservatory, Ward's portable, I6o

Contorted, 40

Contortive, III, I93

Contrayerva, 587

Convallariea, 6I4

Convergent, 84

Convolute, III, I94, 339

Convolvulacer, 542

Convolvulus, 544

Copaifera, 482

Copaiva, 482

Copalchi bark, 582

Copper-coloured trees, 392

Copper in plants, 132

Coptis, 427

Coquilla-nuts, 622

Coral-flower, 479

Corallina, 654

Coralline, 40

Corchorus, $45^{\circ}$

Corculum, 335

Cordate, 89,203

Cordiaceae, 545

Cordilleras, flora of, 686

Cord-Rush, 627

Cordyline, $6 \mathrm{r} 6$

Corema, 579

Coriander, 508

Coriariace $x, 470$

Cork, 58, 595

Corky layer of bark, 58

Corm, 48, I 5

Cormogenæ, 638

Comacea, 509

Corn-plants, distribution of, 668

Cornus, 5 Io
Corona, 209

Corolla, I99, 200

irregularities 2 II

Corolliflorye, 526

Corollifloral, 2I4

Corolline appendages, 210

hairs, $34,20 \mathrm{r}$

Coronet, 2 Io

Coronilla, $4^{8}$ r

Corpuscles of Brown, 293

Correa, 467

Corrigiola, 499

Corrugated, I93, 203

Corsican Moss, 655

Cortical system, 56

Corydalis, 434

Corylacere, 594

Corylus, 595

Corymb, I7 8

Corymbiferæ, 5 I8

Corynophallus, 626

Coryphine 2,621

Coscinium, $43^{\circ}$

Costate, 84

Cotton, r6, 33, 448

Cotton-grass, 628

Cotyledon, 500

Cotyledons, ror, 33I, 334,339

__ folding of, 339

- of Welwitschia, $33^{8}$

- verticillate, $33^{8}$

Couch-grass, $63^{2}$

Couratari, dehisence of fruit of, 307

Coverings of the seed, 326

Cowbane, 508

Cowberry, 526

Cowitch, 480

- hairs of, 33

Cow-plant, 536

Cowslip, $55^{8}$

Cow-tree, 537,587

Cow-wheat, $53^{2}$

Cranberry, 526

Cranes-bill, 462

Crassula, 499

Crassulacea, 499

- fruit of, 312

Craterium, 649

Credneria, $75^{\circ}$

Cremocarp, 305, 3 II

Crenate, 86

Crescentia, 54I

Crescentiee, 540

Cress, $43^{6}$

fruit of, 3 I 5

Crested, 20I

Crests, 224

Cretaceous flora of England, 709

Cretaceous fossils,

750

Creyat, 556

Crinum, 6rI

Crisp, 90, 203

Crithmum, 507
Crocus, 609

Crops, nutritive products of, 167

- rotation of, 133

Crosses, 297

Croton-oil, 581

Crowberry, 579

Crowfoot, 426

Crown grafting, 325

Crown Imperial, 6r5

Crown of the root, 37 , $46, \operatorname{lr}_{3}$

Crozophora, $5^{8} 3$

Crucifera, 306,434 divisions of, 340

- fertilisation in, 284

${ }^{28}$ Region of, 686

Cruciferous corolla, 205

Cryptocarya, 569

Cryptogamic reproduction, organs of, 233

Cryptogamous, I7r

plants, 635.

in, $\frac{}{266}$, fertilisation $-{ }^{-}$, pistillidia, 250

- - - spores, 258

Crystals in cells, ro

Crystalworts, 644

Ctenis, 747

Cuba Bast, 448

Cubeba, 59r

Cubeb-pepper, 59I

Cuckoo-pint, 625

Cucullate, $25^{\circ}$

Cucumber, 495

- squirting, 343

Cucumis, 494

Cucumites, 751

Cucurbitace $2,3 \pi 4,494$

Cudbear, I7 1,647

Culm, 44

Cultivation, effect on organs of the flower, 374

Cumin, 508

Cuneate, 89

Cunninghamia, 598

Cunonieas, 503

Cupania, 459

Cupanoides, 751

Cupressinez, 598

Cupula orcup 3 II

Cupulifera, 594

Curcas, 582

Curculigo, 612

Curcuma, 606

Currant, 3I3, 502

- of Australia, 528

Currants or Corinths, 462

Curved radicle, 340

Cuscuta, 545

Cuscutea, 544

Cuscus or Kuskus, $6_{32}$
Cusparia, 468

Cuspidate, 202

Cuspis, 202

Cusso, 486

Custard-apple, 429

Cutch, 482

Cuticle, 25

Cyanic series of co-

lours, 393

Cyathea, 639

Cycadaceæ, 600 $29 I$

- fossil, 746

— of chalk, 75I

Cycadeostrobus, 750

Cycadinocarpus, 746

Cycadites, $75^{\circ}$

Cycas, 6oI

Cyclamen, $55^{8}$

Cyclanther, 624

Cyclanthus, 624

Cyclogens, 53

Cyclosis, 146

Cydonia, 486

Cylindrenchyma, 4

Cytinacea, 577

Cymbiform, 202

Cyme, 182

Cyme, biparous, 783

contracted bi-

parous, 184

- contracted scor-

pioid, 187

- dichotomous, ${ }^{2} 8_{3}$ helicoid, 185 racemose uniparous

scorpioid, $r 85$ - trichotomous, 18

- uniparous, $18_{3}$,

Cynanchum, 536

Cynara, 520

Cynarocephalæ, 518

Cynarrhodum, 3 ro

Cymodon, $63 \mathrm{I}$

Cynoglossum, 546

Cynomorium, 577

Cynosurus, 631

Cyperacea, 687

Cyperus, 628

Cypress, fruit of, $3^{17}$

Cypsela, 3 ro

Cyrtandrea, $54^{\circ}$

Cyst, in

Cystidia, 268

Cystocarp, 272

Cystolith, Io, I2

Cytisus, $47^{8}, 48 \mathrm{I}$

Cytoblast, I3

Cytoblastema, 8

Cytogenesis, 13

Cyttaria, 649

Dabeocta, 527

Dactylis, 63x

Dadoxylon, 739

Dredalenchyma, 4

Dxmonorops, 622

Daffodil, 6II

Dahlia, 374

Dalbergia, $47^{8}$ 
Dammara, 599

Dammar resin, 45

Dampiera, 523

Danza, 639

Dandelion, 52x

Daphne, 572

Daphnex, $57^{\mathrm{I}}$

Dardar, 467

Darkness, effect on flowers, 263

- in germination, 346

Darlingtonia, 433

- insects in pit-

chers of, $3^{8} 4$

Darnel-grass, 632

Date, 3 II

Date-palm, 62I

Datisca, 578

Datiscacea, 578

Datura, 549

Daucus, 507

Davallia, 640

Day-lily, 614

Deadly-nightshade,

De Candolle's classification, $4 \mathrm{I} 8$ :

- floral Region, 680

Decandrous, 216

Decayed leaves, colours of, 392

Deciduous leaves, 83

Declinate, 228

Decompound, 92

Decurrent, roo

Decussate, 102

Deduplication, 2ro, $365,37 x$

Definite, 257

inflorescence, 175 , 182

stamens, 216

Defoliation, I23

Degeneration, 2I0, $3^{65}, 3^{69}$

Degradation, 368

Dehiscence, 225, 303, 305

Dehiscent fruits, 303 , 309,312

Delesseria, 654

Delile's floral Region, 685

Delima, 428

Delphinium, 427 fruit of, 312

Dendrobium, 604

Dentate, 86

Deodar, 598

Depressed, $33^{\circ}$

Descending axis, 334

- sap, I44, 146

Desert Region, 685

Desmidiex, 654

-- reproduction of, 269

Desmodium, 377, 48I

Detarium, 477

Determinate Infloresence, I75

Deutzia, $49^{\circ}$
Dextrin, 163

Dhak tree, $4^{80}$

Dhoom pitch, 45 I

Diachanium, 3 II

Diachyma, 80

Diadelphous, 2 I8

Dialycarpous, 309

Dialypetalous, 203

Dialysepalous, Ig6

Diandrous, 216

Dianthus, 445

Diapensiea, 542

Diastase, 165

Diataxis, 406

Diatomacea, 654

Diatoms, preparation of, $79 \mathrm{r}$

$\longrightarrow$ reproduction of, 269

Dicentra, 434

Dichlamydeous, Ig2

Dichogamous plants, fertilisation of, 286

Dichopetalum, 509

Dichotomous cyme, 183

Diclinous, $3^{67}$

Dicotyledonous, 334

_.. embryo, 336,362 germination, 356

—- plants, symmetry in, 364

Dicotyledons, leaves

of, 100 phyllotaxis of, I07

- root of, $4 \mathrm{r}$

Dicranum, 643

Dictamnus, 467

Dictyogens, 6ox

Dictyoxylon, $74^{2}$

Didymocarpea, 540

Didynamous, 228

Dieffenbachia, 685

Dielytra, 434

Diervilla, 5 II

Digestion of plants, I 56

Digestive fluid in pitchers, $3^{84}$

Digger for plants, 796

Digitaliform, 206

Digitalis, $55^{2}$

fruit of, 315

Digitate, 93

Digitipartite, 87

Dilamination, 210, 37r

Dill, 508

Dilleniacer, 428

Dimerous, 363

Dimorphic, 212, 285

plants, fertilisation in, 284 sporangla, 278

Dipecious, or dioicous, $212,273,367$ - plants, fertilisation in, 284

Diœciously - hermaphrodite, 285

Dioicous, 212
Dion, 6or

Dionaa, 44I

muscipula, irrita-

bility in, 380

Dioscorea, 6rт

Dioscoreacea, 610

Diosma, 467

Diospyros, 528

Diphylleia, $43 \mathrm{r}$

Diplecolobex, 435

Diploë, 80

Diploperistomi, 643

Diplostemonous, 2 I5

Diplozygize, 506

Dipsacacere, 5 I5 fruit of, 3 IO

Dipterix, 480

Dipterocarpacea, 4.5 I

Dipterocarpus, 451

Dirca, $57^{2}$

Disa, 604

Dischidia, 536

Disciform, 53

Discoid, 53

Discomycetes, 649

Discs, I7, 268

Disease, potato, 398 , 402

Disease, vine, 403

Diseases of plants, 397

of plants caused

by insects, 402

Diserneston, 507

Disk, 234

Dissected, 87

Dissemination of plants 668

Dissepiment, $24 \mathrm{~T}$

spurious, 244

Dissilient, 306

Distichous, I03

Distractile, 224

Distribution of plants from centres, 672

Dithecal, 222

Dittany, 468, 554

Divergent, 84,197

Divi-divi, $48 \mathrm{I}$

Dockhan, 63I

Dodder, 544

spiral embryo of, 340

suckers of, 40

Dodecandrous, 256

Dodecatheon, $55^{8}$

Dodonæa, 459

Dogbane, 536

Dog's-tail grass, $63 \mathrm{r}$

Dog-tuoth violet, $6 \mathrm{r}_{4}$

Dolabriform, 9o

Dombeya, $45^{\circ}$

Doom-palm, 622

Dorema, 507

Dorsal, 340

Dorsiferous ferns, 639

Dorstenia, I8I, 3Io, 587

- fruit of, $3^{17}$

Dotted ressels, 20

Double coco-nut, 62 I

Double flowers, 2I4, $23^{6}, 3^{69}$
Draba, 435

Dracena, 6I 5

Dracontium, 686

Dragon's-blood, 6r5, 622

Draining, 347

Drimys, 429

Droseracea, 44I

irritability in, $3^{80}$, $3^{82}$

Drosophyllum, 44T

Drupacea, 483

Drupe, 3 II

Drupels, 312

Dryandra, $57^{\circ}$

Drying oils, $x 67$

- paper, 797

plants, mode of, 799

Dryobalanops, $45 x$

Dry rot, I4I, 40I, 650

Duckweed, 626

Ducts, closed,

Dudaim, 549

Dudresnaya, reproduction in, 273

Duguetia, 429

Dulse, 655

Dumb-cane, 625

Dumose, 46

Duramen, 55

Durian, 449

Durmast, 595

Durra, 63I

Durvillea, 654,701

D'Urville's Region, 686

Dust-brand, 399

Dutch-rushes, 637

Dwale, 549

EAGLE-WOOD, 572

Ear-cockles, purples or pepper-corn, 403

Earth-nut, 312, 507

Ebenaceæ, 528

Ebony, 528

Ebracteated, 189

Ecballium, 496

Eccremocarpus, 540:

Echinate, 284

Echinocactus, 502

Echites, 537

Echium, 546

Ectocarpus, 654

Eddoes, 686

Edible nests, 655

Egg-apple, $54^{8}$

plant, 495

Ehretia, 546

Elaborated sap, 244

Elaegnace 570

Elæagnus, 57 1

Elæocarpea, $45^{\circ}$

Elacodendron, $47 \mathrm{I}$

Elaia, 533

Elais, 62I

Elaphrium, 476

Elaterium, 496

Elaters, 643

Elatinacea, 443

Elder, 5 II 
Elecampane, 520

Elemi, 475

Elephant's-foot, 6rI

Elettaria, 606

E.lm, 585

fruit of, 3 II

Elodea, 456, 602

Elymus, 63I

Elyna, 628

Emarginate, 89, 202

Embryo, acotyledonous, 335

- buds, II6

- curved or amphitropal, 342

- dicotyledonous,

337

erect or homotropal, 342

- fixed, rog

- formation of, 330

- inverted or anti-

tropal, $34 \mathrm{I}$

—_ macropodous, 336

ous, $33^{6}$

monocotyledon-

- of coco-nut, 333

- plant, 298

plants, parts of

334

- polycotyledonous,

$33^{3}$ position and form

of, $34 \circ$

- sac, 253

- sac of Yew, 292

Embryogenic process

in gymnospermous

flowering plants, 29 I

- process in angio-

sperms, 294

Embryonal cell, 276

Embryonal corpuscles

in coniferous seeds, $33 \mathrm{I}$

Embryonal vesicles, 293

Embryonary sac, 332

Embryotega, 329

Emetin, 5 53

Emodic Region, $68_{3}$

Empetracea, 579

Empetrum, 579

Empty bracts, 189

Emulsin, r66

Encephalartos, $60 x$

Endemic plants, 670

Endlicher's classification, 4 I9

Endocarp, 300

Endochrome, 266

Endogena, 6or

Endogenous or monocotyledonous stem, 64

- plants, course of sap in, 148

Endophloeum, 57

Endopleura, 327,328

Endorhizal, 42, 356

Endosmometer, 143

Endosmose, 15, I42

Endosperm, 293, 332

\section{Endospermic albumen, Eriolana, 450 332 \\ Endostome, 254 \\ Endothecium, 220 \\ English Mercury, 562 \\ Enneandrous, 216 \\ Ennobling, 325 \\ Ensiform, 9o \\ Entire, 86 \\ Eriophorum, 628
Eriospermea, 6r4 \\ Eryngium, 507 \\ Eryngo, 507 \\ Erysiphe, 649 \\ Erythraa, $54^{\circ}$ \\ Erythrina, 479 \\ Erythrinum, 614}

Entophytic fungi, 400

Envelopes, floral, I92

functions of, 258

Eocene flora, 753

- flora of Europe, 756

Epacridaceæ, 527

- Region of, 689

Epacris, 528

Ephedra, 598

Ephemeral, 262

Epiblast, 337

Epiblema, 26, 38

Epicalyx, r89, 198

Epicarp, 300

Epichilium, 602

Epidendrum, 604

Epidermis, 26

- appendages of, 30

_- of leaf, 79

papilla of, 30 silica in, 28 special functions

of the, $3^{6}$

- wax on, 28

Epigeal, 356

Epigynous, 213, 246

disk, 235

Epilobium, 493

Epimedium, 43r

Epipetalous, 213

Epiphagus, $55 \mathrm{I}$

Epiphloeum, 57

Epiphragm, 642

Epiphytes, 39, I4r

Epirrheology, 657

Episperm or testa, 327

Epithelium, 26, 236

Equal, 86

Equally pinnate, 93

Equisetacea, 636 - embryogeny in, 28I

Equisetites, 745

Equisetum, 637

- fossil, $74^{8}$

- silica in, I3I

Equitant, II2, 340

Erect, 224, 257, 330,

342

Eres, 598

Ergot, 400

- of rye, 634

Erica, 527

- fertilisation in, 289

Ericacea, 526

Ericea, province of, 689

Eriobotrya, 486

Eriocaulon, 627

Eriogonea, 564
Erythrophyll, 39r, 392

Erythroxylacea, 457

Escallonia, 503

Escalloniex, Region of, 686

Eschscholtzia, 433

Essences, I68

Essential characters of classes, $4 \mathrm{II}$

- oils, 168

- organs, Ig2

- organs, Phanero-

gamous plants, 264

- organs of repro-

duction, 2 I

Etario, 3 z2

Etiolation, r62

Eucalypti, Region of, 689

Eucalyptus, $49 \mathrm{I}$

Eugenia, 49I

Eulophia, 605

Euonymus, $47 x$

Eupatorium, 520

Euphorbia, 581

fertilisation of, 287

Euphorbiacex, 579

fruit of, $3{ }^{\mathrm{x}} 5$

Euphrasia, 55x

Euphrasia, fertilisation in, 290

European palm, 622

Euryale, 432

Euryangium, 508

Eutassa, $59^{\circ}$

Euterpe, 62x

Eutoca, 542

Evening Primrose, 492

Evergreen Beech, 595

- - leaves, 83

- Oak, 595

Evernia, 646

Exalbuminous, 332

Exannulate ferns, 639

Excentric, 56

Excrescences, I 6

Exhalation, I2I

Exidia, 650

Exintine, 230

Exogen $x, 425$

Exogenous or Dicotyledonous stem, 49

- fossil stem, $75^{8}$

stem, anomalous, 60

- stems, course of sap in, r44.

trees in coalfields, 739 vascular bundles, 53

Exogonium, 544
Exorhizal, 4t, 357

Exosmose, I5, I42

Exostemma, 513

Exostome, 254

Exothecium, 220

Expansion of flowers, 174

Exserted, 227

Exstipulate, 97

External or extra. rius embryo; 340

Extine, 230

Extra-axillary, $x x 6$, I74

Extrorse, 226

Eye-bright, 582

Eye-piece of microscope, $7^{65}$

Eyes of Potato, 47

Ezrach, 567

FABACE $A$, 476

Fagopyrum, 564

Fagus, 595

Fairy Rings, 4or, 650

Falkland Islands, flora of, 688

$F$ all of leaves, I23

Families, 4 Io

Fan-Palm, 622

Farinaceous or mealy albumen, $333^{\circ}$

Fasciated, I I 7

Fascicle, 184

Fascicled leaves, 369

Fasciculate, 40,107

Fat oils, I67

Fatsia, 509

Faux, 204

Feather-veined, 86

Fecundation, 264 266

- in phanerogams, $28 x$

Fenestrate, 82,3 I6

Fennel, 507

- flower, 428

Ferns, 637

$28 \mathrm{I}$

- in coal measures,

730

Feronia, 455

Fertile, 368

Fertilisation, 264

- agency of birds

in, 290

- by insects, 284

- heteromorphic,

285

homomorphic, 285

in angiospermous

flowering plants, 294

287

284 in cereal grains,

in conifera and

cycadacea, $29 x$ 
Fertilisation in cryptogamous plants, 266 in dichogamous plants, 286

- in Erica, 289

in Euphorbia, 287

- in Euphrasia, 29o

- in Fumariacex, 290

in gymnosperms, $29 \mathrm{I}$ in kidney-bean, 288

- in moncecious, dicecious, and dimorphic plants, 284

- in orchidacea and asclepiadacea, 286

- in Parnassia, 286 in phanerogams, $28 \mathrm{r}$

-..- in Polygala, 289

-.. in Primroses, 285

- in Pringlea, 284

__ in Rhinanthus crista-galli, 290 in Scrophlulariacere and Labiatte, 289

— in sea-pink, 291

object of, 330 self, 284

Ferula, 507

Fescue, 631

Festuca, 63 I

Fever-bush, 569

Feverfew, 520

Fevillea, 494

Fibre in spiral vessels, 18

Fibrils, $3^{8}$

Fibrin, vegetable, I66

Fibro-cellular tissue, 6

Fibrous root, $4^{\circ}$

- tubes, 16

Fibro-vascular tissue, 7

Ficoidex, 500

Ficus, 586 .

Field-book, 796

for drying plants, 796

Fig, I8I, 3xo, 317, 586

- marigold, 500

Figwort, 552

Filament, 216

Filbert. See Hazel, 3 r 1595

Filices, 637

Filmy fern, 639

Fimbriated, 201

Finochio, 507

Fir, 597

- cone of, 377

Fissiparous, 267

- - separation of cells, 14

Fissures, 86

Fistular, roo

Fitches, 427

Fitzroya, $59^{8}$

Fixed embryos, Iog
Fixed oils, 167

Flabellaria, $74 \mathrm{x}$

Flacourtia, $44^{\circ}$

Flag, 628

Flagellum, I I3

Flakes, 445

Flax, 16,463

-.- New Zealand, I6

- Pita, I6

Fleshy cotyledons, 339

- leaves, colours of, 392

or cartilaginous, 333

Floerkea, 465

Flora of Palæozoic period, 728

- of Polynesia, 684

- of Secondary or

Mesozoic period, 745

- of Tertiary or

Cainozoic period, 750

Floral axis, I73

- calendar, $26 \mathrm{r}$

- envelopes, I92 envelopes, de.

velopment of, 2 I I

- envelopes, functions of, 258

- leaves, Ior, $x 89$

watch or clock, 262

whorls, inner,

loras of Britain, their origin, 7 IO

of islands, 673

Flor de coco, 389

Filorets, 187

Florida, Mississippi, and Carolina, flora of, $68 \mathrm{I}$

Floridea, $6_{53}$

- reproduction in, 273

Flower, arrangement on the axis, $I_{72}$

- bud, J93

Flower, position of its parts, 195

Flowering, 359

- ash, 533

- mode of accelerating, $26 \mathrm{x}$

$\longrightarrow$ period of, $26 \mathrm{I}$ plants, fertilisation in, $28 \mathrm{x}$

- Rush, 6z3

Flowerless plants, 266

Flowers, double, 369

causes of want of symmetry, 365

- effect of light and darkness on, 263

Flowers, movements in, $3^{86}$

- odours of, 396 - transformation of parts of, $3^{69}$
Fluid, absorption and circulation of, $\mathrm{I}_{42}$

- in exogenous plants, course of, 146 in plants, rate of movement, ${ }_{54}$

- matter in endogenous plants, $I_{4} 8$ - special novements of, $15 I$

Fluorine, I3I

Flute grafting, 325

Foliaceous, 197, 339

Foliar, 362

Foliola, 86, 9I, I95

Follicle, $3^{12}$

Folliculites, 754

Food of plants, 124 value of certain matters for, 167

Fool's Parsley, 508

Foramen, 254

Forbes' flora of Britain, 708

Forbidden fruit, 454

Forget-me-not, 547

Forked, 223, 237

- style, $24^{8}$

Fork-veined, 84,85

Fornasinia, $48 \mathrm{x}$

Forskäl's floral Region, 685

Forstera, 523

Forster's floral Region, 691

Fossil acrogens, reign of, 728

- botany, 718

-__ botany, works on, 759

flora of carboniferous system, 729

- flora of Silurian and Cambrian system, 728

- genera and species, 724

- plants, determination of, 720 - plants in different strata, 726 plants, mode of preservation, 7I9

- plants, nomenclature of, 722

- plants, number of, 726 72 plants of Chalk Epoch, $75^{\circ}$

- plants, orders of, 725

72 plants, sections of, 787

plants, their

classes, $72 \mathrm{r}$

Fossiliferous formations, 723

- strata, 723

Fothergilla, 504

Four o'clock flower. $56 \mathrm{I}$

Fovilla, 23 I
Foxglove, 552

Fox-grapes, 462

Fractions in phyllo. taxis, $\mathrm{IO}_{4}$

Frames for drying plants, $79^{8}$

Francoacex, $5 \circ 3$

Frankeniacex, 443

Frankincense, 475, 599 Pine, 599

Frasera, 540

Fraxinella, 468

Fraxintus, 533

Free central placenta, 243

French berries, $47^{2}$

Freycinetia, 624

Freziera, 453

Friar's-balsam, 529

Fringes of Passionflower, 209

Fritillary, 6I4

Frog-bit, 6oI

Frogsmouth, or Snapdragon, dehiscence of fruit of, 308

Frond, 637

Fruit, 298

- apocarpous, 309

- chemical compo-

sition of, $32 x, 322$

- classification of, 3 I9

- contents of, $32 x$ dehiscent, 303 dialycarpous, 309

effect of grafting

on, 283

indehiscent, 303

monogynocial

309

multiple or an

thocarpous, 309

- parts which form

it, 293

- period required

for ripening, 322

polygynœcial.

309

- seedless, 319

simple, 309

- indehiscent syncarpous, 3I3

tabular arrange-

ment of, 3 I8

- winged, 3 xI

Fruiting, 320, 359

Frustule, 267

Frutex, 46

Fruticose, 46

Fruticulus, 46 .

Fucacez, 653

reproduction in, 273

Fuchsia, 493

Fuegia, flora of, 688

Fuirena, 628

Fullers' Teazel, 5I5

Fumariaceæ, 434

Fumitory, 434

fertilisation in, 290

Funaria, 643 
Fungi, 647 generation "in, 399

- colour of. 390 germination of, 357 357 Iuminosity in, $3^{89}$

- parasitic, I4T

- on fruits, 400

- fossil, 754 267

- reproduction in, - resting spores of, 402

Fungoid disease, prevention of, $40 \mathrm{O}$

Fungus melitensis, 577

Funiculus, 252, 256

Funnel - shaped, r98, 205

Furcate venation, 84 , 85

Fusiform, r6, 40

GAD, 508

Gahnia, 628

Gairdner's portable microscope, $76_{4}$

Galacex, 503

Galactodendron, 587

Galangal-root, 606

Galanthus, 6 I I

Galbanum, 507

Galbulus, $3{ }^{17}$

Gale, 592

Galeate, 197

Galieæ, 512

Galipea, 468

Galls, 403

Gama-grass, 631

Gamassia, 6r5

Gambeer, 5I4

Gamboge, 456

Gamogastrous, 239

Gamopetalous, 205,206

Gamophyliotis bracts, Igo

Gamosepalous, Ig6

Gangrene, 399

Garcinia, 456

Gardenia, 512

Garlic, 6I5

Garryacea, 510

Gases, effect on plants, 159

Gasteromycetes, 648

Gasterothalamea, 646

Gattine, $65 \mathrm{I}$

Gaudichaudia, $45^{8}$

Gaura, 493

Geaster, 649

Gelidium, 655

Geissolomez, $57^{I}$

Gemmation, Iro

Gemmule, 334

Genera and orders, 4Io

Geniculate, 2I7

Gentian, 539

Gentianaceæ, 539

Genus or kind, 410
Geoffroya, 480

Geographical botany, 657

Geraniacea, 462 fruit of, 3 I 5

Germanic flora in Bri. tain, 709

Germ-cell, 275, 28I

Germen, 235

Germination, 344, 350, 354,372

acotyledonous, 335,357

- dicotyledonous, $35^{6}$ effect of rays of light on, 346 monocotyledonous, 354 requisites for, 345 . - 34 time required for, 357

Gesneraceæ, $54 I$

Geum, 486

Gibbous, 202

Gigartina, 655

Gillia, 542

Gilliesia, 6I8

Gilliesiacer, 618

Gills, 648

Ginger, 605

Ginger-grass, 632

Ginko, 600

Ginseng-root, 509

Gipsy-wort, 554

Glabrous, 33

Gladiolus, 608

Glands, 34

- lenticular, 36

- nectariferous, 35 - vesicular, 36

Glandular hairs, 33 woody tissue, ${ }_{7} 7$

Glans, 3 I I

Glaucium, 433

Glaux, $55^{8}$

Gleicheniea, 639

Globe-amaranth, 562

Globularia, 555

Globule, 234, 274

Glochidiate hairs, 32

Glomerulus, 187

Glossary, 809

Glossology, 406

Gloxinia, 54I

Glucose, I65

Glume, 19r, 208

Glumella, 208

Glumiferz, $68_{7}$

Glutin, I66

Glycyrrhiza, 479

Gnetacex, $39^{8}$

Gnetum, 6o

Godoya, 47o

Godwinia, 686

Goldfussia, 290, 556

Gomphia, $47^{\circ}$

Gomphocarpus, 536

Gompholobium, $48 \mathrm{x}$

Gomphrena, 562

Gongyli, 645
Gonidia, 269, 626

Gonolobus, 536

Goodeniacez, 522

Gooseberry, 313, 502

Goosefoot, 562

Gopher-wood, 599

Gorachand, $48 \mathrm{r}$

Gordonia, 452

Gossypium, $44^{8}$

Gortong, 626

Gourd, 3I 4, 496

Gouty-tree, 449

Grafting, 323

effects of, $3^{2} 3$, 325

of, 325

Grains of Paradise, 606

Gramineæ, 628

Granules of chlorophyll in cells, I 5 I

of latex, $x_{45}$

of pollen, 231

Grape, 353,46 I

- sugar, 165

Grasses, fertilisation of, 656

flowers of, 208

seed of, $34 \mathrm{I}$

Grass-trees, 6I5 - of Parnassus, 455

Gratiola, 55z

Greek Valerian, 542

Greenheart-tree, 568

Greenland, fossil plants of, $75^{8}$

Green Laver, 655

- snow, 655

Greffe des charlatans, 323

Grenadilla, 498

Grevillea, $57^{\circ}$

Grewia, 45I

Grossulariaceæ, 502

Ground-nut, 480

Gruby's portable compound microscope, 768

Guaiacum, 466

Gualtheria, 527

Guano, 137

Guarana, 459

Guatteria, 429

Guava, 492

Gueldres Rose, 5 II

Guernsey-Lily, 6 I2

Guettarda, 512

Guilandina, $48 \mathrm{I}$

Guimauve, 447

Guinea-corn, 630

Guinea-hen-weed, $5^{6} 3$

Gulf-weed, 655 , 700

Gum-Arabic, I63, 48z

Gum-Dragon, 48。

Gum, effect of alkalies on, 164

Gum-lac, $5^{82}$

Gum-tree, 491

Gunnera, 493

Gunyang, 548

Gutta-percha, 170, 531

Guttifera, $45^{6}$
Gymnema, 536

Gymnocarpous, 645

Gymnospermæ, 596

Gymnospermous, 25z, $3^{26}$

- Howering plants,

fertilisation in, 29I

Gymnosperms, fossil, 745

Gymnospora, 644

Gymnostomum, 643

Gynandrous, 2I3, 220

Gynerium, 63I

Gynizus, 238, 250

Gynobase, 247

Gynocardia, 440

Gynccium, 212, 235

Gynophore, 240

Gynostegium, 534

Gynostemium, 220

Gypsum as a manure, 139

Gyration, I5

Gyrinopsis, $57^{2}$

Gyrocarpex, 489

Gyrogonites, 752, 754

Gyrophora, 647

HabrothamnUS, $54^{8}$

Hæmanthus, 6II

Hamatoxylon, $47^{8}$, $48 \mathrm{I}$

Hamodoraceæ, 6ro

Hiemodotum, 6ro

Hagenia, 486

Haidingera, 747

Hairs, 30

- calycine, rgg circulation

fluids in, 37

- collecting, 33 ,

247

corolline, 34,201

form of, 30 glandular, 33 in Aristolochia,

287

irritable and irri-

tant, 33

on calyx, 197

on filament, $2 \pi 7$

on style, 237,247 ,

290

radical, 34

— ramentaceous, 32 stellate, 31

Hakea, 570

Halesia, 529

Half-equitant, II2

Half-inferior, 246

Half-superior, 246

Halimocnemis, 563

Halonia, 734

Halophytes, $56_{3}$

Halorageacea, 493

Haloragis, 493

Hamamelidacere, 504

Hamelia, 512

Hand-plant, 449

Haplozygiz, 506

Hare-bell, 524

Hare's-foot fern, 640 
Hartnack's ' micro- Heterorhizal, 43, 357 scope, 767 " Heterosciadea, 506 - student's microscope, $7^{67}$

Haschisch, 585

Hastate, 89,203

Haulm, 44

Hawthorn, 314

Hazel, fruit of, $32 x$

- nut, 595

Heart's-ease, 44I

Heart-wood, 55

Heat during flowering, 259,288

Heather, 527

Heaths, 526

Hedera, 509

Hedge-hyssop, 552

Hedyotis, 5 I 2

Hedysarum, 478, 48r

Heer on Polar fossil plants, 756

Heimia, ${ }_{48} 7$

Hekistotherms, 664

Heliamphora, 433

Helianthemum, 439

Helianthus, 521

Helicoid, 185

Helicterex, 448

Helicteres, capsule of, 315

Heliotrope, 546

Heliotropiea, 546

Hellebore, fruit 3ra

Helleborez, 427

Helosis, 577

Helvella, 649

Helwingia, 509

Hemerocallidea, 614

Hemicarps, 3 II

Hemlock, 508

- Spruce, 599

Hemp, 584

Hen and Chickens

Daisy, I9I

Henbane, 549

- dehiscence of fruit of, 307

- pyxidium 3 I5

Henna, 487

Hepaticæ, 643

- reproduction in, 274

Heracleum, 506

Herbaceous, 50, 197

Herbarium cases, 802

formation of, 795 paper, $80 x$

Herbs defined, 46

Hermannia, 450

Hermaphrodite, 212

Hermodactyle, $6: 6$

Hernandiex, 572

Hesperidium, $3^{\text {I4 }}$

Heterocephalous, 518

Heterochromous, 517

Heterodromous, ro6

Hetercecium, 402

Heterogenesis, 15

Heteromorphic, 285
Heterosporous, 635

Heterotropal, 256

Heuchera, 504

Hevea, $58 \mathrm{z}$

Hexagonienchyma, 3

Hexandrous, 216

Hiang-Kwan, 650

Hiatus, 206

Hibbertia, 428

Hibernacula, r 10

Hibiscea, 447

Hibiscus, 448

Hickory, 596

Hidden-veined, $8_{3}$

Hieracium, 520

Hightea, 751

Hilum, 253, $329^{\circ}$

Himalayan flora, $68_{3}$, 696

Hinged dehiscence, 226

Hippocratex, $47 \mathrm{I}$

Hippomane, $58 \mathrm{r}$

Hippophaë, 57 I

Hippuris, 493

Hiptage, $45^{8}$

Hiraa, $45^{\circ}$

- fruit of, 3II

Hirneola, 65o

Hirsute, 33

Hirtus, 33

Hispid, 33

of, Histogenétic mole-

cules, 13

Histology, $76 \mathrm{r}$

Hog-plum, 474

Holland's triplet, 763

Holly, 530

Hollyhock, 447

Holoptelea, 585

Homaliaceas, 573

Homochromous, 5 I7

Homodromous, 106

Homologues of tendrils, I20

Homomorphic, 285

Homotropal, 342

Honeysuckle, 5Ix

Honkeneja, 445

Hook-climbers, $3^{86}$

Hooked hairs, $3^{2}$

Hooker on insular floras, 673

Hooker's classification, 423

Hop, 585

Hordeum, 630

Horehound, 554

Hornbeam, 595

Hornwort, 588

Horny albumen, 333

Horse-chestnut, 459

Horse-radish, 437

Horse-radish tree, $48_{3}$

Horsetails, 28x, 636

Hottentot's Fig, 510

Houseleek, 499

Houttuynia, 590

Hoya, 536

Hudsonia, 439 fruit of, 3 T7
Hugonia, 465

Humboldt's floral Region, 686

Humiriacez, 460

Humulis, ${ }^{8}{ }_{5}$

Humus, I 26, r 34 coal of, I34

Hungarian balsam, 599

Hura, $58 \mathrm{I}$

Husk, 3II -

Huyghenian eye-piece or ocular, $7^{6} 5$

Hya-hya, 537

Hyacinthus, $6 \mathrm{I} 6$

Hybridisation, 297

Hybrids, 297, 409

nomenclature of, 409

Hydnocarpus, 440

Hydnora, 577

Hydnum, 649

Hydrangea, 503

Hydrastis, 428

Hydrocera, 464

Hydrocharidacea, 6or

Hydrocharis, 602

Hydrochloric acid gas, effect on plants, " 160

Hydrocotyle, 506

Hydrocyanic acid, ryo

Hydrodictyon, 655

Hydrogen in plants, I26

Hydrogeton, 626

Hydrolea, 542

Hydropeltis, 432

Hydrophyllaceæ, 542

Hydrophyta, 652

Hygrophorus, 650

Hymenza, $48 \mathrm{I}$

Hymenium, 647

Hymenomycetes, 648

Hymenophyllea, 639

Hymenophyllites, 745

Hymenothalamex, 645

Hyoscyamus, 549

Hypanthodium, I8r

Hypecoum, 434

Hypericaceæ, $45^{8}$

Hypha, 269, 646

Hyphane, 622

Hyphomycetes, 649

Hypnum, 643

Hypocarpogean, 344

Hypochilium, 602

Hypocotyledonary, 4I

Hypocrateriform, 205

Hypogeal, 356

Hypogynous, 2 ra

Hypoxidacez, 612

Hypoxis, 6rz

Hypsometrical tempe-

raturés, $66 \mathrm{r}$

Hyptis, 555

Hyssop, 554

of Scripture, $43^{8}$

Hyssopus, 554

Hysterophyta, 647

ICACINA, 453

Iceland Moss, 646

Ice plant, 500

Idiothalamea, 646
Ignatia, $53^{8}$

Ilex, $53^{\circ}$

Ilicinea, 529

Illecebrea, 499

Illicium, 429

capsule of 3 I 5

Imbibition, 124

Imbricated, II0, I94

Impatiens, 464

Impari-pinnate, 93

Impregriation, 29I

Inarching, 324

Included, 227

Incumbent, 340

Indefinite inflores-

cence, $174,18 \mathrm{r}$

- stamens, 216

- vascular bundles,

53

Indehiscent fruits, 303 , 309, 3I3

Indeterminate, 174

India-rubber, 582

Indian Archipelago, flora of, 684

- arrow-root, 606

-.. corn, 630

- cress, 465

- cress, fruit of, $3 I I$ fig, 500

- flora, 683

- hemp, 585 shot, 607

Tobacco, 525

Indigo, $I 7 x, 480$

Indigofera, 480

Induplicate, II2, 193

Indusium, 63

Inenchyma, 6

Inferior applied to ovary and flower, I95, 246

Inflated, 198,200

Inflorescence, $\mathbf{x}, \mathrm{r}_{72}$ compound definite, 186 compound inde-

finite, $r 8 \mathrm{I}$ determinate, definite, or terminal, 175 , $x_{2}$

- diagrams to illustrate types of, 187

indefinite or axil-

lary, indeterminate, $174,176:$

- mixed, 186

- tabular view of, I88

Infundibuliform, 205

Innate, 224

Inocarpus, $\mathbf{5 7 2}$

Inorganic compounds, I24

constituents of plants, 128

- matters, iron absorbed, I32

- tabular view of, I29

Insectivorous plants, 382 
Insects, diseases of Isle of Sheppey, fossil plants caused by, 403 -4 fertilisation by, 284 in Darlingtonia and Nepenthes, $3^{8} 4$ - in fertilisation of orchids, 286

- in pitchers, 384 pollen carried by, 284

Insular floras, 673

Integer, 86

Integument, general, 25 Integuments, 326

- ovular, 253

Interbreeding, prevention of close, 286

Intercellular spaces, 7 passages or canals, 7

Interfoliar, 98

Internal membrane of seed, 327

- or intrarius embryo, 340

Internodes, 45, IoI

Interpetiolary, 98

Interruptedly pinnate, 93

Intextine, $23^{\circ}$

Intine, 230

Intrarius, 340

Introrse, 226

Inula, 520

Inulin, 163

Inverted, 257, $34 \mathrm{I}$

Involucel, xgo

Involucre, 190

Involute, III

Iodine, ro, $\mathrm{I}_{32}$

Ionidium, 44 I

Ipecacuan, 5r3

glands of, 35

Ipomoea, 544

Ireland, flora of, 705

Iridaceæ, 608

Iridæa, 655

Iris, 609

Irish Moss, 655

Iron in plants, 132

Ironwood, 528

Irregular monopetalous or gamopetalous corollas, 206

- polypetalous corollas, 205

- stamens, 283

Irritability, $374,3^{8} 3$

- of Dionaza and

Drosera, 380

- of twining plants

and tendrils, $3^{8} 5$

Irritable hairs, 33

Irritant hairs, 33

Isatis, 437

Isertia, 5 I2

Isocheimal lines, 659

Isoetacea, 640

Isoetes, reproduction of, 278 plants of, 75 I

Ispaghúl, 566

Isomeric, 166

Isonandra, $53 \mathrm{I}$

Isosporous, 635

Isostemonous, 2I5

Isotheral lines, 659

Itea, 504

Ivory Palm, 622

Ivory, vegetable, 333

Ivy, 509

Ixia, 608

JABORANDI, 59 I

Jack fruit, 3 I 6

Jacob's ladder, 542

Jacquinia, 53 I

Jagery, 62I

Jalap, 544

Jamaica pepper, 492

Janipha, $5^{82}$

Japan Lacquer, 474

Japanese flora, $68 z$

Jars for holding preparations, 803

Jasminaceæ, 537

Jasmine, 532

Jateorhiza, $43^{\circ}$

Jatropha, 582 684

Jerusalem artichoke, $52 I$

Jessamine, 53 I

Jew's Ear, 650

Jew's-mallow, $45^{\circ}$

Job's-tears, 632

Jonquille, II 2

Juglandacea, 595

Juglans, 596

Jujube, 473

Juncacex, 619

Juncagineæ, 623

Juncus, 6rg

Jungermannieæ, 643 274

Juniper, fruit of, $3 x$

Juniperus, 599

Jussiza, 493

Jussieu's classification, 418

Justicia, 556

Jute, $45^{\circ}$

K.EMPFER's floral Re-

Kalmia, 527

- fertilisation of 283

Kamalo, 58z

Kandelia, 488

Kaneh, 632

Kaneh-bosem, $6_{32}$

Kangaroo apple, $54^{8}$

- grass, 631

Karcom, 609

Kat, 47 I

Kava, 59r

Kawrie-pine, 599

Keel, 205
Java, upper Region of, gion, 682
Keg-fig, 528

Kelp, 655

Kerguelen Island cab-

bage, 437

Kernel, 326

Kiddah, 568

Kiduey bean, fertilisation in, 288

Kie-kie, 624

Kigelia, 54I

Kind or genus, 410

Kinic acid, I 7o

Kinnabaris, 622

Kino, 480

Kirschenwasser, 486

Kishuim, 495

Kleistogamous, 656

Knots, II6

Knotwort, $49^{8}$

Kochia, 563

Kokerboon, 6r5

Kola, 449

Kombe poison, 537

Koochla, $53^{8}$

Koosht, 520

Kousso, 486

Krameria, 442

Kumquat, 455

Kussemeth, 630

Kwei-hwa, 533

LABELLUM or lip, 205

Labia, 206

Labiatæ, 552 289

- fruit of, 3 II

- Region of, 680

Labiate, I98, 206

Labiatiflore, 519

Laburnum, 479

Lace-bark, 572

Lace-plant, 626

Lacinix, 7, 198

Laciniated, 87 , 201

Lacis, 588

Lacistema, 590

Lacistemace 289

Lacquer, 474

Lactuca, 522

Lactucarium, 522

Lacuna, I3

Ladanum, 439

Lagenaria, 496

Lagerströmia, 487

Lagetta, 572

Lamb's Lettuce, 5 I5

Lamellax, 249, 648

Lamiaceæ, $55 \mathrm{I}$

Lamina, 20I

of leaf, 82

Laminaria, 654 zone of, in Britain, $7 \times 6$

Lamium, 554

Lanceolate, 89

Lancewood, 430

Langsat, 460

Lansium, 460

Lantana, 556

Laportea, 584

Larch, 599
Larch, cone of ' 3 I7

Lardizabala, $43 I$

Larix, 599

Larkspur, 427

Lasiandra, 489

Lasiopetalum, 450

Lastrea, 639

Latent, II 2, II 7

Lateral, 108, 247, 340

- applied to the

parts of a flower, I95

dehiscence, 226

Latex, 2r, 445

- granules in, 145

Lathrae, 55 I

Lathyrus, 48I

Laticiferous vessels, 2I, I 45

movements

in, 145

Latiseptze, 436

Latitudinal range of vegetation, 678

Lattice-plant, 686

Lauracea, $\mathbf{5 6 6}$

- fossil, 754

- Region of, 699

Laurelia, 589

Laurus, 567

Laurustinus, 5 II

Lavender, 554

Laver, 655

Lavoisiera, 489

Lawsonia, 487

Layering, Ir 3

Leaf, 79

- arrangement, IOI climbers, 386

the type of all

parts of the flower,

172

Leaf-buds, ro8, 335

- aerial, II4

- anomalies of, 116

- axillary, 108

_._. extra-axillary, II?

- lateral, 108, 112

- subterranean, Ix4

- transformations

of, 116

Leafless acacias, 96

Leaflets, 86, 9I

Leaf-stalk, 94

Leafy bracts, I89

Leather-wood, 572

Leaves of acotyledons, IOI

aerial, 79

analogy of car-

pels to, 235

- anomalous forms of, 99

- arrangement in the bud, III

arrangement on the axis, ror

- buds on, $118,35^{8}$

- calycine, I95

cauline, ror

clustered or fas-

cicled, 369 
Leaves, colouring "inatter of, 392 9I compound, 85, 86,

deciduous, 83 , I23 diseases of, caused by insects, 403 effect of hydrochloric and sulphurous acid gas on, $I 60$ - effect on the atmosphere, $\mathrm{x21}$, 557

- evergreen, 83 , I23 exhalation of, I2I fall of, 123 floral, Tor, 789 forms of, 85 functions of; I2I general summary of conformation of, 93

- of dicotyledons, 100 of monocotyledons, ror

- primordial, ror, 335 propagation by, II 8

radical, ror

- ramal, ror

- seminal, ror, 339

- simple, 85,86

- skeleton, 79 spiral, $9 \mathrm{r}$

- spiral arrange-

ment of, 103

- structure of, 79

- submerged, 79, 8I

- succulent, go

- transpiration of, I 2 I

vascular system of, 79

venation of, 83

Lebonah, 475

Lecanora, 647

Lecca-gum, 533

Lechea, 439

Lecidea, 646

Lecotropal, 255

Lecythideæ, 49 I

Lecythis, 492

Ledum, 527

Lee2, $46 \mathrm{x}$

Leek, 6IS

-Legume, lomentaceous, 3 T2

- orpod, 3I2

Legumin, vegetable, I66

Leguminosæ, 476

Lertilisation in, 289 fossil, 754

- fruit of, $3^{\text {ra }}$

Lemnex, 625

Lemon, 314, 454

Lemon-grass, $63 \mathrm{I}$

Lemon-plant, $55^{8}$

Lenses, 762

- for microscope, 762
Lentibulariacea, 557

Lenticels, 36

Lenticular glands, 36

Lentisk, 474

Leontice, $43^{I}$

Leopard's-bane, $52 I$

Leopoldinia, 622

Lepidium, 435

Lepidocaryinæ, 62r

Lepidocaryum, 621

Lepidodendron, 733

Lepidophyllum, 730

Lepidostrobus, 733

Lepidote, 3 I

Lepis, $3 I$

Lepistemon, 544

Leptanthus, 6 r8

Leptolæna, 452

Leptosiphon, $54^{2}$

Leptospermum, 49r

Leschenaultia, 523

Lessonia, 654

Letterwood, $5^{8} 7$

Lettuce, 522

Leucodendron, 570

Leucojum, 6Is

Leucopogon, $5 z^{8}$

Leycesteria, $5 \mathrm{xT}$

Lianas, 45

Lias, flora of, 747

Liber, 57

Libocedrus, 598

Lichenes, 644

Lichenin, or Lichenstarch, 646

Lichens, fertilisation of, 269

Region of, 679

Lid, 199, 232, 307

Life of plants, duration of the, 359

Light, as affecting plant distribution, 667

- effect of different rays on the colours of plants, 390

- effect of rays on germination, 346

- effect of rays on plants, 159

- effect on flowers, 258,263

- effect on growth of plants, 354

- effects on respiration of plants, I5 6

effect of, on sensi-

tive plants, 376

Lign Aloes, 572

Ligneous stem, 50

- tissue, 16

Lignin, 9, 155

Lignum-vitæ, 466

Ligulate, 207

Ligule, 99

Ligulifioræe, 5 r9

Ligustrum, 534

Lilac, 533

Liliaceæ, 6r3

Lilies of the field, $6 \pi_{5}$

Lilium, 6I5

Lily of the fields, $6 \mathrm{x} 2$
Lily of the valley, $6 \pi_{4}$

Limb, zor

- of calyx, I98

- of leaf, 82

Lime, 455

Lime in plants, I32 in soils, I35 phosphate

sulphate of as ma-

nures, 139

Lime tree, 450

Limnanthacea, 465

Limnanthes, 465

Limnocharis, 624

Limonia, 454

Linacea, 463

Linaria 582

Linden-tree, $45^{\circ}$

Lindley's classification, 420

Linear, 88, 203

Linen, 16

Ling, 527

Linnzea, 5 II

Linnzus ${ }^{2}$ artificial system, tabular view of classes and orders of, $4 \mathrm{I} 4$

floral Region, 680

Linnean artificial system, $4 I_{3}$

- system, foundation of, 264 216

Linseed oil, 464

Lip, $x 98,205$

Liparis, 604

Lipped, 206

Liquidambar, 504

Liquid manures, I 40 :

Liquiritia, 479

Liquorice, 479

Lirellae, 645

Liriodendron, 429

- fruit of, 3 I2

Lissanthe, 528

Listera, 604

- fertilisation in, 288

Litchi, 459

Lithospermum, 547

Litmus, 627

Littoral zone of Britain, 7 I5

Liverwort, 643 274

Lizard's tail, 590

Loasacea, 493

Lobed, 87

Lobeliacex, 525

Loblolly Pine, 599

Localities of plants, 668

Loculament, 225, 24T

Loculicidai, 304

Locusta, 179

Locust-tree, $48 \mathrm{I}$

Lodicula, 208

Lodoicea, 62I

Loganiacea, 537

Logwood, $48 \mathrm{I}$
Lolium, 63x

Lombardy Poplar, 592

Lomentacea, 436

Lomentaceous legume, $3^{12}$

Lomentum, 312

Lonchopteris, $73^{2}$

London clay, fossils

of, $75^{\mathrm{I}}$

Longan, 459

Long purples, 605

Lonicerea, 5 II

Loosestrife, $4^{8} 7$

Loquat, 486

Loranthacea, 574

Loranthus, 575

Lote-bush, 473

Lotus, 478

- bean, $43^{2}$

-.. tree, $45^{8}$

Love-apple, 549

Love-lies-bleeding, 562

Lucerne, 479

Lucuma, 531

Luffa, 496

Luhea, 450

Luminosity of plants, 389

Luminous fungi in coal-mines, $3^{89}$

Lung-wort, 647

Lupinus, 479

Lupulin, 585

Lurp, 49T

Luzula, 6 I9

Lychnis, 445

Iychnophora, 521

Lycoperdon, $65 \mathrm{I}$

Lycopersicum, 549

Lycopod, 64I

Lycopodiacea, 640

- reproduction in, 278

Lycopodites, 733

Lycopodium, $64 \mathrm{I}$

Lycopus, 554

Lygeum, 632

Lyginodendron, 742

Lygodium, 639

Lymphatic, 33

Lyrate, 87

Lythracea, 487

Lythrum, trimorphic flowers of, 285

MABA, 5

Macadamia, 570

Macahuba-palm, 622

Mace, 328,569

Mackinlaya, 509

Maclura, 587

M'Nab, Dr. W. R., on

Calamites, 737

Macrochloa, 632

Macrocystis, 654, 7or

Macropiper, 59I

Macropodous embryo, 336

Macrosporangía, 278

Macrospores, 278, 640,

Macrozamia, 600 
Madder, 5 I 4

Madeira, plants of, $68 \mathrm{I}$

Madhuca tree, $53 \mathrm{r}$

Madia, 521

Masa, 531

Magalhaens and Tierra del Fuego flora, 688

Magnolia, fruit, 3rz

Magnoliaceze, 428

Magnolias, Region of, $68 \mathrm{I}$

Mahogany, 460

- fruit of, 3 I5

Mahonia, 43I

Maiden-hair, 640

Maize, 630 fruit of, 3 II

Malachadenia, 605

Male Shield-fern, 639

Malesherbia, 497

Malic acid, I70

Malicorium, 3I 4

Mallotus, 582

Mallow, 446

Malpighiaceæ, 457

Malvacex, 446

Mammee apple, 457

Manchineel, $5^{8 \mathrm{r}}$

Mandragora, 549

Mandrake, 549

Manganese in plants, I32

Mangifera, 473

Mango, 3II

Mangold-wurzel, $56 z$

Mangosteen, 457

Mangrove, -488

Manicaria, 622

Manihot, 582

Manilla hemp, 608

Manioc, 582

Manna, 443, 479, 533, 599

- ash, 533
sugar, I65

Mannite, 165

- in seaweeds, 165

Mantellia, 750

Manure,application of. I 36

Manures, comparative value of, 137

Manuring with green crops, I 40

-with sea-weeds, I40

Manzanita, 527

Maple, $45^{8}$

- sugar, 164

Maranta, 607

Marantacea, 606

Maraschino, 486

Marattia, 640

Marattiea, 639

Marcescent, 200, 2 II

Marcgraavia, peduncular pitchers of, 290

Marcgravia, 452

Marchantia, 644

Marchantieæ, 643 274
Mare's-tail, 493

Margaric acid, 168

Marginate, 198

Margosa, 460

Marine flora of Britain, 714

- vegetation, zones of, 699

Marjorain, 554

Marking-nut, 474

Marmalade, 53 I

Marrubium, 554

Marsdenia, 536

Marsh Mallow, 447 trefoil, 540

Marsilea, 640

Marsileacea, 640

- reproduction of, 279

Martynia, 54I

Marvel of Peru, 560

Mask-like, 207

Mastich, 474

Maté, $53^{\circ}$

Matico, 59r

Mattulla, 32

Maturation of the pericarp, 319 of the seed, 343

Mauritia, 622

Mayaca, 623

May-apple, 428

Meadow grass, $63 x$

saffron, 616

Mealy, 333

Mechoacan-root, 544

Meconic acid, I70

Meconopsis, 433

Medicago, 479

Medick, 479

Mediterranean flora, 680

Medlar, 3 I4

of Surinam, 53 $\mathrm{I}$

Medullary rays, 50, 59, 75

- sheath, 53,75

Megacarpaea, 435

Megasporangia, 278

Megaspores, 278

Megatherms, $66_{3}$

Megistotherms, $66_{4}$

Melaleuca, $49 x$

Melampyrum, 55I

Melanosporea, 653

Melanthace 2,616

Melanthium, $6 \mathrm{I} 6$

Melastomaceæ, 489

Region of, 687

Melegueta pepper, 606

Meliacez, 459

Melilotus, 479

Meliosma, 459

Melissa, 554

Melloca, 446

Melocanna, 632

Melon, 3I4, 495

Memecylon, 489

Meninia, 556

of, Menispermacea, 430

Mentagraphytes, $65 \mathrm{I}$
Mentha, 554

Mentzelia, $494^{\circ}$

Menyanther, 539

Menziesia, 527

Merenchyma, 3

Mericarps, 3II

Merismatic division of cells, I4, 267

Merithaili, 36z

Mertensia, 547

Merulius, 650

Mesembryaceæ, 510

Mesembryanthema, Region of, 689

Mesembryanthemum, 500

Mesocarp, 300

Mesochillium, 642

Mesophloum, 57

Mesophyllum, 80

Mesosperm, 327

Mesotherms, $66_{4}$

Mesua, 457

Metamorphic rocks, 723

Metamorphoses, vegetable, 362

Metasperms, 292

Meteoric flowers, 263

Meteorological influence on odours of plants, 396

Metroxylon, 621

Mexico and Guiana, flora of, 686

Mexico, flora of Highlands of, 686

Meyen's phyto-geographical zones, 692 -. zones, tabular view of, 694

Mezereon, 572

Michaux's floral region, 68I

Miconia, $4^{89}$

Microcachrys, 597

Microgonidium, 270

Micrometer, $77 \mathbf{r}$

Micropyle, 329,254

Microscope, $76 \pi, 763$

- compound, 765

- focal adjustment of, 779

- its uses, $76 \mathrm{r}$

mode of using it,

775 simple, 763

- works on the, 793

Microscopic apparatus, 771 manipulation, 772 objects for examination, 780

- objects, preservation of, 783

- observations, sources of error in, 776

- re-agents, 773

- test objects, 772

Microscopical demon-

strations, objects and illustrative tissues, $78 \mathrm{r}$

Microscopical slides, 785

78 specimens in a

case, 792

- turn-table, 786

Microsporangia, 278

Microspores, 278, 640

Microtherm, $66_{4}$

Miersia, 6I8

Mignonette, $43^{8}$

Mikania, 52I

Mildew, 399

Milk-tree, 537

Milk-vessels, 2 I

Milk-wort, 44I

Millet, 631

Mimosa, 482

Mimosites, 75I, 755

Mimulus, $55^{2}$

Mimusops, 531

Miners, 403

Mint, 554

Miocene, Arctic fossil flora, 755

—- flora, 754

- flora of Europe, 756

Miostemonous, 215

Mirabilis, $56 \mathrm{I}$

Mistleto, I42, $57 \mathrm{I}$

Mixed inflorescence, I86

Mock-apple, 496 orange, 490

Modecca, 497

Moisture, effect - of, in distribution of plants, 662 344

Mollugo, 500

Momordica, 494

Monadelphous, 218

Monandrous, 216

Monembryony, 330

Monetia, 534

Muniliform, 217

- root, 40

- vessels, 20

Monimia, 589

Monimiace 588

Monkey-bread, 449

Monkey-pot, 307, 3I5, 492

Monkey's dinner-bell, $5^{8 \mathrm{I}}$

Monkshood, 427

Monk's-rhubarb, 565

Monocarpic, 359

Monochlamydeze, 566

Monochlamydeous, I92

Monoclinous, 367

Monocotyledones, $60 \mathrm{r}$

Monocotyledonous, 334

$\frac{334}{}$ embryo, $336,3^{62}$

Monocotyledons,

leaves of, ror

—phyllotaxis of, ror 
Monocotyledons, root of, 42

Monoecious or monoicous, $212,273,567$

plants, fertilisation in, 284

Monogamia, 415

Monogynoecial, 309

Monopetalous, 203

Monophyllous, Ig6

Monosepalous, xg6

Monospermous, 309

Monothecal, 222

Monotropeæ, 526

Montpellier Scammony, 536

Monstera, 685

Monstrosities of calyx, Ig6

of flowers, $I_{72}$

Montia, 446

Montinia, 493

Moon-plant, 545

n_ seed, 430

Moracea, 586

Mora wood, $48 \mathrm{I}$

Morchella, 649

Morel, 649

Morina, 5 I5

Morinda, $5 \times 4$

Moringaceæ, 482

Morphia, 433

Morphology, 362

Morus, 586

Mosses, 64 I

- leafy, 276

- morphology of,

643

preparation of,

800

276

reproduction in,

Mountain Tobacco,52I

Mountains of Europe,

flora of, 679

Mouriria, 489

Movements in cells,

I5I in flowers, 386

- in plants, 375

-... in plants, causes of, $37^{8}$

Moving cells of vaucheria, 269

- spores, 265

Moxa, 521

Mucor, 649

Mucronate, 89

Mucuna, 480

Mucus, definite, 26

Mudar, 536

Mueller on fertilisation of grains, 656

Mulberry, 316, 586

Mull, Miocene flora of, 755

Mullein, 552

Multicostate, 84,93

Multifid, 87, 248

Multijugate, 93

Multilocular, 24x, 299

Multipartite, $24^{8}$
Multiple, $309^{\circ}$

or Polygyncecial

Fruits, 316

Multiplication of parts of flower, 365,370

Mummy-cloth, I6

Mummy-wheat, 630

Munjeet, 5I4

Munsteria, 75T

Muriform cellular tissue, 4 ,

Musa, 608

Musaceæ, 607

Muscæ volitantes, 777

Muscardine, $65^{\circ}$

Musci, 64I Region of, 679

Muscovado Sugar, 164

Mushroom, 649

- family, 647

Mussanda, 5I4

Mustard, 437 tree, 534

Mycelium, 357

Mycoderma, 650

Mylitta, $65^{\circ}$

Myoporinea, 555

Myoporum, 555

Myosotis, 547

Myrica, 592

Myricacea, 592

Myricarize, 443

Myriophyllum, 493

Myristica, 569

Myristicaceæ, 569

Myrobalans, 489

Myrosin, 169

Myrospermum, 480

Myroxylon, 480

Myrrh, 475

Myrsinaceæ, 531

Myrtacere, 490 Region of, 699

Myzodendron, 574

NABEE, 427

Nachet's achromatic microscope, 769

Nadelholzer, 88

Naiadacez, 686

Naias, 686

Naked, 252

Nannari, 536

Napiform, 40

Narcissus, 6rt

Nardoo-plant, 640

Nardostachys, 515

Narthecium, 6I6

Narthex, 507

Nascent, 21I

Naseberry, 53I

Nasturtium of gardens, 465

Natural grafting, 324

_... selection, 407 system, 406, $4 \mathbf{r} 5$

$\mathrm{Navicular,} 202$

Nectandra, 568

Nectaries, 209, 234, 369 in Orchids, 288

Nectariferous glands,

35
Nectarine, 485

Needle trees, 88

Nelsoniea, 556

Nelumbium, 432

Nelumbonex, 432

Nemophila, 542

Neottia, 604

Nepenthaceæ, $57^{8}$

Nepenthes, 578

insects in pitchers of, $3^{8} 4$

Nephelium, 459

Nerd, or Nard, 5Is

Nerium, 537

Neroli oil, 454

Nertera, $5^{\text {I2 }}$

Nervation, 83

Netted veins, 84

Nettle, 584

__ fertilisation of, 283

- tree, 585

Neurada, 485

Neuropteris, 732

Neuter, 368

New Zealand Flax, 6I 5

- flora of, $69 \mathrm{I}$

spinach, 500

Nicker tree, 48I

Nicotina, $55^{\circ}$

Nicotiana, $55^{\circ}$

Nidularia, 649

Nigella, 427

Night-flowering plants, 262

Cereus, 50x

Nightshade, $54^{8}$

Nilssonia, 749

Nincopipe, 559

Nipa, 624

Nipadites, 75 I

Nisa, 574

Nitella, 651

Nitraria, $45^{8}$

Nitrogen in plants, 127

Nodes, 45, ror

Nodules, woody, ri 6

Nodulose, 40

Nöggerathia, 74I, 745

Nolana, 547

Nomenclature of classes, 4II

Norfolk Island pine, 598

North Asiatic flora, 680

North European flora, 680

Northern part of North America, flora of, $68 \mathrm{I}$

Norway spruce, 599

Nosology, 397

Nostoc, 646, 654

Nostochinex, 654

Notorhizea, 340,435

Nourishment of plants, 124

Noyau, 486

Nuclei, 25 I

Nucleoli, 25I

Nucleus of a cell, 9
Nucleus or kernel, 253, 326

Nuculanium, 3I5

Nucule, 25I, 274

Nucumentacea, 436

Number of species of plants, 658

Nuphar, 432

Nut or glans, 3II

Nutmeg, 3II, 328, 569

Nutrition, requisites for, 125

Nutritive organs, functions of, I24

products of different crops, 167

Nux vomica, 538

Nyctaginacea, 560

Nyctanthes, 532

Nympharace, 43 I

Nymphaa alba, seed of, 326

Nyssa, 5ro

OAK apples, 403

- lungs, 647

spangles, 404

Oaks and Firs, Region of, 680

Oats, 630

Obcordate, 89, 202

Object-glass of microscope, 765

Objectives of Ross and Gundlach, 794

Oblique, 86, 202

Oblong, 89

Obovate, 89

Obsolete, r98

Obvolute, Ixa

Oceanic Region, 684

Ochnacex, 469

Ochrea, 97

Ochro, 448

Ocotea, 568

Octandrous, 216

Octangular, 46

Ocymum, 554

Odours in natural orders, 396, 397

$\longrightarrow$ of flowers in fertilisation, 284,288

CEdogonium, reproduction of, 270

Enanthe, 508

Enothera, 493

Offset, r $_{3}$

Oidium, 650

Oil in seeds, 168

- in fruits, $32 \mathrm{~T}$

in vegetables, 167

Oils in cells, 12

Oily albumen, 333

Olacacea, 453

Olax, 453

Oldenlandia, 5r4

Oldfieldia, 532

Old-man's-beard, $6 \mathbf{r} 3$

Oleacea, $53^{2}$

Oleander, 537

Oleaster, 570

Oleic acid, $x 68$ 
Olibanum, 475

Oligandrous, 216

Oligospermous, 3 I2

Olive, 533

Omam, 508

Omphalea, 583

Omphalobium, 476

Omphalode, 329

Onagracex, 492

Oncidium, 604

Oncober, 440

Onion, 6I5

Onobrychis, 479

Onygena, 649

Oogones, 272

Oogonia, 268

Oolitic flora, 748

Oophoridia, 278

Oosporangia, 272

Oospore, 268

Opening of flowers, 262

Operculate, I99, 232, 307

Operculum, 307

Ophelia, $54^{\circ}$

Ophiocaryon, 459

Opbioglossacee, production of, $28 \mathrm{I}$

Ophioglossea, 639

Ophiopogonex, 614

Ophrys, 604

Opilia, 453

Opium Poppy, 433

Opoponax, 507

Opposite, Io2, Irz

Opuntia, 502

Orach, 562

Orange, 3I4, 454

Orbicular, 87

Orchid flower, section of (Darwin), 373

Orchids, fertilisation of, by insects, 288

nectaries in, 288

Orchil, 647

Orchidaceæ, 602 dehiscence of

fruit of, 306

fertilisation of, 286

Orchideous, 205

Order or family, 4 ro

Orders in northern hemisphere, 678

in southern hemisphere, 678

restricted in distribution, 677

Orebim, 592

Oregon flora, 682

Oreodaphne, 569

Organic acids, Iz7

- bases, r 70 compounds, 124 constit

Organ-nut, 429

Organogeny, 243

Organography, 7r8

Organs, compound, 25

- elementary, $\mathbf{I}$ $\mid \begin{aligned} & \text { Organs of nutrition or } \\ & \text { vegetation, } 25 \\ & \text { of reproduction, }\end{aligned}$ 25, I7I of reproduction, functions of, $26_{4}$ - subordination in, value of, 4 I 6 $3^{6} 5$ symmetry of, $36_{3}$

Oriental Plane, 594

Origanum, 554

Ornus, 533

Orobanchacea, 550

Orris-root, 609

Orthoploceæ, 340,435

Orthotrichum, 643

Orthotropal, 255, 330

Orthotropous, 255

Orthosperma, 506

Oryza, 630

Osbeckia, 489

Oscillatoria, 654

Osmose, 143

Osmundea, 639

Osyris, 574

Otozamites, 749

Ourari poison, $53^{8}$

Ouvirandra, 626

Ovary, divisions in, 240

- or germen, 235

position of, 246

Ovenchyma, 4

Ovule, 235, 25I

coverings of, 253

- dehiscence of, 252

number in the

ovary, 257

position in the

ovary, 256

Ovules of gymnosperms, 292

Oxalic acid, r7o

Oxalidace ${ }^{2}, 46$

Oxalis, movements in leaves of, 377

Oxlip, 558

Oxycoccus, 526

Oxygen in plants, 126

- absorbed by

flowers, 258

- effect on colours, 393.

in germination, 345

Oyster-plant of America, 522

Pacific Islands, flora of, 684

Padina, 654

Paderia, 5I2

Pronia, 427

Paiophyll, 392

Pakyoth, 496

Palzontological bo:

tany, 718

Palate, 207

Palea, 208

Palea of artichoke, 1901
Palissya, 748

Paliurus, 473.

Palma Christi, 58I

Palmacites, $75^{2}$

Palmæ, 6r9

Palmate, 87

Palmatifid, 87

Palmellacex, 654

Palmite, 6rg

Palm, dichotomous stem of, 69 - oil, 621

Palms of chalk, 75 I I08 phyllotaxis of,

- Region of, 687 of, 66

Palo de Vaca, 587

Palo de Velas, $54 \mathrm{I}$

Pampas-grass, $63 \mathrm{I}$

Panama hats, 624

Panax, 509

Pancratium, 6I2

Pandanacea, 624

Pandanocarpum,.75I

Pandanus, 624

Panduriform, 87

Pangium, 440

Panicle, I77, 208

Panicum, 631

Panspermism, I5

Pansy, 44I

Papaveracea, 433

Papaw, 3r4

- tree, 497

Papayacea, 496

Papayrolez, $44^{\circ}$

Paper mulberry, 587

- for drying plants, 797

- reeds, 628

Papilionaceous corolla, 205

Papillae of roots, 38

ㄱ opidermis, 30

Pappus, I99

Papyrus, 628

Para rubber, $5^{82}$

Paracorolla, 2Io

Paraguay Tea, 530

Paraphyses, 210

Parasites, 40, I4I

Parasitic fungi, I4I

Parastemones, 210

Pareira-brava, 430

Parenchyma, 37,80

Pariglin, $6 \mathrm{r}_{7}$

Paris, 618

Paritium, $44^{8}$

Parideæ, 618

Parietal placenta, 242

Parietaria, 584 fertilisation of, 283

Parietin, 647

Pari-pinnate, 93

Parkia, $47^{8}$

Parmelia, 647

Parmentiera, 54I

Parnassia, 455

Parnassia, fertilisation of, 283,286
Paronychiacea, 498

Paropsia, 497

Parsley, 507

Parsnip, 507

Parthenogenesis, 265

Partite, 86

Partitions, 86

Passifloraceæ, 497

Passion-flower, 498

Pastilles, 529

Pastinaca, 507

Patchouly, 554

Patellax, 645

Patulous, 197

Paullinia, 459

Pavia, 459

Peach, 3II, 485

Pear, 3I 4, 486

Peas, 477

Pecopteris, 73I

Pectic and pectosic acid, 164,321

Pectinate, 87

Pectinated stomata, 637

Pedaliea, 540

Pedate, 87

Pedatifid, 87

Pedicel, I72

Pedicellate, $\mathbf{1 7 2}$

Peduncle, $\mathbf{I}_{72}$

- Heshy, 3 zo hollow, 74

Pedunculate, I 72

Peg-grafting, 325

Pelargonium, 462

Pellitory, 584

- of Spain, 520

Peloria, 552

Pelorisation, 372

Peltate, 87, 250, 257

Peltate hairs, 33

Penæaceæ, 57I

Pencil-cedar, 599

Penicillium, 650

Penny-royal, 554

Pentadesma, 456

Pentagonal, 363

Pentamerous, 363

Pentandrous, 2x6

Pentapetalous, 203

Pentaphyllous, I97

Pentasepalous, 197

Penthorum, 500

Pentstemon, 55 I

Pepo or Peponida, 3I4

Pepper, 59r

Pepper, Jamaica, 492

Pepper-brand, 399

Peppercorn, 403

Peppermint, 554

Pepperwort, 640

Perenchyma, Io

Perennial, 355

Pereskia, 501

Perfoliate, Ioo

Perianth, $x 93$

Pericarp, 298, 300

maturation of the, 319

Pericarpial coverings, 326 
Perichatial, 64I

Pericladium, 97

Periderm, $5^{8}$

Perigone, 193

Perigynium, 209

Perigynous, 213, 246

Periodical phenomena in plants, 263

Perisperm or albumen,

$254,327,331$

Pexispermic, 343

Peripherical, 34I

Periploca, 536,

Perispore, 335

Peristomatic, 28

Peristome, 6.1

Perithecia, 268

Peritropous, 257

Periwinkle, 537

Permian fossils, 744

Pernambuco-wood, 482

Persea, 569

Persian flora, 685

Persimon, 528

Persistent, 2II, 248

Personate, 207

Persoonia, 570

Pertuse, 8I

Perula, rog

Peruvian cherry, 549

Petaline hairs, 20I

Petaloidere, 6or

Petals, 200

anomalies in, 209

Petiolary, 98, 120

Petiolate, 339

Petiole, 82, 94

Petioles, anomalous forms of, 99

Petiolules, 92

Petiverieas, 563

Petroselinum, 507

Pettigrew's views on circulation in plants, I47

Pelumos, 589

Peuce, 748

Peziza, 649

Phacelia, 542

Phæosporeæ, 653

Phalaris, 63x

Phallus, 650

Phanerogamous, I7I

- plants, 425

- plants, 425 organs of, 264

- plants, fertilisation in, $28 \mathrm{I}$

Pharbitis, 545

Phascum, 643

Phaseolea, $47^{8}$

Phaseolites, 754

Phaseolus, 48I

Philadelphacea, 489

Philesia, 6r7

Philippodendron, 450

Philydrum, 6ro

Phillyrea, 533

Phleum, 63I

Phlorizin, 166

Phlox, 54r

Phoenicites, 754
Phoenix, 62I

Phoranthium, I73

Phormium, 6r5

Phosphorescent rics, 389

Phragmata, 244

Phycochrome, 646

Phylica, 472

Phylla, I95

Phyllanthus, 580

Phyllaries, Igo

Phyllocladus, 597

Phyllodium, 96

Phyllogen, 67

Phylloid, I73

Phyllolobe $2,47^{6}$

Phyllophor, 67

Phyllotaxis, Ior fractions in, ro4

- of acotyledons, IO7

of bracts, 189

- of dicotyledons, 107

- of monocotyledons, 107 of palms, 108 of pines, I08

Physalis, 549

Physic-nut, 582

Physiognomic plants, 675

Physomyces, 649

Physomycetes, 649

Physostigma, $48 \mathrm{I}$

Phytelephas, 622

Phytochlor, 258

Phyto-geographic $\mathrm{Re}$ gions, 678

Phytolaccacea, 563

Phytons, rog, 362

Phytozoa, 265

Phytozoids, 234

Piassaba, 622

Picea, 599

Picotees, 445

Picraena, 469

Picrotoxin, 430

Pietra fungaia, 650

Pig-nut, 507

Pigs'-faces, 500

Pileorhiza, 38

Pileus, 647

Pili, 3o

Pilocarpus, 467

Pilose, 33, 199

Pilularia, 640

Pimenta, or Pimento, 492 .

Pimpinella, 508

Pinakenchyma, 4

Pinaster, 599

Pinckneya, 5I3

Pine-apple, 3I6, 6r3

- Pines, phyllotaxis of, ro8

Pin-eyed, 212

Piney resin, 45I

Piney tallow, 45I

Pinguicula, 383,557

Pinites, $739,754,757$

- succinifera, 754
Pink, 445

Pink-root, 539

Pinnate, 92

Pinnatifid, 86 , 20I

Pinnatipartite, 87

Pinus, 599

Pinus fossil, 755

Piper, 59I

Piperacea, 590

R'egion of, 686

Piratinera, $5^{87}$

Piscidia, 48 $\mathrm{r}$

Pisonia, 56r

Pissadendron, 739

Pistacia or Pistachionuts, 473

Pisteæ, 685

Pistil, Igr, 21 r, 234

- mature, 298

Pistillary cords, 240 , 252

Pistillate, 368

Pistilidium, 250, 265

Pistilliferous, 212,264 , $3^{68}$

Pisum, 478

Pita flax, 6r2

Pitch, $59^{8}$

Pitcher, 383

- of Cephalotus, 504

${ }^{5}$ of Darlingtonia $3^{84}$ of Discidia, 504 of Marcgraavia, 290

of Nepenthes, 504 of Sarracenia, 504 plant, $57^{8}$

Pith, 50, 52, 75

Pitted vessels, 20

Pittosporacea, 465

Pitus, 739

Placenta, 240, 315

- attachment of seeds to the, 329

- axile, 243

- central, $24 \mathrm{I}$

- formation of, 24 I

- free central, 243

- marginal, 24I

- parietal, 242

Placentaries, 240

Placentation, 243

Plaited, III

Plane-trees, 594 -... of Scotiand, $45^{8}$

Planera, 585

Planta tristes, 262

Plantaginacer, 559

Plantago, 560

Plantain, 608

Planting of trees, 78 , 136

Platanacea, 593

Platanus, 594

Platylobea, 436

Platystemon, 433

Plectranthus, 554

Pleiotracheæ, I8

Pleospora, 65I

Plerandra, 509
Pleurenchyma, $\mathbf{6}$

Pleurisy-root, 536

Pleurocarpi, 643

Pleurorhizea, 340, 435

Plicate, $\mathrm{r}$ I

Pliocene flora, 756

Plocaria, 655

Plum, 3II, 485

Plumbaginaceæ, 559

Plumbago, 559

Plumose, 199

Plumule and radicle, 334

or ascending axis, 334

Poa, 631

Pod, 3I2

Podalyriea, $47^{8}$

Podocarp, 305

Podocarpus, 599

Podophyllum, 428

Podosperm, 253

Podostemacea, 588

Podostemon, 588

Pogostemon, 554

Poison-elder, 474

- ivy, 474

- oak, 474

-..- sumach, 474

- vine, 474

Poisoning plants in herbarium, 8or

Poisons, effect of, on plants, 133

Poke, ${ }^{6} 63$

Polar fossil flora, 756

695

Polariser, 769

Polemoniacea, $54 x$

Polianthes, $6 \mathrm{r}_{4}$

Pollard-trees, II3

Pollen, 216, 226

- application to the stigma, 282

- carried by insects and wind, 284

- coverings of, 230 duration of vita-

lity of, 291

- grains, forms, and

number of, $\mathbf{2 3 2}, \mathbf{2 8 2}$ granules, $23 \mathrm{I}$

masses, 220 scattering of, $28 \mathrm{z}$ tube, 233

tubes, extent to which they penetrate, 295

- tubes in gymnosperms, 293

- tubes, number of, 233

utricle, 228

Pollinia, 229, 286

Polyadelphous, 219

Polyandrous, 216

Polycarpic, 359

Polycarpon, 445, 499

Polychroit, 609

Polycotyledonous, 338

Polyembryony, 33 
Polygala, fertilisation of, 289

Polygalaceze, $44 \mathrm{I}$

Polygamia, 563

Polygamous, 212, 367

Polygonacex, 563

Polygonal, $33^{\circ}$

Polygonum, 564

Polygynoecial, 309. $3 \times 6$

Polynesian Region, 684

Polypetalous, 203

Polyphyllous, Igo, Ig6

Polypodiex, 639

Polyporus, $65^{\circ}$

Polysepalous, ro6

Polyspermous, 312

Polystemonous, 215

Polytrichum, 643

Pomaderris, $47^{2}$

Pome, 314

Pomer, 484

Pomegranate, 31 3, 492

Pompelmoose, 455

Pondweed, 626

Ponga, 639

Pontederia, 618

Pontederiacez, 618

Poor man's weather glass, 262,559

Poplar, 592

Poppy, 433

- capsule of, 308 , 3 I5

Populus, 592

Porphyra, 655

Porrigophytes, 65 I

Portland dirt-bed, 749

- sago, 163,685

Portugal Laurel, 486

Portulacacea, 445

Posterior applied to parts of a flower, 195

Postica, 226

Potalia, $53^{8}$

Potamex, 626

Potamogeton, 626

Potash and soda as manures, ${ }_{13} 8$

- in plants, ${ }^{2} 32$

Potato, 3I3, 548

- disease, 398, 402

- eyes of, 47

- starch in, 162

Potentilla, 486

Potentillea, 484

Poteriea, 484

Pothocites, 742

Pothos, 625

Pounce, 599

Prafloration, 193

Prafoliation, I ro

Pramorse, 47

Prangos, 507

Pretrea, 54I

Prickles, 32

Prickly ash, 468

- pear, 501

- pole, 622

Primary colours, 390

veins, 83

Primine, 254
Primordial, 335

Primordial leaves, ror

Primrose, $55^{8}$

pin-eyed, 285

thumb-eyed, or

thrum-eyed, 285

Primroses, fertilisation in, 285

Primula, 558

Primulace $x, 557$

Prince's feather, 562

Pringlea, 437 antiscorbutica,

fertilisation in, 284

Prinos, 530

Prionium, 6rg

Prismatical, 9o

Prismenchyma, 4

Privet, 534

Procumbent, 45

Products and secre-

tions of plants, 124, I6I

— azotised, 166

- resinous, 169

Pro-embryo, 293

Progression' of sap, J24 of sap, cause of, I4 8

Proliferous, IIg

- bracts, IgI

plants, 357

Propagation by grafting, 324

by leaves, II8

Propagulum, Ix3

Prosenchyma, 4, I6

Protandrous, 212, 286

Protea, $57^{\circ}$

Proteacea, 570

Prothallus of ferms, 294

Protium, 475

Protococcus, 655

Protogynous, 212, 286

Protoplasm, 8

Pruning trees, II 3

Prunus, 485

Psamma, 632

Psaronius, 732

Pseudo bulb, 47

Pseudospermous, 303

Psidium, 492

Psychotria, 512

Ptelea, 468

Pteris, 640

Pterocarpus, 480

Pterophyllum, 747

Ptychotes, 508

Pubescent, 33

Puccoon, 434

Puchurim beans, $56 \mathrm{~g}$

Puff-balls, 65x

Pulse, 479

Pulverised soil, 347

Pulvinus, 94

Pumpkin, 495

Punica, 492

Punctated woody tissue, I7

Purples, 403

Pursh's floral Region,
Purslane, 445

Putamen, 3or

Putty-wort, 605

Puya fibre, 584

Pycnides, 269

Pyrena, $3 x 5$

Pyrenean flora of Ireland, 708

Pyrenees, flora of, 696

Pyrenocarpei, 646

Pyrethrum, 5zo

Pyrolere, 527

Pyrrhosa, 570

Pyrularia, 574

Pyrus, 486

Pythagorean bean, 432

Pyxidium, 3I5

Quadrangular, 46

Quadrifurcate, 223

Quadrijugate, $\mathrm{IO}_{4}$

Quadrilocular, 222, $24 \mathrm{I}$

Quadripartite, 198

Qualea, 488

Quamoclit, 544

Ouartine, 254

Quassia, 469

Quaternate, 93

Quercitron, 595

Ouercus, 595

Quillaia, 486

Quillaieæ, 484

Quill-wort, 640

Quinate, 93

Quince, 3I 4, 486

Quincuncial, 106

Qstivation, I94

Quincunx, 107

Quinine, $5 \times 3$

Ouinoa, 56z

Quinquangular, 46

Quinquecostate, 84

Quinquefid, 87, x97

Quinquepartite, 87 , Ig8

Quintine, 254

Quisqualis, 489

Quitch-grass, 63I

Quiver-tree, 6 55

RACEME, I77

-. of capitula, $18 z$

Races, 407

Rachiopteris, 732

Rachis, 172

Racodium, $65^{\circ}$

Radical hairs, 34

- leaves, IoI

Radicle, direction ' of the, 343

- or young root, $4 \mathbf{r}$, 334

Radicular merithral, 362

Radii, I80

Radiola, 463

Radish, 437

Rafflesia, $57^{8}$

Rafflesiacex, 577

Rain, coloured, 282

Raisins, 462
Ramal leaves, ror

Ramentaceous, 32

Rampion, 525

Ramsden eye-piece or ocular, 765

Ranunculace $x, 426$

Ranunculeæ, 427

Ranunculus, 427

fruit of, 3 Io

Rape, 437

Raphe, 256, 329

Raphides, II

Raspberry, 312, 485

Ratafia, 486

Ratsbane, 573

Rattan Palm, 622

Rattoons, $I 6_{4}$

Ravenala, 608

Rays of light, effect in germination, 346 354

Reaumuria, 443

Receptacle, I73, I8n 78 of secretions, $\pi 2$

Reclinate, xro, 339

Red cedar, 599 gum, red robin, red rust, and red rag, 399 snow, 654 whortleberry, 526

Reduplicate, 193

Reed mace, 686

Region of Amyridacez, 685 of the Asiatic

Islands, 684 of Asters and

Solidagos, 68r of Cactacea and

Piperacea, 686 of Cinchonas, 686 of Epacridacea

and Eucalypti, $68 \mathrm{~g}$

- of Escalloniz and

Calceolariæ, 686

- of Highlands of

Mexico, 686

- of Labiatze and

Caryophyllacez, 680 - of Magnolias, 68x

- of Mesembryan-

thema and Stapelize, 689

_ of New Zealand, 69I

of Palma and

Melastomacea, 687

of Saxifrages and

Mosses, 679

- of. Shrubby Composite, 687

of Ternstrox-

miacere, and Celas. tracex, 682

- of Tree Rhododendrons, 683

- of Tropical Africa, 685 
Region of Umbelliferæ and Cruciferæ, 680 - of Zingiberacea, 683

Regma, $3 \times 5$

Regular monopetalous or gamopetalous corollas, 205

- polypetalous corollas, 204

Reindeer Moss, 647

Reinwardt's fossil Region, 684

Renealmia, 606

Reniform, 89

Replicate, rro

Replum, 244, 306, 315

Representative plants, 674

Reproduction, essential organs, I7J, 2 II

- in Cryptogams, 233,266

- in phanerogams, $264,28 \mathrm{I}$

- in Vallisneria, 282

Resedacea, 438

Resinous glands, 35

products, 169

Respiration of plants, I22, I 55

Respiratory process in plants, three views of, ${ }^{58}$

Restiacea, 687

Resting spores, 402

Restio, 687

Restricted plants, as regards distribution, $67 \circ$

Reticulated vessels, Ig

veins, 84

Reticulum, 32, 97

Retinaculum, 229

Retuse, 89

Revolute, xxт

Rhabdocarpum, 746

Rhamnaces, $47^{2}$

Rhatany, $44^{2}$

Rheea fibre, 584

Rheum, 565

Rhexia, 489

Rhinanthea, 55I

Rhinanthus Cristagalli, fertilisation in, 290

Rhizanths, I42

Rhizobola, 452

Rhizocarpez, 640

Rhizocarps, reproduction of, 279

Rhizogens, 37

Rhizome, 47, II3

Rhizomorpha, 650

Rhizophoracez, 488

Rhododendron, 527

Rhododendrons, tree, Region of, $68_{3}$

Rhodolæna, 452

Rhodoleia, 504

Rhodosporee, 653

Rhodymenia, 655
Rhubarb, 565

Rhus, 474

Ribes, 502

Ribesiacea, 502

Ribwort, 559

Ricciee, 644

Rice, $63^{\circ}$

Rice-paper, 53, 509

Ricinus, 58x

Rictus, 207

Rimmon, 492

Ringent, I98, 206

Ripening of fruits, $32 x$

- of seeds in gym-

nosperms, 293

Robinia, 479

Rocambole, 6I5

Roccella, 647

Rock-rose, 439

Rohun bark, 460

Root, 37

abnormal, 39

absorption by, 142

adventitious, 39 ,

$33^{6}$

- aerial, 39

- buds on, 40

climbers, 386

covering of, 40

crown of, $37, I_{3}$,

146

forms of, 40
functions of, 43
grafting, 324

of acotyledons, 43

of dícotyledons

or exogens, 4 I

- of monocotyle-

dons, 42

- parasitic, $\mathbf{I}_{42}$

- stack, 47

- structure of, $3^{8}$

Rootlets, 336

Rosa, 486

Rosaceæ, $48_{3}$

Rosaceous corolla, 204

Rose, 3 I2

—. apple, 492

— fruit of, 310

- of Jericho, 437

Rosewood, 48 I

Rosmarinus, 554

Rosemary, 554

Rostellum, 229

Rotate, 206

Rotation in cells, I5I

of crops, 133

Rottlera; 582

Roxburgh's floral $\mathrm{Re}$ gion, 683

Royal, or flowering fern, 639

Royena, 628

Rubeæ, 484

Rubiacez, 5 II

Rudimentary leaves, 334

Rue 467

Ruellia, 556

Ruiz and Pavon's floral Region, 686

Ruizia, 589
Rumex, 56

Ruminated albumen, 333

Runcinate, 87

Runner, $\mathbf{I r}_{3}$

Ruppia, 626

Rush, 6Ig

Rust, I4I, 399

Rutacea, 467

Rye, 630

- fruit of, 3 rI

- spurred Rye, or

Ergot of, 400

Rye-grass, 63I

SABAL, 622

Sabiacere, 473

Sabicu, 482

Saccate, 202

Saccharine glands, 35

Saccharum, 63 r

Sack-tree, 587

Safflower, 520

Saffron, 609

Sagapenum, 507

Sage, 554

Sageretia, 473

Sagittaria, 623

Sagittate, 89, 203

Sago, $x 63,601$

fruit of, $3^{\text {II }}$

Palm, 62I

- Portland, 163

Saguera, 62x

Sagus, 62r

Saintfoin, 479

St. Helena, flora of

${ }^{674}{ }^{67}$ Hilaire's floral

Region, 687

St. Ignatius's Bean, $53^{8}$

St. John's Bread, 48 I wort, 455

Sal, 45 I

Salacia, 47x

Salep, 605

Salicaceæ, $59 x$

Salicin, 166, $59 z$

Salicormia, 563

Saline plants; province of, 680

Salisburya, 600

Salix, 592

Salpiglossis, 55 $\mathrm{I}^{\prime}$

Salsafy, 522

Salsola, 563

Salsola and Salicornia, province of, 680

Salvadoracee, 534

Salver-shaped, 205

Salvia, 554

Salvinia, 640

Samadera, 469

Samara, 3rx

Samaroid Achanium, 3II

Sambucus, 5 II

Samolus, $55^{8}$

Samphire, 507

Samydacea, 573

Sandal-wood, 574
Sandarach, 599

Sandbox, fruit of, 315

Sanguinaria, 434

Sanguisonbeae, 484

Sanicula, 506

Santalacea, 574

Sap ascending, I44, 146

- changes in composition of, $x 45$

- circulation of, 124

- course of, in acro-

genous plants, 148

elaborated, de-

scent of, $\mathbf{1}_{4} 6$

wood, 55

Sapindace $2,45^{8}$

Sapodilla, $53 x$

Saponaria, 445

Saponine, 445

Sapotacex, $53^{\circ}$

Sappan-wood, 482

Saprolegniea, 653

reproduction of, 272

Sapucaia-nuts, 492

Saurauja, 452

Sarcinula, 655

Sarcocarp, 3or, $3 \mathrm{Iz}$

Sarcocolla, $57 \mathbf{r}$

Sarcoderm, 327

Sarcolaena, $45^{2}$

Sarcolobea, 476

Sarcophyte, 577

Sarcosperm, 327

Sargassum, 654, 700

Sarmenta, rzr

Sarmentum, 45

Sarnian Flora; 706

Sarracenia, $3^{8} 3$

Sarraceniace 232

Sarsaparilla, 617

Sarza, 4I 7

Sasanqua Tea, 453

Sassafras, 568

Satin-grass, $63 x$

Satin-wood, 460

Satureia, 554

Saururaceæ, 590

Saururus, $59^{\circ}$

Sauvagesiez, $44^{\circ}$

Savin, 599

Savoury, 554

Sayoys, 437

Saxifrağacez, 502

Region of; 679

Scabiosa, 5 I 5

Scabrous hairs, 32

Scavola, 523

Scalariform vessels, 19

Scale-mosses, 643

Scales, 99, I04, I09, rgo, 208

- of Pine-apple, 290

Scammony, 544

Scandent, 45

Scandinavian fora of Britain, 709

Scape, I73

Scar, 82, 95.

Scarlet-runner, $48 \mathrm{r}$ 
Scepacea, 580

Scheuchzeria, 623

Schinus, 474

Schizæa, 639

Schizanthus, 55I

Schizopetalon, 435

Schizandra, 429

Schizocarp, 306

Schoenus, 628

Schouw's phyto-geographic regions, $\sigma_{79}$

Scilla, 614

Scillere, $6 \mathrm{I}_{4}$

Scions, 325

Scirpus, 628

Scitaminea, 605

Scleranthea, 499

Scleria, 628

Sclerogen,

Scolymus, 520

Scorodosma, 507

Scorpioid, 185

Scorzonera, 522

Scotch fir, 599

myrtle, 592

- thistle, 520

Scottish mountains, flora of, 707

Screw-pine, 624

Scrophulariacea, 55I 289

Scurvy-grass, 437

Scutellaria, 554

Scythian or tartarian lamb, 640

Scytosiphon, 654

Sea Buckthorn, 57 I

Sea-kale, 437

Sea-pink, 559 fertilisation of, $29 x$

Seaside grape, 565

Sea-weeds, 652

.. mannite in, I65

- manuring with, 140

Sebesten-plums, 545

Secale, 630

Secundine, 253

Securidaca, 442

Sedges, flowers of, 208

Sedum, 490

Seed, 298, 325

composition

the, 343

- coverings of, 326

- dissexnination of,

343

_ forms of, $33^{\circ}$

- maturation and

functions of the, 343 modes of trans-

porting, 348, 803 number of, 344

— of gymnosperms, 293 position of, 330 sowing of, 345 -..vitality of, 346,350 Seedless fruits, 3 I9

Selaginea, 558

Selaginella, 640
Selaginella, colouring| Shorea, $45 \mathrm{~T}$ matter of, 392 Short-styled, 285 reproduction of, Shrubs, defined, 46 278

Selaginites, 733

Selago, 555

Self-fertilisation, 284

Semecarpus, 474

Semi-anatropal ovile, 256

Semi-equitant, $34 \circ$

Seminal leaves, 339 - lobes, 339

Seminude, 252, 326

Sempervivum, 499 - province of, 680

Senebiera, 435

Senecio, 520

Senega or Seneka root, 442

Senegal gum, I63

Senftenbergia, fructification of 730

Senna, $48 x$

Sensitive plants, 376 - effect of anxsthetic agents on, 386 effect of light and chemicals on, 377

Sepals, I95

- forms and size of, 197

Septate, 234

Septemfid, 87

Septempartite, 87

Septenate, 93

Septicidal, 304

Septifrugal, 305

Septulatæe, 436

Septum, 222, 224, 24 I

Sequoia, 598

fossil, 753

Sericeous, 33

Serrate, 86

Sesamum, 54x

Sessile glands, 34,35

- leaf, 82

Sesuvea, 500

Setaceous, 32

Seta, 32, 250

Setaria, 63r

Setose, 32

Sexes of plants, 264

Seychelles palm, 62r

Shaddock, 314, 454

Shaked, 485

Shallon, 527

Shallot, 615

Shamrock, 465, 479

Shea butter, $53 \mathrm{I}$

Sheath, 336

- medullary, 53 - of leaf, 82

Sheathing bracts, I9I

Sheep's sorrel, 564

She-oak, 593

Shesh, 585

Shifting crops, I 34

Shikmim, 586

Shittah-tree, 482

Shola, 53

Shoom, 6r5
Side grafting, 325

- saddle flower, 432

Sidea, 447

Sigillaria, 736

Silenea, 445

Silica, 129, 131, 135

Silicula, 3I5

Siliculose, 436

Siliqua, 306, 3I 5

Siliquosa, 436

Silk cotton, $44^{8}$

plant, 536

Silver fir, 599

— grain, 59

- oak, 570

- tree, 570

Simarubace 468

Simple leaves, 85

Sinapis, 435

Siphocampylos, 525

Siphonia, 582

Sissoo, 480

Sisyrinchium, 608

Sium, 507

Size of trees, 360

Skirret, 507

Skorodon, 6r5

Skunk cabbage, 625

Sleep of plants, 375

Slipper-like, 207

Slips, 325

Sloe, 486

Smeathmannia, 497

Smilaceae, 6 I 7

Smilax, 6r7

Smith and Beck's microscope, $77^{\circ}$

Smut, I4r, 399

- balls, 399

Snake-gourd, 496

- nut, 459

- root, 448,459

- wood, $53^{8}, 5^{87}$

Snowball, 5 II

Snowberry, 5 II

Snowdrop, 6I2 trees, 529

Snowflake, 6rz

Soapwort, $45^{8}$

Soboles, 47, II 3

Soda in plants, 132

Soil as influencing plant distribution, 662

Soil, mode of estimating the nature of, I 35

- pulverised, 347

Soils, chemical composition of, 134

Solanacere, 547

Solanum, 548

Soldanella, $55^{8}$

Solenostemma, 536

Solid oils, I67

Solidagos, Region of, 68ः

Sollya, 466

Solomon's seal, 47

Solutions used for poi- soning and preserv-

ing plants, 801,802

Sonchus, 520

Sooranjee, 514

Soot as a manure, ${ }_{3} 8$

Sorghum, 630, 63I

Sori, 638

Sorosis, 316

Sorrel, 564

Souari-nuts, 454

Sour-sop, 430

South America, flora of highest parts of, 686

South American flora, extra-tropical, 687

Soutbern wood, 521

Sow-bread, $55^{8}$

Sowing of seeds, 345

Soymida, 460

Spadix, simple, I79

Sparganium, 625

Spatha or Spathe, IgI

Spathellax, Igr

Spathodea, 540

Spathulate, 89

Spawn, 357

Spearmint, 554

Species, 406

number of known, 405

- and sub-species, definition of, 406

- variation in, 407

Specific names, 410

Specimens preserved in a moist state, 802

Spelt, 630

Sperm cells, $28 \mathrm{r}$

Spermacoce, 5Iz

Spermagones, 268

Spermatia, 268

Spermatozoa, 265

Spermatozoids, 234, 265

Spermoderm, 327

Sphzrenchyma, 3

Sphzria, 65I

Spharococcus, 655

Sphæroplea, reproduction of, $27 \mathrm{I}$

Spharozyga, 655

Sphagnea, 643

Sphenophyllum, $73^{8}$

Sphenopteris, 73I

Spherical, 284

Spherical aberration, 762

Spice-wood, 569

Spiderwort, 623

Spigelia, 539

Spike, r78

compound, 182

Spikelets, r79, 208

Spikenard, 5 I 5

Spinach, New' Zealand, 520

Spinacia, 562

Spinage, 562

Spindle tree, 328,47 r

Spines, IIg

Spiraeer, 484 
Spiral cycles of leaves, Iog

- leaves, 9 I

- twiners, 386

- vessels, I7

Spirals in fir cones, so5

Spirolobeæ, 435

Spitzbergen, fossil plants of, 738,755

Splachnum, 643

Spondias, 474

Sponea, 585

Spongioles, 38

-absorption by, $\mathbf{I}_{42}$

Spontaneous generation, 15

Sporangia, 250

- in coal, 729

Sporangiferous, 280

Spore, compound, 268

Spore of acotyledons, 334

Spores, 250

moving, 265

Spores of fungi, resting, 402

Sporidium, 335

Sporocarp, 640

Sporophores, 647

Sprengelia, 528

Spruce, 599

- cone of, 317

Spurges, 579

Spurge-laurel, 572

Spurious dissepiments, 244

Spurred, rg8

rye, 400

Squamz, I9o, 208

Squamash, 6I5

Squash, 495

Squill, 6 64,615

Squirting cucumber, 496

Staavia, 504

Stachytarpheta, 556

Stackhousiacea, $47^{\circ}$

Stagmaria, 474

Stamens, ror, 212

abortive, 2 Ig

- cohesion of, 227

development, structure, and form of, $2 I 4$

irritable, 283

length of, 227

long, short, and

medium, 285

- of grasses; 224 , 656

$$
215
$$

Staminal degenerations, 369

Staminiferous, $2 \times 2$, 264,368

Staminodes, 219

Stamminodium, 36,227

Standard, 205.

Stangeria, 600

Stanhopea, 604

Stapelia, 536
Stapelia, fertilisation of, 284 Region of, $68 \mathrm{~g}$

Staphyleacez, 472

Star-anise, 429

- apple, $53 \mathrm{r}$

Star-like, 206

Starch, ro, 162 changed into

sugar, 163,260 in fruits, 321

in seeds, $16_{3}, 350$

Staticea, 559

Statistics of vegetation, 677

Stavesacre, 427

Stearic acid, 168

Stearin, I68

Stearoptene, I69

Steeping seeds, I40

Stelis, 604

Stellate, 206

-... hairs, 3 I

Stem, 44, 335

- - acotyledonous or acrogenous, 49 aerial, 46 anomalous exogenous, 60

creeping, II4

- exogenous or di-

cotyledonous, 49 herbaceous, 50 hypocotyledon-

ary, 4I

internal structure of, 49

ligneous, 50

monocotyledon-

ous or endogenous, 49,64

- parasites, I42

- protuberances on, 46

4 special functions of, 75

- subterranean, 46

Sterculiacea, $44^{8}$

Sterigmata, 268

Sterile, 227, 368

Sternbergia, 6I2, 74I

Stevensonia, 62I

Sticta, 647

Stigma, 235, 248, 282

- development, 290

—- of Campanula, z9o sensitive, 248

- structure and posi-

tion of, 248

Stigmaria, 734

Stilago, 588

Stillingia, 582

Stings, 34

Stinking rust, 399

Stipe, 44

Stipels, 99

Stipitate, 180, 240

glands, 34

Stipulate, 97

Stipules, 82, 97

forms of, 99

Stock, 44, 323
Stomata, 28, 80

development and

forms of, 29

- - in anthers, 220

- number in square

inch of surface, $3^{\circ}$

Stonecrop, 499

Stone of fruit, 301

Stone-pine, 599

Storax, 529

Stramonium, 549

Strap-shaped, 207

Stratiotes, 602

Strawberry, 3I2, $4^{85}$

- fruit of, 310

- tree, 527

Strelitzia, 608

Streptocarpus, cotyledons of, $33^{8}$

Strobilus, I79, I90, 3 I7

Strophanthus, 537

Strophiolate, 329

Strophioles, 329

Struma, 95

Strumose, 218

Strychnia, $53^{8}$

Strychnez, $53^{8}$

Strychnos, $53^{8}$

Stupose, 33, 217

Style, 246

- feathery, 3 I0

- form and struc-

ture of, 236,247 length of, 248 - of Campanula, 290 of Goldfussia, 290 position of, 246

Stylewort, 523

Stylidiacea, 523

Stylopod, 506

Stylospores, 269

Styphelia, 528

Styracacea, 529

Styrax, 529

Sub-arctic zone, plants of, 693

Sub-classes, 4II

Suberic acid, 168

Suberous layer, 58

Sub-genus, 4IO

Sub-orders; 4IO

Subordination of characters, 4I6

Sub-species, 409

Subterranean

leafbuds, $\mathrm{Ir}_{4}$

Subtropical zone, plants of, 693

Subulate, 89, 216

Succulent fruits, 309 , 3II, 3I3

- leaves, 90

peduncle, 173

Suckers, II4

of Dodder, 40

Suffrutex, 46

Suffruticose, 46

Sugar, I64

- beet, 164

- cane, $164,63 I$

grape, $16_{5}$ import of, 164
Sugar in fruits, $32 x$

in seeds, 350

manna, $x 65$

maple, $\mathbf{x} 64$

Muscovado, 164

- starch changed

to, $x 6_{3}$

Suke, 586

Sulphates as a manure,

I39

Sulphur showers, 282

Sulphuretted hydrogen, effect on plants. 160

Sulphurous acid gas, effect on leaves, 160

Sumach, 474

Sumatra camphor, 451

- flora of, 684

Sumbul root, 508

Sundew, 44I

Sunflower, $52 x$

Sun spots as affecting vegetation, 399

Superior applied to the parts of a flower, I95

Supervolute, III

Suppression of organs. 365

Supradecompound, 92

Surculi, 114

Surinam medlar, $53^{\mathrm{r}}$

Suspended, 257, $33^{\circ}$

Suspensor, 253

Sutural, 303

Sutures, 224, 240

Swallow's nest, 655

Swamp-pine, 599

- Sassafras, 429

Swartzia, $47^{8}$

Swartz's Region, 687

Sweet bay, 567

- cane, 632

- fern, 592

- flag, 625

- sop, 430

- vernal grass, 63 I

Swietenia, 460

Sycamine tree, 586

Sycamore, $45^{8}$

fruit of, $3 \mathrm{~T}$

Sycamorus, 586

Syconus, $36 x$

Sylhet varnish, 474

Symbols, 4 Iz

and abbreviations, $83^{\circ}$

for number of parts of the flower, $3^{6} 4$ 3 for unisexual

flowers, 367

Symmetrical, 203

Symmetry, 363

causes of want of $3^{6} 5$ in acotyledons, 365 in Crucifera, 436 in dicotyledons, 364 in monocotyle dons, 365 
Symplocarpus, 625

Symplocez, 529

Synantheræ, 5x7

Symantherous, 227

Synaptase, I66

Syncarpous, 239 fruits, 313

indehiscent fruits, 313

Syngenesious, 227

Synochreate, 98

Syringa, 490, 533

System, Linnean, 4I3

natural, 4I5

Systematic Botany,

Taxonomy, classifi-

cation of plants, 405

TABASHEeR, I $3 x$

Tabernzemontana, 537

Tacamahac, 592

Tacsonia, 498

Talauma, 429

Talinum, 446

Tallow-tree, 582

Tamar, 62I

Tamaricaceae, $44^{2}$

Tamarindus, $48 \mathrm{r}$

Tamarisk, 443

Tanacium, 541

Tangena nut, 537

Tanghinia, 537

Tangle, 655

Tannic acid and Tannin, I7o

Tansy, 521

Taphrenchyma, 20

Tapioca, 163,582

Tap-root, 40

Tapura, 573

Taraxacum, 521

Tarragon, 52I

Tartarian lamb, 640

Tartaric acid, I70

Tawhara, 6a4

Taxinea, 598

Taxodium, 598

Taxonomy, 405

Taxus, 600,634

Tea, 452

Teak-tree, 555

Teak of Africa, 583

Teashur, 582

Teazel, 515

Tecoma, 54I

Tectona, 555

Teel seeds, 541

Teenah, 586

Tegmenta, Ioo

Telegraph plant, 377

Telfairia, 494

Temperate zone cooler, plants of, 693

warmer, plants of, 693

Temperature, altitudi$\mathrm{nal}$ range of, $66 \mathrm{r}$

- effects of, in the distribution of plants, 658

_ requisite for germination, 345
Temperature of plants, $3^{88}$

Tendril, 97, 120, I74

bearers, 386 coiling of, $3^{85}$

homologues of, I20

Tephrosia, 480

Teratology, 365 cohesion and ad-

hesion, $37^{\circ}$

multiplication and

chorization, 37 I

Tercine, 254

Terminal, 108 inflorescence, I75

Terminalia, 489

Terminology, 406

Ternate, 93

Ternstroemiacea, 452

Region of, 682

Tertiary fossils, $75 \mathrm{I}$ ${ }_{756}$ flora of Europe,

Tesselated epicarp of sago, 3 II

Testa, 327

Testudinaria, 6rI

Tetracera, 428

Tetradynamous, 228

Tetragonal, $36_{3}$

Tetragonia, 500

Tetrameles, $57^{8}$

Tetramerous, 363

Tetrandrous, $2 \times 6$

Tetranthera, 567

Tetrapetalous, 203

Tetraspore, 273,335

Tetratheca, 442

Tetrathecal, 222

Teucrium, 554

Thalamiflorae, 425

Thalamifloral, 214

Thalamus or Torus, I74, IgI

Thallogena, 644

Thallogens, 44, 268, 635

Thallophyta, 44, 635, 644

Thallus, 44

Thaumatopteris, 747

Theca, 250, 267

Thecaphore, 240

Theine, 452, 530

Theobroma, 450

Theophrasta, $53 \mathrm{I}$

Thesium, $\mathbf{5 7 4}$

Thistle, 520

Thorns, I I9

Thorn-apple, 549

Thorough-draining, 348

Thrift, 559

Throat, 204

Thuites, 749

Thuja, 599

Thunbergiea, 556

Thunberg's floral $\mathrm{Re}$ gion, 680

Thus, 599

Thyme, 554
Thymelæacea, $57^{\text {T }}$

Thymus, 554

Thyrsus, 184

Ti, 616

Tigellary, 82

Tigelle, 334

Tiglium, 58I

Tiliacex, 450

Tillandsia, $6 x_{3}$

Timothy grass, $6_{3} I$

Tinospora, $43^{\circ}$

Tissues, $I, 16,17$ 23

Tobacco, 550

Toddalia, 468

Tofieldia, 6 I6

Tomato, 549

Tomentose, 33

Tomentum, 33

Tonka-bean, 480

Tongue-grafting, 325

Toothache-tree, 509

Toothwort, 55I, 559

Tormentil, 486

Tornelia, 625

Torreya, 598

Torrid zone, plants of, 692

Tortoise plant, 6II

Tortula, 643

Torula, 649

Torus, I74, $19 x$

Tous-les-mois, 607

Towel-gourd, 496

Toxicophloea, 537

Tracheæ, I8

Trachenchyma, I7

Trachylobium, 482

Tradescantia, 623

- rotation in, I53

Tragacanth, I63, 479

Tragopogon, 522

Transpiration, I2I

Transudation, $I_{5}$

Transverse dehiscence,

225, 307

Irapa, 493

Traveller's tree, 608

Tree-beard, 613

Tree-ferns, 638

Region of, 698

Tree-lilies, 610

Tree-nettle, 584

Trees, branching of,

$\stackrel{45}{-}$ defined, 46

- on the Grimsel, as

regards altitude, $66_{2}$

- planting of, 78

- size and age of, 360

Trefoil, 479

Trema, 585

Tremandracea, 442

Triadelphous, 2I9

Triandrous, 216

Triangular, 46, 330, 363

Triassic fossils, 746

Tribes, 238, 410

Tribulus, 466
Tricerastes, 578'

Trichadenia, 440

Trichilia, 460

Trichodesmium, 655

Trichogynium, 272

Trichomanes, 639

Trichophore, 273

Trichosanthes, 496

Trichotomous cyme, I83

Tricoccous, 306

Tricostate, 84

Trientalis, $55^{8}$

Trifid, 87, I97, 248

Trifolium, 479

Triglochin, 623

Trigonal, 363

Trigonocarpum, 746

Trigonocarpus, 74I

Trigonous, 46

Trijugate, Io4

Trilamellar, 249

Trilliacea, $6 \mathrm{I7}$

Trillium, 618

Trilobate, 249

Trilocular, $24 \mathrm{~T}$

Trimerous, 363

Trimorphic flowers of Lythrum, 285

Trioeciously-hermaphrodite, 286

Tripartite, $87,198,248$

Tripinnate, 92

Tripinnatifid, 87

Tripe de Roche, 647

Tripetalous, 203

Triplosporites, 733

Triptilion, 520

Triptolomea, $48 \mathrm{I}$

Triquetrous, 46

Trisepalous, 197

Tristichous, I0 3

Triternate, 93

Triticum, 630

Trivial names, 4 Io

Trixis, 520

Tropeolacea, 465

Trophosperm, 253

Tropical zone, plants of, 692

Trochodendron, 429

Truffie, 649

Triutis, 623

Trumpet-leaf, 432

Trumpet-flower, 540

Trumpet-wood, 588

Truncate, 89 , 198

Truncus, 44

Tryma, 312

Tsuga, 598

Tube of calyx, 198 .

Tuber, 47, II4, 649

china, $6 \mathrm{r}_{7}$

Tubercular, $4 \circ$

Tubercularia, 649

Tuberose, 6r4

Tubular, 206

Tubuliflora, 519

Tulip, $6 \mathbf{r}_{4}$

Tulipex, 614

Tulip-tree, 420

Turbinate, I 98 
Turio, II4

Turmeric, 606

Turneraceæ, 498

Turnip, 437

Turnsole, 583

Turn-table for microscopic preparations, 786

Turpentine, 599

Chian, 474

Tusșac-grass, 63 I

Tussilago, 520

Tutsan, 455

Twining plants, 385 - stems, 45

Twisted, 40, III zstivation, I93

Tylophora, 536

Tylosis, 22

Tyndaridea, 655

Typha, 626

Typhineæ, 628

UDORA, 602

Ugni, 492

Ulex, $48 \mathrm{r}$

Ullucus, 446

Ulmacez, 585

Ulmine, 134

Ulmus, 585

Ulodendron, 734

Ulva, 655

Umari, 480

Umbel, 180

Umbelliferze, 505 fruit of, 3II Region of, 680

Umbellules, I8o

Umbilical cord, 253

Umbilicaria, 646

Umbilicus, 329

Umiri, 460

Unazotised matter in plants, $x 6_{7}$

Uncaria, 5 I4

Uncinate hairs, $3^{2}$

Undershrub, 46

Undulated, 90

Unequally pinnate, 93

Unguiculate, 2or

Unguis, 20x

Unicorn plant, 54I

Unicostate, 84,92

Unijugate, 92, I04

Unilateral, 248 inflorescence, $r 8_{4}$

Unilocular, 222, 242, 299

Uniparous cyme, I83

Unipetalous, 203

Unisexual, 212, 367

Univalvular, 303

Unlining, 37I

Unsymmetrical, 203, 364

Upas Antiar, $\mathbf{5}^{87}$

Upas Tieuté, 538

Urania, 608

Urceola, 537

Urceolaria, 646

Urceolate, 206

Uredo, 649
Urginea, $6 \mathrm{r}_{4}$

Urn-mosses, 643

- shaped, 206

Urostigma, 586

Urtica, 584

Urticacez, 583

Utricle, $3,8,228,3$ Io

Utricularia, 557

Uva, 3 I3

Uvaria, 429

Uvularieæ, 616

VACCINIACE 525

Vacoa, or Baquois, 624

Vagina, 82, 97, 337

Vaginula, $64 \mathrm{~T}$

Vahea, 537

Valerian, 5I5 Greek, 542

Valerianacea, 5 I 4

Valerianella, 5 I 5

Valleculæ, 506

Vallisneria, 602 282

rotation in cells of, I52

Valonia, 595

Values of different organs, 4 I6

Valvate, II I, 193

Valves, 303

Valvular, 315

Vanda, 604

Vanilla, 605

Varieties, 407

Variolaria, 647

Varnishes, 474

Varronia, 545

Vascular bundles in acrogens, 7 I

- bundles in calyx, r97

bundles in endogens, 67

- bundles in exo-

gens, 53

- tissue, I6

Vasiform tissue, 20

Vateria, $45^{2}$

Vaucheria, 269

Vaucheriea, 653

Vegetable brimstone, $64 I$

- ivory, 333

— marrow, 496 wax, 168

Vegetation, altitudinal range of, 695

- general phenomena of, 374

influenced by external agents, 657 - of the globe, its origin, $67 x$

Veinless, 83

Veinlets, 84

Veins, 83

Velleia, 523

Vellozia, 6 ro

Velum, 647

Velutinus, 33
Velvety, 33

Venation, tabular arrangement of, 84

Ventral, or outer suture, 240,303

Venus's fly-trap, 380, $44 I$

Veratrea, 6r6

Veratrum, 6x6

Verbascum, 55T

Verbena, $\mathbf{5 5 5}$

Verbenacea, 555

Verjuice, 46I

Vermiform vessels, zo

Vernal grass, 63I

Vernation, xio

Vernonia, 520

Veronica, 552

Verruca, 36

Versatile, 224

Verschaffeltia, 62I

Verticil, Ioz

Vertical theory wood formation, 76

Verticillaster, 184

Verticillate, I02

Veryain, 556

Vesicle, embryonal, 293

Vesicles,

Vesicular, 200

Vesicular glands, 36

Vessels of plants, $I 6$

-laticiferous, movements in, 145

Vetivert, 632

Vexillary, I95

Vexillum, or standard, 205

Viburnum, 5II

Victoria, 432

Victor's Laurel, 567

Villi, 30

Villous, 33

Vinca, 537

Vine, 460

- disease, 400, 403

Violacer, 440

Violet, 440

Virginia, Pennsylvania, and New

York, flora of, 68I

Virginian Creeper, 462 Snake-root, 577

Viscum, 575

Vismia, 456

Vitacese, 460

Vitality of seeds, 346

Vitellus, 328

Vitex, 556

Vittre, $I_{3}$

Viviparous, 357

Viviparous bracts, I 1

Vivianiacea, 463

Vochysiacea, 488

Volatile oils, I68

Volkmannia, 738

Voltzia, 747

Volva, 647

WACHENDORFIEA, $6 r_{4}$

Wagenboom, 570
Wahlenberg's floral

Region, 679

Wake-robin, 625

Walchia, 745

Wallflower, fruit of, 3 I5

Wallich's floral Region, 683

Walnut, 3I I, 596

Ward's cases, 160,349

Warts, 36, 224

Water-beans, 432

Water-chestnut, 493

- dock, 564

- dropwort, 508

- flannel, 655

- hemlock, 508

- in plants, 167

- lilies, $43 I$

- melon, 495 ;

- net, 655

— pepper, 443,564

- pitcher, .432

- plantain, 623

shield, 432

- tree, 608

Watson's British floral provinces, 704

- climatic or ascending zones of vegetation in Britain, 713

division of areas

of British plants, 702

Wattle-trees, 482

Wavy, 90, 203

Wax-flower, 536 - myrtle, 592

- palm, 622

Wax, vegetable, I68

Way-bred, 560

Wealden flora, $75^{\circ}$

Weinmannia, 504

Weld, $43^{8}$

Wellingtonia, 598

Welwitschia, 600 - permanent cotyledons of, $33^{8}$

West Indian Region, 687

Wetherellia, 751

Wheat, $63^{\circ}$

- barley, and oats, fertilisation of, 634 nutritive . matter of, $x 66$

Wheel-shaped, 206

Whin, 48x

Whip-grafting, 325

White Hellebore, 6I6

Whorl, ron

Whortleberry, 526

Wig-tree, 474

Wild-cotton, 536

- ipecacuan, 536

Willdenovia, 627

Williamson on calamites, $7 \dot{3} 7$

- on the carboniferous flora, 734

Williamsonia, 749

Willows, 592 
Willow-strife, 487 Wilson on fertilisation of wheat, oats, and barley, 634

Wimble or peg grafting, 325

Winged fruits, 3 II

Wings of corolla, 205

Winter's-bark, 429

Winter cherry, 549 green, 527

Winterex, 429

Wistaria, 479

Witch-hazel, 504

Witsenia, 608

Woad, 437

Wollaston's 763

doublet,
Wood, durability of, 55 formation of, 76

Woodruff, $5{ }^{14}$

Woody layers, 53 nodules, Ir6

Woodsia, $\sigma_{39}$

Wood-sorrel, 464

Woolly, 33

Woorali poison, $53^{8}$

Wormskíoldia, 498

Wormseed, $52 \mathrm{I}$

Wormwood, 521

Wrightia, 537

Wukkum-wood, 482

Wych elm, $5^{85}$

Xanthic series of colours, 393

Xanthophyll, 39r, 392 $\mathrm{X}$ anthorrhoea, 6I5

Xanthoxylacea, 468

Xerophilous plants, $66_{3}$

Xylopia, 430

Xyridacea, 618

YAM, 6II

Yew, 600

- age of, $36 \mathrm{I}$

embryo sac of, 292

- fruit of, 317

Yucca, 6r5

ZATT, 533

Zamia, 600

Zamites, 747

Zannichellia, 626
Zanthoxylacex, 468

Zanzibar copal, 482

Zea, 630

Zebra-plant, 607 wood, 476

Zieria, 467

Zingiber, 605

Zingiberacea, 605

Region of, 683

Zizania, 63I, 634

Zizyphus, 473

Zones of wood, 53

Zoophilous, 284

Zoospores, 265

Zostera, 626

Zosterites, 753

Zygophyllaceæ, 466

Zygospore, 268

THE END.

Printed by R. \& R. ClaRk, Edinlurgh. 


\section{BALFOUR'S BOTANICAL WORKS.}

In one vol., Third Edition, royal 8vo, pp. 1117, with 1800 Illustrations, price $21 \mathrm{~s}$.

\section{CLASS-BOOK OF BOTANY.}

Being an Introduction to the Study of the Vegetable Kingdom.

By J. HUTTON BALFOUUR, M.D., F.R.S.,

Professor of Medicine and Botany in the University of Edinburgh, Regius

Keeper of the Royal Botanic Garden, and Queen's Botanist for Scotland.

(May also be had in two Parts, price 21s.)

"In Dr. Balfour's 'Class-Book of Botany,' the author seems to have exhausted every attainable source of information. Few, if any, works on this subject contain such a mass of carefully collected and condensed matter, and certainly none are more copiously or better illustrated." Hooker's Journal of Botany.

"Professor Balfour's 'Class-Book of Botany' is too well and favourably known to botanists, whether teachers or learners, to require any introduction to our readers. It is, as far as we know, the only work which a lecturer can take in his hand as a safe text-book for the whole of such a course as is required to prepare students for our University or medical examinations. Every branch of Botany, structural and morphological, physiological, systematic, geographical, and palæontological, is treated in so exhaustive a manner as to leave little to be desired.

"The work is one indispensable to the class-room, and should be in the hands of every teacher."-Nature.

"One of the best books to place in the hands of a student." Annals of Nat. History.

"One of the most complete and elegant class-books on Botany which has been published. It contains all that a student may require, both in description and illustration."-Lancet. 
Uniform with "Class-Book of Botany," In one Vol., illustrated with four Lithographic Plates and upwards of 100 Woodcuts.

Price 7s. 6 d.

\section{INTRODUCTION TO THE STUDY OF PALAENTOLOGICAL BOTANY.}

"Professor Balfour has published, in the form of a separate work, and with additions, that portion of his Class-Book of Botany which contains an introduction to fossil botany. The importance of the study of fossils, particularly in their relations to time and space, is now universally admitted as being essential to a thorough study of all the natural sciences; and geologists, especially, admit that, but for palæontology, their science would not have made such progress as it has; and such a book as this must be considered as a valuable aid to the study. It, of course, presupposes acquaintance with botany pure, or the botany of the present time, for only he who is intimate with existing flora and fauna has a right to decide in regard to fossils, and is therefore intended only for advanced students in botany. On a work of this kind we cannot give a detailed criticism. We may mention, however, that Professor Balfour takes Brogniart's division of the fossil flora into three great epochs:-1. The reign of acrogens.; 2. The reign of gymnosperms; and 3 . The reign of angiosperms. The first should be particularly interesting to Edinburgh students, embracing, as it does, the silurian, carboniferous, and permian epochs; the vicinity of our city being particularly rich in carboniferous fossils, which, moreover, belonging chiefly to the fern class, have a special value from their retaining their forms better than cellular plants, and the cellular portions of vascular plants. The portions of the book which refer to coal will also be found interesting by a Iarger circle of students than that composed merely of palæontological and botanical students. The fact that Professor Balfour is the author of this book is a sufficient guarantee of the excellence of its method, the accuracy of its information, and the lucidity of its style; and we have no doubt that it will serve the purpose for which its author designed it-namely, of encouraging students to take up and peruse with enthusiasm the subject of fossil botany. We may ald that, in point of typography and wealth of illustrations, it is equal, if not superior, to any book of the kind we have seen."-Edinburgh Courant. 
"Although the literature of Palceontological Botany is very extensive, it consists either of costly and voluminous works or papers scattered widely through the Transactions of various Societies, none of which are adapted to the use of those students who wish to extend their study of general botany to this interesting but less known branch of the subject. From every point of view the study of the fossil flora of the globe must be of great interest; it widens the field of the modern botanist; it is absolutely essential to the geologist; and to the general student it gives much information regarding the former history of the globe and the nature of its products. Take, for instance, Coal, and we find in Professor Balfour's manual the following interesting information :-

“" The Carboniferous period is one of the most important as regards fossil plants. The vegetable forms are numerous, and have a great similarity throughout the whole system, whether exhibited in the Old or the New World. The important substance called coal owes its origin to the plants of this epoch. It has been subjected to great pressure and long-continued metamorphic action, and hence the appearance of the plants has been much altered. It is difficult to give a definition of coal. The varieties of it are numerous. There is a gradual transition from anthracite to household and parrot coal; and the limit between coal and what is called bituminous shale is by no means distinct. Coal may be said to be chemically-altered vegetable matter, interstratified with the rocks, and capable of being used as fuel. On examining this section of coal under the microscope, we can detect vegetable tissues, both of a cellular and vascular nature. In Wigan cannel coal, vegetable structure is seen through the whole mass. Such is likewise the case with other cannel, parrot, and gas coals. In common household coal, also, evident traces of organic tissue have been observed.'

"Very much more equally important and clearly-expressed informar tion is given upon this interesting subject, and the gexeral style of Professor Balfour's whole work, although upon a little known and perhaps not popularly attractive subject, is such as will be sure to awaken an interest in the real student. It is profusely illustrated with most admirable woodcuts, and two plates from the pencil of Mr. William Carruthers add greatly to the value of the book."Scotsman.

"We can give Dr Balfour's book a cordial recommendation to geological students, as it contains very much valuable matter, presented in a succinct and tabulated form, and it will prove interesting to the general reader both from the felicitous manner in which so difficult a subject is treated, and from the numerous woodcuts and excellent lithographs with which the work is embellished."-Chemist and Druggist. 
In fcp. 8vo, cloth, illustrated with 427 Wood Engravings,

Price 3s. 6d.

\section{ELEMENTS OF BOTANY}

FOR THE USE OF SCHOOLS.

"This new work by Professor Balfour is perfectly distinct in its scope and object from the well-known 'Manual,' and other works of the same author. Its object is to provide a text-book for candidates for school examinations and non-gremial examinations by the universities. While, therefore, elementary, it is thoroughly scientific ; while popular in one sense, it is very far removed from the vagueness of so-called popular handbooks. In the first part the structure and functions of plants and their organs are examined, and illustrated by woodcuts. The second part consists of classification, and here the technical terms are carefully and simply explained as they occur. One of the most admirable features of the work is, that here, after describing each order, one of the most common weeds belonging to it, accessible to every student, is taken, and carefully illustrated in detail, to explain the distinctive characters of its class. At the end of each division a series of questions are appended, most valuable to the teacher and school lecturer, and not less so to the private student, to enable him to test his acquisition of the subject, and to point out the most important facts. A very complete glossary of scientific terms is appended.

"When we recall the dry and dictionary-like manuals to which we were forced to have recourse in our younger days, to learn the Linnæan system-as inviting to a boy as so many pages of Johnson's Dictionary -we can but envy our juvenile successors with Professor Balfour for their instructor and mentor."-The Contemporary Review.

"We have before us another of those admirable elementary textbooks of natural science which our foremost professors do not now disdain to compile for the young. Written in an admirably clear and simple style, profusely illustrated by woodcuts on nearly every page, and containing fewer words of six and seven syllables ending in ous than any other book on Botany which we ever remember to have read, it is exactly suited for scholastic purposes as a first book of natural science. It will also be found invaluable by any person who wishes to acquire the leading principles of Botany with the least trouble and in the most interesting way."-Examiner. 
Sir John F. W. Herschel, Bart., K.H., \&c.

I.

In crown 8vo, cloth, Fourth Edition, Price 5s.

\section{PHYSICAL GEOGRAPHY.}

By the late SIR J. F. HERSCHEL.

"An admirable manual of the whole science."-BRITISH QUARTERLY REVIEW.

"The book is a most fascinating one."-EDdCational Trmes.

"It is utterly impossible to give an account of the immense amount of information so admirably and lucidly compressed in the Volume before us."-London Review.

\section{By the Same,}

II.

In fcap. 8vo, cloth, Price 3s. 6d.

\section{METEOROLOGY.}

"Contains a brief but elaborate survey of the whole domain of Meteorological Science."-BRITISH QUARTERLY ReVIEW.

"As Text-Books for College and School use, on the subjects of which they respectively treat, thers is nothing in the whole range of our Educational literature which can at all be compared with them."-EDdcational Times.

EDINBURGH : ADAM AND CHARLES BLACK. 


\section{Owen's Palæontology.}

In 8vo, Second Edition, with Index and Glossary, and Illustrated with nearly Two Hundred Wood Engravings, price 10s. $6 \mathrm{~d}$.

\section{PALAONTOLOGY;}

Or, A systematic Summary of ExTinct ANIMALS and their Geological Relations.

By RICHARD OWEN, F.R.S., Superintendent of the Natural History Department in the British Museum.

"No one with any pretensions to science should be without Owen's Palæontology."-Lancet.

"The Prince of Palæontologists has here presented us with a most comprehensive survey of the characters, succession, geological position, and geographical distribution, of the various forms of life that have passed away."-MEDICAL TIMES AND GAZETTE.

"The volume cannot fail to be acceptable, both to the palæontologist and to the general reader. The former will welcome it as quite the best and most reliable handbook of his science that has yet appeared, and the latter will find in it a concise but comprehensive summary of the results as yet attained in this most interesting branch of physical investigation."-Literary GazeTTF. 



tis

ming

7.

s.

(6)

${ }^{2}+x^{2}$

*3.

tix

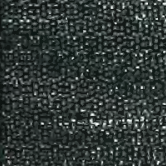

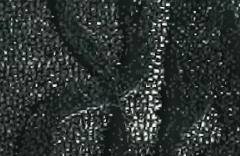

ㄱix

13.

H.

(4)

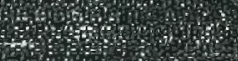

is:

被

20.75\%

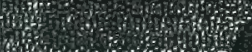

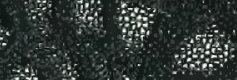

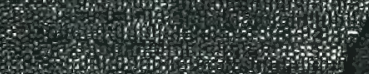

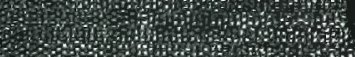

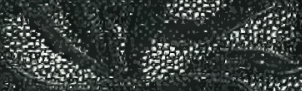

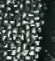

8

13.

30 .

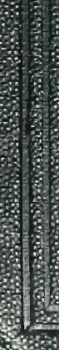

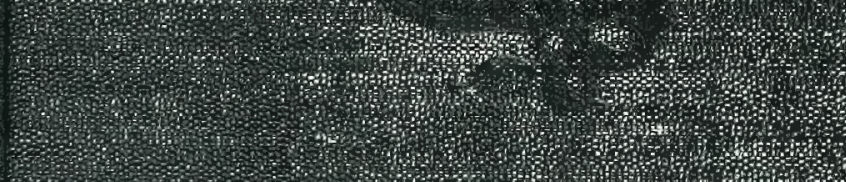

V.7.

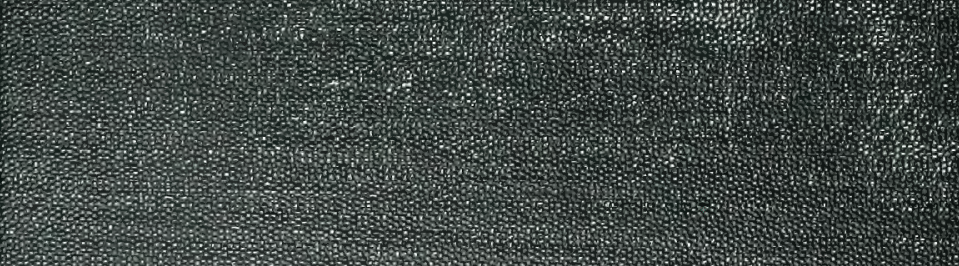

(3) 